The Marine Mammal Commission Compendium of Selected Treaties, International Agreements, and Other Relevant Documents on Marine Resources, Wildlife, and the Environment

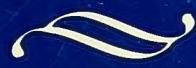

First Update 


\section{ADVISORY BOARD \\ for the \\ Marine Mammal Commission \\ Compendium}

\section{First Update}

Dayton L. Alverson

Donald J. Barry

Donald C. Baur

Michael J. Bean

Henry R. Beasley

Kenneth Berlin

Patricia Birnie

E.U. Curtis Bohlen

Marjorie A. Browne

Eugene H. Buck

William T. Burke

Donald A. Carr

David A. Colson

Penny Dalton

Paul K. Dayton

Prudence Fox

John Grandy IV

Scott A. Hajost
Margaret Frailey Hayes

Grant James Hewison

Casey Jarman

James C. Kilbourne

Lee A. Kimball

Steven G. Kohl

Jack W. Lentfer

George J. Mannina, Jr.

Edward L. Miles

Steven Murawski

William F. Perrin

Arnold W. Reitze, Jr.

John E. Reynolds, III

Marilou M. Righini

R. Tucker Scully

Brent Scott Stewart

James P. Walsh

Warren S. Wooster 


\title{
The Marine Mammal Commission Compendium of Selected Treaties, International Agreements, and Other Relevant Documents on Marine Resources, Wildlife, and the Environment
}

\author{
Compiled by \\ Richard L. Wallace \\ for the \\ Marine Mammal Commission \\ Bethesda, Maryland \\ 1997

\section{First Update}

\author{
Published with the partial support of: \\ National Marine Fisheries Service \\ U.S. Department of Commerce \\ and
}

Bureau of Oceans and International Environmental and Scientific Affairs U.S. Department of State 
.

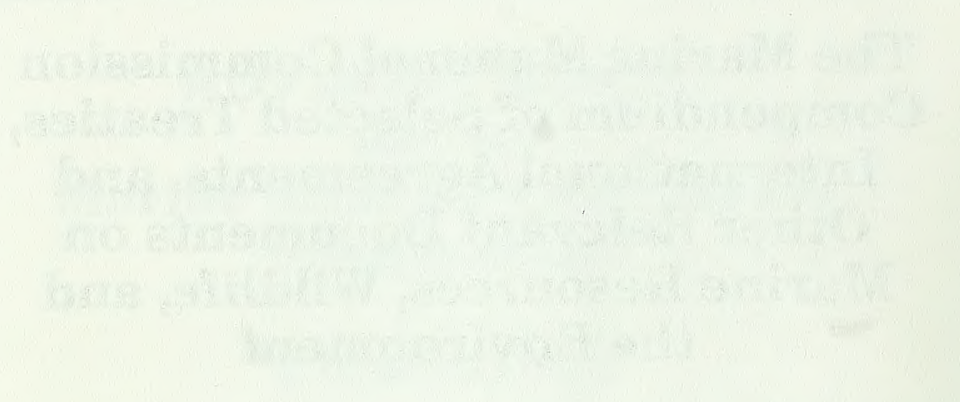

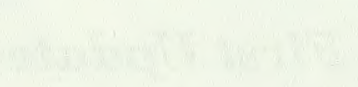

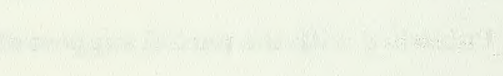




\section{Table of Contents}

Compendium Update Preface . . . . . . . . . . . . . . . xvii

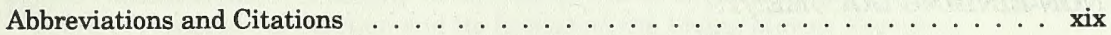

MULTILATERAL DOCUMENTS

\section{ANTARCTICA}

Measures Approved or Recommended Under Article IX in Furtherance of the Principles and Objectives of the Antarctic Treaty, Venice, $1992 \ldots \ldots \ldots \ldots$. . . . 3

Measures Approved or Recommended Under Article IX in Furtherance of the Principles and Objectives of the Antarctic Treaty, Kyoto, 1994 . . . . . . . . . 28

Measures Approved or Recommended Under Article IX in Furtherance of the Principles and Objectives of the Antarctic Treaty, Seoul, $1995 \ldots \ldots$. . . . . . 35

\section{ENVIRONMENT AND NATURAL RESOURCES . . . . . . 65}

Convention on Conservation of Nature in the South Pacific, Apia, 1976 . . . . . . 67

Agreement on the Conservation of Bats in Europe, London, $1991 \ldots \ldots \ldots \ldots$

International Guidelines for Preventing the Introduction of Unwanted Aquatic

Organisms and Pathogens from Ships' Ballast Water and Sediment

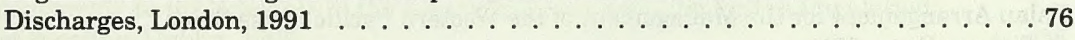

North American Agreement on Environmental Cooperation, Washington, D.C.,

Ottawa, and Mexico City, 1993 . . . . . . . . . . . . . . . 87

Establishment Agreement for the Center for International Forestry Research,

Canberra, 1993

Agreement Establishing the South Pacific Regional Environment Programme (SPREP), Apia, 1993

International Tropical Timber Agreement, Geneva, $1994 \ldots \ldots \ldots \ldots \ldots \ldots \ldots$

Protocol to the 1979 Convention on Long-Range Transboundary Air Pollution on

Further Reduction of Sulphur Emissions, Oslo, 1994 . . . . . . . . . . . . 157

United Nations Convention to Combat Desertification in Those Countries

Experiencing Serious Drought and/or Desertification, Particularly in Africa,

Paris, 1994 
Agreement Relating to the Implementation of Part XI of the United Nations Convention on the Law of the Sea of 10 December 1982, New York, 1994

Convention to Ban the Importation into Forum Island Countries of Hazardous and Radioactive Wastes and to Control the Transboundary Movement and Management of Hazardous Wastes within the South Pacific Region, Waigani, 1995

NON-BINDING DOCUMENTS

Action Plan for Biosphere Reserves, Paris, 1984 .

The Nuuk Declaration on Environment and Development in the Arctic, Nuuk, 1993

ICES Code of Practice on the Introductions and Transfers of Marine Organisms, Copenhagen, 1994 288

The Seville Strategy and the Statutory Framework of the World Network of

Biosphere Reserves, Paris, 1995

\section{FISHERIES}

Nauro Agreement Concerning Co-operation in the Management of Fisheries of

Common Interest, Nauro, 1982

An Arrangement Implementing the Nauro Agreement Setting Forth

Minimum Terms and Conditions of Access to the Fisheries Zones of the Parties, Koror, 1993

A Second Arrangement Implementing the Nauro Agreement Setting Forth Additional Minimum Terms and Conditions of Access to the Fisheries Zones of the Parties, Koror, 1990 . . . . . . . . . . . . . . 323

Western Indian Ocean Tuna Organisation Convention, Mahe, 1991

Palau Arrangement for the Management of the Western Pacific Purse Seine

Fishery, Suva, 1992

Agreement to Promote Compliance with International Conservation and

Management Measures by Fishing Vessels on the High Seas, Rome, 1993

Convention for the Conservation of Southern Bluefin Tuna, Canberra, 1993 356

Convention on the Conservation and Management of Pollock Resources in the

Central Bering Sea, Washington, D.C., 1994

Federated States of Micronesia Arrangement for Regional Fisheries Access,

Honiara, 1994 
United Nations General Assembly Resolution $48 / 445$ on Large-Scale Pelagic Drift-net Fishing and Its Impact on the Living Marine Resources of the World's Oceans and Seas, New York, 1993.

Code of Practice for Minimizing the Risks of Introducing Fish Species, Cairo, 1990

United Nations General Assembly Resolution 49/116 on Unauthorized Fishing in Zones of National Jurisdiction and Its Impact on the Living Marine Resources of the World's Oceans and Seas, New York, 1994

United Nations General Assembly Resolution 49/118 on Fisheries Bycatch and Discards and Their Impact on the Sustainable Use of the World's Living Marine Resources, New York, 1994

United Nations General Assembly Resolution 49/121 on the U.N. Conference on Straddling Fish Stocks and Highly Migratory Fish Stocks, New York, 1994

United Nations General Assembly Resolution 49/436 on Large-Scale Pelagic

Drift-net Fishing and Its Impact on the Living Marine Resources of the

World's Oceans and Seas, New York, 1994 .

Declaration of Panama, Panama City, 1995

\section{MARINE MAMMALS}

Agreement on the Regulation of Whaling, London, 1937

Amendments to the Schedule to the International Convention for the Regulation of Whaling, Kyoto, 1993

Amendments to the Schedule to the International Convention for the Regulation of Whaling, Puerto Vallarta, 1994

Amendments to the Schedule to the International Convention for the Regulation of Whaling, Dublin, 1995 .

\section{MARINE POLLUTION}

Protocol Concerning Marine Pollution Resulting from Exploration and Exploitation of the Continental Shelf to the Kuwait Regional Convention for Cooperation on the Protection of the Marine Environment from Pollution, Kuwait, 1989

Protocol for the Protection of the Marine Environment against Pollution from Land-Based Sources to the Kuwait Regional Convention for Cooperation on the Protection of the Marine Environment from Pollution, Kuwait, 1990

Convention Concerning the Prevention of Major Industrial Accidents, Geneva, 1993 
Amendments to the Convention on the International Maritime Organization, London, 1993

Amendments to the Annexes to the Convention on the Prevention of Marine

Pollution by Dumping of Wastes and Other Matter, 1972, Concerning Phasing

Out Sea Disposal of Industrial Waste, London, 1993

Final Act of the Conference of Plenipotentiaries on the Convention for the

Protection of the Mediterranean Sea Against Pollution and Its Protocols,

Barcelona, 1995 .

BILATERAL DOCUMENTS

\section{ARGENTINA}

Environment and Natural Resources

Agreement Between the U.S. National Oceanic and Atmospheric

Administration and the Ministry of Culture and Education of

Argentina for Cooperation in the GLOBE Program, Buenos Aires, 1995

AUSTRALIA

Environment and Natural Resources

Memorandum of Understanding Between the Environmental Protection

Agency of the United States of America and the Commonwealth

Environment Protection Agency of Australia for Cooperation in the

Field of Environmental Protection, Canberra, 1994

Memorandum of Understanding Between the United States National

Oceanic and Atmospheric Administration and the Department of the

Environment, Sport and Territories of Australia for Cooperation in the

GLOBE Program, Canberra, 1995

AUSTRIA

Environment and Natural Resources . . . . . . . . . . . . . . . 553

Memorandum of Understanding on Cooperation in Environmental

Aspects of Energy Policy and the Protection of the Global Climate

Between the Department of Energy of the United States of America

and the Federal Ministry of Environment, Youth and Family Affairs of

the Republic of Austria, Vienna, 1994 . . . . . . . . . . . . . . . 555

Agreement Between the National Oceanic and Atmospheric

Administration of the United States of America and the Federal

Ministry of Education of the Republic of Austria for Cooperation in the

GLOBE Program, Vienna, 1995 


\section{BELGIUM}

Environment and Natural Resources

Memorandum of Understanding Between the National Oceanic and

Atmospheric Administration of the United States of America and the Ministry of Education of the German-Speaking Community (Belgium) for Cooperation in the GLOBE Program, Brussels, 1995

Memorandum of Understanding Between the National Oceanic and Atmospheric Administration of the United States of America and the Department of Education of the Flemish Community (Belgium) for Cooperation in the GLOBE Program, Brussels, 1995

\section{BENIN}

Environment and Natural Resources

Agreement of Cooperation Between the Government of the United

States of America and the Government of the Republic of Benin for

Cooperation in the GLOBE Program, Cotonou, 1995

\section{BOLIVIA}

Environment and Natural Resources .

Agreement Between the Government of the United States of America and the Government of Bolivia for Cooperation in the GLOBE

Program, La Paz, 1995 .

\section{CANADA}

Environment and Natural Resources

Memorandum of Understanding Between the United States Department of Agriculture and Forestry Canada on Cooperation in the Field of

Forestry-Related Programs, Washington, D.C., 1990

Agreement Between the Government of the United States of America and the Government of Canada on Cooperation in the Boreal Ecosystem-Atmosphere Study (BOREAS), Washington, D.C., 1994

Fisheries

Amendment to the Treaty Between the Government of the United States of America and the Government of Canada Concerning Pacific Salmon, Washington, D.C., 1993

Agreement Between the Government of the United States of America and the Government of Canada for the Conservation of Salmon Stocks Originating from the Yukon River, Washington, D.C., 1995

Agreement Between the Government of the United States of America and the Government of Canada on the Establishment of a Mediation Procedure Regarding the Pacific Salmon Treaty, Montreal, 1995 
Fisheries

Memorandum of Understanding Between the Government of the United

States of America and the Government of the People's Republic of

China on Effective Cooperation and Implementation of United

Nations General Assembly Resolution 46/215 of December 20, 1991,

Washington, D.C., 1993

Amendment to the Agreement Between the Government of the United

States of America and the Government of the People's Republic of

China Concerning Fisheries off the Coasts of the United States,

Beijing, 1994

COSTA RICA

Environment and Natural Resources

Statement of Intent for Bilateral Sustainable Development, Cooperation and Joint Implementation of Measures to Reduce Emissions of Greenhouse Gases Between the Government of the United States of America and the Government of the Republic of Costa Rica, Washington, D.C., 1994

CZECH REPUBLIC

Environment and Natural Resources .

Agreement Between the U.S. National Oceanic and Atmospheric

Administration and the Ministry of Education, Youth, and Sports of the Czech Republic for Cooperation in the GLOBE Program, Prague, 1995

\section{EGYPT}

Environment and Natural Resources .

Agreement Between the National Oceanic and Atmospheric

Administration of the United States of America and the Ministry of

Education of the Arab Republic of Egypt for Cooperation in the

GLOBE Program, Cairo, 1995 . 


\section{EUROPEAN COMMUNITY}

Environment and Natural Resources . . . . . . . . . . . . . . . . . 655

Memorandum of Understanding Between the National Science

Foundation in Washington, D.C., for the United States of America and the European Science Foundation in Strasbourg, France on the

Participation of the European Science Foundation Consortium in the Ocean Drilling Program as a Regular Member, Washington, D.C., and Strasbourg, 1993

FINLAND

Environment and Natural Resources . . . . . . . . . . . . . . . 6663

Agreement Between the U.S. National Oceanic and Atmospheric

Administration and the National Board of Education of Finland for

Cooperation in the GLOBE Program, Helsinki, 1995

FRANCE

Environment and Natural Resources

Memorandum of Understanding Between the National Science

Foundation in Washington, D.C., for the United States of America and

Institut Francais de Recherche pour l'Exploitation de la Mer on the

Participation of France in the Ocean Drilling Program, Washington,

D.C., and Paris, 1993

GERMANY .

Environment and Natural Resources .

Memorandum of Understanding Between the National Science

Foundation in Washington, D.C., for the United States of America and

the Deutsche Forschungsgemeinschaft on the Participation of the

Federal Republic of Germany in the Ocean Drilling Program as a

Regular Member, Washington, D.C., and Bonn, 1993

IRELAND

Environment and Natural Resources . . . . . . . . . . . . . . . . . . . 689

Agreement Between the U.S. National Oceanic and Atmospheric

Administration and the Department of Education of Ireland for

Cooperation in the GLOBE Program, Dublin, 1995 
Environment and Natural Resources . 697

Agreement Between the National Oceanic and Atmospheric

Administration of the United States of America and the Ministries of

the Environment, and Education, Culture and Sport of the State of Israel for Cooperation in the GLOBE Program, Jerusalem, 1995 .

Environment and Natural Resources

Memorandum of Understanding Between the Geological Survey of the

Department of the Interior of the United States of America and the Public Works Research Institute of the Ministry of Construction of Japan Concerning Cooperation in the Field of Hydrology, Water

Resources, and Global Climate Change, Reston and Tsukuba, $1992 \ldots 707$

Protocol, Reston and Tsukuba, 1995 . . . . . . . . . . 711

Memorandum of Understanding Between the National Science

Foundation in Washington, D.C., for the United States of America and the Ocean Research Institute of the University of Tokyo in Tokyo, Japan on the Participation of Japan in the Ocean Drilling Program as

a Regular Member, Washington, D.C., and Tokyo, 1993 . . . . . . . . . 713

Fisheries

Agreement Between the Government of the United States of America and the Government of Japan Establishing a Consultative Committee on Fisheries, Washington, D.C., 1992

Agreement Between the Government of the United States of America and the Government of Japan on Maritime Fishing Boundaries, Tokyo, 1994

KAZAKHSTAN, REPUBLIC OF . . . . . . . . . . 727

Environment and Natural Resources . . . . . . . . . . . . . . . . . 727

Agreement Between the Government of the United States of America and the Government of the Republic of Kazakhstan for Cooperation in the Fields of Protection of the Environment and Natural Resources, Washington, D.C., 1995

Agreement Between the Government of the United States of America and the Government of the Republic of Kazakhstan for Cooperation in the GLOBE Program, Washington, D.C., 1995 


\section{KOREA, REPUBLIC OF}

Environment and Natural Resources . . . . . . . . . . . . . . . . . . 741

Agreement Between the National Oceanic and Atmospheric

Administration of the United States of America and the Ministry of

Education of the Republic of Korea for Cooperation in the GLOBE

Program, Seoul, 1995

Fisheries

Amendment to the Agreement Between the Government of the United

States of America and the Government of the Republic of Korea

Concerning Fisheries off the Coasts of the United States, Washington,

D.C., 1993 .

\section{KYRGYZSTAN, REPUBLIC OF}

Environment and Natural Resources . . . . . . . . . . . . . . . . . . . 753

Agreement Between the National Oceanic and Atmospheric

Administration of the United States of America and the Ministry of

Education of the Republic of Kyrgyzstan for Cooperation in the

GLOBE Program, Washington, D.C., 1995

\section{LATVIA}

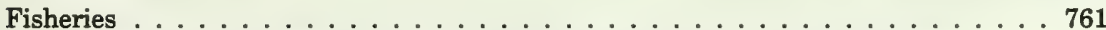

Agreement Between the Government of the United States of America

and the Government of the Republic of Latvia Concerning Fisheries off the Coasts of the United States, Washington, D.C., 1993 . . . . . . . 763

Amendment, Riga, 1995 . . . . . . . . . . . . . . 771

\section{MALAYSIA}

Marine Pollution .

Agreement Between the Government of the United States of America

and the Government of Malaysia Concerning the Transboundary

Movement of Hazardous Wastes from Malaysia to the United States,

Kuala Lumpur, 1995

MEXICO

Environment and Natural Resources . . . . . . . . . . . . . . . . . . . . 781

Agreement Between the Government of the United States of America

and the Government of the United Mexican States on Improvements

to the Conveying Capacity of the International Boundary Segment of

the Colorado River, San Diego, 1994 
Agreement Between the Government of the United States of America and the Government of the United Mexican States Concerning the Establishment of a Border Environment Cooperation Commission and a North American Development Bank, Washington, D.C., and Mexico City, 1993

Non-Binding Documents

Memorandum of Understanding Between the Southwest Fisheries

Center of the National Marine Fisheries Service, U.S. Department of Commerce and the National Fisheries Institute of the Mexican Secretariat of Fisheries on Fishery Research and Technological Cooperation, Manzanillo, 1992

\section{MOLDOVA}

Environment and Natural Resources .

Agreement Between the Government of the United States of America and the Government of Moldova for Cooperation in the GLOBE Program, Washington, D.C., 1995

\section{THE NETHERLANDS}

Environment and Natural Resources . . . . . . . . . . . . . . . . 825

Memorandum of Understanding Between the Government of the United

States of America and the Government of the Netherlands for

Cooperation in the GLOBE Program, Washington, D.C., 1995

\section{NORWAY}

Environment and Natural Resources . . . . . . . . . . . . . . . . . 833

Agreement Between the Department of Defense of the United States of

America and the Ministry of Defense of the Kingdom of Norway for

Cooperation on Environmental Protection in Defense Matters,

Baltimore, 1994

Agreement Between the Government of the United States of America and the Government of Norway for Cooperation in the GLOBE

Program, Washington, D.C., 1995 
POLAND

Fisheries

Amendment to the Agreement Between the Government of the United

States of America and the Government of the Republic of Poland

Concerning Fisheries off the Coasts of the United States, Washington,

D.C., 1993 .

\section{ROMANIA}

Environment and Natural Resources.

Agreement Between the U.S. National Oceanic and Atmospheric

Administration and the Ministry of Education of Romania for

Cooperation in the GLOBE Program, Bucharest and Washington,

D.C., 1995 .

\section{RUSSIA}

Environment and Natural Resources . . . . . . . . . . . . . . . . . 865

Agreement Between the Government of the United States of America and the Government of the Russian Federation on Cooperation in Research on Radiation Effects for the Purpose of Minimizing the Consequences of Radioactive Contamination on Health and the Environment, Moscow, 1994 .

Memorandum of Understanding Between the Forest Service of the

United States Department of Agriculture and the Federal Forest

Service of Russia on Cooperation in the Field of Forestry, Washington,

D.C., 1994 .

Agreement Between the Government of the United States of America

and the Government of the Russian Federation on Cooperation in the

Field of Protection of the Environment and Natural Resources,

Washington, D.C., 1994

Agreement Between the Government of the United States of America

and the Government of the Russian Federation for Cooperation in the

GLOBE Program, Moscow, 1994

Agreement Between the Government of the United States of America and the Government of the Russian Federation on Cooperation in the

Prevention of Pollution of the Environment of the Arctic, Moscow, 1994

Fisheries

Amendment to the Agreement Between the Government of the United

States and the Government of the Russian Federation on Mutual

Fisheries Relations, Washington, D.C., 1993

Amendment to the Agreement Between the Government of the United

States and the Government of the Russian Federation on Mutual

Fisheries Relations, Washington, D.C., 1993-1994 
Non-Binding Documents . . . . . . . . . . . . . . . . . . . 901

Protocol of the U.S.-Russia Workshop on Sea Otter Biology under the

Marine Mammal Project, 02.05-61 U.S.-Russia Environmental

Agreement, Wasilla, 22 October 1993 . . . . . . . . . . . . . . . 903

Protocol of the Twelfth Meeting of the Marine Mammal Project,

U.S.-Russia Environmental Protection Agreement, Anchorage, 1993 . . . . 907

Protocol of the U.S./Russia Technical Consultation for the Conservation

of Polar Bears of the Chukchi/Bering Sea Region, Nome, 1994 . . . . . 914

Protocol of the Fifth U.S.-Russia Workshop on Sea Otter Biology,

Paratunka, $1995 \ldots \ldots$. . . . . . . . . . . . . . 916

Protocol of the First Technical Meeting Concerning the Intention of the

United States and Russia to Conclude Bilateral Agreements on the

Conservation and Management of the Pacific Walrus,

Petropavlovsk-Kamchatskiy, 1995

Protocol of the U.S.-Russia Working Meeting for the Preparation of Draft

Principles for the Conservation and Management of the

Chukotka-Alaska Population of Polar Bears,

Petropavlovsk-Kamchatskiy, 1995

Protocol of the Thirteenth Working Group Meeting Under Project

02.05-61 "Marine Mammals," of the U.S.-Russia Environmental

Agreement, Paratunka, 1995

SWEDEN

Environment and Natural Resources . . . . . . . . . . . . . . . . . 935

Agreement Between the Department of Defense of the United States of

America and the Armed Forces of the Kingdom of Sweden for

Cooperation on Environmental Protection in Defense Matters,

Stockholm, 1995

\section{TUNISIA}

Environment and Natural Resources . . . . . . . . . . . . . . . . . . . 949

Agreement Between the National Oceanic and Atmospheric

Administration of the United States of America and the Ministry of

Environment of Tunisia for Cooperation in the GLOBE Program,

Washington, D.C., 1995

\section{TURKEY, REPUBLIC OF}

Environment and Natural Resources . . . . . . . . . . . . . . . . . . 957

Agreement Between the Government of the Republic of Turkey and the

Government of the United States of America for Cooperation in the

GLOBE Program, Ankara, 1995 


\section{UNITED KINGDOM}

Environment and Natural Resources . . . . . . . . . . . . . . . . . . . 965

Memorandum of Understanding Between the National Science

Foundation in Washington, D.C., for the United States of America and

Natural Environment Research Council on the Participation of the

United Kingdom in the Ocean Drilling Program as a Regular Member,

Swindon, 1992

Fisheries

Convention Between the Government of the United States of America

and the Government of the United Kingdom Concerning Sockeye

Salmon Fisheries in the Fraser River System, Washington, D.C., 1930 . . . . 977

Other

Treaty Between the Government of the United States of America and the

Government of the United Kingdom of Great Britain and Northern

Ireland on the Delimitation in the Caribbean of a Maritime Boundary

Relating to Puerto Rico/U.S. Virgin Islands and the British Virgin

Islands, London, 1993

Treaty Between the Government of the United States of America and the

Government of the United Kingdom of Great Britain and Northern

Ireland on the Delimitation in the Caribbean of a Maritime Boundary

Relating to the U.S. Virgin Islands and Anguilla, London, 1993

\section{URUGUAY}

Environment and Natural Resources . . . . . . . . . . . . . . . . . . . 993

Agreement Between the National Oceanic and Atmospheric

Administration of the United States of America and the Ministry of

Housing, Land Use Planning, and the Environment of the Oriental

Republic of Uruguay for Cooperation in the GLOBE Program,

Montevideo, 1995.

Cooperative Agreement Between the National Oceanic and Atmospheric

Administration and the Alaska Eskimo Whaling Commission, Washington,

D.C., 1984

Inuvialuit Game Council and North Slope Borough Management Agreement for

Polar Bears of the Southern Beaufort Sea, Inuvik, 1988

Memorandum of Agreement Between the U.S. Fish and Wildlife Service, the Alaska Sea Otter Commission, and the Alaska Department of Fish and Game, Anchorage, 1994 



\section{Preface}

This is the first in a series of updates to the reference work entitled The Marine Mammal Commission Compendium of Selected Treaties, International Agreements, and Other Relevant Documents on Marine Resources, Wildlife, and the Environment, compiled for the Marine Mammal Commission in 1994 by Richard L. Wallace. That work began as a result of a 1991 project which required gathering two decades of treaties and international agreements concerning the management of high seas fisheries. Finding and acquiring copies of the documents proved difficult at best, and highlighted the general need to develop a collection of fisheries agreements that would facilitate analysis of international law in this area. While pursuing the desired agreements, it became clear that access to international legal documents in many fields concerning wildlife, natural resources, and the environment was limited by a lack of organization and delays in publishing. Many treaties and agreements outlining the United States' international legal obligations were inaccessible to all but the most intrepid researcher. Under Mr. Wallace's skilled direction, what began as a simple research project soon blossomed into an enormous undertaking to collect and publish a broad and nearcomprehensive collection of international legal documents concerning wildlife, natural resources, and the environment.

The project resulted in the original Compendium, a three-volume, 3,500-page collection of international environmental and natural resource law. The original Compendium compiled for the first time in one place the complete texts of more than $\mathbf{4 0 0}$ international agreements, including bilateral and multilateral treaties, agreements, conventions, accords, memoranda of understanding, amendments and protocols, and other relevant documents. It included documents current through 31 December 1992, as well as a selection of historically important documents. Since its publication, the original Compendium has become the preeminent source of international environmental law available anywhere, and has been adopted for use by legal scholars, government officials, researchers, and students of international law around the world.

This First Update, also carefully and ably compiled by Mr. Wallace, continues the tradition of excellence established by the original Compendium. It includes in more than 1,000 pages the complete texts of more than 110 international legal documents concluded between 1 January 1993 and 31 December 1995, as well as several older but still relevant documents not included in the original Compendium. Like the original, the First Update is divided into two sections comprising multilateral and bilateral documents involving the United States, and then organized logically into several subject areas. Within the multilateral section, the documents are arranged using the same subject areas as the original Compendium: Antarctica, Environment and Natural Resources, Fisheries, Marine Mammals, Marine Pollution, and Other. Within the bilateral section, the documents are arranged alphabetically by nation. Subheadings under each nation correspond to the subject headings given above.

Other elements of the First Update also follow the example of the original Compendium. Each document is accompanied by useful background information, including its primary source citation, the city in which the document was concluded, the date on which it was concluded, and, where applicable, the date it entered into force and the depositary nation for 
instruments of ratification. Agreements that are noted as not being in force for the United States fall into three categories. These include agreements not yet signed by the United States, those signed by the United States but not yet ratified by the U.S. Congress, and those the terms of which limit their membership or participation to particular states or regions or establish other criteria that exclude the United States from becoming a party.

As with the original Compendium, strict quality control measures were undertaken. Guidance was again provided by the Advisory Board to ensure the most useful and appropriate content, structure, and format. Every document was meticulously reviewed for completeness, legibility, and consistency with other versions, where applicable. During scanning and typesetting, every document was subject to strict quality control measures, including four separate proof readings. A final review of the entire First Update was done before it went to press.

Almost all the documents included in the First Update were obtained from individuals or offices of the U.S. Department of State, the National Marine Fisheries Service of the U.S. Department of Commerce, or the Fish and Wildlife Service of the U.S. Department of the Interior. Sources of other documents include the International Whaling Commission, International Labour Office, International Council for the Exploration of the Sea, South Pacific Forum Secretariat, South Pacific Forum Fisheries Agency, Ministry of Foreign Affairs of the Soloman Islands, and the University of the South Pacific Department of Law.

I am grateful to many individuals for their participation in this project. First and foremost my thanks go to Richard L. Wallace. His leadership, attention to detail, and devotion to the projects made both the original Compendium and this First Update possible. Special thanks are also due the Marine Mammal Commission's three commissioners, John E. Reynolds, III, Vera Alexander, and Paul K. Dayton, who were faithful in their support throughout the project. I am grateful for the generous support of the National Marine Fisheries Service of the U.S. Department of Commerce and the Bureau of Oceans and International Environmental and Scientific Affairs of the U.S. Department of State. Their financial, research, and practical support has been crucial to the success of the projects.

The Advisory Board continued its willing and generous support, providing assistance from the earliest stages of the original Compendium through the completion of the First Update.

Several advisors went above and beyond the call of duty in their assistance to $\mathrm{Mr}$. Wallace in identifying, tracking down, and providing documents for the First Update. Lee A. Kimball again proved herself a friend and scholar in the field of international law. Her continual encouragement and assistance are greatly appreciated. Grant James Hewison also provided vital help, especially in procuring documents concerning issues of import to the South Pacific region. Henry R. Beasley, of the National Marine Fisheries Service, and Donald C. Baur, of Perkins Coie, also provided crucial support in identifying and collecting documents.

Finally, the staff members of the U.S. Department of State's Office of the Assistant Legal Advisor for Treaty Affairs have been and remain irreplaceable in their knowledge and assistance.

John R. Twiss, Jr.

Executive Director

Marine Mammal Commission

Bethesda, Maryland

July 1997 


\section{Abbreviations and Citations}

The following list identifies abbreviations and citations used to indicate primary sources of documents in this volume:

TIAS United States Treaties and Other

International Acts Series

TS

United States Treaty Series

UST

United States Treaties and Other

International Agreements 



\section{U L T I L A}

Antarctica 



\title{
Measures Approved or Recommended Under Article IX in Furtherance of the Principles and Objectives of the Antarctic Treaty, Venice, 1992
}

\author{
Done at Venice 20 November 1992 \\ Primary source citation: Copy of text provided by the \\ U.S. Department of State
}

Recommendation XVII-1

\section{ENVIRONMENTAL MONITORING AND DATA MANAGEMENT}

The Representatives,

Recalling Recommendations XV-5, XV-16, XVI-12 and paragraphs 106-109 of the Report of the XVIth ATCM;

Noting the report and the valuable work of the First Meeting of Experts on Environmental Monitoring in Antarctica (XVII ATCM/INFO 9) and the recommendations set forth in the afore mentioned report;

Noting that better data management can improve the quality of Antarctic Environmental Monitoring, operations, and science;

Noting additionally the report by SCAR-COMNAP (XVII ATCM/WP 5) describing actions that could be taken to develop a coordinated data management system with the intent to improve the comparability and accessibility of both scientific and environmental data being collected by national programmes, as called for by ATCM Recommendations XIII-5 and XV-16.

Recognising that, in the Final Act of the Protocol on Environmental Protection to the Antarctic Treaty, it was agreed that it was desirable to ensure effective implementation at an early date; and that paragraph 69 of the Report of the XVIth ATCM exhorts the Consultative Parties to ratify the Protocol as soon as possible, and that meanwhile efforts also should be made to implement the provisions of the Annexes as rapidly and completely as possible.

Acknowledging that in order to meet the requirements of the Protocol on Environmental Protection to the Antarctic Treaty that calls, under Articles 3.2 (d) and 3.2 (e), for regular and effective monitoring, to allow assessment of the adverse impacts of human activities, it is necessary to focus environment impact monitoring particularly on anthropogenic effects at a local level;

Aware that once established, the Committee for Environmental Protection may offer its advice on these measures, consistent with its terms of reference as provided for in the Protocol;

Aware that applied monitoring can be expensive and may require long term commitment and that any environmental monitoring should be scientifically defensible, practicable and cost-effective; 
Recommend to their Governments that they:

1. Through their SCAR National Committees request SCAR to consider and provide advice on:

(i) The types of long-term programmes, if any, necessary to verify that human activities (such as tourism, scientific research or other activities) do not have significant adverse effects on birds, seals and plants; and

(ii) emission standards that should be established to ensure that the combustion of fossil fuels and incineration of waste do not contaminate the Antarctic atmosphere, terrestrial, ice, aquatic or marine environments in a way that would compromise their scientific values;

2. Ask their COMNAP Representatives in consultation with SCAR to establish research programmes at a representative subset of facilities in Antarctica to determine how different types and sizes of facilities in different localities (eg. coastal and inland stations on rocks and on ice shelves) affect the Antarctic environment;

3. Provide a list of the Antarctic data sets being compiled and archived by their nationals and make this list available to other Parties, SCAR and COMNAP, as soon as possible, to form the basis for the development of an Antarctic Data Directory;

4. Establish, as appropriate, national arrangements for obtaining expert advice on the types of data products and data access mechanisms which would best meet both the basic scientific requirements and long-term environmental monitoring requirements.

\section{Recommendation XVII-2}

\section{REVISED DESCRIPTIONS AND PROPOSED MANAGEMENT PLANS FOR SPECIALLY PROTECTED AREAS}

The Representatives,

Recalling Recommendations XV-8 and XV-9;

Noting that revised Area Descriptions and proposed Management Plans have been approved by the Scientific Committee on Antarctic Research (SCAR);

Noting also that the format of these revised Area Descriptions and proposed Management Plans accord with Article 5 of Annex V of the Protocol on Environmental Protection to the Antarctic Treaty adopted under Recommendation XVI-10;

Recommend to their Governments that for the Specially Protected Areas listed below:

(i) the Descriptions inserted in Annex B, Specially Protected Areas, of the Agreed Measures for the Conservation of Antarctic Fauna and Flora be deleted;

(ii) the Descriptions and Management Plans of Specially Protected Areas, annexed to this Recommendation, be inserted in Annex B, Specially Protected Areas, of the Agreed Measures for the Conservation of Antarctic Fauna and Flora.

The Specially Protected Areas involved are:

AREA No. 1 Taylor Rookery, Mac Robertson Land;

AREA No. 2 Rookery Islands, Holme Bay, Mac Robertson Land; 
AREA No. 3 Ardery Island and Odbert Island, Budd Coast;

AREA No. 20 "New College Valley", Caughley Beach, Cape Bird, Ross Island.

\section{MANAGEMENT PLAN FOR SPECIALLY PROTECTED AREA (SPA) No.1}

\section{TAYLOR ROOKERY, MAC ROBERTSON LAND}

\section{DESCRIPTION OF VALUES TO BE PROTECTED}

The area was originally designated a Specially Protected Area because it contains a colony of emperor penguins (Aptenodytes forsteri) which is one of the few, and probably the largest, of the known colonies of this species located wholly on land. Almost all other emperor penguins rookeries are located on sea ice. The rookery is also important because of long-term monitoring of the population of the penguins (since 1954). The colony is ideal for counting since it is surrounded by small rocky hills which make it possible to observe every bird without entering the breeding area. A photographic census programme has been carried out annually since 1988, and it is believed that this method has resulted in almost complete accuracy of counting.

\section{AIMS AND OBJECTIVES}

Management of the Area aims to:

* prevent unnecessary disturbance to the emperor penguin colony at Taylor Rookery; and

* permit research of a compelling scientific nature which can not be undertaken elsewhere, while ensuring no significant disturbance to the ecosystem of the area including the penguin colony.

\section{MANAGEMENT ACTIVITIES}

The management plan and activities in the area should be kept under review to ensure that the values for which the area was designated are being fully protected. Inspection visits may be made only when considered essential for management purposes.

\section{PERIOD OF DESIGNATION}

Designated under ATCM Recommendation IV-1 in November 1966, for an indefinite period.

\section{DESCRIPTION OF THE AREA}

(a) Geographical coordinates and natural features of the Area:

The Area consists of the whole of the northernmost rock exposure on the east side of Taylor Glacier, Mac Robertson Land $\left(67^{\circ} 26^{\prime} \mathrm{S} ; 60^{\circ} 50^{\prime} \mathrm{E}\right)$. The rookery is located on a low lying rock outcrop in the South-West corner of a bay formed by Taylor Glacier to the West, the polar ice cap to the South and the islands of Colbeck Archipelago to the East. The area is surrounded by sea ice to the North and East. The Area is some 90 kilometres West of Mawson station. There is ice free terrain adjacent to the glacier on the western boundary and to the south the rock rises steeply to meet the ice of the plateau. The rock itself forms a horseshoe around a central flat area of exposed rock and moraine. This Area is covered with snow in winter and is occupied by the emperor penguins. The compressed snow melts in summer to form a shallow lake and stream which exits to the North-East. The sides of the horseshoe are rounded ridges of rock which are bare and smoothed by ice.

Otherwise the terrain is rough and dissected with cracks and fissures. The average height of the ridges is about 30 meters. The Area also has a raised beach which is typical of several found along the coast of Mac Robertson Land. The beach is composed of locally derived pebbles, cobbles and boulders between $1 \mathrm{~cm}$ and $1 \mathrm{~m}$ across. It slopes upwards from the shoreline to a well defined platform several meters broad and 3 to $6 \mathrm{~m}$ above sea level.

There are no boundary markers since the Area is easily defined by its natural features. 


\section{(b) Access to the Area}

Access to the Area is only in accordance with a permit or authority issued by a Contracting Party or its authorised representative.

Restrictions apply to the mode of transport to and within the Area, and access points are prescribed; see Section 8 (a).

(c) Location of structures including scientific stations, research and refuge facilities both within and near the Area:

There are no structures within the Area and no permanent structures are permitted. A four-berth refuge is located in the Colbeck Archipelago, approximately 5 kilometers to the North-East of the Area (see Map B): Mawson Station $\left(67^{\circ} 36^{\prime} \mathrm{S}, 62^{\circ} 53^{\prime} \mathrm{E}\right)$ is approximately 90 kilometers to the East.

(d) Location of other protected areas in or near the Area:

The Rookery Islands (Specially Protected Area No. 2) are located some 80 kilometers to the East of Taylor Rookery (see Map A).

\section{IDENTIFICATION OF RESTRICTED ZONES}

Access to the emperor penguin colony, marked on Map C, is prohibited unless authorised in a permit.

\section{MAPS OF THE AREA}

Map A shows the location of the Area in relation to the Mawson region;

Map B shows the location of the field hut on the Colbeck Archipelago, and access routes to the Area;

Map $\mathbf{C}$ shows the Area in greater detail, including the usual location of the penguin colony, and the area where all activity such as landing helicopters and installing field huts or field camps should take place, where permitted.

\section{CONDITIONS UNDER WHICH PERMITS MAY BE GRANTED}

Criteria for issuing a permit to enter the Area are that:

* it is issued for a compelling scientific purpose which can not be undertaken elsewhere;

* the actions permitted will not jeopardise the natural ecological system existing in the Area; and

* the actions permitted are in accordance with the management plan for the Area.

\section{Conditions applying:}

(a) Access to and movement within the Area:

i) Whatever possible, access should be from sea ice to the east of Colbeck Archipelago, to avoid disturbance to the birds by crossing their pathways from the rookery to the sea (see Map B). Persons in the vicinity, not approaching the colony, should also be aware of the penguins pathways, and take care to cause as little disturbance to them as possible.

ii) Travel to the Area may be by oversnow vehicle, which is generally only possible during the period 1 May to 25 December, or by helicopter. Vehicle entry to the Area is prohibited. Oversnow vehicles used for transport to the Area are to be left outside the Area, to the East, and entry must be by foot. The approach route for vehicles is marked on Map B. 
iii) Helicopters are not permitted to land in the Area unless sea ice conditions outside the Area are such that it would be hazardous for aircraft to land on ice or for personnel to walk on it. If sea ice conditions are not suitable, helicopters are authorised to land in the Area, to the North-East at the point marked " $\mathrm{H}$ ", where a headland to the South obscures the colony from view (see Map C). Map B shows the helicopter access route.

iv) The following conditions apply to the use of helicopters:

* helicopters are to approach the Area from the East over the sea ice and, where sea ice conditions permit, land outside the Area, with access being by foot (see Map B);

* overflight of the rookery is prohibited;

* when landing outside the Area, helicopters should not land, take off or fly within 500 meters of the rookery;

* if landing inside the Area is essential due to sea ice conditions helicopters should land in the North-East of the Area at the point marked " $\mathrm{H}$ ", where a headland to the South obscures the colony from view (see Map C);

* helicopters approaching to land in the Area must fly as low as possible over the sea ice to avoid disturbing the colony; and

* helicopters are not to be refueled within the Area.

v) There are no marked pedestrian routes within the Area; pedestrian should keep well away from the penguins, unless disturbance to the penguins is authorised by permit. Movement in and around the Area should be such that, in general, the routes used by the birds are not crossed.

vi) Dogs are not to be used for transport to the Area.

(b) Activities which are, or may be, conducted within the Area, including restrictions on time and place:

i) The penguins are particularly sensitive to disturbance during the following periods:

* when they are incubating eggs, from mid-May to mid-July; and

* from mid-July, when feeding chicks to mid-December, when the chicks fledge. However penguins are known to be present at the rookery during every month except February, when no recorded expeditions to the rookery have been made; restrictions therefore apply yearround.

ii) The emperor penguin colony is ideal for counting. Normally the best vantage point for viewing and photographing the penguins is a rocky headland which runs adjacent to Taylor Glacier, on the western side of the rookery. The ideal time for a census is from 22 June to 5 July, since during this time only incubating males are present, each representing one breeding pair. An ongoing photographic census programme has been carried out since 1988.

iii) Other activities which may be conducted in the Area:

* compelling scientific research which can not be undertaken elsewhere and which will not jeopardise the ecosystem of the Area; and

* compelling management activities, which if not carried out would jeopardise the values for which the Area was designated. 
(c) The installation, modification, and removal of structures:

No structures are to be installed in the Area unless essential for scientific purposes; any structure installed should be removed when it is no longer required. Only the minimum number of personnel necessary to install and to remove the structure should be used. Temporary field huts if permitted, should be placed well away from the penguin colony at the point marked " $\mathrm{X}$ ", to the North-East of the Area, where a headland to the South obscures the colony from view (see Map C).

(d) The location of field camps:

See (c) above.

(e) Restriction on materials and organisms which may be brought into the Area:

i) No poultry products, including dried food containing egg powder, are to be taken into the Area.

ii) No depots of food or other supplies are to be left within the Area beyond the season for which they are required.

iii) Fuel is not to be depoted in the Area, unless required by a visitor for personal use, (i.e.) for cooking/heating in a field hut, and is to be removed when no longer required.

(f) The taking of, or harmful interference with, native flora and fauna:

Taking of, or harmful interference with, native flora and fauna is prohibited unless specifically authorised by permit issued in accordance with the Agreed Measures for the Conservation of Antarctic Fauna and Flora, or Article 3 of Annex II to the Protocol on Environmental Protection to the Antarctic Treaty, whichever is appropriate.

(g) The collection or removal of anything not brought into the Area by the permit holder:

There is to be no collection or removal of anything not brought into the Area by permit holder unless specifically authorised by permit for scientific or management purposes.

(h) The disposal of waste:

No wastes, including human wastes, are to be left in the Area.

(i) Measures that may be necessary to ensure that the aims and objectives of the management plan can continue to be met:

* Permits should specify the maximum number of people allowed entry at any one time.

* Visits to the Area should be kept to the minimum necessary to achieve the research and management objectives.

* Access should be permitted where necessary to place or remove structures or equipments.

(j) Requirements for reports:

Each permit holder shall submit a report to the permit issuing authorities detailing the activities undertaken within the Area including a summary of research findings, and comments indicating measures taken to ensure compliance with conditions. Where appropriate, the report may make recommendations relevant to the management of the Area, in particular, as to whether the values for which the Area was designated are being adequately protected. The report should be submitted as soon as practicable after the visit to the Area has been completed. 


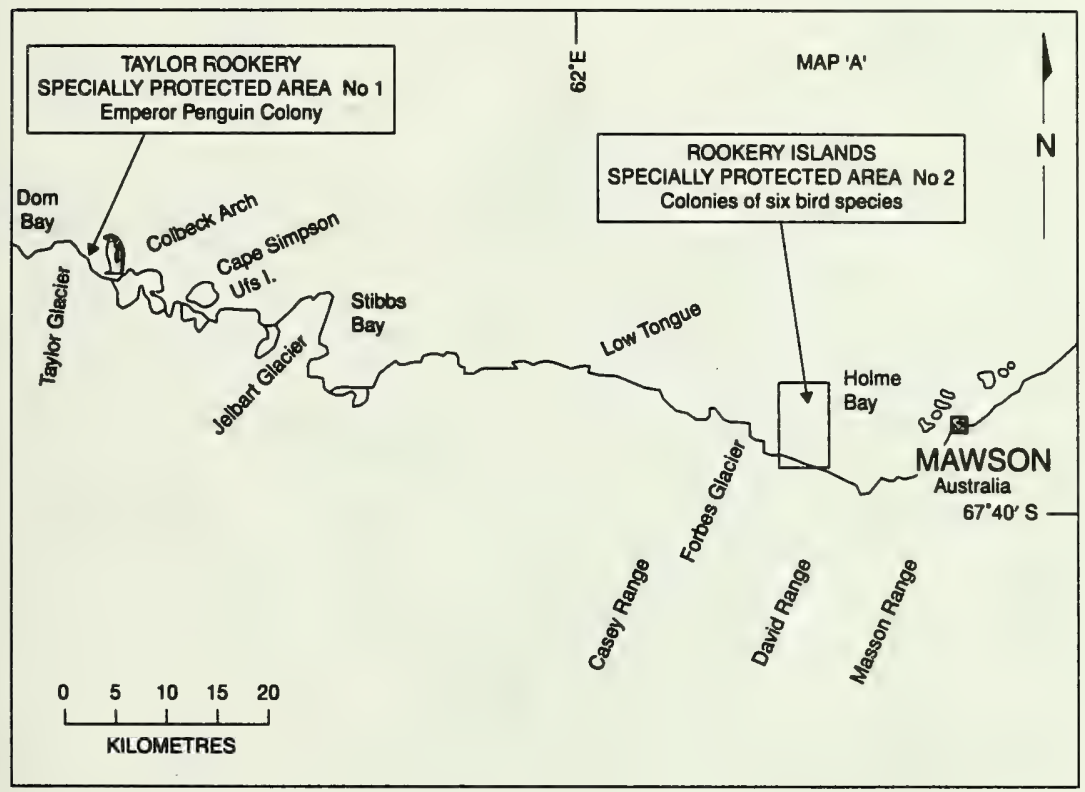




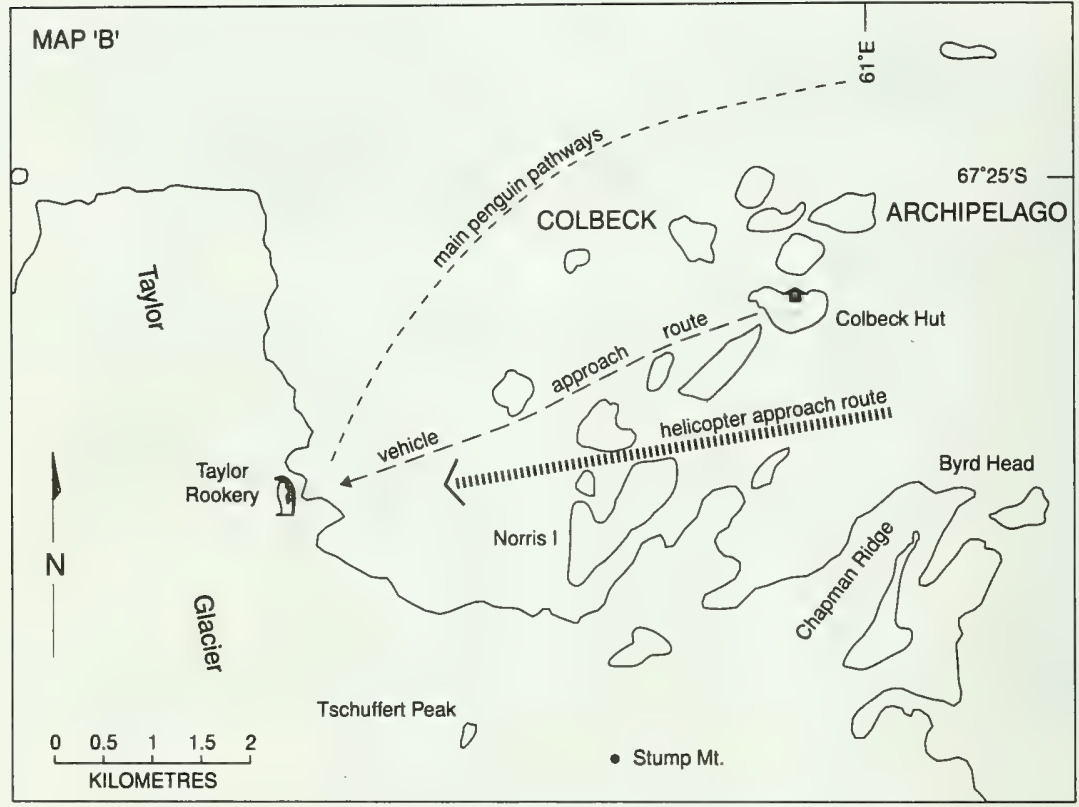




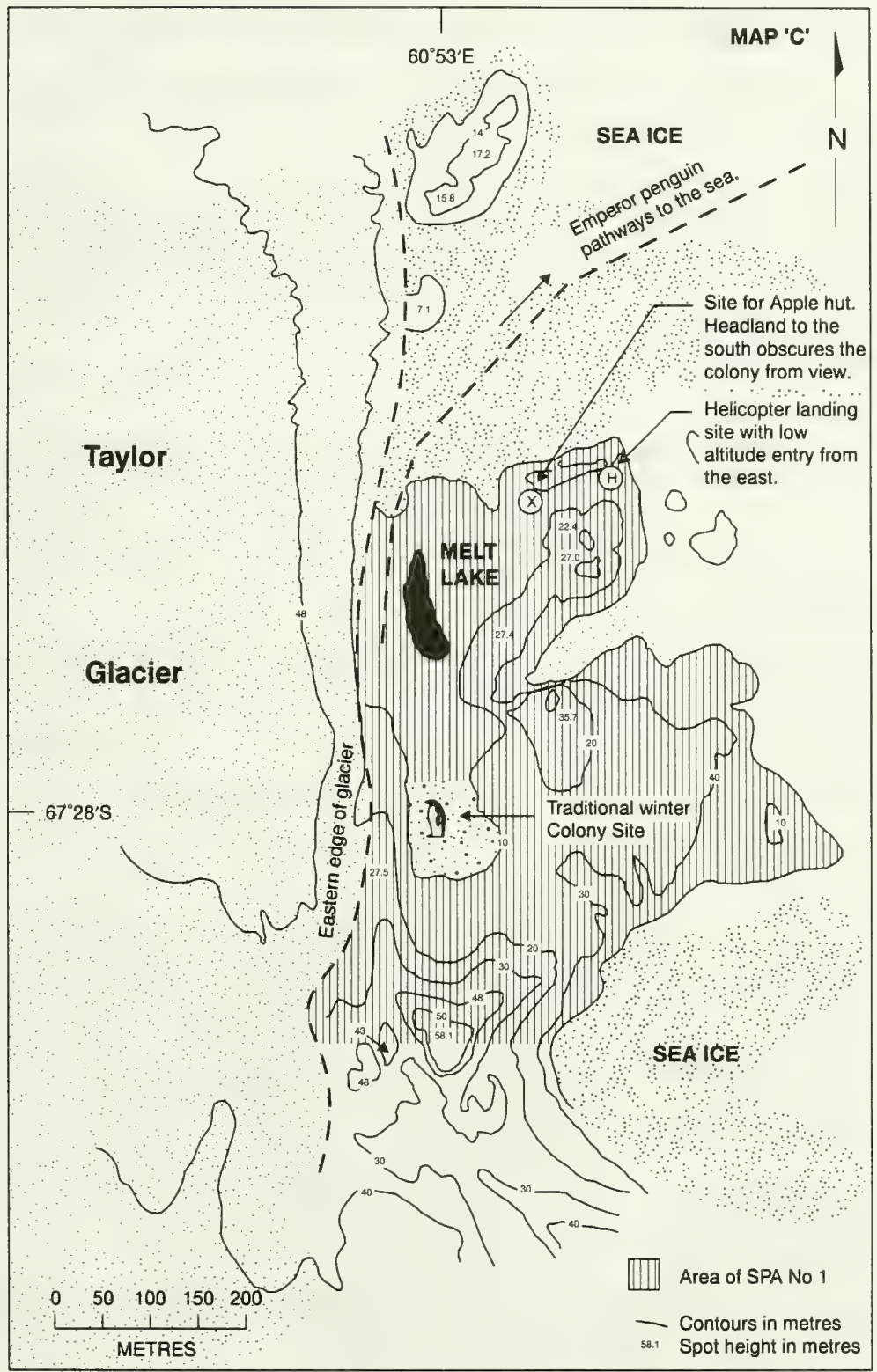




\section{MANAGEMENT PLAN FOR SPECIALLY PROTECTED AREA (SPA) No.2}

\section{ROOKERY ISLANDS, HOLME BAY, Mac ROBERTSON LAND}

\section{DESCRIPTION OF VALUES TO BE PROTECTED}

The Rookery Islands contain breeding colonies of six bird species resident in the Mawson area; Adélie penguin (Pygoscelis adeliae), Cape petrel (Daption capensis), snow petrel (Pagodroma nivea), southern giant petrel (Macronectes giganteus), Wilson's storm petrel (Oceanites oceanicus) and the Antarctic skua (Catharacta maccormicki). The southern giant petrel breeds nowhere else in the region. The designation of the Area aims to safeguard this unusual association of six species and ensure the preservation of a sample offshore island habitat.

\section{AIMS AND OBJECTIVES}

Management of the Area aims to:

* maintain a reference area unmodified by human interference;

* permit research of a compelling scientific nature which can not be undertaken elsewhere, while ensuring no significant disturbance to the ecosystem of the Area and maintaining the status of the SPA as a reference area; and

* ensure that the breeding colony of southern giant petrels, which is close to the point of local extinction, is not endangered by human impacts.

\section{MANAGEMENT ACTIVITIES}

The management plan and activities in the Area should be kept under review to ensure that the values for which the Area was designated are being fully protected. Inspection visits may be made only when considered essential for management purposes.

\section{PERIOD OF DESIGNATION}

Designated under ATCM Recommendation IV-1 in November 1966 for an indefinite period.

\section{DESCRIPTION OF THE AREA}

(a) Geographical coordinates and natural features of the area:

Rookery Islands are a group of small islands and rocks in the south-western part of Holme Bay, Mac Robertson Land, approximately 10 kilometres to the west of the Australian station, Mawson. The Area comprises the islands and rocks lying within the rectangle marked on the Map B (see Section 7), the general location of which is latitude $67^{\circ} 37^{\prime} \mathrm{S}$, longitude $62^{\circ} 33^{\prime} \mathrm{E}$. There are no boundary markers delimiting the site. There are approximately 75 small islands. They range in size from small rocks which barely remain above water at high tide to the largest members of the group which are Giganteus Island (approximately $400 \mathrm{~m}$ long, $400 \mathrm{~m}$ wide and 30 $\mathrm{m}$ high) and Rookery Island which is of similar area but slightly more elongated. Rookery Island is the highest of the group reaching an altitude of $62 \mathrm{~m}$. Raised beaches are evident on Giganteus Island. The Rookery Islands are outcrops of the Mawson Charnockite, a rock type which is found over an area of at least 2000 square kilometers along the Mawson Coast of Mac Robertson Land.

There are terrestrial algae, as yet unidentified, but no known mosses or lichens. There are no freshwater bodies on the Rookery Islands.

(b) Access to the Area:

Access to the Area is only in accordance with a current permit issued by a Contracting Party or its authorised representative. No access points are prescribed. Restrictions apply to the mode of transport and to the proximity of access points to breeding colonies; for this refer to Section (8). 
(c) Location of structures including scientific stations, research and refuge facilities both within and near the Area:

There are no structures within the Area. Mawson Station $\left(67^{\circ} 36^{\prime} \mathrm{S}, 62^{\circ} 53^{\prime} \mathrm{E}\right)$ is approximately 10 kilometers to the east.

(d) Location of other protected areas in or near the Area:

Taylor Rookery (Specially Protected Area No.1) is approximately 80 kilometres west of the islands at latitude $67^{\circ} 26^{\prime} \mathrm{S}$, longitude $60^{\circ} 50^{\prime} \mathrm{E}$.

\section{IDENTIFICATION OF RESTRICTED ZONES}

Access to Giganteus Island is prohibited except where a permit specifies otherwise. See 8 (a) (vi) below.

\section{MAPS OF THE AREA}

Map A shows the location of the Rookery Islands in the Mawson area, and

Map B is a more detailed Map of the Area.

\section{CONDITIONS UNDER WHICH PERMITS MAY BE GRANTED}

Criteria for issuing a permit to enter the Area are that:

* it is issued for a compelling scientific purpose which can not be undertaken elsewhere;

* the actions permitted will not jeopardise the natural ecological system existing in the Area; and

* the actions permitted are in accordance with the management plan for the Area.

\section{Conditions applying:}

(a) Access to and movement within the Area:

i) Travel may be by oversnow vehicles (depending on sea ice conditions). Visitors must ensure that vehicles are taken no closer than 200 meters from concentrations of birds and that they are always left at the shoreline.

ii) As helicopter access may at times be the only viable means of reaching the islands, and as the islands are small in size, aircraft may land within 500 metres of breeding colonies. Permission to land a helicopter may be granted for essential scientific purposes only if it can be demonstrated that disturbance will be minimal.

iii) No refueling within the Area.

iv) Overflight of the islands is prohibited except where essential for scientific purposes. Such overflight is to be at an altitude of no less than 500 metres.

v) Dogs are not to be used for transport within the Area.

vi) Access to Giganteus Island is prohibited except for the purpose of monitoring the southern giant petrels (Macronectes giganteus) or for activities which may be conducted without threat to their population status. As the breeding colony is close to the point of local extinction and the birds are easily disturbed, the number of persons granted entry for this purpose must be strictly limited and include an experienced ornithologist. 
(b) Activities which are, or may be conducted within the Area, including restrictions on time and place:

i) Compelling scientific activities which cannot be conducted elsewhere.

ii) Compelling management activities, which if not carried out would jeopardise the values for which the Area was designated.

(c) The installation, modification, or removal of structures:

No structures including field huts, are to be installed in the Area unless essential for scientific purposes; any structure installed should be removed when no longer required. Only the minimum number of personnel necessary to install and remove the structure should be used.

(d) The location of field camps:

See (c) above.

(e) Restrictions on material and organisms which may be brought into the Area:

i) Fuel is not to be depoted in the Area, unless required by a researcher for personal use, i.e. for cooking/heating in a field hut, and is to be removed when no longer required.

ii) No poultry products, including dried food containing egg powder, are to be taken into the Area.

iii) No food or other supplies should be left within the Area beyond the season for which they are required.

(f) The taking of, or harmful interference with, native flora and fauna:

Taking of, or harmful interference with, native flora and fauna is prohibited unless specifically authorised by permit in accordance with the Agreed Measures for the Conservation of Antarctic Fauna and Flora, or Article 3 of Annex II to the Protocol on Environmental Protection to the Antarctic Treaty, whichever is appropriate.

(g) The collection or removal of anything not brought into the Area by the permit holder:

There is to be no collection or removal of anything not brought into the Area by the permit holder unless specifically authorised by permit for scientific or management purposes.

(h) The disposal of waste:

No wastes, including human wastes, are to be left in the Area.

(i) Measures that may be necessary to ensure that the aims and objectives of the management plan can continue to be met:

* permits should specify the maximum numbers of personnel who may enter the Area;

* visits to the Area should be kept to the minimum necessary to achieve research and management objectives;

* access should be permitted where necessary to place or remove structures or equipments. 
Requirements for reports:

Each permit holder shall submit a report to the permit-issuing authority detailing the activities undertaken within the Area including a summary of research findings, and comments indicating measures taken to ensure compliance with conditions. Where appropriate, the report may make recommendations relevant to the management of the Area, in particular, as to whether the values for which the Area was designed are being adequately protected. The report should be submitted as soon as practicable after the visit to the Area has been completed.

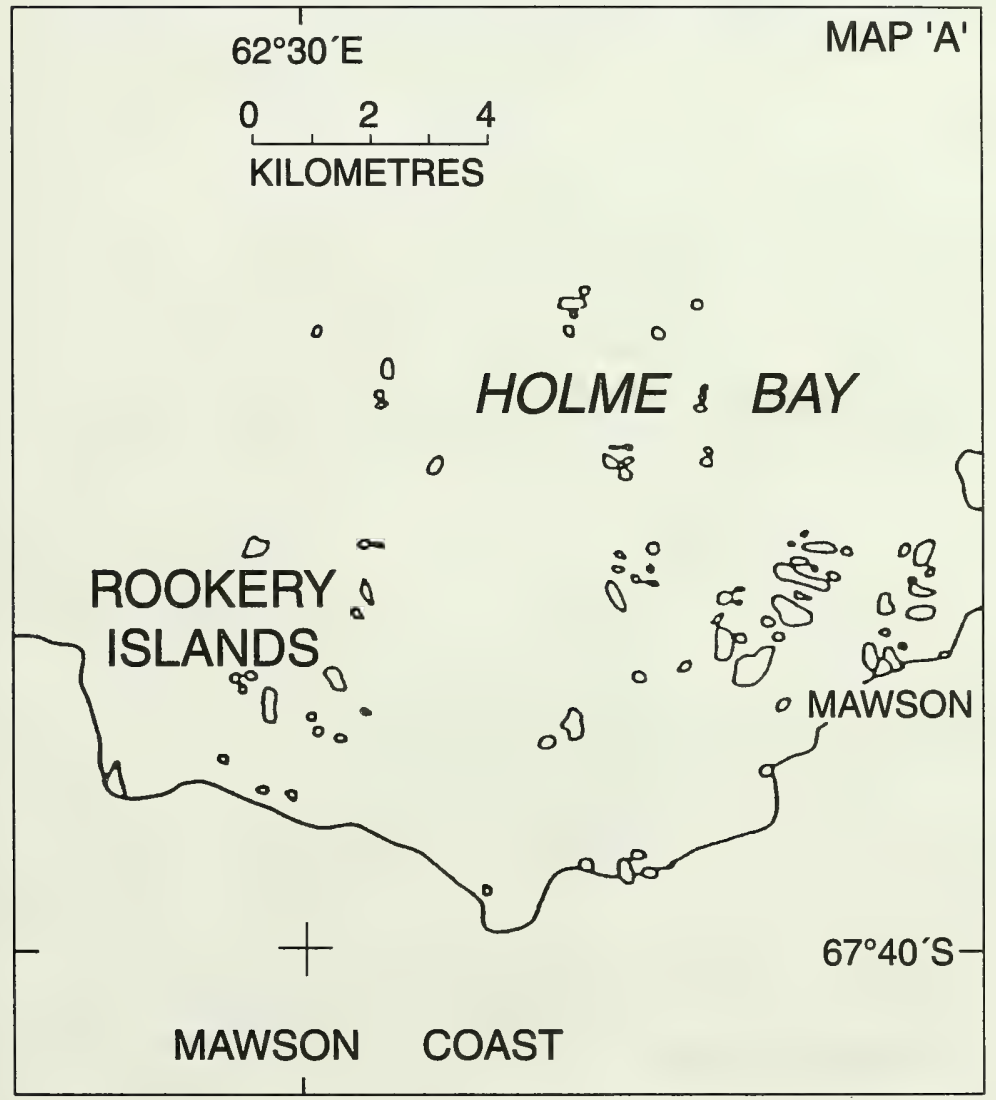




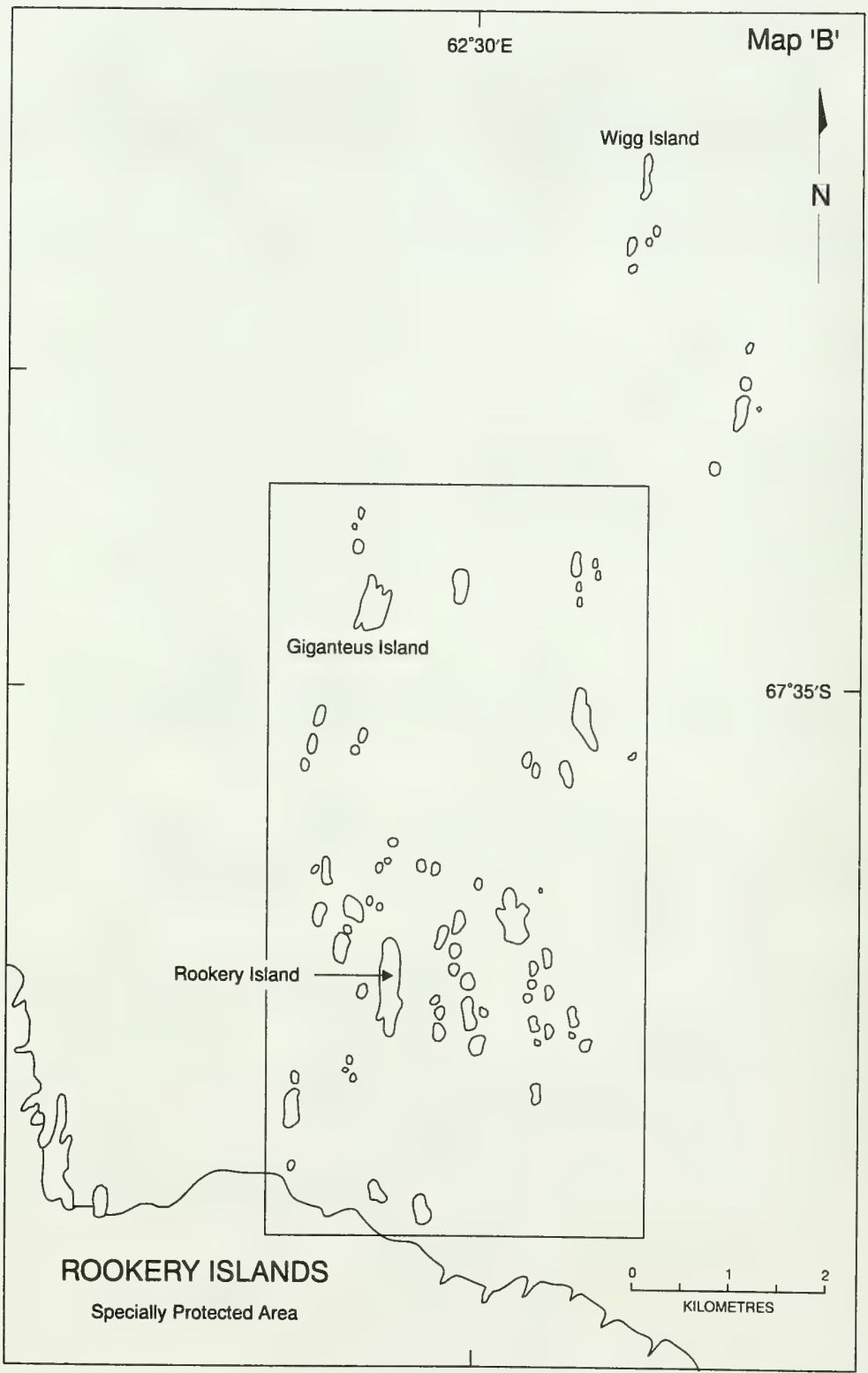




\section{MANAGEMENT PLAN FOR SPECIALLY PROTECTED AREA (SPA) No.3}

\section{ARDERY ISLAND AND ODBERT ISLAND, BUDD COAST}

\section{DESCRIPTION OF THE VALUES TO BE PROTECTED}

Ardery and Odbert Islands support several breeding species of petrel and provide a sample of their habitat. There is no other readily accessible place in eastern Antarctica where the four genera of fulmarine petrels (Thalassoica antarctica, Fulmarus glacialoides, Daption capensis and Pagodroma nivea) breed in the same place in sufficient numbers to allow comparative study. Study of these four genera at one location is of high ecological importance both from the point of view of understanding and of monitoring the Southern Ocean ecosystem. It is believed that Ardery Island is unique insofar as it is the only area in the Antarctic which harbours two different subspecies of snow petrels. Studies on morphological or ecological differences between these two subspecies are not possible anywhere else. In addition both islands have breeding populations of Wilson's storm petrels (Oceanites oceanicus) and Antarctic skuas (Catharacta maccormicki) and Odbert Island supports breeding populations of Adélie penguins (Pygoscelis adeliae).

\section{AIMS AND OBJECTIVES}

Management of the Area aims to:

* prevent unnecessary disturbance to the colonies of petrels on Ardery and Odbert Islands; and

* permit research of a compelling scientific nature which cannot be undertaken elsewhere, while ensuring that this has no significant impact on the ecosystem in the area.

\section{MANAGEMENT ACTIVITIES}

The management plan and activities in the Area should be kept under review to ensure that the values for which the Area was designated are being fully protected. Inspection visits may be made only when considered essential for management purposes.

\section{PERIOD OF DESIGNATION}

Designated under Recommendation IV-3 in November 1966 for an indefinite period.

\section{DESCRIPTION OF THE AREA}

(a) Geographical coordinates and natural features of the Area:

Ardery Island $\left(66^{\circ} 22^{\prime} \mathrm{S}, 110^{\circ} 28^{\prime} \mathrm{E}\right)$ and Odbert Island $\left(66^{\circ} 22^{\prime} \mathrm{S}, 110^{\circ} 33^{\prime} \mathrm{E}\right)$ form part of the Windmill Islands group lying in the East of Vincennes Bay, off the Budd Coast (see Map A). They are located $5 \mathrm{~km}$ and $0.6 \mathrm{~km}$ respectively to the West of Robinson Ridge, South of Casey Station. Odbert Island is approximately $2.5 \mathrm{~km}$ long and $0.5 \mathrm{~km}$ wide. It has a rocky coast which raises steeply from the sea to a plateau. The highest point is $100 \mathrm{~m}$ above sea level. The plateau is dissected by a series of valleys which run to the South from the high flat rim on the northern side. These valleys are snow-covered in winter. The hill tops remain essentially ice and snow free. In some years the island remains joined to Robinson Ridge on the mainland by sea ice. Ardery Island is a steep ice-free island approximately $1 \mathrm{~km}$ long and $0.5 \mathrm{~km}$ wide, with an East-West orientation. The highest point is $113 \mathrm{~m}$ above mean sea level.

The terrain on both islands is rugged and dissected by fissures. The cliffs are fractured and have many narrow exposed ledges which in Summer are occupied by nesting sea birds. On the hillsides and plateau region, the exposed rock is ice-smoothed and the valley floors are covered with moraine. Both islands have several small tarns which are frozen in Winter and filled with melt water in Summer. Many of these are ephemeral and dry out towards the end of Summer. Others which are located below snow banks, are fed continuously by melt water. 


\section{(b) Access to the Area:}

Access to the Area may only be in accordance with a permit or authority issued by a Contracting Party or its authorised representative.

Defined landing sites for access by sea and helicopters to Ardery and Odbert Islands are shown on Map B and $\mathrm{C}$ respectively. On Ardery Island the preferred boat landing site is at Robertson Landing where there are three rock anchors present to tie down a boat or other equipment. It should be noted that all three boat landing sites marked on Map B are within 200 metres of colonies of birds, however they represent the only safe landing sites on the island and if landings are undertaken carefully there is no disturbance to the birds.

There are no defined pedestrian routes within the Area, however pedestrians should avoid disturbance of the birds at all times.

(c) Location of structures including scientific stations, research and refuge facilities both within and near the Area:

There are no structures within the Area and no permanent structures are permitted.

The islands lie approximately $12 \mathrm{~km}$ South of Casey Station.

A four-berth refuge hut is located on Robinson's Ridge, $0.5 \mathrm{~km}$ from the shore.

(d) Location of other protected areas in or near the Area:

North-East Bailey Peninsula ( $66^{\circ} 17^{\prime} \mathrm{S}, 110^{\circ} 32^{\prime} \mathrm{E}$ ) (Site of Special Scientific Interest No 16) and Clark Peninsula $\left(66^{\circ} 15^{\prime} \mathrm{S}, 110^{\circ} 36^{\prime} \mathrm{E}\right)$ (Site of Special Scientific Interest No 17) lie opposite the Windmill Islands (see Map A).

\section{IDENTIFICATION OF RESTRICTED ZONES}

Access to the petrel and Adelie penguin colonies marked on Maps B and C is prohibited unless authorised in a permit.

\section{MAPS OF THE AREA}

Three maps of the Area are attached.

Map A shows the Area and its location.

Map B (Ardery Island), and

Map C (Odbert Island) show preferred helicopter approaches and landing sites, landing sites for access by water and the location of the petrel and Adelie breeding colonies.

\section{CONDITIONS UNDER WHICH PERMITS MAY BE GRANTED}

Criteria for issuing a permit to enter the Area are that:

* it is issued for a compelling scientific purpose which cannot be pursued elsewhere;

* the actions permitted will not jeopardise the natural ecological system existing in Area; and

* the actions permitted are in accordance with the management plan for the Area. 


\section{Conditions applying:}

(a) Access to and movement within the Area:

i) Travel to the island should be by foot, oversnow vehicle or boat where possible; oversnow vehicles used to visit the islands must be left at the shoreline and movement within the area should be by foot.

ii) If access to the islands is not possible by sea or over sea-ice, then helicopters may be used subject to the following conditions:

* overflight of the islands should be avoided at all times, except where it is considered essential for scientific purposes. In these instances, overflight must be at an altitude or horizontal distance of no less than $\mathbf{5 0 0}$ metres;

* during the breeding season of penguins and petrels, defined here as the period from 1 November to 1 April, helicopter movement to the islands should be kept to the minimum;

* refueling is not to take place within the Area;

* only personnel who are required to carry out work in the Area should leave the helicopter;

* the approach to Ardery Island should be at a high altitude and from a southern direction as the lowest densities of birds are on the southern cliffs (see Map B);

* the approach to Odbert Island should preferably be from the South, avoiding cliff areas because of the nesting petrels (see Map C).

(b) Activities which are, or may be, conducted within the Area, including restrictions on time and place:

i) Compelling scientific activities which cannot be conducted elsewhere.

ii) Compelling management activities, which if not carried out would jeopardise the values for which the Area was designated.

iii) Where activities necessitate interference with the birds care should be taken to cause the least possible disturbance, particularly during the period 1 November to 1 April.

(c) The installation, modification, or removal of structures:

No structures may be erected in the Area unless essential for research purposes. Any structures installed on the islands must be removed when no longer required. Installation of a field hut on Ardery Island should take place wherever possible before 1 November when the breeding season commences and removal should be after 1 April when the fledglings have departed. Installation and removal should be by oversnow transport unless sea-ice conditions prevent this. For use of helicopters see (a) ii above.

(d) The location of field camps:

If required for field work, a hut may be erected on Ardery Island at the point specified on Map B. There are 8 solid rock anchors available at this spot.

(e) Restrictions on materials and organisms which may be brought into the Area:

i) Fuel is not to be depoted on the islands, unless required by a researcher for personal use, i.e. for cooking/heating etc., in a field hut on Ardery Island, and is to be removed at the same time as the hut.

ii) No poultry products, including dried food containing egg powder, are to be taken into the Area. 
(f) The taking of or harmful interference with native flora and fauna:

Taking of, or harmful interference with, native flora and fauna is prohibited unless specifically authorised by permit issued in accordance with the Agreed Measures for the Conservation of Antarctic Fauna and Flora, or Article 3 of the Annex II to the Protocol on Environmental Protection to the Antarctic Treaty, whichever is appropriate.

(g) The collection or removal of anything not brought into the Area by the permit holder:

There is to be no collection or removal of anything not brought into the Area by the permit holder unless specifically authorised by permit for scientific or management purposes.

(h) The disposal of waste:

No wastes, including human wastes, are to be left in the Area.

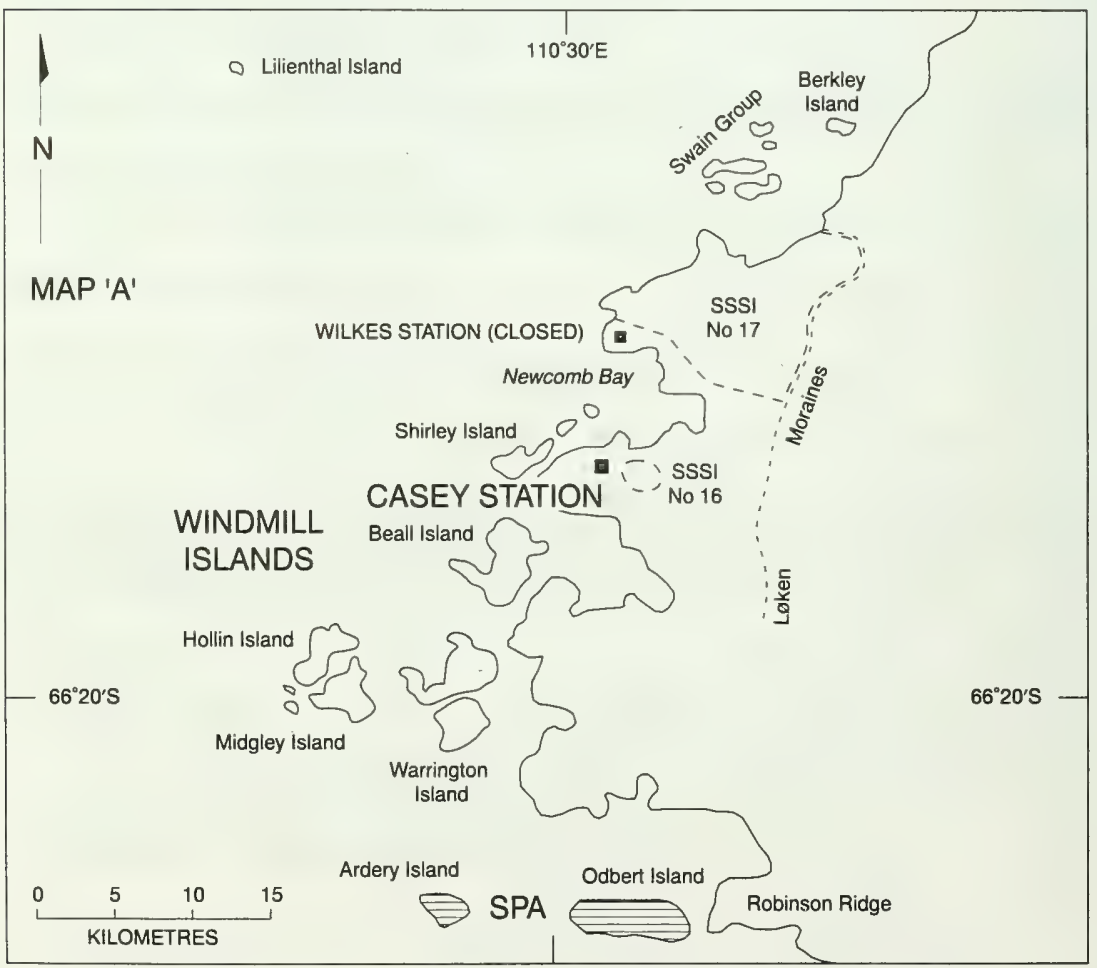




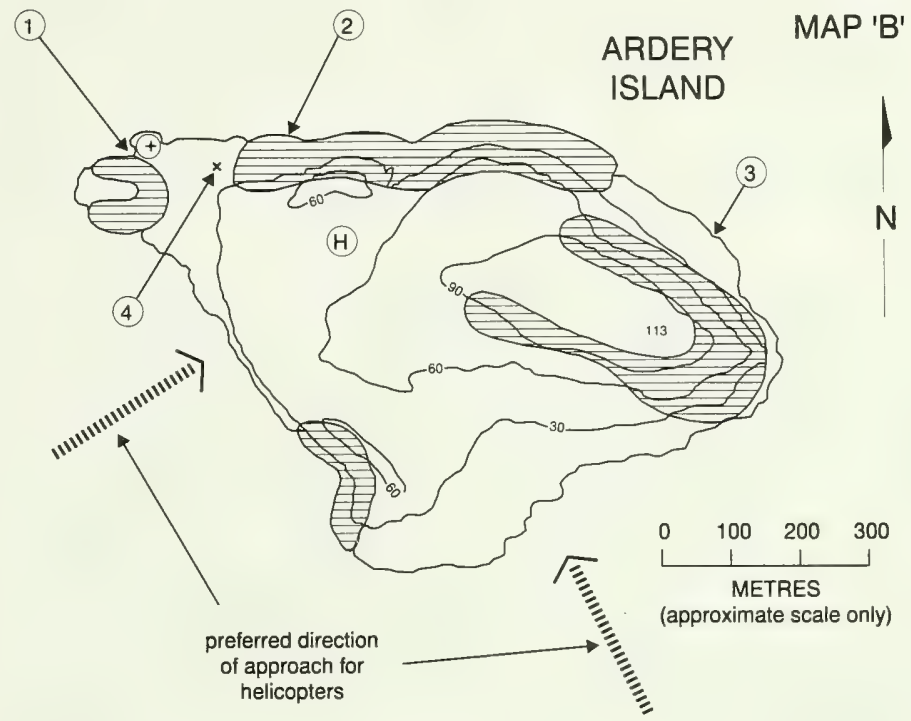

\section{LEGEND}

(1) Recommended landing: Robertson Landing

(2) Cave Landing

(3) Penney Landing

(4) Recommended location for Apple Hut - 8 rock anchors present. The northemmost is marked by a cairn of stones.
(H) Best helicopter landing for general purposes but landing anywhere in the flat central areas of Ardery Island is possible.

( 3 rock anchors (for eg boat)

\section{petrel colonies}

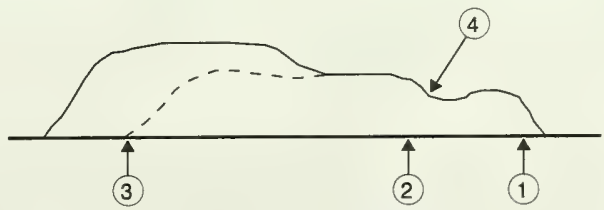

Ardery Island as seen when approaching from the north. (Numbers refer to those in map above) 


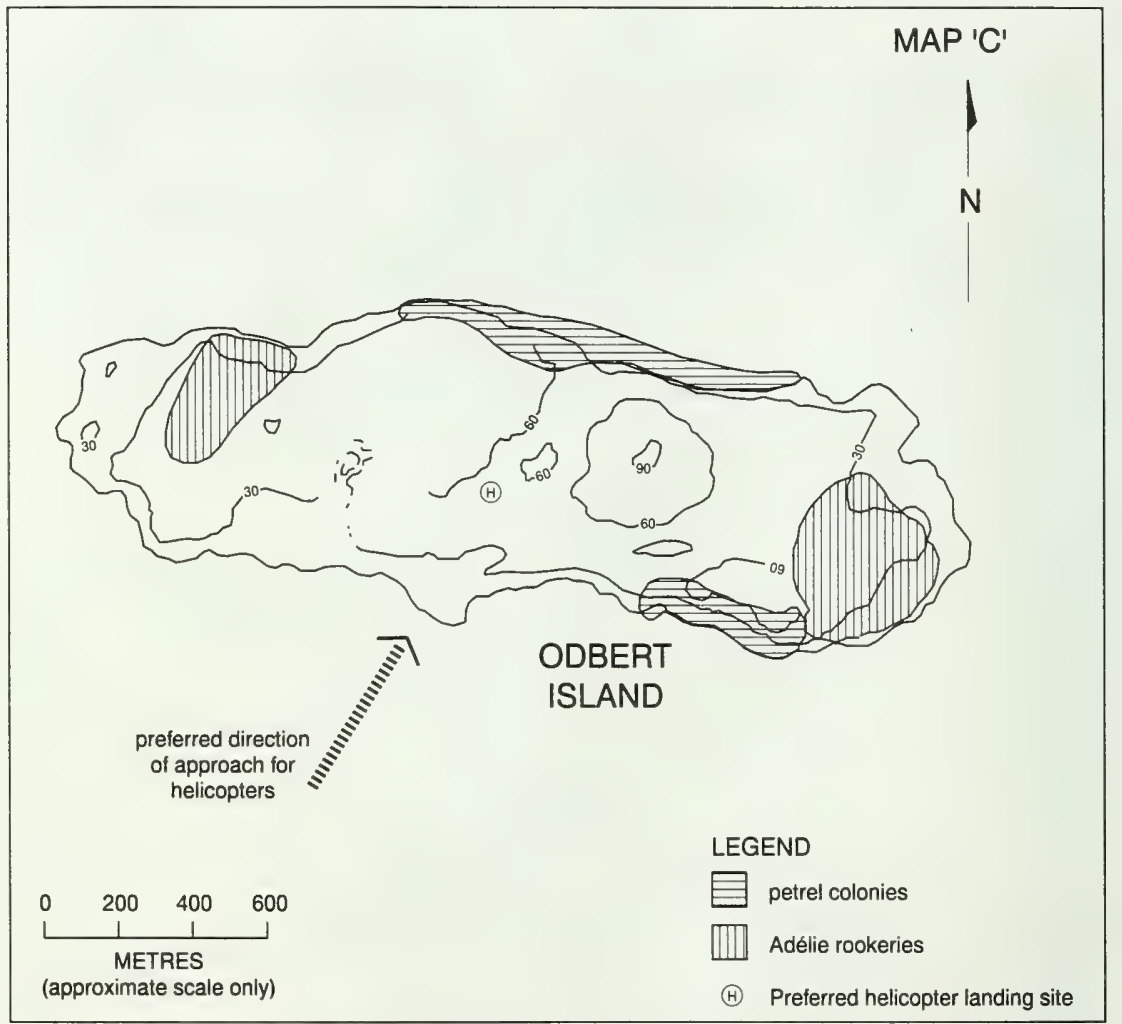

(i) Measures that may be necessary to ensure that the aims and objectives of the management plan can continue to be met:

* permits should specify the maximum number of people allowed entry at any one time;

* visits to the Area should be kept to the minimum necessary to achieve the research and management objectives;

* access should be permitted where necessary to place or remove structures or equipments.

(j) Requirements for reports:

Each permit holder shall submit a report to the permit-issuing authority detailing the activities undertaken within the Area including a summary of research findings, and comments indicating measures taken to ensure compliance with conditions. Where appropriate, the report may make recommendations relevant to the management of the Area, in particular, as to whether the values for which the Area was designated are being adequately protected. The report should be submitted as soon as practicable after the visit to the Area has been completed. 


\section{SPECIALLY PROTECTED AREA (SPA) No 20}

\section{“NEW COLLEGE VALLEY", Caughley Beach, Cape Bird, Ross Island}

\section{GEOGRAPHICAL LOCATION}

The site is in latitude $77^{\circ} 14^{\prime} \mathrm{S}$, longitude $166^{\circ} 23^{\prime} \mathrm{E}$, in the northern part of Cape Bird ice-free area. It lies between Northern Rookery and Middle Rookery and is about $250 \mathrm{~m}$ South of the Summer research station.

\section{MANAGEMENT PLAN}

\section{Description of Area}

\section{Topography}

The Area consists of the generally west-facing ice-free slopes lying between the cliff top above Caughley Beach and a line parallel to and about $100 \mathrm{~m}$ East of the edge of the Mount Bird Ice Cap, and between a line South of the main stream bed of "Keble Valley" and the South ridge of "New College Valley". It is surrounded to the North, South and East by Site of Special Scientific Interest No 10, and to the West terminates at the cliff tops above Caughley Beach. Its total area is about 10 ha.

The ground is largely covered by stones and boulders of volcanic origin which have been reworked by glacial action. There are a few glacial erratic boulders of different origin.

The major feature of the site is "New College Valley" which has been cut by the vigorous flows of meltwater received from the Mount Bird Ice Cap during Summer. Tributaries to this stream and two other smaller streams in the area are fed by melt from persistent summer snowdrifts and have eroded their own shallow gullies and channels.

\section{Biological features}

A general description of the vegetation is provided by Broady (1984/89) as part of a broad survey of vegetation at Cape Bird and two other ice-free areas on Ross Island. Longton $(1973,1974)$ classified the bryophyte community at Caughley Beach as the Bryum antarcticum Sociation in which B.antarcticum is dominant with occasional B.argenteum. It is not clear from the information presented whether the site examined was actually inside the SPA but, if not, it was certainly very close. Sketch maps of moss and algae stands within the SPA are provided by Broady (1984).

Stream vegetation includes luxuriant red-brown oscillatoriacean (Cyanobacteria) mats, rich epilithic green filaments and crusts of chlorophyte algae, and colonies of Nostoc (Cyanobacteria).

The more or less north-west-facing slopes of the main valley and smaller gullies support extensive moss stands as scattered small cushions and as confluent growths up to several square meters in extent (total cover, over $200 \mathrm{~m}^{\circ}$ ). Often the plants and surrounding soil become covered with a white mineral encrustation if meltwater supply ceases during the Summer and vegetation and soils dessicate. The maximum development of moss is found along the borders of shallow channels taking meltwater from snow drifts. Also scattered cushions no more than $5 \mathrm{~cm}$ in diameter are found on moist ground where melt percolations are not channelled but seep broadly over the surface. Bryophyte biomass at Caughley Beach (Longton, 1974) was estimated as 14 and $938 \mathrm{~g}$ dry weight per square metre for two stands, with $1.4 \%$ and $84.7 \%$ cover respectively.

The mosses are generally associated with abundant red-brown oscillatoriacean mats and occasionally with colonies of Nostoc. Other areas of soaked ground are dominated by either Nostoc colonies (approximately $100 \mathrm{~m}$ ) or oscillatoriacean mats (approximately $200 \mathrm{~m}$ ).

Skuas (Catharacta maccormicki) nest on the beach below the cliffs to the West of the site and frequently overfly and land within the SPA. Adélie penguins (Pygoscelis adeliae) from large nearby rookeries 
occasionally traverse the area. Nutrient enrichment of soils occurs from deposited guano as well as from windblown particulates from the large penguin rookeries to the North and South.

\section{ii) Reason for designation}

The area contains some of the most luxuriant stands on Ross Island of moss and algae vegetation and associated microflora and microfauna. Because of the susceptibility of this vegetation to damage from trampling, the designation of the area provides protection for its biota, so that the area may serve as a conservation reserve representative of the adjacent Site of Special Scientific Interest.

\section{iii) Date of designation and originator}

The site was established by Recommendation XIII-12 following its proposal to SCAR by New Zealand in October 1984.

iv) Access points

The site can be accessed only by passing through the adjacent SSSI. It is best reached by a route directly South-East from the summer research station to the North. Care should be taken to avoid any areas of vegetation along the way.

\section{v) Entry permit requirement}

Entry to the area is only in strict accordance with a current permit, issued by the participating Government or its authorised representative, specifically for a compelling scientific purpose which cannot be served elsewhere or for site inspection (but see "Inspection and maintenance" below), and which will not jeopardise any aspect of the natural ecosystem or its biota within the area (see Antarctic Treaty Agreed Measures ior the Conservation of Antarctic Fauna and Flora, Article VIII). Details of the visit should be included in the national annual report of Exchange of Information for the same Antarctic station in which the activities were carried out.

vi) Prohibition

To avoid or minimize human impact it is forbidden to:

(a) drive any vehicle within the Area;

(b) land a helicopter within the Area;

(c) overfly the Area by an aircraft below $250 \mathrm{~m}$ above the highest point;

(d) incinerate, bury or otherwise dispose of any nonhuman and human waste within the Area; all such waste must be removed from the Area;

(e) leave depots of fuels, food, or any other supply within the Area;

(f) erect any form of building within the Area;

(g) use any sampling or other equipment within the Area which has not been sterilized using an acceptable method.

\section{vii) Pedestrian routes}

Every precaution must be taken to keep clear of visible vegetation and also waterlogged ground, whether this has visible vegetation or not. During Summer all these areas are easily damaged by trampling. Saturated ground, especially where situated on sloping terrain, is very prone to slip when traversed by foot and the marking of deep footprints would be unavoidable. Routes should be taken which pass upslope of persistent summer snow drifts, especially during times of thaw. In this way saturated ground would be most easily avoided. 


\section{viii) Scientific research and samplimg}

All activities must conform strictly with those specified in the permit to enter the Area. Only for exceptional purposes would sampling of vegetation be permitted as there are similar areas of vegetation in the adjacent SSSI, as well as outside the designated areas to the South of the site.

Persons permitted to enter the site should take all reasonable precautions to avoid introducing plants and micro-organisms from elsewhere. All sampling apparatus should be sterilized before use and boots should be thoroughly cleaned before entry.

\section{ix) inspection and maintenance}

Inspection visits to the Area should be made once every year to assess the state of the site and to monitor any significant biological or environmental changes. However, entry to the site is not necessary for these visits as its state can be readily viewed from the surrounding SSSI. Also, as the site is small and contains rich terrestrial moss and algal vegetation, on site inspection visits could themselves cause damage.

\section{BIBLIOGRAPHY}

BROADY, P.A. 1984. The Vegetation of Cape Bird, Ross Island, Antarctica. Melbourne University Programme in Antarctic Studies, Report No 62, 42pp, 15 tables, 140 figs.

BROADY, P.A. 1989. Broadscale patterns in the distribution of aquatic and terrestrial vegetation at three ice-free regions on Ross Island, Antarctica. Hydrobiologia, 172: 77-95.

LONGTON, R.E. 1973. A classification of terrestrial vegetation near McMurdo Sound, continental Antarctica. Canadian Journal of Botany, 51:2339-46.

LONGTON, R.E. 1974. Microclimate and biomass in communities in the Bryum association on Ross Island, continental Antarctica. The Bryologist, 77: 109-22.

(Postscript: It is intended to place signs close to the boundaries on this site and to choose boundaries which more closely follow natural features. The latter requires a more detailed map than presently available. Action on both of these will be taken this coming Summer).

\section{Recommendation XVII-3}

\section{ANTARCTIC PROTECTED AREAS}

\section{NEW HISTORIC SITES AND MONUMENTS}

\section{WOODEN PLAQUE AND ROCK CAIRN AT PENGUINS BAY}

The Representatives,

Recalling Recommendations I-IX, V-4, VI-14, VII-9, XII-7, XIII-16 and XIV-8;

Recommend to their Governments that the following historic monuments be added to the "List of Historic Monuments Identified and Described by the proposing Government or Governments" annexed to Recommendation VII-9, and that thereafter they be accorded the respect and protection required by the Recommendation recalled above:

Wooden plaque and rock cairn located at Penguins Bay, southern coast of Seymour Island (Marambio), James Ross Archipelago $\left(64^{\circ} 16^{\prime} 00^{\prime \prime} \mathrm{S}-56^{\circ} 39^{\prime} 10^{\prime \prime} \mathrm{W}\right)$. This plaque was placed on 10 November 1903 by the crew of a rescue mission of the Argentinian Corvette "Uruguay" in the site where they met members of the Swedish expedition led by Dr. Otto Nordenskjold. 
The text of the wooden plaque reads as follows:

10.XI.1903 "Uruguay," (Argentine Navy) in its journey to give assistance to the Swedish Antarctic expedition.

In January 1990, a rock cairn was erected by Argentina in memory of this event in the place where the plaque is located.

\section{Recommendation XVII-4}

\section{GLOBAL CHANGE RESEARCH AND INTERNATIONAL COOPERATION IN ANTARCTICA}

The Representatives,

Recalling Articles II \& III of the Antarctic Treaty and Article VI of the Protocol on Environmental Protection to the Antarctic Treaty, and Recommendation XV-14 on the promotion of international scientific cooperation;

Reaffirming the Declaration adopted at the XVIth Consultative Meeting on the occasion of the 30th anniversary of the entry into force of the Antarctic Treaty;

Noting the recognition in Agenda 21 of the United Nations Conference on the Environment and Development of the importance of Antarctica and the Southern Ocean for the study of global change processes;

Acknowledging the role that intensified coordination of national research programmes and increased international cooperation should play, such as SCAR's publication on "the role of Antarctica in global change";

Conscious as well that the development of an implementation plan for Antarctic research contribution to the International Geosphere - Biosphere Programme represents a significant step to be accomplished during the Decade of International Antarctic Scientific Cooperation (1991-2000) proclaimed by the XVIth ATCM;

Recommend to their Governments that they:

1. welcome the decision adopted by the Scientific Committee for Antarctic Research at XXII SCAR to establish a new group of specialists on global change and the Antarctic, in order to provide linkages and communications between national programmes, SCAR Working Group and other Groups of Specialists in areas of relevant Antarctic research;

2. encourage SCAR to articulate, in close cooperation with COMNAP, a management structure to implement a coordinated programme for global change research in the Antarctic and to contribute through the development of Regional Research Centres (RRC's) to the IGBP System for Analysis, Research and Training (START) and to other major regional and international programs on global change research;

3. support initiatives such as the proposal of the SCAR Working Group on Biology and the offer made by Chile to hold a workshop on the coordination of biological research on King George Island (Isla 25 de Mayo); the Cooperative geoscience of the South Shetland Islands (COGS) whose second workshop was sponsored by the National Institute of Polar Research of Japan; and similar initiatives to coordinate research in glaciology and solar-terrestrial studies;

4. note with appreciation the completion of SCAR's proposal for coordinated Antarctic research (the role of Antarctica in global change: part 2) to be published late in 1992 and the plan to implement a regional program of global change research in the Antarctic, through:

i) continuing identification of high priority research needs in process studies, monitoring, and modelling;

ii) identifying other needs in the implementation of the programme, such as logistics, data management, etc; 
iii) organising workshops and symposia to synthesise and discuss research results;

5. that the above mentioned regional programme of Global Change research in the Antarctic should be given a high scientific priority and supported to the greater extent feasible by Governments;

6. may consider applying to the Global Environmental Facility (GEF) and other acceptable funding mechanisms to support the proposed new group of specialists and their work. 


\title{
Measures Approved or Recommended Under Article IX in Furtherance of the Principles and Objectives of the Antarctic Treaty, Kyoto, 1994
}

\author{
Done at Kyoto 22 April 1994 \\ Primary source citation: Copy of text provided by the \\ U.S. Department of State
}

\section{Recommendation XVIII-1}

\section{Tourism and non-Governmental Activities}

The Representatives,

Reaffirming the exceptional character of the Antarctic environment given in particular the fragility of its fauna and flora and of the setting which the Antarctic offers for the conduct of scientific activities;

Acknowledging the increase in the development of tourist activities in the Antarctic;

Noting that those who visit the Antarctic and organise or conduct tourism and non-governmental activities in the Antarctic are currently subject to legally binding obligations pursuant to national legislation implementing the Antarctic Treaty and associated legal instruments;

Noting further that such visitors or organisers will be subject to additional legally binding obligations upon entry into force of the Protocol on Environmental Protection to the Antarctic Treaty;

Recognizing the need for visitors and organisers to have practical guidance on how best to plan and carry out any visits to the Antarctic;

Recalling the Final Act of the Eleventh Special Antarctic Treaty Consultative Meeting, at which the Protocol was adopted, in which the signatories of the Final Act decided that the Annexes of the Protocol should be applied in accordance with their legal systems and to the extent practicable;

Desiring to ensure that those who visit the Antarctic carry out their visits or tours strictly in accordance with existing obligations and in so far as is consistent with existing national law, in accordance with the Protocol, pending its entry into force;

Desiring further to facilitate the early entry into force of the Protocol and of the implementation of its provisions in relation to those who visit or organise tours to the Antarctic.

Recommend to their Governments that: 
1. They circulate widely and as quickly as possible the Guidance for Visitors to the Antarctic, and the Guidance for Those Organising and Conducting Tourism and Non-governmental Activities in the Antarctic annexed to this Recommendation.

2. They urge those intending to visit or organise and conduct tourism and non-governmental activities in the Antarctic to act in accordance with the attached guidance consistent with the relevant provisions of their applicable national law.

\section{ATTACHMENT}

\section{Guidance for Visitors to the Antarctic}

Activities in the Antarctic are governed by the Antarctic Treaty of 1959 and associated agreements, referred to collectively as the Antarctic Treaty system. The Treaty established Antarctica as a zone of peace and science.

In 1991, the Antarctic Treaty Consultative Parties adopted the Protocol on Environmental Protection to the Antarctic Treaty, which designates the Antarctic as a natural reserve. The Protocol sets out environmental principles, procedures and obligations for the comprehensive protection of the Antarctic environment, and its dependent and associated ecosystems. The Consultative Parties have agreed that, pending its entry into force, as far as possible and in accordance with their legal system, the provisions of the Protocol should be applied as appropriate.

The Environmental Protocol applies to tourism and non-governmental activities as well as governmental activities in the Antarctic Treaty Area. It is intended to ensure that these activities do not have adverse impacts on the Antarctic environment, or on its scientific and aesthetic values.

This Guidance for Visitors to the Antarctic is intended to ensure that all visitors are aware of, and are therefore able to comply with, the Treaty and the Protocol. Visitors are, of course, bound by national laws and regulations applicable to activities in the Antarctic.

\section{A) PROTECT ANTARCTIC WILDLIFE}

Taking or harmful interference with Antarctic wildlife is prohibited except in accordance with a permit issued by a national authority.

1) Do not use aircraft, vessels, small boats, or other means of transport in ways that disturb wildlife, either at sea or on land.

2) Do not feed, touch, or handle birds or seals, or approach or photograph them in ways that cause them to alter their behavior. Special care is needed when animals are breeding or moulting.

3) Do not damage plants, for example by walking, driving, or landing on extensive moss beds or lichen-covered scree slopes.

4) Do not use guns or explosives. Keep noise to the minimum to avoid frightening wildlife.

5) Do not bring non-native plants or animals into the Antarctic (e.g. live poultry, pet dogs and cats, house plants).

\section{B) RESPECT PROTECTED AREAS}

A variety of areas in the Antarctic have been afforded special protection because of their particular ecological, scientific, historic or other values. Entry into certain areas may be prohibited except in accordance with a permit issued by an appropriate national authority. Activities in and near designated Historic Sites and Monuments and certain other areas may be subject to special restrictions. 
1) Know the locations of areas that have been afforded special protection and any restrictions regarding entry and activities that can be carried out in and near them.

2) Observe applicable restrictions.

3) Do not damage, remove or destroy Historic Sites or Monuments, or any artefacts associated with them.

\section{C) RESPECT SCIENTIFIC RESEARCH}

Do not interfere with scientific research, facilities or equipment.

1) Obtain permission before visiting Antarctic science and logistic support facilities; reconfirm arrangements 24-72 hours before arriving; and comply strictly with the rules regarding such visits.

2) Do not interfere with, or remove, scientific equipment or marker posts, and do not disturb experimental study sites, field camps, or supplies.

\section{D) BE SAFE}

Be prepared for severe and changeable weather. Ensure that your equipment and clothing meet Antarctic standards. Remember that the Antarctic environment is inhospitable, unpredictable and potentially dangerous.

1) Know your capabilities, the dangers posed by the Antarctic environment, and act accordingly. Plan activities with safety in mind at all times.

2) Keep a safe distance from all wildlife, both on land and at sea.

3) Take note of, and act on, the advice and instructions from your leaders; do not stray from your group.

4) Do not walk onto glaciers or large snow fields without proper equipment and experience; there is a real danger of falling into hidden crevasses.

5) Do not expect a rescue service; self-sufficiency is increased and risks reduced by sound planning, quality equipment, and trained personnel.

6) Do not enter emergency refuges (except in emergencies). If you use equipment or food from a refuge, inform the nearest research station or national authority once the emergency is over.

7) Respect any smoking restrictions, particularly around buildings, and take great care to safeguard against the danger of fire. This is a real hazard in the dry environment of Antarctica.

\section{E) KEEP ANTARCTICA PRISTINE}

Antarctica remains relatively pristine, and has not yet been subjected to large scale human perturbations. It is the largest wilderness area on earth. Please keep it that way.

1) Do not dispose of litter or garbage on land. Open burning is prohibited.

2) Do not disturb or pollute lakes or streams. Any materials discarded at sea must be disposed of properly.

3) Do not paint or engrave names or graffiti on rocks or buildings.

4) Do not collect or take away biological or geological specimens or man-made artefacts as a souvenir, including rocks, bones, eggs, fossils, and parts or contents of buildings.

5) Do not deface or vandalise buildings, whether occupied, abandoned, or unoccupied, or emergency refuges. 


\section{Guidance for those Organising and Conducting Tourism and Non-governmental Activities in the Antarctic}

Antarctica is the largest wilderness area on earth, unaffected by large scale human activities. Accordingly, this unique and pristine environment has been afforded special protection. Furthermore, it is physically remote, inhospitable, unpredictable and potentially dangerous. All activities in the Antarctic Treaty Area, therefore, should be planned and conducted with both environmental protection and safety in mind.

Activities in the Antarctic are subject to the Antarctic Treaty of 1959 and associated legal instruments, referred to collectively as the Antarctic Treaty system. These include the Convention for the Conservation of Antarctic Seals (CCAS' 1972), the Convention on the Conservation of Antarctic Marine Living Resources (CCAMLR' 1980) and the Recommendations and other measures adopted by the Antarctic Treaty Consultative Parties under the Antarctic Treaty.

In 1991, the Consultative Parties to the Antarctic Treaty adopted the Protocol on Environmental Protection to the Antarctic Treaty. This Protocol sets out environmental principles, procedures and obligations for the comprehensive. protection of the Antarctic environment, and its dependent and associated ecosystems. The Consultative Parties have agreed that, pending its entry into force, as far as possible and in accordance with their legal systems, that the provisions of the Protocol should be applied as appropriate.

The Environmental Protocol designates Antarctica as a natural reserve devoted to peace and science, and applies to both governmental and non-governmental activities in the Antarctic Treaty Area. The Protocol seeks to ensure that human activities, including tourism, do not have adverse impacts on the Antarctic environment, nor on its scientific and aesthetic values.

The Protocol states, as a matter of principle, that all activities are to be planned and conducted on the basis of information sufficient to evaluate their possible impact on the Antarctic environment and its associated ecosystems, and on the value of Antarctica for the conduct of scientific research. Organisers should be aware that the Environmental Protocol requires that "activities shall be modified, suspended or cancelled if they result in or threaten to result in impacts upon the Antarctic environment or dependent or associated ecosystems."

Those responsible for organising and conducting tourism and nongovernmental activities must comply fully with national laws and regulations which implement the Antarctic Treaty system, as well as other national laws and regulations implementing international agreements on environmental protection, pollution and safety that relate to the Antarctic Treaty Area. They should also abide by the requirements imposed on organisers and operators under the Protocol on Environmental Protection and its Annexes, in so far as they have not yet been implemented in national law.

\section{KEY OBLIGATIONS ON ORGANISERS AND OPERATORS}

1) Provide prior notification of, and reports on, their activities to the competent authorities of the appropriate Party or Parties.

2) Conduct an assessment of the potential environmental impacts of their planned activities.

3) Provide for effective response to environmental emergencies, especially with regard to marine pollution.

4) Ensure self-sufficiency and safe operations.

5) Respect scientific research and the Antarctic environment, including restrictions regarding protected areas, and the protection of flora and fauna.

6) Prevent the disposal and discharge of prohibited waste. 


\section{PROCEDURES TO BE FOLLOWED BY ORGANISERS AND OPERATORS}

\section{(A) When planning to go to the Antarctic}

Organisers and operators should:

1) Notify the competent national authorities of the appropriate Party or Parties of details of their planned activities with sufficient time to enable the Party(ies) to comply with their information exchange obligations under Article VII (5) of the Antarctic Treaty. The information to be provided is listed in Attachment A.

2) Conduct an environmental assessment in accordance with such procedures as may have been established in national law to give effect to Annex I of the Protocol, including, if appropriate, how potential impacts will be monitored.

3) Obtain timely permission from the national authorities responsible for any stations they propose to visit.

4) Provide information to assist in the preparation of: contingency response plans in accordance with Article 15 of the Protocol; waste management plans in accordance with Annex III of the Protocol; and marine pollution contingency plans in accordance with Annex IV of the Protocol.

5) Ensure that expedition leaders and passengers are aware of the location and special regimes which apply to Specially Protected Areas and Sites of Special Scientific Interest (and on entry into force of the Protocol, Antarctic Specially Protected Areas and Antarctic Specially Managed Areas) and of Historic Sites and Monuments and, in particular, relevant management plans.

6) Obtain a permit, where required by national law, from the competent national authority of the appropriate Party or Parties, should they have a reason to enter such areas, or a monitoring site (CEMP Site) designated under CCAMLR.

7) Ensure that activities are fully self-sufficient and do not require assistance from Parties unless arrangements for it have been agreed in advance.

8) Ensure that they employ experienced and trained personnel, including a sufficient number of guides.

9) Arrange to use equipment, vehicles, vessels, and aircraft appropriate to Antarctic operations.

10) Be fully conversant with applicable communications, navigation, air traffic control and emergency procedures.

11) Obtain the best available maps and hydrographic charts, recognising that many areas are not fully or accurately surveyed.

12) Consider the question of insurance (subject to requirements of national law).

13) Design and conduct information and education programmes to ensure that all personnel and visitors are aware of relevant provisions of the Antarctic Treaty system.

14) Provide visitors with a copy of the Guidance for Visitors to the Antarctic.

(B) When in the Antarctic Treaty Area

Organisers and operators should:

1) Comply with all requirements of the Antarctic Treaty system, and relevant national laws, and ensure that visitors are aware of requirements that are relevant to them.

2) Reconfirm arrangements to visit stations 24-72 hours before their arrival and ensure that visitors are aware of any conditions or restrictions established by the station.

3) Ensure that visitors are supervised by a sufficient number of guides who have adequate experience and training in Antarctic conditions and knowledge of the Antarctic Treaty system requirements. 
4) Monitor environmental impacts of their activities, if appropriate, and advise the competent national authorities of the appropriate Party or Parties of any adverse or cumulative impacts resulting from an activity, but which were not foreseen by their environmental impact assessment.

5) Operate ships, yachts, small boats, aircraft, hovercraft, and all other means of transport safely and according to appropriate procedures, including those set out in the Antarctic Flight Information Manual (AFIM).

6) Dispose of waste materials in accordance with Annex III and IV of the Protocol. These annexes prohibit, among other things, the discharge of plastics, oil and noxious substances into the Antarctic Treaty Area; regulate the discharge of sewage and food waste; and require the removal of most wastes from the area.

7) Co-operate fully with observers designated by Consultative Parties to conduct inspections of stations, ships, aircraft and equipment under Article VII of the Antarctic Treaty, and those to be designated under Article 14 of the Environmental Protocol.

8) Co-operate in monitoring programmes undertaken in accordance with Article 3(2)(d) of the Protocol.

9) Maintain a careful and complete record of their activities conducted.

C) On completion of the activities

Within three months of the end of the activity, organisers and operators should report on the conduct of it to the appropriate national authority in accordance with national laws and procedures. Reports should include the name, details and state of registration of each vessel or aircraft used and the name of their captain or commander; actual itinerary; the number of visitors engaged in the activity; places, dates and purposes of landings and the number of visitors landed on each occasion; any meteorological observations made, including those made as part of the World Meteorological Organization (WMO) Voluntary Observing Ships Scheme; any significant changes in activities and their impacts from those predicted before the visit was conducted; and action taken in case of emergency.

\section{D) Antarctic Treaty System Documents and Information}

Most Antarctic Treaty Parties can provide, through their national contact points, copies of relevant provisions of the Antarctic Treaty system and information about national laws and procedures, including:

- The Antarctic Treaty (1959)

- Convention for the Conservation of Antarctic Seals (1972)

- Convention on the Conservation of Antarctic Marine Living Resources (1980)

- Protocol on Environmental Protection to the Antarctic Treaty (1991)

- Recommendations and other measures adopted under the Antarctic Treaty

- Final Reports of Consultative Meetings

- Handbook of the Antarctic Treaty System (1994)

- Handbook of the Antarctic Treaty System (in Spanish, 1991 edition) 


\section{ATTACHMENT A}

\section{INFORMATION TO BE PROVIDED IN ADVANCE NOTICE}

Organisers should provide the following information to the appropriate national authorities in the format requested.

1. name, nationality, and contact details of the organiser;

2. where relevant, registered name and national registration and type of any vessel or aircraft to be used (including name of the captain or commander, call-sign, radio frequency, INMARSAT number);

3. intended itinerary including the date of departure and places to be visited in the Antarctic Treaty Area;

4. activities to be undertaken and purpose;

5. number and qualifications of crew and accompanying guides and expedition staff;

6. estimated number of visitors to be carried;

7. carrying capacity of vessel;

8. intended use of vessel;

9. intended use and type of aircraft;

10. number and type of other vessels, including small boats, to be used in the Antarctic Treaty Area;

11. information about insurance coverage;

12. details of equipment to be used, including for safety purposes, and arrangements for self-sufficiency;

13. and other matters required by national laws. 


\title{
Measures Approved or Recommended Under Article IX in Furtherance of the Principles and Objectives of the Antarctic Treaty, Seoul, 1995
}

\author{
Done at Seoul 19 May 1995 \\ Primary source citation: Copy of text provided by the \\ U.S. Department of State
}

MEASURE 1 (1995)

\section{REVISED DESCRIPTIONS AND MANAGEMENT PLANS FOR SPECIALLY PROTECTED AREAS}

The Representatives of the Consultative Parties,

Recalling Recommendations XV-8 and XV-9 / VIII-3;

Noting that revised Area Descriptions and proposed Management Plans have been approved by the Scientific Committee on Antarctic Research (SCAR);

Noting also that the format of these revised Area Descriptions and proposed Management Plans accord with Article 5 of Annex V of the Protocol on Environmental Protection to the Antarctic Treaty adopted under Recommendation XVI-10;

Recommend to their Governments the following Measure for approval in accordance with paragraph 4 of Article IX of the Antarctic Treaty:

For the Specially Protected Areas listed below:

(i) the Descriptions inserted in Annex B, Specially Protected Areas, of the Agreed Measures for the Conservation of Antarctic Fauna and Flora shall be deleted;

(ii) the Descriptions and Management Plans of Specially Protected Areas, annexed to this measure shall be inserted in Annex B, Specially Protected Areas, of the Agreed Measures for the Conservation of Antarctic Fauna and Flora.

The Specially Protected Areas concerned are:

Area No. 13 Moe Island, South Orkney Islands (Annex A);

Area No. 15 Southern Powell Island and adjacent islands, South Orkney Islands (Annex B) 


\title{
Annex A to Measure 1 (1995)
}

\author{
Management Plan \\ for Specially Protected Area (SPA) No. 13
}

\author{
MOE ISLAND, SOUTH ORKNEY ISLANDS
}

\section{Description of Values to be Protected}

The Area was originally designated in Recommendation IV-13 (1966, SPANo. 13) after a proposal by the United Kingdom on the grounds that Moe Island provided a representative sample of the maritime Antarctic ecosystem, that intensive experimental research on the neighbouring Signy Island might alter its ecosystem and that Moe Island should be specially protected as a control area for future comparison.

These grounds are still relevant. Whilst there is no evidence that research activities at Signy Island have significantly altered the ecosystems there, a major change has occurred in the low altitude terrestrial system as a result of the rapidly expanding Antarctic fur seal (Arctocephalus gazella) population. Plant communities on nearby Signy Island have been physically disrupted by trampling by fur seals and nitrogen enrichment from the seals' excreta has resulted in replacement of bryophytes and lichens by the macro-alga Prasiola crispa. Low-lying lakes have been significantly affected by enriched run-off from the surrounding land. So far Moe Island has not been invaded by fur seals to any great extent and its topography makes it less likely that seals will penetrate to the more sensitive areas.

The values to be protected are those associated with the biological composition and diversity of a near-pristine example of the maritime Antarctic terrestrial and littoral marine ecosystems. In particular, Moe Island contains the greatest continuous expanses of Chorisodontium-Polytrichum moss turf found in the Antarctic. Moe Island has been visited on few occasions and has never been the site of occupation for periods of more than a few hours.

\section{Aims and Objectives}

Management of Moe Island aims to:

- avoid major changes to the structure and composition of the terrestrial vegetation, in particular the moss turf banks;

- prevent unnecessary human disturbance to the Area;

permit research of a compelling scientific nature which cannot be served elsewhere, particularly research related to determining the differences between the ecology of an undisturbed island and that of an adjacent occupied and fur seal perturbed island.

\section{Management Activities}

Ensure that the biological condition of Moe Island is adequately monitored, preferably by non invasive methods, and that the sign-boards are serviced.

If fur seals were to gain access to the interior of Moe Island it would be necessary to take action to prevent damage to the vulnerable moss banks. This action would most likely consist of the erection of a seal-proof fence at the head of the gully at the northeast of Landing Cove. Any direct management activities in the Area would be subject to an environmental impact assessment before any decision to proceed is taken.

\section{Period of Designation}

Designated for an indefinite period. 


\section{Maps}

Map 1 shows the location of Moe Island in relation to the South Orkney Islands. Map 2 shows Moe Island in greater detail.

\section{Description of the Area}

\section{6(i) Geographical coordinates, boundary markers and natural features}

Moe Island, South Orkney Islands, is a small irregularly-shaped island lying $300 \mathrm{~m}$ off the southwestern extremity of Signy Island, from which it is separated by Fyr Channel. It is about $1.3 \mathrm{~km}$ from the northeast to southwest and $1 \mathrm{~km}$ from northwest to southeast. Its position on Admiralty Chart No. 1775 , latitude $60^{\circ} 44^{\prime} \mathrm{S}$, longitude $45^{\circ} 45^{\prime} \mathrm{W}$, does not agree closely with that in Map 2 (lat. $60^{\circ} 44^{\prime} \mathrm{S}$, long. $45^{\circ} 41^{\prime} \mathrm{W}$ ).

The island rises precipitously on the northeastern and southeastern sides to Snipe Peak ( $226 \mathrm{~m}$ altitude). There is a subsidiary summit above South Point ( $102 \mathrm{~m}$ altitude) and lower hills on each of three promontories on the western side above Corral Point $(92 \mathrm{~m})$, Conroy Point $(39 \mathrm{~m})$ and Spaull Point $(56 \mathrm{~m})$. Small areas of permanent ice remain on the east- and south-facing slopes with late snow lying on the steeply dipping western slopes. There are no permanent streams or pools.

The rocks are metamorphic quartz mica schists, with occasional biotite and quartz-rich beds. There is a thin bed of undifferentiated amphibolite on the northeastern coast. Much of the island is overlain with glacial drift and scree. Soils are predominantly immature deposits of fine to coarse clays and sands intermixed with gravels, stones and boulders. They are frequently sorted by freeze-thaw action in high or exposed locations into small-scale circles, polygons, stripes and lobes. There are deep accumulations of peat (up to $2 \mathrm{~m}$ thick on western slopes), considerable expanses of the surface of which are bare and eroded.

The dominant plant communities are Andreaea-Usnea fellfield and banks of Chorisodontium-Polytrichum moss turf (the largest known example of this community type in the Antarctic). These moss banks constitute a major biological value and the reason for the designation of the Area. The cryptogamic flora is diverse.

The mites Gamasellus racovitzai and Stereotydeus villosus and the springtail Cryptopygus antarcticus are common under stones.

There were five colonies of chinstrap penguins (Pygoscelis antarctica) totaling about 11,000 pairs in 1978-79. A more recent visit (February 1994) noted fewer than 100 pairs on the northern side of Landing Cove and more than a thousand on the southern side. Numerous other birds breed on the island, notably about 2000 pairs of cape petrels (Daption capensis) in 14 colonies (1966) and large numbers of Antarctic prions (Pachyptila desolata).

Weddell seals (Leptonychotes weddelli) and leopard seals (Hydruga leptonyx) are found in the bays on the west side of the island. Increasing numbers of fur seals (Arctocephalus gazella), mostly juvenile males, come ashore on the north side of Landing Cove and have caused some damage to vegetation in that area. However, it is possible that the nature of the terrain will restrict these animals to this small headland where damage may intensify.

\section{6(ii) Restricted zones within the Area}

None.

\section{6(iii) Location of structures within the Area}

A marker board is located at the back of the small shingle beach in the northeast corner of Landing Cove, beyond the splash zone on top of a flat rock, to which it is bolted. The board was erected on 2 February 1994.

There is a cairn and the remains of a survey mast, erected in 1965-66, on Spaull Point. This mast is of interest for lichenometric studies and should not be removed. There are no other structures on Moe Island. 


\section{6(iv) Location of other Protected Areas within close proximity}

SPA No. 13, Moe Island, and SPA No. 14, Lynch Island, lies about $10 \mathrm{~km}$ north-northeast of Moe Island. SPA No. 18, North Coronation Island, lies about $19 \mathrm{~km}$ away on the northern side of Coronation Island. SPA No. 15, Southern Powell island, is about $41 \mathrm{~km}$ to the east.

\section{Permit Conditions}

Entry into the Area is prohibited except in accordance with a Permit issued by appropriate national authorities.

Conditions for issuing a permit to enter the Area are that:

- it is issued only for a compelling scientific purpose which cannot be served elsewhere

- the actions permitted will not jeopardize the natural ecological system in the Area

- any management activities are in support of the objectives of the Management Plan

- the actions permitted are in accordance with this Management Plan

- the Permit, or an authorised copy, must be carried within the Specially Protected Area

- a report or reports are supplied to the authority or authorities named in the Permit.

\section{7(i) Access to and movement within the Area}

There are no restrictions on landing from the sea, which is the preferred method. No special access points are specified, but landings are usually most safely made at the northeast corner of Landing Cove.

Helicopter landings should be avoided where practicable. Helicopters may land only on the col between hill $89 \mathrm{~m}$ and the western slope of Snipe Peak. To avoid overflying bird colonies approach should preferably be from the south, though an approach from the north is permissible.

It is forbidden to overfly the Area below $250 \mathrm{~m}$ altitude above the highest point except for access to the landing point specified above.

No pedestrian routes are designated but persons on foot should at all times avoid disturbances to birds or damage to vegetation and periglacial features. Vehicles are prohibited on Moe Island.

7(ii) Activities which are or may be conducted within the Area, including restrictions on time and place

- Compelling scientific research which cannot be undertaken elsewhere and which will not jeopardize the ecosystem of the Area

- Essential management activities, including monitoring

7(iii) Installation, modification or removal of structures

No structures are to be erected in the Area, or scientific equipment installed, except for essential scientific or management activities, as specified in the Permit.

\section{7(iv) Location of field camps}

Parties should not normally camp in the Area. If this is essential for reasons of safety, tents should be erected having regard to causing the least damage to vegetation or disturbance to fauna.

7(v) Restrictions on materials and organisms which may be brought into the Area

No living animals or plant material shall be deliberately introduced into the Area. 
No poultry products, including food products containing uncooked dried eggs, shall be taken into the Area.

No herbicides or pesticides shall be brought into the Area. Any other chemicals, which may be introduced for a compelling scientific purpose specified in the Permit, shall be removed from the Area at or before the conclusion of the activity for which the Permit was granted.

Fuel, food and other materials are not to be deposited in the Area, unless required for essential purposes connected with the activity for which the Permit has been granted. All such materials introduced are to be removed when no longer required. Permanent depots are not permitted.

\section{7(vi) Taking or harmful interference with native flora and fauna}

This is prohibited, except in accordance with a Permit. Where animal taking or harmful interference is involved this should be in accordance with the SCAR Code of Conduct for Use of Animals for Scientific Purposes in Antarctica, as a minimum standard.

\section{7(vii) Collection and removal of anything not brought into the Area by the Permit holder}

Material may be collected or removed from the Area only in accordance with a Permit, except that debris of man-made origin may be removed from the beaches of the Area and dead or pathological specimens of fauna or flora may be removed for laboratory examination.

7(viii) Disposal of waste

All non-human wastes shall be removed from the Area. Human waste may be deposited in the sea.

7(ix) Measures that may be necessary to ensure that the aims and objectives of the Management Plan continue to be met

Permits may be granted to enter the Area to carry out biological monitoring and site inspection activities, which may involve the collection of small amounts of plant material or small numbers of animals for analysis or audit, to erect or maintain notice boards, or protective measures.

\section{7(x) Requirements for reports}

The Principal Permit Holder for each issued Permit shall submit a report of activities conducted in the Area using the accepted Visit Report form suggested by SCAR. This report shall be submitted to the authority named in the Permit as soon as practicable, but not later than 6 months after the visit has taken place. Such reports should be

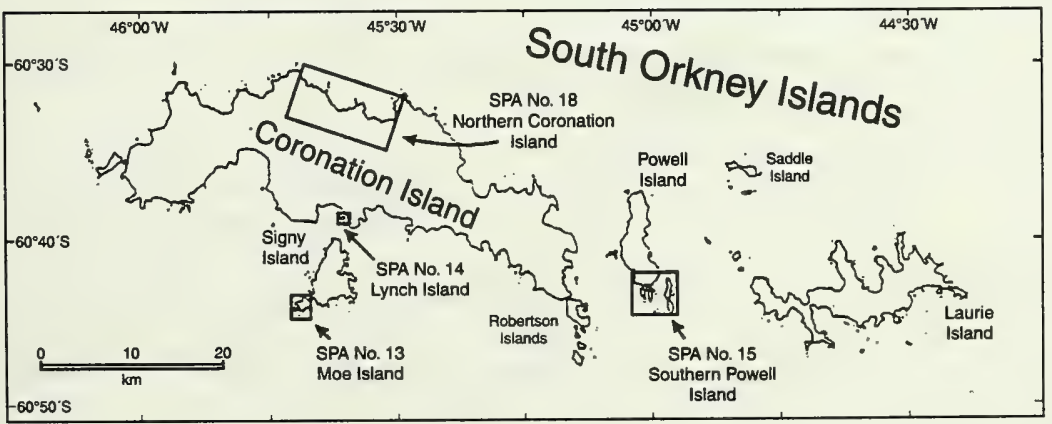

Map 1. Moe Island Specially Protected Area in relation to the South Orkney Islands 


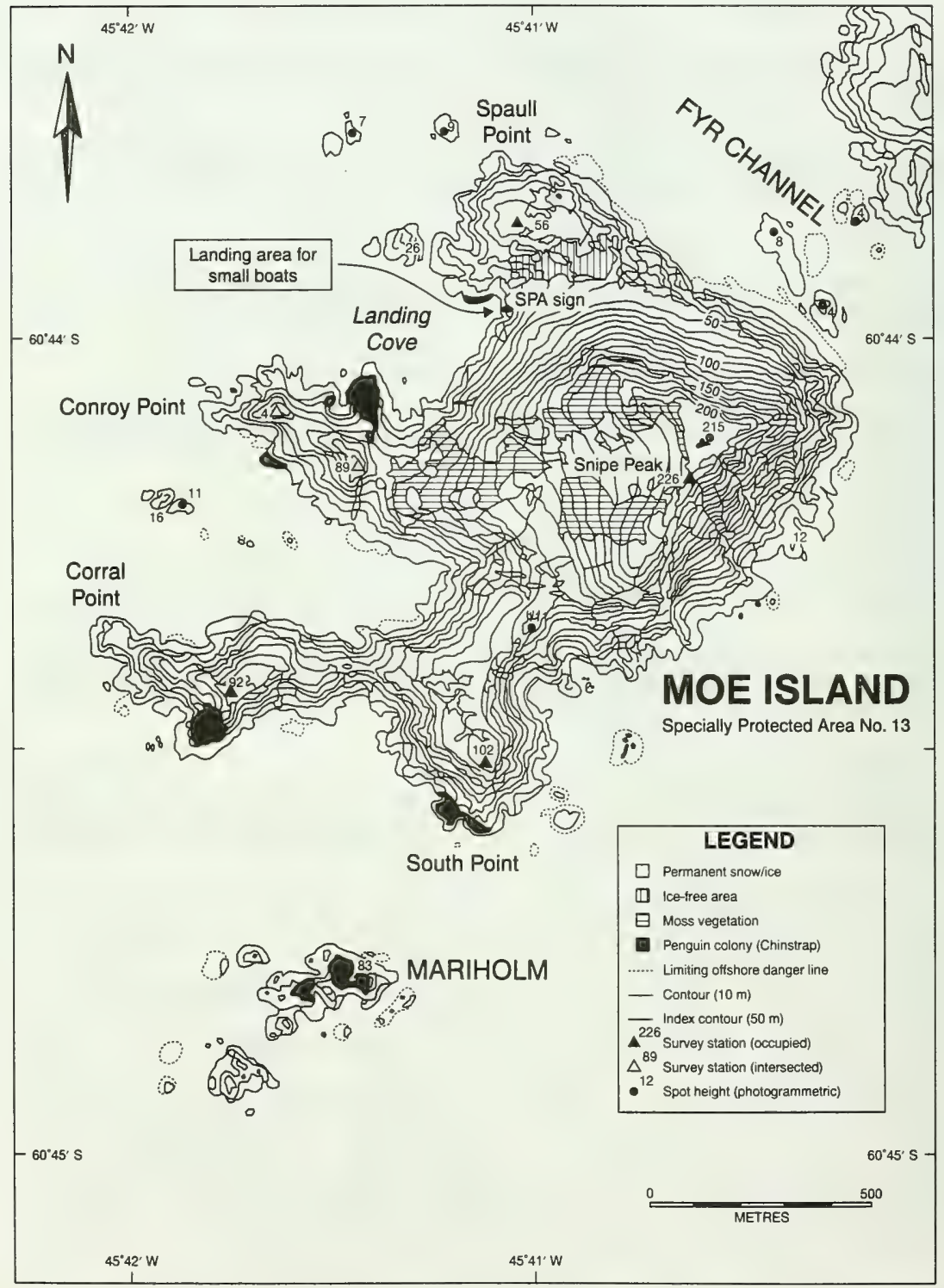

Map 2. Moe Island Specially Protected Area 
stored indefinitely and made accessible to interested Parties, SCAR, CCAMLR and COMNAP if requested, to provide the documentation of human activities within the Area necessary for good management.

\section{Annex B to Measure 1 (1995)}

\section{Management Plan for Specially Protected Area (SPA) No. 15}

\section{SOUTHERN POWELL ISLAND AND ADJACENT ISLANDS, SOUTH ORKNEY ISLANDS}

\section{Description of Values to be Protected}

The Area was originally designated in Recommendation IV-15 (1966, SPANo. 15) after a proposal by the United Kingdom on the grounds that Southern Powell Island and the adjacent islands support substantial vegetation and a considerable bird and mammal fauna. The Area was representative of the natural ecology of the South Orkney Islands, and was rendered more important by the nucleus of an expanding colony of Antarctic fur seals (Arctocephalus gazella).

These grounds are still relevant, though the expansion of the fur seal colony is progressing only slowly.

The values to be protected are primarily those associated with the large concentrations of breeding birds and seals, and to a lesser extent, the terrestrial vegetation.

\section{Aims and Objectives}

Management of southern Powell Island and adjacent islands aims to:

- avoid major changes in the structure and composition of the terrestrial vegetation;

- prevent unnecessary human disturbance to the Area;

- permit research of a compelling scientific nature which cannot be served elsewhere.

\section{Management Activities}

Because of its use as an anchorage in the past, it is important that the signs, which identify the Area as a Specially Protected Area and point out that landing without a Permit is forbidden, are maintained.

Visits should be made as necessary to assess the biological composition of the Area, in particular the state of the fur seal colony, and to maintain sign boards.

\section{Period of Designation}

Designated under ATCM Recommendation IV-15 for an indefinite period.

\section{Maps}

Map 1 shows the location of southern Powell Island in relation to the South Orkney Islands. Map 2 shows the Area in greater detail. 


\section{Description of the Area}

\section{6(i) Geographical coordinates and natural features}

The Area, which is centered on latitude $60^{\circ} 42^{\prime} \mathrm{S}$ and longitude $45^{\circ} 01 \mathrm{~W}$ includes all of Powell Island, South Orkney Islands, south of the latitude of the southern summit of John Peaks ( $375 \mathrm{~m}$ altitude), together with the whole of Fredriksen Island, Michelsen Island (a tidal peninsula at the southern tip of Powell Island), Christoffersen Island, Grey Island and unnamed adjacent islands. All but the Crutchley Ice Piedmont of southern Powell Island are ice-free in summer, though there are patches of semipermanent or late-lying snow in places.

The rocks of southern Powell Island, Michelsen Island and Christoffersen Island are conglomerates of Cretaceous-Jurassic age. The two promontories to the west of John Peaks are Carboniferous greywacke-shales. There are boulders containing plant fossils in the glacial deposits around Falkland Harbour. Much of central and southern Fredriksen Island is composed of sandstone and dark phyllitic shales. The north-east, and probably most of the north, of this island is highly sheared conglomerate with laminated mudstone. The Area has a thick mantle of glacial fill, strongly influenced by seabird guano.

Michelsen Island is almost devoid of land vegetation, although on the rocks there are extensive communities of lichens dominated by nitrophilous crustose species. These are also widespread on Fredriksen Island and elsewhere on bird-influenced cliffs and rocks near the shore. The most diverse vegetation on Powell Island occurs on the two promontories and associated scree west of Falkland Harbour. Here, and on Christoffersen Island and the northern part of Fredriksen Island, moss banks with underlying peat occur. Wet areas support stands of moss carpet. There are extensive areas of the nitrophilous macroalga Prasiola crispa associated with the penguin colonies in the area. Snow alga are prominent on the ice piedmont and snow patches in late summer.

No information is available on the arthropod fauna, but this is probably very similar to that at Signy Island. The springtails Cryptopygus antarcticus and Parisotoma octoculata and the mites Alaskozetes antarcticus, Stereotydeus villosus and Gamasellus racovitzai occur in great numbers beneath stones.

There are few observations on marine biota in the Area, but this is likely to be very similar to the wellresearched Signy Island area. The relatively enclosed Falkland-Ellefsen Harbour area and the bay on the east side of the peninsula are highly influenced by glacial run-off from the ice piedmont.

Large numbers of penguins and petrels breed throughout the Area. There are many thousand pairs of chinstrap penguins (Pygoscelis antarctica), mostly on Fredriksen Island. Similarly large numbers of Adelie penguins (P. adeliae) occur principally on the southern Powell-Michelsen Island area. Here there are also several thousand pairs of gentoo penguins ( $P$. papua) and a very few scattered pairs of macaroni penguins (Eudyptes chrysolophus) breeding among the gentoos.

Other breeding birds include southern giant petrels (Macronectes giganteus), cape petrels (Daption capensis), snow petrels (Pagodroma nivea), Wilson's storm petrels (Oceanites oceanicus), blue-eyed shags (Phalacrocorax atriceps), Dominican gulls (Larus dominicanus), brown skuas (Catharacta lonnbergi), sheathbills (Chionis alba), and possibly Antarctic prions (Pachyptila desolata) and blackbellied storm petrels (Fregatta tropica).

Michelsen Island is the longest known breeding site in the Antarctic of fur seals since their near extermination in the nineteenth century. The number of pups born annually has increased slowly but fairly steadily from 11 in 1956 to about 60 in 1989. Thirty-four live pups were recorded in January 1994. Many non-breeding males visit the Area during the summer. Other seals are frequent on the beaches, mainly elephant seals (Mirounga leonina) and Weddell seals (Leptonychotes weddelli.). Leopard seals (Hydrurga leptonyx) and crabeater seals (Lobodon carcinophagus) are occasionally seen on ice floes.

\section{6(ii) Restricted zones within the Area}

None

6(iii) Location of structures within the Area

A marker board (erected January 1994) is positioned on southern Powell Island on top of a small rock outcrop at the back of the shingle beach on the east side of the southern promontory of the island. 
On Michelsen Island the marker board (erected January 1994) is situated on a low-lying rock about $50 \mathrm{~m}$ from the shoreline at the back of a high shingle beach at the southern tip of the island.

On Christoffersen Island the marker board (erected January 1994) is located on a small promontory on the northeastern shore of the island at the entrance to Falkland Harbour. The board is located at the back of the beach just below a small Adelie penguin rookery.

On Fredriksen Island a marker board (erected January 1994) is located at the northern end of the pebble boulder beach on the western side of the island, below a small chinstrap penguin rookery. The board is at the back of the beach on top of a small rock outcrop.

There are no other structures within the Area, but various mooring chains and rings associated with the use of Ellefsen and Falkland Harbours by floating whale factories in the 1920 s are to be found on the shore.

\section{6(iv) Location of other Protected Areas within close proximity}

SPA No. 13, Moe Island, and SPA No. 14, Lynch Island, are about $35 \mathrm{~km}$ west by south and about $35 \mathrm{~km}$ west of the Area respectively. SPA No. 18, North Coronation Island, is about the same distance away on the northern side of Coronation Island.

\section{Permit Conditions}

Entry into the Area is prohibited except in accordance with a Permit issued by an appropriate national authority as designated under Article 7 of Annex V of the Protocol on Environmental Protection to the Antarctic Treaty.

Conditions for issuing a Permit to enter the Area are that:

- it is issued only for a compelling scientific purpose which cannot be served elsewhere;

- the actions permitted will not jeopardise the natural ecological system in the Area;

- any management activities are in support of the objectives of this Management Plan;

- the actions permitted are in accordance with this Management Plan;

- the Permit must be carried within the Specially Protected Area;

- a report or reports are supplied to the authority or authorities named in the Permit.

\section{7(i) Access to and movement within the Area}

Anchoring within Falkland Harbour and Ellefsen Harbour is prohibited except in emergency.

No pedestrian routes are designated within the Area, but persons on foot should avoid walking on vegetated areas or disturbing wildlife wherever possible. Vehicles are not allowed in the Area.

It is forbidden to overfly the Area below $250 \mathrm{~m}$ altitude above the highest point except for purposes of landing (when essential) on the beach on the east side of the southern most tip of Powell Island.

7(ii) Activities which are or may be conducted within the Area, including restrictions on time and place

- Compelling scientific research which cannot be undertaken elsewhere

- essential management activities, including monitoring. 


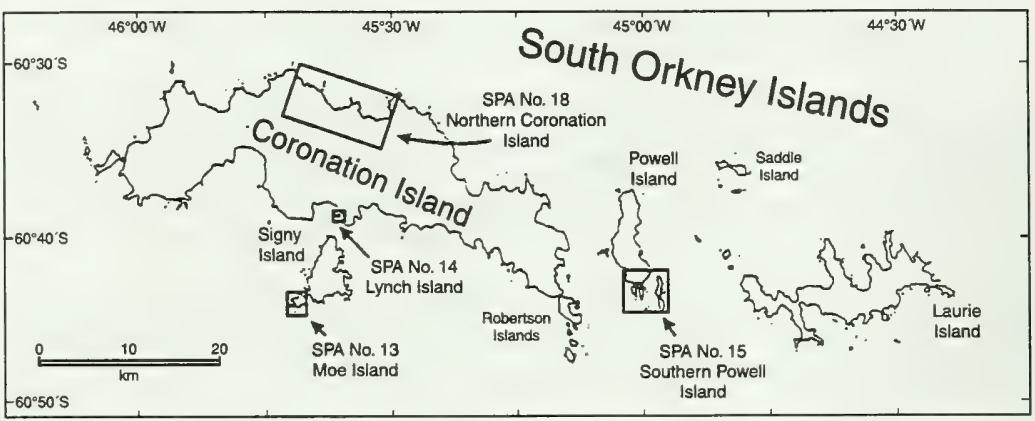

Map 1. Southern Powell Island and adjacent islands Specially Protected Area in relation to the South Orkney Islands

7(iii) Installation, modification or removal of structures

No structures are to be erected in the Area, or scientific equipment installed, except for essential scientific or management activities, as specified in the Permit.

\section{7(iv) Location of field camps}

Parties shall not camp in the Area, except in an emergency for reasons of safety. In this case, tents should be erected having regard to causing the least damage to the vegetation or disturbance to fauna.

\section{7 (v) Restrictions on materials and organisms which may be brought into the Area}

No living animals or plant material shall be deliberately introduced into the Area.

No poultry products, including food products containing uncooked dried eggs, shall be taken into the Area.

No herbicides or pesticides shall be brought into the Area. Any other chemicals, which may be introduced for a compelling scientific purpose specified in the Permit, shall be removed from the Area at or before the conclusion of the activity for which the Permit was granted.

Fuel, food or other materials are not to be deposited in the Area, unless required for essential purposes connected with the activity for which the Permit has been granted. All such materials are to be removed when no longer required.

\section{7(vi) Taking or harmful interference with native flora and fauna}

This is prohibited except in accordance with a Permit. Where animal taking or harmful interference is involved this should be in accordance with the SCAR Code of Conduct for Use of Animals for Scientific Purposes in Antarctica, as a minimum standard.

\section{7 (vii) Collection and removal of anything not brought into the area by the Permit holder}

Material may be collected or removed from the Area only in accordance with a Permit, except that debris of man-made origin may be removed from the beaches of the Area and dead or pathological specimens of fauna or flora may be removed for laboratory examinations. 


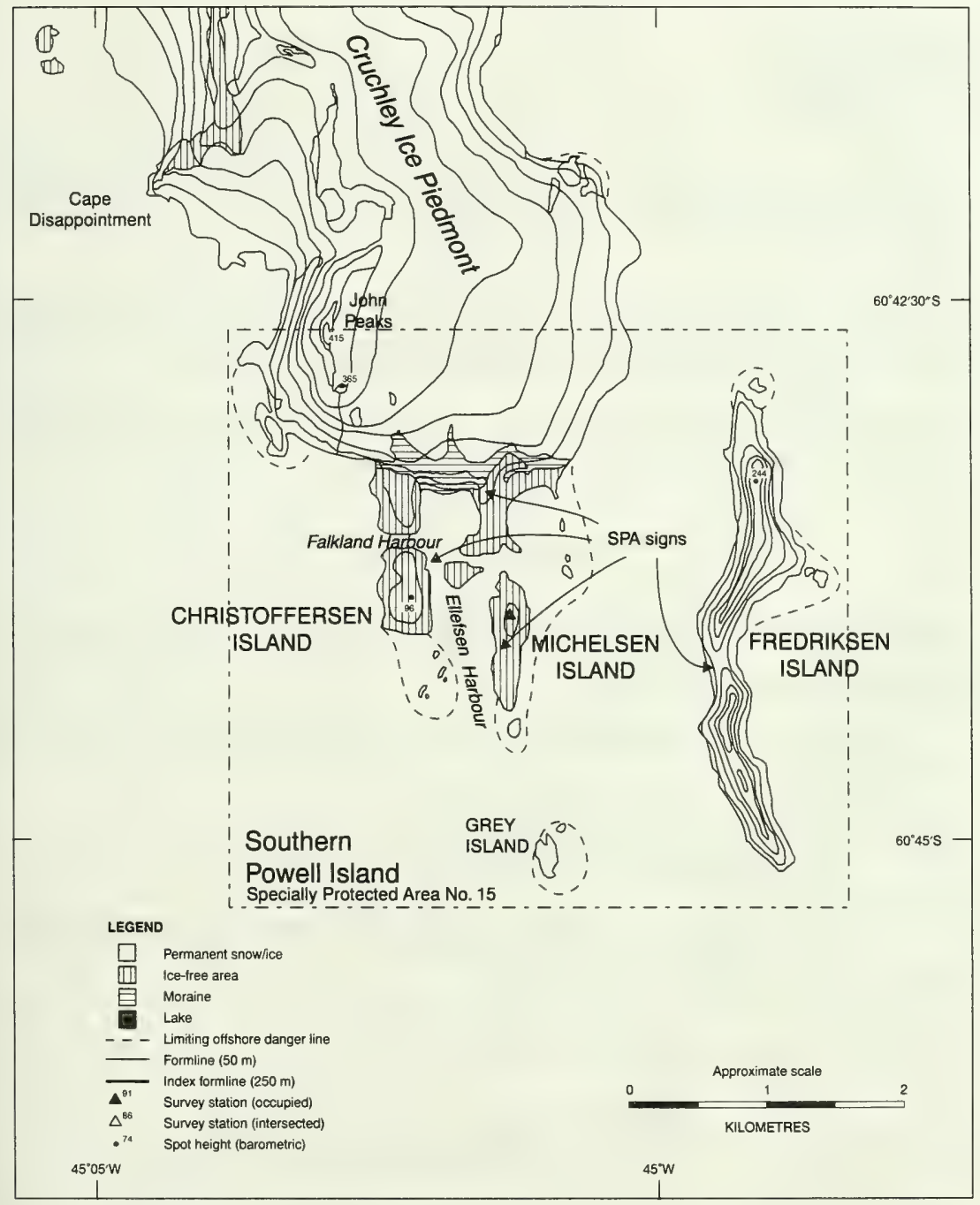

Map 2. Southern Powell Island and adjacent islands Specially Protected Area 
7(viii) Disposal of waste

All non-human wastes shall be removed from the Area. Human waste may be deposited in the sea.

7(ix) Measures that may be necessary to ensure that the aims and objectives of the Management Plan continue to be met

Permits may be granted to enter the Area to carry out biological monitoring and site inspection activities, which may involve the collection of small amounts of plant material or small numbers of animals for analysis or audit, or to erect or maintain notice boards, or to carry out protective measures.

\section{7(x) Requirements for reports}

The principal Permit holder for each issued Permit shall submit a report of activities conducted in the Area using the accepted Visit Report form. This report shall be submitted to the appropriate authority or authorities named in the Permit as soon as practicable, but not later than six months after the visit has taken place.

Such reports should be stored indefinitely by the appropriate authority and made accessible to interested Parties, SCAR, CCAMLR and COMNAP if requested, to provide the documentation of human activities within the Area necessary for good management.

\section{Measure 2 (1995)}

\section{Revised Description and Management Plan for Sites of Special Scientific Interest}

The Representatives of the Consultative Parties,

Recommend to their Governments the following Measure for approval in accordance with paragraph 4 of Article IX of the Antarctic Treaty;

For the Site of Special Scientific Interest mentioned below:

(i) the Management Plan inserted in the Annex to Recommendation XIII-8 Facilitation of scientific research: Sites of Special Scientific Interest, be deleted;

(ii) the Management Plan of the Site of Special Scientific Interest, annexed to this Recommendation, be inserted in the Annex to Recommendation XIII-8 Facilitation of scientific research: Sites of Special Scientific Interest.

The Site of Special Scientific Interest concerned is:

SSSI No. 11 Tramway Ridge, Mt. Erebus, Ross Island.

\section{Management Plan for Site of Special Scientific Interest (SSSI) No. 11 TRAMWAY RIDGE, MT. EREBUS, ROSS ISLAND}

\section{Description of Values to be Protected}

The lower end of Tramway Ridge was originally designated in Recommendation XIII-8 (1985, SSSI No. 11) after a proposal by New Zealand on the grounds that the Area supports an unusual ecosystem of exceptional scientific value to botanists, physiologists and microbiologists. Mt. Erebus $(3794 \mathrm{~m})$ is one of only three known high altitude localities of fumarolic activity and associated vegetation in the Antarctic. Tramway Ridge is an ice free area of gently sloping warm ground $1.5 \mathrm{~km}$ to the Northwest of the main crater of Mt. Erebus, located at an elevation of between $3350 \mathrm{~m}$ and $3400 \mathrm{~m}$. The single, as yet unidentified, moss species found in the Area is unusual in that it persists in the protonematal stage. An unusual variety of a common thermophilic cyanobacterium is especially noteworthy. The 
plant communities which have developed on the fumarolic soils within the Area differ significantly from those found elsewhere in Antarctica. The regional uniqueness of the communities is of substantial scientific interest and value. The very limited geographical extent of the ecosystem, its unusual biological features, its exceptional scientific values and the ease with which it could be disturbed through trampling or alien introductions, are such that the Area requires long-term special protection.

\section{Aims and Objectives}

Management at Tramway Ridge aims to:

- avoid degradation of, or substantial risk to, the values of the Area;

- prevent unnecessary human disturbance to the Area;

- permit research on the unique vegetation and microbial communities while ensuring they are protected from over-sampling;

- minimise the possibility of introduction of alien plants, animals and microbes to the Area;

- preserve a part of the Area, which is declared a Restricted Zone, as a reference site for future studies;

- permit visits for management purposes in support of the objectives of the management plan.

\section{Management Activities}

The following management activities are to be undertaken to protect the values of the Area:

- Durable wind direction indicators should be erected close to the designated helicopter landing site whenever it is anticipated there will be a number of landings near the Area in a given season. These should be replaced as needed and removed when no longer required.

- Markers, which should be clearly visible from the air and pose no significant threat to the environment, should be placed to mark the helicopter landing pad.

- A line of flags should be placed to mark the preferred snowmobile route (Map A) between the USAP Upper and Lower Erebus Huts, which should pass no closer than $200 \mathrm{~m}$ to the Area.

- Signs illustrating the location, boundaries and clearly stating entry restrictions shall be placed on posts marking the boundaries of the Area.

- Signs showing the location of the Area (stating the special restrictions that apply) shall be displayed prominently, and a copy of this Management Plan should be kept available, in all of the research hut facilities located close to the summit of Mt. Erebus.

- Markers, signs or structures erected within the Area for scientific or management purposes shall be maintained in good condition.

- Visits shall be made as necessary (no less than once every five years) to assess whether the Area continues to serve the purposes for which it was designated and to ensure management and maintenance measures are adequate.

- National Antarctic Programmes operating in the region shall consult together with a view to ensuring these steps are carried out.

\section{Period of Designation}

Designated for an indefinite period. 


\section{Maps and Photographs}

Map A: Tramway Ridge, Mt. Erebus, location image-map. Image is rectified by a fine transformation and scale is approximate. Photography USGS/DOSLI (SN7842) 11 November 1993.

Map B: Tramway Ridge, protected area orthophotograph. Orthophoto and protected area boundary coordinates are tied to the Camp Area Plane Datum 1981, a local framework, using the WGS72 spheroid. Precise GPS coordinates for the site will differ: these were unavailable at the time of mapping. Photography US Navy (SN6480) 9 February 1980.

Map C: Tramway Ridge, protected area map. Contours are derived from a digital elevation model generated using a $10 \mathrm{~m}$ grid for the orthophotograph in Map B: accuracy $\pm 2 \mathrm{~m}$. Precise area of warm ground is subject to variation seasonally and inter-annually.

Figure 1: Perspective view of the Tramway Ridge area from an elevation of $6200 \mathrm{~m}, 5000 \mathrm{~m}$ out from the Area at a bearing of $215^{\circ} \mathrm{SW}$, showing the protected area boundary, the location of the USAP Erebus huts, and the preferred helicopter landing site and snowmobile route. Image source: Map A.

\section{Description of the Area}

\section{6(i) Geographical coordinates, boundary markers and natural features}

The boundary of the designated Area is defined as a square of $200 \mathrm{~m}$ by $200.8 \mathrm{~m}$ which encompasses most of the warm ground area of lower Tramway Ridge $\left(167^{\circ} 06^{\prime} 35^{\prime \prime} \mathrm{E}, 77^{\circ} 31^{\prime} 05^{\prime \prime} \mathrm{S}\right.$ : Map B). The Area is divided into two parts of almost equal size, the northern half being a Restricted Zone. The boundaries of the Area and the Restricted Zone (marked by signposts at each corner) and prominent features are shown on Map B. Several boundary signposts have been offset owing to dangerous ground at the actual corner point.

The Area is in general on a gentle slope of about $5^{\circ}$, with much of the ice-free ground in the form of terraces which have a typical vertical height of about $0.5 \mathrm{~m}$ and steeper sides of up to $30^{\circ}$ in slope. The steep sides of the terraces have the maximum development of crusts of vegetation, and it is from these sides that visible steam emissions occur. Visible vegetation covers about $16 \%$ of the Area. Low ice hummocks of up to about $1 \mathrm{~m}$ high are distributed over the Area where steam has frozen. Surface ground temperatures are up to about $75^{\circ} \mathrm{C}$.

The steam-warmed lithosols in the Area provide an unusual habitat of limited extent. The acid reaction of the soils, the constant supply of moisture by condensation of steam and the regular supply of geothermal heat produce conditions which contrast markedly with most Antarctic soils. There is no evidence of the presence of microinvertebrate animals in the soils. The vegetation comprises protonematal moss and diverse microalgae, which has developed on the fumarolic soils and differs significantly from other Antarctic plant communities. The single moss species, which has not yet been identified, is unusual in that it has never been seen to produce leaves but persists in the protonematal stage. The vegetation occurs in zones related to surface temperature. Warmest ground, from about $35-60^{\circ} \mathrm{C}$, is colonised by dark blue-green and reddish-brown mats of cyanobacteria, whereas cooler surfaces of about $10-30^{\circ} \mathrm{C}$ are dominated by green crusts of coccoid chlorophytes and moss protonema. Bare ground lacking a macroscopically visible vegetation occurs between $0-20^{\circ} \mathrm{C}$.

The algal flora comprises four cyanobacteria and 11 coccoid chlorophytes. The presence of a thermophilic cyanobacterium is especially noteworthy as it is an unusual variety of the hot spring cyanobacterium Mastigocladus laminosus, which is common elsewhere in the world. Thermophilic bacteria have been isolated at $60^{\circ} \mathrm{C}$. These include heterotrophic and a thiosulfate-utilising autotrophic species.

\section{6(ii) Restricted zones within the Area}

The northern half of the Area is designated a Restricted Zone in order to preserve part of the Area as a reference site for future comparative studies, while the southern half of the Area (which is essentially similar in biology, features and character) is available for research programmes and sample collection. The south boundary of the Restricted Zone is defined by a line that bisects the Area into two halves (Map B), and is marked at both ends by signposts. This boundary may be identified on the ground approximately as an extension westwards of the south ridge line of lower Tramway Ridge. The other three boundaries of the Restricted Zone are defined by the boundaries of the Area. Access 
to the Restricted Zone is strictly prohibited until such time as it is agreed by management plan review that access should be allowed.

\section{6(iii) Structures within and near the Area}

Signposts mark the corner points of the boundaries. The USAP Lower and Upper Erebus Huts are located approximately $1 \mathrm{~km}$ to the Northeast $(3400 \mathrm{~m})$ and Southeast $(3612.5 \mathrm{~m})$ respectively.

6(iv) Location of other SPAs within close proximity of the Area

None.

\section{Permit Conditions}

Permits may be issued only by appropriate national authorities. Conditions for issuing a Permit to enter the Area are that:

- it is issued only for scientific study of the ecosystem, or for a compelling scientific or management purpose that cannot be served elsewhere;

- access to the Restricted Zone shall be prohibited;

- the actions permitted are not likely to jeopardise the natural ecological system or scientific values of the Area;

- any management activities are in support of the objectives of the Management Plan;

- the actions permitted are in accordance with the Management Plan;

- any Permit issued shall be valid for a stated period.

\section{7(i) Access to and movement within the Area}

Landing of helicopters within the Area is strictly prohibited. Helicopter overflight of the Area should be avoided, except for essential scientific or management purposes when helicopters shall in no instance fly lower than $30 \mathrm{~m}$ above the ground surface of the Area. Use of helicopter smoke bombs is strictly prohibited within $200 \mathrm{~m}$ of the Area and is discouraged nearby. For short-duration visits which do not require camp establishment, access by helicopter should be to a designated landing site, located outside of the Area and $300 \mathrm{~m}$ to the Northwest (Map A and Figure 1). For visits which require camp establishment, helicopter access should be to the USAP Upper or Lower Erebus Huts, and thence on foot or by land vehicle to the edge of the Area at Tramway Ridge. Landing of helicopters at other sites close to the Area is strongly discouraged. Only those persons specifically authorised by Permit are allowed to enter the Area. No special restrictions apply to the air or land routes used to move to and from the Area, although those traveling between the Upper and Lower Erebus Huts should keep to the preferred snowmobile route and stay at least $200 \mathrm{~m}$ from the protected area boundary.

Access into the Area shall be on foot and land vehicles are prohibited. Visitors should avoid walking on visible vegetation and, as far as practicable, areas of warm ground. Visitors should be aware that walking in the Area can compact soil, alter temperature gradients (which may change rates of steam release), and break thin ice crusts which may form over warm ground, with resulting damage to soil and biota below. The presence of snow or ice surfaces is not a guaranteed indication of a suitable pathway: therefore every reasonable effort should be made to minimise the effects of walking activity. Pedestrian traffic should be kept to the minimum necessary consistent with the objectives of any permitted activities. 


\section{7(ii) Activities that are or may be conducted in the Area, including restrictions on time or place}

- Scientific research which will not jeopardise the ecosystem of the Area;

- Essential management activities, including monitoring;

- Entry to the Restricted Zone is prohibited.

\section{7(iii) Installation, modification or removal of structures}

No structures, except for boundary markers and signs, are to be erected within the Area except as specified in a Permit. All scientific equipment installed in the Area must be approved by Permit and clearly identified by country, name of the principal investigator and year of installation. All such items should be made of materials that pose minimal risk of contamination of the Area. Removal of specific equipment for which the Permit has expired shall be the responsibility of the authority which granted the original Permit.

\section{7(iv) Location of field camps}

Camping required for work in the Area should be near the existing USAP Upper or Lower Erebus Hut sites, and is discouraged anywhere within $500 \mathrm{~m}$ of the boundaries of the Area (Map A).

\section{7(v) Restrictions on materials and organisms which can be brought into the Area}

To avoid compromising the microbial ecosystem for which this site is protected no living animals, plant material or microorganisms shall be deliberately introduced into the Area and precautions shall be taken against accidental introductions. No herbicides or pesticides shall be brought into the Area. Any other chemicals, including radio-nuclides or stable isotopes, which may be introduced for scientific or management purposes specified in the Permit, shall be removed from the Area at or before the conclusion of the activity for which the Permit was granted.

Fuels are not to be brought into the Area. Food shall not be consumed within the Area. Equipment and other materials are not to be stored in the Area, unless required for essential purposes connected with the activity for which the Permit has been granted. All such materials introduced shall be for a stated period only, shall be removed at or before the conclusion of that stated period, and shall be stored and handled so that risk of their introduction into the environment is minimised.

\section{7(vi) Taking of or harmful interference with native flora or fauna}

Taking of or harmful interference with native flora or fauna is prohibited, except in accordance with a Permit. Where taking of animals or harmful interference is involved this should be in accordance with the SCAR Code of Conduct for the Use of Animals for Scientific Purposes in Antarctica, as a minimum standard.

\section{7(vii) Collection or removal of anything not brought into the Area by the Permit holder}

Material may be collected or removed from the Area only in accordance with a Permit. Material of human origin, not brought into the Area by the Permit Holder, but which is likely to compromise the values of the Area may be removed from any part of the Area, including the Restricted Zone.

\section{7(viii) Disposal of waste}

All wastes, including all human wastes, must be removed from the Area. Excretion of human wastes is prohibited within the Area.

7(ix) Measures that are necessary to ensure that aims and objectives of the Management Plan can continue to be met

1. The Permit, or an authorised copy, must be carried within the Area.

2. Permits may be granted to enter the Area to carry out biological monitoring and site inspection activities, which may involve the collection of small samples for analysis or audit to erect or maintain signposts, or protective measures. 
3. To help maintain the scientific value derived from the unique communities found at Tramway Ridge visitors shall take special precautions against introductions, especially when visiting several thermal regions in a season. Of particular concern are microbial or vegetation introductions sourced from:

- thermal areas, both Antarctic non-Antarctic;

- soils at any other Antarctic sites, including those near stations;

- soils from regions outside Antarctica.

To this end, visitors shall take the following measures to minimise the risk of introductions:

(a) Any sampling equipment or markers brought into the Area shall be sterilised and maintained in a sterile condition before being used within the Area. To the maximum extent practicable, footwear and other equipment used or brought into the Area (including backpacks or carry-bags) shall be thoroughly cleaned or sterilised and maintained in this condition before entering the Area;

(b) Sterilisation should be by an acceptable method, such as by UV light, autoclave or by washing exposed surfaces in $70 \%$ ethanol solution in water.

(c) Sterile protective overclothing shall be worn. The overclothing shall be suitable for working at temperatures of $-20^{\circ} \mathrm{C}$ or below and comprise at a minimum sterile overalls to cover arms, legs and body and sterile gloves suitable for placing over the top of cold-weather gloves.

\section{7(x) Requirements for reports}

Parties should ensure that the principal holder of each permit issued submit to the appropriate authority a report describing the activities undertaken. Such reports should include, as appropriate, the information identified in the Visit Report form suggested by SCAR. Parties should maintain a record of such activities and, in the Annual Exchange of Information, should provide summary descriptions of activities conducted by persons subject to their jurisdiction, in sufficient detail to allow evaluation of the effectiveness of the management plan. Parties should, wherever possible, deposit originals or copies of such original reports in a publicly accessible archive to maintain a record of usage, to be used both in any review of the management plan and in organising the scientific use of the Area.

Unreproducible image: Map A - Tramway Ridge, Mt. Erebus: Antarctic Specially Protected Area No. XX Location image-map.

Unreproducible image: Map B - Tramway Ridge, Mt. Erebus: Antarctic Specially Protected Area No. XX

Unreproducible image: Figure 1 - Tramway Ridge, Mt. Erebus: Antarctic Specially Protected Area No. XX

Perspective view from $215^{\circ} \mathrm{SW}$ 

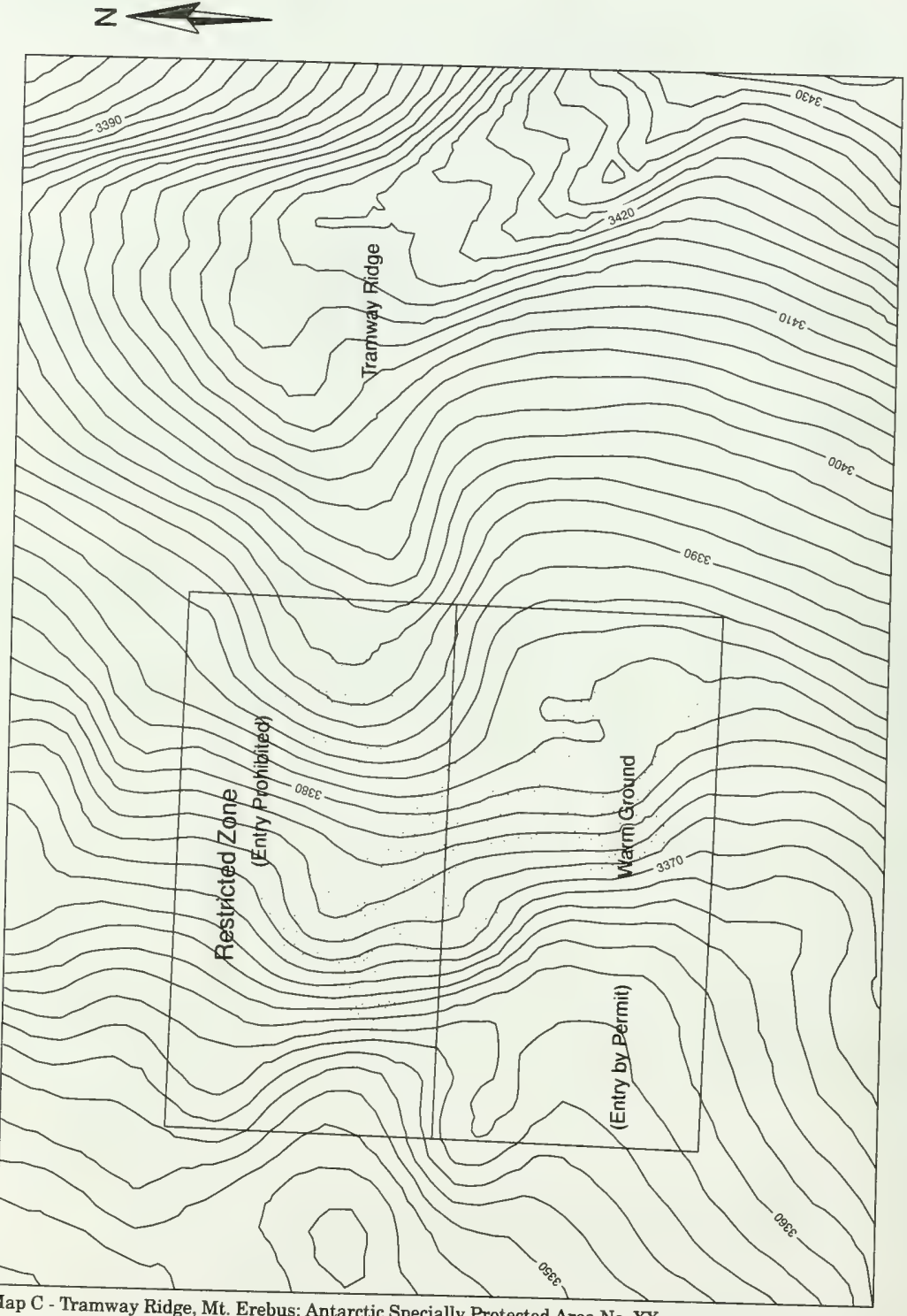

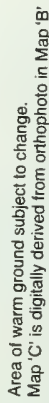




\section{Measure 3 (1995)}

\section{Antarctic Protected Area System: Specially Protected Areas}

Specially Protected Area No. 24: Pointe-Geologie Archipelago (Jean Rostand, Alexis Carrel, Lamarck and Claude Bernard Islands, Bon Docteur Nunatak)

The Representatives of the Consultative Parties,

Recalling Recommendations XV-8 and XV-9;

Noting that a Management Plan for the above Area has been approved by the Scientific Committee on Antarctic Research (SCAR);

Considering that the Point Geologie Archipelago is important as a representative area of considerable biological, geological and aesthetic value; contains a high diversity of animals and plants and is an important area for scientific research; and that long-term research and monitoring programmes on bird colonies and geology have been conducted in the area since 1952 ;

Recommend to their Governments the following Measure for approval in accordance with paragraph 4 of Article IX of the Antarctic Treaty:

That the following Area shall be inserted in Annex B, Specially Protected Areas, of the Agreed Measures for the Conservation of Antarctic Fauna and Flora, together with the annexed Management Plan:

Specially Protected Area No. 24

Jean Rostand, Alexis Carrel, Lamarck and Claude Bernard Islands, Bon Docteur Nunatak and Breeding Marine Emperor Penguin Colony ( 140 to $140^{\circ} 02^{\prime} \mathrm{E} ; 66^{\circ} 39^{\prime} 30^{\prime \prime}$ to $66^{\circ} 40^{\prime} 33^{\prime \prime} \mathrm{S}$ ) in the heart of Pointe-Geologie Archipelago, coastal area of Adelie Land in the vicinity of Astrolabe Glacier.

\section{Annex to Measure 3 (1995)}

\section{SPECIALLY PROTECTED AREA NO. 24 \\ POINTE-GEOLOGIE ARCHIPELAGO}

\section{JEAN ROSTAND, ALEXIS CARREL, LAMARCK AND CLAUDE \\ BERNARD ISLANDS, BON DOCTEUR NUNATAK AND MARINE \\ EMPEROR PENGUIN BREEDING COLONY \\ MANAGEMENT PLAN}

\section{DESCRIPTION OF VALUES TO BE PROTECTED}

Four islands and the breeding site of Emperor penguins are proposed for a new Specially Protected Area on the ground that it provides a representative sample of aesthetic, biological and geological values of terrestrial Antarctic ecosystems. 
One mammal specie, Weddell seal (Leptonychotes weddeili) and various bird species are nesting here: Emperor penguin (Aptenodytes forsteri); South Polar skua (Catharacta maccormicki); Adelie penguin (pygoscelis adeliae); Wilson's storm petrel (Oceanites oceanicus); Southern giant petrel (Macronectes giganteus); Snow petrel (Pagodroma nivea); Capy petrel (Daption capensis).

Well-marked hills display asymetrical transverse profiles with gently dipping northern slopes compared to the steeper southern ones. The terrain is affected by numerous cracks and fractures leading to very rough surfaces. The basement rocks mainly consist of sillimanite, cordierite and garnet-rich gneisses which are intruded by abundant dikes of pink anatexites. The lowest parts of the islands are covered by morainic boulders (from a few centimeters to more than a meter across).

Long-term research and monitoring programmes have been continuing a long time already (since 1952 or 1964 according to the species). A data base implemented in 1981 is directed by C.E.B.C. (Centre d'Etudes biologiques de Chize).

The Emperor penguins breeding colony is a site of Special Scientific Interest which could further be included in the Convention on Conservation of Antarctic Marine Living Resources Environmental Monitoring Programme (CCAMLR/CEMP) in order to achieve the Convention's requirements.

\section{AIMS AND OBJECTIVES}

Management of Point-Géologie area aims to:

* prevent unnecessary disturbance on the area face to the growing flux of cruising tourist ship.

* permit research of a compelling scientific nature which cannot be served elsewhere.

* avoid major change to the structure and composition of flora and fauna and the association of different species of vertebrates harboured in the area, which therefore constitutes one of the most representative for both faunistic and scientific interest on Adelie coast.

* permit research on ethological, ecological, physiological and biochemical programmes in progress especially those related to demographic monitoring and impact assessment of surrounding human activities comprising tourism. Physiology and biochemistry programmes relating to fasting mechanisms and thermogenesis of emperor penguins could be pursued in compliance with permit provisions.

* permit research in geology with a particular attention to the programmation of visits, especially when thermomechanical means for sampling are required.

\section{MANAGEMENT ACTIVITIES}

The Plan is kept under review to ensure that the values of the area are wholly protected. Any direct management action to the area would be subject to an environmental impact assessment before being undertaken.

Inspection visits are restricted to essential management purposes.

\section{PERIOD OF DESIGNATION}

The Area is designated for an indefinite period.

\section{MAPS}

Map 2 shows with dotted lines location of each island and other zones of the area inside Pointe-Géologie Archipelago. 


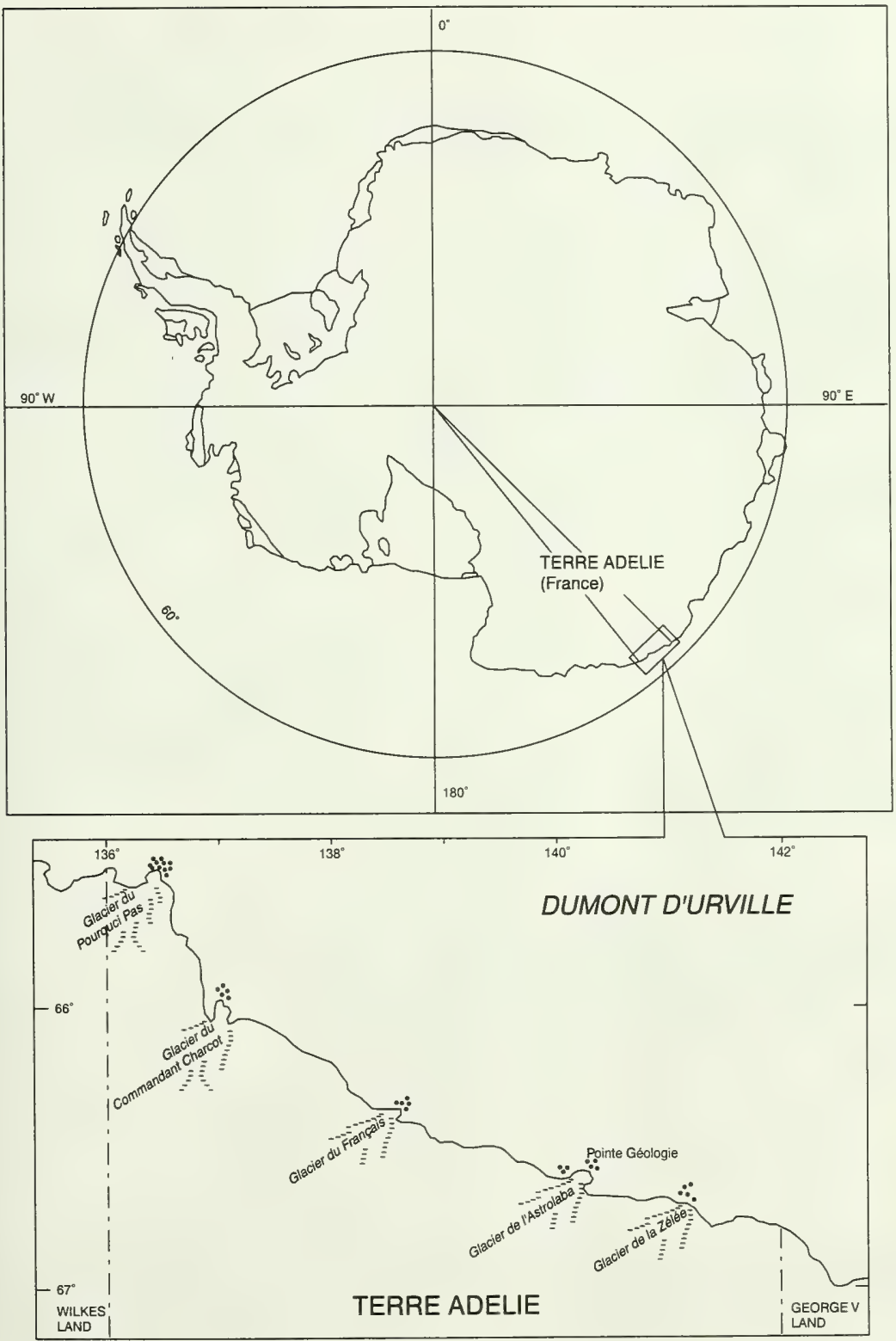




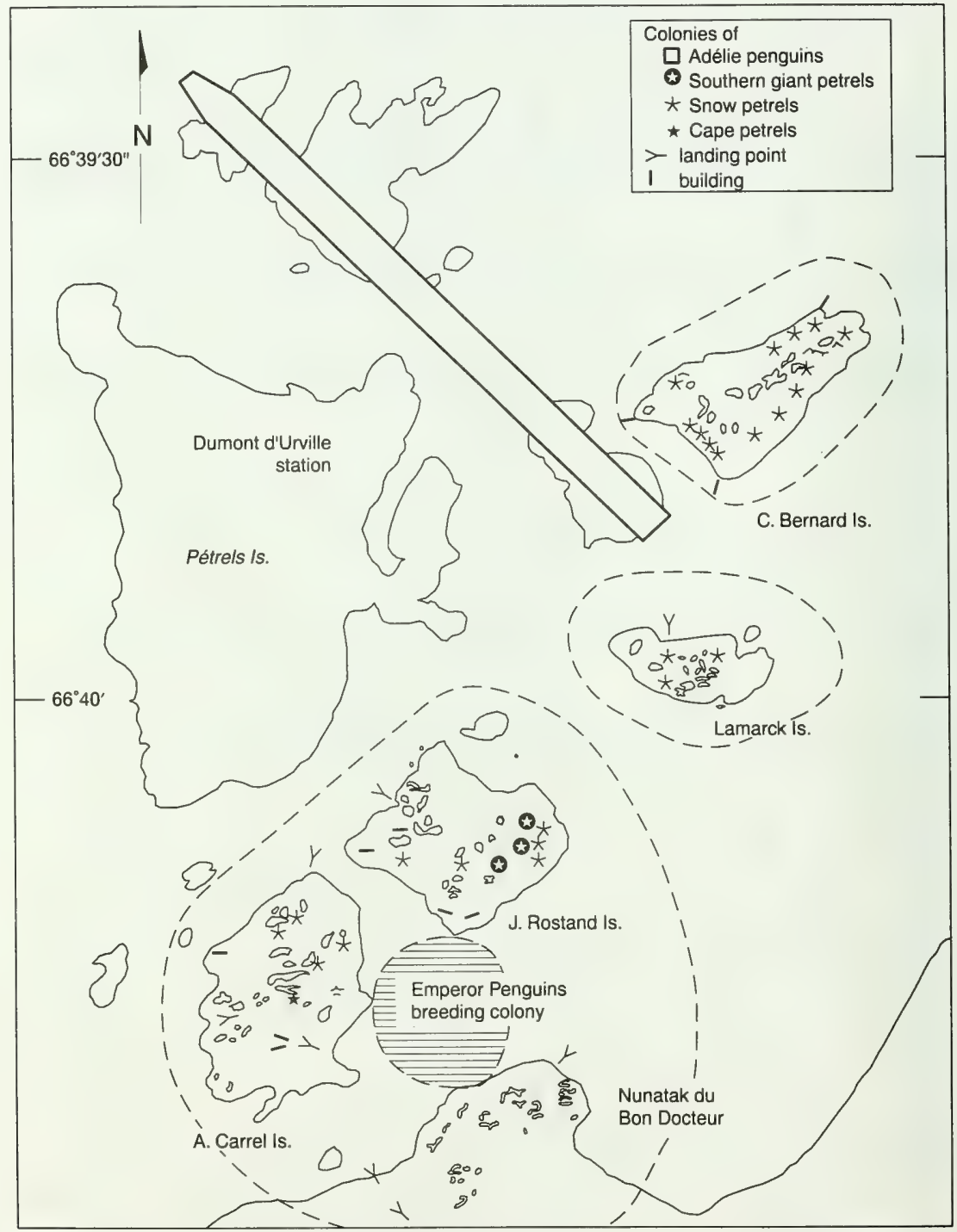

Map 1. Pointe Géologie Archipelago showing the Specially Protected Area (dotted lines) and avifauna breeding sites. The South polar skuas territories and the Wilson's storm petrels nests are not mapped (see table 1). The additional access of terrestrial vehicles to the continent (Nunatak) is indicated with large arrows. 


\section{DESCRIPTION OF THE AREA}

\section{i) Geographical coordinates, boundary markers and natural features}

Jean ROSTAND. Alexis CARREL. LAMARCK and Claude BERNARD Islands. Bon Docteur Nunatak and Emperor penguins breeding colony are situated in the heart of Pointe-Géologie Archipelago, coastal area of Adelie Land $\left(140\right.$ to $140^{\circ} 02^{\prime} \mathrm{E} ; 66^{\circ} 39^{\prime} 30^{\prime \prime}$ to $\left.66^{\circ} 40^{\prime} 30^{\prime \prime} \mathrm{S}\right)$.

The area consists of the southernmost exposure of the Pointe-Géologie Archipelago, between the Petrels Island and the Western edge of the Astrolable glacier. It is a very large ice free ground within Adelie Land.

As a whole, the surface of the outcropping rocks does not exceed 2 square kilometers. The highest points are distributed along NE-SW ridges (Cl. Bernard Island: 47.6m; J.B. Lamarck Island: $22.2 \mathrm{~m}$; J. Rostand Island: $36.39 \mathrm{~m}$; Carrel Island: $28.24 \mathrm{~m}$ and Nunatak: $28.50 \mathrm{~m}$ ). During the summer, only the southern flanks of the islands are still covered by compressed snow caps. There are no boundary markers since natural features delimit the wholly protected islands. However, markers could further be set up in Nunatak. No tracks or roads exist in the area.

Table 1. Annual breeding area of seabirds in the Specially Protected Area (SPA). The population breeding within the SPA is given compared to the Pointe Geologie (PG) population (from Thomas 1986).

\begin{tabular}{|c|c|c|c|c|c|c|c|}
\hline Islands & $\begin{array}{l}\text { Emperor } \\
\text { penguin }\end{array}$ & $\begin{array}{c}\text { Adelie } \\
\text { penguin }\end{array}$ & $\begin{array}{c}\text { South } \\
\text { polar skua }\end{array}$ & $\begin{array}{l}\text { Snow } \\
\text { petrel }\end{array}$ & $\begin{array}{c}\text { Cape } \\
\text { petrel }\end{array}$ & $\begin{array}{c}\text { Wilson's } \\
\text { storm petrel }\end{array}$ & $\begin{array}{c}\text { Southern } \\
\text { giant petrel }\end{array}$ \\
\hline Claude Bernard & - & 3421 & 5 & 153 & 192 & 178 & - \\
\hline Lamarck & - & 1007 & 1 & 38 & 15 & 45 & - \\
\hline Jean Rostand & - & 4793 & 3 & 53 & 18 & 35 & 11 \\
\hline Alexis Carrel & - & 4075 & 6 & 25 & - & 72 & - \\
\hline Nunatak & - & 1961 & 1 & 11 & - & 41 & - \\
\hline $\begin{array}{l}\text { Emperor Penguin } \\
\text { Breeding Colony }\end{array}$ & 3119 & - & - & - & - & - & - \\
\hline Total & 3119 & 15257 & 16 & 280 & 225 & 371 & 11 \\
\hline \%SPA/P & 100 & 71 & 67 & 36 & 68 & 31 & 79 \\
\hline
\end{tabular}

Table 2. Presence of birds on breeding colonies.

\begin{tabular}{|lccccccc|}
\hline & $\begin{array}{c}\text { Emperor } \\
\text { penguin }\end{array}$ & $\begin{array}{c}\text { Adelie } \\
\text { penguin }\end{array}$ & $\begin{array}{c}\text { South } \\
\text { polar skua }\end{array}$ & $\begin{array}{c}\text { Snow } \\
\text { petrel }\end{array}$ & $\begin{array}{c}\text { Cape } \\
\text { petrel }\end{array}$ & $\begin{array}{c}\text { Wilson's } \\
\text { storm petrel }\end{array}$ & $\begin{array}{c}\text { Southern } \\
\text { giant petrel }\end{array}$ \\
\hline First arrival & March & October & October & September & October & November & July \\
First laying & May & November & November & November & November & December & October \\
Last departure & January & March & March & March & March & March & April
\end{tabular}


Table 3. Sensibility to human disturbance and status of the Pointe Geologie populations.

\begin{tabular}{lccccccc|}
\hline & $\begin{array}{c}\text { Emperor } \\
\text { penguin }\end{array}$ & $\begin{array}{c}\text { Adelie } \\
\text { penguin }\end{array}$ & $\begin{array}{c}\text { South } \\
\text { polar skua }\end{array}$ & $\begin{array}{c}\text { Snow } \\
\text { petrel }\end{array}$ & $\begin{array}{c}\text { Cape } \\
\text { petrel }\end{array}$ & $\begin{array}{c}\text { Wilson's } \\
\text { storm petrel }\end{array}$ & $\begin{array}{c}\text { Southern } \\
\text { giant petrel }\end{array}$ \\
\hline $\begin{array}{l}\text { Sensibility to } \\
\text { human disturbance }\end{array}$ & High & Medium & Low & Medium & High & High & High \\
Status 1952-1984 & decreasing & increasing & stable & $?$ & $?$ & $?$ & decreasing \\
Status 1984-1993 & stable & increasing & stable & stable & stable & $?$ & stable
\end{tabular}

\section{ii) Identification of restricted or prohibited zones}

Access to every part of the area is prohibited unless authorized by a permit.

Location of breeding colonies is shown on the map. The birds are present in colonies from October to March, except Emperor penguins, which breed in winter (Table 2). Their sensibility to human disturbance varies depending on the species (Table 3). The implantation of the Dumont d'Urville station has resulted in a drastic decrease of the populations of Emperor penguins and Southern giant petrels in Pointe-Géologie Archipelago. For the last ten years the breeding areas of these birds have been protected and the populations are now consecutively stable (Table 3 ).

No one, except permit holders, is allowed to approach or to disturb the Emperor penguin colony in any manner when eggs are incubating from mid-July, to mid-December when the chicks fledge. The particularly sensitive Emperor penguins are equally protected beyond the definite limits of their breeding area since the colony is not always located in the same place.

The southeastern part of Jean Rostand Island is designated as a Restricted Zone in order to preserve the remaining breeding colony of Southern giant petrels. All access to the Restricted Zone is prohibited during the breeding period from August to February. The access is restricted to one ornithologist permit holder in order to monitor the population three times each year. The boundary of the Restricted Zone is defined by a 20 meters-width buffer zone around the colony and is marked on the soil. The prohibition of access to the Restricted Zone shall be for an indefinite period, but shall be subject to reevaluation each time the Management Plan is reviewed.

\section{Location of structures in the Area}

Prevost hut and a shelter are located on ROSTAND Island. There are no other buildings anywhere else in the Area.

iv) Location in or near the area of other "Antarctic Specially Protected Areas" or "Antarctic Specially Managed Areas".

The region nearby is being considered for an "Antarctic Specially Managed Area" (ASMA) including Dumont d'Urville station and other surrounding areas of activities.

\section{CONDITIONS UNDER WHICH PERMITS MAY BE GRANTED}

\section{i) Access to and movement within the Area}

No helicopters, nor terrestrial vehicles are authorised within the Area. No overflights over the Area, either by helicopters or other aeroplanes are authorized.

Access to the area is therefore only permitted by foot or by zodiacs (in summer).

However, very rare departures of terrestrial vehicles from Nunatak are allowed. Only when sea ice conditions hinder from proceeding otherwise and with special attention to the presence of birds in the area.

Access to and movement within the area shall, in any case, be limited in order to avoid unnecessary disturbance to birds, especially by crossing their pathways and to ensure that breeding areas or their access are not damaged or endangered. 
ii) Activities which are or may be conducted within the Area, including restrictions on time and place

- compelling scientific activities which cannot be conducted elsewhere and for necessary management activities with regard to the special provisions relating to Emperor penguins and the Restricted Zone of Southern Giant Petrels (see 6.ii).

- visitors granted entry in the Area by a permit shall ensure that no disturbances will occur from their visits to monitoring programmes.

\section{iii) Installation, modification or removal of structures}

No structures are to be erected in the area or scientific equipment installed except for essential scientific or management activities as specified in the permit.

iv) The location of field camps

Only safety tents should be erected with the intent of causing the least damage or disturbance to fauna.

v) Restriction on materials and organisms which may be brought into the Area

- no living animals or plant materials shall be deliberately introduced into the Area

- no poultry products, including food products containing uncooked dried eggs should be taken into the Area

- no chemicals shall be brought into the Area, except chemicals which may be introduced for a compelling scientific purpose as specified in the permit. Any chemical introduced shall be removed from the Area at or before the conclusion of the activity for which the permit was granted

- fuel, food and other materials are not to be deposited in the area, unless required for essential purposes connected with the activity for which the permit has been granted. Such materials introduced are to the removed when no longer required. Permanent depots are not permitted.

vi) The taking of or harmful interference with flora and fauna

Taking of or harmful interference with native flora and fauna is prohibited, except in accordance with a permit. Where animal taking or harmful interference is involved, this should be in accordance with the SCAR Code of Conduct for the Use of Animals for Scientific Purposes in Antarctica, as a minimum standard.

vii) The collection or removal of anything not brought into the Area by the permit holder

Collection or removal of anything not brought into the Area by a permit holder is prohibited unless specified in the permit for scientific or management purposes. However, debris of man-made origin may be removed from the area and dead or pathological specimens of fauna or flora may be removed for laboratory examination.

\section{viii) The disposal of waste}

All non-human wastes shall be removed from the Area.

ix) Measures that may be necessary to ensure that the aims and objectives of the Management Plan can continue to be met

Permits may be granted to enter the Area to carry out monitoring, other scientific programmes and sites inspection activities, which may involve the collection of small amounts of biological materials and animals.

Permits shall specify the maximum number of persons allowed entry at one time.

Visits to the Area should be kept to the minimum necessary to achieve the scientific and management objectives. 
Parties should ensure that the principal holder of each permit issued submit to the appropriate authority a report describing the activities undertaken. Such reports should include, as appropriate, the information identified in the Visit Report form suggested by SCAR. Parties should maintain a record of such activities and, in the Annual Exchange of Information, should provide summary descriptions of activities conducted by persons subject to their jurisdiction, in sufficient detail to allow evaluation of the effectiveness of the management plan. Parties should, wherever possible, deposit originals or copies of such original reports in a publicly accessible archive to maintain a record of usage, to be used both in any review of the management plan and in organising the scientific use of the Area.

\section{MEASURE 4 (1995)}

\section{ANTARCTIC PROTECTED AREA SYSTEM: NEW HISTORIC SITES AND MONUMENTS}

The Representatives of the Consultative Parties,

Recalling the Measures adopted in Recommendations 1-IX, V-4, VI-14, VII-9, XII-7, XIII-16, and XIV-8;

Recommend to their Governments the following Measure for approval in accordance with paragraph 4 of Article IX of the Antarctic Treaty; that the following historic monuments be added to the "List of Historic Monuments Identified and Described by the Proposing Government or Governments" annexed to Recommendation VII-9.

Port Lockroy, Base A, on Goudier Island, off Wiencke Island, Antarctic Peninsula (Lat $64^{\circ} 49^{\prime}$ S, Long $63^{\circ} 31^{\prime}$ W). Of historic importance as an Operation Tabarin base and for scientific research.

Argentine Islands, Base F (Wordie House), South-west corner of Winter Island, one of the group known as the Argentine Islands (Lat $65^{\circ} 15^{\prime} \mathrm{S}$, Long $64^{\circ} 16^{\prime} \mathrm{W}$ ). Of historic interest as an example of an early British scientific base.

- Horseshoe Island, Base Y, Marguerite Bay, West Graham Land (Lat $67^{\circ} 49^{\prime}$ S, Long $67^{\circ} 18^{\prime}$ W). Noteworthy as a relatively unaltered and completely equipped base of a later period. Blaiklock, the refuge hut nearby, is taken to be an integral part of the base.

- Stonington Island, Base E, Northern end of Stonington Island, Marguerite Bay, West Graham Land (Long $68^{\circ} 11^{\prime} \mathrm{S}, 67^{\circ} 00^{\prime} \mathrm{W}$ ). Of historical importance in the early period of exploration and later British Antarctic Survey (BAS) history of the $1960 \mathrm{~s}$ and 70 s.

- Message Post, Svend Foyn Island. A pole with a box attached was placed on 16 January 1895 during the whaling expedition of Henryk Bull and Captain Leonard Kristensen of the ship "Antarctica." It was examined and found intact by the British Antarctic Expedition of 1898-1900 and then sighted from the beach by the USS Edisto in 1956 and USCGS Glacier in 1965 (latitude approximately $71^{\circ} 52^{\prime} \mathrm{S}$, longitude $\left.171^{\circ} 10^{\prime} \mathrm{E}\right)$.

- Prestrud's Cairn, at the foot of main bluff Scott Nunataks, Queen Alexandra Mountains. A small rock cairn at the foot of the main bluff on the north side of the Aunataks by Lieutenant $\mathrm{K}$. Prestrud on 3 December 1911 during the Norwegian Antarctic Expedition of 1910-1912 (latitude $77^{\circ} 12^{\prime} \mathrm{S}$, longitude $154^{\circ} 30^{\prime} \mathrm{W}$ ).

- Rock Shelter "Granite House", Cape Geology, Granite Harbour. This shelter was constructed in December 1911 for use as a field kitchen by Taylor's second geological excursion during the British Antarctic Expedition of 1910-1913. It was enclosed on three sides with granite boulder walls and used as a sledge to form a roof tree which supported seal skins anchored by heavy rocks (latitude $77^{\circ} 00^{\prime} \mathrm{E}$, longitude $162^{\circ} 32^{\prime} \mathrm{E}$ ). A 1981 inspection of the "house" found it in good condition although the sledge had begun to disintegrate. The most recent visit to the site in 1990 reported that this deterioration was accelerating. 
- Depot, Hells Gate Moraine, Inexpressible Island, Terra Nova Bay. An emergency depot, consisting of a sledge loaded with supplies and equipment, was placed on 25 January 1913 by the British Antarctic Expedition at the close of the 1910-1913 expedition. The depot was established by the crew of the Terra Nova to provide security in the event the ship was unable to return and pick them up (latitude $74^{\circ} 56^{\prime} \mathrm{S}$, longitude $163^{\circ} 48^{\prime} \mathrm{E}$ ). In 1994, the sledge and supplies were removed in order to stabilise their condition as wind and scoria particles had started to cause rapid deterioration.

- Message Post, Cape Crozier. Erected on 22 January 1902 by Captain Robert F Scott's Discovery Expedition (the National Antarctic Expedition of 1901-1904) and consists of a post to which a metal cylinder was attached containing an account of the Expedition's movements. It was intended to provide information for the expedition relief ships (latitude $77^{\circ} 27^{\prime} \mathrm{S}$, longitude $69^{\circ} 16^{\prime} \mathrm{E}$ ). The message post, although weathered, still stands, its grain blasted into high relief by countless storms. The record cylinder no longer exists.

- Message Post, Cape Wadworth, Coulman Island. A metal cylinder nailed to a red pole 8 meters above sea level placed by Captain R. F. Scott on 15 January 1902 . He also painted the rocks behind the post red and white to make it more conspicuous (latitude $73^{\circ} 19^{\prime} \mathrm{S}$, longitude $169^{\circ} 47^{\prime} \mathrm{E}$ ).

- Whalers Bay Whaling Station, Whalers Bay, Deception Island. Established in 1906 by Captain Adolfo Andresen. Of historical importance as an example of an Antarctic whaling station.

\section{Measure 5 (1995)}

\section{HISTORIC SITES AND MONUMENTS: AMENDMENT}

The Representatives of the Consultative Parties,

Recalling Recommendations I-IX, VI-14, VII-9, XII-7, XIII-16 and XIV-8;

Recommend to their Governments the following Measure for approval in accordance with paragraph 4 of Article IX of the Antarctic Treaty:

That the description of Historic Site Number 14, which is contained in the "List of Historic Monuments Identified and Described by the proposing Government or Governments" annexed to Recommendation VII-9, be amended to read:

\section{Site Number 14: Inexpressible Island, Terra Nova Bay, Scott Coast}

"Site of ice cave at Inexpressible Bay, Terra Nova Bay, constructed in March 1912 by Victor Campbell's Northern Party, British Antarctic Expedition, 1910-13 (Lat 70 $54^{\prime} \mathrm{S}$, Long $163^{\circ} 43^{\prime} \mathrm{E}$ ). The Party spent the winter of 1912 in this ice cave. 


\section{Annex B \\ Decisions}

\section{Decision 1 (1995) \\ Measures, Decisions and Resolutions}

1. Measures

(a) A text which contains provisions intended to be legally binding once it has been approved by all the Antarctic Treaty Consultative Parties will be expressed as a Measure recommended for approval in accordance with paragraph 4 of Article IX of the Antarctic Treaty, and referred to as a "Measure."

(b) Measures will be numbered consecutively, followed by the year of adoption.

2. Decisions

(a) A decision taken at an Antarctic Treaty Consultative Meeting on an internal organizational matter will be operative at adoption or at such other time as may be specified, and will be referred to as a "Decision."

(b) Decisions will be numbered consecutively, followed by the year of adoption.

3. Resolutions

(a) A hortatory text adopted at an Antarctic Treaty Consultative Meeting will be contained in a Resolution.

(b) Resolutions will be numbered consecutively, followed by the year of adoption.

4. Final Reports of ATCMs

(a) Part II, Annex A of the Final Report of each Antarctic Treaty Consultative Meeting will contain the full text of Measures adopted at the Meeting.

(b) Part II, Annex B of the Final Report of each Antarctic Treaty Consultative Meeting will contain the full text of any Decisions adopted at that Meeting.

(c) Part II, Annex C of the Final Report of each Antarctic Treaty Consultative Meeting will contain the full text of any Resolutions adopted at that Meeting.

5. Nothing in this Decision affects in any way anything done by previous Antarctic Treaty Consultative Meetings.

6. This Decision will be operative at adoption. 


\section{Decision 2 (1995)}

\section{Rules of Procedure: Amendment}

Rule 24 of the Rules of Procedure, as amended at the XVIIth Antarctic Treaty Consultative Meeting, shall be replaced by the following:

"Measures, Decisions, and Resolutions and Final Report

24. Without prejudice to Rule 21, Measures, Decisions and Resolutions, as referred to in Decision 1 (1995), shall be adopted by the Representatives of all Consultative Parties present and will thereafter be subject to the provisions of Decision 1 (1995)." 



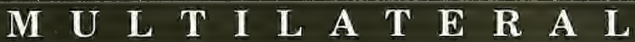

\section{ENVIrONMENT AND}

Natural Resources 



\section{Convention on Conservation of Nature in the South Pacific, Apia, 1976}

Done at Apia 12 June 1976

Entered into force 28 June 1990*

Depositary: Western Samoa

Primary source citation: Copy of text provided by

IUCN/the World Conservation Union

\section{CONVENTION ON CONSERVATION OF NATURE IN THE SOUTH PACIFIC, APIA, 1976}

THE CONTRACTING PARTIES,

HAVING IN MIND the Principles set out in the Declaration adopted by the United Nations Conference on the Human Environment at Stockholm in June 1972;

CONVINCED of the urgency for action inspired by these Principles, especially in relation to the maintenance of the capacity of the earth to produce essential renewable natural resources, the safeguarding of representative samples of natural ecosystems, and the safeguarding of the heritage of wildlife and its habitat;

CONSCIOUS of the importance of natural resources from a nutritional, scientific, educational, cultural and aesthetic point of view;

CONSCIOUS also of the dangers threatening these irreplaceable resources;

RECOGNIZING the special importance in the South Pacific of indigenous customs and traditional cultural practices and the need to give due consideration to such matters;

DESIROUS of taking action for the conservation, utilization and development of these resources through careful planning and management for the benefit of present and future generations;

HAVE AGREED as follows:

\section{ARTICLE I}

For the purpose of this Convention:

(a) "Protected area" means national park or national reserve;

* The United States is not a party to this Convention. 
(b) "National park" means an area established for the protection and conservation of ecosystems, containing animal and plant species, geomorphological sites and habitats of special scientific, educative and recreational interest or a natural landscape of great beauty, which is under the control of the appropriate public authority and open to visits by the public;

(c) "National reserve" means an area recognized and controlled by the appropriate public authority and established for protection and conservation of nature, and includes strict nature reserve, managed nature reserve, wilderness reserve, fauna or flora reserve, game reserve, bird sanctuary, geological or forest reserve, archaeological reserve and historical reserve, these being reserves affording various degrees of protection to the natural and cultural heritage according to the purposes for which they are established.

\section{ARTICLE II}

1. Each Contracting Party shall, to the extent that it is itself involved, encourage the creation of protected areas which together with existing protected areas will safeguard representative samples of the natural ecosystems occurring therein (particular attention being given to endangered species), as well as superlative scenery, striking geological formations, and regions and objects of aesthetic interest or historic, cultural, or scientific value.

2. Each Contracting Party shall notify the body charged with the continuing bureau duties under this Convention of the establishment of any protected area and of the legislation and the methods of administrative control adopted in connection therewith.

\section{ARTICLE III}

1. The boundaries of national parks shall not be altered so as to reduce their areas, nor shall any portions of such parks be capable of alienation, except after the fullest examination.

2. The resources of national parks shall not be subject to exploitation for commercial profit, except after the fullest examination.

3. The hunting, killing, capture or collection of specimens (including eggs and shells) of the fauna and destruction or collection of specimens of the flora in national parks shall be prohibited, except when carried out by or under the direction or control of the appropriate authorities or for duly authorized scientific investigations.

4. Provision shall be made for visitors to enter and use national parks, under appropriate conditions, for inspirational, educative, cultural and recreative purposes.

\section{ARTICLE IV}

National reserves shall be maintained inviolate, as far as practicable, it being understood that in addition to such uses as are consistent with the purposes for which a national reserve was established, permission may be given to carry out scientific investigations.

\section{ARTICLE V}

1. The Contracting Parties shall, in addition to the protection given to indigenous fauna and flora in protected areas, use their best endeavours to protect such fauna and flora (special attention being given to migratory species) so as to safeguard them from unwise exploitation and other threats that may lead to their extinction. 
2. Each Contracting Party shall establish and maintain a list of species of its indigenous fauna and flora that are threatened with extinction. Such lists shall be prepared as soon as possible after this Convention has come into force and shall be communicated to the body charged with the continuing bureau duties under this Convention.

3. Each Contracting Party shall protect as completely as possible as a matter of special urgency and importance the species included in the list it has established in accordance with the provisions of the last preceding paragraph. The hunting, killing, capture or collection of specimens (including eggs and shells) of such species shall be allowed only with the permission of the appropriate authority. Such permission shall be granted only under special circumstances, in order to further scientific purposes or when essential for the maintenance of the equilibrium of the ecosystem or for the administration of the area in which the animal or plant is found.

4. Each Contracting Party shall carefully consider the consequences of the deliberate introduction into ecosystems of species which have not previously occurred therein.

\section{ARTICLE VI}

Notwithstanding the provisions of Articles III, IV and V, a Contracting Party may make appropriate provision for customary use of areas and species in accordance with traditional cultural practices.

\section{ARTICLE VII}

1. The Contracting Parties shall cooperate amongst themselves in promoting the objectives of this Convention, especially within the framework of the South Pacific Commission.

2. The Contracting Parties shall wherever practicable conduct research relating to the conservation of nature. They shall as appropriate coordinate such research with research carried out by other Parties. They shall cooperate in the exchange of information on the results of such research and on the management of protected areas and of protected species.

3. The Contracting Parties shall cooperate in the interchange and training of personnel for the conservation of nature.

4. The Contracting Parties shall work towards harmonization of objectives relating to the conservation of nature.

5. With a view to attaining the objectives of this Convention the Contracting Parties shall examine the possibility of developing programmes of education and public awareness relating to conservation of nature.

\section{ARTICLE VIII}

1. The Contracting Parties shall maintain consultations with one another with the object of giving effect to the provisions of this Convention.

2. The South Pacific Commission shall provide for the continuing bureau duties under this Convention, including the circulation to the Contracting Parties of information and documents to be provided by the Parties under the provisions of the Convention.

\section{ARTICLE IX}

AState may at the time of deposit of its instrument of ratification, acceptance, approval or accession declare that the provisions of this Convention on Conservation of Nature in the South Pacific do not apply to its territories outside the territorial scope of the South Pacific Commission. 


\section{ARTICLE X}

This Convention shall be open for signature at Apia until 31 December 1977 by all States members of the South Pacific Commission or eligible to be invited to become members of that Commission.

\section{ARTICLE XI}

This Convention shall be subject to ratification, acceptance or approval. Instruments of ratification, acceptance or approval shall be deposited with the Government of the Independent State of Western Samoa which shall be the Depositary.

\section{ARTICLE XII}

This Convention shall be open indefinitely for accession by the States referred to in Article $\mathbf{X}$ and by other States which are unanimously invited by the Contracting Parties to accede to it. Instruments of accession shall be deposited with the Depositary.

\section{ARTICLE XIII}

1. This Convention shall enter into force ninety days after the date of deposit of the fourth instrument of ratification, acceptance, approval or accession with the Depositary.

2. For each State which ratifies, accepts or approves this Convention or accedes thereto after the deposit of the fourth instrument of ratification, acceptance, approval or accession, the Convention shall enter into force ninety days after the deposit by such State of its instrument of ratification, acceptance, approval or accession.

\section{ARTICLE XIV}

Any Contracting Party many denounce this Convention by written notification to the Depositary at any time after five years from the date of entry into force of the Convention. The denunciation shall take effect twelve months after the Depositary has received the notification.

\section{ARTICLE XV}

1. The original of this Convention in the English and French languages, each version being equally authentic, shall be deposited with the Depositary, which shall transmit certified copies thereof to all States that have signed it or deposited instruments of accession to it.

2. The Depositary shall inform all signatory and acceding States of signatures, deposits of instruments of ratification, acceptance, approval or accession, entry into force of this Convention, and notifications of denunciation.

3. The Depositary shall transmit certified copies of this Convention to the Secretary-General of the United Nations for registration and publication in accordance with Article 102 of the Charter of the United Nations.

IN WITNESS WHEREOF the undersigned, being duly authorized by their Governments, have signed this Convention.

DONE at Apia this twelfth day of June One Thousand Nine Hundred and Seventy-Six. 


\section{Agreement on the Conservation of Bats in Europe, London, 1991}

Done at London 10 September 1991

Not in force*

Depositary: United Kingdom

Primary source citation: Copy of text provided

by the United Nations

\section{AGREEMENT \\ ON THE CONSERVATION OF BATS IN EUROPE}

The Contracting Parties

Recalling the Convention on the Conservation of Migratory Species of Wild Animals opened for signature in Bonn on 23 June 1979;

Recognising the unfavourable conservation status of bats in Europe and non-European Range States and in particular the serious threat to them from habitat degradation, disturbance of roosting sites and certain pesticides;

Conscious that the threats facing bats in Europe and non-European Range States are common to both migratory and nonmigratory species and that roosts are often shared by migratory and nonmigratory species;

Recalling that the first meeting of the Conference of the Parties to the Convention on the Conservation of Migratory Species of Wild Animals held in Bonn in October 1985 agreed to add European species of CHIROPTERA (Rhinolophidae and Vespertilionidae) to Appendix II of the Convention and instructed the Secretariat of the Convention to take appropriate measures to develop an Agreement for these species; in Europe;

Convinced that the conclusion of an Agreement for these species would greatly benefit the conservation of bats

Have agreed as follows:

\section{ARTICLE I \\ Scope and Interpretation}

For the purposes of this Agreement:

(a) "Convention" means the Convention on the Conservation of Migratory Species of Wild Animals (Bonn 1979);

*The United States is not a party to this Agreement. This Agreement was concluded pursuant to the 1979 Convention on the Conservation of Migratory Species of Wild Animals. 
(b) "Bats" means European populations of CHIROPTERA (Rhinolophidae and Vespertilionidae) occurring in Europe and non-European Range States;

(c) "Range State" means any State (whether or not it is a party to the Convention) that exercises jurisdiction over any part of the range of a species covered by this Agreement;

(d) "Regional Economic Integration Organisation" means an organisation constituted by sovereign States to which this Agreement applies and which has competence in respect of matters covered by this Agreement and has been duly authorised, in accordance with its internal procedures, to sign, ratify, accept, approve or accede to it;

(e) "Parties" means, unless the context otherwise indicates, Parties to this Agreement;

(f) "In Europe" means the continent of Europe.

\section{ARTICLE II General Provisions}

1. This Agreement is an AGREEMENT within the meaning of paragraph 3 of Article IV of the Convention.

2. The provisions of this Agreement shall not relieve Parties of their obligations under any existing treaty, convention or agreement.

3. Each Party to this Agreement shall designate one or more competent authorities to whom it shall assign responsibility for the implementation of this Agreement. It shall communicate the name and address of its authority or authorities to the other Parties to this Agreement.

4. Appropriate administrative and financial support for this Agreement shall be determined by its Parties in consultation with the Parties to the Convention.

\section{ARTICLE III Fundamental Obligations}

1. Each Party shall prohibit the deliberate capture, keeping or killing of bats except under permit from its competent authority.

2. Each Party shall identify those sites within its own area of jurisdiction which are important for conservation status, including for the shelter and protection, of bats. It shall, taking into account as necessary economic and social considerations, protect such sites from damage or disturbance. In addition, each Party shall endeavour to identify and protect important feeding areas for bats from damage or disturbance.

3. When deciding which habitats to protect for general conservation purposes each Party shall give due weight to habitats that are important for bats.

4. Each Party shall take appropriate measures to promote the conservation of bats and shall promote public awareness of the importance of bat conservation.

5. Each Party shall assign to an appropriate body responsibilities for the provision of advice on bat conservation and management within its territory particularly with regard to bats in buildings. Parties shall exchange information on their experiences in this matter.

6. Each Party shall take such additional action as it considers necessary to safeguard populations of bats which it identifies as being subject to threat and shall report under Article VI on the action taken. 
7. Each Party shall, as appropriate, promote research programmes relating to the conservation and management of bats. Parties shall consult each other on such research programmes, and shall endeavour to coordinate such research and conservation programmes.

8. Each Party shall, wherever appropriate, consider the potential effects of pesticides on bats, when assessing pesticides for use, and shall endeavour to replace timber treatment chemicals which are highly toxic to bats with safer alternatives.

\section{ARTICLE IV National Implementation}

1. Each Party shall adopt and enforce such legislative and administrative measures as may be necessary for the purpose of giving effect to this Agreement.

2. The provisions of this Agreement shall in no way affect the right of Parties to adopt stricter measures concerning the conservation of bats.

\section{ARTICLE V Meetings of the Parties}

1. There shall be periodic meetings of the Parties to this Agreement. The Government of the United Kingdom shall call the first meeting of the Parties to the Agreement not later than 3 years after the date of entry into force of the Agreement. The Parties to the Agreement shall adopt rules of procedure for their meetings and financial rules, including the provisions on the budget and the scale of contributions for the next financial period. Such rules shall be adopted by a two-thirds majority of the Parties present and voting. Decisions taken under the financial rules shall require a three-quarters majority of the Parties present and voting.

2. At their meetings the Parties may establish such scientific and other working groups as they see fit.

3. Any Range State or Regional Economic Integration Organisation not a Party to this Agreement, the Secretariat of the Convention, the Council of Europe in its capacity as the Secretariat of the Convention on the Conservation of European Wildlife and Natural Habitats and similar intergovernmental organisations may be represented by observers at meetings of the Parties. Any agency or body technically qualified in the conservation and management of bats may be represented by observers at meetings of the Parties unless at least one-third of the Parties present object. Only Parties may vote at meetings of the Parties.

4. Except as provided for in paragraph 5 below, each Party to this Agreement shall have one vote.

5. Regional Economic Integration Organisations which are Parties to this Agreement shall, in matters within their competence, exercise their right to vote with a number of votes equal to the number of their Member States which are Parties to the Agreement and present at the time of the vote. A Regional Economic Integration Organisation shall not exercise its right to vote if its Member States exercise theirs, and vice versa.

\section{ARTICLE VI Reports on Implementation}

Each Party shall present to each meeting of the Parties an up-to-date report on its implementation of this Agreement. It shall circulate the report to the Parties not less than 90 days before the opening of the ordinary meeting. 


\section{ARTICLE VII \\ Amendment of the Agreement}

1. This Agreement may be amended at any meeting of the Parties.

2. Proposals for amendment may be made by any Party.

3. The text of any proposed amendment and the reasons for it shall be communicated to the Depositary at least 90 days before the opening of the meeting. The Depositary shall transmit copies forthwith to the Parties.

4. Amendments shall be adopted by a two-thirds majority of the Parties present and voting and shall enter into force for those Parties which have accepted them 60 days after the deposit of the fifth instrument of acceptance of the amendment with the Depositary. Thereafter, they shall enter into force for a Party 30 days after the date of deposit of its instrument of acceptance of the amendment with the Depositary.

\section{ARTICLE VIII Reservations}

The provisions of this Agreement shall not be subject to general reservations. However, a Range State or Regional Economic Integration Organisation may, on becoming a Party in accordance with Articles X or XI, enter a specific reservation with regard to any particular species of bat.

\section{ARTICLE IX Settlement of Disputes}

Any dispute which may arise between Parties with respect to the interpretation or application of the provisions of this Agreement shall be subject to negotiation between the Parties involved in the dispute.

\section{ARTICLE X Signature, Ratification, Acceptance and Approval}

This Agreement shall be open to signature by Range States or Regional Economic Integration Organisatione who may become Parties either by:

(a) signature without reservation in respect of ratification, acceptance or approval; or

(b) signature with reservation in respect of ratification, acceptance or approval, followed by ratification, acceptance or approval.

Instruments of ratification, acceptance or approval shall be deposited with the Depositary.

This Agreement shall remain open for signature until the date of entry into force of the Agreement.

\section{ARTICLE XI \\ Accession}

This Agreement shall be open for accession by Range States or Regional Economic Integration Organisations after the date of entry into force of the Agreement. Instruments of accession shall be deposited with the Depositary. 


\section{ARTICLE XII \\ Entry into Force}

This Agreement shall enter into force on the ninetieth day following the date on which five Range States have become Parties in accordance with Article X. Thereafter it shall enter into force for a signatory or acceding State on the thirtieth day after the deposit of its instrument of ratification, acceptance, approval or accession.

\section{ARTICLE XIII Denunciation and Termination}

Any Party may denounce this Agreement by written notification to the Depositary at any time. The denunciation shall take effect twelve months after the date on which the Depositary has received the notification. The Agreement shall remain in force for at least ten years, and thereafter shall terminate on the date on which there cease to be at least five Parties thereto.

\section{ARTICLE XIV Depositary}

The original of the Agreement, in English, French and German, each version being equally authentic, shall be deposited with the Government of the United Kingdom, which shall be the Depositary and shall transmit certified copies thereof to all States and any Regional Economic Integration Organisations that have signed the Agreement or deposited instruments of ratification, acceptance, approval or accession.

The Depositary shall inform all Range States and Regional Economic Integration Organisations of signatures, deposit of instruments of ratification, acceptance, approval or accession, entry into force of this Agreement, amendments thereto, reservations and notifications of denunciation. 


\title{
International Guidelines for Preventing the Introduction of Unwanted Aquatic Organisms and Pathogens from Ships' Ballast Water and Sediment Discharges, London, 1991
}

\author{
Done at London 4 July 1991 \\ Primary source citation: Copy of text provided by the \\ U.S. Department of State
}

\begin{abstract}
ANNEX 16
RESOLUTION MEPC.50(31)

adopted on 4 July 1991

INTERNATIONAL GUIDELINES FOR PREVENTING THE INTRODUCTION OF UNWANTED AQUATIC ORGANISMS AND PATHOGENS FROM SHIPS' BALLAST WATER AND SEDIMENT DISCHARGES
\end{abstract}

THE MARINE ENVIRONMENT PROTECTION COMMITTEE,

RECALLING Resolution 18 of the International Conference on Marine Pollution, 1973, requesting research into the role of ballast water as a medium for the spreading of epidemic disease bacteria,

RECOGNIZING that the discharge of ballast water and sediment has led to unplanned and unwanted introductions of non-native plants, animals and pathogens that are known to have caused injury to public health and property and to the environment,

FURTHER RECOGNIZING the need to alert Member States to the significance of the problem and to seek international co-operative measures to resolve it,

OBSERVING that the unwanted introduction of plants, animals and pathogens through the uncontrolled discharge of ballast water and sediment has important global implications that can be effectively, equitably and responsibly addressed through coordinated and co-operative action,

ACKNOWLEDGING that Member States have a right to introduce ballast water and sediment discharge procedures to protect their waters from unwanted plants, animals and pathogens carried in ships' ballast water and sediment,

FURTHER ACKNOWLEDGING that port States and Administrations have a responsibility to help ensure that ballast water, loaded in their ports and harbours, or carried in their ships, does not contain plants, animals or pathogens that pose a threat to the waters of other States,

BEING CONSCIOUS of the essential role that the carriage of ballast water performs in the safe and effective operation of ships, 
BEING AWARE of the need to work collaboratively to seek effective methods that can be safely used to minimize the probability that aquatic organisms and pathogens will be transferred between geographic areas by way of ships' ballast water or sediment,

HAVING CONSIDERED the International Guidelines for Preventing the Introduction of Unwanted Aquatic Organisms and Pathogens from Ships' Ballast Water and Sediment Discharges,

1. ADOPTS the International Guidelines for Preventing the Introduction of Unwanted Aquatic Organisms and Pathogens from Ships' Ballast Water and Sediment Discharges;

2. RECOMMENDS that Member States apply appropriate provisions of the Guidelines to minimize the probability that ballast water and sediment will contain unwanted aquatic organisms and pathogens and as guidance in the development of a long-term solution to the problem of the discharge of ballast water and sediment leading to the unplanned and unwanted introductions of non-native plants, animals and pathogens that are known to have caused injury to public health and property and to the environment;

3. URGES Member States and non-governmental organizations to carry out and co-operate in research into all aspects of the problem, with a view to further developing the Guidelines as a basis for a new technical annex to MARPOL 73/78;

4. FURTHER URGES Member States to carry out research into the extent of the problem in their waters and to notify the Organization of their findings;

5. REQUESTS the Secretary-General to arrange for the circulation, to all Member States and non-governmental organizations, of all submitted research data and information on the problem.

\section{ANNEX \\ INTERNATIONAL GUIDELINES FOR PREVENTING THE INTRODUCTION OF UNWANTED AQUATIC ORGANISMS AND PATHOGENS FROM SHIPS' BALLAST WATER AND SEDIMENT DISCHARGES}

1

\section{Introduction}

1.1 Studies carried out in several countries have shown that many species of bacteria, plants, and animals can survive in a viable form in the ballast water and sediment carried in ships, even after journeys of several weeks' duration. Subsequent discharge of contaminated ballast water or sediment, into the waters of port States, may result in the establishment of unwanted species which can seriously upset the existing ecological balance. Although other media have been identified for transferring organisms between geographically separated water bodies, ballast water discharge from ships appears to have been among the most prominent. The introduction of diseases may also arise as a result of port State waters being innoculated with large quantities of ballast water containing viruses or bacteria, thereby posing health threats to indigenous human, animal and plant life.

1.2 The potential for ballast water discharges to cause harm, was recognized by Resolution 18 of the International Conference on Marine Pollution, 1973, from which conference emerged the MARPOL Convention. Resolution 18 called upon the World Health Organization, in collaboration with the International Maritime Organization, to carry out research into the role of ballast water as a medium for the spreading of epidemic disease bacteria.

1.3 It is the aim of these Guidelines to provide Administrations and Port State Authorities with guidance on procedures that will minimize the risk from the introduction of unwanted aquatic organisms and pathogens from ships' ballast water and sediment. The selection of an appropriate procedure will depend upon several factors, including the type or types of organisms being targeted, the level of risks involved, its environmental acceptability, and the economic and ecological costs involved.

1.4 The choice of procedures will also depend upon whether the measure is a short-term response to an identified problem or a long-term strategy aimed at completely eliminating the possibility of the introduction of species by ballast water. In the short term, operational measures such as ballast water exchange at sea may be appropriate where they have been shown to be effective and are accepted by Port State Authorities and Administrations. For the longer term, more effective strategies, possibly involving structural or equipment modifications to ships, may need to be considered. 
For the purposes of these guidelines, the following definitions apply:

"Administration" means the Government of the State under whose authority the ship is operating.

"Member States" means States that are Members of the International Maritime Organization.

"Organization” means the International Maritime Organization (IMO).

"Port State Authority" means any official or organization authorized by the Government of a port State to administer guidelines or enforce standards and regulations relevant to the implementation of national and international shipping control measures.

\section{$3 \quad$ Application}

The Guidelines can apply to all ships, however a Port State Authority shall determine the extent to which these Guidelines do apply.

\section{$4 \quad$ General principles}

4.1 Member States may adopt ballast water and sediment discharge procedures to protect the health of their citizens from foreign infectious agents, to safeguard fisheries and aquaculture production against similar exotic risks and to protect the environment generally.

4.2 Application of ballast water and sediment discharge procedures to minimize the risk of importing unwanted aquatic organisms and pathogens may range from regulations based upon quarantine laws to guidelines providing suggested measures for controlling or reducing the problem.

4.3 In all cases, a Port State Authority must consider the overall effect of ballast water and sediment discharge procedures on the safety of ships and those on board. Regulations or guidelines will be ineffective if compliance is dependent upon the acceptance of operational measures that put a ship or its crew at risk.

4.4 Ballast water and sediment discharge procedures should be practicable, effective, designed to minimize cost and delays to ships, and based upon these Guidelines whenever practicable.

4.5 The ability of aquatic organisms and pathogens to survive, after transportation in ballast water, may be reduced if significant differences in ambient conditions prevail - e.g. salinity, temperature, nutrients and light intensity.

4.6 If fresh water (FW), brackish water (BW) and fully saline water (SW) are considered, the following matrix provides, in most cases, an indication of the probability that aquatic organisms and pathogens will survive after being transferred. 


\begin{tabular}{|c|c|c|c|}
\hline $\begin{array}{l}\text { Discharged } \\
\text { Ballast } \\
\begin{array}{l}\text { Receiving } \\
\text { Waters }\end{array}\end{array}$ & FW & BW & SW \\
\hline FW & HIGH & MED & LOW \\
\hline BW & MED & HIGH & HIGH \\
\hline SW & LOW & HIGH & HIGH \\
\hline
\end{tabular}

\section{PROBABILITY OF ORGANISMS SURVIVAL AND REPRODUCTION}

4.7 The duration of ballast water within an enclosed ballast tank will also be a factor in determining the number of surviving organisms. For example, even after 60 days some organisms may remain in ballast water in a viable condition.

4.8 Because some aquatic organisms and pathogens that may exist in sediments carried by ships can survive for several months or longer, disposal of such sediment should be carefully managed and reported to Port State Authorities.

4.9 In implementing ballast water and sediment discharge procedures, Port State Authorities should take account of all relevant factors.

5

$\underline{\text { Implementation }}$

5.1 Member States, applying ballast water and sediment discharge procedures, should notify the Organization of specific requirements and provide to the Organization, for the information of other Member States and non-governmental organizations, copies of any regulations, standards or guidelines being applied.

5.2 Administrations and non-governmental shipping organizations should provide the widest possible distribution of information on ballast water and sediment discharge procedures being applied to shipping by Port State Authorities. Failure to do so may lead to unnecessary delays for ships seeking entry to port States where ballast water and sediment discharge procedures are being applied.

5.3 In accordance with paragraph 5.2 above, ship operators and ships' crews should be familiar with the requirements of Port State Authorities with respect to ballast water and sediment discharge procedures, including information that will be needed to obtain entry clearance. In this respect, Masters should be made aware that penalties may be applied by Port State Authorities for failure to comply with national requirements.

5.4 Member States and non-governmental organizations should provide to the Organization, for circulation, details of any research and development studies that they carry out, with respect to the control of aquatic organisms and pathogens in ballast water and sediment found in ships.

5.5 Administrations are encouraged to report to the Organization incidences where compliance with ballast water and sediment discharge procedures required by Port State Authorities have resulted in ship safety problems, unacceptably high costs, or delays to ships. 
5.6 Member States should provide, to the Organization, details of annual compliance records for ballast water and sediment discharge procedures that they are applying. These records should report all incidences of non-compliance with regulations or guidelines and cite, by ship's name, official number and flag, all non-complying vessels.

5.7 Member States should notify the Organization of any local outbreaks of infectious diseases or water-borne organisms, that have been identified as a cause of concern to health and environmental authorities in other countries, and for which ballast water or sediment discharges may be vectors of transmission. This information should be relayed by the Organization, without delay, to all Member States and non-governmental organizations. Member States should ensure that problem species, endemic to their waters, are not being transferred from locally loaded ballast water. Masters of ships should be notified of the existence of problem species, including local outbreaks of phytoplankton blooms, and advised to exchange or treat their ballast water and sediment accordingly.

5.8 Member States should determine the environmental sensitivity of their waters to the extent deemed necessary. Ballast water and sediment discharge procedures should take into account the environmental sensitivity of these waters.

\section{$6 \quad$ Ship operational procedures}

6.1 When loading ballast, every effort should be made to ensure that only clean ballast water is being taken on and that the uptake of sediment with the ballast water is minimized. Where practicable, ships should endeavour to avoid taking on ballast water in shallow water areas, or in the vicinity of dredging operations, to reduce the likelihood that the water will contain silt, which may harbour the cysts of unwanted aquatic organisms and pathogens, and to otherwise reduce the probability that unwanted aquatic organisms and pathogens are present in the water. Areas where there is a known outbreak of diseases, communicable through ballast water, or in which phytoplankton blooms are occurring, should be avoided wherever practicable as a source of ballast.

6.2 When taking on ballast water, records of the dates, geographical locations, salinity and amount of ballast water taken on should be recorded in the ship's log book. To enable monitoring by the Organization and Port State Authorities, a report in the format shown in the appendix to these Guidelines should be completed by the ship's Master and made available to the Port State Authority. Procedures to be followed by the ship should be described in detail in the ship's operational manual. The sample used to determine the salinity of loaded ballast water should be obtained, wherever possible, from the ballast tanks themselves or from a supply piping tap. Surface sea water samples should not be taken as indicative of the water in the ballast tanks since seawater salinity may vary significantly with depth.

6.3 Subject to accessibility, all sources of sediment retention such as anchors, cables, chain lockers and suction wells should be cleaned routinely to reduce the possibility of spreading contamination.

$7 \quad$ Strategies for preventing the introduction of unwanted aquatic organisms and pathogens from ship's ballast water and sediment discharges

\subsection{General}

7.1.1 In determining appropriate strategies for ballast water and sediment discharge procedures, the following criteria, inter alia, should be taken into account:

— operational practicability;

- effectiveness;

— seafarer and ship safety;

- environmental acceptability;

- water and sediment control;

- monitoring; and

- cost effectiveness. 
7.1.2 Approaches that may be effective in controlling the incidence and introduction of aquatic organisms and pathogens, include:

- the non-release of ballast water;

- ballast water exchange and sediment removal at sea or in areas designated as acceptable for the purpose by the Port State Authority;

- ballast water management practices-'aimed at preventing or minimizing the uptake of contaminated water or sediment in ballasting and deballasting operations; and

— discharge of ballast water into shore-based facilities for treatment or controlled disposal.

7.1.3 In considering which particular approach, or combination of approaches to use, Port State Authorities should have regard to the factors listed in paragraph 7.1.1.

\subsection{Non-release of ballast water}

The most effective means of preventing the introduction of unwanted aquatic organisms and pathogens from ships' ballast waters and sediments is to avoid, wherever possible, the discharge of ballast water.

\subsection{Ballast water exchange and sediment removal}

7.3.1 In the absence of more scientifically based means of control, exchange of ballast water in deep ocean areas or open seas currently offers a means of limiting the probability that fresh water or coastal species will be transferred in ballast water. Responsibility for deciding on such action must rest with the Master, taking into account prevailing safety, stability and structural factors and influences at the time.

7.3.2 Unlike coastal and estuarine waters that are rich in nutrients and life forms, deep ocean water or open seas contain few organisms. Those that do exist are unlikely to adapt readily to a new coastal or fresh water environment, hence the probability of transferring unwanted organisms, through ballast water discharges, can be greatly reduced by ocean or open sea ballast exchanges preferably in water depths of $2,000 \mathrm{~m}$ or more. In those cases where ships do not encounter water depths of at least $2,000 \mathrm{~m}$, exchange of ballast water should occur well clear of coastal and estuarine influences. There is evidence to suggest that, despite contact with water of high salinity, the cysts of some organisms can survive for protracted periods in the sediment within ballast tanks and elsewhere on a ship. Hence, where ballast water exchange is being used as a control measure, care should be taken to flush out ballast tanks, chain lockers and other locations where silt may accumulate, to dislodge and remove such accumulations, wherever practicable.

7.3.3 Care should also be taken when removing sediment deposits while a ship is in port or in coastal waters to ensure that the sediment is not disposed of directly into adjacent waters. Sediment should be removed to land-fill locations designated by the port State Authority or, alternatively, sterilized to kill all living organisms that it may contain prior to being discharged into local water bodies or otherwise disposed.

7.3.4 Ships likely to be required to exchange ballast during a voyage should take into account the following requirements:

.1 stability to be maintained at all times to values not less than those recommended by the Organization (or required by the Administration);

.2 longitudinal stress values not to exceed those permitted by the ship's classification society with regard to prevailing sea conditions; and

.3 exchange of ballast in tanks or holds where significant structural loads may be generated by sloshing action in the partially filled tank or hold to be carried out in favourable sea and swell conditions such that the risk of structural damage is minimized. 
7.3.5 Where the requirements of paragraph 7.3.4 cannot be met during an "at sea" exchange of ballast water, a "flow through" exchange of ballast water may be an acceptable alternative for those tanks. Procedures for exchange of this type should be approved by the Administration.

7.3.6 Where the requirements of paragraph 7.3.4 can be met during an "at sea" exchange of ballast water, before taking on exchange ballast water, tanks should be drained until pump suction is lost. This will minimize the likelihood of residual organism survival.

7.3.7 Where a port State Authority requires that an "at sea" exchange of ballast water be made, and, due to weather, sea conditions or operational impracticability such action cannot be taken, the ship should report this fact to the port State Authority prior to entering its national waters, so that appropriate alternative action can be arranged.

7.3.8 Alternative action will also be necessary in those instances where ships may not leave a continental shelf during their voyage. Unless specific alternative instructions have been issued by a port State Authority applying ballast water and sediment controls, ships should report non-compliance prior to entering the port State's waters.

7.3.9 Port State Authorities applying ballast water exchange and sediment removal procedures may require ships to complete a ballast water control form or some other acceptable system of reporting. A model form for this purpose is in the appendix. Port State Authorities should arrange for such reporting forms to be distributed to ships, together with instructions for completion of the form and procedures for its return to the appropriate authorities.

7.3.10 In those cases where a ship arrives at a port without having carried out an "at sea" ballast water exchange, or has otherwise failed to carry out any alternative procedures acceptable to port State Authorities, the ship may be required to proceed to an approved location to carry out the necessary exchange, treat the ballast water "in situ", seal the ballast tanks against discharge in the port State's waters, pump the ballast water to a shore reception facility, or prove, by laboratory analysis, that the ballast water is acceptable.

7.3.11 To facilitate administration of ballast water exchange and sediment removal procedures on board ships, a responsible officer familiar with those procedures should be appointed to maintain appropriate records and to ensure that all ballast water exchange and sediment removal procedures are followed and recorded. Written ballast water and sediment removal procedures should be included in the ship's operational manual.

7.3.12 Port State Authorities applying ballast water exchange and sediment discharge procedures may wish to monitor compliance with and effectiveness of their controls.

7.3.13 Effectiveness monitoring may also be undertaken by port State Authorities, by taking and analysing ballast water and sediment samples from ships complying with prescribed exchange procedures, to test for the continued survival of unwanted aquatic organisms and pathogens.

7.3.14 Where ballast water or sediment sampling for compliance or effectiveness monitoring is being undertaken, port State Authorities should minimize delays to ships when taking such samples. Use of plankton nets, either by a vertical tow through ballasted deep tanks or cargo holds, or by attachment to an open firemain hydrant, suitably cross-connected to the ballast main, is one suggested means of ballast water sampling. Sediment samples may be taken from areas where sediment is most likely to accumulate such as around outlet pipes, bulkhead and hold corners, etc. to the extent that these are accessible. Appropriate safety precautions must be employed wherever the taking of water or sediment samples requires tank entry.

7.3.15 Port State Authorities may also wish, subject to relevant safety considerations, to sample sediment in suction wells, chain lockers or other areas where sediment may accumulate.

7.3.16 In some cases, ships bound for ports which apply strategies for preventing the introduction of unwanted aquatic organisms and pathogens from ships' ballast water and sediments may avoid "at sea" exchange of ballast water, or other control procedures, by having their ballast water or harbour source samples analysed by a laboratory that is acceptable to the port State Authority. Where sampled and analysed ballast or harbour source water is found to be free from unwanted aquatic organisms or pathogens, an analyst's certificate, attesting to that fact, should be made available to port State Authorities. When analysis of ballast or harbour source water or sediment is being used as a control procedure, port State Authorities should provide Administrations with a target listing of unwanted aquatic organisms or pathogens. 
7.3.17 Port State Authorities may sample or require samples to analyse ballast water and sediment, before permitting a vessel to proceed to discharge its ballast water in environmentally sensitive locations. In the event that unwanted aquatic organisms or pathogens are found to be present in the samples, ships may be prohibited from discharging ballast or sediment, except to shore reception facilities or in designated marine areas.

\subsection{Ballast water management practices}

7.4.1 Port State Authorities may allow the use of appropriate ballast water management practices, aimed at preventing or minimizing the uptake and discharge of contaminated water or sediment in ballasting and deballasting operations. Such practices may be used when adjudged as reducing the risks of introducing unwanted aquatic organisms and pathogens to a level acceptable to Port State Authorities, who may set conditions with which such practices need to comply for this purpose.

7.4.2 Such conditions should include appropriate ballast water management plans, training of ships' officers and crew, and the nomination of key control personnel.

\subsection{Shore reception facilities}

7.5.1 Where adequate shore reception facilities exist, discharge of ship's ballast water in port into such facilities may provide an acceptable means of control. Port State Authorities utilizing this strategy should ensure that the discharged ballast water has been effectively treated before release. Any treatment used should itself be environmentally acceptable.

7.5.2 Reception facilities should be made available for the safe disposal of tank sediment when ships are undergoing repair or refit. Sediment, removed from ballast tanks and other areas of accumulation, should be disposed of in accordance with paragraph 7.3.3 above.

7.5.3 Member States should provide the Organization and ships with information on the locations, capacities, availability, and any applicable fees relevant to reception facilities being provided for the safe disposal of ballast water and removed sediment.

\section{$8 \quad$ Training, education and ships management plans}

8.1 Administrations and non-governmental shipping organizations should ensure that ships' crews are made aware of the ecological and health hazards posed by the indiscriminate loading and discharging of ballast water and of the need to maintain tanks and equipment, such as anchors, cables and hawse pipes, free from sediment.

8.2 Training curricula for ships' crews should include instruction on the application of ballast water and sediment discharge procedures, based upon the information contained in these Guidelines. Instruction should also be provided on the maintenance of $\log$ book records, indicating the dates and times of ballast water loading, exchange or discharge, salinity and the geographical location where such operations are carried out.

8.3 Ships' crews should receive adequate instruction on the methods of ballast water and sediment discharge procedures being applied on their ship, including appropriate safety training in the relevant procedures.

8.4 Ballast water management plans should be incorporated in ships' operational manuals for the guidance of the ships' crews. Such plans should include, but not necessarily be limited to, information on the following:

- ballast water loading and discharging procedures and precautions;

— ballast water and sediment sampling and testing;

— controls applied by port State Authorities;

- reporting and information requirements;

- exchange and treatment options or requirements;

- crew safety guidelines; 
— sediment disposal arrangements; and

- crew education and training.

8.5 Ships' operational manuals should include reference to these Guidelines and to the need to comply with any ballast water and sediment discharge procedures imposed by port State Authorities.

\section{$9 \quad$ Future considerations}

9.1 There is a clear need to research and develop revised and additional measures, particularly as new information on organisms and pathogens of concern becomes available. Areas for further research include, inter alia:

- treatment by chemicals and biocides;

- heat treatment;

- oxygen deprivation control;

- tank coatings;

- filters; and

- ultraviolet light disinfection.

It must be made clear, however, that there is a lack of research knowledge and practical experience on the cost, safety, effectiveness and environmental acceptability of these possible approaches. Any proposed chemical or biocidal treatments should be environmentally safe and in compliance with international conventions. Authorities carrying out or commissioning research studies into these or other relevant areas are encouraged to work co-operatively and provide information on the results to the Organization.

9.2 In the longer term and to the extent possible, changes in ship design may be warranted to prevent the introduction of unwanted aquatic organisms and pathogens from ships. For example, subdivision of tanks, piping arrangements and pumping procedures should be designed and constructed to minimize uptake and accumulation of sediment in ballast tanks.

9.3 Classification societies are urged to include provisions for ballast water and sediment discharge procedures in their rule requirements. 


\section{APPENDIX \\ BALLAST WATER CONTROL REPORT FORM \\ (To be completed by ship's Master prior to arrival and provided to Port State Authority upon request)}

NAME OF SHIP:

PORT OF REGISTRY:

OFFICIAL NO. OR

CALL SIGN:

OWNERS/OPERATORS:

AGENT:

IMO GUIDELINES CARRIED?

$\mathrm{YES} / / \mathrm{NO} /]$

CONTROL ACTION TAKEN?

I] Non-release of ballast

I] Ballast water exchange

I] Ballast water management practices

I] Use of shore reception facilities

If Other (specify) $\ldots \ldots \ldots \ldots \ldots \ldots$

1] Nil 


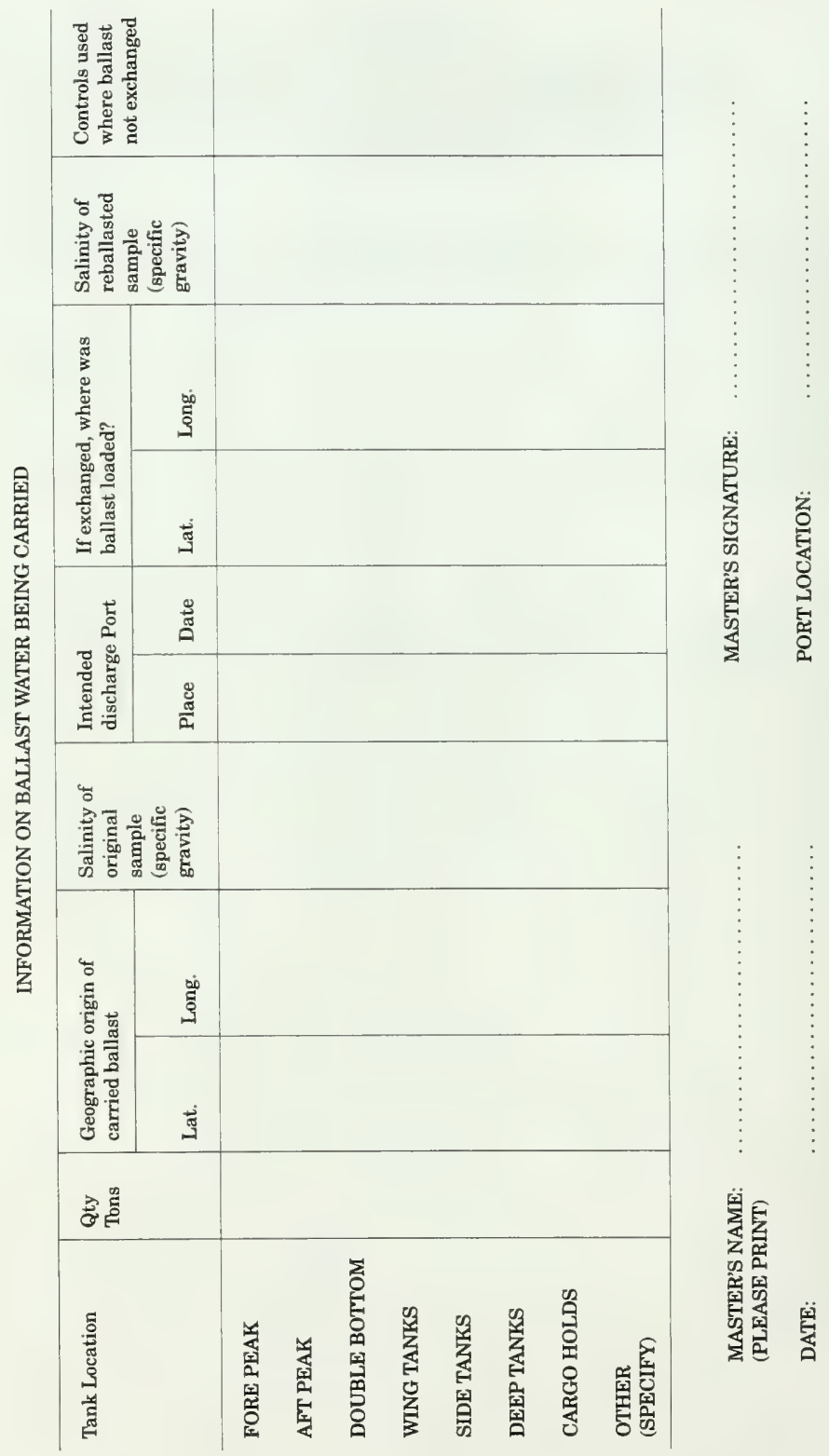




\section{North American Agreement on Environmental Cooperation, Washington, D.C., Ottawa, and Mexico City, 1993}

Done at Washington, D.C. 9 and 14 September 1993, Ottawa 12 and 14 September 1993, and Mexico City 8 and 14 September 1993

Entered into force 1 January 1994

Primary source citation: Copy of text provided by the

U.S. Department of State

\section{NORTH AMERICAN AGREEMENT ON ENVIRONMENTAL COOPERATION BETWEEN THE GOVERNMENT OF THE UNITED STATES OF AMERICA, THE GOVERNMENT OF CANADA AND THE GOVERNMENT OF THE UNITED MEXICAN STATES}

\section{3}

\section{PREAMBLE}

The Government of the United States of America, the Government of Canada and the Government of the United Mexican States:

CONVINCED of the importance of the conservation, protection and enhancement of the environment in their territories and the essential role of cooperation in these areas in achieving sustainable development for the well-being of present and future generations;

REAFFIRMING the sovereign right of States to exploit their own resources pursuant to their own environmental and development policies and their responsibility to ensure that activities within their jurisdiction or control do not cause damage to the environment of other States or of areas beyond the limits of national jurisdiction;

RECOGNIZING the interrelationship of their environments;

ACKNOWLEDGING the growing economic and social links between them, including the North American Free Trade Agreement (NAFTA);

RECONFIRMING the importance of the environmental goals and objectives of the NAFTA, including enhanced levels of environmental protection; 
EMPHASIZING the importance of public participation in conserving, protecting and enhancing the environment;

NOTING the existence of differences in their respective natural endowments, climatic and geographical conditions, and economic, technological and infrastructural capabilities;

REAFFIRMING the Stockholm Declaration on the Human Environment of 1972 and the Rio Declaration on Environment and Development of 1992;

RECALLING their tradition of environmental cooperation and expressing their desire to support and build on international environmental agreements and existing policies and laws, in order to promote cooperation between them; and

CONVINCED of the benefits to be derived from a framework, including a Commission, to facilitate effective cooperation on the conservation, protection and enhancement of the environment in their territories;

\section{HAVE AGREED AS FOLLOWS:}

\section{PART ONE}

\section{OBJECTIVES}

\section{Article 1: Objectives}

The objectives of this Agreement are to:

(a) foster the protection and improvement of the environment in the territories of the Parties for the well-being of present and future generations;

(b) promote sustainable development based on cooperation and mutually supportive environmental and economic policies;

(c) increase cooperation between the Parties to better conserve, protect, and enhance the environment, including wild flora and fauna:

(d) support the environmental goals and objectives of the NAFTA;

(e) avoid creating trade distortions or new trade barriers;

(f) strengthen cooperation on the development and improvement of environmental laws, regulations, procedures, policies and practices;

(g) enhance compliance with, and enforcement of, environmental laws and regulations;

(h) promote transparency and public participation in the development of environmental laws, regulations and policies;

(i) promote economically efficient and effective environmental measures; and

(j) promote pollution prevention policies and practices. 


\section{PART TWO}

\section{OBLIGATIONS}

\section{Article 2: General Commitments}

1. Each Party shall, with respect to its territory:

(a) periodically prepare and make publicly available reports on the state of the environment;

(b) develop and review environmental emergency preparedness measures;

(c) promote education in environmental matters, including environmental law;

(d) further scientific research and technology development in respect of environmental matters;

(e) assess, as appropriate, environmental impacts; and

(f) promote the use of economic instruments for the efficient achievement of environmental goals.

2. Each Party shall consider implementing in its law any recommendation developed by the Council under Article 10(5)(b).

3. Each Party shall consider prohibiting the export to the territories of the other Parties of a pesticide or toxic substance whose use is prohibited within the Party's territory. When a Party adopts a measure prohibiting or severely restricting the use of a pesticide or toxic substance in its territory, it shall notify the other Parties of the measure, either directly or through an appropriate international organization.

\section{Article 3: Levels of Protection}

Recognizing the right of each Party to establish its own level of domestic environmental protection and environmental development policies and priorities, and to adopt or modify accordingly its environmental laws and regulations, each Party shall ensure that its laws and regulations provide for high levels of environmental protection and shall strive to continue to improve those laws and regulations.

\section{Article 4: Publication}

1. Each Party shall ensure that its laws, regulations, procedures and administrative rulings of general application respecting any matter covered by this Agreement are promptly published or otherwise made available in such a manner as to enable interested persons and Parties to become acquainted with them.

2. To the extent possible, each Party shall:

(a) publish in advance any such measure that it proposes to adopt; and

(b) provide interested persons and Parties a reasonable opportunity to comment on such proposed measures.

\section{Article 5: Government Enforcement Action}

1. With the aim of achieving high levels of environmental protection and compliance with its environmental laws and regulations, each Party shall effectively enforce its environmental laws and regulations through appropriate government action, subject to Article 37, such as:

(a)

appointing and training inspectors; 
(b) monitoring compliance and investigating suspected violations, including through on-site inspections;

(c) seeking assurances of voluntary compliance and compliance agreements;

(d) publicly releasing non-compliance information;

(e) issuing bulletins or other periodic statements on enforcement procedures;

(f) promoting environmental audits;

(g) requiring record keeping and reporting;

(h) providing or encouraging mediation and arbitration services;

(i) using licenses, permits or authorizations;

(j) initiating, in a timely manner, judicial, quasi-judicial or administrative proceedings to seek appropriate sanctions or remedies for violations of its environmental laws and regulations;

(k) providing for search, seizure or detention; or

(1) issuing administrative orders, including orders of a preventative, curative or emergency nature.

2. Each Party shall ensure that judicial, quasi-judicial or administrative enforcement proceedings are available under its law to sanction or remedy violations of its environmental laws and regulations.

3. Sanctions and remedies provided for a violation of a Party's environmental laws and regulations shall, as appropriate:

(a) take into consideration the nature and gravity of the violation, any economic benefit derived from the violation by the violator, the economic condition of the violator, and other relevant factors; and

(b) include compliance agreements, fines, imprisonment, injunctions, the closure of facilities, and the cost of containing or cleaning up pollution.

\section{Article 6: Private Access to Remedies}

1. Each Party shall ensure that interested persons may request the Party's competent authorities to investigate alleged violations of its environmental laws and regulations and shall give such requests due consideration in accordance with law.

2. Each Party shall ensure that persons with a legally recognized interest under its law in a particular matter have appropriate access to administrative, quasi-judicial or judicial proceedings for the enforcement of the Party's environmental laws and regulations.

3. Private access to remedies shall include rights, in accordance with the Party's law, such as:

(a) to sue another person under that Party's jurisdiction for damages;

(b) to seek sanctions or remedies such as monetary penalties, emergency closures or orders to mitigate the consequences of violations of its environmental laws and regulations;

(c) to request the competent authorities to take appropriate action to enforce that Party's environmental laws and regulations in order to protect the environment or to avoid environmental harm; or

(d) to seek injunctions where a person suffers, or may suffer, loss, damage or injury as a result of conduct by another person under that Party's jurisdiction contrary to that Party's environmental laws and regulations or from tortious conduct. 


\section{Article 7: Procedural Guarantees}

1. Each Party shall ensure that its administrative, quasi-judicial and judicial proceedings referred to in Articles $5(2)$ and 6(2) are fair, open and equitable, and to this end shall provide that such proceedings:

(a) comply with due process of law:

(b) are open to the public, except where the administration of justice otherwise requires;

(c) entitle the parties to the proceedings to support or defend their respective positions and to present information or evidence; and

(d) are not unnecessarily complicated and do not entail unreasonable charges or time limits or unwarranted delays.

2. Each Party shall provide that final decisions on the merits of the case in such proceedings are:

(a) in writing and preferably state the reasons on which the decisions are based;

(b) made available with undue delay to the parties to the proceedings and, consistent with its law, to the public; and

(c) based on information or evidence in respect of which the parties were offered the opportunity to be heard.

3. Each Party shall provide, as appropriate, that parties to such proceedings have the right, in accordance with its law, to seek review and, where warranted, correction of final decisions issued in such proceedings.

4. Each Party shall ensure that tribunals that conduct or review such proceedings are impartial and independent and do not have any substantial interest in the outcome of the matter.

\section{PART THREE}

\section{COMMISSION FOR ENVIRONMENTAL COOPERATION}

\section{Article 8: The Commission}

1. The Parties hereby establish the Commission for Environmental Cooperation.

2. The Commission shall comprise a Council, a Secretariat and a Joint Public Advisory Committee.

\section{Section A: The Council}

\section{Article 9: Council Structure and Procedures}

1. The Council shall comprise cabinet-level or equivalent representatives of the Parties, or their designees.

2. The Council shall establish its rules and procedures.

3. The Council shall convene:

(a) at least once a year in regular session; and

(b) in special session at the request of any Party. 
Regular sessions shall be chaired successively by each Party.

4. The Council shall hold public meetings in the course of all regular sessions. Other meetings held in the course of regular or special sessions shall be public where the Council so decides.

5. The Council may:

(a) establish, and assign responsibilities to, ad hoc or standing committees, working groups or expert groups;

(b) seek the advice of non-governmental organizations or persons, including independent experts; and

(c) take such other action in the exercise of its functions as the Parties may agree.

6. All decisions and recommendations of the Council shall be taken by consensus, except as the Council may otherwise decide or as otherwise provided in this Agreement.

7. All decisions and recommendations of the Council shall be made public, except as the Council may otherwise decide or as otherwise provided in this Agreement.

\section{Article 10: Council Functions}

1. The Council shall be the governing body of the Commission and shall:

(a) serve as a forum for the discussion of environmental matters within the scope of this Agreement;

(b) oversee the implementation and develop recommendations on the further elaboration of this Agreement and, to this end, the Council shall, within four years after the date of entry into force of this Agreement, review its operation and effectiveness in the light of experience;

(c) oversee the Secretariat;

(d) address questions and differences that may arise between the Parties regarding the interpretation or application of this Agreement;

(e) approve the annual program and budget of the Commission; and

(f) promote and facilitate cooperation between the Parties with respect to environmental matters.

2. The Council may consider, and develop recommendations regarding:

(a) comparability of techniques and methodologies for data gathering and analysis, data management and electronic data communications on matters covered by this Agreement;

(b) pollution prevention techniques and strategies;

(c) approaches and common indicators for reporting on the state of the environment;

(d) the use of economic instruments for the pursuit of domestic and internationally agreed environmental objectives;

(e) scientific research and technology development in respect of environmental matters;

(f) promotion of public awareness regarding the environment;

(g) transboundary and border environmental issues, such as the long-range transport of air and marine pollutants; 
(h) exotic species that may be harmful;

(i) the protection of endangered and threatened species;

(k) environmental emergency preparedness and response activities;

(1) environmental matters as they relate to economic development;

(m) the environmental implications of goods throughout their life cycles;

(n) human resource training and development in the environmental field;

(o) the exchange of environmental scientists and officials;

(p) approaches to environmental compliance and enforcement;

(q) ecologically sensitive national accounts;

(r) eco-labelling; and

(s) other matters as it may decide.

3. The Council shall strengthen cooperation on the development and continuing improvement of environmental laws and regulations, including by:

(a) promoting the exchange of information on criteria and methodologies used in establishing domestic environmental standards; and

(b) without reducing levels of environmental protection, establishing a process for developing recommendations on greater compatibility of environmental technical regulations, standards and conformity assessment procedures in a manner consistent with the NAFTA.

4. The Council shall encourage:

(a) effective enforcement by each Party of its environmental laws and regulations;

(b) compliance with those laws and regulations; and

(c) technical cooperation between the Parties.

5. The Council shall promote and, as appropriate, develop recommendations regarding:

(a) public access to information concerning the environment that it held by public authorities of each Party, including information on hazardous materials and activities in its communities, and opportunity to participate in decision-making processes related to such public access; and

(b) appropriate limits for specific pollutants, taking into account differences in ecosystems.

6. The Council shall cooperate with the NAFTA Free Trade Commission to achieve the environmental goals and objectives of the NAFTA by:

(a) acting as a point of inquiry and receipt for comments from non-governmental organizations and persons concerning those goals and objectives;

(b) providing assistance in consultations under Article 1114 of the NAFTA where a Party considers that another Party is waiving or derogating from, or offering to waive or otherwise derogate from, an environmental measure as an encouragement to establish, acquire, expand or retain an investment of an investor, with a view to avoiding any such encouragement; 
(c) contributing to the prevention or resolution of environment-related trade disputes by:

(i) seeking to avoid disputes between the Parties;

(ii) making recommendations to the Free Trade Commission with respect to the avoidance of such disputes, and

(iii) identifying experts able to provide information or technical advice to NAFTA cornmittees, working groups and other NAFTA bodies;

(d) considering on an ongoing basis the environmental effects of the NAFTA; and

(e) otherwise assisting the Free Trade Commission in environment-related matters.

7. Recognizing the significant bilateral nature of many transboundary environmental issues, the Council shall, with a view to agreement between the Parties pursuant to this Article within three years on obligations, consider and develop recommendations with respect to:

(a) assessing the environmental impact of proposed projects subject to decisions by a competent government authority and likely to cause significant adverse transboundary effects, including a full evaluation of comments provided by other Parties and persons of other Parties;

(b) notification, provision of relevant information and consultation between Parties with respect to such projects; and

(c) mitigation of the potential adverse effects of such projects.

8. The Council shall encourage the establishment of each Party of appropriate administrative procedures pursuant to its environmental laws to permit another Party to seek the reduction, elimination or mitigation of transboundary pollution on a reciprocal basis.

9. The Council shall consider and, as appropriate, develop recommendations on the provision by a Party, on a reciprocal basis, of access to and rights and remedies before its courts and administrative agencies for persons in another Party's territory who have suffered or are likely to suffer damage or injury caused by pollution originating in its territory as if the damage or injury were suffered in its territory.

\section{Section B: The Secretariat}

\section{Article 11: Secretariat Structure and Procedures}

1. The Secretariat shall be headed by an Executive Director, who shall be chosen by the Council for a three-year term, which may be renewed by the Council for one additional three-year term. The position of Executive Director shall rotate consecutively between nationals of each Party. The Council may remove the Executive Director solely for cause.

2. The Executive Director shall appoint and supervise the staff of the Secretariat, regulate their powers and duties and fix their remuneration in accordance with general standards to be established by the Council. The general standards shall provide that:

(a) staff shall be appointed and retained, and their conditions of employment shall be determined, strictly on the basis of efficiency, competence and integrity;

(b) in appointing staff, the Executive Director shall take into account lists of candidates prepared by the Parties and by the Joint Public Advisory Committee: 
(c) due regard shall be paid to the importance of recruiting an equitable proportion of the professional staff from among the nationals of each Party; and

(d) the Executive Director shall inform the Council of all appointments.

3. The Council may decide, by a two-thirds vote, to reject any appointment that does not meet the general standards. Any such decision shall be made and held in confidence.

4. In the performance of their duties, the Executive Director and the staff shall not seek or receive instructions from any government or any other authority external to the Council. Each Party shall respect the international character of the responsibilities of the Executive Director and the staff and shall not seek to influence them in the discharge of their responsibilities.

5. The Secretariat shall provide technical, administrative and operational support to the Council and to committees and groups established by the Council, and such other support as the Council may direct.

6. The Executive Director shall submit for the approval of the Council the annual program and budget of the Commission, including provision for proposed cooperative activities and for the Secretariat to respond to contingencies.

7. The Secretariat shall, as appropriate, provide the Parties and the public information on where they may receive technical advice and expertise with respect to environmental matters.

8. The Secretariat shall safeguard:

(a) from disclosure information it receives that could identify a non-governmental organization or person making a submission if the person or organization so requests or the Secretariat otherwise considers it appropriate; and

(b) from public disclosure any information it receives from any non-governmental organization or person where the information is designated by that non-governmental organization or person as confidential or proprietary.

\section{Article 12: Annual Report of the Commission}

1. The Secretariat shall prepare an annual report of the Commission in accordance with instructions from the Council. The Secretariat shall submit a draft of the report for review by the Council. The final report shall be released publicly.

2. The report shall cover:

(a) activities and expenses of the Commission during the previous year;

(b) the approved program and budget of the Commission for the subsequent year;

(c) the actions taken by each Party in connection with its obligations under this Agreement, including data on the Party's environmental enforcement activities;

(d) relevant views and information submitted by non-governmental organizations and persons, including summary data regarding submissions, and any other relevant information the Council deems appropriate;

(e) recommendations made on any matter within the scope of this Agreement; and

(f) any other matter that the Council instructs the Secretariat to include.

3. The report shall periodically address the state of the environment in the territories of the Parties. 


\section{Article 13: Secretariat Reports}

1. The Secretariat may prepare a report of the Council on any matter within the scope of the annual program. Should the Secretariat wish to prepare a report on any other environmental matter related to the cooperative functions of this Agreement, it shall notify the Council and may proceed unless, within 30 days of such notification, the Council objects by a two-thirds vote to the preparation of this report. Such other environmental matters shall not include issues related to whether a Party has failed to enforce its environmental laws and regulations. Where the Secretariat does not have specific expertise in the matter under review, it shall obtain the assistance of one or more independent experts of recognized experience in the matter to assist in the preparation of the report.

2. In preparing such a report, the Secretariat may draw upon any relevant technical, scientific or other information, including information:

(a) that is publicly available;

(b) submitted by interested non-governmental organizations and persons;

(c) submitted by the Joint Public Advisory Committee;

(d) furnished by a Party;

(e) gathered through public consultations, such as conferences, seminars and symposia; or

(f) developed by the Secretariat, or by independent experts engaged pursuant to paragraph 1.

3. The Secretariat shall submit its report to the Council, which shall make it publicly available, normally within 60 days following its submission, unless the Council otherwise decides.

\section{Article 14: Submissions on Enforcement Matters}

1. The Secretariat may consider a submission from any non-governmental organization or person asserting that a Party is failing to effectively enforce its environmental law, if the Secretariat finds that the submission:

(a) is in writing in a language designated by that Party in a notification to the Secretariat;

(b) clearly identifies the person or organization making the submission;

(c) provides sufficient information to allow the Secretariat to review the submission, including any documentary evidence on which the submission may be based;

(d) appears to be aimed at promoting enforcement rather than at harassing industry;

(e) indicates that the matter has been communicated in writing to the relevant authorities of the Party and indicates the Party's response, if any; and

(f) is filed by a person or organization residing or established in the territory of a Party.

2. Where the Secretariat determines that a submission meets the criteria set out in paragraph 1 , the Secretariat shall determine whether the submission merits requesting a response from the Party. In deciding whether to request a response, the Secretariat shall be guided by whether:

(a) the submission alleges harm to the person or organization making the submission;

(b) the submission, alone or in combination with other submissions, raises matters whose further study in this process would advance the goals of this Agreement;

(c) private remedies available under the Party's law have been pursued; and 
(d) the submission is drawn exclusively from mass media reports.

Where the Secretariat makes such a request, it shall forward to the Party a copy of the submission and any supporting information with the submission.

3. The Party shall advise the Secretariat within 30 days or, in exceptional circumstances and on notification to the Secretariat, within 60 days of delivery of the request:

(a) whether the matter is the subject of a pending judicial or administrative proceeding, in which case the Secretariat shall proceed no further; and

(b) of any other information that the Party wishes to submit, such as

(i) whether the matter was previously the subject of a judicial or administrative proceeding, and

(ii) whether private remedies in connection with the matter are available to the person or organization making the submission and whether they have been pursued.

\section{Article 15: Factual Record}

1. If the Secretariat considers that the submission, in the light of any response provided by the Party, warrants developing a factual record, the Secretariat shall so inform the Council and provide it reasons.

2. The Secretariat shall prepare a factual record if the Council, by a two-thirds vote, instructs it to do so.

3. The preparation of a factual record by the Secretariat pursuant to this Article shall be without prejudice to any further steps that may be taken with respect to any submission.

4. In preparing a factual record, the Secretariat shall consider any information furnished by a Party and may consider any relevant technical, scientific or other information:

(a) that is publicly available;

(b) submitted by interested non-governmental organizations or persons;

(c) submitted by the Joint Public Advisory Committee; or

(d) developed by the Secretariat or by independent experts.

5. The Secretariat shall submit a draft factual record to the Council. Any Party may provide comments on the accuracy of this draft within $\mathbf{4 5}$ days thereafter.

6. The Secretariat shall incorporate, as appropriate, any such comments in the final factual record and submit it to the Council.

7. The Council may, by a two-thirds vote, make the final factual record publicly available, normally within 60 days following its submission.

\section{Section C: Advisory Committee}

\section{Article 16: Joint Public Advisory Committee}

1. The Joint Public Advisory Committee shall comprise 15 members, unless the Council otherwise decides. Each Party or, if the Party so decides, its National Advisory Committee convened under Article 17, shall appoint an equal number of members. 
2. The Council shall establish the rules of procedure for the Joint Public Advisory Committee, which shall choose its own chair.

3. The Joint Public Advisory Committee shall convene at least once a year at the time of the regular session of the Council and at such other times as the Council, or the Committee's chair with the consent of a majority of its members, may decide.

4. The Joint Public Advisory Committee may provide advice to the Council on any matter within the scope of this Agreement, including on any documents provided to it under paragraph 6, and on the implementation and further elaboration of this Agreement, and may perform such other functions as the Council may direct.

5. The Joint Public Advisory Committee may provide relevant technical, scientific or other information to the Secretariat, including for purposes of developing a factual record under Article 15. The Secretariat shall forward to the Council copies of any such information.

6. The Secretariat shall provide to the Joint Public Advisory Committee at the time they are submitted to the Council copies of the proposed annual program and budget of the Commission, the draft annual report, and any report the Secretariat prepares pursuant to Article 13.

7. The Council may, by a two-thirds vote, make a factual record available to the Joint Public Advisory Committee.

\section{Article 17: National Advisory Committees}

Each Party may convene a national advisory committee, comprising members of its public, including representatives of non-governmental organizations and persons, to advise it on the implementation and further elaboration of this Agreement.

\section{Article 18: Governmental Committees}

Each Party may convene a governmental committee, which may comprise or include representatives of federal and state or provincial governments, to advise it on the implementation and further elaboration of this Agreement.

\section{Section D: Official Languages}

\section{Article 19: Official Languages}

The official languages of the Commission shall be English, French and Spanish. All annual reports under Article 12, reports submitted to the Council under Article 13, factual reports submitted to the Council under Article 15(6) and panel reports under Part Five shall be available in each official language at the time they are made public. The Council shall establish rules and procedures regarding interpretation and translation.

\section{PART FOUR}

\section{COOPERATION AND PROVISION OF INFORMATION}

\section{Article 20: Cooperation}

1. The Parties shall at all times endeavor to agree on the interpretation and application of this Agreement, and shall make every attempt through cooperation and consultations to resolve any matter that might affect its operation. 
2. To the maximum extent possible, each Party shall notify any other Party with an interest in the matter of any proposed or actual environmental measure that the Party considers might materially affect the operation of this Agreement or otherwise substantially affect that other Party's interests under this Agreement.

3. On request of any other Party, a Party shall promptly provide information and respond to questions pertaining to any such actual or proposed environmental measure, whether or not that other Party has been previously notified of that measure.

4. Any Party may notify any other Party of, and provide to that Party, any credible information regarding possible violations of its environmental law, specific and sufficient to allow the other Party to inquire into the matter. The notified Party shall take appropriate steps in accordance with its law to so inquire and to respond to the other Party.

\section{Article 21: Provision of Information}

1. On request of the Council or the Secretariat, each Party shall, in accordance with its law, provide such information as the Council or the Secretariat may require, including:

(a) promptly making available any information in its possession required for the preparation of a report or factual record, including compliances and enforcement data; and

(b) taking all reasonable steps to make available any other such information requested.

2. If a Party considers that a request for information from the Secretariat is excessive or otherwise unduly burdensome, it may so notify the Council. The Secretariat shall revise the scope of the request to comply with any limitations established by the Council by a two-thirds vote.

3. If a Party does not make available information requested by the Secretariat, as may be limited pursuant to paragraph 2 , it shall promptly advise the Secretariat of its reasons in writing.

\section{PART FIVE}

\section{CONSULTATION AND RESOLUTION OF DISPUTES}

\section{Article 22: Consultations}

1. Any Party may request in writing consultations with any other Party regarding whether there has been a persistent pattern of failure by that other Party to effectively enforce its environmental law.

2. The requesting Party shall deliver the request to the other Party and to the Secretariat.

3. Unless the Council otherwise provides in its rules and procedures established under Article 9(2), a third Party that considers it has a substantial interest in the matter shall be entitled to participate in the consultations on delivery of written notice to the other Parties and to the Secretariat.

4. The consulting Parties shall make every attempt to arrive at a mutually satisfactory resolution of the matter through consultations under this Article.

\section{Article 23: Initiation of Procedures}

1. If the consulting Parties fail to resolve the matter pursuant to Article 22 within 60 days of delivery of a request for consultations, or such other period as the consulting Parties may agree, any such Party may request in writing a special session of the Council. 
2. The requesting Party shall state in the request the matter complained of and shall deliver the request to the other Parties and to the Secretariat.

3. Unless it decides otherwise, the Council shall convene within 20 days of delivery of the request and shall endeavor to resolve the dispute promptly.

4. The Council may:

(a) call on such technical advisers or create such working groups or expert groups as it deems necessary,

(b) have recourse to good offices, conciliation, mediation or such other dispute resolution procedures, or

(c) make recommendations, as may assist the consulting Parties to reach a mutually satisfactory resolution of the dispute. Any such recommendations shall be made public if the Council, by a two-thirds vote, so decides.

5. Where the Council decides that a matter is more properly covered by another agreement or arrangement to which the consulting Parties are party, it shall refer the matter to those Parties for appropriate action in accordance with such other agreement or arrangement.

\section{Article 24: Request for an Arbitral Panel}

1. If the matter has not been resolved within 60 days after the Council has convened pursuant to Article 23 , the Council shall, on the written request of any consulting Party and by a two-thirds vote, convene an arbitral panel to consider the matter where the alleged persistent pattern of failure by the Party complained against to effectively enforce its environmental law relates to a situation involving workplaces, firms, companies or sectors that produce goods or provide services:

(a) traded between the territories of the Parties; or

(b) that compete, in the territory of the Party complained against, with goods or services produced or provided by persons of another Party.

2. A third Party that considers it has a substantial interest in the matter shall be entitled to join as a complaining Party on delivery of written notice of its intention to participate to the disputing Parties and the Secretariat. The notice shall be delivered at the earliest possible time, and in any event no later than seven days after the date of the vote of the Council to convene a panel.

3. Unless otherwise agreed by the disputing Parties, the panel shall be established and perform its functions in a manner consistent with the provisions of this Part.

\section{Article 25: Roster}

1. The Council shall establish and maintain a roster of up to 45 individuals who are willing and able to serve as panelists. The roster members shall be appointed by consensus for terms of three years, and may be reappointed.

2. Roster members shall:

(a) have expertise or experience in environmental law or its enforcement, or in the resolution of disputes arising under international agreements, or other relevant scientific, technical or professional expertise or experience;

(b) be chosen strictly on the basis of objectivity, reliability and sound judgment;

(c) be independent of, and not be affiliated with or take instructions from, any Party, the Secretariat or the Joint Public Advisory Committee; and 
(d) comply with a code of conduct to be established by the Council.

\section{Article 26: Qualifications of Panelists}

1. All panelists shall meet the qualifications set out in Article 25(2).

2. Individuals may not serve as panelists for a dispute in which:

(a) they have participated pursuant to Article 23(4); or

(b) they have, or a person or organization with which they are affiliated has, an interest, as set out in the code of conduct established under Article 25(2)(d).

\section{Article 27: Panel Selection}

1. Where there are two disputing Parties, the following procedures shall apply:

(a) The panel shall comprise five members.

(b) The disputing Parties shall endeavor to agree on the chair of the panel within 15 days after the Council votes to convene the panel. If the disputing Parties are unable to agree on the chair within this period, the disputing Party chosen by lot shall select within five days a chair who is not a citizen of that Party.

(c) Within 15 days of selection of the chair, each disputing Party shall select two panelists who are citizens of the other disputing Party.

(d) If a disputing Party fails to select its panelists within such period, such panelists shall be selected by lot from among the roster members who are citizens of the other disputing Party.

2. Where there are more than two disputing Parties, the following procedures shall apply:

(a) The panel shall comprise five members.

(b) The disputing Parties shall endeavor to agree on the chair of the panel within 15 days after the Council votes to convene the panel. If the disputing Parties are unable to agree on the chair within this period, the Party or Parties on the side of the dispute chosen by lot shall select within 10 days a chair who is not a citizen of such Party or Parties.

(c) Within 30 days of selection of the chair, the Party complained against shall select two panelists, one of whom is a citizen of a complaining Party, and the other of whom is a citizen of another complaining Party. The complaining Parties shall select two panelists who are citizens of the Party complained against.

(d) If any disputing Party fails to select a panelist within such period, such panelist shall be selected by lot in accordance with the citizenship criteria of subparagraph (c).

3. Panelists shall normally be selected from the roster. Any disputing Party may exercise a peremptory challenge against any individual not on the roster who is proposed as a panelist by a disputing Party within 30 days after the individual has been proposed.

4. If a disputing Party believes that a panelist is in violation of the code of conduct, the disputing Parties shall consult and, if they agree, the panelist shall be removed and a new panelist shall be selected with this Article.

\section{Article 28: Rules of Procedure}

1. The Council shall establish Model Rules of Procedure. The procedures shall provide: 
(a) a right to at least one hearing before the panel;

(b) the opportunity to make initial and rebuttal written submissions; and

(c) that no panel may disclose which panelists are associated with majority or minority opinions.

2. Unless the disputing Parties otherwise agree, panels convened under this Part shall be established and conduct their proceedings in accordance with the Model Rules of Procedure.

3. Unless the disputing Parties otherwise agree within 20 days after the Council votes to convene the panel, the terms of reference shall be:

"To examine, in light of the relevant provisions of the Agreement, including those contained in Part Five, whether there has been a persistent pattern of failure by the Party complained against to effectively enforce its environmental law, and to make findings, determinations and recommendations in accordance with Article $31(2)$."

\section{Article 29: Third Party Participation}

A Party that is not a disputing Party, on delivery of a written notice to the disputing Parties and to the Secretariat, shall be entitled to attend all hearings, to make written and oral submissions to the panel and to receive written submissions of the disputing Parties.

\section{Article 30: Role of Experts}

On request of a disputing Party, or on its own initiative, the panel may seek information and technical advice from any person or body that it deems appropriate, provided that the disputing Parties so agree and subject to such terms and conditions as such Parties may agree.

\section{Article 31: Initial Report}

1. Unless the disputing Parties otherwise agree, the panel shall base its report on the submissions and arguments of the Parties and on any other information before it pursuant to Article 30.

2. Unless the disputing Parties otherwise agree, the panel shall, within 180 days after the last panelist is selected, present to the disputing Parties an initial report containing:

(a) findings of fact;

(b) its determination as to whether there has been a persistent pattern of failure by the Party complained against to effectively enforce its environmental law, or any other determination requested in the terms of reference; and

(c) in the event the panel makes an affirmative determination under subparagraph (b), its recommendations, if any, for the resolution of the dispute, which normally shall be that the Party complained against adopt and implement an action plan sufficient to remedy the pattern of non-enforcement.

3. Panelists may furnish separate opinions on matters not unanimously agreed.

4. Adisputing Party may submit written comments to the panel on its initial report within 30 days of presentation of the report.

5. In such an event, and after considering such written comments, the panel, on its own initiative or on the request of any disputing Party, may:

(a) request the views of any participating Party; 
(b) reconsider its report; and

(c) make any further examination that it considers appropriate.

\section{Article 32: Final Report}

1. The panel shall present to the disputing Parties a final report, including any separate opinions on matters not unanimously agreed, within 60 days of presentation of the initial report, unless the disputing Parties otherwise agree.

2. The disputing Parties shall transmit to the Council the final report of the panel, as well as any written views that a disputing Party desires to be appended, on a confidential basis within 15 days after it is presented to them.

3. The final report of the panel shall be published five days after it is transmitted to the Council.

\section{Article 33: Implementation of Final Report}

If, in its final report, a panel determines that there has been a persistent pattern of failure by the Party complained against to effectively enforce its environmental law, the disputing Parties may agree on a mutually satisfactory action plan, which normally shall conform with the determinations and recommendations of the panel. The disputing Parties shall promptly notify the Secretariat and the Council of any agreed resolution of the dispute.

\section{Article 34: Review of Implementation}

1. If, in its final report, a panel determines that there has been a persistent pattern of failure by the Party complained against to effectively enforce its environmental law, and:

(a) the disputing Parties have not agreed on an action plan under Article 33 within 60 days of the date of the final report, or

(b) the disputing Parties cannot agree on whether the Party complained against is fully implementing

(i) an action plan agreed under Article 33,

(ii) an action plan deemed to have been established by a panel under paragraph 2, or

(iii) an action plan approved or established by a panel under paragraph 4,

any disputing Party may request that the panel be reconvened. The requesting Party shall deliver the request in writing to the other Parties and to the Secretariat. The Council shall reconvene the panel on delivery of the request to the Secretariat.

2. No Party may make a request under paragraph 1(a) earlier than 60 days, or later than 120 days, after the date of the final report. If the disputing Parties have not agreed to an action plan and if no request was made under paragraph 1(a), the last action plan, if any, submitted by the Party complained against to the complaining Party or Parties within 60 days of the date of the final report, or such other period as the disputing Parties may agree, shall be deemed to have been established by the panel 120 days after the date of the final report.

3. A request under paragraph 1(b) may be made no earlier than $\mathbf{1 8 0}$ days after an action plan has been:

(a) agreed under Article 33;

(b) deemed to have been established by a panel under paragraph 2; or

(c) approved or established by a panel under paragraph 4;

and only during the term of any such action plan. 
4. Where a panel has been reconvened under paragraph 1(a), it:

(a) shall determine whether any action plan proposed by the Party complained against is sufficient to remedy the pattern of non-enforcement and

(i) if so, shall approve the plan, or

(ii) if not, shall establish such a plan consistent with the law of the Party complained against, and

(b) may, where warranted, impose a monetary enforcement assessment in accordance with Annex 34,

within 90 days after the panel has been reconvened or such other period as the disputing Parties may agree.

5. Where a panel has been reconvened under paragraph $1(b)$, it shall determine either that:

(a) the Party complained against is fully implementing the action plan, in which case the panel may not impose a monetary enforcement assessment, or

(b) the Party complained against is not fully implementing the action plan, in which case the panel shall impose a monetary enforcement assessment in accordance with Annex 34,

within 60 days after it has been reconvened or such other period as the disputing Parties may agree.

6. A panel reconvened under this Article shall provide that the Party complained against shall fully implement any action plan referred to in paragraph 4 (a)(ii) or 5(b), and pay any monetary enforcement assessment imposed under paragraph $4(\mathrm{~b})$ or $5(\mathrm{~b})$, and any such provisions shall be final.

\section{Article 35: Further Proceeding}

A complaining Party may, at any time beginning 180 days after a panel determination under Article 34(5)(b), request in writing that a panel be reconvened to determine whether the Party complained against is fully implementing the action plan. On delivery of the request to the other Parties and the Secretariat, the Council shall reconvene the panel. The panel shall make the determination within 60 days after it has been reconvened or such other period as the disputing Parties may agree.

\section{Article 36: Suspension of Benefits}

1. Subject to Annex $36 \mathrm{~A}$, where a Party fails to pay a monetary enforcement assessment within 180 days after it is imposed by a panel:

(a) under Article 34(4)(b), or

(b) under Article 34(5)(b), except where benefits may be suspended under paragraph 2(a),

any complaining Party or Parties may suspend, in accordance with Annex 36B, the application to the Party complained against of NAFTA benefits in an amount no greater than that sufficient to collect the monetary enforcement assessment.

2. Subject to Annex 36A, where a panel has made a determination under Article 34(5)(b) and the panel:

(a) has previously imposed a monetary enforcement assessment under Article 34(4)(b) or established an action plan under Article 34(4)(a)(ii); or

(b) has subsequently determined under Article 35 that a Party is not fully implementing an action plan; 
the complaining Party or Parties may, in accordance with Annex 36B, suspend annually the application to the Party complained against of NAFTA benefits in an amount no greater than the monetary enforcement assessment imposed by the panel under Article 34(5)(b).

3. Where more than one complaining Party suspends benefits under paragraph 1 or 2 , the combined suspension shall be no greater than the amount of the monetary enforcement assessment.

4. Where a Party has suspended benefits under paragraph 1 or 2, the Council shall, on the delivery of a written request by the Party complained against to the other Parties and the Secretariat, reconvene the panel to determine whether the monetary enforcement assessment has been paid or collected, or whether the Party complained against is fully implementing the action plan, as the case may be. The panel shall submit its report within $\mathbf{4 5}$ days after it has been reconvened. If the panel determines that the assessment has been paid or collected, or that the Party complained against is fully implementing the action plan, the suspension of benefits under paragraph 1 or 2 , as the case may be, shall be terminated.

5. On the written request of the Party complained against, delivered to the other Parties and the Secretariat, the Council shall reconvene the panel to determine whether the suspension of benefits by the complaining Party or Parties pursuant to paragraph 1 or 2 is manifestly excessive. Within 45 days of the request, the panel shall present a report to the disputing Parties containing its determination.

\section{PART SIX}

\section{GENERAL PROVISIONS}

\section{Article 37: Enforcement Principle}

Nothing in this Agreement shall be construed to empower a Party's authorities to undertake environmental law enforcement activities in the territory of another Party.

\section{Article 38: Private Rights}

No Party may provide for a right of action under its law against any other Party on the ground that another Party has acted in a manner inconsistent with this Agreement.

\section{Article 39: Protection of Information}

1. Nothing in this Agreement shall be construed to require a Party to make available or allow access to information:

(a) the disclosure of which would impede its environmental law enforcement; or

(b) that is protected from disclosure by its law governing business or proprietary information, personal privacy or the confidentiality of governmental decision making.

2. If a Party provides confidential or proprietary information to another Party, the Council, the Secretariat or the Joint Public Advisory Committee, the recipient shall treat the information on the same basis as the Party providing the information.

3. Confidential or proprietary information provided by a Party to a panel under this Agreement shall be treated in accordance with the rules of procedure established under Article 28. 


\section{Article 40: Relation to Other Environmental Agreements}

Nothing in this Agreement shall be construed to affect the existing rights and obligations of the Parties under other international environmental agreements, including conservation agreements, to which such Parties are party.

\section{Article 41: Extent of Obligations}

Annex 41 applies to the Parties specified in that Annex.

\section{Article 42: National Security}

Nothing in this Agreement shall be construed:

(a) to require any Party to make available or provide access to information the disclosure of which it determines to be contrary to its essential security interests; or

(b) to prevent any Party from taking any actions that it considers necessary for the protection of its essential security interests relating to

(i) arms, ammunition and implements of war, or

(ii) the implementation of national policies or international agreements respecting the non-proliferation of nuclear weapons or other nuclear explosive devices.

\section{Article 43: Funding of the Commission}

Each Party shall contribute an equal share of the annual budget of the Commission, subject to the availability of appropriated funds in accordance with the Party's legal procedures. No Party shall be obligated to pay mure than any other Party in respect of an annual budget.

\section{Article 44: Privileges and Immunities}

The Executive Director and staff of the Secretariat shall enjoy in the territory of each Party such privileges and immunities as are necessary for the exercise of their functions.

\section{Article 45: Definitions}

1. For purposes of this Agreement:

A Party has not failed to "effectively enforce its environmental law" or to comply with Article 5(1) in a particular case where the action or inaction in question by agencies or officials of that Party:

(a) reflects a reasonable exercise of their discretion in respect of investigatory, prosecutorial, regulatory or compliance matters; or

(b) results from bona fide decisions to allocate resources to enforcement in respect of other environmental matters determined to have higher priorities;

"non-governmental organization" means any scientific, professional, business, non-profit, or public interest organization or association which is neither affiliated with, nor under the direction of, a government;

"persistent pattern" means a sustained or recurring course of action or inaction beginning after the date of entry into force of this Agreement; 
"province" means a province of Canada, and includes the Yukon Territory and the Northwest Territories and their successors; and

"territory" means for a Party the territory of that Party as set out in Annex 45.

2. For purposes of Article 14(1) and Part Five:

(a) "environmental law" means any statute or regulation of a Party, or provision thereof, the primary purpose of which is the protection of the environment, or the prevention of a danger to human life or health, through

(i) the prevention, abatement or control of the release, discharge, or emission of pollutants or environmental contaminants,

(ii) the control of environmentally hazardous or toxic chemicals, substances, materials and wastes, and the dissemination of information related thereto, or

(iii) the protection of wild flora or fauna, including endangered species, their habitat, and specially protected natural areas

in the Party's territory, but does not include any statute or regulation, or provision thereof, directly related to worker safety or health.

(b) For greater certainty, the term "environmental law" does not include any statute or regulation, or provision thereof, the primary source of which is managing the commercial harvest or exploitation, or subsistence or aboriginal harvesting, of natural resources.

(c) The primary purpose of a particular statutory or regulatory provision for purposes of subparagraphs (a) and (b) shall be determined by reference to its primary purpose, rather than to the primary purpose of the statute or regulation of which it is part.

3. For purposes of Article 14(3), "judicial or administrative proceeding" means:

(a) a domestic judicial, quasi-judicial or administrative action pursued by the Party in a timely fashion and in accordance with the law. Such actions comprise: mediation; arbitration; the process of issuing a license, permit, or authorization; seeking an assurance of voluntary compliance or a compliance agreement; seeking sanctions or remedies in an administrative or judicial forum; and the process of issuing an administrative order; and

(b) an international dispute resolution proceeding to which the Party is party.

\title{
PART SEVEN
}

\section{FINAL PROVISIONS}

\author{
Article 46: Annexes
}

The Annexes to this Agreement constitute an integral part of the Agreement.

\section{Article 47: Entry into Force}

This Agreement shall enter into force on January 1, 1994, immediately after entry into force of the NAFTA, on an exchange of written notifications certifying the completion of necessary legal procedures. 


\section{Article 48: Amendments}

1. The Parties may agree on any modification of or addition to this Agreement.

2. When so agreed, and approved in accordance with the applicable legal procedures of each Party, a modification or addition shall constitute an integral part of this Agreement.

\section{Article 49: Accession}

Any country or group of countries may accede to this Agreement subject to such terms and conditions as may be agreed between such country or countries and the Council and following approval in accordance with the applicable legal procedures of each country.

\section{Article 50: Withdrawal}

A Party may withdraw from this Agreement six months after it provides written notice of withdrawal to the other Parties. If a Party withdraws, the Agreement shall remain in force for the remaining Parties.

\section{Article 51: Authentic Texts}

The English, French, and Spanish texts of this Agreement are equally authentic.

IN WITNESS WHEREOF, the undersigned, being duly authorized by the respective Governments, have signed this Agreement.

\section{ANNEX 34 \\ MONETARY ENFORCEMENT ASSESSMENTS}

1. For the first year after the date of entry into force of this Agreement, any monetary enforcement assessment shall be no greater than 20 million dollars (U.S.) or its equivalent in the currency of the Party complained against. Thereafter, any monetary enforcement assessment shall be no greater than .007 percent of total trade in goods between the Parties during the most recent year for which data are available.

2. In determining the amount of the assessment, the panel shall take into account:

(a) the pervasiveness and duration of the Party's persistent pattern of failure to effectively enforce its environmental law;

(b) the level of enforcement that could reasonably be expected of a Party given its resource constraints;

(c) the reasons, if any, provided by the Party for not fully implementing an action plan;

(d) efforts made by the Party to begin remedying the pattern of non-enforcement after the final report of the panel; and

(e) any other relevant factors.

3. All monetary enforcement assessments shall be paid in the currency of the Party complained against into a fund established in the name of the Commission by the Council and shall be expended at the direction of the Council to improve or enhance the environment or environmental law enforcement in the Party complained against, consistent with its law. 


\section{ANNEX 36A}

\section{CANADIAN DOMESTIC ENFORCEMENT AND COLLECTION}

1. For the purposes of this Annex, "panel determination" means:

(a) a determination by a panel under Article 34(4)(b) or 5(b) that provides that Canada shall pay a monetary enforcement assessment; and

(b) a determination by a panel under Article 34(5)(b) that provides that Canada shall fully implement an action plan where the panel:

(i) has previously established an action plan under Article 34(4)(a)(ii) or imposed a monetary enforcement assessment under Article 34(4)(b); or

(ii) has subsequently determined under Article 35 that Canada is not fully implementing an action plan.

2. Canada shall adopt and maintain procedures that provide that:

(a) subject to subparagraph (b), the Commission, at the request of a complaining Party, may in its own name file in a court of competent jurisdiction a certified copy of a panel determination;

(b) the Commission may file in court a panel determination that is a panel determination described in paragraph 1(a) only if Canada has failed to comply with the determination within 180 days of when the determination was made;

(c) when filed, the panel determination, for purposes of enforcement, shall become an order of the court;

(d) the Commission may take proceedings for enforcement of a panel determination that is made an order of the court, in that court, against the person against whom the panel determination is addressed in accordance with paragraph 6 of Annex 41;

(e) proceedings to enforce a panel determination that has been made an order of the court shall be conducted by way of summary proceedings;

(f) in proceedings to enforce a panel determination that is a panel determination described in paragraph 1(b) and that has been made an order of the court, the court shall promptly refer any question of fact or any question of interpretation of the panel determination to the panel that made the panel determination, and the decision of the panel shall be binding on the court;

(g) a panel determination that has been made an order of the court shall not be subject to domestic review or appeal; and

(h) an order made by the court in proceedings to enforce a panel determination that has been made an order of the court shall not be subject to review or appeal.

3. Where Canada is the Party complained against, the procedures adopted and maintained by Canada under this Annex shall apply and the procedures set out in Article 36 shall not apply.

4. Any change by Canada to the procedures adopted and maintained by Canada under this Annex that have the effect of undermining the provisions of this Annex shall be considered a breach of this Agreement. 


\section{ANNEX 36B \\ SUSPENSION OF BENEFITS}

1. Where a complaining Party suspends NAFTA tariff benefits in accordance with this Agreement, the Party may increase the rates of duty on originating goods of the Party complained against to levels not to exceed the lesser of:

(a) the rate that was applicable to those goods prior to the date of entry into force of the NAFTA, and

(b) the Most-Favored-Nation rate applicable to those goods on the date the Party suspends such benefits,

and such increase may be applied only for such time as is necessary to collect, through such increase, the monetary enforcement assessment.

2. In considering what tariff or other benefits to suspend pursuant to Article 36(1) or (2):

(a) a complaining Party shall first seek to suspend benefits in the same sector or sectors as that in respect of which there has been a persistent pattern of failure by the Party complained against to effectively enforce its environmental law; and

(b) a complaining Party that considers it is not practicable or effective to suspend benefits in the same sector or sectors may suspend benefits in other sectors.

\section{ANNEX 41 \\ EXTENT OF OBLIGATIONS}

1. On the date of signature of this Agreement, or of the exchange of written notifications under Article 47, Canada shall set out in a declaration a list of any provinces for which Canada is to be bound in respect of matters within their jurisdiction. The declaration shall be effective on delivery to the other Parties, and shall carry no implication as to the internal distribution of powers within Canada. Canada shall notify the other Parties six months in advance of any modifications to its declaration.

2. When considering whether to instruct the Secretariat to prepare a factual record pursuant to Article 15, the Council shall take into account whether the submission was made by a non-governmental organization or enterprise incorporated or otherwise organized under the laws of a province not included in the declaration made under paragraph 1.

3. Canada may not request consultations under Article 22 or a Council meeting under Article 23 or request the establishment of a panel or join as a complaining Party under Article 24 against another Party at the instance, or primarily for the benefit, of any government of a province not included in the declaration made under paragraph 1.

4. Canada may not request a Council meeting under Article 23, or request the establishment of a panel or join as a complaining Party under Article 24 concerning whether there has been a persistent pattern of failure by another Party to effectively enforce its environmental law, unless Canada states in writing that the matter would be under federal jurisdiction if it were to arise within the territory of Canada, or:

(a) Canada states in writing that the matter would be under provincial jurisdiction if it were to arise within the territory of Canada; and

(b) the provinces included in the declaration account for at least 55 percent of Canada's Gross Domestic Product (GDP) for the most recent year in which data are available; and

(c) where the matter concerns a specific industry or sector, at least 55 percent of total Canadian production in that industry or sector is accounted for by the provinces included in the declaration for the most recent year in which data are available. 
5. No other Party may request a Council meeting under Article 23 or request the establishment of a panel or join as a complaining Party under Article 24 concerning whether there has been a persistent failure to effectively enforce an environmental law of a province unless that province is included in the declaration made under paragraph 1 and the requirements of subparagraphs $4(b)$ and (c) have been met.

6. Canada shall, no later than the date on which an arbitral panel is convened pursuant to Article 24 respecting a matter within the scope of paragraph 5 of this Annex, notify in writing the complaining Parties and the Secretariat of whether any monetary enforcement assessment or action plan imposed by a panel under Article 34(4) or 34(5) against Canada shall be addressed to Her Majesty in right of Canada or Her Majesty in right of the province concerned.

7. Canada shall use its best efforts to make this Agreement applicable to as many of its provinces as possible.

8. Two years after the date of entry into force of this Agreement, the Council shall review the operation of this Annex and, in particular, shall consider whether the Parties should amend the thresholds established in paragraph 4.

\section{ANNEX 45 \\ COUNTRY-SPECIFIC DEFINITIONS}

For purposes of this Agreement:

"territory" means:

(a) with respect to Canada, the territory to which its customs laws apply, including any areas beyond the territorial seas of Canada within which, in accordance with international law and its domestic law, Canada may exercise rights with respect to the seabed and subsoil and their natural resources;

(b) with respect to Mexico,

(i) the states of the Federation and the Federal District,

(ii) the islands, including the reefs and keys, in adjacent seas,

(iii) the islands of Guadalupe and Revillagigedo situated in the Pacific Ocean,

(iv) the continental shelf and the submarine shelf of such islands, keys and reefs,

(v) the waters of the territorial seas, in accordance with international law, and its interior maritime waters,

(vi) the space located above the national territory, in accordance with international law, and

(vii) any areas beyond the territorial seas of Mexico within which, in accordance with international law, including the United Nations Convention on the Law of the Sea, and its domestic law, Mexico may exercise rights with respect to the seabed and subsoil and their natural resources; and

(c) with respect to the United States,

(i) the customs territory of the United States, which includes the 50 states, the District of Columbia and Puerto Rico,

(ii) the foreign trade zones located in the United States and Puerto Rico; and

(iii) any areas beyond the territorial seas of the United States within which, in accordance with international law and its domestic law, the United States may exercise rights with respect to the seabed and subsoil and their natural resources. 
DONE in triplicate at

Washington, D.C., on the 9th day and the 14th day of September 1993, Ottawa, on the 12th day and the 14th day of September 1993,

Mexico, D.F., on the 8th day and the 14th day of September 1993.

FAIT en trois exemplaires à

Washington, D.C., le 9ième jour et le 14ième jour de septembre 1993, Ottawa, le 12ième jour et le 14ième jour de septembre 1993, Mexico, D.F., le 8ième jour et le 14ième jour de septembre 1993.

HECHO en tres originales en

Washington, D.C., a los 9 días y a los 14 días de septiembre 1993, Ottawa, a los 12 días y a los 14 días de septiembre 1993,

México, D.F., a los 8 días y a los 14 días de septiembre 1993.

\title{
[Signature] \\ FOR THE GOVERNMENT OF THE UNITED STATES OF AMERICA POUR LE GOUVERNEMENT DES ÉTATS-UNIS D'AMÉRIQUE POR EL GOBIERNO DE LOS ESTADOS UNIDOS DE AMÉRICA
}

\author{
[Signature] \\ FOR THE GOVERNMENT OF CANADA \\ POUR LE GOUVERNEMENT DU CANADA \\ POR EL GOBIERNO DE CANADÁ
}

[Signature]

FOR THE GOVERNMENT OF THE UNITED MEXICAN STATES POUR LE GOUVERNEMENT DES ÉTATS-UNIS MEXICAINS POR EL GOBIERNO DE LOS ESTADOS UNIDOS MEXICANOS 


\title{
Establishment Agreement for the Center for International Forestry Research, Canberra, 1993
}

\author{
Done at Canberra 5 March 1993 \\ Entered into force 5 March 1993; entered into force \\ 3 May 1993 for the United States \\ Depositary: Australia \\ Primary source citation: TIAS 11960
}

\section{ESTABLISHMENT AGREEMENT FOR THE CENTER FOR INTERNATIONAL FORESTRY RESEARCH}

WHEREAS the Consultative Group on International Agricultural Research (hereinafter referred to as CGIAR) is an informal association of national governments, international organizations and private institutions co-sponsored by the World Bank, the Food and Agricultural Organization of the United Nations (hereinafter referred to as FAO) and the United Nations Development Programme (hereinafter referred to as UNDP) formed for the purpose of contributing to sustainable improvements in the productivity of agriculture, forestry and fisheries in developing countries in ways that enhance nutrition and well-being, especially among low-income people;

WHEREAS the CGIAR has agreed that there should be established a Center for International Forestry Research (CIFOR) which will be concerned with forestry research that benefits developing countries;

WHEREAS, acknowledging that different regions in the world have their own unique and differing problems whose solution could be aided by international research, CIFOR will be a decentralized body with a headquarters in Indonesia and regional programs located in various countries;

WHEREAS CIFOR is intended to be an International Research Center within the CGIAR system;

WHEREAS members of the CGIAR intend to provide funds for the regular budget of CIFOR to enable the Center to assume its functions; and

WHEREAS the Parties to this Agreement wish to create CIFOR as an independent institution with suitable governance, full juridical personality and appropriate international status, authorities, privileges and immunities and the conditions necessary to enable it to operate effectively toward the attainment of its objectives;

THE PARTIES HAVE AGREED AS FOLLOWS: 


\section{Article 1 \\ Establishment}

There shall be established an independent international organization entitled the "Center for International Forestry Research" (hereinafter referred to as "CIFOR" or "the Center") which shall operate in accordance with the Constitution appended hereto and forming an integral part of this Agreement.

\section{Article 2 \\ Financial obligations}

The Parties shall not be under any obligation to provide financial support to CIFOR beyond voluntary contributions. The Parties shall not be under any responsibility, individually or collectively, for any debts, liabilities or obligations of the Center. Financing of the Center's activities shall be undertaken pursuant to Article 17 of the Constitution.

\section{Article 3 \\ Signature and accession}

1. This Agreement shall be open for signature by States at Canberra at the Department of Foreign Affairs and Trade of Australia. It shall remain open for signature for a period of two years from the date of first signature.

2. After the expiration of the period specified in paragraph 1, this Agreement shall remain open for accession by any State, subject to prior approval by the Board of Trustees of CIFOR by simple majority.

3. Instruments of accession shall be deposited with the Depositary of this Agreement.

4. The Government of Australia shall be the Depositary of this Agreement.

\section{Article 4 Entry into force}

1. This Agreement and the Constitution appended hereto shall enter into force upon signature by three States. The three original signatories to this Agreement shall thereafter be referred to as "the sponsors".

2. For each State depositing an instrument of accession, after the entry into force of this Agreement, this Agreement shall enter into force on the first day of the month after the date of receipt by the Depositary of such instrument.

\section{Article 5 Amendment}

The amendment of this Agreement and fundamental provisions of the Constitution (as defined in Article 21 of the Constitution) shall be subject to the approval of the Parties to this Agreement. Such proposed amendments shall, following approval by the Board, be conveyed to Parties to this Agreement and shall enter into force 30 days after receipt by the Depositary of instruments of acceptance of the amendment from all Parties to this Agreement. 


\section{Article 6 \\ Withdrawal and dissolution}

Any Party to this Agreement may withdraw upon six months written notice to the other Parties through the Depositary. Such withdrawal shall in no way affect contractual or other obligations entered into by the Center prior to notice of withdrawal being given.

\section{Article 7 \\ Authentic Text}

The authentic text of the present Agreement, including the Constitution appended thereto, shall be in the English language.

IN WITNESS WHEREOF, the undersigned Plenipotentiaries, being duly authorized by their respective Governments, have signed this Agreement.

DONE at Canberra in a single original in the English language, on the fifth day of March, 1993.

[Signature]

For the Government of Australia:

[Signature]

For the Government of Sweden:

[Signature]

For the Government of Switzerland:

For the Government of the

United States of America: [Signature] May 3, 1993

For the Government of

For the Government of

For the Government of

For the Government of

For the Government of

For the Government of

For the Government of

For the Government of

For the Government of

For the Government of 


\title{
CONSTITUTION FOR THE CENTER FOR INTERNATIONAL FORESTRY RESEARCH
}

\author{
Article 1 \\ Establishment
}

The Center for International Forestry Research (hereinafter referred to as "CIFOR" or "the Center") is hereby constituted as an international organization and governed by this constitution.

\section{Article 2 \\ Status}

1. The Center shall operate as a non-profit autonomous organization, international in status and non-political in management, staffing and operations. The Center shall be organized exclusively for the purpose of scientific research, information dissemination, and technology transfer in forestry.

2. CIFOR shall possess full juridical international personality and enjoy such legal capacities as may be necessary for the exercise of its functions and the fulfilment of its purpose.

\section{Article 3}

\section{Location of Headquarters}

The country of location of CIFOR's headquarters shall be designated by the Board of Trustees of CIFOR after consultation within the Consultative Group on International Agricultural Research (hereinafter referred to as "CGIAR"), and in accordance with the requirements for the exercise of the functions and the fulfilment of the purposes of CIFOR. The Board of Trustees may establish offices in other locations as required to support the Center's programs.

\section{Article 4 \\ Purpose}

1. The purpose of the Center is to contribute to the sustained well-being of people in developing countries, particularly in the tropics, through collaborative strategic and applied research and related activities in forest systems and forestry, and by promoting the transfer of appropriate new technologies and the adoption of new methods of social organization, for national development.

2. By "forestry" is meant the science, the art and the practice of managing and using for human benefit the natural resources that occur on and in association with lands bearing forest or with a forest vocation. A "forest system" is a functional complex of forest and its biophysical, social, cultural, economic and political environment.

\section{Article 5 \\ Guiding principles}

The Center's guiding principles are:

(a) The provision of a focal point within the CGIAR for leadership in forestry research worldwide by defining and updating a global research agenda of priority problems and by assessing the Center's comparative advantage vis-à-vis existing institutions;

(b) A commitment to strategic research aimed at better understanding of mechanisms and processes, and adopting an ecosystem approach to forest systems, an holistic view in policy and socio-economic studies, and an integrated approach in forest products utilization research; 
(c) The marshalling of the necessary critical mass of interdisciplinary scientific expertise and resources to ensure efficient and effective implementation of activities to meet clearly defined program objectives; and

(d) A recognition that research must remain relevant to and serve the needs of developing countries in their efforts to achieve sustainable land-use practices, minimise further degradation of forested lands and promote social equity.

\section{Article 6}

\section{Activities}

1. CIFOR shall conduct, promote and support research that can provide the basis for sustainable forestry and forest systems in developing countries, thereby enhancing the environment, development and well-being of their peoples.

2. CIFOR shall formulate a research program to underpin the science of forestry, by developing and maintaining the necessary scientific and technological base and the necessary staff expertise. This program shall be directed towards innovation and technology development and the transfer of the results of such work to CIFOR's stakeholders for the ultimate benefit of people in developing countries.

3. CIFOR shall operate through a variety of mechanisms suited to the needs of its constituent programs, including networking, collaborative and contractual arrangements, and in-house research.

4. CIFOR shall monitor forestry research globally and shall obtain and process information relevant to developing countries. CIFOR shall act as a distributor of this information where and when it is needed.

5. CIFOR shall keep itself informed of the policies, practices and capabilities of other agencies active in forestry and forestry research and shall, upon request, serve in an advisory role on these matters within and outside the CGIAR.

6. CIFOR shall perform such other activities as its Board of Trustees may find necessary or useful in furtherance of its purpose set forth in Article 4 hereof.

7. CIFOR's activities shall contribute to increasing the forestry research capacity of developing countries. These activities shall be undertaken in the context of strategic problem-solving research aimed at:

Objective 1. Understanding the biophysical and socioeconomic environments of present and potential forest systems and forestry, and their functional relationships.

Objective 2. Creating the potential for sustainable improved productivity of forest systems for the benefit of people in developing countries.

Objective 3. Providing analysis, information and advice to assist in making policy decisions about forests and land use.

Objective 4. Increasing national forestry research capacity.

\section{Article 7}

Powers

1. In furtherance of the aforesaid aims and activities, CIFOR shall have the following powers:

(a) to receive or otherwise lawfully obtain from any governmental authority or from any corporation, company, association, person, firm, foundation or other entity whether international, regional or national, such charters, licences, rights, concessions or similar rights, and assistance - financial or otherwise - as are conducive to and necessary for the attainment of the aims of the Center; 
(b) to receive, acquire or otherwise lawfully obtain from any governmental authority or from any corporation, company, association, person, firm, foundation or other entity, whether international, regional or national, by donation, grant, exchange, devise, bequest, purchase or lease, either absolutely or in trust, contributions consisting of such properties, real, personal, or mixed including funds and valuable effects or items, as may be useful or necessary to pursue the aims and activities of the Center and to hold, operate, administer, use, sell, convey or dispose of the said properties;

(c) to enter into Agreements, Memoranda of Understanding and Contracts;

(d) to employ persons according to its own regulations;

(e) to institute, and defend in, legal proceedings; and

(f) to perform all acts and functions as may be found necessary, expedient, suitable or proper for the furtherance, accomplishment or attainment of any and/or all of the purposes and activities herein stated, or which shall appear, at any time, as conducive to or necessary and useful for the aims and activities of the Center.

2. No part of the earnings of the Center shall inure to the benefit of, or be distributable to, its members, trustees, officers, or other private persons, except that the Center shall be authorized and empowered to pay reasonable compensation for services rendered and to make payments and distributions in furtherance of the purpose set forth in Article 4 hereof.

\section{Article 8 \\ Organs}

The organs of CIFOR shall be:

(a) The Board of Trustees (hereinafter referred to as "the Board"); and

(b) The Director General.

\section{Article 9 \\ Composition of the Board}

1. The Board shall consist of up to seventeen members, selected as follows:

(a) three members elected by the Board upon nomination by the CGIAR, and up to eleven members-at-large elected by the Board;

(b) one Chairperson appointed in accordance with Article 13 below;

(c) one ex-officio member appointed by the court which hosts the headquarters of CIFOR;

(d) the Chairperson of the Board of Trustees of the International Centre for Research in Agroforestry (hereinafter referred to as "ICRAF"), as an ex-officio member; and

(e) the Director General of CIFOR as a non-voting ex-officio member.

2. The members of the Board, except the Director General who serves as a member for her/his whole term of office and the member appointed by the host country, shall be appointed for terms of no more than three years as determined by the Board in advance of the appointment. Vacancies among members nominated by the CGIAR and among the members-at-large by reason of their retirement, death, incapacity or any other cause shall be filled in the same manner as the original appointments. A new member appointed to replace a member during the latter's term may be appointed for the remaining term of the member being replaced or for some other term of no more than three years. 
3. The members of the Board are eligible for reappointment for a second term but shall not serve more than two successive terms, except that the member elected as Chairperson may have her/his term extended by the Board in order to coincide with her/his appointment as Chairperson, provided that no member shall serve for more than eight consecutive years on the Board. To ensure continuity of policies and operations, members shall serve staggered terms as determined by the Board.

4. The members of the Board - other than the ex-officio members - serve in a personal capacity and shall not be considered, nor shall they act, as official representatives of governments or organizations.

5. The term of office and the selection of the member appointed by the host country shall be determined by the host country.

6. Regard shall be paid especially to proposed members' professional experience and qualifications, to appropriate geographical distribution, and to organizations or countries which have concern for and provide substantial support to the Center. Approximately one-half of all Board members shall come from developing countries covered by CIFOR's activities.

7. The Center shall provide a Secretary to the Board from among the senior staff of CIFOR, on nomination of the Director General and selection by the Board.

\section{Article 10}

\section{The Founding Board}

1. The Founding Board shall consist of fifteen members, selected as follows:

(a) three voting members selected by the members of the CGIAR as their nominees;

(b) up to eleven voting members selected by the members of the CGIAR in accordance with Article 9 , paragraph 6; and

(c) the Chairperson of the Board of Trustees of the ICRAF, as an ex-officio voting member.

2. Following the conclusion of a headquarters agreement between CIFOR and its host country, the host country may appoint an ex-officio member to serve as a voting member of the Founding Board.

3. The Founding Board shall elect a Director General of CIFOR in accordance with Article 14, paragraph 1, to serve on the Founding Board as an ex-officio non-voting member.

4. At the inaugural meeting of the Founding Board a Chairperson shall be elected in accordance with Article 13, paragraph 1 , below.

5. Founding members of the Board (those referred to in subparagraphs 1(a) and (b)), may serve for a minimum period of three years and a maximum of six years. At the end of the first three year period one half of the Board members shall retire. The order of retirement shall be determined by the Board.

6. When a vacancy occurs amongst members of the Founding Board, such vacancy shall be filled as follows:

(a) Non-ex-officio voting members shall be replaced by election by the Board in accordance with Article 12.

(b) The Chairperson shall be re-elected in accordance with Article 13.

(c) Ex-officio members of the Board shall be reappointed in the same manner as their original appointments.

Subsequent appointments to the Board shall be made in accordance with Article 9 . 


\section{Article 11}

\section{Functions and powers of the Board}

1. The Board shall govern CIFOR in all affairs of the Center. Its role shall be to ensure that:

(a) the Center has objectives, programs and plans that are consistent with its purpose;

(b) the Center is managed effectively by the Director General in harmony with the agreed objectives, programs and budgets, and in accordance with legal and regulatory requirements; and

(c) the future well-being of CIFOR is not jeopardized by exposing its financial resources, its staff or its credibility to imprudent risks.

2. To this end, the Board shall have the following duties:

(a) definition of objectives and approval of plans to meet the Center's purpose and to monitor the achievement of this purpose;

(b) specification of policies to be followed by the Director General in pursuing the specified objectives;

(c) appointment of the Director General, determination of her/his terms of employment, monitoring her/his performance and dismissal of the Director General if her/his performance is inadequate;

(d) approval of the Center's broad organizational framework;

(e) approval of personnel policies including scales of salaries and benefits;

(f) determination of priorities relating to major elements within and between the Center's programs;

(g) approval of the Center's program and budget and the Center's Annual Report;

(h) ensuring the Center's cost-effectiveness, financial integrity and accountability;

(i) appointment of an external auditor and approval of an annual audit plan;

(j) approval of an investment policy and monitoring of its implementation;

(k) overseeing of major borrowing, major expansion including the acquisition of major equipment and facilities, and the disposal of major assets;

(1) ensuring that due consideration is given to the recommendations and suggestions made by reviews pertinent to the Center's operation and activities;

(m) ensuring that Board members have no conflict of interest;

(n) maintaining the composition of the Board with respect to the expertise needed to discharge the full range of its responsibilities, and monitoring and evaluating the performance of the Center; and

(o) perform all other acts that may be considered necessary, suitable and proper for the attainment of the purpose of the Center as set forth in Article 4 hereof.

3. The Board shall designate an Executive Committee of its members which shall have the power to act for the Board in the interim between Board meetings, and on matters which the Board delegates to it. All interim actions of the executive committee shall be reported to the full Board at its next meeting.

4. The Board may establish such other subsidiary committees as it deems necessary for the performance of its functions. 
5. The Board shall ensure that appropriate mechanisms are in place for adequate consultation with recognized international stakeholders.

6. The Director General of ICRAF may be invited to be an observer on the Board, for as long as reciprocity of such arrangement is agreed with ICRAF.

\section{Article 12}

\section{Voting by the Board}

Voting by the Board of Trustees is regulated as follows:

(a) each member of the Board has one vote, except the Director General who has no vote;

(b) the Chairperson of the Board has a casting vote; and

(c) decisions of the Board shall be made by a majority of the voting members present except as specified otherwise in this Constitution.

\section{Article 13}

\section{Procedure of the Board}

1. The Board shall elect one member as Chairperson from among the non-ex-officio members. The normal term of the Chairperson shall be three years. The Board may re-elect its Chairperson for a second term of not more than three years, provided that total Board membership shall not exceed eight years at the expiry of such second term.

2. The Board shall meet at least once annually.

3. The Board shall adopt its own rules of procedure, consistent with this Constitution.

4. A majority of the members shall constitute a quorum for Board meetings.

\section{Article 14}

Appointment of the Director General

1. The appointment of the Director General of CIFOR, her/his term of office, and any termination for cause shall be decided by a two-thirds majority of all voting members of the Board.

2. The Director General shall be appointed initially for a fixed term not exceeding five years with a substantive review of the Director General's performance before the end of that term. The appointment may be renewed for a second term to be determined by the Board.

\section{Article 15}

\section{Functions and powers of the Director General}

1. The Director General is responsible to the Board for the operation and management of CIFOR and for assuring that its programs and objectives are properly developed and carried out. The Director General is the Chief Executive Officer of the Center.

2. The Director General shall implement the policies determined by the Board, follow the guidelines laid down by the Board for the functioning of the Center and carry out the directions of the Board. Specifically, the Director General shall:

(a) develop strategic and operational plans for the functioning of the Center and keep these plans under continuing review; 
(b) develop program and budget submissions and prepare the Center's Annual Report;

(c) supervise the planning and direction of the Center's research programs and other activities to ensure effective programming and project implementation, analysis and evaluation of on-going programs and to provide vision and insight into global problems in developing strategies for future programs;

(d) recruit and manage highly qualified and appropriately experienced staff;

(e) keep and have available for review by the Board and other appropriate parties, financial accounts and other records on a current basis;

(f) keep the Chairperson of the Board advised on matters of consequence that relate to the Center; and

(g) perform such other functions as are delegated to her/him by the Board.

3. The Director General is the legal representative of CIFOR and is authorized by the Board to sign all deeds, contracts, agreements, and other legal documents which are necessary to ensure the normal operation of the Center. The Board may stipulate the extent to which these powers may be delegated by the Director General. Such delegation shall be evidenced by an instrument in writing, naming the person(s) or position(s) to whom the delegation is made. Contracts and agreements which affect the governance, objectives, location, expansion or dissolution of CIFOR, or major issues of the relationship with the host country, shall be subject to approval by the Board.

\section{Article 16}

Staffing

1. The paramount consideration in the employment of staff and in the determination of the conditions of service shall be the necessity of securing the highest standards of quality, efficiency, competence and integrity.

2. The staff shall be appointed by the Director General under staff regulations approved by the Board.

3. Employment practices of CIFOR shall not discriminate on the basis of gender, race, creed, colour, age, marital status or sexual preference.

4. Salary scales, insurance, pension schemes and any other terms of employment shall be laid down in staff regulations.

\section{Article 17 \\ Financing}

1. The financial operations of the Center shall be governed by financial regulations to be adopted by the Board.

2. The regular budget of the Center shall be funded primarily by members of the CGIAR.

3. In accordance with Article 19, the Center may enter into financial arrangements with other sources to implement its program.

4. The budget of the Center shall be subject to annual approval by the Board.

5. A full financial audit of the operations of the Center shall be conducted on an annual basis by an independent international accounting firm appointed by the Board upon recommendation by the Director General. The results of such audits shall be made available by the Director General to the Board for its consideration and approval, and to those CGLAR members funding the Center. 


\section{Article 18 \\ Relationship with the CGIAR}

CIFOR is an International Research Center within the CGIAR system. As such, the Center shall provide the CGIAR with details of its program and budget as approved by the Board. In addition, the Board shall arrange for periodic review of its program and of its management by an independent review panel appointed in consultation with the CGIAR.

Article 19

Relationships with other Organizations

In order to achieve its objectives in the most efficient way, CIFOR may enter into agreements for cooperation with relevant national, regional or international organizations, foundations, agencies and institutions.

\section{Article 20 \\ Rights, privileges and immunities}

1. CIFOR shall make arrangements with its host country to ensure that the Center, its staff members and official visitors shall enjoy in the territory of the host country the same rights, privileges and immunities as are customarily accorded to other international organizations, their officials, staff and official visitors. Such rights, privileges and immunities shall be specifically defined in a Headquarters Agreement with the host country.

2. Similarly, CIFOR may, pursuant to Article 7, subparagraph 1(c), of this Constitution, enter into agreements or arrangements with the other countries in which it works for the purpose of granting CIFOR, its officials and staff such privileges and immunities as are required for such work.

3. The privileges and immunities referred to in the preceding paragraphs are to be provided solely to ensure in all circumstances the unimpeded functioning of CIFOR, and the complete independence of the persons to whom they are accorded.

\section{Article 21}

\section{Amendments}

This Constitution may be amended by the Board by a three-fourths majority of all voting members of the Board, provided notice of such a proposed amendment together with its full text shall have been mailed to all members of the Board at least eight weeks in advance of meetings, or such notice is waived by all voting members of the Board. Amendments of fundamental provisions of the Constitution shall be, in addition, subject to approval by the Parties to the Establishment Agreement in accordance with Article 5 of that Agreement. Those provisions shall include: the status, country of location and the purpose of the Center, the number and method of selection of the Board members, and the dissolution of CIFOR.

\section{Article 22 \\ Dissolution}

1. Subject to approval of a majority of the Parties to the Establishment Agreement, CIFOR may be dissolved by a three-fourths majority of all voting members of the Board, if it is determined that the purpose of CIFOR has been achieved to a satisfactory degree or if it is determined that CIFOR will no longer be able to function effectively.

2. Upon dissolution, any remaining debts, liabilities or obligations of the Center shall be subject to Article 2 of the Establishment Agreement. In case of dissolution, the deposition of assets other than land and fixed capital improvements thereon, shall be determined by the Parties to the Establishment Agreement, who have made a financial contribution to the Center in the financial year prior to dissolution (hereafter "the contributors"), after receiving recommendations from the Board. The disposition of any land and permanent fixed capital improvements thereon shall, upon dissolution, be similarly determined by the contributors, subject to the relevant provisions of the 
Headquarters Agreement with the host country. Upon dissolution of CIFOR, the assets of the Center - excluding the land and fixed capital improvements thereon - shall firstly be used for paying for, or making provisions for, payment of all the liabilities and debts of the Center. Following payment of such liabilities, any remaining assets of CIFOR shall be disposed of by the contributors exclusively for the purposes of the Center in such a manner, or to such organization or organizations, dedicated to and operated exclusively for educational or scientific purposes as the contributors shall determine. Any such assets not disposed of in accordance with the provisions of this Article, shall be disposed of in accordance with the relevant laws of the jurisdiction in which the headquarters of CIFOR are located. 


\title{
Agreement Establishing the South Pacific Regional Environment Programme (SPREP), Apia, 1993
}

\author{
Done at Apia 16 June 1993 \\ Entered into force 31 August 1995* \\ Depositary: Western Samoa \\ Primary source citation: Copy of text provided by the \\ U.S. Department of State
}

\section{AGREEMENT ESTABLISHING THE SOUTH PACIFIC REGIONAL ENVIRONMENT PROGRAMME (SPREP)}

\author{
Certified as True Copies of the Original. \\ [Signature] \\ (Mose Pouvi Sua) \\ SECRETARY FOR FOREIGN AFFAIRS
}

[seal]

\section{THE PARTIES,}

Recognising the importance of protecting the environment and conserving the natural resources of the South Pacific region;

Conscious of their responsibility to preserve their natural heritage for the benefit and enjoyment of present and future generations and their role as custodians of natural resources of global importance;

Recognising the special hydrological, geological, atmospheric and ecological characteristics of the region which require special care and responsible management;

Seeking to ensure that resource development takes proper account of the need to protect and preserve the unique environmental values of the region and of the principles of sustainable development;

Recognising the need for co-operation within the region and with competent international, regional and sub-regional organisations in order to ensure coordination and co-operation in efforts to protect the environment and use the natural resources of the region on a sustainable basis;

Wishing to establish a comprehensive Programme to assist the region in maintaining and improving its environment and to act as the central coordinating point for environmental protection measures within the region;

\footnotetext{
* This agreement has not been ratified by and is therefore not yet in force for the United States.
} 
Recalling the decision taken at the Conference on the Human Environment in the South Pacific, held at Rarotonga, Cook Islands, on 8-11 March 1982, to establish the South Pacific Regional Environment Programme as a separate entity within the South Pacific Commission;

Recalling with appreciation the role of UNEP, ESCAP, the South Pacific Forum and the South Pacific Conference in supporting the establishment and encouraging the development of the South Pacific Regional Environment Programme as a regional programme and as part of the UNEP Regional Seas Programme;

Noting with satisfaction that the Convention for the Protection of the Natural Resources and Environment of the South Pacific Region, done at Noumea on 24 November 1986, and its related Protocols, and the Convention on Conservation of Nature in the South Pacific, done at Apia on 12 June 1976, entered into force in 1990;

Appreciative of the valuable efforts that have been undertaken by the South Pacific Regional Environment Programme to promote environmental protection within the region and the support given to the Programme by the South Pacific Commission;

Taking into account the decisions of the Third and Fourth Intergovernmental Meetings of the South Pacific Regional Environment Programme, held in Noumea in September 1990 and July 1991, and the endorsement of the Thirtieth South Pacific Conference, held in Noumea in October 1990; and

Desiring to accord the South Pacific Regional Environment Programme the full and formal legal status necessary to operate as an autonomous body, to manage fully its own affairs and to provide the basis for the continued operation of SPREP in accordance with the traditions of cooperation in the region;

\section{HAVE AGREED AS FOLLOWS:}

\section{Article 1}

\section{Establishment of SPREP}

1. The South Pacific Regional Environment Programme (hereinafter referred to as SPREP) is hereby established as an intergovernmental organisation.

2. The organs of SPREP are the SPREP Meeting and the Secretariat.

3. The Secretariat shall be located in Apia, Western Samoa, unless the SPREP Meeting decides otherwise.

\section{Article 2}

\section{Purposes}

1. The purposes of SPREP are to promote co-operation in the South Pacific region and to provide assistance in order to protect and improve its environment and to ensure sustainable development for present and future generations. SPREP shall achieve these purposes through the Action Plan adopted from time to time by the SPREP Meeting, setting the strategies and objectives of SPREP.

2. The Action Plan shall include:

(a) co-ordinating regional activities addressing the environment;

(b) monitoring and assessing the state of the environment in the region including the impacts of human activities on the ecosystems of the region and encouraging development undertaken to be directed towards maintaining or enhancing environmental qualities; 
(c) promoting and developing programmes, including research programmes, to protect the atmosphere and terrestrial, freshwater, coastal and marine ecosystems and species, while ensuring ecologically sustainable utilisation of resources;

(d) reducing, through prevention and management, atmospheric, land based, freshwater and marine pollution;

(e) strengthening national and regional capabilities and institutional arrangements;

(f) increasing and improving training, educational and public awareness activities; and

(g) promoting integrated legal, planning and management mechanisms.

\title{
Article 3
}

\section{SPREP Meetings}

1. The SPREPMeeting shall be open to the Membership of the Parties to this Agreement and, with the appropriate authorisation of the Party having responsibility for its international affairs, of each of the following:

\author{
American Samoa \\ French Polynesia \\ Guam \\ New Caledonia \\ Northern Mariana Islands \\ Palau \\ Tokelau \\ Wallis and Futuna.
}

2. The SPREP Meeting shall be held at such times as the SPREP Meeting may determine. A special SPREP Meeting may be held at any time as provided in the Rules of Procedure.

3. The SPREP Meeting shall be the plenary body and its functions shall be:

(a) to provide a forum for Members to consult on matters of common concern with regard to the protection and improvement of the environment of the South Pacific region and, in particular, to further the purposes of SPREP;

(b) to approve and review the Action Plan for SPREP and to determine the general policies of SPREP;

(c) to adopt the report of the Director on the operation of SPREP;

(d) to adopt the work programmes of SPREP and review progress in their implementation;

(e) to adopt the Budget estimates of SPREP;

(f) to make recommendations to Members;

(g) to appoint the Director;

(h) to give directions to the Director concerning the implementation of the Work Programme;

(i) to approve rules and conditions for the appointment of the staff of the Secretariat; and

(j) to carry out such other functions as are specified in this Agreement or are necessary for the effective functioning of SPREP. 
4. The SPREP Meeting may establish such committees and subcommittees and other subsidiary bodies as it considers necessary.

5. In addition to the functions referred to in paragraph (3) of this Article, the SPREP Meeting shall, through such mechanisms as it considers appropriate, consult and co-operate with the Meetings of Parties to:

(a) the Convention on Conservation of Nature in the South Pacific adopted at Apia on 12 June 1976;

(b) the Convention for the Protection of the Natural Resources and Environment of the South Pacific Region adopted at Noumea on 24 November 1986 and related Protocols; and

(c) any other international or regional Agreement that may be concluded for the protection of the environment of the South Pacific region,

with a view to ensuring the achievement of the purpose of SPREP and of this Agreement and facilitating the achievement of the purposes of those Conventions.

\section{Article 4}

\section{Meeting Procedure}

1. The SPREP Meeting shall elect from among its Members a Chairperson and such other officers as it decides, who shall remain in office until the next SPREP Meeting. In principle, the role of the Chairperson shall rotate as decided by the SPREP Meeting.

2. The SPREP Meeting shall adopt its own Rules of Procedure.

3. (a) The Parties shall ensure the full involvement of all Members in the work of the SPREP Meeting. The work of the SPREP Meeting shall be conducted on the basis of consensus of all Members, taking into account the practices and procedures of the South Pacific region.

(b) In the event that a decision is required in the SPREP Meeting, that decision shall be taken by a consensus of the Parties. The consensus of the Parties shall ensure that the views of all Members of the SPREP Meeting have been properly considered and taken into account in reaching that consensus.

4. The attendance by observers in SPREP Meetings shall be provided for in the Rules of Procedure.

5. The SPREP Meeting shall be convened by the Director.

6. The working languages of SPREP shall include English and French.

\section{Article 5}

\section{Budget}

1. The Budget estimates for SPREP shall be prepared by the Director.

2. Adoption of the Budget of SPREP and determination of all other questions relating to the Budget shall be by consensus.

3. The SPREP Meeting shall adopt financial regulations for the administration of SPREP. Such regulations may authorise SPREP to accept contributions from private and public sources. 


\section{Article 6}

\section{Director}

1. The Director of SPREP shall be the head of the Secretariat.

2. The Director shall appoint staff to the Secretariat in accordance with such rules and conditions as the SPREP Meeting may determine.

3. The Director shall report annually to the South Pacific Conference and the South Pacific Forum on the activities of SPREP.

4. The Director shall be responsible to the SPREP Meeting for the administration and management of SPREP and such other functions as the SPREP Meeting may decide.

\section{Article 7}

\section{Functions of the Secretariat}

1. The functions of the Secretariat shall be to implement the activities of SPREP, which shall include:

(a) to promote, undertake and co-ordinate the implementation of the SPREP Action Plan through the annual Programmes of Work, and review and report regularly on progress thereon to Members;

(b) to carry out research and studies as required to implement the SPREP Action Plan through the annual Programmes of Work;

(c) to advise and assist Members on the implementation of activities carried out under the SPREP Action Plan or consistent with its purpose;

(d) to provide a means of regular consultation among Members on the implementation of activities under the SPREP Action Plan and on other relevant issues;

(e) to co-ordinate and establish working arrangements with relevant national, regional and international organisations;

(f) to gather and disseminate relevant information for Members and other interested Governments and organisations;

(g) to promote the development and training of personnel of Members and to promote public awareness and education, including the publication of materials;

(h) to assist Members in the acquisition, interpretation and evaluation of scientific and technical data and information;

(i) to undertake such other activities and follow such procedures as the SPREP Meeting may decide; and

(j) to seek financial and technical resources for SPREP.

2. In addition to the functions described in paragraph (1) of this Article, the Secretariat shall be responsible for the co-ordination and implementation of any functions that the SPREP Meeting may agree to undertake relating to:

(a) the Convention on Conservation of Nature in the South Pacific; 
(b) the Convention for the Protection of the Natural Resources and Environment of the South Pacific Region, the Protocol for the Prevention of Pollution of the South Pacific Region by Dumping, and the Protocol Concerning Co-operation in Combating Pollution Emergencies in the South Pacific Region; and

(c) any other international or regional Agreement that may be concluded for the protection of the environment of the South Pacific region.

\section{Article 8}

\section{Legal Status, Privileges and Immunities}

1. SPREP shall have such legal personality as is necessary for it to carry out its functions and responsibilities and, in particular, shall have the capacity to contract, to acquire and dispose of moveable and immoveable property and to sue and be sued.

2. SPREP, its officers and employees, together with representatives to the SPREP Meeting, shall enjoy such privileges and immunities necessary for the fulfilment of their functions, as may be agreed between SPREP and the Party in whose territory the Secretariat is located, and as may be provided by other Parties.

\section{Article 9}

\section{Sovereign Rights and Jurisdiction of States}

Nothing in this Agreement shall be interpreted as prejudicing the sovereignty of the Parties over their territory, territorial sea, internal or archipelagic waters, or their sovereign rights:

(a) in their exclusive economic zones and fishing zones for the purpose of exploring or exploiting, conserving and managing the natural resources, whether living or non-living, of the waters superjacent to the sea-bed and of the sea-bed and its subsoil, and with regard to other activities for the economic exploitation and exploration of the zone; or

(b) over their continental shelves for the purpose of exploring them and exploiting the natural resources thereof.

\section{Article 10}

\section{Signature, Ratification, Acceptance, Approval and Accession}

1. This Agreement shall be open for signature from the sixteenth day of June 1993 until the sixteenth day of June 1994, and shall thereafter remain open for accession, by:

\begin{tabular}{|c|c|c|}
\hline Australia & $\begin{array}{l}\text { Republic of the } \\
\text { Marshall Islands }\end{array}$ & Kingdom of Tonga \\
\hline Cook Islands & H & Tuvalu \\
\hline $\begin{array}{l}\text { Federated States } \\
\text { of Micronesia }\end{array}$ & New Zealand & $\begin{array}{l}\text { United Kingdom of } \\
\text { Great Britain and } \\
\text { Northern Ireland on }\end{array}$ \\
\hline Republic of Fiji & Niue & $\begin{array}{l}\text { behalf of Pitcairn } \\
\text { Islands }\end{array}$ \\
\hline Republic of France & Papua New Guinea & \\
\hline Republic of Kiribati & Solomon Islands & $\begin{array}{l}\text { United States of } \\
\text { America }\end{array}$ \\
\hline
\end{tabular}

Republic of Vanuatu

Western Samoa. 
2. This Agreement is subject to ratification, acceptance, or approval by the Signatories.

3. Reservations to this Agreement shall not be permitted.

4. This Agreement shall enter into force thirty days from the date of deposit of the tenth instrument of ratification, acceptance, approval, or accession with the Depositary, and thereafter for each State, thirty days after the date of deposit of its instrument of ratification, acceptance, approval, or accession with the Depositary.

5. Following the expiry of the period when this Agreement is open for signature, and provided that this Agreement has entered into force, this Agreement shall be open for accession by any State other than those referred to in this Article which, desiring to accede to this Agreement, may so notify the Depositary, which shall in turn notify the Parties. In the absence of a written objection by a Party within six months of receipt of such notification, a State may accede by deposit of an instrument of accession with the Depositary, and accession shall take effect thirty days after the date of deposit.

6. The Government of Western Samoa is hereby designated as the Depositary.

7. The Depositary shall transmit certified copies of this Agreement to all Members and shall register this Agreement in accordance with Article 102 of the Charter of the United Nations.

\section{Article 11}

\section{Amendment and Withdrawal}

1. Any Party may propose amendments to this Agreement for consideration by the SPREP Meeting. The text of any amendment shall be circulated to Members no less than six months in advance of the Meeting at which it is to be considered.

2. An amendment shall be adopted at a SPREP Meeting by consensus of all Parties attending the SPREPMeeting and shall enter into force thirty days after the receipt by the Depositary of instruments of ratification, acceptance or approval of that amendment by all Parties.

3. Any Party to this Agreement may withdraw from this Agreement by giving written notice to the Depositary. Withdrawal shall take effect one year after receipt of such notice by the Depositary.

IN WITNESS WHEREOF the undersigned, being duly authorised by their respective Governments, have signed this Agreement.

Done at Apia this sixteenth day of June 1993 in a single copy in the English and French languages, the two texts being equally authentic.

For the Government of Australia:

this ___ day of ___ 1993

For the Government of the Cook Islands:
this day of 1993

For the Government of the Federated States of Micronesia:

this day of 
For the Government of the Republic of Fiji:

For the Government of the Republic of France:

For the Government of the Republic of Kiribati:

For the Government of the Republic of the Marshall Islands:

For the Government of the Republic of Nauru:

For the Government of New Zealand:

For the Government of Niue:

For the Government of Papua New Guinea:

For the Government of Solomon Islands:

For the Government of the Kingdom of Tonga:

\section{[Signature]}

this 16th day of June 1993

\section{[Signature]}

this 16 th day of June 1993

\section{[Signature]}

this 16 th day of June 1993

\section{[Signature]}

this 16th day of June 1993

\section{[Signature]}

this 16th day of June 1993

this day of 1993

[Signature]

this 16th day of June 1993

[Signature]

this 16 th day of June 1993

[Signature]

this 16th day of June 1993

this day of 1993 
For the Government of Tuvalu:

\section{For the Government of the United Kingdom of Great Britain and Northern Ireland on behalf of Pitcairn Islands:}

For the Government of the United States of America:

For the Government of the Republic of Vanuatu:

For the Government of Western Samoa:

\section{[Signature]}

this 16th day of June 1993

this day of 1993

\section{[Signature]}

this 16 th day of June 1993

\section{[Signature]}

this 16 th day of June 1993

\section{[Signature]}

this 16 th day of June 1993 


\section{International Tropical Timber Agreement, Geneva, 1994}

Done at Geneva 26 January 1994

Entered into force 1 February 1995

Depositary: United Nations

Primary source citation: Copy of text provided by the

U.S. Department of State

\section{INTERNATIONAL TROPICAL TIMBER AGREEMENT 1994}

\section{UNITED NATIONS \\ 1994}

\section{PREAMBLE}

The Parties to this Agreement,

Recalling the Declaration and the Programme of Action on the Establishment of ANew International Economic Order; the Integrated Programme for Commodities; ANew Partnership for Development: the Cartagena Commitment and the relevant objectives contained in the Spirit of Cartagena,

Recalling the International Tropical Timber Agreement, 1983, and recognizing the work of the International Tropical Timber Organization and its achievements since its inception, including a strategy for achieving international trade in tropical timber from sustainably managed sources,

Recalling further the Rio Declaration on Environment and Development, the Non-Legally Binding Authoritative Statement of Principles for a Global Consensus on the Management, Conservation and Sustainable Development of all Types of Forests, and the relevant Chapters of Agenda 21 as adopted by the United Nations Conference on Environment and Development in June 1992, in Rio de Janeiro; the United Nations Framework Convention on Climate Change; and the Convention on Biological Diversity,

Recognizing the importance of timber to the economies of countries with timber-producing forests,

Further recognizing the need to promote and apply comparable and appropriate guidelines and criteria for the management, conservation and sustainable development of all types of timber-producing forests,

Taking into account the linkages of tropical timber trade and the international timber market and the need for taking a global perspective in order to improve transparency in the international timber market, 
Noting the commitment of all members, made in Bali, Indonesia, in May 1990, to achieve exports of tropical timber products from sustainably managed sources by the year 2000 and recognizing Principle 10 of the Non-Legally Binding Authoritative Statement of Principles for a Global Consensus on the Management, Conservation and Sustainable Development of all Types of Forests which states that new and additional financial resources should be provided to developing countries to enable them to sustainably manage, conserve and develop their forests, including through afforestation, reforestation and combatting deforestation and forest and land degradation,

Noting also the statement of commitment to maintain, or achieve by the year 2000 , the sustainable management of their respective forests made by consuming members who are parties to the International Tropical Timber Agreement, 1983 at the fourth session of the United Nations Conference for the Negotiation of a Successor Agreement to the International Tropical Timber Agreement, 1983 in Geneva on 21 January 1994,

Desiring to strengthen the framework of international cooperation and policy development between members in finding solutions to the problems facing the tropical timber economy,

Have agreed as follows:

\section{CHAPTER I. OBJECTIVES}

\section{Article 1}

Objectives

Recognizing the sovereignty of members over their natural resources, as defined in Principle 1 (a) of the Non-Legally Binding Authoritative Statement of Principles for a Global Consensus on the Management, Conservation and Sustainable Development of all Types of Forests, the objectives of the International Tropical Timber Agreement, 1994 (hereinafter referred to as "this Agreement") are:

(a) To provide an effective framework for consultation, international cooperation and policy development among all members with regard to all relevant aspects of the world timber economy;

(b) To provide a forum for consultation to promote non-discriminatory timber trade practices;

(c) To contribute to the process of sustainable development;

(d) To enhance the capacity of members to implement a strategy for achieving exports of tropical timber and timber products from sustainably managed sources by the year 2000 ;

(e) To promote the expansion and diversification of international trade in tropical timber from sustainable sources by improving the structural conditions in international markets, by taking into account, on the one hand, a long-term increase in consumption and continuity of supplies, and, on the other, prices which reflect the costs of sustainable forest management and which are remunerative and equitable for members, and the improvement of market access;

(f) To promote and support research and development with a view to improving forest management and efficiency of wood utilization as well as increasing the capacity to conserve and enhance other forest values in timber-producing tropical forests;

(g) To develop and contribute towards mechanisms for the provision of new and additional financial resources and expertise needed to enhance the capacity of producing members to attain the objectives of this Agreement;

(h) To improve market intelligence with a view to ensuring greater transparency in the international timber market, including the gathering, compilation, and dissemination of trade-related data, including data related to species being traded; 
(i) To promote increased and further processing of tropical timber from sustainable sources in producing member countries with a view to promoting their industrialization and thereby increasing their employment opportunities and export earnings;

(j) To encourage members to support and develop industrial tropical timber reforestation and forest management activities as well as rehabilitation of degraded forest land, with due regard for the interests of local communities dependent on forest resources;

(k) To improve marketing and distribution of tropical timber exports from sustainable managed sources;

(1) To encourage members to develop national policies aimed at sustainable utilization and conservation of timber-producing forests and their genetic resources and at maintaining the ecological balance in the regions concerned, in the context of tropical timber trade;

(m) To promote the access to, and transfer of, technologies and technical cooperation to implement the objectives of this Agreement, including on concessional and preferential terms and conditions, as mutually agreed; and

(n) To encourage information-sharing on the international timber market.

\section{CHAPTER II. DEFINITIONS}

\section{Article 2}

\section{Definitions}

For the purposes of this Agreement:

1. "Tropical timber" means non-coniferous tropical wood for industrial uses, which grows or is produced in the countries situated between the Tropic of Cancer and the Tropic of Capricorn. The term covers logs, sawnwood, veneer sheets and plywood. Plywood which includes in some measure conifers of tropical origin shall also be covered by this definition;

2. "Further processing" means the transformation of logs into primary wood products, semi-finished and finished products made wholly or almost wholly of tropical timber;

3. "Member" means a Government or an intergovernmental organization referred to in article 5 which has consented to be bound by this Agreement whether it is in force provisionally or definitively;

4. "Producing member" means any country with tropical forest resources and/or a net exporter of tropical timber in volume terms which is listed in annex A and which becomes a party to this Agreement, or any country with tropical forest resources and/or a net exporter of tropical timber in volume terms which is not so listed and which becomes a party to this Agreement and which the Council, with the consent of that country, declares to be a producing member;

5. "Consuming member" means any country listed in annex B which becomes a party to this Agreement, or any country not so listed which becomes a party to this Agreement and which the Council, with the consent of that country, declares to be a consuming member;

6. "Organization" means the International Tropical Timber Organization established in accordance with article 3;

7. "Council" means the International Tropical Timber Council established in accordance with article 6;

8. "Special vote" means a vote requiring at least two thirds of the votes cast by producing members present and voting and at least 60 per cent of the votes cast by consuming members present and voting, counted separately, on 
condition that these votes are cast by at least half of the producing members present and voting and at least half of the consuming members present and voting;

9. "Simple distributed majority vote" means a vote requiring more than half of the votes cast by producing members present and voting and more than half of the votes cast by consuming members present and voting, counted separately;

10. "Financial year" means the period from 1 January to 31 December inclusive;

11. "Freely usable currencies" means the deutsche mark, the French franc, the Japanese yen, the pound sterling, the United States dollar and any other currency which has been designated from time to time by a competent international monetary organization as being in fact widely used to make payments for international transactions and widely traded in the principal exchange markets.

\section{CHAPTER III. ORGANIZATION AND ADMINISTRATION}

\section{Article 3 \\ Headquarters and structure of the International Tropical Timber Organization}

1. The International Tropical Timber Organization established by the International Tropical Timber Agreement, 1983 shall continue in being for the purposes of administering the provisions and supervising the operation of this Agreement.

2. The Organization shall function through the Council established under article 6, the committees and other subsidiary bodies referred to in article 26 and the Executive Director and staff.

3. The headquarters of the Organization shall be in Yokohama, unless the Council, by special vote, decides otherwise.

4. The headquarters of the Organization shall at all times be located in the territory of a member.

\section{Article 4}

\section{Membership in the Organization}

There shall be two categories of membership in the Organization, namely:

(a) Producing; and

(b) Consuming.

\section{Article 5}

\section{Membership by intergovernmental organizations}

1. Any reference in this Agreement to "Governments" shall be construed as including the European Community and any other intergovernmental organization having responsibilities in respect of the negotiation, conclusion and application of international agreements, in particular commodity agreements. Accordingly, any reference in this Agreement to signature, ratification, acceptance or approval, or to notification of provisional application, or to accession shall, in the case of such intergovernmental organizations, be construed as including a reference to signature, ratification, acceptance or approval, or to notification of provisional application, or to accession, by such intergovernmental organizations. 
2. In the case of voting on matters within their competence, such intergovernmental organizations shall vote with a number of votes equal to the total number of votes attributable to their member States in accordance with article 10. In such cases, the member States of such intergovernmental organizations shall not be entitled to exercise their individual voting rights.

\section{CHAPTER IV. INTERNATIONAL TROPICAL TIMBER COUNCIL}

\section{Article 6 \\ Composition of the International Tropical Timber Council}

1. The highest authority of the Organization shall be the International Tropical Timber Council, which shall consist of all the members of the Organization.

2. Each member shall be represented in the Council by one representative and may designate alternates and advisers to attend sessions of the Council.

3. An alternate representative shall be empowered to act and vote on behalf of the representative during the latter's absence or in special circumstances.

\section{Article 7}

\section{Powers and functions of the Council}

1. The Council shall exercise all such powers and perform or arrange for the performance of all such functions as are necessary to carry out the provisions of this Agreement.

2. The Council shall, by special vote, adopt such rules and regulations as are necessary to carry out the provisions of this Agreement and as are consistent therewith, including its own rules of procedure and the financial rules and staff regulations of the Organization. Such financial rules shall, inter alia, govern the receipt and expenditure of funds under the Administrative Account, the Special Account and the Bali Partnership Fund. The Council may, in its rules of procedure, provide for a procedure whereby it may, without meeting, decide specific questions.

3. The Council shall keep such records as are required for the performance of its functions under this Agreement.

\section{Article 8}

\section{Chairman and Vice-Chairman of the Council}

1. The Council shall elect for each calendar year a Chairman and a Vice-Chairman, whose salaries shall not be paid by the Organization.

2. The Chairman and the Vice-Chairman shall be elected, one from among the representatives of producing members and the other from among the representatives of consuming members. These offices shall alternate each year between the two categories of members, provided, however, that this shall not prohibit the re-election of either or both, under exceptional circumstances, by special vote of the Council.

3. In the temporary absence of the Chairman, the Vice-Chairman shall act in his place. In the temporary absence of both the Chairman and the Vice-Chairman, or in the absence of one or both of them for the rest of the term for which they were elected, the Council may elect new officers from among the representatives of the producing members and/or from among the representatives of the consuming members, as the case may be, on a temporary basis or for the rest of the term for which the predecessor or predecessors were elected. 


\section{Article 9}

\section{Sessions of the Council}

1. As a general rule, the Council shall hold at least one regular session a year.

2. The Council shall meet in special session whenever it so decides or at the request of:

(a) The Executive Director, in agreement with the Chairman of the Council; or

(b) A majority of producing members or a majority of consuming members; or

(c) Members holding at least 500 votes.

3. Sessions of the Council shall be held at the headquarters of the organization unless the Council, by special vote, decides otherwise. If on the invitation of any member the Council meets elsewhere than at the headquarters of the Organization, that member shall pay the additional cost of holding the meeting away from headquarters.

4. Notice of any sessions and the agenda for such sessions shall be communicated to members by the Executive Director at least six weeks in advance, except in cases of emergency, when notice shall be communicated at least seven days in advance.

\section{Article 10}

\section{Distribution of votes}

1. The producing members shall together hold 1,000 votes and the consuming members shall together hold 1,000 votes.

2. The votes of the producing members shall be distributed as follows:

(a) Four hundred votes shall be distributed equally among the three producing regions of Africa, Asia-Pacific and Latin America. The votes thus allocated to each of these regions shall then be distributed equally among the producing members of that region;

(b) Three hundred votes shall be distributed among the producing members in accordance with their respective shares of the total tropical forest resources of all producing members; and

(c) Three hundred votes shall be distributed among the producing members in proportion to the average of the values of their respective net exports of tropical timber during the most recent three-year period for which definitive figures are available.

3. Notwithstanding the provisions of paragraph 2 of this article, the total votes allocated to the producing members from the African region, calculated in accordance with paragraph 2 of this article, shall be distributed equally among all producing members from the African region. If there are any remaining votes, each of these votes shall be allocated to a producing member from the African region: the first to the producing member which is allocated the highest number of votes calculated in accordance with paragraph 2 of this article, the second to the producing member which is allocated the second highest number of votes, and so on until all the remaining votes have been distributed.

4. For purposes of the calculation of the distribution of votes under paragraph 2 (b) of this article, "tropical forest resources" means productive closed broad-leaved forests as defined by the Food and Agriculture Organization (FAO).

5. The votes of the consuming members shall be distributed as follows: each consuming member shall have 10 initial votes: the remaining votes shall be distributed among the consuming members in proportion to the average volume of their respective net imports of tropical timber during the three-year period commencing four calendar years prior to the distribution of votes. 
6. The Council shall distribute the votes for each financial year at the beginning of its first session of that year in accordance with the provisions of this article. Such distribution shall remain in effect for the rest of that year, except as provided for in paragraph 7 of this article.

7. Whenever the membership of the Organization changes or when any member has its voting rights suspended or restored under any provision of this Agreement, the Council shall redistribute the votes within the affected category or categories of members in accordance with the provisions of this article. The Council shall, in that event, decide when such redistribution shall become effective.

8. There shall be no fractional votes.

\section{Article 11}

\section{Voting procedure of the Council}

1. Each member shall be entitled to cast the number of votes it holds and no member shall be entitled to divide its votes. A member may, however, cast differently from such votes any votes which it is authorized to cast under paragraph 2 of this article.

2. By written notification to the Chairman of the Council, any producing member may authorize, under its own responsibility, any other producing member, and any consuming member may authorize, under its own responsibility, any other consuming member, to represent its interests and to cast its votes at any meeting of the Council.

3. When abstaining, a member shall be deemed not to have cast its votes.

\section{Article 12}

\section{Decisions and recommendations of the Council}

1. The Council shall endeavour to take all decisions and to make all recommendations by consensus. If consensus cannot be reached, the Council shall take all decisions and make all recommendations by a simple distributed majority vote, unless this Agreement provides for a special vote.

2. Where a member avails itself of the provisions of article 11, paragraph 2, and its votes are cast at a meeting of the Council, such member shall, for the purposes of paragraph 1 of this article, be considered as present and voting.

\section{Article 13}

\section{Quorum for the Council}

1. The quorum for any meeting of the Council shall be the presence of a majority of members of each category referred to in article 4, provided that such members hold at least two thirds of the total votes in their respective categories.

2. If there is no quorum in accordance with paragraph 1 of this article on the day fixed for the meeting and on the following day, the quorum on the subsequent days of the session shall be the presence of a majority of members of each category referred to in article 4, provided that such members hold a majority of the total votes in their respective categories.

3. Representation in accordance with article 11, paragraph 2 , shall be considered as presence. 


\section{Article 14}

\section{Cooperation and coordination with other organizations}

1. The Council shall make arrangements as appropriate for consultations and cooperation with the United Nations and its organs, including the United Nations Conference on Trade and Development (UNCTAD) and the Commission on Sustainable Development (CSD), intergovernmental organizations, including the General Agreement on Tariffs and Trade (GATT) and the Convention on International Trade in Endangered Species of Wild Fauna and Flora (CITES), and non-governmental organizations.

2. The Organization shall, to the maximum extent possible, utilize the facilities, services and expertise of existing intergovernmental, governmental or non-governmental organizations, in order to avoid duplication of efforts in achieving the objectives of this Agreement and to enhance the complementarity and the efficiency of their activities.

\section{Article 15}

\section{Admission of observers}

The Council may invite any non-member Government or any of the organizations referred to in article 14, article 20 and article 29 , interested in the activities of the organization to attend as observers any of the meetings of the Council.

\section{Article 16}

\section{Executive Director and staff}

1. The Council shall, by special vote, appoint the Executive Director.

2. The terms and conditions of appointment of the Executive Director shall be determined by the Council.

3. The Executive Director shall be the chief administrative officer of the Organization and shall be responsible to the Council for the administration and operation of this Agreement in accordance with decisions of the Council.

4. The Executive Director shall appoint the staff in accordance with regulations to be established by the Council. The Council shall, by special vote, decide the number of executive and professional staff the Executive Director may appoint. Any changes in the number of executive and professional staff shall be decided by the Council by special vote. The staff shall be responsible to the Executive Director.

5. Neither the Executive Director nor any member of the staff shall have any financial interest in the timber industry or trade, or associated commercial activities.

6. In the performance of their duties, the Executive Director and staff shall not seek or receive instructions from any member or from any authority external to the Organization. They shall refrain from any action which might reflect adversely on their positions as international officials ultimately responsible to the Council. Each member shall respect the exclusively international character of the responsibilities of the Executive Director and staff and shall not seek to influence them in the discharge of their responsibilities. 


\section{CHAPTER V. PRIVILEGES AND IMMUNITIES}

\section{Article 17}

\section{Privileges and immunities}

1. The Organization shall have legal personality. It shall in particular have the capacity to contract, to acquire and dispose of movable and immovable property, and to institute legal proceedings.

2. The status, privileges and immunities of the Organization, of its Executive Director, its staff and experts, and of representatives of members while in the territory of Japan shall continue to be governed by the Headquarters Agreement between the Government of Japan and the International Tropical Timber Organization signed at Tokyo on 27 February 1988, with such amendments as may be necessary for the proper functioning of this Agreement.

3. The Organization may conclude, with one or more countries, agreements to be approved by the Council relating to such capacity, privileges and immunities as may be necessary for the proper functioning of this Agreement.

4. If the headquarters of the Organization is moved to another country, the member in question shall, as soon as possible, conclude with the Organization a headquarters agreement to be approved by the Council. Pending the conclusion of such an Agreement, the Organization shall request the new host Government to grant, within the limits of its national legislation, exemption from taxation on remuneration paid by the Organization to its employees, and on the assets, income and other property of the Organization.

5. The headquarters agreement shall be independent of this Agreement. It shall, however, terminate:

(a) By agreement between the host Government and the Organization;

(b) In the event of the headquarters of the Organization being moved from the country of the host Government; or

(c) In the event of the Organization ceasing to exist.

\section{CHAPTER VI. FINANCE}

\section{Article 18}

\section{Financial accounts}

1. There shall be established:
(a) The Administrative Account;
(b) The Special Account;
(c) The Bali Partnership Fund; and
(d) Such other accounts as the Council shall deem appropriate and necessary.

2. The Executive Director shall be responsible for the administration of these accounts and the Council shall make provision therefor in the financial rules of the Organization. 


\section{Article 19}

\section{Administrative Account}

1. The expenses necessary for the administration of this Agreement shall be brought into the Administrative Account and shall be met by annual contributions paid by members in accordance with their respective constitutional or institutional procedures and assessed in accordance with paragraphs 3,4 and 5 of this article.

2. The expenses of delegations to the Council, the committees and any other subsidiary bodies of the Council referred to in article 26 shall be met by the members concerned. In cases where a member requests special services from the Organization, the Council shall require that member to pay the costs of such services.

3. Before the end of each financial year, the Council shall approve the administrative budget of the Organization for the following financial year and shall assess the contribution of each member to that budget.

4. The contribution of each member to the administrative budget for each financial year shall be in the proportion which the number of its votes at the time the administrative budget for that financial year is approved bears to the total votes of all the members. In assessing contributions, the votes of each member shall be calculated without regard to the suspension of any member's voting rights or any redistribution of votes resulting therefrom.

5. The initial contribution of any member joining the Organization after the entry into force of this Agreement shall be assessed by the Council on the basis of the number of votes to be held by that member and the period remaining in the current financial year, but the assessment made upon other members from the current financial year shall not thereby be altered.

6. Contributions to administrative budgets shall become due on the first day of each financial year. Contributions of members in respect of the financial year in which they join the Organization shall be due on the date on which they become members.

7. If a member has not paid its full contribution to the administrative budget within four months after such contribution becomes due in accordance with paragraph 6 of this article, the Executive Director shall request that member to make payment as quickly as possible. If that member has still not paid its contribution within two months after such request, that member shall be requested to state the reasons for its inability to make payment. If at the expiry of seven months from the due date of contribution, that member has still not paid its contribution, its voting rights shall be suspended until such time as it has paid in full its contribution, unless the Council, by special vote, decides otherwise. If, on the contrary, a member has paid its full contribution to the administrative budget within four months after such contribution becomes due in accordance with paragraph 6 of this article, the member's contribution shall receive a discount as may be established by the Council in the financial rules of the Organization.

8. A member whose rights have been suspended under paragraph 7 of this article shall remain liable to pay its contribution.

\section{Article 20}

\section{Special Account}

1. There shall be established two sub-accounts under the Special Account:

(a) The Pre-Project Sub-Account; and

(b) The Project Sub-Account.

2. The possible sources of finance for the Special Account may be:

(a) The Common Fund for Commodities;

(b) Regional and international financial institutions; and 
(c) Voluntary contributions.

3. The resources of the Special Account shall be used only for approved pre-projects or projects.

4. All expenditures under the Pre-Project Sub-Account shall be reimbursed from the Project Sub-Account if projects are subsequently approved and funded. If within six months of the entry into force of this Agreement the Council does not receive any funds for the Pre-Project Sub-Account, it shall review the situation and take appropriate action.

5. All receipts pertaining to specific identifiable pre-projects or projects under the Special Account shall be brought into that Account. All expenditures incurred on such pre-projects or projects, including remuneration and travel expenses of consultants and experts, shall be charged to the same Account.

6. The Council shall, by special vote, establish terms and conditions on which it would, when and where appropriate, sponsor projects for loan financing, where a member or members have voluntarily assumed full obligations and responsibilities for such loans. The Organization shall have no obligations for such loans.

7. The Council may nominate and sponsor any entity with the consent of that entity, including a member or members, to receive loans for the financing of approved projects and to undertake all the obligations involved, except that the Organization shall reserve to itself the right to monitor the use of resources and to follow up on the implementation of projects so financed. However, the Organization shall not be responsible for guarantees voluntarily provided by individual members or other entities.

8. No member shall be responsible by reason of its membership in the Organization for any liability arising from borrowing or lending by any other member or entity in connection with projects.

9. In the event that voluntary unearmarked funds are offered to the Organization, the Council may accept such funds. Such funds may be utilized for approved pre-projects and projects.

10. The Executive Director shall endeavour to seek, on such terms and conditions as the Council may decide, adequate and assured finance for pre-projects and projects approved by the Council.

11. Contributions for specified approved projects shall be used only for the projects for which they were originally intended, unless otherwise decided by the Council in agreement with the contributor. After the completion of a project, the organization shall return to each contributor for specific projects the balance of any funds remaining pro rata to each contributor's share in the total of the contributions originally made available for financing that project, unless otherwise agreed to by the contributor.

\section{Article 21}

\section{The Bali Partnership Fund}

1. A Fund for sustainable management of tropical timber-producing forests is hereby established to assist producing members to make the investments necessary to achieve the objective of article 1 (d) of this Agreement.

2. The Fund shall be constituted by:

(a) Contributions from donor members;

(b) Fifty per cent of income earned as a result of activities related to the Special Account;

(c) Resources from other private and public sources which the Organization may accept consistent with its financial rules.

3. Resources of the Fund shall be allocated by the Council only for pre-projects and projects for the purpose set out in paragraph 1 of this article and approved in accordance with article 25. 
4. In allocating resources of the Fund, the Council shall take into account:

(a) The special needs of members whose forestry sectors' contribution to their economies is adversely affected by the implementation of the strategy for achieving the exports of tropical timber and timber products from sustainably managed sources by the year 2000 ;

(b) The needs of members with significant forest areas who establish conservation programmes in timberproducing forests.

5. The Council shall examine annually the adequacy of the resources available to the Fund and endeavour to obtain additional resources needed by producing members to achieve the purpose of the Fund. The ability of members to implement the strategy referred to in paragraph 4 (a) of this article will be influenced by the availability of resources.

6. The Council shall establish policies and financial rules for the operation of the Fund, including rules covering the settlement of accounts on termination or expiry of this Agreement.

\section{Article 22}

\section{Forms of payment}

1. Contributions to the Administrative Account shall be payable in freely usable currencies and shall be exempt from foreign-exchange restrictions.

2. Financial contributions to the Special Account and the Bali Partnership Fund shall be payable in freely usable currencies and shall be exempt from foreign-exchange restrictions.

3. The Council may also decide to accept other forms of contributions to the Special Account or the Bali Partnership Fund, including scientific and technical equipment or personnel, to meet the requirements of approved projects.

\section{Article 23}

\section{Audit and publication of accounts}

1. The Council shall appoint independent auditors for the purpose of auditing the accounts of the Organization.

2. Independently audited statements of the Administrative Account, of the Special Account and of the Bali Partnership Fund shall be made available to members as soon as possible after the close of each financial year, but not later than six months after that date, and be considered for approval by the Council at its next session, as appropriate. A summary of the audited accounts and balance sheet shall thereafter be published.

\section{CHAPTER VII. OPERATIONAL ACTIVITIES}

\section{Article 24}

\section{Policy work of the Organization}

In order to achieve the objectives set out in article 1, the Organization shall undertake policy work and project activities in the areas of Economic Information and Market Intelligence, Reforestation and Forest Management and Forest Industry, in a balanced manner, to the extent possible integrating policy work and project activities. 


\section{Article 25}

\section{Project activities of the Organization}

1. Bearing in mind the needs of developing countries, members may submit pre-project and project proposals to the Council in the fields of research and development, market intelligence, further and increased wood processing in producing member countries, and reforestation and forest management. Pre-projects and projects should contribute to the achievement of one or more of the objectives of this Agreement.

2. The Council, in approving pre-projects and projects, shall take into account:

(a) Their relevance to the objectives of this Agreement;

(b) Their environmental and social effects;

(c) The desirability of maintaining an appropriate geographical balance;

(d) The interests and characteristics of each of the developing producing regions;

(e) The desirability of equitable distribution of resources among the fields referred to in paragraph 1 of this article;

(f) Their cost-effectiveness; and

(g) The need to avoid duplication of efforts.

3. The Council shall establish a schedule and procedure for submitting, appraising, and prioritizing pre-projects and projects seeking funding from the Organization, as well as for their implementation, monitoring and evaluation. The Council shall decide on the approval of pre-projects and projects for financing or sponsorship in accordance with article 20 or article 21.

4. The Executive Director may suspend disbursement of the organization's funds to a pre-project or project if they are being used contrary to the project document or in cases of fraud, waste, neglect or mismanagement. The Executive Director will provide to the Council at its next session a report for its consideration. The Council shall take appropriate action.

5. The Council may, by special vote, terminate its sponsorship of any pre-project or project.

\section{Article 26}

\section{Establishment of Committees}

1. The following are hereby established as Committees of the Organization:

(a) Committee on Economic Information and Market Intelligence;

(b) Committee on Reforestation and Forest Management;

(c) Committee on Forest Industry; and

(d) Committee on Finance and Administration.

2. The Council may, by special vote, establish such other committees and subsidiary bodies as it deems appropriate and necessary.

3. Participation in each of the committees shall be open to all members. The rules of procedure of the committees shall be decided by the Council. 
4. The committees and subsidiary bodies referred to in paragraphs 1 and 2 of this article shall be responsible to, and work under the general direction of, the Council. Meetings of the committees and subsidiary bodies shall be convened by the Council.

\section{Article 27}

\section{Functions of the Committees}

1. The Committee on Economic Information and Market Intelligence shall:

(a) Keep under review the availability and quality of statistics and other information required by the Organization;

(b) Analyse the statistical data and specific indicators as decided by the Council for the monitoring of international timber trade;

(c) Keep under continuous review the international timber market, its current situation and short-term prospects on the basis of the data mentioned in subparagraph (b) above and other relevant information, including information related to undocumented trade;

(d) Make recommendations to the Council on the need for, and nature of, appropriate studies on tropical timber, including prices, market elasticity, market substitutability, marketing of new products, and long-term prospects of the international tropical timber market, and monitor and review any studies commissioned by the Council;

(e) Carry out any other tasks related to the economic, technical and statistical aspects of timber assigned to it by the Council;

(f) Assist in the provision of technical cooperation of developing member countries to improve their relevant statistical services.

2. The Committee on Reforestation and Forest Management shall:

(a) Promote cooperation between members as partners in development of forest activities in member countries, inter alia, in the following areas:
(i) Reforestation;
(ii) Rehabilitation;
(iii) Forest management;

(b) Encourage the increase of technical assistance and transfer of technology in the fields of reforestation and forest management to developing countries;

(c) Follow up ongoing activities in this field, and identify and consider problems and possible solutions to them in cooperation with the competent organizations;

(d) Review regularly the future needs of international trade in industrial tropical timber and, on this basis, identify and consider appropriate possible schemes and measures in the field of reforestation, rehabilitation and forest management;

(e) Facilitate the transfer of knowledge in the field of reforestation and forest management with the assistance of competent organizations;

(f) Coordinate and harmonize these activities for cooperation in the field of reforestation and forest management with relevant activities pursued elsewhere, such as those under the auspices of the Food and Agriculture Organization of the United Nations (FAO), the United Nations Environment 
Programme (UNEP), the World Bank, the United Nations Development Programme (UNDP), regional development banks and other competent organizations.

3. The Committee on Forest Industry shall:

(a) Promote cooperation between member countries as partners in the development of processing activities in producing member countries, inter alia, in the following areas:

(i) Product development through transfer of technology;

(ii) Human resources development and training;

(iii) Standardization of nomenclature of tropical timber;

(iv) Harmonization of specifications of processed products;

(v) Encouragement of investment and joint ventures; and

(vi) Marketing, including the promotion of lesser known and lesser used species;

(b) Promote the exchange of information in order to facilitate structural changes involved in increased and further processing in the interests of all member countries, in particular developing member countries;

(c) Follow up ongoing activities in this field, and identify and consider problems and possible solutions to them in cooperation with the competent organizations;

(d) Encourage the increase of technical cooperation for the processing of tropical timber for the benefit of producing member countries.

4. In order to promote the policy and project work of the Organization in a balanced manner, the Committee on Economic Information and Market Intelligence, the Committee on Reforestation and Forest Management and the Committee on Forest Industry shall each:

(a) Be responsible for ensuring the effective appraisal, monitoring and evaluation of pre-projects and projects;

(b) Make recommendations to the Council relating to pre-projects and projects;

(c) Follow up the implementation of pre-projects and projects and provide for the collection and dissemination of their results as widely as possible for the benefit of all members;

(d) Develop and advance policy ideas to the Council;

(e) Review regularly the results of project and policy work and make recommendations to the Council on the future of the Organization's programme;

(f) Review regularly the strategies, criteria and priority areas for programme development and project work contained in the Organization's Action Plan and recommend revisions to the Council;

(g) Take account of the need to strengthen capacity building and human resource development in member countries;

(h) Carry out any other task related to the objectives of this Agreement assigned to them by the Council.

5. Research and development shall be a common function of the Committees referred to in paragraphs 1,2 , and 3 of this article. 
6. The Committee on Finance and Administration shall:

(a) Examine and make recommendations to the Council regarding the approval of the Organization's administrative budget proposals and the management operations of the Organization;

(b) Review the assets of the organization to ensure prudent asset management and that the organization has sufficient reserves to carry out its work;

(c) Examine and make recommendations to the Council on the budgetary implications of the Organization's annual work programme, and the actions that might be taken to secure the resources needed to implement it;

(d) Recommend to the Council the choice of independent auditors and review the independent audited statements;

(e) Recommend to the council any modifications it may judge necessary to the Rules of Procedure or the Financial Rules;

(f) Review the Organization's revenues and the extent to which they constrain the work of the Secretariat.

\title{
CHAPTER VII. RELATIONSHIP WITH THE COMION FUND FOR COMMODITIES
}

\author{
Article 28 \\ Relationship with the Common Fund for Commodities
}

The Organization shall take full advantage of the facilities of the Common Fund for Commodities.

\section{CHAPTER IX. STATISTICS, STUDIES AND INFORMATION}

\section{Article 29 \\ Statistics, studies and information}

1. The Council shall establish close relationships with relevant intergovernmental, governmental and non-governmental organizations, in order to help ensure the availability of recent reliable data and information on the trade in tropical timber, as well as relevant information on non-tropical timber and on the management of timber-producing forests. As deemed necessary for the operation of this Agreement, the Organization, in cooperation with such organizations, shall compile, collate and, where relevant, publish statistical information on production, supply, trade, stocks, consumption and market prices of timber, the extent of timber resources and the management of timber-producing forests.

2. Members shall, to the fullest extent possible not inconsistent with their national legislation, furnish, within a reasonable time, statistics and information on timber, its trade and the activities aimed at achieving sustainable management of timber-producing forests as well as other relevant information as requested by the Council. The Council shall decide on the type of information to be provided under this paragraph and on the format in which it is to be presented.

3. The Council shall arrange to have any relevant studies undertaken of the trends and of short- and long-term problems of the international timber markets and of the progress towards the achievement of sustainable management of timber-producing forests. 


\section{Article 30}

\section{Annual report and review}

1. The Council shall, within six months after the close of each calendar year, publish an annual report on its activities and such other information as it considers appropriate.

2. The Council shall annually review and assess:

(a) The international timber situation;

(b) Other factors, issues and developments considered relevant to achieve the objectives of this Agreement.

3. The review shall be carried out in the light of:

(a) Information supplied by members in relation to national production, trade, supply, stocks, consumption and prices of timber;

(b) Other statistical data and specific indicators provided by members as requested by the Council;

(c) Information supplied by members on their progress towards the sustainable management of their timber-producing forests;

(d) Such other relevant information as may be available to the Council either directly or through the organizations in the United Nations system and intergovernmental, governmental or non-governmental organizations.

4. The Council shall promote the exchange of views among member countries regarding:

(a) The status of sustainable management of timber-producing forests and related matters in member countries;

(b) Resource flows and requirements in relation to objectives, criteria and guidelines set by the Organization.

5. Upon request, the Council shall endeavour to enhance the technical capacity of member countries, in particular developing member countries, to obtain the data necessary for adequate information-sharing, including the provision of resources for training and facilities to members.

6. The results of the review shall be included in the reports of the Council's deliberations.

\section{CHAPTER X. MISCELLANEOUS}

\section{Article 31}

\section{Complaints and disputes}

Any complaint that a member has failed to fulfil its obligations under this Agreement and any dispute concerning the interpretation or application of this Agreement shall be referred to the Council for decision. Decisions of the Council on these matters shall be final and binding. 


\section{Article 32}

\section{General obligations of members}

1. Members shall, for the duration of this Agreement, use their best endeavours and cooperate to promote the attainment of its objectives and to avoid any action contrary thereto.

2. Members undertake to accept and carry out the decisions of the Council under the provisions of this Agreement and shall refrain from implementing measures which would have the effect of limiting or running counter to them.

\section{Article 33}

\section{$\underline{\text { Relief from obligations }}$}

1. Where it is necessary on account of exceptional circumstances or emergency or force majeure not expressly provided for in this Agreement, the Council may, by special vote, relieve a member of an obligation under this Agreement if it is satisfied by an explanation from that member regarding the reasons why the obligation cannot be met.

2. The Council, in granting relief to a member under paragraph 1 of this article, shall state explicitly the terms and conditions on which, and the period for which, the member is relieved of such obligation, and the reasons for which the relief is granted.

\section{Article 34}

\section{Differential and remedial measures and special measures}

1. Developing importing members whose interests are adversely affected by measures taken under this Agreement may apply to the Council for appropriate differential and remedial measures. The Council shall consider taking appropriate measures in accordance with section III, paragraphs 3 and 4, of resolution 93 (IV) of the United Nations Conference on Trade and Development.

2. Members in the category of least developed countries as defined by the United Nations may apply to the Council for special measures in accordance with section III, paragraph 4, of resolution 93 (IV) and with paragraphs 56 and 57 of the Paris Declaration and Programme of Action for the Least Developed Countries for the 1990s.

\section{Article 35}

\section{Review}

The Council shall review the scope of this Agreement four years after its entry into force.

\section{Article 36}

\section{Non-discrimination}

Nothing in this Agreement authorizes the use of measures to restrict or ban international trade in, and in particular as they concern imports of and utilization of, timber and timber products. 


\section{CHAPTER XI. FINAL PROVISIONS}

\section{Article 37}

\section{Depositary}

The Secretary-General of the United Nations is hereby designated as the depositary of this Agreement.

\section{Article 38}

\section{Signature, ratification, acceptance and approval}

1. This Agreement shall be open for signature, at United Nations Headquarters from 1 April 1994 until one month after the date of its entry into force, by Governments invited to the United Nations Conference for the Negotiation of a Successor Agreement to the International Tropical Timber Agreement, 1983.

2. Any Government referred to in paragraph 1 of this article may:

(a) At the time of signing this Agreement, declare that by such signature it expresses its consent to be bound by this Agreement (definitive signature); or

(b) After signing this Agreement, ratify, accept or approve it by the deposit of an instrument to that effect with the depositary.

\section{Article 39}

\section{Accession}

1. This Agreement shall be open for accession by the Governments of all States upon conditions established by the Council, which shall include a time-limit for the deposit of instruments of accession. The Council may, however, grant extensions of time to Governments which are unable to accede by the time-limit set in the conditions of accession.

2. Accession shall be effected by the deposit of an instrument of accession with the depositary.

\section{Article 40}

\section{Notification of provisional application}

A signatory Government which intends to ratify, accept or approve this Agreement, or a Government for which the Council has established conditions for accession but which has not yet been able to deposit its instrument, may, at any time, notify the depositary that it will apply this Agreement provisionally either when it enters into force in accordance with article $\mathbf{4 1}$, or, if it is already in force, at a specified date.

\section{Article 41}

\section{Entry into force}

1. This Agreement shall enter into force definitively on 1 February 1995 or on any date thereafter, if $\mathbf{1 2}$ Governments of producing countries holding at least 55 per cent of the total votes as set out in annex A to this Agreement, and 16 Governments of consuming countries holding at least 70 per cent of the total votes as set out in annex B to this Agreement have signed this Agreement definitively or have ratified, accepted or approved it or acceded thereto pursuant to article 38 , paragraph 2 , or article 39 . 
2. If this Agreement has not entered into force definitively on 1 February 1995, it shall enter into force provisionally on that date or on any date within six months thereafter, if 10 Governments of producing countries holding at least 50 per cent of the total votes as set out in annex A to this Agreement, and 14 Governments of consuming countries holding at least 65 per cent of the total votes as set out in annex B to this Agreement have signed this Agreement definitively or have ratified, accepted or approved it pursuant to article 38, paragraph 2, or have notified the depositary under articie $\mathbf{4 0}$ that they will apply this Agreement provisionally.

3. If the requirements for entry into force under paragraph 1 or paragraph 2 of this article have not been met on 1 September 1995, the Secretary-General of the United Nations shall invite those Governments which have signed this Agreement definitively or have ratified, accepted or approved it pursuant to article 38, paragraph 2, or have notified the depositary that they will apply this Agreement provisionally, to meet at the earliest time practicable to decide whether to put this Agreement into force provisionally or definitively among themselves in whole or in part. Governments which decide to put this Agreement into force provisionally among themselves may meet from time to time to review the situation and decide whether this Agreement shall enter into force definitively among themselves.

4. For any Government which has not notified the depositary under article 40 that it will apply this Agreement provisionally and which deposits its instrument of ratification, acceptance, approval or accession after the entry into force of this Agreement, this Agreement shall enter into force on the date of such deposit.

5. The Executive Director of the Organization shall convene the Council as soon as possible after the entry into force of this Agreement.

\section{Article 42}

\section{Amendments}

1. The Council may, by special vote, recommend an amendment of this Agreement to members.

2. The Council shall fix a date by which members shall notify the depositary of their acceptance of the amendment.

3. An amendment shall enter into force 90 days after the depositary has received notifications of acceptance from members constituting at least two thirds of the producing members and accounting for at least 75 per cent of the votes of the producing members, and from members constituting at least two thirds of the consuming members and accounting for at least 75 per cent of the votes of the consuming members.

4. After the depositary informs the Council that the requirements for entry into force of the amendment have been met, and notwithstanding the provisions of paragraph 2 of this article relating to the date fixed by the Council, a member may still notify the depositary of its acceptance of the amendment, provided that such notification is made before the entry into force of the amendment.

5. Any member which has not notified its acceptance of an amendment by the date on which such amendment enters into force shall cease to be a party to this Agreement as from that date, unless such member has satisfied the Council that its acceptance could not be obtained in time owing to difficulties in completing its constitutional or institutional procedures, and the Council decides to extend for that member the period for acceptance of the amendment. Such member shall not be bound by the amendment before it has notified its acceptance thereof.

6. If the requirements for the entry into force of the amendment have not been met by the date fixed by the Council in accordance with paragraph 2 of this article, the amendment shall be considered withdrawn.

\section{Article 43}

\section{Withdrawal}

1. A member may withdraw from this Agreement at any time after the entry into force of this Agreement by giving written notice of withdrawal to the depositary. That member shall simultaneously inform the Council of the action it has taken. 
2. Withdrawal shall become effective 90 days after the notice is received by the depositary.

3. Financial obligations to the Organization incurred by a member under this Agreement shall not be terminated by its withdrawal.

\section{Article 44 \\ Exclusion}

If the Council decides that any member is in breach of its obligations under this Agreement and decides further that such breach significantly impairs the operation of this Agreement, it may, by special vote, exclude that member from this Agreement. The Council shall immediately so notify the depositary. Six months after the date of the Council's decision, that member shall cease to be a party to this Agreement.

\section{Article 45}

\section{Settlement of accounts with withdrawing or excluded members or members unable to accept an amendment}

1. The Council shall determine any settlement of accounts with a member which ceases to be a party to this Agreement owing to:

(a) Non-acceptance of an amendment to this Agreement under article 42;

(b) Withdrawal from this Agreement under article 43; or

(c) Exclusion from this Agreement under article 44.

2. The Council shall retain any contribution paid to the Administrative Account, to the Special Account or to the Bali Partnership Fund by a member which ceases to be a party to this Agreement.

3. A member which has ceased to be a party to this Agreement shall not be entitled to any share of the proceeds of liquidation or the other assets of the Organization. Nor shall such member be liable for payment of any part of the deficit, if any, of the Organization upon termination of this Agreement.

\section{Article 46}

\section{Duration, extension and termination}

1. This Agreement shall remain in force for a period of four years after its entry into force unless the Council, by special vote, decides to extend, renegotiate or terminate it in accordance with the provisions of this article.

2. The Council may, by special vote, decide to extend this Agreement for two periods of three years each.

3. If, before the expiry of the four-year period referred to in paragraph 1 of this article, or before the expiry of an extension period referred to in paragraph 2 of this article, as the case may be, a new agreement to replace this Agreement has been negotiated but has not yet entered into force either definitively or provisionally, the Council may, by special vote, extend this Agreement until the provisional or definitive entry into force of the new agreement.

4. If a new agreement is negotiated and enters into force during any period of extension of this Agreement under paragraph 2 or paragraph 3 of this article, this Agreement, as extended, shall terminate upon the entry into force of the new agreement.

5. The Council may at any time, by special vote, decide to terminate this Agreement with effect from such date as it may determine. 
6. Notwithstanding the termination of this Agreement, the Council shall continue in being for a period not exceeding 18 months to carry out the liquidation of the Organization, including the settlement of accounts, and, subject to relevant decisions to be taken by special vote, shall have during that period such powers and functions as may be necessary for these purposes.

7. The Council shall notify the depositary of any decision taken under this article.

\section{Article 47}

\section{Reservations}

Reservations may not be made with respect to any of the provisions of this Agreement.

\section{Article 48}

\section{Supplementary and transitional provisions}

1. This Agreement shall be the successor to the International Tropical Timber Agreement, 1983.

2. All acts by or on behalf of the Organization or any of its organs under the International Tropical Timber Agreement, 1983, which are in effect on the date of entry into force of this Agreement and the terms of which do not provide for expiry on that date shall remain in effect unless changed under the provisions of this Agreement.

IN WITNESS WHEREOF the undersigned, being duly authorized thereto, have affixed their signatures under this Agreement on the dates indicated.

DONE at Geneva, on twenty-six January, one thousand nine hundred and ninety-four, the text of this Agreement in the Arabic, Chinese, English, French, Russian and Spanish languages being equally authentic.

\section{ANNEX A}

\section{List of producing countries with tropical forest resources and/or net exporters of tropical timber in volume terms, and allocation of votes for the purposes of article 41}

$\begin{array}{lr}\text { Bolivia } & 21 \\ \text { Brazil } & 133 \\ \text { Cameroon } & 23 \\ \text { Colombia } & 24 \\ \text { Congo } & 23 \\ \text { Costa Rica } & 9 \\ \text { Côte d'Ivoire } & 23 \\ \text { Dominican Republic } & 9 \\ \text { Ecuador } & 14 \\ \text { El Salvador } & 9 \\ \text { Equatorial Guinea } & 23 \\ \text { Gabon } & 23 \\ \text { Ghana } & 23 \\ \text { Guyana } & 14 \\ \text { Honduras } & 9 \\ \text { India } & 34 \\ \text { Indonesia } & 170 \\ \text { Liberia } & 23 \\ \text { Malaysia } & 139\end{array}$




\begin{tabular}{lr} 
Mexico & 14 \\
Myanmar & 33 \\
Panama & 10 \\
Papua New Guinea & 28 \\
Paraguay & 11 \\
Peru & 25 \\
Philippines & 25 \\
Tanzania, United Republic of & 23 \\
Thailand & 20 \\
Togo & 23 \\
Trinidad and Tobago & 9 \\
Venezuela & 10 \\
Zaire & 23 \\
\multicolumn{1}{c}{ Total } & \\
&
\end{tabular}

\section{ANNEX B \\ List of consuming countries and allocation of votes for the purposes of article 41}

\begin{tabular}{lr} 
Afghanistan & 10 \\
Algeria & 13 \\
Australia & 18 \\
Austria & 11 \\
Bahrain & 11 \\
Bulgaria & 10 \\
Canada & 12 \\
Chile & 10 \\
China & 36 \\
Egypt & 14 \\
European Community & $302)$ \\
$\quad$ Belgium/Luxembourg & 26 \\
Denmark & 11 \\
$\quad$ France & 44 \\
$\quad$ Germany & 35 \\
Greece & 13 \\
Ireland & 13 \\
Italy & 35 \\
Netherlands & 40 \\
Portugal & 18 \\
Spain & 25 \\
United Kingdom & 42 \\
Finland & 10 \\
Japan & 320 \\
Nepal & 10 \\
New Zealand & 10 \\
Norway & 10 \\
Republic of Korea & 97 \\
Russian Federation & 13 \\
Slovakia & 11 \\
Sweden & 10 \\
Switzerland & 11 \\
United States of America & 51 \\
$\quad$ Total & 1000 \\
\hline &
\end{tabular}




\title{
Protocol to the 1979 Convention on Long-Range Transboundary Air Pollution on Further Reduction of Sulphur Emissions, Oslo, 1994
}

\author{
Done at Oslo 14 June 1994 \\ Not in force \\ Primary source citation: United Nations Certified \\ True Copy XXVII.I.(e)
}

\section{PROTOCOL TO THE 1979 CONVENTION ON LONG-RANGE TRANSBOUNDARY AIR POLLUTION ON FURTHER REDUCTION OF SULPHUR EMISSIONS}

The Parties,

Determined to implement the Convention on Long-range Transboundary Air Pollution,

Concerned that emissions of sulphur and other air pollutants continue to be transported across international boundaries and, in exposed parts of Europe and North America, are causing widespread damage to natural resources of vital environmental and economic importance, such as forests, soils and waters, and to materials, including historic monuments, and, under certain circumstances, have harmful effects on human health,

Resolved to take precautionary measures to anticipate, prevent or minimize emissions of air pollutants and mitigate their adverse effects,

Convinced that where there are threats of serious or irreversible damage, lack of full scientific certainty should not be used as a reason for postponing such measures, taking into account that such precautionary measures to deal with emissions of air pollutants should be cost-effective,

Mindful that measures to control emissions of sulphur and other air pollutants would also contribute to the protection of the sensitive Arctic environment,

Considering that the predominant sources of air pollution contributing to the acidification of the environment are the combustion of fossil fuels for energy production, and the main technological processes in various industrial sectors, as well as transport, which lead to emissions of sulphur, nitrogen oxides, and other pollutants,

Conscious of the need for a cost-effective regional approach to combating air pollution that takes account of the variations in effects and abatement costs between countries,

Desiring to take further and more effective action to control and reduce sulphur emissions, 
Cognizant that any sulphur control policy, however cost-effective it may be at the regional level, will result in a relatively heavy economic burden on countries with economies that are in transition to a market economy,

Bearing in mind that measures taken to reduce sulphur emissions should not constitute a means of arbitrary or unjustifiable discrimination or a disguised restriction on international competition and trade,

Taking into consideration existing scientific and technical data on emissions, atmospheric processes and effects on the environment of sulphur oxides, as well as on abatement costs,

Aware that, in addition to emissions of sulphur, emissions of nitrogen oxides and of ammonia are also causing acidification of the environment,

Noting that under the United Nations Framework Convention on Climate Change, adopted in New York on 9 May 1992, there is agreement to establish national policies and take corresponding measures to combat climate change, which can be expected to lead to reductions of sulphur emissions,

Affirming the need to ensure environmentally sound and sustainable development,

Recognizing the need to continue scientific and technical cooperation to elaborate further the approach based on critical loads and critical levels, including efforts to assess several air pollutants and various effects on the environment, materials and human health,

Underlining that scientific and technical knowledge is developing and that it will be necessary to take such developments into account when reviewing the adequacy of the obligations entered into under the present Protocol and deciding on further action,

Acknowledging the Protocol on the Reduction of Sulphur Emissions or Their Transboundary Fluxes by at least 30 per cent, adopted in Helsinki on 8 July 1985, and the measures already taken by many countries which have had the effect of reducing sulphur emissions,

Have agreed as follows:

\section{Article 1}

\section{DEFINITIONS}

For the purposes of the present Protocol,

1. "Convention" means the Convention on Long-range Transboundary Air Pollution, adopted in Geneva on 13 November 1979;

2. "EMEP" means the Cooperative Programme for Monitoring and Evaluation of the Long-range Transmission of Air Pollutants in Europe;

3. "Executive Body" means the Executive Body for the Convention constituted under article 10, paragraph 1, of the Convention;

4. "Commission" means the United Nations Economic Commission for Europe;

5. "Parties" means, unless the context otherwise requires, the Parties to the present Protocol;

6. "Geographical scope of EMEP" means the area defined in article 1, paragraph 4, of the Protocol to the 1979 Convention on Long-range Transboundary Air Pollution on Long-term Financing of the Cooperative Programme for Monitoring and Evaluation of the Long-range Transmission of Air Pollutants in Europe (EMEP), adopted in Geneva on 28 September 1984; 
7. "SOMA" means a sulphur oxides management area designated in annex III under the conditions laid down in article 2, paragraph 3;

8. "Critical load" means a quantitative estimate of an exposure to one or more pollutants below which significant harmful effects on specified sensitive elements of the environment do not occur, according to present knowledge;

9. "Critical levels" means the concentration of pollutants in the atmosphere above which direct adverse effects on receptors, such as human beings, plants, ecosystems or materials, may occur, according to present knowledge;

10. "Critical sulphur deposition" means a quantitative estimate of the exposure to oxidized sulphur compounds, taking into account the effects of base cation uptake and base cation deposition, below which significant harmful effects on specified sensitive elements of the environment do not occur, according to present knowledge;

11. "Emission" means the discharge of substances into the atmosphere;

12. "Sulphur emissions" means all emissions of sulphur compounds expressed as kilotonnes of sulphur dioxide (kt $\mathrm{SO}_{2}$ ) to the atmosphere originating from anthropogenic sources excluding from ships in international traffic outside territorial waters;

13. "Fuel" means any solid, liquid or gaseous combustible material with the exception of domestic refuse and toxic or dangerous waste;

14. "Stationary combustion source" means any technical apparatus or group of technical apparatus that is co-located on a common site and is or could be discharging waste gases through a common stack, in which fuels are oxidized in order to use the heat generated;

15. "Major new stationary combustion source" means any stationary combustion source the construction or substantial modification of which is authorized after 31 December 1995 and the thermal input of which, when operating at rated capacity, is at least $50 \mathrm{MW}_{\mathrm{th}}$. It is a matter for the competent national authorities to decide whether a modification is substantial or not, taking into account such factors as the environmental benefits of the modification;

16. "Major existing stationary combustion source" means any existing stationary combustion source the thermal input of which, when operating at rated capacity, is at least $50 \mathrm{MW}_{\mathrm{th}}$;

17. "Gas oil" means any petroleum product within HS 2710 , or any petroleum product which, by reason of its distillation limits, falls within the category of middle distillates intended for use as fuel and of which at least $85 \%$ by volume, including distillation losses, distils at $350^{\circ} \mathrm{C}$;

18. "Emission limit value" means the permissible concentration of sulphur compounds expressed as sulphur dioxide in the waste gases from a stationary combustion source expressed in terms of mass per volume of the waste gases expressed in $\mathrm{mg} \mathrm{SO} 2 / \mathrm{Nm}^{3}$, assuming an oxygen content by volume in the waste gas of $3 \%$ in the case of liquid and gaseous fuels and $6 \%$ in the case of solid fuels;

19. "Emission limitation" means the permissible total quantity of sulphur compounds expressed as sulphur dioxide discharged from a combustion source or group of combustion sources located either on a common site or within a defined geographical area, expressed in kilotonnes per year;

20. "Desulphurization rate" means the ratio of the quantity of sulphur which is separated at the combustion source site over a given period to the quantity of sulphur contained in the fuel which is introduced into the combustion source facilities and which is used over the same period;

21. "Sulphur budget" means a matrix of calculated contributions to the deposition of oxidized sulphur compounds in receiving areas, originating from the emissions from specified areas. 


\section{Article 2}

\section{BASIC OBLIGATIONS}

1. The Parties shall control and reduce their sulphur emissions in order to protect human health and the environment from adverse effects, in particular acidifying effects, and to ensure, as far as possible, without entailing excessive costs, that depositions of oxidized sulphur compounds in the long term do not exceed critical loads for sulphur given, in annex I, as critical sulphur depositions, in accordance with present scientific knowledge.

2. As a first step, the Parties shall, as a minimum, reduce and maintain their annual sulphur emissions in accordance with the timing and levels specified in annex II.

3. In addition, any Party:

(a) Whose total land area is greater than 2 million square kilometres;

(b) Which has committed itself under paragraph 2 above to a national sulphur emission ceiling no greater than the lesser of its 1990 emissions or its obligation in the 1985 Helsinki Protocol on the Reduction of Sulphur Emissions or Their Transboundary Fluxes by at least 30 per cent, as indicated in annex II;

(c) Whose annual sulphur emissions that contribute to acidification in areas under the jurisdiction of one or more other Parties originate only from within areas under its jurisdiction that are listed as SOMAs in annex III, and has presented documentation to this effect; and

(d) Which has specified upon signature of, or accession to, the present Protocol its intention to act in accordance with this paragraph,

shall, as a minimum, reduce and maintain its annual sulphur emissions in the area so listed in accordance with the timing and levels specified in annex II.

4. Furthermore, the Parties shall make use of the most effective measures for the reduction of sulphur emissions, appropriate in their particular circumstances, for new and existing sources, which include, inter alia:

- Measures to increase energy efficiency;

- Measures to increase the use of renewable energy;

- Measures to reduce the sulphur content of particular fuels and to encourage the use of fuel with a low sulphur content, including the combined use of high-sulphur with low-sulphur or sulphur-free fuel;

- Measures to apply best available control technologies not entailing excessive cost,

using the guidance in annex IV.

5. Each Party, except those Parties subject to the United States/Canada Air Quality Agreement of 1991, shall as a minimum:

(a) Apply emission limit values at least as stringent as those specified in annex $\mathrm{V}$ to all major new stationary combustion sources;

(b) No later than 1 July 2004 apply, as far as possible without entailing excessive costs, emission limit values at least as stringent as those specified in annex $\mathrm{V}$ to those major existing stationary combustion sources the thermal input of which is above $500 \mathrm{MW}_{\mathrm{th}}$ taking into account the remaining lifetime of a plant, calculated from the date of entry into force of the present Protocol, or apply equivalent emission limitations or other appropriate provisions, provided that these achieve the sulphur emission ceilings specified in annex II and, subsequently, further approach the critical loads as given in annex I; and no later than 1 July 2004 apply emission limit values or emission limitations to those major existing stationary combustion sources the thermal input of which is between 50 and $500 \mathrm{MW}_{\text {th }}$ using annex $\mathrm{V}$ as guidance. 
(c) No later than two years after the date of entry into force of the present Protocol apply national standards for the sulphur content of gas oil at least as stringent as those specified in annex V. In cases where the supply of gas oil cannot otherwise be ensured, a State may extend the time period given in this subparagraph to a period of up to ten years. In this case it shall specify, in a declaration to be deposited together with the instrument of ratification, acceptance, approval or accession, its intention to extend the time period.

6. The Parties may, in addition, apply economic instruments to encourage the adoption of cost-effective approaches to the reduction of sulphur emissions.

7. The Parties to this Protocol may, at a session of the Executive Body, in accordance with rules and conditions which the Executive Body shall elaborate and adopt, decide whether two or more Parties may jointly implement the obligations set out in annex II. These rules and conditions shall ensure the fulfilment of the obligations set out in paragraph 2 above and also promote the achievement of the environmental objectives set out in paragraph 1 above.

8. The Parties shall, subject to the outcome of the first review provided for under article 8 and no later than one year after the completion of that review, commence negotiations on further obligations to reduce emissions.

\section{Article 3}

\section{EXCHANGE OF TECHNOLOGY}

1. The Parties shall, consistent with their national laws, regulations and practices, facilitate the exchange of technologies and techniques, including those that increase energy efficiency, the use of renewable energy and the processing of low-sulphur fuels, to reduce sulphur emissions, particularly through the promotion of:

(a) The commercial exchange of available technology;

(b) Direct industrial contacts and cooperation, including joint ventures;

(c) The exchange of information and experience;

(d) The provision of technical assistance.

2. In promoting the activities specified in paragraph 1 above, the Parties shall create favourable conditions by facilitating contacts and cooperation among appropriate organizations and individuals in the private and public sectors that are capable of providing technology, design and engineering services, equipment or finance.

3. The Parties shall, no later than six months after the date of entry into force of the present Protocol, commence consideration of procedures to create more favourable conditions for the exchange of technology to reduce sulphur emissions.

\section{Article 4}

\section{NATIONAL STRATEGIES, POLICIES, PROGRAMMES, MEASURES AND INFORMATION}

1. Each Party shall, in order to implement its obligations under article 2:

(a) Adopt national strategies, policies and programmes, no later than six months after the present Protocol enters into force for it; and

(b) Take and apply national measures to control and reduce its sulphur emissions. 
2. Each Party shall collect and maintain information on:

(a) Actual levels of sulphur emissions, and of ambient concentrations and depositions of oxidized sulphur and other acidifying compounds, taking into account, for those Parties within the geographical scope of EMEP, the work plan of EMEP; and

(b) The effects of depositions of oxidized sulphur and other acidifying compounds.

\section{Article 5}

\section{REPORTING}

1. Each Party shall report, through the Executive Secretary of the Commission, to the Executive Body, on a periodic basis as determined by the Executive Body, information on:

(a) The implementation of national strategies, policies, programmes and measures referred to in article 4, paragraph 1;

(b) The levels of national annual sulphur emissions, in accordance with guidelines adopted by the Executive Body, containing emission data for all relevant source categories; and

(c) The implementation of other obligations that it has entered into under the present Protocol,

in conformity with a decision regarding format and content to be adopted by the Parties at a session of the Executive Body. The terms of this decision shall be reviewed as necessary to identify any additional elements regarding the format and/or content of the information that are to be included in the reports.

2. Each Party within the geographical scope of EMEP shall report, through the Executive Secretary of the Commission, to EMEP, on a periodic basis to be determined by the Steering Body of EMEP and approved by the Parties at a session of the Executive Body, information on the levels of sulphur emissions with temporal and spatial resolution as specified by the Steering Body of EMEP.

3. In good time before each annual session of the Executive Body, EMEP shall provide information on:

(a) Ambient concentration and deposition of oxidized sulphur compounds and

(b) Calculations of sulphur budgets.

Parties in areas outside the geographical scope of EMEP shall make available similar information if requested to do so by the Executive Body.

4. The Executive Body shall, in accordance with article 10, paragraph 2 (b), of the Convention, arrange for the preparation of information on the effects of depositions of oxidized sulphur and other acidifying compounds.

5. The Parties shall, at sessions of the Executive Body, arrange for the preparation, at regular intervals, of revised information on calculated and internationally optimized allocations of emission reductions for the States within the geographical scope of EMEP, with integrated assessment models, with a view to reducing further, for the purposes of article 2, paragraph 1, of the present Protocol, the difference between actual depositions of oxidized sulphur compounds and critical load values.

\section{Article 6}

\section{RESEARCH, DEVELOPMENT AND MONITORING}

The Parties shall encourage research, development, monitoring and cooperation related to: 
(a) The international harmonization of methods for the establishment of critical loads and critical levels and the elaboration of procedures for such harmonization;

(b) The improvement of monitoring techniques and systems and of the modelling of transport, concentrations and deposition of sulphur compounds;

(c) Strategies for the further reduction of sulphur emissions based on critical loads and critical levels as well as on technical developments, and the improvement of integrated assessment modelling to calculate internationally optimized allocations of emission reductions taking into account an equitable distribution of abatement costs;

(d) The understanding of the wider effects of sulphur emissions on human health, the environment, in particular acidification, and materials, including historic and cultural monuments, taking into account the relationship between sulphur oxides, nitrogen oxides, ammonia, volatile organic compounds and tropospheric ozone;

(e) Emission abatement technologies, and technologies and techniques to enhance energy efficiency, energy conservation and the use of renewable energy;

(f) The economic evaluation of benefits for the environment and human health resulting from the reduction of sulphur emissions.

\section{Article 7}

\section{COMPLIANCE}

1. An Implementation Committee is hereby established to review the implementation of the present Protocol and compliance by the Parties with their obligations. It shall report to the Parties at sessions of the Executive Body and may make such recommendations to them as it considers appropriate.

2. Upon consideration of a report, and any recommendations, of the Implementation Committee, the Parties, taking into account the circumstances of a matter and in accordance with Convention practice, may decide upon and call for action to bring about full compliance with the present Protocol, including measures to assist a Party's compliance with the Protocol, and to further the objectives of the Protocol.

3. The Parties shall, at the first session of the Executive Body after the entry into force of the present Protocol, adopt a decision that sets out the structure and functions of the Implementation Committee as well as procedures for its review of compliance.

4. The application of the compliance procedure shall be without prejudice to the provisions of article 9 of the present Protocol.

\section{Article 8}

\section{REVIEWS BY THE PARTIES AT SESSIONS OF THE EXECUTIVE BODY}

1. The Parties shall, at sessions of the Executive Body, pursuant to article 10, paragraph 2 (a), of the Convention, review the information supplied by the Parties and EMEP, the data on the effects of depositions of sulphur and other acidifying compounds and the reports of the Implementation Committee referred to in article 7, paragraph 1, of the present Protocol.

2. (a) The Parties shall, at sessions of the Executive Body, keep under review the obligations set out in the present Protocol, including: 
(i) Their obligations in relation to their calculated and internationally optimized allocations of emission reductions referred to in article 5 , paragraph 5 ; and

(ii) The adequacy of the obligations and the progress made towards the achievement of the objectives of the present Protocol;

(b) Reviews shall take into account the best available scientific information on acidification, including assessments of critical loads, technological developments, changing economic conditions and the fulfilment of the obligations on emission levels;

(c) In the context of such reviews, any Party whose obligations on sulphur emission ceilings under annex II hereto do not conform to the calculated and internationally optimized allocations of emission reductions for that Party, required to reduce the difference between depositions of sulphur in 1990 and critical sulphur depositions within the geographical scope of EMEP by at least $60 \%$, shall make every effort to undertake revised obligations;

(d) The procedures, methods and timing for such reviews shall be specified by the Parties at a session of the Executive Body. The first such review shall be completed in 1997.

\section{Article 9}

\section{SETTLEMENT OF DISPUTES}

1. In the event of a dispute between any two or more Parties concerning the interpretation or application of the present Protocol, the Parties concerned shall seek a settlement of the dispute through negotiation or any other peaceful means of their own choice. The parties to the dispute shall inform the Executive Body of their dispute.

2. When ratifying, accepting, approving or acceding to the present Protocol, or at any time thereafter, a Party which is not a regional economic integration organization may declare in a written instrument submitted to the Depositary that, in respect of any dispute concerning the interpretation or application of the Protocol, it recognizes one or both of the following means of dispute settlement as compulsory ipso facto and without agreement, in relation to any Party accepting the same obligation:

(a) Submission of the dispute to the International Court of Justice;

(b) Arbitration in accordance with procedures to be adopted by the Parties at a session of the Executive Body as soon as practicable, in an annex on arbitration.

A Party which is a regional economic integration organization may make a declaration with like effect in relation to arbitration in accordance with the procedures referred to in subparagraph (b) above.

3. Adeclaration made under paragraph 2 above shall remain in force until it expires in accordance with its terms or until three months after written notice of its revocation has been deposited with the Depositary.

4. A new declaration, a notice of revocation or the expiry of a declaration shall not in any way affect proceedings pending before the International Court of Justice or the arbitral tribunal, unless the parties to the dispute agree otherwise.

5. Except in a case where the parties to a dispute have accepted the same means of dispute settlement under paragraph 2, if after twelve months following notification by one Party to another that a dispute exists between them, the Parties concerned have not been able to settle their dispute through the means mentioned in paragraph 1 above, the dispute shall be submitted, at the request of any of the parties to the dispute, to conciliation.

6. For the purpose of paragraph 5 , a conciliation commission shall be created. The commission shall be composed of an equal number of members appointed by each party concerned or, where parties in conciliation share the same interest, by the group sharing that interest, and a chairman chosen jointly by the members so appointed. The commission shall render a recommendatory award, which the parties shall consider in good faith. 


\section{Article 10}

\section{ANNEXES}

The annexes to the present Protocol shall form an integral part of the Protocol. Annexes I and IV are recommendatory in character.

\section{Article 11}

\section{AMENDMENTS AND ADJUSTMENTS}

1. Any Party may propose amendments to the present Protocol. Any Party to the Convention may propose an adjustment to annex II to the present Protocol to add to it its name, together with emission levels, sulphur emission ceilings and percentage emission reductions.

2. Such proposed amendments and adjustments shall be submitted in writing to the Executive Secretary of the Commission, who shall communicate them to all Parties. The Parties shall discuss the proposed amendments and adjustments at the next session of the Executive Body, provided that those proposals have been circulated by the Executive Secretary to the Parties at least ninety days in advance.

3. Amendments to the present Protocol and to its annexes II, III and V shall be adopted by consensus of the Parties present at a session of the Executive Body, and shall enter into force for the Parties which have accepted them on the ninetieth day after the date on which two thirds of the Parties have deposited with the Depositary their instruments of acceptance thereof. Amendments shall enter into force for any other Party on the ninetieth day after the date on which that Party has deposited its instrument of acceptance thereof.

4. Amendments to the annexes to the present Protocol, other than to the annexes referred to in paragraph 3 above, shall be adopted by consensus of the Parties present at a session of the Executive Body. On the expiry of ninety days from the date of its communication by the Executive Secretary of the Commission, an amendment to any such annex shall become effective for those Parties which have not submitted to the Depositary a notification in accordance with the provisions of paragraph 5 below, provided that at least sixteen Parties have not submitted such a notification.

5. Any Party that is unable to approve an amendment to an annex, other than to an annex referred to in paragraph 3 above, shall so notify the Depositary in writing within ninety days from the date of the communication of its adoption. The Depositary shall without delay notify all Parties of any such notification received. A Party may at any time substitute an acceptance for its previous notification and, upon deposit of an instrument of acceptance with the Depositary, the amendment to such an annex shall become effective for that Party.

6. Adjustments to annex II shall be adopted by consensus of the Parties present at a session of the Executive Body and shall become effective for all Parties to the present Protocol on the ninetieth day following the date on which the Executive Secretary of the Commission notifies those Parties in writing of the adoption of the adjustment.

\section{Article 12}

\section{SIGNATURE}

1. The present Protocol shall be open for signature at Oslo on 14 June 1994, then at United Nations Headquarters in New York until 12 December 1994 by States members of the Commission as well as States having consultative status with the Commission, pursuant to paragraph 8 of Economic and Social Council resolution 36 (IV) of 28 March 1947 , and by regional economic integration organizations, constituted by sovereign States members of the Commission, which have competence in respect of the negotiation, conclusion and application of international agreements in matters covered by the Protocol, provided that the States and organizations concerned are Parties to the Convention and are listed in annex II. 
2. In matters within their competence, such regional economic integration organizations shall, on their own behalf, exercise the rights and fulfil the responsibilities which the present Protocol attributes to their member States. In such cases, the member States of these organizations shall not be entitled to exercise such rights individually.

\section{Article 13}

\section{RATIFICATION, ACCEPTANCE, APPROVAL AND ACCESSION}

1. The present Protocol shall be subject to ratification, acceptance or approval by Signatories.

2. The present Protocol shall be open for accession as from 12 December 1994 by the States and organizations that meet the requirements of article 12, paragraph 1.

\section{Article 14}

\section{DEPOSITARY}

The instruments of ratification, acceptance, approval or accession shall be deposited with the SecretaryGeneral of the United Nations, who will perform the functions of Depositary.

\section{Article 15}

\section{ENTRY INTO FORCE}

1. The present Protocol shall enter into force on the ninetieth day following the date on which the sixteenth instrument of ratification, acceptance, approval or accession has been deposited with the Depositary.

2. For each State and organization referred to in article 12, paragraph 1, which ratifies, accepts or approves the present Protocol or accedes thereto after the deposit of the sixteenth instrument of ratification, acceptance, approval or accession, the Protocol shall enter into force on the ninetieth day following the date of deposit by such Party of its instrument of ratification, acceptance, approval or accession.

\section{Article 16}

\section{WITHDRAWAL}

At any time after five years from the date on which the present Protocol has come into force with respect to a Party, that Party may withdraw from it by giving written notification to the Depositary. Any such withdrawal shall take effect on the ninetieth day following the date of its receipt by the Depositary, or on such later date as may be specified in the notification of the withdrawal.

\section{Article 17}

\section{AUTHENTIC TEXTS}

The original of the present Protocol, of which the English, French and Russian texts are equally authentic, shall be deposited with the Secretary-General of the United Nations. 
IN WITNESS WHEREOF the undersigned, being duly authorized thereto, have signed the present Protocol.

DONE at Oslo, this fourteenth day of June one thousand nine hundred and ninety-four.

\section{Annex I}

\section{CRITICAL SULPHUR DEPOSITION}

(5-percentile in centigrams of sulphur per square metre per year)

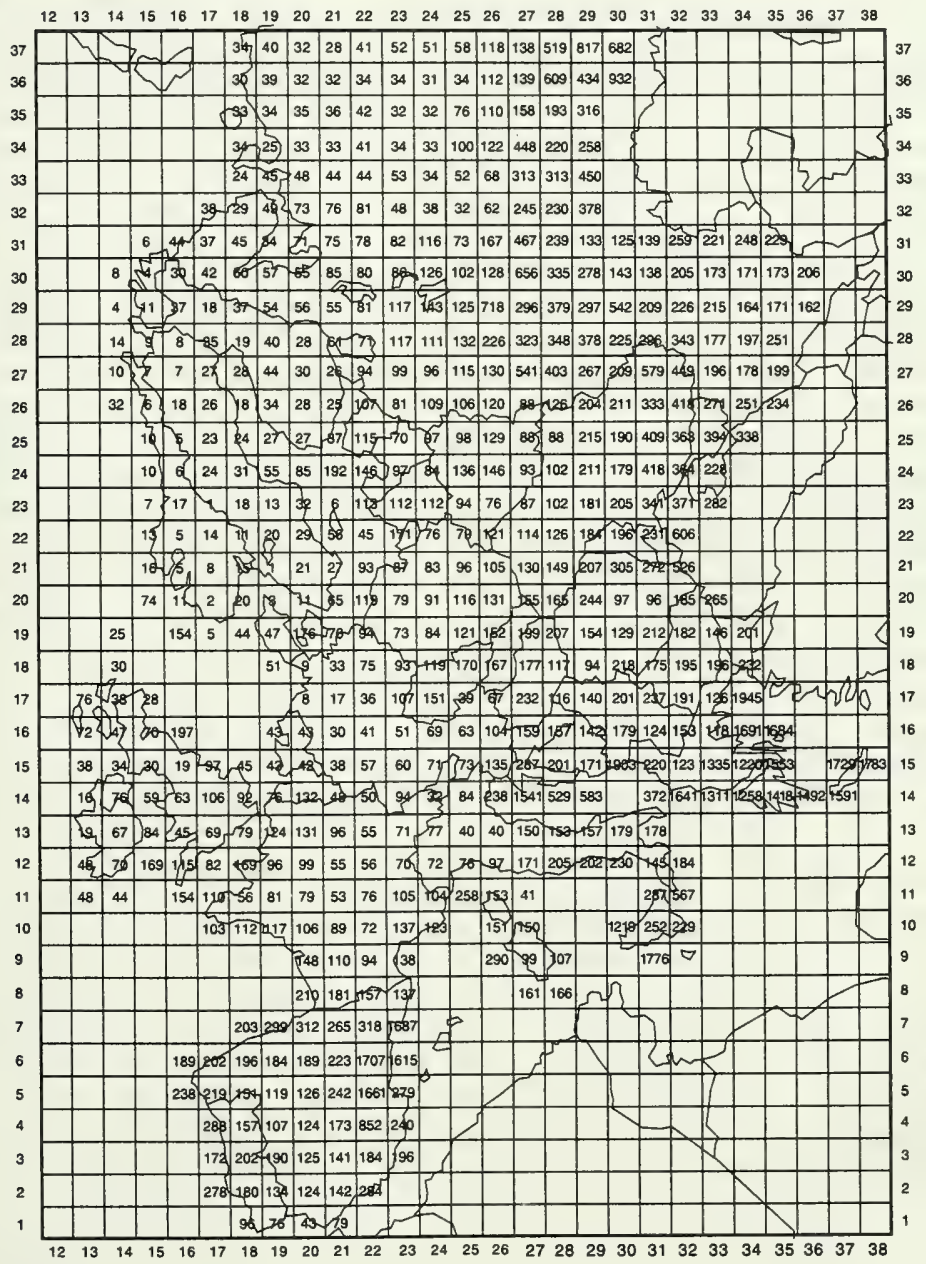




\section{Annex II}

\section{SULPHUR EMISSION CEILINGS AND PERCENTAGE EMISSION REDUCTIONS}

The sulphur emission ceilings listed in the table below give the obligations referred to in paragraphs 2 and 3 of article 2 of the present Protocol. The 1980 and 1990 emission levels and the percentage emission reductions listed are given for information purposes only.

\begin{tabular}{|c|c|c|c|c|c|c|c|c|}
\hline & \multicolumn{2}{|c|}{$\begin{array}{c}\text { Emission } \\
\text { levels } \\
\text { kt } \mathrm{SO}_{2} \text { per year }\end{array}$} & \multicolumn{3}{|c|}{$\begin{array}{l}\text { Sulphur emission } \\
\text { ceilings } \\
\text { kt } \mathrm{SO}_{2} \text { per year }\end{array}$} & \multicolumn{3}{|c|}{$\begin{array}{c}\text { Percentage emission } \\
\text { reductions } \\
\text { (base year } 1980^{\mathrm{b}} \text { ) }\end{array}$} \\
\hline & 1980 & 1990 & 2000 & 2005 & 2010 & 2000 & 2005 & 2010 \\
\hline Austria & 397 & 90 & 78 & & & 80 & & \\
\hline Belarus & 740 & & 456 & 400 & 370 & 38 & 46 & 50 \\
\hline Belgium & 828 & 443 & 248 & 232 & 215 & 70 & 72 & 74 \\
\hline Bulgaria & 2050 & 2020 & 1374 & 1230 & 1127 & 33 & 40 & 45 \\
\hline Canada - national & 4614 & 3700 & 3200 & & & 30 & & \\
\hline - SOMA & 3245 & & 1750 & & & 46 & & \\
\hline Croatia & 150 & 160 & 133 & 125 & 117 & 11 & 17 & 22 \\
\hline Czech Republic & 2257 & 1876 & 1128 & 902 & 632 & 50 & 60 & 72 \\
\hline Denmark & 451 & 180 & 90 & & & 80 & & \\
\hline Finland & 584 & 260 & 116 & & & 80 & & \\
\hline France & 3348 & 1202 & 868 & 770 & 737 & 74 & 77 & 78 \\
\hline Germany & 7494 & 5803 & 1300 & 990 & & 83 & 87 & \\
\hline Greece & 400 & 510 & 595 & 580 & 570 & 0 & 3 & 4 \\
\hline Hungary & 1632 & 1010 & 898 & 816 & 653 & 45 & 50 & 60 \\
\hline Ireland & 222 & 168 & 155 & & & 30 & & \\
\hline Italy & 3800 & & 1330 & 1042 & & 65 & 73 & \\
\hline Liechtenstein & 0.4 & 0.1 & 0.1 & & & 75 & & \\
\hline Luxembourg & 24 & & 10 & & & 58 & & \\
\hline Netherlands & 466 & 207 & 106 & & & 77 & & \\
\hline Norway & 142 & 54 & 34 & & & 76 & & \\
\hline Poland & 4100 & 3210 & 2583 & 2173 & 1397 & 37 & 47 & 66 \\
\hline Portugal & 266 & 284 & 304 & 294 & & 0 & 3 & \\
\hline Russian Federation & 7161 & 4460 & 4440 & 4297 & 4297 & 38 & 40 & 40 \\
\hline Slovakia & 843 & 539 & 337 & 295 & 240 & 60 & 65 & 72 \\
\hline Slovenia & 235 & 195 & 130 & 94 & 71 & 45 & 60 & 70 \\
\hline Spain & 3319 & 2316 & 2143 & & & 35 & & \\
\hline Sweden & 507 & 130 & 100 & & & 80 & & \\
\hline Switzerland & 126 & 62 & 60 & & & 52 & & \\
\hline Ukraine & 3850 & & 2310 & & & 40 & & \\
\hline United Kingdom & 4898 & 3780 & 2449 & 1470 & 980 & 50 & 70 & 80 \\
\hline European Community & 25513 & & 9598 & & & 62 & & \\
\hline
\end{tabular}




\section{Annex II (continued)}

\section{Notes}

a/ If, in a given year before 2005 , a Party finds that, due to a particularly cold winter, a particularly dry summer and an unforeseen short-term loss of capacity in the power supply system, domestically or in a neighbouring country, it cannot comply with its obligations under this annex, it may fulfil those obligations by averaging its national annual sulphur emissions for the year in question, the year preceding that year and the year following it, provided that the emission level in any single year is not more than $20 \%$ above the sulphur emission ceiling.

The reason for exceedance in any given year and the method by which the three-year average figure will be achieved, shall be reported to the Implementation Committee.

b/ For Greece and Portugal percentage emission reductions given are based on the sulphur emission ceilings indicated for the year 2000 .

c European part within the EMEP area.

\section{Annex III}

\section{DESIGNATION OF SULPHUR OXIDES MANAGEMENT AREAS (SOMAs)}

The following SOMA is listed for the purposes of the present Protocol:

\section{South-east Canada SOMA}

This is an area of 1 million $\mathrm{km}^{2}$ which includes all the territory of the provinces of Prince Edward Island, Nova Scotia and New Brunswick, all the territory of the province of Quebec south of a straight line between Havre-St.Pierre on the north coast of the Gulf of Saint Lawrence and the point where the Quebec-Ontario boundary intersects the James Bay coastline, and all the territory of the province of Ontario south of a straight line between the point where the Ontario-Quebec boundary intersects the James Bay coastline and Nipigon River near the north shore of Lake Superior.

\section{Annex IV \\ CONTROL TECHNOLOGIES FOR SULPHUR EMISSIONS FROM STATIONARY SOURCES}

\section{INTRODUCTION}

1. The aim of this annex is to provide guidance for identifying sulphur control options and technologies for giving effect to the obligations of the present Protocol.

2. The annex is based on information on general options for the reduction of sulphur emissions and in particular on emission control technology performance and costs contained in official documentation of the Executive Body and its subsidiary bodies.

3. Unless otherwise indicated, the reduction measures listed are considered, on the basis of operational experience of several years in most cases, to be the most well-established and economically feasible best available technologies. However, the continuously expanding experience of low-emission measures and technologies at new plants as well as of the retrofitting of existing plants will necessitate regular review of this annex. 
4. Although the annex lists a number of measures and technologies spanning a wide range of costs and efficiencies, it cannot be considered as an exhaustive statement of control options. Moreover, the choice of control measures and technologies for any particular case will depend on a number of factors, including current legislation and regulatory provisions and, in particular, control technology requirements, primary energy patterns, industrial infrastructure, economic circumstances and specific in-plant conditions.

5. The annex mainly addresses the control of oxidized sulphur emissions considered as the sum of sulphur dioxide $\left(\mathrm{SO}_{2}\right)$ and sulphur trioxide $\left(\mathrm{SO}_{3}\right)$, expressed as $\mathrm{SO}_{2}$. The share of sulphur emitted as either sulphur oxides or other sulphur compounds from non-combustion processes and other sources is small compared to sulphur emissions from combustion.

6. When measures or technologies are planned for sulphur sources emitting other components, in particular nitrogen oxides $\left(\mathrm{NO}_{\mathrm{x}}\right.$ ), particulates, heavy metals and volatile organic compounds (VOCs), it is worthwhile to consider them in conjunction with pollutant-specific control options in order to maximize the overall abatement effect and minimize the impact on the environment and, especially, to avoid the transfer of air pollution problems to other media (such as waste water and solid waste).

\section{MAJOR STATIONARY SOURCES FOR SULPHUR EMISSIONS}

7. Fossil fuel combustion processes are the main source of anthropogenic sulphur emissions from stationary sources. In addition, some non-combustion processes may contribute considerably to the emissions. The major stationary source categories, based on EMEP/CORINAIR'90, include:

(i) Public power, cogeneration and district heating plants:

(a) Boilers;

(b) Stationary combustion turbines and internal combustion engines;

(ii) Commercial, institutional and residential combustion plants:

(a) Commercial boilers;

(b) Domestic heaters;

(iii) Industrial combustion plants and processes with combustion:

(a) Boilers and process heaters;

(b) Processes, e.g. metallurgical operations such as roasting and sintering, coke oven plants, processing of titanium dioxide $\left(\mathrm{TiO}_{2}\right)$, etc;

(c) Pulp production;

(iv) Non-combustion processes, e.g. sulphuric acid production, specific organic synthesis processes, treatment of metallic surfaces;

(v) Extraction, processing and distribution of fossil fuels;

(vi) Waste treatment and disposal, e.g. thermal treatment of municipal and industrial waste.

8. Overall data (1990) for the ECE region indicate that about $88 \%$ of total sulphur emissions originate from all combustion processes ( $20 \%$ from industrial combustion), $5 \%$ from production processes and $7 \%$ from oil refineries. The power plant sector in many countries is the major single contributor to sulphur emissions. In some countries, the industrial sector (including refineries) is also an important $\mathrm{SO}_{2}$ emitter. Although emissions from refineries in the ECE region are relatively small, their impact on sulphur emissions from other sources is large due to the sulphur in the oil products. Typically $60 \%$ of the sulphur intake present in the crudes remains in the products, $30 \%$ is recovered as elemental sulphur and $10 \%$ is emitted from refinery stacks. 


\section{GENERAL OPTIONS FOR REDUCTION OF SULPHUR EMISSIONS FROM COMBUSTION}

9. General options for reduction of sulphur emissions are:

(i) Energy management measures:*/

(a) Energy saving

The rational use of energy (improved energy efficiency/process operation, cogeneration and/or demand-side management) usually results in a reduction in sulphur emissions.

\section{(b) Energy mix}

In general, sulphur emissions can be reduced by increasing the proportion of non-combustion energy sources (i.e. hydro, nuclear, wind, etc.) to the energy mix. However, further environmental impacts have to be considered.

(ii) Technological options:

(a) Fuel switching

The $\mathrm{SO}_{2}$ emissions during combustion are directly related to the sulphur content of the fuel used.

Fuel switching (e.g. from high- to low-sulphur coals and/or liquid fuels, or from coal to gas) leads to lower sulphur emissions, but there may be certain restrictions, such as the availability of low-sulphur fuels and the adaptability of existing combustion systems to different fuels. In many ECE countries, some coal or oil combustion plants are being replaced by gas-fired combustion plants. Dual-fuel plants may facilitate fuel switching.

(b) Fuel cleaning

Cleaning of natural gas is state-of-the-art technology and widely applied for operational reasons.

Cleaning of process gas (acid refinery gas, coke oven gas, biogas, etc.) is also state-of-the-art technology.

Desulphurization of liquid fuels (light and middle fractions) is state-of-the-art technology.

Desulphurization of heavy fractions is technically feasible; nevertheless, the crude properties should be kept in mind. Desulphurization of atmospheric residue (bottom products from atmospheric crude distillation units) for the production of low-sulphur fuel oil is not, however, commonly practised; processing low-sulphur crude is usually preferable. Hydro-cracking and full conversion technology have matured and combine high sulphur retention with improved yield of light products. The number of full conversion refineries is as yet limited. Such refineries typically recover 80 to $90 \%$ of the sulphur intake and convert all residues into light products or other marketable products. For this type of refinery, energy consumption and investment costs are increased. Typical sulphur content for refinery products is given in table 1 below.

Current technologies to clean hard coal can remove approximately $50 \%$ of the inorganic sulphur (depending on coal properties) but none of the organic sulphur. More effective technologies are being developed which, however, involve higher specific investment and costs. Thus the efficiency of sulphur removal by coal cleaning is limited compared to flue gas desulphurization. There may be a country-specific optimization potential for the best combination of fuel cleaning and flue gas cleaning. 


\section{Table 1}

\section{Sulphur content from refinery products (S content (\%))}

\begin{tabular}{lcc}
\hline & Typical present values & Anticipated future values \\
\hline Gasoline & 0.1 & 0.05 \\
Jet kerosene & 0.1 & 0.01 \\
Diesel & $0.05-0.3$ & $<0.05$ \\
Heating oil & $0.1-0.2$ & $<0.1$ \\
Fuel oil & $0.2-3.5$ & $<1$ \\
Marine diesel & $0.5-1.0$ & $<0.5$ \\
Bunker oil & $3.0-5.0$ & $<1$ (coastal areas) \\
& & $<2$ (high seas) \\
\hline
\end{tabular}

(c) Advanced combustion technologies

These combustion technologies with improved thermal efficiency and reduced sulphur emissions include: fluidized-bed combustion (FBC): bubbling (BFBC), circulating (CFBC) and pressurized (PFBC); integrated gasification combined-cycle (IGCC); and combined-cycle gas turbines (CCGT).

Stationary combustion turbines can be integrated into combustion systems in existing conventional power plants which can increase overall efficiency by 5 to $7 \%$, leading, for example, to a significant reduction in $\mathrm{SO}_{2}$ emissions. However, major alterations to the existing furnace system become necessary.

Fluidized-bed combustion is a combustion technology for burning hard coal and brown coal, but it can also burn other solid fuels such as petroleum coke and low-grade fuels such as waste, peat and wood. Emissions can additionally be reduced by integrated combustion control in the system due to the addition of lime/limestone to the bed material. The total installed capacity of FBC has reached approximately $30,000 \mathrm{MW}_{\text {th }}$ (250 to 350 plants), including $8,000 \mathrm{MW}_{\text {th }}$ in the capacity range of greater than $50 \mathrm{MW}_{\mathrm{th}}$. By-products from this process may cause problems with respect to use and/or disposal, and further development is required.

The IGCC process includes coal gasification and combined-cycle power generation in a gas and steam turbine. The gasified coal is burnt in the combustion chamber of the gas turbine. Sulphur emission control is achieved by the use of state-of-the-art technology for raw gas cleaning facilities upstream of the gas turbine. The technology also exists for heavy oil residues and bitumen emulsions. The installed capacity is presently about $1,000 \mathrm{MW}_{\mathrm{el}}$ (5 plants).

Combined-cycle gas-turbine power stations using natural gas as fuel with an energy efficiency of approximately 48 to $52 \%$ are currently being planned.

(d) Process and combustion modifications

Combustion modifications comparable to the measures used for $\mathrm{NO}_{\mathrm{x}}$ emission control do not exist, as during combustion the organically and/or inorganically bound sulphur is almost completely oxidized (a certain percentage depending on the fuel properties and combustion technology is retained in the ash).

In this annex dry additive processes for conventional boilers are considered as process modifications due to the injection of an agent into the combustion unit. However, experience has shown that, when applying these processes, thermal capacity is lowered, the $\mathrm{Ca} / \mathrm{S}$ ratio is high and sulphur removal low. Problems with the further utilization of the by-product have to be considered, so that this solution should usually be applied as an intermediate measure and for smaller units (table 2). 


\section{Table 2}

\section{Emissions of sulphur oxides obtained from the application of technological options to fossil-fuelled boilers}

\begin{tabular}{|c|c|c|c|c|c|c|c|c|}
\hline & \multicolumn{2}{|c|}{$\begin{array}{l}\text { Uncontrolled } \\
\text { emissions }\end{array}$} & \multicolumn{2}{|c|}{$\begin{array}{l}\text { Additive } \\
\text { injection }\end{array}$} & \multicolumn{2}{|c|}{$\begin{array}{c}\text { Wet } \\
\text { scrubbing }\end{array}$} & \multicolumn{2}{|c|}{$\begin{array}{c}\text { Spray dry } \\
\text { absorption b/ }\end{array}$} \\
\hline Reduction efficiency (\%) & & & up to 60 & & 95 & & up to 90 & \\
\hline $\begin{array}{l}\text { Energy efficiency } \\
\left.\mathrm{kW}_{\mathrm{el}} / 10^{3} \mathrm{~m}^{3} / \mathrm{h}\right)\end{array}$ & & & $0.1-1$ & & $6-10$ & & $3 \cdot 6$ & \\
\hline $\begin{array}{l}\text { Total installed capacity } \\
\left(\mathrm{ECE} \text { Eur)(MW } \mathrm{MW}_{\text {th }}\right)\end{array}$ & & & & & 194,000 & & 16,000 & \\
\hline Type of by-product & & & $\begin{array}{l}\text { Mix of C. } \\
\text { and fly as }\end{array}$ & $\begin{array}{l}\text { a salts } \\
\text { shes }\end{array}$ & $\begin{array}{l}\text { Gypsum (sludg } \\
\text { water) }\end{array}$ & /waste & $\begin{array}{l}\mathrm{Mix} \text { of } \mathrm{CaSo}_{3} \\
\text { and fly ashes }\end{array}$ & $1 / 2 \mathrm{H}_{2} \mathrm{O}$ \\
\hline \multirow[t]{2}{*}{$\begin{array}{l}\text { Specific investment } \\
\left(\text { cost } \mathrm{ECU}(1990) / \mathrm{kW}_{\mathrm{el}}\right)\end{array}$} & & & $20-50$ & & $60-250$ & & $50-220$ & \\
\hline & $\mathrm{mg} / \mathrm{m}^{3 \mathrm{~s}}$ & $\mathrm{~g} / \mathrm{kWh}_{\mathrm{el}}$ & $\mathrm{mg} / \mathrm{m}^{3} \mathrm{~g}$ & $\mathrm{~g} / \mathrm{kWh}_{\mathrm{el}}$ & $\mathrm{mg} / \mathrm{m}^{3} \mathrm{c}$ & $\mathrm{g} / \mathrm{kWh}_{\mathrm{el}}$ & $\mathrm{mg} / \mathrm{m}^{3} \mathrm{~s}$ & $\mathrm{~g} / \mathrm{kWh}_{\mathrm{el}}$ \\
\hline Hard coal d & $\begin{array}{l}1,000- \\
10,000\end{array}$ & $3.5-35$ & $\begin{array}{l}400 \\
4,000\end{array}$ & $1.4-14$ & $\begin{array}{l}<400 \\
(<200,1 \% \mathrm{~S})\end{array}$ & $\begin{array}{l}<1.4 \\
<0.7\end{array}$ & $\begin{array}{l}<400 \\
(<200,1 \% \mathrm{~S})\end{array}$ & $\begin{array}{l}<1.4 \\
<0.7\end{array}$ \\
\hline Brown coal d & $\begin{array}{l}1,000- \\
20,000\end{array}$ & $4.2-84$ & $\begin{array}{l}400- \\
8,000\end{array}$ & $1.7-33.6$ & $\begin{array}{l}<400 \\
(<200,1 \% \mathrm{~S})\end{array}$ & $\begin{array}{l}<1.7 \\
<0.8\end{array}$ & $\mid \begin{array}{l}<400 \\
(<200,1 \% \mathrm{~S})\end{array}$ & $\begin{array}{l}<1.7 \\
<0.8\end{array}$ \\
\hline \multirow[t]{2}{*}{ Heavy oil d/ } & $\begin{array}{l}1,000- \\
10,000\end{array}$ & 2.8-28 & $\begin{array}{l}400- \\
4,000\end{array}$ & $1.1-11$ & $\begin{array}{l}<400 \\
(<200,1 \% \mathrm{~S})\end{array}$ & $\begin{array}{l}<1.1 \\
<0.6\end{array}$ & $\begin{array}{l}<400 \\
(<200,1 \% \mathrm{~S})\end{array}$ & $\begin{array}{l}<1.1 \\
<0.6\end{array}$ \\
\hline & \multicolumn{2}{|c|}{$\begin{array}{l}\text { Ammonia } \\
\text { scrubbing }{ }^{b /}\end{array}$} & \multicolumn{2}{|c|}{$\begin{array}{l}\text { Wellman } \\
\text { Lord a/ }\end{array}$} & \multicolumn{2}{|c|}{$\begin{array}{l}\text { Activated } \\
\text { carbon } \mathrm{a}\end{array}$} & \multicolumn{2}{|c|}{$\begin{array}{l}\text { Combined } \\
\text { catalytic }{ }^{a}\end{array}$} \\
\hline Reduction efficiency (\%) & \multicolumn{2}{|l|}{ up to 90} & \multicolumn{2}{|l|}{95} & \multicolumn{2}{|l|}{95} & \multicolumn{2}{|l|}{95} \\
\hline $\begin{array}{l}\text { Energy efficiency } \\
\left(\mathrm{kW}_{\mathrm{e}} / 10^{3} \mathrm{~m}^{3} / \mathrm{h}\right)\end{array}$ & \multicolumn{2}{|l|}{ 3-10 } & \multicolumn{2}{|l|}{$10-15$} & \multicolumn{2}{|l|}{$4-8$} & \multicolumn{2}{|l|}{2} \\
\hline $\begin{array}{l}\text { Total installed capacity } \\
\text { (ECE Eur) (MW } \text { (th })\end{array}$ & \multicolumn{2}{|l|}{200} & \multicolumn{2}{|l|}{2,000} & \multicolumn{2}{|l|}{700} & \multicolumn{2}{|l|}{1,300} \\
\hline Type of by-product & \multicolumn{2}{|c|}{$\begin{array}{l}\text { Ammonia } \\
\text { fertilizer }\end{array}$} & \multicolumn{2}{|c|}{$\begin{array}{l}\text { Elemental S } \\
\text { Sulphuric acid } \\
\text { (99 vol.\%) }\end{array}$} & \multicolumn{2}{|l|}{$\begin{array}{l}\text { Elemental S } \\
\text { Sulphuric acid } \\
(99 \text { vol.\%) }\end{array}$} & \multicolumn{2}{|l|}{$\begin{array}{l}\text { Sulphuric acid } \\
\text { (70 wt.\%) }\end{array}$} \\
\hline \multirow{2}{*}{$\begin{array}{l}\text { Specific investment } \\
\left(\text { cost } \mathrm{ECU}(1990) / \mathrm{kW}_{\mathrm{el}}\right)\end{array}$} & \multicolumn{2}{|c|}{$230-270$} & \multicolumn{2}{|c|}{$200-300 \mathrm{~s} /$} & \multicolumn{2}{|l|}{$280-320 \mathrm{e} / \mathrm{f}$} & \multicolumn{2}{|l|}{$320-350^{e / /}$} \\
\hline & $\mathrm{mg} / \mathrm{m}^{3} \mathrm{c}$ & $\mathrm{g} / \mathrm{kWh} \mathrm{h}_{\mathrm{el}}$ & $\mathrm{mg} / \mathrm{m}^{3 \mathrm{~g}}$ & $\mathrm{~g} / \mathrm{kWh} \mathrm{el}_{\mathrm{el}}$ & $\mathrm{mg} / \mathrm{m}^{3} \mathrm{~s}^{\prime}$ & $\mathrm{g} / \mathrm{kWh}_{\mathrm{el}}$ & $\mathrm{mg} / \mathrm{m}^{3} \mathrm{~g}$ & $\mathbf{g} / \mathbf{k W h} \mathbf{h}_{\mathrm{el}}$ \\
\hline Hard coal d & $\begin{array}{l}<400 \\
(<200 \\
1 \% \mathrm{~S})\end{array}$ & $\begin{array}{l}<1.4 \\
<0.7\end{array}$ & $\begin{array}{l}<400 \\
(<200 \\
1 \% \mathrm{~S})\end{array}$ & $\begin{array}{l}<1.4 \\
<0.7\end{array}$ & $\begin{array}{l}<400 \\
(<200,1 \% \mathrm{~S})\end{array}$ & $<1.4$ & $\begin{array}{l}<400 \\
(<200,1 \% \mathrm{~S})\end{array}$ & $\begin{array}{l}<1.4 \\
<0.7\end{array}$ \\
\hline Brown coal d/ & $\begin{array}{l}<400 \\
(<200 \\
1 \% S)\end{array}$ & $\begin{array}{l}<1.7 \\
<0.8\end{array}$ & $\begin{array}{l}<400 \\
(<200 \\
1 \% \mathrm{~S})\end{array}$ & $\begin{array}{l}<1.7 \\
<0.8\end{array}$ & $\begin{array}{l}<400 \\
(<200,1 \% \mathrm{~S})\end{array}$ & $\begin{array}{l}<1.7 \\
<0.8\end{array}$ & $\begin{array}{l}<400 \\
(<200,1 \% \mathrm{~S})\end{array}$ & $\begin{array}{l}<1.7 \\
<0.8\end{array}$ \\
\hline Heavy oil $\stackrel{d}{d}$ & $\begin{array}{l}<400 \\
(<200 \\
1 \% \mathrm{~S})\end{array}$ & $<1.1$ & $\begin{array}{l}<400 \\
(<200 \\
1 \% \mathrm{~S})\end{array}$ & $\begin{array}{l}<1.1 \\
<0.6\end{array}$ & $\begin{array}{l}<400 \\
(<200,1 \% \mathrm{~S})\end{array}$ & $\begin{array}{l}<1.1 \\
<0.6\end{array}$ & $\begin{array}{l}<400 \\
(<200,1 \% \mathrm{~S})\end{array}$ & $<1.1$ \\
\hline
\end{tabular}




\section{Table 2 (continued)}

\section{Notes}

a/ For high sulphur content in the fuel the removal efficiency has to be adapted. However, the scope for doing so may be process-specific. Availability of these processes is usually $95 \%$.

b/ Limited applicability for high-sulphur fuels.

c/ Emission in $\mathrm{mg} / \mathrm{m}^{3}$ (STP), dry, $6 \%$ oxygen for solid fuels, $3 \%$ oxygen for liquid fuels.

d/ Conversion factor depends on fuel properties, specific fuel gas volume and thermal efficiency of boiler (conversion factors $\left(\mathrm{m}^{3} / \mathrm{kWh}_{\mathrm{el}}\right.$, thermal efficiency: $36 \%$ ) used: hard coal: 3.50 ; brown coal: 4.20 ; heavy oil: 2,80 ).

e/ Specific investment cost relates to a small sample of installations.

f) Specific investment cost includes denitrification process.

The table was established mainly for large combustion installations in the public sector. However, the control options are also valid for other sectors with similar exhaust gases.

(e) Flue gas desulphurization (FGD) processes

These processes aim at removing already formed sulphur oxides, and are also referred to as secondary measures. The state-of-the-art technologies for flue gas treatment processes are all based on the removal of sulphur by wet, dry or semi-dry and catalytic chemical processes.

To achieve the most efficient programme for sulphur emission reductions beyond the energy management measures listed in (i) above a combination of technological options identified in (ii) above should be considered.

In some cases options for reducing sulphur emissions may also result in the reduction of emissions of $\mathrm{CO}_{2}, \mathrm{NO}_{\mathrm{x}}$ and other pollutants.

In public power, cogeneration and district heating plants, flue gas treatment processes used include: lime/limestone wet scrubbing (LWS), spray dry absorption (SDA); Wellman Lord process (WL), ammonia scrubbing (AS), and combined $\mathrm{NO}_{\mathrm{x}} / \mathrm{SO}_{\mathrm{x}}$ removal processes (activated carbon process $(\mathrm{AC})$ and combined catalytic $\mathrm{NO}_{\mathrm{z}} / \mathrm{SO}_{\mathrm{x}} \mathrm{removal}$ ).

In the power generation sector, LWS and SDA cover $85 \%$ and $10 \%$, respectively, of the installed FGD capacity.

Several new flue gas desulphurization processes, such as electron beam dry scrubbing (EBDS) and Mark 13A, have not yet passed the pilot stage.

Table 2 above shows the efficiency of the above-mentioned secondary measures based on the practical experience gathered from a large number of implemented plants. The implemented capacity as well as the capacity range are also mentioned. Despite comparable characteristics for several sulphur abatement technologies, local or plant-specific influences may lead to the exclusion of a given technology.

Table 2 also includes the usual investment cost ranges for the sulphur abatement technologies listed in sections (ii) (c), (d) and (e). However, when applying these technologies to individual cases it should be noted that investment costs of emission reduction measures will depend amongst other things on the particular technologies used, the required control systems, the plant size, the extent of the required reduction and the time-scale of planned maintenance cycles. The table thus gives only a broad range of investment costs. Investment costs for retrofit generally exceed those for new plants. 


\section{CONTROL TECHNIQUES FOR OTHER SECTORS}

10. The control techniques listed in section 9 (ii) (a) to (e) are valid not only in the power plant sector but also in various other sectors of industry. Several years of operational experience have been acquired, in most cases in the power plant sector.

11. The application of sulphur abatement technologies in the industrial sector merely depends on the process's specific limitations in the relevant sectors. Important contributors to sulphur emissions and corresponding reduction measures are presented in table 3 below.

\section{Table 3}

\begin{tabular}{ll}
\multicolumn{1}{c}{ Source } & \multicolumn{1}{c}{ Reduction measures } \\
\hline $\begin{array}{l}\text { Roasting of non-ferrous sulphides } \\
\text { Viscose production }\end{array}$ & Wet sulphuric acid catalytic process (WSA) \\
\hline Sulphuric acid production & Double-contact process \\
\hline Kraft pulp production & Double-contact process, improved yield \\
\hline
\end{tabular}

12. In the sectors listed in table 3 , process-integrated measures, including raw materials changes (if necessary combined with sector-specific flue gas treatment), can be used to achieve the most effective reduction of sulphur emissions.

13. Reported examples are the following:

(a) In new kraft pulp mills, sulphur emission of less than $1 \mathrm{~kg}$ of sulphur per tonne of pulp $\mathrm{AD}$ (air dried) can be achieved; $\stackrel{* *}{-}$

(b) In sulphite pulp mills, 1 to $1.5 \mathrm{~kg}$ of sulphur per tonne of pulp $\mathrm{AD}$ can be achieved;

(c) In the case of roasting of sulphides, removal efficiencies of 80 to $99 \%$ for 10,000 to $200,000 \mathrm{~m}^{3 / \mathrm{h}}$ units have been reported (depending on the process);

(d) For one iron ore sintering plant, an FGD unit of $320,000 \mathrm{~m}^{3} / \mathrm{h}$ capacity achieves a clean gas value below $100 \mathrm{mg} \mathrm{SO} / \mathrm{Nm}^{3}$ at $6 \% \mathrm{O}_{2}$;

(e) Coke ovens are achieving less than $400 \mathrm{mg} \mathrm{SO} / \mathrm{Nm}^{3}$ at $6 \% \mathrm{O}_{2}$;

(f) Sulphuric acid plants achieve a conversion rate larger than $99 \%$;

(g) Advanced Claus plant achieves sulphur recovery of more than $99 \%$.

\section{BY-PRODUCTS AND SIDE-EFFECTS}

14. As efforts to reduce sulphur emissions from stationary sources are increased in the countries of the ECE region, the quantities of by-products will also increase.

15. Options which would lead to usable by-products should be selected. Furthermore, options that lead to increased thermal efficiency and minimize the waste disposal issue whenever possible should be selected. Although most by-products are usable or recyclable products such as gypsum, ammonia salts, sulphuric acid or sulphur, factors such as market conditions and quality standards need to be taken into account. Further utilization of FBC and SDA by-products have to be improved and investigated, as disposal sites and disposal criteria limit disposal in several countries. 
16. The following side-effects will not prevent the implementation of any technology or method but should be considered when several sulphur abatement options are possible:

(a) Energy requirements of the gas treatment processes;

(b) Corrosion attack due to the formation of sulphuric acid by the reaction of sulphur oxides with water vapour;

(c) Increased use of water and waste water treatment;

(d) Reagent requirements;

(e) Solid waste disposal.

\section{MONITORING AND REPORTING}

17. The measures taken to carry out national strategies and policies for the abatement of air pollution include: legislation and regulatory provisions, economic incentives and disincentives, as well as technological requirements (best available technology).

18. In general, standards are set, per emission source, according to plant size, operating mode, combustion technology, fuel type and whether it is a new or existing plant. An alternative approach also used is to set a target for the reduction of total sulphur emissions from a group of sources and to allow a choice of where to take action to reach this target (the bubble concept).

19. Efforts to limit the sulphur emissions to the levels set out in the national framework legislation have to be controlled by a permanent monitoring and reporting system and reported to the supervising authorities.

20. Several monitoring systems, using both continuous and discontinuous measurement methods, are available. However, quality requirements vary. Measurements are to be carried out by qualified institutes using measuring and monitoring systems. To this end, a certification system can provide the best assurance.

21. In the framework of modern automated monitoring systems and process control equipment, reporting does not create a problem. The collection of data for further use is a state-of-the-art technique; however, data to be reported to competent authorities differ from case to case. To obtain better comparability, data sets and prescribing regulations should be harmonized. Harmonization is also desirable for quality assurance of measuring and monitoring systems. This should be taken into account when comparing data.

22. To avoid discrepancies and inconsistencies, key issues and parameters, including the following, must be well defined:

(a) Definition of standards expressed as ppmv, $\mathrm{mg} / \mathrm{Nm}^{3}, \mathrm{~g} / \mathrm{GJ}, \mathrm{kg} / \mathrm{h}$ or $\mathrm{kg} /$ tonne of product. Most of these units need to be calculated and need specification in terms of gas temperature, humidity, pressure, oxygen content or heat input value;

(b) Definition of the period over which standards are to be averaged, expressed as hours, months or a year;

(c) Definition of failure times and corresponding emergency regulations regarding bypass of monitoring systems or shut-down of the installation;

(d) Definition of methods for back-filling of data missed or lost as result of equipment failure;

(e) Definition of the parameter set to be measured. Depending on the type of industrial process, the necessary information may differ. This also involves the location of the measurement point within the system.

23. Quality control of measurements has to be ensured. 


\section{Annex V}

\section{EMISSION AND SULPHUR CONTENT LIMIT VALUES}

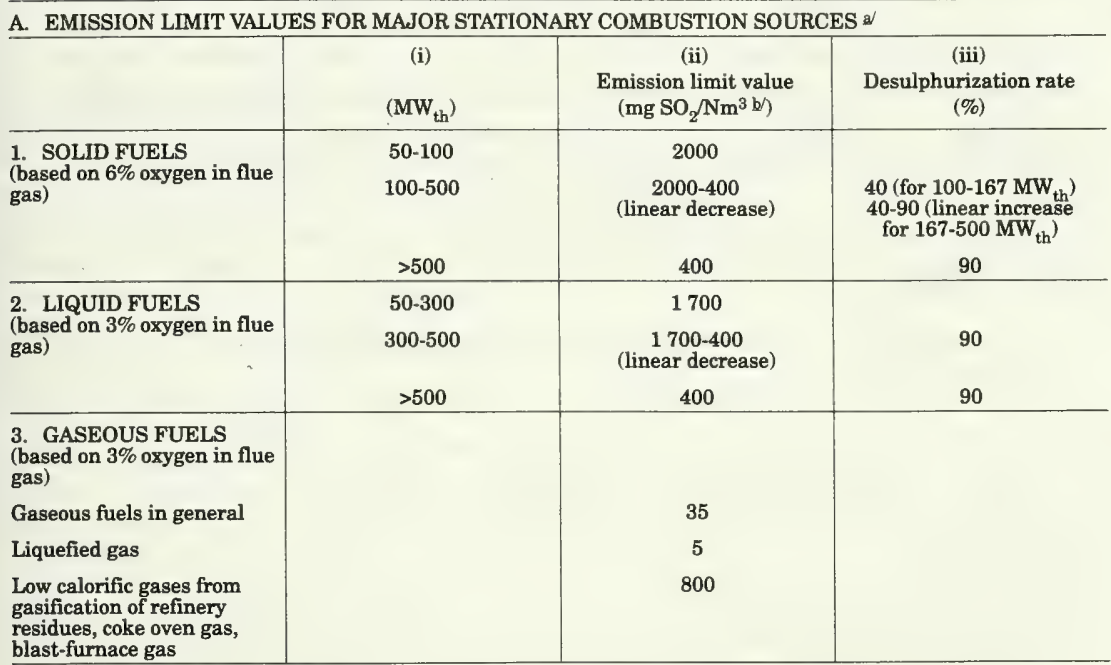

\begin{tabular}{l|c}
\hline B. GAS OIL & Sulphur content (\%) \\
\hline Diesel for on-road vehicles & 0.05 \\
Other types & 0.2 \\
\hline
\end{tabular}

\section{Notes}

a/ As guidance, for a plant with a multi-fuel firing unit involving the simultaneous use of two or more types of fuels, the competent authorities shall set emission limit values taking into account the emission limit values from column (ii) relevant for each individual fuel, the rate of thermal input delivered by each fuel and, for refineries, the relevant specific characteristics of the plant. For refineries, such a combined limit value shall under no circumstances exceed $1700 \mathrm{mg} \mathrm{SO} / \mathrm{Nm}^{3}$.

In particular, the limit values shall not apply to the following plants:

Plants in which the products of combustion are used for direct heating, drying, or any other treatment of objects or materials, e.g. reheating furnaces, furnaces for heat treatment;

Post-combustion plants, i.e. any technical apparatus designed to purify the waste gases by combustion which is not operated as an independent combustion plant;

Facilities for the regeneration of catalytic cracking catalysts;

Facilities for the conversion of hydrogen sulphide into sulphur;

Reactors used in the chemical industry; 
- Coke battery furnaces;

- Cowpers;

- Waste incinerators;

- Plants powered by diesel, petrol and gas engines or by gas turbines, irrespective of the fuel used.

In a case where a Party, due to the high sulphur content of indigenous solid or liquid fuels, cannot meet the emission limit values set forth in column (ii), it may apply the desulphurization rates set forth in column (iii) or a maximum limit value of $800 \mathrm{mg} \mathrm{SO} 2 / \mathrm{Nm}^{3}$ (although preferably not more than $650 \mathrm{mg} \mathrm{SO} / \mathrm{Nm}^{3}$ ). The Party shall report any such application to the Implementation Committee in the calendar year in which it is made.

Where two or more separate new plants are installed in such a way that, taking technical and economic factors into account, their waste gases could, in the judgement of the competent authorities, be discharged through a common stack, the combination formed by such plants is to be regarded as a single unit.

b/ $\quad \mathrm{mg} \mathrm{SO}_{2} / \mathrm{Nm}^{3}$ is defined at a temperature of $273^{\circ} \mathrm{K}$ and a pressure of $101.3 \mathrm{kPa}$, after correction for the water vapour content. 


\title{
United Nations Convention to Combat Desertification in Those Countries Experiencing Serious Drought and/or Desertification, Particularly in Africa, Paris, 1994
}

\author{
Done at Paris 17 June 1994 \\ Entered into force 26 December 1996* \\ Depositary: United Nations \\ Primary source citation: United Nations Certified \\ True Copy (XXVII.10)
}

\section{UNITED NATIONS CONVENTION TO COMBAT DESERTIFICATION IN THOSE COUNTRIES EXPERIENCING SERIOUS DROUGHT AND/OR DESERTIFICATION, PARTICULARLY IN AFRICA}

The Parties to this Convention,

Affirming that human beings in affected or threatened areas are at the centre of concerns to combat desertification and mitigate the effects of drought,

Reflecting the urgent concern of the international community, including States and international organizations, about the adverse impacts of desertification and drought,

Aware that arid, semi-arid and dry sub-humid areas together account for a significant proportion of the Earth's land area and are the habitat and source of livelihood for a large segment of its population,

Acknowledging that desertification and drought are problems of global dimension in that they affect all regions of the world and that joint action of the international community is needed to combat desertification and/or mitigate the effects of drought,

Noting the high concentration of developing countries, notably the least developed countries, among those experiencing serious drought and/or desertification, and the particularly tragic consequences of these phenomena in Africa,

Noting also that desertification is caused by complex interactions among physical, biological, political, social, cultural and economic factors, 
Considering the impact of trade and relevant aspects of international economic relations on the ability of affected countries to combat desertification adequately,

Conscious that sustainable economic growth, social development and poverty eradication are priorities of affected developing countries, particularly in Africa, and are essential to meeting sustainability objectives,

Mindful that desertification and drought affect sustainable development through their interrelationships with important social problems such as poverty, poor health and nutrition, lack of food security, and those arising from migration, displacement of persons and demographic dynamics,

Appreciating the significance of the past efforts and experience of States and international organizations in combating desertification and mitigating the effects of drought, particularly in implementing the Plan of Action to Combat Desertification which was adopted at the United Nations Conference on Desertification in 1977,

Realizing that, despite efforts in the past, progress in combating desertification and mitigating the effects of drought has not met expectations and that a new and more effective approach is needed at all levels within the framework of sustainable development,

Recognizing the validity and relevance of decisions adopted at the United Nations Conference on Environment and Development, particularly of Agenda 21 and its chapter 12, which provide a basis for combating desertification,

Reaffirming in this light the commitments of developed countries as contained in paragraph 13 of chapter 33 of Agenda 21,

Recalling General Assembly resolution 47/188, particularly the priority in it prescribed for Africa, and all other relevant United Nations resolutions, decisions and programmes on desertification and drought, as well as relevant declarations by African countries and those from other regions,

Reaffirming the Rio Declaration on Environment and Development which states, in its Principle 2, that States have, in accordance with the Charter of the United Nations and the principles of international law, the sovereign right to exploit their own resources pursuant to their own environmental and developmental policies, and the responsibility to ensure that activities within their jurisdiction or control do not cause damage to the environment of other States or of areas beyond the limits of national jurisdiction,

Recognizing that national Governments play a critical role in combating desertification and mitigating the effects of drought and that progress in that respect depends on local implementation of action programmes in affected areas,

Recognizing also the importance and necessity of international cooperation and partnership in combating desertification and mitigating the effects of drought,

Recognizing further the importance of the provision to affected developing countries, particularly in Africa, of effective means, inter alia substantial financial resources, including new and additional funding, and access to technology, without which it will be difficult for them to implement fully their commitments under this Convention,

Expressing concern over the impact of desertification and drought on affected countries in Central Asia and the Transcaucasus,

Stressing the important role played by women in regions affected by desertification and/or drought, particularly in rural areas of developing countries, and the importance of ensuring the full participation of both men and women at all levels in programmes to combat desertification and mitigate the effects of drought,

Emphasizing the special role of non-governmental organizations and other major groups in programmes to combat desertification and mitigate the effects of drought,

Bearing in mind the relationship between desertification and other environmental problems of global dimension facing the international and national communities, 
Bearing also in mind the contribution that combating desertification can make to achieving the objectives of the United Nations Framework Convention on Climate Change, the Convention on Biological Diversity and other related environmental conventions,

Believing that strategies to combat desertification and mitigate the effects of drought will be most effective if they are based on sound systematic observation and rigorous scientific knowledge and if they are continuously re-evaluated,

Recognizing the urgent need to improve the effectiveness and coordination of international cooperation to facilitate the implementation of national plans and priorities,

Determined to take appropriate action in combating desertification and mitigating the effects of drought for the benefit of present and future generations,

Have agreed as follows:

\section{PART I}

\section{INTRODUCTION}

\section{Article 1 \\ Use of terms}

For the purposes of this Convention:

(a) "desertification" means land degradation in arid, semi-arid and dry sub-humid areas resulting from various factors, including climatic variations and human activities;

(b) "combating desertification" includes activities which are part of the integrated development of land in arid, semi-arid and dry sub-humid areas for sustainable development which are aimed at:

(i) prevention and/or reduction of land degradation;

(ii) rehabilitation of partly degraded land; and

(iii) reclamation of desertified land;

(c) "drought" means the naturally occurring phenomenon that exists when precipitation has been significantly below normal recorded levels, causing serious hydrological imbalances that adversely affect land resource production systems;

(d) "mitigating the effects of drought" means activities related to the prediction of drought and intended to reduce the vulnerability of society and natural systems to drought as it relates to combating desertification;

(e) "land" means the terrestrial bio-productive system that comprises soil, vegetation, other biota, and the ecological and hydrological processes that operate within the system;

(f) "land degradation" means reduction or loss, in arid, semi-arid and dry sub-humid areas, of the biological or economic productivity and complexity of rainfed cropland, irrigated cropland, or range, pasture, forest and woodlands resulting from land uses or from a process or combination of processes, including processes arising from human activities and habitation patterns, such as:

(i) soil erosion caused by wind and/or water;

(ii) deterioration of the physical, chemical and biological or economic properties of soil; and 
(iii) long-term loss of natural vegetation;

(g) "arid, semi-arid and dry sub-humid areas" means areas, other than polar and sub-polar regions, in which the ratio of annual precipitation to potential evapotranspiration falls within the range from 0.05 to 0.65 ;

(h) "affected areas" means arid, semi-arid and/or dry sub-humid areas affected or threatened by desertification;

(i) “affected countries" means countries whose lands include, in whole or in part, affected areas;

(j) "regional economic integration organization" means an organization constituted by sovereign States of a given region which has competence in respect of matters governed by this Convention and has been duly authorized, in accordance with its internal procedures, to sign, ratify, accept, approve or accede to this Convention;

(k) “developed country Parties" means developed country Parties and regional economic integration organizations constituted by developed countries.

\section{Article 2 \\ Objective}

1. The objective of this Convention is to combat desertification and mitigate the effects of drought in countries experiencing serious drought and/or desertification, particularly in Africa, through effective action at all levels, supported by international cooperation and partnership arrangements, in the framework of an integrated approach which is consistent with Agenda 21, with a view to contributing to the achievement of sustainable development in affected areas.

2. Achieving this objective will involve long-term integrated strategies that focus simultaneously, in affected areas, on improved productivity of land, and the rehabilitation, conservation and sustainable management of land and water resources, leading to improved living conditions, in particular at the community level.

\section{Article 3 \\ Principles}

In order to achieve the objective of this Convention and to implement its provisions, the Parties shall be guided, inter alia, by the following:

(a) the Parties should ensure that decisions on the design and implementation of programmes to combat desertification and/or mitigate the effects of drought are taken with the participation of populations and local communities and that an enabling environment is created at higher levels to facilitate action at national and local levels;

(b) the Parties should, in a spirit of international solidarity and partnership, improve cooperation and coordination at subregional, regional and international levels, and better focus financial, human, organizational and technical resources where they are needed;

(c) the Parties should develop, in a spirit of partnership, cooperation among all levels of government, communities, non-governmental organizations and landholders to establish a better understanding of the nature and value of land and scarce water resources in affected areas and to work towards their sustainable use; and

(d) the Parties should take into full consideration the special needs and circumstances of affected developing country Parties, particularly the least developed among them. 


\title{
PART II
}

\section{GENERAL PROVISIONS}

\author{
Article 4 \\ General obligations
}

1. The Parties shall implement their obligations under this Convention, individually or jointly, either through existing or prospective bilateral and multilateral arrangements or a combination thereof, as appropriate, emphasizing the need to coordinate efforts and develop a coherent long-term strategy at all levels.

2. In pursuing the objective of this Convention, the Parties shall:

(a) adopt an integrated approach addressing the physical, biological and socio-economic aspects of the processes of desertification and drought;

(b) give due attention, within the relevant international and regional bodies, to the situation of affected developing country Parties with regard to international trade, marketing arrangements and debt with a view to establishing an enabling international economic environment conducive to the promotion of sustainable development;

(c) integrate strategies for poverty eradication into efforts to combat desertification and mitigate the effects of drought;

(d) promote cooperation among affected country Parties in the fields of environmental protection and the conservation of land and water resources, as they relate to desertification and drought;

(e) strengthen subregional, regional and international cooperation;

(f) cooperate within relevant intergovernmental organizations;

(g) determine institutional mechanisms, if appropriate, keeping in mind the need to avoid duplication; and

(h) promote the use of existing bilateral and multilateral financial mechanisms and arrangements that mobilize and channel substantial financial resources to affected developing country Parties in combating desertification and mitigating the effects of drought.

3. Affected developing country Parties are eligible for assistance in the implementation of the Convention.

\section{Article 5}

\section{Obligations of affected country Parties}

In addition to their obligations pursuant to article 4, affected country Parties undertake to:

(a) give due priority to combating desertification and mitigating the effects of drought, and allocate adequate resources in accordance with their circumstances and capabilities;

(b) establish strategies and priorities, within the framework of sustainable development plans and/or policies, to combat desertification and mitigate the effects of drought;

(c) address the underlying causes of desertification and pay special attention to the socio-economic factors contributing to desertification processes;

(d) promote awareness and facilitate the participation of local populations, particularly women and youth, with the support of non-governmental organizations, in efforts to combat desertification and mitigate the effects of drought; and 
(e) provide an enabling environment by strengthening, as appropriate, relevant existing legislation and, where they do not exist, enacting new laws and establishing long-term policies and action programmes.

\section{Article 6}

\section{Obligations of developed country Parties}

In addition to their general obligations pursuant to article 4, developed country Parties undertake to:

(a) actively support, as agreed individually or jointly, the efforts of affected developing country Parties, particularly those in Africa, and the least developed countries, to combat desertification and mitigate the effects of drought;

(b) provide substantial financial resources and other forms of support to assist affected developing country Parties, particularly those in Africa, effectively to develop and implement their own long-term plans and strategies to combat desertification and mitigate the effects of drought;

(c) promote the mobilization of new and additional funding pursuant to article 20, paragraph 2 (b);

(d) encourage the mobilization of funding from the private sector and other non-governmental sources; and

(e) promote and facilitate access by affected country Parties, particularly affected developing country Parties, to appropriate technology, knowledge and know-how.

\section{Article 7 \\ Priority for Africa}

In implementing this Convention, the Parties shall give priority to affected African country Parties, in the light of the particular situation prevailing in that region, while not neglecting affected developing country Parties in other regions.

\section{Article 8}

\section{Relationship with other conventions}

1. The Parties shall encourage the coordination of activities carried out under this Convention and, if they are Parties to them, under other relevant international agreements, particularly the United Nations Framework Convention on Climate Change and the Convention on Biological Diversity, in order to derive maximum benefit from activities under each agreement while avoiding duplication of effort. The Parties shall encourage the conduct of joint programmes, particularly in the fields of research, training, systematic observation and information collection and exchange, to the extent that such activities may contribute to achieving the objectives of the agreements concerned.

2. The provisions of this Convention shall not affect the rights and obligations of any Party deriving from a bilateral, regional or international agreement into which it has entered prior to the entry into force of this Convention for it. 


\title{
PART III
}

\section{ACTION PROGRAMIES, SCIENTIFIC AND TECHNICAL COOPERATION AND SUPPORTING MEASURES}

\author{
Section 1: Action programmes
}

\author{
Article 9 \\ Basic approach
}

1. In carrying out their obligations pursuant to article 5, affected developing country Parties and any other affected country Party in the framework of its regional implementation annex or, otherwise, that has notified the Permanent Secretariat in writing of its intention to prepare a national action programme, shall, as appropriate, prepare, make public and implement national action programmes, utilizing and building, to the extent possible, on existing relevant successful plans and programmes, and subregional and regional action programmes, as the central element of the strategy to combat desertification and mitigate the effects of drought. Such programmes shall be updated through a continuing participatory process on the basis of lessons from field action, as well as the results of research. The preparation of national action programmes shall be closely interlinked with other efforts to formulate national policies for sustainable development.

2. In the provision by developed country Parties of different forms of assistance under the terms of article 6 , priority shall be given to supporting, as agreed, national, subregional and regional action programmes of affected developing country Parties, particularly those in Africa, either directly or through relevant multilateral organizations or both.

3. The Parties shall encourage organs, funds and programmes of the United Nations system and other relevant intergovernmental organizations, academic institutions, the scientific community and non-governmental organizations in a position to cooperate, in accordance with their mandates and capabilities, to support the elaboration, implementation and follow-up of action programmes.

\section{Article 10}

National action programmes

1. The purpose of national action programmes is to identify the factors contributing to desertification and practical measures necessary to combat desertification and mitigate the effects of drought.

2. National action programmes shall specify the respective roles of government, local communities and land users and the resources available and needed. They shall, inter alia:

(a) incorporate long-term strategies to combat desertification and mitigate the effects of drought, emphasize implementation and be integrated with national policies for sustainable development;

(b) allow for modifications to be made in response to circumstances and be sufficiently flexible at the local level to cope with different socio-economic, biological and geo-physical conditions;

(c) give particular attention to the implementation of preventive measures for lands that are not yet degraded or which are only slightly degraded;

(d) enhance national climatological, meteorological and hydrological capabilities and the means to provide for drought early warning;

(e) promote policies and strengthen institutional frameworks which develop cooperation and coordination, in a spirit of partnership, between the donor community, governments at all levels, local populations and community groups, and facilitate access by local populations to appropriate information and technology; 
(f) provide for effective participation at the local, national and regional levels of non-governmental organizations and local populations, both women and men, particularly resource users, including farmers and pastoralists and their representative organizations, in policy planning, decision-making, and implementation and review of national action programmes; and

(g) require regular review of, and progress reports on, their implementation.

3. National action programmes may include, inter alia, some or all of the following measures to prepare for and mitigate the effects of drought:

(a) establishment and/or strengthening, as appropriate, of early warning systems, including local and national facilities and joint systems at the subregional and regional levels, and mechanisms for assisting environmentally displaced persons;

(b) strengthening of drought preparedness and management, including drought contingency plans at the local, national, subregional and regional levels, which take into consideration seasonal to interannual climate predictions;

(c) establishment and/or strengthening, as appropriate, of food security systems, including storage and marketing facilities, particularly in rural areas;

(d) establishment of alternative livelihood projects that could provide incomes in drought prone areas; and

(e) development of sustainable irrigation programmes for both crops and livestock.

4. Taking into account the circumstances and requirements specific to each affected country Party, national action programmes include, as appropriate, inter alia, measures in some or all of the following priority fields as they relate to combating desertification and mitigating the effects of drought in affected areas and to their populations: promotion of alternative livelihoods and improvement of national economic environments with a view to strengthening programmes aimed at the eradication of poverty and at ensuring food security; demographic dynamics; sustainable management of natural resources; sustainable agricultural practices; development and efficient use of various energy sources; institutional and legal frameworks; strengthening of capabilities for assessment and systematic observation, including hydrological and meteorological services, and capacity building, education and public awareness.

\section{Article 11 \\ Subregional and regional action programmes}

Affected country Parties shall consult and cooperate to prepare, as appropriate, in accordance with relevant regional implementation annexes, subregional and/or regional action programmes to harmonize, complement and increase the efficiency of national programmes. The provisions of article 10 shall apply mutatis mutandis to subregional and regional programmes. Such cooperation may include agreed joint programmes for the sustainable management of transboundary natural resources, scientific and technical cooperation, and strengthening of relevant institutions.

\section{Article 12 \\ International cooperation}

Affected country Parties, in collaboration with other Parties and the international community, should cooperate to ensure the promotion of an enabling international environment in the implementation of the Convention. Such cooperation should also cover fields of technology transfer as well as scientific research and development, information collection and dissemination and financial resources. 


\section{Article 13}

\section{Support for the elaboration and implementation of action programmes}

1. Measures to support action programmes pursuant to article 9 include, inter alia:

(a) financial cooperation to provide predictability for action programmes, allowing for necessary long-term planning;

(b) elaboration and use of cooperation mechanisms which better enable support at the local level, including action through non-governmental organizations, in order to promote the replicability of successful pilot programme activities where relevant;

(c) increased flexibility in project design, funding and implementation in keeping with the experimental, iterative approach indicated for participatory action at the local community level; and

(d) as appropriate, administrative and budgetary procedures that increase the efficiency of cooperation and of support programmes.

2. In providing such support to affected developing country Parties, priority shall be given to African country Parties and to least developed country Parties.

\section{Article 14 \\ Coordination in the elaboration and implementation of action programmes}

1. The Parties shall work closely together, directly and through relevant intergovernmental organizations, in the elaboration and implementation of action programmes.

2. The Parties shall develop operational mechanisms, particularly at the national and field levels, to ensure the fullest possible coordination among developed country Parties, developing country Parties and relevant intergovernmental and non-governmental organizations, in order to avoid duplication, harmonize interventions and approaches, and maximize the impact of assistance. In affected developing country Parties, priority will be given to coordinating activities related to international cooperation in order to maximize the efficient use of resources, to ensure responsive assistance, and to facilitate the implementation of national action programmes and priorities under this Convention.

\section{Article 15 \\ Regional implementation annexes}

Elements for incorporation in action programmes shall be selected and adapted to the socio-economic, geographical and climatic factors applicable to affected country Parties or regions, as well as to their level of development. Guidelines for the preparation of action programmes and their exact focus and content for particular subregions and regions are set out in the regional implementation annexes.

\section{Section 2: Scientific and technical cooperation}

\section{Article 16 \\ Information collection, analysis and exchange}

The Parties agree, according to their respective capabilities, to integrate and coordinate the collection, analysis and exchange of relevant short term and long term data and information to ensure systematic observation of land degradation in affected areas and to understand better and assess the process and effects of drought and desertification. This would help accomplish, inter alia, early warning and advance planning for periods of adverse climatic 
variation in a form suited for practical application by users at all levels, including especially local populations. To this end, they shall, as appropriate:

(a) facilitate and strengthen the functioning of the global network of institutions and facilities for the collection, analysis and exchange of information, as well as for systematic observation at all levels, which shall, inter alia:

(i) aim to use compatible standards and systems;

(ii) encompass relevant data and stations, including in remote areas;

(iii) use and disseminate modern technology for data collection, transmission and assessment on land degradation; and

(iv) link national, subregional and regional data and information centers more closely with global information sources;

(b) ensure that the collection, analysis and exchange of information address the needs of local communities and those of decision makers, with a view to resolving specific problems, and that local communities are involved in these activities;

(c) support and further develop bilateral and multilateral programmes and projects aimed at defining, conducting, assessing and financing the collection, analysis and exchange of data and information, including, inter alia, integrated sets of physical, biological, social and economic indicators;

(d) make full use of the expertise of competent intergovernmental and non-governmental organizations, particularly to disseminate relevant information and experiences among target groups in different regions;

(e) give full weight to the collection, analysis and exchange of socio-economic data, and their integration with physical and biological data;

(f) exchange and make fully, openly and promptly available information from all publicly available sources relevant to combating desertification and mitigating the effects of drought; and

(g) subject to their respective national legislation and/or policies, exchange information on local and traditional knowledge, ensuring adequate protection for it and providing appropriate return from the benefits derived from it, on an equitable basis and on mutually agreed terms, to the local populations concerned.

\section{Article 17}

\section{Research and development}

1. The Parties undertake, according to their respective capabilities, to promote technical and scientific cooperation in the fields of combating desertification and mitigating the effects of drought through appropriate national, subregional, regional and international institutions. To this end, they shall support research activities that:

(a) contribute to increased knowledge of the processes leading to desertification and drought and the impact of, and distinction between, causal factors, both natural and human, with a view to combating desertification and mitigating the effects of drought, and achieving improved productivity as well as sustainable use and management of resources;

(b) respond to well-defined objectives, address the specific needs of local populations and lead to the identification and implementation of solutions that improve the living standards of people in affected areas;

(c) protect, integrate, enhance and validate traditional and local knowledge, know-how and practices, ensuring, subject to their respective national legislation and/or policies, that the owners of that 
knowledge will directly benefit on an equitable basis and on mutually agreed terms from any commercial utilization of it or from any technological development derived from that knowledge;

(d) develop and strengthen national, subregional and regional research capabilities in affected developing country Parties, particularly in Africa, including the development of local skills and the strengthening of appropriate capacities, especially in countries with a weak research base, giving particular attention to multidisciplinary and participative socio-economic research;

(e) take into account, where relevant, the relationship between poverty, migration caused by environmental factors, and desertification;

(f) promote the conduct of joint research programmes between national, subregional, regional and international research organizations, in both the public and private sectors, for the development of improved, affordable and accessible technologies for sustainable development through effective participation of local populations and communities; and

(g) enhance the availability of water resources in affected areas, by means of, inter alia, cloud-seeding.

2. Research priorities for particular regions and subregions, reflecting different local conditions, should be included in action programmes. The Conference of the Parties shall review research priorities periodically on the advice of the Committee on Science and Technology.

\section{Article 18}

\section{Transfer, acquisition, adaptation and development of technology}

1. The Parties undertake, as mutually agreed and in accordance with their respective national legislation and/or policies, to promote, finance and/or facilitate the financing of the transfer, acquisition, adaptation and development of environmentally sound, economically viable and socially acceptable technologies relevant to combating desertification and/or mitigating the effects of drought, with a view to contributing to the achievement of sustainable development in affected areas. Such cooperation shall be conducted bilaterally or multilaterally, as appropriate, making full use of the expertise of intergovernmental and non-governmental organizations. The Parties shall, in particular:

(a) fully utilize relevant existing national, subregional, regional and international information systems and clearing-houses for the dissemination of information on available technologies, their sources, their environmental risks and the broad terms under which they may be acquired;

(b) facilitate access, in particular by affected developing country Parties, on favourable terms, including on concessional and preferential terms, as mutually agreed, taking into account the need to protect intellectual property rights, to technologies most suitable to practical application for specific needs of local populations, paying special attention to the social, cultural, economic and environmental impact of such technology;

(c) facilitate technology cooperation among affected country Parties through financial assistance or other appropriate means;

(d) extend technology cooperation with affected developing country Parties, including, where relevant, joint ventures, especially to sectors which foster alternative livelihoods; and

(e) take appropriate measures to create domestic market conditions and incentives, fiscal or otherwise, conducive to the development, transfer, acquisition and adaptation of suitable technology, knowledge, know-how and practices, including measures to ensure adequate and effective protection of intellectual property rights.

2. The Parties shall, according to their respective capabilities, and subject to their respective national legislation and/or policies, protect, promote and use in particular relevant traditional and local technology, knowledge, know-how and practices and, to that end, they undertake to: 
(a) make inventories of such technology, knowledge, know-how and practices and their potential uses with the participation of local populations, and disseminate such information, where appropriate, in cooperation with relevant intergovernmental and non-governmental organizations;

(b) ensure that such technology, knowledge, know-how and practices are adequately protected and that local populations benefit directly, on an equitable basis and as mutually agreed, from any commercial utilization of them or from any technological development derived therefrom;

(c) encourage and actively support the improvement and dissemination of such technology, knowledge, know-how and practices or of the development of new technology based on them; and

(d) facilitate, as appropriate, the adaptation of such technology, knowledge, know-how and practices to wide use and integrate them with modern technology, as appropriate.

\section{Section 3: Supporting measures}

\section{Article 19 \\ Capacity-building, education and public awareness}

1. The Parties recognize the significance of capacity-building - that is to say, institution-building, training and development of relevant local and national capacities-in efforts to combat desertification and mitigate the effects of drought. They shall promote, as appropriate, capacity-building:

(a) through the full participation at all levels of local people, particularly at the local level, especially women and youth, with the cooperation of non-governmental and local organizations;

(b) by strengthening training and research capacity at the national level in the field of desertification and drought;

(c) by establishing and/or strengthening support and extension services to disseminate relevant technology methods and techniques more effectively, and by training field agents and members of rural organizations in participatory approaches for the conservation and sustainable use of natural resources;

(d) by fostering the use and dissemination of the knowledge, know-how and practices of local people in technical cooperation programmes, wherever possible;

(e) by adapting, where necessary, relevant environmentally sound technology and traditional methods of agriculture and pastoralism to modern socio-economic conditions;

(f) by providing appropriate training and technology in the use of alternative energy sources, particularly renewable energy resources, aimed particularly at reducing dependence on wood for fuel;

(g) through cooperation, as mutually agreed, to strengthen the capacity of affected developing country Parties to develop and implement programmes in the field of collection, analysis and exchange of information pursuant to article 16;

(h) through innovative ways of promoting alternative livelihoods, including training in new skills;

(i) by training of decision makers, managers, and personnel who are responsible for the collection and analysis of data for the dissemination and use of early warning information on drought conditions and for food production;

(j) through more effective operation of existing national institutions and legal frameworks and, where necessary, creation of new ones, along with strengthening of strategic planning and management; and 
(k) by means of exchange visitor programmes to enhance capacity-building in affected country Parties through a long-term, interactive process of learning and study.

2. Affected developing country Parties shall conduct, in cooperation with other Parties and competent intergovernmental and non-governmental organizations, as appropriate, an interdisciplinary review of available capacity and facilities at the local and national levels, and the potential for strengthening them.

3. The Parties shall cooperate with each other and through competent intergovernmental organizations, as well as with non-governmental organizations, in undertaking and supporting public awareness and educational programmes in both affected and, where relevant, unaffected country Parties to promote understanding of the causes and effects of desertification and drought and of the importance of meeting the objective of this Convention. To that end, they shall:

(a) organize awareness campaigns for the general public;

(b) promote, on a permanent basis, access by the public to relevant information, and wide public participation in education and awareness activities;

(c) encourage the establishment of associations that contribute to public awareness;

(d) develop and exchange educational and public awaraness material, where possible in local languages, exchange and second experts to train personnel of affected developing country Parties in carrying out relevant education and awareness programmes, and fully utilize relevant educational material available in competent international bodies;

(e) assess educational needs in affected areas, elaborate appropriate school curricula and expand, as needed, educational and adult literacy programmes and opportunities for all, in particular for girls and women, on the identification, conservation and sustainable use and management of the natural resources of affected areas; and

(f) develop interdisciplinary participatory programmes integrating desertification and drought awareness into educational systems and in non-formal, adult, distance and practical educational programmes.

4. The Conference of the Parties shall establish and/or strengthen networks of regional education and training centers to combat desertification and mitigate the effects of drought. These networks shall be coordinated by an institution created or designated for that purpose, in order to train scientific, technical and management personnel and to strengthen existing institutions responsible for education and training in affected country Parties, where appropriate, with a view to harmonizing programmes and to organizing exchanges of experience among them. These networks shall cooperate closely with relevant intergovernmental and non-governmental organizations to avoid duplication of effort.

\section{Article 20}

\section{Financial resources}

1. Given the central importance of financing to the achievement of the objective of the Convention, the Parties, taking into account their capabilities, shall make every effort to ensure that adequate financial resources are available for programmes to combat desertification and mitigate the effects of drought.

2. In this connection, developed country Parties, while giving priority to affected African country Parties without neglecting affected developing country Parties in other regions, in accordance with article 7, undertake to:

(a) mobilize substantial financial resources, including grants and concessional loans, in order to support the implementation of programmes to combat desertification and mitigate the effects of drought;

(b) promote the mobilization of adequate, timely and predictable financial resources, including new and additional funding from the Global Environment Facility of the agreed incremental costs of those activities concerning desertification that relate to its four focal areas, in conformity with the relevant provisions of the Instrument establishing the Global Environment Facility; 
(c) facilitate through international cooperation the transfer of technology, knowledge and know-how; and

(d) explore, in cooperation with affected developing country Parties, innovative methods and incentives for mobilizing and channelling resources, including those of foundations, non-governmental organizations and other private sector entities, particularly debt swaps and other innovative means which increase financing by reducing the external debt burden of affected developing country Parties, particularly those in Africa.

3. Affected developing country Parties, taking into account their capabilities, undertake to mobilize adequate financial resources for the implementation of their national action programmes.

4. In mobilizing financial resources, the Parties shall seek full use and continued qualitative improvement of all national, bilateral and multilateral funding sources and mechanisms, using consortia, joint programmes and parallel financing, and shall seek to involve private sector funding sources and mechanisms, including those of non-governmental organizations. To this end, the Parties shall fully utilize the operational mechanisms developed pursuant to article 14.

5. In order to mobilize the financial resources necessary for affected developing country Parties to combat desertification and mitigate the effects of drought, the Parties shall:

(a) rationalize and strengthen the management of resources already allocated for combating desertification and mitigating the effects of drought by using them more effectively and efficiently, assessing their successes and shortcomings, removing hindrances to their effective use and, where necessary, reorienting programmes in light of the integrated long-term approach adopted pursuant to this Convention;

(b) give due priority and attention within the governing bodies of multilateral financial institutions, facilities and funds, including regional development banks and funds, to supporting affected developing country Parties, particularly those in Africa, in activities which advance implementation of the Convention, notably action programmes they undertake in the framework of regional implementation annexes; and

(c) examine ways in which regional and subregional cooperation can be strengthened to support efforts undertaken at the national level.

6. Other Parties are encouraged to provide, on a voluntary basis, knowledge, know-how and techniques related to desertification and/or financial resources to affected developing country Parties.

7. The full implementation by affected developing country Parties, particularly those in Africa, of their obligations under the Convention will be greatly assisted by the fulfillment by developed country Parties of their obligations under the Convention, including in particular those regarding financial resources and transfer of technology. In fulfilling their obligations, developed country Parties should take fully into account that economic and social development and poverty eradication are the first priorities of affected developing country Parties, particularly those in Africa.

\section{Article 21 \\ Financial mechanisms}

1. The Conference of the Parties shall promote the availability of financial mechanisms and shall encourage such mechanisms to seek to maximize the availability of funding for affected developing country Parties, particularly those in Africa, to implement the Convention. To this end, the Conference of the Parties shall consider for adoption inter alia approaches and policies that:

(a) facilitate the provision of necessary funding at the national, subregional, regional and global levels for activities pursuant to relevant provisions of the Convention;

(b) promote multiple-source funding approaches, mechanisms and arrangements and their assessment, consistent with article 20 ; 
(c) provide on a regular basis, to interested Parties and relevant intergovernmental and non-governmental organizations, information on available sources of funds and on funding patterns in order to facilitate coordination among them;

(d) facilitate the establishment, as appropriate, of mechanisms, such as national desertification funds, including those involving the participation of non-governmental organizations, to channel financial resources rapidly and efficiently to the local level in affected developing country Parties; and

(e) strengthen existing funds and financial mechanisms at the subregional and regional levels, particularly in Africa, to support more effectively the implementation of the Convention.

2. The Conference of the Parties shall also encourage the provision, through various mechanisms within the United Nations system and through multilateral financial institutions, of support at the national, subregional and regional levels to activities that enable developing country Parties to meet their obligations under the Convention.

3. Affected developing country Parties shall utilize, and where necessary, establish and/or strengthen, national coordinating mechanisms, integrated in national development programmes, that would ensure the efficient use of all available financial resources. They shall also utilize participatory processes involving non-governmental organizations, local groups and the private sector, in raising funds, in elaborating as well as implementing programmes and in assuring access to funding by groups at the local level. These actions can be enhanced by improved coordination and flexible programming on the part of those providing assistance.

4. In order to increase the effectiveness and efficiency of existing financial mechanisms, a Global Mechanism to promote actions leading to the mobilization and channelling of substantial financial resources, including for the transfer of technology, on a grant basis, and/or on concessional or other terms, to affected developing country Parties, is hereby established. This Global Mechanism shall function under the authority and guidance of the Conference of the Parties and be accountable to it.

5. The Conference of the Parties shall identify, at its first ordinary session, an organization to house the Global Mechanism. The Conference of the Parties and the organization it has identified shall agree upon modalities for this Global Mechanism to ensure inter alia that such Mechanism:

(a) identifies and draws up an inventory of relevant bilateral and multilateral cooperation programmes that are available to implement the Convention;

(b) provides advice, on request, to Parties on innovative methods of financing and sources of financial assistance and on improving the coordination of cooperation activities at the national level;

(c) provides interested Parties and relevant intergovernmental and non-governmental organizations with information on available sources of funds and on funding patterns in order to facilitate coordination among them; and

(d) reports to the Conference of the Parties, beginning at its second ordinary session, on its activities.

6. The Conference of the Parties shall, at its first session, make appropriate arrangements with the organization it has identified to house the Global Mechanism for the administrative operations of such Mechanism, drawing to the extent possible on existing budgetary and human resources.

7. The Conference of the Parties shall, at its third ordinary session, review the policies, operational modalities and activities of the Global Mechanism accountable to it pursuant to paragraph 4, taking into account the provisions of article 7. On the basis of this review, it shall consider and take appropriate action. 


\section{PART IV}

\section{INSTITUTIONS}

\section{Article 22 \\ Conference of the Parties}

1. A Conference of the Parties is hereby established.

2. The Conference of the Parties is the supreme body of the Convention. It shall make, within its mandate, the decisions necessary to promote its effective implementation. In particular, it shall:

(a) regularly review the implementation of the Convention and the functioning of its institutional arrangements in the light of the experience gained at the national, subregional, regional and international levels and on the basis of the evolution of scientific and technological knowledge;

(b) promote and facilitate the exchange of information on measures adopted by the Parties, and determine the form and timetable for transmitting the information to be submitted pursuant to article 26, review the reports and make recommendations on them;

(c) establish such subsidiary bodies as are deemed necessary for the implementation of the Convention;

(d) review reports submitted by its subsidiary bodies and provide guidance to them;

(e) agree upon and adopt, by consensus, rules of procedure and financial rules for itself and any subsidiary bodies;

(f) adopt amendments to the Convention pursuant to articles 30 and 31;

(g) approve a programme and budget for its activities, including those of its subsidiary bodies, and undertake necessary arrangements for their financing;

(h) as appropriate, seek the cooperation of, and utilize the services of and information provided by, competent bodies or agencies, whether national or international, intergovernmental or non-governmental;

(i) promote and strengthen the relationship with other relevant conventions while avoiding duplication of effort; and

(j) exercise such other functions as may be necessary for the achievement of the objective of the Convention.

3. The Conference of the Parties shall, at its first session, adopt its own rules of procedure, by consensus, which shall include decision-making procedures for matters not already covered by decision-making procedures stipulated in the Convention. Such procedures may include specified majorities required for the adoption of particular decisions.

4. The first session of the Conference of the Parties shall be convened by the interim secretariat referred to in article 35 and shall take place not later than one year after the date of entry into force of the Convention. Unless otherwise decided by the Conference of the Parties, the second, third and fourth ordinary sessions shall be held yearly, and thereafter, ordinary sessions shall be held every two years.

5. Extraordinary sessions of the Conference of the Parties shall be held at such other times as may be decided either by the Conference of the Parties in ordinary session or at the written request of any Party, provided that, within three months of the request being communicated to the Parties by the Permanent Secretariat, it is supported by at least one third of the Parties. 
6. At each ordinary session, the Conference of the Parties shall elect a Bureau. The structure and functions of the Bureau shall be determined in the rules of procedure. In appointing the Bureau, due regard shall be paid to the need to ensure equitable geographical distribution and adequate representation of affected country Parties, particularly those in Africa.

7. The United Nations, its specialized agencies and any State member thereof or observers thereto not Party to the Convention, may be represented at sessions of the Conference of the Parties as observers. Any body or agency, whether national or international, governmental or non-governmental, which is qualified in matters covered by the Convention, and which has informed the Permanent Secretariat of its wish to be represented at a session of the Conference of the Parties as an observer, may be so admitted unless at least one third of the Parties present object. The admission and participation of observers shall be subject to the rules of procedure adopted by the Conference of the Parties.

8. The Conference of the Parties may request competent national and international organizations which have relevant expertise to provide it with information relevant to article 16, paragraph (g), article 17, paragraph 1 (c) and article 18, paragraph 2 (b).

\section{Article 23}

\section{Permanent Secretariat}

1. A Permanent Secretariat is hereby established.

2. The functions of the Permanent Secretariat shall be:

(a) to make arrangements for sessions of the Conference of the Parties and its subsidiary bodies established under the Convention and to provide them with services as required;

(b) to compile and transmit reports submitted to it;

(c) to facilitate assistance to affected developing country Parties, on request, particularly those in Africa, in the compilation and communication of information required under the Convention;

(d) to coordinate its activities with the secretariats of other relevant international bodies and conventions;

(e) to enter, under the guidance of the Conference of the Parties, into such administrative and contractual arrangements as may be required for the effective discharge of its functions;

(f) to prepare reports on the execution of its functions under this Convention and present them to the Conference of the Parties; and

(g) to perform such other secretariat functions as may be determined by the Conference of the Parties.

3. The Conference of the Parties, at its first session, shall designate a Permanent Secretariat and make arrangements for its functioning.

\section{Article 24 \\ Committee on Science and Technology}

1. A Committee on Science and Technology is hereby established as a subsidiary body of the Conference of the Parties to provide it with information and advice on scientific and technological matters relating to combating desertification and mitigating the effects of drought. The Committee shall meet in conjunction with the ordinary sessions of the Conference of the Parties and shall be multidisciplinary and open to the participation of all Parties. It shall be composed of government representatives competent in the relevant fields of expertise. The Conference of the Parties shall decide, at its first session, on the terms of reference of the Committee. 
2. The Conference of the Parties shall establish and maintain a roster of independent experts with expertise and experience in the relevant fields. The roster shall be based on nominations received in writing from the Parties, taking into account the need for a multidisciplinary approach and broad geographical representation.

3. The Conference of the Parties may, as necessary, appoint ad hoc panels to provide it, through the Committee, with information and advice on specific issues regarding the state of the art in fields of science and technology relevant to combating desertification and mitigating the effects of drought. These panels shall be composed of experts whose names are taken from the roster, taking into account the need for a multidisciplinary approach and broad geographical representation. These experts shall have scientific backgrounds and field experience and shall be appointed by the Conference of the Parties on the recommendation of the Committee. The Conference of the Parties shall decide on the terms of reference and the modalities of work of these panels.

\section{Article 25 \\ Networking of institutions, agencies and bodies}

1. The Committee on Science and Technology shall, under the supervision of the Conference of the Parties, make provision for the undertaking of a survey and evaluation of the relevant existing networks, institutions, agencies and bodies willing to become units of a network. Such a network shall support the implementation of the Convention.

2. On the basis of the results of the survey and evaluation referred to in paragraph 1 , the Committee on Science and Technology shall make recommendations to the Conference of the Parties on ways and means to facilitate and strengthen networking of the units at the local, national and other levels, with a view to ensuring that the thematic needs set out in articles 16 to 19 are addressed.

3. Taking into account these recommendations, the Conference of the Parties shall:

(a) identify those national, subregional, regional and international units that are most appropriate for networking, and recommend operational procedures, and a time-frame, for them; and

(b) identify the units best suited to facilitating and strengthening such networking at all levels.

\section{PART V}

\section{PROCEDURES}

\section{Article 26 \\ Communication of information}

1. Each Party shall communicate to the Conference of the Parties for consideration at its ordinary sessions, through the Permanent Secretariat, reports on the measures which it has taken for the implementation of the Convention. The Conference of the Parties shall determine the timetable for submission and the format of such reports.

2. Affected country Parties shall provide a description of the strategies established pursuant to article 5 and of any relevant information on their implementation.

3. Affected country Parties which implement action programmes pursuant to articles 9 to 15 shall provide a detailed description of the programmes and of their implementation.

4. Any group of affected country Parties may make a joint communication on measures taken at the subregional and/or regional levels in the framework of action programmes.

5. Developed country Parties shall report on measures taken to assist in the preparation and implementation of action programmes, including information on the financial resources they have provided, or are providing, under the Convention. 
6. Information communicated pursuant to paragraphs 1 to 4 shall be transmitted by the Permanent Secretariat as soon as possible to the Conference of the Parties and to any relevant subsidiary body.

7. The Conference of the Parties shall facilitate the provision to affected developing countries, particularly those in Africa, on request, of technical and financial support in compiling and communicating information in accordance with this article, as well as identifying the technical and financial needs associated with action programmes.

\section{Article 27}

\section{Measures to resolve questions on implementation}

The Conference of the Parties shall consider and adopt procedures and institutional mechanisms for the resolution of questions that may arise with regard to the implementation of the Convention.

\section{Article 28}

\section{Settlement of disputes}

1. Parties shall settle any dispute between them concerning the interpretation or application of the Convention through negotiation or other peaceful means of their own choice.

2. When ratifying, accepting, approving, or acceding to the Convention, or at any time thereafter, a Party which is not a regional economic integration organization may declare in a written instrument submitted to the Depositary that, in respect of any dispute concerning the interpretation or application of the Convention, it recognizes one or both of the following means of dispute settlement as compulsory in relation to any Party accepting the same obligation:

(a) arbitration in accordance with procedures adopted by the Conference of the Parties in an annex as soon as practicable;

(b) submission of the dispute to the International Court of Justice.

3. A Party which is a regional economic integration organization may make a declaration with like effect in relation to arbitration in accordance with the procedure referred to in paragraph 2 (a).

4. A declaration made pursuant to paragraph 2 shall remain in force until it expires in accordance with its terms or until three months after written notice of its revocation has been deposited with the Depositary.

5. The expiry of a declaration, a notice of revocation or a new declaration shall not in any way affect proceedings pending before an arbitral tribunal or the International Court of Justice unless the Parties to the dispute otherwise agree.

6. If the Parties to a dispute have not accepted the same or any procedure pursuant to paragraph 2 and if they have not been able to settle their dispute within twelve months following notification by one Party to another that a dispute exists between them, the dispute shall be submitted to conciliation at the request of any Party to the dispute, in accordance with procedures adopted by the Conference of the Parties in an annex as soon as practicable.

\section{Article 29 \\ Status of annexes}

1. Annexes form an integral part of the Convention and, unless expressly provided otherwise, a reference to the Convention also constitutes a reference to its annexes.

2. The Parties shall interpret the provisions of the annexes in a manner that is in conformity with their rights and obligations under the articles of this Convention. 


\section{Article 30 \\ Amendments to the Convention}

\section{Any Party may propose amendments to the Convention.}

2. Amendments to the Convention shall be adopted at an ordinary session of the Conference of the Parties. The text of any proposed amendment shall be communicated to the Parties by the Permanent Secretariat at least six months before the meeting at which it is proposed for adoption. The Permanent Secretariat shall also communicate proposed amendments to the signatories to the Convention.

3. The Parties shall make every effort to reach agreement on any proposed amendment to the Convention by consensus. If all efforts at consensus have been exhausted and no agreement reached, the amendment shall, as a last resort, be adopted by a two-thirds majority vote of the Parties present and voting at the meeting. The adopted amendment shall be communicated by the Permanent Secretariat to the Depositary, who shall circulate it to all Parties for their ratification, acceptance, approval or accession.

4. Instruments of ratification, acceptance, approval or accession in respect of an amendment shall be deposited with the Depositary. An amendment adopted pursuant to paragraph 3 shall enter into force for those Parties having accepted it on the ninetieth day after the date of receipt by the Depositary of an instrument of ratification, acceptance, approval or accession by at least two thirds of the Parties to the Convention which were Parties at the time of the adoption of the amendment.

5. The amendment shall enter into force for any other Party on the ninetieth day after the date on which that Party deposits with the Depositary its instrument of ratification, acceptance or approval of, or accession to the said amendment.

6. For the purposes of this article and article 31, "Parties present and voting" means Parties present and casting an affirmative or negative vote.

\section{Article 31}

\section{Adoption and amendment of annexes}

1. Any additional annex to the convention and any amendment to an annex shall be proposed and adopted in accordance with the procedure for amendment of the Convention set forth in article 30 , provided that, in adopting an additional regional implementation annex or amendment to any regional implementation annex, the majority provided for in that article shall include a two-thirds majority vote of the Parties of the region concerned present and voting. The adoption or amendment of an annex shall be communicated by the Depositary to all Parties.

2. An annex, other than an additional regional implementation annex, or an amendment to an annex, other than an amendment to any regional implementation annex, that has been adopted in accordance with paragraph 1 , shall enter into force for all Parties to the Convention six months after the date of communication by the Depositary to such Parties of the adoption of such annex or amendment, except for those Parties that have notified the Depositary in writing within that period of their non-acceptance of such annex or amendment. Such annex or amendment shall enter into force for Parties which withdraw their notification of non-acceptance on the ninetieth day after the date on which withdrawal of such notification has been received by the Depositary.

3. An additional regional implementation annex or amendment to any regional implementation annex that has been adopted in accordance with paragraph 1, shall enter into force for all Parties to the Convention six months after the date of the communication by the Depositary to such Parties of the adoption of such annex or amendment, except with respect to:

(a) any Party that has notified the Depositary in writing, within such six month period, of its non-acceptance of that additional regional implementation annex or of the amendment to the regional implementation annex, in which case such annex or amendment shall enter into force for Parties which withdraw their notification of non-acceptance on the ninetieth day after the date on which withdrawal of such notification has been received by the Depositary; and 
(b) any Party that has made a declaration with respect to additional regional implementation annexes or amendments to regional implementation annexes in accordance with article 34, paragraph 4, in which case any such annex or amendment shall enter into force for such a Party on the ninetieth day after the date of deposit with the Depositary of its instrument of ratification, acceptance, approval or accession with respect to such annex or amendment.

4. If the adoption of an annex or an amendment to an annex involves an amendment to the Convention, that annex or amendment to an annex shall not enter into force until such time as the amendment to the Convention enters into force.

\title{
Article 32 \\ Right to vote
}

1. Except as provided for in paragraph 2, each Party to the Convention shall have one vote.

2. Regional economic integration organizations, in matters within their competence, shall exercise their right to vote with a number of votes equal to the number of their member States that are Parties to the Convention. Such an organization shall not exercise its right to vote if any of its member States exercises its right, and vice versa.

\section{PART VI}

\section{FINAL PROVISIONS}

\author{
Article 39 \\ Signature
}

This Convention shall be opened for signature at Paris, on 14-15 October 1994, by States Members of the United Nations or any of its specialized agencies or that are Parties to the Statute of the International Court of Justice and by regional economic integration organizations. It shall remain open for signature, thereafter, at the United Nations Headquarters in New York until 13 October 1995.

\section{Article 34}

\section{Ratification, acceptance, approval and accession}

1. The Convention shall be subject to ratification, acceptance, approval or accession by States and by regional economic integration organizations. It shall be open for accession from the day after the date on which the Convention is closed for signature. Instruments of ratification, acceptance, approval or accession shall be deposited with the Depositary.

2. Any regional economic integration organization which becomes a Party to the Convention without any of its member States being a Party to the Convention shall be bound by all the obligations under the Convention. Where one or more member States of such an organization are also Party to the Convention, the organization and its member States shall decide on their respective responsibilities for the performance of their obligations under the Convention. In such cases, the organization and the member States shall not be entitled to exercise rights under the Convention concurrently.

3. In their instruments of ratification, acceptance, approval or accession, regional economic integration organizations shall declare the extent of their competence with respect to the matters governed by the Convention. They shall also promptly inform the Depositary, who shall in turn inform the Parties, of any substantial modification in the extent of their competence.

4. In its instrument of ratification, acceptance, approval or accession, any Party may declare that, with respect to it, any additional regional implementation annex or any zmendment to any regional implementation annex 
shall enter into force only upon the deposit of its instrument of ratification, acceptance, approval or accession with respect thereto.

\section{Article 35 \\ Interim arrangements}

The secretariat functions referred to in article 23 will be carried out on an interim basis by the secretariat established by the General Assembly of the United Nations in its resolution 47/188 of 22 December 1992, until the completion of the first session of the Conference of the Parties.

\section{Article 36 \\ Entry into force}

1. The Convention shall enter into force on the ninetieth day after the date of deposit of the fiftieth instrument of ratification, acceptance, approval or accession.

2. For each State or regional economic integration organization ratifying, accepting, approving or acceding to the Convention after the deposit of the fiftieth instrument of ratification, acceptance, approval or accession, the Convention shall enter into force on the ninetieth day after the date of deposit by such State or regional economic integration organization of its instrument of ratification, acceptance, approval or accession.

3. For the purposes of paragraphs 1 and 2 , any instrument deposited by a regional economic integration organization shall not be counted as additional to those deposited by States members of the organization.

\section{Article 37}

\section{Reservations}

No reservations may be made to this Convention.

\section{Article 38}

Withdrawal

1. At any time after three years from the date on which the Convention has entered into force for a Party, that Party may withdraw from the Convention by giving written notification to the Depositary.

2. Any such withdrawal shall take effect upon expiry of one year from the date of receipt by the Depositary of the notification of withdrawal, or on such later date as may be specified in the notification of withdrawal.

\section{Article 39 \\ Depositary}

The Secretary-General of the United Nations shall be the Depositary of the Convention.

\section{Article 40 \\ Authentic texts}

The original of the present convention, of which the Arabic, Chinese, English, French, Russian and Spanish texts are equally authentic, shall be deposited with the Secretary-General of the United Nations.

IN WITNESS WHEREOF the undersigned, being duly authorized to that effect, have signed the present Convention. 
DONE AT Paris, this 17th day of June one thousand nine hundred and ninety-four.

\title{
ANNEX I \\ REGIONAL IMPLEMENTATION ANNEX FOR AFRICA
}

\author{
Article 1 \\ Scope
}

This Annex applies to Africa, in relation to each Party and in conformity with the Convention, in particular its article 7, for the purpose of combating desertification and/or mitigating the effects of drought in its arid, semi-arid and dry sub-humid areas.

\section{Article 2 \\ Purpose}

The purpose of this Annex, at the national, subregional and regional levels in Africa and in the light of its particular conditions, is to:

(a) identify measures and arrangements, including the nature and processes of assistance provided by developed country Parties, in accordance with the relevant provisions of the Convention;

(b) provide for the efficient and practical implementation of the Convention to address conditions specific to Africa; and

(c) promote processes and activities relating to combating desertification and/or mitigating the effects of drought within the arid, semi-arid and dry sub-humid areas of Africa.

\section{Article 3}

\section{Particular conditions of the African region}

In carrying out their obligations under the Convention, the Parties shall, in the implementation of this Annex, adopt a basic approach that takes into consideration the following particular conditions of Africa:

(a) the high proportion of arid, semi-arid and dry sub-humid areas;

(b) the substantial number of countries and populations adversely affected by desertification and by the frequent recurrence of severe drought;

(c) the large number of affected countries that are land-locked;

(d) the widespread poverty prevalent in most affected countries, the large number of least developed countries among them, and their need for significant amounts of external assistance, in the form of grants and loans on concessional terms, to pursue their development objectives;

(e) the difficult socio-economic conditions, exacerbated by deteriorating and fluctuating terms of trade, external indebtedness and political instability, which induce internal, regional and international migrations;

(f) the heavy reliance of populations on natural resources for subsistence which, compounded by the effects of demographic trends and factors, a weak technological base and unsustainable production practices, contributes to serious resource degradation; 
(g) the insufficient institutional and legal frameworks, the weak infrastructural base and the insufficient scientific, technical and educational capacity, leading to substantial capacity-building requirements; and

(h) the central role of actions to combat desertification and/or mitigate the effects of drought in the national development priorities of affected African countries.

\section{Article 4}

\section{Commitments and obligations of African country Parties}

1. In accordance with their respective capabilities, African country Parties undertake to:

(a) adopt the combating of desertification and/or the mitigation of the effects of drought as a central strategy in their efforts to eradicate poverty;

(b) promote regional cooperation and integration, in a spirit of solidarity and partnership based on mutual interest, in programmes and activities to combat desertification and/or mitigate the effects of drought;

(c) rationalize and strengthen existing institutions concerned with desertification and drought and involve other existing institutions, as appropriate, in order to make them more effective and to ensure more efficient use of resources;

(d) promote the exchange of information on appropriate technology, knowledge, know-how and practices between and among them; and

(e) develop contingency plans for mitigating the effects of drought in areas degraded by desertification and/or drought.

2. Pursuant to the general and specific obligations set out in articles 4 and 5 of the Convention, affected African country Parties shall aim to:

(a) make appropriate financial allocations from their national budgets consistent with national conditions and capabilities and reflecting the new priority Africa has accorded to the phenomenon of desertification and/or drought;

(b) sustain and strengthen reforms currently in progress towards greater decentralization and resource tenure as well as reinforce participation of local populations and communities; and

(c) identify and mobilize new and additional national financial resources, and expand, as a matter of priority, existing national capabilities and facilities to mobilize domestic financial resources.

\section{Article 5 \\ Commitments and obligations of developed country Parties}

1. In fulfilling their obligations pursuant to articles 4, 6 and 7 of the Convention, developed country Parties shall give priority to affected African country Parties and, in this context, shall:

(a) assist them to combat desertification and/or mitigate the effects of drought by, inter alia, providing and/or facilitating access to financial and/or other resources, and promoting, financing and/or facilitating the financing of the transfer, adaptation and access to appropriate environmental technologies and know-how, as mutually agreed and in accordance with national policies, taking into account their adoption of poverty eradication as a central strategy;

(b) continue to allocate significant resources and/or increase resources to combat desertification and/or mitigate the effects of drought; and 
(c) assist them in strengthening capacities to enable them to improve their institutional frameworks, as well as their scientific and technical capabilities, information collection and analysis, and research and development for the purpose of combating desertification and/or mitigating the effects of drought.

2. Other country Parties may provide, on a voluntary basis, technology, knowledge and know-how relating to desertification and/or financial resources, to affected African country Parties. The transfer of such knowledge, know-how and techniques is facilitated by international cooperation.

\section{Article 6 \\ Strategic planning framework for sustainable development}

1. National action programmes shall be a central and integral part of a broader process of formulating national policies for the sustainable development of affected African country Parties.

2. A consultative and participatory process involving appropriate levels of government, local populations, communities and non-governmental organizations shall be undertaken to provide guidance on a strategy with flexible planning to allow maximum participation from local populations and communities. As appropriate, bilateral and multilateral assistance agencies may be involved in this process at the request of an affected African country Party.

\section{Article 7}

\section{Timetable for preparation of action programmes}

Pending entry into force of this Convention, the African country Parties, in cooperation with other members of the international community, as appropriate, shall, to the extent possible, provisionally apply those provisions of the Convention relating to the preparation of national, subregional and regional action programmes.

\section{Article 8 \\ Content of national action programmes}

1. Consistent with article 10 of the Convention, the overall strategy of national action programmes shall emphasize integrated local development programmes for affected areas, based on participatory mechanisms and on integration of strategies for poverty eradication into efforts to combat desertification and mitigate the effects of drought. The programmes shall aim at strengthening the capacity of local authorities and ensuring the active involvement of local populations, communities and groups, with emphasis on education and training, mobilization of non-governmental organizations with proven expertise and strengthening of decentralized governmental structures.

2. National action programmes shall, as appropriate, include the following general features:

(a) the use, in developing and implementing national action programmes, of past experiences in combating desertification and/or mitigating the effects of drought, taking into account social, economic and ecological conditions;

(b) the identification of factors contributing to desertification and/or drought and the resources and capacities available and required, and the setting up of appropriate policies and institutional and other responses and measures necessary to combat those phenomena and/or mitigate their effects; and

(c) the increase in participation of local populations and communities, including women, farmers and pastoralists, and delegation to them of more responsibility for management.

3. National action programmes shall also, as appropriate, include the following:

(a) measures to improve the economic environment with a view to eradicating poverty:

(i) increasing incomes and employment opportunities, especially for the poorest members of the community, by: 
- developing markets for farm and livestock products;

- creating financial instruments suited to local needs;

- encouraging diversification in agriculture and the setting-up of agricultural enterprises; and

- developing economic activities of a para-agricultural or non-agricultural type;

(ii) improving the long-term prospects of rural economies by the creation of:

- incentives for productive investment and access to the means of production; and

- $\quad$ price and tax policies and commercial practices that promote growth;

(ii) defining and applying population and migration policies to reduce population pressure on land; and

(iv) promoting the use of drought resistant crops and the application of integrated dry-land farming systems for food security purposes;

(b) measures to conserve natural resources:

(i) ensuring integrated and sustainable management of natural resources, including:

- agricultural land and pastoral land;

- vegetation cover and wildlife;

- forests;

- water resources; and

- biological diversity;

(ii) training with regard to, and strengthening, public awareness and environmental education campaigns and disseminating knowledge of techniques relating to the sustainable management of natural resources; and

(iii) ensuring the development and efficient use of diverse energy sources, the promotion of alternative sources of energy, particularly solar energy, wind energy and bio-gas, and specific arrangements for the transfer, acquisition and adaptation of relevant technology to alleviate the pressure on fragile natural resources;

(c) measures to improve institutional organization:

(i) defining the roles and responsibilities of central government and local authorities within the framework of a land use planning policy;

(ii) encouraging a policy of active decentralization, devolving responsibility for management and decision-making to local authorities, and encouraging initiatives and the assumption of responsibility by local communities and the establishment of local structures; and

(iii) adjusting, as appropriate, the institutional and regulatory framework of natural resource management to provide security of land tenure for local populations; 
(d) measures to improve knowledge of desertification:

(i) promoting research and the collection, processing and exchange of information on the scientific, technical and socio-economic aspects of desertification;

(ii) improving national capabilities in research and in the collection, processing, exchange and analysis of information so as to increase understanding and to translate the results of the analysis into operational terms; and

(iii) encouraging the medium- and long-term study of:

- socio-economic and cultural trends in affected areas;

- qualitative and quantitative trends in natural resources; and

- the interaction between climate and desertification; and

(e) measures to monitor and assess the effects of drought:

(i) developing strategies to evaluate the impacts of natural climate variability on regional drought and desertification and/or to utilize predictions of climate variability on seasonal to interannual time scales in efforts to mitigate the effects of drought;

(ii) improving early warning and response capacity, efficiently managing emergency relief and food aid, and improving food stocking and distribution systems, cattle protection schemes and public works and alternative livelihoods for drought prone areas; and

(iii) monitoring and assessing ecological degradation to provide reliable and timely information on the process and dynamics of resource degradation in order to facilitate better policy formulations and responses.

\section{Article 9}

\section{Preparation of national action programmes and implementation and evaluation indicators}

Each affected African country Party shall designate an appropriate national coordinating body to function as a catalyst in the preparation, implementation and evaluation of its national action programme. This coordinating body shall, in the light of article 3 and as appropriate:

(a) undertake an identification and review of actions, beginning with a locally driven consultation process, involving local populations and communities and with the cooperation of local administrative authorities, developed country Parties and intergovernmental and non-governmental organizations, on the basis of initial consultations of those concerned at the national level;

(b) identify and analyze the constraints, needs and gaps affecting development and sustainable land use and recommend practical measures to avoid duplication by making full use of relevant ongoing efforts and promote implementation of results;

(c) facilitate, design and formulate project activities based on interactive, flexible approaches in order to ensure active participation of the population in affected areas, to minimize the negative impact of such activities, and to identify and prioritize requirements for financial assistance and technical cooperation;

(d) establish pertinent, quantifiable and readily verifiable indicators to ensure the assessment and evaluation of national action programmes, which encompass actions in the short, medium and long terms, and of the implementation of such programmes; and

(e) prepare progress reports on the implementation of the national action programmes. 


\section{Article 10 \\ Organizational framework of subregional action programmes}

1. Pursuant to article 4 of the Convention, African country Parties shall cooperate in the preparation and implementation of subregional action programmes for central, eastern, northern, southern and western Africa and, in that regard, may delegate the following responsibilities to relevant subregional intergovernmental organizations:

(a) acting as focal points for preparatory activities and coordinating the implementation of the subregional action programmes;

(b) assisting in the preparation and implementation of national action programmes;

(c) facilitating the exchange of information, experience and know-how as well as providing advice on the review of national legislation; and

(d) any other responsibilities relating to the implementation of subregional action programmes.

2. Specialized subregional institutions may provide support, upon request, and/or be entrusted with the responsibility to coordinate activities in their respective fields of competence.

\section{Article 11}

\section{Content and preparation of subregional action programmes}

Subregional action programmes shall focus on issues that are better addressed at the subregional level. They shall establish, where necessary, mechanisms for the management of shared natural resources. Such mechanisms shall effectively handle transboundary problems associated with desertification and/or drought and shall provide support for the harmonious implementation of national action programmes. Priority areas for subregional action programmes shall, as appropriate, focus on:

(a) joint programmes for the sustainable management of transboundary natural resources through bilateral and multilateral mechanisms, as appropriate;

(b) coordination of programmes to develop alternative energy sources;

(c) cooperation in the management and control of pests as well as of plant and animal diseases;

(d) capacity-building, education and public awareness activities that are better carried out or supported at the subregional level;

(e) scientific and technical cooperation, particularly in the climatological, meteorological and hydrological fields, including networking for data collection and assessment, information sharing and project monitoring, and coordination and prioritization of research and development activities;

(f) early warning systems and joint planning for mitigating the effects of drought, including measures to address the problems resulting from environmentally induced migrations;

(g) exploration of ways of sharing experiences, particularly regarding participation of local populations and communities, and creation of an enabling environment for improved land use management and for use of appropriate technologies;

(h) strengthening of the capacity of subregional organizations to coordinate and provide technical services, as well as establishment, reorientation and strengthening of subregional centers and institutions; and

(i) development of policies in fields, such as trade, which have impact upon affected areas and populations, including policies for the coordination of regional marketing regimes and for common infrastructure. 


\section{Article 12}

\section{Organizational framework of the regional action programme}

1. Pursuant to article 11 of the Convention, African country Parties shall jointly determine the procedures for preparing and implementing the regional action programme.

2. The Parties may provide appropriate support to relevant African regional institutions and organizations to enable them to assist African country Parties to fulfil their responsibilities under the Convention.

\section{Article 13 \\ Content of the regional action programme}

The regional action programme includes measures relating to combating desertification and/or mitigating the effects of drought in the following priority areas, as appropriate:

(a) development of regional cooperation and coordination of subregional action programmes for building regional consensus on key policy areas, including through regular consultations of subregional organizations;

(b) promotion of capacity-building in activities which are better implemented at the regional level;

(c) the seeking of solutions with the international community to global economic and social issues that have an impact on affected areas taking into account article 4, paragraph 2 (b) of the Convention;

(d) promotion among the affected country Parties of Africa and its subregions, as well as with other affected regions, of exchange of information and appropriate techniques, technical know-how and relevant experience; promotion of scientific and technological cooperation particularly in the fields of climatology, meteorology, hydrology, water resource development and alternative energy sources; coordination of subregional and regional research activities; and identification of regional priorities for research and development;

(e) coordination of networks for systematic observation and assessment and information exchange, as well as their integration into world-wide networks; and

(f) coordination of and reinforcement of subregional and regional early warning systems and drought contingency plans.

\section{Article 14 \\ Financial resources}

1. Pursuant to article 20 of the Convention and article 4, paragraph 2, affected African country Parties shall endeavour to provide a macroeconomic framework conducive to the mobilization of financial resources and shall develop policies and establish procedures to channel resources more effectively to local development programmes, including through non-governmental organizations, as appropriate.

2. Pursuant to article 21, paragraphs 4 and 5 of the Convention, the Parties agree to establish an inventory of sources of funding at the national, subregional, regional and international levels to ensure the rational use of existing resources and to identify gaps in resource allocation, to facilitate implementation of the action programmes. The inventory shall be regularly reviewed and updated.

3. Consistent with article 7 of the Convention, the developed country Parties shall continue to allocate significant resources and/or increased resources as well as other forms of assistance to affected African country Parties on the basis of partnership agreements and arrangements referred to in article 18, giving, inter alia, due attention to matters related to debt, international trade and marketing arrangements in accordance with article 4, paragraph 2 (b) of the Convention. 


\section{Article 15 \\ Financial mechanisms}

1. Consistent with article 7 of the Convention underscoring the priority to affected African country Parties and considering the particular situation prevailing in this region, the Parties shall pay special attention to the implementation in Africa of the provisions of article 21, paragraph 1 (d) and (e) of the Convention, notably by:

(a) facilitating the establishment of mechanisms, such as national desertification funds, to channel financial resources to the local level; and

(b) strengthening existing funds and financial mechanisms at the subregional and regional levels.

2. Consistent with articles 20 and 21 of the Convention, the Parties which are also members of the governing bodies of relevant regional and subregional financial institutions, including the African Development Bank and the African Development Fund, shall promote efforts to give due priority and attention to the activities of those institutions that advance the implementation of this Annex.

3. The Parties shall streamline, to the extent possible, procedures for channelling funds to affected African country Parties.

\section{Article 16}

\section{Technical assistance and cooperation}

The Parties undertake, in accordance with their respective capabilities, to rationalize technical assistance to, and cooperation with, African country Parties with a view to increasing project and programme effectiveness by, inter alia:

(a) limiting the costs of support measures and backstopping, especially overhead costs; in any case, such costs shall only represent an appropriately low percentage of the total cost of the project so as to maximize project efficiency;

(b) giving preference to the utilization of competent national experts or, where necessary, competent experts from within the subregion and/or region, in project design, preparation and implementation, and to the building of local expertise where it does not exist; and

(c) effectively managing and coordinating, as well as efficiently utilizing, technical assistance to be provided.

\section{Article 17}

Transfer, acquisition, adaptation and access to environmentally sound technology

In implementing article 18 of the Convention relating to transfer, acquisition, adaptation and development of technology, the Parties undertake to give priority to African country Parties and, as necessary, to develop with them new models of partnership and cooperation with a view to strengthening capacity-building in the fields of scientific research and development and information collection and dissemination to enable them to implement their strategies to combat desertification and mitigate the effects of drought.

\section{Article 18}

\section{Coordination and partnership agreements}

1. African country Parties shall coordinate the preparation, negotiation and implementation of national, subregional and regional action programmes. They may involve, as appropriate, other Parties and relevant intergovernmental and non-governmental organizations in this process. 
2. The objectives of such coordination shall be to ensure that financial and technical cooperation is consistent with the Convention and to provide the necessary continuity in the use and administration of resources.

3. African country Parties shall organize consultative processes at the national, subregional and regional levels. These consultative processes may:

(a) serve as a forum to negotiate and conclude partnership agreements based on national, subregional and regional action programmes; and

(b) specify the contribution of African country Parties and other members of the consultative groups to the programmes and identify priorities and agreements on implementation and evaluation indicators, as well as funding arrangements for implementation.

4. The Permanent Secretariat may, at the request of African country Parties, pursuant to article 23 of the Convention, facilitate the convocation of such consultative processes by:

(a) providing advice on the organization of effective consultative arrangements, drawing on experiences from other such arrangements;

(b) providing information to relevant bilateral and multilateral agencies concerning consultative meetings or processes, and encouraging their active involvement; and

(c) providing other information that may be relevant in establishing or improving consultative arrangements.

5. The subregional and regional coordinating bodies shall, inter alia:

(a) recommend appropriate adjustments to partnership agreements;

(b) monitor, assess and report on the implementation of the agreed subregional and regional programmes; and

(c) aim to ensure efficient communication and cooperation among African country Parties.

6. Participation in the consultative groups shall, as appropriate, be open to Governments, interested groups and donors, relevant organs, funds and programmes of the United Nations system, relevant subregional and regional organizations, and representatives of relevant non-governmental organizations. Participants of each consultative group shall determine the modalities of its management and operation.

7. Pursuant to article 14 of the Convention, developed country Parties are encouraged to develop, on their own initiative, an informal process of consultation and coordination among themselves, at the national, subregional and regional levels, and, at the request of an affected African country Party or of an appropriate subregional or regional organization, to participate in a national, subregional or regional consultative process that would evaluate and respond to assistance needs in order to facilitate implementation.

\section{Article 19}

\section{Follow-up arrangements}

Follow-up of this Annex shall be carried out by African country Parties in accordance with the Convention as follows

(a) at the national level, by a mechanism the composition of which should be determined by each affected African country Party and which shall include representatives of local communities and shall function under the supervision of the national coordinating body referred to in article 9;

(b) at the subregional level, by a multidisciplinary scientific and technical consultative committee, the composition and modalities of operation of which shall be determined by the African country Parties of the subregion concerned; and 
(c) at the regional level, by mechanisms defined in accordance with the relevant provisions of the Treaty establishing the African Economic Community, and by an African Scientific and Technical Advisory Committee.

\title{
ANNEX II \\ REGIONAL IMPLEMENTATION ANNEX FOR ASIA
}

\begin{abstract}
Article 1
Purpose

The purpose of this Annex is to provide guidelines and arrangements for the effective implementation of the Convention in the affected country Parties of the Asian region in the light of its particular conditions.
\end{abstract}

\section{Article 2}

\section{Particular conditions of the Asian region}

In carrying out their obligations under the Convention, the Parties shall, as appropriate, take into consideration the following particular conditions which apply in varying degrees to the affected country Parties of the region:

(a) the high proportion of areas in their territories affected by, or vulnerable to, desertification and drought and the broad diversity of these areas with regard to climate, topography, land use and socio-economic systems;

(b) the heavy pressure on natural resources for livelihoods;

(c) the existence of production systems, directly related to widespread poverty, leading to land degradation and to pressure on scarce water resources;

(d) the significant impact of conditions in the world economy and social problems such as poverty, poor health and nutrition, lack of food security, migration, displaced persons and demographic dynamics;

(e) their expanding, but still insufficient, capacity and institutional frameworks to deal with national desertification and drought problems; and

(f) their need for international cooperation to pursue sustainable development objectives relating to combating desertification and mitigating the effects of drought.

\section{Article 3 \\ Framework for national action programmes}

1. National action programmes shall be an integral part of broader national policies for sustainable development of the affected country Parties of the region.

2. The affected country Parties shall, as appropriate, develop national action programmes pursuant to articles 9 to 11 of the Convention, paying special attention to article 10, paragraph 2 (f). As appropriate, bilateral and multilateral cooperation agencies may be involved in this process at the request of the affected country Party concerned. 


\section{Article 4 \\ National action programmes}

1. In preparing and implementing national action programmes, the affected country Parties of the region, consistent with their respective circumstances and policies, may, inter alia, as appropriate:

(a) designate appropriate bodies responsible for the preparation, coordination and implementation of their action programmes;

(b) involve affected populations, including local communities, in the elaboration, coordination and implementation of their action programmes through a locally driven consultative process, with the cooperation of local authorities and relevant national and non-governmental organizations;

(c) survey the state of the environment in affected areas to assess the causes and consequences of desertification and to determine priority areas for action;

(d) evaluate, with the participation of affected populations, past and current programmes for combating desertification and mitigating the effects of drought, in order to design a strategy and elaborate activities in their action programmes;

(e) prepare technical and financial programmes based on the information derived from the activities in subparagraphs (a) to (d);

(f) develop and utilize procedures and benchmarks for evaluating implementation of their action programmes;

(g) promote the integrated management of drainage basins, the conservation of soil resources, and the enhancement and efficient use of water resources;

(h) strengthen and/or establish information, evaluation and follow-up and early warning systems in regions prone to desertification and drought, taking account of climatological, meteorological, hydrological, biological and other relevant factors; and

(i) formulate in a spirit of partnership, where international cooperation, including financial and technical resources, is involved, appropriate arrangements supporting their action programmes.

2. Consistent with article 10 of the Convention, the overall strategy of national action programmes shall emphasize integrated local development programmes for affected areas, based on participatory mechanisms and on the integration of strategies for poverty eradication into efforts to combat desertification and mitigate the effects of drought. Sectoral measures in the action programmes shall be grouped in priority fields which take account of the broad diversity of affected areas in the region referred to in article 2 (a).

\section{Article 5 \\ Subregional and joint action programmes}

1. Pursuant to article 11 of the Convention, affected country Parties in Asia may mutually agree to consult and cooperate with other Parties, as appropriate, to prepare and implement subregional or joint action programmes, as appropriate, in order to complement, and increase effectiveness in the implementation of, national action programmes. In either case, the relevant Parties may jointly agree to entrust subregional, including bilateral or national organizations, or specialized institutions, with responsibilities relating to the preparation, coordination and implementation of programmes. Such organizations or institutions may also act as focal points for the promotion and coordination of actions pursuant to articles 16 to 18 of the Convention.

2. In preparing and implementing subregional or joint action programmes, the affected country Parties of the region shall, inter alia, as appropriate: 
(a) identify, in cooperation with national institutions, priorities relating to combating desertification and mitigating the effects of drought which can better be met by such programmes, as well as relevant activities which could be effectively carried out through them;

(b) evaluate the operational capacities and activities of relevant regional, subregional and national institutions;

(c) assess existing programmes relating to desertification and drought among all or some parties of the region or subregion and their relationship with national action programmes; and

(d) formulate in a spirit of partnership, where international cooperation, including financial and technical resources, is involved, appropriate bilateral and/or multilateral arrangements supporting the programmes.

3. Subregional or joint action programmes may include agreed joint programmes for the sustainable management of transboundary natural resources relating to desertification, priorities for coordination and other activities in the fields of capacity-building, scientific and technical cooperation, particularly drought early warning systems and information sharing, and means of strengthening the relevant subregional and other organizations or institutions.

\section{Article 6 \\ Regional activities}

Regional activities for the enhancement of subregional or joint action programmes may include, inter alia, measures to strengthen institutions and mechanisms for coordination and cooperation at the national, subregional and regional levels, and to promote the implementation of articles 16 to 19 of the Convention. These activities may also include:

(a) promoting and strengthening technical cooperation networks;

(b) preparing inventories of technologies, knowledge, know-how and practices, as well as traditional and local technologies and know-how, and promoting their dissemination and use;

(c) evaluating the requirements for technology transfer and promoting the adaptation and use of such technologies; and

(d) encouraging public awareness programmes and promoting capacity-building at all levels, strengthening training, research and development and building systems for human resource development.

\section{Article 7}

Financial resources and mechanisms

1. The Parties shall, in view of the importance of combating desertification and mitigating the effects of drought in the Asian region, promote the mobilization of substantial financial resources and the availability of financial mechanisms, pursuant to articles 20 and 21 of the Convention.

2. In conformity with the Convention and on the basis of the coordinating mechanism provided for in article 8 and in accordance with their national development policies, affected country Parties of the region shall, individually or jointly:

(a) adopt measures to rationalize and strengthen mechanisms to supply funds through public and private investment with a view to achieving specific results in action to combat desertification and mitigate the effects of drought;

(b) identify international cooperation requirements in support of national efforts, particularly financial, technical and technological; and 
(c) promote the participation of bilateral and/or multilateral financial cooperation institutions with a view to ensuring implementation of the Convention.

3. The Parties shall streamline, to the extent possible, procedures for channelling funds to affected country Parties in the region.

\section{Article 8}

\section{Cooperation and coordination mechanisms}

1. Affected country Parties, through the appropriate bodies designated pursuant to article 4, paragraph 1 (a), and other Parties in the region, may, as appropriate, set up a mechanism for, inter alia, the following purposes:

(a) exchange of information, experience, knowledge and know-how;

(b) cooperation and coordination of actions, including bilateral and multilateral arrangements, at the subregional and regional levels;

(c) promotion of scientific, technical, technological and financial cooperation pursuant to articles 5 to 7;

(d) identification of external cooperation requirements; and

(e) follow-up and evaluation of the implementation of action programmes.

2. Affected country Parties, through the appropriate bodies designated pursuant to article 4, paragraph 1 (a), and other Parties in the region, may also, as appropriate, consult and coordinate as regards the national, subregional and joint action programmes. They may involve, as appropriate, other Parties and relevant intergovernmental and non-governmental organizations in this process. Such coordination shall, inter alia, seek to secure agreement on opportunities for international cooperation in accordance with articles 20 and 21 of the Convention, enhance technical cooperation and channel resources so that they are used effectively.

3. Affected country Parties of the region shall hold periodic coordination meetings, and the Permanent Secretariat may, at their request, pursuant to article 23 of the Convention, facilitate the convocation of such coordination meetings by:

(a) providing advice on the organization of effective coordination arrangements, drawing on experience from other such arrangements;

(b) providing information to relevant bilateral and multilateral agencies concerning coordination meetings, and encouraging their active involvement; and

(c) providing other information that may be relevant in establishing or improving coordination processes.

\section{ANNEX III}

\section{REGIONAL IMPLEMENTATION ANNEX FOR LATIN AMERICA AND THE CARIBBEAN}

\section{Article 1 \\ Purpose}

The purpose of this Annex is to provide general guidelines for the implementation of the Convention in the Latin American and Caribbean region, in light of its particular conditions. 


\section{Article 2 \\ Particular conditions of the Latin American and Caribbean region}

The Parties shall, in accordance with the provisions of the Convention, take into consideration the following particular conditions of the region:

(a) the existence of broad expanses which are vulnerable and have been severely affected by desertification and/or drought and in which diverse characteristics may be observed, depending on the area in which they occur; this cumulative and intensifying process has negative social, cultural, economic and environmental effects which are all the more serious in that the region contains one of the largest resources of biological diversity in the world;

(b) the frequent use of unsustainable development practices in affected areas as a result of complex interactions among physical, biological, political, social, cultural and economic factors, including international economic factors such as external indebtedness, deteriorating terms of trade and trade practices which affect markets for agricultural, fishery and forestry products; and

(c) a sharp drop in the productivity of ecosystems being the main consequence of desertification and drought, taking the form of a decline in agricultural, livestock and forestry yields and a loss of biological diversity; from the social point of view, the results are impoverishment, migration, internal population movements, and the deterioration of the quality of life; the region will therefore have to adopt an integrated approach to problems of desertification and drought by promoting sustainable development models that are in keeping with the environmental, economic and social situation in each country.

\section{Article 3}

\section{Action programmes}

1. In conformity with the Convention, in particular its articles 9 to 11 , and in accordance with their national development policies, affected country Parties of the region shall, as appropriate, prepare and implement national action programmes to combat desertification and mitigate the effects of drought as an integral part of their national policies for sustainable development. Subregional and regional programmes may be prepared and implemented in accordance with the requirements of the region.

2. In the preparation of their national action programmes, affected country Parties of the region shall pay particular attention to article 10, paragraph 2 (f) of the Convention.

\section{Article 4 \\ Content of national action programmes}

In the light of their respective situations, the affected country Parties of the region may take account, inter alia, of the following thematic issues in developing their national strategies for action to combat desertification and/or mitigate the effects of drought, pursuant to article 5 of the Convention:

(a) increasing capacities, education and public awareness, technical, scientific and technological cooperation and financial resources and mechanisms;

(b) eradicating poverty and improving the quality of human life;

(c) achieving food security and sustainable development and management of agricultural, livestock-rearing, forestry and multipurpose activities;

(d) sustainable management of natural resources, especially the rational management of drainage basins;

(e) sustainable management of natural resources in high-altitude areas; 
(f) rational management and conservation of soil resources and exploitation and efficient use of water resources;

(g) formulation and application of emergency plans to mitigate the effects of drought;

(h) strengthening and/or establishing information, evaluation and follow-up and early warning systems in areas prone to desertification and drought, taking account of climatological, meteorological, hydrological, biological, soil, economic and social factors;

(i) developing, managing and efficiently using diverse sources of energy, including the promotion of alternative sources;

(j) conservation and sustainable use of biodiversity in accordance with the provisions of the Convention on Biological Diversity;

(k) consideration of demographic aspects related to desertification and drought; and

(l) establishing or strengthening institutional and legal frameworks permitting application of the Convention and aimed, inter alia, at decentralizing administrative structures and functions relating to desertification and drought, with the participation of affected communities and society in general.

\section{Article 5 \\ Technical, scientific and technological cooperation}

In conformity with the Convention, in particular its articles 16 to 18 , and on the basis of the coordinating mechanism provided for in article 7, affected country Parties of the region shall, individually or jointly:

(a) promote the strengthening of technical cooperation networks and national, subregional and regional information systems, as well as their integration, as appropriate, in world-wide sources of information;

(b) prepare an inventory of available technologies and know-how and promote their dissemination and use;

(c) promote the use of traditional technology, knowledge, know-how and practices pursuant to article 18, paragraph 2 (b), of the Convention;

(d) identify transfer of technology requirements; and

(e) promote the development, adaptation, adoption and transfer of relevant existing and new environmentally sound technologies.

\section{Article 6}

\section{Financial resources and mechanisms}

In conformity with the Convention, in particular its articles 20 and 21 , on the basis of the coordinating mechanism provided for in article 7 and in accordance with their national development policies, affected country Parties of the region shall, individually or jointly:

(a) adopt measures to rationalize and strengthen mechanisms to supply funds through public and private investment with a view to achieving specific results in action to combat desertification and mitigate the effects of drought;

(b) identify international cooperation requirements in support of national efforts; and

(c) promote the participation of bilateral and/or multilateral financial cooperation institutions with a view to ensuring implementation of the Convention. 


\section{Article 7 \\ Institutional framework}

1. In order to give effect to this Annex, affected country Parties of the region shall:

(a) establish and/or strengthen national focal points to coordinate action to combat desertification and/or mitigate the effects of drought; and

(b) set up a mechanism to coordinate the national focal points for the following purposes:

(i) exchanges of information and experience;

(ii) coordination of activities at the subregional and regional levels;

(iii) promotion of technical, scientific, technological and financial cooperation;

(iv) identification of external cooperation requirements; and

(v) follow-up and evaluation of the implementation of action programmes.

2. Affected country Parties of the region shall hold periodic coordination meetings and the Permanent Secretariat may, at their request, pursuant to article 23 of the Convention, facilitate the convocation of such coordination meetings, by:

(a) providing advice on the organization of effective coordination arrangements, drawing on experience from other such arrangements;

(b) providing information to relevant bilateral and multilateral agencies concerning coordination meetings, and encouraging their active involvement; and

(c) providing other information that may be relevant in establishing or improving coordination processes.

\section{ANNEX IV \\ REGIONAL IMPLEMENTATION ANNEX FOR THE NORTHERN MEDITERRANEAN}

\section{Article I \\ Purpose}

The purpose of this Annex is to provide guidelines and arrangements necessary for the effective implementation of the Convention in affected country Parties of the northern Mediterranean region in the light of its particular conditions.

\section{Article 2}

\section{Particular conditions of the northern Mediterranean region}

The particular conditions of the northern Mediterranean region referred to in article 1 include:

(a) semi-arid climatic conditions affecting large areas, seasonal droughts, very high rainfall variability and sudden and high-intensity rainfall;

(b) poor and highly erodible soils, prone to develop surface crusts; 
(c) uneven relief with steep slopes and very diversified landscapes;

(d) extensive forest coverage losses due to frequent wildfires;

(e) crisis conditions in traditional agriculture with associated land abandonment and deterioration of soil and water conservation structures;

(f) unsustainable exploitation of water resources leading to serious environmental damage, including chemical pollution, salinization and exhaustion of aquifers; and

(g) concentration of economic activity in coastal areas as a result of urban growth, industrial activities, tourism and irrigated agriculture.

\section{Article 3}

\section{Strategic planning framework for sustainable development}

1. National action programmes shall be a central and integral part of the strategic planning framework for sustainable development of the affected country Parties of the northern Mediterranean.

2. A consultative and participatory process, involving appropriate levels of government, local communities and non-governmental organizations, shall be undertaken to provide guidance on a strategy with flexible planning to allow maximum local participation, pursuant to article 10, paragraph $2(f)$ of the Convention.

\section{Article 4 \\ Obligation to prepare national action programmes and timetable}

Affected country Parties of the northern Mediterranean region shall prepare national action programmes and, as appropriate, subregional, regional or joint action programmes. The preparation of such programmes shall be finalized as soon as practicable.

\section{Article 5}

\section{Preparation and implementation of the national programmes}

In preparing and implementing national action programmes pursuant to articles 9 and 10 of the Convention, each affected country Party of the region shall, as appropriate:

(a) designate appropriate bodies responsible for the preparation, coordination and implementation of its programme;

(b) involve affected populations, including local communities, in the elaboration, coordination and implementation of the programme through a locally driven consultative process, with the cooperation of local authorities and relevant non-governmental organizations;

(c) survey the state of the environment in affected areas to assess the causes and consequences of desertification and to determine priority areas for action;

(d) evaluate, with the participation of affected population, past and current programmes in order to design a strategy and elaborate activities in the action programme;

(e) prepare technical and financial programmes based on the information gained through the activities in subparagraphs (a) to (d); and

(f) develop and utilize procedures and benchmarks for monitoring and evaluating the implementation of the programme. 


\section{Article 6 \\ Content of national action programmes}

Affected country Parties of the region may include, in their national action programmes, measures relating to:

(a) legislative, institutional and administrative areas;

(b) land use patterns, management of water resources, soil conservation, forestry, agricultural activities and pasture and range management;

(c) management and conservation of wildlife and other forms of biological diversity;

(d) protection against forest fires;

(e) promotion of alternative livelihoods; and

(f) research, training and public awareness.

\section{Article 7}

\section{Subregional, regional and joint action programmes}

1. Affected country Parties of the region may, in accordance with article 11 of the Convention, prepare and implement subregional and/or regional action programmes in order to complement and increase the efficiency of national action programmes. Two or more affected country Parties of the region, may similarly agree to prepare a joint action programme between or among them.

2. The provisions of articles 5 and 6 shall apply mutatis mutandis to the preparation and implementation of subregional, regional and joint action programmes. In addition, such programmes may include the conduct of research and development activities concerning selected ecosystems in affected areas.

3. In preparing and implementing subregional, regional or joint action programmes, affected country Parties of the region shall, as appropriate:

(a) identify, in cooperation with national institutions, national objectives relating to desertification which can better be met by such programmes and relevant activities which could be effectively carried out through them;

(b) evaluate the operational capacities and activities of relevant regional, subregional and national institutions; and

(c) assess existing programmes relating to desertification among Parties of the region and their relationship with national action programmes.

Article 8

Coordination of subregional, regional and joint action programmes

Affected country Parties preparing a subregional, regional or joint action programme may establish a coordination committee composed of representatives of each affected country Party concerned to review progress in combating desertification, harmonize national action programmes, make recommendations at the various stages of preparation and implementation of the subregional, regional or joint action programme, and act as a focal point for the promotion and coordination of technical cooperation pursuant to articles 16 to 19 of the Convention. 


\section{Article 9 \\ Non-eligibility for financial assistance}

In implementing national, subregional, regional and joint action programmes, affected developed country Parties of the region are not eligible to receive financial assistance under this Convention.

\section{Article 10}

\section{Coordination with other subregions and regions}

Subregional, regional and joint action programmes in the northern Mediterranean region may be prepared and implemented in collaboration with those of other subregions or regions, particularly with those of the subregion of northern Africa. 


\title{
Agreement Relating to the Implementation of Part XI of the United Nations Convention on the Law of the Sea of 10 December 1982, New York, 1994
}

\author{
Done at New York 28 July 1994 \\ Entered into force 28 July 1996* \\ Depositary: United Nations \\ Primary source citation: United Nations Certified \\ True Copy XX.6(a)
}

\section{AGREEMENT RELATING TO THE IMPLEMENTATION OF PART XI OF THE UNITED NATIONS CONVENTION ON THE LAW OF THE SEA OF 10 DECEMBER 1982}

\section{The States Parties to this Agreement,}

Recognizing the important contribution of the United Nations Convention on the Law of the Sea of 10 December 1982 (hereinafter referred to as "the Convention") to the maintenance of peace, justice and progress for all peoples of the world,

Reaffirming that the seabed and ocean floor and subsoil thereof, beyond the limits of national jurisdiction (hereinafter referred to as "the Area"), as well as the resources of the Area, are the common heritage of mankind,

Mindful of the importance of the Convention for the protection and preservation of the marine environment and of the growing concern for the global environment,

Having considered the report of the Secretary-General of the United Nations on the results of the informal consultations among States held from 1990 to 1994 on outstanding issues relating to Part XI and related provisions of the Convention (hereinafter referred to as "Part XI"),

Noting the political and economic changes, including market-oriented approaches, affecting the implementation of Part XI,

Wishing to facilitate universal participation in the Convention,

Considering that an agreement relating to the implementation of Part XI would best meet that objective,

Have agreed as follows:

\footnotetext{
* This Agreement is not in force for the United States.
} 


\section{Article 1}

\section{Implementation of Part XI}

1. The States Parties to this Agreement undertake to implement Part XI in accordance with this Agreement.

2. The Annex forms an integral part of this Agreement.

\section{Article 2}

\section{Relationship between this Agreement and Part XI}

1. The provisions of this Agreement and Part XI shall be interpreted and applied together as a single instrument. In the event of any inconsistency between this Agreement and Part XI, the provisions of this Agreement shall prevail.

2. Articles 309 to 319 of the Convention shall apply to this Agreement as they apply to the Convention.

\section{Article 3}

\section{Signature}

This Agreement shall remain open for signature at United Nations Headquarters by the States and entities referred to in article 305, paragraph 1 (a), (c), (d), (e) and (f), of the Convention for 12 months from the date of its adoption.

\section{Article 4}

\section{Consent to be bound}

1. After the adoption of this Agreement, any instrument of ratification or formal confirmation of or accession to the Convention shall also represent consent to be bound by this Agreement.

2. No State or entity may establish its consent to be bound by this Agreement unless it has previously established or establishes at the same time its consent to be bound by the Convention.

3. A State or entity referred to in article 3 may express its consent to be bound by this Agreement by:

(a) Signature not subject to ratification, formal confirmation or the procedure set out in article 5;

(b) Signature subject to ratification or formal confirmation, followed by ratification or formal confirmation;

(c) Signature subject to the procedure set out in article 5; or

(d) Accession.

4. Formal confirmation by the entities referred to in article 305 , paragraph 1 (f), of the Convention shall be in accordance with Annex IX of the Convention.

5. The instruments of ratification, formal confirmation or accession shall be deposited with the Secretary-General of the United Nations. 


\section{Article 5}

\section{Simplified procedure}

1. A State or entity which has deposited before the date of the adoption of this Agreement an instrument of ratification or formal confirmation of or accession to the Convention and which has signed this Agreement in accordance with article 4, paragraph 3 (c), shall be considered to have established its consent to be bound by this Agreement 12 months after the date of its adoption, unless that State or entity notifies the depositary in writing before that date that it is not availing itself of the simplified procedure set out in this article.

2. In the event of such notification, consent to be bound by this Agreement shall be established in accordance with article 4, paragraph 3 (b).

\section{Article 6}

\section{Entry into force}

1. This Agreement shall enter into force 30 days after the date on which 40 States have established their consent to be bound in accordance with articles 4 and 5 , provided that such States include at least seven of the States referred to in paragraph 1 (a) of resolution II of the Third United Nations Conference on the Law of the Sea (hereinafter referred to as "resolution II") and that at least five of those States are developed States. If these conditions for entry into force are fulfilled before 16 November 1994, this Agreement shall enter into force on 16 November 1994.

2. For each State or entity establishing its consent to be bound by this Agreement after the requirements set out in paragraph 1 have been fulfilled, this Agreement shall enter into force on the thirtieth day following the date of establishment of its consent to be bound.

\section{Article 7}

\section{Provisional application}

1. If on 16 November 1994 this Agreement has not entered into force, it shall be applied provisionally pending its entry into force by:

(a) States which have consented to its adoption in the General Assembly of the United Nations, except any such State which before 16 November 1994 notifies the depositary in writing either that it will not so apply this Agreement or that it will consent to such application only upon subsequent signature or notification in writing;

(b) States and entities which sign this Agreement, except any such State or entity which notifies the depositary in writing at the time of signature that it will not so apply this Agreement;

(c) States and entities which consent to its provisional application by so notifying the depositary in writing;

(d) States which accede to this Agreement.

2. All such States and entities shall apply this Agreement provisionally in accordance with their national or internal laws and regulations, with effect from 16 November 1994 or the date of signature, notification of consent or accession, if later.

3. Provisional application shall terminate upon the date of entry into force of this Agreement. In any event, provisional application shall terminate on 16 November 1998 if at that date the requirement in article 6, paragraph 1, of consent to be bound by this Agreement by at least seven of the States (of which at least five must be developed States) referred to in paragraph 1 (a) of resolution II has not been fulfilled. 


\section{Article 8}

\section{States Parties}

1. For the purposes of this Agreement, "States Parties" means States which have consented to be bound by this Agreement and for which this Agreement is in force.

2. This Agreement applies mutatis mutandis to the entities referred to in article 305, paragraph 1 (c), (d), (e) and (f), of the Convention which become Parties to this Agreement in accordance with the conditions relevant to each, and to that extent "States Parties" refers to those entities.

\section{Article 9}

\section{Depositary}

The Secretary-General of the United Nations shall be the depositary of this Agreement.

\section{Article 10}

\section{Authentic texts}

The original of this Agreement, of which the Arabic, Chinese, English, French, Russian and Spanish texts are equally authentic, shall be deposited with the Secretary-General of the United Nations. Agreement.

IN WITNESS WHEREOF, the undersigned Plenipotentiaries, being duly authorized thereto, have signed this

DONE AT NEW YORK, this 28 day of July, one thousand nine hundred and ninety-four.

\section{ANNEX}

\section{SECTION 1. COSTS TO STATES PARTIES AND INSTITUTIONAL ARRANGEMENTS}

1. The International Seabed Authority (hereinafter referred to as "the Authority") is the organization through which States Parties to the Convention shall, in accordance with the regime for the Area established in Part XI and this Agreement, organize and control activities in the Area, particularly with a view to administering the resources of the Area. The powers and functions of the Authority shall be those expressly conferred upon it by the Convention. The Authority shall have such incidental powers, consistent with the Convention, as are implicit in, and necessary for, the exercise of those powers and functions with respect to activities in the Area.

2. In order to minimize costs to States Parties, all organs and subsidiary bodies to be established under the Convention and this Agreement shall be cost-effective. This principle shall also apply to the frequency, duration and scheduling of meetings.

3. The setting up and the functioning of the organs and subsidiary bodies of the Authority shall be based on an evolutionary approach, taking into account the functional needs of the organs and subsidiary bodies concerned in order that they may discharge effectively their respective responsibilities at various stages of the development of activities in the Area. 
4. The early functions of the Authority upon entry into force of the Convention shall be carried out by the Assembly, the Council, the Secretariat, the Legal and Technical Commission and the Finance Committee. The functions of the Economic Planning Commission shall be performed by the Legal and Technical Commission until such time as the Council decides otherwise or until the approval of the first plan of work for exploitation.

5. Between the entry into force of the Convention and the approval of the first plan of work for exploitation, the Authority shall concentrate on:

(a) Processing of applications for approval of plans of work for exploration in accordance with Part XI and this Agreement;

(b) Implementation of decisions of the Preparatory Commission for the International Seabed Authority and for the International Tribunal for the Law of the Sea (hereinafter referred to as "the Preparatory Commission") relating to the registered pioneer investors and their certifying States, including their rights and obligations, in accordance with article 308 , paragraph 5, of the Convention and resolution II, paragraph 13;

(c) Monitoring of compliance with plans of work for exploration approved in the form of contracts;

(d) Monitoring and review of trends and developments relating to deep seabed mining activities, including regular analysis of world metal market conditions and metal prices, trends and prospects;

(e) Study of the potential impact of mineral production from the Area on the economies of developing land-based producers of those minerals which are likely to be most seriously affected, with a view to minimizing their difficulties and assisting them in their economic adjustment, taking into account the work done in this regard by the Preparatory Commission;

(f) Adoption of rules, regulations and procedures necessary for the conduct of activities in the Area as they progress. Notwithstanding the provisions of Annex III, article 17, paragraph 2 (b) and (c), of the Convention, such rules, regulations and procedures shall take into account the terms of this Agreement, the prolonged delay in commercial deep seabed mining and the likely pace of activities in the Area;

(g) Adoption of rules, regulations and procedures incorporating applicable standards for the protection and preservation of the marine environment;

(h) Promotion and encouragement of the conduct of marine scientific research with respect to activities in the Area and the collection and dissemination of the results of such research and analysis, when available, with particular emphasis on research related to the environmental impact of activities in the Area;

(i) Acquisition of scientific knowledge and monitoring of the development of marine technology relevant to activities in the Area, in particular technology relating to the protection and preservation of the marine environment;

(j) Assessment of available data relating to prospecting and exploration;

(k) Timely elaboration of rules, regulations and procedures for exploitation, including those relating to the protection and preservation of the marine environment.

6. (a) An application for approval of a plan of work for exploration shall be considered by the Council following the receipt of a recommendation on the application from the Legal and Technical Commission. The processing of an application for approval of a plan of work for exploration shall be in accordance with the provisions of the Convention, including Annex III thereof, and this Agreement, and subject to the following:

(i) A plan of work for exploration submitted on behalf of a State or entity, or any component of such entity, referred to in resolution II, paragraph 1 (a) (ii) or (iii), other than a registered pioneer investor, which had already undertaken substantial activities in the Area prior to the entry into force of the Convention, or its successor in interest, shall be considered to have met the financial and technical qualifications necessary for approval of a plan of work if the sponsoring State or States certify that the applicant has expended an amount equivalent to at least US\$ 30 million in research and exploration activities and has expended no less than $\mathbf{1 0}$ per cent of that amount in the location, survey and evaluation of the area referred to in the plan of work. If the plan of work otherwise satisfies the requirements of the Convention 
and any rules, regulations and procedures adopted pursuant thereto, it shall be approved by the Council in the form of a contract. The provisions of section 3, paragraph 11, of this Annex shall be interpreted and applied accordingly;

(ii) Notwithstanding the provisions of resolution II, paragraph 8 (a), a registered pioneer investor may request approval of a plan of work for exploration within 36 months of the entry into force of the Convention. The plan of work for exploration shall consist of documents, reports and other data submitted to the Preparatory Commission both before and after registration and shall be accompanied by a certificate of compliance, consisting of a factual report describing the status of fulfillment of obligations under the pioneer investor regime, issued by the Preparatory Commission in accordance with resolution II, paragraph 11 (a). Such a plan of work shall be considered to be approved. Such an approved plan of work shall be in the form of a contract concluded between the Authority and the registered pioneer investor in accordance with Part XI and this Agreement. The fee of US $\$ 250,000$ paid pursuant to resolution II, paragraph 7 (a), shall be deemed to be the fee relating to the exploration phase pursuant to section 8, paragraph 3, of this Annex. Section 3, paragraph 11, of this Annex shall be interpreted and applied accordingly;

(iii) In accordance with the principle of non-discrimination, a contract with a State or entity or any component of such entity referred to in subparagraph (a) (i) shall include arrangements which shall be similar to and no less favourable than those agreed with any registered pioneer investor referred to in subparagraph (a) (ii). If any of the States or entities or any components of such entities referred to in subparagraph (a) (i) are granted more favourable arrangements, the Council shall make similar and no less favourable arrangements with regard to the rights and obligations assumed by the registered pioneer investors referred to in subparagraph (a) (ii), provided that such arrangements do not affect or prejudice the interests of the Authority;

(iv) A State sponsoring an application for a plan of work pursuant to the provisions of subparagraph (a) (i) or (ii) may be a State Party or a State which is applying this Agreement provisionally in accordance with article 7 , or a State which is a member of the Authority on a provisional basis in accordance with paragraph 12;

(v) Resolution II, paragraph 8 (c), shall be interpreted and applied in accordance with subparagraph (a) (iv).

(b) The approval of a plan of work for exploration shall be in accordance with article 153, paragraph 3, of the Convention.

7. An application for approval of a plan of work shall be accompanied by an assessment of the potential environmental impacts of the proposed activities and by a description of a programme for oceanographic and baseline environmental studies in accordance with the rules, regulations and procedures adopted by the Authority.

8. An application for approval of a plan of work for exploration, subject to paragraph 6 (a) (i) or (ii), shall be processed in accordance with the procedures set out in section 3, paragraph 11, of this Annex.

9. A plan of work for exploration shall be approved for a period of 15 years. Upon the expiration of a plan of work for exploration, the contractor shall apply for a plan of work for exploitation unless the contractor has already done so or has obtained an extension for the plan of work for exploration. Contractors may apply for such extensions for periods of not more than five years each. Such extensions shall be approved if the contractor has made efforts in good faith to comply with the requirements of the plan of work but for reasons beyond the contractor's control has been unable to complete the necessary preparatory work for proceeding to the exploitation stage or if the prevailing economic circumstances do not justify proceeding to the exploitation stage.

10. Designation of a reserved area for the Authority in accordance with Annex III, article 8, of the Convention shall take place in connection with approval of an application for a plan of work for exploration or approval of an application for a plan of work for exploration and exploitation.

11. Notwithstanding the provisions of paragraph 9, an approved plan of work for exploration which is sponsored by at least one State provisionally applying this Agreement shall terminate if such a State ceases to apply this 
Agreement provisionally and has not become a member on a provisional basis in accordance with paragraph 12 or has not become a State Party.

12. Upon the entry into force of this Agreement, States and entities referred to in article 3 of this Agreement which have been applying it provisionally in accordance with article 7 and for which it is not in force may continue to be members of the Authority on a provisional basis pending its entry into force for such States and entities, in accordance with the following subparagraphs:

(a) If this Agreement enters into force before 16 November 1996, such States and entities shall be entitled to continue to participate as members of the Authority on a provisional basis upon notification to the depositary of the Agreement by such a State or entity of its intention to participate as a member on a provisional basis. Such membership shall terminate either on 16 November 1996 or upon the entry into force of this Agreement and the Convention for such member, whichever is earlier. The Council may, upon the request of the State or entity concerned, extend such membership beyond 16 November 1996 for a further period or periods not exceeding a total of two years provided that the Council is satisfied that the State or entity concerned has been making efforts in good faith to become a party to the Agreement and the Convention;

(b) If this Agreement enters into force after 15 November 1996, such States and entities may request the Council to grant continued membership in the Authority on a provisional basis for a period or periods not extending beyond 16 November 1998. The Council shall grant such membership with effect from the date of the request if it is satisfied that the State or entity has been making efforts in good faith to become a party to the Agreement and the Convention;

(c) States and entities which are members of the Authority on a provisional basis in accordance with subparagraph (a) or (b) shall apply the terms of Part XI and this Agreement in accordance with their national or internal laws, regulations and annual budgetary appropriations and shall have the same rights and obligations as other members, including:

(i) The obligation to contribute to the administrative budget of the Authority in accordance with the scale of assessed contributions;

(ii) The right to sponsor an application for approval of a plan of work for exploration. In the case of entities whose components are natural or juridical persons possessing the nationality of more than one State, a plan of work for exploration shall not be approved unless all the States whose natural or juridical persons comprise those entities are States Parties or members on a provisional basis;

(d) Notwithstanding the provisions of paragraph 9, an approved plan of work in the form of a contract for exploration which was sponsored pursuant to subparagraph (c) (ii) by a State which was a member on a provisional basis shall terminate if such membership ceases and the State or entity has not become a State Party;

(e) If such a member has failed to make its assessed contributions or otherwise failed to comply with its obligations in accordance with this paragraph, its membership on a provisional basis shall be terminated.

13. The reference in Annex III, article 10, of the Convention to performance which has not been satisfactory shall be interpreted to mean that the contractor has failed to comply with the requirements of an approved plan of work in spite of a written warning or warnings from the Authority to the contractor to comply therewith.

14. The Authority shsll have its own budget. Until the end of the year following the year during which this Agreement enters into force, the administrative expenses of the Authority shall be met through the budget of the United Nations. Thereafter, the administrative expenses of the Authority shall be met by assessed contributions of its members, including any members on a provisional basis, in accordance with articles 171, subparagraph (a), and 173 of the Convention and this Agreement, until the Authority has sufficient funds from other sources to meet those expenses. The Authority shall not exercise the power referred to in article 174, paragraph 1, of the Convention to borrow funds to finance its administrative budget.

15. The Authority shall elaborate and adopt, in accordance with article 162, paragraph 2 (o) (ii), of the Convention, rules, regulations and procedures based on the principles contained in sections $2,5,6,7$ and 8 of this Annex, as well as any additional rules, regulations and procedures necessary to facilitate the approval of plans of work for exploration or exploitation, in accordance with the following subparagraphs: 
(a) The Council may undertake such elaboration any time it deems that all or any of such rules, regulations or procedures are required for the conduct of activities in the Area, or when it determines that commercial exploitation is imminent, or at the request of a State whose national intends to apply for approval of a plan of work for exploitation;

(b) If a request is made by a State referred to in subparagraph (a) the Council shall, in accordance with article 162, paragraph 2 (o), of the Convention, complete the adoption of such rules, regulations and procedures within two years of the request;

(c) If the Council has not completed the elaboration of the rules, regulations and procedures relating to exploitation within the prescribed time and an application for approval of a plan of work for exploitation is pending, it shall none the less consider and provisionally approve such plan of work based on the provisions of the Convention and any rules, regulations and procedures that the Council may have adopted provisionally, or on the basis of the norms contained in the Convention and the terms and principles contained in this Annex as well as the principle of non-discrimination among contractors.

16. The draft rules, regulations and procedures and any recommendations relating to the provisions of Part XI, as contained in the reports and recommendations of the Preparatory Commission, shall be taken into account by the Authority in the adoption of rules, regulations and procedures in accordance with Part XI and this Agreement.

17. The relevant provisions of Part XI, section 4, of the Convention shall be interpreted and applied in accordance with this Agreement.

\section{SECTION 2. THE ENTERPRISE}

1. The Secretariat of the Authority shall perform the functions of the Enterprise until it begins to operate independently of the Secretariat. The Secretary-General of the Authority shall appoint from within the staff of the Authority an interim Director-General to oversee the performance of these functions by the Secretariat.

These functions shall be:

(a) Monitoring and review of trends and developments relating to deep seabed mining activities, including regular analysis of world metal market conditions and metal prices, trends and prospects;

(b) Assessment of the results of the conduct of marine scientific research with respect to activities in the Area, with particular emphasis on research related to the environmental impact of activities in the Area;

(c) Assessment of available data relating to prospecting and exploration, including the criteria for such activities;

(d) Assessment of technological developments relevant to activities in the Area, in particular technology relating to the protection and preservation of the marine environment;

(e) Evaluation of information and data relating to areas reserved for the Authority;

(f) Assessment of approaches to joint-venture operations;

(g) Collection of information on the availability of trained manpower;

(h) Study of managerial policy options for the administration of the Enterprise at different stages of its operations.

2. The Enterprise shall conduct its initial deep seabed mining operations through joint ventures. Upon the approval of a plan of work for exploitation for an entity other than the Enterprise, or upon receipt by the Council of an application for a joint-venture operation with the Enterprise, the Council shall take up the issue of the functioning of the Enterprise independently of the Secretariat of the Authority. If joint-venture operations with the Enterprise accord with sound commercial principles, the Council shall issue a directive pursuant to article 170, paragraph 2 , of the Convention providing for such independent functioning. 
3. The obligation of States Parties to fund one mine site of the Enterprise as provided for in Annex IV, article 11, paragraph 3, of the Convention shall not apply and States Parties shall be under no obligation to finance any of the operations in any mine site of the Enterprise or under its joint-venture arrangements.

4. The obligations applicable to contractors shall apply to the Enterprise. Notwithstanding the provisions of article 153, paragraph 3, and Annex III, article 3, paragraph 5, of the Convention, a plan of work for the Enterprise upon its approval shall be in the form of a contract concluded between the Authority and the Enterprise.

5. A contractor which has contributed a particular area to the Authority as a reserved area has the right of first refusal to enter into a joint-venture arrangement with the Enterprise for exploration and exploitation of that area. If the Enterprise does not submit an application for a plan of work for activities in respect of such a reserved area within 15 years of the commencement of its functions independent of the Secretariat of the Authority or within 15 years of the date on which that area is reserved for the Authority, whichever is the later, the contractor which contributed the area shall be entitled to apply for a plan of work for that area provided it offers in good faith to include the Enterprise as a joint-venture partner.

6. Article 170, paragraph 4, Annex IV and other provisions of the Convention relating to the Enterprise shall be interpreted and applied in accordance with this section.

\section{SECTION 3. DECISION-MAKING}

1. The general policies of the Authority shall be established by the Assembly in collaboration with the Council.

2. As a general rule, decision-making in the organs of the Authority should be by consensus.

3. If all efforts to reach a decision by consensus have been exhausted, decisions by voting in the Assembly on questions of procedure shall be taken by a majority of members present and voting, and decisions on questions of substance shall be taken by a two-thirds majority of members present and voting, as provided for in article 159 , paragraph 8 , of the Convention.

4. Decisions of the Assembly on any matter for which the Council also has competence or on any administrative, budgetary or financial matter shall be based on the recommendations of the Council. If the Assembly does not accept the recommendation of the Council on any matter, it shall return the matter to the Council for further consideration. The Council shall reconsider the matter in the light of the views expressed by the Assembly.

5. If all efforts to reach a decision by consensus have been exhausted, decisions by voting in the Council on questions of procedure shall be taken by a majority of members present and voting, and decisions on questions of substance, except where the Convention provides for decisions by consensus in the Council, shall be taken by a two-thirds majority of members present and voting, provided that such decisions are not opposed by a majority in any one of the chambers referred to in paragraph 9. In taking decisions the Council shall seek to promote the interests of all the members of the Authority.

6. The Council may defer the taking of a decision in order to facilitate further negotiation whenever it appears that all efforts at achieving consensus on a question have not been exhausted.

7. Decisions by the Assembly or the Council having financial or budgetary implications shall be based on the recommendations of the Finance Committee.

8. The provisions of article 161, paragraph 8 (b) and (c), of the Convention shall not apply.

9. (a) Each group of States elected under paragraph 15 (a) to (c) shall be treated as a chamber for the purposes of voting in the Council. The developing States elected under paragraph 15 (d) and (e) shall be treated as a single chamber for the purposes of voting in the Council.

(b) Before electing the members of the Council, the Assembly shall establish lists of countries fulfilling the criteria for membership in the groups of States in paragraph 15 (a) to (d). If a State fulfils the criteria for membership 
in more than one group, it may only be proposed by one group for election to the Council and it shall represent only that group in voting in the Council.

10. Each group of States in paragraph 15 (a) to (d) shall be represented in the Council by those members nominated by that group. Each group shall nominate only as many candidates as the number of seats required to be filled by that group. When the number of potential candidates in each of the groups referred to in paragraph 15 (a) to (e) exceeds the number of seats available in each of those respective groups, as a general rule, the principle of rotation shall apply. States members of each of those groups shall determine how this principle shall apply in those groups.

11. (a) The Council shall approve a recommendation by the Legal and Technical Commission for approval of a plan of work unless by a two-thirds majority of its members present and voting, including a majority of members present and voting in each of the chambers of the Council, the Council decides to disapprove a plan of work. If the Council does not take a decision on a recommendation for approval of a plan of work within a prescribed period, the recommendation shall be deemed to have been approved by the Council at the end of that period. The prescribed period shall normally be 60 days unless the Council decides to provide for a longer period. If the Commission recommends the disapproval of a plan of work or does not make a recommendation, the Council may nevertheless approve the plan of work in accordance with its rules of procedure for decision-making on questions of substance.

(b) The provisions of article 162, paragraph 2 (j), of the Convention shall not apply.

12. Where a dispute arises relating to the disapproval of a plan of work, such dispute shall be submitted to the dispute settlement procedures set out in the Convention.

13. Decisions by voting in the Legal and Technical Commission shall be by a majority of members present and voting.

14. Part XI, section 4, subsections B and C, of the Convention shall be interpreted and applied in accordance with this section.

15. The Council shall consist of 36 members of the Authority elected by the Assembly in the following order:

(a) Four members from among those States Parties which, during the last five years for which statistics are available, have either consumed more than 2 per cent in value terms of total world consumption or have had net imports of more than 2 per cent in value terms of total world imports of the commodities produced from the categories of minerals to be derived from the Area, provided that the four members shall include one State from the Eastern European region having the largest economy in that region in terms of gross domestic product and the State, on the date of entry into force of the Convention, having the largest economy in terms of gross domestic product, if such States wish to be represented in this group;

(b) Four members from among the eight States Parties which have made the largest investments in preparation for and in the conduct of activities in the Area, either directly or through their nationals;

(c) Four members from among States Parties which, on the basis of production in areas under their jurisdiction, are major net exporters of the categories of minerals to be derived from the Area, including at least two developing States whose exports of such minerals have a substantial bearing upon their economies;

(d) Six members from among developing States Parties, representing special interests. The special interests to be represented shall include those of States with large populations, States which are land-locked or geographically disadvantaged, island States, States which are major importers of the categories of minerals to be derived from the Area, States which are potential producers of such minerals and least developed States;

(e) Eighteen members elected according to the principle of ensuring an equitable geographical distribution of seats in the Council as a whole, provided that each geographical region shall have at least one member elected under this subparagraph. For this purpose, the geographical regions shall be Africa, Asia, Eastern Europe, Latin America and the Caribbean and Western Europe and Others.

16. The provisions of article 161 , paragraph 1 , of the Convention shall not apply. 


\section{SECTION 4. REVIEW CONFERENCE}

The provisions relating to the Review Conference in article 155, paragraphs 1, 3 and 4, of the Convention shall not apply. Notwithstanding the provisions of article 314, paragraph 2, of the Convention, the Assembly, on the recommendation of the Council, may undertake at any time a review of the matters referred to in article 155, paragraph 1, of the Convention. Amendments relating to this Agreement and Part XI shall be subject to the procedures contained in articles 314,315 and 316 of the Convention, provided that the principles, regime and other terms referred to in article 155, paragraph 2 , of the Convention shall be maintained and the rights referred to in paragraph 5 of that article shall not be affected.

\section{SECTION 5. TRANSFER OF TECHNOLOGY}

1. In addition to the provisions of article $\mathbf{1 4 4}$ of the Convention, transfer of technology for the purposes of Part XI shall be governed by the following principles:

(a) The Enterprise, and developing States wishing to obtain deep seabed mining technology, shall seek to obtain such technology on fair and reasonable commercial terms and conditions on the open market, or through joint-venture arrangements;

(b) If the Enterprise or developing States are unable to obtain deep seabed mining technology, the Authority may request all or any of the contractors and their respective sponsoring State or States to cooperate with it in facilitating the acquisition of deep seabed mining technology by the Enterprise or its joint venture, or by a developing State or States seeking to acquire such technology on fair and reasonable commercial terms and conditions, consistent with the effective protection of intellectual property rights. States Parties undertake to cooperate fully and effectively with the Authority for this purpose and to ensure that contractors sponsored by them also cooperate fully with the Authority;

(c) As a general rule, States Parties shall promote international technical and scientific cooperation with regard to activities in the Area either between the parties concerned or by developing training, technical assistance and scientific cooperation programmes in marine science and technology and the protection and preservation of the marine environment.

2. The provisions of Annex III, article 5, of the Convention shall not apply.

\section{SECTION 6. PRODUCTION POLICY}

1. The production policy of the Authority shall be based on the following principles.

(a) Development of the resources of the Area shall take place in accordance with sound commercial principles;

(b) The provisions of the General Agreement on Tariffs and Trade, its relevant codes and successor or superseding agreements shall apply with respect to activities in the Area;

(c) In particular, there shall be no subsidization of activities in the Area except as may be permitted under the agreements referred to in subparagraph (b). Subsidization for the purpose of these principles shall be defined in terms of the agreements referred to in subparagraph (b);

(d) There shall be no discrimination between minerals derived from the Area and from other sources. There shall be no preferential access to markets for such minerals or for imports of commodities produced from such minerals, in particular:

(i) By the use of tariff or non-tariff barriers; and 
(ii) Given by States Parties to such minerals or commodities produced by their state enterprises or by natural or juridical persons which possess their nationality or are controlled by them or their nationals;

(e) The plan of work for exploitation approved by the Authority in respect of each mining area shall indicate an anticipated production schedule which shall include the estimated maximum amounts of minerals that would be produced per year under the plan of work;

(f) The following shall apply to the settlement of disputes concerning the provisions of the agreements referred to in subparagraph (b):

(i) Where the States Parties concerned are parties to such agreements, they shall have recourse to the dispute settlement procedures of those agreements;

(ii) Where one or more of the States Parties concerned are not parties to such agreements, they shall have recourse to the dispute settlement procedures set out in the Convention;

(g) In circumstances where a determination is made under the agreements referred to in subparagraph (b) that a State Party has engaged in subsidization which is prohibited or has resulted in adverse effects on the interests of another State Party and appropriate steps have not been taken by the relevant State Party or States Parties, a State Party may request the Council to take appropriate measures.

2. The principles contained in paragraph 1 shall not affect the rights and obligations under any provision of the agreements referred to in paragraph 1 (b), as well as the relevant free trade and customs union agreements, in relations between States Parties which are parties to such agreements.

3. The acceptance by a contractor of subsidies other than those which may be permitted under the agreements referred to in paragraph 1 (b) shall constitute a violation of the fundamental terms of the contract forming a plan of work for the carrying out of activities in the Area.

4. Any State Party which has reason to believe that there has been a breach of the requirements of paragraphs 1 (b) to (d) or 3 may initiate dispute settlement procedures in conformity with paragraph 1 (f) or (g).

5. AState Party may at any time bring to the attention of the Council activities which in its view are inconsistent with the requirements of paragraph 1 (b) to (d).

6. The Authority shall develop rules, regulations and procedures which ensure the implementation of the provisions of this section, including relevant rules, regulations and procedures governing the approval of plans of work.

7. The provisions of article 151, paragraphs 1 to 7 and 9 , article 162, paragraph 2 (q), article 165, paragraph 2 (n), and Annex III, article 6, paragraph 5, and article 7, of the Convention shall not apply.

\section{SECTION 7. ECONOMIC ASSISTANCE}

1. The policy of the Authority of assisting developing countries which suffer serious adverse effects on their export earnings or economies resulting from a reduction in the price of an affected mineral or in the volume of exports of that mineral, to the extent that such reduction is caused by activities in the Area, shall be based on the following principles:

(a) The Authority shall establish an economic assistance fund from a portion of the funds of the Authority which exceeds those necessary to cover the administrative expenses of the Authority. The amount set aside for this purpose shall be determined by the Council from time to time, upon the recommendation of the Finance Committee. Only funds from payments received from contractors, including the Enterprise, and voluntary contributions shall be used for the establishment of the economic assistance fund; 
(b) Developing land-based producer States whose economies have been determined to be seriously affected by the production of minerals from the deep seabed shall be assisted from the economic assistance fund of the Authority;

(c) The Authority shall provide assistance from the fund to affected developing land-based producer States, where appropriate, in cooperation with existing global or regional development institutions which have the infrastructure and expertise to carry out such assistance programmes;

(d) The extent and period of such assistance shall be determined on a case-by-case basis. In doing so, due consideration shall be given to the nature and magnitude of the problems encountered by affected developing land-based producer States.

2. Article 151, paragraph 10, of the Convention shall be implemented by means of measures of economic assistance referred to in paragraph 1. Article 160, paragraph 2 (1), article 162, paragraph 2 (n), article 164, paragraph 2 (d), article 171, subparagraph (f), and article 173, paragraph 2 (c), of the Convention shall be interpreted accordingly.

\section{SECTION 8. FINANCLAL TERMS OF CONTRACTS}

1. The following principles shall provide the basis for establishing rules, regulations and procedures for financial terms of contracts:

(a) The system of payments to the Authority shall be fair both to the contractor and to the Authority and shall provide adequate means of determining compliance by the contractor with such system;

(b) The rates of payments under the system shall be within the range of those prevailing in respect of land-based mining of the same or similar minerals in order to avoid giving deep seabed miners an artificial competitive advantage or imposing on them a competitive disadvantage;

(c) The system should not be complicated and should not impose major administrative costs on the Authority or on a contractor. Consideration should be given to the adoption of a royalty system or a combination of a royalty and profit-sharing system. If alternative systems are decided upon, the contractor has the right to choose the system applicable to its contract. Any subsequent change in choice between alternative systems, however, shall be made by agreement between the Authority and the contractor;

(d) An annual fixed fee shall be payable from the date of commencement of commercial production. This fee may be credited against other payments due under the system adopted in accordance with subparagraph (c). The amount of the fee shall be established by the Council;

(e) The system of payments may be revised periodically in the light of changing circumstances. Any changes shall be applied in a non-discriminatory manner. Such changes may apply to existing contracts only at the election of the contractor. Any subsequent change in choice between alternative systems shall be made by agreement between the Authority and the contractor;

(f) Disputes concerning the interpretation or application of the rules and regulations based on these principles shall be subject to the dispute settlement procedures set out in the Convention.

2. The provisions of Annex III, article 13, paragraphs 3 to 10, of the Convention shall not apply.

3. With regard to the implementation of Annex III, article 13, paragraph 2, of the Convention, the fee for processing applications for approval of a plan of work limited to one phase, either the exploration phase or the exploitation phase, shall be US $\$ 250,000$. 


\section{SECTION 9. THE FINANCE COMMITTEE}

1. There is hereby established a Finance Committee. The Committee shall be composed of 15 members with appropriate qualifications relevant to financial matters. States Parties shall nominate candidates of the highest standards of competence and integrity.

2. No two members of the Finance Committee shall be nationals of the same State Party.

3. Members of the Finance Committee shall be elected by the Assembly and due account shall be taken of the need for equitable geographical distribution and the representation of special interests. Each group of States referred to in section 3, paragraph 15 (a), (b), (c) and (d), of this Annex shall be represented on the Committee by at least one member. Until the Authority has sufficient funds other than assessed contributions to meet its administrative expenses, the membership of the Committee shall include representatives of the five largest financial contributors to the administrative budget of the Authority. Thereafter, the election of one member from each group shall be on the basis of nomination by the members of the respective group, without prejudice to the possibility of further members being elected from each group.

4. Members of the Finance Committee shall hold office for a term of five years. They shall be eligible for re-election for a further term.

5. In the event of the death, incapacity or resignation of a member of the Finance Committee prior to the expiration of the term of office, the Assembly shall elect for the remainder of the term a member from the same geographical region or group of States.

6. Members of the Finance Committee shall have no financial interest in any activity relating to matters upon which the Committee has the responsibility to make recommendations. They shall not disclose, even after the termination of their functions, any confidential information coming to their knowledge by reason of their duties for the Authority.

7. Decisions by the Assembly and the Council on the following issues shall take into account recommendations of the Finance Committee:

(a) Draft financial rules, regulations and procedures of the organs of the Authority and the financial management and internal financial administration of the Authority;

(b) Assessment of contributions of members to the administrative budget of the Authority in accordance with article 160, paragraph 2 (e), of the Convention;

(c) All relevant financial matters, including the proposed annual budget prepared by the Secretary-General of the Authority in accordance with article 172 of the Convention and the financial aspects of the implementation of the programmes of work of the Secretariat;

(d) The administrative budget;

(e) Financial obligations of States Parties arising from the implementation of this Agreement and Part XI as well as the administrative and budgetary implications of proposals and recommendations involving expenditure from the funds of the Authority;

(f) Rules, regulations and procedures on the equitable sharing of financial and other economic benefits derived from activities in the Area and the decisions to be made thereon.

8. Decisions in the Finance Committee on questions of procedure shall be taken by a majority of members present and voting. Decisions on questions of substance shall be taken by consensus.

9. The requirement of article 162, paragraph $2(y)$, of the Convention to establish a subsidiary organ to deal with financial matters shall be deemed to have been fulfilled by the establishment of the Finance Committee in accordance with this section. 


\section{Convention to Ban the Importation into Forum Island Countries of Hazardous and Radioactive Wastes and to Control the Transboundary Movement and Management of Hazardous Wastes Within the South Pacific Region, Waigani, 1995}

Done at Waigani 16 September 1995

Not in Force*

Depositary: South Pacific Forum Secretariat

Primary source citation: Copy of text provided by the

South Pacific Forum Secretariat

\section{CONVENTION TO BAN THE IMPORTATION INTO FORUM ISLAND COUNTRIES OF HAZARDOUS AND RADIOACTIVE WASTES AND TO CONTROL THE TRANSBOUNDARY MOVEMENT AND MANAGEMENT OF HAZARDOUS WASTES WITHIN THE SOUTH PACIFIC REGION}

\section{PREAMBLE}

The Parties to this Convention:

Conscious of their responsibility to protect, preserve and improve the environment of the South Pacific for the good health, benefit and enjoyment of present and future generations of the people of the South Pacific;

Concerned about the growing threat to human health and the environment posed by the increasing generation of hazardous wastes and the disposal of such wastes by environmentally unsound methods;

Concerned also about the dangers posed by radioactive wastes to the people and environment of the South Pacific;

Aware that their responsibilities to protect, preserve and improve the environment of the South Pacific can be met only by cooperative effort among all peoples of the South Pacific based on an understanding of the needs and capacities of all Parties;

\footnotetext{
* The United States is not a party to this convention.
} 
Taking full account of the Programme of Action for the Sustainable Development of Small Island Developing States adopted in Barbados on 6 May 1994;

Noting with concern that a number of approaches have been made to certain Island Countries of the South Pacific by unscrupulous foreign waste dealers for the importation into and the disposal within the South Pacific of hazardous wastes generated in other countries;

Concerned by the slowness of progress towards a satisfactory resolution of the issues surrounding international trade in goods which have been banned, cancelled or refused registration in the country of manufacture for human health or environmental reasons;

Recalling their commitments under existing regional treaties and arrangements for the protection and preservation of the environment of the South Pacific, including the Convention for the Protection of the Natural Resources and Environment of the South Pacific Region, signed in Noumea on 24 November 1986, the Protocol concerning Cooperation in Combating Pollution Emergencies in the South Pacific Region, adopted by Parties on 25 November 1986, and the South Pacific Nuclear Free Zone Treaty, signed in Rarotonga on 6 August 1985;

Further Recalling the Basel Convention on the Control of Transboundary Movements of Hazardous Wastes and their Disposal adopted by the Conference of the Plenipotentiaries on 22 March 1989, and noting decisions of its Conference of the Parties including Decision II 12 of 25 Marck 1994;

Desiring to conclude an agreement under Article 11 of the Basel Convention;

Mindful of the International Atomic Energy Agency (IAEA) Code of Practice on the International Transboundary Movement of Radioactive Waste and recognising the need for its strict observance in the South Pacific Region;

Noting as well the preliminary negotiations on a Convention on the Safe Management of Nuclear Waste;

Further Recalling the Declaration of the United Nations Conference on the Human Environment (Stockholm, 1972), the Cairo Guidelines and Principles for the Environmentally Sound Management of Hazardous Wastes adopted by the Governing Council of the United Nations Environment Programme (UNEP) by Decision 14/30 of 17 June 1987 and the Recommendations of the United Nations Committee of Experts on the Transport of Dangerous Goods (formulated in 1957 and updated biennially);

Recalling also Agenda 21 adopted by the United Nations Conference on Environment and Development in Rio de Janeiro on 14 June 1992, which reaffirms that effective control of the generation, storage, treatment, recycling and reuse, transport, recovery, and disposal of hazardous wastes is of paramount importance for proper health, environmental protection and natural resources management and sustainable development;

Resolving to prohibit the importation of hazardous wastes into Pacific Island Developing Parties, and to regulate and facilitate the environmentally sound management of such wastes generated within the Convention Area; and

Resolving also to prohibit the importation of all radioactive wastes into Pacific Island Developing Parties while at the same time recognising that the standards, procedures and the authorities responsible for the environmentally sound management of radioactive wastes will differ from those in respect of hazardous wastes.

Have agreed as follows:

\section{ARTICLE 1 \\ Definitions}

For the purposes of this Convention:

"Approved site or facility" means a site or facility for the disposal of hazardous wastes which is authorised or permitted to operate for this purpose by a relevant authority of the Party where the site or facility is located; 
"Area under the jurisdiction of a Party" means any land, marine area or airspace within which a Party exercises administrative and regulatory responsibility in accordance with international law in regard to the protection of human health or the environment;

"Authorised transboundary movement" means a transboundary movement of hazardous wastes to which the consent of the Parties concerned has been given in accordance with the provisions of this Convention;

"Basel Convention" means the Convention on the Control of Transboundary Movements of Hazardous Wastes and their Disposal, 1989;

"Carrier" means any person who carries out the transport of hazardous wastes;

"Cleaner production" means the conceptual and procedural approach to production that demands that all phases of the life-cycle of a product or process should be addressed, with the objective of prevention or minimisation of short and long-term risks to humans and to the environment;

"Competent authority" means any one governmental authority designated by a Party to be responsible within such geographical areas as the Party may think fit for receiving the notification of a transboundary movement of hazardous wastes and any information related to it, and for responding to such a notification, as provided in Article 6 of this Convention;

"Convention Area" shall comprise:

(i) the land territory, internal waters, territorial sea, continental shelf, archipelagic waters and exclusive economic zones established in accordance with international law of:

- American Samoa

- Australia

- Cook Islands

- Federated States of Micronesia

- Fiji

- French Polynesia

- Guam

- Kiribati

- Republic of Marshall Islands

- Nauru

- New Caledonia and Dependencies

- New Zealand

- Niue
- The Commonwealth of Northern Mariana Islands

- Republic of Palau

- Papua New Guinea

- Pitcairn Islands

- Solomon Islands

- Tokelau

- Tonga

- Tuvalu

- Vanuatu

- Wallis and Futuna

- Western Samoa;

(ii) those areas of high seas which are enclosed from all sides by the exclusive economic zones referred to in sub-paragraph (i);

(iii) areas of the Pacific Ocean which have been included in the Convention Area pursuant to Article 2.6 ;

"Countries concerned" means countries of export, import or transit whether or not Parties to this Convention;

"Days" means calendar days unless otherwise specified;

"Disposal" means any operation specified in Annex V to this Convention;

"Disposer" means any person for whom hazardous wastes are destined and who carries out the actual disposal of such wastes;

"Domestically prohibited goods" means substances or products which have been banned, cancelled or refused registration by government regulatory action, or voluntarily withdrawn from registration in the country of manufacture, for human health or environmental reasons; 
"Environmentally sound management of hazardous wastes" means taking all practicable steps to ensure that hazardous wastes are managed in a manner which will protect human health and the environment against the adverse effects which may result from such wastes;

"Exporter" means any person under the jurisdiction of the exporting Party who arranges for hazardous wastes to be exported;

"Exporting Party" means a Party from which a transboundary movement of hazardous wastes is planned to be initiated or is initiated;

"Focal point" means the entity of a Party referred to in Article 5 of this Convention responsible for receiving and submitting information as provided for in Articles 7 and 14;

"Forum Island Countries" means all Members of the South Pacific Forum with the exception of Australia and New Zealand;

"Generator" means any person whose activity produces hazardous wastes or, if that person is not known, the person who is in possession and/or control of those wastes;

"Hazardous wastes" means wastes as specified in Article 2 of this Convention;

"LAEA" means the International Atomic Energy Agency;

"Illegal traffic" means any transboundary movement of hazardous wastes as specified in Article 9 of this Convention;

"Importer" means any person under the jurisdiction of the importing Party who arranges for hazardous wastes to be imported;

"Importing Party" means a Party to which transboundary movement of hazardous wastes is planned or takes place for the purpose of disposal therein or for the purpose of loading prior to disposal in an area not under the national jurisdiction of any State;

"London Convention" means the Convention on the Prevention of Marine Pollution by Dumping of Wastes and Other Matter, 1972;

"Management" means the prevention and reduction of hazardous wastes and the collection, transport, storage, and treatment or disposal, of hazardous wastes including after-care of disposal sites;

"Other Party" means a Party listed in Annex IV or any Party which is accepted by the Conference of the Parties to be an Other Party in accordance with the procedures established pursuant to Article 13.4(g);

"Pacific Island Developing Party" means a Party listed in Annex III or any Party which is accepted by the Conference of the Parties to be a Pacific Island Developing Party in accordance with the procedures established pursuant to Article 13.4(g);

"Party" means a Party to this Convention;

"Person" means any natural or legal person;

"Precautionary principle" means the principle that in order to protect the environment, the precautionary approach shall be widely applied by Parties according to their capabilities. Where there are threats of serious or irreversible damage, lack of full scientific certainty shall not be used as a reason for postponing cost-effective measures to prevent environmental degradation;

"Radioactive wastes" means wastes which, as a result of being radioactive, are subject to other international control systems, including international instruments, applying specifically to radioactive materials;

"Secretariat" means the Secretariat established pursuant to Article 14 of this Convention; 


\section{"SPREP" means the South Pacific Regional Environment Programme;}

"Transboundary movement" means any movement of hazardous wastes from an area under the jurisdiction of any Party, to or through an area under the jurisdiction of another Party, or to or through an area not under the jurisdiction of another Party, provided at least two Parties are involved in the movement;

"Transit Party" means any Party, other than the exporting Party or importing Party, through which a movement of hazardous wastes is planned or takes place;

"Vessels" and "Aircraft" mean waterborne or airborne craft of any type whatsoever. This expression includes air cushioned craft and floating craft, whether self-propelled or not;

"Wastes" means substances or materials which are disposed of, or are intended to be disposed of, or are required to be disposed of, by provisions of national legislation.

\section{ARTICLE 2 \\ Scope of the Convention and Area of Coverage}

\section{Scope of the Convention}

1. The following substances shall be "hazardous wastes" for the purposes of this Convention:

(a) Wastes that belong to any category contained in Annex I of this Convention, unless they do not possess any of the characteristics contained in Annex II of this Convention; and

(b) Wastes that are not covered under sub-paragraph (a) above, but which are defined as, or are considered to be, hazardous wastes by the national legislation of the exporting, importing or transit Party to, from or through which such wastes are to be sent.

2. Radioactive wastes are excluded from the scope of this Convention except as specifically provided for in Articles 4.1, 4.2, 4.3, and 4.5 of this Convention.

3. Wastes which derive from the normal operations of a vessel, the discharge of which is covered by another international instrument, shall not fall within the scope of this Convention.

4. Nothing in this Convention shall affect in any way the sovereignty of States over their territorial sea, the sovereign rights and jurisdiction that States have in their exclusive economic zones and continental shelves, and the exercise by vessels and aircraft of all States of navigational rights and freedoms, as provided for in international law and as reflected in the 1982 United Nations Convention on the Law of the Sea and other relevant international instruments.

5. Nothing in this Convention shall affect in any way the rights and obligations of any Party under international law including under other international agreements in force. Such agreements include the London Convention as amended; the 1982 United Nations Convention on the Law of the Sea, including in particular Articles 31, 210 and 236 thereof; the South Pacific Nuclear Free Zone Treaty, 1985, including in particular Article 7 thereof; and the International Convention for the Prevention of Pollution from Ships, 1973.

\section{Area of Coverage}

6. A Party may add areas under its jurisdiction within the Pacific Ocean between the Tropic of Cancer and 60 degrees South latitude and between 130 degrees East longitude and 120 degrees West longitude to the Convention Area. Such addition shall be notified to the Depositary who shall promptly notify the other Parties and the Secretariat. Such areas shall be incorporated within the Convention Area ninety days after notification to the Parties by the Depositary, provided there has been no objection to the proposal to add new areas by any Party. If there is any such objection the Parties concerned will consult with a view to resolving the matter. 


\section{ARTICLE 3 \\ National Definitions of Hazardous Wastes}

1. Each Party shall, within six months of becoming a Party to this Convention, inform the Secretariat of the wastes, other than those listed in Annex I of this Convention, considered or defined as hazardous under its national legislation and of any requirements concerning transboundary movement procedures applicable to such wastes.

2. Each Party shall subsequently inform the Secretariat of any significant changes to the information it has provided pursuant to paragraph 1 of this Article.

3. The Secretariat shall forthwith inform all Parties of the information it has received pursuant to paragraphs 1 and 2 of this Article.

4. Parties shall be responsible for making the information transmitted to them by the Secretariat under paragraph 3 of this Article available to their exporters, importers and other appropriate bodies.

\section{ARTICLE 4 \\ General Obligations}

\section{Hazardous Wastes and Radioactive Wastes Import and Export Ban}

(a) Each Pacific Island Developing Party shall take appropriate legal, administrative and other measures within the area under its jurisdiction to ban the import of all hazardous wastes and radioactive wastes from outside the Convention Area. Such import shall be deemed an illegal and criminal act; and

(b) Each Other Party shall take appropriate legal, administrative and other measures within the area under its jurisdiction to ban the export of all hazardous wastes and radioactive wastes to all Forum Island Countries, or to territories located in the Convention Area with the exception of those that have the status of Other Parties in accordance with Annex IV. Such export shall be deemed an illegal and criminal act.

2. To facilitate compliance with paragraph 1 of this Article, all Parties:

(a) Shall forward in a timely manner all information relating to illegal hazardous wastes and radioactive wastes import activity within the area under its jurisdiction to the Secretariat who shall distribute the information as soon as possible to all Parties; and

(b) Shall cooperate to ensure that no illegal import of hazardous wastes and radioactive wastes from a non-Party enters areas under the jurisdiction of a Party to this Convention.

3. Ban on Dumping of Hazardous Wastes and Radioactive Wastes at Sea

(a) Each Party which is a Party to the London Convention, the South Pacific Nuclear Free Zone Treaty, 1985, the 1982 United Nations Convention on the Law of the Sea or the Protocol for the Prevention of Pollution of the South Pacific Region by Dumping, 1986, reaffirms the commitments under those instruments which require it to prohibit dumping of hazardous wastes and radioactive wastes at sea; and

(b) Each Party which is not a Party either to the London Convention or the Protocol for the Prevention of Pollution of the South Pacific Region by Dumping, 1986, should consider becoming a Party to both of those instruments.

\section{Wastes Located in the Convention Area}

Each Party shall: 
(a) Ensure that within the area under its jurisdiction, the generation of hazardous wastes is reduced at its source to a minimum taking into account social, technological and economic needs;

(b) Take appropriate legal, administrative and other measures to ensure that within the area under its jurisdiction, all transboundary movements of hazardous wastes generated within the Convention Area are carried out in accordance with the provisions of this Convention;

(c) Ensure the availability of adequate treatment and disposal facilities for the environmentally sound management of hazardous wastes, which shall be located, to the extent practicable, within areas under its jurisdiction, taking into account social, technological and economic considerations. However, where Parties are for geographic, social or economic reasons unable to dispose safely of hazardous wastes within those areas, cooperation should take place as provided for under Article 10 of this Convention;

(d) In cooperation with SPREP, participate in the development of programmes to manage and simplify the transboundary movement of hazardous wastes which cannot be disposed of in an environmentally sound manner in the countries in which they are located. Provided that such programmes do not derogate from the environmentally sound management of hazardous wastes as required by this Convention, they may be registered as arrangements under Article 11 of this Convention;

(e) Develop a national hazardous wastes management strategy which is compatible with the SPREP South Pacific Regional Pollution Prevention, Waste Minimization and Management Programme;

(f) Submit to the Secretariat such reports as the Conference of the Parties may require regarding the hazardous wastes generated in the area under its jurisdiction in order to enable the Secretariat to produce a regular hazardous wastes report;

(g) Subject to Article 11 of this Convention, prohibit within the area under its jurisdiction hazardous wastes from being exported to or imported from non-Parties within the Convention Area; and

(h) Take appropriate legal, administrative and other measures to prohibit vessels flying its flag or aircraft registered in its territory from carrying out activities in contravention of this Convention.

\section{Radioactive Wastes}

(a) Parties shall give active consideration to the implementation of the IAEA Code of Practice on the International Transboundary Movement of Radioactive Wastes and such other international and national standards which are at least as stringent; and

(b) Subject to available resources, Parties shall actively participate in the development of the Convention on the Safe Management of Nuclear Waste.

\section{Domestically Prohibited Goods:}

(a) Subject to available resources, Parties shall endeavour to participate in relevant international fora to find an appropriate global solution to the problems associated with the international trade of domestically prohibited goods; and

(b) Nothing in this Convention shall be interpreted as limiting the sovereign right of Parties to act individually or collectively, consistent with their international obligations, to ban the importation of domestically prohibited goods into areas under their jurisdiction.

\section{ARTICLE 5 \\ Competent Authorities and Focal Points}

1. To facilitate the implementation of this Convention, each Party shall designate or establish one competent authority and one focal point. A Party need not designate or establish new or separate authorities to perform the functions of the competent authority and the focal point. 
2. The competent authority shall be responsible for the implementation of notification procedures for transboundary movement of hazardous wastes in accordance with the provisions of Article 6 of this Convention.

3. The focal point shall be responsible for transmitting and receiving information in accordance with the provisions of Article 7 of this Convention.

4. The Parties shall inform the Secretariat, within three months of the date of the entry into force of this Convention for them, which authorities they have designated or established as the competent authority and the focal point.

\section{ARTICLE 6 \\ Notification Procedures for Transboundary Movements of Hazardous Wastes between Parties}

1. The exporting Party shall notify, or shall require the generator or exporter to notify, in writing, through its competent authority, the competent authority of the countries concerned of any proposed transboundary movement of hazardous wastes. Such notification shall contain the declarations and information specified in Annex VI A of this Convention, written in a language acceptable to the importing Party. Only one notification needs to be sent to each country concerned.

2. The importing Party shall acknowledge within reasonable time, which in the case of Other Parties shall not exceed fourteen working days, the receipt of the notification referred to in paragraph 1 of this Article. The importing Party shall have sixty days after issuing the acknowledgement to inform the notifier that it is consenting to the movement, with or without conditions, denying permission for the movement or requesting additional information. In the event that additional information has been sought, a new period of twenty one days recommences from the time of receipt of the additional information.

3. The exporting Party shall not allow the transboundary movement until it has received:

(a) Written consent of the importing Party;

(b) Written consent from every transit Party;

(c) Written consent of every non-Party country of transit;

(d) Written confirmation from the importing Party of the existence of a contract between the exporter and the disposer specifying the environmentally sound management of the wastes in question; and

(e) Written confirmation from the exporter of the existence of adequate insurance, bond or other guarantee satisfactory to the exporting Party.

4. Each transit Party shall acknowledge within reasonable time, which, in the case of Other Parties shall not exceed fourteen working days, the receipt of the notification referred to in paragraph 1 of this Article. Each transit Party shall have sixty days after issuing the acknowledgement to inform the notifier that it is consenting to the movement, with or without conditions, denying permission for the movement or requesting additional information. In the event that additional information has been sought, a new period of twenty one days recommences from the time of receipt of the additional information.

5. In the case of a transboundary movement of hazardous wastes, where the wastes are legally defined as or are considered to be hazardous wastes only:

(a) By the exporting Party, the requirement at paragraph 10 of this Article, that any transboundary movement shall be covered by insurance, bond or other guarantee shall be as required by the exporting Party; or

(b) By the importing Party, or the transit Party, the requirements of paragraphs 1, 3, 4, and 6 of this Article that apply to the exporter and exporting Party, shall apply mutatis mutandis to the importer or disposer and importing Party, respectively; or

(c) By any transit Party, the provisions of paragraph 4 of this Article shall apply to such Party. 
6. The exporting Party may, subject to the written consent of the countries concerned, allow the generator or the exporter to use a general notification where hazardous wastes having the same physical and chemical characteristics are shipped regularly to the same disposer via the same customs office of exit of the exporting Party, via the same customs office of entry of the importing Party, and, in the case of transit, via the same customs office of entry and exit of the Party or Parties of transit.

7. The countries concerned may make their written consent to the use of the general notification referred to in paragraph 6 of this Article subject to the supply of certain information, such as the exact quantities or periodical lists of hazardous wastes to be shipped.

8. The general notification and written consent referred to in paragraphs 6 and 7 of this Article may cover multiple shipments of hazardous wastes during a maximum period of twelve months.

9. Each transboundary movement of hazardous wastes shall be accompanied by a movement document which includes the information listed in Annex VI B. The Parties to this Convention shall require that each person who takes charge of a transboundary movement of hazardous wastes sign the movement document either upon delivery or receipt of the wastes in question. They shall also require the disposer to inform both the exporter and the competent authority of the exporting Party of receipt by the disposer of the wastes in question and, in due course, of the completion of disposal as specified in the notification. If no such information is received by the exporting Party, the competent authority of the exporting Party or the exporter shall so notify the importing Party.

10. Any transboundary movement of hazardous wastes shall be covered by insurance, bond or other guarantee as may be required or agreed to by the importing Party or any transit Party.

\section{ARTICLE 7}

\section{Transmission of Information}

1. The Parties shall ensure that in the case of an accident occurring during the transboundary movement of hazardous wastes or their disposal which is likely to present risks to human health and the environment in other States and Parties, those States and Parties and the Secretariat are immediately informed.

2. The Parties shall inform one another, through the Secretariat, of:

(a) Changes regarding the designation of competent authorities and/or focal points, pursuant to Article 5 of this Convention; and

(b) Changes in their national definition of hazardous wastes, pursuant to Article 3 of this Convention.

3. The Parties, consistent with national laws and regulations, shall set up information collection and dissemination mechanisms on hazardous wastes to enable the Secretariat to fulfil the functions listed in Article 14.

\section{ARTICLE 8}

\section{Duty to Re-import}

1. The exporting Party shall adopt appropriate administrative and legal measures to ensure that when an authorised transboundary movement of hazardous wastes cannot be completed in accordance with the terms of the contract or of this Convention, the wastes in question are returned to it by the exporter. To this end, the importing Party and the transit Party or Parties shall not oppose, hinder or prevent the return of those wastes to the exporting Party.

2. Notwithstanding the provisions of paragraph 1 of this Article, where an authorised transboundary movement of hazardous wastes cannot be completed within the terms of the contract or the terms of this Convention, the exporting Party need not re-import those wastes provided that alternative arrangements are made for the disposal of the wastes in a manner which is compatible with the environmentally sound management of hazardous wastes as required by this Convention and other international legal obligations. Such disposal shall take place within ninety days from the time that the importing Party informed the exporting Party and the Secretariat, or such other period of time as the Parties concerned agree. 


\section{ARTICLE 9 \\ Mlegal Traffic}

1. For the purpose of this Convention, any transboundary movement of hazardous wastes shall be deemed to be illegal traffic if:

(a) Carried out without notification, pursuant to the provisions of this Convention, to all countries concerned;

(b) Carried out without the consent, pursuant to the provisions of this Convention, of a country concerned;

(c) Consent is obtained from countries concerned through falsification, misrepresentation or fraud;

(d) The contents do not conform in a material way with the supporting documentation;

(e) It results in deliberate disposal of hazardous wastes in contravention of this Convention, other relevant international instruments and of general principles of international law; or

(f) It is in contravention of the import or export bans established by Article 4.1.

2. Each Party shall introduce or adopt appropriate national legislation to prevent and punish illegal traffic. The Parties shall cooperate with a view to achieving the objects of this Article.

3. (a) In the case of a transboundary movement of hazardous wastes deemed to be illegal traffic as the result of conduct on the part of the exporter or generator, the exporting Party shall ensure that, within thirty days from the time the exporting Party has been informed about the illegal traffic or such other period of time the countries concerned may agree, the wastes in question are either:

(i) taken back by the exporter or generator or if necessary by itself into the exporting Party; or, if impracticable,

(ii) . otherwise disposed of in accordance with the provisions of this Convention;

(b) In the case of paragraph 3(a)(i) of this Article, the Parties concerned shall not oppose, hinder or prevent the return of those wastes to the exporting Party.

4. In the case of a transboundary movement of hazardous wastes deemed to be illegal traffic as a result of conduct on the part of the importer or disposer, the importing Party shall ensure that the wastes in question are disposed of in an environmentally sound manner by the importer or disposer or, if necessary, by itself within thirty days from the time the illegal traffic has come to the attention of the importing Party or such time as the countries concerned may agree. To this end, the importing Party and the exporting Party shall cooperate, as necessary, in the disposal of the wastes in an environmentally sound manner.

5. In cases where the responsibility for the illegal traffic cannot be assigned either to the exporter or generator or to the importer or disposer, the Parties concerned or any other Parties, as appropriate, shall ensure through cooperation that the wastes in question are disposed of as soon as possible in an environmentally sound manner either in the exporting Party or the importing Party or elsewhere as appropriate.

6. The Secretariat shall undertake the necessary coordination with the Secretariat of the Basel Convention in relation to the effective prevention and monitoring of illegal traffic in hazardous wastes. Such coordination shall include:

(a) Exchanging information on incidents or alleged incidents of illegal traffic in the Convention Area and on the appropriate steps to remedy such incidents; and

(b) Providing assistance in the field of capacity building including development of national legislation and of appropriate infrastructure in the Pacific Island Developing Parties with a view to the prevention and penalization of illegal traffic of hazardous wastes. 


\section{ARTICLE 10 \\ Cooperation Among Parties and International Cooperation}

1. The Parties to this Convention shall cooperate with one another, non-Parties and relevant regional and international organisations, to facilitate the availability of adequate treatment and disposal facilities and to improve and achieve the environmentally sound management of hazardous wastes. Such facilities shall be located within the Convention Area to the extent practicable taking into account social, technological and economic considerations.

2. To this end, the Parties shall:

(a) Upon request, make information available, whether on a bilateral or regional basis, with a view to promoting the environmentally sound management of hazardous wastes, including harmonisation of relevant technical standards and practices;

(b) Cooperate in monitoring the effects of hazardous wastes and their management on human health and the environment;

(c) Cooperate, subject to their national laws and policies, in the development and implementation of new environmentally sound and cleaner production technologies and the improvement of existing technologies. Such cooperation shall be with a view to eliminating, as far as practicable, the generation of hazardous wastes and achieving more effective and efficient methods of ensuring their management in an environmentally sound manner, including the study of the economic, social and environmental impacts of the adoption of such new and improved technologies;

(d) Cooperate, subject to their national laws and policies, actively in the transfer of technology and management systems related to the environmentally sound management of hazardous wastes. They shall also cooperate in developing the technical capacity and infrastructure of Parties, especially those which may need and request technical assistance in this field; and

(e) Cooperate in developing appropriate technical guidelines and/or codes of practice.

3. The Secretariat shall encourage Other Parties and other concerned developed countries to take all practicable steps to promote, facilitate and finance, as appropriate, the transfer of, or access to, environmentally sound technologies and know-how to Pacific Island Developing Parties, to enable them to implement the provisions of this Convention. Other Parties undertake to cooperate with the Secretariat in this regard.

4. Taking into account the needs of developing countries, Parties shall encourage cooperation with international organisations in order to promote, among other things, public awareness, the development of rational management of hazardous wastes, and the adoption of new technologies which are environmentally sound, including cleaner production technologies.

\section{ARTICLE 11}

\section{Bilateral, Regional or Multilateral Agreements or Arrangements}

1. Notwithstanding the provisions of Article 4.4(g), Parties to this Convention may enter into bilateral, regional or multilateral agreements or arrangements with non-Parties regarding the transboundary movement and management of hazardous wastes provided that such agreements or arrangements do not derogate from the provisions of Article 4.1 or from the environmentally sound management of such wastes as required by this Convention.

2. The Parties shall notify the Secretariat of any bilateral, regional or multilateral agreements or arrangements referred to in paragraph 1 of this Article and those which they have entered into prior to the entry into force of this Convention for them, for the purpose of controlling transboundary movements of hazardous wastes which take place entirely among the parties to such agreements or arrangements.

3. The provisions of this Convention shall not affect transboundary movements of hazardous wastes which take place pursuant to such agreements or arrangements provided that such agreements or arrangements are compatible with the environmentally sound management of hazardous wastes as required by this Convention. 


\section{ARTICLE 12 \\ Liabilities and Compensation}

The Conference of the Parties shall consider the preparation and adoption of appropriate arrangements in the field of liability and compensation arising from transboundary movements of hazardous wastes in the Convention Area without prejudice to the application and further development of relevant rules of international law.

\section{ARTICLE 13 \\ Conference of the Parties}

1. A Conference of the Parties to this Convention is hereby established. The first meeting of the Conference of the Parties shall be convened not later than one year after the entry into force of this Convention. Thereafter, ordinary meetings of the Conference of the Parties shall be held at regular intervals to be determined by the Conference at its first meeting. The quorum for meetings of the Conference of the Parties shall be two-thirds of the Parties.

2. The Conference of the Parties shall adopt by consensus at its first ordinary meeting, or as soon as practicable thereafter, Rules of Procedure. It shall also adopt by consensus financial rules, including the scale of contributions of the Parties to this Convention to the regular budget.

3. The first meeting of the Conference of the Parties shall consider the adoption of any additional measures in accordance with the Precautionary principle relating to the implementation of this Convention.

4. The Conference of the Parties shall keep under continuous review and evaluation the effective implementation of this Convention, and in particular, shall:

(a) Promote the harmonisation, at high levels of protection, of appropriate legislation, policies, strategies and measures for minimising harm to human health and the environment;

(b) Consider and adopt, where necessary, amendments to this Convention, and its annexes, taking into consideration, inter alia, available scientific, technical, economic and environmental information;

(c) Examine and approve the regular budget prepared by the Secretariat in accordance with Article 14;

(d) Consider and undertake any additional action that may be necessary for the achievement of the purposes of this Convention in the light of experience gained in the operation of the Convention and developments elsewhere;

(e) Consider and adopt protocols as necessary;

(f) Establish and/or designate such subsidiary bodies or agencies as are deemed necessary for the implementation of this Convention; and

(g) Determine and adopt appropriate rules and procedures for the acceptance of new Parties to this Convention in accordance with Article 23 and Annexes III and IV.

5. Any State which is eligible to become a Party to this Convention may be represented as an observer at meetings of the Conference of the Parties. Any other State or any body or agency, whether national, regional or international, governmental or non-governmental, with an interest in the subject matter of this Convention which has informed the Secretariat of its wish to be represented as an observer at a meeting of the Conference of the Parties, may be admitted unless at least one-third of the Parties present object. The admission and participation of observers shall be subject to the rules of procedure adopted by the Conference of the Parties. 


\section{ARTICLE 14}

\section{Secretariat}

1. A Secretariat for this Convention is hereby established. The functions of the Secretariat shall be to:

(a) Arrange and service meetings of the Parties to this Convention;

(b) Prepare the regular budget of the Conference of the Parties, as required by this Convention;

(c) Prepare and transmit reports based upon information received in accordance with Articles 3, 4, 7, and 11 of this Convention;

(d) Prepare and transmit information derived from meetings of subsidiary bodies and agencies established under Article 13 of this Convention or provided by relevant inter-governmental and non-governmental entities;

(e) Ensure coordination with the Secretariat of the Basel Convention and other relevant international and regional bodies, and in particular to enter into such administrative arrangements as may be required for the effective discharge of its functions;

(f) Communicate with the competent authorities and focal points established by the Parties in accordance with Article 5 of this Convention as well as appropriate inter-governmental and non-governmental organisations which may provide financial and/or technical assistance in the implementation of this Convention;

(g) Compile information concerning approved sites and facilities available for the disposal of hazardous wastes and means of transport to these sites and facilities and to circulate this information;

(h) Receive and convey on request to Parties information on available sources of technical and scientific expertise;

(i) Receive and convey on request to Parties information on consultants or consulting firms having the necessary technical competence in the field which can assist them with examining a notification for a transboundary movement of hazardous wastes, the concurrence of a shipment of hazardous wastes with the relevant notification, and/or whether the proposed disposal facilities for hazardous wastes are environmentally sound, when they have reason to believe that the wastes in question will not be managed in an environmentally sound manner;

(j) Assist Parties to this Convention in their identification of cases of illegal traffic and to circulate immediately to the Parties concerned any information it has received regarding illegal traffic, and to undertake the necessary coordination with the Secretariat of the Basel Convention as provided for in Article 9.6;

(k) To cooperate with countries concerned and with relevant and competent international organisations and agencies in the provision of experts and equipment for the purpose of rapid assistance in the event of an emergency situation in the Convention Area;

(1) To report the information prescribed in paragraph 2 of this Article, to the Parties to this Convention, before the end of each calendar year; and

(m) To perform such other functions relevant to the purposes of this Convention as may be determined by the Conference of the Parties. 
2. The Secretariat shall transmit to the Parties, before the end of each calendar year, a report taking into account material provided by Parties under Articles 4.4(f) and 7.3 on the previous calendar year, containing the following:

(a) Information regarding transboundary movement of hazardous wastes in which Parties have been involved, including:

(i) the quantity of hazardous wastes exported, their category, characteristics, destination, any transit country and disposal method as stated in the notification;

(ii) the amount of hazardous wastes imported, their category, characteristics, origin, and disposal methods;

(iii) disposals which did not proceed as intended; and

(iv) efforts to achieve a reduction of the amount of hazardous wastes subject to transboundary movement.

(b) Information on measures adopted by Parties in the implementation of this Convention;

(c) Information where it is available on the effects on human health and the environment from the generation, transportation and disposal of hazardous wastes in the Convention Area. The information may take the form of statistical data;

(d) Information on accidents occurring during transboundary movements, treatment and disposal of hazardous wastes and on measures undertaken to deal with them;

(e) Information on environmentally sound treatment and disposal options operated by Parties; and

(f) Information on measures undertaken by Parties for the development of cleaner production technologies for the reduction and/or elimination of the production of hazardous wastes.

3. The Secretariat's functions shall be carried out by SPREP.

\section{ARTICLE 15 \\ Revolving Fund}

The Conference of the Parties shall consider the establishment of a revolving fund to assist on an interim basis in case of emergency situations to minimise damage from disasters or accidents arising from transboundary movement or disposal of hazardous wastes within the Convention Area.

\section{ARTICLE 16 \\ Amendments to this Convention}

1. Any Party may propose amendments to this Convention.

2. Amendments to this Convention may be adopted only at a meeting of the Conference of the Parties at which at least two-thirds of the Parties are represented. The text of any proposed amendment to this Convention shall be communicated to the Parties by the Secretariat at least six months before the meeting at which it is proposed for adoption. The Secretariat shall also communicate proposed amendments to the Signatories to this Convention and to the Depositary for their information.

3. The Parties shall make every effort to reach agreement on any proposed amendment to this Convention by consensus. If all efforts at consensus have been exhausted, and no agreement reached, the amendment shall, as a last resort, be adopted by a two-thirds majority vote of Parties present and voting, each Party having one vote, and shall be submitted by the Depositary to all Parties for ratification, approval or acceptance. 
4. Instruments of ratification, acceptance or approval of amendments shall be deposited with the Depositary. Amendments shall enter into force between Parties having accepted such amendments on the ninetieth day following the date of receipt by the Depositary of the instruments of at least three-fourths of the Parties to this Convention. Thereafter the amendments shall enter into force for any other Party on the ninetieth day after the date on which that Party deposits its instrument.

5. For the purpose of this Article, "Parties present and voting" means Parties present and casting an affirmative or negative vote.

\section{ARTICLE 17 \\ Protocols to this Convention}

1. The Conference of the Parties may, at any ordinary meeting, adopt protocols to this Convention.

2. The text of any proposed protocol shall be communicated to the Parties by the Secretariat at least six months before the meeting at which it is proposed for adoption.

3. The procedure specified in Article 16.3 shall apply to the adoption of, and any amendments to, any protocol.

4. The requirements for the entry into force of any protocol or subsequent amendments to such protocol shall be established by that protocol.

5. Decisions under any protocol shall be taken only by the Parties to that protocol.

\section{ARTICLE 18 \\ Adoption and Amendment of Annexes}

1. The annexes to this Convention shall form an integral part of this Convention and, unless expressly provided otherwise, a reference to this Convention constitutes, at the same time a reference to any annexes thereto. Such annexes shall be restricted to scientific, technical and administrative matters.

2. The following procedures shall apply to the proposal, adoption and entry into force of additional annexes, or amendments to annexes, to this Convention:

(a) Such additional annexes or amendments to annexes shall be proposed and adopted according to the procedure laid down in Articles 16.1, 16.2 and 16.3 of this Convention;

(b) Any Party that is unable to accept such additional annexes or amendments to annexes, shall so notify the Depositary, in writing, within six months from the date of the communication of the adoption by the Depositary. The Depositary shall without delay notify all Parties of any such notification received. A Party may at any time substitute an acceptance for a previous declaration of objection and the annexes or amendments to annexes shall thereupon enter into force for that Party; and

(c) Upon the expiration of six months from the date of the circulation of the communication by the Depositary, the annexes or amendments to annexes shall enter into force for all Parties to this Convention, which have not submitted a notification in accordance with the provisions of sub-paragraph (b) above.

3. If an additional annex or an amendment to an annex involves an amendment to this Convention or to any protocol, the additional annex or amended annex shall not enter into force until such time as the amendment to this Convention or to the protocol enters into force. 


\section{ARTICLE 19 \\ Verification}

1. Any Party which has reason to believe that another Party is acting or has acted in breach of its obligations under this Convention may inform the Secretariat thereof, and in such an event, shall simultaneously and immediately inform, directly or through the Secretariat, the Party against whom the allegations are made. All relevant information should be submitted by the Secretariat to the Parties.

2. The Conference of the Parties shall consider the adoption of a protocol dealing with detailed procedures and arrangements for the verification of alleged breaches of obligations under this Convention.

\section{ARTICLE 20}

\section{Settlement of Disputes}

1. In case of a dispute between Parties as to the interpretation or application of, or compliance with, this Convention or any protocol thereto, the Parties concerned shall seek a settlement of the dispute through negotiation, mediation or any other peaceful means of their own choice.

2. If the Parties concerned cannot settle their dispute through the means mentioned in paragraph 1 of this Article, the dispute, if the Parties to the dispute agree, shall be submitted to arbitration under the conditions set out in Annex VII of this Convention or to the International Court of Justice. However, failure to reach common agreement on submission of the dispute to arbitration or to the International Court of Justice shall not absolve the Parties from the responsibility of continuing to seek to resolve it by the means referred to in paragraph 1.

3. When ratifying, accepting, approving or acceding to this Convention, or at any time thereafter, a Party may declare that it recognises as compulsory ipso facto and without special agreement, in relation to any Party accepting the same obligation:

(a) Arbitration in accordance with the procedures set out in Annex VII; and/or

(b) Submission of the dispute to the International Court of Justice.

Such declaration shall be notified in writing to the Secretariat which shall communicate it to the Parties.

\section{ARTICLE 21}

Signature

1. This Convention shall be open for signature by the Members of the South Pacific Forum at Waigani, Papua New Guinea, on 16 September 1995.

2. This Convention shall remain open for signature by the Members of the South Pacific Forum from 22 September 1995 until 21 March 1996 at the South Pacific Forum Secretariat, Suva.

\section{ARTICLE 22}

Ratification, Acceptance or Approval

This Convention shall be subject to ratification, acceptance or approval by Members of the South Pacific Forum. Instruments of ratification, acceptance or approval shall be deposited with the Depositary.

\section{ARTICLE 23}

\section{Accession}

1. This Convention shall be open for accession by Members of the South Pacific Forum from the day after the date on which the Convention is closed for signature. The instruments of accession shall be deposited with the Depositary. 
2. Other States not members of the South Pacific Forum which have territories in the Convention Area may accede to the Convention. In addition, other States which do not have territories in the Convention Area may also accede to the Convention pursuant to a decision of the Conference of the Parties under Article 13.4(g).

\section{ARTICLE 24 \\ Entry into Force}

This Convention shall enter into force thirty days from the date of deposit of the tenth instrument of ratification, acceptance, approval or accession and thereafter for each State thirty days after the deposit of its instrument of ratification, acceptance, approval or accession.

\section{ARTICLE 25 \\ Reservations and Declarations}

1. No reservations or exceptions shall be made to this Convention.

2. Paragraph 1 of this Article does not preclude a signatory or Party when signing, ratifying or acceding to this Convention, from making declarations or statements, however phrased or named, with a view, inter alia, to the harmonisation of its laws and regulations with the provisions of this Convention, provided that such declarations or statements do not purport to exclude or to modify the legal effect of the provisions of this Convention in their application to that Party.

\section{ARTICLE 26}

Withdrawal

1. At any time after three years from the date on which this Convention has entered into force for a Party, that Party may withdraw by giving written notification to the Depositary.

2. Withdrawal shall be effective one year after receipt of notification by the Depositary, or on such later date as may be specified in the notification.

3. Withdrawal shall not exempt any withdrawing Party from fulfilling any obligations it might have incurred under this Convention, whilst a Party to this Convention.

\section{ARTICLE 27 \\ Depositary}

The Secretary General of the South Pacific Forum Secretariat shall be the Depositary of this Convention and of any protocols thereto.

\section{ARTICLE 28 \\ Registration}

This Convention, as soon as it enters into force, shall be registered by the Depositary with the Secretary-General of the United Nations in conformity with Article 102 of the Charter of the United Nations.

IN WITNESS WHEREOF the undersigned, being duly authorised to that effect, have signed this Convention:

\section{For the Government of \\ Australia \\ [Signature]}

For the Government of the Cook Islands [Signature] 
For the Government of the Federated States of Micronesia [Signature]

\section{For the Government of the}

Republic of Kiribati

[Signature]

\section{For the Government of}

New Zealand

[Signature]

For the Government of the

Republic of Palau

[Signature]

For the Government of the

Republic of the Marshall Islands

\section{For the Government of Tonga}

[Signature]

For the Government of Vanuatu

[Signature]

\author{
For the Government of the \\ Republic of Fiji \\ [Signature]
}

\section{For the Government of the \\ Republic of Nauru \\ [Signature]}

For the Government of Niue

[Signature]

\section{For the Government of Papua New Guinea \\ [Signature]}

\section{For the Government of Solomon Islands \\ [Signature]}

\section{For the Government of Tuvalu}

\section{For the Government of Western Samoa \\ [Signature]}

DONE at Waigani, Papua New Guinea, on the sixteenth day of September in the year one thousand nine hundred and ninety five, in a single original in the English language.

\section{ANNEX I \\ CATEGORIES OF WASTES WHICH ARE HAZARDOUS WASTES}

\section{Wastes Streams:}

Y1 : Clinical wastes from medical care in hospitals, medical centres and clinics.

Y2 : Wastes from the production and preparation of pharmaceutical products.

Y3 : Waste pharmaceuticals, drugs and medicines.

Y4 : Wastes from the production, formulation and use of biocides and phytopharmaceuticals.

Y5 : Wastes from the manufacture, formulation and use of wood preserving chemicals.

Y6 : Wastes from the production, formulation and use of organic solvents.

Y7 : Wastes from heat treatment and tempering operations containing cyanides.

Y8 : Waste mineral oils unfit for their originally intended use.

Y9 : Waste oils/water, hydrocarbons/water mixtures, emulsions.

Y10 : Waste substances and articles containing or contaminated with polychlorinated biphenyls (PCBs) and/or polychlorinated terphenyls (PCTs) and/or polybrominated biphenyls (PBBs).

Y11 : Waste tarry residues arising from refining, distillation and any pyrolytic treatment.

Y12 : Wastes from production, formulation and use of inks, dyes, pigments, paints, lacquers, varnish.

Y13 : Wastes from production, formulation and use of resins, latex, plasticisers, glues/adhesives. 
Y14 : Waste chemical substances arising from research and development or teaching activities which are not identified and/or are new and whose effects on human health and/or the environment are not known.

Y15 : : Wastes of an explosive nature not subject to other legislation.

Y16 : Wastes from production, formulation and use of photographic chemicals and processing materials.

Y17 : Wastes resulting from surface treatment of metals and plastics.

Y18 : $\quad$ Residues arising from industrial waste disposal operations.

Y46 : Wastes collected from households, including sewage and sewage sludges with the exception of clean sorted recyclable wastes which do not possess any of the hazardous characteristics defined in Annex II.

Y47 : $\quad$ Residues arising from the incineration of household wastes.

\section{Waste shaving as constituents:}

Y19 : $\quad$ Metal carbonyls.

Y20 : $\quad$ Beryllium; beryllium compounds.

Y21 : Hexavalent chromium compounds.

Y22 : $\quad$ Copper compounds.

Y23 : Zinc compounds.

Y24 : Arsenic; arsenic compounds.

Y25 : $\quad$ Selenium; selenium compounds.

Y26 : Cadmium; cadmium compounds.

Y27 : Antimony; antimony compounds.

Y28 : Tellurium; tellurium compounds.

Y29 : Mercury; mercury compounds.

Y30 : Thallium; thallium compounds.

Y31 : Lead; lead compounds.

Y32 : Inorganic fluorine compounds excluding calcium fluoride.

Y33 : Inorganic cyanides.

Y34 : $\quad$ Acidic solutions or acids in solid form.

Y35 : $\quad$ Basic solutions or bases in solid form.

Y36 : Asbestos (dust and fibres).

Y37 : Organic phosphorus compounds.

Y38 : Organic cyanides.

Y39 : Phenols; phenol compounds including chlorophenols.

Y40 : Ethers.

Y41 : Halogenated organic solvents.

Y42 : Organic solvents excluding halogenated solvents.

Y43 : Any congenor of polychlorinated dibenzo-furan.

Y44 : Any congenor of polychlorinated dibenzo-p-dioxin.

Y45 : Organohalogen compounds other than substances referred to in this Annex (e.g. Y39, Y41, Y42, Y43, Y44). 


\section{ANNEX II \\ LIST OF HAZARDOUS CHARACTERISTICS}

\section{UN CLASS* CODE CHARACTERISTICS}

1

\section{H1}

H3

4.1

4.2

H4.2

4.3

5.1

5.2

H.5.2

6.1

H6.1

6.2

H6.2

H8

\section{Explosive}

An explosive substance or waste is a solid or liquid substance or waste (or mixture of substances or wastes) which is in itself capable by chemical reaction of producing gas at such a temperature and pressure and at such speed as to cause damage to the surroundings.

\section{Flammable liquids}

The word "flammable" has the same meaning as "inflammable". Flammable liquids are liquids, or mixtures of liquids, or liquids containing solids in solution or suspension (for example, paints, varnishes, lacquers, etc., but not including substances or wastes otherwise classified on account of their dangerous characteristics) which give off a flammable vapour at temperatures of not more than 60.5 degrees C, closed-cup test, or not more than 65.6 degrees C, open-cup test. (Since the results of open-cup tests and of closed-cup tests are not strictly comparable and even individual results by the same test are often variable, regulations varying from the above figures to make allowance for such differences would be within the spirit of this definition).

\section{H4.1 Flammable solids}

Solids, or waste solids, other than those classed as explosives, which under conditions encountered in transport are readily combustible, or may cause or contribute to fire through friction.

Substances or wastes liable to spontaneous combustion

Substances or wastes which are liable to spontaneous heating under normal conditions encountered in transport, or to heating up on contact with air, and being then liable to catch fire.

H4.3 Substances or wastes which, in contact with water, emit flammable gases

Substances or wastes which, by interaction with water, are liable to become spontaneously flammable or to give off flammable gases in dangerous quantities.

\section{Oxidizing}

Substances or wastes which, while in themselves not necessarily combustible, may, generally by yielding oxygen cause, or contribute to, the combustion of other materials.

\section{Organic peroxides}

Organic substances or wastes which contain the bivalent-O - O-structure are thermally unstable substances which may undergo exothermic self-accelerating decomposition.

Poisonous (Acute)

Substances or wastes liable either to cause death or serious injury or to harm human health if swallowed or inhaled or by skin contact.

Infectious substances

Substances or wastes containing viable micro organisms or their toxins which are known or suspected to cause disease in animals or humans.

\section{Corrosives}

Substances or wastes which, by chemical action, will cause severe damage when in contact with living tissue, or in the case of leakage, will materially damage, or even destroy, other goods or the means of transport; they may also cause other hazards.

\footnotetext{
* Corresponds to the hazard classification system included in the United Nations Recommendations on the Transport of Dangerous Goods (ST/SG/AC.10/1/Rev.5, United Nations, New York, 1988).
} 
9

9

9

H10 Liberation of toxic gases in contact with air or water

Substances or wastes which, by interaction with air or water, are liable to give off toxic gases in dangerous quantities.

H11 Toxic (Delayed or chronic)

Substances or wastes which, if they are inhaled or ingested or if they penetrate the skin, may involve delayed or chronic effects, including carcinogenicity.

H12 Ecotoxic

Substances or wastes which, if released, present or may present immediate or delayed adverse impacts to the environment by means of bioaccumulation and/or toxic effects upon biotic systems.

H13 Capable, by any means, after disposal, of yielding another material, e.g. leachate, which possesses any of the characteristics listed above.

Tests

The potential hazards posed by certain types of wastes are not yet fully documented; tests to define quantitatively these hazards do not exist. Further research is necessary in order to develop means to characterise potential hazards posed to human health and the environment by these wastes. Standardised tests have been derived with respect to pure substances and materials. Many countries have developed national tests which can be applied to materials listed in Annex I, in order to decide if these materials exhibit any of the characteristics listed in this Annex.

\section{ANNEX III}

\section{PACIFIC ISLAND DEVELOPING PARTIES}

(1) The following Members of the South Pacific Forum, on becoming party to this Convention, shall be considered to be Pacific Island Developing Parties for the purposes of the Convention:

- Cook Islands

- Federated States of Micronesia

- Fiji

- Kiribati

- Republic of Marshall Islands

- Nauru

- Niue

- Republic of Palau

- Papua New Guinea

- Solomon Islands

- Tonga

- Tuvalu

- Vanuatu

- Western Samoa.

(2) The Conference of the Parties may, in accordance with Article 13.4(g), and upon agreement with such prospective party, accept the status of any new Party to this Convention as a Pacific Island Developing Party. 


\section{ANNEX IV}

\section{OTHER PARTIES}

(1) The following Members of the South Pacific Forum, on becoming party to this Convention, shall be considered to be Other Parties for the purposes of the Convention:

- Australia

- New Zealand.

(2) (a) The Conference of the Parties may, in accordance with Article 13.4(g), and upon agreement with such prospective party, accept the status of any new Party to this Convention as an Other Party;

(b) An Other Party may designate a territory located within the Convention Area to which, upon agreement by the Conference of the Parties, the provisions of Article 4.1 of this Convention shall be applied mutatis mutandis in the same manner as they apply to a Pacific Island Developing Party.

\section{ANNEX V}

\section{DISPOSAL OPERATIONS}

A. OPERATIONS WHICH DO NOT LEAD TO THE POSSIBILITY OF RESOURCE RECOVERY, RECYCLING, RECLAMATION, DIRECT RE-USE OR ALTERNATIVE USES.

Section A encompasses all such disposal operations which occur in practice.

D1 Deposit into or onto land (e.g. landfill, etc).

D2 Land treatment (e.g. biodegradation of liquid or sludgy discards in soils, etc).

D3 Deep injection (e.g. injection of pumpable discards into wells, salt domes or naturally occurring repositories, etc).

D4 Surface impoundment (e.g. placement of liquid or sludge discards into pits, ponds, or lagoons, etc).

D5 Specially engineered landfill (e.g. placement into lined discrete cells which are capped and isolated from one another and the environment, etc).

D6 Release into a water body except seas/oceans.

D7 Release into seas/oceans including sea-bed insertion.

D8 Biological treatment not specified elsewhere in this Annex which results in final compounds or mixtures which are discarded by means of any of the operations in Section $A$.

D9 Physico-chemical treatment not specified elsewhere in this Annex which results in final compounds or mixtures which are discarded by means of any of the operations in Section A (e.g. evaporation, drying, calcination, neutralisation, precipitation, etc).

D10 Incineration on land.

D11 Incineration at sea.

D12 Permanent storage (e.g. emplacement of containers in a mine, etc).

D13 Blending or mixing prior to submission to any of the operations in Section A. 
D14 Repackaging prior to submission to any of the operations in Section A.

D15 Storage pending any of the operations in Section A.

B. OPERATIONS WHICH MAY LEAD TO RESOURCE RECOVERY, RECYCLING, RECLAMATION, DIRECT RE-USE OR ALTERNATIVE USES.

Section B encompasses all such operations with respect to materials legally defined as or considered to be hazardous wastes and which otherwise would have been destined for operations included in Section A.

R1 Use as a fuel (other than in direct incineration) or other means to generate energy.

R2 Solvent reclamation/regeneration.

R3 Recycling/reclamation of organic substances which are not used as solvents.

R4 Recycling/reclamation of metals and metal compounds.

R5 Recycling/reclamation of other inorganic materials.

R6 Regeneration of acids and bases.

R7 Recovery of components used for pollution abatement.

R8 Recovery of components from catalysts.

R9 Used oil re-refining or other reuses of previously used oil.

R10 Land treatment resulting in benefit to agriculture or ecological improvement.

R11 Uses of residual materials obtained from any of the operations numbered R1-R10.

R12 Exchange of wastes for submission to any of the operations numbered R1-R11.

R13 Accumulation of material intended for any operation in Section B.

\section{ANNEX VI A}

\section{INFORMATION TO BE PROVIDED ON NOTIFICATION}

1. Reason for wastes export.

2. Exporter of the wastes. $1 /$

3. Generator(s) of the wastes and site of generation. $1 /$

4. Importer and disposer of the wastes and actual site of disposal. $1 /$

5. Intended carrier(s) of the wastes or their agents, if known. 1

6. Country of export of the wastes.

Competent authority. 2/

7. Expected countries of transit.

Competent authority. 2/

8. Country of import of the wastes.

Competent authority. $2 /$ 
9. General or single notification.

10. Projected date(s) of shipment(s) and period of time over which wastes are to be exported and proposed itinerary (including point of entry and exit). 3 /

11. Means of transport envisaged (road, rail, sea, air, inland waters).

12. Information relating to insurance. $4 /$

13. Designation and physical description of the wastes including $Y$ number and UN number and its composition 5/ and information on any special handling requirements including emergency provisions in case of accidents.

14. Type of packaging envisaged (e.g. bulk, drummed, tanker).

15. Estimated quantity in weight/volume. 6/

16. Process by which the wastes are generated. 7/

17. For wastes listed in Annex I, classifications from Annex II: hazardous characteristic, $H$ number, and UN class.

18. Method of disposal as per Annex V.

19. Declaration by the generator and exporter that the information is correct.

20. Information transmitted (including technical description of the plant) to the exporter or generator from the disposer of the wastes upon which the latter has based their assessment that there was no reason to believe that the wastes will not be managed in an environmentally sound manner in accordance with the laws and regulations of the country of import.

21. Information concerning the contract between the exporter and the disposer.

\section{NOTES:}

1V Full name and address, telephone, telex or telefax number and the name, address, telephone, telex, or telefax number of the person to be contacted.

2/ Full name and address, telephone, telex or telefax number.

3/ In the case of a general notification covering several shipments, either the expected dates of each shipment or, if this is not known, the expected frequency of the shipments will be required.

4/ Information to be provided on relevant insurance requirements and how they are met by exporter, carrier, and disposer.

5/ The nature and the concentration of the most hazardous components, in terms of toxicity and other dangers presented by the wastes both in handling and in relation to the proposed disposal method.

6/ In the case of a general notification covering several shipments, both the estimated total quantity and the estimated quantities for each individual shipment will be required.

7/ Insofar as this is necessary to assess the hazard and determine the appropriateness of the proposed disposal operations. 


\title{
ANNEX VI B \\ INFORMATION TO BE PROVIDED ON THE MOVEMENT DOCUMENT
}

1. Exporter of the wastes. $1 /$

2. Generator(s) of the wastes and site of generation. $\mathbf{Y}$

3. Disposer of the wastes and actual site of disposal. $1 /$

4. Carrier(s) of the wastes $1 /$ or their agent( 8 ).

5. Subject of general or single notification.

6. The date the transboundary movement started and date(s) and signature on receipt by each person who takes charge of the wastes.

7. Means of transport (road, rail, inland waterway, sea, air) including countries of export, transit and import, also point of entry and exit where these have been designated.

8. General description of the wastes (physical state, proper UN shipping name and class, UN number, Y number and $\mathrm{H}$ number as applicable).

9. Information on special handling requirements including emergency provisions in case of accidents.

10. Type and number of packages.

11. Quantity in weight/volume.

12. Declaration by the generator or exporter that the information is correct.

13. Declaration by the generator or exporter indicating no objection from the competent authorities of all Parties.

14. Certification by disposer of receipt at designated disposal facility and indication of method of disposal and of the approximate date of disposal.

\section{NOTES:}

The information required on the movement document shall where possible be integrated into one document with that required under transport rules. Where this is not possible, the information should complement rather than duplicate that required under the transport rules. The movement document shall carry instructions as to who is to provide information and fill-out any form.

1) Full name and address, telephone, telex or telefax number and the name, address, telephone, telex or telefax number of the person to be contacted in case of emergency.

\section{ANNEX VII}

\section{ARBITRATION}

\begin{abstract}
ARTICLE 1
Unless the agreement referred to in Article 20 of this Convention provides otherwise, the arbitration procedure shall be conducted in accordance with Articles 2 to 10 below.
\end{abstract}




\section{ARTICLE 2}

The claimant party shall notify the Secretariat that the Parties have agreed to submit the dispute to arbitration pursuant to Articles 20.2 or 20.3 of this Convention and include, in particular, the articles of this Convention, the interpretation or application of which, are at issue. The Secretariat shall forward the information thus received to all Parties to this Convention.

\section{ARTICLE 3}

The arbitral tribunal shall consist of three members. Each of the Parties to the dispute shall appoint an arbitrator, and the two arbitrators so appointed shall designate by common agreement the third arbitrator, who shall be the president of the arbitral tribunal. The latter shall not be a national of one of the Parties to the dispute, nor have their usual place of residence in the territory of one of the Parties, nor be employed by any of them, nor have dealt with the case in any other capacity.

\section{ARTICLE 4}

1. If the president of the arbitral tribunal has not been designated within two months of the appointment of the second arbitrator, the Secretary General of the Forum Secretariat in consultation with the Director of SPREP shall, at the request of either Party, designate that person within a further two months period.

2. If one of the Parties to the dispute does not appoint an arbitrator within two months of the receipt of the request, the other Party may inform the Secretary General of the Forum Secretariat who shall, in consultation with the Director of SPREP, designate the president of the arbitral tribunal within a further two months period. Upon designation, the president of the arbitral tribunal shall request the Party which has not appointed an arbitrator to do so within two months. After such period, the president shall inform the Secretary General of the Forum Secretariat who shall make this appointment within a further two months period, in consultation with the Director of SPREP.

\section{ARTICLE 5}

1. The arbitral tribunal shall render its decision in accordance with international law and in accordance with the provisions of this Convention.

2. Any arbitral tribunal established under the provisions of this Annex shall decide its own rules of procedure.

\section{ARTICLE 6}

1. The decisions of the arbitral tribunal, both on procedure and on substance, shall be taken by majority vote of its members.

2. The arbitral tribunal may take all appropriate measures in order to establish the facts. It may, at the request of one of the Parties, recommend essential interim measures of protection.

3. The Parties to the dispute shall provide all facilities necessary for the effective conduct of the proceedings.

4. The absence or default of a Party in the dispute shall not constitute an impediment to the proceedings.

\section{ARTICLE 7}

The arbitral tribunal may hear and determine counter-claims arising directly out of the subject matter of the dispute. 


\section{ARTICLE 8}

Unless the arbitral tribunal determines otherwise because of the particular circumstances of the case, the expenses of the arbitral tribunal, including the remuneration of its members, shall be borne by the Parties to the dispute in equal shares. The arbitral tribunal shall keep a record of all its expenses, and shall furnish a final statement thereof to the Parties.

\section{ARTICLE 9}

Any Party that has an interest of a legal nature in the subject matter of the dispute which may be affected by the decision in the case, can intervene in the proceedings with the consent of the arbitral tribunal.

\section{ARTICLE 10}

1. The arbitral tribunal shall render its award within five months of the date on which it is established unless it finds it necessary to extend the time-limit for a period which should not exceed five months.

2. The award of the arbitral tribunal shall be accompanied by a statement of reasons. It shall be final and binding upon the Parties to the dispute.

3. Any dispute which may arise between the Parties concerning the interpretation or execution of the award may be submitted by either Party to the arbitral tribunal which made the award or, if the latter cannot be seized thereof, to another tribunal constituted for this purpose in the same manner as the first. 


\section{U L}

\section{ENVIRONMENT AND Natural Resources}

$\begin{array}{lllllllllllllllllll}\mathbf{N} & \mathrm{O} & \mathbf{N} & -\mathrm{B} & \mathrm{I} & \mathbf{N} & \mathrm{D} & \mathrm{I} & \mathbf{N} & \mathrm{G} & \mathrm{D} & \mathrm{O} & \mathrm{C} & \mathrm{U} & \mathrm{M} & \mathrm{E} & \mathbf{N} & \mathrm{T} & \mathrm{S}\end{array}$ 



\title{
Action Plan for Biosphere Reserves, Paris, 1984
}

\author{
Done at Paris 8 December 1984 \\ Primary source citation: Copy of text provided by \\ UNESCO
}

\section{ACTION PLAN FOR BIOSPHERE RESERVES}

On the basis of the results of the First International Biosphere Reserve Congress, jointly convened in Minsk in 1983 by Unesco and UNEP in co-operation with FAO and IUCN, at the invitation of the USSR, and of consultations with conservation specialists and scientists which have since taken place, an Action Plan for Biosphere Reserves was adopted by the International Co-ordinating Council of the Programme on Man and the Biosphere at its eighth session (Paris, 3-8 December 1984) and is presented in this document as a programme framework.

This framework identifies a range of actions for consideration by governments and concerned international organizations in developing the multiple functions of biosphere reserves within the overall context of the MAB Programme. Those actions concretely serve the implementation of the World Conservation Strategy. While a number of actions are of a permanent nature, the stress is placed on activities which can be carried out in the period 1985-89. In summary, governments and international organizations are invited to undertake activities which will improve and expand the international biosphere reserve network, to develop basic knowledge for conserving ecosystems and biological diversity, and to make biosphere reserves more effective in linking conservation and development in fulfilling the broad objectives of MAB. Although each government has its own priorities, from an international perspective there is a minimum set of activities which should be implemented in each biosphere reserve and for which international organizations should provide support as appropriate. These are: baseline inventories of flora and fauna and their uses; monitoring; preparation of a history of research; establishment of research facilities and research programmes; establishment of training and education programmes; and preparation of a management plan which addresses biosphere reserve functions. The approved Action Plan, together with an indication of financing requirements, will be submitted in due course for consideration by the governing organs of UNEP, Unesco, FAO and IUCN.

\section{Introduction}

1. The Man and the Biosphere (MAB) Programme, launched in 1971, is a worldwide programme of international scientific co-operation dealing with people-environment interactions in the whole range of bioclimatic and geographic situations of the biosphere-from polar to tropical zones, from islands and coastal areas to high mountain regions, from sparsely populated regions to dense human settlements. Research under the MAB Programme is designed to provide the information needed to solve practical problems of resource management. It also aims to fill the still significant gaps in the understanding of the structure and function of ecosystems, and of the impact of different types of human intervention. Key ingredients in the MAB Programme are the involvement of decision-makers and local people in research projects, training and demonstration in the field and the pooling of disciplines from the social, biological and physical sciences in addressing complex environmental problems.

2. The International Co-ordinating Council which supervises the MAB Programme, at its first session in 1971, decided that one of the themes of this programme was to be the 'conservation of natural areas and the genetic material they contain'. Under this theme was introduced the concept of the biosphere reserve which was intended to be a series of protected areas, linked through a coordinated international network, which would demonstrate the value of conservation and its relationship with development. The concept was innovative because of this network character 
and because it combined nature conservation with scientific research, environmental monitoring, training, demonstration, environmental education and local participation.

3. Since the very beginning of the implementation of the concept of biosphere reserves as representative ecological areas, the international biosphere reserve network has formed a geographic focus for implementing the MAB Programme.

4. The first biosphere reserves were designated in 1976. Subsequently, the network has grown steadily until 1984; at present, it consists of a total of 243 in 65 countries. In this same period, co-operation with other international organizations involved with conservation and sustainable development has been strengthened, particularly the Food and Agriculture Organization (FAO), the United Nations Environment Programme (UNEP) and the International Union for Conservation of Nature and Natural Resources (IUCN). Representatives of these organizations meet together regularly through the Ecosystem Conservation Group to co-ordinate action.

5. FAO has a major interest in biosphere reserves because of their contribution to the in situ conservation of genetic resources, especially wild crop relatives, forest species, and ancestors and close relatives of domestic livestock. UNEP is promoting the value of the international network for conservation in general, and in particular, for environmental monitoring using comparable methodologies and parameters. IUCN considers that biosphere reserves constitute a useful concept for regional planning in which conservation is linked directly with sustainable development, in line with the World Conservation Strategy.

6. It was therefore in the joint interests of FAO, UNEP, IUCN and Unesco that the First International Biosphere Reserve Congress was convened in 1983 to review the experience of the past ten years and to establish a general framework to guide the future development of the biosphere reserve network.

\section{The characteristics of biosphere reserves}

7. The main characteristics of biosphere reserves are:

(a) Biosphere reserves are protected areas of representative terrestrial and coastal environments which have been internationally recognized for their value in conservation and in providing the scientific knowledge, skills and human values to support sustainable development.

(b) Biosphere reserves are united to form a worldwide network which facilitates sharing of information relevant to the conservation and management of natural and managed ecosystems.

(c) Each biosphere reserve includes representative examples of natural or minimally disturbed ecosystems (core areas) within one of the world's biogeographical provinces; and as many of the following types of areas as possible:

(i) centres of endemism and of genetic richness or unique natural features of exceptional scientific interest (which may be part or all of the core area);

(ii) areas suitable for experimental manipulation to develop, assess and demonstrate the methods for sustainable development;

(iii) examples of harmonious landscapes resulting from traditional patterns of land use;

(iv) examples of modified or degraded ecosystems that are suitable for restoration to natural or near natural conditions.

Collectively, the various types of above areas provide the framework for carrying out the scientific and management functions of biosphere reserves.

(d) Each biosphere reserve should be large enough to be an effective conservation unit, and have value as a benchmark for measurements of long-term changes in the biosphere.

(e) Biosphere reserves should provide opportunities for ecological research, education, demonstration and training. 
(f) The 'buffer zone' may consist of any one or some combination of (ii) to (iv) of (c) above, which are areas suitable or used for research purposes. In addition, the 'buffer zone' may also include a large area which may be undelineated but where efforts are made to develop co-operative activities which ensure that uses are managed in a manner compatible with the conservation and research functions of the other areas of the reserve cited in (c) above. This multiple-use area may contain a variety of agricultural activities, settlements and other uses and may vary in space and time, thus forming an 'area of co-operation' or 'zone of influence'.

(g) Biosphere reserves must have adequate long-term legislative, regulatory or institutional protection. Biosphere reserves may coincide with or incorporate existing or proposed protected areas, such as national parks or protected research sites. This is because some of these protected areas are often the best examples of the natural unaltered landscape or because they constitute suitable areas for carrying out the various functions of biosphere reserves.

(h) People should be considered as part of a biosphere reserve. People constitute an essential component of the landscape and their activities are fundamental for its long-term conservation and compatible use. People and their activities are not excluded from a biosphere reserve; rather they are encouraged to participate in its management and this ensures a stronger social acceptance of conservation activities.

(i) Normally, there is no need for changes in land-holding or regulation following the designation of a biosphere reserve except where changes are required to ensure the strict protection of the core area or of specific research sites.

8. The above characteristics however may give an insufficient impression of the breadth of the concept. Successful biosphere reserves constitute models of the harmonious marriage of conservation and development. They provide visible examples of the application of the World Conservation Strategy-sustainable development in action.

\section{Functions of biosphere reserves}

\section{Conservation as an open system}

9. Although it has long been clear that the whole variety of organisms and ecosystems cannot be safeguarded satisfactorily forever if their sole refuges are protected areas of the more conventional types, this is the only approach that has been applied widely in practice so far. If genetic conservation is to be successful in weathering natural and man-induced environmental change, a more open system of conservation is required, in which areas of undisturbed natural ecosystems can be surrounded by areas of sympathetic and compatible use. The biosphere reserve provides these conditions. It should, perhaps, be looked upon less as a 'reserve' than as an area of ecologically representative landscape in which land use is controlled, but may range from complete protection to intensive, yet sustainable, production. Under certain circumstances these areas need not even be contiguous but separate from one another ('cluster concept' of biosphere reserves). This arrangement of graded control allows for a flexibility of treatment that is necessary if conservation is to be assured under changing circumstances.

10. Because they contain a substantial proportion of the indigenous flora and fauna of a biogeographic region, biosphere reserves are important reservoirs of genetic material. These resources increasingly find application in developing new pharmaceuticals, industrial chemicals, building materials, food sources, pest control agents, and other products to improve human well-being. The genetic resources of biosphere reserves also may provide genetic material for re-establishing indigenous species in areas where they have been eradicated, thereby enhancing the stability and diversity of regional ecosystems. Within particular natural regions, biosphere reserves are linked to form local and regional networks with other types of protected areas which safeguard complementary ecosystems and elements of biological diversity.

11. A unique aspect of biosphere reserves is the conservation, where practicable, of traditional land use systems, illustrating harmonious relationships between indigenous populations and the environment. These systems often reflect centuries of human experience and can provide information of immense value in improving the productivity and sustainability of modern land use and management practices. In addition to providing important sites for scientific study, the inclusion of such areas can help to foster pride on the part of local populations in their traditions, and to provide the basis for improving their means of livelihood, through the judicious use of science and technology, in ways which respect these traditions. 


\section{Research and monitoring function}

12. Because of their secure protection, generally large size, and the inclusion of areas free from significant human impact, biosphere reserves typically provide ideal sites for monitoring changes in the physical and biological components of the biosphere. Their protection and scientific mission make biosphere reserves particularly attractive sites for gathering scientific information. Scientists can have more confidence than in most other areas that the integrity of study sites will be respected, and that collected data will contribute to a growing data bank of increasing scientific significance. As land use changes and human impacts progressively decrease the availability of suitable monitoring sites, scientific interest in biosphere reserves will increase.

13. In most protected areas, research is a secondary function which is intended to provide information to enable effective response to immediate resource management problems within the protected areas themselves. In biosphere reserves, interdisciplinary research programmes involving the natural and social sciences are encouraged to develop models for sustainable conservation of the ecosystems of a large natural region. Biosphere reserves provide sites for co-ordinated research, including research to determine requirements for conserving biological diversity, to assess the impacts of pollution on the structure and functions of ecosystems, to evaluate the effects of traditional and modern land use practices on ecosystem processes, and to develop sustainable production systems for degraded areas.

14. Additionally, the international network provides a framework for comparative studies of similar problems in different parts of the world; for testing, standardizing and transferring new methodologies; and for co-ordinating the development of information management systems.

\section{The education and training function}

15. Biosphere reserves can serve as important field centres for the education and training of scientists, resource managers, protected area administrators, visitors, and local people. The strong emphasis on developing educational and training programmes within biosphere reserves is probably unique. The nature of these programmes depends on the particular conditions, capabilities, and needs of the biosphere reserve and the surrounding region. However, the following kinds of activities are generally encouraged: academic and professional training; environmental education; demonstration and extension; training for local people supplemented by the provision of employment opportunities.

\section{The co-operation function}

16. Co-operation not only serves as the master integrator of the other functions, but also provides the moral force behind the biosphere reserve concept. Biosphere reserve status can provide a framework for improving co-operation at the local, regional, and international level. Co-operation is increasingly regarded as an aspect of good management for all categories of protected areas. However, biosphere reserves are distinguished from other categories of protected areas in several ways, as follows.

17. First, co-operation has been embodied, specifically and visibly, in the biosphere reserve concept from its inception. Unlike other protected areas, it is an essential part of the symbolism, and a key factor in fostering personal commitment on the part of growing numbers of people.

18. Second, co-operation at the local and regional levels is broadly based, involving diverse interests and people with different perspectives. Efforts are directed towards finding practical and sustainable strategies for dealing with complex and interrelated environmental, land use, and socio-economic problems affecting a particular biogeographic region. For this reason, the range of interests involved in planning and implementing the biosphere reserve concept typically includes biosphere reserve administrators, natural and social scientists, resource managers, environmental and development interests, government decision-makers and local people. Communication between these groups is based on the need to integrate conservation and development within the biogeographic region, and on the recognition of the value of a biosphere reserve. Through these co-operative efforts, an area around the biosphere reserve can eventually be developed, which represents a zone of influence in which co-operative activities and harmonious land uses can be implemented. The spatial dimensions of this area expand as more participants co-operate in building the biosphere reserve. Developing the network of co-operation for carrying out the mission of the biosphere reserve is an open-ended process. 


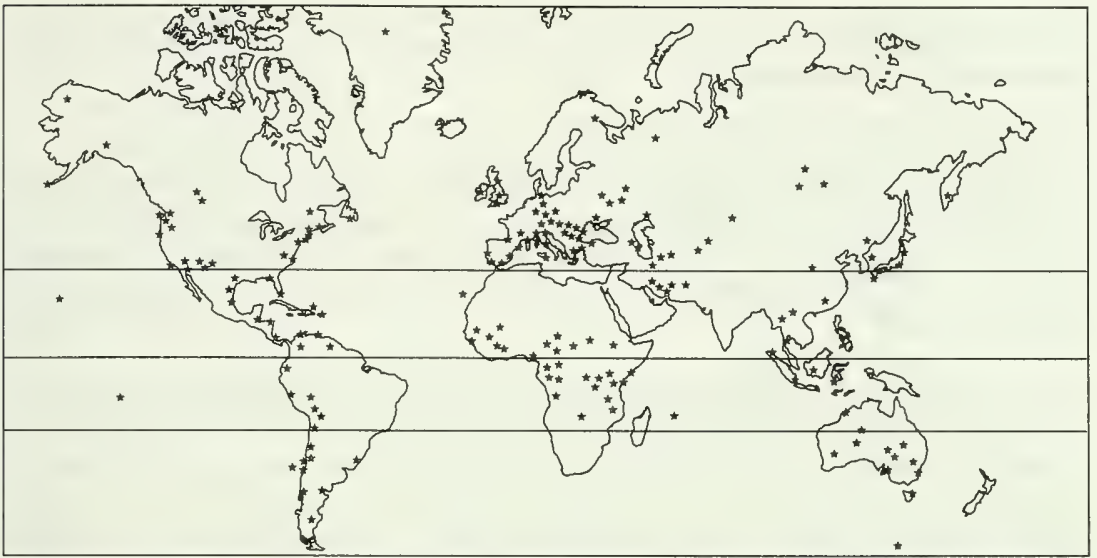

Schematic map indicating the location of existing biosphere reserves. At the end of 1984, 243 biosphere reserves had been designated in 65 countries. In some areas, particularly Europe, where their density is high, individual stars may correspond to several biosphere reserves.

19. Biosphere reserves can also provide the catalyst for establishing appropriate mechanisms to marshal the professional capabilities of government agencies and academic institutions to provide a perspective on the ecosystem use and management problems of particular regions.

20. Finally, all biosphere reserves are part of the international network, which provides a framework for communication within and among biogeographic regions. Co-operation involves the sharing of technology and information, and the development of co-ordinated monitoring and research projects, to provide better information on problems of common interest. Biosphere reserves are particularly suitable for co-operative monitoring of regional and global pollutants and their effects on natural and managed ecosystems, for co-operative ecosystem modelling, for assessment and forecasting, and in comparative assessment of alternative systems for managing renewable resources. Co-operation may also involve the exchange and training of specialists to assist in selecting biosphere reserves and developing their functions.

\section{The Action Plan}

21. There are three main thrusts in the programme framework of the Action Plan, all designed to promote and implement the concept of the biosphere reserve and to make it a more effective agent for sustainable development. These are: improving and expanding the network; using the network to increase knowledge; and making biosphere reserves more effective in demonstrating the value of integrating conservation and development.

\section{Improving and expanding the network}

22. One of the principal objectives of the Action Plan is to improve and expand the world coverage of biosphere reserves by including: (a) representative ecological areas within each of the world's biogeographical regions, in their natural state and as modified by man to varying degrees; (b) centres of endemism and of genetic richness; and (c) areas for carrying the full range of biosphere reserve functions.

\section{Developing basic knowledge for conserving ecosystems and biological diversity}

23. A number of actions are concerned with generating and disseminating useful knowledge, in particular: (a) using biosphere reserves for background global monitoring of chosen biological, chemical and physical variables; (b) carrying out research in basic ecological processes, which can be applied in management, and in 'conservation science'; (c) monitoring the results and effectiveness of management; (d) assembling traditional knowledge about the use of 
species and ecosystems; and (e) spreading all such knowledge by example, publication, wide dissemination in various other forms, training, exchange of staff and of local people and by setting up demonstration biosphere reserves to illustrate these matters to a wide public.

\section{Making biosphere reserves more effective in linking conservation and development}

24. Existing and new biosphere reserves are to be made more effective in various ways: (a) ensuring that biosphere reserves meet the criteria and serve the purposes intended for them, and are not just other sorts of protected areas given another name; (b) guaranteeing their protection by legislation and/or management; (c) linking goals of conservation and development; (d) improving the effectiveness of management and monitoring the standards of management; (e) incorporating in present and future management the traditional skills of those who live in and around biosphere reserves; and ( $f$ ensuring the understanding and participation of local people who are affected by the biosphere reserves.

25. Although it is expected that biosphere reserves will be established and maintained on a permanent basis, the Action Plan concentrates on recommendations for action during the period 1985 to 1989 , which coincides with the United Nations Systems-wide Medium-term Environment Programme as well as the medium-term plans of several of the sponsoring organizations. It is designed to be both realistic and practical. Some actions will be initiated or undertaken by United Nations organizations (in particular Unesco, UNEP, FAO, WHO and WMO) and by IUCN. Due consideration will be given to appropriate requirements of the World Conservation Strategy and other relevant action plans such as the United Nations Plan to Combat Desertification. However, most actions will be a matter for individual countries to implement in accordance with their own priorities. Success, therefore, will largely depend on the support of governments-in their domestic policies, in the attitudes they take in the governing bodies of international organizations and in asking for and giving technical assistance.

26. This Action Plan presents a set of recommended actions which governments and international organizations can implement, better to fulfil the functions of biosphere reserves. Given a reasonable level of funding and international support, substantial progress can be made in implementing most of these recommendations by 1989. It is proposed that a meeting be held to review the progress made and draw up directions for future actions in 1990.

27. Every government establishes its own priorities for implementing activities in biosphere reserves. These activities all contribute to the worldwide network to the extent that their results are shared among the co-operating nations. However, from an international perspective, there is a minimum set of activities which should be implemented in each biosphere reserve. These include:

- Baseline inventories of species of fauna and flora and their present and traditional uses (to provide the basis for further research, monitoring, and information activities).

- Establishment of procedure for monitoring key biological parameters.

- Preparation of a history of research, which specifies what research has been carried out and includes a complete bibliography of relevant publications, as well as an analysis of the relationship with other ongoing pilot projects, and especially national or international projects of the MAB Programme.

- Establishment of research facilities and a research programme which outlines the research activities envisaged for the following five years or so.

- Establishment of a training/education programme appropriate for local needs and conditions.

- Preparation of a management plan which specifies the steps to be taken in developing biosphere reserve functions (this may often involve only minor alterations to existing management plans). 


\section{Objectives and actions}

\section{Objective 1. International network: to enhance the role of the international network of biosphere reserves in global ecosystem conservation}

28. In spite of vigorous action during the past decade to make governments aware of the importance of biosphere reserves and to promote their establishment, there are still many gaps and deficiencies in the network.

- Many important representative types of ecosystem are still to be included, especially of coastal and aquatic ecosystems.

- Only a few biosphere reserves established so far cover the full range of purposes for which biosphere reserves were intended.

- Few reserves have been established which include centres of high biological diversity and endemism, particularly the centres of concentration of the wild relatives of economically important plants and animals.

- The significance of the biosphere reserve concept and the added importance of having a network are not fully appreciated, so a number of countries have not yet responded, and others have proposed areas that only partially profit from the advantages offered by this concept of land use.

29. This is an important objective; because, without a full network, many of the other objectives can only be partially satisfied. Action on it is, therefore, crucial. Promotion of the philosophy of the biosphere reserve and strengthening the network are, of course, tasks that will never be fully complete; but it should be possible by 1990 to lay firm groundwork for subsequent continuing action.

\section{Recommended actions}

Action 1. In order to provide the basis for a rational selection of biosphere reserves that would give a complete biogeographical cover, IUCN, in co-operation with UNEP, should prepare and publish:

Classification of 'representative ecological areas' on land; and classification of 'representative ecological areas' covering intertidal and marine habitats in coastal areas.

Action 2. In order to move rapidly and systematically in expanding the network of biosphere reserves, Unesco, UNEP, FAO and IUCN should co-ordinate their planned activities and develop a phased programme to identify gaps in ecosystem representation and biosphere reserve functions, and to stimulate action based on these evaluations. The results of these evaluations should be widely publicized.

Action 3. Governments should be urged to take such action as appropriate to fill the identified gaps in ecosystem representation and biosphere reserve functions. In this they are encouraged to consult and co-operate with the governments of neighbouring countries to develop a coherent and co-ordinated approach. Governments should also develop basic information for refining and accelerating the selection of biosphere reserves, and should take full advantage of recent advances in remote-sensing.

Action 4. In order to take the first steps in establishing a series of biosphere reserves covering the main areas of specific and genetic diversity, FAO and IUCN should develop a survey of centres of endemism, and of centres of concentration of wild relatives of economic species, starting with a pilot project for one biogeographic realm and for a few selected groups of organisms. Following completion of the pilot project, Unesco, UNEP, FAO and IUCN should, if appropriate, develop a programme for extending the project to other parts of the world and to other groups.

Action 5. In order to make the network of aquatic and wetland biosphere reserves more complete and effective, IUCN should convene a working group to examine the special managerial, legislative and institutional problems related to such reserves and develop necessary guidelines for their solution.

Action 6. Unesco should immediately establish a Biosphere Reserve Scientific Advisory Panel to refine criteria for the selection and management of biosphere reserves, to evaluate proposals for new biosphere reserves and to review from time to time the effectiveness of the network. 


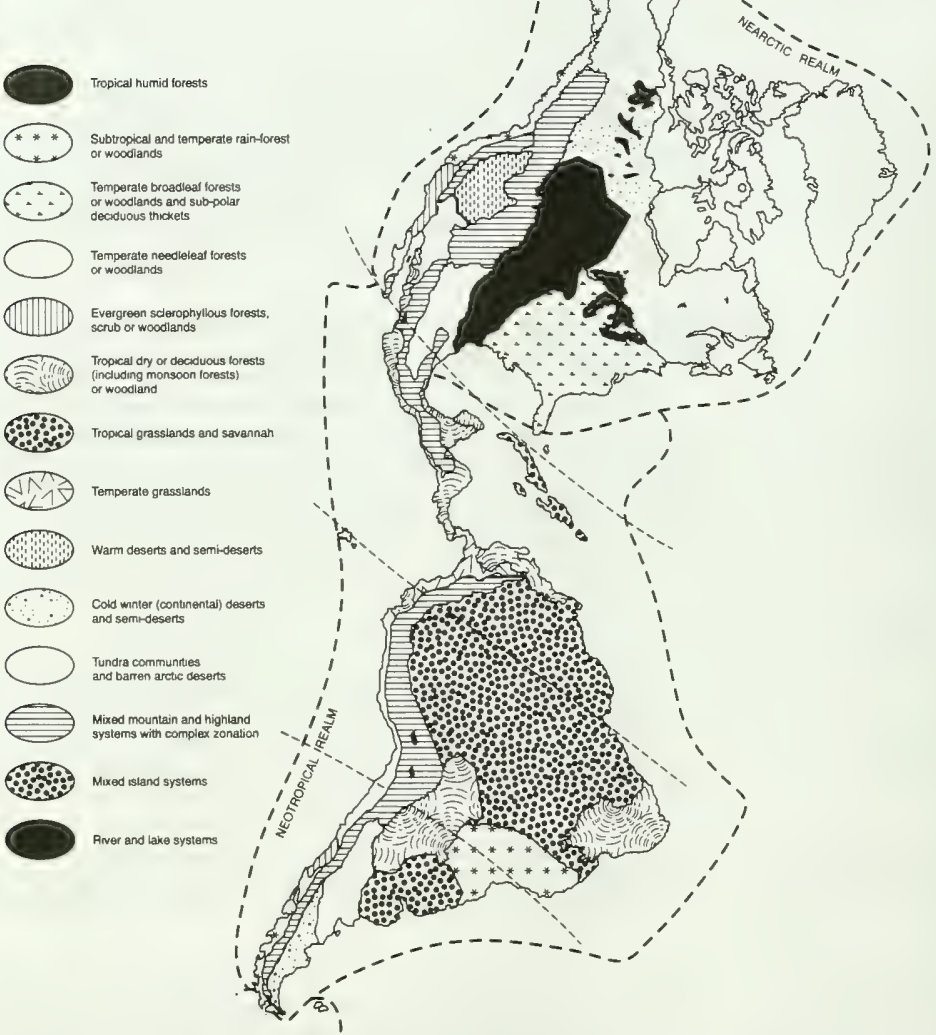

Map indicating the major biomes of the world. The international network of biosphere reserves is intended to cover systematically all biogeographical provinces. Although existing classifications of these provinces have been used so far, a more detailed and refined classification is being worked out for guiding the further development of the network.

\section{Objective 2. Management: to improve and upgrade the management of existing and new biosphere reserves to correspond with their multipurpose objectives}

30. The long-term security of biosphere reserves should be assured through legal instruments, regulations or a management framework directly applicable to the biosphere reserve or to its separate management units and land ownerships. In many countries, the legal and administrative protection normally afforded to national parks, ecological research areas and other protected areas is adequate for the protection of biosphere reserves. Where such legal and administrative protection does not exist, it should be developed especially for the area concerned before it is nominated as a biosphere reserve.

31. In the land surrounding the core area and the research sites, the objective is to encourage uses and activities which do not adversely affect the conservation and research functions of the biosphere reserve. Protection in these 


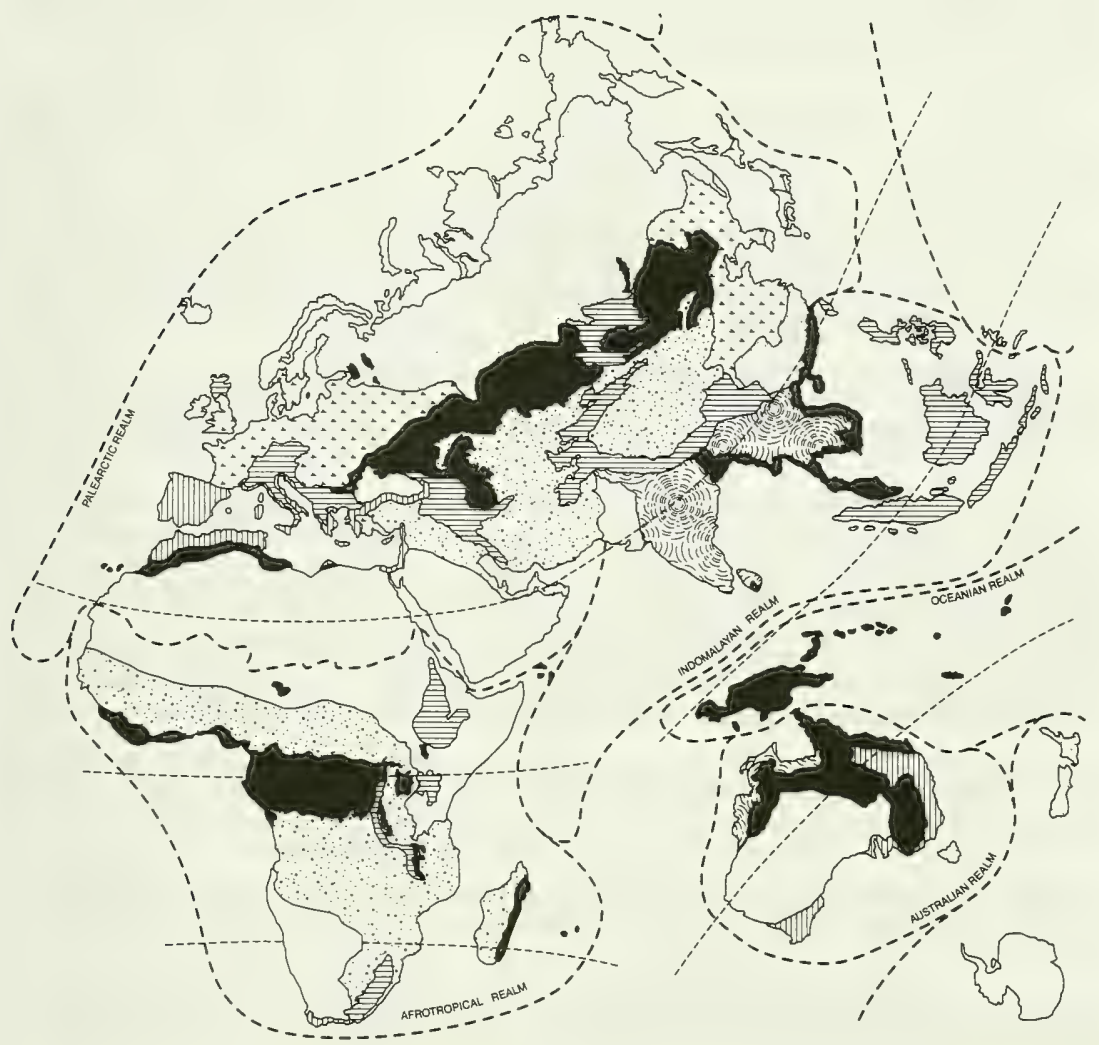

areas may involve laws or regulations to promote land uses which are compatible with the biosphere reserve. However, the buffer zones and surrounding areas frequently are multiple-use areas in which compatible uses depend on voluntary co-operation to protect the biosphere reserve. A wide range of situations, involving various combinations of legal instruments, administrative regulations, and voluntary co-operation are possible depending on the particular ecological, socio-economic, cultural and institutional context of the reserve. In the particular case of marine habitats in coastal areas, special provision should be made so that the adjacent littoral and the catchment basins of its drainage system are adequately protected.

\section{Recommended actions}

Action 7. To ensure an adequate basis for protection and management of biosphere reserves, governments and responsible administrators are encouraged to review legal instruments relating to biosphere reserve units and to pursue revisions where needed.

Action 8. In order to assess the adequacy of existing laws and to help design new legislation, where appropriate, IUCN in co-operation with FAO should collect and synthesize information on the managerial requirements of 
biosphere reserves, on the legislative measures used by governments to secure these, and on the institutional arrangements which can be adopted for the satisfactory administration and management of biosphere reserves. FAO, IUCN and Unesco should make this information available on request and prepare and publish guidelines on the subject.

Action 9. To improve the effectiveness of biosphere reserves in carrying out their multiple functions, MAB National Committees should be asked to review the management of existing biosphere reserves, develop management guidelines, and recommend implementing measures to improve the standard of management appropriate to the legal, administrative, ecological, cultural and socio-economic conditions affecting the reserves.

Action 10. In order to assist in the task of bringing the management of biosphere reserves up to the highest possible standard, FAO and IUCN, in co-operation with UNEP and Unesco, should assist biosphere reserve administrators to develop model management plans for up to four biosphere reserves chosen to cover a range of different purposes, and should distribute these extensively.

Action 11. Unesco, in co-operation with UNEP, FAO and IUCN, should continue to provide missions to governments to advise on selection, establishment, legislation and management of national systems of biosphere reserves, and on the setting up and management of such reserves. Biosphere reserves should be recommended as an integral part of any National Conservation Strategy.

\section{Objective 3. In situ conservation: to promote the conservation of key species and ecosystems in biosphere reserves}

32. There are great differences between species in their requirements for space and in the size of population that is genetically viable and would preserve its full genetic potential. These considerations are very significant in the choice of biosphere reserves (their size, shape and internal heterogeneity) and in their management; in general the smaller and more uniform the reserve, the more intervention likely to be required. Special problems are associated with wide-ranging vertebrates, especially predatory mammals and birds, and with migratory species. These are fields in which more research is needed and in which new knowledge and experience is constantly accumulating.

33. Closer collaboration and a greater exchange of information is needed between those dealing with the in situ and the ex situ conservation of the same groups of organisms.

\section{Recommended actions}

Action 12. In order to ensure the conservation in situ of key species and ecosystems, governments should be asked to take specific and urgent measures in relation to particular species and ecosystems of great importance or under particular threat.

Action 13. In order to illustrate the principles and methods of in situ conservation of wild relatives of economically important species, pilot projects should be initiated by FAO, in co-operation with UNEP, to demonstrate management techniques allowing their conservation in existing or potential biosphere reserves.

Action 14. FAO, in co-operation with Unesco, should set up mechanisms for the exchange of information between those biosphere reserves providing for the in situ conservation of selected groups of organisms and those institutions dealing with the ex situ conservation of the same groups.

Objective 4. Research: to promote co-ordinated research projects on conservation science and ecology within biosphere reserves

34. The development of the research function of biosphere reserves commands the highest priority. Biosphere reserves provide securely protected sites for carrying out long-term basic and applied research programmes to develop the scientific basis for the sustainable use and the long-term conservation of these natural and managed ecosystems, in conformity with the objectives of the MAB Programme.

35. The data obtained from long-term research programmes in biosphere reserves are particularly valuable for the development of models to enable the prediction of environmental changes and trends, and their possible effects on human society. 
36. Of particular importance is the role of biosphere reserves in providing an international framework for comparative research, between natural and managed ecosystems within a given biosphere reserve or between separate biosphere reserves in the network which either have analogous ecological characteristics or similar ecological problems. MAB research undertaken within the biosphere reserve network can be linked, to great mutual advantage, to other international research programmes.

\section{Recommended actions}

Action 15. In order to develop the research potential of the biosphere reserve network, governments should be encouraged to set up co-operative, bilateral or multilateral pilot projects involving: (a) basic and applied research; (b) comparative research involving managed and natural ecosystems; (c) comparative research involving biosphere reserves with analogous ecological characteristics or similar ecological problems; (d) application of new technologies (e.g. remote sensing or modelling) in such research; and (e) development and expansion of north-south, south-south, and north-north linkages for research and educational purposes.

Action 16. Unesco should try to marshal resources from other institutions to assist governments to conduct research in selected biosphere reserves on the priority research topics identified under the MAB Programme (such as on tropical mountains, soil biological processes, succession and regeneration, multipurpose plants, restoration of degraded ecosystems, etc.) in order to strengthen the cohesiveness of the Programme.

Action 17. Unesco, in co-operation with FAO, WHO and IUCN, should develop and maintain a register of plant and animal taxa occurring in biosphere reserves. This register should include basic information on the ecology, distribution and status of these taxa, paying due attention to those of potential agricultural or medical interest. In addition, Unesco, in co-operation with these same organizations, should organize the systematic collection and storage of information on the uses (traditional and modern) of these taxa and should build up a data bank and an information service to synthesize and disseminate this information.

Action 18. Unesco, in co-operation with UNEP, should review the development of the science relating to the conservation of biological diversity and should publish a review of the state-of-the-art and recommendations for action.

Action 19. Unesco should try to marshal the resources from other institutions to assist governments to conduct research in conservation science relating to biosphere reserves, with emphasis on studies to guide the design of protected areas and the management of genetic resources.

Action 20. In order to show how development may be based on local knowledge, Unesco, in co-operation with UNEP, should assist governments to initiate pilot projects to demonstrate how knowledge of traditional uses may be combined with modern scientific work to allow rational, sustainable use of local resources.

Action 21. In order to promote the restoration of degraded ecosystems, Unesco should encourage governments to support research in this field and should develop a mechanism for the exchange and dissemination of information about relevant successful experiences in biosphere reserves.

\section{Objective 5. Monitoring: to develop monitoring activities in biosphere reserves in order to provide a basis for scientific research and management activities and contribute to the understanding of environmental change}

37. Because of their scientific objectives and protective status, many biosphere reserves are of particular value for the long-term monitoring of global biogeochemical cycles, ecological processes, and the effects of human use on the biosphere (particularly as sites for monitoring background levels of pollutants). Fully and properly used, they can make a great contribution to global monitoring and can provide ground truth data for remote sensing and other purposes. In this, close collaboration is needed with UNEP (GEMS programme), WMO (World Climate Programme), FAO and other organizations.

\section{Recommended actions}

Action 22. In order to maximize the contribution of biosphere reserves to international environmental monitoring programmes, UNEP (GEMS) and Unesco should encourage governments to make biosphere reserves available for global environmental monitoring programmes. UNEP in collaboration with FAO, WHO, WMO, ICSU and other 
interested organizations should: (a) identify those parameters of global scientific significance that can be easily and inexpensively monitored on a long-term basis, and design appropriate monitoring programmes; (b) develop standardized, reliable, and widely applicable methods for collecting and comparing data and assuring quality control; (c) select biosphere reserves which are suitable for this work and promote the use of these sites with the governments concerned; and (d) seek support for the monitoring of abiotic and biotic parameters of different ecosystem components (e.g. litter, soil, atmosphere, water, etc.) in biosphere reserves, including biological indicators of environmental change.

Action 23. In order to increase its contribution towards the integrated monitoring of the biosphere, WMO should further develop any methodologies and instrumentation necessary for the monitoring of the atmospheric component and initiate collection and analysis of the relevant data. WMO should also, as far as possible and appropriate, use biosphere reserves for background monitoring of the atmosphere and for long-term monitoring of climate.

\section{Objective 6. Regional planning: to enhance the role of biosphere reserves in regional planning and development}

38. Integrated rural development projects which strengthen the functions of biosphere reserves are a means for ensuring the success of the biosphere reserve concept. One of the most valuable features of biosphere reserves is that they offer an excellent way of integrating conservation with development-by building on the knowledge of indigenous peoples about the sustainable management of their ecosystems and about the properties and values of the plants and animals therein. When this is appropriately supplemented by modern science and technology, such knowledge should enable even better use to be made of those ecosystems while preserving their essential character-and to do this in ways that benefit local peoples and are acceptable to them. Such measures will also serve to safeguard the primitive cultivars of economic crops. This path of development is especially suitable in many areas of the developing world but could also be followed with advantage in some of the less favoured rural areas of developed countries.

39. This path may take a number of forms, for example:

- Increasing the productivity of locally adapted systems of farming, in ways that retain the richness of the local flora and fauna and the protective character of the vegetation.

- Developing, around core areas that should be strictly protected as genetic reserves, patterns of more productive yet sustainable land use that are of benefit to local people and are acceptable to them.

- Linking biosphere reserves to major development projects to ensure that these contain appropriate elements of protection and of the sustainable use of local ecosystems.

40. Biosphere reserves, by definition and intent, have economic and social benefits for local people, but also have value in demonstrating sustainable development tied to conservation in the wider biogeographical region. While biosphere reserves have these inherent benefits, they need to be publicized. Biosphere reserves provide a framework demonstrating the economic benefits which can result from the protection of natural and managed ecosystems.

\section{Recommended actions}

Action 24. To demonstrate the value of biosphere reserves in integrated regional planning, governments should develop existing biosphere reserves as models of balanced and sustainable development. These models should be used to demonstrate the economic and social benefits of conservation. Where biosphere reserves have not yet been established, governments should set up such areas, and also consider nominating for biosphere reserve designation successful projects which integrate conservation (involving a protected area) and rural development, or projects which have such potential.

Action 25. In order to ensure that large development projects contain the requisite elements of conservation, the World Bank and other international and regional development-financing organizations should ensure that any development project financed by them should not affect the basic functions of existing biosphere reserves. These organizations should support the establishment of biosphere reserves as a compensatory measure to mitigate the adverse ecological effects of the development project, financed by them, which would affect major ecosystems. They should also consider support for rural development projects involving biosphere reserves which will help to develop the full range of biosphere reserve functions. 
Objective 7. Local participation: to promote local participation in the management of biosphere reserves

41. For biosphere reserves to be successful, it is essential that they be locally acceptable. This is not always easy for a number of reasons. There may be conflict between the requirements of short-term economic pursuits and conservation; there may be different local views on land use; and the local and national interests may diverge. Careful consultation and planning are necessary, as well as a continual dialogue involving tact, understanding and imagination.

42. Moreover, the situation is seldom stable. Growing populations, changing expectations, improved technology or communications, and economic pressures from outside may change the whole pattern of land use and local perceptions of priorities. The biosphere reserve should be able to evolve in harmony with all these changes to enable local populations to adjust to demographic and economic transitions without environmental deterioration.

\section{Recommended actions}

Action 26. In order to obtain the commitment of people who live in or adjacent to biosphere reserves, governments should ensure that these people are encouraged to participate in planning for the management of the area. Where possible, they should also participate in the scientific research, monitoring, and other activities taking place in the reserve. Furthermore, governments should encourage the setting up of mechanisms for consultation so that conflicts may be resolved and changing local perceptions may be reflected in the management of the reserve.

Action 27. Unesco, in co-operation with governments, should develop pilot projects in biosphere reserves to demonstrate the successful involvement of local people, and should arrange for the transfer of staff, knowledge and skills among such projects.

Action 28. Unesco, in co-operation with governments, should collect and disseminate information about successful arrangements for consultation and participation. Unesco should in particular encourage studies on the mechanism of participation of institutions and local people in the development of biosphere reserve functions under different social, economic and cultural conditions.

Objective 8. Environmental education and training: to promote environmental education and training related to biosphere reserves and to use the full potential of the reserves for these purposes

43. Biosphere reserves play a valuable role in environmental education and in the training of specialists and practitioners. They can introduce local people to the idea that protecting natural areas and sustainable development are to their benefit. Local people could also be made aware of the wider national and international significance of the areas in which they live. Biosphere reserves could also be used much more in educating various sectors of the public in these same things.

44. The network would also provide ideal conditions for training resource managers and research workers. Because of the special features of the network, there are exceptional opportunities for sharing experience of working in comparable ecosystems and analogous conditions in other parts of the world, and for developing special relations in international training between pairs or groups of institutions with shared problems or interests.

\section{Recommended actions}

Action 29. Unesco should assist governments to strengthen the environmental education function of biosphere reserves, and to provide facilities which will heighten the awareness of local people and visitors on environmental matters.

Action 30. Unesco should assist governments to include conservation as a subject in the curricula of training institutions, with particular reference to the role of the biosphere reserve concept and network, and to use their biosphere reserves for field training of specialists in ecology and life sciences, as well as future biosphere reserve managers. 
Objective 9. Information: to use fully the potential of the network to generate and spread knowledge about the conservation and management of the biosphere and to promote the biosphere reserve concept through information and demonstration

45. An important purpose of the biosphere reserve network is the generation and dissemination of knowledge. This concept of an information network, in particular, distinguishes biosphere reserves from other protected areas. The full potential of this aspect of the biosphere reserve network should be developed.

46. It is important that the information from biosphere reserves be published in scientific literature, in the form of guidelines and handbooks presented as attractive and persuasive materials for various sectors of the public. Personal contact is also very important. The exchange of people among biosphere reserves can play a vital role in enabling the sharing of skills and experience.

\section{Recommended actions}

Action 31. Unesco, in co-operation with UNEP and IUCN, should prepare and distribute attractive brochures and audiovisual material which would explain the characteristics and functions of biosphere reserve networks to a wide audience.

Action 32. To develop the biosphere reserve information system, Unesco should: (a) determine a suitable structure for a decentralized system for collection, storage, synthesis, evaluation and dissemination of information associated with biosphere reserves; (b) define the various potential users and beneficiaries of the particular kinds of information; (c) establish mechanisms that ensure that this information reaches the intended users.

Action 33. Governments should be asked to contribute to the biosphere reserve information system by providing the following types of information: (a) publications and audio-visual material relating directly to the biosphere reserve concept; (b) basic information on the geographical, biological (including species' lists), and social characteristics of each biosphere reserve; (c) bibliography of scientific literature relating to individual biosphere reserves; (d) legislative and administrative provisions for biosphere reserves; (e) the details of management plans; (f) history of relevant research and monitoring.

Action 34. Unesco should use already existing information systems to disseminate scientific bibliographies and data relating to biosphere reserves.

Action 35. Unesco should encourage governments to develop model biosphere reserves which demonstrate to the international scientific community, to national and local leaders, and to politicians and decision makers the usefulness and international importance of biosphere reserves for conservation, science and society. 


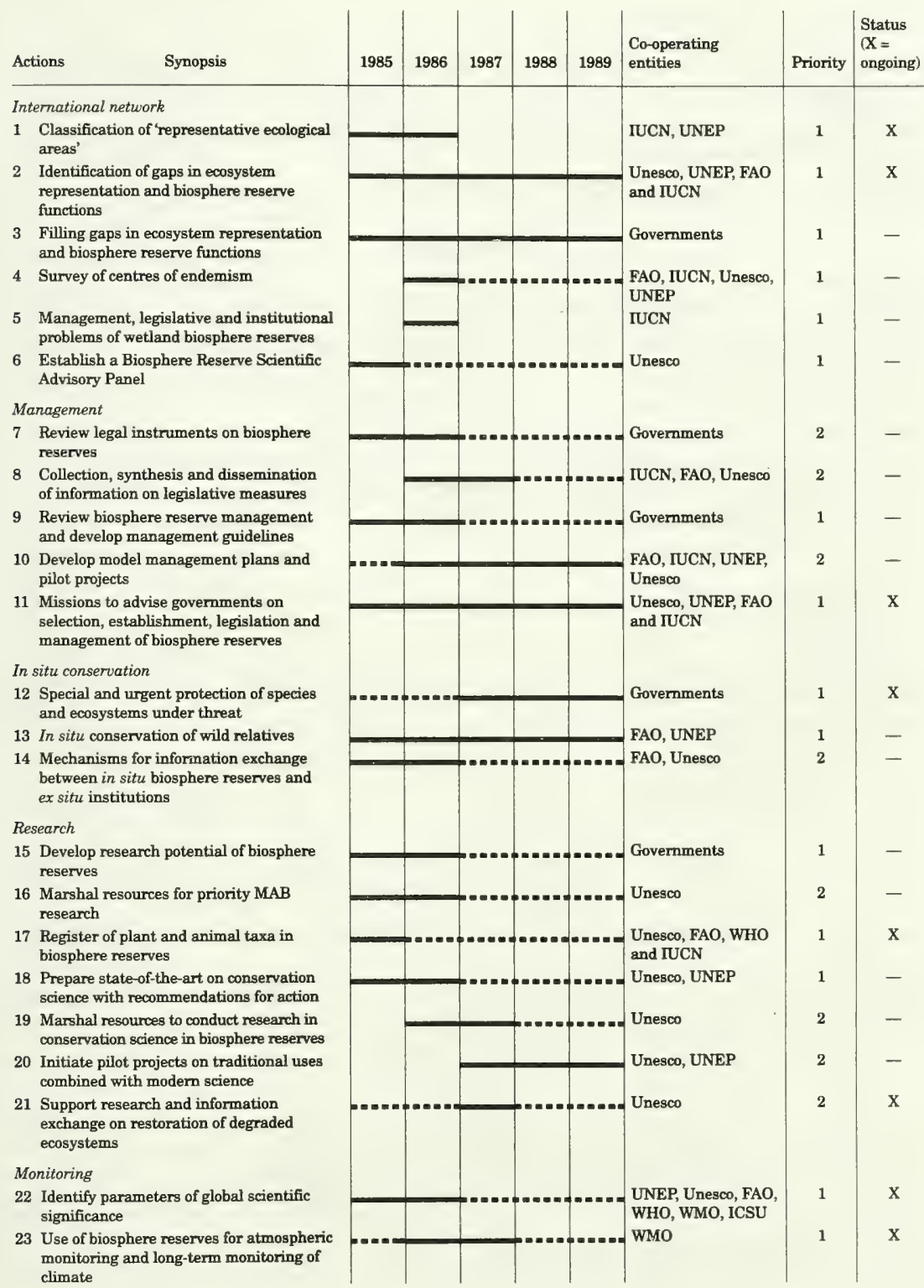




\begin{tabular}{|c|c|c|c|c|c|c|c|c|}
\hline Synopsis & 1985 & 1986 & 1987 & 1988 & 1989 & $\begin{array}{l}\text { Co-operating } \\
\text { entities }\end{array}$ & Priority & $\begin{array}{l}\text { Status } \\
\mathrm{X}= \\
\text { ongoing) }\end{array}$ \\
\hline \multicolumn{9}{|l|}{ Regional planning } \\
\hline $\begin{array}{l}24 \text { Develop model biosphere reserves to } \\
\text { demonstrate value in integrated regional } \\
\text { planning }\end{array}$ & & & & & & Governments & 1 & $\mathrm{x}$ \\
\hline $\begin{array}{l}25 \text { Involve biosphere reserves in development } \\
\text { projects }\end{array}$ & & & & & & $\begin{array}{l}\text { World Bank, } \\
\text { development } \\
\text { financing } \\
\text { organizations }\end{array}$ & 1 & $\mathrm{x}$ \\
\hline \multicolumn{9}{|l|}{ Local participation } \\
\hline $\begin{array}{l}26 \text { Ensure local involvement in biosphere } \\
\text { reserves }\end{array}$ & & & & & & Governments & 1 & $\mathrm{x}$ \\
\hline $\begin{array}{l}27 \text { Develop pilot projects based upon } \\
\text { principles of local involvement }\end{array}$ & & & & & & Unesco & 2 & - \\
\hline $\begin{array}{l}28 \text { Disseminate information and study } \\
\text { mechanisms for the particjpation of local } \\
\text { people in biosphere reserves }\end{array}$ & & & & & & Unesco & 1 & $\mathrm{x}$ \\
\hline \multicolumn{9}{|l|}{ Education and training } \\
\hline $\begin{array}{l}29 \text { Strengthen environmental education } \\
\text { function in biosphere reserves }\end{array}$ & & & & & & Unesco & 1 & $\mathrm{x}$ \\
\hline $\begin{array}{l}30 \text { Promote conservation in curricula and use } \\
\text { of biosphere reserves in field training }\end{array}$ & & & & & & Unesco & 2 & - \\
\hline Information & & & & & & & & \\
\hline $\begin{array}{l}31 \text { Prepare and distribute promotional } \\
\text { material on biosphere reserves }\end{array}$ & & & & & & Unesco, UNEP, IUCN & 1 & - \\
\hline $\begin{array}{l}32 \text { Develop decentralized information system } \\
\text { on biosphere reserves }\end{array}$ & & & & & & Unesco & 2 & - \\
\hline $\begin{array}{l}33 \text { Governments to contribute to this } \\
\text { information system }\end{array}$ & & & & & & Governments & 1 & $\mathrm{x}$ \\
\hline $\begin{array}{l}34 \text { Use existing information systems to } \\
\text { disseminate biosphere reserve data }\end{array}$ & & & & & & Unesco & 2 & - \\
\hline $\begin{array}{l}35 \text { Develop model biosphere reserves in range } \\
\text { of ecological and socio-economic context }\end{array}$ & & & & & & Unesco & 1 & $\mathbf{x}$ \\
\hline
\end{tabular}




\title{
The Nuuk Declaration on Environment and Development in the Arctic, Nuuk, 1993
}

\author{
Done at Nuuk 16 September 1993 \\ Primary source citation: Copy of text provided by the \\ United Nations
}

\section{THE NUUK DECLARATION ON ENVIRONMENT AND DEVELOPMENT IN THE ARCTIC}

\section{We, the Ministers of the Arctic Countries,}

Recognizing the special role and responsibilities of the Arctic Countries with respect to the protection of the Arctic environment,

Acknowledging that the Arctic environment consists of ecosystems with unique features and resources which are especially slow to recover from the impact of human activities, and as such, require special protective measures,

Further acknowledging that the indigenous peoples who have been permanent residents of the Arctic for millenia, are at risk from environmental degradation,

Determined, individually and jointly, to conserve and protect the Arctic environment for the benefit of present and future generations, as well as for the global environment,

Noting that in order to achieve sustainable development, environmental protection shall constitute an integral part of the development process and cannot be considered in isolation from it,

Recognizing the importance of applying the results of the United Nations Conference on Environment and Development to the Arctic region,

Welcoming the efforts of the eight Arctic Countries to implement, through the Arctic Environmental Protection Strategy, relevant provisions of the Rio Declaration, Agenda 21 and the Forest Principles, efforts which include the Arctic Monitoring and Assessment Program (AMAP), and the Working Groups on the Conservation of Arctic Flora and Fauna (CAFF), Emergency Prevention, Preparedness and Response, and the Protection of the Arctic Marine Environment,

Affirming Principle 2 of the Rio Declaration on Environment and Development which affirms that States have, in accordance with the Charter of the United Nations and the principles of international law, the sovereign right to exploit their own resources pursuant to their own environmental and developmental policies, and the responsibility to ensure that activities within their jurisdiction or control do not cause damage to the environment of other States or of areas beyond the limits of national jurisdiction,

Further affirming Principle 22 of the Rio Declaration, which states that: "indigenous people and their communities ... have a vital role in environmental management and development because of their knowledge and traditional 
practices. States should recognize and duly support their identity, culture and interests and enable their effective participation in the achievement of sustainable development."

hereby make the following Declaration:

1. We reaffirm our commitment to the protection of the Arctic Environment as a priority and to the implementation of the Arctic Environmental Protection Strategy.

2. We adopt the report of the Second Ministerial Conference of the Arctic Environmental Protection Strategy, and endorse its provisions to implement the Strategy, in particular:

seeking resources to enable each country to fully participate in the program activities under the Arctic Environmental Protection Strategy;

- endeavouring to support, through these resources, joint projects in order to ensure that each country is able to participate in the activities of the Arctic Monitoring and Assessment Program (AMAP), including the completion of national implementation plans and the comprehensive assessment of results;

establishing a working group to assess the need for further action or instruments to prevent pollution of the Arctic marine environment and to evaluate the need for action in appropriate international fora to obtain international recognition of the particularly sensitive character of the ice-covered sea areas of the Arctic;

- reaffirming the commitment to sustainable development, including the sustainable use of renewable resources by indigenous peoples, and to that end agreeing to establish a Task Force for this purpose;

underlining the necessity of a notification system and improved cooperation for mutual aid in case of accidents in the Arctic area;

- reaffirming that management, planning and development activities shall provide for the conservation, sustainable use and protection of Arctic flora and fauna for the benefit and enjoyment of present and future generations, including local populations and indigenous peoples.

3. We will cooperate to conserve, protect and, as appropriate, restore the ecosystems of the Arctic. We will in particular cooperate to strengthen the knowledge base and to develop information and monitoring systems for the Arctic region.

4. We recognize that effective domestic environmental legislation is a prerequisite to the protection of the environment. As Ministers we shall promote legislation required for the protection of the Arctic environment.

5. We support the achievements of the United Nations Conference on Environment and Development, and state our beliefs that the Principles of the Rio Declaration on Environment and Development have particular relevance with respect to sustainable development in the Arctic.

6. We believe that decisions relating to Arctic activities must be made in a transparent fashion and therefore undertake to facilitate, through national rules and legislation, appropriate access to information concerning such decisions, to participation in such decisions and to judicial and administrative proceedings.

7. We recognize the special role of the indigenous peoples in environmental management and development in the Arctic, and of the significance of their knowledge and traditional practices, and will promote their effective participation in the achievement of sustainable development in the Arctic.

8. We believe that development in the Arctic must incorporate the application of precautionary approaches to development with environmental implications, including prior assessment and systematic observation of the impacts of such development. Therefore we shall maintain, as appropriate, or put into place as quickly as possible, an internationally transparent domestic process for the environmental impact assessment of proposed activities that are likely to have a significant adverse impact on the Arctic environment and are subject to decisions by competent national authorities. To this end we support the implementation of the provisions of the Convention on Environmental Impact Assessment in a Transboundary Context. 
9. We underline the importance of prior and timely notification and consultation regarding activities that may have significant adverse transboundary environmental effects, including preparedness for natural disasters and other emergencies that are likely to produce sudden harmful effects on the Arctic environment or its peoples.

10. We recognize the need for effective application of existing legal instruments relevant to protection of the Arctic environment, and will cooperate in the future development of such instruments, as needed. We support the early ratification of the United Nations Conventions on Biological Diversity and Climate Change.

11. We undertake to consider the development of regional instruments concerned with the protection of the Arctic environment.

In witness whereof we have signed the present Declaration.

For the Government of Canada:

For the Government of Denmark:

[Signature]

LEE CLARK

For the Government of Finland:

[Signature]

SIRPA PIETIKÄINEN

For the Government of Norway:

[Signature]

BØRRE PETTERSEN

For the Government of Sweden:

[Signature]

GORAN A. PERSSON
[Signature]

NIELS HELVEG PETERSEN

[Signature]

SVEND AUKEN

For the Government of Iceland:

[Signature]

ÖSSUR SKARHÉDINSSON

For the Government of the Russian Federation:

[Signature]

VICTOR I. DANILOV-DANILIAN

For the Government of the United States of America:

[Signature]

DAVID A. COLSON

Nuuk, 16 September 1993

\section{REPORT}

Representatives of the Governments of Canada, Denmark, Finland, Iceland, Norway, the Russian Federation, Sweden and the United States of America met on 16 September 1993 at Nuuk, Greenland, for the Second Ministerial Conference on the Protection of the Arctic Environment. The Ministerial Conference was also attended by observers from Chile, Germany, the Netherlands, Poland, the United Nations Environment Programme, the Nordic Council, the Northern Forum, the International Arctic Science Committee, the Inuit Circumpolar Conference, the Saami Council, and the Russian Association of Peoples of the North.

The Ministers reaffirmed their commitment to protect and preserve the Arctic environment and fully recognized the special relationship of the indigenous peoples and local populations to the Arctic and their unique contribution to the protection of the Arctic environment.

The Ministers noted that protection of the Arctic environment requires that development activities be pursued in a sustainable manner, taking into account the special sensitivity of the Arctic environment, including the need to apply precautionary approaches. This requires prior assessment and systematic observation of the impacts of such development. The Ministers agreed to maintain, as appropriate, or put into place as quickly as possible, domestic processes for the environmental impact assessment of proposed activities that are likely to have a significant adverse impact on the Arctic environment, and are subject to decisions by competent national authorities. To this end, the Ministers supported the implementation of the provisions of the Convention on Environmental Impact Assessment in a Transboundary Context. 
The Ministers reviewed progress in the elaboration and implementation of the Arctic Environmental Protection Strategy (AEPS), and confirmed their intention to monitor, on a continuing basis, the threats to the Arctic environment through the preparation and updating of reports on the state of the Arctic environment, in order to initiate further cooperative action.

\section{Arctic Monitoring and Assessment Program (AMAP)}

The Ministers considered and accepted with appreciation the status report entitled "Update on Issues of Concern to the Arctic Environment", prepared by the Task Force of the Arctic Monitoring and Assessment Program. They noted with satisfaction that the Arctic Countries have now developed a comprehensive monitoring program which focuses on the monitoring of three priority categories of pollutants (persistent organics, heavy metals and radionuclides) in the atmospheric, terrestrial, freshwater, and marine environments and in humans. They noted that the comprehensive plan also includes monitoring on sub-regional priorities such as acidification and Arctic haze, oil pollution, UV radiation and eutrophication. They welcomed the national reports on how AMAP would be implemented and noted the necessity of developing the methodology of assessment.

Joint efforts by AMAP and relevant other international organizations to collect data on emissions and discharges of contaminants, and to develop atmospheric transport models linking source regions with Arctic receptors, are also underway. These latter activities, when completed, will assist in providing information with which to evaluate the effectiveness of control proposals.

It is of concern that the Arctic continues to be a depository for loadings of persistent organic contaminants, such as PCBs and DDT, through long-range transport from industrialized and agricultural areas in Asia, Europe, and North and Central America and through local sources. Persistent organics accumulate in the fatty tissues of wildlife. This is of particular concern in the Arctic, where lipid-rich wildlife are consumed by local residents, thereby providing a pathway for these contaminants to humans. Researchers and health authorities fear that chronic exposure to persistent organics may have harmful effects on top predators and humans.

Studies continue to confirm that the Arctic acts as a sink for heavy metals which enter the northern environments from local sources and from sources outside the Arctic. Research has shown that effects on ecosystems in the Arctic are evident in areas with particularly high emissions of heavy metals. Exposure for humans has in several areas exceeded the norms of the World Health Organization. In the marine environment, mammals in some areas contain elevated concentrations of heavy metals, especially mercury and cadmium.

The concentration levels of radionuclides in the Arctic Ocean which have been observed at the present time are generally low and do not appear to pose a widespread risk at present. But, knowledge of sources and releases is insufficient and assessments of future consequences cannot be performed at this stage. There is significant concern with regard to the risks associated with potential releases of radionuclides into the environment from different sources, including dumped radioactive materials and wastes, run-off, leakages and accidental releases. Authorities thus agree that additional investigation is necessary, and studies should continue.

Taking into account different negative consequences for terrestrial and aquatic ecosystems and also for human health caused by methods and technologies applied for the use of Arctic natural resources (first of all through chemical pollution observed in the environment of regions with high concentration of industrial and mining enterprises) the eight Arctic Countries nationally and in collaboration with other states and international organizations and in the framework of bilateral and multilateral agreements, will undertake urgent measures

- to exchange available information and data on emissions and discharges of contaminants to the Arctic Region, and to promote, as appropriate, the exchange of relevant know-how, experience and technologies on which to base effective pollution abatement measures;

- to identify and, as appropriate, assess sources of contamination and their pathways to the Arctic, including an inventory of waste sites of imminent and substantial endangerment to human health and the Arctic environment;

- to develop, on the basis of these and other assessments, proposals aimed at reduction of discharges, contamination and cleaning-up by countries of their regions affected by severe contamination and to gain support for these reductions in the nations with the responsibility for the contaminations.

Studies continue to demonstrate that acid deposition is a severe environmental threat in large regions of the Arctic, particularly northern Fennoscandia and the Kola Peninsula. Acidifying substances are emitted by industry and the combustion of fuels, and reach the Arctic environment from local and distant sources. 
The Ministers noted with satisfaction the progress achieved within the United Nations Economic Commission for Europe (UN-ECE) to undertake the work necessary to provide by 1994 the basis for possible protocols to control and reduce emissions of these substances under the auspices of the Convention on Long-range Transboundary Air Pollution (LRTAP). The Ministers agreed to support the development of appropriate protocols under the LRTAP auspices, and to consult with non-ECE nations whose emissions and discharges may affect the Arctic, to achieve their participation in the protocols. They also agreed to continue to take measures to reduce and/or control the use of a number of persistent organic pollutants and heavy metals which may include the ultimate goal of eliminating the emission or discharge of organohalogen compounds to dangerous levels in the marine environment as noted in the Earth Summit.

The Ministers agreed to accord acidification priority pollutant status in a subregional context under AMAP, and to aim at an ambitious protection level, in line with the agreed European reference scenario, in the on-going negotiations on the second Sulphur Protocol. The Arctic implications of nitrogen depositions in relation to acidification should be considered when the second step of the Protocol on reduction and control of Nitrogen Oxides under the said Convention will be negotiated.

Depletion of the ozone layer has been detected in the Northern Hemisphere and can be expected to continue for some time. Ozone reduction results in enhancement of UV-B radiation which has harmful effects on ecosystems and humans.

Climate change, resulting from anthropogenic enhancement of the earth's natural greenhouse effect, is expected to be significant in the Polar regions. Increased temperature and precipitation in the Arctic may result in dramatic ecological and socioeconomic effects.

Noting the existing global cooperation on climate change and stratospheric ozone programs, the Ministers requested AMAP to regularly review the integrated results of these programs with a view to identifying gaps in the scope of the monitoring and research under these fora and with a view to ensuring that specific issues related to the Arctic region are placed on the agenda of the appropriate international bodies. The Ministers also requested AMAP to coordinate their monitoring programs with those planned by other programs in order to maximize data collection in logistically difficult areas and to integrate results as well as to contribute to the assessment of potential synergistic effects of multiple stresses on the Arctic and its inhabitants.

\section{Radioactive Pollution}

The Ministers agreed that their respective Governments within their jurisdiction will

- ensure that nuclear installations that may affect the Arctic meet international nuclear and radiological safety standards established by the International Atomic Energy Agency (IAEA);

- ensure that no disposal of radioactive waste or material will be made in Arctic waters in violation of provisions of the London Convention (1972). They will work and cooperate to provide, in the nearest possible future, conditions for a ban on all dumping of radioactive waste in Arctic waters, taking into account the revision of the London Convention;

- initiate action to prevent further increase in activity levels of anthropogenically-derived radionuclides, irrespective of sources, and to reduce such levels, in order to keep the contamination as low as reasonably achievable;

- initiate clean-up programs for contaminated areas, as appropriate.

The Ministers decided to request AMAP, in cooperation with appropriate international and national agencies

- to establish reliable and comprehensive systems for identification and characterization of present and potential sources of significant radioactive contamination and for monitoring levels of such contamination;

- to establish data bases of sources, type and levels of radionuclide contamination of the atmospheric, the aquatic and the terrestrial environments of the Arctic and Northern areas;

- to perform a long term assessment of potential releases to the environment of radioactive materials (e.g. from nuclear installations, waste disposal sites and contaminated regions), and to improve risk prediction capabilities. 
Based on i.a. the AMAP risk assessment, the Ministers agreed that their respective Governments would, as appropriate, undertake measures to reduce environmental threats.

The Ministers noted with satisfaction the establishment of a subgroup of AMAP with the mandate to forge linkages between AMAP, and, in particular, the International Atomic Energy Agency (IAEA), the Nuclear Energy Agency of the OECD (NEA), the North Atlantic Cooperation Council (NACC), NATO's Committee of Challenge of Modern Society (CCMS) and relevant organizations at the regional level (e.g. the Barents Euro-Arctic Council) to improve required coordination, and to provide initial guidance to the radiological assessment process.

\section{AMAP Structure}

The Ministers, allowing for the institutional character of the work of AMAP, decided to substitute the AMAP Task Force by a Working Group to be responsible for the guidance of the work of AMAP, as decided upon at Rovaniemi and at Nuuk.

The Ministers requested AMAP to maintain a directory of bilateral and multilateral agreements related to environmental matters in the Arctic.

\section{Protection of the Arctic Marine Environment}

The Ministers noted, with concern, the information provided by AMAP, by the report on Facts and Problems Related to Radioactive Waste Disposal in the Seas Adjacent to the Territory of the Russian Federation (White Book), and by other studies regarding threats to the Arctic marine environment from land-based and maritime sources. Taking into account Chapter 17 of Agenda 21, adopted by the United Nations Conference on Environment and Development (UNCED), they agreed, in implementing chapter 7 of the AEPS, to establish a joint process

- to assess the need, taking into consideration the nature of the threats, for further action or instruments on the international and/or national level to prevent pollution of the Arctic marine environment;

- to coordinate work with the AMAP and CAFF (Conservation of Arctic Flora and Fauna) working groups in addressing the Arctic marine environment;

- to evaluate the need for coordinated action in appropriate international fora to obtain international recognition of the particularly sensitive character of the ice-covered sea areas of the Arctic.

A Working Group, led by Norway, with representatives from all Arctic Countries, was formed to manage this initiative and to report on its findings and recommendations before the next Ministerial Conference.

The Ministers acknowledged the work of the CIS office of the Advisory Committee on Protection of the Sea (ACOPS) and noted the conclusions and recommendations of the ACOPS conference on pollution of the coasts of the CIS, with special emphasis on the Arctic, held in Arkhangelsk, Russian Federation, 19-23 July 1993.

\section{Emergency Prevention, Preparedness and Response}

The Ministers noted with satisfaction that the eight Arctic Countries have embarked upon cooperative action on emergency prevention, preparedness and response in the Arctic and endorsed the recommendations presented in the progress report. A list of contact points and a reporting system have been established for notification and mutual assistance in the Arctic area.

The Ministers requested the Emergency Prevention, Preparedness and Response Working Group, led by Sweden,

- to complete, by the end of 1994, the inventory and qualitative risk assessment for facilities or activities that may pose a risk of significant accidental pollution;

- to propose, as a supplement to existing international agreements, adequate arrangements for prevention, preparedness and response in those parts of the Arctic area where regional or bilateral cooperation is not in place;

- to improve cooperation in the field of research and development related to emergency prevention, preparedness and response through existing cold-climate mechanisms such as the Arctic Marine Oil Spill Progamme (AMOP);

- to promote mutual aid mechanisms for assessment of and response to emergencies; 
- to consider further cooperative measures in the field of emergency prevention, preparedness and response. This would include the involvement of indigenous peoples.

The Ministers welcomed the generous offer of the United States to host the next meeting of this group in 1994.

\section{Conservation of Arctic Flora and Fauna (CAFF)}

The Ministers noted with satisfaction the progress achieved through the Conservation of Arctic Flora and Fauna (CAFF) Working Group. The CAFF Working Group has created a distinct forum for scientists, indigenous peoples and conservation managers to exchange information and data, to cooperate on the exchange of information on the research and management of Arctic flora and fauna and their habitats, and to examine and improve upon regulatory and conservation practices.

\section{The Ministers endorsed}

- the direction and thrust of the CAFF program, as reflected in the work plan adopted in its first two meetings;

- the practical approach taken by the CAFF to focus on specific issues through these work plans, as exemplified in the draft "State of Habitat Protection in the Arctic" Report;

- the CAFF program as a concrete example of cooperation to implement the conservation measures called for in the Convention on Biological Diversity;

- CAFF as a demonstration of international cooperation for conservation and sustainable use of Arctic resources using an ecosystem approach; and

- the initiatives undertaken by CAFF to link conservation and wise use of flora and fauna to other components of the AEPS, through, for example, intensified cooperation with AMAP to ensure coherence in Arctic environmental protection efforts.

The Ministers noted with pleasure the progress made by the CAFF Working Group towards improving the conservation of Arctic flora and fauna.

The Ministers considered the following specific CAFF projects:

\section{Habitat Conservation}

The Ministers were looking forward to the completion of the report on "State of Habitat Protection in the Arctic" as recommended by the CAFF Working Group. The report will include the following subjects: mapping of protected areas in the Arctic; review of management practices and regulations pertaining to these protected areas; assessment of gaps in the protected area system; and examples of habitat conservation measures outside the protected areas in the Arctic.

In addition, the Ministers requested the CAFF Working Group to prepare a plan for developing a network of Arctic protected areas that will ensure necessary protection of Arctic ecosystems, recognize the role of indigenous cultures, and provide a common process by which Arctic Countries may advance formation of circumpolar protected areas.

\section{Integrating Indigenous Knowledge}

The Ministers acknowledged the efforts of the CAFF Working Group to identify specific initiatives for developing a process of collecting and integrating indigenous ecological knowledge and better defining participation of indigenous peoples in the overall Arctic Environmental Protection Strategy. These initiatives include, inter alia, an environmental and ecological mapping project based on traditional knowledge and a directory of indigenous knowledge data bases.

The Ministers reaffirmed their commitment to the principle of sustainable utilization and conservation of Arctic resources, particularly for the benefit of indigenous peoples.

\section{Flora and Fauna Conservation}

The Ministers noted with satisfaction that the CAFF Working Group has successfully compiled circumpolar lists of rare, vulnerable and endangered species of flora and fauna, and is now turning its attention to the conservation needs of a selected number of those species. CAFF's review of existing species names and of identification criteria for species at risk, together with its decision to develop means for comparability, is encouraged by the Ministers. 
The Ministers also acknowledged the importance of CAFF's identification of the full spectrum of human-caused threats to Arctic species and their habitats and endorsed its decision to further evaluate them.

All this work will help to further define gaps in knowledge about the Arctic ecosystems, identify sensitive indicators of environmental change, focus attention on resource conservation issues of common interest and concern, and is leading to the development of appropriate conservation strategies, as exemplified by the preparation of the Circumpolar Murre Conservation Strategy. The Ministers encouraged CAFF's continuation of the ecosystem approach as a basis for promoting more effective conservation of Arctic resources.

\section{CAFF and AEPS}

The Ministers noted with pleasure the initiative of the CAFF Working Group and the AMAP Task Force to collaborate on ensuring compatibility of the two programs. The Ministers further acknowledged the decision of both the CAFF Working Group and the AMAP Task Force to collaborate to identify specific joint initiatives such as species lists for monitoring activities and compatible data bases. In due course, linkages between CAFF and the AEPS activities on the Protection of the Marine Environment and Emergency Prevention, Preparedness and Response should also be developed.

\section{CAFF Structure}

The Ministers endorsed the administrative structure adopted by CAFF establishing a chair and vice chair, and the decision to develop a scientific framework for the CAFF program. The Ministers welcomed the generous offers of Iceland to host the 1994 meeting and of Russia to host the 1995 session. The Ministers noted with pleasure CAFF's decision to establish a secretariat on an interim basis, generously funded by the Canadian Government for its first year.

\section{Indigenous Knowledge}

The Ministers reaffirmed their commitment to sustainable development, including the sustainable use of renewable resources by indigenous peoples. In consequence, the Ministers agreed that a Task Force should be established by the Senior Arctic Officials to explore and propose additional steps governments should take to this end, and welcomed the kind offer of the Canadian Government to propose the terms of reference and the work plan for the Task Force by the end of 1993 .

To enhance the participation and contribution of indigenous people in the conservation and protection of the Arctic environment, and in order to bring their knowledge to bear on these matters, the Ministers agreed to explore various sources of support for indigenous organizations accredited to the AEPS, to enable them to determine how best they should participate in the AEPS.

The Ministers accepted the generous offer by the Government of Iceland to host a seminar on indigenous knowledge, and further agreed that this meeting would be an opportune time to review the situation in this area.

\section{Consultations in International Fora}

The Ministers agreed that, when appropriate, informal consultations among the eight Arctic Countries on Arctic environmental issues should be held in connection with meetings in relevant international fora, at the initiative of the country designated to host the next Ministerial Conference or the next Senior Arctic Affairs Officials Meeting, respectively.

\section{Financial and Organizational Questions}

The Ministers underlined the importance of resources being made available and endeavouring to support projects to ensure that each country is able to participate in the activities of the Arctic Environmental Protection Strategy, including the completion of their national AMAP implementation plans and to participate in the comprehensive assessment of its results. The Ministers noted that the AMAP Audit Report recommends the allocation of additional resources for the implementation of AMAP to the extent that can ensure the fulfillment of the goals set in the AEPS and in this report. The Ministers also noted that the CAFF Report identifies the need to develop strategies for financial support of projects and look forward to its recommendations.

The Ministers requested Senior Arctic Affairs Officials to keep the question of a financing strategy on their agenda with a view to presenting, in due course, recommendations to the Ministers.

The Ministers expressed their gratitude to the Governments of Norway and Canada for providing AMAP and CAFF with initial funding for their respective secretariats and called upon participating countries to consider contributing 
resources to these secretariats. The Ministers also expressed their appreciation of the support of the coordination activities, provided by the Government of Denmark and the Home Rule Government of Greenland, in preparation of the Ministerial Conference.

\section{Participation of Observers}

The Ministers noted the interest of some non-Arctic Governments, intergovernmental organizations, and non-governmental organizations to participate in Ministerial Conferences and other meetings of the AEPS. They reaffirmed that the decision to invite observers should be based on a pragmatic and functional evaluation of their involvement in and contribution to Arctic environmental questions, and they noted a procedure, adopted by the Senior Arctic Affairs Officials, to accredit new observers.

Taking into account that it is of great importance for the success of the Arctic Environmental Protection Strategy that the ecological and environmental knowledge of circumpolar indigenous peoples is effectively incorporated into the process, the Ministers agreed to continue to promote cooperation with the Arctic indigenous peoples, including representatives of the Inuit Circumpolar Conference, the Saami Council and the Russian Association of Peoples of the North.

\section{Date and Venue of the Third Ministerial Conference}

The Ministers accepted the kind invitation of the Government of Canada to host the next Ministerial Conference in 1995 , at a date to be decided.

The Ministers also requested Senior Arctic Affairs Officials to hold regular consultative meetings, at least once a year, to monitor and review progress in the implementation of the AEPS.

Nuuk, 16 September 1993

Annex I

\section{Participation of indigenous peoples}

Statement 1) by Mr. Svend Auken, Minister for the Environment of Denmark

"The Danish Government and the Greenland Home Rule Government have noticed the recommendations of the indigenous peoples' organizations regarding a special program area within the AEPS to address all issues related to the participation of indigenous peoples.

We have also noticed the idea of establishing a Secretariat with the aim of creating and supporting such a program.

The Government of Denmark, in cooperation with the Greenland Home Rule Government, is pleased to announce that we can support this recommendation not only verbally, but also by offering to establish a small Secretariat for this purpose in Denmark.

The aim of the Secretariat would be to allow indigenous peoples' organizations to participate in the AEPS process, e.g.

- by facilitating meetings among indigenous peoples'organizations to assist them in how to best make contributions to the AEPS process,

- by facilitating timely distribution of AEPS documentation to the indigenous habitants of the Arctic,

- by facilitating on-going work on indigenous knowledge,

- by facilitating the dialogue among indigenous peoples' organizations.

The time frame for the establishment of the Secretariat will be connected with the seminar in Iceland on traditional knowledge."

1) This statement is reproduced for information purposes and is not part of the report. 


\title{
ICES Code of Practice on the Introductions and Transfers of Marine Organisms, Copenhagen, 1994
}

\author{
Done at Copenhagen September 1994 \\ Primary source citation: Copy of text provided by the \\ International Council for the Exploration of the Sea
}

\section{ICES CODE OF PRACTICE ON THE INTRODUCTIONS AND TRANSFERS OF MARINE ORGANISMS 1994}

\begin{abstract}
Preamble
Global interest in marine aquaculture (mariculture) began to increase dramatically in the 1950 s and 1960s. A natural complement to this interest was the search for fish, shellfish (molluscan and crustacean), and plant species whose biology was well known and which already had achieved or could achieve success in mass cultivation. Once identified, these species were thus potential candidates for movement to new locations in the world for the purpose of establishing new fisheries and new mariculture resources. Such animals and plants that are not native to these new locations are referred to as non-indigenous, introduced, exotic, or alien species. Organisms transported and released within their present range are referred to as transferred species.
\end{abstract}

While great successes have been achieved by these activities, leading to the creation of new and important fishery and mariculture resources, three challenges have surfaced over the past several decades relative to the global translocation of species to new regions.

The first challenge is posed by the inadvertent coincident movement of harmful organisms associated with the target (host) species. The mass transfer of large numbers of animals and plants without inspection, quarantine, or other management procedures has inevitably led to the simultaneous introduction of disease agents, causing harm to the development and growth of the new fishery resources and to native fisheries.

The second challenge lies in the ecological and environmental impacts of introduced and transferred species, especially those that may escape the confines of cultivation and become established as wild stocks. These new populations can have an impact on native species.

The third and most recent challenge to be addressed stems from the genetic impact of introduced and transferred species, relative to the mixing of farmed and wild stocks as well as to the release of genetically modified organisms.

The International Council for the Exploration of the Sea, through its Working Group on Introductions and Transfers of Marine Organisms and its cooperation with other ICES Working Groups and with the European Inland Fisheries Advisory Commission (EIFAC) of the Food and Agriculture Organization of the United Nations (FAO), has addressed these three levels of concern since 1973.

On 10 October 1973, the Council adopted the first version of what was to become an internationally recognized "Code of Practice" on the movement and translocation of non-native species for fisheries enhancement and mariculture 
purposes. The Code was set forth "to reduce the risks of adverse effects arising from introduction by non-indigenous marine species". Subsequent modifications proposed by the ICES Working Group on the Pathology and Diseases of Marine Organisms in 1978 and by the then newly reconvened ICES Working Group on the Introduction of NonIndigenous Marine Organisms in 1979, led to the publication of a "Revised Code" adopted by ICES in October 1979. The "1979 Code" became the standard for international policy and the version of the Code most widely used, cited, and translated for the next 10 years. Minor revisions and additions over the decade resulted in the adoption in October 1990 of a "1990 Revised Code."

The "1994 Code" presented here was adopted by ICES in September 1994 (ICES, 1994). It incorporates further changes and adds critical new sections relative to genetic issues. The latter include consideration, under Section IV (c), of the need to assess the genetic impacts that releases-such as of farmed salmon or other fish-could have on the natural genetic diversity of native stocks and thus on the environment in general; and a new Section $V$ on recommended procedures for the consideration of the release of genetically modified organisms.

\section{A brief outline of the ICES Code of Practice 1994}

The ICES Code of Practice sets forth recommended procedures and practices to diminish the risks of detrimental effects from the intentional introduction and transfer of marine (including brackish water) organisms. The Code is aimed at a broad audience since it applies to both public (commercial and governmental) and private (including scientific) interests. In short, any persons engaged in activities that could lead to the intentional or accidental release of exotic species should be aware of the procedures covered by the Code of Practice.

The Code is divided into five sections of recommendations relating to: (1) the steps to take prior to introducing a new species, (2) the steps to take after deciding to proceed with an introduction, (3) the prevention of unauthorized introductions by Member Countries, (4) policies for ongoing introductions or transfers which have been an established part of commercial practice, and (5) the steps to take prior to releasing genetically modified organisms. A section on "Definitions" is included with the Code.

The content of Sections I, II, and IV has been referred to above and in ICES reports (ICES, 1984, 1988, and 1994). Section III, while brief, acknowledges the need to understand the vectors, other than intentional releases, that can bring exotic species to one's shores. In recent years, for example, the release of exotic organisms via a ship's ballast water has become a pressing issue, with profound implications for fisheries resources, mariculture, and other activities. Section $V$ is the newer section noted earlier.

The Code is presented in a manner that permits broad and flexible application to a wide range of circumstances and requirements in many different countries, while at the same time adhering to a set of basic scientific principles and guidelines.

ICES Member Countries contemplating new introductions are requested to present to the Council a detailed prospectus on the rationale and plans for any new introduction; the contents of the prospectus are detailed in Section I of the Code. The Council may then request its Working Group on Introductions and Transfers of Marine Organisms to consider the prospectus and comment on it. The Working Group, in turn, may request more information before commenting on a proposal.

If an introduction or transfer proceeds, ICES requests Member Countries to keep the Council informed about it, both through providing details of the brood stock established and the fate of the progeny, and through submitting progress reports after a species is released into the wild. The specifics of this stage are detailed in Section II of the Code.

ICES has published two extended guides to the Code, one in 1984 as Cooperative Research Report (CRR) No. 130, entitled "Guidelines for Implementing the ICES Code of Practice Concerning Introductions and Transfers of Marine Species", and one in 1988 as Cooperative Research Report No. 159, entitled "Codes of Practice and Manual of Procedures for Consideration of Introductions and Transfers of Marine and Freshwater Organisms". These reports are available in many libraries and from the ICES Secretariat. The Working Group on Introductions and Transfers of Marine Organisms is in the process (1995) of revising these documents, and inquiry regarding the date when the new ICES Cooperative Research Report will be available should be addressed to ICES. 
ICES views the Code of Practice as a guide to recommendations and procedures. As with all Codes, the current one has evolved with experience and with changing technological developments. The latest (1994) version of the Code reflects the past 20 years of experience with its use and application and with the evolution of new fisheries and genetic technologies. While initially designed for the ICES Member Countries concerned with the North Atlantic and adjacent seas, the Code soon found use as far away as the Pacific islands.

We are pleased to present the ICES Code of Practice in this fashion for wide consideration, and we welcome advice and comments from both Member Countries and our colleagues throughout the world. Recommendations and suggestions should be directed to the General Secretary of ICES in Copenhagen, Denmark.

James T. Carlton

Chairman, ICES Working Group on Introductions and Transfers of Marine Organisms

Katherine Richardson

Chairman, ICES Advisory Committee on the Marine Environment

\section{ICES Code of Practice on the Introductions and Transfers of Marine Organisms 1994}

The introduction and transfer of marine organisms, including genetically modified organisms, carry the risk of introducing not only pests and disease agents but also many other species. Both intentional and unintentional introductions may have undesirable ecological and genetic effects in the receiving ecosystem, as well as potential economic impacts. This Code of Practice provides recommendations for dealing with new intentional introductions, and also recommends procedures for species which are part of existing commercial practice, in order to reduce the risks of adverse effects that could arise from such movements.

I Recommended procedure for all species prior to reaching a decision regarding new introductions. (A recommended procedure for introduced or transferred species which are part of current commercial practice is given in Section IV; a recommended procedure for the consideration of the release of genetically modified organisms is given in Section V.)

(a) Member Countries contemplating any new introduction should be requested to present to the Council at an early stage a detailed prospectus on the proposed new introduction(s) for evaluation and comment.

(b) The prospectus should include the purpose and objectives of the introduction, the stage(s) in the life cycle proposed for introduction, the area of origin and the target area(s) of release, and a review of the biology and ecology of the species as these pertain to the introduction (such as the physical, chemical, and biological requirements for reproduction and growth, and natural and human-mediated dispersal mechanisms).

(c) The prospectus should also include a detailed analysis of the potential impacts on the aquatic ecosystem of the proposed introduction. This analysis should include a thorough review of:

(i) the ecological, genetic, and disease impacts and relationships of the proposed introduction in its natural range and environment;

(ii) the potential ecological, genetic, and disease impacts and relationships of the proposed introduction in the proposed release site and environment. These aspects should include but not necessarily be limited to:

- potential habitat breadth,

- prey (including the potential for altered diets and feeding strategies),

- predators,

- competitors, 
- hybridization potential and changes in any other genetic attributes, and

- the role played by disease agents and associated organisms and epibiota.

Potential predation upon, competition with, disturbance of, and genetic impacts upon, native and previously introduced species should receive the utmost attention. The potential for the proposed introduction and associated disease agents and other organisms to spread beyond the release site and interact with species in other regions should be addressed. The effects of any previous intentional or accidental introductions of the same or similar species in other regions should be carefully evaluated.

(d) The prospectus should conclude with an overall assessment of the issues, problems, and benefits associated with the proposed introduction. Quantitative risk assessments, as far as reasonably practicable, could be included.

(e) The Council should then consider the possible outcome of the proposed introduction, and offer advice on the acceptability of the choice.

II If the decision is taken to proceed with the introduction, the following action is recommended:

(a) A brood stock should be established in a quarantine situation approved by the country of receipt, in sufficient time to allow adequate evaluation of the stock's health status.

The first generation progeny of the introduced species can be transplanted to the natural environment if no disease agents or parasites become evident in the first generation progeny, but not the original import. In the case of fish, brood stock should be developed from stocks imported as eggs or juveniles, to allow sufficient time for observation in quarantine.

(b) The first generation progeny should be placed on a limited scale into open waters to assess ecological interactions with native species.

(c) All effluents from hatcheries or establishments used for quarantine purposes in recipient countries should be sterilized in an approved manner (which should include the killing of all living organisms present in the effluents).

(d) A continuing study should be made of the introduced species in its new environment, and progress reports submitted to the International Council for the Exploration of the Sea.

III Regulatory agencies of all Member Countries are encouraged to use the strongest possible measures to prevent unauthorized or unapproved introductions.

IV Recommended procedure for introduced or transferred species which are part of current commercial practice.

(a) Periodic inspection (including microscopic examination) of material prior to exportation to confirm freedom from introducible pests and disease agents. If inspection reveals any undesirable development, importation must be immediately discontinued. Findings and remedial actions should be reported to the International Council for the Exploration of the Sea.

and/or

(b) Quarantining, inspection, and control, whenever possible and where appropriate.

(c) Consider and/or monitor the genetic impact that introductions or transfers have on indigenous species, in order to reduce or prevent detrimental changes to genetic diversity.

It is appreciated that countries will have different requirements toward the selection of the place of inspection and control of the consignment, either in the country of origin or in the country of receipt. 
V Recommended procedure for the consideration of the release of genetically modified organisms (GMOs).

(a) Recognizing that little information exists on the genetic, ecological, and other effects of the release of genetically modified organisms into the natural environment (where such releases may result in the mixing of altered and wild populations of the same species, and in changes to the environment), the Council urges Member Countries to establish strong legal measures* to regulate such releases, including the mandatory licensing of physical or juridical persons engaged in genetically modifying, or in importing, using, or releasing any genetically modified organism.

(b) Member Countries contemplating any release of genetically modified organisms into open marine and fresh water environments are requested at an early stage to notify the Council before such releases are made. This notification should include a risk assessment of the effects of this release on the environment and on natural populations.

(c) It is recommended that, whenever feasible, initial releases of GMOs be reproductively sterile in order to minimize impacts on the genetic structure of natural populations.

(d) Research should be undertaken to evaluate the ecological effects of the release of GMOs.

\section{DEFINTTIONS}

For the application of this Code, the following definitions should be used.

\section{Brood stock}

Specimens of a species, either as eggs, juveniles, or adults, from which a first or subsequent generation may be produced for possible introduction to the environment.

\section{Country of origin}

The country where the species is native.

\section{Current commercial practice}

Established and ongoing cultivation, rearing, or placement of an introduced or transferred species in the environment for economic or recreational purposes, which has been ongoing for a number of years.

\section{Disease agent}

For the purpose of the Code, "disease agent" is understood to mean all organisms, including parasites, that cause disease. (A list of prescribed disease agents, parasites, and other harmful agents is made for each introduced or transferred species in order that adequate methods for inspection are available. The discovery of other agents, etc., during such inspection should always be recorded and reported.)

\section{Genetic diversity}

All of the genetic variation in an individual, population, or species (ICES, 1988).

\section{Genetically modified organism (GMO)}

An organism in which the genetic material has been altered anthropogenically.**

\section{Introduced species}

\section{( = non-indigenous species, = exotic species)}

- Such as the European Economic Community "Council Directive of 23 April 1990 on the Deliberate Release into the Environment of Genetically Modified Organisms (90/220/EEC)", Official Journal of European Communities, No. L; 117: 15-27 (1990).

** Such technologies include the isolation, characterization, and modification of genes and their introduction into living cells as well as techniques for the production of living cells with new combinations of genetic material by the fusion of two or more cells. 
Any species intentionally or accidentally transported and released by humans into an environment outside its present range.

\section{Marine species}

Any aquatic species that does not spend its entire life cycle in fresh water.

\section{Quarantined species}

Any species held in a confined or enclosed system that is designed to prevent any possibility of the release of the species, or any of its disease agents or any other associated organisms into the environment.

\section{Transferred species \\ (= transplanted species)}

Any species intentionally or accidentally transported and released within its present range.

\section{NOTES}

(a) It is understood that an introduced species is what is also referred to as an introduction, and a transferred species as a transfer.

(b) Introduced species are understood to include exotic species, while transferred species include exotic individuals or populations of a species.

(c) It is understood for the purpose of the Code that introduced and transferred species may have the same potential to carry and transmit disease or any other associated organisms into a new locality where the disease or associated organism does not at present occur.

\section{REFERENCES}

ICES. 1984. Guidelines for Implementing the ICES Code of Practice Concerning Introductions and Transfers of Marine Species. Cooperative Research Report No. 130.20 pp.

ICES. 1988. Codes of Practice and Manual of Procedures for Consideration of Introductions and Transfers of Marine and Freshwater Organisms. Cooperative Research Report No. 159. 44 pp.

ICES. 1994. Report of the ICES Advisory Committee on the Marine Environment, 1994, Annex 3. ICES Cooperative Research Report No. 204. 122 pp. 


\title{
The Seville Strategy and the Statutory Framework of the World Network of Biosphere Reserves, Paris, 1995
}

\author{
Done at Paris November 1995 \\ Primary source citation: Copy of text provided by \\ UNESCO
}

\section{BIOSPHERE RESERVES \\ THE SEVILLE STRATEGY and \\ THE STATUTORY FRAMEWORK OF THE WORLD NETWORK}

\author{
Man and the Biosphere Programme
}

\section{CONTENTS}

28 C/Resolution 2.4 of the UNESCO General Conference . . . . . . . . . . . . . . . . .

The Seville Strategy for Biosphere Reserves $\ldots \ldots \ldots \ldots \ldots \ldots \ldots \ldots \ldots \ldots$

Biosphere Reserves: the first twenty years

The Biosphere Reserve Concept

The Vision from Seville for the 21st century

Goals

Implementation indicators

Statutory Framework of the World Network of Biosphere Reserves . . . . . . . . . . . .

Biosphere reserves are designed to deal with one of the most important questions the world faces today: How can we reconcile the conservation of biodiversity, the quest for economic and social development and the maintenance of associated cultural values? Biosphere reserves are areas of terrestrial and coastal/marine ecosystems which are internationally recognised under UNESCO's Man and the Biosphere (MAB) Programme. In March 1995, an interna. tional conference of experts was organised by UNESCO in Seville (Spain). The Seville Strategy that was elaborated there recommends the action to be taken for the future development of biosphere reserves in the 21st century. The Seville Conference also helped to finalise a Statutory Framework setting out the conditions for the functioning of the World Network of Biosphere Reserves. Both these documents were adopted as $28 \mathrm{C} /$ Resolution 2.4 of the UNESCO General Conference in November 1995 which is presented in this document. One of the highlights of these documents is the new 
role that biosphere reserves can play in serving to implement the results of the United Nations Conference on Environment and Development (Rio 1995) and notably the Convention on Biological Diversity.

\section{C/Resolution 2.4 of the UNESCO General Conference (November 1995)}

\section{The General Conference,}

Emphasizing that the Seville Conference has confirmed the special importance of the biosphere reserves established within the framework of the programme on Man and the Biosphere (MAB) for the conservation of biological diversity, in harmony with the safeguarding of the cultural values associated with them,

Considering that biosphere reserves constitute ideal sites for research, long-term monitoring, training, education and the promotion of public awareness while enabling local communities to become fully involved in the conservation and sustainable use of resources,

Considering that they are also demonstration sites and hubs of action in the context of regional development and land-use planning,

Considering that the World Network of Biosphere Reserves thus makes a major contribution to the implementation of the goals set by Agenda 21 and by the international conventions adopted at and after the Rio Conference, in particular the Convention on Biological Diversity,

Believing that it is necessary to expand and improve the present Network and to encourage regional and world-level exchanges, in particular by providing support for the efforts of the developing countries to establish, strengthen and promote biosphere reserves,

1. Approves the Seville Strategy2 and invites the Director-General to deploy the resources necessary for its effective implementation and to ensure that it enjoys the widest possible dissemination to all parties concerned;

2. Invites Member States to implement the Seville Strategy and to muster the resources necessary for that purpose;

3. Invites international and regional intergovernmental organizations and the appropriate nongovernmental organizations to co-operate with UNESCO to ensure the operational development of the World Network of Biosphere Reserves and appeals to the funding bodies to mobilize the corresponding resources;

4. Adopts the Statutory Framework of the World Network of Biosphere Reserves, annexed hereto, and invites:

(a) Member States to have regard to it in determining and implementing their policies in respect of biosphere reserves;

(b) the Director-General to provide the secretariat of the World Network of Biosphere Reserves in accordance with the provisions of the Statutory Framework and thus contribute to the smooth functioning and strengthening of the Network.

\section{BIOSPHERE RESERVES: THE FIRST TWENTY YEARS}

Biosphere reserves are designed to deal with one of the most important questions the World faces today: how can we reconcile conservation of biodiversity and biological resources with their sustainable use? An effective Biosphere reserve involves natural and social scientists; conservation and development groups; management authorities and local communities-all working together on this complex issue.

The concept of biosphere reserves was originated by a Task Force of UNESCO's Man and the Biosphere (MAB) Programme in 1974. The biosphere reserve network was launched in 1976, and, as of March 1995, had grown to include 324 reserves in 82 countries. The network is a key component in MAB's objective of achieving a sustainable 
balance between the sometimes-conflicting goals of conserving biological diversity, promoting economic development, and maintaining associated cultural values. Biosphere reserves are sites where this objective is tested, refined, demonstrated and implemented.

In 1983, UNESCO and UNEP jointly convened the First International Biosphere Reserve Congress in Minsk (Belarus), in cooperation with FAO and IUCN. The Congress's activities gave rise in 1984 to an "Action Plan for Biosphere Reserves," which was formally endorsed by the UNESCO General Conference and by the Governing Council of UNEP. While much of this Action Plan remains valid today, the context in which biosphere reserves operate has changed considerably as was shown by the UNCED process and, in particular, the Convention on Biological Diversity. The Convention was signed at the "Earth Summit" in Rio de Janeiro in June 1992, entered into force in December 1993 and has now been ratified by more than 100 countries. The major objectives of the Convention are: conservation of biological diversity; sustainable use of its components; and fair and equitable sharing of benefits arising from the utilization of genetic resources. Biosphere reserves promote this integrated approach and are thus well placed to contribute to the implementation of the Convention.

In the decade since the Minsk Congress, thinking about protected areas as a whole and about the biosphere reserves has been developing along parallel lines. Most importantly, the link between conservation of biodiversity and the development needs of local communities - a central component of the biosphere reserve approach-is now recognized as a key feature of the successful management of most national parks, nature reserves and other protected areas. At the Fourth World Congress on National Parks and Protected Areas, held in Caracas, Venezuela, in February 1992, the world's protected-area planners and managers adopted many of the ideas (community involvement, the links between conservation and development, the importance of international collaboration) that are essential aspects of biosphere reserves. The Congress also approved a resolution in support of biosphere reserves.

There have also been important innovations in the management of biosphere reserves themselves. New methodologies for involving stakeholders in decision-making processes and resolving conflicts have been developed, and increased attention has been given to the need to use regional approaches. New kinds of biosphere reserves, such as cluster and transboundary reserves, have been devised, and many biosphere reserves have evolved considerably, from a primary focus on conservation to a greater integration of conservation and development through increasing cooperation among stakeholders. And new international networks, fueled by technological advances, including more powerful computers and the Internet, have greatly facilitated communication and cooperation between biosphere reserves in different countries.

In this context, the Executive Board of UNESCO decided in 1991 to establish an Advisory Committee for Biosphere Reserves. This Advisory Committee considered that it was time to evaluate the effectiveness of the 1984 Action Plan, to analyze its implementation, and to develop a strategy for biosphere reserves as we move into the 21st Century.

To this end, and in accordance with Resolution 27/C/2.3 of the General Conference, UNESCO organised the International Conference on Biosphere Reserves at the invitation of the Spanish authorities in Seville (Spain) from 20 to 25 March 1995. This Conference was attended by some 400 experts from 102 countries and 15 international and regional organisations. The Conference was organised to enable an evaluation of the experience in implementing the 1984 Action Plan, a reflection on the role for biosphere reserves in the context of the 21st century (which gave rise to the vision statement) and the elaboration of a draft Statutory Framework for the World Network. The Conference drew up the Seville Strategy which is presented below. The International Co-ordinating Council of the Man and the Biosphere (MAB) Programme, meeting for its 13th session (12-16 June 1995) gave its strong support to the Seville Strategy.

\section{THE BIOSPHERE RESERVE CONCEPT}

Biosphere reserves are "areas of terrestrial and coastal/marine ecosystems or a combination thereof, which are internationally recognized within the framework of UNESCO's Programme on Man and the Biosphere (MAB) (Statutory Framework of the World Network of Biosphere Reserves). Reserves are nominated by national governments; each reserve must meet a minimal set of criteria and adhere to a minimal set of conditions before being admitted to the Network. Each biosphere reserve is intended to fulfill three complementary functions: a conservation function, to preserve genetic resources, species, ecosystems and landscapes; a development function, to foster sustainable economic and human development, and a logistic support function, to support demonstration projects, environ- 
mental education and training, and research and monitoring related to local, national and global issues of conservation and sustainable development.

Physically, each biosphere reserve should contain three elements: one or more core areas, which are securely protected sites for conserving biological diversity, monitoring minimally disturbed ecosystems, and undertaking non-destructive research and other low-impact uses (such as education); a clearly identified buffer zone, which usually surrounds or adjoins the core areas, and is used for cooperative activities compatible with sound ecological practices, including environmental education, recreation, ecotourism and applied and basic research; and a flexible transition area, or area of cooperation, which may contain a variety of agricultural activities, settlements and other uses and in which local communities, management agencies, scientists, non-governmental organizations, cultural groups, economic interests and other stakeholders work together to manage and sustainably develop the area's resources. Although originally envisioned as a series of concentric rings, the three zones have been implemented in many different ways in order to meet local needs and conditions. In fact, one of the greatest strengths of the biosphere reserve concept has been the flexibility and creativity with which it has been realized, in various situations.

Some countries have enacted legislation specifically to establish biosphere reserves. In many others, the core areas and buffer zones are designated (in whole or in part) as protected areas under national law. A large number of biosphere reserves simultaneously belong to other national systems of protected areas (such as national parks or nature reserves) and/or other international networks (such as World Heritage or Ramsar sites).

Ownership arrangements may vary, too. The core areas of biosphere reserves are mostly public land but can be also privately owned or belong to non-governmental organizations. In many cases, the buffer zone is in private or community ownership, and this is generally the case for the transition area. The Seville Strategy for Biosphere Reserves reflects this wide range of circumstances.

\section{THE VISION FROM SEVILLE FOR THE 21ST CENTURY}

What future does the world face as we move towards the 21 st century? Current trends in population growth and distribution, increasing demands for energy and natural resources, globalisation of the economy and the effects of trade patterns on rural areas, the erosion of cultural distinctiveness, centralization and difficulty of access to relevant information, and uneven spread of technological innovations-all these paint a sobering picture of environment and development prospects in the near future.

The UNCED process laid out the alternative of working towards sustainable development, incorporating care of the environment and greater social equity, including respect for rural communities and their accumulated wisdom. Agenda 21, the Conventions on Biological Diversity, Climate Change, and Desertification, and other multi-lateral agreements, show the way forward at the international level.

But the global community also needs working examples that encapsulate the ideas of UNCED for promoting both conservation and sustainable development. These examples can only work if they express all the social, cultural, spiritual and economic needs of society, and are also based on sound science.

Biosphere reserves offer such models. Rather than forming islands in world increasingly affected by severe human impacts, they can become theatres for reconciling people and nature, they can bring knowledge of the past to the needs of the future, they can demonstrate how to overcome the problems of the sectoral nature of our institutions. In short, biosphere reserves are much more than just protected areas.

Thus biosphere reserves are poised to take on a new role. Not only will they be a means for the people who live and work within and around them to attain a balanced relationship with the natural world, they will also contribute to the needs of society as a whole by showing a way to a more sustainable future. This is at the heart of our vision for biosphere reserves in the 21st century.

The International Conference on Biosphere Reserve, organised by UNESCO in Seville (Spain) on 20-25 March 1995, adopted a two-pronged approach:

- to examine past experience in implementing the innovative concept of the biosphere reserve; 
- to look to the future to identify what emphasis should now be given to their three functions of conservation, development and logistical support.

The Seville Conference concluded that, in spite of the problems and limitations encountered with the establishment of biosphere reserves, the programme as a whole had been innovative and had had many successes. In particular, the three basic functions would be as valid as ever in the coming years. In the implementation of these functions and in the light of the analysis undertaken, the following ten key directions were identified by the Conference and which are the foundations of the new Seville Strategy.

1. Strengthen the contribution which biosphere reserves make to the implementation of international agreements promoting conservation and sustainable development, especially to the Convention on Biological Diversity and other agreements such as those on climate change, desertification and forests.

2. Develop biosphere reserves that include a wide variety of environmental, biological, economic and cultural situations, going from largely undisturbed regions and spreading towards cities. There is a particular potential, and need, to apply the biosphere reserve concept in the coastal and marine environment.

3. Strengthen the emerging regional, inter-regional and thematic networks of biosphere reserves as components within the World Network of Biosphere Reserves.

4. Reinforce scientific research, monitoring, training and education in biosphere reserves since conservation and rational use of resources in these areas require a sound base in the natural and social sciences as well as the humanities. This need is particularly acute in countries where biosphere reserves lack human and financial resources and should receive priority attention.

5. Ensure that all zones of biosphere reserves contribute appropriately to conservation, sustainable development and scientific understanding.

6. Extend the transition area to embrace large areas suitable for approaches such as ecosystem management, and use biosphere reserves to explore and demonstrate approaches to sustainable development at the regional scale, For this, more attention should be given to the transition area.

7. Reflect more fully the human dimensions of biosphere reserves. Connections should be made between cultural and biological diversity. Traditional knowledge and genetic resources should be conserved and their role in sustainable development should be recognized and encouraged.

8. Promote the management of each biosphere reserve essentially as a "pact" between the local community and society as a whole. Management should be open, evolving and adaptive. Such an approach will help ensure that biosphere reserves - and their local communities-are better placed to respond to external political, economic and social pressures.

9. Bring together all interest groups and sectors in a partnership approach to biosphere reserves both at site and network levels. Information should flow freely among all concerned.

10. Invest in the future. Biosphere reserves should be used to further our understanding of humanity's relationship with the natural world, through programmes of public awareness, information and formal and informal education, based on a long-term, inter-generational perspective.

In sum, biosphere reserves should preserve and generate natural and cultural values through management that is scientifically correct, culturally creative and operationally sustainable. The World Network of Biosphere Reserves, as implemented through the Seville Strategy, is thus an integrating tool which can help to create greater solidarity among peoples and nations of the world.

\section{THE STRATEGY}

The following Strategy provides recommendations for developing effective biosphere reserves and for setting out the conditions for the appropriate functioning of the World Network of Biosphere Reserves. It does not repeat the 
general principles of the Convention on Biological Diversity nor Agenda 21, but instead identifies the specific role of biosphere reserves in developing a new vision of the relationship between conservation and development. Thus, the document is deliberately focused on a few priorities.

The Strategy suggests the level (international, national, individual biosphere reserve) at which each recommendation will be most effective. However, given the large variety of different national and local management situations, these recommended levels of actions should be seen merely as guidelines, and adapted to fit the situation at hand. Especially note that the "national" level should be interpreted to include other governmental levels higher than the individual reserve (e.g., provincial, state, county, etc.). In some countries, national or local NGOs may also be appropriate substitutes for this level. Similarly, the "international" level often includes regional and inter-regional activities.

The Strategy also includes recommended Implementation Indicators, i.e. a check-list of actions that will enable all involved to follow and evaluate the implementation of the Strategy. Criteria used in developing the Indicators were: availability (can the information be gathered relatively easily), simplicity (are the data unambiguous), and usefulness (will the information be useful to reserve managers, National Committees, and/or the network at large). One role of the Implementation Indicators is to assemble a database of successful implementation mechanisms and to exchange this information among all members of the network.

\section{GOAL I: USE BIOSPHERE RESERVES TO CONSERVE NATURAL AND CULTURAL DIVERSITY}

Objective I.1: Improve the coverage of natural and cultural biodiversity by means of the World Network of Biosphere Reserves.

\section{Recommended at the international level:}

1. Promote biosphere reserves as means of implementing the goals of the Convention on Biological Diversity.

2. Promote a comprehensive approach to biogeographical classification that takes into account such ideas as vulnerability analysis, in order to develop a system encompassing socio-ecological factors.

\section{Recommended at the national level:}

3. Prepare a biogeographical analysis of the country as a basis, inter alia, for assessing coverage of the World Biosphere Reserve Network.

4. In light of the analysis, and taking into account existing protected areas, establish, strengthen or extend biosphere reserves as necessary, giving special attention to fragmented habitats, threatened ecosystems, and fragile and vulnerable environments, both natural and cultural.

Objective 1.2: Integrate biosphere reserves into conservation planning.

Recommended at the international level:

1. Encourage the establishment of transboundary biosphere reserves as a means of dealing with the conservation of organisms, ecosystems, and genetic resources that cross national boundaries.

\section{Recommended at the national level:}

2. Integrate biosphere reserves in strategies for biodiversity conservation and sustainable use, in plans for protected areas, and in the national biodiversity strategies and action plans provided for in Article 6 of the Convention on Biological Diversity.

3. When applicable, include projects to strengthen and develop biosphere reserves in programmes to be initiated and funded under the Convention on Biological Diversity and other multilateral conventions.

4. Link biosphere reserves with each other, and with other protected areas, through green corridors and in other ways that enhance biodiversity conservation, and ensure that these links are maintained. 
5. Use biosphere reserves for in situ conservation of genetic resources, including wild relatives of cultivated and domesticated species, and consider using the reserves as rehabilitation/re-introduction sites, and link them as appropriate with ex situ conservation and use programmes.

\section{GOAL II: UTILIZE BIOSPHERE RESERVES AS MODELS OF LAND MANAGEMENT AND OF APPROACHES TO SUSTAINABLE DEVELOPMENT}

Objective II.1: Secure the support and involvement of local people.

\section{Recommended at the international level:}

1. Prepare guidelines for key aspects of biosphere reserve management, including the resolution of conflicts, provision of local benefits, and involvement of stakeholders in decision-making and in responsibility for management.

Recommended at the national level:

2. Incorporate biosphere reserves into plans for implementing the sustainable use goals of Agenda 21 and the Convention on Biological Diversity.

3. Establish, strengthen or extend biosphere reserves to include areas where traditional life styles and indigenous uses of biodiversity are practiced (including sacred sites), and/or where there are critical interactions between people and their environment (e.g., peri-urban areas, degraded rural areas, coastal areas, freshwater environments and wetlands).

4. Identify and promote the establishment of activities compatible with the goals of conservation through the transfer of appropriate technologies which include traditional knowledge and which promote sustainable development in the buffer and transition zones.

Recommended at the individual reserve level:

5. Survey the interests of the various stakeholders and fully involve them in planning and decision-making regarding the management and use of the reserve.

6. Identify and address factors that lead to environmental degradation and unsustainable use of biological resources.

7. Evaluate the natural products and services of the reserve and use these evaluations to promote environmentally sound and economically sustainable income opportunities for local people.

8. Develop incentives for the conservation and sustainable use of natural resources, and develop alternative means of livelihood for local populations when existing activities are limited or prohibited within the biosphere reserve.

9. Ensure that the benefits derived from the use of natural resources are equitably shared with the stakeholders, by such means as sharing the entrance fees, sale of natural products or handicrafts, use of local construction techniques and labour, and development of sustainable activities (e.g., agriculture, forestry, etc.).

Objective II.2: Ensure better harmonization and interaction among the different biosphere reserve zones.

\section{Recommended at the national level:}

1. Ensure that each biosphere reserve has an effective management policy or plan and an appropriate authority or mechanism to implement it.

2. Develop means of identifying incompatibilities between the conservation and sustainable use functions of biosphere reserves and take measures to ensure that an appropriate balance between the functions is maintained. 


\section{Recommended at the individual reserve level:}

3. Develop and establish institutional mechanisms to manage, coordinate and integrate the biosphere reserve's programmes and activities.

4. Establish a local consultative framework in which the reserve's economic and social stakeholders are represented, including the full range of interests (e.g., agriculture, forestry, hunting and extracting, water and energy supply, fisheries, tourism, recreation, research).

Objective II.3: Integrate biosphere reserves into regional planning.

Recommended at the national level:

1. Include biosphere reserves in regional development policies and in regional land-use planning projects.

2. Encourage the major land-use sectors near each biosphere reserve to adopt practices favouring sustainable land use.

\section{Recommended at the individual reserve level:}

3. Organise forums and set up demonstration sites for the examination of socio-economic and environmental problems of the region and for the sustainable utilization of biological resources important to the region.

\section{GOAL III: USE BIOSPHERE RESERVES FOR RESEARCH, MONITORING, EDUCATION, AND TRAINING}

Objective III.1: Improve knowledge of the interactions between humans and the biosphere.

\section{Recommended at the international level:}

1. Use the World Biosphere Reserve Network to conduct comparative environmental and socio-economic research, including long-term research that will require decades to complete.

2. Use the World Biosphere Reserve Network for international research programmes that deal with topics such as biological diversity, desertification, water cycles, ethnobiology, and global change.

3. Use the World Biosphere Reserve Network for cooperative research programs at the regional and inter-regional levels, such as those existing for the Southern Hemisphere, East Asia and Latin America.

4. Encourage the development of innovative, interdisciplinary research tools for biosphere reserves, including flexible modelling systems for integrating social, economic and ecological data.

5. Develop a clearing house for research tools and methodologies in biosphere reserves.

6. Encourage interactions between the World Biosphere Reserve Network and other research and education networks, and facilitate the use of the biosphere reserves for collaborative research projects of consortia of universities and other institutions of higher learning and research, in the private as well as public sector, and at non-governmental as well as governmental levels.

Recommended at the national level:

7. Integrate biosphere reserves with national and regional scientific research programmes, and link these research activities to national and regional policies on conservation and sustainable development.

Recommended at the individual reserve level:

8. Use biosphere reserves for basic and applied research, particularly projects with a focus on local issues, interdisciplinary projects incorporating both the natural and the social sciences, and projects involving the 
rehabilitation of degraded ecosystems, the conservation of soils and water and the sustainable use of natural resources.

9. Develop a functional system of data management for rational use of research and monitoring results in the management of the biosphere reserve.

Objective III.2: Improve monitoring activities.

Recommended at the international level:

1. Use the World Biosphere Reserve Network, at the international, regional, national and local levels, as priority long-term monitoring sites for international programs focused on topics such as terrestrial and marine observing systems, global change, biodiversity, and forest health.

2. Encourage the adoption of standardized protocols for meta-data concerning the description of flora and fauna, to facilitate the interchange, accessibility and utilization of scientific information generated in biosphere reserves.

\section{Recommended at the national level:}

3. Encourage the participation of biosphere reserves in national programmes of ecological and environmental monitoring and development of linkages between biosphere reserves and other monitoring sites and networks.

\section{Recommended at the individual reserve level:}

4. Use the reserve for making inventories of fauna and flora, collecting ecological and socio-economic data, making meteorological and hydrological observations, studying the effects of pollution, etc., for scientific purposes and as the basis for sound site management.

5. Use the reserve as an experimental area for the development and testing of methods and approaches for the evaluation and monitoring of biodiversity, sustainability and quality of life of its inhabitants.

6. Use the reserve for developing indicators of sustainability (in ecological, economic, social and institutional terms) for the different productive activities carried out within the buffer zones and transition areas.

7. Develop a functional system of data management for rational use of research and monitoring results in the management of the biosphere reserve.

Objective III.3: Improve education, public awareness, and involvement.

Recommended at the international level:

1. Facilitate exchange of experience and information between biosphere reserves, with a view to strengthening the involvement of volunteers and local people in biosphere reserve activities.

2. Promote the development of communication systems for diffusing information on biosphere reserves and on experiences at the field level.

\section{Recommended at the national level:}

3. Include information on conservation and sustainable use, as practiced in biosphere reserves, in school programmes and teaching manuals, and in media efforts.

4. Encourage participation of biosphere reserves in international networks and programmes, to promote crosscutting linkages in education and public awareness. 
Recommended at the individual reserve level:

5. Encourage involvement of local communities, school children and other stakeholders in education and training programs and in research and monitoring activities within biosphere reserves.

6. Produce visitors' information about the reserve, its importance for conservation and sustainable use of biodiversity, its socio-cultural aspects, and its recreational and educational programs and resources.

7. Promote the development of ecology field educational centers within individual reserves, as facilities for contributing to the education of schoolchildren and other groups.

Objective III.4: Improve training for specialists and managers.

\section{Recommended at the international level:}

1. Utilize the World Biosphere Reserve Network to support and encourage international training opportunities and programmes.

2. Identify representative biosphere reserves to serve as regional training centers.

\section{Recommended at the national level:}

3. Define the training needed by biosphere reserve managers in the 21st century and develop model training programmes on such topics as how to design and implement inventory and monitoring programmes in biosphere reserves, how to analyze and study socio-cultural conditions, how to solve conflicts, and how to manage resources cooperatively in an ecosystem or landscape context.

Recommended at the individual reserve level:

4. Use the reserve for on-site training and for national, regional and local seminars.

5. Encourage appropriate training and employment of local people and other stakeholders to allow their full participation in inventory, monitoring and research in programmes in biosphere reserves.

6. Encourage training programmes for local communities and other local agents (such as decision makers, local leaders and agents working in production, technology transfer, and community development programmes) in order to allow their full participation in the planning, management and monitoring processes of biosphere reserves.

\section{GOAL IV: IMPLEMENT THE BIOSPHERE RESERVE CONCEPT}

Objective IV.1: Integrate the functions of biosphere reserves.

\section{Recommended at the international level:}

1. Identify and publicize demonstration (model or illustrative examples of) biosphere reserves, whose experiences will be beneficial to others, at the national, regional and international levels.

2. Give guidance/advice on the elaboration and periodic review of strategies and national action plans for biosphere reserves.

3. Organize forums and other information exchange mechanisms for biosphere reserve managers.

4. Prepare and disseminate information on how to develop management plans or policies for biosphere reserves.

5. Prepare guidance on management issues at biosphere reserve sites, including, inter alia, methods to ensure local participation, case studies of various management options, and techniques of conflict resolution. 
Recommended at the national level:

6. Ensure that each biosphere reserve has an effective management policy or plan and an appropriate authority or mechanism to implement it.

7. Encourage private-sector initiatives to establish and maintain environmentally and socially sustainable activities in appropriate zones of biosphere reserves and in surrounding areas, in order to stimulate community development.

8. Develop and periodically review strategies and national action plans for biosphere reserves; these strategies should strive for complementarity and added value of biosphere reserves with respect to other national instruments for conservation.

9. Organize forums and other information exchange mechanisms for biosphere reserve managers.

Recommended at the individual reserve level:

10. Identify and map the different zones of biosphere reserves and define their respective status.

11. Prepare, implement and monitor an overall management plan or policy that includes all of the zones of biosphere reserves.

12. Where necessary, in order to preserve the core area, re-plan the buffer and transition zones according to sustainable development criteria.

13. Define and establish institutional mechanisms to manage, coordinate and integrate the reserve's programmes and activities.

14. Ensure that the local community participate in planning and management of biosphere reserves.

15. Encourage private sector initiatives to establish and maintain environmentally and socially sustainable activities in the reserve and surrounding areas.

Objective IV.2: Strengthen the World Biosphere Reserve Network

\section{Recommended at the international level:}

1. Facilitate provision of adequate resources for implementation of the Statutory Framework of the World Network of Biosphere Reserves.

2. Facilitate the periodic review by each country of its biosphere reserves, as required in the Statutory Framework of the World Network of Biosphere Reserves, and assist countries in taking measures to make their biosphere reserves functional.

3. Support the functioning of the Advisory Committee for Biosphere Reserves and fully consider and utilize its recommendations and guidance.

4. Lead the development of communication among biosphere reserves, taking into account their communication and technical capabilities, and strengthen existing and planned regional or thematic networks.

5. Develop creative connections and partnerships with other networks of similar managed areas, and with international governmental and non-governmental organizations with goals congruent with those of biosphere reserves.

6. Promote and facilitate twinning between biosphere reserve sites and foster transboundary reserves.

7. Give biosphere reserves more visibility by disseminating information materials, developing communication policies, and highlighting their roles as members of the World Biosphere Reserve Network. 
8. Wherever possible, advocate the inclusion of biosphere reserves in projects financed by bilateral and multilateral aid organizations.

9. Mobilize private funds, from businesses, NGOs and foundations, for the benefit of biosphere reserves.

10. Develop standards and methodologies for collecting and exchanging various types of data, and assist their application across the network of biosphere reserves.

11. Monitor, assess and follow up on the implementation of the Seville Strategy, utilizing the Implementation Indicators, and analyze the factors that aid in attainment of the indicators, as well as those that hinder such attainment.

\section{Recommended at the national level:}

12. Facilitate provision of adequate resources for implementation of the Statutory Framework of the World Network of Biosphere Reserves.

13. Develop a national-level mechanism to advise and coordinate the biosphere reserves; and fully consider and utilize its recommendations and guidance.

14. Prepare an evaluation of the status and operations of each of the country's biosphere reserves, as required in the Statutory Framework, and provide appropriate resources to address any deficiencies.

15. Develop creative connections and partnerships with other networks of similar managed areas and with international governmental and non-governmental organizations with goals congruent with those of the biosphere reserves.

16. Seek opportunities for twinning between biosphere reserve and establish trans-boundary biosphere reserves, where appropriate.

17. Give biosphere reserves more visibility by disseminating information materials, developing communication policies, and highlighting their roles as members of the Network.

18. Include biosphere reserves in proposals for financing from international and bilateral funding mechanisms, including the Global Environment Facility.

19. Mobilize private funds, from businesses, NGOs and foundations, for the benefit of biosphere reserves.

20. Monitor, assess and follow up on the implementation of the Seville Strategy, utilizing the Implementation Indicators, and analyze the factors that aid in attainment of the indicators, as well as those that hinder such attainment.

Recommended at the individual reserve level:

21. Give biosphere reserves more visibility by disseminating information materials, developing communication policies, and highlighting their roles as members of the Network.

22. Mobilize private funds, from businesses, NGOs and foundations, for the benefit of biosphere reserves.

23. Monitor, assess and follow up on the implementation of the Seville Strategy, utilizing the Implementation Indicators, and analyze the factors that aid in attainment of the indicators, as well as those that hinder such attainment. 


\section{IMPLEMENTATION INDICATORS}

CROSS REFERENCE

International level

Biosphere reserves included in implementation of the Convention on Biological Diversity

Improved biogeographical system developed

New trans-boundary reserves developed

Guidelines developed and published

Network-wide research programmes implemented

Biosphere reserves incorporated into international research programmes

Regional and inter-regional research programmes developed

Interdisciplinary research tools developed

Clearing house for research tools and methodologies developed

Interactions developed with other research and education networks

Biosphere reserves incorporated into international monitoring programmes

Standardized protocols and methodologies adopted for data and for data exchange

Mechanism developed for exchanging experiences and information between biosphere reserves

Biosphere reserve communication system implemented

International training opportunities and programmes developed

Regional training centers identified and developed

Demonstration biosphere reserves identified and publicized

Guidance provided on elaboration and review of strategies and national action plans for biosphere reserves

Mechanisms developed for information exchange among reserve managers

Statutory Framework of the World Network of Biosphere Reserves are implemented at the international and national levels

Advisory Committee for Biosphere Reserves is functional and effective

Regional or thematic networks developed or strengthened

I.1.1

I.1.2

I.2.1; IV.2.6

II.1.1; IV.1.4; IV.1.5

III.1.1

III.1.2

III.1.3

III.1.4

III.1.5

III.1.6

III.2.1

III. 2.2 ; IV.2.10

III.3.1

III.3.2; IV.2.4; IV.2.7

III.4.1

III.4.2

IV.1.1

IV.1.2

IV.1.3

IV.2.1; IV. 2.2

IV.2.3

IV.2.4

IV.2.5

and organizations

Mechanisms developed to foster twinning between biosphere reserves

IV.2.6

Information and promotional materials developed for the Biosphere Reserve

IV.2.7

Network

Strategies developed for including biosphere reserves in bilateral and

IV.2.8

multilateral aid projects

Strategies developed for mobilizing funds from businesses, NGOs and foundations

IV.2.9

Data standards and methodologies applied across the World Network

IV.2.10

Mechanisms developed for monitoring and assessing the implementation of the

IV.2.11

Seville Strategy 


\section{IMPLEMENTATION INDICATORS}

\section{CROSS REFERENCE}

National level

Biogeographical analysis prepared

Analysis of need for new or extended biosphere reserves is completed

I.1.4; II.1.3

Biosphere reserves included in national strategies and other responses to the

I.2.2; I.1.3

Convention on Biological Diversity and other conventions

Links developed between biosphere reserves

In situ conservation plans for genetic resources in biosphere reserves

I. 2.5

Biosphere reserves incorporated into sustainable development plans

II.1.2

Biosphere reserves developed or strengthened to include traditional life styles and in areas of critical people-environment interactions

Conservation and sustainable use activities identified and promoted

II.1.3

Effective management plans or policies in place at all reserves

Mechanisms developed for identifying incompatibilities between conservation and sustainable use functions and to insure an appropriate balance between these functions

Biosphere reserves included in regional development and land-use planning projects

Land-use sectors near biosphere reserves are encouraged to adopt sustainable practices

Biosphere reserves are integrated into national and regional research programmes which are linked to conservation and development policies

Biosphere reserves are integrated into national monitoring programmes and are linked to similar monitoring sites and networks

Principles of conservation and sustainable use, as practiced in biosphere reserves, integrated into school programmes

Biosphere reserves participate in international education networks and programmes

Model training programmes for biosphere reserve managers are developed

Mechanisms developed to review national strategies and action plans for biosphere reserves

Mechanisms developed for information exchange among reserve managers

Statutory Framework of the World Network of Biosphere Reserves are implemented at the national level

National-level mechanism developed to advise and coordinate biosphere reserves

Interactions developed between biosphere reserves and similar managed areas and organizations with congruent goals

Mechanisms developed to foster twinning between biosphere reserves

II.1.4

II.2.1; IV.1.6

II.2.2

II.3.2; IV.1.7

III.1.7

III.2.3

III.3.3

III.3.4

III.4.3

IV.1.8

IV.1.9

IV.2.12; IV.2.14

IV.2.13

IV.2.15

IV.2.16

Information and promotional materials developed for the Biosphere Reserve

IV.2.17

Network

Strategies developed for including biosphere reserves in bilateral and

multilateral aid projects

Strategies developed for mobilizing funds from businesses, NGOs and

foundations

Mechanisms developed for monitoring and assessing the implementation of the

Seville Strategy 
Individual reserve level

Survey made of stakeholders interests

II.1.5

Factors leading to environmental degradation and unsustainable use are

identified

Survey made of the natural products and services of the biosphere reserve

II. 1.7

Incentives identified for sustainable use by local populations

II.1.8

Plan prepared for equitable sharing of benefits

II.1.9

Mechanisms developed to manage, coordinate and integrate the reserve's programs and activities

Local consultative framework implemented

II.2.3; IV.1.10; IV.1.12

Regional demonstration sites developed

Coordinated research and monitoring plan implemented

II.2.4

Functional data management system implemented

Reserve is used for developing and testing of monitoring methods

II.3.3

III.1.8; III.2.4

III.1.9; III. 2.7

III.2.5

Reserve is used for developing indicators of sustainability relevant to local populations

III. $2.5 ;$ II. 2.6

Local stakeholders are included in education, training, research and

III.3.5; III.4.5 monitoring programs

Information for visitors to the reserve developed

III.3.6

Ecology field centre developed at the reserve

Reserve is used for on-site training activities

III.4.4

A local educational and training programme is in place

III.4.6

Different zones of biosphere reserves identified and mapped

IV.1.10

IV.1.12

Buffer and transitions reformulated to promote sustainable development and preserve the core area

Local community involved in planning and managing reserve

Private-sector initiatives to establish and maintain environmentally and

IV.1.15

socially sustainable activities are encouraged

Information and promotional materials developed for the Biosphere Reserve

IV.2.21

Network

Strategies developed for mobilizing funds from businesses, NGOs and

IV.2.22 foundations

Mechanisms developed for monitoring and assessing the implementation of the

Seville Strategy

\section{IV.2.23}

\section{STATUTORY FRAMEWORK OF THE WORLD NETWORK OF BIOSPHERE RESERVES}

\section{Introduction}

Within UNESCO's Man and the Biosphere (MAB) programme, biosphere reserves are established to promote and demonstrate a balanced relationship between humans and the biosphere. Biosphere reserves are designated by the International Co-ordinating Council of the MAB Programme, at the request of the State concerned. Biosphere reserves, each of which remains under the sole sovereignty of the State where it is situated and thereby submitted to State legislation only, form a World Network in which participation by the States is voluntary.

The present Statutory Framework of the World Network of Biosphere Reserves has been formulated with the objectives of enhancing the effectiveness of individual biosphere reserves and strengthening common understanding, communication and co-operation at regional and international levels. 
This Statutory Framework is intended to contribute to the widespread recognition of biosphere reserves and to encourage and promote good working examples. The delisting procedure foreseen should be considered as an exception to this basically positive approach, and should be applied only after careful examination, paying due respect to the cultural and socio-economic situation of the country, and after consulting the government concerned.

The text provides for the designation, support and promotion of biosphere reserves, while taking account of the diversity of national and local situations. States are encouraged to elaborate and implement national criteria for biosphere reserves which take into account the special conditions of the State concerned.

\section{Article 1-Definition}

Biosphere reserves are areas of terrestrial and coastal/marine ecosystems or a combination thereof, which are internationally recognized within the framework of UNESCO's programme on Man and the Biosphere (MAB), in accordance with the present Statutory Framework.

\section{Article 2-World Network of Biosphere Reserves}

1. Biosphere reserves form a worldwide network, known as the World Network of Biosphere Reserves, hereafter called the Network.

2. The Network constitutes a tool for the conservation of biological diversity and the sustainable use of its components, thus contributing to the objectives of the Convention on Biological Diversity and other pertinent conventions and instruments.

3. Individual biosphere reserves remain under the sovereign jurisdiction of the States where they are situated. Under the present Statutory Framework, States take the measures which they deem necessary according to their national legislation.

\section{Article 3-Functions}

In combining the three functions below, biosphere reserves should strive to be sites of excellence to explore and demonstrate approaches to conservation and sustainable development on a regional scale:

(i) conservation - contribute to the conservation of landscapes, ecosystems, species and genetic variation;

(ii) development-foster economic and human development which is socio-culturally and ecologically sustainable;

(iii) logistic support-support for demonstration projects, environmental education and training, research and monitoring related to local, regional, national and global issues of conservation and sustainable development.

\section{Article 4-Criteria}

General criteria for an area to be qualified for designation as a biosphere reserve:

1. It should encompass a mosaic of ecological systems representative of major biogeographic regions, including a gradation of human interventions.

2. It should be of significance for biological diversity conservation.

3. It should provide an opportunity to explore and demonstrate approaches to sustainable development on a regional scale.

4. It should have an appropriate size to serve the three functions of biosphere reserves, as set out in Article 3 .

5. It should include these functions, through appropriate zonation, recognizing: 
(a) a legally constituted core area or areas devoted to long-term protection, according to the conservation objectives of the biosphere reserve, and of sufficient size to meet these objectives;

(b) a buffer zone or zones clearly identified and surrounding or contiguous to the core area or areas, where only activities compatible with the conservation objectives can take place;

(c) an outer transition area where sustainable resource management practices are promoted and developed.

6. Organizational arrangements should be provided for the involvement and participation of a suitable range of inter alia public authorities, local communities and private interests in the design and carrying out the functions of a biosphere reserve.

7. In addition, provisions should be made for:

(a) mechanisms to manage human use and activities in the buffer zone or zones;

(b) a management policy or plan for the area as a biosphere reserve;

(c) a designated authority or mechanism to implement this policy or plan;

(d) programmes for research, monitoring, education and training.

\section{Article 5-Designation procedure}

1. Biosphere reserves are designated for inclusion in the Network by the International Co-ordinating Council (ICC) of the MAB programme in accordance with the following procedure:

(a) States, through National MAB Committees where appropriate, forward nominations with supporting documentation to the secretariat after having reviewed potential sites, taking into account the criteria as defined in Article 4;

(b) the secretariat verifies the content and supporting documentation: in the case of incomplete nomination, the secretariat requests the missing information from the nominating State;

(c) nominations will be considered by the Advisory Committee for Biosphere Reserves for recommendation to ICC;

(d) ICC of the MAB programme takes a decision on nominations for designation.

The Director-General of UNESCO notifies the State concerned of the decision of ICC.

2. States are encouraged to examine and improve the adequacy of any existing biosphere reserve, and to propose extension as appropriate, to enable it to function fully within the Network. Proposals for extension follow the same procedure as described above for new designations.

3. Biosphere reserves which have been designated before the adoption of the present Statutory Framework are considered to be already part of the Network. The provisions of the Statutory Framework therefore apply to them.

\section{Article 6-Publicity}

1. The designation of an area as a biosphere reserve should be given appropriate publicity by the State and authorities concerned, including commemorative plaques and dissemination of information material.

2. Biosphere reserves within the Network, as well as the objectives, should be given appropriate and continuing promotion. 


\section{Article 7-Participation in the Network}

1. States participate in or facilitate co-operative activities of the Network, including scientific research and monitoring, at the global, regional and subregional levels.

2. The appropriate authorities should make available the results of research, associated publications and other data, taking into account intellectual property rights, in order to ensure the proper functioning of the Network and maximize the benefits from information exchanges.

3. States and appropriate authorities should promote environmental education and training, as well as the development of human resources, in co-operation with other biosphere reserves in the Network.

\section{Article 8-Regional and thematic subnetworks}

States should encourage the constitution and co-operative operation of regional and/or thematic subnetworks of biosphere reserves, and promote development of information exchanges, including electronic information, within the framework of these subnetworks.

\section{Article 9-Periodic review}

1. The status of each biosphere reserve should be subject to a periodic review every ten years, based on a report prepared by the concerned authority, on the basis of the criteria of Article 4, and forwarded to the secretariat by the State concerned.

2. The report will be considered by the Advisory Committee for Biosphere Reserves for recommendation to ICC.

3. ICC will examine the periodic reports from States concerned.

4. If ICC considers that the status or management of the biosphere reserve is satisfactory, or has improved since designation or the last review, this will be formally recognized by ICC.

5. If ICC considers that the biosphere reserve no longer satisfies the criteria contained in Article 4, it may recommend that the State concerned take measures to ensure conformity with the provisions of Article 4 , taking into account the cultural and socio-economic context of the State concerned. ICC indicates to the secretariat actions that it should take to assist the State concerned in the implementation of such measures.

6. Should ICC find that the biosphere reserve in question still does not satisfy the criteria contained in Article 4, within a reasonable period, the area will no longer be referred to as a biosphere reserve which is part of the Network.

7. The Director-General of UNESCO notifies the State concerned of the decision of ICC.

8. Should a State wish to remove a biosphere reserve under its jurisdiction from the Network, it notifies the secretariat. This notification shall be transmitted to ICC for information. The area will then no longer be referred to as a biosphere reserve which is part of the Network.

\section{Article 10-Secretariat}

1. UNESCO shall act as the secretariat of the Network and be responsible for its functioning and promotion. The secretariat shall facilitate communication and interaction among individual biosphere reserves and among experts. UNESCO shall also develop and maintain a world-wide accessible information system on biosphere reserves, to be linked to other relevant initiatives.

2. In order to reinforce individual biosphere reserves and the functioning of the Network and subnetworks, UNESCO shall seek financial support from bilateral and multilateral sources.

3. The list of biosphere reserves forming part of the Network, their objectives and descriptive details, shall be updated, published and distributed by the secretariat periodically. 



\section{U L}

\section{FISHERIES}





\title{
Nauru Agreement Concerning Co-operation in the Management of Fisheries of Common Interest, Nauru, 1982
}

\author{
Done at Nauru 11 February 1982
}

Entered into force 2 December 1982*

Depositary: Solomon Islands

Primary source citation: Copy of text provided by the Ministry of Foreign Affairs of the Solomon Islands

\section{NAURU AGREEMENT CONCERNING CO-OPERATION IN THE MANAGEMENT OF FISHERIES OF COMMON INTEREST}

The Federated States of Micronesia, the Republic of Kiribati, the Marshall Islands, the Republic of Nauru, the Republic of Palau, Papua New Guinea and Solomon Islands:

TAKING into account the work of the Third United Nations Conference on the Law of the Sea;

NOTING that in accordance with the relevant principles of international law each of the Parties has established an exclusive economic zone or fisheries zone (hereinafter respectively called "the Fisheries Zones") which may extend 200 nautical miles from the baselines from which their respective territorial seas are measured and within which they respectively and separately exercise sovereign rights for the purposes of exploring, exploiting, conserving and managing all living marine resources;

HAVING REGARD to the objectives of the South Pacific Forum Fisheries Agency Convention and in particular the promotion of regional co-operation and co-ordination of fisheries policies and the need for the urgent implementation of these objectives through regional or sub-regional arrangements;

CONSCIOUS of the exploitation of the common stocks of fish, both within the Fisheries Zones and in the waters adjacent thereto, by the distant water fishing nations;

MINDFUL of their dependence, as developing island states, upon the rational development and optimum utilisation of the living resources occuring within the Fisheries Zones and in particular, the common stocks of the fish therein;

RECOGNISING that only by co-operation in the management of the Fisheries Zones may their peoples be assured of receiving the maximum benefits from such resources; and

DESIROUS of establishing, without prejudice to the sovereign rights of each Party, arrangements by which this may be achieved;

* The United States is not a party to this Agreement. 


\section{HAVE AGREED AS FOLLOWS:}

\section{ARTICLE I}

The Parties shall seek, without any derogation of their respective sovereign rights, to co-ordinate and harmonise the management of fisheries with regard to common stocks within the Fisheries Zones, for the benefit of their peoples.

\section{ARTICLE II}

The Parties shall seek to establish a coordinated approach to the fishing of the common stocks in the Fisheries Zones by foreign fishing vessels and in particular:

(a) shall establish principles for the granting of priority to applications by fishing vessels of the Parties to fish within the Fisheries Zones over other foreign fishing vessels;

(b) shall establish, as a minimum, uniform terms and conditions under which the Parties may licence foreign fishing vessels to fish within the Fisheries Zones regarding:

(i) the requirement that each foreign fishing vessel apply for and possess a licence or permit;

(ii) the placement of observers on foreign fishing vessels;

(iii) the requirement that a standardized form of log book be maintained on a day-to-day basis which shall be produced at the direction of the competent authorities;

(iv) the timely reporting to the competent authorities of required information concerning the entry, exit and other movement and activities of foreign fishing vessels within the Fisheries Zones; and

(v) standardized identification of foreign fishing vessels;

(c) seek to establish other uniform terms and conditions under which the Parties may licence foreign fishing vessels to fish within the Fisheries Zones, including:

(i) the payment of an access fee, which shall be calculated in accordance with principles established by the Parties;

(ii) the requirement to supply to the competent authorities complete catch and effort data for each voyage;

(iii) the requirement to supply to the competent authorities such additional information as the Parties may determine to be necessary;

(iv) the requirement that the flag State or organisations having authority over a foreign fishing vessel take such measures as are necessary to ensure compliance by such vessel with the relevant fisheries laws of the Parties; and

(v) such other terms and conditions as the Parties may from time to time consider necessary.

\section{ARTICLE III}

The Parties shall seek to standardize their respective licensing procedures and in particular:

(a) seek to establish and adopt uniform measures and procedures relating to the licensing of foreign fishing vessels, including application formats, licensing formats and other relevant documents; and 
(b) explore the possibility of establishing, without prejudice to the respective sovereign rights of the Parties, a centralised licensing system of foreign fishing vessels.

\title{
ARTICLE IV
}

The Parties shall seek the assistance of the South Pacific Forum Fisheries Agency in establishing procedures and administrative arrangements for the exchange and analysis of:

(a) statistical data concerning catch and effort by fishing vessels in the Fisheries Zones relating to the common stocks of fish; and

(b) information relating to vessel specifications and fleet composition.

\section{ARTICLE V}

1. The Parties shall seek the assistance of the South Pacific Forum Fisheries Agency in providing secretariat services for implementing and co-ordinating the provisions of this Agreement.

2. An annual meeting of the Parties shall be convened preceding or following the regular session of the Forum Fisheries Committee in order to promote the implementation of this Agreement. Additional meetings may be convened at the request of three or more Parties. Such requests shall be communicated to the Director of the Forum Fisheries Agency who will inform the other Parties.

3. With the concurrence of the Parties, members of the South Pacific Forum Fisheries Agency, not Parties to this Agreement, may attend, as observers, the meetings referred to in this Article.

\section{ARTICLE VI}

The Parties shall, where appropriate, co-operate and co-ordinate the monitoring and surveillance of foreign fishing activities by:
(a) arranging for the rapid exchange of information collected through national surveillance activities;
(b) exploring the feasibility of joint surveillance; and
(c) developing other appropriate measures.

\begin{abstract}
ARTICLE VII
The Parties shall seek to develop co-operative and co-ordinated procedures to facilitate the enforcement of their fisheries laws and shall in particular examine the various means by which a regime of reciprocal enforcement may be established.
\end{abstract}

\section{ARTICLE VIII}

Nothing contained in this Agreement shall be construed as a derogation of any of the rights and obligations undertaken by any of the Parties under the South Pacific Forum Fisheries Agency Convention or any other international agreement in effect on the date on which this Agreement enters into force. 


\section{ARTICLE IX}

The Parties shall conclude arrangements where necessary to facilitate the implementation of the terms and to attain the objectives of this Agreement. The Parties concluding such arrangements shall lodge copies with the depositary of this Agreement.

\section{ARTICLE X}

1. This Agreement shall be open for signature by the States named in the preamble hereto and shall be subject to ratification.

2. This Agreement shall enter into force thirty days following receipt by the depositary of the fifth instrument of ratification. Thereafter it shall enter into force for any signing or acceding State thirty days after receipt by the depositary of an instrument of ratification or accession.

3. This Agreement shall be deposited with the Government of Solomon Islands which shall be responsible for its registration with the United Nations.

4. Following entry into force, this Agreement shall be open for accession by other States with the concurrence of all of the Parties to this Agreement.

5. Reservations to this Agreement shall not be permitted.

\section{ARTICLE XI}

1. This Agreement is a binding international agreement concluded among States and is governed by international law.

2. Any Party may withdraw from this Agreement by giving written notice to the depositary. Withdrawal shall take effect one year after receipt of such notice.

3. Any amendments to this Agreement proposed by a Party shall only be adopted by unanimous decision of the Parties.

IN WITNESS WHEREOF the undersigned, duly authorised by their respective Governments, have signed the Agreement.

DONE at Nauru this 11th day of February One Thousand Nine Hundred and Eighty Two.

[Signature]

For the Government of the

Federated States of Micronesia

[Signature]

For the Government of the

Marshall Islands

\section{[Signature]}

For the Government of the

Republic of Palau

[Signature]

For the Government of

Solomon Islands
[Signature]

For the Government of the

Republic of Kiribati

[Signature]

For the Government of the Republic of Nauru

[Signature]

For the Government of

Papua New Guinea 


\title{
An Arrangement Implementing the Nauru Agreement Setting Forth Minimum Terms and Conditions of Access to the Fisheries Zones of the Parties, Koror, 1993
}

\author{
Done at Koror 3 May 1993 \\ Entered into effect* \\ Primary source citation: Copy of text provided by the \\ University of the South Pacific Department of Law
}

\section{AN ARRANGEMENT IMPLEMENTING THE NAURU AGREEMENT SETTING FORTH MINIMUM TERMS AND CONDITIONS OF ACCESS TO THE FISHERIES ZONES OF THE PARTIES}

Pursuant to Article II, III, VII and IX of the Nauru Agreement Concerning Cooperation in the Management of Fisheries of Common Interest, hereinafter referred to as the "Nauru Agreement", wherein the Parties thereto agreed to conclude arrangements to facilitate the implementation of the Nauru Agreement, the Federated States of Micronesia, the Republic of Kiribati, the Republic of the Marshall Islands, the Republic of Nauru, the Republic of Palau, Papua New Guinea and Solomon Islands

HAVE AGREED AS FOLLOWS:

\section{ARTICLE I \\ SOUTH PACIFIC FORUM FISHERIES AGENCY REGIONAL REGISTER OF FISHING VESSELS}

The Parties shall participate in, and comply with, the Procedures for the Establishment and Operation of the South Pacific Forum Fisheries Agency Regional Register of Fishing Vessels, adopted by the South Pacific Forum Fisheries Committee at Apia, Western Samoa on 5 May 1983.

ARTICLE II

\section{LICENSING TERMS AND CONDITIONS}

The Parties shall establish the following minimum terms and conditions and utilise the following common formats in all of their subsequent foreign fishing agreements and their licensing requirements concerning foreign vessels fishing the common stocks of fish within the Fisheries Zones:

\footnotetext{
- The United States is not a party to this Arrangement.
} 


\section{Licensing Procedures}

(a) each foreign fishing vessel subject to this Arrangement shall be individually licensed;

(b) applications for fishing licences shall be made by telex, cable, or letter to a Party or its designated representative;

(c) payment, or the guarantee of payment, of licence fees shall be required prior to the issue of a licence;

(d) upon receipt, the licence document shall be carried on the licensed vessel and produced on demand. Production of a current valid licence number, issued in accordance with the provisions herein, shall be sufficient evidence that a vessel is licensed, pending receipt of the licence document;

(e) there shall be no refund of fees paid for the issue of a fishing licence;

(f) there shall be no transfer of licences.

\section{Authorised Personnel}

The owner, charterer, operator, master or any other person responsible for the operation of a licensed vessel shall:

(a) allow authorised personnel to board the licensed vessel at any location as determined by the licensing Party in consultation with the person responsible for the operation of the vessel, including at ports where voyages commence or at ports within the Fisheries Zones or at sea, and to remain on board;

(b) permit authorised personnel to gather information relevant to the Fisheries Zones of any of the Parties;

(c) provide maintenance for authorised personnel, including food, accommodation and medical care of a standard at least equivalent to that provided for officers of the licensed vessel;

(d) allow authorised personnel access to facilities and equipment including satellite navigators, radios, other navigation aids and charts in order to carry out their duties on board the licensed vessel;

(e) provide reasonable facilities for authorised personnel and assist them to carry out their duties;

(f) allow authorised personnel access to catch on board for the purpose of collecting management related and biological information and sample;

(g) disembark authorised personnel at an agreed location;

(h) allow representatives of the Parties to be present at the unloading of the catch for the purpose of collecting management related and biological information and samples.

\section{Catch Reporting and Maintenance of Log Book}

The owner, charterer, operator, master or any other person responsible for the operation of a licensed vessel shall ensure the maintenance of catch data and log books in the following respects:

(a) keep daily catch and effort records on board the vessel within the Fisheries Zones on common catch data forms, the formats of which are set out in Appendix I;

(b) keep the relevant common catch data form current at all times and produce it on demand to any authorised personnel;

(c) make the data required on the regional catch data form available to the licensing Party or its representative within $\mathbf{4 5}$ days after the completion of each voyage. 


\section{Timely Report of Catch, Entry and Exit}

The owner, charterer, operator, master or any other person responsible for the operation of a licensed vessel, except vessels under 20 gross registered tons, shall report accordingly to instructions provided by the licensing Party, in the following respects:

(a) notice of entry of the vessel to the Fisheries Zone of the Party shall be given. Communication in this respect shall be made in the format set out in Appendix II (1);

(b) the position of the vessel shall be reported while within the Fisheries Zone of the Party on a weekly basis together with the total catch of the vessel for the last seven days in the format as set out in Appendix II (2);

(c) at the time of exit from the Fisheries Zone of the Party, the vessel's position, the total amount of fish on board and the total catch for the days elapsed since either the entry report or the previous weekly report, as the case may be, shall be reported in the format as set out in Appendix III (3);

(d) where an agreement authorises fishing in the zones of more than one party, the requirements of paragraphs (a) and (c) may be satisfied by reporting entry and exit into and from the combined zones of the Parties concerned.

\section{Identification of Licensed Vessels}

The owner, charterer, operator, master or any other person responsible for the operation of a licensed vessel shall ensure that the licensed vessel displays standard identification marks in the following respects:

(a) the radio call sign of the vessel be displayed in a prominent position on the vessel where it can be readily identified from the air or sea;

(b) in cases where the vessel does not possess a radio call sign, the vessel registration number be displayed in the manner described above;

(c) the letters and numbers described above be at least one metre high, clear and distinct and coloured black on white, white on black or similar contrasting colours;

(d) the vessel's name be painted clearly in English in large letters on the bow and stern of the vessel.

\section{ARTICLE III \\ LEGISLATIVE EFFECT}

1. Each Party agrees to ensure compliance with the minimum terms and conditions of access set out in Article II of this Arrangement, if necessary by the enactment of legislation.

2. Each Party shall communicate to the Government of Solomon Islands, as the depositary of the Nauru Agreement, the text of any legislation it has enacted in order to give effect to this Arrangement.

\section{ARTICLE IV}

\section{SIGNATURE AND EFFECT}

1. This Arrangement shall be open for signature by the Parties to the Nauru Agreement.

2. This Arrangement shall take effect for each signatory immediately upon signature.

3. This Arrangement shall be deposited with the Government of Solomon Islands.

4. Reservations of this Arrangement shall not be permitted. 


\section{ARTICLE V \\ WITHDRAWAL OR AMENDMENT}

1. Any Party may withdraw from this Arrangement by giving written notice to the depositary. Withdrawal shall take effect one year after receipt of such notice.

2. Any amendments to this Arrangement proposed by a Party shall be adopted only by unanimous decision of the Parties to this Arrangement.

\section{Article VI \\ THE NAURU AGREEMENT}

This Arrangement is subordinated to and governed by the Nauru Agreement.

IN WITNESS WHEREOF the undersigned, being duly authorised by their respective Governments have signed this Arrangement.

\section{[Signature]}

Federated States of Micronesia

[Signature]

REPUBLIC OF KIRIBATI

[Signature]

REPUBLIC OF THE MARSHALL ISLANDS

[Signature]

REPUBLIC OF NAURU
[Signature]

REPUBLIC OF PALAU

[Signature]

The IndePendent State of Papua NEw GuINEA

\section{[Signature]}

SOLOMON ISLANDS

[Signature]

Tuvalu 


\section{A Second Arrangement Implementing the Nauru Agreement Setting Forth Additional Minimum Terms and Conditions of Access to the Fisheries Zones of the Parties, Koror, 1990}

Done at Koror 19 September 1990

Entered into force 3 May 1993*

Primary source citation: Copy of text provided by the Ministry of Foreign Affairs of the Solomon Islands

\section{A SECOND ARRANGEMENT IMPLEMENTING THE NAURU AGREEMENT SETTING FORTH ADDITIONAL MINIMUM TERMS AND CONDITIONS OF ACCESS TO THE FISHERIES ZONES OF THE PARTIES}

Pursuant to Articles II, III, and IX of the Nauru Agreement Concerning Cooperation in the Management of Fisheries of Common Interest, hereafter referred to as the "Nauru Agreement", wherein the Parties thereto agreed to conclude arrangements to facilitate the implementation of the Nauru Agreement, the Federated States of Micronesia, the Republic of Kiribati, the Republic of the Marshall Islands, the Republic of Nauru, the Republic of Palau, Papua New Guinea and Solomon Islands

HAVE AGREED AS FOLLOWS:

\section{ARTICLE I}

Licensing Terms and Conditions

In addition to those terms and conditions provided in Article 11 of An Arrangement Implementing the Nauru Agreement Setting Forth Minimum Terms and Conditions of Access to the Fisheries Zones of the Parties, the Parties shall establish the following minimum terms and conditions and utilize the prescribed common formats in all of their subsequent foreign fishing agreements and their licensing requirements concerning foreign vessels fishing the common stocks of fish within the Fisheries Zones and shall not issue licences unless the minimum terms and conditions are accepted and observed:

1. Transshipment at Sea Prohibited

The owner, charterer, operator, master or any other person responsible for the operation of a licensed vessel (hereafter referred to as "the operator") shall not transship fish at sea whether such transshipment is done

* The United States is not a party to this Arrangement. 
within a fisheries zone of a licensing Party or on the high seas and shall transship only through ports designated by the licensing Party;

\section{High Seas Catch Reporting and Maintenance of Log Books}

Where a vessel is licensed to fish in one or more Fisheries Zones and is also used for fishing in the high seas during a fishing trip, the operator shall:

(a) keep daily catch and effort records on board the vessel within the high seas on prescribed forms;

(b) keep the relevant catch data form current at all times and produce it on demand to any authorized personnel; and

(c) in accordance with the Minutes of an Agreement made in Palau on 19 September 1990, send by registered airmail to each licensing Party or its representative the following reports covering catch and effort in each Zone and the high seas for the whole trip:

i) a preliminary report within 14 days of the completion of a trip; and

ii) a final report within 45 days of the completion of the trip.

\section{Observers}

Upon request by a licensing Party, observers shall be placed on board licensed vessels and the operator and/or fishermen's association and/or flag state government shall pay the costs of such observers including:

(a) full travel costs from the licensing country to the vessel and return;

(b) salary; and

(c) full insurance coverage.

\section{ARTICLE II}

\section{Electronic Position and Data Transfer Technology}

The operator and/or fishermen's association and/or flag state government shall ensure that an appropriate electronic positioning monitoring and data transfer device is installed and maintained in good working order on the vessel upon the request of the licensing Party.

\section{ARTICLE III}

\section{Signature and Effect}

1. This Arrangement shall be open for signature by the Parties to the Nauru Agreement.

2. This Arrangement shall take effect 30 days following receipt by the depositary of the fifth instrument of approval. Thereafter, it shall take effect for any signing party $\mathbf{3 0}$ days after receipt by the depositary of the instrument of approval.

3. This Arrangement shall be deposited with the Government of the Solomon Islands.

4. Reservations to this Arrangement shall not be permitted. 


\section{ARTICLE IV}

\section{Amendment and Withdrawal}

1. Any Party may withdraw from this Arrangement by giving written notice to the depositary. Withdrawal shall take effect one year after receipt of such notice.

2. Any amendment to this Arrangement proposed by the Party shall be adopted only by unanimous decision of the Parties to this Arrangement.

\section{ARTICLE V}

\section{The Nauru Agreement}

This Arrangement is subordinate to and governed by the Nauru Agreement.

IN WITNESS WHEREOF the undersigned, being duly authorized by their respective Governments have signed this Arrangement.

[Signature]

For the Federated States of Micronesia

By [Signature]

Its [Signature]

Done at Koron this 19th day of September

One Thousand Nine Hundred and Ninety.

[Signature]

For the Republic of Kiribati

By [Signature]

Its [Signature]

Done at Koron this 19th day of September One Thousand Nine Hundred and Ninety.

[Signature]

For the Republic of the Marshall Islands By [Signature]

Its [Signature]

Done at Koron this 19th day of September One Thousand Nine Hundred and Ninety.

[Signature]

For the Republic of Nauru

By [Signature]

Its [Signature]

Done at Koron this 19th day of September One Thousand Nine Hundred and Ninety.

[Signature]

For the Republic of Palau

By [Signature]

Its [Signature]

Done at Koron this 19th day of September One Thousand Nine Hundred and Ninety. 


\section{[Signature]}

For Papua New Guinea

By [Signature]

Its [Signature]

Done at Koron this 19th day of September

One Thousand Nine Hundred and Ninety.

[Signature]

For the Solomon Islands

By [Signature]

Its [Signature]

Done at Koron this 19th day of September One Thousand Nine Hundred and Ninety. 


\section{Western Indian Ocean Tuna Organisation Convention, Mahe, 1991}

Done at Mahe 19 June 1991

Entered into force*

Depositary: Seychelles

Primary source citation: Copy of text provided by the

U.S. Department of State

\section{WESTERN INDIAN OCEAN TUNA ORGANISATION CONVENTION}

THE PARTIES,

Recognising their common interest in the conservation, management and optimum utilization of the living marine resources of the Western Indian Ocean region and in particular of the highly migratory tuna and tuna-like species;

Desiring to cooperate with a view to ensuring the conservation, management and optimum utilization of tuna and tuna-like species in the Western Indian Ocean;

Considering the United Nations Convention on the Law of the Sea opened for signature on 10th December 1982;

Desiring to promote regional cooperation and coordination in respect of fisheries policies;

Concerned to secure the maximum benefits from the tuna and tuna-like species of the region for their peoples;

HAVE AGREED AS FOLLOWS:

\section{Article 1}

\section{ESTABLISHMENT}

1. The contracting parties hereby establish the Western Indian Ocean Tuna Organisation (hereafter referred to as "the Organisation").

2. The Organisation shall consist of a Board, a Committee and a Secretariat.

3. The headquarters of the Organisation shall be in Seychelles.

* The United States is not a party to this Convention. 


\section{Article 2}

\section{OBJECTIVES}

The objectives of the Organisation are to promote cooperation and coordination among its members in respect of, inter alia:

(a) harmonization of policies with respect to fisheries;

(b) relations with distant water fishing nations;

(c) fisheries surveillance and enforcement according to arrangements which may be concluded;

(d) fisheries development, in particular development of fishing capacity of members and fish technology, processing and marketing;

(e) access to exclusive economic zones of Members, according to arrangements which may be concluded.

\section{Article 3}

\section{MEMBERSHIP}

1. Membership of the Organisation shall be open to:

(a) any founding State described in Annex I;

(b) with unanimous approval of parties, any independent coastal State bordering the Western Indian Ocean whose territory is situated principally in the Western Indian Ocean region, having a common interest with parties in the conservation, management and optimum utilization of the highly migratory tuna and tuna-like species of the region occurring within and beyond its exclusive economic zone.

2. For the purposes of this Article, "Western Indian Ocean region" is the area described in Annex II.

\section{Article 4}

\section{BOARD}

1. Each Member shall appoint to the Board one representative, who shall be the Minister responsible for fisheries, or any other Minister.

2. The Board shall hold regular sessions at least once a year. A special session shall be held at any time at the request of a majority of Members.

3. The Board shall adopt such rules of procedure as it considers necessary.

4. The Board shall determine the policy of the Organisation and may direct the Committee on any matter pertaining to the policies and functions of the Organisation. 


\section{Article 5}

\section{COMMITTEE}

1. Each Member shall be represented on the Committee by the senior official responsible for fisheries or a related area.

2. The Board shall appoint a Chairman and two Vice-Chairmen from among the Committee members on such conditions as it may determine.

3. The Committee shall meet as often as required and at least once a year.

4. The Committee shall endeavour to take decisions by consensus. In the absence of consensus, and unless otherwise provided in this Convention, a two-thirds majority of voting members shall be required for a decision.

5. The Committee shall adopt such rules of procedure and other internal administrative regulations as it considers necessary.

6. The Committee may establish such sub-committees, including technical and budget sub-committees, as it considers necessary.

7. The Committee shall act in an executive capacity and have the following functions and responsibilities, inter alia, to:

(a) provide technical advice and guidance to the Board;

(b) provide a forum for Members to consult together on any matter of common concern in relation to fisheries;

(c) provide direction to the Secretariat with respect to its functions and responsibilities;

(d) carry out such other functions as may be required.

\section{Article 6}

\section{SECRETARIAT}

1. The Board shall appoint a Director and may appoint a Deputy Director of the Secretariat on such conditions as it may determine.

2. The Director may appoint such other staff in accordance with such rules and on such conditions as the Committee may determine.

3. The Secretariat shall, in accordance with the objects of the Organisation, have the following functions, inter alia:

(a) collect, analyse, evaluate and distribute to Members relevant information on matters including:

(i) statistics on the living marine resources of the region and in particular tuna and tunalike species;

(ii) fisheries management plans and procedures, legislation and agreements;

(iii) prices, transport, processing and marketing of fish and fish products;

(iv) fishing patterns and technology;

(v) fisheries surveillance and enforcement; 
(b) provide on request to any Member:

(i) technical advice and information;

(ii) assistance in any relevant matters;

(c) seek to establish working arrangements with relevant regional and international organisations;

(d) submit to the Committee an annual report, including audited financial statements, on the activities of the Organisation for the preceding year, and submit for approval a work programme and budget for the succeeding year;

(e) maintain effective relations with donor organisations;

(f) undertake such other functions as the Committee may direct.

\section{Article 7}

\section{FUNDING}

The Organisation shall be funded by:

(a) contributions from Members;

(b) other sources, including grants, donations and other forms of assistance,

as may be from time to time agreed by the Board.

\section{Article 8}

\section{LEGAL STATUS, PRIVILEGES AND IMMUNITIES}

1. The Organisation shall have international legal personality and such legal capacity as may be necessary for the exercise of its functions and the fulfillment of its purposes, in particular the capacity to conclude agreements at the international level, to contract, to acquire and dispose of moveable and immoveable property and to sue and to be sued in accordance with its legal and diplomatic status.

2. Subject to approval by the Board, an agreement shall promptly be concluded between the Organisation and the Government of Seychelles providing for such privileges and immunities as may be necessary for the proper discharge of the functions of the Organisation.

\section{Article 9}

\section{INFORMATION}

1. The Members shall, upon the request of the Secretariat, provide such available and accessible data and information as the Secretariat may need for the purposes of this Convention, including:

(a) copies of all relevant laws, regulations and administrative instructions, including those relating to the conservation and management of species covered by this Convention, and any amendment or repeal thereof;

(b) details on action taken with respect to decisions of the Committee. 
2. All information, data and reports submitted to the Organisation by the Members shall be treated as confidential and utilised solely for the official purposes of the Organisation.

\section{Article 10}

\section{SPECIES}

The species covered by this Convention shall be those set out in Annex III.

\section{Article 11}

\section{DEPOSITARY}

The Government of Seychelles shall be the Depositary for this Convention.

\section{Article 12}

\section{SIGNATURE, ACCEPTANCE AND ENTRY INTO FORCE}

1. This Convention shall be open for signature by founding States referred to in Article 3 .

2. Acceptance of this Convention shall be effected by the deposit of an instrument of acceptance with the Depositary.

3. This Convention shall enter into force on receipt of the third such instrument of acceptance.

\section{Article 13}

\section{ACCESSION}

1. Founding States and coastal States of the region referred to in Article 3 may, in accordance with the provisions of that Article, accede to this Convention by the deposit of an instrument of acceptance with the Depositary.

2. Accession will be effective upon receipt of the instrument of acceptance by the Depositary.

\section{Article 14}

\section{RESERVATIONS}

No reservations may be made to this Convention.

\section{Article 15}

\section{AMENDMENT}

1. Proposals for amendment may be made by any Member of the Board in writing, addressed to the Depositary, which shall promptly notify all Members of the Organisation. 
2. Amendments shall be effective upon receipt by the Depositary of instruments of acceptance from two-thirds of the Members of the Organisation.

\section{Article 16}

\section{WITHDRAWAL}

1. Any Member may withdraw from this Convention at any time after the expiry of two years from the date upon which this Convention entered into force with respect to that Member.

2. A withdrawal shall be in writing and addressed to the Depositary, which shall promptly notify all Members of the Organisation.

3. Such withdrawal shall become effective sixty days after receipt by the Depositary.

\section{Article 17}

\section{TERMINATION}

This Convention shall be terminated if and when membership drops below three.

\section{Article 18}

\section{ARBITRATION}

1. Any dispute regarding the interpretation or application of this Convention, if not settled by the parties or the Board, shall be referred to an arbitration tribunal.

2. The tribunal shall be composed of three persons:

(a) one person appointed by each party to the dispute;

(b) an independent chairman, appointed by the Board in consultation with the parties to the dispute.

3. In the event the Board determines that arrangements under paragraph 2 are impracticable, it shall appoint an independent person to establish the tribunal.

4. (a) Unless the parties otherwise agree, the arbitration shall take place in a member country not party to the dispute.

(b) The applicable rules of procedure for the tribunal shall be those in force in the member country where the arbitration takes place.

5. The decision of the tribunal shall be final and binding upon the parties to the dispute.

\section{Article 19}

\section{OFFICLAL LANGUAGES}

The official languages of the Organisation shall be English and French.

DONE in MAHE, SEYCHELLES, in English and French, each text being equally authentic, this 19 day of June 1991. 


\section{ANNEX I}

In accordance with Article 3, the following are founding States for the purposes of this Convention:

Comores

India

Kenya

Madagasacar

Maldives

Mauritius

Mozambique

Seychelles

Sri Lanka

Tanzania

\section{ANNEX II}

In accordance with Article 3, the area of the Western Indian Ocean region is as follows:

Starting along latitude $11^{\circ} 00^{\prime} \mathrm{N}$ from the Eastern Coast of India and through the following coordinates:

Lat. $11^{\circ} 00^{\prime} \mathrm{N}$ and long. $85^{\circ} 00^{\prime} \mathrm{E}$

Lat. $3^{\circ} 00^{\prime} \mathrm{N}$ and long. $85^{\circ} 00^{\prime} \mathrm{E}$

Lat. $3^{\circ} 00^{\prime} \mathrm{N}$ and long. $80^{\circ} 00^{\prime} \mathrm{E}$

Lat. $45^{\circ} 00^{\prime} \mathrm{S}$ and long. $80^{\circ} 00^{\prime} \mathrm{E}$

Lat. $45^{\circ} 00^{\prime} \mathrm{S}$ and long. $30^{\circ} 00^{\prime} \mathrm{E}$

and proceed along meridian $30^{\circ} 00^{\prime} \mathrm{E}$ to the Coast of Africa.

\section{ANNEX III}

In accordance with Article 10, following are the tuna and tuna-like species for the purposes of this Convention.

\section{TUNA AND TUNA-LIKE SPECIES}

\section{ENGLISH NAME}

1. Yellowfin tuna

2. Skipjack tuna

3. Bigeye tuna

4. Albacore tuna

5. Southern bluefin tuna

6. Longtail tuna

7. Frigate tuna

8. Bullet tuna
FRENCH NAME

Albacore

Listao

Thon Obese

Germon

Thon rouge du Sud

Thon mignon

Auxide

Bonite

\section{SCIENTIFIC NAME}

Thunnus albacares

Katsuwonus pelamis

Thunnus obesus

Thunnus alalunga

Thunnus maccoyii

Thunnus tonggol

Auxis thazard

Auxis rochei 


$\begin{array}{llll}\text { 9. } & \text { Kawakawa } & \text { Thonine oriental } & \text { Euthynus affinis } \\ \text { 10. } & \text { Narrow-barred Spanish mackerel } & \text { Thazard raye (Indo-Pacifique) } & \text { Scomberomorus commerson } \\ \text { 11. } & \text { Indo-Pacific King mackerel } & \text { Thazard ponctue (Indo-Pacifique) } & \text { Scomberomorus guttatus } \\ \text { 12. } & \text { Indo-Pacific blue marlin } & \text { Makaire bleu (Indo-Pacifique) } & \text { Makaira mazara } \\ \text { 13. } & \text { Black marlin } & \text { Makaire noir } & \text { Makaira indica } \\ \text { 14. } & \text { Striped marlin } & \text { Makaire rouge } & \text { Tetrapturus audax } \\ \text { 15. } & \text { Indo-Pacific sailfish } & \text { Voilier (Indo-Pacifique) } & \text { Istiophorus platypterus } \\ \text { 16. Swordfish } & \text { Espadon } & \text { Xiphias gladius }\end{array}$




\title{
Palau Arrangement for the Management of the Western Pacific Purse Seine Fishery, Suva, 1992
}

\author{
Done at Suva 28 October 1992
}

Entered into force 1 November 1995*

Depositary: South Pacific Forum Fisheries Agency

Primary source citation: Copy of text provided by

the South Pacific Forum Fisheries Agency

\section{ARRANGEMENT FOR THE MANAGEMENT OF THE WESTERN PACIFIC PURSE SEINE FISHERY}

\section{THE PARTIES}

TAKING into account the United Nations Convention on the Law of the Sea, 1982, in particular Articles 56(1)(a) and 61;

ACKNOWLEDGING that in accordance with the relevant principles of international law each of the Parties has established an exclusive economic zone or fisheries zone (hereinafter called the "the exclusive economic zones") which extends up to two hundred nautical miles from the baseline from which their respective territorial seas are measured and within which they respectively and separately exercise sovereign rights for the purposes of exploring, exploiting, conserving and managing all living marine resources;

HAVING REGARD to the objectives of the South Pacific Forum Fisheries Agency Convention 1979 and the Nauru Agreement Concerning Cooperation in the Management of Fisheries of Common Interest 1982 and in particular the promotion of regional cooperation and coordination of fisheries policies and the need for implementation of these objectives through regional and subregional arrangements;

RECOGNISING the responsibilities of coastal states and fishing states to cooperate with each other in the conservation and management of the living marine resources of the high seas and taking into account the special interest of coastal states in highly migratory species while outside their exclusive economic zones;

RECOGNISING that in order to ensure sustained conservation of living marine resources both within and beyond the exclusive economic zone, fisheries management regimes must effectively maintain the ecological relationship between dependent and associated populations, prevent any decrease in the size of harvested populations below those necessary to ensure their stable recruitment, and avoid adverse impacts upon the marine environment and further recognising that in order to ensure conservation and promote optimum utilisation of the living resources fishing must be carried out only on the basis of ecologically sound practices, effectively monitored and enforced;

REAFFIRMING the obligation of fishing nations to provide full and verifiable data on their fishing operations;

MINDFUL of the dependence of countries of the South Pacific upon the rational development and utilization of the living marine resources and the continued abundance of these rescurces;

* The United States is not a party to this Arrangement. 
ACCEPTING the right of all members of the South Pacific Forum Fisheries Agency to become Parties to this Arrangement;

HAVE AGREED AS FOLLOWS:

\section{ARTICLE 1 \\ DEFINITIONS AND INTERPRETATIONS}

\subsection{In this Arrangement -}

(a) "Purse Seine Fisheries Management Area" (hereinafter referred to as "the Area") means the exclusive economic zones or fisheries zones of the Parties hereto including adjacent high seas areas in the Western Pacific within which purse seine vessels operate.

(b) "Party" means a State party to this Arrangement, and "Parties" means all such States from time to time;

(c) "Party to the Nauru Agreement" means a Party to the Nauru Agreement Concerning Cooperation in the Management of Fisheries of Common Interest, 1982; and

(d) "member of the Forum Fisheries Agency" means a Party to the South Pacific Forum Fisheries Agency Convention, 1979.

(e) "Regional Register" means the Regional Register of Foreign Fishing Vessels maintained by the South Pacific Forum Fisheries Agency.

(f) "domestic vessel" means any fishing vessel -

(i) wholly owned by the Government of a Party or by any public corporation or body established by or under any law of a Party, all of the shares in which are beneficially owned by the Government of the Party;

(ii) wholly owned and controlled by one or more natural persons who are citizens or permanent residents of the Party in which the vessel is based under the relevant laws relating to nationality and citizenship of that Party; or

(iii) wholly owned and controlled by any company, society or other association of persons incorporated or established under the laws of the Party in which the vessel is based.

(g) "locally-based foreign fishing vessel" means a foreign fishing vessel which is based in a Party, lands all of its catch in that Party and/or operates under a joint venture arrangement in the territory of that Party which is approved by the Government of that Party or under arrangements whereby the operator of the vessel is participating in shore based developments or is otherwise making a substantial contribution to the development of the domestic tuna industry of the licensing Party.

(h) "foreign fishing vessel" means any fishing vessel other than a domestic vessel or a locally-based foreign fishing vessel.

\section{ARTICLE 2 SCOPE OF THE ARRANGEMENT}

2.1 The understandings found in this document will apply to all species of tuna and tuna-like species (including bill-fish and other incidental by-catch (hereinafter referred to as "tuna")), taken by purse seine vessels, wherever they may occur in the Area. 


\section{ARTICLE 3 MANAGEMENT MEETINGS}

3.1 The Parties to this Arrangement will meet once a year for the purpose of reviewing the current status of tuna stocks and to establish necessary measures for their management and conservation.

3.2 The functions of the Management Meeting are -

(a) to consider all available information including scientific data relating to catch and operations of purse seine fishing vessels within the Area and economic and socio-economic information relating to the impact of the fishery on Parties;

(b) to consider management measures, which may include, but are not limited to -

(i) the regulation of fishing effort by purse seine vessels which have good standing on the Regional Register, including the number of vessels by size class, operation type, carrying capacity, fishing power and technological capability or other grouping subject to the criteria set out in Article 5.1;

(ii) the allocation of licences as indicated in Annex 1 hereto for fishing access to the exclusive economic zones of Parties including licence denial for those foreign fishing vessels unwilling to cooperate in these management and conservation measures by failing to provide high seas catch and effort data;

(iii) the establishment of closed areas and closed seasons; and

(iv) any other management measure deemed necessary from time to time.

(c) the establishment and implementation of a system of observation and inspection consistent with regionally agreed initiatives;

(d) the more effective implementation of the First and Second Implementing Arrangements entered into pursuant to the Nauru Agreement Concerning Cooperation in the Management of Fisheries of Common Interest, 1982. The said Implementing Arrangements are annexed to this Arrangement as Annex 2;

(e) the development of surveillance and enforcement procedures consistent with regionally agreed initiatives;

(f) the referral of matters for consideration by Special Working Groups as may be considered necessary from time to time;

(g) the adoption of a budget for the management of tuna resources; and

(h) the determination of the level of contributions by Parties.

3.3 Any allocation of licences under subparagraph 3.2(b)(ii) above will take into account the strong dependence of South Pacific coastal states on fisheries resources and the special importance to them of the conservation and optimum utilization of highly migratory species of tuna in the region.

3.4 All secretariat services and arrangements for meetings will be performed by the Forum Fisheries Agency.

3.5 Each Party will ensure that its nationals and fishing vessels comply with any management measures adopted by the Management Meeting. 


\section{ARTICLE 4 \\ DECISIONS OF THE MANAGEMENT MEETING}

The decisions of the Management Meeting will be arrived at by consensus and will be binding on the Parties.

\section{ARTICLE 5 ALLOCATION OF LICENCES}

5.1 Provided vessels have good standing on the Regional Register, Parties to this Arrangement undertake to allocate licences in the following order of priority -

(a) domestic vessels;

(b) domestic vessels of another Party to this arrangement or vessels jointly operated by or on behalf of the Government of the Party in which the vessel is based and one or more other Parties;

(c) locally-based foreign fishing vessels;

(d) foreign fishing vessels with established access arrangements over previous years and with good records of compliance with national laws and regulations, the minimum terms and conditions and reporting requirements of Parties; and

(e) new foreign fishing entrants to the fishery.

\section{ARTICLE 6 \\ LICENCE ALLOCATION CRITERIA}

6.1 The Parties agree that the number of licences that may be issued to purse seine vessels of individual fleets will not exceed the limits set out in Annex 1 hereto.

6.2 Additional licences may be issued as set out in Annex 1 hereto. A premium of at least $20 \%$ will be applied to the fees payable for such additional licences.

6.3 The agreed limits on the number of licences that may be issued will be reviewed by the Management Meeting. The Parties agree that any alteration to the above maximum allocations, including the allocation of additional licences, must be approved by all the Parties. It is further understood that the Parties will aim to reduce the number of additional licences available.

6.4 In allocating licences to individual foreign purse seine vessels the Parties will apply the following criteria. Licences will be issued -

(a) firstly on the basis of the vessel's record of compliance with the national laws and regulations and reporting requirements of Parties; and

(b) secondly in chronological order of applications submitted to Parties.

6.5 Vessels with poor records of reporting and compliance with national laws and regulations of Parties will receive the lowest priority in the allocation of available licences. 


\section{ARTICLE 7 SPECIAL WORKING GROUPS}

7.1 The Management Meeting may designate Special Working Groups to examine issues arising out of the implementation of this Arrangement.

7.2 Each Party will have the right to appoint a representative to any Special Working Group.

7.3 Where expertise is not available within the Area, the Management Meeting may invite external expertise to participate in the meetings of the Groups. The costs of external experts' participation may be met by Parties to this Arrangement.

7.4 The recommendations of any Special Working Groups will be submitted in writing to the Management Meeting. The recommendations shall not be binding on Parties or the Management Meeting.

\section{ARTICLE 8 \\ INFORMAL CONSULTATIONS WITH OTHER STATES AND INTERNATIONAL ORGANISATIONS}

8.1 The Parties recognise the need to cooperate with other states or international organisations having an interest in the tuna resources within the Area.

8.2 The Parties agree that such cooperation will take place through informal consultations between the Parties and other states or international organisations.

\section{ARTICLE 9 SECRETARIAT}

9.1 The Director of the Forum Fisheries Agency will assist the Parties in the implementation and coordination of the provisions of this Arrangement.

9.2 The Director will coordinate the licensing mechanism under this Arrangement. This will include -

(a) evaluating the level of compliance by assessing returned catch reports on the South Pacific Commission/FFA Regional Tuna Fisheries Database; and

(b) evaluating reports received from Parties relating to compliance by purse seine vessels with Parties national laws and reporting requirements.

9.3 The Parties agree to comply with the rules and procedures relating to the operation of the Regional Register as agreed upon from time to time by the Forum Fisheries Committee.

9.4 In addition, the Parties will notify the Director of the name, call sign, local licence or registration number and regional register number, if any, of all purse seine vessels licensed to fish in their exclusive economic zones, regardless of whether such vessels are considered for the purposes of national legislation as foreign, domestic, domestic-based, locally-based foreign fishing vessels or otherwise, at two monthly intervals. Deadlines shall be set at the first day of the month for January, March, May, July, September and November.

9.5 The Director will notify the Parties of the name, call sign and registration number of all purse seine vessels licensed to fish in the exclusive economic zones of all the Parties each month and the number of licences available for allocation at any given time will be determined by reference to the list distributed by the Director. 


\section{ARTICLE 10 \\ CONSULTATIONS AND DISPUTE SETTLEMENT}

10.1 At the request of any Party, consultations will be held with any other Party within sixty (60) days of the date of receipt of the request. All other Parties will be notified of such requests for consultations and any Party will be permitted to participate in such consultations.

10.2 Any dispute arising out of the interpretation or implementation of this Arrangement between two or more Parties will be settled through peaceful negotiations.

\section{ARTICLE 11 ENTRY INTO FORCE}

11.1 This Arrangement will be open for signature by the Parties to the Nauru Agreement and is subject to ratification.

11.2 This Arrangement will enter into force 14 days following receipt by the depositary of instruments of ratification by five signatories including the Federated States of Micronesia, Republic of Kiribati and the Independent State of Papua New Guinea. Thereafter it shall enter into force for any signing or acceding State 30 days after receipt by the depositary of the instrument of ratification or accession.

11.3 The depositary for this Arrangement shall be the South Pacific Forum Fisheries Agency.

11.4 Following entry into force this Arrangement shall be open for accession by other members of the Forum Fisheries Agency not Parties to the Nauru Agreement.

11.5 Reservations to this Arrangement shall not be permitted.

11.6 Any Party may withdraw from this Arrangement by giving written notice to the depositary. Withdrawal shall take effect one year after receipt of such notice.

11.7 Any amendments to this Arrangement proposed by a Party shall be adopted by consensus.

IN WITNESS WHEREOF the undersigned, duly authorised by their respective Governments, have signed this Arrangement.

$D O N E$ at Suva this day of October 1992

Federated States of Micronesia

Republic of Kiribati

Republic of the Marshall Islands

Republic of Nauru
Republic of Palau

Papua New Guinea

Solomon Islands

Tuvalu

\section{ANNEX I}

\section{AGREED PURSE SEINE LICENCE NUMBERS}

The maximum number of licences for purse seine vessels agreed to by the 11th Annual Meeting of the Parties to the Nauru Agreement, Tarawa, Kiribati, 14-17 April, 1992 is as follows: 


\section{Multilateral Access}

USA (Treaty)

2. Bilateral Access

a) FFA Members

Australia

b) Foreign

Japan

Taiwan

South Korea

Philippines

Indonesia

3. Domestic / Locally-based foreign vessels

All Parties
Single (Additional) Group (Additional)

40

$(10)^{1}(5)^{2}$
Sub-Total $(a+b)$
32

30

32

6

3

109

10

159
(32) (5)

\section{4}

2

(5)

(5)

(22)

6

TOTAL $(1+2+3)$
1 As agreed in relation to an extension of the Treaty on Fisheries Between the Governments of Certain Pacific Island States and the Government of the
United States of America

2 Special licences for joint ventures/developmental licences as agreed with the United States in relation to an extension of the US Treaty

Attachment H — ANNEX I (Revised 1993)

\section{AGREED PURSE SEINE LICENCE NUMBERS}

The maximum number of licences for purse seine vessels agreed to by the 12th Annual Meeting of the Parties to the Nauru Agreement, Airai, Palau, 3 - 5 May 1993 is as follows. It is agreed that this revised table amends the understanding reached between the Parties at the 11th Annual Meeting of the Parties at Tarawa in April 1992, and shall remain in effect until further amended by the Parties or by a Management Meeting under Article III of the Arrangement for the Management of the Western Pacific Purse Seine Fishery

\section{Single PS (Additional) Group PS (Additional)}

1. Multilateral Access

$$
\text { USA (Treaty) }
$$

2. Bilateral Foreign Access

$$
\text { Japan }
$$

Taiwan

South Korea

Philippines

Subtotal (bilateral foreign)

$$
40 \quad 1(10)^{2(5)}
$$

32

4

2 
Single PS (Additional) Group PS (Additional)

3. Domestic / Locally Based Foreign Vessels/

Bilateral Access (FFA Members)

Total Allocation ${ }^{3}$

(a) Domestic / Bilateral Access (FFA Members)

FSM (4)

Solomon Islands (3)

(b) Locally-based Foreign Fishing Vessels

Russia (6)

Total $(1+2+3)$

${ }^{1}$ As agreed in relation to an extension of the Treaty on Fisheries Between the Governments of Certain Pacific Island States and the Government of the United States of America

2 Special licences for joint venture/developmental licences as agreed with the United States in relation to an extension of the US Treaty

3 The remaining available licence allocation for domestic, locally-based foreign fishing vessels and bilateral access for FFA members as at May 1993 is 11

\section{ANNEX 2}

\section{AN ARRANGEMENT IMPLEMENTING THE NAURU AGREEMENT SETTING FORTH MINIMUM TERMS AND CONDITIONS OF ACCESS TO THE FISHERIES ZONES OF THE PARTIES}

Pursuant to Article II, III, VII and IX of the Nauru Agreement Concerning Cooperation in the Management of Fisheries of Common Interest, hereinafter referred to as the "Nauru Agreement", wherein the Parties thereto agreed to conclude arrangements to facilitate the implementation of the Nauru Agreement, the Federated States of Micronesia, the Republic of Kiribati, the Republic of the Marshall Islands, the Republic of Nauru, the Republic of Palau, Papua New Guinea and Solomon Islands,

\section{HAVE AGREED AS FOLLOWS}

\section{Article I}

South Pacific Forum Fisheries Agency Regional Register of Fishing Vessels

The Parties shall participate in, and comply with, the Procedures for the Establishment and Operation of the South Pacific Forum Fisheries Agency Regional Register of Fishing Vessels, adopted by the South Pacific Forum Fisheries Committee at Apia, Western Samoa on 5 May 1983.

\section{Article II}

\section{Licensing Terms and Conditions}

The Parties shall establish the following minimum terms and conditions and utilize the following common formats in all of their subsequent foreign fishing agreements and their licensing requirements concerning foreign vessels fishing the common stocks of fish within the Fisheries Zones:

\section{Licensing Procedures}

(a) each foreign fishing vessel subject to this Arrangement shall be individually licensed;

(b) applications for fishing licences shall be made by telex, cable, or letter to a Party or its designated representative;

(c) payment, or the guarantee of payment, of licence fees shall be required prior to the issue of a licence;

(d) upon receipt, the licence document shall be carried on the licensed vessel and produced on demand. Production of a current valid licence number, issued in accordance with the provisions herein, shall be sufficient evidence that a vessel is licensed, pending receipt of the licence document;

(e) there shall be no refund of fees paid for the issue of a fishing licence;

(f) there shall be no transfer of licences; 


\section{Authorised Personnel}

The owner, charterer, operator, master or any other person responsible for the operation of a licensed vessel shall:

(a) allow authorised personnel to board the licensed vessel at any location as determined by the licensing Party in consultation with the person responsible for the operation of the vessel, including at ports where voyages commence or at ports within the Fisheries Zones or at sea, and to remain on board;

(b) permit authorised personnel to gather information relevant to the Fisheries Zones of any of the Parties;

(c) provide maintenance for authorised personnel, including food, accommodation and medical care of a standard at least equivalent to that provided for officers of the licensed vessel;

(d) allow authorised personnel access to facilities and equipment including satellite navigators, radios, other navigation aids and charts in order to carry out their duties on board the licensed vessel;

(e) provide reasonable facilities for authorised personnel and assist them to carry out their duties;

(f) allow authorised personnel access to catch on board for the purpose of collecting management related and biological information and sample;

(g) disembark authorised personnel at an agreed location;

(h) allow representatives of the Parties to be present at the unloading of the catch for the purpose of collecting management related and biological information and samples.

3. Catch Reporting and Maintenance of Log Book

The owner, charterer, operator, master or any other person responsible for the operation of a licensed vessel shall ensure the maintenance of catch data and log books in the following respects:

(a) keep daily catch and effort records on board the vessel within the Fisheries Zones on common catch data forms, the formats of which are set out in Appendix I;

(b) keep the relevant common catch data form current at all times and produce it on demand to any authorized personnel;

(c) make the data required on the regional catch data form available to the licensing Party or its representative within $\mathbf{4 5}$ days after the completion of each voyage.

\section{Timely Report of Catch, Entry and Exit}

The owner, charterer, operator, master or any other person responsible for the operation of a licensed vessel, except vessels under 20 gross registered tons, shall report according to instructions provided by the licensing Party, in the following respects:

(a) notice of entry of the vessel to the Fisheries Zone of the Party shall be given. Communication in this respect shall be made in the format set out in Appendix II(1);

(b) the position of the vessel shall be reported while within the Fisheries Zone of the Party on a weekly basis together with the total catch of the vessel for the last seven days in the format as set out in Appendix II (2);

(c) at the time of exit from the Fisheries Zone of the Party, the vessel's position, the total amount of fish on board and the total catch for the days elapsed since either the entry report or the previous weekly report, as the case may be, shall be reported in the format as set out in Appendix II (3);

(d) where an agreement authorizes fishing in the zones of more than one Party, the requirements of paragraphs (a) and (c) may be satisfied by reporting entry and exit into and from the combined zones of the Parties concerned.

\section{Identification of Licensed Vessels}

The owner, charterer, operator, master or any other person responsible for the operation of a licensed vessel shall ensure that the licensed vessel displays standard identification marks in the following respects:

(a) the radio call sign of the vessel be displayed in a prominent position on the vessel where it can be readily identified from the air or sea;

(b) in cases where the vessel does not possess a radio call sign, the vessel registration number be displayed in the manner described above;

(c) the letters and numbers described above be at least one metre high, clear and distinct and coloured black on white, white on black or similar contrasting colours;

(d) the vessel's name be painted clearly in English in large letters on the bow and stern of the vessel. 


\section{Article III}

\section{Legislative Effect}

1. Each Party agrees to ensure compliance with the minimum terms and conditions of access set out in Article II of this Arrangement, if necessary by the enactment of legislation.

2. Each Party shall communicate to the Government of Solomon Islands, as the depositary of the Nauru Agreement, the text of any legislation it has enacted in order to give effect to this Arrangement.

\section{Article IV}

\section{Signature and Effect}

1. This Arrangement shall be open for signature by the Parties to the Nauru Agreement.

2. This Arrangement shall take effect 30 days following signature by the fourth Party. Thereafter, it shall take effect for any signing Party 30 days after receipt by the depositary of notification of signature.

3. This Arrangement shall be deposited with the Government of Solomon Islands.

4. Reservations of this Arrangement shall not be permitted.

\section{Article V}

Withdrawal or Amendment

1. Any Party may withdraw from this Arrangement by giving written notice to the depositary. Withdrawal shall take effect one year after receipt of such notice.

2. Any amendments to this Arrangement proposed by a Party shall be adopted only by unanimous decision of the Parties to this Arrangement.

\section{Article VI}

\section{The Nauru Agreement}

This Arrangement is subordinated to and governed by the Nauru Agreement.

IN WITNESS WHEREOF the undersigned, being duly authorised by their respective Governments have signed this Arrangement.

Federated States of Micronesia

Republic of Kiribati

Republic of the Marshall Islands

Republic of Nauru

Republic of Palau

Papua New Guinea

Solomon Islands

\section{A SECOND ARRANGEMENT IMPLEMENTING THE NAURU AGREEMENT SETTING FORTH ADDITIONAL TERMS AND CONDITIONS OF ACCESS TO THE FISHERIES ZONES OF THE PARTUES}

Pursuant to Articles II, III, and IX of the Nauru Agreement Concerning Cooperation in the Management of Fisheries of Common Interest, hereafter referred to as the "Nauru Agreement", wherein the Parties thereto agreed to conclude arrangements to facilitate the implementation of the Nauru Agreement, the Federated States of Micronesia, the Republic of Kiribati, the Republic of the Marshall Islands, the Republic of Nauru, the Republic of Palau, Papua New Guinea and Solomon Islands 


\section{HAVE AGREED AS FOLLOWS:}

\section{Article I}

\section{Licensing Terms and Conditions}

In addition to those terms and conditions provided in Article II of An Arrangement Implementing the Nauru Agreement Setting Forth Minimum Terms and Conditions of Access to the Fisheries Zones of the Parties, the Parties shall establish the following minimum terms and conditions and utilize the prescribed common formats in all of their subsequent foreign fishing agreements and their licensing requirements concerning foreign vessels fishing the common stocks of fish within the Fisheries Zones and shall not issue licences unless the minimum terms and conditions are accepted and observed:

\section{Transhipment at Sea Prohibited}

The owner, charterer, operator, master or any other person responsible for the operation of a licensed vessel (hereafter referred to as "the operator") shall not tranship fish at sea whether such transhipment is done within a fisheries zone of a licensing Party or on the high seas and shall tranship only through ports designated by the licensing Party;

\section{High Seas Catch Reporting and Maintenance of Log Books}

Where a vessel is licensed to fish in one or more Fisheries Zones and is also used for fishing in the high seas during a fishing trip, the operator shall:

(a) keep daily catch and effort records on board the vessel within the high seas on prescribed forms;

(b) keep the relevant catch data form current at all times and produce it on demand to any authorized personnel; and

(c) in accordance with the Minutes of an Agreement made in Palau on 19 September 1990, send by registered airmail to each licensing Party or its representative the following reports covering catch and effort in each Zone and the high seas for the whole trip:

(i) a preliminary report within 14 days of the completion of a trip; and

(ii) a final report within $\mathbf{4 5}$ days of the completion of the trip .

\section{Observers}

Upon request by a licensing Party, observers shall be placed on board licensed vessels and the operator and/or fishermen's association and/or flag state government shall pay the costs of such observers including:

(a) full travel costs from the licensing country to the vessel and return;

(b) salary; and

(c) full insurance coverage.

\section{Article II}

\section{Electronic Position and Data Transfer Technology}

The operator and/or fishermen's association and/or flag state government shall ensure that an appropriate electronic positioning monitoring and data transfer device is installed and maintained in good working order on the vessel upon the request of the licensing Party.

\section{Article III}

Signature and Effect

1. This Arrangement shall be open for signature by the Parties to the Nauru Agreement.

2. This Arrangement shall take effect 30 days following receipt by the depositary of the fifth instrument of approval. Thereafter, it shall take effect for any signing Party 30 days after receipt by the depositary of the instrument of approval.

3. This Arrangement shall be deposited with the Government of the Solomon Islands.

4. Reservations to this Arrangement shall not be permitted. 


\section{Article IV}

Amendment and Withdrawal

1. Any party may withdraw from this Arrangement by giving written notice to the depositary. Withdrawal shall take effect one year after receipt of such notice.

2. Any amendment to this Arrangement proposed by a party shall be adopted only by unanimous decision of the Parties to this Arrangement.

\section{Article V}

\section{The Nauru Agreement}

This Arrangement is subordinate to and governed by the Nauru Agreement.

IN WITESS WHEREOF the undersigned, being duly authorised by their respective Governments have signed this Agreement.

DONE at Koror this 19th day of September 1990

Federated States of Micronesia

Republic of Kiribati

Republic of the Marshall Islands

Republic of Nauru

Republic of Palau

Papua New Guinea

Solomon Islands 


\title{
Agreement to Promote Compliance with International Conservation and Management Measures by Fishing Vessels on the High Seas, Rome, 1993
}

Done at Rome 24 November 1993

\author{
Not in force \\ Depositary: United Nations \\ Primary source citation: United States Treaty \\ Document 103-24
}

\begin{abstract}
AGREEMENT TO PROMOTE COMPLIANCE WITH INTERNATIONAL CONSERVATION AND MANAGEMENT MEASURES BY FISHING VESSELS ON THE HIGH SEAS
\end{abstract}

\author{
PREAMBLE
}

The Parties to this Agreement,

Recognizing that all States have the right for their nationals to engage in fishing on the high seas, subject to the relevant rules of international law, as reflected in the United Nations Convention on the Law of the Sea,

Further recognizing that, under international law as reflected in the United Nations Convention on the Law of the Sea, all States have the duty to take, or to cooperate with other States in taking, such measures for their respective nationals as may be necessary for the conservation of the living resources of the high seas,

Acknowledging the right and interest of all States to develop their fishing sectors in accordance with their national policies, and the need to promote cooperation with developing countries to enhance their capabilities to fulfill their obligations under this Agreement,

Recalling that Agenda 21, adopted by the United Nations Conference on Environment and Development, calls upon States to take effective action, consistent with international law, to deter reflagging of vessels by their nationals as a means of avoiding compliance with applicable conservation and management rules for fishing activities on the high seas,

Further recalling that the Declaration of Cancun, adopted by the International Conference on Responsible Fishing, also calls on States to take action in this respect,

Bearing in mind that under Agenda 21, States commit themselves to the conservation and sustainable use of marine living resources on the high seas, 
Calling upon States which do not participate in global, regional or subregional fisheries organizations or arrangements to join or, as appropriate, to enter into understandings with such organizations or with parties to such organizations or arrangements with a view to achieving compliance with international conservation and management measures,

Conscious of the duties of every State to exercise effectively its jurisdiction and control over vessels flying its flag, including fishing vessels and vessels engaged in the transhipment of fish,

Mindful that the practice of flagging or reflagging fishing vessels as a means of avoiding compliance with international conservation and management measures for living marine resources, and the failure of flag States to fulfill their responsibilities with respect to fishing vessels entitled to fly their flag, are among the factors that seriously undermine the effectiveness of such measures,

Realizing that the objective of this Agreement can be achieved through specifying flag States' responsibility in respect of fishing vessels entitled to fly their flags and operating on the high seas, including the authorization by the flag State of such operations, as well as through strengthened international cooperation and increased transparency through the exchange of information on high seas fishing,

Noting that this Agreement will form an integral part of the International Code of Conduct for Responsible Fishing called for in the Declaration of Cancun,

Desiring to conclude an international agreement within the framework of the Food and Agriculture Organization of the United Nations, hereinafter referred to as FAO, under Article XIV of the FAO Constitution,

Have agreed as follows:

\section{ARTICLE 1-DEFINITIONS}

For the purposes of this Agreement:

(a) "fishing vessel" means any vessel used or intended for use for the purposes of the commercial exploitation of living marine resources, including mother ships and any other vessels directly engaged in such fishing operations;

(b) "international conservation and management measures" means measures to conserve or manage one or more species of living marine resources that are adopted and applied in accordance with the relevant rules of international law as reflected in the 1982 United Nations Convention on the Law of the Sea. Such measures may be adopted either by global, regional or subregional fisheries organizations, subject to the rights and obligations of their members, or by treaties or other international agreements;

(c) "length" means

(i) for any fishing vessel built after 18 July 1982, 96 percent of the total length on a waterline at 85 percent of the least moulded depth measured from the top of the keel, or the length from the foreside of the stem to the axis of the rudder stock on that waterline, if that be greater. In ships designed with a rake of keel the waterline on which this length is measured shall be parallel to the designed waterline;

(ii) for any fishing vessel built before $18 \mathrm{July} 1982$, registered length as entered on the national register or other record of vessels;

(d) "record of fishing vessels" means a record of fishing vessels in which are recorded pertinent details of the fishing vessel. It may constitute a separate record for fishing vessels or form part of a general record of vessels; 
(e) "regional economic integration organization" means a regional economic integration organization to which its member States have transferred competence over matters covered by this Agreement, including the authority to make decisions binding on its member States in respect of those matters;

(f) "vessels entitled to fly its flag" and "vessels entitled to fly the flag of a State", includes vessels entitled to fly the flag of a member State of a regional economic integration organization.

\section{ARTICLE II,-APPLICATION}

1. Subject to the following paragraphs of this Article, this Agreement shall apply to all fishing vessels that are used or intended for fishing on the high seas.

2. A Party may exempt fishing vessels of less than 24 meters in length entitled to fly its flag from the application of this Agreement unless the Party determines that such an exemption would undermine the object and purpose of this Agreement, provided that such exemptions:

(a) shall not be granted in respect of fishing vessels operating in fishing regions referred to in paragraph 3 below, other than fishing vessels that are entitled to fly the flag of a coastal State of that fishing region; and

(b) shall not apply to the obligations undertaken by a Party under paragraph 1 of Article III, or paragraph 7 of Article VI of this Agreement.

3. Without prejudice to the provisions of paragraph 2 above, in any fishing region where bordering coastal States have not yet declared exclusive economic zones, or equivalent zones of national jurisdiction over fisheries, such coastal States as are Parties to this Agreement may agree, either directly or through appropriate regional fisheries organizations, to establish a minimum length of fishing vessels below which this Agreement shall not apply in respect of fishing vessels flying the flag of any such coastal State and operating exclusively in such fishing region.

\section{ARTICLE II.-FLAG STATE RESPONSIBIITY}

1. (a) Each Party shall take such measures as may be necessary to ensure that fishing vessels entitled to fly its flag do not engage in any activity that undermines the effectiveness of international conservation and management measures.

(b) In the event that a Party has, pursuant to paragraph 2 of Article II, granted an exemption for fishing vessels of less than 24 metres in length entitled to fly its flag from the application of other provisions of this Agreement, such Party shall nevertheless take effective measures in respect of any such fishing vessel that undermines the effectiveness of international conservation and management measures. These measures shall be such as ensure that the fishing vessel ceases to engage in activities that undermine the effectiveness of the international conservation and management measures.

2. In particular, no Party shall allow any fishing vessel entitled to fly its flag to be used for fishing on the high seas unless it has been authorized to be so used by the appropriate authority or authorities of that Party. A fishing vessel so authorized shall fish in accordance with the conditions of the authorization.

3. No Party shall authorize any fishing vessel entitled to fly its flag to be used for fishing on the high seas unless the Party is satisfied that it is able, taking into account the links that exist between it and the fishing vessel concerned, to exercise effectively its responsibilities under this Agreement in respect of that fishing vessel.

4. Where a fishing vessel that has been authorized to be used for fishing on the high seas by a Party ceases to be entitled to fly the flag of that Party, the authorization to fish on the high seas shall be deemed to have been canceled. 
5. (a) No Party shall authorize any fishing vessel previously registered in the territory of another Party that has undermined the effectiveness of international conservation and management measures to be used for fishing on the high seas, unless it is satisfied that

(i) any period of suspension by another Party of an authorization for such fishing vessel to be used for fishing on the high seas has expired; and

(ii) no authorization for such fishing vessel to be used for fishing on the high seas has been withdrawn by another Party within the last three years.

(b) The provisions of subparagraph (a) above shall also apply in respect of fishing vessels previously registered in the territory of a State which is not a Party to this Agreement, provided that sufficient information is available to the Party concerned on the circumstances in which the authorization to fish was suspended or withdrawn.

(c) The provisions of subparagraphs (a) and (b) shall not apply where the ownership of the fishing vessel has subsequently changed, and the new owner has provided sufficient evidence demonstrating that the previous owner or operator has no further legal, beneficial or financial interest in, or control of the fishing vessel.

(d) Notwithstanding the provisions of subparagraphs (a) and (b) above, a Party may authorize a fishing vessel, to which those subparagraphs would otherwise apply, to be used for fishing on the high seas, where the Party concerned, after having taken into account all relevant facts, including the circumstances in which the fishing authorization has been withdrawn by the other Party or State, has determined that to grant an authorization to use the vessel for fishing on the high seas would not undermine the object and purpose of this Agreement.

6. Each Party shall ensure that all fishing vessels entitled to fly its flag that it has entered in the record maintained under Article IV are marked in such a way that they can be readily identified in accordance with generaliy accepted standards, such as the FAO Standard Specifications for the Marking and Identification of Fishing Vessels.

7. Each Party shall ensure that each fishing vessel entitled to fly its flag shall provide it with such information on its operations as may be necessary to enable the Party to fulfill its obligations under this Agreement, including in particular information pertaining to the area of its fishing operations and to its catches and landings.

8. Each Party shall take enforcement measures in respect of fishing vessels entitled to fly its flag which act in contravention of the provisions of this Agreement, including, where appropriate, making the contravention of such provisions an offence under national legislation. Sanctions applicable in respect of such contraventions shall be of sufficient gravity as to be effective in securing compliance with the requirements of this Agreement and to deprive offenders of the benefits accruing from their illegal activities. Such sanctions shall, for serious offences, include refusal, suspension or withdrawal of the authorization to fish on the high seas.

\section{ARTICLE IV.-RECORDS OF FISHING VESSELS}

Each Party shall, for the purposes of this Agreement, maintain a record of fishing vessels entitled to fly its flag and authorized to be used for fishing on the high seas, and shall take such measures as may be necessary to ensure that all such fishing vessels are entered in that record.

\section{ARTICLE V.-INTERNATIONAL COOPERATION}

1. The Parties shall cooperate as appropriate in the implementation of this Agreement, and shall, in particular, exchange information, including evidentiary material, relating to activities of fishing vessels in order to assist the flag State in identifying those fishing vessels flying its flag reported to have engaged in activities undermining international conservation and management measures, so as to fulfill its obligations under Article III.

2. When a fishing vessel is voluntarily in the port of a Party other than its flag State, that Party, where it has reasonable grounds for believing that the fishing vessel has been used for an activity that undermines the effectiveness of international conservation and management measures, shall promptly notify the flag State accord- 
ingly. Parties may make arrangements regarding the undertaking by port States or such investigatory measures as may be considered necessary to establish whether the fishing vessel has indeed been used contrary to the provisions of this Agreement.

3. The Parties shall, when and as appropriate, enter into cooperative agreements or arrangements of mutual assistance on a global, regional, subregional or bilateral basis so as to promote the achievement of the objectives of this Agreement.

\section{ARTICLE VL-EXCHANGE OF INFORMATION}

1. Each Party shall make readily available to FAO the following information with respect to each fishing vessel entered in the record required to be maintained under Article IV:
(a) name of fishing vessel, registration number, previous names (if known), and port of registry;
(b) previous flag (if any);
(c) International Radio Call Sign (if any);
(d) name and address of owner or owners;
(e) where and when built;
(f) type of vessel;
(g) length.

2. Each Party shall, to the extent practicable, make available to FAO the following additional information with respect to each fishing vessel entered in the record required to be maintained under Article IV:
(a) name and address of operator (manager) or operators (managers) (if any);
(b) type of fishing method or methods;
(c) moulded depth;
(d) beam;
(e) gross register tonnage;
(f) power of main engine or engines.

3. Each Party shall promptly notify to FAO any modifications to the information listed in paragraphs 1 and 2 of this Article.

4. FAO shall circulate periodically the information provided under paragraphs 1,2, and 3 of this Article to all Parties, and, on request, individually to any Party. FAO shall also, subject to any restrictions imposed by the Party concerned regarding the distribution of information, provide such information on request individually to any global, regional or subregional fisheries organization.

5. Each Party shall also promptly inform FAO of-
(a) any additions to the record;
(b) any deletions from the record by reason of- 
(i) the voluntary relinquishment or non-renewal of the fishing authorization by the fishing vessel owner or operator;

(ii) the withdrawal of the fishing authorization issued in respect of the fishing vessel under paragraph 8 of Article III;

(iii) the fact that the fishing vessel concerned is no longer entitled to fly its flag;

(iv) the scrapping, decommissioning or loss of the fishing vessel concerned; or

(v) any other reason.

6. Where information is given to FAO under paragraph 5(b) above, the Party concerned shall specify which of the reasons listed in that paragraph is applicable.

7. Each Party shall inform FAO of

(a) any exemption it has granted under paragraph 2 of Article II, the number and type of fishing vessel involved and the geographical areas in which such fishing vessels operate; and

(b) any agreement reached under paragraph 3 of Article II.

8. (a) Each Party shall report promptly to FAO all relevant information regarding any activities of fishing vessels flying its flag that undermine the effectiveness of international conservation and management measures, including the identity of the fishing vessel or vessels involved and measures imposed by the Party in respect of such activities. Reports on measures imposed by a Party may be subject to such limitations as may be required by national legislation with respect to confidentiality, including, in particular, confidentiality regarding measures that are not yet final.

(b) Each Party, where it has reasonable grounds to believe that a fishing vessel not entitled to fly its flag has engaged in any activity that undermines the effectiveness of international conservation and management measures, shall draw this to the attention of the flag State concerned and may, as appropriate, draw it to the attention of FAO. It shall provide the flag State with full supporting evidence and may provide FAO with a summary of such evidence. FAO shall not circulate such information until such time as the flag State has had an opportunity to comment on the allegation and evidence submitted, or to object as the case may be.

9. Each Party shall inform FAO of any cases where the Party, pursuant to paragraph 5 (d) of Article III, has granted an authorization notwithstanding the provisions of paragraph 5 (a) or 5 (b) of Article III. The information shall include pertinent data permitting the identification of the fishing vessel and the owner or operator and, as appropriate, any other information relevant to the Party's decision.

10. FAO shall circulate promptly the information provided under paragraphs 5, 6, 7, 8 and 9 of this Article to all Parties, and, on request, individually to any Party. FAO shall also, subject to any restrictions imposed by the Party concerned regarding the distribution of information, provide such information promptly on request individually to any global, regional or subregional fisheries organization.

11. The Parties shall exchange information relating to the implementation of this Agreement, including through FAO and other appropriate global, regional and subregional fisheries organizations.

\section{ARTICLE VII.-COOPERATION WITH DEVELOPING COUNTRIES}

The Parties shall cooperate, at a global, regional, subregional or bilateral level, and, as appropriate, with the support of FAO and other international or regional organizations, to provide assistance, including technical assistance, to Parties that are developing countries in order to assist them in fulfilling their obligations under this Agreement. 


\section{ARTICLE VII_-NON.PARTIES}

1. The Parties shall encourage any State not party to this Agreement to accept this Agreement and shall encourage any non-Party to adopt laws and regulations consistent with the provisions of this Agreement.

2. The Parties shall cooperate in a manner consistent with this Agreement and with international law to the end that fishing vessels entitled to fly the flags of non-Parties do not engage in activities that undermine the effectiveness of international conservation and management measures.

3. The Parties shall exchange information amongst themselves, either directly or through FAO, with respect to activities of fishing vessels flying the flags of non-Parties that undermine the effectiveness of international conservation and management measures.

\section{ARTICLE IX.SETTLEMENT OF DISPUTES}

1. Any Party may seek consultations with any other Party or Parties on any dispute with regard to the interpretation or application of the provisions of this Agreement with a view to reaching a mutually satisfactory solution as soon as possible.

2. In the event that the dispute is not resolved through these consultations within a reasonable period of time, the Parties in question shall consult among themselves as soon as possible with a view to having the dispute settled by negotiation, inquiry, mediation, conciliation, arbitration, judicial settlement or other peaceful means of their own choice.

3. Any dispute of this character not so resolved shall, with the consent of all Parties to the dispute, be referred for settlement to the International Court of Justice, to the International Tribunal for the Law of the Sea upon entry into force of the 1982 United Nations Convention on the Law of the Sea or to arbitration. In the case of failure to reach agreement on referral to the International Court of Justice, to the International Tribunal for the Law of the Sea or to arbitration, the Parties shall continue to consult and cooperate with a view to reaching settlement of the dispute in accordance with the rules of international law relating to the conservation of living marine resources.

\section{ARTICLE X-ACCEPTANCE}

1. This Agreement shall be open to acceptance by any Member or Associate Member of FAO, and to any non-member State that is a member of the United Nations, or of any of the specialized agencies of the United Nations or of the International Atomic Energy Agency.

2. Acceptance of this Agreement shall be effected by the deposit of an instrument of acceptance with the Director-General of FAO, hereinafter referred to as the Director-General.

3. The Director-General shall inform all Parties, all Members and Associate Members of FAO and the Secretary-General of the United Nations of all instruments of acceptance received.

4. When a regional economic integration organization becomes a Party to this Agreement, such regional economic integration organization shall, in accordance with the provisions of Article II.7 of the FAO Constitution, as appropriate, notify such modifications or clarifications to its declaration of competence submitted under Article II.5 of the FAO Constitution as may be necessary in light of its acceptance of this Agreement. Any Party to this Agreement may, at any time, request a regional economic integration organization that is a Party to this Agreement to provide information as to which, as between the regional economic integration organization and its Member States, is responsible for the implementation of any particular matter covered by this Agreement. The regional economic integration organization shall provide this information within a reasonable time. 


\section{ARTICLE XI.-ENTRY INTO FORCE}

1. This Agreement shall enter into force as from the date of receipt by the Director-General of the twenty-fifth instrument of acceptance.

2. For the purpose of this Article, an instrument deposited by a regional economic integration organization shall not be counted as additional to those deposited by member States of such an organization.

\section{ARTICLE XII.-RESERVATIONS}

Acceptance of this Agreement may be made subject to reservations which shall become effective only upon unanimous acceptance by all Parties to this Agreement. The Director-General shall notify forthwith all Parties of any reservation. Parties not having replied within three months from the date of the notification shall be deemed to have accepted the reservation. Failing such acceptance, the State or regional economic integration organization making the reservation shall not become a Party to this Agreement.

\section{ARTICLE XII_-AMENDMENTS}

1. Any proposal by a Party for the amendment of this Agreement shall be communicated to the DirectorGeneral.

2. Any proposed amendment of this Agreement received by the Director-General from a Party shall be presented to a regular or special session of the Conference for approval and, if the amendment involves important technical changes or imposes additional obligations on the Parties, it shall be considered by an advisory committee of specialists convened by FAO prior to the Conference.

3. Notice of any proposed amendment of this Agreement shall be transmitted to the Parties by the Director-General not later than the time when the agenda of the session of the Conference at which the matter is to be considered is dispatched.

4. Any such proposed amendment of this Agreement shall require the approval of the Conference and shall come into force as from the thirtieth day after acceptance by two-thirds of the Parties. Amendments involving new obligations for Parties, however, shall come into force in respect of each Party only on acceptance by it and as from the thirtieth day after such acceptance. Any amendment shall be deemed to involve new obligations for Parties unless the Conference, in approving the amendment, decides otherwise by consensus.

5. The instruments of acceptance of amendments involving new obligations shall be deposited with the Director-General, who shall inform all Parties of the receipt of acceptance and the entry into force of amendments.

6. For the purpose of this Article, an instrument deposited by a regional economic integration organization shall not be counted as additional to those deposited by member States of such an organization.

\section{ARTICLE XIV,-WITHDRAWAL}

Any Party may withdraw from this Agreement at any time after the expiry of two years from the date upon which the Agreement entered into force with respect to that Party, by giving written notice of such withdrawal to the Director-General who shall immediately inform all the Parties and the Members and Associate Members of FAO of such withdrawal. Withdrawal shall become effective at the end of the calendar year following that in which the notice of withdrawal has been received by the Director-General. 


\section{ARTICLE XV_-DUTIES OF THE DEPOSITARY}

The Director-General shall be the Depositary of this Agreement. The Depositary shall:

(a) send certified copies of this Agreement to each Member and Associate Member of FAO and to such non-member States as may become party to this Agreement;

(b) arrange for the registration of this Agreement, upon its entry into force, with the Secretariat of the United Nations in accordance with Article 102 of the Charter of the United Nations;

(c) inform each Member and Associate Member of FAO and any non-member States as may become Party to this Agreement of:

(i) instruments of acceptance deposited in accordance with Article X;

(ii) the date of entry into force of this Agreement in accordance with Article XI;

(iii) proposals for and the entry into force of amendments to this Agreement in accordance with Article XIII;

(iv) withdrawals from this Agreement pursuant to Article XIV.

\section{ARTICLE XVI.-AUTHENTIC TEXTS}

The Arabic, Chinese, English, French, and Spanish texts of this Agreement are equally authentic. 


\section{Convention for the Conservation of Southern Bluefin Tuna, Canberra, 1993}

Done at Canberra 10 May 1993

Not in force*

Primary source citation: Copy of text provided by the

National Marine Fisheries Service, U.S. Department

of Commerce

\section{CONVENTION FOR THE CONSERVATION OF SOUTHERN BLUEFIN TUNA}

The Parties to this Convention:

Considering their mutual interest in southern bluefin tuna;

Recalling that Australia, Japan and New Zealand have already taken certain measures for the conservation and management of southern bluefin tuna;

Paying due regard to the rights and obligations of the Parties under relevant principles of international law;

Noting the adoption of the United Nations Convention on the Law of the Sea in 1982;

Noting that States have established exclusive economic or fishery zones within which they exercise, in accordance with international law, sovereign rights or jurisdiction for the purpose of exploring and exploiting, conserving and managing the living resources;

Recognising that southern bluefin tuna is a highly migratory species which migrates through such zones;

Noting that the coastal States through whose exclusive economic or fishery zones southern bluefin tuna migrates exercise sovereign rights within such zones for the purpose of exploring and exploiting, conserving and managing the living resources including southern bluefin tuna;

Acknowledging the importance of scientific research for the conservation and management of southern bluefin tuna and the importance of collecting scientific information relating to southern bluefin tuna and ecologically related species;

Recognising that it is essential that they cooperate to ensure the conservation and optimum utilisation of southern bluefin tuna;

Have agreed as follows:

\section{Article 1}

This Convention shall apply to southern bluefin tuna (Thunnus maccoyii).

\footnotetext{
* The United States is not a party to this Convention.
} 


\section{Article 2}

For the purposes of this Convention:

(a) "ecologically related species" means living marine species which are associated with southern bluefin tuna, including but not restricted to both predators and prey of southern bluefin tuna;

(b) "fishing" means:

(i) the catching, taking or harvesting of fish, or any other activity which can reasonably be expected to result in the catching, taking or harvesting of fish; or

(ii) any operation at sea in preparation for or in direct support of any activity described in sub-paragraph (i) above.

\section{Article 3}

The objective of this Convention is to ensure, through appropriate management, the conservation and optimum utilisation of southern bluefin tuna.

\section{Article 4}

Nothing in this Convention nor any measures adopted pursuant to it shall be deemed to prejudice the positions or views of any Party with respect to its rights and obligations under treaties and other international agreements to which it is party or its positions or views with respect to the law of the sea.

\section{Article 5}

1. Each Party shall take all action necessary to ensure the enforcement of this Convention and compliance with measures which become binding under paragraph 7 of Article 8.

2. The Parties shall expeditiously provide to the Commission for the Conservation of Southern Bluefin Tuna scientific information, fishing catch and effort statistics and other data relevant to the conservation of southern bluefin tuna and, as appropriate, ecologically related species.

3. The Parties shall cooperate in collection and direct exchange, when appropriate, of fisheries data, biological samples and other information relevant for scientific research on southern bluefin tuna and ecologically related species.

4. The Parties shall cooperate in the exchange of information regarding any fishing for southern bluefin tuna by nationals, residents and vessels of any State or entity not party to this Convention.

\section{Article 6}

1. The Parties hereby establish and agree to maintain the Commission for the Conservation of Southern Bluefin Tuna (hereinafter referred to as "the Commission").

2. Each Party shall be represented on the Commission by not more than three delegates who may be accompanied by experts and advisers.

3. The Commission shall hold an annual meeting before 1 August each year or at such other time as it may determine. 
4. At each annual meeting the Commission shall elect from among the delegates a Chair and a Vice-Chair. The Chair and the Vice-Chair shall be elected from different Parties and shall remain in office until the election of their successors at the next annual meeting. A delegate, when acting as Chair, shall not vote.

5. Special meetings of the Commission shall be convened by the Chair at the request of a Party supported by at least two other Parties.

6. A special meeting may consider any matter of relevance to this Convention.

7. Two-thirds of the Parties shall constitute a quorum.

8. The rules of procedure of the Commission and other internal administrative regulations as may be necessary to carry out its functions shall be decided upon at the first meeting of the Commission and may be amended by the Commission as occasion may require.

9. The Commission shall have legal personality and shall enjoy in its relations with other international organisations and in the territories of the Parties such legal capacity as may be necessary to perform its functions and achieve its ends. The immunities and privileges which the Commission and its officers shall enjoy in the territory of a Party shall be subject to agreement between the Commission and the Party concerned.

10. The Commission shall determine the location of its headquarters at such time as a Secretariat is established pursuant to paragraph 1 of Article 10.

11. The official languages of the Commission shall be Japanese and English. Proposals and data may be submitted to the Commission in either language.

\section{Article 7}

Each Party shall have one vote in the Commission. Decisions of the Commission shall be taken by a unanimous vote of the Parties present at the Commission meeting.

\section{Article 8}

1. The Commission shall collect and accumulate information described below:

(a) scientific information, statistical data and other information relating to southern bluefin tuna and ecologically related species;

(b) information relating to laws, regulations and administrative measures on southern bluefin tuna fisheries;

(c) any other information relating to southern bluefin tuna.

2. The Commission shall consider matters described below:

(a) interpretation or implementation of this Convention and measures adopted pursuant to it;

(b) regulatory measures for conservation, management and optimum utilisation of southern bluefin tuna;

(c) matters which shall be reported by the Scientific Committee prescribed in Article 9;

(d) matters which may be entrusted to the Scientific Committee prescribed in Article 9;

(e) matters which may be entrusted to the Secretariat prescribed in Article 10;

(f) other activities necessary to carry out the provisions of this Convention. 
3. For the conservation, management and optimum utilisation of southern bluefin tuna:

(a) the Commission shall decide upon a total allowable catch and its allocation among the Parties unless the Commission decides upon other appropriate measures on the basis of the report and recommendations of the Scientific Committee referred to in paragraph 2(c) and (d) of Article 9; and

(b) the Commission may, if necessary, decide upon other additional measures.

4. In deciding upon allocations among the Parties under paragraph 3 above the Commission shall consider:

(a) relevant scientific evidence;

(b) the need for orderly and sustainable development of southern bluefin tuna fisheries;

(c) the interests of Parties through whose exclusive economic or fishery zones southern bluefin tuna migrates;

(d) the interests of Parties whose vessels engage in fishing for southern bluefin tuna including those which have historically engaged in such fishing and those which have southern bluefin tuna fisheries under development;

(e) the contribution of each Party to conservation and enhancement of, and scientific research on, southern bluefin tuna;

(f) any other factors which the Commission deems appropriate.

5. The Commission may decide upon recommendations to the Parties in order to further the attainment of the objective of this Convention.

6. In deciding upon measures under paragraph 3 above and recommendations under paragraph 5 above, the Commission shall take full account of the report and recommendations of the Scientific Committee under paragraph 2(c) and (d) of Article 9.

7. All measures decided upon under paragraph 3 above shall be binding on the Parties.

8. The Commission shall notify all Parties promptly of measures and recommendations decided upon by the Commission.

9. The Commission shall develop, at the earliest possible time and consistent with international law, systems to monitor all fishing activities related to southern bluefin tuna in order to enhance scientific knowledge necessary for conservation and management of southern bluefin tuna and in order to achieve effective implementation of this Convention and measures adopted pursuant to it.

10. The Commission may establish such subsidiary bodies as it considers desirable for the exercise of its duties and functions.

\section{Article 9}

1. The Parties hereby establish the Scientific Committee as an advisory body to the Commission.

2. The Scientific Committee shall:

(a) assess and analyse the status and trends of the population of southern bluefin tuna;

(b) coordinate research and studies of southern bluefin tuna;

(c) report to the Commission its findings or conclusions, including consensus, majority and minority views, on the status of the southern bluefin tuna stock and, where appropriate, of ecologically related species; 
(d) make recommendations, as appropriate, to the Commission by consensus on matters concerning the conservation, management and optimum utilisation of southern bluefin tuna;

(e) consider any matter referred to it by the Commission.

3. A meeting of the Scientific Committee shall be held prior to the annual meeting of the Commission. A special meeting of the Scientific Committee shall be called at any time at the request of a Party provided that such request is supported by at least two other Parties.

4. The Scientific Committee shall adopt and amend as necessary its rules of procedure. The rules and any amendments thereto shall be approved by the Commission.

5. (a) Each Party shall be a member of the Scientific Committee and shall appoint to the Committee a representative with suitable scientific qualifications who may be accompanied by alternates, experts and advisers.

(b) The Scientific Committee shall elect a Chair and a Vice-Chair. The Chair and the Vice-Chair shall be elected from different Parties.

\section{Article 10}

1. The Commission may establish a Secretariat consisting of an Executive Secretary to be appointed by the Commission and appropriate staff on conditions as may be determined by the Commission. The staff shall be appointed by the Executive Secretary.

2. Until such time as a Secretariat is established, the Chair of the Commission shall nominate from within his or her Government an official to act as Secretary to the Commission to perform the secretariat functions set out in paragraph 3 below for a term of one year. At each annual meeting of the Commission, the Chair shall advise the Parties of the name and address of the Secretary.

3. The Secretariat functions shall be prescribed by the Commission, and shall include the following:

(a) receiving and transmitting the Commission's official communications;

(b) facilitating the collection of data necessary to accomplish the objective of this Convention;

(c) preparing administrative and other reports for the Commission and the Scientific Committee.

\section{Article 11}

1. The Commission shall decide upon an annual budget.

2. The contributions to the annual budget from each Party shall be calculated on the following basis:

(a) $30 \%$ of the budget shall be divided equally among all the Parties; and

(b) $70 \%$ of the budget shall be divided in proportion to the nominal catches of southern bluefin tuna among all the Parties.

3. Notwithstanding the provisions of Article 7, any Party that has not paid its contributions for two consecutive years shall not enjoy the right to participate in the decision-making process in the Commission until it has fulfilled its obligations, unless the Commission decides otherwise.

4. The Commission shall decide upon, and amend as occasion may require, financial regulations for the conduct of the Commission and for the exercise of its functions. 
5. Each Party shall meet its own expenses arising from attendance at meetings of the Commission and of the Scientific Committee.

\section{Article 12}

The Commission shall collaborate with other inter-governmental organisations which have related objectives, inter alia, to obtain the best available information including scientific information to further the attainment of the objective of this Convention and shall seek to avoid duplication with respect to their work. The Commission may make arrangements with such inter-governmental organisations to these ends.

\section{Article 13}

With a view to furthering the attainment of the objective of this Convention, the Parties shall cooperate with each other to encourage accession by any State to this Convention where the Commission considers this to be desirable.

\section{Article 14}

1. The Commission may invite any State or entity not party to this Convention, whose nationals, residents or fishing vessels harvest southern bluefin tuna, and any coastal State through whose exclusive economic or fishery zone southern bluefin tuna migrates, to send observers to meetings of the Commission and of the Scientific Committee.

2. The Commission may invite inter-governmental or, on request, non-governmental organisations having special competence concerning southern bluefin tuna to send observers to meetings of the Commission.

\section{Article 15}

1. The Parties agree to invite the attention of any State or entity not party to this Convention to any matter relating to the fishing activities of its nationals, residents or vessels which could affect the attainment of the objective of this Convention.

2. Each Party shall encourage its nationals not to associate with the southern bluefin tuna fishery of any State or entity not party to this Convention, where such association could affect adversely the attainment of the objective of this Convention.

3. Each Party shall take appropriate measures aimed at preventing vessels registered under its laws and regulations from transferring their registration for the purpose of avoiding compliance with the provisions of this Convention or measures adopted pursuant to it.

4. The Parties shall cooperate in taking appropriate action, consistent with international law and their respective domestic laws, to deter fishing activities for southern bluefin tuna by nationals, residents or vessels of any State or entity not party to this Convention where such activity could affect adversely the attainment of the objective of this Convention.

\section{Article 16}

1. If any dispute arises between two or more of the Parties concerning the interpretation or implementation of this Convention, those Parties shall consult among themselves with a view to having the dispute resolved by negotiation, inquiry, mediation, conciliation, arbitration, judicial settlement or other peaceful means of their own choice. 
2. Any dispute of this character not so resolved shall, with the consent in each case of all parties to the dispute, be referred for settlement to the International Court of Justice or to arbitration; but failure to reach agreement on reference to the International Court of Justice or to arbitration shall not absolve parties to the dispute from the responsibility of continuing to seek to resolve it by any of the various peaceful means referred to in paragraph 1 above.

3. In cases where the dispute is referred to arbitration, the arbitral tribunal shall be constituted as provided in the Annex to this Convention. The Annex forms an integral part of this Convention.

\section{Article 17}

1. This Convention shall be open for signature by Australia, Japan and New Zealand.

2. This Convention is subject to ratification, acceptance or approval by these three States in accordance with their respective internal legal procedures, and will enter into force on the date of deposit of the third instrument of ratification, acceptance or approval.

\section{Article 18}

After the entry into force of this Convention, any other State, whose vessels engage in fishing for southern bluefin tuna, or any other coastal State through whose exclusive economic or fishery zone southern bluefin tuna migrates, may accede to it. This Convention shall become effective for any such other State on the date of deposit of that State's instrument of accession.

\section{Article 19}

Reservations may not be made with respect to any of the provisions of this Convention.

\section{Article 20}

Any Party may withdraw from this Convention twelve months after the date on which it formally notifies the Depositary of its intention to withdraw.

\section{Article 21}

1. Any Party may at any time propose an amendment to this Convention.

2. If one-third of the Parties request a meeting to discuss a proposed amendment the Depositary shall call such a meeting.

3. An amendment shall enter into force when the Depositary has received instruments of ratification, acceptance or approval thereof from all the Parties.

\section{Article 22}

1. The original of this Convention shall be deposited with the Government of Australia, which shall be the Depositary. The Depositary shall transmit certified copies thereof to all other Signatories and acceding States.

2. This Convention shall be registered by the Depositary pursuant to Article 102 of the Charter of the United Nations. 
IN WITNESS WHEREOF the undersigned, being duly authorised thereto, have signed this Convention.

DONE AT Canberra on the tenth day of May 1993, in a single original, in the English and Japanese languages, each text being equally authentic.

\section{ANNEX FOR AN ARBITRAL TRIBUNAL}

1. The arbitral tribunal referred to in paragraph 3 of Article 16 shall be composed of three arbitrators who shall be appointed as follows:

(a) The party commencing proceedings shall communicate the name of an arbitrator to the other party which, in turn, within a period of forty days following such notification, shall communicate the name of the second arbitrator. The parties shall, within a period of sixty days following the appointment of the second arbitrator, appoint the third arbitrator, who shall not be a national of either party and shall not be of the same nationality as either of the first two arbitrators. The third arbitrator shall preside over the tribunal.

(b) If the second arbitrator has not been appointed within the prescribed period, or if the parties have not reached agreement within the prescribed period on the appointment of the third arbitrator, that arbitrator shall be appointed, at the request of either party, by the Secretary-General of the Permanent Court of Arbitration, from among persons of international standing not having the nationality of a State which is a Party to this Convention.

2. The arbitral tribunal shall decide where its headquarters will be located and shall adopt its own rules of procedure.

3. The award of the arbitral tribunal shall be made by a majority of its members, who may not abstain from voting.

4. Any Party which is not a party to the dispute may intervene in the proceedings with the consent of the arbitral tribunal.

5. The award of the arbitral tribunal shall be final and binding on all parties to the dispute and on any party which intervenes in the proceedings and shall be complied without delay. The arbitral tribunal shall interpret the award at the request of one of the parties to the dispute or of any intervening party.

6. Unless the arbitral tribunal determines otherwise because of the particular circumstances of the case, the expenses of the tribunal, including the remuneration of its members, shall be borne by the parties to the dispute in equal shares.

[signature]

For Australia [signature]

For Japan

[signature]

For New Zealand 


\title{
Convention on the Conservation and Management of Pollock Resources in the Central Bering Sea, Washington, D.C., 1994
}

\author{
Done at Washington, D.C. 16 June 1994 \\ Entered into force 8 December 1995 \\ Depositary: United States \\ Primary source citation: United States Treaty \\ Document 103-27
}

\section{CONVENTION ON THE CONSERVATION AND MANAGEMENT OF POLLOCK RESOURCES IN THE CENTRAL BERING SEA}

The Parties to this convention,

Recognizing the urgent necessity to cooperate in taking measures for the conservation and management of pollock resources in the central Bering Sea consistent with international law, and

Noting the adoption of the United Nations Convention on the Law of the Sea in 1982,

Have agreed as follows:

\section{ARTICLE I}

This Convention applies to the high seas area of the Bering Sea beyond 200 nautical miles from the baselines from which the breadth of the territorial sea of the coastal States of the Bering Sea is measured (hereinafter referred to as "the Convention Area"), except as otherwise provided in this Convention. Activities under this Convention, for scientific purposes, may extend beyond the Convention Area within the Bering Sea.

\section{ARTICLE II}

The objectives of this Convention shall be:

1. to establish an international regime for conservation, management, and optimum utilization of pollock resources in the Convention Area;

2. to restore and maintain the pollock resources in the Bering Sea at levels which will permit their maximum sustainable yield; 
3. to cooperate in the gathering and examining of factual information concerning pollock and other living marine resources in the Bering Sea; and

4. to provide, if the Parties agree, a forum in which to consider the establishment of necessary conservation and management measures for living marine resources other than pollock in the Convention Area as may be required in the future.

\section{ARTICLE III}

1. To achieve the objectives of this Convention, the Parties agree to:

(a) convene an Annual Conference of the Parties; and

(b) establish a Scientific and Technical Committee.

2. The Parties shall adopt and amend as necessary rules of procedure both for the Annual Conferences and the Scientific and Technical Committee.

\section{ARTICLE IV}

1. The functions of the Annual Conference shall be:

(a) to establish the allowable harvest level for pollock in the Convention Area (hereinafter referred to as "the $A H L^{\text {") }}$ for the succeeding year;

(b) to establish an individual national quota of pollock in the Convention Area (hereinafter referred to as "the INQ") for the succeeding year for each Party;

(c) to adopt other appropriate conservation and management measures for the pollock resources in the Convention Area;

(d) to establish a plan of work for the Scientific and Technical Committee (hereinafter referred to as "the Plan of Work");

(e) to receive reports from each Party relating to measures taken to investigate and penalize violations of provisions of this Convention and measures adopted pursuant thereto;

(f) to establish the terms and conditions for any trial fishing operations for pollock in the Convention Area and to determine the scope of any cooperative scientific research on living marine resources other than pollock covered by this Convention;

(g) to discuss cooperative enforcement measures;

(h) to consider the effectiveness of the Central Bering Sea Observer Program established pursuant to Article XI and to adopt a manual of the procedures for boarding and inspection referred to in Article $\mathrm{XI}$;

(i) to consider matters related to the conservation and management of living marine resources other than pollock in the Convention Area;

(j) to discuss scientific data and conservation measures of the coastal States of the Bering Sea related to pollock fishing in the Bering Sea;

(k) to discuss fishery support operations in the Convention Area, including the environmental impact of such operations; 
(1) to adopt amendments to the Annex to this Convention; and

(m) to perform other functions as follow from provisions of this Convention or as are necessary to attain the objectives of this Convention.

2. The Party that hosts the Annual Conference shall publish and maintain a record of all conservation and management measures in force in the Convention Area.

3. In exercising its functions under paragraph 1 above, the Annual Conference shall take full account of the reports and recommendations of the Scientific and Technical Committee.

\section{ARTICLE V}

1. Each Party has one vote in making decisions at the Annual Conference.

2. Except as provided elsewhere in this Convention, decisions of the Annual Conference on matters of substance shall be taken by consensus. A matter shall be deemed to be of substance if any Party considers it to be of substance.

3. Decisions on matters other than those referred to in paragraph 2 above shall be taken by a simple majority of the votes of all Parties casting affirmative or negative votes.

\section{ARTICLE VI}

1. The Annual Conferences shall be held in rotation among the Parties.

2. The site of the next Annual Conference shall be decided by the previous Annual Conference.

3. The Parties shall at the end of each Annual Conference elect a Chairperson and a Vice-Chairperson who shall serve until the end of the next Annual Conference.

\section{ARTICLE VII}

1. The Annual Conference shall establish by consensus the AHL for the succeeding year, based upon an assessment of the Aleutian Basin pollock biomass by the Scientific and Technical Committee.

2. If every effort to achieve consensus has failed, the AHL shall be determined in accordance with the provisions of Part I of the Annex.

\section{ARTICLE VII}

1. The Annual Conference shall establish by consensus the INQ for the succeeding year for each Party, the total of which shall not exceed the AHL, with the understanding that an INQ shall not be transferred to any other Party or non-Party to this Convention.

2. If every effort to achieve consensus has failed, the Parties agree that fishing for pollock in the Convention Area shall take place pursuant to the provisions of Part 2 of the Annex. 


\section{ARTICLE IX}

1. The Scientific and Technical Committee, which shall be comprised of at least one representative from each Party, shall compile, exchange, and analyze information on fisheries harvests, and pollock and other living marine resources covered by this Convention in accordance with the Plan of Work established by the Annual Conference, and shall investigate other scientific matters as may be referred to it by the Annual Conference. It shall also establish forms and procedures for the Parties to submit fisheries data as required by Article X.

2. The Scientific and Technical Committee shall hold a meeting prior to the Annual Conference and shall report to the Annual Conference the results of its meeting.

3. The Scientific and Technical Committee shall strive to adopt its reports by consensus. If every effort to achieve consensus has failed, the report shall include the differing views of the representatives of the Parties to the Scientific and Technical Committee.

4. The Scientific and Technical Committee shall make recommendations to the Annual Conference with respect to the conservation and management of pollock, including the AHL for the succeeding year.

5. The Scientific and Technical Committee may perform such functions as follow from other provisions of this Convention or as the Annual Conference may determine.

\section{ARTICLE X}

1. The Parties shall cooperate in the conduct of scientific research on the pollock resources and, as may be determined by the Annual Conference, on other living marine resources covered by this Convention, including research on the determination of migratory patterns of pollock within and beyond the Convention Area. The Parties shall also cooperate in exchanging scientific data on these resources and in adopting standardized methodologies for such scientific research.

2. The Parties shall annually submit fisheries data to the Scientific and Technical Committee including catch and effort statistics, time and area of fishing operations, incidental taking of anadromous species or other living marine resources, or other biological and technical data as may be required to meet the objectives of this Convention.

3. Each Party shall, at the request of any other Party, consult bilaterally for the purpose of accommodating scientific observers from the requesting Party on board any fishing vessel of the requested Party in the Convention Area.

4. For any year in which the AHL is zero, the Annual Conference may authorize trial fishing operations for pollock in the Convention Area to be conducted by the fishing vessels of the Parties in accordance with a research plan that was submitted by any Party concerned and is approved by the Annual Conference, based upon the recommendations of the Scientific and Technical Committee. The terms and conditions for such operations shall be established by the Annual Conference.

\section{ARTICLE XI}

1. Each Party shall take all necessary measures to ensure that its nationals and fishing vessels flying its flag comply with the provisions of this Convention and measures adopted pursuant thereto. For purposes of this Convention, "fishing vessel" means any vessel used or intended for use for the purposes of the commercial exploitation of living marine resources, including mother ships and any other vessels directly engaged in such fishing operations.

2. Each Party shall:

(a) ensure that its fishing vessels fish for pollock in the Convention Area only pursuant to specific authorization issued by that Party; and 
(b) ensure that fishing operations for pollock by its fishing vessels undertaken in violation of the provisions of this Convention or of such authorization constitute an offense under its national legislation.

3. Each Party shall require its fishing vessels that fish for pollock in the Convention Area:

(a) to use real-time satellite position fixing transmitters while in the Bering Sea;

(b) to notify the other Parties of their intention to enter the Convention Area 48 hours prior to such entry, the procedures for which shall be established by the Annual Conference; and

(c) to notify the other Parties of the location of any transshipments of fish and fish products to transport vessels 24 hours prior to such transshipment.

4. The Parties shall exchange:

(a) information collected by real-time satellite position-fixing transmitters on a real-time basis through bilateral channels; and

(b) catch data on a sufficiently regular basis, established by the Annual Conference, to ensure effective implementation of the relevant conservation and management measures.

5. The Parties shall establish a Central Bering Sea Observer Program in accordance with the following principles:

(a) Each fishing vessel of the Parties that fishes for pollock in the Convention Area shall accept one observer of a Party other than its flag-State Party, upon request of such Party, under conditions established bilaterally sufficiently in advance by the Parties concerned. If such an observer is not available, the fishing vessel shall have on board one observer from its flag-State Party.

(b) The observers shall be trained and certified in accordance with the procedures to be included in the Program.

(c) The Program shall have as its objective a significant level of coverage by observers sent by non-flag-State Parties.

(d) With respect to observers sent by non-flag-State Parties, each Party shall require its fishing vessels to bear the costs of meals and accommodation of such observers. Other matters relating to costs shall be arranged between the Parties concerned.

(e) The activities of observers shall include monitoring the implementation of conservation and management measures adopted pursuant to this Convention (e.g., measures relating to fishing activities, location thereof, incidental catch, and fishing gear) and reporting of their findings to the flag-State Party and observer's Party.

6. Each Party may enforce the provisions of this Convention within the Convention Area in accordance with the following:

(a) Each Party consents to the boarding and inspection of fishing vessels flying its flag and located in the Convention Area by duly authorized officials of any other Party for compliance with this Convention or measures adopted pursuant thereto.

(b) Such officials may inspect the vessel (other than crew quarters and engineering spaces), catch, fishing gear, and relevant documents and logbooks, and question the master, the fishing master, and other officers on board.

(c) When conducting inspections, such officials shall present credentials issued by their Governments, minimize interference with and inconvenience to the operations of the fishing vessel undertaken 
pursuant to this Convention, and follow procedures set forth in a manual adopted by the Annual Conference.

7. Where an inspection of a fishing vessel undertaken under paragraph 6 above reveals evidence of a violation of the provisions of this Convention or of measures adopted pursuant thereto:

(a) The flag-State Party shall be notified promptly of alleged violations. The flag-State Party shall take appropriate measures in accordance with its national laws and regulations, including prompt investigation. The flag-State Party shall order the fishing vessel to cease operations in violation of the provisions of this Convention or of measures adopted pursuant thereto and, in appropriate cases, shall order the fishing vessel to leave the Convention Area immediately.

(b) In any case in which the fishing vessel has:

i. engaged in fishing for pollock, other than authorized trial fishing, in the Convention Area in any year:

(1) in which the AHL is zero;

(2) while fishing for pollock is not allowed in accordance with the provisions of this Convention;

(3) after the total catch of pollock of the fishing vessel's Party has reached the INQ of that Party;

ii. operated in the Convention Area without specific authorization from the flag-State Party; or

iii. operated in the Convention Area without an observer or without an operable real-time satellite position transmitter, in circumstances set forth in a manual adopted by the Annual Conference;

and the flag-State Party is not in a position to take immediate control of or otherwise carry out its responsibility for the operation of the fishing vessel, the officials of the boarding Party may continue the boarding initiated under paragraph 6 above until officials of the flag-State Party board the fishing vessel or the flag-State Party otherwise carries out its responsibility for the operation of the fishing vessel. In such circumstances, the Parties concerned shall cooperate to ensure full compliance with this Convention and with conservation and management measures adopted pursuant thereto. In particular, the Parties concerned shall consult and take such practical steps as may be necessary to ensure such compliance.

(c) Only the authorities of the flag-State Party may try the offense and impose penalties therefor. The evidence necessary for establishing the offense, insofar as it is under the control of any of the Parties, shall be furnished, in accordance with the respective laws and regulations of the Parties, as promptly as possible to the Party having jurisdiction to try the offense and shall be taken into account, and utilized as appropriate, by the relevant authorities of that Party.

(d) Penalties provided for in the relevant laws and regulations of the Parties shall reflect the seriousness of the infractions.

\section{ARTICLE XII}

1. The Parties agree to invite the attention of any non-Party to this Convention to any matter relating to the fishing operations of its nationals, residents, or vessels flying its flag that could affect adversely the attainment of the objectives of this Convention.

2. The Parties shall, consistent with international law, encourage any non-Party to respect the provisions of this Convention and any conservation and management measures adopted pursuant thereto. 
3. If fishing operations by nationals, residents, or vessels of any non-Party could affect adversely the attainment of the objectives of this Convention, the Parties shall take measures, individually or collectively, which are consistent with international law, and which they deem necessary and appropriate, to deter such operations.

4. Each Party shall take appropriate measures aimed at preventing fishing vessels registered under its laws and regulations from transferring their registration for the purpose of avoiding compliance with the provisions of this Convention or conservation and management measures adopted pursuant thereto.

5. The Parties may, by unanimous agreement, invite the representative of any non-Party to participate as an observer at the Annual Conferences.

\section{ARTICLE XIII}

If any dispute arises between two or more of the Parties concerning the interpretation or application of this Convention, those Parties shall consult among themselves with a view to having the dispute resolved by available peaceful means of their own choice.

\section{ARTICLE XIV}

1. The Annex to this Convention shall form an integral part of this Convention. All references to this Convention shall be understood as including the Annex.

2. The Annex to this Convention shall be considered amended upon the acceptance by the Governments of all Parties of a proposed amendment to the Annex adopted by the Annual Conference in accordance with the provisions of subparagraph 1(l) of Article IV. An amendment to the Annex shall enter into force on the date upon which the Depositary receives notification in writing from all Parties of their acceptance of the amendment.

3. The Depositary shall notify all Parties of the date of receipt of each notification of acceptance of an amendment to the Annex.

\section{ARTICLE XV}

The official language of the Annual Conference and the Scientific and Technical Committee shall be English.

\section{ARTICLE XVI}

1. This Convention shall be open for signature at Washington by the People's Republic of China, Japan, the Republic of Korea, the Republic of Poland, the Russian Federation, and the United States of America.

2. This Convention shall enter into force on the thirtieth day following the date on which at least four signatory States, including the Russian Federation and the United States of America, which are the coastal States of the Bering Sea, have deposited their instrument of ratification, acceptance, or approval with the Depositary.

3. This Convention shall enter into force for each of the other signatory States on the thirtieth day following the date of deposit of that State's instrument of ratification, acceptance, or approval.

4. After the entry into force of this Convention, the Parties may, by unanimous agreement, invite other States whose nationals and fishing vessels wish to conduct fishing for pollock in the Convention Area to become Parties to this Convention. This Convention shall enter into force for any such other State on the thirtieth day following the date of deposit of the State's instrument of accession. 


\section{ARTICLE XVII}

1. Any Party may at any time propose an amendment to this Convention other than the Annex by providing the text of such a proposal to the Depositary. The Depositary shall promptly circulate any such proposals to all Parties.

2. If one-half of the Parties request a meeting to discuss a proposed amendment, the Depositary shall call such a meeting, which shall take place no sooner than sixty days following the date of circulation of the proposal pursuant to paragraph 1 above.

3. An amendment shall enter into force when the Depositary has received instruments of ratification, acceptance, or approval thereof from all Parties.

\section{ARTICLE XVIII}

After three years from entry into force of this Convention, any Party may withdraw from this Convention twelve months after the date on which it notifies the Depositary in writing of its intention to withdraw.

\section{ARTICLE XIX}

Nothing in this Convention nor any measures adopted pursuant thereto shall be deemed to prejudice the positions or views of any Party with respect to its rights and obligations under treaties and other international agreements to which it is Party or its positions or views with respect to the law of the sea.

\section{ARTICLE XX}

The original of this Convention shall be deposited with the Government of the United States of America, which shall be Depositary. The Depositary shall transmit certified copies thereof to all other signatory States and acceding States.

IN WITNESS WHEREOF the undersigned, being duly authorized thereto, have signed this Convention.

DONE AT Washington this sixteenth day of June, 1994, in a single original, in the English language.

FOR THE PEOPLE'S REPUBLIC OF CHINA:

[Signature]

FOR JAPAN:

FOR THE REPUBLIC OF KOREA:

[Signature]

FOR THE REPUBLIC OF POLAND:

FOR THE RUSSIAN FEDERATION:

[Signature]

FOR THE UNITED STATES OF AMERICA:

[Signature] 


\section{ANNEX}

\section{PART 1}

Pursuant to paragraph 2 of Article VII, the AHL shall be determined as follows:

(a) Based on scientific and technical information reviewed by the Scientific and Technical Committee, one institution each designated by the Russian Federation and the United States of America, as the coastal States of the Bering Sea, shall jointly establish the Aleutian Basin pollock biomass.

(b) If there is insufficient scientific and technical information available to allow the two institutions designated pursuant to paragraph (a) above to establish the Aleutian Basin pollock biomass, the Parties agree that, for the purpose of this Convention, the pollock biomass for the Specific Area (note) as determined by the United States institution designated pursuant to paragraph (a) above shall be deemed to represent 60 percent of the Aleutian Basin pollock biomass.

(c) If the Aleutian Basin pollock biomass is less than 1.67 million metric tons, the AHL shall be zero and, therefore, there shall be no directed fishing on the Aleutian Basin pollock stock.

(d) If the Aleutian Basin pollock biomass is equal to or above 1.67 million metric tons, the AHL shall be determined in accordance with the following table:

Aleutian Basin pollock biomass

AHL

1.67 million metric tons or more but less than 2.0 million metric tons

130,000 metric tons

2.0 million metric tons or more but less than 2.5 million metric tons

$\underline{190,000 \text { metric tons }}$

Determined by consensus at the

2.5 million metric tons or more Annual Conference

Note: The Specific Area is the area south of a straight line between a point at $55^{\circ} 46 \mathrm{~N}$. and $170^{\circ} 00^{\circ} \mathrm{W}$. and a point at $54^{\circ} 30^{\prime} \mathrm{N}$. and $167^{\circ} 00 \mathrm{~W}$. and between the meridian $167^{\circ} 00 \mathrm{~W}$ and the meridian $170^{\circ} 00 \mathrm{~W}$., and north of the Aleutian Islands and straight lines between the islands connecting the following coordinates in the order listed:

$52^{\circ} 49.2^{\prime} \mathrm{N} .169^{\circ} 40.4{ }^{\prime} \mathrm{W}$, $52^{\circ} 49.8^{\prime} \mathrm{N} .169^{\circ} 06.3^{\top} \mathrm{W}$, $53^{\circ} 23.8^{\prime} \mathrm{N} .167^{\circ} 50.1$ W. $53^{\circ} 18.7^{\prime} \mathrm{N} .167^{\circ} 51.4^{\prime} \mathrm{W}$. 


\title{
Federated States of Micronesia Arrangement for Regional Fisheries Access, Honiara, 1994
}

\author{
Done at Honiara 30 November 1994 \\ Entered into force 25 September 1995* \\ Depositary: South Pacific Forum Fisheries Agency \\ Primary source citation: Copy of text provided by the \\ South Pacific Forum Fisheries Agency
}

\section{THE FEDERATED STATES OF MICRONESIA ARRANGEMENT FOR REGIONAL FISHERIES ACCESS}

\section{PREAMBLE}

The Parties to this Arrangement,

RECALLING that, in accordance with international law, each of the Parties has established an exclusive economic or fisheries zone which extends up to two hundred nautical miles from the baseline from which their respective territorial seas are measured and within which they respectively and separately exercise sovereign rights for the purposes of exploring, exploiting, conserving and managing all living marine resources;

HAVING REGARD to the objectives of the South Pacific Forum Fisheries Agency Convention 1979 and the Nauru Agreement Concerning Cooperation in the Management of Fisheries of Common Interest 1982 and in particular the promotion of regional cooperation and coordination of fisheries policies and the need for implementation of these objectives through regional and sub-regional arrangements;

NOTING the decision of the thirteenth annual meeting of the Parties to the Nauru Agreement held at Honiara on 29 April 1994 to effectively manage and control the purse seine fishery in the Central and Western Pacific region by a scheduled reduction in the number of foreign purse seine fishing vessels to be allowed access to fish;

CONSCIOUS of the need for greater participation by their nationals in fisheries for highly migratory fish stocks in the Central and Western Pacific region and the need to develop and promote their own national fisheries industries;

COMMITTED to cooperating to secure for their nationals and for the region as a whole the maximum sustainable economic benefits from the tuna resources of the Central and Western Pacific region;

DESIRING to establish terms and conditions under which fishing vessels which provide long-term, sustainable and quantifiable economic benefits to the Parties may be granted preferential access to the exclusive economic and fisheries zones of the Parties;

HAVE AGREED as follows:

* The United States is not a party to this Arrangement. 


\section{PART I \\ DEFINITIONS AND OBJECTIVES}

\section{ARTICLE 1 DEFINITIONS}

In this Arrangement:

(a) "Administrator" means the Administrator prescribed under Article 7;

(b) "applicable national law" means any provision of a law, however described, of a Party which governs the fishing activities of fishing vessels, being a law identified in Schedule 1 of Annex V;

(c) "Arrangement Area" means the exclusive economic or fisheries zones of the Parties to this Arrangement except for waters closed to fishing in accordance with Schedule 2 of Annex V;

(d) "eligibility criteria" means the criteria set out in Annex III;

(e) "eligible fishing vessel" means a fishing vessel of the Parties which has been duly entered on the Register of Eligible Fishing Vessels maintained by the Administrator pursuant to Article 3 of this Arrangement;

(f) "fishing" means:

(i) searching for, catching, taking or harvesting fish;

(ii) attempting to search for, catch, take or harvest fish;

(iii) engaging in any other activity which can reasonably be expected to result in the locating, catching, taking or harvesting of fish;

(iv) placing, searching for or recovering fish aggregating devices or associated electronic equipment such as radio beacons;

(v) any operations at sea directly in support of, or in preparation for, any activity described in this paragraph;

(vi) use of any other vehicle, air or sea-borne, for any of the activities described in this paragraph except for emergencies involving the health and safety of any person on board a vessel or the safety of a vessel; or

(vii) any related activity;

(g) "fishing vessel of the Parties" means any purse seine fishing vessel flying the flag of or based in a Party to this Arrangement;

(h) "home Party" in respect of a fishing vessel, means the Party which has issued a licence, permit or authorization to the vessel, authorizing the vessel to fish in the exclusive economic or fisheries zone of that Party and through which the application for entry on the Register of Eligible Fishing Vessels pursuant to Article 3 is made, and the phrase "home Party of a vessel" shall be construed accordingly;

(i) "operator" means any person who is in charge of, directs or controls a vessel, including the owner, charterer or master;

(j) "Party" means a State Party to this Arrangement and "Parties" means all such States from time to time;

(k) "regional access licence" means a regional access licence issued to fishing vessels of the Parties pursuant to this Arrangement; 
(1)

"related activities" in relation to fishing means:

(i) refuelling or supplying fishing boats, selling or supplying fishing equipment or performing other activities in support of fishing;

(ii) on-shore storing, buying or processing of fish or fish products from the time they are first landed; or

(iii) storing, buying, transhipping, processing or transporting fish or fish products taken from the Arrangement Area up to the time such fish or fish products are first landed;

(m) "transhipment" means the transfer of any or all of the fish on board a vessel onto another vessel, either directly or by off-loading the fish from the vessel onto the shore and thence immediately onto another vessel, for the purposes of transporting that fish elsewhere.

\section{ARTICLE 2 \\ OBJECTIVES OF THIS ARRANGEMENT}

The objectives of this Arrangement shall be:

(a) to cooperate to secure, for the mutual benefit of the Parties, the maximum sustainable economic benefits from the exploitation of the tuna resources of the Central and Western Pacific;

(b) to promote greater participation by nationals of the Parties in fisheries and assist in the development of national fisheries industries of the Parties;

(c) to establish a licensing regime under which fishing vessels of the Parties may gain access to the waters within the Arrangement Area on terms and conditions no less favourable than those granted by the Parties to foreign fishing vessels under bilateral and multilateral access arrangements;

(d) to establish and enforce agreed criteria to ensure that only those fishing operations which are capable of providing genuine and quantifiable economic benefits to the Parties are eligible for licences pursuant to this Arrangement;

(e) to allow access to the exclusive economic and fisheries zones of the Parties by purse seine fishing vessels on terms and conditions which are consistent with the provisions of the Palau Arrangement for the Management of the Western Pacific Purse Seine Fishery; and

(f) to further the objectives of the Nauru Agreement Concerning Cooperation in the Management of Fisheries of Common Interest, 1982.

\section{PART II}

\section{REGISTRATION AND LICENSING}

\section{ARTICLE 3 \\ REGISTER OF ELIGIBLE FISHING VESSELS}

1. The Administrator shall, for the purposes of this Arrangement, maintain a Register of Eligible Fishing Vessels which shall contain the following information in respect of each vessel entered on the Register:

(a) the name of the vessel;

(b) international radio call sign;

(c) country of registration;

(d) regional registration number; 
(e) name and address of owner or owners;

(f) name and address of operator (where different from the owner); and

(g) the name of the home Party of the vessel.

2. Where a Party to this Arrangement is satisfied that a fishing vessel of that Party satisfies the eligibility criteria, that Party may apply to enter such fishing vessel on the Register of Eligible Fishing Vessels. Applications for registration shall be made in the form set out in Annex I.

3. Upon receipt of a duly completed application the Administrator shall forthwith enter the vessel concerned on the Register of Eligible Fishing Vessels. The Administrator shall immediately notify the Parties, and the operator of the vessel, of the entry of a vessel onto the Register of Eligible Fishing Vessels and shall circulate the details of the vessel to all Parties.

4. It shall be a condition of entry onto the Register of Eligible Fishing Vessels that:

(a) for each day that an eligible fishing vessel is:

(i) in the Arrangement Area; or

(ii) on the high seas, during the course of a fishing trip involving fishing in the Arrangement Area; and

(b) immediately following the off-loading of any fish from an eligible fishing vessel,

an entry or entries shall be completed in ink in the English language on the catch report form as set out in Annex II. Such forms shall be posted by registered airmail to the Administrator within fourteen days following the date of completion of the off-loading operation.

5. The Administrator shall notify the Parties at three-monthly intervals of the name, call sign, registration number, home Party and Regional Register number of all fishing vessels of the Parties entered on the Register of Eligible Fishing Vessels.

\section{ARTICLE 4 VOLUNTARY DELETION}

Where for any reason the licence issued by the home Party in respect of a vessel is cancelled, withdrawn, voluntarily relinquished or not renewed, or where the home Party is satisfied that the vessel concerned has not satisfied or no longer satisfies the eligibility criteria, that Party shall forthwith request the Administrator to delete the vessel from the Register of Eligible Fishing Vessels. The Administrator shall comply with any such request by the home Party and shall immediately notify the Parties of the deletion of the vessel from the Register of Eligible Fishing Vessels and the reason for the deletion.

\section{ARTICLE 5 REVIEW AND EVALUATION}

1. At least two months prior to the Annual Meeting of the Parties under Article 6, the Administrator shall, in respect of each registered vessel, or, as appropriate, the fishing enterprise under which such registered vessel operates, request, through the home Party of the vessel concerned, the information specified in paragraph 2 of this Article and shall compile a report on the operations of each vessel with respect to the eligibility criteria for consideration at the Annual Meeting of the Parties. The home Party of the vessel shall take such measures as may be necessary to ensure that the information specified in paragraph 2 of this Article is provided to the Administrator in a timely manner.

2. In compiling a report to the Parties pursuant to paragraph 1 of this Article the Administrator shall request the following information: 
(a) details of equity holdings;

(b) number of nationals trained;

(c) number and proportion of nationals employed and the total payroll to national employees;

(d) details of onshore investments;

(e) details of local purchases made; and

(f) any further information as may be necessary.

3. The Annual Meeting of the Parties shall consider the report of the Administrator in respect of each vessel, including any information supplied through the home Party by the operator of the vessel or the fishing enterprise pursuant to paragraphs 1 and 2 of this Article and shall review the operations of all vessels entered on the Register of Eligible Fishing Vessels and assess the extent to which the vessel, or the fishing enterprise, as appropriate, has satisfied the eligibility criteria and fulfilled the objectives of this Arrangement.

4. The Annual Meeting of the Parties may request the Administrator, the home Party of the vessel, or the operator, to provide such further information as may be necessary and may request an independent evaluation of the operations of the vessel or the fishing enterprise under which that vessel operates against the eligibility criteria. In such a case, the Administrator shall consult with the home Party of the vessel as to the appropriate method for conducting the independent evaluation and the home Party shall take all necessary steps to facilitate the evaluation, including by providing all relevant information to the Administrator.

5. Where, following the review and evaluation under paragraph 3 of this Article, and taking into account the findings of any independent review under paragraph 4 of this Article, the Parties determine, at the Annual Meeting or at a Special Meeting of the Parties, that the vessel, or the fishing enterprise under which that vessel operates, has not met the eligibility criteria and has not fulfilled the objectives of this Arrangement, or where insufficient information has been made available to enable any evaluation to take place, the Parties shall direct the Administrator to delete the vessel from the Register of Eligible Fishing Vessels.

\section{ARTICLE 6 ACCESS TO THE ARRANGEMENT AREA}

1. Before a fishing vessel of the Parties may be issued with a regional access licence pursuant to this Arrangement, the vessel must first be duly registered on the Register of Eligible Fishing Vessels.

2. Where a fishing vessel of the Parties is duly registered in accordance with the provisions of Article 3 , the operator may apply, through the home Party of the vessel, to the Administrator, in accordance with the procedures set out in Annex IV, for a regional access licence authorizing the vessel to fish in the Arrangement Area.

3. It shall be a condition of any regional access licence issued pursuant to this Arrangement that the vessel in respect of which the regional access licence is issued is operated in accordance with the requirements of Annex V.

4. A regional access licence may be denied by the Administrator on the grounds set out in Annex IV.

5. Where a fishing vessel of the Parties is deleted from the Register of Eligible Fishing Vessels in accordance with the provisions of this Arrangement, any regional access licence issued in respect of that vessel shall, in the case of voluntary deletion from the register or non-renewal of registration, be cancelled thirty days following the deletion of the vessel from the Register of Eligible Fishing Vessels or upon the date of expiry of the licence, whichever is the sooner. In the case of deletion from the Register of Eligible Fishing Vessels for any other reason, the regional access licence shall be cancelled immediately upon the deletion from the register.

6. If full payment of any amount due as a result of a final judgment or other final determination deriving from an occurrence relating to this Arrangement in waters within the jurisdiction of a Party, is not made to that Party within sixty days, the regional access licence for the vessel involved shall be suspended at the request of that Party and that vessel shall not be authorized to fish in the Arrangement Area until that amount is paid to that Party. For 
the purposes of this Article "final judgment" means a judgment of a court of a Party from which no appeal proceedings have been initiated within sixty days.

7. The Administrator shall maintain a record of all regional access licences issued pursuant to this Arrangement, including the date of issue and expiry of such licences.

8. The Administrator shall notify the Parties each month of the name, call sign, registration number, regional access licence number and expiry date of such licence of all purse seine vessels licensed to fish in the Arrangement Area under this Arrangement.

\section{PART III}

\section{ADMINISTRATION}

\section{ARTICLE 7 ADMINISTRATOR}

1. The Administrator of this Arrangement shall be the Director of the South Pacific Forum Fisheries Agency.

2. The Administrator shall be responsible to the Parties for:

(a) performing the functions required of the Administrator by this Arrangement;

(b) receiving information, documents and payments in accordance with the terms of this Arrangement;

(c) convening meetings of the Parties;

(d) coordinating the observer programme under this Arrangement; and

(e) performing any other function in order to satisfy any requirement of this Arrangement.

3. The Administrator's functions prescribed in this Arrangement shall be performed consistently with any direction given by the Parties at the Annual Meeting or at a Special Meeting of the Parties.

4. In performing the Administrator's functions prescribed under this Arrangement, the Administrator shall consult with the Parties and shall take all necessary steps to ensure that all reports and other information required by the Parties are provided in a timely manner.

\section{ARTICLE 8 MEETINGS OF THE PARTIES}

1. The Parties agree to convene an Annual Meeting of the Parties. The Annual Meeting shall be convened immediately preceding or following the annual meeting of the Parties to the Nauru Agreement. The purposes of the Annual Meeting shall be:

(a) to review the operations of all vessels entered on the Register of Eligible Fishing Vessels and assess the extent to which each vessel, or fishing enterprise, as appropriate, has satisfied the eligibility criteria and fulfilled the objectives of this Arrangement;

(b) to review the eligibility criteria;

(c) to adopt amendments to this Arrangement;

(d) to review the level of fees for regional access licences;

(e) to discuss cooperative enforcement measures; 
(f) to consider the effectiveness of the observer programme established pursuant to Article 17 and to adopt procedures for the implementation of the programme;

(g) to consider and approve an administrative costs budget, which shall consist only of the direct costs of performing functions and providing services in accordance with this Arrangement;

(h) to consider requests to accede to this Arrangement by member States of the Forum Fisheries Agency pursuant to Article 22(2); and

(i) to perform any other functions to satisfy any requirement of this Arrangement or as are necessary to attain the objectives of this Arrangement.

2. The Administrator shall, upon request by any Party, and with the approval of at least two other Parties, convene a Special Meeting of the Parties at the date and place determined by the Administrator in consultation with the Parties.

3. Member countries of the South Pacific Forum Fisheries Agency, not Party to this Arrangement, may attend, as observers, meetings of the Parties held pursuant to this Arrangement.

4. The Parties shall adopt and amend, as necessary, rules of procedure for the Annual Meeting and Special Meetings of the Parties. Pending agreement on such rules of procedure, the rules of procedure applicable to meetings of the Forum Fisheries Committee shall apply.

\section{ARTICLE 9 \\ PROVISION OF INFORMATION}

1. The Administrator shall provide all data received pursuant to this Arrangement to the Parties in a timely manner in accordance with this Arrangement, and in particular shall:

(a) provide all data relating to fishing activities in waters under the jurisdiction of any Party to that Party;

(b) provide all data relating to the fishing activities of an eligible fishing vessel to the home Party of that vessel; and

(c) distribute such data, including high seas data, as may be agreed by the Parties.

2. The Administrator shall maintain the confidentiality of all data which is received pursuant to this Arrangement, unless:

(a) this Arrangement provides otherwise;

(b) the Parties agree otherwise;

(c) the Administrator is authorized by a Party to release data relating to fishing activities in waters under that Party's jurisdiction; or

(d) the Administrator is authorized by the home Party of a vessel to release data relating to the fishing operations of that vessel.

3. Each Party shall ensure that the confidentiality is maintained of any data received pursuant to this Arrangement concerning fishing activity in the exclusive economic or fisheries zone of any other Party.

4. For the purposes of this Arrangement, each Party shall provide to the Administrator, as early as practicable, a description of any area considered by its Government to be subject to its fisheries jurisdiction. 


\title{
ARTICLE 10 \\ DISTRIBUTION OF PAYMENTS
}

1. Any payment received by the Administrator pursuant to this Arrangement shall be deposited within one week of receipt in United States dollars in an insured or Government guaranteed bank account or accounts so that the deposits will earn the highest amount of interest reasonably available.

2. The Administrator shall distribute any amount received pursuant to this Arrangement in the manner described in Annex VI.

\section{ARTICLE 11 \\ AUDITING OF ACCOUNTS}

1. The Administrator shall arrange for the auditor of the South Pacific Forum Fisheries Agency to audit any account in which amounts deposited in accordance with Article 10 are held, prior to the distribution of any amount in accordance with this Arrangement.

2. The Administrator shall permit each Party to inspect any raw data, books and accounts which relate to the Administrator's functions pursuant to this Arrangement.

\section{PART IV}

\section{COMPLIANCE AND ENFORCEMENT}

\author{
ARTICLE 12 \\ COMPLIANCE POWERS
}

1. Each Party shall ensure, to the fullest extent possible in accordance with its laws and regulations, that its fishing vessels shall not engage in fishing within the exclusive economic or fisheries zone of any other Party unless duly licensed under this Arrangement or under other licensing arrangements.

2. Nationals and fishing vessels of one Party which fail to comply with the provisions of this Arrangement or with the laws and regulations of any other Party relating to fisheries shall be dealt with in accordance with the relevant laws and regulations of that Party.

\section{ARTICLE 13 COOPERATION IN ENFORCEMENT}

1. Each Party shall, at the request of any other Party, take all reasonable measures to assist in the investigation of an alleged violation of this Arrangement.

2. Where a Party has probable cause to believe that a fishing vessel of the Parties, while within the waters under the jurisdiction of that Party:

(a) did not have a licence to fish;

(b) was involved in an infringement of an applicable national law;

(c) was involved in any incident in which an authorized officer or observer was allegedly assaulted with resultant bodily harm, physically threatened, forcefully resisted, refused boarding or subjected to physical intimidation or physical interference in the performance of his or her duties as authorized pursuant to this Arrangement;

(d) transhipped or off-loaded catch otherwise than in accordance with Annex V;

(e) was used for fishing in waters closed to fishing pursuant to Annex V; 
was used for fishing in any Limited Area as described in Annex V, except as authorized in accordance with that Annex;

(g) was used for fishing for any kinds of fish other than tunas, except that other kinds of fish may be caught as an incidental by-catch;

(h) was involved in an incident in which evidence which otherwise could have been used in proceedings concerning the vessel has been intentionally destroyed; or

(i) was involved in a serious violation of any other provision of this Arrangement or of a law or regulation, other than a violation described in sub-paragraphs (a) to (h) of this paragraph,

and such vessel has not submitted to the jurisdiction of the Party concerned, that Party may request the home Party of the vessel to fully investigate the alleged violation, whereupon the home Party shall investigate and report as soon as practicable and in any case within two months to the requesting Party and the Administrator on that investigation and on any action taken or proposed to be taken by the home Party in accordance with this Article in relation to the alleged violation.

3. In the event that a report provided pursuant to paragraph 2 of this Article establishes to the satisfaction of the Parties concerned that there are reasonable grounds to believe that the vessel concerned has been involved in a violation of this Arrangement as set out in paragraph 2, the home Party of the vessel shall, at the request of the Party in whose waters the violation took place,

(a) in the case of a fishing vessel flying the flag of the home Party:

(i) take all necessary measures to ensure that the vessel concerned submits to the jurisdiction of the requesting Party; or

(ii) take appropriate action against the vessel to the extent permitted by its national laws and regulations or otherwise to the mutual satisfaction of the Parties concerned,

(b) in the case of any other fishing vessel:

(i) use its best efforts to ensure that the operator of the vessel submits to the jurisdiction of the requesting Party; or

(ii) to the extent possible under its national laws and regulations, or under any agreement in force between the investigating Party and the flag State of the vessel concerned, take appropriate action against the vessel or the operator of the vessel.

\section{ARTICLE 14 \\ ARREST AND SEIZURE}

1. Where the authorities of one Party arrest or seize nationals or fishing vessels of another Party, the arresting Party shall promptly notify the other Party of the action taken. The arresting Party shall also notify the flag State of the vessel where the home Party of the vessel concerned is not also the flag State.

2. Nationals and fishing vessels, including members of the crew of such fishing vessels (whether or not such crew are nationals of a Party), of any Party arrested or seized pursuant to this Arrangement shall be promptly released upon the posting of reasonable bond or security as determined by the courts of the arresting Party. Penalties applied in accordance with this Arrangement for fishing violations may not include imprisonment or corporal punishment.

\section{ARTICLE 15 \\ JOINT SURVEILLANCE}

The Parties shall cooperate in the enforcement of the provisions of this Arrangement and their fisheries laws and regulations in accordance with the provisions of the Niue Treaty on Cooperation in Fisheries Surveillance and 
Law Enforcement in the South Pacific Region and to this end shall cooperate to develop regionally agreed procedures for the conduct of fisheries surveillance and law enforcement in the Arrangement Area.

\section{ARTICLE 16 \\ PORT STATE ENFORCEMENT}

Whenever a fishing vessel of the Parties enters a port or offshore terminal of one of the Parties, the port State may inspect documents and catch on board such vessel and, when such inspection discloses reasonable grounds for believing that the vessel has contravened the provisions of this Arrangement, may detain the vessel for such reasonable period as is necessary for the home Party, or, if the home Party, is not the flag State of the vessel, the flag State, to take control of the vessel or otherwise take responsibility for enforcement purposes.

\section{ARTICLE 17}

\section{OBSERVER PROGRAMME}

1. The Parties shall establish an observer programme for the purposes of implementing and achieving the objectives of this Arrangement and shall establish appropriate administrative measures for the effective implementation of such a programme in accordance with the following principles:

(a) Each fishing vessel of the Parties licensed under this Arrangement shall, upon request by the Administrator, accept one observer of a Party other than the home Party of the vessel, under the conditions set out in Part 7 of Annex V. If such an observer is not available, the fishing vessel shall have on board one observer from the home Party.

(b) Observers shall be trained and certified in accordance with the procedures to be agreed under the programme. Each of the Parties shall be entitled to have its nationals included in the programme.

(c) The programme shall have as its objective a significant level of coverage by observers of the total number of trips by fishing vessels of the Parties licensed pursuant to this Arrangement and, unless otherwise agreed at the outset of the trip, observer operations will be based on the placement of observers at ports of trip origin for complete trips.

(d) The activities of observers shall include monitoring the level of compliance with the provisions of this Arrangement and reporting of their findings to the Administrator and the home Party of the vessel.

(e) The Parties shall facilitate the placing of observers, including the provision of visas, if required.

(f) The Administrator shall ensure that a reasonable period of notice of the placement of an observer is given, which should, wherever practicable, be at least fourteen days.

(g) The Administrator shall ensure that all reports received from observers placed under the provisions of this Arrangement are circulated widely, in a timely manner, to all Parties which may be affected by or have an interest in the reports.

2. The Administrator shall coordinate the observer programme.

\section{PART V \\ SETTLEMENT OF DISPUTES}

\section{ARTICLE 18 CONSULTATIONS}

At the request of any Party, consultations on the interpretation or implementation of this Arrangement will be held with any other Party within sixty days of the date of receipt of the request. All other Parties will be notified by the requesting Party of such requests for consultations and, subject to the agreement of the Parties concerned, any Party may be permitted to participate, as an observer, in such consultations. 


\section{ARTICLE 19 \\ DISPUTE SETTLEMENT}

1. The Parties shall settle any dispute between them concerning or arising out of the interpretation or implementation of this Arrangement by peaceful means of their own choice, including arbitration.

2. Where a dispute arises between Parties concerning or arising out of the interpretation or implementation of this Arrangement, the parties to the dispute shall proceed expeditiously to an exchange of views regarding its settlement by negotiation or other peaceful means.

\section{PART VI}

FINAL PROVISIONS

\section{ARTICLE 20 \\ SIGNATURE}

This Arrangement shall remain open for signature at the South Pacific Forum Fisheries Agency Headquarters by the Parties to the Nauru Agreement Concerning Cooperation in the Management of Fisheries of Common Interest 1982 for twelve months from the date of its adoption.

\section{ARTICLE 21 \\ ENTRY INTO FORCE}

1. This Arrangement is not subject to ratification and will enter into force thirty days after signature by whichever is the last to sign of the Federated States of Micronesia, the Republic of Kiribati and the Independent State of Papua New Guinea.

2. For each State acceding to this Arrangement after its entry into force, this Arrangement shall enter into force on the thirtieth day following the date that an instrument signifying accession by that State is received by the depositary.

\section{ARTICLE 22 \\ ACCESSION}

1. This Arrangement shall remain open for accession by Parties to the Nauru Agreement Concerning Cooperation in the Management of Fisheries of Common Interest 1982.

2. Following entry into force this Arrangement shall remain open for accession by any other State, being a member State of the Forum Fisheries Agency, with the concurrence of the Parties.

\section{ARTICLE 23 \\ RESERVATIONS}

Reservations to this Arrangement shall not be permitted.

\section{ARTICLE 24 \\ AMENDMENT}

1. Except as otherwise specifically provided in the Annexes to this Arrangement, any amendment to this Arrangement proposed by a Party shall be adopted only by unanimous decision of all of the Parties to this Arrangement at the Annual Meeting or at a Special Meeting of the Parties. 
2. An amendment shall be incorporated in this Arrangement and shall have effect from the thirtieth day following the date upon which all the Parties have notified the depositary of their acceptance of the proposed amendment.

3. Any Party which proposes to establish or amend a Closed Area or Limited Area for the purposes of this Arrangement shall notify the Administrator of the details of its proposal at least four calendar months prior to the Annual Meeting of the Parties. The Administrator shall promptly notify the other Parties of such proposal.

4. Any proposal made in accordance with paragraph 3 of this Article shall be tabled as a non-negotiable amendment to Annex V at the Annual Meeting of the Parties, and no Party shall propose any amendment thereto during that meeting, except with the consent of the Party proposing the amendment.

\section{ARTICLE 25 \\ WITHDFAWAL}

1. Any Party may withdraw from this Arrangement by giving written notice to the depositary. Withdrawal shall take effect one year after receipt of such notice.

2. If this Arrangement ceases to have effect for any Party, this Arrangement shall cease to have effect for that Party from such time that all distributions are made, pursuant to Article 10 and Annex VI, which affect that Party.

\section{ARTICLE 26 \\ STATUS OF ANNEXES}

The Annexes form an integral part of this Arrangement and, unless expressly provided otherwise, a reference to this Arrangement includes a reference to the Annexes relating thereto.

\section{ARTICLE 27 \\ DEPOSITARY}

The depositary for this Arrangement shall be the South Pacific Forum Fisheries Agency.

IN WITNESS WHEREOF the undersigned plenipotentiaries, being duly authorized thereto, have signed this Arrangement.

DONE AT Honiara on the thirtieth day of November, Nineteen Hundred and Ninety Four.

[Signature]

FEDERATED STATES OF MICRONESIA

REPUBLIC OF THE MARSHALL ISLANDS

[Signature]

REPUBLIC OF PALAU

SOLOMON ISLANDS
[Signature]

REPUBLIC OF KIRIBATI

REPUBLIC OF NAURU

INDEPENDENT STATE OF PAPUA NEW GUINEA

TUVALU 


\section{FEDERATED STATES OF MICRONESIA ARRANGEMENT FOR REGIONAL FISHERIES ACCESS}

\section{ANNEX I - APPLICATION FOR REGISTRATION}

Forum Fisheries Agency

PO Box 629

Honiara

Solomon Islands
Phone (677) 21124

Fax (677) 23995

Telex HQ 66336

INSTRUCTIONS: $\quad *$ Underline Surname

* Address means complete mailing address

Part A:

To be completed by vessel owner, charterer or authorised agent

Vessel

Namne of Vessel

Radio Call Sign

Regional Registration No.

Country of Registration (Flag)

If the vessel is not currently on the Regional Register of Foreign Fishing Vessels, an application for registration must accompany this form

\section{Vessel Owner}

Name

Address

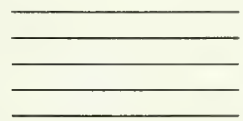

Vessel Operator

If different from Vessel Owner

Name

Address
Tel No

Fax No

Telex No
Tel No

Fax No

Telex No

\section{Home Party}

Name of authorised officer

Signature
Authority

Date

$(\mathrm{dd} / \mathrm{mm} / \mathbf{y y})$

Points Evaluation (show points given by home Party for each attribute)

\begin{tabular}{|l|l|l|l|l|l|l|l|l|}
\hline Equity & Flag & $\begin{array}{l}\text { Nationals } \\
\text { Employed }\end{array}$ & $\begin{array}{l}\text { Local } \\
\text { Purchases }\end{array}$ & $\begin{array}{l}\text { Onshore } \\
\text { Investment }\end{array}$ & $\begin{array}{l}\text { Total } \\
\text { Points }\end{array}$ \\
\hline
\end{tabular}




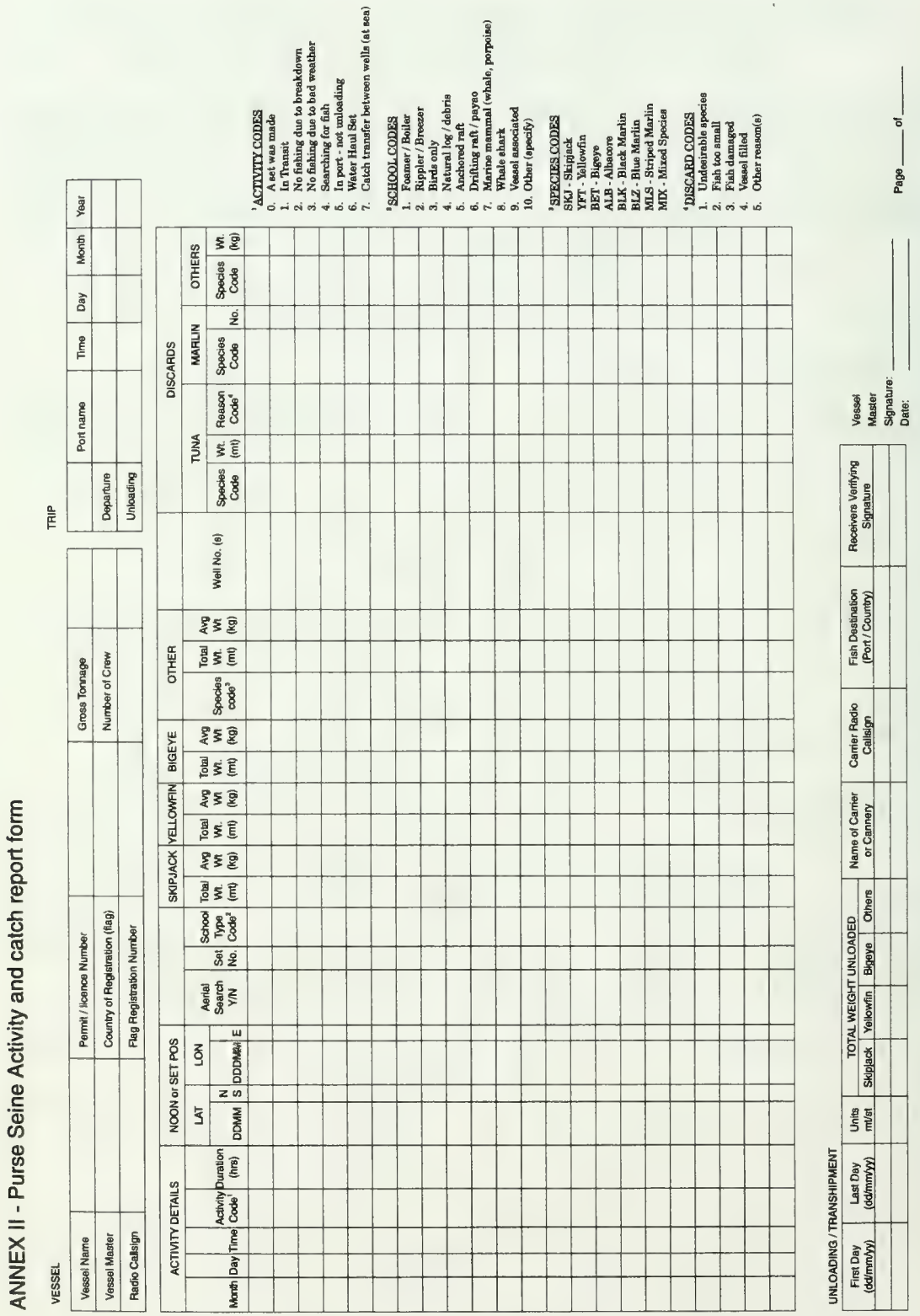




\section{ANNEX III \\ ELIGIBILITY CRITERIA}

1. In this Annex:

(a) "equity" means the percentage of the total capital invested by the Government or nationals of a Party in the enterprise and the vessel. In cases where the vessel is owned by the enterprise, the measure is simply the percentage of equity in the enterprise;

(b) "the enterprise" means the operation the subject of the application for a regional access licence, and includes the operator of a vessel, a corporation, a joint venture operation and any other form of corporate entity;

(c) "local purchases" means the annual value in U.S. dollars of the purse seine related purchases made by the enterprise in the territory of Parties, apportioned across the number of eligible fishing vessels operated by the enterprise;

(d) "onshore investment" means the value in U.S. dollars of purse seine industry related investments by the enterprise in the territory of Parties, apportioned across the number of eligible fishing vessels operated by the enterprise;

(e) "nationals employed" means the average number of nationals of Parties employed annually by the enterprise in purse seine related activities, apportioned across the number of eligible fishing vessels operated by the enterprise.

2. Eligible fishing vessels will be evaluated against the following criteria: the amount of equity, the number and proportion of nationals employed, total payroll to national employees, the level of technology and skills transfer, including training, the value of local purchases and the level of onshore investment, the flag of the vessel and with reference to the objectives of the Arrangement specified in Article 2.

3. In addition to the evaluation under paragraph 2 of this Annex, the points evaluation system, shown in the Schedule, will be used to assess whether the operations of the vessel meet the objectives of this Arrangement. A vessel must score a minimum of 25 points in order to meet the eligibility criteria.

\section{SCHEDULE \\ POINTS EVALUATION SYSTEM}

\begin{tabular}{|l|l|l|l|l|l|}
\hline Points & Equity & Vessel flag & $\begin{array}{c}\text { Nationals } \\
\text { employed }\end{array}$ & $\begin{array}{c}\text { Local purchases } \\
\text { (US\$) }\end{array}$ & $\begin{array}{c}\text { Onshore } \\
\text { Investment (US\$) }\end{array}$ \\
\hline 10 & $100 \%$ & Party & $>50$ & $>700,000$ & $>5,000,000$ \\
\hline 8 & $>50 \%$ & & $31-50$ & $500,000-700,000$ & $2,000,000-5,000,000$ \\
\hline 5 & $30-49 \%$ & $\begin{array}{l}\text { State eligible to } \\
\text { accede to this } \\
\text { Arrangement }\end{array}$ & $16-30$ & $250,000-500,000$ & $500,000-2,000,000$ \\
\hline 2 & $10-29 \%$ & & $5-15$ & $50,000-250,000$ & $100,000-500,000$ \\
\hline
\end{tabular}




\section{ANNEX IV \\ REGIONAL ACCESS LICENSING PROCEDURE}

1. An application for a regional access licence shall be submitted to the Administrator by facsimile, telex or cable, in the following format:
(a) name of vessel;
(b) call sign;
(c) regional register number;
(d) period of RAL requested;
(e) desired effective date of licence
(f) bank reference number for fee
as: NAME / CALL SIGN / RREG\# / [3] or [12] / ddmmyy / ref\#

2. Every application for a regional access licence must be accompanied by the appropriate fee and, where applicable, the observer levy as set out in Schedule 1. A regional access licence shall be valid for a period of 12 months or a period of 3 months.

3. Upon receiving the application for a regional access licence as above the Administrator shall promptly review the application and shall:

(a) upon approval of the application:

(i) promptly issue a regional access licence to the applicant, inform the applicant of the date of issue and the licence number and dispatch the regional access licence to the applicant; and

(ii) promptly notify all Parties of the name and call sign of the vessel, date of issue of the regional access licence and the licence number,

by facsimile or telex at the latest before the lapse of four working days, exclusive of the day on which such application was made;

(b) upon denial of an application, notify the applicant by facsimile or telex of the denial and the reason for the denial at the latest before the lapse of four working days, exclusive of the day on which such application was made.

4. A regional access licence shall be denied:

(a) where the application is not in accordance with the requirements of this Annex;

(b) where the fishing vessel in respect of which application for a regional access licence has been made is not an eligible fishing vessel;

(c) where the fishing vessel in respect of which application for a regional access licence has been made does not, at the time of making the application, have good standing on the Regional Register of Foreign Fishing Vessels; or

(d) where there has been a failure to satisfy a final judgment or other final determination for a breach of this Arrangement by the operator of the vessel in respect of which application for a regional access licence has been made, until such time as the final judgment or other final determination is satisfied, and provided that a subsequent change in ownership of a vessel shall not affect the application of this provision. 
5. Where an application for a regional access licence has been denied on one or more of the grounds set out in paragraph 4 of this Annex the applicant shall be entitled to re-submit the application after taking any necessary corrective action.

6. A regional access licence issued under this Article shall be issued to the applicant in the form set out in Schedule 2.

\section{SCHEDULE 1}

FEES

1. The following fee calculation formula shall be applied in accordance with the following principles.

2. Fees shall be paid based on real data on the actual catch performance of vessels operating under this Arrangement in the preceding year and data on the average price for tuna in the preceding year.

3. In order to reflect their different catching capacities, a different fee structure for each size class of vessel shall apply. The size classes are:

(a) less than 700 GRT

(b) $700-1,000$ GRT

(c) greater than 1,000 GRT

4. For each size class, the formula for calculating the fee shall be:

$\mathrm{FEE}=\quad$ average regional catch per vessel $\quad \mathrm{x}$ average price of tuna $\quad \mathrm{x} 5 \%$

5. Subject to paragraph 8 , the regional catch per vessel for each size class shall be calculated as the average of the catches of each vessel in that size class in the preceding year or, where a 3 month regional access licence is applied for, the average of the catches of each vessel in that size class in the preceding year divided by four.

6. The average price will be calculated by the Administrator on the basis of the average price for the preceding twelve months at the major markets. The source of market information will be reviewed at each Annual Meeting of the Parties.

7. The fee shall be paid in two equal instalments. The first instalment shall be paid on application for a regional access licence and the second instalment shall be paid upon expiry of the licence period. In addition, an observer levy of US $\$ 2,400$ per vessel per year shall be payable upon first application for a regional access licence in any twelve month period.

8. During the period commencing from the date of adoption of this Arrangement until the date of the first Annual Meeting of the Parties pursuant to Article 8, the fee calculation formula set out in paragraph 4 shall be modified by using estimates of the expected regional catch of each size class of vessel as follows:

\begin{tabular}{|l|c|}
\hline \multicolumn{1}{|c|}{ Size class } & Regional catch \\
\hline less than 700 GRT & $1,700 \mathrm{mt}$ \\
\hline $700-1,000$ GRT & $2,000 \mathrm{mt}$ \\
\hline greater than 1,000 GRT & $2,500 \mathrm{mt}$ \\
\hline
\end{tabular}

9. Twelve months following the date of adoption of this Arrangement, the Administrator shall reconcile the payments made according to the modified formula set out in paragraph 8 against an amount equivalent to $5 \%$ of the realised average value of the catch of each size class based on the catch data supplied pursuant to this Arrangement. 
If the initial fee paid was lower than the amount needed to provide a fee of $5 \%$ of the average value of the catch, vessel operators would be required to make an additional payment.

SCHEDULE 2

REGIONAL ACCESS LICENCE FORM

\title{
THE FEDERATED STATES OF MICRONESIA ARRANGEMENT FOR REGIONAL FISHERIES ACCESS
}

\section{Regional Access Licence}

The vessel described in this licence is hereby authorised to engage in fishing in the Arrangement Area for the period of validity of in this licence, in accordance with the terms and conditions referred to in Annex V of the Federated States of Micronesia Arrangement for Regional Fisheries Access.

\section{REGIONAL ACCESS LICENCE NUMBER:}

\author{
VESSEL NAME: \\ INTERNATIONAL RADIO CALL SIGN: \\ COUNTRY OF REGISTRATION (FLAG): \\ COUNTRY OF REGISTRATION NUMBER: \\ NAME OF VESSEL MASTER: \\ HOME PARTY:
}

\section{PERIOD OF VALIDITY}

This licence is valid from to

(inclusive).

Signature of Issuing Officer:

Date:

\section{ANNEX V \\ PART 1 \\ INTRODUCTORY}

1. In this Annex:

(a) "Closed Area" means an area described in Schedule 2;

(b) "designated area" means a port or area authorized by the Parties for the purposes of transhipment and described in Schedule 4;

(c) "Limited Area" means an area described in Schedule 3;

(d) "the vessel" means the vessel in respect of which a regional access licence pursuant to Article 6 of this Arrangement is issued. 
2. Schedule 1 may be amended from time to time by the inclusion by any Party of any applicable national law and, for the purposes of this Arrangement, except as provided in this paragraph, the amendment shall take effect from the date that the amended Schedule has been notified to each of the remaining Parties. Any Party proposing an amendment shall use its best endeavours to provide advance notice to the Parties of the amendment.

3. Nothing in this Annex and its Schedules, nor acts or activities taking place thereunder, shall constitute recognition of the claims or the positions of any of the Parties concerning the legal status and extent of waters and zones claimed by any Party. In the claimed waters and zones, the freedoms of navigation and overflight and other uses of the sea related to such freedoms are to be exercised in accordance with international law.

\section{PART 2 \\ COMPLIANCE WTTH APPLICABLE NATIONAL LAWS}

4. The operator of the vessel shall comply with each of the applicable national laws, and shall be responsible for the compliance by the vessel and its crew with each of the applicable national laws, and the vessel shall be operated in accordance with those laws.

\section{PART 3}

\section{PROHIBITIONS}

5. The vessel shall not be used for fishing for any kinds of fish other than tunas, except that other kinds of fish may be caught as an incidental by-catch, nor for any method of fishing other than the purse seine method.

6. Except as may be permitted by the home Party in the waters of the home Party or as may be otherwise permitted by this Arrangement, the vessel shall not be used for fishing in any Closed Area.

7. The vessel shall not be used for fishing in any Limited Area except in accordance with the requirements set out in Schedule 3, which are applicable to that Limited Area.

8. No fish on board the vessel shall be transhipped at sea.

\section{PART 4 \\ TRANSHPMENT}

9. Within the Arrangement Area, transhipment shall be permitted only at a designated area at the time and in the manner authorized by the Party in whose zone the transhipment is to take place.

10. Schedule 4 may be amended from time to time by the inclusion by any Party of any designated area and, for the purposes of this Arrangement, the amendment shall take effect from the date that the amended Schedule has been notified to each of the remaining Parties.

11. The master and each member of the crew of the vessel from which any fish taken in the Arrangement Area is transhipped shall:

(a) allow and assist any person identified as an officer of the Party in whose zone the transhipment is to take place to:

(i) have full access to the vessel and any place where such fish is being transhipped and the use of facilities and equipment which the officer may determine is necessary to carry out his or her duties;

(ii) have full access to the bridge, fish on board and areas which may be used to hold, process, weigh and store fish;

(iii) collect samples; 
(iv) have full access to the vessel's records including its log and documentation for the purpose of inspection and copying; and

(v) gather any other information required to fully monitor the activity without interfering unduly with the lawful operation of the vessel;

(b) not assault, obstruct, resist, delay, refuse boarding to, intimidate or interfere with any such officer in the performance of his or her duties.

12. Notwithstanding any additional terms and conditions that may be agreed between the operator of the vessel and the Party in whose zone the transhipment is to take place, catch shall only be transhipped to a carrier vessel which, at the time the transhipment takes place, is duly registered in good standing on the Regional Register of Foreign Fishing Vessels and is duly licensed in accordance with national laws and regulations.

\section{PART 5 \\ REPORTING}

13. Information relating to the position of and catch on board the vessel shall be provided by telex or facsimile, in the format described in Part 1 of Schedule 5, to the Administrator at the following times:

(a) at least 24 hours prior to the estimated time of entry into or departure from port; and

(b) each Wednesday.

14. Information relating to the position of and catch on board the vessel shall be provided to the relevant Party, in the format described in Part 1 of Schedule 5, as follows:

(a) at the time of entry into and of departure from waters which are, for any purpose, subject to the jurisdiction of a Party;

(b) each Wednesday while within the waters of that Party;

(c) at least 24 hours prior to the estimated time of entry into or departure from port;

(d) upon entry into and departure from a Closed Area; and

(e) as otherwise set out in Part 2 of Schedule 5.

\section{PART 6 \\ ENFORCEMENT}

15. The master and each member of the crew of the vessel shall immediately comply with every instruction and direction given by an authorized and identified officer of the Party within whose jurisdiction the vessel is present, including to stop, to move to a specified location, and to facilitate safe boarding and inspection of the vessel, its licence, gear, equipment, records, facilities, fish and fish products. Such boarding and inspection shall be conducted as much as possible in a manner so as not to interfere unduly with the lawful operation of the vessel. The operator and each member of the crew shall facilitate and assist in any action by an authorized officer of the Party within whose jurisdiction the vessel is present and shall not assault, obstruct, resist, delay, refuse boarding to, intimidate or interfere with an authorized officer in the performance of his or her duties.

16. The operator shall ensure that a recent and up-to-date copy of the International Code of Signals (INTERCO) is on board and accessible at all times.

17. The international distress frequency, $2.182 \mathrm{MHz}$, and $156.8 \mathrm{MHz}$ (Channel 16 , VHF) shall be monitored continuously from the vessel for the purpose of facilitating communication with the search and rescue, fisheries management, surveillance and enforcement authorities of the Parties. 
18. The operator shall comply with the 1989 FAO Standard Specifications for the Marking and Identification of Fishing Vessels. In particular the international radio call sign of the vessel shall be painted in white on a black background, or in black on a white background in the following manner:

(a) on the vessel's hull or superstructure, with each letter and number being at least one metre high and having a stroke width of 16.7 centimetres, with the background extending to provide a border around the mark of not less than 16.7 centimetres;

(b) on the vessel's deck, on the body of any helicopter and on the hull of any skiff, with each letter and number being at least 30 centimetres high, and having a stroke width of 5 centimetres wide with the background extending to provide a border around the mark of not less than 5 centimetres; and

(c) on any other equipment being carried by and intended to be separated from the vessel during normal fishing operations, with each letter and number being at least 10 centimetres high and having a stroke width of 1.7 centimetres, with the background extending to provide a border around the mark of not less than 1.7 centimetres,

and at all times while the vessel is within the Arrangement Area or a Closed Area, all parts of these markings shall be clear, distinct and uncovered.

19. The regional access licence shall be carried on board the vessel at all times and produced at the request of an authorized enforcement official of any of the Parties. Prior to receipt of the regional access licence, a duly certified copy, facsimile or telex confirmation thereof or the correct citation of the regional access licence number shall satisfy this requirement.

\section{PART 7 OBSERVERS}

20. The operator and each member of the crew of the vessel shall allow and assist any person duly identified as an observer to:

(a) board the vessel for scientific, compliance, monitoring and other functions;

(b) have full access to and the use of facilities and equipment on board the vessel which the observer may determine is necessary to carry out his or her duties, including full access to the bridge, fish on board and areas which may be used to hold, process, weigh and store fish;

(c) collect samples;

(d) have full access to the vessel's records, including its logs and documentation for the purpose of inspection and copying;

(e) have reasonable access to navigation equipment, charts, and radios;

(f) gather any other information relating to fisheries in the Arrangement Area without interfering unduly with the lawful operation of the vessel;

(g) disembark at the point and time notified by the Administrator; and

(h) carry out all duties safely,

and no operator or crew member of the vessel shall assault, obstruct, resist, delay, refuse boarding to, intimidate or interfere with an observer in the performance of his or her duties.

21. The operator shall provide the observer, while on board the vessel, at no expense to the Parties or the Administrator, with full insurance cover and with food, accommodation and medical facilities equivalent to those provided to officers of the vessel. 
22. The operator of the vessel from which any fish taken in the Arrangement Area is off-loaded shall allow, or arrange for, and assist any person authorized for this purpose by the Parties to have full access to any place where such fish is off-loaded, to collect samples and to gather any other information relating to fisheries in the Arrangement Area.

\section{PART 8 \\ MISCELLANEOUS REQUIREMENTS}

23. At all times while the vessel is in a Closed Area, the fishing gear of the vessel shall be stowed in such a manner as not to be readily available for fishing. In particular, the boom shall be lowered as far as possible so that the vessel cannot be used for fishing but so that the skiff is accessible for use in emergency situations; the helicopter, if any, shall be tied down; and launches shall be secured.

24. The vessel shall be operated in such a way that the activities of traditional and locally-based artisanal fishermen and fishing vessels are not disrupted or in any other way adversely affected.

25. Any information required to be recorded, or to be notified, communicated or reported pursuant to a requirement of this Arrangement shall be true, complete and correct. Any change in circumstances which has the effect of rendering any such information false, incomplete or misleading shall be notified to the Administrator immediately.

26. It is understood that a region-wide vessel tracking system applicable to all vessels licensed to fish in the Arrangement Area may be established. Fishing vessels of the Parties with a licence to fish under this Arrangement shall participate in such a system and shall install and operate a transponder of a type and in such a manner as may be agreed by the Parties. It is understood that data derived through the system shall be treated as confidential business information and that the terms and conditions for access to that information shall be a matter of discussions between the Parties.

27. At any time when the vessel is within the waters of a Party the operator shall, upon request by the relevant authorities of that Party, take reasonable steps to assist those authorities in search and rescue operations at sea.

\section{SCHEDULE 1 \\ APPLICABLE NATIONAL LAWS}

Federated States of Micronesia

Titles 18, 19 and 24 of the Code of the Federated States of Micronesia and regulations promulgated thereunder.

\section{Kiribati}

Fisheries Ordinance, 1979

Fisheries (Amendment) Act, 1984

Marine Zones (Declaration) Act, 1983

Fisheries (Amendment) Act, 1992

\section{Marshall Islands}

Title 33, Marine Resources Act, as amended by P.L. 1989-56, P.L. 1991-43 and P.L. 1992-25 of the Marshall Islands Revised Code

\section{Nauru}

Interpretation Act, 1971

Interpretation Act (Amendment) Act No. 1, 1975

Interpretation Act (Amendment) Act No.2, 1975

Marine Resources Act, 1978 
Palau

Palau National Code, Title 27

Papua New Guinea

Fisheries Act, 1994

Fisheries Regulations, 1994

Fisheries (Torres Strait Protected Zone) Act, 1984

National Seas Act (Cap 361)

Whaling Act (Cap 225)

\section{$\underline{\text { Solomon Islands }}$}

Delimitation of Marine Waters Act, 1978

Fisheries Act, 1972

Fisheries Limits Act, 1977

Fisheries Regulations, 1972

Fisheries (Foreign Fishing Vessels) Regulations, 1981

$\underline{\text { Tuvalu }}$

Fisheries Act (Cap 45)

Fisheries (Foreign Fishing Vessel) Regulations, 1982

Marine Zones (Declaration) Act, 1983

\section{SCHEDULE 2}

\section{CLOSED AREAS}

Federated States of Micronesia Twelve nautical mile territorial sea and within one nautical mile of the edge of all named banks and reefs as depicted on the following charts:

DMAHTC No.81019 (2nd. edn., Mar. 1945; revised 7/17/72, corrected through NM 3/78 of June 21, 1978)

DMAHTC No.81023 (3rd. edn., Aug. 7, 1976)

DMAHTC No.81002 (4th. edn., Jan. 26, 1980; corrected through NM 4/80)

Within a two nautical mile radius of any fish aggregating device of the government, a citizen or any other body established under the laws of the Federated States of Micronesia.

Kiribati Gilbert Group: within archipelagic waters as established in accordance with the Marine Zones Declaration Act 1983, within 3 nautical miles of any anchored fish aggregating device for which notification of its location shall be given by geographical coordinates.

Phoenix Group: within 12 nautical miles drawn from the baselines from which the territorial sea is measured; within 2 nautical miles of any anchored fish aggregating device for which notification of its location shall be given by geographical coordinates.

Line Group: within 12 nautical miles drawn from the baselines from which the territorial sea is measured; within 2 nautical miles of any anchored fish aggregating device for which notification of its location shall be given by geographical coordinates.

Marshall Islands 12 nautical mile territorial sea and area within two nautical miles of any anchored fish aggregating device for which notification of its location shall be given by geographical coordinates.

Nauru The territorial waters as defined by Nauru Interpretation Act, 1971, Section 2. 
Palau Within 12 nautical miles of all island baselines in the Palau Islands; the area -

(a) commencing at the north-easternmost intersection of the outer limit of the 12 nautical mile territorial sea of Palau by the arc of a circle having a radius of 50 nautical miles and its centre at Latitude $070^{\circ} 16^{\prime} 34^{\prime \prime}$ North, Longitude $134^{\circ} 28^{\prime} 25^{\prime \prime}$ East, being at about the centre of the reef entrance to Malakal Pass;

(b) running thence generally south-easterly, southerly, south-westerly, westerly, north-westerly, northerly and north-easterly along that arc to its intersection by the outer limit of the 12 nautical mile territorial sea; and

(c) thence generally northerly, north-easterly, easterly, south-easterly and southerly along that outer limit to the point of commencement.

NOTE: Where for the purpose of this paragraph it is necessary to determine the position on the surface of the Earth of a point, line or area it shall be determined by reference to the World Geodetic System 1984, that is to say, by reference to $a$ spheroid having its centre at the centre of the Earth and a major (equatorial) radius of $6,378,137$ metres and $a$ flattening of $1 / 298.2572$.

Papua New Guinea In addition to its territorial sea and internal waters, within the area bounded by the following parallels and meridians: from latitude $0^{\circ} 30^{\prime}$ South to latitude $3^{\circ} 30^{\prime}$ South, and from longitude $149^{\circ}$ East to longitude $153^{\circ}$ East.

Solomon Islands Internal waters, territorial sea, archipelagic waters and within 5 nautical miles of any anchored fish aggregating device for which notification of its location shall be given by geographical coordinates.

Tuvalu Territorial sea and waters within two nautical miles of all named banks, i.e. Macau, Kosciusko, Rose, Bayonnaise and Hera, in the Tuvalu EEZ, as depicted on the chart entitled "Tuvalu Fishery Limits" prepared by the United Kingdom Hydrographic Department, Taunton, January 11, 1981.

\author{
SCHEDULE 3 \\ LIMTTED AREAS
}

\title{
SCHEDULE 4
}

DESIGNATED PORTS FOR TRANSHIPMENT

\section{Federated States of Micronesia}

Pohnpei

Chuuk (Weno)

Yap (Tomil Harbour)

Kosrae (Okat Harbour)

\section{Kiribati}

Tarawa

Kiritimati

Marshall Islands

Majuro

Papua New Guinea

Lae

Kavieng

Lorengau (Manus Island)

Madang (Sek Harbour) 


\section{Misima}

Port Moresby

Rabaul

Wewak

\section{Solomon Islands}

\section{Honiara}

Noro

Tulagi

\section{SCHEDULE 5 \\ REPORTING DETAILS}

\section{PART 1 \\ FORMAT FOR REPORTS TO ADMINISTRATOR AND NATIONAL AUTHORITIES}

\section{Zone Entry and Exit Reports}

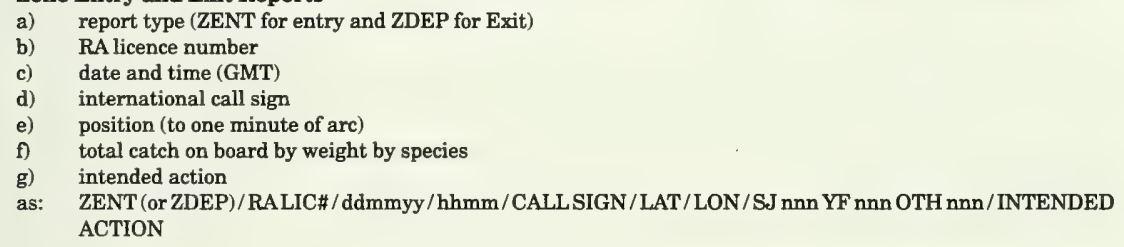

\section{Weekly Reports}
a) report type (WEEK)
b) RA licence number
c) date and time (GMT)
d) international call sign
e) noon position (to one minute of arc)
f) catch taken in zone by weight by species
g) number of fishing days
h) intended action
as: WEEK / RA LIC\# / ddmmyy / hhmm / CALL SIGN / LAT / LON / SJ nnn YF nnn / OTH nnn FISH DAYS / INTENDED ACTION

\section{Port Entry Reports}

a) report type (PENT)

b) RA licence number

c) date and time (GMT)

d) international call sign

e) position (to one minute of arc)

f) total catch on board by weight by species

g) intended action

h) port name

i) estimated date and time of entry into port (GMT)

as: IPENT / RA LIC\# / ddmmyy / hhmm / CALL SIGN / LAT / LON / SJ nnn YF nnn OTH nnn / INTENDED ACTION / PORT NAME / ddmmyy / hhmm

\section{Port Departure Reports}

a) report type (PDEP)

b) RA licence number 
c) date and time (GMT)

d) international call sign

e) position (to one minute of arc)

f) total catch on board by weight by species

g) intended action

h) port name

i) estimated time of departure from port (GMT)

j) catch unloaded by weight by species

as: PDEP/RALIC\#/ddmmyy/hhmm/CALLSIGN/LAT/LON/SJ nnn YF nnn OTH nnn/INTENDED ACTION/ PORT NAME / ddmmyy / hhmm / SJ nnn YF nnn OTH nnn

\section{Closed Area Entry and Exit Reports}

a) report type (CENT for entry and CDEP for Exit)

b) RA licence number

c) date and time (GMT)

d) international call sign

e) position (to one minute of arc)

f) total catch on board by weight by species

g) intended action

as: CENT (or CDEP) / RA LIC\# / ddmmyy / hhmm / CALL SIGN / LAT / LON / SJ nnn YF nnn OTH nnn / INTENDED ACTION

\section{PART 2 \\ ADDITIONAL NATIONAL REPORTING REQUIREMENTS}

Kiribati

\section{Refuelling Notice}

At least 24 hours before refuelling from a licensed tanker:

a) report type (FUEL)

b) registration or Licence number

c) call sign or signal letters

d) date of reporting (GMT)

e) position of reporting (to one minute of arc)

f) amount of fuel on board (kilolitres)

g) estimated date of bunkering

h) estimated position of bunkering

i) name of tanker

eg: FUEL / 89TKSPS001TN / JJAP2 / 06.02.90 / 0130S; 17010E / 08.02.90 / 0131S; 17030E / CHEMSION

\section{Bunkering Activity Report}

Immediately after refuelling from a licensed tanker:

a) report type (BUNK)

b) registration or licence number

c) call sign or signal letters

d) starting date and time bunkering (GMT)

e) starting position of bunkering

f) amount of fuel received in kilolitres

g) ending position of bunkering

h) name of tanker

eg: $\quad$ BUNK / 89TKS-S001TN / JJAP2 / 08.02.90:1200Z / 0131S;17030E / 160 / 08.02.90:1800Z / 0131S;17035E / CRANE PHOENIX 


\section{ANNEX VI \\ DISTRIBUTION OF PAYMENTS}

1. In this Annex:

(a) "the distribution period" shall be 1 January to 31 December;

(b) "licence fees" means the total licence fees attributable to each distribution period, calculated in accordance with this paragraph, including accrued interest thereon and any licence fees carried forward from the previous distribution period, after the deduction of administrative costs in accordance with paragraph 4. Where a regional access licence expires after the end of the distribution period during which it was issued, the fees received in respect of that regional access licence shall be pro-rated by time between that distribution period and the next;

(c) "regional catch" for a Party means the aggregate of the catch reported in each distribution period as having been taken in the exclusive economic or fisheries zone of that Party under regional access licences pursuant to this Arrangement. Provided that any catch taken in the waters of a Party by fishing vessels of that Party under regional access licences shall not be taken into account when calculating the regional catch for that Party;

(d) "regional price per tonne" means the aggregate licence fees divided by the aggregate of the regional catch for all Parties.

2. The Administrator shall, as soon as practicable after all catch information for each annual distribution period is available, distribute all licence fees to the Parties in accordance with paragraph 5 . Such payments shall be made not later than four months after the end of the distribution period unless the Parties agree otherwise. The Administrator shall provide details of each distribution of licence fees to the Annual Meeting of the Parties convened in accordance with Article 6.

3. The Administrator shall deduct from the total licence fees received such amount in administrative costs as may be approved by the Parties in accordance with Article 6.

4. The Administrator shall apply the observer levy for the purpose of implementing the observer programme in accordance with the administrative procedures agreed by the Parties from time to time.

5. The distribution to each Party shall be the sum of the regional catch for that Party multiplied by the regional price per tonne. 


\section{Federated States of Micronesia Arrangement for REgIONAL FISHERIES ACCESS}

\section{Status of Implementation}

The text of the Federated States of Micronesia Arrangement for Regional Fisheries Access was adopted and initialled by Ministers attending the Tenth Special (Ministerial Level) Session of the Parties to the Nauru Agreement Concerning Cooperation in the Management of Fisheries of Common Interest, 1982 at Honiara, Solomon Islands on 29 November 1994.

The Arrangement was opened for signature on 30 November 1994 and signed by Ministers from Federated States of Micronesia, Kiribati and Palau.

Table of signatures and accessions

\begin{tabular}{||l|c|c||}
\hline & Date of signature & Date of accession \\
\hline Federated States of Micronesia & $30-11-94$ & \\
\hline Kiribati & $30-11-94$ & \\
\hline Marshall Islands & & \\
\hline Nauru & $30-11-94$ & \\
\hline Palau & & \\
\hline Papua New Guinea & & \\
\hline Solomon Islands & & \\
\hline Tuvalu & & \\
\hline
\end{tabular}




\section{U L T I L A}

\section{FISHERIES}

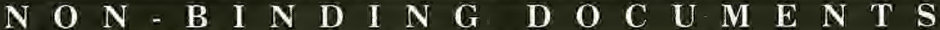





\section{United Nations General Assembly Resolution $48 / 445$ on Large-Scale Pelagic Drift-net Fishing and Its Impact on the Living Marine Resources of the World's Oceans and Seas, New York, 1993}

\section{Done at New York 21 December 1993 \\ Primary source citation: Copy of text provided by \\ the United Nations}

48/445. Large-scale pelagic drift-net fishing and its impact on the living marine resources of the world's oceans and seas

Date: 21 December 1993

Meeting: 86

Adopted without a vote

Report: A/48/717/Add. 6

The General Assembly, on the recommendation of the Second Committee and taking note with appreciation of the report of the Secretary-General, ${ }^{55}$ decided:

(a) To reaffirm the importance it attaches to compliance with its resolution 46/215 of 20 December 1991;

(b) To express its appreciation of the measures taken by members of the international community, international organizations and regional economic integration organizations to implement and support the objectives of resolution $46 / 215$, while expressing concern at reports of conduct and activities inconsistent with the terms of resolution 46/215;

(c) To call on all members of the international community, intergovernmental organizations, regional economic integration organizations and appropriate non-governmental organizations to provide the Secretary-General with information relevant to the implementation of resolution $46 / 215$, and requests the Secretary-General to report to it at its forty-ninth session, and to submit subsequently annual updates on further developments relevant to the implementation of resolution $46 / 215$. 


\title{
Code of Practice for Minimizing the Risks of Introducing Fish Species, Cairo, 1990
}

\author{
Done at Cairo 25 October 1990 \\ Primary source citation: Copy of text provided by the \\ Food and Agriculture Organization of the United \\ Nations
}

\section{FOOD AND AGRICULTURE ORGANIZATION OF THE UNITED NATIONS}

Provisional Agenda

Item $6(\mathrm{c})(\mathrm{v})$

\section{COMMITTEE FOR INLAND FISHERIES OF AFRICA Eighth Session \\ Cairo, Egypt, 21-25 October 1990}

\section{CODE OF PRACTICE FOR MINIMIZING THE RISKS OF INTRODUCTION OF FISH SPECIES}

Background

During the Sixth Session of the Committee for Inland Fisheries of Africa (CIFA) the need was recognized for a Code of Practice to reduce the risks of introductions of inland aquatic species into and within Africa. Pursuant to the suggestion that each country nominate a national expert to serve on a CIFA correspondence working group to study and develop such a code a group was set up in October 1986 with the following membership:

P.M. Denyoh (Ghana); J. Yonazi (Tanzania); G.N. Shimang (Nigeria); N. Boulous (Egypt); S. Mashapha (Lesotho); M. Diagne (Senegal).

This group examined the existing EIFAC/CES Code of Practice and suggested that this Code be considered for acceptance by the Committee subject to certain modifications to bring it into line with the needs of CIFA. These observations were transmitted to the Seventh Session of CIFA who mandated the Secretariat to finalize the Code on the basis of comments received and to circulate it to member countries for comment.

The amended Code was transmitted to all member countries on 20 June 1988 and, as no replies have been received either in favour or against the Code in its present form, this is submitted to the Committee for approval. 


\section{CODE OF PRACTICE}

(a) Recommended procedure prior to reaching a decision regarding proposed introductions (this procedure does not apply to introductions or transfers which are part of current commercial practice)

(i) Member countries contemplating any introduction should be requested to present to CIFA or a designated sub-group of CIFA at an early stage information on the species, area of origin, proposed place of introduction and objectives, with such information on its habitat, associated organisms, etc., as is available. CIFA should then consider the possible outcome of the introduction and offer advice whether to proceed with further evaluation.

(ii) Appropriate authorities of the importing country should examine each "candidate for admission" to assess the justification for the introduction, its relationship with other members of the ecosystem, details of its biology and ecology and the possibility of introducing associated pathogenic organisms and parasites.

(iii) The probable effects of introduction into the new area should be assessed carefully, including an examination of the effects of any previous introductions of this or similar species in other areas, and a prediction of the final range of the species assuming it could form breeding populations in natural waters.

(iv) The above procedures ( $\mathrm{i}$, ii and iii) should be carried out by following the Review and Decision Model as set out in Appendix 1.

(b) Recommended action. If the decision is taken to proceed with the introduction, the following action is recommended:

(i) A broodstock should be established in an approved quarantine situation. Broodstocks should be developed from stocks imported as eggs, in order to minimize the possibility of contamination by pathogenic organisms, parasites or by other species of fish. All effluents from establishments used for quarantine purposes should be sterilized in an approved manner.

(ii) Should the importation of eggs not be possible, importations of juvenile or adult fishes to serve as broodstock should only be made with fish accompanied by a certificate as to their perfect state of health. This broodstock should be maintained in an approved quarantine situation.

(iii) If no communicable pathogenic organisms including parasites become evident, the first generation progeny, but not the original import, of the introduced species can be transplanted to culture sites, or to the natural environment, preferably to small isolated and restricted river basins or lakes.

\section{(c) Recommended actions after introduction}

(i) A continuing study should be made of the introduced species in its new environment and progress reports submitted to CIFA.

(ii) Every effort should be made to contain the species within the water bodies or water courses into which introduction was intended.

(d) Regulatory agencies of all member countries are encouraged to use the strongest possible measures to prevent unauthorized or unapproved introductions and transfers

(e) Recommended procedure for introductions or transfers which are part of current commercial practice (the procedure laid down by the "Draft Convention to prevent the spread of major communicable fish diseases" should be adhered to, especially:)

(i) Periodic inspection (including adequate microscopic and microbiological examinations) by the receiving country of material for prior mass transplantation to confirm freedom from introdu- 
cable pests and diseases. If inspection reveals any undesirable development, importation must be immediately discontinued. Findings and remedial actions should be reported to CIFA.

(ii) Inspection and control of each consignment on arrival.

(iii) Quarantining or disinfection where appropriate.

(iv) Establishment of broodstocks certified free of specified pathogens.

While the codes give broad direction toward control of introductions and transfers, there is still a need for more specific instruction on their implementation, i.e., a checklist of procedures to be followed for consideration of an introduction and follow-up instructions should one be approved.

\section{Consideration of Requests for Introductions or Transfers at the National Level}

Any country dealing with or contemplating introductions or transfers of aquatic organisms (marine or freshwater) between countries or within national boundaries should have or enact legislation for regulating such activity. A national coordination/consultation mechanism to review, recommend on and monitor (when approval is granted) any such activity should be established to advise administrators on the use of the regulating legislation.

This national committee or working group would ensure that all prospective applicants, private or government, wanting to introduce or transfer species would submit properly prepared requests to be vetted for acceptability. Such a working group could actually be duplicated on a regional basis to reflect different environment conditions. Continuity on the national scene could be addressed by regions periodically meeting to discuss common goals and regional concerns and through adoption of the Code of Practice. Appropriate regulations would be required to ensure compliance with approved protocols should permission be granted. Potential applicants would have to be made aware of the regulations through a national education campaign.

Where an introduction into one country may adversely affect another, the national working group on introductions and transfers should forward the application to a duly constituted group of interested CIFA member countries for a risk analysis and recommendations prior to making a decision on an application.

\section{APPENDIX I \\ Review and Decision Model for Evaluating Proposed Introductions of Aquatic Organisms}

\section{Level of Review I}

(a) Purpose of introduction. Does the proposing entity have valid reasons for introducing the aquatic organism? Could no native species serve the same function?

(b) Abundance in native range. Knowledge of the population abundance of the organism in its native range is an important aspect of the evaluation. Is it endangered, threatened or rare? Is it exploited from the wild or under culture?

(c) Communicable pathogenic organisms and parasites. The evaluation would include assessing the safeguards for avoiding transmission of communicable pathogenic organisms or parasites to the proposed receiving system(s).

(d) Site of introduction. It is important to discern from the outset whether the organism would be stocked in an open or closed system. Would it be stocked in or have potential access to a major drainage? If it is to be maintained in a closed system, the proposing entity must identify steps it would take to guard against accidental escape. 


\section{Decision I}

A proposal for an introduction would be rejected if:

- reasons for introduction were not deemed valid;

- the introduction is for reasons other than conservation where the organism is endangered, threatened, or rare in its native range, or

- the proposing entity has not established that adequate safeguards would be taken to avoid introduction of communicable pathogenic organisms and parasites. The proposal would be approved at this stage when the above criteria are met and provided that the introduction is perceived as being limited to a closed system. When this last condition is not fully met, the evaluation process would proceed to the next level of review.

\section{Level of Review II}

This and subsequent levels of review are directed to experts selected by the Working Group. In Level II the acclimation potential is assessed (Question 5 of the "opinionnaire"). Should pertinent information be insufficient, as evidenced by more than 50 percent of the experts marking "don't know" on the "opinionnaire", the Working Group might suggest that the proposing entity conduct research with a limited number of specimens under confined conditions for the purpose of obtaining the required data. The Working Group may suggest that all research be conducted within the organism's native range.

\section{Decision II}

The proposal for the introduction would be approved when there is a strong chance that the organism would not establish a self-sustaining population, or when evidence is insufficient for making a seasonable prediction.

\section{Level of Review III}

The level of review is based on predicting the potential impact of the organism on the ecological integrity of the system(s) where it is proposed for introduction. In addition, the analysis of benefit and risk would include assessing the array of potential impacts on man. Review at this level requires detailed knowledge on the ecological relations of the organism in its native habitat, as well as considerable information on the community structure of the proposed receiving system(s).

\section{Decision III}

The introduction would be rejected if the available information suggests (average "opinionnaire" values 2) that the organism would exert a major adverse impact on the receiving system(s) or on man. The proposal would be approved when indications are for the opposite outcomes. If the available information is not considered conclusive, the evaluation should proceed to Level of Review IV.

\section{Level of Review IV}

Level of Review IV requires development of a detailed literature review based on the format for a Food and Agriculture Organization (United Nations) Species Synopsis. However, additional sections concerning impacts of introduction (documented or potential) would also be required. Once the synopsis is prepared, this information will be sent again to the experts so they can attempt to arrive at a recommendation.

\section{Decision IV}

On the basis of an analysis of the second round of "opinionnaire" data, the Working Group would either approve or reject the proposed introduction. Additional review (Level $\mathrm{V}$ ) would be necessary whenever the current data base is not considered sufficient, or if it is unclear whether the introduction is desirable. 


\section{Level of Review V}

This level of review requires that research be conducted to complete the species synopsis or to assess the potential impact of the introduction on the indigenous flora and fauna and habitats. It might be suggested that research be conducted under controlled conditions near the site where the introduction is contemplated or the Working Group may suggest that all studies be carried out within the organism's native range.

\section{Decision V}

Using all information collected at this stage, the Working Group should be able to make an informed recommendation regarding the proposed introduction. However, the Working Group may find it necessary to suggest additional research if important questions remain to be resolved. In such a situation, the fifth and final evaluation stage would become a loop of the "Review" and "Decision" models until a recommendation could be made.

Table 1

Opinionnaire for appraisal of introductions of aquatic organisms.

(Kohler and Stanley, in press)

No Unlikely Possibly Probably Yes $\begin{aligned} & \text { Do not } \\ & \text { know }\end{aligned}$

1. Is the need valid and are no native species available that could serve the stated need?

2. Is the organism safe from overexploitation in its native range?

3. Are safeguards adequate to guard against importation of disease/parasites?

4. Would the introduction be limited to closed system?

5. Would the organism be unable to establish a self-sustaining population in the range of habitats that would be available?

6. Would the organism have mostly positive ecological impacts?

7. Would most consequences of the introduction be beneficial to humans?

8. Is data base adequate to develop a complete species synopsis?

9. Does data base indicate desirability for introduction?

10. Based on all available information, do the benefits of the exotic fish introduction outweigh the risks?
1

1

1

1

1

1

1

1

1

1

1
2

2

2

2

2

2

2

2

2

2
3

3

3

3

4

4

4

4

5

5
$\mathrm{X}$

X

$\mathrm{X}$

X

$\mathrm{X}$

X

$\mathrm{X}$

X

$\mathrm{X}$

Note: Each member of an evaluation board or panel of experts should circle the number which closer matches his/her opinion regarding the probability for the occurrence of the event. If information is unavailable or too uncertain: "do not know" should be marked. 


\section{Table 2}

Review and decision model for evaluating proposed introduction of aquatic organisms (Kohler and Stanley, in press) (simplified by Steinmetz, 1987)

Review level

\section{Level of Review I}

1. Is the need valid and are no native species available that could serve the stated need?

$$
\text { Opinionnaire value* }
$$

2

2
2. Is the organism safe from overexploitation in its native range?

3. Are safeguards adequate to guard against importation of disease/parasites?

4. Would the introduction be limited to closed system?

\section{Level of Review II}

5. Would the organism be unable to establish a self-sustaining population in the range of habitats that would be available?

\section{Level of Review III}

6. Would the organism have mostly positive ecological impacts?

7. Would most consequences of the introduction be beneficial to humans?

\section{Level of Review IV}

8. Is data base adequate to develop complete species synopsis?

9. Does data base indicate desirability for introduction?

10. Would benefits exceed risks?
2

2

2

2

3

3

3

3

$\begin{array}{llll}2 & & \text { - reject } \\ 3 & 2 & \text { - to review level IV } \\ 3 & & \text { - to next question } \\ 2 & & \text { - reject } \\ 3 & 2 & \text { - to review level IV } \\ 3 & & \text { - approve }\end{array}$

3

3

2

32

2

2

3
- reject

- to next question

- reject

- to next question

- reject

- to next question

- approve

- to review level II
- approve

- to review level III

- conduct detailed lit.rev.(1)

- to next question

- reject

- conduct research (2)

- approve

- reject

- approve

(1) Thereafter next step question 9

(2) Research focused on potential impact on indigenous species and habitats. Thereafter question 10. Value 32 restart research

* Refer to Table 1 


\title{
United Nations General Assembly Resolution 49/116 on Unauthorized Fishing in Zones of National Jurisdiction and Its Impact on the Living Marine Resources of the World's Oceans and Seas, New York, 1994
}

\author{
Done at New York 19 December 1994 \\ Primary source citation: Copy of text provided by the \\ United Nations
}

\section{UNITED NATIONS GENERAL ASSEMBLY RESOLUTION 49/116 (1994)}

49/116 Unauthorized fishing in zones of national jurisdiction and its impact on the living marine resources of the world's oceans and seas

Date: 19 December 1994 Meeting: 92

Adopted without a vote Report: A/49/729/Add.6

The General Assembly,

Inviting all members of the international community, particularly those with fishing interests, to strengthen their cooperation in the conservation and management of living marine resources in accordance with international law as reflected in the United Nations Convention on the Law of the Sea, ${ }^{1}$

Recalling Agenda 21, ${ }^{2}$ adopted by the United Nations Conference on Environment and Development, in particular its chapter 17, concerning the sustainable development and conservation of the marine living resources of areas under national jurisdiction,

Recalling also the Programme of Action for the Sustainable Development of Small Island Developing States, ${ }^{3}$ adopted by the Global Conference on the Sustainable Development of Small Island Developing States, in particular chapter 4, concerning the sustainable development and conservation of the coastal and marine resources of areas under national jurisdiction,

1 Official Records of the Third United Nations Conference on the Law of the Sea, vol, XVII (United Nations publication, Sales No. E.84.V.3), document ACONF.62/122

2 Report of the United Nations Conference on Environment and Development, Rio de Janeiro, 3-14 June 1992 (United Nations publication, Sales No. E.93.I.8 and corrigenda) vol. I: Resolutions adopted by the Conference, resolution 1, annex II.

3 Report of the Global Conference on the Sustainable Development of Small Island Developing States, Bridgetown, 25 April-6 May 1994 (United Nations publication, Sales No. E.94.I.18 and corrigenda). 
Noting that, in the Rio Declaration on Environment and Development ${ }^{4}$ the international community recognized that the special situation and needs of developing countries, particularly the least developed and those most environmentally vulnerable, should be given special priority,

Expressing deep concern at the detrimental impact of unauthorized fishing in zones under national jurisdiction, where the overwhelming proportion of the global fish catch is harvested, on the sustainable development of the world's fishery resources and on the food security and economies of many States, particularly the developing countries,

Reaffirming the rights and duties of coastal States to ensure proper conservation and management measures with respect to the living resources in zones under their national jurisdiction, in accordance with international law, as reflected in the United Nations Convention on the Law of the Sea,

Taking note of recent discussions, at the international, regional and subregional levels, on fisheries conservation and management measures, and on compliance with and enforcement thereof,

1. Calls upon States to take the responsibility, consistent with their obligations under international law as reflected in the United Nations Convention on the Law of the Sea, ${ }^{5}$ to take measures to ensure that no fishing vessels entitled to fly their national flag fish in zones under the national jurisdiction of other States unless duly authorized by the competent authorities of the coastal State or States concerned; such authorized fishing operations should be carried out in accordance with the conditions set out in the authorization;

2. Calls upon development assistance organizations to make it a high priority to support efforts, including through financial and/or technical assistance by the developing coastal States, in particular the least developed countries and the small island developing States, to improve the monitoring and control of fishing activities, and the enforcement of fishing regulations;

3. Requests the Secretary-General to bring the present resolution to the attention of all members of the international community, relevant intergovernmental organizations, the organizations and bodies of the United Nations system, regional and subregional fisheries bodies, and relevant non-governmental organizations;

4. Also requests the Secretary-General to submit to the General Assembly, at its fiftieth Session, a report on the steps taken and on problems encountered in the implementation of the present resolution, and thereafter as may be determined by the Assembly.

4 Report of the United Nations Conference on Environment and Development, Rio de Janeiro, 3-14 June 1992 (United Nations publication, Sales No. E.93.I.8 and corrigenda) vol. I: Resolutions adopted by the Conference, resolution 1, annex I.

5 Official Records of the Third United Nations Conference on the Law of the Sea, vol. XVII (United Nations publication, Sales No. E.84.V.3), document A/CONF.62/122. 


\title{
United Nations General Assembly Resolution 49/118 on Fisheries Bycatch and Discards and Their Impact on the Sustainable Use of the World's Living Marine Resources, New York, 1994
}

\author{
Done at New York 19 December 1994 \\ Primary source citation: Copy of text provided by \\ the United Nations
}

\section{United Nations General Assembly Resolution 49/118 (1994)}

49/118 Fisheries bycatch and discards and their impact on the sustainable use of the world's living marine resources

Date: 19 December 1994

Meeting: 92

Adopted without a vote

Report: A/49/729/Add.6

The General Assembly,

Recognizing that in relevant provisions of the United Nations Convention on the Law of the Sea, ${ }^{1}$ States are called upon to take into consideration, when establishing conservation and management measures for target fisheries, the effects on associated or dependent species, taking into account the best scientific evidence available,

Recalling that the United Nations Conference on Environment and Development, held in Rio de Janeiro in 1992, and the International Conference on Responsible Fishing, held in Cancun, Mexico, also in 1992, agreed to promote the development and use of selective fishing gears and practices that minimized waste in the catch of target fish species and minimized bycatch of non-target fish and non-fish species,

Recalling also that the World Fisheries Conference, held in Athens in 1992, discussed various aspects of the fisheries discard issue,

Noting the work of the Food and Agriculture Organization of the United Nations on fisheries bycatch and discards in the development of an international code of conduct for responsible fishing and the fact that the United Nations Conference on Straddling Fish Stocks and Highly Migratory Fish Stocks is considering provisions on fisheries bycatch and discards,

Recognizing the efforts that international organizations and members of the international community have made to reduce bycatch and discards in fishing operations and the need for continued international cooperation in this field,

1 Official Records of the Third United Nations Conference on the Law of the Sea, vol. XVII (United Nations publication, Sales No. E.84.V.3), document ACONF $62 / 122$ 
Recognizing also that improvements in monitoring and assessing bycatch and discards and in bycatch reduction techniques continue to be necessary,

1. Notes the important role that fisheries play in contributing to a sustainable food supply and livelihood of present and future generations;

2. Believes that the issue of bycatch and discards in fishing operations warrants serious attention by the international community;

3. Also believes that a continued and effective response to the issue of addressing fisheries bycatch and discards is necessary so as to ensure the long-term and sustainable development of fisheries, taking into account the relevant principles contained in the Rio Declaration on Environment and Development; ${ }^{2}$

4. Invites the Food and Agriculture Organization of the United Nations to formulate fisheries bycatch and discard provisions in its international code of conduct for responsible fishing, taking into account work being done elsewhere;

5. Invites the United Nations Conference on Straddling Fish Stocks and Highly Migratory Fish Stocks to elaborate fisheries bycatch and discard provisions, taking into account work being done elsewhere;

6. Invites relevant subregional and regional fisheries management organizations and arrangements and the Food and Agriculture Organization of the United Nations to review, within their respective competences, the impact of fisheries bycatch and discards on the sustainable use of living marine resources, taking into account, as appropriate, the relevant deliberations of the Food and Agriculture Organization of the United Nations with respect to the international code of conduct for responsible fishing and the relevant deliberations of the United Nations Conference on Straddling Fish Stocks and Highly Migratory Fish Stocks;

7. Decides to consider this question at its fiftieth session, under the item entitled "Environment and sustainable development".

2 Report of the United Nations Conference on Environment and Development, Rio de Janeiro, 3-14 June 1992 (United Nations publication, Sales No. E. 93.I.8 and corrigenda (vol. I: Resolutions adopted by the Conference, resolution 1, annex I. 


\title{
United Nations General Assembly Resolution 49/121 on the U.N. Conference on Straddling Fish Stocks and Highly Migratory Fish Stocks, New York, 1994
}

\author{
Done at New York 19 December 1994 \\ Primary source citation: Copy of text provided by \\ the United Nations
}

\section{United Nations General Assembly Resolution 49/121 (1994)}

49/121. United Nations Conference on Straddling Fish Stocks and Highly Migratory Fish Stocks

Date: 19 December 1994

Adopted without a vote
Meeting: 92

Report: A/49/729/Add.3

\section{The General Assembly,}

Recalling its resolutions 47/192 of 22 December 1992 and 48/194 of 21 December 1993, concerning the United Nations Conference on Straddling Fish Stocks and Highly Migratory Fish Stocks,

Welcoming the report of the Secretary-General on the progress made by the Conference at its third and fourth sessions in 1994, ${ }^{1}$

Taking note of the recommendation of the Conference to the General Assembly that it provide for the convening of two further sessions in 1995 to enable the Conference to complete its work, ${ }^{2}$

Convinced that the widest possible participation in the Conference is important to ensure its success,

1. Notes the progress made by the United Nations Conference on Straddling Fish Stocks and Highly Migratory Fish Stocks at its previous sessions;

2. Approves the convening in New York of two further sessions of the Conference, from $27 \mathrm{March}$ to 12 April 1995 and from 24 July to 4 August 1995, in accordance with the recommendation of the Conference;

3. Requests the Secretary-General to provide services for those two sessions of the Conference, including facilities for holding two simultaneous meetings during the sessions;

4. Urges the Conference to complete its work before the fiftieth session of the General Assembly; 
5. Renews its request to Governments and regional economic integration organizations to contribute to the voluntary fund established in accordance with paragraph 9 of General Assembly resolution 47/192 for the purpose of assisting developing countries, especially those most concerned by the subject-matter of the Conference, in particular the least developed among them, to participate fully and effectively in the Conference, and expresses its appreciation for the contributions to the fund made so far;

6. Requests the Secretary-General to submit to the General Assembly at its fiftieth session the final report on the work of the Conference;

7. Decides to include in the provisional agenda of its fiftieth session, under the item entitled "Environment and sustainable development", a sub-item entitled "Sustainable use and conservation of the marine living resources of the high seas: report of the United Nations Conference on Straddling Fish Stocks and Highly Migratory Fish Stocks". 


\title{
United Nations General Assembly Resolution 49/436 on Large-Scale Pelagic Drift-net Fishing and Its Impact on the Living Marine Resources of the World's Oceans and Seas, New York, 1994
}

\author{
Done at New York 19 December 1994 \\ Primary source citation: Copy of text provided by \\ the United Nations
}

\section{United Nations General Assembly Dec:̇sion 49/436 (1994)}

49/436. Large-scale pelagic drift-net fishing and its impact on the living marine resources of the world's oceans and seas

Date: 19 December 1994

Meeting: 92

Adopted without a vote

The General Assembly, on the recommendation of the Second Committee, ${ }^{1}$ recalling its decision $48 / 445$ of 21 December 1993, and taking note with appreciation of the report of the Secretary-General on large-scale pelagic drift-net fishing, ${ }^{2}$ decided:

(a) To reaffirm the importance it attaches to compliance with its resolution 4 $4_{1 / 2}^{2}: 5$ of 20 December 1991 , in particular, to those provisions of the resolution calling for full implementation of a global inoratorium on all large-scale pelagic drift-net fishing on the high seas of the world's oceans and seas, including enclosed seas and semi-enclosed seas;

(b) To acknowledge and express its appreciation of the measures taken and the substantial progress achieved since 1992, individually and collectively, by members of the international community, international organizations and regional economic integration organizations to implement and support the objectives of its resolution 46/215;

(c) To express further serious concern that, despite the measures taken and the progress made, there are reports of continuing conduct and activities inconsistent with the terms of its resolution 46/215, and to urge authorities of members of the international community to take greater enforcement responsibility to ensure full compliance with resolution $46 / 215$ and to impose appropriate sanctions, consistent with international law, against acts contrary to the terms of the resolution;

(d) To call upon all members of the international community, intergovernmental organizations, regional economic integration organizations and appropriate non-governmental organizations to provide the Secretary-General with information relevant to the implementation of resolution 46/215, and to request the Secretary-General to take into account the present decision in preparing his report, in accordance with decision 48/445, on further developments relating to the implementation of resolution 46/215. 


\title{
Declaration of Panama, Panama City, 1995
}

\author{
Done at Panama City 4 October 1995 \\ Primary source citation: Copy of text provided by the \\ U.S. Department of State
}

\section{DECLARATION OF PANAMA}

The Governments of Belize, Colombia, Costa Rica, Ecuador, France ${ }^{1}$, Honduras, Mexico, Panama, Spain ${ }^{1}$, United States of America, Vanuatu and Venezuela, meeting in Panama City, Republic of Panama on October 4, 1995, hereby reaffirm the commitments and objectives of the La Jolla Agreement of (1) progressively reducing dolphin mortality in the eastern Pacific Ocean (EPO) fishery to levels approaching zero through the setting of annual limits and (2) with a goal of eliminating dolphin mortality in this fishery, seeking ecologically sound means of capturing large yellowfin tunas not in association with dolphins.

Recognizing the strong commitments of nations participating in the La Jolla Agreement and the substantial successes realized through multilateral cooperation and supporting national action under that Agreement, the Governments meeting in Panama, including those which are, or have announced their intention to become, members of the Inter-American Tropical Tuna Commission (IATTC), announce their intention to formalize by January 31, 1996, the La Jolla Agreement as a binding legal instrument which shall be open to all nations with coastlines bordering the EPO or with vessels fishing for tuna in this region. This shall be accomplished by adoption of a binding resolution of the IATTC or other legally binding instrument. The adoption of the IATTC resolution or other legally binding instrument, that utilizes to the maximum extent possible the existing structure of the IATTC, is contingent upon the enactment of changes in United States law as envisioned in Annex I to this Declaration. The binding legal instrument shall build upon the strengths and achievements of the La Jolla Agreement, the working groups established under it, and the actions of the Governments participating in that Agreement. This binding legal instrument shall consist of the La Jolla Agreement, its appendices, and the decisions of the governments under that Agreement as modified to achieve the objectives and commitments contained herein.

The Governments meeting in Panama agree that in concluding, adopting, and implementing this binding legal instrument, they will:

Commit to the conservation of ecosystems and the sustainable use of living marine resources related to the tuna fishery within the EPO. Adopt conservation and management measures that ensure the long-term sustainability of tuna stocks and other stocks of living marine resources in the EPO. Such measures shall be based on the best scientific evidence, including that based on a precautionary methodology, and shall be designed to maintain or restore the biomass of harvested stocks at or above levels capable of producing maximum sustainable yield, and with the goal to maintain or restore the biomass of associated stocks at or above levels capable of producing maximum sustainable yield. These measures and methodology should take into consideration, and account for, natural variation, recruitment rate, natural mortality rate, population growth rate, individual growth rate, population parameters $\mathrm{K}$ and $\mathrm{r}$, and scientific uncertainty.

Commit, according to their capacities and in coordination with the IATTC, to the assessment of the catch and bycatch of juvenile yellowfin tuna and other stocks of living marine resources related to the tuna fishery in the EPO and the

\footnotetext{
${ }^{1}$ Spain and France support the commitments of this Declaration under reservation because of the legislation related to fisheries of the European Union.
} 
establishment of measures to, inter alia, avoid, reduce and minimize the bycatch of juvenile yellowfin tuna and bycatch of non-target species, in order to ensure the long-term sustainability of all these species, taking into consideration the interrelationships among species in the ecosystem.

Commit in the exercise of their national sovereignty to enact and enforce this instrument through domestic legislation and/or regulation, as appropriate.

Adopt cooperative measures to ensure compliance with this instrument, building upon decision IGM 6/93, Appendix IV, “Guiding Principles Respecting Relationships between States Both Party and Non-Party to the Agreement," taken by the nations participating in the La Jolla Agreement Working Group in Vanuatu in June 1993, and advance the work of the Working Group on Compliance, building upon decision IGM 6/93, Appendix V, "Options for Action Against Nations Not Complying With the Agreement." (Annex II)

Enhance the practice of reviewing and reporting on compliance with this instrument, building upon past practices under the La Jolla Agreement.

Establish a per-stock per-year cap of between $0.2 \%$ of the Minimum Estimated Abundance (Nmin) (as calculated by the U. S. National Marine Fisheries Service or equivalent calculation standard) and $0.1 \%$ of Nmin, but in no event shall the total annual mortality exceed 5000 consistent with the commitments and objectives stated in the preamble above. In the year 2001 , the per-stock per-year cap shall be $0.1 \%$ of $\mathrm{Nmin}$.

Conduct in 1998 a scientific review and assessment of progress toward the year 2001 objective, and consider recommendations as appropriate. Up to the year 2001, in the event that annual mortality of $0.2 \%$ of Nmin is exceeded for any stock, all sets on that stock and on any mixed schools containing members of that stock shall cease for that fishing year. Beginning in the year 2001, in the event that annual mortality of $0.1 \%$ of Nmin for any stock is exceeded, all sets on that stock and on any mixed schools containing members of that stock shall cease for that fishing year. In the event that annual mortality of $0.1 \%$ of $\mathrm{Nmin}$ is exceeded for either Eastern Spinner or Northeastern Spotted dolphin stocks, the governments commit to conduct a scientific review and assessment and consider further recommendations.

Establish a per-vessel maximum annual DML consistent with the established per-year mortality caps.

Establish a system that provides incentives to vessel captains to continue to reduce dolphin mortality, with the goal of eliminating dolphin mortality in the EPO.

Establish or strengthen National Scientific Advisory Committees (NATSAC), or the equivalent, of qualified experts, operating in their individual capacities, which shall advise their respective governments on mechanisms to facilitate research, and on the formulation of recommendations for achieving the objectives and commitments contained herein, or strengthen existing structures in order to conform with the requirements delineated herein. Membership to NATSACs shall include, inter alia, qualified scientists from the public and private sector and NGOs. The NATSACs shall:

1. Receive and review data, including data provided to national authorities by the IATTC.

2. Advise and recommend to their governments measures and actions that should be undertaken to conserve and manage the stocks of living marine resources of the EPO;

3. Make recommendations to their governments regarding research needs, including ecosystems; fishing practices; and gear technology research, including the development and use of selective, environmentally safe and cost-effective fishing gear; and the coordination and facilitation of such research;

4. Conduct scientific reviews and assessments by the year 1998 regarding progress toward the year 2001 objective stated above, and make appropriate recommendations to their governments concerning these reviews and assessments, as well as additional assessments in the year 2001 as provided above;

5. Consult other experts as needed;

6. Assure the regular and timely full exchange of data among the parties and the NATSACs on catch of tuna and associated species and bycatch, including dolphin mortality data, for the purposes of developing 
conservation and management recommendations to their governments as well as recommendations for enforcement and scientific research while not violating the confidentiality of business-confidential data;

7. Establish procedures to, inter alia, hold public meetings and maintain the confidentiality of businessconfidential data.

Reports of the NATSACS, including of their cooperative meetings, shall be available to the parties and the public.

The NATSACs shall cooperate, through regular and timely meetings, including at a minimum in conjunction with the meetings of the LATTC, in the review of data and the status of stocks, and in the development of advice for achieving the objectives and commitments contained herein.

Promote transparency in their implementation of this Declaration, including through public participation as appropriate.

As soon as possible, the nations of the Intergovernmental Group convened under the auspices of the IATTC will initiate discussions related to formulation of a new, permanent, binding instrument.

[Signature]

FOR THE GOVERNMENT OF

BELIZE

[Signature]

FOR THE GOVERNMENT OF

COSTA RICA

[Signature]

FOR THE GOVERNMENT OF

FRANCE

[Signature]

FOR THE GOVERNMENT OF

MEXICO

[Signature]

FOR THE GOVERNMENT OF

SPAIN

[Signature]

FOR THE GOVERNMENT OF

VANUATU
[Signature]

FOR THE GOVERNMENT OF

COLOMBIA

[Signature]

FOR THE GOVERNMENT OF

ECUADOR

[Signature]

FOR THE GOVERNMENT OF

HONDURAS

[Signature]

FOR THE GOVERNMENT OF

PANAMA

[Signature]

FOR THE GOVERNMENT OF

THE UNITED STATES

[Signature]

FOR THE GOVERNMENT OF

VENEZUELA

\section{ANNEX I}

Envisioned changes in United States law:

1. Primary and Secondary Embargoes. Effectively lifted for tuna caught in compliance with the La Jolla Agreement as formalized and modified through the processes set forth in the Panama Declaration.

2. Market Access². Effectively opened to tuna caught in compliance with the La Jolla Agreement as formalized and modified through the processes set forth in the Panama Declaration with respect to States to include: IATTC Member States and other States that have initiated steps, in accordance with Article 5.3 of the IATTC Convention, to become members of that organization.

"Spain maintains a reservation on point number two of the Annex "Market Access," pending further review. 
3.

Labeling. The term "dolphin safe" may not be used for any tuna caught in the EPO by a purse seine vessel in a set in which a dolphin mortality occurred as documented by observers by weight calculation and well location.

\section{ANNEX II}

Appendix IV.

Guiding Principles respecting relationships between States both Party and Non-Party to the Agreement

The Parties to the Agreement Incorporate into the Agreement a guiding principle that no Party shall act in a manner that assists non-parties to avoid compliance with the objectives of the Agreement.

When a coastal state that is a Party issues a license to engage in fishing in its Exclusive Economic Zone portion of the eastern Pacific Ocean (EPO), either directly or through a licensing agreement, to a vessel of a non-party, the license should be subject to the provisions of the Agreement

The Parties should consider prohibiting persons under their jurisdiction from assisting in any way vessels of non-complying Parties or non-parties operating in the fishery.

Any state whose vessels are conducting purse-seine tuna-fishing operations in the EPO should be invited to join the Agreement. The Parties should draw the attention of any state that is not a party to the Agreement to any activity undertaken by its nationals or vessels which, in the opinion of the Parties, affects the implementation of the objectives of the Agreement.

Appendix V.

A. Options for Action With Respect to Nations Party to the Agreement

Diplomatic actions:

- Collective representation to the non-complying nation. This would constitute a communication emanating from plenary meeting of the participating nations after consultation with the non-complying nation.

- Diplomatic communication. Each participating nation, acting individually or in concert with other nations, would undertake a diplomatic demarche to the non-complying nation.

Public opinion actions:

- Dissemination of information regarding the non-compliance of the nation to the public through appropriate media, e.g., a press conference.

Operational restrictions:

- Denial of access to the Exclusive Economic Zones of nations party to the agreement for fishing operations by tuna fishing vessels of the non-complying nation. The scope of this action would have to be determined by the International Review Panel (IRP) by defining what constitutes a tuna-fishing vessel, i.e., vessels covered by the Agreement, or other tuna-fishing vessels as well. This action should not restrict freedom of navigation or other rights of vessels under international law.

- Restriction of access to ports and port servicing facilities for tuna fishing vessels of the non-complying nation. This would not apply to vessels in distress.

- Refusal of logistical support and/or supplies to tuna-fishing vessels of the non-complying nation.

- Reduction of Dolphin Mortality Limits (DMLs) to all vessels of the non-complying Party by specified percentages. DMLs would be restored immediately upon a determination that the nation is in compliance. 
Economic sanctions:

- Trade measures. The Working Group discussed at length trade measures against non-complying nations. These might include embargoes or other restrictions on the imports of, for example, tuna, other fish products, other marine Products, or other products.

- The consideration of such measures was recognized to be an extremely delicate and evolving policy issue for which few guidelines exist in international law. The Working Group noted ongoing discussions concerning this issue in other international fora. In light of these considerations, the Working Group agreed that trade measures should receive further review by the Parties prior to making any recommendation in this respect.

- Fines (monetary penalties). The Working Group considered that the IRP should identify procedures for imposing fines, including defining the value of the fines (this could be based on a percentage of the amount of the commercial value of the catch), and the destination of the fines (e.g., an international trust fund) as issues that the Parties should discuss. The Working Group noted that there apparently is no precedent for such fines.

B. Options for Action With Respect to Nations Not Party to the Agreement

Diplomatic actions:

- Collective representation to the non-party. This would constitute a communication emanating from a plenary meeting of the participating nations after consultations with the non-party.

- Diplomatic communication. Each participating nation, acting individually or in concert with other nations, would undertake a diplomatic demarche to the non-party.

Public opinion actions:

- Dissemination of information regarding the non-compliance of the non-party to the public through appropriate media, e.g., a press conference.

Operational restrictions:

- Restriction of access to ports and port servicing facilities for tuna-fishing vessels of the non-party. The scope of this action would have to be determined by the IRP by defining what constitutes a tuna-fishing vessel, i.e., solely vessels covered by the Agreement, or other tuna-fishing vessels as well. This action should not restrict freedom of navigation and other rights of vessels under international law, and particularly would not apply to vessels in distress.

- Refusal of logistical support and/or supplies to tuna fishing vessels of the non-party nation.

- Prohibiting nationals from assisting in any way vessels of the non-party operating in the fishery.

Economic sanctions:

- The Working Group noted that economic sanctions with respect to non-parties call into consideration all the issues raised above with respect to the imposition of such sanctions on Parties, and noted that the imposition of such sanctions with respect to non-parties involves additional complex legal considerations. The Working Group recommends that the Parties consider whether such sanctions against non-parties are an appropriate means of promoting compliance with the objectives of the Agreement and whether they are consistent with international law. 



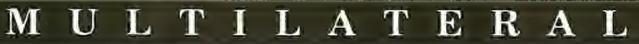

Marine Mammals 



\title{
Agreement on the Regulation of Whaling, London, 1937*
}

\author{
Done at London 5 August 1937 \\ Entered into force 7 May 1938 \\ Depositary: United Kingdom \\ Primary source citation: United States Treaty \\ Series 933
}

\section{Agreement for the Regulation of Whaling}

THE Governments of the Union of South Africa, the United States of America, the Argentine Republic, the Commonwealth of Australia, Germany, the United Kingdom of Great Britain and Northern Ireland, the Irish Free State, New Zealand and Norway, desiring to secure the prosperity of the whaling industry and, for that purpose, to maintain the stock of whales, have agreed as follows:

\section{Article 1}

The contracting Governments will take appropriate measures to ensure the application of the provisions of the present Agreement and the punishment of infractions against the said provisions, and, in particular, will maintain at least one inspector of whaling on each factory ship under their jurisdiction. The inspectors shall be appointed and paid by Governments.

\section{Article 2}

The present Agreement applies to factory ships and whale catchers and to land stations as defined in Article 18 under the jurisdiction of the contracting Governments, and to all waters in which whaling is prosecuted by such factory ships and/or whale catchers.

\section{ARTicle 3}

Prosecutions for infractions against or contraventions of the present Agreement and the regulations made thereunder shall be instituted by the Government or a Department of the Government.

\section{Article 4}

It is forbidden to take or kill Grey Whales and/or Right Whales.

\footnotetext{
* This Agreement was superseded by the International Convention for the Regulation of Whaling, Washington, 1946.
} 


\section{Article 5}

It is forbidden to take or kill any Blue, Fin, Humpback or Sperm whales below the following lengths, viz.:

(a) Blue whales . . . . . . . . . . . . . . . . . . . 70 feet

(b) Fin whales . . . . . . . . . . . . . . . . 55 feet

(c) Humpback whales . . . . . . . . . . . . . . . . 35 feet

(d) Sperm whales . . . . . . . . . . . . . . . . . . . 35 feet

\section{Article 6}

It is forbidden to take or kill calves, or suckling whales or female whales which are accompanied by calves or suckling whales.

\section{Article 7}

It is forbidden to use a factory ship or a whale catcher attached thereto for the purpose of taking or treating baleen whales in any waters south of $40^{\circ}$ South Latitude, except during the period from the 8 th day of December to the 7th day of March following, both days inclusive, provided that in the whaling season 1937-38 the period shall extend to the 15th day of March, 1938, inclusive.

\section{Article 8}

It is forbidden to use a land station or a whale catcher attached thereto for the purpose of taking or treating whales in any area or in any waters for more than six months in any period of twelve months, such period of six months to be continuous.

\section{Article 9}

It is forbidden to use a factory ship or a whale catcher attached thereto for the purpose of taking or treating baleen whales in any of the following areas, viz:

(a) in the Atlantic Ocean north of $40^{\circ}$ South Latitude and in the Davis Strait, Baffin Bay and Greenland Sea;

(b) in the Pacific Ocean east of $150^{\circ}$ West Longitude between $40^{\circ}$ South Latitude and $35^{\circ}$ North Latitude;

(c) in the Pacific Ocean west of $150^{\circ}$ West Longitude between $40^{\circ}$ South Latitude and $20^{\circ}$ North Latitude;

(d) in the Indian Ocean north of $40^{\circ}$ South Latitude.

\section{Article 10}

Notwithstanding anything contained in this Agreement, any contracting Government may grant to any of its nationals a special permit authorising that national to kill, take and treat whales for purposes of scientific research subject to such restrictions as to number and subject to such other conditions as the contracting Government thinks fit, and the killing, taking and treating of whales in accordance with the terms in force under this article shall be exempt from the operation of this Agreement.

Any contracting Government may at any time revoke a permit granted by it under this article. 


\section{ARTicle 11}

The fullest possible use shall be made of all whales taken. Except in the case of whales or parts of whales intended for human food or for feeding animals, the oil shall be extracted by boiling or otherwise from all blubber, meat (except the meat of sperm whales) and bones other than the internal organs, whale bone and flippers, of all whales delivered to the factory ship or land station.

\section{Article 12}

There shall not at any time be taken for delivery to any factory ship or land station a greater number of whales than can be treated efficiently and in accordance with article 11 of the present Agreement by the plant and personnel therein within a period of thirty-six hours from the time of the killing of each whale.

\section{Article 13}

Gunners and crews of factory ships, land stations and whale catchers shall be engaged on terms such that their remuneration shall depend to a considerable extent upon such factors as the species, size and yield of whales taken, and not merely upon the number of the whales taken, and no bonus or other remuneration, calculated by reference to the results of their work, shall be paid to the gunners and crews of whale catchers in respect of any whales the taking of which is forbidden by this Agreement.

\section{ARTiCle 14}

With a view to the enforcement of the preceding article, each contracting Government shall obtain, in respect of every whale catcher under its jurisdiction, an account showing the total emolument of each gunner and member of the crew and the manner in which the emolument of each of them is calculated.

\section{ARTiCle 15}

Articles 5, 9,13 and 14 of the present Agreement, in so far as they impose obligations not already in force, shall not until the 1st day of December, 1937, apply to factory ships, land stations or catchers attached thereto which are at present operating or which have already taken practical measures with a view to whaling operations during the period before the said date. In respect of such factory ships, land stations and whale catchers, the Agreement shall in any event come into force on the said date.

\section{ARTiCle 16}

The contracting Governments shall obtain with regard to all factory ships and land stations under their jurisdiction records of the number of whales of each species treated at each factory ship or land station and as to the aggregate amounts of oil of each grade and quantities of meal, guano and other products derived from them, together with particulars with respect to each whale treated in the factory ship or land station as to the date and place of taking, the species and sex of the whale, its length and, if it contains a foetus, the length and sex, if ascertainable, of the foetus.

\section{ARTiCle 17}

The contracting Governments shall, with regard to all whaling operations under their jurisdiction, communicate to the International Bureau for Whaling Statistics at Sandefjord in Norway the statistical information specified 
in Article 16 of the present Agreement together with any information which may be collected or obtained by them in regard to the calving grounds and migration routes of whales.

In communicating this information the Governments shall specify:

(a) the name and tonnage of each factory ship;

(b) the number and aggregate tonnage of the whale catchers;

(c) a list of the land stations which were in operation during the period concerned.

\section{Article 18}

In the present Agreement the following expressions have the meanings respectively assigned to them, that is to say:

"factory ship" means a ship in which or on which whales are treated whether wholly or in part;

"whale catcher" means a ship used for the purpose of hunting, taking, towing, holding on to, or scouting for whales;

"land station" means a factory on the land, or in the territorial waters adjacent thereto, in which or at which whales are treated whether wholly or in part;

"baleen whale" means any whale other than a toothed whale;

"blue whale" means any whale known by the name of blue whale, Sibbald's rorqual or sulphur bottom;

"fin whale" means any whale known by the name of common finback, common finner, common rorqual, finback, fin whale, herring whale, razor-back, or true fin whale;

"grey whale" means any whale known by the name of grey whale, California grey, devil fish, hard head, mussel digger, grey back, rip sack;

"humpback whale" means any whale known by the name of bunch, humpback, humpback whale, humpbacked whale, hump whale or hunchbacked whale;

"right whale" means any whale known by the name of Atlantic right whale, Arctic right whale, Biscayan right whale, bowhead, great polar whale, Greenland right whale, Greenland whale, Nordkaper, North Atlantic right whale, North Cape whale, Pacific right whale, pigmy right whale, Southern pigmy right whale or Southern right whale;

"sperm whale" means any whale known by the name of sperm whale, spermacet whale, cachalot or pot whale;

"length" in relation to any whale means the distance measured on the level in a straight line between the tip of the upper jaw and the notch between the flukes of the tail.

\section{ARticle 19}

The present Agreement shall be ratified and the instruments of ratification shall be deposited with the Government of the United Kingdom of Great Britain and Northern Ireland as soon as possible. It shall come into force upon the deposit of instruments of ratification by a majority of the signatory Governments, which shall include the Governments of the United Kingdom, Germany and Norway; and for any other Government not included in such majority on the date of the deposit of its instrument of ratification.

The Government of the United Kingdom will inform the other Governments of the date on which the Agreement thus comes into force and the date of any ratification received subsequently.

\section{Article 20}

The present Agreement shall come into force provisionally on the 1st day of July, 1937, to the extent to which the signatory Governments are respectively able to enforce it; provided that if any Government within two months of the signature of the Agreement informs the Government of the United Kingdom that it is unwilling to ratify it the provisional application of the Agreement in respect of that Government shall thereupon cease.

The Government of the United Kingdom will communicate the name of any Government which has signified that it is unwilling to ratify the Agreement to the other Governments, any of whom may within one month of such communication withdraw its ratification or accession or signify its unwillingness to ratify as the case may be, and the provisional application of the Agreement in respect of that Government shall thereupon cease. Any such 
withdrawal or communication shall be notified to the Government of the United Kingdom, by whom it will be transmitted to the other Governments.

\section{Article 21}

The present Agreement shall, subject to the preceding article, remain in force until the 30 th day of June, 1938, and thereafter if, before that date, a majority of the contracting Governments, which shall include the Governments of the United Kingdom, Germany and Norway, shall have agreed to extend its duration. In the event of such extension it shall remain in force until the contracting Governments agree to modify it, provided that any contracting Government may, at any time after the 30th day of June, 1938, by giving notice on or before the 1st day of January in any year to the Government of the United Kingdom (who on receipt of such notice shall at once communicate it to the other contracting Governments) withdraw from the Agreement, so that it shall cease to be in force in respect of that Government after the 30th day of June following, and that any other contracting Government may, by giving notice in the like manner within one month of the receipt of such communication, withdraw also from the Agreement, so that it shall cease to be in force respecting it after the same date.

\section{Article 22}

Any Government which has not signed the present Agreement may accede thereto at any time after it has come into force. Accession shall be effected by means of a notification in writing addressed to the Government of the United Kingdom and shall take effect immediately after the date of its receipt.

The Government of the United Kingdom will inform all the Governments which have signed or acceded to the present Agreement of all accessions received and the date of their receipt.

In faith whereof the Undersigned, being duly authorised, have signed the present Agreement.

Done in London the 8th day of June, 1937, in a single copy, which shall remain deposited in the archives of the Government of the United Kingdom of Great Britain and Northern Ireland, by whom certified copies will be transmitted to all the other contracting Governments.

For the Government of the Union of South Africa:

F. J. DU ToIT

For the Government of the United

States of America:

HERSCHEL V. JOHNSON

REMINGTON KELLOGG

For the Government of the Argentine

Republic:

ManUel E. MaLbRáN

M. FinCATI

T. L. MARINI

For the Government of the Commonwealth of Australia:

S.M. BRUCE
For the Government of Germany: WOHLTAT

For the Government of the United Kingdom of Great Britain and Northern Ireland:

HENRY G. MAURICE

GEO. HOGARTH

For the Government of the Irish

Free State:

SEAN O'FAOLAIN O'DULCHAONTIGH

For the Government of New

Zealand:

G. MCNAMARA

For the Government of Norway: BIRGER BERGERSEN 


\title{
Amendments to the Schedule of the International Convention for the Regulation of Whaling, Kyoto, 1993
}

\author{
Done at Kyoto 14 May 1993 \\ Entered into force 31 August 1993 \\ Primary source citation: International Whaling \\ Commission Circular Communication RG/JAC/00228
}

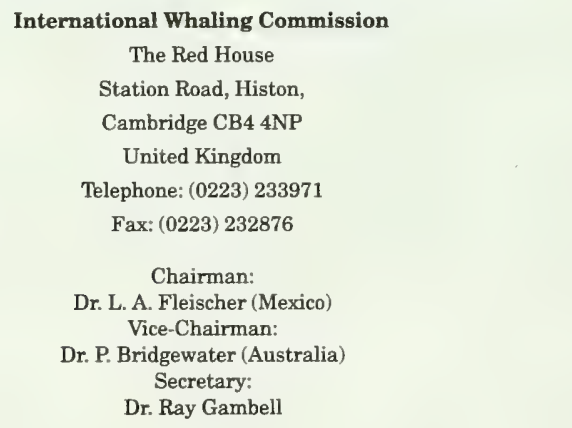

Our Ref: RG/NJH/19815

2 June 1993

\section{CIRCULAR COMMUNICATION TO COMMISSIONERS \\ AND CONTRACTING GOVERNMENTS \\ Amendments to the Schedule \\ International Convention for the Regulation of Whaling, 1946}

At its 45th Meeting held in Kyoto, Japan, 10-14 May 1993, the International Whaling Commission adopted the following amendments to the Schedule (changes in bold type): 


\section{Amend paragraph 13(b)(4) to read}

For the seasons 1993/94 to 1995/96 the taking of $2^{2}$ humpback whales each season is permitted by Bequians of St Vincent and The Grenadines, but only when the meat and products of such whales are to be used exclusively for local consumption in St Vincent and The Grenadines.

\section{Footnote:}

2 Each year this figure will be reviewed and if necessary amended on the basis of the advice of the Scientific Committee.

Revise paragraphs 11 and 12, and Tables 1, 2 and 3

by substitution of the dates $1993 / 94$ pelagic season, 1994 coastal season, 1994 season, or 1994 as appropriate.

These amendments become effective with respect to each Contracting Government ninety days following the date of this letter, in accordance with Article V of the Convention, unless any Contracting Government lodges an objection, in which case the procedure under Article V, paragraph 3 of the Convention will be followed.

The ninety days period will expire on 31 August 1993. In the absence of objections by that date the amendments will become effective. Contracting Governments will be notified accordingly.

Contracting Governments are reminded that Article V paragraph 3 of the Convention requires them to acknowledge receipt of this notification of amendments, a copy of which is being sent to each Commissioner.

Dr R. Gambell

Secretary to the Commission 


\section{International Whaling Commission}

The Red House

Station Road, Histon,

Cambridge CB4 4NP

United Kingdom

Telephone: (0223) 233971

Fax: (0223) 232876

Chairman:

Dr. L. A. Fleischer (Mexico)

Vice-Chairman:

Dr. P. Bridgewater (Australia)

Secretary:

Dr. Ray Gambell

Our Ref: RG/JAC/00228

1 September 1993

\section{CIRCULAR COMMUNICATION TO COMMISSIONERS AND CONTRACTING GOVERNMENTS}

Amendments to the Schedule of the

International Convention for the Regulation of Whaling, 1946

Adopted at the 45th Annual Meeting

The Secretary refers to his Circular Communication dated 2 June 1993 (ref: RG/VJH/19815) notifying the amendments to the Schedule of the International Convention for the Regulation of Whaling, 1946, adopted at the 45th Annual Meeting of the International Whaling Commission held in Kyoto, Japan, 10-14 May 1993.

No objections have been received within the period of 90 days from the date of notification of these amendments and in accordance with Article V, paragraph 3 of the Convention, the amendments become effective for all Contracting Governments from 31 August 1993.

In accordance with Article V, paragraph 3, the Secretary requests an acknowledgement of this Communication, a copy of which is also being sent to each Commissioner.

A new edition of the Schedule, to replace the version dated November 1992 and incorporating these latest amendments, will be printed and circulated in due course.

Dr. R. Gambell

Secretary to the Commission 


\title{
Amendments to the Schedule to the International Convention for the Regulation of Whaling, Puerto Vallarta, 1994
}

\author{
Done at Puerto Vallarta 27 May 1994 \\ Primary source citation: Copy of text provided by the \\ International Whaling Commission
}

\section{AMENDMENTS TO THE SCHEDULE}

At its 46th Annual Meeting held in Puerto Vallarta, Mexico, 23-27 May 1994, the International Whaling Commission adopted the following amendments to the Schedule (changes in bold type):

1. Designate existing paragraph 7 as subparagraph $7(a)$, and add the following sub-paragraph:

(b) In accordance with Article V(1)(c) of the Convention, commercial whaling, whether by pelagic operations or from land stations, is prohibited in a region designated as the Southern Ocean Sanctuary. This Sanctuary comprises the waters of the Southern Hemisphere southwards of the following line: starting from 40 degrees $S, 50$ degrees $W$; thence due east to 20 degrees $E$; thence due south to 55 degrees $\mathrm{S}$; thence due east to 130 degrees $\mathrm{E}$; thence due north to 40 degrees $\mathrm{S}$; thence due east to 130 degrees W; thence due south to 60 degrees $S$; thence due east to 50 degrees $W$; thence due north to the point of beginning. This prohibition applies irrespective of the conservation status of baleen and toothed whale stocks in this Sanctuary, as may from time to time be determined by the Commission. However, this prohibition shall be reviewed ten years after its initial adoption and at succeeding ten year intervals, and could be revised at such times by the Commission. Nothing in this sub-paragraph is intended to prejudice the special legal and political status of Antarctica.

\section{Amend subparagraph 13(b)(1)(i) to read:}

(i) For the years 1995, 1996, 1997 and 1998, the number of bowhead whales landed shall not exceed 204 , and the number of bowhead whales struck shall not exceed 68 in 1995, 67 in 1996, 66 in 1997, and 65 in 1998, except that any unused portion of the strike quota for each year shall be carried forward from that year and added to the strike quota of any subsequent years, provided that no more than 10 strikes shall be added to the strike quota for any one year.

3. Amend paragraph 13(b)(2)(i) to read:

(i) The number of gray whales taken in accordance with this sub-paragraph in each of the years 1995, 1996 and 1997 shall not exceed the limit shown in Table 1.

4. Amend Table 1 for the North Pacific Eastern Stock of gray whales so that the catch limit is $\mathbf{1 4 0}$ with the same footnote. 
5. Amend Table 1 so that for West Greenland fin whales:

the number in Table 1 is changed to 19 , with a footnote 2 ) reading:

${ }^{2}$ Available to be taken by aborigines pursuant to paragraph 13(b)3. Catch limit for each of the years 1995, 1996 and 1997.

6. Amend Table 1 so that the North Atlantic central stock of minke whales has a footnote 2) which reads as above.

7. Amend paragraph $13(b) 3(i i)$ to read:

(ii) For each of the years 1995,1996 and 1997, the number of minke whales struck from the West Greenland stock shall not exceed 165 , and the total number of whales struck shall not exceed 465 in these three years.

8. Revise paragraphs 11 and 12, and Tables 1,2 and 3:

by substitution of the dates $1994 / 95$ pelagic season, 1995 coastal season, 1995 season, or 1995 as appropriate. 


\title{
Amendments to the Schedule to the International Convention for the Regulation of Whaling, Dublin, 1995
}

\author{
Done at Dublin 2 June 1995 \\ Primary source citation: Copy of text provided by the \\ International Whaling Commission
}

\section{AMENDMENTS TO THE SCHEDULE}

As a consequence of the decisions taken at the 47th Annual Meeting the following amendments to the Schedule were necessary:

Revise paragraphs 11 and 12 , and Tables 1,2 and 3 by substituting the dates $1995 / 1996$ pelagic season, 1996 coastal season, 1996 season, or 1996 as appropriate. 



\section{U $\begin{array}{llllllllll} & \text { T } & \text { I } & \text { L } & \text { A } & \text { T } & \text { E } & \mathbf{R} & \mathbf{A} & \mathbf{L}\end{array}$}

Marine Pollution 



\title{
Protocol Concerning Marine Pollution Resulting from Exploration and Exploitation of the Continental Shelf to the Kuwait Regional Convention for Cooperation on the Protection of the Marine Environment from Pollution, Kuwait, 1989
}

\author{
Done at Kuwait 29 March 1989 \\ Primary source citation: Copy of text provided by the \\ United Nations
}

\section{Kuwait/ROMPE}

\section{PROTOCOL CONCERNING MARINE POLLUTION RESULTING FROM EXPLORATION* AND EXPLOITATION OF THE CONTINENTAL SHELF}

The contracting States

Being Parties to the Kuwait Regional Convention for Co-operation on the Protection of the Marine Environment from Pollution (hereinafter referred to as "the Convention") and to the Protocol concerning Regional Co-operation in Combating Pollution by Oil and other Harmful Substances in case of Emergency;

Being Aware of the Articles 76, 197 and 208 of the United Nations Convention on the Law of the Sea (1982);

Recognizing the danger posed to the marine environment and to human health by pollution from exploration and exploitation of the Continental Shelf, and the serious problems resulting therefrom in the Sea Area under their national jurisdictions;

Conscious of the need for further and more particular measures to prevent and control marine pollution from exploration and exploitation of the seabed and its subsoil;

Being mindful of their existing obligations under International Law; and

Prompted by the desire to implement Article III, paragraph (b), Article VII, and Article XIX of the Convention; 


\section{Have agreed as follows:}

\section{Article I}

For the purposes of this Protocol:

1. "Centre" means the Marine Emergency Mutual Aid Centre established under Article III paragraph 1 of the "Protocol Concerning Regional Co-operation in Combating Pollution by Oil and other Harmful Substances in Cases of Emergency".

2. "Certifying Authority" means any person or body of persons authorized by the Contracting State to issue a certificate of safety and fitness for purpose;

3. "Chemical Use Plan" means a plan drawn up by the operator of an offshore installation which shows

(a) the chemical he intends to use in his operations;

(b) the purpose or purposes for which he intends to use the chemicals;

(c) the maximum concentrations of the chemicals he intends to use within any other substances, and maximum amounts he intends to use in any specified period;

(d) the area within which the chemical may escape into the marine environment: provided that where there is no known danger of a chemical escaping into the marine environment, it need not be included in the plan;

4. "Competent State Authority" means any Government department, Agency or other Authority in the Contracting State designated to exercise the power or discharge the function referred to in the Protocol, with such designation to be formally communicated to the Organization;

5. "Contracting State" means any State which has become a party to this Protocol;

6. "Convention" means the Kuwait Regional Convention for Co-operation on the Protection of the Marine Environment from Pollution;

7. "Council" means the organ of the Organization comprised of the Contracting States and established in accordance with Article XVI, paragraph (b)(i) of the Convention;

8. "Garbage" means kitchen and domestic waste, refuse and solid wastes, other than any for which provision is made by any other Article of this Protocol, save for Article XII;

9. "Guidelines" means only guidelines issued by the Organization and any amendments thereto in each case approved by the Council;

10. "Licence" means a licence, permit including work permit, or authorization, formally issued under the authority of a Contracting State for undertaking an offshore operation;

11. "Marine Pollution" shall have the meaning given to it in Article I (1) of the Convention;

12. "Offshore installation" means any structure, plan or vessel, whether floating or fixed to or under the seabed, placed in a location in the Protocol Area (defined in item 16 in this Article for the purpose of offshore operations, including any tanker for the time being moored and used for the temporary storage of oil, and including any plan for treating, storing or regaining control of the flow of crude oil; and for the purposes of certification under Article VI, an installation includes any integral part of the structure, plant, equipment or vessel, any attached lifting gear or safety mechanism, and any other part or equipment specified by the Contracting State as part of the installation; 
13. "Offshore Operations" means any operations conducted in the Sea Area for the purposes of exploring of oil or natural gas or for the purpose of exploiting those resources, including any treatment before transport to shore and any transport the same by pipeline to shore. It includes also any work of construction, repair, maintenance, inspection or like operation incidental to the main purpose of exploration or exploitation.

14. "Operator" means any natural or juridical person who undertakes offshore operations as defined under item (13) of Article I of the Protocol.

15. "Organization" shall have the meaning given to it in Article I (c) of the Convention.

16. "Protocol Area" means all parts of the Continental Shelf of a Contracting State which fall within the Sea Area as defined in paragraph (a) of Article II of the Convention and all parts of its Continental Shelf contiguous therewith.

17. "Sewage" means -

(i) drainage and other waste from any form of toilet, urinal or water closet;

(ii) drainage from medical premises such as dispensary or sick bay, via wash-basins, wash-tubs, and rains located in such premises;

(iii) other wastewaters when mixed with significant quantities of the drainage defined above;

18. "Special Area" means that part of the Sea Area located northwest of the rhumb line between Ras Al Hadd $\left(22^{\circ} 30 \mathrm{~N}, 59^{\circ} 48^{\prime} \mathrm{E}\right)$ and Ras $\mathrm{Al} \mathrm{Fasteh}\left(25^{\circ} 04^{\prime} \mathrm{N}, 61^{\circ} 25^{\prime} \mathrm{E}\right)$.

\section{Article II}

Contracting States shall require that all appropriate measures are taken to prevent, abate and control marine pollution from offshore operations in those parts of the Protocol Area within their respective jurisdictions taking into account the best available and economically feasible technology. Contracting States acting individually or jointly shall also take all appropriate steps to combat marine pollution from offshore operations within the parts of the Protocol Area under their jurisdiction.

Such obligations shall be without prejudice to the more specific obligations accepted under this Protocol.

\section{Article III}

Each Contracting State shall ensure that in the Protocol Area under its jurisdiction any offshore operation shall be conducted under a licence, which may be granted subject to such conditions for the protection of the marine environment and coastal areas as the Competent State Authority sees fit to impose. The Competent State Authority shall require the operator to comply with relevant laws and regulations issued under the authority of the State, and shall have the power to take such measures as are necessary to enforce compliance therewith.

\section{Article IV}

1. Each Contracting State shall take measures to ensure the following:

(a) Before licensing any offshore operation which could cause significant risks of pollution in the Protocol Area or any adjacent coastal area, the Competent State Authority shall call for submission of an assessment of the potential environmental effects thereof. No such operation shall commence until a statement of those effects has been submitted, and no licence shall be granted until the Competent State Authority is satisfied that the operation will entail no unacceptable risk of such damage in the Protocol Area or any adjacent coastal area. 
(b) In deciding to call for an environmental impact statement, and in determining its scope, the Competent State Authority shall have regard to the guidelines issued by the Organization.

(c) Whenever a Competent State Authority has called for and received an environmental impact statement, it shall send to the Organization a summary of the potential environment effects referred to in that statement. The Organization shall, within four days of its receipt, despatch copies of that summary to all the other Contracting States. The Competent State Authority before granting a licence for the proposed operation, shall allow all other Contracting States to submit representations to it through the Organization within a stated time which shall be reasonable taking into account the type of operation and the urgency of the need for a decision. It shall consider any such representations before licensing the said operation.

Notwithstanding the obligation to send a summary to the Organization, the Contracting State shall have the right to withhold information which might prejudice its national security.

2. Whenever a Contracting State does not call for an assessment of the environmental impact of a proposed offshore operation, it shall consider calling for a survey of the marine environment and the aquatic life therein to be made before the start of the proposed operation. The survey is to be carried out by or under the direct supervision of a body independent of the operator and approved by the Competent State Authority.

3. The guidelines on environmental impact assessment to be issued by the Organization shall contain guidance on the type of operation, and the circumstances in which it would cause significant risk of pollution in the Protocol Area or any adjacent coastal area.

\section{Article V}

1. Each Contracting State shall endeavour to ensure that offshore operations within its jurisdiction shall not cause unjustifiable interference with lawful navigation, fishing or any other activity carried on under a bilateral or multilateral agreement or on the basis of international law, and that in siting an installation, due regard shall be had to existing pipelines and cables. Regard shall also be had to the need for protection sites of special ecological and cultural interest.

2. Each Contracting State shall take steps to ensure that, within the area of its jurisdiction, operators of offshore installations survey the seabed in the vicinity of their installations, and remove any debris resulting from their operations which might interfere with lawful fishing:

(a) in the case of a pipeline, or other sub-sea apparatus immediately following completion of the work of installation;

(b) in the case of a production platform, immediately following its removal;

(c) in any case when the Competent State Authority might reasonably require survey and clean-up.

\section{Article VI}

Each Contracting State shall take all practicable measures to ensure that every offshore installation to be used in that part of the Protocol Area within its jurisdiction is certified by a Certifying Authority or its designee that it is safe and fit for the purpose for which it is to be used so as to ensure that it will not cause accidental damage to the marine environment.

\section{Article VII}

Each Contracting State shall take all practicable measures to ensure the following: 
1. Operators shall at all times have available to their offshore installations, in good working order, equipment and devices to minimize the risk of accidental pollution and to facilitate prompt response to a pollution emergency, in accordance with good oil field or other relevant industry practice.

2. Any such plant or equipment not included as part of an installation for the purposes of Article VI shall be subject to prior examination and approval by or on behalf of the Competent State Authority, and to periodic inspection, in accordance with good oil field or other relevant industry practice.

3. Blow-out preventers and other safety equipment shall be tested periodically by the operator or on his behalf, and exercises in their operation carried out periodically, in accordance with good oil field or other relevant industry practice.

4. Offshore installations above sea level shall carry lights and other warning instruments, in accordance with international maritime practice, maintained in good working order, and those lights and instruments shall also be operated in accordance with international maritime practice.

5. All persons engaged in offshore operations shall have had or be given training in accordance with good oil field practice. Any person employed on an offshore installation for the first time shall undergo an induction course, and shall be given a manual which includes instruction on emergency procedures.

\section{Article VIII}

Each Contracting State shall take all practicable measures to ensure the following:

1. No operator shall start work on any stage of his offshore operations within its jurisdiction until he has:

(a) prepared a contingency plan to deal with any event which may occur as a result of the operations, and which may cause significant pollution to the marine environment;

(b) had that plan approved by the Competent State Authority;

(c) shown to the satisfaction of that State authority that he has available to him sufficient expertise and resources to put that plan fully into operation.

2. No contingency plan shall be approved unless it can be co-ordinated with any existing national or local contingency plans, and any plans prepared by the Centre, and unless the operator can be required to participate in any exercise conducted in the implementation of such contingency plans.

3. Any person conducting offshore operations shall make and maintain arrangements to ensure that when an event occurs as a result of his operations which may cause significant pollution of the marine environment, a full report of that event is sent immediately to the State authority designated to receive such reports.

4. The respective roles and powers of the industry and the authorities shall be fully understood before an oil spill emergency, and shall be clearly defined in the operator's contingency plan, and in any national and local contingency plans.

\section{Article IX}

1. Each Contracting State shall take all practicable measures to ensure, subject to paragrapgh 2 below, the following:

(a) In that part of the Protocol Area which is a 'Special Area' no machinery space drainage from an offshore installation shall be discharged into the sea unless the oil content thereof does not exceed $15 \mathrm{mg}$. per litre whilst undiluted. Any Contracting State may impose a more restrictive level in any area under its jurisdiction. 
(b) No other discharge from an offshore installation into the sea within the Protocol Area, except one derived from drilling operations, shall have an oil content, whilst undiluted, greater than that stipulated for the time being by the Organization. The oil content so stipulated shall not be greater than $40 \mathrm{mg}$. per litre as an average in any calendar month, and shall not at any time exceed $100 \mathrm{mg}$. per litre.

(c) Discharge points for oily wastes shall be well below the surface of the sea as appropriate.

(d) All necessary precautions shall be taken to minimize losses of oil into the sea from oil and gas collected or flared from well testing.

2. Measures passed in compliance with paragraph 1 of this Article may provide that there is no breach of their requirements if, when the oil content of a discharge is greater than the permitted concentrations, that excess was due to some accident or other cause beyond the control of the operator and his employees, and that they took all reasonable precautions and exercised all due diligence to avoid such excess. Alternatively, a defence of equivalent effect may be provided.

3. Each Contracting State shall ensure that the operator may be required to conduct surveys of environmental conditions in the vicinity of his offshore installation, periodically or on such occasions as the Competent State Authority may reasonably require.

The State itself may conduct or have conducted such a survey. If, without apparent reason, the results of that survey show a significant difference from the results of the operator's most recent survey, without prejudice to any other legal action, the State may charge the cost of its own survey to the operator.

4. Each Contracting State shall pass measures necessary to ensure the following:

(a) Oil-based drilling fluids shall not be used in drilling operations in those parts of the Protocol Area within its jurisdiction except with the express sanction of the Competent State Authority. Such sanction shall not be given unless the Authority is satisfied that the use of such fluid is justified because of exceptional circumstances. If such fluid is used, the drill cuttings shall be effectively treated to minimize their oil content before being appropriately disposed of. Any wash water shall not be discharged at any place from which they may be carried to mix with the same drill cuttings. The discharge point for the cuttings shall, as appropriate, be well below the surface of the water.

(b) No oil-based drilling fluid shall be discharged to any parts of the Protocol Area within its jurisdiction.

(c) Water-based drilling muds discharged from offshore operations must not contain persistent systemic toxins which may continue to pose an environmental threat after the initial drilling fluid discharge.

\section{Article X}

1. Each Contracting State shall take all practicable measures to ensure the following:

(a) Disposal into the sea of the following is prohibited:

(i) all plastics, including but not limited to synthetic ropes, synthetic fishing nets and plastic garbage bags;

(ii) all other garbage, including paper products, rags, glass, metal, bottles, crockery, dunnage, lining and packing materials;

(b) Disposal into the sea of food wastes shall be made as far as practicable from land, but in any case not less than 12 nautical miles from the nearest land.

(c) When the garbage is mixed with other discharges having different disposal or discharge requirements the more severe requirements shall apply. 
(d) Sewage shall not be discharged into the Protocol Area from an installation permanently manned by ten or more persons unless:

(i) it has been comminuted and disinfected using a system approved by the Competent State Authority and is discharged at a distance of more than four nautical miles from the nearest land; or

(ii) it is discharged at a distance of more than twelve nautical miles from the nearest land; or

(iii) it has passed through a treatment plant approved by the Competent State Authority;

and in any case the discharge does not produce visible floating solids or discolouration of the surrounding water.

2. Each Contracting State shall provide at convenient points on its coastline, reception facilities for general garbage from manned offshore installations operating in the area of its jurisdiction.

\section{Article XI}

1. Each Contracting State shall take all appropriate measures to ensure the following:

(a) Each operator of an offshore installation shall prepare, and submit for approval by the Competent State Authority, a "Chemical Use Plan". Application for amendments to the Plan may be submitted subsequently and approved. If at any time he wishes to use a chemical outside the scope of his approved plan, and that chemical may escape into the marine environment, he shall notify the competent State Authority, except that in case of emergency to prevent the risk of injury to persons or extensive damage to property, the notification need not be given prior to the use of the chemical.

(b) The Competent State Authority has a power to prohibit, limit or regulate the use of a chemical or product and to impose conditions on its storage and its use, for the purpose of protecting the marine environment. In exercising that power, the Authority shall have regard to any guidelines issued by the Organization.

2. Each Contracting State shall take appropriate measures to ensure that seismic operations in the Protocol Area shall take into account the guidelines issued by the Organization.

\section{Article XII}

Each Contracting State shall require that, for offshore operations in any part of the Protocol Area within its jurisdiction, the operators shall:

(a) provide adequate system for collection and proper disposal of all unwanted substances or articles;

(b) give proper instructions on their use;

(c) endeavour to provide for penalties for improper disposal.

\section{Article XIII}

1. Each Contracting State shall ensure that the Competent State Authority has the power to require the operator of an offshore installation:

(a) in the case of a pipeline-

(i) to flush and remove any residual pollutants from the pipeline, and 
(ii) to bury the pipeline, or remove part and bury the remaining parts therof, so as to eliminate for the foreseeable future any risk of hindrance to navigation or fishing, taking all circumstances into account.

(b) in the case of platforms and other seabed apparatus and structures, to remove the installation in whole or in part to ensure the safety of navigation and in the interests of fishing.

Each Contracting State shall also take all practicable measures to ensure that the operator has sufficient resources to guarantee that any such requirements can be met.

2. Where Contracting States have a common interest in fishing grounds in the Protocol Area, they shall endeavour to adopt a common policy on the removal of installations.

In determining in any case whether or not installations must be removed, Contracting States shall have regard to any guidelines issued by the Organization. Whether pipelines are removed or not, they shall be flushed to remove residual pollutants.

3. Contracting States shall pass, and take all practicable steps to enforce, measures to ensure that no offshore installation which in use has floated at or near the sea-surface, and no equipment from an offshore installation, shall be deposited on the seabed of the continental shelf when it is no longer needed.

\section{Article XIV}

1. The provisions of the Convention relating to Protocols shall apply to this Protocol.

2. Procedures for Amendments to Protocols and their Annexes adopted in accordance with Article XX and XXI of the Convention shall apply to this Protocol.

3. The Rules of Procedures and Financial Rules adopted pursuant to Article XXII of the Convention shall apply to this Protocol.

\section{Article XV}

1. This Protocol shall be opened for signature in ........ from ....... to ....... by any State which is party to the Kuwait Regional Convention for Co-operation on the Protection of the Marine Environment from Pollution.

2. This Protocol shall be subject to ratification, acceptance, approval or accession by the States parties to the Convention. Instruments of ratification, acceptance, approval or accession shall be deposited with the Government of Kuwait, which shall assume the functions of the Depository.

3. This Protocol shall enter into force on the ninetieth day following the deposit of at least five instruments of ratification, acceptance or approval of, or accession to, the Protocol by the States as referred to in paragraph 2 of this Article.

IN WITNESS WHEREOF the undersigned, being duly authorized by their respective Governments, have signed this Protocol.

DONE AT ....... this ........ in the year ........ in Arabic, English and Persian languages, the texts being equally authentic. In case of a dispute as to the interpretation or application of this Protocol, the English text shall be authoritative. 


\section{Protocol for the Protection of the Marine Environment against Pollution from Land-Based Sources to the Kuwait Regional Convention for Cooperation on the Protection of the Marine Environment from Pollution, Kuwait, 1990}

Done at Kuwait 21 February 1990

Primary source citation: Copy of text provided by the United Nations

\section{PROTOCOL FOR THE PROTECTION OF THE MARINE ENVIRONMENT AGAINST POLLUTION FROM LAND-BASED SOURCES}

\section{February 1990}

\section{REGIONAL ORGANIZATION FOR THE PROTECTION OF THE MARINE ENVIRONMENT (ROPME) KUWAIT}

THE CONTRACTING STATES

BEING PARTIES to the Kuwait Regional Convention for Cooperation on the Protection of the Marine Environment from Pollution;

RECOGNIZING the danger posed to the marine environment and to human health by pollution from land-based sources and the serious problems resulting therefrom in coastal waters of many Contracting States, principally due to the release of untreated, insufficiently treated and/or inadequately disposed of domestic or industrial discharges;

NOTING that existing measures to prevent, abate and combat pollution caused by discharges from land-based sources need to be strengthened on a national and a regional basis; 
BEING AWARE of Articles 194, 207, 212 and 213 of the United Nations Convention on the Law of the Sea (1982); and the Montreal Guidelines for the Protection of the Marine Environment against Pollution from Land-Based Sources (1985); and

DESIROUS to strengthen the implementation of Article III, paragraph (b) and Article VI of the Convention;

HAVE AGREED as follows:*

\section{Article I \\ Definitions}

For the purpose of this Protocol:

1. "Combined Treatment" means common treatment of industrial effluents along with domestic sewage;

2. "Competent State Authority" means the Authority designated by the Contracting State for the purpose of this Protocol;

3. "Contracting State" means any State which has become a party to this Protocol;

4. "Convention" means the Kuwait Regional Convention for Co-operation on the Protection of the Marine Environment from Pollution;

5. "Council" means the organ of the Organization as referred to in subparagaph (i) of paragraph (b) of Article XVI of the Convention;

6. "Freshwater Limit" means the place in watercourses where, at low tide and in a period of low freshwater flow, there is an appreciable increase in salinity due to the presence of sea-water;

7. "Joint Pretreatment/Treatment" means common pretreatment/treatment of the effluents from more than one industrial source;

8. "Land-Based Sources" means municipal, industrial or agricultural sources, both fixed and mobile on land, discharges from which reach the Marine Environment, as outlined in Article III of this Protocol;

9. "Marine Environment" means the Protocol Area as defined in Article II of this Protocol;

10. "Organization" means the Regional Organization for the Protection of the Marine Environment established in accordance with Article XVI of the Convention;

11. "Pollution" means "Marine Pollution" as defined in paragraph (a) of Article I of the Convention.

\section{Article II Area of Application}

The area to which this Protocol applies (hereinafter referred to as the "Protocol Area") shall be the Sea Area as defined in Article II, paragraph (a) of the Convention, together with the waters on the landward side of the baselines from which the breadth of the territorial sea of the Contracting States is measured and extending, in the case of watercourses, up to the freshwater limit and including intertidal zones and saltwater marshes communicating with the sea.

\footnotetext{
- A Meeting of the Plenipotentiaries was held in Kuwait on 21 February 1990 for signing the Protocol concerning the Protection of the Marine Environment against Pollution from Land-Based Sources.
} 


\section{Article III \\ Sources of Pollution}

This Protocol shall apply to discharges reaching the Protocol Area from land-based sources within the territories of the Contracting States, in particular:

(a) from outfalls and pipelines discharging into the sea;

(b) through rivers, canals or other watercourses, including underground watercourses;

(c) from fixed or mobile offshore facilities serving purposes other than exploration and exploitation of the sea bed, its subsoil and the continental shelf; and

(d) from any other land-based sources situated within the territories of the Contracting States, whether through water, through the atmosphere or directly from the coast.

\section{Article IV \\ Source Control}

1. The Contracting States undertake to implement the action programmes based on source control as outlined in Annex I to this Protocol. To this end, they shall develop and implement, jointly or individually, as appropriate, the necessary programmes and measures.

2. The programmes and measures and the timetables for their implementation aimed at reducing pollution from land-based sources, shall be fixed by the Contracting States and periodically reviewed and revised, if necessary every two years, in accordance with the provisions of Article XIV of this Protocol.

\section{Article V \\ Joint and/or Combined Effluent Treatment}

1. The Contracting States in their endeavour not to inhibit the development of new industries, and especially that of small industrial operations, and recognizing the economic and technical difficulties often encountered by such operations in properly treating their effluents individually, undertake to implement, to the extent possible, industrial location planning programmes as outlined in Annex II to this Protocol. To this end, they shall develop and implement, jointly and/or individually, as appropriate, the necessary programmes and measures.

2. The Regional guidelines and criteria along with programmes and measures and the time-tables for their implementation, aimed at reducing pollution from land-based sources through joint and/or combined effluent treatment, shall be fixed by the Contracting States and periodically reviewed and revised, if necessary every two years, in accordance with the provisions of Article XIV of this Protocol.

\section{Article VI \\ Regional and Local Regulations/Permits for Release of Wastes}

1. As outlined in Annex III to this Protocol, the Contracting States shall progressively develop and adopt, in cooperation with competent Regional and International organizations as appropriate:

(a) Regional guidelines, standards or criteria, as appropriate, for the quality of sea-water used for specific purposes that is necessary for the protection of human health, living resources and ecosystems; 
(b) Regional regulations for the waste discharge and/or degree of treatment for all significant types of land-based sources;

(c) Stricter local regulations for waste discharge and/or degree of treatment for specific sources based on local pollution problems and desirable water usage considerations.

Stricter regulations for specific sources serve the purpose of preserving the quality of seawater required for the intended use. In developing such regulations the local ecological, geographical and physical characteristics, as well as, the level of existing pollution in the Marine Environment shall be taken into consideration.

2. The programmes for the implementation of the above measures shall be adopted and shall take into account, for their progressive application, the cost of measures involved, the capacity to modify existing installations, the economic capacity of the Contracting States and their need for sustainable development.

3. Polluters shall be required to obtain a permit to discharge from the Competent State Authorities. Such permits shall allow for review and modification of discharge conditions reflecting the periodic update of regulations.

4. Guidelines, standards or criteria, as well as regulations, programmes and measures, shall be developed and adopted in accordance with the provisions of Article XIV of this Protocol and periodically updated, if necessary every two years, to reflect the increasing information through the monitoring programme described in Article VII of this Protocol, the changes in the industrial and other human activities and possible advances in science and the pollution control technologies.

\section{Article VII Monitoring and Data Management}

1. The Contracting States, within the framework of the provisions of Article $\mathrm{X}$ of the Convention, shall carry out monitoring activities, if necessary in co-operation with the competent Regional and International organizations, in order to:

a) collect data on natural conditions of the Protocol Area as regards its physical, biological and chemical characteristics;

b) collect data on inputs of substances or energy that cause or potentially cause pollution from land-based sources, including information on the distribution of sources and the quantities of pollutants introduced to the Protocol Area;

c) assess systematically the levels of pollution within their internal and territorial waters, in particular with regard to the substances that may have a potential significant impact on the Marine Environment. For the selection of the sampling locations and substances to be measured, information available, inter alia, from source inventories, discharge outfalls and marine environment characteristics shall be considered; and

d) evaluate the effectiveness of measures taken under this Protocol in meeting the environmental objectives.

2. Contracting States shall collaborate jointly or collectively to establish comparable monitoring programmes, as well as analytical quality control programmes and to promote data storage, retrieval and exchange.

\section{Article VIII \\ Environmental Impact Assessment}

1. The Contracting States shall require on priority basis an assessment of the potential environmental impacts during the planning and implementation stages of selected development projects within their territories, 
particularly in the coastal areas, which may cause significant risks of pollution from land-based sources to the Protocol Area, in order to ensure that appropriate measures are taken to prevent or mitigate such risks.

2. The Contracting States shall develop, with the assistance of the Organization, technical and other guidelines concerning the assessment of the potential environmental impacts of development projects referred to in paragraph 1, including possible transboundary effects. The assessment should, where appropriate, contain inter alia the following:

(a) A description of the geographical location of the activities to be carried out;

(b) A description of the initial ecological state of the marine environment and the coastal area which may be affected by the activities;

(c) An indication of the nature, aims and scope of the proposed activities;

(d) A description of the methods, installations and other means to be used;

(e) A description of the foreseeable direct and indirect long-term and short-term effects of the activities on the Marine Environment, including fauna, flora and the ecological balance;

(f) Astatement setting out the measures proposed to reduce to the minimum the risk of pollution by carrying out the activities and, in addition, possible process and pollution abatement alternatives to such measures;

(g) An indication of the measures to be taken for the protection of the Marine Environment from pollution during and, as appropriate, at the end of the proposed activities;

(h) Definition of commitments to ongoing environmental management and monitoring;

(i) Cost-benefit analysis as appropriate;

(j) Abrief summary of the assessment.

3. The implementation of the selected projects referred to in paragraph 1 should be made subject to a prior written authorization from the Competent State Authorities which takes fully into account the findings of the environmental impact assessment.

4. The Contracting States shall co-operate with the Organization to develop procedures for the dissemination to all Contracting States of the reports on the results of such assessment with a view to enable the Contracting States which may be affected by the environmental impacts of the development projects to consult with the Contracting State concerned.

\section{Article IX Scientific and Technological Co-operation}

The Contracting States, in conformity with Article $\mathrm{X}$ of the Convention, shall co-operate in scientific and technological fields related to pollution from land-based sources, particularly research on inputs, pathways and effects of pollutants and on the development of new methods for their treatment, reduction or elimination. To this end, the Contracting States shall, in particular, endeavour to:

(a) exchange scientific and technical information;

(b) co-ordinate their research programmes of common nature. 


\section{Article $\mathrm{X}$ \\ Scientific, Technical and Other Assistance}

1. The Contracting States shall, directly or with the assistance of the Organization or competent Regional and International organizations, co-operate with a view to formulate and implement programmes of assistance, particularly in the fields of science, education and technology, for the prevention, reduction and control of pollution from land-based sources.

2. Such technical assistance shall include, in particular, the training of scientific and technical personnel, as well as the acquisition, utilization, maintenance and production of appropriate equipment.

\section{Article XI \\ Watercourses Shared by States}

1. If discharges from a watercourse which flows through the territories of Contracting States are likely to cause pollution of the Protocol Area, the Contracting States in question, in accordance with the provisions of this Protocol in so far as each of them is concerned, are called upon to co-operate with a view to ensuring its full application.

2. AContracting State shall not be responsible for any pollution originating on the territory of a non-Contracting State. However, the Contracting State shall endeavour to co-operate with such State so as to make possible full application of the Protocol.

\section{Article XII \\ Exchange of Information}

1. The Contracting States shall inform one another directly or through the Organization of measures taken, of results achieved and, if the case arises, of difficulties encountered in the application of this Protocol. Procedures for the collection and submission of such information shall be determined by the Council.

2. Such information shall include inter alia:

(a) Relevant statistical data in accordance with Articles VI and VII of this Protocol;

(b) Data resulting from monitoring as provided for in Article VII of this Protocol;

(c) Quantities of pollutants discharged or emitted from their territories;

(d) Measures taken in accordance with Articles IV, V and VI of this Protocol.

\section{Article XIII \\ Responsibility and Liability for Damage}

1. Contracting States shall ensure that recourse is available in accordance with their legal systems for prompt and adequate compensation or other relief in respect of damage caused by pollution of the Marine Environment by natural or juridical persons under their jurisdiction.

2. Contracting States shall formulate and adopt appropriate procedures for the determination of liability for damage resulting from pollution from land-based sources. 


\section{Article XIV \\ Institutional Arrangements}

The Council, in accordance with Article XVII of the Convention, shall be responsible for keeping under review the implementation of this Protocol. To this end, the Council shall, inter alia:

(a) consider the efficacy of the measures adopted and the advisability of adopting any other measures, in particular in the form of annexes;

(b) revise and amend any annex to this Protocol, as appropriate;

(c) formulate, adopt and review programmes and measures in accordance with Articles IV, V, VI, VII, IX and $\mathrm{X}$ of this Protocol;

(d) adopt Regional guidelines, standards or criteria in accordance with Articles IV, V and VI of this Protocol;

(e) formulate procedures for exchange of information in accordance with Articles VIII and XII of this Protocol;

(f) consider information submitted by the Contracting States under Articles VIII and XII of this Protocol;

(g) discharge such other functions as appropriate for the application of this Protocol; and

(h) establish any such institutional mechanism as deemed necessary for the achievement of the objectives of this Protocol.

\section{Article XV General Provisions}

1. The provisions of the Convention relating to any Protocol shall apply to this Protocol.

2. Procedures for amendments to Protocols and their Annexes adopted in accordance with Articles XX and XXI of the Convention shall apply to this Protocol.

3. The Rules of Procedures and Financial rules adopted pursuant to Article XXII of the Convention, and amendments thereto, shall apply to this Protocol.

4. The Annexes form an integral part of this Protocol unless expressly provided otherwise thereto.

\section{Article XVI \\ Final Provisions}

1. This Protocol shall be open for signature in the State of Kuwait from 21 February to 21 May 1990 by any State which is party to the Kuwait Regional Convention for Co-operation on the Protection of the Marine Environment from Pollution.

2. This Protocol shall be subject to ratification, acceptance, approval or accession by the States parties to the Convention. Instruments of ratification, acceptance, approval or accession shall be deposited with the Government of Kuwait which shall assume the functions of the Depository.

3. This Protocol shall enter into force on the ninetieth day following the date of deposit of at least five instruments of ratification, acceptance or approval of, or accession to this Protocol by the States as referred to in paragraph 1 of this Article. 
IN WITNESS WHEREOF the undersigned Plenipotentiaries, being duly authorized by their respective Governments, have signed this Protocol.

DONE AT KUWAIT this twenty-first day of February, in the year one thousand nine hundred ninety in the Arabic, English and Persian languages, the texts being equally authentic.

\section{ANNEXES}

\section{Annex I \\ Pollution Abatement through Source Control}

With regard to the issue of pollution abatement through source control referred to in Article IV of this Protocol, consideration should be given to the control and progressive replacement of products, installations and industrial or other processes causing significant pollution to the Marine Environment. In this regard, particular attention will be given, but not limited, to the following factors:

a) Curtailment and/or regulation of import, transportation, manufacturing or processing of certain harmful substances.

b) Change of raw materials.

c) Change of manufacturing processes.

d) Good operating and housekeeping practices.

e) Segregation of waste streams and minimization of pollutant dilution prior to treatment.

f) Recovery, re-use and recycling.

The programmes, measures and the timetables required for the implementation of source control will be developed and priorities allocated on the basis of the results of on-going assessment studies.

Problem areas of Regional interest, where cost effective measures can be implemented, will receive attention for the purpose of establishing general management schemes. Such areas are, for example, the collection, treatment, and proper disposal of spent lubricating oils, blood and paunch from slaughterhouses, the control of fuel combustion processes and the implementation of source control in selected processes within large industries.

\section{Annex II \\ Promotion of joint and/or combined Effluent Treatment}

Without undue prejudice to the multifaceted constraints that often govern the selection of the location of new industries, a programme will be undertaken, as referred to in Article VI of this Protocol, to promote:

a) agglomeration of industries in a way that enhances the possibility of joint effluent pretreatment and/or treatment, as the need may be;

b) location within the limits of city sewer systems of certain types of industry so as to enhance combined treatment of industrial and domestic wastes.

Promotion of joint and/or combined effluent treatment, if properly planned, could result in greatly reduced treatment, monitoring and enforcement costs as well as in increased treatment reliabilities. To this end, Regional guidelines and criteria will be developed dealing with topics of common interest, such as: 
- the compatibility of effluent from different sources;

— pretreatment requirements prior to discharge into domestic and/or industrial sewer systems;

- cost sharing for the construction and operation of treatment plants.

Such guidelines and criteria will assist Contracting States in developing their own specific programmes and measures. While initial plans may deal with the location problem of new industries, the end objective will be the progressive attraction of existing selected small industries as the infrastructure and facilities are developed in the designated areas.

\section{Annex III \\ Guidelines, Regulations and Permits for the Release of Wastes}

1. With a view to guidelines, standards or criteria, as well as to regulations, programmes, measures, and discharge permits for release of wastes referred to in Article VI of this Protocol, particular attention will be given, inter alia, to the following factors:

a) Regional regulations for the waste discharge and/or degree of treatment should be specific for each kind of source and, if necessary, may be different between existing and new sources. Their development should be based on treatment technology, cost and nature of pollutants considerations, as well as on an overview of the state of environment in the Protocol Area.

b) Regional guidelines and, as appropriate, standards or criteria should be developed for the quality of sea water used for specific purposes.

c) For areas where the water quality standards for the intended use cannot be achieved through the implementation of the above Regional regulations, stricter local regulations for the waste discharge and/or degree of treatment should be developed. Such local regulations will apply to the specific sources in the areas under consideration.

d) Regional regulations along with the programmes, measures and the timetables required for the implementation should be developed on a priority basis, inter alia, for the following types of wastes:

i) Ballast water, slops, bilges and other oily water discharges generated by land-based reception facilities and ports through loading and repair operations.

ii) Brine water and mud discharges from oil and gas drilling and extraction activities from land-based sources.

iii) Oily and toxic sludges from crude oil and refined products storage facilities.

iv) Effluents and emissions from petroleum refineries.

v) Effluents and emissions from petrochemical and fertilizer plants.

vi) Toxic effluents and emissions from industries such as chlor-alkali, primary aluminium production, pesticides, insecticides, and lead recovery plants.

vii) Emissions from natural gas flaring and desulfurization plants.

viii) Dust emissions from major industrial sources, such as cement, lime, asphalt and concrete plants.

ix) Effluents and emissions from power and desalination plants. 
x) Wastes generated from coastal development activities which may have a significant impact on the Marine Environment.

xi) Sewage and solid wastes.

e) As the diagram 1 attached to this Annex illustrates, pollution abatement is an iterative process. Pollution abatement action will start from high priority measures, which will be selected to be pragmatic, cost-effective, while addressing the most critical environmental problems as perceived today. The monitoring programme as specified in Article VII of this Protocol, will be providing the necessary feedback for the required corrective action by yielding the database for assessing the effectiveness of implemented programmes, the current state of the environment and its trends. Corrective action, whenever required, will be taken through periodic updates of the regulations, programmes and measures and review of the conditions in discharge permits, in accordance with the provisions of Articles IV and VI of this Protocol.

2. Provisions for establishing criteria governing the issue of permits for the discharging of waste matter in the Marine Environment, should also take into consideration inter alia the following:

\section{a) Characteristics and Composition of Waste}

i) Type and size of waste source, e.g. industrial process.

ii) Type of waste (origin, average composition).

iii) Form of waste (solid, liquid, sludge, slurry).

iv) Total amount (volume discharged, e.g. per year).

v) Discharge pattern (continuous, intermittent, seasonally variable, etc.).

vi) Concentrations with respect to major constituents.

vii) Properties: physical, e.g. solubility and density; chemical and biochemical, e.g. oxygen demand, nutrients; and biological, e.g. presence of viruses, bacteria, yeast, parasites.

viii) Toxicity.

ix) Persistence: physical, chemical and biological.

x) Accumulation and biotransformation in biological materials or sediments.

xi) Susceptibility to physical, chemical and biochemical changes and interaction in the aquatic environment with other dissolved organic and inorganic materials.

xii) Probability of producing taints or other changes reducing marketability of resources, e.g. fish, shellfish, etc.

\section{b) Characteristics of Discharge Site and Receiving Marine Environment}

i) Hydrographic, meteorological, geological, biological and topographical characteristics of the discharge site.

ii) Location and type of the discharge (outfall, canal, outlet, etc.) and its relation to other areas, e.g. amenity areas, spawning, nursery and fishing areas, shellfish grounds and exploitable resources.

iii) Rate of disposal per specific period, e.g. quantity per day, per week and per month.

iv) Initial dilution achieved at the point of discharge into the receiving marine environment. 
v) Methods of packaging and containment, if any.

vi) Dispersion characteristics such as effects of currents, tides and wind on horizontal transport and vertical mixing.

vii) Water characteristics, e.g. temperature, $\mathrm{pH}$, salinity, stratification, oxygen indices of pollution - dissolved oxygen (DO), chemical oxygen demand (COD), biochemical oxygen demand (BOD) nitrogen present in organic and mineral form including ammonia, suspended matter, other nutrients and productivity.

viii) Existence and effects of other discharges which have been made in the discharge site, e.g. heavy metal background levels and organic carbon content.

\section{c) Availability of Waste Technologies}

The methods of waste reduction and discharge for industrial effluents as well as domestic sewage should be selected taking into account the availability and feasibility of:

i) Alternative treatment processes;

ii) Re-use or elimination methods;

iii) On-land disposal alternative; and

iv) Appropriate low-waste technologies.

\section{d) General Considerations and Conditions}

i) Possible effects on amenities, e.g. presence of floating or stranded materials, turbidity, objectionable odour, discoloration and foaming.

ii) Effects on human health through pollution impact on: Edible marine organisms; bathing waters; aesthetics; etc. 


\title{
Convention Concerning the Prevention of Major Industrial Accidents, Geneva, 1993
}

\author{
Done at Geneva 22 June 1993 \\ Entered into force \\ Depositary: International Labour Office \\ Primary source citation: Copy of text provided by the \\ International Labour Office
}

\section{INTERNATIONAL LABOUR CONFERENCE}

\section{Convention 174}

\section{CONVENTION CONCERNING THE PREVENTION OF MAJOR INDUSTRIAL ACCIDENTS}

The General Conference of the International Labour Organization,

Having been convened at Geneva by the Governing Body of the International Labour Office, and having met in its 80th Session on 2 June 1993, and

Noting the relevant international labour Conventions and Recommendations and, in particular, the Occupational Safety and Health Convention and Recommendation, 1981, and the Chemicals Convention and Recommendation, 1990, and stressing the need for a global and coherent approach, and

Noting also the ILO Code of practice on the Prevention of major industrial accidents, published in 1991, and

Having regard to the need to ensure that all appropriate measures are taken to:
(a) prevent major accidents;
(b) minimize the risks of major accidents;
(c) minimize the effects of major accidents, and

Considering the causes of such accidents including organizational errors, the human factor, component failures, deviation from normal operational conditions, outside interference and natural forces, and

Having regard to the need for cooperation, within the International Programme on Chemical Safety, between the International Labour Organization, the United Nations Environment Programme and the World Health Organization, as well as with other relevant intergovernmental organizations, and 
Having decided upon the adoption of certain proposals with regard to the prevention of major industrial accidents, which is the fourth item on the agenda of the session, and

Having determined that these proposals shall take the form of an international Convention;

adopts this twenty-second day of June of the year one thousand nine hundred and ninety-three the following Convention, which may be cited as the Prevention of Major Industrial Accidents Convention, 1993.

\section{Part I. SCOPE ANd Definitions}

\section{Article 1}

1. The purpose of this Convention is the prevention of major accidents involving hazardous substances and the limitation of the consequences of such accidents.

2. This Convention applies to major hazard installations.

3. This Convention does not apply to:

(a) nuclear installations and plants processing radioactive substances except for facilities handling nonradioactive substances at these installations;

(b) military installations;

(c) transport outside the site of an installation other than by pipeline.

4. A Member ratifying this Convention may, after consulting the representative organizations of employers and workers concerned and other interested parties who may be affected, exclude from the application of the Convention installations or branches of economic activity for which equivalent protection is provided.

\section{Article 2}

Where special problems of a substantial nature arise so that it is not immediately possible to implement all the preventive and protective measures provided for in this Convention, a Member shall draw up plans, in consultation with the most representative organizations of employers and workers and with other interested parties who may be affected, for the progressive implementation of the said measures within a fixed time-frame.

\section{Article 3}

For the purposes of this Convention:

(a) the term "hazardous substance" means a substance or mixture of substances which by virtue of chemical, physical or toxicological properties, either singly or in combination, constitutes a hazard;

(b) the term "threshold quantity" means for a given hazardous substance or category of substances that quantity, prescribed in national laws and regulations by reference to specific conditions, which if exceeded identifies a major hazard installation;

(c) the term "major hazard installation" means one which produces, processes, handles, uses, disposes of or stores, either permanently or temporarily, one or more hazardous substances or categories of substances in quantities which exceed the threshold quantity;

(d) the term "major accident" means a sudden occurrence - such as a major emission, fire or explosion - in the course of an activity within a major hazard installation, involving one or more hazardous substances and leading to a serious danger to workers, the public or the environment, whether immediate or delayed; 
(e) the term "safety report" means a written presentation of the technical, management and operational information covering the hazards and risks of a major hazard installation and their control and providing justification for the measures taken for the safety of the installation;

(f) the term "near miss" means any sudden event involving one or more hazardous substances which, but for mitigating effects, actions or systems, could have escalated to a major accident.

\section{PART II. General PRINCIPLES}

\section{Article 4}

1. In the light of national laws and regulations, conditions and practices, and in consultation with the most representative organizations of employers and workers and with other interested parties who may be affected, each Member shall formulate, implement and periodically review a coherent national policy concerning the protection of workers, the public and the environment against the risk of major accidents.

2. This policy shall be implemented through preventive and protective measures for major hazard installations and, where practicable, shall promote the use of the best available safety technologies.

\section{Article 5}

1. The competent authority, or a body approved or recognized by the competent authority, shall, after consulting the most representative organizations of employers and workers and other interested parties who may be affected, establish a system for the identification of major hazard installations as defined in Article 3 (c), based on a list of hazardous substances or of categories of hazardous substances or of both, together with their respective threshold quantities, in accordance with national laws and regulations or international standards.

2. The system mentioned in paragraph 1 above shall be regularly reviewed and updated.

\section{Article 6}

The competent authority, after consulting the representative organizations of employers and workers concerned, shall make special provision to protect confidential information transmitted or made available to it in accordance with Articles 8, 12,13 or 14, whose disclosure would be liable to cause harm to an employer's business, so long as this provision does not lead to serious risk to the workers, the public or the environment.

\section{PART III. RESPONSIBILITIES OF EMPLOYERS}

\section{IDENTIFICATION}

\section{Article 7}

Employers shall identify any major hazard installation within their control on the basis of the system referred to in Article 5.

\section{NOTIFICATION}

\section{Article 8}

1. Employers shall notify the competent authority of any major hazard installation which they have identified:

(a) within a fixed time-frame for an existing installation;

(b) before it is put into operation in the case of a new installation. 
2. Employers shall also notify the competent authority before any permanent closure of a major hazard installation.

\section{ARRANGEMENTS AT THE LEVEL OF THE INSTALLATION}

\section{Article 9}

In respect of each major hazard installation employers shall establish and maintain a documented system of major hazard control which includes provision for:

(a) the identification and analysis of hazards and the assessment of risks including consideration of possible interactions between substances;

(b) technical measures, including design, safety systems, construction, choice of chemicals, operation, maintenance and systematic inspection of the installation;

(c) organizational measures, including training and instruction of personnel, the provision of equipment in order to ensure their safety, staffing levels, hours of work, definition of responsibilities, and controls on outside contractors and temporary workers on the site of the installation;

(d) emergency plans and procedures, including:

(i) the preparation of effective site emergency plans and procedures, including emergency medical procedures, to be applied in case of major accidents or threat thereof, with periodic testing and evaluation of their effectiveness and revision as necessary;

(ii) the provision of information on potential accidents and site emergency plans to authorities and bodies responsible for the preparation of emergency plans and procedures for the protection of the public and the environment outside the site of the installation;

(iii) any necessary consultation with such authorities and bodies;

(e) measures to limit the consequences of a major accident;

(f) consultation with workers and their representatives;

(g) improvement of the system, including measures for gathering information and analysing accidents and near misses. The lessons so learnt shall be discussed with the workers and their representatives and shall be recorded in accordance with national law and practice.

\section{SAFETY REPORT}

Article 10

1. Employers shall prepare a safety report based on the requirements of Article 9.

2. The report shall be prepared:

(a) in the case of existing major hazard installations, within a period after notification prescribed by national laws or regulations;

(b) in the case of any new major hazard installation, before it is put into operation. 


\section{Article 11}

Employers shall review, update and amend the safety report:

(a) in the event of a modification which has a significant influence on the level of safety in the installation or its processes or in the quantities of hazardous substances present;

(b) when developments in technical knowledge or in the assessment of hazards make this appropriate;

(c) at intervals prescribed by national laws or regulations;

(d) at the request of the competent authority.

Article 12

Employers shall transmit or make available to the competent authority the safety reports referred to in Articles 10 and 11.

\section{ACCIDENT REPORTING}

Article 13

Employers shall inform the competent authority and other bodies designated for this purpose as soon as a major accident occurs.

\section{Article 14}

1. Employers shall, within a fixed time-frame after a major accident, present a detailed report to the competent authority containing an analysis of the causes of the accident and describing its immediate on-site consequences, and any action taken to mitigate its effects.

2. The report shall include recommendations detailing actions to be taken to prevent a recurrence.

\section{PART IV. RESPONSIBILTTIES OF COMPETENT AUTHORITIES}

\section{OFF-SITE EMERGENCY PREPAREDNESS}

\section{Article 15}

Taking into account the information provided by the employer, the competent authority shall ensure that emergency plans and procedures containing provisions for the protection of the public and the environment outside the site of each major hazard installation are established, updated at appropriate intervals and coordinated with the relevant authorities and bodies.

\section{Article 16}

The competent authority shall ensure that:

(a) information on safety measures and the correct behaviour to adopt in the case of a major accident is disseminated to members of the public liable to be affected by a major accident without their having to request it and that such information is updated and redisseminated at appropriate intervals;

(b) warning is given as soon as possible in the case of a major accident;

(c) where a major accident could have transboundary effects, the information required in (a) and (b) above is provided to the States concerned, to assist in cooperation and coordination arrangements. 


\section{SITING OF MAJOR HAZARD INSTALILATIONS}

\section{Article 17}

The competent authority shall establish a comprehensive siting policy arranging for the appropriate separation of proposed major hazard installations from working and residential areas and public facilities, and appropriate measures for existing installations. Such a policy shall reflect the General Principles set out in Part II of the Convention.

\section{INSPECTION}

\section{Article 18}

1. The competent authority shall have properly qualified and trained staff with the appropriate skills, and sufficient technical and professional support, to inspect, investigate, assess, and advise on the matters dealt with in this Convention and to ensure compliance with national laws and regulations.

2. Representatives of the employer and representatives of the workers of a major hazard installation shall have the opportunity to accompany inspectors supervising the application of the measures prescribed in pursuance of this Convention, unless the inspectors consider, in the light of the general instructions of the competent authority, that this may be prejudicial to the performance of their duties.

\section{Article 19}

The competent authority shall have the right to suspend any operation which poses an imminent threat of a major accident.

\section{PART V. RightS AND DUTIES OF WORKERS AND THEIR REPRESENTATIVES}

\section{Article 20}

The workers and their representatives at a major hazard installation shall be consulted through appropriate cooperative mechanisms in order to ensure a safe system of work. In particular, the workers and their representatives shall:

(a) be adequately and suitably informed of the hazards associated with the major hazard installation and their likely consequences;

(b) be informed of any orders, instructions or recommendations made by the competent authority;

(c) be consulted in the preparation of, and have access to, the following documents:

(i) the safety report;

(ii) emergency plans and procedures;

(iii) accident reports;

(d) be regularly instructed and trained in the practices and procedures for the prevention of major accidents and the control of developments likely to lead to a major accident and in the emergency procedures to be followed in the event of a major accident;

(e) within the scope of their job, and without being placed at any disadvantage, take corrective action and if necessary interrupt the activity where, on the basis of their training and experience, they have reasonable justification to believe that there is an imminent danger of a major accident, and notify their supervisor or raise the alarm, as appropriate, before or as soon as possible after taking such action; 
(f) discuss with the employer any potential hazards they consider capable of generating a major accident and have the right to notify the competent authority of those hazards.

Article 21

Workers employed at the site of a major hazard installation shall:

(a) comply with all practices and procedures relating to the prevention of major accidents and the control of developments likely to lead to a major accident within the major hazard installation;

(b) comply with all emergency procedures should a major accident occur.

\section{PART VI. RESPONSIBILITY OF EXPORTING STATES}

\section{Article 22}

When, in an exporting member State, the use of hazardous substances, technologies or processes is prohibited as a potential source of a major accident, the information on this prohibition and the reasons for it shall be made available by the exporting member State to any importing country.

\section{PART VII. FINAL PROVISIONS}

Article 23

The formal ratifications of this Convention shall be communicated to the Director-General of the International Labour Office for registration.

\section{Article 24}

1. This Convention shall be binding only upon those Members of the International Labour Organization whose ratifications have been registered with the Director-General.

2. It shall come into force 12 months after the date on which the ratifications of two Members have been registered with the Director-General.

3. Thereafter, this Convention shall come into force for any Member 12 months after the date on which its ratification has been registered.

\section{Article 25}

1. A Member which has ratified this Convention may denounce it after the expiration of ten years from the date on which the Convention first comes into force, by an act communicated to the Director-General of the International Labour Office for registration. Such denunciation shall not take effect until one year after the date on which it is registered.

2. Each Member which has ratified this Convention and which does not, within the year following the expiration of the period of ten years mentioned in the preceding paragraph, exercise the right of denunciation provided for in this Article, will be bound for another period of ten years and, thereafter, may denounce this Convention at the expiration of each period of ten years under the terms provided for in this Article.

\section{Article 26}

1. The Director-General of the International Labour Office shall notify all Members of the International Labour Organization of the registration of all ratifications and denunciations communicated to him by the Members of the Organization. 
2. When notifying the Members of the Organization of the registration of the second ratification communicated to him, the Director-General shall draw the attention of the Members of the Organization to the date upon which the Convention will come into force.

\section{Article 27}

The Director-General of the International Labour Office shall communicate to the Secretary-General of the United Nations for registration in accordance with Article 102 of the Charter of the United Nations full particulars of all ratifications and acts of denunciations registered by him in accordance with the provisions of the preceding Articles.

\section{Article 28}

At such times as it may consider necessary, the Governing Body of the International Labour Office shall present to the General Conference a report on the working of this Convention and shall examine the desirability of placing on the agenda of the Conference the question of its revision in whole or in part.

\section{Article 29}

1. Should the Conference adopt a new Convention revising this Convention in whole or in part, then, unless the new Convention otherwise provides-

(a) the ratification by a Member of the new revising Convention shall ipso jure involve the immediate denunciation of this Convention, notwithstanding the provisions of Article 25 above, if and when the new revising Convention shall have come into force;

(b) as from the date when the new revising Convention comes into force this Convention shall cease to be open to ratification by the Members.

2. This Convention shall in any case remain in force in its actual form and content for those Members which have ratified it but have not ratified the revising Convention.

\section{Article 30}

The English and French versions of the text of this Convention are equally authoritative. 


\title{
Amendments to the Convention on the International Maritime Organization, London, 1993
}

Done at London 4 November 1993

Not in force

Primary source citation: Copy of text provided by the

U.S. Department of State

\author{
Resolution A.735(18) \\ Adopted on 4 November 1933 \\ (Agenda item 10)
}

\section{AMENDMENTS TO THE CONVENTION ON THE INTERNATIONAL MARITIME ORGANIZATION}

THe Assembly,

RECALLING that at its seventeenth regular session several delegations expressed concern about the outcome of the elections to the Council for the 1992-1993 biennium,

NoTING that the Council at its sixty-eighth session established an Ad Hoc Working Group, open to all Members of the Organization, to consider possible amendments to the provisions for elections to the Council,

NOTING WITH SATISFACTION that the needed revisions in the IMO Convention have all been initiated within the Organization and have been considered in a spirit of goodwill and mutual accommodation and adopted with the general agreement of Members,

HAVING CONSIDERED the amendments to the IMO Convention recommended by the Ad Hoc Working Group on Elections to the Council and approved by the Council at its sixty-ninth session,

1. ADOPTS amendments to Articles 16, 17 and 19 of the Convention on the International Maritime Organization, the texts of which are contained in the annex to this resolution;

2. REQUESTS the Secretary-General of the Organization to deposit the adopted amendments with the SecretaryGeneral of the United Nations in accordance with Article 67 of the IMO Convention and to receive instruments of acceptance and declarations as provided for in Article 68; and

3. INVITES the Members of the Organization to accept these amendments at the earliest possible date after receiving copies thereof by communicating the appropriate instrument of acceptance to the Secretary-General in accordance with Article 68 of the Convention. 


\section{Annex}

\section{AMENDMENTS TO THE CONVENTION ON THE INTERNATIONAL MARITIME ORGANIZATION}

\section{PART VI}

\section{The Council}

\section{Article 16}

Replace text of Article 16 by:

The Council shall be composed of forty Members elected by the Assembly.

\section{Article 17}

Replace text of Article 17 by:

In electing the Members of the Council, the Assembly shall observe the following criteria:

(a) Ten shall be States with the largest interest in providing international shipping services;

(b) Ten shall be other States with the largest interest in international seaborne trade;

(c) Twenty shall be States not elected under (a) or (b) above which have special interests in maritime transport or navigation, and whose election to the Council will ensure the representation of all major geographic areas of the world.

\section{Article 19(b)}

Replace text of Article 19(b) by:

(b) Twenty-six Members of the Council shall constitute a quorum. 


\section{Amendments to the Annexes to the Convention on the Prevention of Marine Pollution by Dumping of Wastes and Other Matter, 1972, Concerning Phasing Out Sea Disposal of Industrial Waste, London, 1993}

Done at London 12 November 1993

Entered into force 20 February 1994

Primary source citation: Copy of text provided by the U.S. Department of State

\section{RESOLUTION LC.49(16) adopted on 12 November 1993}

\section{AMENDMENTS TO THE ANNEXES TO THE CONVENTION ON THE PREVENTION OF MARINE POLLUTION BY DUMPING OF WASTES AND OTHER MATTER, 1972 CONCERNING PHASING OUT SEA DISPOSAL OF INDUSTRIAL WASTE}

THE SIXTEENTH CONSULTATIVE MEETING,

RECALLING articles I and II of the Convention on the Prevention of Marine Pollution by Dumping of Wastes and Other Matter which state, inter alia, that Contracting Parties shall individually and collectively promote the effective control of all sources of pollution of the marine environment and that they shall harmonize their policies to prevent marine pollution caused by dumping,

RECOGNIZING the commitment of Contracting Parties under article IX of the Convention in respect of technical assistance,

NOTING in this regard the undertaking reached by UNCED, Agenda 21, chapter 34.14(b) on "Transfer of environmentally sound technology, co-operation and capacity-building",

RECALLING ALSO resolution LDC.43(13) by which Contracting Parties agreed, inter alia, that the dumping of industrial waste at sea would cease by 31 December 1995 at the latest and that they should endeavour to adopt individual or regional commitments to cease dumping of industrial waste before 31 December 1995,

RECALLING FURTHER resolution LDC.44(14) on the application of a precautionary approach in environmental protection within the framework of the London Convention 1972, 
NOTING ALSO that several Contracting Parties, individually or under regional agreements covering the dumping of wastes, have already phased out sea disposal of industrial waste,

WELCOMING the efforts undertaken within the framework of other conventions in order to develop and adopt technical guidelines for the environmentally sound management of hazardous wastes on land,

RECALLING the encouragement by UNCED, Agenda 21, chapter 17.30(b)(ii) to the Contracting Parties to take appropriate steps to stop ocean dumping of hazardous substances,

REAFFIRMING the agreement that Contracting Parties commit themselves to take all necessary steps to enable all Contracting Parties to comply with phasing out of sea disposal of industrial waste, including the promotion of technical assistance to this end taking into account the outcome of the Global Waste Survey,

REAFFIRMING ALSO the agreement that Contracting Parties facilitate access to, and transfer of, environmentally sound technologies particularly to developing countries to promote:

- the modification of industrial processes in such a way as to reduce and eliminate the amount of waste generated;

- the recycling of wastes or the reuse of them in other industries;

- the environmentally sound management of wastes on land;

- the further development of alternative and environmentally sound means of disposal,

REAFFIRMING FURTHER the agreement that a better protection of the marine environment by cessation of dumping of industrial waste should not result in unacceptable environmental effects elsewhere,

ADOPTS the following amendments to the Annexes to the Convention in accordance with articles XIV(4)(a) and $\mathrm{XV}(2)$ thereof:
(a) amendments to Annex I; and
(b) amendments to Annex II;

the texts of which are set out in the attachment to this resolution,

REQUESTS the Secretary-General of the International Maritime Organization to inform the Contracting Parties of the above-mentioned amendments in accordance with article XV(1)(b) of the Convention.

\section{ATTACHMENT}

\section{Annex I}

The following text is added to Annex I as a new paragraph 11:

“11 Industrial waste as from 1 January 1996.

For the purposes of this Annex:

"Industrial waste" means waste materials generated by manufacturing or processing operations and does not apply to:
(a) dredged material;
(b) sewage sludge; 
(c) fish waste, or organic materials resulting from industrial fish processing operations;

(d) vessels and platforms or other man-made structures at sea, provided that material capable of creating floating debris or otherwise contributing to pollution of the marine environment has been removed to the maximum extent;

(e) uncontaminated inert geological materials the chemical constituents of which are unlikely to be released into the marine environment;

(f) uncontaminated organic materials of natural origin.

Dumping of wastes and other matter specified in subparagraphs (a) - (f) above shall be subject to all other provisions of Annex I, and to the provisions of Annexes II and III.

This paragraph shall not apply to the radioactive wastes or any other radioactive matter referred to in paragraph 6 of this Annex."

2 The following phrase is added to the beginning of the existing text of paragraph 9:

"Except for industrial waste as defined in paragraph 11 below, ..."

3 In paragraph 9, the word "spoils" is replaced by "material".

\section{Annex II}

1 "Beryllium, chromium, nickel and vanadium and their compounds" are moved from Annex II, paragraph B to paragraph A of Annex II. The remainder of the text of paragraph B is deleted. The subsequent sections are redesignated accordingly.

2 The existing text of paragraph $\mathrm{F}$ is replaced by the following:

"Materials which, though of a non-toxic nature, may become harmful due to the quantities in which they are dumped, or which are liable to seriously reduce amenities." 


\title{
Final Act of the Conference of Plenipotentiaries on the Convention for the Protection of the Mediterranean Sea Against Pollution and Its Protocols, Barcelona, 1995
}

\author{
Done at Barcelona 10 June 1995 \\ Not in force* \\ Depositary: Spain \\ Primary source citation: Copy of text provided by the \\ United Nations
}

\section{FINAL ACT OF THE CONFERENCE OF PLENIPOTENTIARIES ON THE CONVENTION FOR THE PROTECTION OF THE MEDITERRANEAN SEA AGAINST POLLUTION AND ITS PROTOCOLS}

1. The Conference of Plenipotentiaries on the Convention for the Protection of the Mediterranean Sea against Pollution and its Protocols was convened by the Executive Director of the United Nations Environment Programme in pursuance of a recommendation adopted by the Eighth Ordinary Meeting of the Contracting Parties to the Convention for the Protection of the Mediterranean Sea against Pollution and its related Protocols (Antalya, 12-15 October 1993). The recommendation called upon the Contracting Parties to the Barcelona Convention to examine amendments to the Mediterranean Action Plan and the Convention and its Protocols, and the possibility of adapting the texts to the latest developments in international environmental law (UNEP(OCA)/MED IG.3/5).

2. At the kind invitation of the Government of Spain, the Conference was convened in Barcelona, on 9 and 10 June 1995.

3. The following Contracting Parties to the Convention for the Protection of the Mediterranean Sea against Pollution were invited to participate in the Conference: Albania, Algeria, Bosnia and Herzegovina, Croatia, Cyprus, Egypt, European Community, France, Greece, Israel, Italy, Lebanon, Libyan Arab Jamahiriya, Malta, Monaco, Morocco, Slovenia, Spain, Syrian Arab Republic, Tunisia and Turkey.

4. The following Contracting Parties accepted the invitation and participated in the Conference: Albania, Algeria, Bosnia and Herzegovina, Croatia, Cyprus, Egypt, European Community, France, Greece, Israel, Italy, Libyan Arab Jamahiriya, Malta, Monaco, Morocco, Slovenia, Spain, Tunisia and Turkey.

- The United States in not a party to this Convention. 
5. Representatives of the following United Nations bodies, Specialized Agencies and Intergovernmental and Non-Governmental Organizations also attended the Conference as observers:

\section{United Nations:}

- United Nations Environment Programme (UNEP)

- United Nations Information Centre (UNIC)

Specialized Agencies:

- Food and Agriculture Organization of the United Nations (FAO)

- World Health Organization (WHO)

- World Meteorological Organization (WMO)

- International Maritime Organization (IMO)

- International Atomic Energy Agency (IAEA) Marine Environment Laboratory in Monaco

- Intergovernmental Oceanographic Commission of UNESCO (IOC)

- World Bank

\section{Intergovernmental and Non-Governmental Organizations:}

- Amigos del Mediterraneo

- Arab Centre for the Studies of Arid Zones and Dry Lands (ACSAD)

- Arab Office for Youth and Environment (AOYE)

- Association pour la Protection de la Nature et de l'Environnement de Kairouan (APNEK)

- Centre for Environment and Development for the Arab Region and Europe (CEDARE)

- Convention on Wetlands (RAMSAR)

- Coordinating Unit for the Black Sea Environmental Programme

- Centre des Régions euroméditerrannéenes pour l'Environnement (CREE)

- Ecomediterrania

- Europe Conservation

- European Chemical Industry Council (CEFIC)

- European Environmental Bureau (EEB)

- European Investment Bank (EIB)

- Forum for the Lagoon of Venice

- Foundation for International Studies

- Friends of the Earth

- Greenpeace International

- Institut Méditerranéen de l'eau (IME-MEDWAN)

- Instituto Universitario de Ciencias Ambientales

- International Centre for Coastal and Ocean Policy Studies (ICCOPS)

- International Centre for Coastal Resources Research (CIIRC)

- Inter-Parliamentary Union (IPU)

- International Juridical Organization for Environment and Development (IJO)

- International Ocean Institute (IOI)

- La Facolta dell'Arte e della Scienza

- MAREVTVO Associazione Ambientalista

- Medcities Network

- Mediterranean Association to Save the Sea Turtles (MEDASSET)

- Mediterranean Information Office for Environment Culture and Sustainable Development (MIO-ECSDE)

- MEDWET

- Oil Industry International Exploration and Production Forum (E \& P Forum)

- Research and Conservation of Island and Coastal Ecosystems in the Mediterranean (MEDMARAVIS)

- Society for the Protection of Nature (DHDK)

- Station Biologique de la Tour de Valat

- Turkish Marine Environment Protection Association (TURMEPA)

- World Wide Fund for Nature International (WWF)

6. The Conference had been preceded by the Ninth Ordinary Meeting of the Contracting Parties, convened in Barcelona from 5 to 8 June 1995, which prepared the final texts of the following instruments for adoption by 
the Conference of Plenipotentiaries: the amendments to the Convention for the Protection of the Mediterranean Sea against Pollution; the amendments to the Protocol for the Prevention of Pollution of the Mediterranean Sea by Dumping from Ships and Aircraft; and the Barcelona Resolution on the Environment and Sustainable Development in the Mediterranean Basin. It also prepared for adoption and signature by the Conference of Plenipotentiaries the Protocol concerning Specially Protected Areas and Biological Diversity in the Mediterranean.

7. At the opening ceremony, the Conference heard a welcoming address by Mr. José Borell, Minister for Public Works, Transport and Environment of Spain.

8. The Conference also heard a message from Ms. Elizabeth Dowdeswell, Executive Director of the United Nations Environment Programme, which was conveyed by Mr. Lucien Chabason, Coordinator of the Mediterranean Action Plan. H.E. Mr Nourdine Benomar Alami (Morocco), President of the Bureau of the Contracting Parties, addressed the Meeting.

9. The Conference adopted the following agenda:

1. Opening of the Conference

2. Rules of procedure

3. Election of officers

4. Adoption of the Agenda and organization of work

5. Adoption of the amendments to the Convention for the Protection of the Mediterranean Sea against Pollution and its Protocols:

(a) adoption of the amendments to the Convention for the Protection of the Mediterranean Sea against Pollution (Barcelona Convention)

(b) adoption of the amendments to the Protocol for the Prevention of Pollution of the Mediterranean Sea by Dumping from Ships and Aircraft (Dumping Protocol)

(c) adoption of the Protocol concerning Specially Protected Areas and Biological Diversity in the Mediterranean

6. Adoption of the Barcelona Resolution on the Environment and Sustainable Development in the Mediterranean Basin

7. Report of the credentials committee

8. Adoption of the Final Act of the Conference

9. Signature of the Final Act of the Conference

10. Signature of the Protocol concerning Specially Protected Areas and Biological Diversity in the Mediterranean

11. Closure of the Conference.

10. The Conference applied the Rules of Procedure for the meeting and conferences of the Contracting Parties to the Convention for the Protection of the Mediterranean Sea against Pollution and its related Protocols (UNEP(OCA)/MED IG.43/6, Annex XI).

11. In conformity with Rule 20 of the Rules of Procedure, the Conference elected the following Bureau:

President:

H.E. Mr José Borrell

(Spain)

Vice-President:

H.E. Mr Nourdine Benomar Alami

(Morocco) 


$\begin{array}{lll}\text { Vice-President: } & \text { H.E. Ms Corinne Lepage } & \text { (France) } \\ \text { Vice-President: } & \text { H.E. Mr Mohamed Mehdi Mlika } & \text { (Tunisia) } \\ \text { Vice-President: } & \text { H.E. Mr Paolo Baratta } & \text { (Italy) } \\ \text { Rapporteur: } & \text { MrViktor Simoncic } & \text { (Croatia) }\end{array}$

12. Mr Lucien Chabason, Coordinator of the Coordinating Unit for the Mediterranean Action Plan, served as the Secretary-General of the Conference, and Mr Ljubomir Jeftic, Deputy Coordinator (MAP), served as Executive Secretary of the Conference.

13. The main documents which served as the basis for the deliberations of the Conference were:

UNEP(OCA)/MED IG.6/3

UNEP(OCA)/MED IG.6/4

UNEP(OCA)/MED IG.6/5

UNEP(OCA)/MED IG.6/6
Amendments to the Convention for the Protection of the Mediterranean Sea against Pollution (Barcelona Convention)

Amendments to the Protocol for the Prevention of Pollution of the Mediterranean Sea by Dumping from Ships and Aircraft (Dumping Protocol)

Protocol concerning Specially Protected Areas and Biological Diversity in the Mediterranean

Barcelona Resolution on the Environment and Sustainable Development in the Mediterranean Basin with two Annexes: Action Plan for the Protection of the Marine Environment and the Sustainable Development of the Coastal Areas in the Mediterranean - MAP Phase II (Annex I); and Priority Fields of Activities for the Environment and Development in the Mediterranean Basin -1996-2005 (Annex II)

14. In conformity with the Rules of Procedure, the Conference decided that the Bureau, comprising the President, the four Vice-Presidents and the Rapporteur, should act as the Credentials Committee.

15. The Credentials Committee met on 9 June 1995 to examine the credentials of representatives attending the Conference and found that all representatives were appropriately accredited.

16. The Conference approved the report of the Credentials Committee on 10 June 1995.

17. On the basis of its deliberations, the Conference adopted the following texts:

(a) Amendments to the Convention for the Protection of the Mediterranean Sea against Pollution (Barcelona Convention)

(b) Amendments to the Protocol for the Prevention of Pollution of the Mediterranean Sea by Dumping from Ships and Aircraft (Dumping Protocol)

(c) Protocol concerning Specially Protected Areas and Biological Diversity in the Mediterranean

(d) Barcelona Resolution on the Environment and Sustainable Development in the Mediterranean Basin (with its two Appendices on the Action Plan for the Protection of the Marine Environment and the Sustainable Development of the Coastal Areas in the Mediterranean - MAP Phase II (Appendix I) and the Priority Fields of Activities for the Environment and Development in the Mediterranean Basin 1996-2005 (Appendix II)).

18. The Conference decided that the Annexes to the Protocol concerning Specially Protected Areas and Biological Diversity in the Mediterranean would be adopted at a later meeting of Plenipotentiaries.

19. The text of the Protocol concerning Specially Protected Areas and Biological Diversity in the Mediterranean, will be open for signature in Barcelona on 10 June 1995, and will remain open for signature in Madrid until 10 June 1996, by any Coastal State of the Mediterranean Region invited to the Conference, by the European Community, and by any similar regional economic grouping of which at least one member is a Coastal State 
of the Mediterranean Sea Area and which exercises competence in fields covered by the Barcelona Convention and its Protocols.

20. The Conference also adopted the following resolutions, which are appended to this Final Act:

I. Adoption of the Barcelona Resolution on the Environment and Sustainable Development in the Mediterranean Basin (with its two Appendices on the Action Plan for the Protection of the Marine Environment and the Sustainable Development of the Coastal Areas in the Mediterranean (MAP Phase II) and the Priority Fields of Activities for the Environment and Development in the Mediterranean Basin - 1996-2005)

II. Adoption of the Amendments to the Convention for the Protection of the Mediterranean Sea against Pollution and its Protocol for the Prevention of Pollution of the Mediterranean Sea by Dumping from Ships and Aircraft

III. Signature, ratification, acceptance and approval of and accession to the Protocol concerning Specially Protected Areas and Biological Diversity in the Mediterranean

IV. Interim arrangements

V. Tribute to the Government of Spain.

IN WITNESS WHEREOF the representatives of the following Contracting Parties have signed this Final Act:

Mr Lirim Selfo

[Signature]

For the Republic of Albania

S.E. M. Muhamed Nezirovic

[Signature]

For the Republic of Bosnia and Herzegovina

H.E. Mr Costas Petrides

[Signature]

For the Republic of Cyprus

S.E. Mme Corinne Lepage

[Signature]

For the French Republic

H.E. Mr Yossi Sarid

[Signature]

for the State of Israel

H.E. Mr Mubarek Elshamekh

[Signature]

For the Socialist People's Libyan Arab Jamahiriya

S.E. M. Jean Pastorelli

[Signature]

For the Principality of Monaco

H.E. Mr Robert Krmelj

[Signature]

For the Republic of Slovenia
S.E. M. Abdelrahmane Meziane

Cherif

[Signature]

For the People's Democratic

Republic of Algeria

Mr Viktor Simoncic

[Signature]

For the Republic of Croatia

Mr Mohamed Abdel-Rahman Fawzi

[Signature]

For the Arab Republic of Egypt

H.E. Ms Elisavet Papazoi

[Signature]

For the Hellenic Republic

S.E. Mr Paolo Baratta

[Signature]

For the Italian Republic

H.E. Mr F. Zammit Dimech

[Signature]

For the Republic of Malta

S.E. M. Nourdine Benomar Alami

[Signature]

For the Kingdom of Morrocco

S.E. M. José Borrell Fontelles

[Signature]

For the Kingdom of Spain 
S.E. M. Mohamed Mehdi Mlika

[Signature]

For the Republic of Tunisia

S.E. Mme Corinne Lepage

[Signature]

For the European Community

S.E. M. José Borrell Fontelles

[Signature]

For the President of the Conference
H.E. M. Murat Sungur Bursa

[Signature]

For the Republic of Turkey

Mr Fernand Thurmes

[Signature]

For the European Community

M. Lucien Chabason

[Signature]

For the Secretary General of the

Conference

Mr Ljubomir Jeftic

[Signature]

For the Executive Secretary of the Conference

DONE AT BARCELONA this tenth day of June one thousand nine hundred and ninety five in a single copy in the Arabic, English, French and Spanish languages, the four texts being equally authoritative. 


\section{RESOLUTION I \\ Adoption of the Barcelona Resolution on the Environment and Sustainable Development in the Mediterranean Basin}

\section{RESOLUTION I \\ Adoption of the Barcelona Resolution on the Environment and Sustainable Development in the Mediterranean Basin}

The Conference,

Recalling the recommendations of the Ninth Ordinary Meeting of the Contracting Parties held in Barcelona from 5 to 8 June 1995 to approve a "Barcelona Resolution on the Environment and Sustainable Development in the Mediterranean Basin", the "Action Plan for the Protection of the Marine Environment and the Sustainable Development of the Coastal Areas of the Mediterranean (MAP-Phase II)" and the "Priority Fields of Activities for the Environment and Development in the Mediterranean Basin (1996-2005)",

Desirous of ensuring that the revision of the Mediterranean Action Plan (MAP) carried out as a result of these recommendations is effectively implemented,

Noting with satisfaction that the recommended revision of the Mediterranean Action Plan substantially meets the challenge of sustainable development in the Mediterranean context,

1. Adopts the Barcelona Resolution on the Environment and Sustainable Development in the Mediterranean Basin, the text of which is contained in the Annex to this Resolution together with its two Appendices, the Action Plan for the Protection of the Marine Environment and the Sustainable Development of the Coastal Areas of the Mediterranean (MAP Phase II) (Appendix I) and the Priority Fields of Activities for the Environment and Development in the Mediterranean Basin (1996-2005) (Appendix II);

2. Invites the Contracting Parties to implement the Barcelona Resolution by the most effective means in view of the special importance of orienting the Mediterranean Action Plan towards the objective of sustainable development.

\section{ANNEX \\ BARCELONA RESOLUTION \\ ON THE ENVIRONMENT AND SUSTAINABLE DEVELOPMENT IN THE MEDITERRANEAN BASIN}

The Ministers in charge of the Environment in the Mediterranean countries representing the Governments and the member of the European Commission in charge of the Environment, having met in Barcelona, Spain, on 10 June 1995, within the framework of the Mediterranean Action Plan:

Recalling that the Mediterranean Action Plan was approved at Barcelona in 1975 by the Governments of the Mediterranean States and the European Community to monitor and protect the Mediterranean marine environment and ensure the integrated planning of the development and management of the resources of the basin on the basis of multilateral cooperation under the auspices of the United Nations Environment Programme,

Recalling the adoption of the Barcelona Convention for the Protection of the Mediterranean Sea against Pollution and its Protocols in 1976 and subsequent years,

Recognizing the important contribution of the Mediterranean Action Plan, MED POL, and Regional Activity Centres, as well as the cooperating international organizations, to protection of the marine environment and 
promotion and establishment of an environmental legal system and environmental institutional structure at the regional and national levels in the Mediterranean basin,

Taking into account the results of the successive meetings in Genoa (1985), Nicosia (1990), Cairo (1992), Casablanca (1993) and recognizing the results of the Tunis Ministerial Conference (1994), the importance of its declaration and resolutions for the promotion of sustainable development in the Mediterranean taking into account the Rio Declaration and Agenda 21,

Conscious of the differences in socio-economic development still existing among the Mediterranean coastal States,

Concerned by the continued pressures on the marine and coastal areas and their ecosystems, due to the process of urbanization, population growth and economic development which has resulted in degradation of human and natural resources in the Mediterranean, as clearly indicated by the Blue Plan scenarios,

Recognizing the progress achieved since the adoption of the Genoa Declaration on the Second Mediterranean Decade (1985), while noting that the state of the environmental quality of the Mediterranean Sea requires greatly intensified action,

Expressing their satisfaction at being able to adopt the amendments to the Barcelona Convention, which substantially extend its field of application and provide principles with which to meet the challenge of sustainable development,

Stressing the importance of the adoption of the amendments to the Protocol for the Prevention of Pollution of the Mediterranean Sea by Dumping from Ships and Aircraft in accordance with relevant international conventions which will ensure improved protection of the Mediterranean Sea,

Stressing also the importance of the adoption of the new Protocol concerning Specially Protected Areas and Biological Diversity in the Mediterranean with a view to ensuring the conservation and better management of biological diversity, especially endangered species and valuable natural sites,

Recalling the importance of the resolution adopted at the Tunis Conference on the use of land use tools with a view to ensuring the conservation of nature and natural sites of the Mediterranean coastal areas,

Reconfirming their commitment to the protection of the Mediterranean environment, individually and collectively, through understanding, dialogue, cooperation and solidarity among the peoples of the region,

Confirming their commitment to promote sustainable development when formulating and implementing national and regional environment and development policies, bearing in mind the Rio and Tunis Declarations,

Aware that the European Union has decided to convene a Euro-Mediterranean Ministerial Conference to be held in Barcelona on 27 and 28 November 1995 with a view to strengthening Euro-Mediterranean partnership between the countries of the European Union and other Mediterranean countries,

1. Adopt the Mediterranean Action Plan Phase II, as contained in Annex I to this Resolution, which should aim to achieve the following objectives:

- integrate the environment in economic, social, cultural and other development, as well as land use policies;

- ensure sustainable management of natural marine and coastal resources, bearing in mind Agenda MED 21 ;

- conserve nature and protect species as well as sites and landscapes of ecological or cultural value;

- prevent pollution of the Mediterranean Sea and of its coastal areas;

- establish national enforcement and control mechanisms which would follow up the implementation of Convention, its related protocols and the adopted protection measures; 
- strengthen cooperation with relevant international governmental organizations, and the United Nations specialized agencies at all stages of development and implementation of the specific activities;

- enhance the support and involvement of international, regional and national non-governmental organizations (NGOs) and the public;

2. Commit themselves to the full implementation of the Mediterranean Action Plan Phase II, the Barcelona Convention and its Protocols, and to this end adopt the Priority Fields of Activities for the Environment and Development in the Mediterranean Basin (1996-2005) contained in Annex II to this Resolution;

3. Decide that within the framework of the Mediterranean Action Plan a Mediterranean Commission on Sustainable Development (MCSD) should be set up, and start work during the first half of 1996;

4. Entrust the Coordinating Unit with the task of concluding the process of preparing the Protocol on the Prevention of Pollution of the Mediterranean resulting from the Transboundary Movements of Hazardous Wastes and their Disposal and the amendments to the Land-Based Sources Protocol, and request that the Executive Director of UNEP convene a Conference of Plenipotentiaries to adopt these protocols by March 1996;

5. Commit themselves to undertake all necessary measures to incorporate and integrate the conservation of biological diversity as an objective in economic development, land, and natural resource planning policies, and to reinforce as a matter of urgency all field action pursuant to the conservation of threatened species, habitats, and sites of ecological value;

6. Agree to the reduction by the year 2005 of discharges and emissions which could reach the marine environment, of substances which are toxic, persistent and liable to bioaccumulate, in particular the organohalogens, to levels that are not harmful to man or nature, with a view to their gradual elimination; to this end, to implement substantial reductions of such discharges and emissions, and if necessary, to supplement the reduction measures with programmes aiming at banning the use of such substances; and instruct the Contracting Parties to review regularly the relevant timetables;

With the aim of eliminating by the year 2005 the greatest possible number of these substances, in particular the organohalogens, and in order to facilitate and speed up the definition of methods, programmes and timetables, by categories of substance and by industrial branches, and of the best available techniques, they entrust UNEP with organizing consultation with the Contracting Parties, scientific experts, industrialists and NGOs;

A first meeting will be held as soon as possible and by 1 July 1996 at the latest;

7. Commit themselves to promote actively the transfer of clean technologies, in particular to developing countries, to encourage the establishment of clean production centres where required, to research, promote, collect and disseminate information on clean production processes;

8. Commit themselves to demonstrating solidarity with populations in the Mediterranean basin suffering from the consequences of aggression and terrorism, by developing and implementing programmes to rehabilitate areas, environments and resources affected by destructive actions;

9. Commit themselves to cooperate and strengthen solidarity with Mediterranean populations in case of natural disasters and major technical accidents by implementing programmes to rehabilitate affected areas and the environment;

10. Entrust the Coordinating Unit with the task of mobilizing additional funds and resources to carry out the activities envisaged by the Mediterranean Action Plan Phase II and the Priority Field of Activities for the Environment and Development in the Mediterranean Basin (1996-2005);

11. Request evaluation of the results of implementation of the envisaged activities in view of the objectives defined within the framework of the Mediterranean Action Plan Phase II and tasks accorded by the Priority Fields of Activities for the Environment and Development in the Mediterranean Basin (1996-2005) which is subject to a mechanism for monitoring its implementation; 
12. Agree to transmit to the Euro-Mediterranean Conference the documents adopted at the Conference of Plenipotentiaries on the Barcelona Convention held on 9 and 10 June 1995 as a contribution to the efforts of the Conference inter alia to ensure the protection of the environment and the sustainable development of the region and to strengthen regional cooperation within the framework of MAP;

13. Request the Mediterranean Commission on Sustainable Development, in which NGOs will be duly represented, to examine the feasibility of creating a special fund for the promotion of projects related to nature conservation and integrated coastal management, complementary to the Mediterranean Trust Fund and aimed at mobilizing and ensuring additional, necessary financial resources;

14. Invite all social and economic actors concerned, especially local communities, the scientific and educative community, companies and non-governmental organizations to associate themselves with the implementation of the Mediterranean Action Plan Phase II;

15. Invite international organizations and other financial and development programmes to associate themselves with the implementation of the new phase of the Mediterranean Action Plan, and to coordinate and harmonize their programmes relevant to the Mediterranean region with Mediterranean Action Plan;

16. Decide to meet again at the Tenth Ordinary Meeting of the Contracting Parties in Tunisia in 1997.

\section{APPENDIX I \\ ACTION PLAN FOR THE PROTECTION OF THE MARINE ENVIRONMENT AND THE SUSTAINABLE DEVELOPMENT OF THE COASTAL AREAS OF THE MEDITERRANEAN (MAP PHASE II)}

Introduction

In 1975, Mediterranean countries and the EEC adopted the Mediterranean Action Plan (MAP) and in 1976 the Convention for the Protection of the Mediterranean Sea against Pollution (Barcelona Convention). The main objectives of MAP were to assist the Mediterranean Governments to assess and control marine pollution, to formulate their national environment policies, to improve the ability of governments to identify better options for alternative patterns of development and to make better rational choices for allocation of resources.

Although the initial focus of the MAP was on marine pollution control, experience soon confirmed that socio-economic trends, combined with poor management and planning of development, are the root of most environmental problems, and that meaningful and lasting environmental protection is inseparably linked to social and economic development. Therefore, the focus of MAP gradually shifted from a sectoral approach to pollution control to integrated coastal zone planning and management as the key tool through which solutions are being sought.

Although it is difficult to assess progress achieved, there is direct and indirect evidence that a large number of concrete actions were taken by many countries in conformity with the requirements and provisions of MAP, thus influencing the environmental policies and practices of the Mediterranean countries. MAP has been a significant instrument for change and progress concerning environmental matters in the Mediterranean. Among achievements of particular importance are the creation of awareness concerning the importance of a healthy environment for the present and future of the Mediterranean and its people; a marked change of attitude towards protection of the environment, the policy making level and creating a sense of solidarity and the need to act collectively for the better future of the Mediterranean.

Major shortcomings in the protection of the Mediterranean marine environment and its coastal region are the inappropriate management of the coastal zone due to the lack of adequate coastal zone planning and management; inadequate national legislation and its effective enforcement; weak institutional structures and inadequate human resources allocated for these types of activities; and lack of mobilization of adequate financial resources and clear political commitment to solve the existing problems. 
MAP Phase II was designed taking into account the achievements and shortcomings of MAP's first twenty years of existence, as well as the results of recent developments such as the United Nations Conference on Environment and Development (Rio de Janeiro, 1992), the Eighth Meeting of the Contracting Parties to the Barcelona Convention (Antalya, 1993), and the Conference "Med 21" on Sustainable Development in the Mediterranean (Tunis, 1994).

\section{Objectives}

The main objectives are:

- to ensure sustainable management of natural marine and land resources and to integrate the environment in social and economic development, and land-use policies;

- to protect the marine environment and coastal zones through prevention of pollution, and by reduction and, as far as possible, elimination of pollutant inputs, whether chronic or accidental;

- to protect nature, and protect and enhance sites and landscapes of ecological or cultural value;

- to strengthen solidarity among Mediterranean coastal States in managing their common heritage and resources for the benefit of present and future generations; and

- to contribute to improvement of the quality of life.

\section{Implementation}

The Mediterranean coastal States bear full responsibility for conducting their policies for an improved environment and sustainable development. In this context, they are responsible for the implementation of the Barcelona Convention, its Protocols and MAP.

In carrying out their tasks, the Contracting Parties receive the support of the Secretariat of the Barcelona Convention entrusted to UNEP and its Coordinating Unit, and, under the Unit's supervision, of MAP's Regional Activity Centres (RACs).

The specific tasks entrusted to the Secretariat and the RACs in order to implement the activities of MAP, as well as the corresponding budgets, are decided upon by the meetings of the Contracting Parties to the Barcelona Convention.

The MAP Coordinating Unit establishes and strengthens relations with other regional seas programmes, the secretariats of the international conventions relevant to the region, the United Nations Commission on Sustainable Development and the international financial institutions related to environment and sustainable development in the Mediterranean.

The Contracting Parties to the Barcelona Convention will regularly involve the UN specialized agencies concerned in the formulation and implementation of the MAP Phase II programme of activities.

The Contracting Parties will involve local, provincial and regional authorities, as appropriate, in the formulation and implementation of the MAP Phase II programme of activities.

The Contracting Parties will also associate in the MAP Phase II activities, non-governmental organizations involved in the protection of the environment and the promotion of sustainable development, as well as organizations representing economic activities.

In implementing sustainable development, priority will be given to strengthening institutional capacity and policy coordination at national as well as regional, provincial and local levels, as appropriate. In this context, particular attention will be given to the implementation of existing legal instruments such as the Barcelona Convention and its Protocols, to the introduction of economic instruments for integrated resource management, and to rigorous planning of coastal zones and management of natural resources. 


\section{SUSTAINABLE DEVELOPMENT IN THE MEDITERRANEAN}

\section{INTEGRATING ENVIRONMENT AND DEVELOPMENT}

Management and conservation of natural resources, and orientation of technological and institutional change in such a manner as to ensure the attainment and continued satisfaction of human needs for present and future generations, are vital for the Mediterranean basin. The complex interaction between environmental components (water, forest, soil) and socio-economic sectors (agriculture, industry, energy, tourism, transport) requires integration of environmental policies into development policies. At regional level, corresponding activities will be developed [within the framework of the Mediterranean Commission on Sustainable Development to be established and implemented within MAP] in collaboration with the relevant international organizations, and with the support of the Secretariat together with relevant RACs, when appropriate.

\subsection{Economic activities and the environment}

In the Mediterranean basin, with its limited and fragile natural resources, recent socioeconomic developments have given rise to major changes that put its heritage in peril. Population trends, which indicate that a population of 410 million in 1994 may rise to 550 million in 2025, together with modern means of production and consumption are playing a major role in these changes.

Intensification of agriculture is having a major impact on water resources and soil. Since the $1970 \mathrm{~s}$, industrialization has proceeded apace, although heavy and polluting industries show signs of decline. The technologies in use are often obsolete and generate considerable pollution. Industry, which consumes vast amounts of natural resources and energy, competes for space with urban development and major transport infrastructures, particularly on the coast. Tourism, which brings in revenue, by exploiting the attractions of the natural and historical heritage, also competes for the coastline, putting increasing areas of it under concrete. A hundred million tourists from all parts of the world visit the coastal area of the Mediterranean today, the expected figure for the year 2025 being between 170 and 340 million, while domestic tourism is also expected to undergo major growth. Great pressure is exerted on water resources, while overcrowding of natural and historic sites and pressure on land use leads to their destruction, thus reducing capital income from tourism, which is essential for a number of countries.

For these economic activities, the major objectives in relation to sustainable development are:

\subsubsection{Agriculture}

Agricultural production is expected to expand in the Mediterranean region, particularly in the countries of the South and East. Such expansion, for example through the use of irrigation, will have an increasing impact on soil and water quality. Furthermore, arable land is shrinking under pressure of construction, fertility loss, salination and erosion.

The spread of desertification in its various forms poses a threat to social and agricultural development, both in coastal regions and in the hinterland.

In order to contribute to sustainable development, activities should, at their appropriate levels, focus on:

- rational methods for making use of soil and water resources by encouraging farming practices suited to the physical and ecological conditions prevailing in the regions concerned;

- increasing agricultural productivity and production by means of environment-friendly techniques;

- development and use of irrigation techniques using less water and appropriate systems of drainage;

- identification and use of appropriate techniques not only in farming but also to improve local genetic resources; and

- controlling the use of chemicals that pollute soil and water and increasing use of natural fertilizers. 


\subsubsection{Industry}

Industrial development exacerbates a number of existing major problems relating to air and water pollution and degradation of quality of life.

In order to respond to national needs and provide access to Mediterranean and international markets so that sustainable development may be achieved, action should be taken:

- to encourage and facilitate the use of appropriate industrial procedures and clean technologies;

- to facilitate the transfer, adaptation and control of technology among Mediterranean countries;

- to consolidate and accelerate the introduction of programmes for the control and reduction of industrial pollution; and

- to strengthen and expand programmes for the reduction and management of industrial waste.

\subsubsection{Energy}

The growth in energy consumption in the Mediterranean, principally through use of fossil fuels, is adding to the pollution and environmental damage existing in the Mediterranean. There is thus a need to improve management of energy and to introduce policies compatible with sustainable development.

In that context, the objectives to be achieved at Mediterranean, national and local levels and in cooperation with interested international organizations will be:

- to encourage and facilitate the use of new and renewable sources of energy in domestic, industrial, public and private use, including pilot projects;

- to develop techniques for controlling and saving energy; and

- to ensure that any new power stations to be built on the Mediterranean coast are environmentally friendly and to modernize, as appropriate, existing power plants.

\subsubsection{Tourism}

Tourism is one of the major factors affecting the environment and development in the Mediterranean basin. It plays an important role in improving economic conditions in many Mediterranean countries but, on the other hand, has a severe impact on land and marine resources, soil and coastal land, sea, historical and natural sites and landscapes, society and local population.

The main objectives of activities related to tourism, at Mediterranean, national and local levels, will be:

- to assess, monitor and evaluate tourism activities and their impact on environment through, inter alia, appropriate and pertinent indicators;

- to encourage regional and international cooperation that promotes environment friendly tourism compatible with sustainable development;

- to monitor natural, cultural and human tourist resources and undertake regular assessment of environmental impact and carrying capacity; and

- to develop information and training programmes for the actors concerned including raising the awareness of tourists so that they choose tourism that respects the Mediterranean environment.

\subsubsection{Transport}

Evolution of air and land transport associated with expanding economic activity will exert growing pressure on the coastal zone. In particular, the number of cars is expected to treble in the next thirty years. It is essential that 
special attention be given to this clear trend, which will have a major impact on environmental quality in coastal and urban zones.

The main objectives of the programme are:

- to assess and monitor means of transport and their density in coastal zones by using appropriate indicators;

- to identify and encourage use of alternative means of transport less detrimental to the environment; and

- to disseminate information on transport policies and technologies contributing to sustainable development, including those related to public transport.

\subsection{Urban management and the environment}

The Mediterranean urban population, 40 per cent of which is concentrated on the coast, is expected to double by the year 2025 , which will substantially increase settlement of the coast.

The type of urban development resulting from this concentration is a cause of environmental concern for two reasons:

- great pressure is exerted on natural resources, landscapes and natural areas, which are being taken over or destroyed to meet the needs of urban development; and

- the environment created in such built-up areas is unsatisfactory because of the scale of construction and its impact on transport, energy consumption, waste production, loss of space and natural landscapes and increasing demands for infrastructure.

The consequences of these trends are a cause for concern with regard to the sustainability of development:

- deterioration of the urban environment and quality of life have a negative impact on social life and public health; and

- from the economic point of view, built-up areas with a deteriorating environment are likely to become less attractive, particularly to the services sector.

Strategies for sustainable urban management should be formulated by the competent authorities in order to:

- create an institutional framework which will provide for management of built-up areas at the appropriate administrative level;

- encourage the introduction of urban planning taking environmental issues into account through analysis of the urban environment;

- encourage active urban policies directed towards energy saving, non-polluting forms of transport, waste management, sustainable use of water and the creation of town amenities;

- introduce the corresponding financial instruments;

- develop institutional and professional capacities; and

- involve all the actors concerned.

At regional level, cooperation activities will be carried out, encouraging coordinated decentralized cooperation in order to:

- elaborate and disseminate appropriate methodologies;

- promote the exchange of experiences and practice; 
- ensure the training of the actors concerned; and

- contribute to the mobilization of international financial resources for the formulation and implementation of strategies for the urban environment.

\subsection{Sustainable management of natural resources}

At regional level, specific activities in this section will be developed and implemented by the relevant international organizations and programmes, where appropriate, with the support of the Secretariat and RACs.

\subsubsection{Water resources}

Quality and availability of fresh water resources are vital in the Mediterranean not only for human consumption but also for agriculture, industry, tourism and other components of the economy. The interaction of these components should be tackled through integrated plans for water resources management.

The main objectives of this programme are the management and sustainable use of water resources, and are to be achieved through:

- encouragement of the use of tools for management of water demand;

- assessment and monitoring of the qualitative and quantitative status of water resources in each country, inter alia through pertinent indicators;

- preparation in each country of water resources master plans on a basin basis and expansion of existing plans in line with generally accepted principles of sustainable development, making use of an integrated approach, especially in coastal areas and islands;

- preparation or improvement of national legislation directed to the development and implementation of integrated methods for the management and use of water resources; and

- preparation of guidelines, training programmes and means for the exchange of experience on the integrated development, management, use and re-use of water resources.

\subsubsection{Soil}

Soil erosion and desertification are one of the most serious problems affecting the region. Agriculture and forestry are particularly affected leading to a decline in productivity which, in turn, helps to worsen social problems in the region.

The main objective is land conservation and reclamation.

Activities aim at:

- assessment and monitoring of the situation relating to soil degradation by the use of appropriate and pertinent indicators;

- development of effective policies, strategies and programmes which will include mapping, monitoring and protection measures to prevent and combat soil loss and desertification; and

- implementation, at a national level, of the above measures, as well as relevant decisions taken at various international forums such as FAO, UNEP and IUCN that lay special emphasis on the Convention to Combat Desertification, and more specifically its Mediterranean component.

\subsubsection{Living marine resources}

As several fish stocks are under heavy pressure, it is essential to take immediate action at several levels, (fishing community, fisheries organization, government) starting by reinforcing those already existing in order to halt present trends towards the degradation of resources and habitats. 
The objective is the sustainable management of living marine resources at national and regional levels.

Main activities aim at:

- improving the available information base on the status of living marine resources and encouraging research on the effects of environmental degradation and the impact of fishing activity; such information is necessary for the development of management policies for such resources;

- developing common resource management policies inspired by the precautionary principle;

- establishing through the General Fisheries Council for the Mediterranean (GFCM) the legal framework for a cooperative approach to the protection and conservation of living marine resources outside territorial waters;

- ensuring implementation of the Code of Conduct for Responsible Fishing developed by FAO, the Agreement to Promote Compliance with International Conservation and Management Measures by Fishing Vessels on the High Seas and the decisions taken within the framework of the United Nations Conference on Straddling Fish Stocks and Highly Migratory Fish Stocks; and

- promoting environmentally friendly aquaculture.

\subsubsection{Forest and plant coverage}

Degradation of forest and plant coverage is causing increasing concern in the Mediterranean region. Overuse through grazing and the use of wood for fuel in addition to fires and urbanization, are the main causes of deforestation. To tackle these problems, a Mediterranean Forest Action Programme was prepared by FAO, with which MAP will liaise and coordinate its activities. This programme uses an integrated and multidisciplinary approach which is essential to its general conceptual framework as well as to its application within each country.

The activities of this programme aim, in particular, at:

- making a rapid assessment of the state of the forests in each country, and identifying priorities;

- drawing up Forest Directory Plans for each country designed for protection, sustainable management and the multi-purpose use of forests; and

- enhancing cooperation and exchange of information between countries.

\subsection{Integrated coastal area management}

Management strategies for the Mediterranean coastal regions should ensure that limited and fragile resources are used in a sustainable manner by means of planning and regulations to conserve their ecological value and to promote activities to improve the quality of life of the coastal populations.

Integrated coastal area management requires understanding of the links existing between coastal resources, their use and the mutual impact of development and environment.

The objectives of protection and integrated coastal area management are as follows:

- preservation of the biological diversity of coastal ecosystems;

- coastal planning to resolve the competition between urbanization, industrialization, tourism, transport, agriculture and aquaculture, and the preservation of ecosystems for future generations;

- control of human pressure on and use of coastal resources;

- achievement of environmental and economic objectives at an acceptable cost to society; 
- prevention and elimination, as far as possible, of pollution from all urban, industrial, tourist, agricultural and aquaculture sources, solid and liquid waste, and natural and technological hazards;

- participation by the general public and its various associations with a view to stimulating a sense of civic responsibility in the face of these new challenges; and

- development of the institutional capacity and human resources necessary to respond to these many interlinked and often conflicting objectives.

Integrated coastal area management should gradually become the standard approach for tackling the problems affecting Mediterranean coastal areas. To this end, at national and, where relevant, at sub-national level, relevant legislation should be enacted and institutional capacities created or strengthened. Appropriate tools, such as remote sensing, geographic information systems, systemic and prospective analysis, environmental impact assessment and economic instruments, should also be developed and implemented.

This legislation should encourage protection of a large percentage of the coastal strip, prevent continued urbanization and industrialization of the coastline, establish rules for identification of natural areas to be protected, and ensure compatible use of the coast.

At regional level, cooperation activities will be organized in order to:

- elaborate jointly the most appropriate planning methodologies;

- provide training, exchange of information and transfer of knowledge; and

- promote and facilitate cooperation with international institutions likely to support coastal area management policies.

\subsection{Elements for a Mediterranean strategy}

The concerns of sustainable development, highlighted by UNCED and resulting from the complex links between socio-economic development and the environment, must be fully clarified to allow a Mediterranean strategy, as well as national strategies on sustainable development to be defined. The effort to integrate sustainable management of natural resources with stable economic development must be made a priority throughout the Mediterranean. To this end, the main activities at the regional level will be:

- promoting and developing a function for the observation and assessment of the interaction between environment and development in the Mediterranean basin:

- based on existing relevant activities at national and regional level;

- contributing to the provision of technical support for the development of similar national functions when requested by governments;

- receiving, processing and analyzing relevant information on Mediterranean environment and development;

- analyzing developments in the interaction between environment and development in order to assist the decision-making process; and

- elaborating sustainable development indicators applicable to the Mediterranean along the lines developed by UNCED and other international and regional institutions.

- exchanging experiences on sustainable economic development; and

- formulating of practical recommendations to facilitate integration of natural resource management and economic development when preparing national development policies. 
At the national level, the main activities will be:

- establishment of structures - mainly interministerial - such as Commissions on Sustainable Development, aimed at bringing together all institutions engaged in formulating sustainable development policies;

- formulation of national strategies for sustainable development, including in particular creating the relevant financial instruments; and

- formulation of sectoral policies, incorporating environmental issues, in priority areas such as energy, industry, transport, agriculture and tourism.

\subsection{National and local capacity building}

The ability of the Mediterranean countries to embark on the path of sustainable development will largely be determined by their capacity to evaluate problems, determine the level of priority of urgent needs, find response strategies and provide the means to carry out such policies.

- At the national institutional level, policies for sustainsble development call for an organizational framework that will ensure liaison with all relevant public administrations and agencies within the context of interministerial coordination.

- At the local level, capacities for designing and implementing sustainable development strategies will also be developed. fields:

Capacity building will aim at developing the means available, and improving levels of training, in the following

- science and technology related to the interaction between development and the environment;

- management of public services associated with the environment; and

- management of enterprises whose operation has an impact on the environment.

\section{CONSERVATION OF NATURE, LANDSCAPE AND SITES}

The Mediterranean, with its landscapes and its varied and unique natural heritage, with its age-old past made evident by the innumerable historic sites, represents for its inhabitants and for the millions of tourists who visit it every year a common heritage which deserves to be protected and conserved for present and future generations. However, the negative impacts of uncontrolled urban, industrial and tourist development and the lack of appropriate environmental strategies are now becoming very evident. The massive occupation of the coastline and the discharge and dumping of large amounts of solid and liquid wastes into the sea, together with the over-exploitation of natural resources, constitute a threat to the preservation of the ecological balance and the survival of species, as well as to the conservation of several sites of great natural and historic value and of the exceptional Mediterranean landscapes.

In the Mediterranean, examples of coastal management which have the protection of nature, the landscape and historic sites as their objective are still very rare or geographically limited. A shortage of environmentally sound management strategies, under the pressure of rapid socio-economic development, has in fact for too long favoured activities in which the short-term economic advantages were ensured but which had, in the long term, negative effects on the conservation of the Mediterranean coasts. It is evident that this negative trend could be effectively reversed if its consequences for the Mediterranean environment and its biological diversity were made widely known and if the planning and development strategies of the various subregions of the Mediterranean included the rational management of their natural and cultural heritage.

This component of MAP Phase II takes fully into account the Barcelona Convention and the Protocol concerning Specially Protected Areas and Biological Diversity in the Mediterranean and aims at proposing to the Contracting Parties a programme of activities that will assist them to protect and sustainably manage the natural and cultural Mediterranean heritage, thus contributing to the sustainable development of the region. 
The proposed activities have been developed in line with the results of UNCED, in particular Agenda 21, the Convention on Biological Diversity and the action programme MED 21.

The activities will be implemented by the Contracting Parties in coordination with, and with the assistance of, the MAP Secretariat and the competent Regional Activity Centres. They will be implemented, as appropriate, in cooperation and coordination with the relevant programmes of the United Nations and the Secretariats of the Conventions, the European Union, especially its NATURA 2000 Network, and other international organizations concerned, as well as with NGOs and networks particularly active in specific fields, in order to create an integrated and efficient synergy in the region and avoid duplication of work.

Five types of activities will be carried out within the framework of the implementation of the Protocol:

- collection of data and periodic assessment of the situation;

- legal measures;

- planning and management;

- public awareness and participation; and

- exchange of experience and strengthening of natural capabilities.

\subsection{Collection of data and periodic assessment of the situation}

If the level of knowledge on the extent and status of conservation of the historic and cultural heritage of the Mediterranean region can be considered satisfactory, the same cannot be said with regard to the natural heritage, knowledge of which is still very fragmentary. It is therefore important to carry out research and studies to fill the existing gaps for the purpose of defining appropriate action.

The main objective of the present programme is therefore the overall assessment of the status and, where possible, the evolution of biological diversity in the Mediterranean so as to protect it better. It will include:

- at the regional level, the preparation of inventories of natural sites and elements of biological diversity of common Mediterranean interest, and of lists of the threatened and/or endangered species of the region and natural sites; and

- at the national level, the preparation of inventories of species and sites of special natural value as well as of areas with rare or fragile ecosystems that are reserves of biological diversity and are important for threatened and/or endangered species.

Such inventories and lists will be prepared according to common criteria jointly established by the Contracting Parties, will be kept regularly updated and used as the basis for conservation and planning programmes, using as appropriate the best available techniques.

\section{$2.2 \quad$ Legal measures}

Legislation on the protection of the natural and cultural heritage is at present insufficient in many Mediterranean countries and it is therefore necessary to adopt modern and adequate legislation in order to support the implementation of conservation policies.

It is also necessary for the Parties take the measures required to ensure that the legal measures adopted are actually implemented.

The following activities will be implemented:

- the institution by Contracting Parties of appropriate legal provisions by adopting instruments to allow for legal protection of sites of special interest because of their natural and/or cultural value. The methods and inventories developed in the European Union and in international organizations could serve as a basis in 
this respect. Special attention will be given in the Mediterranean to the habitats of threatened species, to insular environments and to archaeological remains, including underwater ports, structures and wrecks;

- the granting of legal protection status to the threatened and/or endangered species identified in the above-mentioned lists. In this regard, the monk seal and the different species of Mediterranean marine turtles and cetaceans deserve special attention;

- the creation of national mechanisms to monitor implementation of the protection measures instituted; and

- the establishment of a list of "Specially Protected Areas of Mediterranean Importance" (SPAMI) and a list of endangered species.

\subsection{Planning and management}

In addition to the legal protection of the sites, it is essential for such sites to be the object of a management system which, while ensuring the preservation of their natural and/or cultural values, would promote the social aspects, in particular those related to education, awareness, research and recreation.

In the planning process for the protected areas, the role that they could play in the development of economically depressed areas, for example, through the promotion of environment-friendly tourism and tourism in cultural sites, should also be taken into account.

It will also be necessary to identify the processes and factors which have or are likely to have adverse effects on the conservation of biological diversity and at the same time to carry out monitoring and periodic assessment of the conservation status of the sites and the species possessing a special status.

Forms of active management are equally necessary for the conservation of most species.

The following activities will therefore be implemented:

- the formulation and adoption of national strategies to ensure the conservation of biological diversity and the cultural heritage and their integration in development and planning policies;

- the formulation and adoption, at the regional and national levels, of specific action plans for the conservation and management of sites, habitats, ecosystems and threatened and/or endangered species and also the implementation of the action plans already adopted;

- the effective management of protected sites, in particular through the formulation, adoption and implementation of specific management plans;

- the establishment of land-policy tools allowing lasting protection of the areas to be protected, including those outside protected areas;

- the encouragement of active public participation in the conservation and management of protected species and sites;

- the establishment of a Mediterranean diploma, awarded in the course of Ordinary Meetings of the Contracting Parties, for a "Specially Protected Area of Mediterranean Importance" (SPAMI) distinguished by the implementation of specific and concrete activities in the field of management and conservation of the Mediterranean natural heritage; and

- the preparation of specific regional activities or projects for the conservation of nature and biological diversity with a view to mobilizing the necessary financial resources outside the Mediterranean Trust Fund.

\subsection{Public awareness and participation}

Without public support, the application of nature protection and conservation measures cannot achieve results commensurate with the challenges and threats looming over the natural heritage of the Mediterranean. 
By informing and inculcating awareness in particular target groups and in the general public, it has been possible in several countries not only to lessen opposition to certain conservation programmes but even, in some cases, to achieve active public participation.

The main objectives of this component are to consolidate awareness and information at both local and national, as well as regional, levels in addition to ensuring the rapid circulation of scientific research results. The following activities will be undertaken:

- development of education and information programmes to arouse public awareness, together with initiatives aimed at special target groups (young people, fishermen, people connected with protected areas);

- promotion of speedy dissemination of available data by various means, including the media, concerning the state of habitats and populations and the threats affecting them, especially for protected species, and on the management and conservation activities and programmes conducted; and

- establishment at national and/or local levels, and periodic assessment of information and awareness programmes in line with the conservation measures carried out or envisaged.

\subsection{Exchange of experience and strengthening of national capabilities}

The protection and management of the natural and cultural heritage need specific competences and adequate financial and technical resources. In the Mediterranean region, there are at present wide differences in the availability of such competences and technologies. For the developing countries of the Mediterranean the improvement of national capabilities in these fields represents an important aspect of strengthening inter-Mediterranean cooperation for the protection of the natural and cultural heritage, and for better participation in regional programmes.

The main objective of the present programme is the improvement of the institutional capabilities of the Mediterranean countries in the field of conservation and management of natural resources and of the cultural heritage.

This objective will be reached through:

- technical cooperation and transfer of knowledge among the Contracting Parties and other actors;

- the establishment of networks to improve the exchange of experience among Mediterranean experts, especially in the field of protected areas and sites;

- the preparation of training programmes in scientific, technical and managerial fields for personnel involved in the formulation and implementation of conservation measures and management; and

- assistance to countries in the formulation of projects eligible to be financed by international financial denors.

\section{ASSESSMENT, PREVENTION AND ELIMINATION OF MARINE POLLUTION}

Since the adoption of the Mediterranean Action Plan in 1975, individual Mediterranean countries and the Mediterranean region as a whole have made considerable progress in the protection of the Mediterranean marine environment against chronic or accidental pollution. Despite such progress, the coastal region of the Mediterranean is under considerable stress. The solution to the problem requires coordinated actions of assessment, prevention and elimination of pollution, bearing in mind the inseparable character of the relationship between economic development and environment.

In line with the concepts and recommendations of UNCED and in particular Agenda 21, this component of MAP Phase II provides the basis for actions related to assessment, prevention and elimination of marine pollution from land-based and sea-based activities, in the perspective of sustainable development.

The main objective of this component is the elimination of pollution of the Mediterranean Sea from land-based and sea-based activities. 


\subsection{Assessment of pollution-related problems}

Assessment of pollution-related problems allows present uncertainties when facing management decisions to be reduced and the links between inputs, concentrations and effects of pollutants clarified. Such an assessment started in the Mediterranean several decades ago in MAP, through its MED POL programme.

Through this programme, which has been implemented jointly with relevant United Nations agencies, a Mediterranean network of over 150 institutions participating in research and monitoring of marine pollution has been established; many of these institutions received assistance in capacity-building.

The results of these activities have been used as a basis for the preparation of assessment documents presented to the Contracting Parties, legal instruments and common measures for pollution control. Even though many data were accumulated on the main pollutants, their sources, and basic pathways and their fate in the environment, gaps in knowledge still exist, among them are a lack of quantitative data on pollution sources, inadequate geographical coverage in the South, poor information on the environmental fate of pollutants and missing links between levels and the effects on biological communities.

The objective of this component is assessment of the following:

- levels and trends in the load of pollutants reaching the Mediterranean Sea from land-based and sea-based sources;

- levels, trends and effects of pollutants in the marine environment;

- risks of pollutants for marine life, fisheries and human health in coastal waters, estuaries and open waters;

- state of the treatment and disposal of liquid and solid waste in the Mediterranean coastal region;

- pollution prevention and clean production processes and the dissemination of information and expertise to allow all parties to implement such processes; and

- extent to which the Mediterranean marine environment is affected by marine pollution from ships and is at risk from a major marine accident.

The activities to be carried out in order to achieve the stated objectives are:

Regional level

- to collect information on the levels and trends of loads of pollutants reaching the Mediterranean Sea;

- to complete the existing network of national programmes for monitoring of pollution, based on adequate observation and monitoring techniques and incorporating mandatory data quality assurance programmes;

- to collect information on the state of the treatment and disposal of liquid and solid wastes in the Mediterranean coastal region and to present such information to the Contracting Parties;

- to collect information on the effects of pollution, including that coming from ships, on the marine environment;

- to provide the Contracting Parties, interested groups and individuals with information about general and specific pollution-related problems and potential short-term and long-term threats to the Mediterranean region; and

- to collect and provide to other Parties information on pollution prevention, elimination and clean production measures and processes in place. 


\section{National level}

- to establish/improve national monitoring programmes through assistance for capacity building of national authorities and individual laboratories, training and data quality assurance programmes.

\subsection{Pollution prevention}

\subsubsection{Prevention and elimination of the pollution of the marine environment from land-based activities}

Marine pollution from land-based sources and activities has long been recognized as a major problem in the marine environment. One of the responses of the Mediterranean countries to this problem was the adoption of the Protocol for the Protection of the Mediterranean Sea against Pollution from Land-Based Sources (LBS Protocol), which came into force in 1983. In the framework of the implementation of the LBS Protocol, by the end of 1994 thirteen Mediterranean recommendations concerning common measures for the control of LBS of pollution had been adopted by the Contracting Parties. As a measure for strengthening the Protocol further, the marine pollution monitoring and research programme (MED POL), carried out in the framework of the Mediterranean Action Plan, is gradually refocusing on problems of direct, relevance to the prevention and elimination of pollution from land-based activities.

The objective of this component is:

- the protection of the Mediterranean marine environment from the pollution from land-based activities. This objective will be met through the specific activities arising from the provisions of the LBS Protocol and common measures for the elimination of pollution. This objective could be achieved through the formulation and adoption of a regional action plan for the reduction and, as far as possible, the elimination of pollution from land-based activities, which will include quantitative objectives and a calendar of implementation. Such a plan should be based on the following principles: integrated coastal zone and river basin management; the precautionary principle; the polluter-pays principle; the clean production technology principle; an anticipatory rather than reactive approach; environmental impact assessment; environmental accounting, economic instruments (user fees, specific taxes, pricing policies and practices) and voluntary agreements (covenants).

The following activities are recommended:

Regional level

- to develop proposals for concrete measures for pollution prevention, reduction and elimination, based on the precautionary approach, as required by the Barcelona Convention and its Protocols;

- to develop technical guidelines for the implementation of the measures adopted and to assist developing countries in their implementation and enforcement;

- to collect information on the implementation of the measures adopted or recommended by the Contracting Parties and on their effectiveness, and to inform the Contracting Parties accordingly; and

- to identify problems experienced by the Contracting Parties in the implementation of the measures and to formulate proposals which may help to overcome those problems.

\section{National level}

- to formulate and implement national action programmes or plans, based on the precautionary approach, to prevent and eliminate pollution from land-based activities. Such programmes or plans should include, as appropriate:

- the setting up or the strengthening of a public administration specialized in the prevention of and fight against pollution and the provision of adequate funds for its funding;

- development of adequate national legal instruments and the formulation and adoption of measures for prevention and elimination of pollution; 
- the creation or strengthening of bodies of environmental inspectors having specific training and administrative authority;

- the use of appropriate economic instruments deriving from the "polluter pays" principle and the precautionary approach;

- encouraging voluntary agreements (covenants) for the reduction and elimination of pollution, where appropriate;

- establishing a calendar for the full implementation of the common measures against pollution adopted by the Contracting Parties, as well as the relevant points of the Genoa Declaration;

- to develop and implement national compliance monitoring programmes, carried out by participating national collaborating institutions; and

- provision for mandatory country reporting on the implementation of national action plans, including the monitoring of compliance.

\subsubsection{Prevention of and response to the pollution of the marine environment from sea-based activities}

This component of MAP Phase II aims at proposing strategies and activities which will support and supplement national efforts for the prevention of, preparedness for and response to the pollution of the marine environment from sea-based activities.

(a) Prevention of pollution of the marine environment from ships

Among the world's oceans, the traffic density of merchant vessels in the Mediterranean is particularly important. About 30 per cent of international sea-borne trade volume originates from or is directed to the 300 Mediterranean ports, or passes through the Mediterranean Sea.

Marine pollution from ships is, to a considerable extent, due to inadequate implementation and insufficient enforcement of international standards. In the course of routine operations, ships may discharge into the sea, a wide variety of substances such as oily wastes, noxious liquid substances, sewage and garbage. The discharge into the sea of such substances is a significant source of pollution of the marine environment. Ship design, maintenance and operation in compliance with the higher standard adopted within the International Maritime Organization, as well as the availability of port reception facilities, will largely reduce pollution to acceptable levels.

Following the Genoa Declaration (1985), which included among priority targets to be achieved the establishment of port reception facilities for dirty ballast waters and other oily residues, an Action Plan concerning the provision of adequate port reception facilities within the Mediterranean region was adopted in the framework of the MAP in Cairo in December 1991.

The objectives of this component are:

- the prevention of pollution of the Mediterranean marine environment from ships by providing incentives and encouragement for the adoption, effective implementation and enforcement of the international conventions for the prevention of the pollution from ships; and

- the establishment, where necessary, of port reception facilities for the collection of liquid and solid wastes generated from ships (oily and chemical residues, sewage and garbage).

The following activities to be carried out in order to achieve the stated objectives will be implemented with the assistance of the competent Regional Activity Centre and the cooperation of the International Maritime Organization:

$\underline{\text { Regional level }}$

- to implement the Action Plan concerning the provision of adequate port reception facilities within the Mediterranean region (adopted in Cairo in December 1991); 
- to promote regional cooperation in the field of Port State Control;

- to promote regional cooperation in monitoring marine pollution from ships, especially that from illegal discharges, enforcing the provisions of MARPOL 73/78 more rigorously; and

- to develop technical guidelines for the establishment and operation of shore reception facilities for wastes generated by maritime transport-related activities.

\section{National level}

- to assist in the design and implementation of projects related to the establishment and operation of port reception facilities; and

- to assist Contracting Parties which face difficulties in ratifying, implementing and enforcing the relevant international conventions.

(b) Preparedness for response to and cooperation in cases of accidental marine pollution

In the Mediterranean Sea the risks of an incident likely to cause massive pollution by oil or by other hazardous substances continues to be high. The Mediterranean Sea is a major route for transporting oil and gas from the Middle East and North Africa to Europe and North America ( 20 per cent of oil carried worldwide by ships), and the region has about 58 major oil loading and unloading ports.

Most of the countries are not in a position to rely solely on their own resources when dealing with a major marine pollution accident. Regional cooperation and mutual assistance are therefore indispensable. The pooling of resources and expertise will provide a cost effective way of combating spills. In order to be quick and effective, both cooperation and assistance have to be planned and organized.

In 1976 the Mediterranean countries adopted a Protocol concerning Cooperation in Combating Oil Pollution of the Mediterranean Sea by Oil and Other Harmful Substances in Cases of Emergency. This Protocol provides the legal and institutional framework for actions of regional cooperation in combating accidental marine pollution and decided to set up a Regional Centre with a view to assisting them in implementing the Protocol. The Regional Centre (REMPEC) is administered by the International Maritime Organization.

Since 1976, activities have been undertaken which have helped to develop the individual and collective capabilities of the coastal States of the Mediterranean to combat accidental marine pollution by oil and hazardous substances.

The objectives of this component are:

- the development of national, bilateral and/or subregional systems for preparedness for and response to accidental marine pollution by oil and other hazardous substances, including organizational structure, contingency plans, trained personnel and appropriate pollution response means; and

- the organization of cooperation among Contracting Parties in preparing for and responding to accidental marine pollution in case of emergency.

The activities to be carried out in order to achieve the stated objectives are:

\section{Regional level}

- to develop and maintain a regional information system including computerized tools for assisting in marine pollution response;

- to adopt measures for facilitating cooperation among countries in order to respond to accidents causing or likely to cause pollution of the sea by oil and other harmful substances;

- to prepare guidelines, manuals, documents and reference publications relevant to preparedness for and response to accidental marine pollution; and 
- to facilitate and coordinate international cooperation and mutual assistance and to provide, in case of emergency, advisory assistance upon request.

\section{Subregional level}

- to develop subregional operational agreements for combating major marine pollution accidents, affecting or likely to affect the territorial sea, coasts and related interests of neighbouring countries.

\section{$\underline{\text { National level }}$}

- to develop a national system, including the training of personnel, for preparedness for and response to accidental marine pollution; and

- to assist in the design and implementation of pilot demonstration projects.

(c) Prevention of the pollution of the marine environment by dumping from ships and aircraft

Pollution of the marine environment by dumping of wastes or other matter from ships and aircraft, if not controlled, poses an environmental danger in the Mediterranean Sea.

The objective of this programme is:

- the prevention and abatement of pollution of the Mediterranean Sea Area caused by dumping from ships and aircraft. This objective will be met through the specific activities arising from the provisions of the Protocol for the Prevention of Pollution of the Mediterranean Sea by Dumping from Ships and Aircraft.

The activities to be carried out in order to achieve the stated objective are:

\section{$\underline{\text { Regional level }}$}

- to collect information on issuance of permits and dumping activities and to present consolidated reports to the Contracting Parties;

- to prepare technical guidelines regarding disposal methodology and monitoring of disposal sites; and

- to assess the implementation of this Protocol, and consider the efficiency of the measures adopted and the need for any other measures.

\section{National level}

- to assist the Contracting Parties to take, individually or through bilateral or multilateral cooperation, all appropriate measures to prevent and abate pollution of the Mediterranean Sea, as specified in the Dumping Protocol;

- to adhere strictly to the adopted procedure on issuance of permits and submission of national annual reports on dumping permits and activities; and

- to develop and implement programmes for the monitoring of established dumping sites.

(d) Prevention and control of the pollution of the marine environment resulting from exploration and exploitation of the continental shelf and the seabed and its subsoil

The activities related to the exploration and exploitation of the continental shelf and the seabed and its subsoil are an important potential source of pollution for the Mediterranean. In particular, exploration, rig construction, drilling mud, water discharge, operational oil discharges, loading and accidents represent a realistic threat to the Mediterranean marine environment.

The objective of this component is the protection of the Mediterranean marine environment from all forms of pollution resulting from offshore activities. This objective will be met through specific activities arising from the 
provisions of the Protocol for the Protection of the Mediterranean Sea against Pollution resulting from Exploration and Exploitation of the Continental Shelf and the Seabed and its Subsoil.

The activities to be carried out in order to achieve the stated objective are:

\section{$\underline{\text { Regional level }}$}

- to promote cooperation among Contracting Parties, with the assistance of competent regional or international organizations, to formulate and implement programmes of assistance to developing countries including training of personnel and acquisition of appropriate equipment; and

- to formulate and adopt common standards for the disposal of oil and oily mixtures and for the use and disposal of drilling fluids and drill cuttings.

\section{$\underline{\text { National level }}$}

- to monitor the effects of the activities on the environment through the creation of national monitoring programmes; and

- to organize research studies and programmes enabling the carrying out of the activities with minimum risk of pollution.

\subsubsection{Prevention and control of the pollution of the environment resulting from transboundary move- ments of hazardous wastes and their disposal}

In the Mediterranean, a crossroads between three continents and countries at different levels of industrial and socio-economic development, transboundary movements of hazardous wastes have become a serious potential threat especially for the developing countries of the region. It is in fact known that only a small part of the hazardous wastes produced is disposed of through hazardous wastes disposal technology.

The objectives of this component are:

- the protection of the Mediterranean environment against pollution caused by transboundary movements and the disposal of hazardous waste;

- the prohibition of all exports of hazardous waste from the OECD countries of the Mediterranean to countries which are not Member States of the European Union; and

- the early ratification and implementation of the draft Protocol for the Prevention of Pollution of the Mediterranean Sea resulting from the Transboundary Movements of Hazardous Wastes and their Disposal, as well as of the Basel Convention.

The activities to be carried out in order to achieve the stated objectives are:

\section{Regional level}

- to develop appropriate guidelines for the evaluation of damage, as well as rules and procedures in the field of liability and compensation for damage resulting from the transboundary movement and disposal of hazardous wastes;

- to develop new clean production methods for reducing and eliminating hazardous wastes; and

- to establish regional cooperation for the prevention and control of transboundary movements of hazardous wastes.

National level

- to assist the Contracting Parties to reduce to a minimum, and where possible eliminate, the generation and transboundary movement of hazardous wastes in the Mediterranean; 
- to assist the Contracting Parties to take appropriate legal, administrative and other measures within the area under their jurisdiction in order to prohibit the export and transit of hazardous wastes to developing countries; and

- to develop programmes for financial and technical assistance to developing countries for the implementation of the Hazardous Wastes Protocol.

\subsection{Supporting measures}

The assessment, prevention and elimination of marine pollution in the Mediterranean cannot be achieved without a strong national institutional basis supported with adequate financial resources, equipment and experts. While the situation in developed countries of the Mediterranean region seems adequate to deal with the implementation of this component, the capacity of the developing countries will need further strengthening.

The objective of this component is the building of the institutional capabilities of the Contracting Parties for the assessment and elimination of marine pollution.

The activities to be carried out in order to achieve the stated objectives are:

- to provide advice on legal, technical and fiscal policies, strategies, and practices which may contribute to the implementation of the measures and targets adopted by the Contracting Parties;

- to prepare guidelines, manuals, documents and reference publications relevant to the implementation of this component;

- to formulate and implement pollution data quality assurance programmes;

- to facilitate the exchange of information and access to and transfer of relevant technologies;

- to organize individual and group training (e.g., seminars, workshops) of national experts (administrators, technicians, scientists) in all subjects relevant to this component;

- to formulate and implement adequate educational and public awareness programmes; and

- to facilitate contacts with international financial institutions in order to obtain financial support for the implementation of specific activities.

\section{INFORMATION AND PARTICIPATION}

Public information and public participation are a dimension essential to the policy of sustainable development and environmental protection.

The objectives of this component are:

- to provide to the general public the information available on the state of the development and environment of the Mediterranean and its evolution, and the measures taken to improve it;

- to enhance the environmental awareness of the population, and create a common approach to the environmental problems of the Mediterranean;

- to facilitate public access to activities for the protection and management of the environment and access to scientific knowledge in a proper manner; and

- to mobilize and ensure the participation and involvement of major actors concerned (local and provincial communities, economic and social groups, consumers, etc).

To achieve the stated objectives on the national and regional levels, the actions needed are: 
- to implement coordinated information campaigns and special activities on environmental protection, directed towards managers and decision-makers, as well as children, students, teachers and tourists;

- to launch educational programmes aimed at informing the public and young people in particular, of the value and the rarity of natural heritage, the need to avoid degradation of natural and urban environments, and the importance of public participation in their conservation and management;

- to continue and expand publication and distribution of brochures, leaflets, posters, reports, newsletters and other information material, as well as the use of the media in all its forms;

- to enhance and strengthen the exchange of information and experience on environmental problems of the region, and to develop cooperation in this field;

- to ensure, through the Coordinating Unit and the Regional Activity Centres, that all relevant IGOs and NGOs have appropriate access to information concerning MAP, and actively participate in MAP activities accordingly; and

- to publish the Report on the State and Evolution of the Mediterranean Environment at regular intervals.

\section{STRENGTHENING OF THE LEGAL FRAMEWORK}

While the development of international environmental law has accelerated rapidly since the Stockholm Conference of 1972, UNCED has placed emphasis on the increased evolution of international environmental law towards sustainable development, paying special attention to the delicate balance between environmental and developmental concerns.

The Agenda 21 programme emphasized the importance of the use of law to achieve this balance and contribute to the process of monitoring compliance.

During their twenty years of cooperation, the Contracting Parties to the Barcelona Convention (1976) have adopted a number of important legal instruments which, result in fostering cooperation. These include:

- Convention for the Protection of the Mediterranean Sea against Pollution (Barcelona, 1976);

- Protocol for the Prevention of Pollution of the Mediterranean Sea by Dumping from Ships and Aircraft (Barcelona, 1976);

- Protocol concerning Co-operation in Combating Pollution of the Mediterranean Sea by Oil and Other Harmful Substances in Cases of Emergency (Barcelona, 1976);

- Protocol for the Protection of the Mediterranean Sea against Pollution from Land-Based Sources (Athens, 1980);

- Protocol concerning Mediterranean Specially Protected Areas (Geneva, 1982); and

- Protocol for the Protection of the Mediterranean Sea against Pollution resulting from Exploration and Exploitation of the Continental Shelf and the Seabed and its Subsoil (Madrid, 1994).

With regard to the legal aspects, MAP Phase II will result in an amended Convention for the Protection of the Mediterranean Sea against Pollution, an amended Protocol for the Prevention of Pollution of the Mediterranean Sea by Dumping from Ships and Aircraft, and a new Protocol concerning Mediterranean Specially Protected Areas and Biodiversity in the Mediterranean.

It is also expected that a new protocol on the protection of the Mediterranean region against pollution deriving from the transboundary movements and disposal of hazardous wastes will soon be adopted, as well as amendments to the Protocol for the Protection of the Mediterranean Sea against Pollution from Land-based Sources.

These amended texts take into consideration the development of international environmental law and the introduction of the sustainable development concept. 
As to the legal aspect, MAP Phase II will be implemented on the basis of the following:

- developing further appropriate legal instruments in order to strengthen and consolidate the legal basis of Mediterranean cooperation;

- supporting the Mediterranean countries, in particular developing countries, in their efforts to develop and upgrade their environmental regulations related to the protection of the environment and sustainable development, be fully involved in regional and international negotiations dealing with the protection of the environment and sustainable development and be assisted in achieving the early entry into force and effective implementation of regional and relevant international environmental agreements;

- providing developing Mediterranean countries with technical assistance in their attempts to enhance their national legislative provisions in the field of environmental protection and sustainable development with a view to clarifying them and enhancing their effectiveness;

- enhancing full, effective and prompt implementation of the legal instruments adopted by the Contracting Parties at the regional level is a prerequisite for future cooperation and partnership of the Mediterranean countries in their efforts to protect their environment and develop their region in a sustainable manner;

- upgrading administrative capacity by means of a system of permits and control, as well as strengthening jurisdictional capacity building, in the field of environmental law at the national level, will contribute largely to the effective implementation of regional and national laws and agreements related to environmental protection and sustainable development in the Mediterranean region; and

- carrying out periodic review and assessment should be undertaken by Mediterranean countries with a view to evaluating and promoting the effectiveness of their regional laws and regulations and to promoting the integration of environmental and sustainable development policies through effective national laws and regional agreements.

The Contracting Parties play a fundamental role in ensuring the success of the Mediterranean Action Plan, in particular by working on the strengthening and development of a legal framework at the national and regional levels related to the protection of the environment and sustainable development.

The Contracting Parties will ensure at all times that the instruments they create at regional and national levels are in keeping with the development of international environmental law.

\section{INSTITUTIONAL AND FINANCLAL ARRANGEMENTS}

\section{INSTITUTIONAL ARRANGEMENTS} following:

At the institutional level, the Mediterranean Action Plan Phase II will be implemented in line with the

- the Contracting Parties to the Barcelona Convention exercise the functions established by the Convention in the framework of their Ordinary and Extraordinary meetings. They approve the activities and budget of MAP Phase II. They appoint a Bureau which assume some of their responsibilities during the interval between meetings of the Contracting Parties;

- the Contracting Parties have designated the United Nations Environment Programme as responsible for carrying out the function of the Secretariat;

- to ensure this function, the Executive Director of UNEP has established a Coordinating Unit. The Unit prepares the meetings of the Contracting Parties and of the Bureau, and is responsible for following up the decisions taken. The Unit maintains relations and coordinates its activities with international and non-governmental organizations. The Unit reports regulariy on its activities and those of the Regional Activity Centres;

- the Regional Activity Centres are established by the Protocols or by the meeting of the Contracting Parties on the proposal of a Party which provides the necessary means and facilities for their operation. They are 
responsible for carrying out specific activities agreed upon by the Contracting Parties under the general guidance and supervision of the Coordinating Unit for the Mediterranean Action Plan of UNEP. Their status is harmonized in formal agreements between UNEP and the host countries;

- The Mediterranean Commission on Sustainable Development is established in the framework of MAP. It constitutes a forum for open dialogue and consultation with all relevant partners on policies for promoting sustainable development in the Mediterranean Basin on the basis of activities and contributions identified by MAP Phase II and implemented by Parties and the MAP in line with Agenda MED 21. It advises on activity programmes and formulates the necessary recommendations for Contracting Parties. The Coordinating Unit provides Secretariat services for the Commission;

- ad hoc advisory working groups may be established by the Contracting Parties to follow up the implementation of the Protocols or of specific programmes;

- each Contracting Party, within its national administration, appoints one or more focal points responsible for the follow-up and coordination of MAP activities at national level, and for ensuring the dissemination of information. Specific focal points are also appointed by the national focal point to follow up implementation of a Protocol or the activities of a Regional Activity Centre.

\section{FINANCLAL ARRANGEMENTS}

The Contracting Parties consider and adopt the budget prepared by the Coordinating Unit. This budget is financed by contributions from the Contracting Parties, voluntary contributions from governments, supporting organizations and selected non-governmental sources, as well as clearly identified counterpart contributions.

The contributions of the Contracting Parties are assessed on the basis of a mutually agreed scale taking into account the United Nations scale of assessment.

The Mediterranean Trust Fund is established within the framework of the United Nations Environment Programme to ensure the effective coordination and funding of the Mediterranean Action Plan. An appropriate revolving fund is maintained.

The Mediterranean Trust Fund is managed in accordance with the financial rules of the United Nations Environment Programme. These rules may be amended in agreement with UNEP.

\section{APPENDIX II PRIORITY FIELDS OF ACTIVITIES FOR THE ENVIRONMENT AND DEVELOPMENT IN THE MEDITERRANEAN BASIN} (1996-2005)

The Ninth Meeting of the Contracting Parties to the Barcelona Convention (Barcelona, 5-8 June 1995) approved, and the Conference of Plenipotentiaries (9-10 June 1995) adopted the following Priority Fields of Activities for the forthcoming decade (1996-2005) which take into account Agenda MED 21.

\section{INTEGRATION OF ENVIRONMENT AND DEVELOPMENT}

(i) To formulate national strategies for sustainable development.

(ii) To develop appropriate instruments for monitoring and assessment of the environment and development in the Mediterranean basin.

(iii) To develop a regional framework and a programme for environmental health action plan within the context of sustainable development. 


\section{INTEGRATED MANAGEMENT OF NATURAL RESOURCES}

\subsection{Integrated water management}

(i) To promote the preparation in each country of instruments for integrated water management based, as far as possible, on hydrographic basins.

(ii) To promote water resources protection and anti-drought measures.

(iii) To promote rational water demand management tools.

(iv) To propose measures and techniques on sustainable utilization of water for various uses.

(v) To promote the establishment of national water resources quality and quantity monitoring systems.

(vi) To promote appropriate treatment and reuse of waste water and saline water.

(vii) To encourage the installation of infrastructures for the treatment of urban sewage of 100 Mediterranean coastal cities corresponding to a pollutant load of approximately 10 million people.

\subsection{Soil management}

(i) To evaluate and monitor the vulnerability of soil resources.

(ii) To protect and preserve soils by implementing preventive measures.

(iii) To promote rehabilitation of degraded land and restoration of plant cover.

\subsection{The fight against erosion and desertification}

(i) To promote measures against erosion and desertification.

(ii) To promote implementation of the Convention on Desertification.

\subsection{Management of forests and plant cover}

(i) To promote sustainable management of forest resources and participate in the Mediterranean Forest Action Programme.

(ii) To enhance national capability and prepare national or regional emergency plans against fire hazard and promote appropriate techniques and means.

\subsection{Management of genetic resources}

(i) To prepare appropriate measures of in-situ protection of genetic resources.

(ii) To promote the creation of a bank of genes and the rational use of genetic resources at country level.

\subsection{Marine living resources}

(i) To develop common resource management policies inspired by the precautionary principle.

(ii) To implement international conventions concerning fisheries especially the code of conduct for responsible fishing.

\section{INTEGRATED MANAGEMENT OF COASTAL AREAS}

(i) To develop appropriate measures and techniques for integrated management of coastal areas and coastline protection. 
(ii) To develop the capabilities of each country in this field through training.

(iii) To formulate and implement programmes on management of coastal areas, particularly in pilot zones.

\section{WASTE MANAGEMENT}

(i) To prepare and adopt national programmes on reduction and environmental management of hazardous wastes on the basis of methodology guidelines for rational environmental management.

(ii) To prepare and adopt national programmes on the environmental management of urban wastes on the basis of methodology guidelines for rational environmental management.

(iii) To encourage the installation of controlled discharges or treatment plants in coastal towns of over 100,000 inhabitants.

(iv) To encourage the installation of at least one secure depot and, where necessary, a treatment plant for hazardous wastes in each Mediterranean country.

(v) To ban export by OECD member countries of toxic wastes and other residues including radioactive materials to Mediterranean countries not members of the European Union.

(vi) To stimulate actions for the control of marine and coastal litter especially persistent synthetic materials.

\section{AGRICULTURE}

(i) To participate in the programmes and activities of international organizations, especially FAO, on sustainable agricultural and rural development in the Mediterranean.

(ii) To encourage the preparation of national and regional strategies in the Mediterranean based on controlled, appropriate and rational use of seeds, fertilizers and pesticides, including improvement of seeds.

(iii) To develop the use of irrigation techniques contributing to water saving.

(iv) To identify pilot areas for developing the application and exchange of experience on sustainable agricultural development.

\section{INDUSTRY AND ENERGY}

(i) To identify the best available and environmentally sound techniques and best environmental practices, prioritizing the aspects of availability, accessibility, cost and effectiveness, especially in the production and use of energy, paper, tanneries and derivatives, cement works, metallurgy, agro-industries, and organic and inorganic chemical industry.

(ii) To promote the development and application of programmes for the transfer, adaptation of and expertise in appropriate technology, prioritizing clean and safe technologies and taking into account the additional costs involved.

(iii) To develop and implement programmes to reduce polluting emissions and monitor industrial residues.

(iv) To promote and facilitate the use of new and renewable sources of energy in the domestic, public and private sectors.

\section{TRANSPORT}

(i) To promote, in accordance with the MARPOL Convention, the installation of port reception facilities for the collection of solid and liquid wastes generated by ships.

(ii) To encourage the installation of navigational aids and monitoring systems. 
(iii) To promote regional cooperation for control of the implementation by ships of the relevant international Conventions on the protection of the marine environment from pollution by ships.

\section{TOURISM}

(i) To develop activities for rational management of coastal tourism.

(ii) To prepare and implement national programmes for the diversification of tourism.

(iii) To encourage the development of tourism that respects the environment and the cultural heritage.

\section{URBAN DEVELOPMENT AND THE ENVIRONMENT}

(i) To encourage town decision-makers to apply sustainable development policies in compliance with Agenda 21 and keeping in mind the United Nations Conference "Habitat II".

(ii) To promote active urban policies for energy control, non-polluting transport, waste management, sustainable use of water, and the creation of urban amenities, paying greater attention to underprivileged districts.

(iii) To develop and implement programmes for the rehabilitation of zones affected by recent hostilities.

\section{INFORMATION}

(i) Tb encourage the development of methodology for applying the participation approach in the process of decision-making related to sustainable development at national and local levels.

(ii) To increase the flow of information on the environment and the Mediterranean Action Plan Phase II to governments and national and international institutions and to promote greater public awareness regarding these matters.

(iii) To prepare public information on the scientific and technical data and information produced by MAP Phase II and to promote and encourage production at national level of public information to back up information and awareness campaigns on the environment and sustainable development.

\section{ASSESSMENT, PREVENTION AND CONTROL OF MARINE POLLUTION}

(i) To assess, on the basis of agreed methodologies, the inputs of pollutants in the sea from watercourses, the atmosphere and diffuse sources, and to evaluate in each country the major sources of marine pollution.

(ii) To prepare evaluations, at national and regional levels, on the quality of the marine environment.

(iii) To promote the reduction of the amount of pollution carried into the marine environment, particularly by strengthening capabilities for implementing the 13 specific measures adopted.

(iv) To prepare and adopt guidelines on the dumping of dredging spoils.

(v) To promote the establishment of national, bilateral and/or subregional systems for preparedness for and response to accidental marine pollution.

\section{CONSERVATION OF NATURE, LANDSCAPE AND SITES}

(i) To prepare and approve national strategies for the conservation of biodiversity.

(ii) To draw up inventories of the elements of Mediterranean biological diversity, lists of threatened species and of sites of natural or cultural value. 
(iii) To draft and approve the annexes to the Protocol concerning Specially Protected Areas and Biological Diversity in the Mediterranean.

(iv) To enhance conservation and rational management of Mediterranean wetlands.

(v) To encourage the establishment of national inspection mechanisms and land-use policy tools allowing protection of the coastal areas to be safeguarded taking into account the specific conditions in each country.

(vi) To apply, in cooperation with other organizations involved, action plans on the monk seal, marine turtles and marine mammals.

\section{RESOLUTION II \\ Adoption of the Amendments to the Convention for the Protection of the Mediterranean Sea against Pollution and its Protocol for the Prevention of Pollution of the Mediterranean Sea by Dumping from Ships and Aircraft}

\section{RESOLUTION II \\ Adoption of the Amendments to the Convention for the Protection of the Mediterranean Sea against Pollution and its Protocol for the Prevention of Pollution of the Mediterranean Sea by Dumping from Ships and Aircraft}

\section{The Conference,}

Recalling the decisions of the Eighth Ordinary Meeting of the Contracting Parties held in Antalya from 12 to 15 October 1993 as well as the recommendation of the Bureau at their Meeting in Rabat in June 1994 calling upon the Contracting Parties to examine amendments to the Mediterranean Action Plan and the Convention and its Protocols,

Recalling further the recommendation of the Ninth Ordinary Meeting of the Contracting Parties held in Barcelona from 5 to 8 June 1995 to approve the amendments to the Convention for the Protection of the Mediterranean Sea against Pollution (hereinafter referred to as "the Barcelona Convention") and to the Protocol for the Prevention of Pollution of the Mediterranean Sea by Dumping from Ships and Aircraft (hereinafter referred to as "the Dumping Protocol",

Having adopted on this tenth day of June 1995 amendments to the Barcelona Convention and the Dumping Protocol, the texts of which are contained in the Annex to this Resolution,

Desirous of ensuring that the amendments to the Barcelona Convention and the Dumping Protocol shall begin to produce beneficial effects at the earliest possible moment,

Having regard to Article 16 of the Convention providing for the amendment of the Convention or Protocols,

Having regard furthermore to Article 29 of the Barcelona Convention, in which the Government of Spain has been designated Depositary of the Convention and of any Protocol thereto,

1. Adopts amendments to the Barcelona Convention consisting of:

(a) amendment to the title;

(b) amendments to the preamble; 
(c) amendments to Articles 1, 2, 3, 4, 5, 6, 7, 8, 11, 12, 13, 14, 15, 18, 20 and 21;

(d) the addition of new Articles 9A, 9B, 11A, 11B, 14A, 14B;

(e) consequential renumbering of Articles 10 to 29,

2. Also adopts amendments to the Dumping Protocol consisting of,

(a) amendment to the title;

(b) amendment to the preamble;

(c) amendments to Articles $1,2,3,4,5,6,7,9,10,11$ and 14;

(d) deletion of Annexes I and II;

(e) amendment to Annex III;

(f) consequential change to the Annex number,

3. Invites the Government of Spain to deposit the adopted amendments to the Barcelona Convention and the Dumping Protocol in accordance with Article 16 of the Convention and to receive instruments of acceptance as provided for in this Article,

4. Also invites the Contracting Parties to accept these amendments at the earliest possible date after receiving copies thereof by notifying the appropriate instrument of acceptance to the Depositary in accordance with Article 16 of the Convention.

\section{ANNEX \\ I. AMENDMENTS TO THE CONVENTION FOR THE PROTECTION OF THE MEDITERRANEAN SEA AGAINST POLLUTION}

\section{A. TITLE}

The title of the Convention is amended as follows:

CONVENTION FOR THE PROTECTION OF THE MARINE ENVIRONMENT AND THE COASTAL REGION OF THE MEDITERRANEAN

\section{B. PREAMBULAR PARAGRAPHS}

The second preambular paragraph of the Convention is amended as follows:

Fully aware of their responsibility to preserve and sustainably develop this common heritage for the benefit and enjoyment of present and future generations,

The following paragraphs are added to the Preamble:

Fully aware that the Mediterranean Action Plan, since its adoption in 1975 and through its evolution, has contributed to the process of sustainable development in the Mediterranean region and has represented a substantive and dynamic tool for the implementation of the activities related to the Convention and its Protocols by the Contracting Parties,

Taking into account the results of the United Nations Conference on Environment and Development, held in Rio de Janeiro from 4 to 14 June 1992, 
Also taking into account the Declaration of Genoa of 1985, the Charter of Nicosia of 1990, the Declaration of Cairo of 1992 on Euro-Mediterranean Cooperation on the Environment within the Mediterranean Basin, the recommendations of the Conference of Casablanca of 1993, and the Declaration of Tunis of 1994 on the Sustainable Development of the Mediterranean,

Bearing in mind the relevant provisions of the United Nations Convention on the Law of the Sea, done at Montego Bay on 10 December 1982 and signed by many Contracting Parties,

\section{ARTICLE 1 : GEOGRAPHICAL COVERAGE}

\section{Paragraph 2 of Article 1 is amended as follows:}

2. The application of the Convention may be extended to coastal areas as defined by each Contracting Party within its own territory.

The following paragraph is added to Article 1 as new paragraph 3:

3. Any Protocol to this Convention may extend the geographical coverage to which that particular Protocol applies.

\section{ARTICLE 2 : DEFINITIONS}

Paragraph (a) of Article 2 is amended as follows:

(a) "Pollution" means the introduction by man, directly or indirectly, of substances or energy into the marine environment, including estuaries, which results, or is likely to result, in such deleterious effects as harm to living resources and marine life, hazards to human health, hindrance to marine activities, including fishing and other legitimate uses of the sea, impairment of quality for use of seawater and reduction of amenities.

\section{E. ARTICLE 3 : GENERAL PROVISIONS}

\section{Paragraphs 1 and 2 of Article 3 are amended as follows:}

1. (renumbered as 2) The Contracting Parties may enter into bilateral or multilateral agreements, including regional or sub-regional agreements for the promotion of sustainable development, the protection of the environment, the conservation and preservation of natural resources in the Mediterranean Sea Area, provided that such agreements are consistent with this Convention and the Protocols and conform to international law. Copies of such agreements shall be communicated to the Organization. As appropriate, Contracting Parties should make use of existing organizations, agreements or arrangements in the Mediterranean Sea Area.

2. (renumbered as 3) Nothing in this Convention and its Protocols shall prejudice the rights and positions of any State concerning the United Nations Convention on the Law of the Sea of 1982.

\section{The following new paragraphs are added to Article 3:}

0. (renumbered as 1) The Contracting Parties, when applying this Convention and its related Protocols, shall act in conformity with international law.

3. (renumbered as 4) The Contracting Parties shall take individual or joint initiatives compatible with international law through the relevant international organizations to encourage the implementation of the provisions of this Convention and its Protocols by all the non-party States.

3bis. (renumbered as 5) Nothing in this Convention and its Protocols shall affect the sovereign immunity of warships or other ships owned or operated by a State while engaged in government non-commercial service. However, each Contracting Party shall ensure that its vessels and aircraft, entitled to sovereign immunity under international law, act in a manner consistent with this Protocol. 


\section{F. ARTICLE 4 : GENERAL OBLIGATIONS}

\section{Article 4 is amended as follows:}

1. The Contracting Parties shall individually or jointly take all appropriate measures in accordance with the provisions of this Convention and those Protocols in force to which they are party to prevent, abate, combat and to the fullest possible extent eliminate pollution of the Mediterranean Sea Area and to protect and enhance the marine environment in that Area so as to contribute towards its sustainable development.

2. The Contracting Parties pledge themselves to take appropriate measures to implement the Mediterranean Action Plan and, further, to pursue the protection of the marine environment and the natural resources of the Mediterranean Sea Area as an integral part of the development process, meeting the needs of present and future generations in an equitable manner. For the purpose of implementing the objectives of sustainable development the Contracting Parties shall take fully into account the recommendations of the Mediterranean Commission on Sustainable Development established within the framework of the Mediterranean Action Plan.

3. In order to protect the environment and contribute to the sustainable development of the Mediterranean Sea Area, the Contracting Parties shall:

(a) apply, in accordance with their capabilities, the precautionary principle, by virtue of which where there are threats of serious or irreversible damage, lack of full scientific certainty shall not be used as a reason for postponing cost-effective measures to prevent environmental degradation;

(b) apply the polluter pays principle, by virtue of which the costs of pollution prevention, control and reduction measures are to be borne by the polluter, with due regard to the public interest;

(c) undertake environmental impact assessment for proposed activities that are likely to cause a significant adverse impact on the marine environment and are subject to an authorization by competent national authorities;

(d) promote cooperation between and among States in environmental impact assessment procedures related to activities under their jurisdiction or control which are likely to have a significant adverse effect on the marine environment of other States or areas beyond the limits of national jurisdiction, on the basis of notification, exchange of information and consultation;

(e) commit themselves to promote the integrated management of the coastal zones, taking into account the protection of areas of ecological and landscape interest and the rational use of natural resources.

4. In implementing the Convention and the related Protocols, the Contracting Parties shall:

(a) adopt programmes and measures which contain, where appropriate, time limits for their completion;

(b) utilize the best available techniques and the best environmental practices and promote the application of, access to and transfer of environmentally sound technology, including clean production technologies, taking into account the social; economic and technological conditions.

5. The Contracting Parties shall cooperate in the formulation and adoption of Protocols, prescribing agreed measures, procedures and standards for the implementation of this Convention.

6. The Contracting Parties further pledge themselves to promote, within the international bodies considered to be competent by the Contracting Parties, measures concerning the implementation of programmes of sustainable development, the protection, conservation and rehabilitation of the environment and of the natural resources in the Mediterranean Sea Area. 


\section{ARTICLE 5 : \\ POLLUTION CAUSED BY DUMPING FROM SHIPS AND AIRCRAFT OR INCINERATION AT SEA}

The Contracting Parties shall take all appropriate measures to prevent, abate and to the fullest possible extent eliminate pollution of the Mediterranean Sea Area caused by dumping from ships and aircraft or incineration at sea.

\section{H. ARTICLE 6 : POLLUTION FROM SHIPS}

\section{Article 6 is amended as follows:}

The Contracting Parties shall take all measures in conformity with international law to prevent, abate, combat and to the fullest possible extent eliminate pollution of the Mediterranean Sea Area caused by discharges from ships and to ensure the effective implementation in that Area of the rules which are generally recognized at the international level relating to the control of this type of pollution.

\section{ARTICLE 7 : POLLUTION RESULTING FROM EXPLORATION AND EXPLOITATION OF THE CONTINENTAL SHELF AND THE SEABED AND ITS SUBSOIL}

\section{Article 7 is amended as follows:}

The Contracting Parties shall take all appropriate measures to prevent, abate, combat and to the fullest possible extent eliminate pollution of the Mediterranean Sea Area resulting from exploration and exploitation of the continental shelf and the seabed and its subsoil.

\section{J. ARTICLE 8 : POLLUTION FROM LAND-BASED SOURCES}

Article 8 is amended as follows:

The Contracting Parties shall take all appropriate measures to prevent, abate, combat and to the fullest possible extent eliminate pollution of the Mediterranean Sea Area and to draw up and implement plans for the reduction and phasing out of substances that are toxic, persistent and liable to bioaccumulate arising from land-based sources. These measures shall apply:

(a) to pollution from land-based sources, originating within the territories of the Parties, and reaching the sea:

- directly from outfalls discharging into the sea or through coastal disposal;

- indirectly through rivers, canals or other watercourses, including underground watercourses, or through run-off;

(b) to pollution from land-based sources transported by the atmosphere.

K. The following new Article 9A is adopted:

\section{ARTICLE 9A (renumbered as Article 10) : CONSERVATION OF BIOLOGICAL DIVERSITY}

The Contracting Parties shall, individually or jointly, take all appropriate measures to protect and preserve biological diversity, rare or fragile ecosystems, as well as species of wild fauna and flora which are rare, depleted, threatened or endangered and their habitats, in the area to which this Convention applies. 


\section{ARTICLE 9B (renumbered as Article 11) : POLLUTION RESULTING FROM THE TRANSBOUNDARY MOVEMENTS OF HAZARDOUS WASTES AND THEIR DISPOSAL}

The Contracting Parties shall take all appropriate measures to prevent, abate and to the fullest possible extent eliminate pollution of the environment which can be caused by transboundary movements and disposal of hazardous wastes, and to reduce to a minimum, and if possible eliminate, such transboundary movements.

Articles 9A and 9B are renumbered as Articles 10 and 11

\section{ARTICLE 11 (renumbered as Article 13) : SCIENTIFIC AND TECHNOLOGICAL COOPERATION}

Paragraph 2 is amended as follows:

2. The Contracting Parties undertake to promote the research on, access to and transfer of environmentally sound technology, including clean production technologies, and to cooperate in the formulation, establishment and implementation of clean production processes.

N. The following new Article 11A is adopted:

\section{ARTICLE 11A (renumbered as Article 14) : ENVIRONMENTAL LEGISLATION}

1. The Contracting Parties shall adopt legislation implementing the Convention and the Protocols.

2. The Secretariat may, upon request from a Contracting Party, assist that Party in the drafting of environmental legislation in compliance with the Convention and the Protocols.

0. The following new Article 11B is adopted:

\section{ARTICLE 11B (renumbered as Article 15) : PUBLIC INFORMATION AND PARTICIPATION}

1. The Contracting Parties shall ensure that their competent authorities shall give to the public appropriate access to information on the environmental state in the field of application of the Convention and the Protocols, on activities or measures adversely affecting or likely to affect it and on activities carried out or measures taken in accordance with the Convention and the Protocols.

2. The Contracting Parties shall ensure that the opportunity is given to the public to participate in decision-making processes relevant to the field of application of the Convention and the Protocols, as appropriate.

3. The provision of paragraph 1. of this Article shall not prejudice the right of Contracting Parties to refuse, in accordance with their legal systems and applicable international regulations, to provide access to such information on the ground of confidentiality, public security or investigation proceedings, stating the reasons for such a refusal. 


\section{P. ARTICLE 12 (renumbered as Article 16) : LIABILITY AND COMPENSATION}

\section{Article 12 is amended as follows:}

The Contracting Parties undertake to cooperate in the formulation and adoption of appropriate rules and procedures for the determination of liability and compensation for damage resulting from pollution of the marine environment in the Mediterranean Sea Area.

\section{Q. ARTICLE 13 (renumbered as Article 17) : INSTITUTIONAL ARRANGEMENTS}

\section{Paragraph (iii) of Article 13 is amended as follows:}

$$
\text { to receive, consider and reply to enquiries and information from the Contracting Parties; }
$$

The following new paragraphs are added to Article 13:

(iii bis) (renumbered as (iv))

to receive, consider and reply to enquiries and information from non-governmental organizations and the public when they relate to subjects of common interest or to activities carried out at the regional level; in this case, the Contracting Parties concerned shall be informed;

(iv bis) (renumbered as (vi))

to regularly report to the Contracting Parties on the implementation of the Convention and of the Protocols;

Paragraphs (iv), (v) and (vi) are renumbered as paragraphs (v), (vii) and (viii) respectively.

\section{R. ARTICLE 14 (renumbered as Article 18) : MEETINGS OF THE CONTRACTING PARTIES}

The following new subparagraph is added to Article 14, paragraph 2:

(vii) to approve the Programme Budget.

S. The following new Article 14A is adopted:

\section{ARTICLE 14A (renumbered as Article 19) : BUREAU}

1. The Bureau of the Contracting Parties shall be composed of representatives of the Contracting Parties elected by the Meetings of the Contracting Parties. In electing the members of the Bureau, the Meetings of the Contracting Parties shall observe the principle of equitable geographical distribution.

2. The functions of the Bureau and the terms and conditions upon which it shall operate shall be set in the Rules of Procedure adopted by the Meetings of the Contracting Parties.

T. The following new Article 14B is adopted:

\section{ARTICLE 14B (renumbered as Article 20) : OBSERVERS}


1. The Contracting Parties may decide to admit as observers at their meetings and conferences:

(a) any State which is not a Contracting Party to the Convention;

(b) any international governmental organization or any non-governmental organization the activities of which are related to the Convention.

2. Such observers may participate in meetings without the right to vote and may present any information or report relevant to the objectives of the Convention.

3. The conditions for the admission and participation of observers shall be established in the Rules of Procedure adopted by the Contracting Parties.

Articles $14 \mathrm{~A}$ and $14 \mathrm{~B}$ are renumbered as Articles 19 and 20

U. ARTICLE 15 (renumbered as Article 21) : ADOPTION OF ADDTTIONAL PROTOCOLS

Paragraph 3 of Article 15 is deleted.

\section{ARTICLE 18 (renumbered as Article 24) : RULES OF PROCEDURE AND FINANCIAL RULES}

Paragraph 2 of Article 18 is amended as follows:

2. The Contracting Parties shall adopt financial rules, prepared in consultation with the Organization, to determine, in particular, their financial participation in the Trust Fund.

\section{W. ARTICLE 20 (renumbered as Article 26) : REPORTS}

\section{Article 20 is amended as follows:}

1. The Contracting Parties shall transmit to the Organization reports on:

(a) the legal, administrative or other measures taken by them for the implementation of this Convention, the Protocols and of the recommendations adopted by their meetings;

(b) the effectiveness of the measures referred to in subparagraph (a) and problems encountered in the implementation of the instruments as mentioned above.

2. The reports shall be submitted in such form and at such intervals as the Meetings of Contracting Parties may determine.

\section{ARTICLE 21 (renumbered as Article 27) : COMPLIANCE CONTROL}

Article 21 is amended as follows:

The meetings of the Contracting Parties shall, on the basis of periodical reports referred to in Article 20 and any other report submitted by the Contracting Parties, assess the compliance with the Convention and the Protocols as well as the measures and recommendations. They shall recommend, when appropriate, the necessary steps to bring about full compliance with the Convention and the Protocols and promote the implementation of the decisions and recommendations.

Articles 10, 16, 17, 19, 22, 23, 24, 25, 26, 27, 28 and 29 are renumbered as Articles 12, 22, 23, 25, 28, 29, 30, 31, $32,33,34$ and 35 respectively. 


\section{AMENDMENTS TO THE PROTOCOL FOR THE PREVENTION OF POLLUTION OF THE MEDITERRANEAN SEA BY DUMPING FROM SHIPS AND AIRCRAFT}

\section{A. TITLE}

The title of the Protocol is amended as follows:

PROTOCOL FOR THE PREVENTION AND ELIMINATION OF POLLUTION OF THE MEDITERRANEAN SEA BY DUMPING FROM SHIPS AND AIRCRAFT OR INCINERATION AT SEA

\section{B. PREAMBULAR PARAgRAPHS}

The second preambular paragraph of the Protocol is amended as follows: matter,

Recognizing the danger posed to the marine environment by the dumping or incineration of wastes or other

The fourth preambular paragraph of the Protocol is amended as follows:

Bearing in mind that Chapter 17 of Agenda 21 of UNCED calls on the Contracting Parties to the Convention on the Prevention of Marine Pollution by Dumping of Wastes and other Matter (London, 1972) to take the necessary measures to end dumping in the ocean and the incineration of hazardous substances,

The following paragraph is added to the Preamble:

Taking into account Resolutions LC 49(16) and LC 50(16), approved by the 16th Consultative Meeting of the 1972 London Convention, which prohibit the dumping and incineration of industrial wastes at sea,

\section{ARTICLE 1}

Article 1 is amended as follows:

The Contracting Parties to this Protocol (hereinafter referred to as the "Parties") shall take all appropriate measures to prevent, abate and eliminate to the fullest extent possible pollution of the Mediterranean Sea caused by dumping from ships and aircraft or incineration at sea.

\section{ARTICLE 2}

\section{Article 2 is amended as follows:}

The area to which this Protocol applies shall be the Mediterranean Sea Area as defined in Article 1 of the Convention for the Protection of the Marine Environment and the Coastal Region of the Mediterranean (hereinafter referred to as "the Convention").

\section{E. ARTICLE 3}

The following new subparagraphs are added to Article 3:

3(c) Any deliberate disposal or storage and burial of wastes or other matter on the seabed or in the marine subsoil from ships or aircraft.

4(bis) (renumbered as 5) "Incineration at sea" means the deliberate combustion of wastes or other matter in the maritime waters of the Mediterranean Sea, with the aim of thermal destruction and does not include activities incidental to the normal operations of ships or aircraft.

Paragraph 5 is renumbered as paragraph 6. 


\section{F. ARTICLE 4}

Article 4 is amended as follows:

1. The dumping of wastes or other matter, with the exception of those listed in paragraph 2 of this Article, is prohibited.

2. The following is the list referred to in the preceding paragraph:

(a) dredged material;

(b) fish waste or organic materials resulting from the processing of fish and other marine organisms;

(c) vessels, until 31 December 2000;

(d) platforms and other man-made structures at sea, provided that material capable of creating floating debris or otherwise contributing to pollution of the marine environment has been removed to the maximum extent, without prejudice to the provisions of the Protocol concerning Pollution Resulting from Exploration and Exploitation of the Continental Shelf, the Seabed and its Subsoil;

(e) inert uncontaminated geological materials the chemical constituents of which are unlikely to be released into the marine environment.

\section{G. ARTICLE 5}

\section{Article 5 is amended as follows:}

The dumping of the wastes or other matter listed in Article 4.2 requires a prior special permit from the competent national authorities.

\section{H. ARTICLE 6}

\section{Article 6 is amended as follows:}

1. The permit referred to in Article 5 shall be issued only after careful consideration of the factors set forth in the Annex to this Protocol or the criteria, guidelines and relevant procedures adopted by the meeting of the Contracting Parties pursuant to paragraph 2 below:

2. The Contracting Parties shall draw up and adopt criteria, guidelines and procedures for the dumping of wastes or other matter listed in Article 4.2 so as to prevent, abate and eliminate pollution.

\section{ARTICLE 7}

\section{Article 7 is amended as follows:}

Incineration at sea is prohibited.

\section{J. ARTICLE 9}

\section{Article 9 is amended as follows:}

If a Party in a critical situation of an exceptional nature considers that wastes or other matter not listed in Article 4.2 of this Protocol cannot be disposed of on land without unacceptable danger or damage, above all for the safety of human life, the Party concerned shall forthwith consult the Organization. The Organization, after consulting the Parties to this Protocol, shall recommend methods of storage or the most satisfactory means of destruction or disposal under the prevailing circumstances. The Party shall inform the Organization of the steps adopted in pursuance of these recommendations. The Parties pledge themselves to assist one another in such situations. 


\section{K. ARTICLE 10}

Subparagraph 1(a) of Article 10 is amended as follows:

(a) issue the permits provided for in Article 5;

Subparagraph 1(b) of Article 10 is deleted.

Subparagraph $1(c)$ is renumbered as subparagraph 1(b).

\section{Paragraph 2 is amended as follows:}

2. The competent authorities of each Party shall issue the permits provided for in Article 5 in respect of the wastes or other matter intended for dumping:

\section{ARTICLE 11}

Paragraph 2 of Article 11 is deleted.

\section{ARTICLE 14}

\section{Paragraph 3 of Article 14 is amended as follows:}

3. The adoption of amendments to the Annex to this Protocol pursuant to Article 17 of the Convention shall require a three-fourths majority vote of the Parties.

\section{N. ANNEX I}

Annex I is deleted.

\section{O. ANNEX II}

Annex II is deleted.

\section{P. ANNEX III}

Annex III is changed to Annex and is amended as follows:

\section{ANNEX}

The factors to be considered in establishing criteria governing the issue of permits for the dumping of matter at sea taking into account Article 6 include: 


\title{
RESOLUTION III \\ Signature, Ratification, Acceptance and Approval of and Accession to the Protocol Concerning Specially Protected Areas and Biological Diversity in the Mediterranean
}

\author{
RESOLUTION III \\ Signature, Ratification, Acceptance and Approval of and Accession \\ to the Protocol Concerning Specially Protected Areas and \\ Biological Diversity in the Mediterranean
}

The Conference,

Recalling the recommendation of the Ninth Ordinary Meeting of the Contracting Parties held in Barcelona from 5 to 8 June 1995 to approve the new Specially Protected Areas Protocol,

Having concluded and adopted on this tenth day of June 1995 the Protocol Concerning Specially Protected Areas and Biological Diversity in the Mediterranean (hereinafter referred to as "the Protocol"),

Desirous of ensuring that the Protocol shall begin to produce beneficial effects at the earliest possible moment,

Having regard to Articles 29 to 32 of the Protocol which govern the signature, ratification, acceptance or approval of the Protocol and accession thereto and its entry into force,

Having regard furthermore to Article 29 of the Convention for the Protection of the Mediterranean Sea against Pollution, in which the Government of Spain has been designated Depositary of the Convention and of any Protocol thereto,

1. Invites the Government of Spain to open the Protocol for signature at Barcelona from 10 June 1995 to 10 June 1996, by all those entitled to sign the said instrument by virtue of Article 29 thereof;

2. Urges all parties that are entitled to sign the Protocol to do so as soon as practicable and to complete at the earliest opportunity the constitutional procedures needed for the ratification, acceptance or approval of the Protocol under their respective statutory or legislative provisions and to transmit the instruments of ratification, acceptance or approval to the Depositary;

3. Calls upon all parties entitled to accede to the Protocol to do so as soon as possible after the period specified in Article 31 of the Protocol. 


\title{
RESOLUTION IV Interim arrangements
}

\author{
RESOLUTION IV \\ Interim arrangements
}

The Conference,

Having adopted the amendments to the Convention for the Protection of the Mediterranean Sea against Pollution (hereinafter referred to as "the Barcelona Convention") and to the Protocol for the Prevention of Pollution of the Mediterranean Sea by Dumping from Ships and Aircraft (hereinafter referred to as "the Dumping Protocol"),

Having also concluded and adopted the Protocol concerning Specially Protected Areas and Biological Diversity in the Mediterranean,

Having regard to Article 13 of the Barcelona Convention in which the United Nations Environment Programme (UNEP) has been designated as responsible for carrying out the secretariat functions of the Convention and of any Protocol thereto,

Desirous of facilitating the earliest practicable implementation of the amendments to the Barcelona Convention and the Dumping Protocol and of the Protocol concerning Specially Protected Areas and Biological Diversity in the Mediterranean,

1. Invites the Contracting Parties and the Executive Director of UNEP to ensure that the Tenth Ordinary Meeting of the Contracting Parties to the Convention for the Protection of the Mediterranean Sea against Pollution and its related Protocols (Tunisia 1997) considers the measures and actions necessary for the successful implementation of the amendments to the Barcelona Convention and the Dumping Protocol and of the Protocol concerning Specially Protected Areas and Biological Diversity in the Mediterranean,

2. Calls on the Executive Director of UNEP to initiate consultations with the Contracting Parties on the workplan and timetable for meetings of experts to elaborate the technical aspects of the amendments to the Barcelona Convention and the Dumping Protocols, and of the provisions of the Protocol concerning Specially Protected Areas and Biological Diversity in the Mediterranean,

3. Invites the Executive Director of UNEP to establish cooperation with relevant regional and international organizations in activities related to the implementation of these instruments. 


\title{
RESOLUTION V \\ Tribute to the Government of Spain
}

\author{
RESOLUTION V \\ Tribute to the Government of Spain
}

The Conference,

Having met in Barcelona on 9 and 10 June 1995 at the gracious invitation of the Government of Spain,

Convinced that the important contribution made by the Government of Spain greatly added to the efficient conduct of its proceedings,

Deeply appreciative of the courtesy and generous hospitality extended by the Government of Spain, the autonomous Government of Catalonia and the Municipality of Barcelona to the members of the delegations, observers and Secretariat attending the Conference,

Expresses its sincere gratitude to the Government of Spain for the cordial welcome which was accorded to the Conference and to those associated with its work and for its contribution to the successful conclusion of the Conference. 


\title{
PROTOCOL CONCERNING SPECIALLY PROTECTED AREAS AND BIOLOGICAL DIVERSITY IN THE MEDITERRANEAN
}

\section{PROTOCOL CONCERNING SPECIALLY PROTECTED AREAS AND BIOLOGICAL DIVERSITY IN THE MEDITERRANEAN}

\section{The Contracting Parties to this Protocol,}

Being Parties to the Convention for the Protection of the Mediterranean Sea against Pollution, adopted at Barcelona on 16 February 1976,

Conscious of the profound impact of human activities on the state of the marine environment and the littoral and more generally on the ecosystems of areas having prevailing Mediterranean features,

Stressing the importance of protecting and, as appropriate, improving the state of the Mediterranean natural and cultural heritage, in particular through the establishment of specially protected areas and also by the protection and conservation of threatened species,

Considering the instruments adopted by the United Nations Conference on Environment and Development and particularly the Convention on Biological Diversity (Rio de Janeiro, 1992),

Conscious that when there is a threat of significant reduction or loss of biological diversity, lack of full scientific certainty should not be invoked as a reason for postponing measures to avoid or minimize such a threat,

Considering that all the Contracting Parties should cooperate to conserve, protect and restore the health and integrity of ecosystems and that they have, in this respect, common but differentiated responsibilities,

Have agreed as follows:

\section{PART I GENERAL PROVISIONS}

\author{
Article 1
}

DEFINITIONS

For the purposes of this Protocol:

(a) "Convention" means the Convention for the Protection of the Mediterranean Sea against Pollution, adopted at Barcelona on 16 February 1976 and amended at Barcelona in 1995;

(b) "Biological diversity" means the variability among living organisms from all sources including, inter alia, terrestrial, marine and other aquatic ecosystems and the ecological complexes of which they are part; this includes diversity within species, between species and of ecosystems;

(c) "Endangered species" means any species that is in danger of extinction throughout all or part of its range;

(d) "Endemic species" means any species whose range is restricted to a limited geographical area;

(e) "Threatened species" means any species that is likely to become extinct within the foreseeable future throughout all or part of its range and whose survival is unlikely if the factors causing numerical decline or habitat degradation continue to operate; 
(f) "Conservation status of a species" means the sum of the influences acting on the species that may affect its long-term distribution and abundance;

(g) "Parties" means the Contracting Parties to this Protocol;

(h) "Organization" means the organization referred to in Article 2 of the Convention;

(i) "Centre" means the Regional Activity Centre for Specially Protected Areas.

Article 2

\section{GEOGRAPHICAL COVERAGE}

1. The area to which this Protocol applies shall be the area of the Mediterranean Sea as delimited in Article 1 of the Convention. It also includes:

- the seabed and its subsoil;

- the waters, the seabed and its subsoil on the landward side of the baseline from which the breadth of the territorial sea is measured and extending, in the case of watercourses, up to the freshwater limit;

- the terrestrial coastal areas designated by each of the Parties, including wetlands.

2. Nothing in this Protocol nor any act adopted on the basis of this Protocol shall prejudice the rights, the present and future claims or legal views of any State relating to the law of the sea, in particular, the nature and the extent of marine areas, the delimitation of marine areas between States with opposite or adjacent cossts, freedom of navigation on the high seas, the right and the modalities of passage through straits used for international navigation and the right of innocent passage in territorial seas, as well as the nature and extent of the jurisdiction of the coastal State, the flag State and the port State.

3. No act or activity undertaken on the basis of this Protocol shall constitute grounds for claiming, contending or disputing any claim to national sovereignty or jurisdiction.

Article 3

\section{GENERAL OBLIGATIONS}

1. Each Party shall take the necessary measures to:

(a) protect, preserve and manage in a sustainable and environmentally sound way areas of particular natural or cultural value, notably by the establishment of specially protected areas;

(b) protect, preserve and manage threatened or endangered species of flora and fauna.

2. The Parties shall cooperate, directly or through the competent international organizations, in the conservation and sustainable use of biological diversity in the area to which this Protocol applies.

3. The Parties shall identify and compile inventories of the components of biological diversity important for its conservation and sustainable use.

4. The Parties shall adopt strategies, plans and programmes for the conservation of biological diversity and the sustainable use of marine and coastal biological resources and shall integrate them into their relevant sectoral and intersectoral policies.

5. The Parties shall monitor the components of biological diversity referred to in paragraph 3 of this Article and shall identify processes and categories of activities which have or are likely to have a significant adverse impact on the conservation and sustainable use of biological diversity, and monitor their effects. 
6. Each Party shall apply the measures provided for in this Protocol without prejudice to the sovereignty or the jurisdiction of other Parties or other States. Any measures taken by a Party to enforce these measures shall be in accordance with international law.

\section{PART II PROTECTION OF AREAS SECTION ONE - SPECIALLY PROTECTED AREAS}

\section{Article 4}

\section{OBJECTIVES}

The objective of specially protected areas is to safeguard:

(a) representative types of coastal and marine ecosystems of adequate size to ensure their long-term viability and to maintain their biological diversity;

(b) habitats which are in danger of disappearing in their natural area of distribution in the Mediterranean or which have a reduced natural area of distribution as a consequence of their regression or on account of their intrinsically restricted area;

(c) habitats critical to the survival, reproduction and recovery of endangered, threatened or endemic species of flora or fauna;

(d) sites of particular importance because of their scientific, aesthetic, cultural or educational interest.

\section{Article 5}

\section{ESTABLISHMENT OF SPECIALLY PROTECTED AREAS}

1. Each Party may establish specially protected areas in the marine and coastal zones subject to its sovereignty or jurisdiction.

2. If a Party intends to establish, in an area subject to its sovereignty or national jurisdiction, a specially protected area contiguous to the frontier and to the limits of a zone subject to the sovereignty or national jurisdiction of another Party, the competent authorities of the two Parties shall endeavour to cooperate, with a view to reaching agreement on the measures to be taken and shall, inter alia, examine the possibility of the other Party establishing a corresponding specially protected area or adopting any other appropriate measures.

3. If a Party intends to establish, in an area subject to its sovereignty or national jurisdiction, a specially protected area contiguous to the frontier and to the limits of a zone subject to the sovereignty or national jurisdiction of a State that is not a Party to this Protocol, the Party shall endeavour to cooperate with that State as referred to in the previous paragraph.

4. If a State which is not party to this Protocol intends to establish a specially protected area contiguous to the frontier and to the limits of a zone subject to the sovereignty or national jurisdiction of a Party to this Protocol, the latter shall endeavour to cooperate with that State as referred to in paragraph 2.

\section{Article 6}

\section{PROTECTION MEASURES}

The Parties, in conformity with international law and taking into account the characteristics of each specially protected area, shall take the protection measures required, in particular:

(a) the strengthening of the application of the other Protocols to the Convention and of other relevant treaties to which they are Parties; 
(b) the prohibition of the dumping or discharge of wastes and other substances likely directly or indirectly to impair the integrity of the specially protected area;

(c) the regulation of the passage of ships and any stopping or anchoring;

(d) the regulation of the introduction of any species not indigenous to the specially protected area in question, or of genetically modified species, as well as the introduction or reintroduction of species which are or have been present in the specially protected area;

(e) the regulation or prohibition of any activity involving the exploration or modification of the soil or the exploitation of the subsoil of the land part, the seabed or its subsoil;

(f) the regulation of any scientific research activity;

(g) the regulation or prohibition of fishing, hunting, taking of animals and harvesting of plants or their destruction, as well as trade in animals, parts of animals, plants, parts of plants, which originate in specially protected areas;

(h) the regulation and if necessary the prohibition of any other activity or act likely to harm or disturb the species or that might endanger the state of conservation of the ecosystems or species or might impair the natural or cultural characteristics of the specially protected area;

(i) any other measure aimed at safeguarding ecological and biological processes and the landscape.

Article 7

\section{PLANNING AND MANAGEMENT}

1. The Parties shall, in accordance with the rules of international law, adopt planning, management, supervision and monitoring measures for the specially protected areas.

2. Such measures should include for each specially protected area:

(a) the development and adoption of a management plan that specifies the legal and institutional framework and the management and protection measures applicable;

(b) the continuous monitoring of ecological processes, habitats, population dynamics, landscapes, as well as the impact of human activities;

(c) the active involvement of local communities and populations, as appropriate, in the management of specially protected areas, including assistance to local inhabitants who might be affected by the establishment of such areas;

(d) the adoption of mechanisms for financing the promotion and management of specially protected areas, as well as the development of activities which ensure that management is compatible with the objectives of such areas;

(e) the regulation of activities compatible with the objectives for which the specially protected area was established and the terms of the related permits;

(f) the training of managers and qualified technical personnel, as well as the development of an appropriate infrastructure.

3. The Parties shall ensure that national contingency plans incorporate measures for responding to incidents that could cause damage or constitute a threat to the specially protected areas.

4. When specially protected areas covering both land and marine areas have been established, the Parties shall endeavour to ensure the coordination of the administration and management of the specially protected area as a whole. 


\title{
SECTION TWO - SPECIALLY PROTECTED AREAS OF MEDITERRANEAN IMPORTANCE
}

\author{
Article 8 \\ ESTABLISHMENT OF THE LIST OF SPECIALLY PROTECTED AREAS \\ OF MEDITERRANEAN IMPORTANCE
}

1. In order to promote cooperation in the management and conservation of natural areas, as well as in the protection of threatened species and their habitats, the Parties shall draw up a "List of Specially Protected Areas of Mediterranean Importance", hereinafter referred to as the "SPAMI List".

2. The SPAMI List may include sites which:

- are of importance for conserving the components of biological diversity in the Mediterranean;

- contain ecosystems specific to the Mediterranean area or the habitats of endangered species;

- are of special interest at the scientific, aesthetic, cultural or educational levels.

3. The Parties agree:

(a) to recognize the particular importance of these areas for the Mediterranean;

(b) to comply with the measures applicable to the SPAMIs and not to authorize nor undertake any activities that might be contrary to the objectives for which the SPAMIs were established.

\section{Article 9}

\section{PROCEDURE FOR THE ESTABLISHMENT AND LISTING OF SPAMIs}

1. SPAMIs may be established, following the procedure provided for in paragraph 2 to 4 of this Article, in: (a) the marine and coastal zones subject to the sovereignty or jurisdiction of the Parties; (b) zones partly or wholly on the high seas.

2. Proposals for inclusion in the List may be submitted:

(a) by the Party concerned, if the area is situated in a zone already delimited, over which it exercises sovereignty or jurisdiction;

(b) by two or more neighbouring Parties concerned if the area is situated, partly or wholly, on the high sea;

(c) by the neighbouring Parties concerned in areas where the limits of national sovereignty or jurisdiction have not yet been defined.

3. Parties making proposals for inclusion in the SPAMI List shall provide the Centre with an introductory report containing information on the area's geographical location, its physical and ecological characteristics, its legal status, its management plans and the means for their implementation, as well as a statement justifying its Mediterranean importance;

(a) where a proposal is formulated under subparagraphs 2 (b) and 2 (c) of this Article, the neighbouring Parties concerned shall consult each other with a view to ensuring the consistency of the proposed protection and management measures, as well as the means for their implementation;

(b) proposals made under paragraph 2 of this Article shall indicate the protection and management measures applicable to the area as well as the means of their implementation.

4. The procedure for inclusion of the proposed area in the List is the following: 
(a) for each area, the proposal shall be submitted to the National Focal Points, which shall examine its conformity with the common guidelines and criteria adopted pursuant to Article 16;

(b) if a proposal made in accordance with subparagraph 2 (a) of this Article is consistent with the guidelines and common criteria, after assessment, the Organization shall inform the meeting of the Parties, which shall decide to include the area in the SPAMI List;

(c) if a proposal made in accordance with subparagraphs 2 (b) and 2 (c) of this Article is consistent with the guidelines and common criteria, the Centre shall transmit it to the Organization, which shall inform the meeting of the Parties. The decision to include the area in the SPAMI list shall be taken by consensus by the Contracting Parties, which shall also approve the management measures applicable to the area.

5. The Parties which proposed the inclusion of the area in the List shall implement the protection and conservation measures specified in their proposals in accordance with paragraph 3 of this Article. The Contracting Parties undertake to observe the rules thus laid down. The Centre shall inform the competent international organizations of the List and of the measures taken in the SPAMIs.

6. The Parties may revise the SPAMI List. To this end, the Centre shall prepare a report.

\title{
Article 10
}

\section{CHANGES IN THE STATUS OF SPAMIS}

Changes in the delimitation or legal status of a SPAMI or the suppression of all or part of such an area shall not be decided upon unless there are important reasons for doing so, taking into account the need to safeguard the environment and comply with the obligations laid down in this Protocol and a procedure similar to that followed for the creation of the SPAMI and its inclusion in the List shall be observed.

\section{PART III \\ PROTECTION AND CONSERVATION OF SPECIES}

\author{
Article 11
}

\section{NATIONAL MEASURES FOR THE PROTECTION AND CONSERVATION OF SPECIES}

1. The Parties shall manage species of flora and fauna with the aim of maintaining them in a favourable state of conservation.

2. The Parties shall, in the zones subject to their sovereignty or national jurisdiction, identify and compile lists of the endangered or threatened species of flora and fauna and accord protected status to such species. The Parties shall regulate and, where appropriate, prohibit activities having adverse effects on such species or their habitats, and carry out management, planning and other measures to ensure a favourable state of conservation of such species.

3. With respect to protected species of fauna, the Parties shall control and, where appropriate, prohibit:

(a) the taking, possession or killing (including, to the extent possible, the incidental taking, possession or killing), the commercial trade, the transport and the exhibition for commercial purposes of these species, their eggs, parts or products;

(b) to the extent possible, the disturbance of wild fauna, particularly during the period of breeding, incubation, hibernation or migration, as well as other periods of biological stress.

4. In addition to the measures specified in the previous paragraph, the Parties shall coordinate their efforts, through bilateral or multilateral action, including if necessary, agreements for the protection and recovery of migratory species whose range extends into the area to which this Protocol applies. 
5. With respect to protected species of flora and their parts and products, the Parties shall regulate, and where appropriate, prohibit all forms of destruction and disturbance, including the picking, collecting, cutting, uprooting, possession of, commercial trade in, or transport and exhibition for commercial purposes of such species.

6. The Parties shall formulate and adopt measures and plans with regard to ex situ reproduction, in particular captive breeding, of protected fauna and propagation of protected flora.

7. The Parties shall endeavour, directly or through the Centre, to consult with range States that are not Parties to this Protocol, with a view to coordinating their efforts to manage and protect endangered or threatened species.

8. The Parties shall make provision, where possible, for the return of protected species exported or held illegally. Efforts should be made by Parties to reintroduce such specimens to their natural habitat.

Article 12

\section{COOPERATIVE MEASURES FOR THE PROTECTION AND CONSERVATION OF SPECIES}

1. The Parties shall adopt cooperative measures to ensure the protection and conservation of the flora and fauna listed in the Annexes to this Protocol relating to the List of Endangered or Threatened Species and the List of Species whose Exploitation is Regulated.

2. The Parties shall ensure the maximum possible protection and recovery of the species of fauna and flora listed in the Annex relating to the List of Endangered or Threatened Species by adopting at the national level the measures provided for in paragraphs 3 and 5 of Article II of this Protocol.

3. The Parties shall prohibit the destruction of and damage to the habitat of species listed in the Annex relating to the List of Endangered or Threatened Species and shall formulate and implement action plans for their conservation or recovery. They shall continue to cooperate in implementing the relevant action plans already adopted.

4. The Parties, in cooperation with competent international organizations, shall take all appropriate measures to ensure the conservation of the species listed in the Annex relating to the List of Species whose Exploitation is Regulated while at the same time authorizing and regulating the exploitation of these species so as to ensure and maintain their favourable state of conservation.

5. When the range area of a threatened or endangered species extends to both sides of a national frontier or of the limit that separates the territories or the areas subject to the sovereignty or the national jurisdiction of two Parties to this Protocol, these Parties shall cooperate with a view to ensuring the protection and conservation and, if necessary, the recovery of such species.

6. Provided that no other satisfactory solutions are available and that the exemption does not harm the survival of the population or of any other species, the Parties may grant exemptions to the prohibitions prescribed for the protection of the species listed in the Annexes to this Protocol for scientific, educational or management purposes necessary to ensure the survival of the species or to prevent significant damage. Such exemptions shall be notified to the Contracting Parties.

Article 13

\section{INTRODUCTION OF NON-INDIGENOUS OR GENETICALLY MODIFIED SPECIES}

1. The Parties shall take all appropriate measures to regulate the intentional or accidental introduction of non-indigenous or genetically modified species to the wild and prohibit those that may have harmful impacts on the ecosystems, habitats or species in the area to which this Protocol applies. 
2. The Parties shall endeavour to implement all possible measures to eradicate species that have already been introduced when, after scientific assessment, it appears that such species cause or are likely to cause damage to ecosystems, habitats or species in the area to which this Protocol applies.

\title{
PART IV \\ PROVISIONS COMMON TO PROTECTED AREAS AND SPECIES
}

\author{
Article 14
}

\section{AMENDMENTS TO ANNEXES}

1. The procedures for amendments to Annexes to this Protocol shall be those set forth in Article 17 of the Convention.

2. All proposed amendments submitted to the meeting of Contracting Parties shall have been the subject of prior evaluation by the meeting of National Focal Points.

Article 15

\section{INVENTORIES}

Each Party shall compile comprehensive inventories of:

(a) areas over which they exercise sovereignty or jurisdiction that contain rare or fragile ecosystems, that are reservoirs of biological diversity, that are important for threatened or endangered species;

(b) species of fauna or flora that are endangered or threatened.

Article 16

\section{GUIDELINES AND COMMON CRITERIA}

The Parties shall adopt:

(a) common criteria for the choice of protected marine and coastal areas that could be included in the SPAMI List which shall be annexed to the Protocol;

(b) common criteria for the inclusion of additional species in the Annexes;

(c) guidelines for the establishment and management of specially protected areas.

The criteria and guidelines referred to in paragraphs (b) and (c) may be amended by the meeting of the Parties on the basis of a proposal made by one or more Parties.

Article 17

\section{ENVIRONMENTAL IMPACT ASSESSMENT}

In the planning process leading to decisions on industrial and other projects and activities that could significantly affect protected areas and species and their habitats, the Parties shall evaluate and take into consideration the possible direct or indirect, immediate or long-term, impact, including the cumulative impact of the projects and activities being contemplated. 


\section{Article 18}

\section{INTEGRATION OF TRADITIONAL ACTIVITIES}

1. In formulating protective measures, the Parties shall take into account the traditional subsistence and cultural activities of their local populations. They shall grant exemptions, as necessary, to meet such needs. No exemption which is allowed for this reason shall:

(a) endanger either the maintenance of ecosystems protected under this Protocol or the biological processes contributing to the maintenance of those ecosystems;

(b) cause either the extinction of, or a substantial reduction in, the number of individuals making up the populations or species of flora and fauna, in particular endangered, threatened, migratory or endemic species.

2. Parties which grant exemptions from the protection measures shall inform the Contracting Parties accordingly.

Article 19

\section{PUBLICITY, INFORMATION, PUBLIC AWARENESS AND EDUCATION}

1. The Parties shall give appropriate publicity to the establishment of specially protected areas, their boundaries, applicable regulations, and to the designation of protected species, their habitats and applicable regulations.

2. The Parties shall endeavour to inform the pubic of the interest and value of specially protected areas and species, and of the scientific knowledge which may be gained from the point of view of nature conservation and other points of view. Such information should have an appropriate place in education programmes. The Parties shall also endeavour to promote the participation of their public and their conservation organizations in measures that are necessary for the protection of the areas and species concerned, including environmental impact assessments.

\section{Article 20}

\section{SCIENTIFIC, TECHNICAL AND MANAGEMENT RESEARCH}

1. The Parties shall encourage and develop scientific and technical research relating to the aims of this Protocol. They shall also encourage and develop research into the sustainable use of specially protected areas and the management of protected species.

2. The Parties shall consult, when necessary, among themselves and with competent international organizations with a view to identifying, planning and undertaking scientific and technical research and monitoring programmes necessary for the identification and monitoring of protected areas and species and assessing the effectiveness of measures taken to implement management and recovery plans.

3. The Parties shall exchange, directly or through the Centre, scientific and technical information concerning current and planned research and monitoring programmes and the results thereof. They shall, to the fullest extent possible, coordinate their research and monitoring programmes, and endeavour jointly to define or standardize their procedures.

4. In technical and scientific research, the Parties shall give priority to SPAMIs and species appearing in the Annexes to this Protocol.

\section{Article 21}

\section{MUTUAL COOPERATION}

1. The Parties shall, directly or with the assistance of the Centre or international organizations concerned, establish cooperation programmes to coordinate the establishment, conservation, planning and management of specially protected areas, as well as the selection, management and conservation of protected species. There 
shall be regular exchanges of information concerning the characteristics of protected areas and species, the experience acquired and the problems encountered.

2. The Parties shall, at the earliest opportunity, communicate any situation that might endanger the ecosystems of specially protected areas or the survival of protected species of flora and fauna to the other Parties, to the States that might be affected and to the Centre.

\section{Article 22}

\section{MUTUAL ASSISTANCE}

1. The Parties shall cooperate, directly or with the assistance of the Centre or the international organizations concerned, in formulating, financing and implementing programmes of mutual assistance and assistance to developing countries that express a need for it with a view to implementing this Protocol.

2. These programmes shall include public environmental education, the training of scientific, technical and management personnel, scientific research, the acquisition, utilization, design and development of appropriate equipment, and transfer of technology on advantageous terms to be agreed among the Parties concerned.

3. The Parties shall, in matters of mutual assistance, give priority to the SPAMIs and species appearing in the Annexes to this Protocol.

\section{Article 23}

\section{REPORTS OF THE PARTIES}

The Parties shall submit to ordinary meetings of the Parties a report on the implementation of this Protocol, in particular on:

(a) the status and the state of the areas included in the SPAMI List;

(b) any changes in the delimitation or legal status of the SPAMIs and protected species;

(c) possible exemptions allowed pursuant to Articles 12 and 18 of this Protocol.

\section{PART V \\ INSTITUTIONAL PROVISIONS}

Article 24

\section{NATIONAL FOCAL POINTS}

Each Party shall designate a National Focal Point to serve as liaison with the Centre on the technical and scientific aspects of the implementation of this Protocol. The National Focal Points shall meet periodically to carry out the functions deriving from this Protocol.

\section{Article 25}

\section{COORDINATION}

1. The Organization shall be responsible for coordinating the implementation of this Protocol. For this purpose, it shall receive the support of the Centre, to which it may entrust the following functions:

(a) assisting the Parties, in cooperation with the competent international, intergovernmental and non-governmental organizations, in:

- establishing and managing specially protected areas in the area to which this Protocol applies; 
- conducting programmes of technical and scientific research as provided for in Article 20 of this Protocol;

- conducting the exchange of scientific and technical information among the Parties as provided for in Article 20 of this Protocol;

- preparing management plans for specially protected areas and species;

- developing cooperative programmes pursuant to Article 21 of this Protocol;

- preparing educational materials designed for various groups;

(b) convening and organizing the meetings of the National Focal Points and providing them with secretariat services;

(c) formulating recommendations on guidelines and common criteria pursuant to Article 16 of this Protocol;

(d) creating and updating databases of specially protected areas, protected species and other matters relevant to this Protocol;

(e) preparing reports and technical studies that may be required for the implementation of this Protocol;

(f) elaborating and implementing the training programmes mentioned in Article 22, paragraph 2;

(g) cooperating with regional and international governmental and non-governmental organizations concerned with the protection of areas and species, provided that the specificity of each organization and the need to avoid the duplication of activities are respected;

(h) carrying out the functions assigned to it in the action plans adopted in the framework of this Protocol;

(i) carrying out any other function assigned to it by the Parties.

\section{Article 26}

\section{MEETINGS OF THE PARTIES}

1. The ordinary meetings of the Parties to this Protocol shall be held in conjunction with the ordinary meetings of the Contracting Parties to the Convention he!d pursuant to Article 14 of the Convention. The Parties may also hold extraordinary meetings in conformity with that Article.

2. The meetings of the Parties to this Protocol are particularly aimed at:

(a) keeping under review the implementation of this Protocol;

(b) overseeing the work of the Organization and of the Centre relating to the implementation of this Protocol and providing policy guidance for their activities;

(c) considering the efficacy of the measures adopted for the management and protection of areas and species, and examining the need for other measures, in particular in the form of Annexes and amendments to this Protocol or to its Annexes;

(d) adopting the guidelines and common criteria provided for in Article 16 of this Protocol;

(e) considering reports transmitted by the Parties under Article 23 of this Protocol, as well as any other pertinent information which the Parties transmit through the Centre;

(f) making recommendations to the Parties on the measures to be adopted for the implementation of this Protocol; 
(g) examining the recommendations of the meetings of the National Focal Points pursuant to Article 24 of this Protocol;

(h) deciding on the inclusion of an area in the SPAMI List in conformity with Article 9, paragraph 4, of this Protocol;

(i) examining any other matter relevant to this Protocol, as appropriate;

(j) discussing and evaluating the exemptions allowed by the Parties in conformity with Articles 12 and 18 of this Protocol.

\section{PART VI FINAL PROVISIONS}

Article 27

\section{EFFECT OF THE PROTOCOL ON DOMESTIC LEGISLATION}

The provisions of this Protocol shall not affect the right of Parties to adopt relevant stricter domestic measures for the implementation of this Protocol.

\section{Article 28}

\section{RELATIONSHIP WITH THIRD PARTIES}

1. The Parties shall invite States that are not Parties to the Protocol and international organizations to cooperate in the implementation of this Protocol.

2. The Parties undertake to adopt appropriate measures, consistent with international law, to ensure that no one engages in any activity contrary to the principles or purposes of this Protocol.

Article 29

\section{SIGNATURE}

This Protocol shall be open for signature in Barcelona on 10 June 1995 and in Madrid from 11 June 1995 to 10 June 1996 by any Contracting Party to the Convention.

Article 30

\section{RATIFICATION, ACCEPTANCE OR APPROVAL}

This Protocol shall be subject to ratification, acceptance or approval. Instruments of ratification, acceptance or approval shall be deposited with the Government of Spain, which will assume the functions of Depositary.

\section{Article 31 \\ ACCESSION}

As from 10 June 1996, this Protocol shall be open for accession by any State and regional economic grouping which is Party to the Convention. 
Article 32

\section{ENTRY INTO FORCE}

1. This Protocol shall enter into force on the thirtieth day following the deposit of the sixth instrument of ratification, acceptance or approval of, or accession to, the Protocol.

2. From the date of its entry into force, this Protocol shall replace the Protocol Concerning Mediterranean Specially Protected Areas of 1982, in the relationship among the Parties to both instruments.

IN WITNESS WHEREOF, the undersigned, being duly authorized, have signed this Protocol.

DONE at Barcelona, on 10 June 1995, in a single copy in the Arabic, English, French and Spanish languages, the four texts being equally authoritative, for signature by any Party to the Convention.

[Signature]

For the Republic of Albania

[Signature]

For the Republic of Bosnia and Herzegovina

[Signature]

For the Republic of Cyprus

[Signature]

For the French Republic

[Signature]

For the State of Israel

[Signature]

For the Lebanese Republic

[Signature]

For the Republic of Malta

[Signature]

For the Kingdom of Morocco

[Signature]

For the Kingdom of Spain

[Signature]

For the Republic of Tunisia

[Signature]

For the European Community

[Signature]

For the Secretary General of the Conference
[Signature]

For the People's Democratic

Republic of Algeria

[Signature]

For the Republic of Croatia

[Signature]

For the Arab Republic of Egypt

[Signature]

For the Hellenic Republic

[Signature]

For the Italian Republic

[Signature]

For the Socialist People's Libyan

Arab Jamahiriya

[Signature]

For the Principality of Monaco

[Signature]

For the Republic of Slovenia

[Signature]

For the Syrian Arab Republic

[Signature]

For the Republic of Turkey

[Signature]

For the President of the Conference

[Signature]

For the Executive Secretary of the

Conference

DONE AT BARCELONA this tenth day of June one thousand nine hundred and ninety five in a single copy in the Arabic, English, French and Spanish languages, the four texts being equally authoritative. 

Argentina

ENVIRONMENT AND NATURAL RESOURCES 



\section{Agreement Between the U.S. National Oceanic and Atmospheric Administration and the Ministry of Culture and Education of Argentina for Cooperation in the GLOBE Program, Buenos Aires, 1995}

Done at Buenos Aires 28 June 1995

Entered into force 28 June 1995

Primary source citation: Copy of text provided by the

U.S. Department of State

\section{AN AGREEMENT BETWEEN THE U.S. NATIONAL OCEANIC AND ATMOSPHERIC ADMINISTRATION AND THE MINISTRY OF CULTURE AND EDUCATION OF ARGENTINA FOR COOPERATION IN THE GLOBE PROGRAM}

\section{PREAMIBLE}

The U.S. National Oceanic and Atmospheric Administration, acting on behalf of itself and other U.S. Government agencies participating in the GLOBE Program (hereinafter, the U.S. side), and the Ministry of Culture and Education of Argentina (hereinafter, the Argentine side),

Intending to increase the awareness of students throughout the world about the global environment,

Seeking to contribute to increased scientific understanding of the Earth, and

Desiring to support improved student achievement in science and mathematics,

Have agreed to cooperate in the Global Learning and Observations to Benefit the Environment (GLOBE) Program as follows:

\section{ARTICLE 1 - THE GLOBE PROGRAM}

The GLOBE Program is an international environmental science and education program that will bring students, teachers, and scientists together to study the global environment. GLOBE will create an international network of 
students in grades K-12 (or equivalent) studying environmental issues, making environmental measurements, and sharing useful environmental data with the international environmental science community.

\section{ARTICLE 2 - RESPECTIVE RESPONSIBILITIES}

A. The U.S. side will:

1. Identify U.S. schools that will participate in the GLOBE Program (details regarding GLOBE schools in Appendix A);

2. Select, in consultation with international scientists and educators, the GLOBE environmental measurements and types of measurement equipment (described in Appendix B);

3. Select Principal Investigator Teams for the GLOBE environmental measurements, and support the U.S. members of the Teams;

4. Calibrate, if necessary, measurement equipment that cannot be calibrated by GLOBE teachers and students;

5. Develop, in consultation with international scientists and educators, GLOBE educational materials;

6. Translate GLOBE instructional materials related to measurement procedures and data reporting protocols into the six United Nations languages, and provide these plus all broader GLOBE educational materials to the Argentine Country Coordinator for further reproduction as necessary;

7. Conduct annual regional training sessions for GLOBE Country Coordinators and GLOBE teachers who will serve as trainers for additional GLOBE teachers in Argentina, and provide a copy of GLOBE training materials to the Argentine Country Coordinator;

8. Design, develop, operate, and maintain GLOBE data processing capabilities and other necessary technology and equipment;

9. Provide GLOBE software, as necessary, for use on Argentine GLOBE school computers. (To the maximum extent possible, textual material appearing on computer screens will be accessible in the student's choice among the six United Nations languages.);

10. Accept environmental data reported from GLOBE schools around the world, and develop and provide resultant global environmental images (visualization products) to the Argentine side; and

11. Evaluate the overall GLOBE Program periodically, in consultation with international GLOBE Country Coordinators, and modify the overall program as appropriate.

B. The Argentine side will:

1. Select Argentine schools to participate in the GLOBE Program (details regarding GLOBE schools in Appendix A) and provide an updated list of Argentine GLOBE schools to the U.S. side at the beginning of each school year;

2. Ensure that Argentine GLOBE schools conduct the fundamental activities of GLOBE schools detailed in Appendix A (take GLOBE environmental measurements, report data, and receive and use resultant global environmental images, using GLOBE educational materials under the guidance of teachers trained to conduct the GLOBE Program);

3. Name an Argentine Government Point of Contact responsible for policy-level communications with the Director of the GLOBE Program; 
4. Name a Country Coordinator responsible for day-to-day management, oversight, and facilitation of the GLOBE Program in Argentina;

5. Ensure that the Country Coordinator and some GLOBE teachers attend GLOBE regional training and in turn provide GLOBE training to at least one teacher in each Argentine GLOBE school;

6. Ensure that GLOBE instructional materials related to measurement procedures and data reporting protocols are utilized in Argentine GLOBE schools, and that broader GLOBE educational materials are appropriately translated, adapted, reproduced, and distributed to all Argentine GLOBE schools;

7. Ensure that Argentine GLOBE schools have the necessary measurement equipment to take GLOBE environmental measurements (described in Appendix B);

8. Ensure that teachers and students at Argentine GLOBE schools calibrate GLOBE measurement equipment according to procedures provided in GLOBE instructional materials;

9. Ensure that Argentine GLOBE schools have the necessary computer and communications systems (described in Appendix C) to report GLOBE environmental measurements and to receive and use GLOBE visualization products, or make agreed alternative arrangements for such reporting and receipt. (At a minimum, the Argentine Country Coordinator will need access to Internet so that all measurement data from Argentine GLOBE schools will be reported via Internet.); and

10. Evaluate GLOBE operations in Argentina periodically and assist the U.S. side in conducting periodic evaluation of the overall GLOBE Program.

\section{ARTICLE 3 - FINANCIAL ARRANGEMENTS}

Each side will bear the costs of fulfilling its respective responsibilities under this agreement. Obligations of each side pursuant to this agreement are subject to its respective funding procedures and the availability of appropriated funds, personnel, and other resources. The conduct of activities under this agreement will be consistent with the relevant laws and regulations of the two sides.

\section{ARTICLE 4 - EXCHANGE OF DATA AND GOODS}

GLOBE environmental measurement data, visualization products, software, and educational materials will be available worldwide without restriction as to their use or redistribution.

\section{ARTICLE 5 - RELEASE OF INFORMATION ABOUT THE GLOBE PROGRAM}

Each side may release information on the GLOBE Program as it may deem appropriate without prior consultation with the other.

\section{ARTICLE 6 - CUSTOMS AND IMMIGRATION}

Each side will, to the extent permitted by its laws and regulations, facilitate the movement of persons and goods necessary to implement this agreement into and out of its territory and accord entry to such goods into its territory free of customs duties and other similar charges. 


\section{ARTICLE 7 - ENTRY INTO FORCE, AMENDMENTS, WITHDRAWAL}

This agreement will enter into force upon signature of the two sides and will remain in force for five years. It will be automatically extended for further five-year periods, unless either side decides to terminate it and so notifies the other side with three months written notice. This agreement may be terminated at any time by either side upon three months prior written notice to the other side. This agreement may be amended by written agreement of the two sides.

Done at on

For the National Oceanic and Atmospheric Administration:

[Signature]
For the Ministry of

Culture and Education:

[Signature]

\section{APPENDIX A GLOBE Schools}

Each partner country will be responsible for identifying its participating schools. Schools should be selected so as to satisfy the objectives of the GLOBE Program. In particular, countries should emphasize the selection of schools that will maximize the number of students worldwide participating in the program. Also, countries should consider involving schools in locations that will yield measurement data that is important to the international environmental science community.

Students at all GLOBE schools throughout the world will conduct the following fundamental activities: they will make environmental measurements at or near their schools; report their data to a GLOBE data processing site; receive vivid graphical global environmental images (visualization products) created from their data and the data from other GLOBE schools around the world; and study the environment by relating their observations and the resulting visualization products to broader environmental topics. All of these activities will be conducted under the guidance of specially trained teachers (GLOBE-trained teachers).

GLOBE educational materials will be used in GLOBE schools under the guidance of GLOBE-trained teachers. These materials will detail procedures for taking environmental measurements and protocols for reporting data; explain the significance of the measurements; guide the use of the visualization products; and integrate the measurement aspects of the program into a broader study of the environment.

Schools throughout the United States and the rest of the world that are not GLOBE schools may become GLOBE affiliate schools by observing the GLOBE Program in operation through the Internet. Students at these schools will benefit from the use of GLOBE visualization products and educational materials accessible on-line. All GLOBE affiliate schools will be encouraged to become participating GLOBE schools.

\section{APPENDIX B GLOBE Environmental Measurements and Equipment}

GLOBE environmental measurements will contribute in a significant way to the scientific understanding of the dynamics of the global environment. Every GLOBE school will conduct a core set of GLOBE environmental measurements in the following critical areas: Atmosphere/Climate, Hydrology/Water Chemistry, and Biology/Geology. Where possible, a GLOBE school may coordinate its activities with those of other neighboring GLOBE schools, so that the complete set of GLOBE measurements will be available from a locality. As the GLOBE Program evolves, elective measurements not common to all GLOBE schools may be added in order to address local environmental issues.

Students at all age levels will be active participants in the GLOBE Program. The actual participation will be designed so as to be grade-appropriate for grades K-5, 6-8, and 9-12 (or equivalent). Younger students will make limited measurements which may be qualitative rather than quantitative. Older students will make additional measure- 
ments and more sophisticated measurements, as appropriate for their grade level. Measurement equipment will not need to be standardized; rather, performance specifications will be provided.

Following is an example list of core measurements and equipment. The full list will be initially determined and periodically updated as provided in Article 2.A.2, based on experience gained in implementing the GLOBE Program.

\section{MEASUREMENTS}

\section{Atmosphere/Climate:}

Air Temperature

\section{Precipitation \\ Cloud Cover/Type}

\section{Hydrology/Water Chemistry:}

Water $\mathrm{pH}$

Water Temperature

Soil Moisture

\section{Biology/Geology:}

Habitat Study

Tree Height

Tree Canopy

Tree Diameter

Species Identification

Phenology

\section{EQUIPMENT NEEDED}

\author{
Max/Min Thermometer \\ Calibration Thermometer \\ Instrument Shelter \\ Rain Gauge \\ Cloud Charts
}

pH Paper, Pen, or Meter

Alcohol Thermometer

Gypsum Block Sensors

Soil Moisture Meter

\section{Compass}

Meter Measuring Tape

Surveying Markers or Stakes

Clinometer

Densiometer

Diameter Tape

Dichotomous Keys

$35 \mathrm{~mm}$ Camera

\section{GLOBE Computer and Communications Systems}

In order to derive maximum benefit from the GLOBE Program, all schools will be encouraged to use an international information network, initially using the Internet, along with classroom computers. The World Wide Web multi-media information-access capability has been selected as the basis for IBM-compatible and Apple Macintosh computer systems to support the required GLOBE school activities of data entry, data analysis, and use of GLOBE environmental images. Following is a description of GLOBE computer and communications systems consistent with current GLOBE requirements.

Overall attributes of the minimum GLOBE school computer configuration that can execute the necessary software are:

For IBM-compatible systems: a $386 \mathrm{SX}$ or higher level processor; at least 4 megabytes of RAM memory ( 8 megabytes preferred); a VGA-capable monitor and display driver (Super VGA preferred); a hard disk storage system with as large a capacity as possible (preferably 300 megabytes or larger); and a direct Internet connection or dial-up capability that can use SLIP or PPP protocols with a 14,400 bps modem (preferably supporting V.42bis data compression which can enable 57,600 bps operation). A printer is desirable.

Software for a higher performance GLOBE school computer system is being developed that will operate on higher performance, multi-media IBM-compatible systems and on Apple Macintosh systems. For IBM-compatible systems: a 486/66 or faster processor; 16 megabytes of RAM memory; 500 megabytes of hard disk space; a Super VGA monitor; a double-speed CD-ROM reader; a Soundblaster-compatible sound card; and an MPEG animation speed-up board will be required. For Apple Macintosh systems: a PowerPC processor; 16 megabytes of RAM memory; 500 megabytes of hard disk space; and a double-speed CD-ROM reader will be required. A communications capability the same as or better than for the minimum configurations above will also be required. A printer will be highly desirable. 
It is recognized that there are a broad range of technological capabilities among potential GLOBE schools. The diversity of technology accessible by schools worldwide may require in some cases that environmental measurements be reported in hardcopy and that a variety of media be used to distribute visualization products, including photographs and broadcast television. All schools that want to participate in the program will be accommodated.

Technology associated with the GLOBE Program will continually evolve to higher levels and participants will be encouraged to upgrade over time. 


\title{
B I L A T E R A L
}

\author{
Australia
}

ENVIRONMENTAND NATURAL RESOURCES 



\section{Memorandum of Understanding Between the Environmental Protection Agency of the United States of America and the Commonwealth Environment Protection Agency of Australia for Cooperation in the Field of Environmental Protection, Canberra, 1994}

Done at Canberra 8 March 1994

Entered into effect 8 March 1994

Primary source citation: Copy of text provided by the U.S. Department of State

\section{MEMORANDUM OF UNDERSTANDING BETWEEN THE ENVIRONMENTAL PROTECTION AGENCY OF THE UNTTED STATES OF AMERICA AND THE COMMONWEALTH ENVIRONMENT PROTECTION AGENCY OF AUSTRALIA FOR COOPERATION IN THE FIELD OF ENVIRONMENTAL PROTECTION}

The Environmental Protection Agency of the United States of America (EPA) and the Commonwealth Environment Protection Agency of Australia (CEPA), together referred to as the "Agencies",

Recognizing that they have common concerns and similar responsibilities for protecting and improving human health in and the natural environments of their respective nations, and a common interest in advancing global environmental improvement and protection;

Noting that the United States and Australia face similar environmental challenges relating to expanding urban populations, concentrated industrial activity, preservation of the environment, and sustainable use of natural resources;

Noting also that cooperation in the field of environmental protection reinforces the two nations' existing economic and technical cooperation;

Have reached the following understandings to guide their cooperation: 


\section{Article I: Purpose}

The Agencies will cooperate in addressing environmental problems of mutual concern by undertaking specific activities which contribute to the protection of the environment. The purpose of this Memorandum of Understanding (hereinafter referred to as the "Memorandum") is to establish the terms under which such cooperation will be undertaken.

\section{Article II: Scope of Cooperative Activity}

The Agencies will establish a program of cooperation on environmental protection. The areas of cooperation under the program may include, but not be limited to: the prevention, control and reduction of air pollution, water pollution, soil pollution, and marine pollution; waste management; advice concerning the management of chemical emergencies; environmental pollution issues relating to the preservation of human health and ecological systems; environmental pollution issues in urban environments; development of emissions inventories and other environmental inventories; product life cycle analyses; clean production processes; environmental monitoring and assessment; advice concerning the development of environmental legislation and regulations; environmental management; and environmental economics.

\section{Article III: Forms of Cooperation}

The forms of cooperation under this Memorandum may consist of the following: temporary assignments of personnel from one Agency to another; study tours by delegations of scientists, scholars, research personnel, technicians and other specialists in the field of environmental protection; transfer of nonproprietary information in the field of environmental protection; joint organization of scientific, technological and other symposia, seminars and lectures of mutual interest; cooperation in joint research and demonstration projects on subjects of mutual interest in the field of environmental protection; and such other forms of cooperation on which the Agencies may jointly decide, in accordance with the objectives and provisions of this Memorandum.

\section{Article IV: Management}

1. Cooperative activities undertaken by the Agencies pursuant to this Memorandum will be jointly determined in writing by the Agencies as implementing arrangements to this Memorandum ("Implementing Arrangements"). Each Implementing Arrangement will be annexed to and form an integral part of this Memorandum, and will set forth the following information:

a. The title, duration, and objective of the activity;

b. The responsibility of each Agency with respect to the activity;

c. The contributions to the activity by each Agency, which may include:

1) Financial contributions; or

2) Contributions of materials, equipment or services;

d. The schedule for implementation of the activity;

e. Reporting procedures, if appropriate;

f. The effective date of the Implementing Arrangement; and

g. Other relevant matters. 
2. Each Agency will designate in writing a Coordinating Officer to administer and coordinate cooperative activities undertaken by the Agencies pursuant to this Memorandum. The functions of the Coordinating Officers will include, but not be limited to:

a. Serving as the primary point of contact for the Agencies with regard to activities undertaken pursuant to this Memorandum;

b. Establishing priorities;

c. Monitoring, reviewing and reporting on the progress of activities to the Agencies, and to other national authorities of their respective countries, as appropriate; and

d. Recommending to the Agencies changes to activities undertaken pursuant to the Memorandum.

\section{Article V: Facilitation}

The Agencies will endeavor to facilitate the implementation of cooperative activities pursuant to this Memorandum. In particular, the Agencies will endeavor to facilitate: (1) the temporary assignment of personnel from one Agency to another by expediting the issuance of all documentation required for such personnel to enter and exit their respective countries; and (2) the entry and exit of equipment and other materials required for activities under this Memorandum.

\section{Article VI: Participation}

Participants in activities under this Memorandum may include representatives of governmental and non-governmental organizations and of the private sector, consistent with applicable law. Each Agency may use the services of and enter into assistance agreements with appropriate institutions (such as universities and governmental and non-governmental organizations) in undertaking activities pursuant to this Memorandum, subject to applicable law.

\section{Article VII: Consultation}

The Agencies will consult promptly and in good faith on any matters that may arise in respect of the implementation of this Memorandum or activities undertaken pursuant to it.

\section{Article VIII: Funding}

1. Unless otherwise specified in an Implementing Arrangement, each Agency will bear the expense of its participation in activities under this Memorandum.

2. The ability of each Agency to carry out activities under this Memorandum will be subject to the availability of appropriated funds, personnel and other resources.

\section{Article IX: Applicability of U.S. Law and of Australian Law}

All activities undertaken pursuant to this Memorandum will be subject to the applicable law of the United States of America and of the Commonwealth of Australia. 


\section{Article X: Relationship to Other Instruments}

Nothing in this Memorandum will be construed to prejudice other existing instruments concluded between the United States of America and the Commonwealth of Australia, or between any agency of the United States of America and any agency of the Commonwealth of Australia.

\section{Article XI: Entry Into Effect, Duration, Amendment and Termination}

This Memorandum will enter into effect upon signature and will remain in force for a period of five (5) years. Thereafter, it may be extended for successive five-year periods upon exchanges of letters between the Agencies.

This Memorandum and its Implementing Arrangements may be amended at any time upon an exchange of letters between the Agencies. The Memorandum may be terminated at any time by either Agency upon not less than ninety (90) days' prior written notice to the other Agency. Unless otherwise jointly determined in writing by the Agencies, the termination of this Memorandum will not affect the validity or duration of activities pursuant to the Memorandum initiated prior to, but not completed at the time of, such termination. standing.

IN WITNESS WHEREOF, the undersigned, being duly authorized, have signed this Memorandum of Under-

SIGNED at Canberra, this eighth day of March, 1994, in duplicate, in the English language.

\section{FOR THE ENVIRONMENTAL PROTECTION AGENCY OF THE UNITED STATES OF AMERICA:}

Edward J. Perkins, Ambassador

\section{FOR THE COMMONWEALTH ENVIRONMENT PROTECTION AGENCY OF AUSTRALIA:}

Barry Carbon, Executive Director 


\section{Memorandum of Understanding Between the United States National Oceanic and Atmospheric Administration and the Department of the Environment, Sport and Territories of Australia for Cooperation in the GLOBE Program, Canberra, 1995}

Done at Canberra 21 April 1995

Entered into force 21 April 1995

Primary source citation: Copy of text provided by the

U.S. Department of State

\section{A MEMORANDUM OF UNDERSTANDING BETWEEN THE UNITED STATES NATIONAL OCEANIC AND ATMOSPHERIC ADMINISTRATION AND THE DEPARTMENT OF THE ENVIRONMENT, SPORT AND TERRITORIES OF AUSTRALIA FOR COOPERATION IN THE GLOBE PROGRAM}

\section{PREAMBLE}

The US National Oceanic and Atmospheric Administration, acting on behalf of itself and other US Government agencies participating in the GLOBE Program (hereinafter, the US side), and the Department of the Environment, Sport and Territories of Australia (hereinafter, the Australian side),

Intending to increase the awareness of students throughout the world about the global environment,

Seeking to contribute to increased scientific understanding of the Earth, and

Desiring to support improved student achievement in science and mathematics,

Have agreed to cooperate in the Global Learning and Observations to Benefit the Environment (GLOBE) Program as follows: 


\section{ARTICLE 1 - THE GLOBE PROGRAM}

The GLOBE program is an international environmental science and education program that will bring students, teachers, and scientists together to study the global environment. GLOBE will create an international network of students in grades K-12 (or equivalent) studying environmental issues, making environmental measurements, and sharing useful environmental data with the international environmental science community.

\section{ARTICLE 2 - RESPECTIVE RESPONSIBILITIES}

A. The United States side will:

1. Identify US schools that will participate in the GLOBE Program (details regarding GLOBE schools in Appendix A);

2. Select, in consultation with international scientists and educators, the GLOBE environmental measurements and types of measurement equipment (described in Appendix B);

3. Select Principal Investigator Teams for the GLOBE environmental measurements, and support the US members of the Teams;

4. Calibrate, if necessary, measurement equipment that cannot be calibrated by GLOBE teachers and students;

5. Develop, in consultation with international scientists and educators, GLOBE educational materials;

6. Translate GLOBE instructional materials related to measurement procedures and data reporting protocols into the six United Nations languages, and provide these plus all broader GLOBE educational materials to the Australian side for further reproduction as necessary;

7. Conduct annual regional training sessions for GLOBE Country Coordinators and GLOBE teachers who will serve as trainers for additional GLOBE teachers in Australia, and provide a copy of GLOBE training materials to the Australian side;

8. Design, develop, operate, and maintain GLOBE data processing capabilities and other necessary technology and equipment;

9. Provide GLOBE software, as necessary, for use on Australian GLOBE school computers. (To the maximum extent possible, textual materials appearing on computer screens will be accessible in the student's choice among the six United Nations languages.);

10. Accept environmental data reported from GLOBE schools around the world, and develop and provide resultant global environmental images (visualisation products) to the Australian side; and

11. Evaluate the overall GLOBE Program periodically in consultation with international GLOBE Country Coordinators, and modify the overall program as appropriate.

B. The Australian side will:

1. Select Australian schools to participate in the GLOBE Program (details regarding GLOBE schools in Appendix A) and provide an updated list of Australian GLOBE schools to the US side at the beginning of each school year;

2. Ensure that Australian GLOBE schools conduct the fundamental activities of GLOBE schools detailed in Appendix A (take GLOBE environmental measurements, report data, and receive and use resultant global environmental images, using GLOBE educational materials under the guidance of teachers trained to conduct the GLOBE Program); 
3. Name an Australian Government Point of Contact responsible for policy-level communications with the Director of the GLOBE Program;

4. Name a Country Coordinator responsible for day-to-day management, oversight, and facilitation of the GLOBE Program in Australia;

5. Ensure that the Country Coordinator and some GLOBE teachers attend GLOBE regional training and in turn provide GLOBE training to at least one teacher in each Australian GLOBE school;

6. Ensure that GLOBE instructional materials related to measurement procedures and data reporting protocols are utilised in Australian GLOBE schools, and that broader GLOBE educational materials are appropriately translated, adapted, reproduced and distributed to all Australian GLOBE schools;

7. Ensure that Australian GLOBE schools have the necessary measurement equipment to take GLOBE environmental measurements (described in Appendix B);

8. Ensure that teachers and students at Australian GLOBE schools calibrate GLOBE measurement equipment according to procedures provided in GLOBE instructional materials;

9. Ensure that Australian GLOBE schools have the necessary computer and communications systems (described in Appendix C) to report GLOBE environmental measurements and to receive and use GLOBE visualization products, or make agreed alternative arrangements for such reporting and receipt. (At a minimum, the Australian country Coordinator will need access to Internet so that all measurement data from Australian GLOBE schools will be reported via Internet.); and

10. Evaluate GLOBE operations in Australia periodically and assist the US side in conducting periodic evaluation of the overall GLOBE Program.

\section{ARTICLE 3 - FINANCIAL ARRANGEMENTS}

Each side will bear the costs of fulfilling its respective responsibilities under this understanding. Obligations of each side pursuant to this understanding are subject to its respective funding procedures and the availability of appropriate funds, personnel, and other resources. The conduct of activities under this understanding will be consistent with the relevant laws and regulations of the two sides.

\section{ARTICLE 4 - EXCHANGE OF DATA AND GOODS}

GLOBE environmental measurement data, visualisation products, software and educational materials will be available worldwide without restriction as to their use or redistribution.

\section{ARTICLE 5 - RELEASE OF INFORMATION ABOUT THE GLOBE PROGRAM}

Each side may release information on the GLOBE Program as it may deem appropriate without prior consultation with the other.

\section{ARTICLE 6 - CUSTOMS AND IMMIGRATION}

Each side will, to the extent permitted by its laws and regulations, facilitate the movement of persons and goods necessary to implement this understanding into and out of its territory and accord entry to such goods into its territory free of customs duties and other similar charges. 


\section{ARTICLE 7 - DURATION AND AMENDMENT}

This understanding will enter into force upon signature of the two sides and will remain in force for five years. It will be automatically extended for further five-year periods, unless either side decides to terminate it and so notifies the other side with three months written notice. This understanding may be terminated at any time by either side upon three months prior written notice to the other side.

This understanding may be amended by written agreement of the two sides. A successor agency may assume the rights and obligations of this MOU upon the written agreement to that effect and the concurrence of both of the present sides which shall not be unreasonably withheld.

IN WITNESS WHEREOF, the undersigned, being duly authorised, have signed this Memorandum of Understanding.

SIGNED at Canberra, this twenty first day of April, 1995, in duplicate, in the English language.

For the National Oceanic and

Atmospheric Administration:

[Signature]

Kaarn J. Weaver

Chargé d'Affaires, a.i.
For the Department of the

Environment, Sport and Territories:

[Signature]

Stuart Hamilton

Secretary

\section{APPENDIX A}

\section{GLOBE Schools}

Each partner country will be responsible for identifying its participating schools. Schools should be selected so as to satisfy the objectives of the GLOBE Program. In particular, countries should emphasise the selection of schools that will maximise the number of students worldwide participating in the program. Also, countries should consider involving schools in locations that will yield measurement data that is important to the international environmental science community.

Students at all GLOBE schools throughout the world will conduct the following fundamental activities: they will make environmental measurements at or near their schools; report their data to a GLOBE data processing site; receive vivid graphical global environmental images (visualisation products) created from their data and the data from other GLOBE schools around the world; and study the environment by relating their observations and the resulting visualisation products to broader environmental topics. All of these activities will be conducted under the guidance of specially trained teachers (GLOBE-trained teachers).

GLOBE educational materials will be used in GLOBE schools under the guidance of GLOBE-trained teachers. These materials will detail procedures for taking environmental measurements and protocols for reporting data; explain the significance of the measurements; guide the use of the visualisation products; and integrate the measurement aspects of the program into a broader study of the environment.

Schools throughout the United States and the rest of the world that are not GLOBE schools may become GLOBE Affiliate schools by observing the GLOBE Program in operation through the Internet. Students at these schools will benefit from the use of GLOBE visualisation products and educational materials accessible on-line. All GLOBE Affiliate schools will be encouraged to become participating GLOBE schools. 


\section{APPENDDX B}

\section{GLOBE Environmental Measurements and Equipment}

GLOBE environmental measurements will contribute in a significant way to the scientific understanding of the dynamics of the global environment. Every GLOBE school will conduct a core set of GLOBE environmental measurements in the following critical areas: Atmosphere/Climate, Hydrology/Water Chemistry, and Biology/Geology. Where possible, a GLOBE school may coordinate its activities with those of other neighbouring GLOBE schools, so that the complete set of GLOBE measurements will be available from a locality. As the GLOBE Program evolves, elective measurements not common to all GLOBE schools may be added in order to address local environmental issues.

Students at all age levels will be active participants in the GLOBE Program. The actual participation will be designed so as to be grade-appropriate for grades $\mathrm{K}-5,6-8$ and $9-12$ (or equivalent). Younger students will make limited measurements which may be qualitative rather quantitative. Older students will make additional measurements and more sophisticated measurements, as appropriate for their grade level. Measurement equipment will not need to be standardised; rather, performance specifications will be provided.

Following is an example list of core measurements and equipment. The full list will be initially determined and periodically updated as provided in Article 2.A.2, based on experience gained in implementing the GLOBE Program.

\section{MEASUREMENTS}

\section{Atmosphere/Climate:}

Air Temperature

Precipitation

Cloud Cover/Type

Hydrology/Water Chemistry:

Water $\mathrm{pH}$

Water Temperature

Soil Moisture

\section{Biology/Geology:}

Habitat Study

Tree Height

Tree Canopy

Tree Diameter

Species Identification

Phenology

\section{EQUIPMENT NEEDED}

\author{
Max/Min Thermometer \\ Calibration Thermometer \\ Instrument Shelter \\ Rain Gauge \\ Cloud Charts
}

\author{
pH Paper, Pen, or Meter \\ Alcohol Thermometer \\ Gypsum block Sensors \\ Soil Moisture Meter
}

\author{
Compass \\ Meter Measuring Tape \\ Surveying Markers or Stakes \\ Clinometer \\ Densiometer \\ Diameter Tape \\ Dichotomous Keys \\ 35mm Camera
}

\section{APPENDIX C}

\section{GLOBE Computer and Communications Systems}

In order to derive maximum benefit from the GLOBE Program, all schools will be encouraged to use an international information network, initially using the Internet, along with classroom computers. The World Wide Web multi-media information-access capability has been selected as the basis for IBM-compatible and Apple Macintosh computer systems to support the required GLOBE school activities of data entry, data analysis, and use of GLOBE environmental images. Following is a description of GLOBE computer and communications systems consistent with current GLOBE requirements. 
Overall attributes of the minimum GLOBE school computer configuration that can execute the necessary software are:

For IBM-compatible systems: a 386 SX or higher level processor; at least 4 megabytes of RAM memory (8 megabytes preferred); a VGA-capable monitor and display driver (Super VGA preferred); a hard disk storage system with as large a capacity as possible (preferably 300 megabytes or larger); and a direct Internet connection or dial-up capability that can use SLIP and PPP protocols with a 14,400 bps modem (preferably supporting V.42bis data compression which can enable 57,600 bps operation). The Windows 3.1 or later operating system is necessary. A printer is desirable.

For Apple Macintosh systems: a 6803020 Mhz or faster processor; at least 4 megabytes of RAM memory (8 megabytes preferred); a hard disk storage system with as large a capacity as possible (preferably 300 megabytes or larger); and a direct Internet connection or dial-up capability that can use SLIP or PPP protocols with a 14,400 bps modem (preferably supporting V.42bis data compression which can enable 57,600 pbs operation. A printer is desirable.

Software for a higher performance GLOBE school computer system is being developed that will operate on higher performance, multi-media IBM-compatible systems and on Apple Macintosh systems. For IBM-compatible systems: a 486/66 or faster processor; 16 megabytes of RAM memory; 500 megabytes of hard disk space; a Super VGA monitor; a double-speed CD-ROM reader; a Soundblaster-compatible sound card; and an MPEG animation speed-up board will be required. For Apple Macintosh systems: a PowerPC processor; 16 megabytes of RAM memory; 500 megabytes of hard disk space; and a double-speed CD-ROM reader will be required. A communications capability the same as or better than for the minimum configurations above will also be required. A printer will be highly desirable.

It is recognised that there is a broad range of technological capabilities among potential GLOBE schools. The diversity of technology accessible by schools worldwide may require in some cases that environmental measurements be reported in hardcopy and that a variety of media be used to distribute visualisation products, including photographs and broadcast television. All schools that want to participate in the program will be accommodated.

Technology associated with the GLOBE Program will continually evolve to higher levels and participants will be encouraged to upgrade over time. 
Austria

ENVIRONMENT AND NATURAL RESOURCES 



\section{Memorandum of Understanding on Cooperation in Environmental Aspects of Energy Policy and the Protection of the Global Climate Between the Department of Energy of the United States of America and the Federal Ministry of Environment, Youth and Family Affairs of the Republic of Austria, Vienna, 1994}

Done at Vienna 18 September 1994

Entered into force 18 September 1994

Primary source citation: Copy of text provided by the U.S. Department of State

\section{MEMORANDUM OF UNDERSTANDING ON COOPERATION IN ENVIRONMENTAL ASPECTS OF ENERGY POLICY AND THE PROTECTION OF GLOBAL CLIMATE BETWEEN THE DEPARTMENT OF ENERGY OF THE UNITED STATES OF AMERICA AND THE FEDERAL MINISTRY OF ENVIRONMENT, YOUTH AND FAMILY AFFAIRS OF THE REPUBLIC OF AUSTRIA}

The Department of Energy of the United States of America and the Federal Ministry of Environment, Youth and Family Affairs of the Republic of Austria (hereinafter "the Parties")

- Affirming the traditionally friendly and mutually-beneficial relations and cooperation between their respective countries;

- Desiring to undertake efforts and endeavours in promoting the development of environmentally sound energy strategies based on sustainable patterns of energy use;

- Desiring to strengthen collaboration between the two countries in combating climate change; and

- Desiring to exchange nonproprietary information, ideas, skills and techniques in the above-mentioned areas of concern, 
Have reached the following understanding to guide their cooperation.

\section{ARTICLE I}

The cooperation contemplated under this Memorandum of Understanding (MOU) may include:

* Exchange of information and discussions on existing national policies in the following areas:

- sufficient growth of energy supplies;

- energy efficiency and conservation measures; and

- $\quad$ protection of the biosphere;

* Cooperation in the organization of workshops and seminars on subjects of mutual interest;

* Exchange of experts and scientists to study problems in the field of energy policy;

* Exchange of relevant nonproprietary data and information; and

* Cooperation in relevant international fora.

\section{ARTICLE II}

Within the framework of Article I, the Parties may particularly focus their cooperation on the following areas:

* Implementation of the United Nations Framework Convention on Climate Change, including the exchange of expertise on National Climate Change Action Plans and development and implementation of agreements under the Convention;

* Options in the field of new and renewable energy technologies and in the field of energy efficiency, encompassing both supply-side and demand-side technologies;

* Tools for energy-efficient management in industry, and demand-side-management practices of utilities; and

- Political instruments to enhance the utilization of new and renewable energy technologies and to foster overall energy efficiency, with a focus on regulation/deregulation in the energy market.

Each Party will work to involve other relevant government institutions and interests of its country to improve the work and cooperation carried out under this MOU.

\section{ARTICLE III}

Each Party will endeavor to facilitate, through cooperation with the appropriate competent authorities, the granting of visas and other forms of official permission for entry to and exit from its territory of personnel of the other country engaged in cooperative activities under this MOU.

\section{ARTICLE IV}

Cooperation under this MOU will be subject to all applicable laws and regulations of the two countries, and to the availability of personnel and appropriated funds. Each party will be responsible for the costs of its own activities under this MOU. 


\section{ARTICLE V}

This MOU may be modified by mutual agreement of the Parties or terminated by either Party. The termination of this MOU will not affect the completion of activities underway.

Signed in duplicate at Vienna, Austria this 18th day of September, 1994.

[Signature]

For the

Department of Energy

of the United States

of America

\section{[Signature]}

For the

Ministry of Environment, Youth and Family Affairs of the Republic of

Austria 


\section{Agreement Between the National Oceanic and Atmospheric}

Administration of the United States of America and the Federal Ministry for Education of the Republic of Austria for Cooperation in the GLOBE Program, Vienna, 1995

Done at Vienna 20 April 1995

Entered into force 20 April 1995

Primary source citation: Copy of text provided by the

U.S. Department of State

\section{AN AGREEMENT BETWEEN THE NATIONAL OCEANIC AND ATMOSPHERIC ADMINISTRATION OF THE UNITED STATES OF AMERICA AND THE FEDERAL MINISTRY FOR EDUCATION OF THE REPUBLIC OF AUSTRIA FOR COOPERATION IN THE GLOBE PROGRAM}

\section{PREAMBLE}

The U.S. National Oceanic and Atmospheric Administration, acting on behalf of itself and other U.S. Government agencies participating in the GLOBE Program (hereinafter, the U.S. side), and the Federal Ministry for Education of the Republic of Austria (hereinafter, the Austrian side),

Intending to increase the awareness of students throughout the world about the global environment,

Seeking to contribute to increased scientific understanding of the Earth, and

Desiring to support improved student achievement in science and mathematics,

Have agreed to cooperate in the Global Learning and Observations to Benefit the Environment (GLOBE) Program as follows: 


\section{ARTICLE 1 - THE GLOBE PROGRAM}

The GLOBE Program is an international environmental science and education program that will bring students, teachers, and scientists together to study the global environment. GLOBE will create an international network of students in grades K-12 (or equivalent) studying environmental issues, making environmental measurements, and sharing useful environmental data with the international environmental science community.

\section{ARTICLE 2 - RESPECTIVE RESPONSIBILITIES}

A. The U.S. side will:

1. Identify U.S. schools that will participate in the GLOBE Program (details regarding GLOBE schools in Appendix A);

2. Select, in consultation with international scientists and educators, the GLOBE environmental measurements and types of measurement equipment (described in Appendix B);

3. Select Principal Investigator Teams for the GLOBE environmental measurements, and support the U.S. members of the Teams;

4. Calibrate, if necessary, measurement equipment that cannot be calibrated by GLOBE teachers and students;

5. Develop, in consultation with international scientists and educators, GLOBE educational materials;

6. Translate GLOBE instructional materials related to measurement procedures and data reporting protocols into the six United Nations languages, and provide these plus all broader GLOBE educational materials to the Austrian side for further reproduction as necessary;

7. Conduct annual regional training sessions for GLOBE Country Coordinators and GLOBE teachers who will serve as trainers for additional GLOBE teachers in the Republic of Austria, and provide a copy of GLOBE training materials to the Austrian side;

8. Design, develop, operate, and maintain GLOBE data processing capabilities and other necessary technology and equipment;

9. Provide GLOBE software, as necessary, for use on Austrian GLOBE school computers. (To the maximum extent possible, textual material appearing on computer screens will be accessible in the student's choice among the six United Nations languages.);

10. Accept environmental data reported from GLOBE schools around the world, and develop and provide resultant global environmental images (visualization products) to the Austrian side; and

11. Evaluate the overall GLOBE Program periodically, in consultation with international GLOBE Country Coordinators, and modify the overall program as appropriate.

B. The Austrian side will:

1. Select Austrian schools to participate in the GLOBE Program (details regarding GLOBE schools in Appendix A) and provide an updated list of Austrian GLOBE schools to the U.S. side at the beginning of each school year;

2. Ensure that Austrian GLOBE schools conduct the fundamental activities of GLOBE schools detailed in Appendix A (take GLOBE environmental measurements, report data, and receive and use resultant global environmental images, using GLOBE educational materials under the guidance of teachers trained to conduct the GLOBE Program); 
3. Name an Austrian Government Point of Contact responsible for policy-level communications with the Director of the GLOBE Program;

4. Name a Country Coordinator responsible for day-to-day management, oversight, and facilitation of the GLOBE Program in the Republic of Austria;

5. Ensure that the Country Coordinator and some GLOBE teachers attend GLOBE regional training and in turn provide GLOBE training to at least one teacher in each Austrian GLOBE school;

6. Ensure that GLOBE instructional materials related to measurement procedures and data reporting protocols are utilized in Austrian GLOBE schools, and that broader GLOBE educational materials are appropriately translated, adapted, reproduced, and distributed to all Austrian GLOBE schools;

7. Ensure that Austrian GLOBE schools have the necessary measurement equipment to take GLOBE environmental measurements (described in Appendix B);

8. Ensure that teachers and students at Austrian GLOBE schools calibrate GLOBE measurement equipment according to procedures provided in GLOBE instructional materials;

9. Ensure that Austrian GLOBE schools have the necessary computer and communications systems (described in Appendix C) to report GLOBE environmental measurements and to receive and use GLOBE visualization products, or make agreed alternative arrangements for such reporting and receipt. (At a minimum, the Austrian Country Coordinator will need access to Internet so that all measurement data from Austrian GLOBE schools will be reported via Internet.); and

10. Evaluate GLOBE operations in the Republic of Austria periodically and assist the U.S. side in conducting periodic evaluation of the overall GLOBE Program.

\section{ARTICLE 3 - FINANCIAL ARRANGEMENTS}

Each side will bear the costs of fulfilling its respective responsibilities under this agreement. Obligations of each side pursuant to this agreement are subject to its respective funding procedures and the availability of appropriated funds, personnel, and other resources. The conduct of activities under this agreement will be consistent with the relevant laws and regulations of the two sides.

\section{ARTICLE 4 - EXCHANGE OF DATA AND GOODS}

GLOBE environmental measurement data, visualization products, software, and educational materials will be available worldwide without restriction as to their use or redistribution.

\section{ARTICLE 5 - RELEASE OF INFORMATION ABOUT THE GLOBE PROGRAM}

Each side may release information on the GLOBE Program as it may deem appropriate without prior consultation with the other.

\section{ARTICLE 6 - CUSTOMS AND IMIIGRATION}

Each side will, to the extent permitted by its laws and regulations, facilitate the movement of persons and goods necessary to implement this agreement into and out of its territory and accord entry to such goods into its territory free of customs duties and other similar charges. 


\section{ARTICLE 7 - ENTRY INTO FORCE, AMENDMENTS, WITHDRAWAL}

This agreement will enter into force upon signature of the two sides and will remain in force for five years. It will be automatically extended for further five-year periods, unless either side decides to terminate it and so notifies the other side with three months written notice. This agreement may be terminated at any time by either side upon three months prior written notice to the other side. This agreement may be amended by written agreement of the two sides.

Done at Vienna on the 20th day of April, 1995, in duplicate.

For the National Oceanic and

Atmospheric Administration:

[Signature]
For the Federal Ministry for

Education:

[Signature]

\section{APPENDIX A GLOBE Schools}

Each partner country will be responsible for identifying its participating schools. Schools should be selected so as to satisfy the objectives of the GLOBE Program. In particular, countries should emphasize the selection of schools that will maximize the number of students worldwide participating in the program. Also, countries should consider involving schools in locations that will yield measurement data that is important to the international environmental science community.

Students at all GLOBE schools throughout the world will conduct the following fundamental activities: they will make environmental measurements at or near their schools; report their data to a GLOBE data processing site; receive vivid graphical global environmental images (visualization products) created from their data and the data from other GLOBE schools around the world; and study the environment by relating their observations and the resulting visualization products to broader environmental topics. All of these activities will be conducted under the guidance of specially trained teachers (GLOBE-trained teachers).

GLOBE educational materials will be used in GLOBE schools under the guidance of GLOBE-trained teachers. These materials will detail procedures for taking environmental measurements and protocols for reporting data; explain the significance of the measurements; guide the use of the visualization products; and integrate the measurement aspects of the program into a broader study of the environment.

Schools throughout the United States and the rest of the world that are not GLOBE schools may become GLOBE Affiliate schools by observing the GLOBE Program in operation through the Internet. Students at these schools will benefit from the use of GLOBE visualization products and educational materials accessible on-line. All GLOBE Affiliate schools will be encouraged to become participating GLOBE schools.

\section{APPENDIX B GLOBE Environmental Measurements and Equipment}

GLOBE environmental measurements will contribute in a significant way to the scientific understanding of the dynamics of the global environment. Every GLOBE school will conduct a core set of GLOBE environmental measurements in the following critical areas: Atmosphere/Climate, Hydrology/Water Chemistry, and Biology/Geology. Where possible, a GLOBE school may coordinate its activities with those of other neighboring GLOBE schools, so that the complete set of GLOBE measurements will be available from a locality. As the GLOBE Program evolves, elective measurements not common to all GLOBE schools may be added in order to address local environmental issues.

Students at all age levels will be active participants in the GLOBE Program. The actual participation will be designed so as to be grade-appropriate for grades $\mathrm{K}-5,6-8$, and 9-12 (or equivalent). Younger students will make limited measurements which may be qualitative rather than quantitative. Older students will make additional measure- 
ments and more sophisticated measurements, as appropriate for their grade level. Measurement equipment will not need to be standardized; rather, performance specifications will be provided.

Following is an example list of core measurements and equipment. The full list will be initially determined and periodically updated as provided in Article 2.A.2, based on experience gained in implementing the GLOBE Program.

\section{MEASUREMENTS}

\section{Atmosphere/Climate:}

Air Temperature

Precipitation

Cloud Cover/Type

Hydrology/Water Chemistry:

Water $\mathrm{pH}$

Water Temperature

Soil Moisture

\section{Biology/Geology:}

Habitat Study

Tree Height

Tree Canopy

Tree Diameter

Species Identification

Phenology

\section{EQUIPMENT NEEDED}

\author{
Max/Min Thermometer \\ Calibration Thermometer \\ Instrument Shelter \\ Rain Gauge \\ Cloud Charts
}

pH Paper, Pen, or Meter

Alcohol Thermometer

Gypsum Block Sensors

Soil Moisture Meter

\section{APPENDIX C \\ GLOBE Computer and Communications Systems}

In order to derive maximum benefit from the GLOBE Program, all schools will be encouraged to use an international information network, initially using the Internet, along with classroom computers. The World Wide Web multi-media information-access capability has been selected as the basis for IBM-compatible and Apple Macintosh computer systems to support the required GLOBE school activities of data entry, data analysis, and use of GLOBE environmental images. Following is a description of GLOBE computer and communications systems consistent with current GLOBE requirements.

Overall attributes of the minimum GLOBE school computer configuration that can execute the necessary software are:

For IBM-compatible systems: a $386 \mathrm{SX}$ or higher level processor; at least 4 megabytes of RAM memory ( 8 megabytes preferred); a VGA-capable monitor and display driver (Super VGA preferred); a hard disk storage system with as large a capacity as possible (preferably 300 megabytes or larger); and a direct Internet connection or dial-up capability that can use SLIP or PPP protocols with a 14,400 bps modem (preferably supporting V.42bis data compression which can enable 57,600 bps operation). The Windows 3.1 or later operating system is necessary. A printer is desirable.

For Apple Macintosh systems: a $6803020 \mathrm{Mhz}$ or faster processor; at least 4 megabytes of RAM memory ( 8 megabytes preferred); a hard disk storage system with as large a capacity as possible (preferably 300 megabytes or larger); and a direct Internet connection or dial-up capability that can use SLIP or PPP protocols with a 14,400 bps modem (preferably supporting V.42bis data compression which can enable 57,600 bps operation). A printer is desirable.

Software for a higher performance GLOBE school computer system is being developed that will operate on higher performance, multi-media IBM-compatible systems and on Apple Macintosh systems. For IBM-compatible systems: 
a 486/66 or faster processor; 16 megabytes of RAM memory; 500 megabytes of hard disk space; a Super VGA monitor; a double-speed CD-ROM reader; a Soundblaster-compatible sound card; and an MPEG animation speed-up board will be required. For Apple Macintosh systems: a PowerPC processor; 16 megabytes of RAM memory; 500 megabytes of hard disk space; and a double-speed CD-ROM reader will be required. A communications capability the same as or better than for the minimum configurations above will also be required. A printer will be highly desirable.

It is recognized that there is a broad range of technological capabilities among potential GLOBE schools. The diversity of technology accessible by schools worldwide may require in some cases that environmental measurements be reported in hardcopy and that a variety of media be used to distribute visualization products, including photographs and broadcast television. All schools that want to participate in the program will be accommodated.

Technology associated with the GLOBE Program will continually evolve to higher levels and participants will be encouraged to upgrade over time. 



\section{B I L A T E R A L}

\section{BELGIUM}

ENVIRONMENTAND NATURAL RESOURCES 



\section{Memorandum of Understanding Between the National Oceanic and Atmospheric Administration of the United States of America and the Ministry of Education of the German-Speaking Community (Belgium) for Cooperation in the GLOBE Program, Brussels, 1995}

Done at Brussels 24 March 1995

Entered into force 24 March 1995

Primary source citation: Copy of text provided by the U.S. Department of State

\section{MEMORANDUM OF UNDERSTANDING BETWEEN THE NATIONAL OCEANIC AND ATMOSPHERIC ADMINISTRATION OF THE UNITED STATES OF AMERICA AND THE MINISTRY OF EDUCATION OF THE GERMAN-SPEAKING COMMUNITY (BELGIUM) FOR COOPERATION IN THE GLOBE PROGRAM}

\section{PREAMBLE}

The National Oceanic and Atmospheric Administration of the United States of America, acting on behalf of itself and other U.S. Government agencies participating in the GLOBE Program (hereinafter, the U.S. side), and the Ministry of Education of the German-speaking Community (Belgium) (hereinafter, the German Community side),

Intending to increase the awareness of students throughout the world about the global environment,

Seeking to contribute to increased scientific understanding of the Earth, and

Desiring to support improved student achievement in science and mathematics,

Wishing to conduct activities in furtherance of the Global Learning and Observations to Benefit the Environment (GLOBE) Program,

Have agreed to the following terms and conditions: 


\section{ARTICLE 1 - THE GLOBE PROGRAM}

The GLOBE Program is an international environmental science and education program that will bring students, teachers, and scientists together to study the global environment. GLOBE will create an international network of students in grades K-12 (or equivalent) studying environmental issues, making environmental measurements, and sharing useful environmental data with the international environmental science community.

\section{ARTICLE 2 - RESPECTIVE RESPONSIBILITIES}

A. The U.S. side will:

1. Identify U.S. schools that will participate in the GLOBE Program (details regarding GLOBE schools in Appendix A);

2. Select, in consultation with international scientists and educators, the GLOBE environmental measurements and types of measurement equipment (described in Appendix B);

3. Select Principal Investigator Teams for the GLOBE environmental measurements, and support the U.S. members of the Teams;

4. Calibrate, if necessary, measurement equipment that cannot be calibrated by GLOBE teachers and students;

5. Develop, in consultation with international scientists and educators, GLOBE educational materials;

6. Translate GLOBE instructional materials related to measurement procedures and data reporting protocols into the six United Nations languages, and provide these plus all broader GLOBE educational materials to the German Community side for further reproduction as necessary;

7. Conduct annual regional training sessions for GLOBE Country Coordinators and GLOBE teachers who will serve as trainers for additional GLOBE teachers in the German Community, and provide a copy of GLOBE training materials to the German Community side;

8. Design, develop, operate, and maintain GLOBE data processing capabilities and other necessary technology and equipment;

9. Provide GLOBE software, as necessary, for use on German Community GLOBE school computers. (To the maximum extent possible, textual material appearing on computer screens will be accessible in the student's choice among the six United Nations languages.);

10. Accept environmental data reported from GLOBE schools around the world, and develop and provide resultant global environmental images (visualization products) to the German Community side; and

11. Evaluate the overall GLOBE Program periodically, in consultation with international GLOBE Country Coordinators, and modify the overall program as appropriate.

B. The German Community side will:

1. Select German Community schools to participate in the GLOBE Program (details regarding GLOBE schools in Appendix A) and provide an updated list of German Community GLOBE schools to the U.S. side at the beginning of each school year;

2. Ensure that German Community GLOBE schools conduct the fundamental activities of GLOBE schools detailed in Appendix A (take GLOBE environmental measurements, report data, and receive and use resultant global environmental images, using GLOBE educational materials under the guidance of teachers trained to conduct the GLOBE Program); 
3. Name a German Community Government Point of Contact responsible for policy-level communications with the Director of the GLOBE Program;

4. Name a Community Coordinator responsible for day-to-day management, oversight, and facilitation of the GLOBE Program in the German Community;

5. Ensure that the Community Coordinator and some GLOBE teachers attend GLOBE regional training and in turn provide GLOBE training to at least one teacher in each German Community GLOBE school;

6. Ensure that GLOBE instructional materials related to measurement procedures and data reporting protocols are utilized in German Community GLOBE schools, and that broader GLOBE educational materials are appropriately translated, adapted, reproduced, and distributed to all German Community GLOBE schools;

7. Ensure that German Community GLOBE schools have the necessary measurement equipment to take GLOBE environmental measurements (described in Appendix B);

8. Ensure that teachers and students at German Community GLOBE schools calibrate GLOBE measurement equipment according to procedures provided in GLOBE instructional materials;

9. Ensure that German Community GLOBE schools have the necessary computer and communications systems (described in Appendix C) to report GLOBE environmental measurements and to receive and use GLOBE visualization products, or make agreed alternative arrangements for such reporting and receipt. (At a minimum, the German Community Coordinator will need access to Internet so that all measurement data from German Community GLOBE schools will be reported via Internet.); and

10. Evaluate GLOBE operations in the German Community periodically and assist the U.S. side in conducting periodic evaluation of the overall GLOBE Program.

\section{AR'TICLE 3 - FINANCIAL AND LEGAL ARRANGEMENTS}

Each side will bear the costs of fulfilling its respective responsibilities under this agreement. Obligations of each side pursuant to this agreement are subject to its respective funding procedures and the availability of appropriated funds, personnel, and other resources.

The conduct of activities under this agreement will be consistent with the relevant laws and regulations of the two sides. Nothing in this Memorandum of Understanding is intended to create binding obligations under international law.

\section{ARTICLE 4 - EXCHANGE OF DATA AND GOODS}

GLOBE environmental measurement data, visualization products, software, and educational materials will be available worldwide without restriction as to their use or redistribution.

\section{ARTICLE 5 - RELEASE OF INFORMATION ABOUT THE GLOBE PROGRAM}

Each side may release information on the GLOBE Program as it may deem appropriate without prior consultation with the other. 


\section{ARTICLE 6 - ENTRY INTO FORCE, AMENDMENTS, WITHDRAWAL}

Activities under this Memorandum of Understanding will begin upon signature by the two sides and will continue for five years. They may be automatically extended for further five-year periods, unless either side decides to discontinue them and so notifies the other side with three months written notice. Activities hereunder may be terminated at any time by either side upon three months prior written notice to the other side. This Memorandum of Understanding may be amended by written agreement of the two sides.

Done at Brussels on the twenty-fourth day of March, 1995.

For the National Oceanic and

Atmospheric Administration of

the United States of America:

[Signature]

For the Ministry of Education of the German-speaking Community (Belgium):

[Signature]
Alan J. Blinken

Ambassador

\author{
Bernd Gentges \\ Minister of Education, \\ Culture, Youth, and \\ Scientific Research
}

\section{APPENDIX A GLOBE Schools}

Each partner will be responsible for identifying its participating schools. Schools should be selected so as to satisfy the objectives of the GLOBE Program. In particular, partners should emphasize the selection of schools that will maximize the number of students worldwide participating in the program. Also, partners should consider involving schools in locations that will yield measurement data that is important to the international environmental science community.

Students at all GLOBE schools throughout the world will conduct the following fundamental activities: they will make environmental measurements at or near their schools; report their data to a GLOBE data processing site; receive vivid graphical global environmental images (visualization products) created from their data and the data from other GLOBE schools around the world; and study the environment by relating their observations and the resulting visualization products to broader environmental topics. All of these activities will be conducted under the guidance of specially trained teachers (GLOBE-trained teachers).

GLOBE educational materials will be used in GLOBE schools under the guidance of GLOBE-trained teachers. These materials will detail procedures for taking environmental measurements and protocols for reporting data; explain the significance of the measurements; guide the use of the visualization products; and integrate the measurement aspects of the program into a broader study of the environment.

Schools throughout the United States and the rest of the world that are not GLOBE schools may become GLOBE Affiliate schools by observing the GLOBE Program in operation through the Internet. Students at these schools will benefit from the use of GLOBE visualization products and educational materials accessible on-line. All GLOBE Affiliate schools will be encouraged to become participating GLOBE schools. 


\section{APPENDIX B \\ GLOBE Environmental Measurements and Equipment}

GLOBE environmental measurements will contribute in a significant way to the scientific understanding of the dynamics of the global environment. Every GLOBE school will conduct a core set of GLOBE environmental measurements in the following critical areas: Atmosphere/Climate, Hydrology/Water Chemistry, and Biology/Geology. Where possible, a GLOBE school may coordinate its activities with those of other neighboring GLOBE schools, so that the complete set of GLOBE measurements will be available from a locality. As the GLOBE Program evolves, elective measurements not common to all GLOBE schools may be added in order to address local environmental issues.

Students at all age levels will be active participants in the GLOBE Program. The actual participation will be designed so as to be grade-appropriate for grades K-5, 6-8, and 9-12 (or equivalent). Younger students will make limited measurements which may be qualitative rather than quantitative. Older students will make additional measurements and more sophisticated measurements, as appropriate for their grade level. Measurement equipment will not need to be standardized; rather, performance specifications will be provided.

Following is an example list of core measurements and equipment. The full list will be initially determined and periodically updated as provided in Article 2.A.2, based on experience gained in implementing the GLOBE Program.

\section{MEASUREMENTS}

Atmosphere/Climate:

Air Temperature

Precipitation

Cloud Cover/Type

Hydrology/Water Chemistry:

Water $\mathrm{pH}$

Water Temperature

Soil Moisture

\section{Biology/Geology: \\ Habitat Study}

Tree Height

Tree Canopy

Tree Diameter

Species Identification

Phenology

\section{EQUIPMENT NEEDED}

\author{
Max/Min Thermometer \\ Calibration Thermometer \\ Instrument Shelter \\ Rain Gauge \\ Cloud Charts
}

pH Paper, Pen, or Meter

Alcohol Thermometer

Gypsum Block Sensors

Soil Moisture Meter

\section{APPENDIX C GLOBE Computer and Communications Systems}

In order to derive maximum benefit from the GLOBE Program, all schools will be encouraged to use an international information network, initially using the Internet, along with classroom computers. The World Wide Web multi-media information-access capability has been selected as the basis for IBM-compatible and Apple Macintosh computer systems to support the required GLOBE school activities of data entry, data analysis, and use of GLOBE environmental images. Following is a description of GLOBE computer and communications systems consistent with current GLOBE requirements. 
Overall attributes of the minimum GLOBE school computer configuration that can execute the necessary software are:

For IBM-compatible systems: a $386 \mathrm{SX}$ or higher level processor; at least 4 megabytes of RAM memory (8 megabytes preferred); a VGA-capable monitor and display driver (Super VGA preferred); a hard disk storage system with as large a capacity as possible (preferably 300 megabytes or larger); and a direct Internet connection or dial-up capability that can use SLIP or PPP protocols with a 14,400 bps modem (preferably supporting V.42bis data compression which can enable 57,600 bps operation). The Windows 3.1 or later operating system is necessary. A printer is desirable.

For Apple Macintosh systems: a $6803020 \mathrm{Mhz}$ or faster processor; at least 4 megabytes of RAM memory (8 megabytes preferred); a hard disk storage system with as large a capacity as possible (preferably 300 megabytes or larger); and a direct Internet connection or dial-up capability that can use SLIP or PPP protocols with a 14,400 bps modem (preferably supporting V.42bis data compression which can enable 57,600 bps operation). A printer is desirable.

Software for a higher performance GLOBE school computer system is being developed that will operate on higher performance, multi-media IBM-compatible systems and on Apple Macintosh systems. For IBM-compatible systems: a 486/66 or faster processor; 16 megabytes of RAM memory; 500 megabytes of hard disk space; a Super VGA monitor; a double-speed CD-ROM reader; a Soundblaster-compatible sound card; and an MPEG animation speed-up board will be required. For Apple Macintosh systems: a PowerPC processor; 16 megabytes of RAM memory; 500 megabytes of hard disk space; and a double-speed CD-ROM reader will be required. A communications capability the same as or better than for the minimum configurations above will also be required. A printer will be highly desirable.

It is recognized that there is a broad range of technological capabilities among potential GLOBE schools. The diversity of technology accessible by schools worldwide may require in some cases that environmental measurements be reported in hardcopy and that a variety of media be used to distribute visualization products, including photographs and broadcast television. All schools that want to participate in the program will be accommodated.

Technology associated with the GLOBE Program will continually evolve to higher levels and participants will be encouraged to upgrade over time. 


\section{Memorandum of Understanding}

Between the National Oceanic and Atmospheric Administration of the United States of America and the Department of Education of the Flemish Community (Belgium) for Cooperation in the GLOBE Program, Brussels, 1995

\section{Done at Brussels 24 March 1995}

Entered into force 24 March 1995

Primary source citation: Copy of text provided by the U.S. Department of State

\section{MEMORANDUM OF UNDERSTANDING BETWEEN THE NATIONAL OCEANIC AND ATMOSPHERIC ADMINISTRATION OF THE UNITED STATES OF AMERICA AND THE DEPARTMENT OF EDUCATION OF THE FLEMISH COMMUNITY (BELGIUM) FOR COOPERATION IN THE GLOBE PROGRAM}

\section{PREAMBLE}

The National Oceanic and Atmospheric Administration of the United States of America, acting on behalf of itself and other U.S. Government agencies participating in the GLOBE Program (hereinafter, the U.S. side), and the Department of Education of the Flemish Community (Belgium) (hereinafter, the Flemish side),

Intending to increase the awareness of students throughout the world about the global environment,

Seeking to contribute to increased scientific understanding of the Earth, and

Desiring to support improved student achievement in science and mathematics,

Wishing to conduct activities in furtherance of the Global Learning and Observations to Benefit the Environment (GLOBE) Program,

Have agreed to the following terms and conditions: 


\section{ARTICLE 1 - THE GLOBE PROGRAM}

The GLOBE Program is an international environmental science and education program that will bring students, teachers, and scientists together to study the global environment. GLOBE will create an international network of students in grades K-12 (or equivalent) studying environmental issues, making environmental measurements, and sharing useful environmental data with the international environmental science community.

\section{ARTICLE 2 - RESPECTIVE RESPONSIBILITIES}

A. The U.S. side will:

1. Identify U.S. schools that will participate in the GLOBE Program (details regarding GLOBE schools in Appendix A);

2. Select, in consultation with international scientists and educators, the GLOBE environmental measurements and types of measurement equipment (described in Appendix B);

3. Select Principal Investigator Teams for the GLOBE environmental measurements, and support the U.S. members of the Teams;

4. Calibrate, if necessary, measurement equipment that cannot be calibrated by GLOBE teachers and students;

5. Develop, in consultation with international scientists and educators, GLOBE educational materials;

6. Translate GLOBE instructional materials related to measurement procedures and data reporting protocols into the six United Nations languages, and provide these plus all broader GLOBE educational materials to the Flemish side for further reproduction as necessary;

7. Conduct annual regional training sessions for GLOBE Country Coordinators and GLOBE teachers who will serve as trainers for additional GLOBE teachers in the Flemish Community, and provide a copy of GLOBE training materials to the Flemish side;

8. Design, develop, operate, and maintain GLOBE data processing capabilities and other necessary technology and equipment;

9. Provide GLOBE software, as necessary, for use on Flemish GLOBE school computers. (To the maximum extent possible, textual material appearing on computer screens will be accessible in the student's choice among the six United Nations languages.);

10. Accept environmental data reported from GLOBE schools around the world, and develop and provide resultant global environmental images (visualization products) to the Flemish side; and

11. Evaluate the overall GLOBE Program periodically, in consultation with international GLOBE Country Coordinators, and modify the overall program as appropriate.

B. The Flemish side will:

1. Select Flemish schools to participate in the GLOBE Program (details regarding GLOBE schools in Appendix A) and provide an updated list of Flemish GLOBE schools to the U.S. side at the beginning of each school year;

2. Ensure that Flemish GLOBE schools conduct the fundamental activities of GLOBE schools detailed in Appendix A (take GLOBE environmental measurements, report data, and receive and use resultant global environmental images, using GLOBE educational materials under the guidance of teachers trained to conduct the GLOBE Program); 
3. Name a Flemish Government Point of Contact responsible for policy-level communications with the Director of the GLOBE Program;

4. Name a Community Coordinator responsible for day-to-day management, oversight, and facilitation of the GLOBE Program in the Flemish Community;

5. Ensure that the Community Coordinator and some GLOBE teachers attend GLOBE regional training and in turn provide GLOBE training to at least one teacher in each Flemish GLOBE school;

6. Ensure that GLOBE instructional materials related to measurement procedures and data reporting protocols are utilized in Flemish GLOBE schools, and that broader GLOBE educational materials are appropriately translated, adapted, reproduced, and distributed to all Flemish GLOBE schools;

7. Ensure that Flemish GLOBE schools have the necessary measurement equipment to take GLOBE environmental measurements (described in Appendix B);

8. Ensure that teachers and students at Flemish GLOBE schools calibrate GLOBE measurement equipment according to procedures provided in GLOBE instructional materials;

9. Ensure that Flemish GLOBE schools have the necessary computer and communications systems (described in Appendix C) to report GLOBE environmental measurements and to receive and use GLOBE visualization products, or make agreed alternative arrangements for such reporting and receipt. (At a minimum, the Flemish Community Coordinator will need access to Internet so that all measurement data from Flemish GLOBE schools will be reported via Internet.); and

10. Evaluate GLOBE operations in the Flemish Community periodically and assist the U.S. side in conducting periodic evaluation of the overall GLOBE Program.

\section{ARTICLE 3 - FINANCIAL AND LEGAL ARRANGEMENTS}

Each side will bear the costs of fulfilling its respective responsibilities under this agreement. Obligations of each side pursuant to this agreement are subject to its respective funding procedures and the availability of appropriated funds, personnel, and other resources.

The conduct of activities under this agreement will be consistent with the relevant laws and regulations of the two sides. Nothing in this Memorandum of Understanding is intended to create binding obligations under international law.

\section{ARTICLE 4 - EXCHANGE OF DATA AND GOODS}

GLOBE environmental measurement data, visualization products, software, and educational materials will be available worldwide without restriction as to their use or redistribution.

\section{ARTICLE 5 - RELEASE OF INFORMATION ABOUT THE GLOBE PROGRAM}

Each side may release information on the GLOBE Program as it may deem appropriate without prior consultation with the other.

\section{ARTICLE 6 - ENTRY INTO FORCE, AMENDMENTS, WTTHDRAWAL}

Activities under this Memorandum of Understanding will begin upon signature by the two sides and will continue for five years. They may be automatically extended for further five-year periods, unless either side decides to 
discontinue them and so notifies the other side with three months written notice. Activities hereunder may be terminated at any time by either side upon three months prior written notice to the other side. This Memorandum of Understanding may be amended by written agreement of the two sides.

Done at Brussels on the twenty-fourth day of March, 1995.

For the National Oceanic and

Atmospheric Administration of

the United States of America:

[Signature]

Alan J. Blinken

Ambassador

For the Department of Education of

the Flemish Community (Belgium):

[Signature]

Luc Van den Bossche

Minister of Education and Civil Service

\section{APPENDIX A GLOBE Schools}

Each partner will be responsible for identifying its participating schools. Schools should be selected so as to satisfy the objectives of the GLOBE Program. In particular, partners should emphasize the selection of schools that will maximize the number of students worldwide participating in the program. Also, partners should consider involving schools in locations that will yield measurement data that is important to the international environmental science community.

Students at all GLOBE schools throughout the world will conduct the following fundamental activities: they will make environmental measurements at or near their schools; report their data to a GLOBE data processing site; receive vivid graphical global environmental images (visualization products) created from their data and the data from other GLOBE schools around the world; and study the environment by relating their observations and the resulting visualization products to broader environmental topics. All of these activities will be conducted under the guidance of specially trained teachers (GLOBE-trained teachers).

GLOBE educational materials will be used in GLOBE schools under the guidance of GLOBE-trained teachers. These materials will detail procedures for taking environmental measurements and protocols for reporting data; explain the significance of the measurements; guide the use of the visualization products; and integrate the measurement aspects of the program into a broader study of the environment.

Schools throughout the United States and the rest of the world that are not GLOBE schools may become GLOBE Affiliate schools by observing the GLOBE Program in operation through the Internet. Students at these schools will benefit from the use of GLOBE visualization products and educational materials accessible on-line. All GLOBE Affiliate schools will be encouraged to become participating GLOBE schools.

\section{APPENDIX B \\ GLOBE Environmental Measurements and Equipment}

GLOBE environmental measurements will contribute in a significant way to the scientific understanding of the dynamics of the global environment. Every GLOBE school will conduct a core set of GLOBE environmental measurements in the following critical areas: Atmosphere/Climate, Hydrology/Water Chemistry, and Biology/Geology. Where possible, a GLOBE school may coordinate its activities with those of other neighboring GLOBE schools, so that the complete set of GLOBE measurements will be available from a locality. As the GLOBE Program evolves, elective measurements not common to all GLOBE schools may be added in order to address local environmental issues. 
Students at all age levels will be active participants in the GLOBE Program. The actual participation will be designed so as to be grade-appropriate for grades K-5, 6-8, and 9-12 (or equivalent). Younger students will make limited measurements which may be qualitative rather than quantitative. Older students will make additional measurements and more sophisticated measurements, as appropriate for their grade level. Measurement equipment will not need to be standardized; rather, performance specifications will be provided.

Following is an example list of core measurements and equipment. The full list will be initially determined and periodically updated as provided in Article 2.A.2, based on experience gained in implementing the GLOBE Program.

\section{MEASUREMENTS}

\section{Atmosphere/Climate:}

Air Temperature

Precipitation

Cloud Cover/Type

Hydrology/Water Chemistry:

Water $\mathrm{pH}$

Water Temperature

Soil Moisture

\section{Biology/Geology: \\ Habitat Study}

Tree Height

Tree Canopy

Tree Diameter

Species Identification

Phenology

\section{EQUIPMENT NEEDED}

\author{
Max/Min Thermometer \\ Calibration Thermometer \\ Instrument Shelter \\ Rain Gauge \\ Cloud Charts
}

pH Paper, Pen, or Meter

Alcohol Thermometer

Gypsum Block Sensors

Soil Moisture Meter

\author{
Compass \\ Meter Measuring Tape \\ Surveying Markers or Stakes \\ Clinometer \\ Densiometer \\ Diameter Tape \\ Dichotomous Keys \\ $35 \mathrm{~mm}$ Camera
}

\section{APPENDIX C GLOBE Computer and Communications Systems}

In order to derive maximum benefit from the GLOBE Program, all schools will be encouraged to use an international information network, initially using the Internet, along with classroom computers. The World Wide Web multi-media information-access capability has been selected as the basis for IBM-compatible and Apple Macintosh computer systems to support the required GLOBE school activities of data entry, data analysis, and use of GLOBE environmental images. Following is a description of GLOBE computer and communications systems consistent with current GLOBE requirements.

Overall attributes of the minimum GLOBE school computer configuration that can execute the necessary software are:

For IBM-compatible systems: a $386 \mathrm{SX}$ or higher level processor; at least 4 megabytes of RAM memory (8 megabytes preferred); a VGA-capable monitor and display driver (Super VGA preferred); a hard disk storage system with as large a capacity as possible (preferably 300 megabytes or larger); and a direct Internet connection or dial-up capability that can use SLIP or PPP protocols with a 14,400 bps modem (preferably supporting V.42bis data compression which can enable 57,600 bps operation). The Windows 3.1 or later operating system is necessary. A printer is desirable.

For Apple Macintosh systems: a $6803020 \mathrm{Mhz}$ or faster processor; at least 4 megabytes of RAM memory ( 8 megabytes preferred); a hard disk storage system with as large a capacity as possible (preferably 300 megabytes or larger); and a direct Internet connection or dial-up capability that can use SLIP or PPP protocols with a 14,400 bps modem (preferably supporting V.42bis data compression which can enable 57,600 bps operation). A printer is desirable. 
Software for a higher performance GLOBE school computer system is being developed that will operate on higher performance, multi-media IBM-compatible systems and on Apple Macintosh systems. For IBM-compatible systems: a 486/66 or faster processor; 16 megabytes of RAM memory; 500 megabytes of hard disk space; a Super VGA monitor; a double-speed CD-ROM reader; a Soundblaster-compatible sound card; and an MPEG animation speed-up board will be required. For Apple Macintosh systems: a PowerPC processor; 16 megabytes of RAM memory; 500 megabytes of hard disk space; and a double-speed CD-ROM reader will be required. A communications capability the same as or better than for the minimum configurations above will also be required. A printer will be highly desirable.

It is recognized that there is a broad range of technological capabilities among potential GLOBE schools. The diversity of technology accessible by schools worldwide may require in some cases that environmental measurements be reported in hardcopy and that a variety of media be used to distribute visualization products, including photographs and broadcast television. All schools that want to participate in the program will be accommodated.

Technology associated with the GLOBE Program will continually evolve to higher levels and participants will be encouraged to upgrade over time. 
BENIN 



\title{
Agreement of Cooperation Between the Government of the United States of America and the Government of the Republic of Benin for Cooperation in the GLOBE Program, Cotonou, 1995
}

\author{
Done at Cotonou 28 April 1995 \\ Entered into force 28 April 1995 \\ Primary source citation: Copy of text provided by the \\ U.S. Department of State
}

\section{AGREEMENT OF COOPERATION BETWEEN THE GOVERNMENT OF THE UNITED STATES OF AMERICA AND THE GOVERNMENT OF THE REPUBLIC OF BENIN REGARDING THE GLOBE PROGRAM}

\section{PREAMBLE}

The Government of the United States of America and the Government of the Republic of Benin (hereinafter the sides):

- Intending to increase the awareness of students throughout the world about the global environment,

— Seeking to contribute to increased scientific understanding of the earth, and

- Desiring to support improved student achievement in science and mathematics,

have agreed to cooperate in the Global Learning and Observations to Benefit the Environment (GLOBE) Program as follows:

\section{SECTION I - PROGRAM DESCRIPTION}

\section{Article I}

The GLOBE Program is an international environmental science and education program that will bring students, teachers, and scientists together to study the global environment. GLOBE will create an international network of students, from age five through the end of high school (the French equivalent is "maternelle" to "établissements secondaires"), studying environmental issues, making environmental measurements, and sharing useful environmental data with the international environmental science community. 


\title{
SECTION 2 - RESPECTIVE RESPONSIBILITIES
}

\begin{abstract}
Article 2
Agencies responsible for cooperation and coordination under this agreement are:

On the U.S. side, the U.S. National Oceanic and Atmospheric Administration, acting in conjunction with other U.S. Government agencies participating in the GLOBE Program;
\end{abstract}

On the Beninese side, the Ministry of National Education.

\section{Article 3}

The U.S. side will:

1. Identify U.S. schools that will participate in the GLOBE Program (details regarding these schools in Appendix A);

2. Determine, in consultation with international scientists and educators, GLOBE environmental data to be collected and types of measurement equipment (described in Appendix B);

3. Select principal investigator teams for GLOBE environmental data collection, and support the U.S. members of the teams;

4. Calibrate, if necessary, measurement equipment that cannot be calibrated by teachers or students;

5. Develop, in consultation with international scientists and educators, appropriate educational materials;

6. Translate GLOBE instructional materials related to measurement procedures and reporting protocols into the six United Nations languages, provide these plus all broader GLOBE educational materials to the Beninese side for further reproduction as necessary;

7. Conduct annual regional training sessions for GLOBE Country Coordinators and GLOBE teachers who will serve as trainers for additional GLOBE teachers in the Republic of Benin, and provide a copy of GLOBE Program training materials to the Republic of Benin;

8. Design, develop, operate, and maintain GLOBE data processing capabilities and other necessary technology and equipment;

9. Provide GLOBE software, as necessary, for use in participating Beninese schools. (To the maximum extent possible, textual material appearing on computer screens will be accessible in the student's choice among the six United Nations languages);

10. Accept environmental data reported from GLOBE schools around the world, and develop and provide resultant global environmental images (visualization products) to the Beninese side; and

11. Evaluate the overall GLOBE Program periodically, in consultation with international GLOBE Country Coordinators, and modify the overall program as appropriate.

\section{Article 4}

The Beninese side will:

1. Select Republic of Benin schools to participate in the GLOBE program and provide an updated list of Republic of Benin GLOBE schools at the beginning of each school year; 
2. Ensure that Republic of Benin GLOBE schools conduct the fundamental activities detailed in Appendix A;

3. Designate a government Point of Contact within the Ministry of National Education responsible for policy-level communications with the Director of the GLOBE Program. The Ministry of National Education will nominate a GLOBE Country Coordinator responsible for day to day management, oversight, and facilitation of the GLOBE Program in the Republic of Benin;

4. Ensure that the Country Coordinator and some GLOBE teachers attend GLOBE regional training and in turn provide GLOBE training to other teachers involved with the GLOBE Program in the Republic of Benin;

5. Ensure that the GLOBE Program instructional materials related to data collection procedures and reporting protocols are utilized in Republic of Benin GLOBE schools, and that GLOBE educational materials are appropriately adapted, reproduced, and distributed to all GLOBE schools;

6. Ensure the supply of measurement equipment necessary for the collection, processing and reporting of environmental data to GLOBE schools in the Republic of Benin as described in Appendix B and C;

7. Ensure that teachers and students at Republic of Benin GLOBE schools calibrate GLOBE measurement equipment according to procedures provided in GLOBE instructional materials;

8. Make arrangements for the Country Coordinator to have access to Internet in order that, where necessary, GLOBE measurement data from Republic of Benin schools can be reported via Internet and GLOBE visualization products can be received via Internet;

9. Evaluate GLOBE operations in the Republic of Benin periodically and assist in conducting periodic evaluations of the overall GLOBE Program.

\section{SECTION III - FINANCLAL ARRANGEMENTS}

\section{Article 5}

1. Each side will bear the costs of fulfilling its respective responsibilities under this agreement;

2. Obligations of each side pursuant to this agreement are subject to its respective funding procedures and the availability of appropriated funds, personnel, and other resources.

\section{SECTION IV - EXCHANGE AND REPORTING OF DATA AND GOODS}

\section{Article 6}

GLOBE environmental measurement data, visualization products, software, and educational materials will be available worldwide without restriction as to their use or redistribution.

\section{Article 7}

Each side may release information on the GLOBE Program as it may deem appropriate without prior consultation with the other. 


\title{
SECTION V - CUSTOMS AND IMMIGRATION PROVISIONS
}

\section{Article 8}

Each side will, in accordance with its laws and regulations, expedite customs and immigration procedures as required for implementation of this agreement.

\section{SECTION VI - GENERAL PROVISIONS}

\begin{abstract}
Article 9
The conduct of activities under this agreement will be consistent with the relevant laws and regulations of the two sides.
\end{abstract}

\section{SECTION VII - FINAL PROVISIONS}

\section{Article 10}

1. This agreement will enter into force upon signature of the two sides;

2. This agreement will remain in force for five years and it will be automatically extended for further five-year periods, unless either side decides to terminate it and notifies the other side with three months written notice;

3. This agreement may be amended by written agreement of the two sides.

Done at Cotonou, on the 28th day of April, 1995 in duplicate in the English and French languages, both texts being equally authentic.

\section{FOR THE GOVERNMENT OF THE UNITED STATES OF AMERICA:}

[Signature]

\section{FOR THE GOVERNMENT OF THE REPUBLIC OF BENIN:}

[Signature]

\section{APPENDIX A - GLOBE SCHOOLS}

Each partner country will be responsible for identifying its participating schools. Schools should be selected so as to satisfy the objectives of the GLOBE Program. In particular, countries should emphasize the selection of schools that will maximize the number of students worldwide participating in the program. Also, countries should consider involving schools in locations that will yield measurement data that is important to the international environmental science community.

Students at all GLOBE schools throughout the world will conduct the following fundamental activities: they will make environmental measurements at or near their schools; report their data to a GLOBE data processing site; receive vivid graphical global environmental images (visualization products) created from their data and the data from other GLOBE schools around the world; and study the environment by relating their observations and the resulting visualization products to broader environmental topics. All of these activities will be conducted under the guidance of specially trained teachers (GLOBE-trained teachers).

GLOBE educational materials will be used in GLOBE schools under the guidance of GLOBE-trained teachers. These materials will detail procedures for taking environmental measurements and protocols for reporting data; explain 
the significance of the measurements; guide the use of the visualization products; and integrate the measurement aspects of the program into a broader study of the environment.

Schools throughout the United States and the rest of the world that are not GLOBE schools may become GLOBE affiliate schools by observing the GLOBE Program in operation through the internet. Students at these schools will benefit from the use of GLOBE visualization products and educational materials accessible on-line. All GLOBE affiliate schools will be encouraged to become participating GLOBE schools.

\section{APPENDIX B - GLOBE ENVIRONMENTAL MEASUREMENTS AND EQUIPMENT}

GLOBE environmental measurements will contribute in a significant way to the scientific understanding of the dynamics of the global environment. Every GLOBE school will conduct a core set of GLOBE environmental measurements in the following critical areas:

Atmosphere/climate, hydrology/water chemistry, and biology/geology. Where possible, a GLOBE school may coordinate its activities with those of other neighboring GLOBE schools, so that the complete set of GLOBE measurements will be available from a locality. As the GLOBE Program evolves, elective measurements not common to all GLOBE schools may be added in order to address local environmental issues.

Students at all age levels will be active participants in the GLOBE Program. The actual participation will be designed so as to be grade-appropriate for grades k-5, 6-8, and 9-12 (or equivalent). Younger students will make limited measurements which may be qualitative rather than quantitative. Older students will make additional measurements and more sophisticated measurements, as appropriate for their grade level. Measurement equipment will not need to be standardized; rather, performance specifications will be provided.

Following is an example list of core measurements and the equipment that will be needed to take these measurements. The full list will be initially determined and periodically updated as provided in Article 2.A.2, based on experience gained in implementing the GLOBE Program.

\section{Measurements}

ATMOSPHERE/CLIMATE STUDIES:

Air Temperature

\section{Precipitation}

Cloud Cover/Type

\section{HYDROLOGY/WATER CHEMISTRY STUDIES:}

Water $\mathrm{pH}$

Water Temperature

Soil Moisture

\section{BIOLOGY/GEOLOGY STUDIES:}

Habitat Study

Tree Height

Tree Canopy

Tree Diameter

Species Identification

Phenology

\section{Equipment Needed}

\author{
Max/Min Thermometer \\ Calibration Thermometer \\ Instrument Shelter \\ Rain Gauge \\ Cloud Chart
}

pH Paper, Pen, or Meter

Alcohol Thermometer

Gypsum Block Sensors

Soil Moisture Meter

\author{
Compass. \\ Meter Measuring Tape \\ Surveying Markers or Stakes \\ Clinometer \\ Densitometer \\ Diameter Tape \\ Dichotomous Keys \\ 35mm Camera
}




\section{APPENDIX C - GLOBE COMPUTER AND COMMUNICATIONS SYSTEMS}

In order to derive maximum benefit from the GLOBE Program, all schools will be encouraged to use an international information network, initially using the internet, along with classroom computers. The World Wide Web multi-media information-access capability has been selected as the basis for IBM-compatible and Apple Macintosh computer systems to support the required GLOBE school activities of data entry, data analysis, and use of GLOBE environmental images. Following is a description of GLOBE computer and communications systems consistent with current GLOBE requirements.

Overall attributes of the minimum GLOBE school computer configuration that can execute the necessary software are:

For IBM-compatible systems: a $386 \mathrm{SX}$ or higher level processor; at least 4 megabytes of RAM memory ( 8 megabytes preferred); a VGA-capable monitor and display driver (Super VGA preferred); a hard disk storage system with as large a capacity as possible (preferably 300 megabytes or larger); and a direct Internet connection or dial-up capability that can use SLIP or PPP protocols with a 14,400 bps modem (preferably supporting V.42bis data compression which can enable 57,600 bps operation). The Windows 3.1 or later operating system is necessary. A printer is desirable.

For Apple Macintosh systems: a $6803020 \mathrm{Mhz}$ or faster processor; at least 4 megabytes of RAM memory (8 megabytes preferred); a hard disk storage system with as large a capacity as possible (preferably 300 megabytes or larger); and a direct Internet connection or dial-up capability that can use SLIP or PPP protocols with a 14,400 bps modem (preferably supporting V.42bis data compression which can enable 57,600 bps operation). A printer is desirable.

Software for a higher performance GLOBE school computer system is being developed that will operate on higher performance, multimedia IBM-compatible systems and on Apple Macintosh systems. For IBM-compatible systems; a 486/66 or faster processor; 16 megabytes of RAM memory; 500 megabytes of hard disk space; a Super VGA monitor; a double-speed CD-ROM reader; a Soundblaster-compatible sound card; and an MPEG animation speed-up board will be required. For Apple Macintosh systems; a PowerPC processor; 16 megabytes of RAM memory; 500 megabytes of hard disk space; and a double-speed CD-ROM reader will be required. A communications capability the same as or better than for the minimum configurations above will also be required. A printer will be highly desirable.

It is recognized that there is a broad range of technological capabilities among potential GLOBE schools. The diversity of technology accessible by schools worldwide may require in some cases that environmental measurements be reported in hardcopy and that a variety of media be used to distribute visualization products, including photographs and broadcast television. All schools that want to participate in the program will be accommodated.

Technology associated with the GLOBE Program will continually evolve to higher levels and participants will be encouraged to upgrade over time. 


\section{BOLIVIA}

ENVIRONMENTAND NATURAL RESOURCES 



\title{
Agreement Between the Government of the United States of America and the Government of Bolivia for Cooperation in the GLOBE Program, La Paz, 1995
}

\author{
Done at La Paz 22 April 1995 \\ Entered into force 22 April 1995 \\ Primary source citation: Copy of text provided by the \\ U.S. Department of State
}

\section{AGREEMENT BETWEEN THE GOVERNMENT OF THE UNITED STATES OF AMERICA AND THE GOVERNMENT OF BOLIVIA FOR COOPERATION IN THE GLOBE PROGRAM}

\section{ARTICLE I - PREAMBLE}

The Government of the United States of America, acting through the U.S. National Oceanic and Atmospheric Administration and other U.S. Government Agencies participating in the GLOBE program (hereinafter, the U.S. side), and the Government of Bolivia, acting through the Ministry of Sustainable Development and the Environment (hereinafter, the Bolivian side),

Intending to increase the awareness of students throughout the world about the global environment,

Seeking to contribute to increased scientific understanding of the Earth, and

Desiring to support improved student achievement in science and mathematics,

Have agreed to cooperate in the Global Learning and Observations to Benefit the Environment (GLOBE) Program as follows:

\section{ARTICLE II - THE GLOBE PROGRAM}

The GLOBE Program is an international environmental science and education program that will bring students, teachers, and scientists together to study the global environment. GLOBE will create an international network of students in grades K-12 (or equivalent) studying environmental issues, making environmental measurements, and sharing useful environmental data with the international environmental science community. 


\section{ARTICLE III - RESPECTIVE RESPONSIBILITIES}

A. The U.S. side will:

1. Identify U.S. schools that will participate in the GLOBE program (details regarding GLOBE schools in Appendix A);

2. Select, in consultation with international scientists and educators, the GLOBE environmental measurements and types of measurement equipment (described in Appendix B);

3. Select principal investigator teams for the GLOBE environmental measurements, and support the U.S. members of the teams;

4. Calibrate, if necessary, measurement equipment that cannot be calibrated by GLOBE teachers and students;

5. Develop, in consultation with international scientists and educators, GLOBE educational materials;

6. Translate GLOBE instructional materials related to measurement procedures and reporting protocols into the six United Nations languages, provide these plus all broader GLOBE educational materials to the Bolivian side for further reproduction as necessary;

7. Conduct annual regional training sessions for GLOBE Country Coordinators and GLOBE teachers who will serve as trainers for additional GLOBE teachers in Bolivia, and provide a copy of GLOBE training materials to the Bolivian side;

8. Design, develop, operate, and maintain GLOBE data processing and visualization product processing capabilities and other necessary technology and equipment;

9. Provide GLOBE software, as necessary, for use on Bolivian GLOBE school computers. (To the maximum extent possible, textual material appearing on computer screens will be accessible in the student's choice among the six United Nations languages.);

10. Accept environmental data reported from GLOBE schools around the world, and develop and provide resultant global environmental images (visualization products) to the Bolivian side; and

11. Evaluate the overall GLOBE Program periodically, in consultation with international GLOBE Country Coordinators, and modify the overall program as appropriate.

B. The Bolivian side will:

1. Select Bolivian schools to participate in the GLOBE Program (details regarding GLOBE schools in Appendix A) and provide an updated list of Bolivian GLOBE schools to the U.S. side at the beginning of each school year;

2. Ensure that Bolivian GLOBE schools conduct the fundamental activities of GLOBE schools detailed in Appendix A (take GLOBE environmental measurements, report data, and receive and use resultant global environmental images, using GLOBE educational materials under the guidance of researchers trained to conduct the GLOBE Program);

3. Name a Bolivian Government Point of Contact responsible for policy-level communications with the Director of the GLOBE Program;

4. Name a Country Coordinator responsible for day-to-day management, oversight, and facilitation of the GLOBE Program in Bolivia;

5. Ensure that the Country Coordinator and some GLOBE teachers attend GLOBE regional training and in turn provide GLOBE training to at least one teacher in each Bolivian GLOBE school; 
6. Ensure that GLOBE instructional materials related to measurement procedures and reporting protocols are utilized in Bolivian GLOBE schools, and that broader GLOBE educational materials are appropriately translated, adapted, reproduced, and distributed to all Bolivian GLOBE schools;

7. Ensure that Bolivian GLOBE schools have the necessary measurement equipment to take global environmental measurements (described in Appendix B);

8. Ensure that teachers and students at Bolivian GLOBE schools calibrate GLOBE measurement equipment according to procedures provided in GLOBE educational materials;

9. Ensure that Bolivian GLOBE schools have the necessary computer and communications systems (described in Appendix C) to report GLOBE environmental measurements and to receive and use GLOBE visualization products, or make agreed alternative arrangements for such reporting and receipt. (At a minimum, the Bolivian Country Coordinator will need access to Internet so that all measurement data from Bolivian GLOBE schools will be reported via Internet.); and

10. Evaluate GLOBE operations in Bolivia periodically and assist the U.S. in conducting periodic evaluation of the overall GLOBE Program.

\section{ARTICLE III - FINANCLAL ARRANGEMENTS}

Each side will bear the costs of fulfilling its respective responsibilities under this agreement. Obligations of each side pursuant to this agreement are subject to its respective funding procedures and the availability of appropriated funds, personnel, and other resources. The conduct of activities under this agreement will be consistent with the relevant laws and regulations of the two sides.

\section{ARTICLE IV - EXCHANGE OF DATA AND GOODS}

GLOBE environmental measurement data, visualization products, software, and educational materials will be available worldwide without restriction as to their use or redistribution.

\section{ARTICLE V - RELEASE OF INFORMATION ABOUT THE GLOBE PROGRAM}

Each side may release information on the GLOBE Program as it may deem appropriate without prior consultation with the other.

\section{ARTICLE VI - CUSTOMS AND IMMIGRATION}

Each side will, to the extent permitted by its laws and regulations, facilitate the movement of persons and goods necessary to implement this agreement into and out of its territory and will accord entry to such goods into its territory free of customs duties and other similar charges.

\section{ARTICLE VII - ENTRY INTO FORCE, AMENDMENTS, WITHDRAWAL}

This agreement will enter into force upon signature of the two sides and will remain in force for five years. It will be automatically extended for further five-year periods, unless either side decides to terminate it and notifies the other side with three months written notice. This agreement may be terminated at any time by either side upon three months prior written notice to the other side. This agreement may be amended by written agreement of the two sides. 
Done at La Paz, on April 22, 1995, in duplicate, in the English and Spanish languages, both texts being equally authentic.

\section{FOR THE GOVERNMENT OF \\ THE UNITED STATES OF AMERICA:}

Curtis Kamman

AMBASSADOR

\author{
FOR THE GOVERNMENT OF \\ BOLIVIA:
}

Dr. Antonio Aranibar Quiroga

MINISTER OF FOREIGN AFFAIRS

Ing. Luis Lema Molina

MINISTER OF SUSTAINABLE

DEVELOPMENT AND THE ENVIRONMENT

\section{APPENDIX A}

\section{GLOBE SCHOOLS}

Each partner country will be responsible for identifying its participating schools. Schools should be selected so as to satisfy the objectives of the GLOBE Program. In particular, countries should emphasize the selection of schools that will maximize the number of students worldwide participating in the program. Also, countries should consider involving schools in locations that will yield measurement data that is important to the international environmental science community.

Students at all GLOBE schools throughout the world will conduct the following fundamental activities: They will make environmental measurements at or near their schools; report their data to a GLOBE data processing site; receive vivid graphical global environmental images (visualization products) created from their data and the data from other schools around the world; and study the environment by relating their observations and the resulting visualization products to broader environmental topics. All of these activities will be conducted under the guidance of specially trained teachers (GLOBE-trained teachers).

GLOBE educational materials will be used in GLOBE schools under the guidance of GLOBE-trained teachers. These materials will detail procedures for taking environmental measurements and protocols for reporting data; explain the significance of the measurements; guide the use of the visualization products; and integrate the experimental aspects of the program into a broader study of the environment.

Schools throughout the United States and the rest of the world that are not GLOBE schools may become GLOBE affiliate schools by observing the GLOBE Program in operation throughout the Internet. Students at these schools will benefit from the use of GLOBE visualization products and educational materials accessible on-line. All GLOBE affiliate schools will be encouraged to become participating GLOBE schools.

\section{APPENDIX B}

\section{GLOBE ENVIRONMENTAL MEASUREMENTS AND EQUIPMENT}

GLOBE environmental measurements will contribute in a significant way to the scientific understanding of the dynamics of the global environment. Every GLOBE school will conduct a core set of GLOBE environmental measurements in the following critical areas: Atmosphere/Climate, Hydrology/Water Chemistry, and Biology/Geology. Where possible, a GLOBE school may coordinate its activities with those of other neighboring GLOBE schools, so that the complete set of GLOBE measurements will be available from a locality. As the GLOBE Program evolves, elective measurements not common to all GLOBE schools may be added in order to address local environmental issues.

Students at all age levels will be active participants in the GLOBE Program. The actual participation will be designed so as to be grade-appropriate for grades K-5, 6-8, and 9-12 (or equivalent). Younger students will make limited measurements which may be qualitative rather than quantitative. Older students will make additional measure- 
ments and more sophisticated measurements, as appropriate for their grade level. Measurement equipment will not need to be standardized; rather, performance specifications will be provided.

Following is an example list of core measurements and the equipment that will be needed to take these measurements. The full list will be initially determined and periodically updated as provided in Article 2.A.2, based on experience gained in implementing the GLOBE Program.

Measurements (Equipment needed):

Atmosphere/Climate studies:

Air temperature (max/min thermometer, calibration thermometer, instrument shelter)

Precipitation (rain gauge)

Cloud cover/type (cloud charts)

Hydrology/Water Chemistry studies:

Water temperature (alcohol thermometer)

Water $\mathrm{pH}$ ( $\mathrm{pH}$ paper, pen, or meter)

Soil moisture (gypsum block sensors, soil moisture meter)

Biology/Geology studies:

Habitat study (compass, meter measuring tape, surveying markers or stakes)

Tree Height (clinometer)

Tree Canopy (Densiometer)

Tree Diameter (Diameter tape)

Species identification (Dichotomous keys)

Phenology ( $35 \mathrm{~mm}$ camera)

\section{APPENDIX C}

\section{GLOBE COMPUTER AND COMMUNICATIONS SYSTEMS}

In order to derive maximum benefit from the GLOBE Program, all schools will be encouraged to use an international information network, initially using the Internet, along with classroom computers. The World Wide Web multi-media information-access capability has been selected as the basis for IBM-compatible and Apple Macintosh computer systems to support the required GLOBE school activities of data entry, data analysis, and use of GLOBE environmental images. Following is a description of GLOBE computer and communications systems consistent with current GLOBE requirements.

Overall attributes of the minimum GLOBE school computer configuration that can execute the necessary software are:

For IBM-compatible systems: a 386 SX or higher level processor; at least 4 megabytes of RAM memory ( 8 megabytes preferred); a VGA-capable monitor and display driver (Super VGA preferred); a hard disk storage system with as large a capacity as possible (preferably 300 megabytes or larger); and a direct Internet connection or dial-up capability that can use SLIP or PPP protocols with a 14,400 bps modem (preferably supporting V.42bis data compression which can enable 57,600 bps operation). The Windows 3.1 or later operating system is necessary. A printer is desirable.

For Apple Macintosh systems: a $6803020 \mathrm{mHz}$ or faster processor; at least 4 megabytes of RAM memory ( 8 megabytes preferred); a hard disk storage system with as large a capacity as possible (preferably 300 megabytes or larger); and a direct Internet connection or dial-up capability that can use SLIP or PPP protocols with a 14,400 bps modem (preferably supporting V.42bis data compression, which can enable 57,600 bps operation). A printer is desirable.

Software for a higher performance GLOBE computer system is being developed that will operate on higher performance, multi-media IBM-compatible systems and on Apple Macintosh systems. For IBM-compatihle systems: 
a 486/66 or faster processor; 16 megabytes of RAM memory; 500 megabytes of hard disk space; a Super VGA monitor; a double-speed CD-ROM reader; a Soundblaster-compatible sound card; and an MPEG animation speed-up board will be required. For Apple Macintosh systems: a PowerPC processor; 16 megabytes of RAM memory; 500 megabytes of hard disk space; and a double-speed CD-ROM reader will be required. A communications capability the same as or better than for the minimum configurations above will also be required. A printer will be highly desirable.

It is recognized that there is a broad range of technological capabilities among potential GLOBE schools. The diversity of technology accessible by schools worldwide may require in some cases that environmental measurements be reported in hard copy and that a variety of media be used to distribute visualization products, including photographs and broadcast television. All schools that want to participate in the program will be accommodated.

Technology associated with the GLOBE Program will continually evolve to higher levels and participants will be encouraged to upgrade over time. 


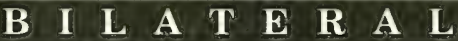

\author{
Canada
}

ENVIRONMENT AND NATURALRESOURCES 



\section{Memorandum of Understanding Between the United States Department of Agriculture and Forestry Canada on Cooperation in the Field of Forestry-Related Programs, Washington, D.C., 1990}

Done at Washington, D.C. 17 May 1990

Entered into force 17 May 1990

Primary source citation: TIAS 11723

\section{MEMORANDUM OF UNDERSTANDING BETWEEN THE UNITED STATES DEPARTMENT OF AGRICULTURE AND FORESTRY CANADA ON COOPERATION IN THE FIELD OF FORESTRY-RELATED PROGRAMS}

\section{Identification of Parties}

This Memorandum of Understanding is entered into between the United States Department of Agriculture and Forestry Canada. The lead agencies under the Memorandum of Understanding will be the Forest Service for the United States Department of Agriculture and Forestry Canada. Recognizing the proprietorship and management responsibilities for forests and forest lands which rest with provincial, territorial and State governments, entities of these governments will be specifically included as signatories under supplements to this Memorandum of Understanding (para. VII) with respect to activities relating to these lands and forests.

\section{Purpose}

The purpose of this Memorandum of Understanding is to document certain agreements and understandings between the United States Department of Agriculture and Forestry Canada to improve coordination of forestry-related programs undertaken in the two countries. This improved coordination is desirable (1) to enhance and maximize program capabilities in forestry in both countries; (2) to encourage joint efforts to resolve common problems; (3) to avoid unplanned duplication of effort; and (4) to help insure that the collection and analysis of data is compatible so that results can be compared and even pooled when desired. 


\section{Background}

In this Memorandum, "forestry-related programs" refers to the ongoing activities of the two forestry agencies and their cooperators. Such programs include but are not limited to planning, conducting, reviewing and analyzing forestry activities related to the management and administration of forest lands, relationships with private landholders, matters associated with wood utilization, and related research and legislative support functions.

\section{Authority}

The participation by the United States Department of Agriculture is authorized by the Food and Agriculture Act of 1977, 7 U.S.C. 3291 (1982); Forest and Rangeland Renewable Resources Research Act of 1978, 16 U.S.C. 1643(c) (1982); and Reciprocal Fire Protection Agreements Act of May 27, 1955, 42 U.S.C. 1856 (1982).

The involvement by Forestry Canada in this Memorandum of Understanding is authorized by the Department of Forestry Act of 1990.

\section{Delegation}

A. The Secretary, United States Department of Agriculture, or such other person whose name and title shall be communicated in writing to the Minister of Forestry, Canada, shall administer this Memorandum of Understanding for the United States Department of Agriculture.

B. The Minister of Forestry, Canada, or such other person whose name and title shall be communicated in writing to the Secretary, United States Department of Agriculture, shall administer this Memorandum of Understanding for Forestry Canada.

\section{Responsibilities of Parties}

The Secretary, United States Department of Agriculture, and the Minister of Forestry, Canada, agree that, subject to the availability of appropriated funds and personnel and in accordance with the laws and regulations of each country, the forestry agencies covered by this Memorandum of Understanding will, where mutually acceptable:

A. Assist each other in planning forestry-related programs.

1. The agencies will identify program areas of mutual interest and concern, and will jointly plan program activities when mutually advantageous.

2. Periodically, the agencies will provide each other with resource documents and summary statements of program and budget emphasis and new and emerging areas of emphasis or concern.

3. Annually, the agencies will exchange summaries of current needs that are related to their resource management programs or to the programs of their cooperators.

4. The agencies will inform each other of significant public involvement activities that help identify user needs and help set agency priorities.

5. To the extent possible, the agencies will develop compatible standards, techniques and reporting systems so that results will be mutually useful.

B. Assist each other in program operation to the extent practical and mutually desirable.

1. The agencies will cooperate in programs that are mutually advantageous, especially those in border situations between the two countries. 
2. As mutually agreeable, each agency will include representatives of the other in reviews of programs of mutual interest.

3. The agencies will share staff, equipment and information in emergency situations such as fire or pest problems. Details will be spelled out in program agreements for the various technical fields and program areas.

4. At least annually, the agencies will prepare status summaries of programs known to be of interest to the other.

C. Assist each other in communicating and sharing information.

1. As may be agreed upon, the agencies will share appropriate planning documents and program anlayses that are produced in the normal course of business.

2. Agencies will explore opportunities to develop a compatible information data base, including forest resource inventories and program reporting.

3. Agencies will cooperate in efforts to disseminate planning and reporting documents to the public as appropriate and mutually agreed to.

\section{Supplementation}

As needed to cover specific plans and programs, this Memorandum of Understanding may be supplemented by specific project agreements signed at the appropriate level for the agencies involved.

\section{Implementation}

Activities resulting from this Memorandum will be coordinated through the heads of the two forestry agencies or their designates. Responsibility for coordination meetings will rotate annually between the incumbents in these two positions. An annual program will be developed by September 30 that describes cooperative activities and coordination needs for the next calendar year. A yearly report will be prepared and submitted to the Secretary and the Minister within two months after the end of the preceding calendar year.

\section{Provisions}

\section{A. Intellectual Property}

In proposed cooperative activities where it is foreseeable that a product or discovery that is eligible for intellectual property protection might result, the parties will agree in advance as to the disposition of intellectual property rights, in their own countries and in third countries, and so state the disposition within the particular project agreement covering these activities.

\section{B. Expenses}

Unless otherwise provided, delegations and individuals visiting either country in accordance with this Memorandum of Understanding will pay their own expenses.

\section{Claims}

The parties to the Memorandum of Understanding do hereby expressly agree that all claims occurring in consequence of the performance of the Memorandum of Understanding will be pursued in accordance with the laws relating to such claims under applicable laws of each country. 


\section{Benefits}

No Member of Congress or no Member of the Senate or House of Commons shall be admitted to share in any part of this Memorandum of Understanding or to receive any benefit that may arise therefrom.

\section{Effective Date}

This memorandum shall enter into force upon signature and shall remain in force for five (5) years unless terminated earlier by either party upon ninety (90) days' written notice to the other party. It may be modified or extended by mutual written agreement.

DONE at Washington, D.C. this 17th day of May, 1990, in duplicate, each in the English and French languages both equally authentic.

FOR

THE UNITED STATES

DEPARTMENT OF AGRICULTURE:

\section{[Signature]}

Secretary, United States

Department of Agriculture

[Signature]

Chief, USDA Forest Service
FOR

FORESTRY CANADA:

[Signature]

Minister of Forestry

[Signature]

Deputy Minister

Forestry Canada 


\section{Agreement Between the Government of the United States of America and the Government of Canada on Cooperation in the Boreal Ecosystem-Atmosphere Study (BOREAS), Washington, D.C., 1994}

Done at Washington, D.C. 18 April 1994

Entered into force 18 April 1994

Primary source citation: Copy of text provided by the U.S. Department of State

AGREEMENT BETWEEN THE GOVERNMENT OF THE UNITED STATES OF AMERICA AND THE GOVERNMENT OF CANADA ON COOPERATION IN THE BOREAL ECOSYSTEM-ATMOSPHERE STUDY (BOREAS)

ACCORD ENTRE LE GOUVERNEMENT DES ÉTATS-UNIS D'AMÉRIQUE ET LE GOUVERNEMENT DU CANADA CONCERNANT LA COOPÉRATION DANS LE CADRE DE L'ÉTUDE DE L'ATMOSPHÈRE ET DES ÉCOSYSTEMES BORÉAUX (BOREAS)

WHEREAS:

The Government of the United States and the Government of Canada, herein referred to as "the Parties," have identified a mutual interest in conducting a joint study to better understand the interaction between the boreal forest biome and the atmosphere; and

The Parties wish to establish a framework for cooperation;

The Parties, therefore, agree as follows: 


\section{ARTICLE 1}

\section{PURPOSE}

The purpose of this Agreement is to provide the basis for cooperation between the National Aeronautics and Space Administration (NASA), an agency of the Government of the United States of America and Energy, Mines and Resources (EMR), a department of the Government of Canada, herein referred to as "the Participants", regarding the joint U.S.-Canada Boreal Ecosystem-Atmosphere Study (BOREAS).

\section{ARTICLE 2}

\section{OBJECTIVES}

A. The Parties shall undertake BOREAS to study the interactions between the boreal forest biome and the atmosphere in order to clarify the roles of these interactions in global change. The study will focus on processes that can be appropriately addressed in a one-year intersive field measurement project supported by three to four years of less intensive in situ and remote sensing monitoring.

B. The specific objectives of BOREAS are:

1. to improve understanding of the biological and physical processes and states which govern the exchanges of carbon, water, trace gases, energy, and heat between boreal forest ecosystems and the atmosphere with particular reference to those processes and states that may be sensitive to global change;

2. to develop the use of remote sensing techniques to transfer understanding of the above processes from local scales to regional scales; and

3. to provide personal development, research, and educational opportunities for individual researchers sponsored by both Parties participating in BOREAS.

\section{ARTICLE 3}

\section{PARTICIPATION}

A. The Parties shall conduct BOREAS as part of the U.S. and Canadian Global Change Research Programs. The goals and objectives of BOREAS are compatible with and have been endorsed by the International GeosphereBiosphere Programme (IGBP) and the International Satellite Land Surface Climatology Project (ISLSCP) of the World Climate Research Program (WCRP). Preliminary scientific planning has determined that BOREAS will be a joint U.S.-Canada initiative in which NASA will lead the U.S. participation in this study and will coordinate the involvement of the National Oceanic and Atmospheric Administration (NOAA), the Environmental Protection Agency (EPA), and the National Science Foundation (NSF). The Canada Centre for Remote Sensing (CCRS) of the Surveys, Mapping, and Remote Sensing Sector will act on behalf of EMR to implement the Canadian contributions to this study. CCRS has been designated to lead the Canadian participation in the study in cooperation with the Canadian BOREAS Coordinating Committee (CBCC). The CBCC will coordinate the involvement of Forestry Canada, Environment Canada, Agriculture Canada, the National Research Council of Canada (NRC), and the Natural Sciences and Engineering Research Council of Canada (NSERC).

B. BOREAS will consist of a three to four year period of low level in situ monitoring observations of two boreal forest biome sites in central Canada. These roughly 400-600 square kilometer sites are the Prince Albert National Park region in Saskatchewan and the Nelson House region near Thompson, Manitoba. In the summer of 1993, one pilot intensive observation campaign was conducted. In 1994, up to five intensive field campaigns will be conducted to cover mid-winter, spring thaw, and early, mid-, and late growing season conditions. These intensive field campaigns will involve approximately 75 Principal Investigator-led international teams, extensive in situ observations at each site, several U.S. and Canadian remote sensing aircraft, and satellite observations. It is planned to base the smaller 
aircraft (e.g., NASA helicopter and C-130) at Prince Albert and Thompson, the larger aircraft (e.g., NASA DC-8) at Saskatoon and/or Churchill, and the NASA ER-2 at Spokane, Washington.

C. A data and information system, the BOREAS Information System (BORIS), will be established to provide the BOREAS Science Team members with a data system from which data for the whole project may be queried, accessed, and extracted. Participating scientists will be expected to submit their data to BORIS in a timely fashion. All those participating in BOREAS shall have access to BORIS and all BOREAS data distributions will be through BORIS, or through the long-term archive to follow BORIS.

\section{ARTICLE 4}

\section{RESPONSIBILITIES OF THE PARTICIPANTS}

A. NASA, for its part, will use its best efforts to ensure fulfillment of the following responsibilities:

1. Participate with CCRS in the planning of the coordinated U.S. and Canadian aircraft and ground-based measurements to be obtained in order to fulfill the scientific objectives of the joint mission;

2. Coordinate the involvement of other U.S. agencies in BOREAS;

3. Arrange, jointly with the participating Canadian agencies, for the provision of required lodging for the U.S. component of the joint team;

4. Provide NASA aircraft equipped with instrumentation for the BOREAS study. Additionally, arrange for proper operational and associated ground support for the NASA aircraft, and coordinate flight of the other U.S. aircraft (e.g., aircraft provided by NOAA, the National Center for Atmospheric Research (NCAR), and the University of Wyoming) participating in the campaign;

5. Organize and conduct the BOREAS aircraft expeditions in consultation with EMR;

6. Provide certain Core Measurements for BOREAS (through in-house labor or contracted support), including agreed-upon surface measurements, tower-based measurements, automatic meteorological stations, aircraft remote sensing measurements and in situ measurements, satellite data, and Geographic Information System (GIS) components. These will be provided in accordance with applicable U.S. laws and NASA data policies;

7. Process, correct, quality assure, and document agreed-upon Core Measurement data and deliver them to the BORIS in a timely fashion;

8. Coordinate and execute agreed-upon joint instrument calibration and comparison experiments and analyses;

9. Participate jointly with CCRS and the other participating agencies in the analysis and publication of the data and results obtained from this cooperative project;

10. Support, staff, and manage the U.S. BOREAS Project office, including the BORIS;

11. Provide funding for U.S. proposals and sponsor the participation of the foreign scientists selected under the joint U.S.-Canada solicitations for scientific participation in BOREAS; and

12. Provide certain support services to be performed in Canada in fulfillment of the objectives of BOREAS. These services include, but are not limited to, the following: BOREAS infrastructure, trails, vehicles, aerial photography, flux towers, site research facilities (including laboratory and storage space), site managers, liaison-field support, field site security, and labour at the study sites. NASA will procure these support services through CCRS by separate contract or other appropriate agreement. In connection with such a procurement, NASA will not pay as an allowable cost, salaries of Canadian government employees. 
B. EMR, for its part, will use its best efforts to ensure fulfillment of the following responsibilities:

1. Participate with NASA in the planning of the coordinated U.S. and Canadian aircraft and ground-based measurements to be obtained in order to fulfill the scientific objectives of the joint mission;

2. Coordinate the involvement in BOREAS of Environment Canada, Forestry Canada, Agriculture Canada, the NRC, and other Canadian participants, and provide a link for discussions with the NSERC;

3. Obtain from Canadian authorities necessary authorization in order to conduct the subject scientific project. In addition, EMR will assist and guide NASA in complying with Canadian government legislation and regulations with respect to aircraft activities and surface level operations;

4. Arrange, jointly with NASA, for the provision of required lodging for the Canadian component of the joint team;

5. Provide CCRS aircraft equipped with instrumentation for the BOREAS study. Additionally, arrange for proper operational and associated ground support for the CCRS aircraft and coordinate other Canadian aircraft (e.g., aircraft provided by the Institute of Aerospace Research (IAR) Twin Otter and the Ontario Center for Remote Sensing's Navajo Chieftain) participating in the campaign;

6. Participate with NASA and the other participating agencies in the organization and conduct of the BOREAS aircraft expeditions;

7. Coordinate the provision of meteorological data provided by Environment Canada, including satellite cloud images, and assistance in forecasting, for planning of aircraft missions for the duration of the BOREAS mission;

8. Provide or arrange for the provision of certain core measurements for BOREAS (through in-house labour or contracted support), including agreed-upon surface measurements, tower-based measurements, automatic meteorological stations, aircraft remote sensing measurements and in situ measurements, satellite data, and GIS components. In particular, provide agreed-upon Landsat Thematic Mapper(TM), Multispectral Scanner System (MSS) and Advanced Very High Resolution Radiometer Local Area Coverage (AVHRR LAC) data. These will be provided in accordance with Canadian data distribution agreements with satellite operators and data distributing companies;

9. Process, correct, quality assure, and document agreed-upon core measurement data and deliver them to the BORIS in a timely fashion;

10. Coordinate and execute agreed-upon joint instrument calibration and comparison experiments and analyses;

11. Participate jointly with NASA and other participating agencies in the analysis and publication of the data and results obtained from this cooperative project;

12. Support, staff, and manage the Canadian BOREAS Secretariat;

13. Provide funding for CCRS proposals selected under the joint U.S.-Canada solicitations for scientific participation in BOREAS and communicate information on the funding commitments of the other Canadian agencies involved in BOREAS; and

14. On behalf of NASA, arrange for the provision of the support services to be performed in Canada in fulfillment of the objectives of this Agreement, as described in paragraph A.12 of NASA's responsibilities above, pursuant to the requirements of a contract or other appropriate arrangement entered into with NASA.

\section{ARTICLE 5}

\section{PROJECT MANAGEMENT}

The Participants' technical points-of-contact to be responsible for coordinating the agreed-upon functions and responsibilities of each Participant are as follows: 
The NASA technical point-of-contact:

Manager

Terrestrial Ecology Program

Science Division

Office of Mission to Planet Earth

NASA Headquarters

Washington, DC 20546

USA

TEL: (202) 358-0272

FAX: (202) 358-2771

The EMR technical point-of-contact:

Director General

Canada Centre for Remote Sensing

Energy Mines and Resources Canada

588 Booth Street

3 rd floor, Room 327

Ottawa, Ontario K1A 0Y7

CANADA

TEL: (613) 947-1222

FAX: (613) 947-1382

\section{ARTICLE 6 \\ FUNDING ARRANGEMENTS}

Each Party agrees to bear the costs of discharging its respective responsibilities as outlined above under this Agreement. The activities of the Parties and the Participants under this Agreement are subject to the availability of appropriated funds.

\section{ARTICLE 7 \\ PUBLIC INFORMATION}

The Parties agree that the release of public information regarding this project may be made by the appropriate Party for its own portion of the Program as desired and, insofar as participation of the other Party is involved, after suitable consultation.

\section{ARTICLE 8 \\ SCIENTIFIC DATA}

The Parties agree that there shall be no period of exclusive use of BOREAS data by the BOREAS Science Team. The BOREAS investigators shall have a reasonable period of time from the completion of the BOREAS field expedition to perform documentation, verification, and correction of their data prior to public release of the data sets. Each BOREAS investigator shall be expected to provide copies of the data collected to BORIS for deposit in the BORIS archive on a schedule that shall permit the archive to be released to the international scientific community as soon as possible, and in accordance with the data handling procedures adopted by the BOREAS Science Team.

The Parties agree that the results of the investigations shall be made available to the scientific community in general through publication in appropriate journals or other established channels. In the event such reports or publications 
are copyrighted, the Parties shall have a royalty-free right under the copyright to reproduce, use, and distribute such copyrighted work for their own purposes.

\section{ARTICLE 9}

\section{INVENTION AND PATENT RIGHTS}

The Parties agree that nothing in this Agreement shall be construed as granting or implying any rights to, or interest in, patents or inventions of the Parties or their contractors or subcontractors.

\section{ARTICLE 10}

\section{LLABILITY}

The Parties agree that, with respect to activities undertaken pursuant to this Agreement, neither Party shall make any claim against the other with respect to injury or death of its own or its contractors' or subcontractors' employees or investigators' employees or with respect to damage of any kind to or loss of its own or its contractors' or subcontractors' or investigators' property caused by either Party, or the Party's contractors, subcontractors, or investigators, whether such injury, death, damage or loss arises through negligence or otherwise, except in the case of willful misconduct. The Parties agree, in the event of damage to third parties for which there is liability under national or international law, to consult promptly as to the possibility of an equitable sharing of any payments that have been or may be agreed in settlement.

This cross-waiver of liability shall not be applicable to claims between a Party and its contractors and subcontractors or to claims made by a natural person.

\section{ARTICLE 11 \\ IMMIGRATION DOCUMENTATION, AIRPORT AND CUSTOMS FEES}

Both Parties will make best efforts, as appropriate, to arrange for the appropriate governmental authorities to waive any immigration documentation fees for persons working on BOREAS; to waive any landing, navigation, airways or airport entry and departure fees for aircraft required for BOREAS; and to provide free customs clearance of equipment and data required for BOREAS.

\section{ARTICLE 12}

\section{EXCHANGE OF TECHNICAL DATA AND GOODS}

Each Party shall furnish to the other Party only those technical data and goods necessary to fulfill the responsibilities of the furnishing party under this Agreement. It is the intent of the Parties to effect such a transfer without restrictions as to use or disclosure, subject to the following:

1. In the event a Party finds it necessary to furnish technical data in carrying out its responsibilities under this Agreement that are proprietary, and for which protection is to be maintained, such technical data shall be marked with a notice indicating that it shall be used and disclosed by the receiving Party and its contractors and subcontractors only for the purposes of fulfilling the receiving Party's responsibilities under this Agreement, and that the technical data shall not be disclosed or retransferred to any other entity without prior written permission of the furnishing Party. The receiving Party agrees to abide by the terms of the notice, and to protect any such marked technical data from unauthorized use and disclosure. 
2. In the event a Party finds it necessary to transfer technical data and goods in carrying out its responsibilities under this Agreement that are export-controlled, the furnishing Party shall mark such technical data with a notice and identify such goods. The notice or identification shall indicate that such technical data and goods shall be used and such technical data shall be disclosed by the receiving Party and its contractors and subcontractors only for the purposes of fulfilling the receiving Party's responsibilities under this Agreement. The notice or identification shall also provide that such technical data shall not be disclosed, and such technical data and goods shall not be retransferred, to any other entity without prior written permission of the furnishing Party. The Parties shall abide by the terms of the notice or identification and shall protect any such marked technical data and identified goods. Nothing in this article requires the Parties to transfer technical data and goods contrary to national laws or regulations related to export controls or control of classified data.

3. The Parties are under no obligation to protect any unmarked technical data or unidentified goods.

\section{ARTICLE 13}

\section{SETTLEMENT OF DISPUTES}

The Parties agree that any dispute as to interpretation or implementation of this Agreement shall be resolved through consultation between the Parties. The dispute shall be first referred to the NASA Associate Administrator for Mission to Planet Earth and the Assistant Deputy Minister (Surveys, Mapping and Remote Sensing) of EMR for resolution. Any dispute which cannot be resolved at this level shall be referred to the NASA Administrator and the Deputy Minister of EMR for settlement.

\section{ARTICLE 14}

\section{AMENDMENTS}

This Agreement may be amended by written consent of the Parties.

\section{ARTICLE 15}

\section{ENTRY INTO FORCE AND TERMINATION}

This Agreement shall enter into force upon signature. It shall remain in force for three years after the completion of the final BOREAS campaign. Either Party may terminate this Agreement upon ninety day's written notice following consultation with the other Party.

DONE in duplicate at Washington on this 18th day of April, 1994, in the English and French languages, each version being equally authentic.

FAIT en deux exemplaire à Washington le 18 jour de avril 1994, en langues française et anglaise, chaque version faisant également foi.

[Signature]

FOR THE GOVERNMENT OF THE

UNITED STATES OF AMERICA

POUR LE GOUVERNEMENT

DES ÉTATS-UNIS D'AMÉRIQUE
[Signature]

FOR THE GOVERNMENT

OF CANADA

POUR LE GOUVERNEMENT

DU CANADA 



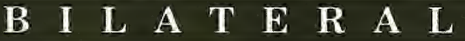

\section{Canada}

F I S H E R I E S 



\title{
Amendment to the Treaty Between the Government of the United States of America and the Government of Canada Concerning Pacific Salmon, Washington, D.C., 1993
}

\author{
Done at Washington, D.C. 24 August and \\ 8 September 1993 \\ Entered into force 8 September 1993* \\ Primary source citation: Copy of text provided by the \\ U.S. Department of State
}

\section{DEPARTMENT OF STATE \\ WASHINGTON}

August 24, 1993

His Excellency

John G. D. de Chastelain,

Ambassador of Canada.

Excellency:

I have the honor to refer to the Treaty between the United States and Canada concerning Pacific Salmon, signed at Ottawa January 28, 1985, and to the recommendations made by the Pacific Salmon Commission (PSC) in their letter of June 25, 1993, in accordance with Article XIII, paragraphs 2 and 3 of the Treaty.

In accordance with Article XIII, paragraph 3 of the Treaty, I have the honor to propose that the present Annex IV of the Treaty be extended for the 1993 fishing season consistent with the PSC letter of June 25, 1993.

I have the further honor to propose that if these proposals are acceptable to the Government of Canada, that this note and Your Excellency's reply shall constitute an agreement between our two Governments, which shall enter into force on the date of Your Excellency's note in reply.

Accept Excellency, the renewed assurances of my highest consideration.

For the Acting Secretary of State:

[Signature]

* The Treaty Concerning Pacific Salmon has been terminated. It has been replaced by the Agreement Between the Government of the United States of America and the Government of Canada for the Conservation of Salmon Stocks Originating from the Yukon River (see page 615). 
Enclosure:

Pacific Salmon Commission Letter of June 25, 1993

\section{PACIFIC SALMON COMMISSION}

\section{ESTABLISHED BY TREATY BETWEEN CANADA \\ AND THE UNITED STATES OF AMERICA \\ MARCH 18, 1985 \\ 600 - 1155 ROBSON STREET}

VANCOUVER, B.C. V6E $1 B 5$

TELEPHONE: (604) 684-8081

FAX: (604) 666-8707

Our File: 70103

$\mathrm{X} 71001$

Your File:

June 25, 1993

The Honorable Warren M. Christopher

Secretary of State

U.S. Department of State

2201 C Street N.W.

Washington, D.C.

20520

Dear Sir:

I have the honor to report to you on understandings reached by the Pacific Salmon Commission regarding certain of the fishery regimes specified in Annex IV of the Pacific Salmon Treaty.

In accordance with Article XIII, Paragraph 2 of the Treaty, the Commission recommends implementation of the following arrangements for 1993:

\section{Transboundary Rivers - Annex IV, Chapter 1.}

With respect to the Transboundary rivers, Canada and the U.S. agree to continue the expired annex provision through 1993. Discussions directed towards adjusting agreed fishing regimes to improve access to enhanced sockeye returns will continue prior to the 1994 season.

\section{Northern B.C. and S.E. Alaska - Annex IV, Chapter 2.}

With respect to Portland Canal chum salmon, Canada and the U.S. agree to prohibit net fisheries in relevant areas as recommended by the bilateral Northern Panel on February 15, 1993. In addition, they agree to continue discussion of restoration and enhancement programs for northern boundary chum salmon.

\section{Fraser River Sockeye and Pink Salmon-Annex IV, Chapter 4.}

Canada and the U.S. agree that the management regime for the Fraser sockeye and pink salmon fishery in 1993 is as follows: 
a) For sockeye salmon:

i) When the estimated TAC is less than 12.062 million fish, the U.S. catch in the Panel area shall not exceed 20 percent of the TAC;

ii) When the estimated TAC is between 12.062 and 15 million fish, the U.S. catch in the Panel area shall not exceed 2.412 million fish plus 10 percent of the TAC between 12.062 and 15 million fish;

iii) When the estimated TAC is greater than 15 million fish, the U.S. catch in the Panel area shall not exceed 2.706 million fish plus 5 percent of the TAC above 15 million fish, but the catch shall not exceed 2.806 million fish;

iv) Differences concerning catches of Fraser sockeye caught outside of the Panel area remain unresolved and will be addressed in connection with negotiations on 1994 arrangements.

v) The U.S. will not fish in 1993 on the early Stuart run in order to provide adequate escapement and viable fisheries in the upper portion of the Fraser River drainage.

b) For pink salmon the total U.S. catch shall be $25.7 \%$ of the TAC, but shall not exceed 3.6 million fish.

c) Calculation of 1993 TACs for Fraser River suckeye and pink salmon, and any catch overages or underages in 1993, shall be specified in Annex IV, Chapter 4 of the treaty and as specified in previous agreements of the Fraser Panel.

d) The dispute referred in Canada's note 189 of November 24, 1992 and the Department of State's Note of December 8, 1992 remains unresolved and will be addressed in connection with negotiations on 1994 arrangements.

e) Based on these arrangements, the Fraser Panel shall develop fishery management plans for the Fraser Panel area as soon as possible.

\section{Coho Salmon - Annex IV, Chapter 5.}

For 1993, Canada will limit its WCVI coho troll fishery to 1.7 million. Other coho Chapter provisions remain unchanged.

\section{Southern B.C. and Washington State Chum Salmon - Annex IV, Chapter 6.}

With respect to southern chum, Canada and the U.S. agree to continue the expired Annex revisions through 1993.

The Commission expects that the relevant management agencies will manage fisheries under their responsibility consistent with these agreements.

The Commission respectfully requests your early approval of these recommendations.

Yours truly,

[Signature]

Yves Fortier

Chair

Pacific Salmon Commission 


\section{Canadian Embassy \\ Ambassade du Canada \\ 501 Pennsylvania Avenue, N.W. \\ Washington, DC. 20001}

September 8, 1993

\section{H.E. David A. Colson}

Deputy Assistant Secretary

Oceans and Fisheries Affairs

Oceans and International Environmental

and Scientific Affairs

Department of State

2201 C Street N.W.

Washington, D.C. 20520

Dear Ambassador Colson,

Thank you for your letter of August 24, 1993 concerning the Pacific Salmon Treaty and the recommendations for extending Annex IV of the Treaty as reflected in the June 25, 1993 letter from the Pacific Salmon Commission.

In accordance with Article XIII, paragraph 3, of the Pacific Salmon Treaty, I am pleased to inform you of Canada's acceptance of these recommendations. You should know that Canada has already indicated its acceptance in a letter to the Pacific Salmon Commission from the Honourable Ross Reid, Minister of Fisheries and Oceans, dated August 26, 1993.

I agree with your proposal that your note of August 24, 1993, and this reply shall constitute the agreement between our two governments effective from the date of this letter.

Accept, sir, the assurances of my highest consideration.

Yours sincerely,

[Signature]

John de Chastelain

Ambassador 


\title{
Agreement Between the Government of the United States of America and the Government of Canada for the Conservation of Salmon Stocks Originating from the Yukon River, Washington, D.C., 1995
}

\author{
Done at Washington, D.C. 3 February 1995 \\ Entered into force 3 February 1995 \\ Primary source citation: Copy of text provided by the \\ U.S. Department of State
}

\section{DEPARTMIENT OF STATE WASHINGTON}

February 3, 1995

His Excellency

Raymond A. Chretien

Ambassador of Canada

Excellency:

I leave the honor to refer to negotiations that have been underway since 1985 on a long-term agreement for the conservation of salmon stocks originating from the Yukon River in Canada.

I have the honor to propose that our two Governments conclude an Interim Agreement incorporating relevant provisions agreed in the negotiations to date in order to allow institutional arrangements to commence functioning while negotiations continue on a long-term agreement which would incorporate the relevant provisions of the Interim Agreement.

To this end, I propose that Annex I to the Treaty between Canada and the United States of America concerning Pacific Salmon, signed at Ottawa on January 28, 1985 ("the Treaty") be amended by adding a new paragraph (d) to establish a Yukon River Panel for salmon originating in the Yukon River. I further propose that Annex IV to the Treaty be amended by adding a new chapter 8 as set forth in Attachment $A$ to this note. Attachment $B$ to this note contains provisions that have been developed in the negotiations to date and that are deferred for the long-term agreement.

(a) this Interim Agreement shall remain in force;

(b) the functions of the Yukon River Panel shall be assumed by a new commission, the "Yukon River Salmon Commission", and the Panel shall thereupon cease to exist; 
(c) other provisions of the Treaty, to the extent they apply to the Yukon River, shall remain in effect as part of this Agreement, mutatis mutandis; and

(d) the Parties shall seek to agree on other measures necessary for the continuation and application of this Agreement.

If this proposal is acceptable to the Government of Canada, I have the further honor to propose that this note, with Attachment A, together with your Excellency's note in reply, shall constitute an Agreement between our two Governments, which will enter into force on the date of your Excellency's note and remain in force until December 31,1997 , unless the Parties agree in writing to extend it.

Accept, Excellency, the renewed assurances of my highest consideration.

For the Secretary of State:

[Signature]

Attachments:

As stated.

\section{ATTACHMENT A}

\section{Yukon River}

\section{Definitions}

1. For the purposes of this Chapter,
(a) "Restoration" means returning a wild salmon stock to its natural production level;
(b) "Enhancement" means expanding a wild salmon stock beyond its natural production level;
(c) "Yukon River" means the entire Yukon River drainage in Canada and the United States;
(d) "Yukon River in Canada" means the entire Yukon River drainage in Canada, including the Porcupine River drainage; and
(e) "Mainstem Yukon River in Canada" means the Yukon River drainage in Canada, excluding the Porcupine River drainage.

\section{Administration}

2. This Chapter applies to salmon originating in the Yukon River.

3. The Parties shall seek to ensure the effective conservation of stocks originating in the Yukon River. The Parties shall implement agreed research and management programs, as provided for in memoranda of understanding and this Chapter, further develop co-operative research and management programs, and shall identify potential restoration and enhancement opportunities.

4. Article II, paragraphs 7, 8, 18, 19, and 20, Article IV, Article V, Article VII, and Article XIII, paragraph 2, shall not apply to salmon referred to in paragraph 2. With regard to Article XII, for matters related to the Yukon River, the Yukon River Panel shall substitute for the Commission.

5. Subject to the approval of the Parties, the Yukon River Panel shall make such by-laws and procedural rules, for itself, as may be necessary for the exercise of its functions and the conduct of its meetings. 
6. Each Party shall designate the responsible management entity for the harvest of salmon referred to in paragraph 2.

7. The Yukon River Panel shall make recommendations to the management entities concerning the conservation and management of salmon originating in the Yukon River in Canada.

8. The responsible management entities shall take into account the proposals of the Yukon River Panel in the adoption of regulations, and shall ensure the enforcement of these regulations.

9. The Parties shall maintain the Yukon River Joint Technical Committee ("JTC") established by paragraph C.2 of the Memorandum of Understanding dated 28 January 1985, reporting to the Yukon River Panel. The JTC shall meet at least once a year to, inter alia:

(a) assemble and refine information on migratory patterns and the extent of exploitation in fisheries harvesting Yukon River origin salmon;

(b) review existing assessment techniques and investigate new ways for determining total return and escapement and make recommendations on optimum spawning escapement objectives;

(c) examine past and current management regimes and recommend how they may be better formulated to achieve escapement objectives;

(d) exchange information on proposed and existing restoration and enhancement programs, identify restoration and enhancement opportunities and evaluate the management consequences of harvests of restored or enhanced fish;

(e) develop and recommend restoration and enhancement programs to be funded by the Yukon River Salmon Restoration and Enhancement Fund;

(f) monitor and coordinate agreed research programs and recommend research required in order of priority to enable the Parties to effectively implement this Chapter;

(g) evaluate annually the status of Canadian origin chum and chinook salmon stocks and make recommendations for adjustments to the rebuilding programs set out in this Chapter;

(h) use existing procedures and investigate new ways to evaluate progress in rebuilding salmon stocks where necessary;

(i) investigate and recommend stock separation studies that would assist in developing specific fishery management programs for individual salmon stocks;

(j) review and analyze the effectiveness of alternate fishery regulatory measures to satisfy conservation objectives;

(k) submit an annual report to the Yukon River Panel on fishery performance, including harvests and fishing effort of all user groups, fish values made available by either side and biological status of stocks;

(l) review information available on coho salmon originating in the Yukon River, and undertake assessments of such stocks;

(m) report on the condition of salmon habitat and measures to be taken to protect or enhance salmon habitat; and

(n) undertake other assignments as agreed by the Yukon River Panel, which may include analysis of socioeconomic characteristics of the fishery.

10. The Yukon River Panel shall make recommendations to the responsible management entities to coordinate management of the Yukon River fisheries that affect Canadian-origin salmon stocks. These entities shall 
exchange annual fishery management plans prior to each season. It is understood that coordinated management of coho salmon is not being considered at this time.

\section{Mainstem Yukon River}

\section{Chum Salmon}

11. With respect to chum salmon originating in the Yukon River in Canada, the Parties agree that spawning escapements have declined in recent years and are now substantially below levels necessary to achieve optimum sustained yield. Recognizing the desirability of rebuilding the stock, the Parties shall, through their respective management entities, implement a brood year rebuilding program for the Canadian mainstem chum stock to attain by 2001 the agreed escapement objective of more than 80,000 chum salmon for each brood year. The rebuilding program shall take into account the relative health of the brood years and endeavor to rebuild the stronger brood years in one cycle and the weaker brood years in three cycles in equal increments. The Yukon River Panel shall establish and modify as necessary the escapement objectives based on recommendations of the JTC.

12. During the rebuilding program for the Canadian mainstem chum stock, Canada will endeavor to manage the harvest of chum salmon in the mainstem Yukon River in Canada within a guideline harvest range of 23,600 in years of weak returns and 32,600 in years of strong returns. The United States will endeavor to deliver to the Canadian border on the mainstem Yukon River the number of chum salmon necessary to meet the spawning escapement objective for that year in the rebuilding program, and provide for a Canadian harvest within the agreed Canadian guideline harvest range. For the years 1992-1995, the United States will endeavor to deliver to the Canadian border on the mainstem Yukon River numbers of chum salmon within the following ranges:

$\begin{array}{rr}1992 & 74,600-112,600 \\ 1993 & 74,600-112,600 \\ 1994 & 84,600-112,600 \\ 1995 & 103,600-112,600\end{array}$

If spawning escapements from 1992 to 1995 reach the levels anticipated, the United States will, for the remainder of the rebuilding period, endeavor to deliver annually between 88,600 and 112,600 chum salmon to the Canadian border on the mainstem Yukon River. However, if the spawning escapement objective is not achieved for any brood year, the Panel shall establish a new rebuilding program for that brood year to complete the rebuilding program by 2001 .

13. During the rebuilding program, for any year when a strong return is anticipated, the Yukon River Panel shall consider recommending a spawning escapement objective substantially above 80,000 . If the Panel makes such a recommendation for that year, the United States will endeavor, for that year, to deliver to the Canadian border on the mainstem Yukon River the number of chum salmon necessary to meet the spawning escapement objective recommended by the Panel, plus the Canadian harvest range for the rebuilding program.

14. These arrangements regarding border escapement and Canadian guideline harvest range set out above for the rebuilding period will terminate not later than the end of 2001.

15. The responsible management entities shall consult closely and where possible coordinate pre-season management planning and in-season responses to run assessments. If during pre-season discussion within the Yukon River Panel consideration is being given to not conducting a directed commercial fishery in Alaska because of serious conservation concerns, Canada will also consider taking such a measure. If it is determined in-season that pre-season management measures agreed to by the Panel are insufficient to achieve agreed spawning escapement levels, the Parties agree to consider taking further conservation measures to meet the escapement objectives.

\section{Chinook Salmon}

16. With respect to chinook salmon originating in the Yukon River in Canada, the Parties agreed that spawning escapements declined substantially below levels necessary to achieve optimum sustainable yields. Recognizing 
the desirability of arresting the decline, the Parties agree to a minimum spawning escapement objective of 18,000 for the Canadian mainstem chinook stock for six years beginning in 1990 . Recognizing the difficulty of managing selectively Yukon River chinook salmon stocks, the Parties will endeavor to meet the spawning escapement objective. During this six-year period, the Panel shall develop a rebuilding program that will result in optimum sustained yields from the stock and recommend measures to implement this program.

17. During the period of 1990 to 1995 inclusive for the Canadian mainstem chinook stocks, the United States will endeavor to deliver annually between 34,800 and 37,800 chinook salmon to the Canadian border on the mainstem Yukon River and Canada will endeavor to manage the harvest of chinook salmon in the mainstem Yukon River in Canada within a guideline harvest range of 16,800 in years of weak returns and 19,800 in years of strong returns.

18. In years of very strong returns the United States agrees to consider, with a view to increasing, the border escapement in order to allow spawning escapement above the stabilization level.

19. The responsible management entities shall consult closely and where possible coordinate pre-season management planning and in-season responses to run assessments. If during pre-season discussion within the Yukon River Panel, consideration is being given to not conducting a directed commercial fishery in Alaska because of serious conservation concerns, Canada will also consider taking such a measure. If it is determined in-season that pre-season management measures agreed to by the Panel are insufficient to achieve agreed spawning escapement levels, the Parties agree to consider taking further conservation measures to meet the escapement objectives.

\section{Porcupine River}

20. The Parties recognize that limited information currently exists for salmon stocks spawned in the Porcupine River drainage in Canada. Information available for the Fishing Branch fall chum salmon stock indicates that spawning escapements for this stock are below interim escapement objectives.

21. The Parties further recognize that the agreed rebuilding program for salmon spawned in the mainstem Yukon River in Canada is expected to contribute increased escapements to Porcupine River stocks.

22. To ensure that maximum benefits accrue to Porcupine River spawning escapements from the rebuilding program for mainstem stocks, the Parties agree:

(a) not to initiate new fisheries on Canadian-origin stocks within the Porcupine River drainage before December 31, 1999; and

(b) if after this period either Party intends to initiate a new fishery on the Porcupine River, that Party shall inform the Yukon River Panel, which shall have the authority to make recommendations for management arrangements to the Parties.

23. The JTC shall compile existing information on the status of Porcupine River salmon stocks and on management and research tools available for management of these stocks. Based on this information, the JTC shall:

(a) advise the Yukon River Panel regarding the status of these stocks and the benefits accruing to Porcupine River salmon spawning escapements from the mainstem rebuilding program;

(b) prepare a range of potential rebuilding options for the Fishing Branch River fall chum salmon, including the option of allowing these stocks to rebuild as a result of the rebuilding program agreed to for the Yukon River mainstem fall chum salmon stock; and

(c) recommend to the Yukon River Panel ways to improve and expand information needed to better manage these stocks for optimum production.

24. Based on information and recommendations provided by the JTC, the Yukon River Panel shall consider making recommendations to the Parties regarding rebuilding, restoration and improved management of these Porcupine River stocks. 


\section{General}

25. If information becomes available that indicates that the catch records that provided the basis for the Canadian guideline harvest range in paragraphs 12 (Chum Salmon) and 17 (Chinook Salmon) are erroneously low, at Canada's request the Yukon River Panel may recommend increasing the ranges set out in these paragraphs to reflect the adjusted figures for the Aboriginal Fishery and the sport fishery catch.

26. With respect to coho salmon originating in the Yukon River in Canada, the Parties agree that the status of these stocks is not known with certainty.

27. The Parties agree that efforts designed to increase the in-river return of Yukon River origin salmon by reducing the marine catches and by-catches of Yukon River salmon would benefit the status of the Yukon River stocks. The Parties agree to identify, quantify and undertake efforts to reduce these catches and by-catches.

28. The Parties agree that the numbers of Canadian-origin Yukon River salmon in U.S. marine catches are presently unknown.

29. The Parties agree that, in light of their respective receipt of benefits from the salmon originating in their territories:

(a) salmon should be afforded unobstructed access to and from, and use of, existing migration, spawning and rearing habitats;

(b) water quality standards should be maintained and enforced;

(c) it is essential to maintain the productive capacity of the salmon habitat on both sides of the boundary in order to achieve the objectives of this Chapter; and

(d) should access be obstructed, water quality standards be degraded or productive capacity of the salmon habitat be diminished to a degree that affects the objectives of this Chapter, the Panel may recommend corrective actions which may include adjustments to fishing patterns, border escapement objectives and guideline harvest ranges.

30. The Parties agree to endeavor, subject to budgetary limitations, to implement the fisheries research and management programs recommended by the JTC for coordinated management of the Yukon River chinook and chum salmon stocks.

\section{Restoration and Enhancement Fund}

31. It is understood that the Parties' implementation of Article III(1)(b) as it pertains to the Yukon River must recognize factors unique to the Yukon River drainage system.

32. The Parties agree that further discussion is required regarding Article III(1)(b) and the percentage of the U.S. harvest of each species of salmon originating in Canadian sections of the river that shall be deemed to be of U.S. origin in order to conclude a long-term agreement. Pending resolution the Parties agree that:

(a) there shall be established a Yukon River Salmon Restoration and Enhancement Fund, hereinafter referred to as "the Fund", to be managed by the Yukon River Panel;

(b) the Fund shall be used for programs and directly associated research and management activities on either side of the border which are based on recommendations by the JTC and are directed at the restoration and enhancement of Canadian origin salmon stocks;

(c) the United States shall seek to provide annually to the Fund by December 31 of each year beginning in 1995 a financial contribution, subject to the availability of appropriated funds. In the event that the annual contribution is not made this agreement shall be suspended until the contribution for that year is made; 
(d) the Parties shall assist the Yukon River Panel in the development and implementation of these programs and shall, in particular, provide from their own budgetary resources, essential support as required for programs in their territories;

(e) during rebuilding as specified in this Chapter, unless the Parties jointly decide otherwise on the basis of recommendations by the Yukon River Panel:

(1) the Parties shall endeavor to allow spawning escapements to increase as a result of the fish produced from restoration activities, taking into account the desirability of avoiding disruption of existing fisheries;

(2) the agreed Canadian guideline harvest levels during rebuilding will not change; and

(3) harvest shares for salmon produced by enhancement activities will be recommended by the Yukon River Panel, taking into account the objectives of the rebuilding programs and the desire to avoid disruptions of existing fisheries.

Following the rebuilding period the catch shares for the fish produced through these programs shall be recommended by the Yukon River Panel; and

(f) the Fund shall be open for additional financial contributions from any source.

33. The Parties shall jointly develop and implement policies and procedures for planning, feasibility studies and operational methods. As a first step, the Parties shall undertake comprehensive cooperative regional planning and field surveys for possible salmon restoration and enhancement programs, the results of which shall be provided to the JTC. As part of this planning process, both Parties should incorporate fish genetic and health guidelines developed by the JTC.

34. The Parties understand that the financial contributions to the Fund shall be used for the programs described in Paragraph 32(b) to provide benefits for U.S. and Canadian fishermen on the Yukon River.

\section{Principles and Guidelines for the Restoration and Enhancement Fund}

\section{Principles}

35. Restoration and enhancement activities shall be consistent with the protection of the existing wild salmon stocks and the habitats upon which they depend.

36. Given the wild nature of the Yukon River and its salmon stocks, and the substantial risks associated with large scale enhancement through artificial propagation, these enhancement activities are inappropriate at this time.

37. Artificial propagation shall not be used as a substitute for effective fishery regulation, stock and habitat management or protection.

\section{Guidelines}

38. The priorities for implementing projects with the Fund shall be in this order: (a) restoring habitat and wild stocks; (b) enhancing habitat; and (c) enhancing wild stocks.

39. Careful planning is necessary before undertaking any restoration or enhancement projects that might impact any wild stock. Projects shall be evaluated by the Yukon River Panel based on a Yukon River basin wide stock rebuilding and restoration plan. A careful assessment and inventory of wild stocks and their health, habitat, and life history must be an integral part of restoration and enhancement planning. 
40. The most stringent of the fish genetics and fish disease policies in place by the responsible management entity of either Party will be applied to salmon restoration or enhancement projects.

41. The JTC shall develop a standard proposal format and implement a procedure for reviewing project proposals for use of the Fund. The JTC shall also develop and implement standard procedures for evaluating proposals for use of the Fund. When appropriate, the JTC will provide an evaluation of the ecological and genetic risks, and socioeconomic impacts, and will identify alternative actions including but not restricted to fishery management actions. The JTC shall establish levels for restored stocks consistent with natural habitat capacity.

42. Following JTC evaluation of proposed projects, each Party shall provide an opportunity for public comment and review of the proposed projects, along with the JTC evaluation.

43. The Yukon River Panel shall then decide which projects to fund, based on these guidelines, the JTC evaluation and any public comments received.

\section{Canadian Embassy Ambassade du Canada}

Washington, February 3, 1995

The Honourable Warren M. Christopher

Secretary of State of the

United States of America

Washington

Excellency,

I have the honour to refer to your Note, dated February 3 1995, the text of which reads as follow:

I have the honor to refer to negotiations that have been underway since 1985 on a long-term agreement for the conservation of salmon stocks originating from the Yukon River in Canada.

I have the honor to propose that our two Governments conclude an interim Agreement incorporating relevant provisions agreed in the negotiations to date in order to allow institutional arrangements to commence functioning while negotiations continue on a long-term agreement which would incorporate the relevant provisions of the interim Agreement.

To this end, I propose that Annex I to the Treaty between Canada and the United States of America concerning Pacific Salmon, signed at Ottawa on January 28, 1985 ("the Treaty") be amended by adding a new paragraph (d) to establish a Yukon River Panel for salmon originating in the Yukon River. I further propose that Annex IV to the Treaty be amended by adding a new chapter 8 as set forth in Attachment $A$ to this note. Attachment $B$ to this note contains provisions that have been developed in the negotiations to date and that are deferred for the long-term agreement.

I further propose that in the event that the Treaty terminates prior to the termination of this Interim Agreement:

(a) this Interim Agreement shall remain in force;

(b) the functions of the Yukon River Panel shall be assumed by a new commission, the "Yukon River Salmon Commission", and the Panel shall thereupon cease to exist,

(c) other provisions of the Theaty, to the extent they apply to the Yukon River, shall remain in effect as part of this Agreement, mutatis mutandis; and

(d) the Parties shall seek to agree on other measures necessary for the continuation and application of this Agreement. 
If this proposal is acceptable to the Government of Canada, I have the further honor to propose that this note, with Attachment A, together with your Excellency's note in reply, shall constitute an Agreement between our two Governments, which will enter into force on the date of your Excellency's note and remain in force until December 31, 1997, unless the Parties agree in writing to extend it.

Accept, Excellency, the renewed assurances of my highest consideration.

I have the honour to inform you that the proposals contained in the above note are acceptable to the Government of Canada and to confirm that that Note and the present note in reply, which is equally authentic in English and French, shall constitute an interim agreement between our two Governments for the conservation of salmon stocks originating from the Yukon River in Canada.

Please accept, Excellency, the renewed assurances of my highest consideration.

[Signsture]

Raymond A. J. Chrétien Ambassador of Canada 


\section{Agreement Between the Government of the United States of America and the Government of Canada on the Establishment of a Mediation Procedure Regarding the Pacific Salmon Treaty, Montreal, 1995}

Done at Monireal 11 September 1995

Entered into force 11 September 1995

Primary source citation: Copy of text provided by the

U.S. Department of State

\section{AGREEMENT BETWEEN THE GOVERNMENT OF THE UNITED STATES OF AMERICA AND THE GOVERNMENT OF CANADA ON THE ESTABLISHMENT OF A MEDIATION PROCEDURE REGARDING THE PACIFIC SALMON TREATY}

THE GOVERNMENT OF THE UNITED STATES OF AMERICA AND THE GOVERNMENT OF CANADA (hereinafter, "the Parties"), being parties to the Treaty Between the Government of Canada and the Government of the United States of America Concerning Pacific Salmon, done at Ottawa on January 28, 1985 (hereinafter, "the Treaty") and to the Memorandum of Understanding of the same date (hereinafter, the "MOU");

AWARE that their disagreement over the interpretation of paragraph 1(b) of Article III of the Treaty has hampered the implementation of the Treaty as a whole;

AWARE also that their disagreement over the relationship of paragraph 1(b) of Article III of the Treaty to the other paragraphs of Article III and to the other provisions of the Treaty, and over the application of paragraph A of the MOU, has hampered the negotiation, adoption and implementation of fishery regimes in accordance with the Treaty;

WISHING to find a solution to their dispute without delay;

HAVE AGREED TO THE FOLLOWING, which shall enter into force upon the signing of this agreement: 


\section{ARTICLE I \\ Appointment of Mediator}

1. The Parties shall jointly appoint a Mediator before August 22, 1995.

2. Should the Parties be unable to appoint a Mediator before the aforesaid date, they shall approach the Secretary General of the United Nations and call upon his good offices to assist them, if possible before September 20, 1995 , in their search for a Mediator acceptable to them.

3. The Mediator shall assume his or her duties within 21 days of his or her appointment, unless otherwise agreed by the Parties.

\section{ARTICLE II}

\section{Mission of the Mediator}

1. The mission of the Mediator shall be to assist the Parties to find a solution to the problem of the implementation of the Treaty as a whole, having regard in particular to paragraph 1(b) of Article III of the Treaty, the relationship of that paragraph to the other paragraphs of Article III and to the other provisions of the Treaty, and the application of paragraph $\mathrm{A}$ of the MOU, in the negotiation, adoption and implementation of fishery regimes in accordance with the Treaty.

2. In the exercise of his or her functions, the Mediator shall facilitate the adoption by the Parties of a mutually acceptable solution, which shall be in accordance with the applicable rules of international law. To this effect the Mediator shall meet with the representatives designated by each Party, including, if a Party so chooses, representatives of its Section of the Pacific Salmon Commission, and may request such documents from a Party as he or she believes would be useful in the fulfillment of his or her mission. During the course of the mediation, the Mediator shall make such proposals and recommendations to the Parties as he or she deems appropriate, designed to assist the Parties to resolve the dispute.

\section{ARTICLE III}

\section{Confidentiality}

The activities of the Mediator, the information gathered by him or her, the intervantions, representations, suggestions, proposals and recommendations made by the Mediator to the Parties, or made by the Parties to the Mediator, and the contents of documents received or produced by the Mediator shall be treated as confidential in nature, and shall not be made public, in whole or in part, except by written consent of both Parties.

\section{ARTICLE IV}

\section{Non-Binding Effect of Mediation}

The mediation shall have no binding effect. 


\section{ARTICLE V \\ Legal Position of the Parties}

None of the activities of the Mediator, or the representations or proposals made by the Parties, shall prejudice the respective legal positions of the Parties. Each Party reserves the right, should the mediation fail, to revert to its previous claim or positions.

\section{ARTICLE VI \\ Termination of Mediation}

It is the intent of the Parties that the mediation be completed as soon as practicable and that any understandings reached as a result of the mediation be available prior to the negotiation of fishing regimes for 1996 . The tentative target date for concluding the mediation is November 30,1995. Upon selecting a mediator, the Parties will review the target date with the mediator and make such adjustment as may be warranted. The Parties also agree that the target date may at any time be extended by agreement.

\section{ARTICLE VII}

\section{Costs}

Each Party shall bear one-half the costs of the Mediator as well as all of its own costs associated with the mediation.

\section{ARTICLE VIII}

\section{Best Efforts}

The Parties shall make their best efforts to resolve the dispute fairly. To that end, they shall engage in good faith in the mediation procedure, cooperate with and assist the Mediator fully in the fulfillment of his or her mission, and consider seriously the proposals and recommendations made by the Mediator.

IN WITNESS WHEREOF, the undersigned, duly authorized by their respective Governments, have signed this Agreement.

DONE in duplicate, at Montreal, this 11th day of September, 1995, in the English and French languages, each version being equally authentic. 


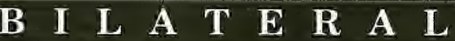

\author{
China
}





\section{Memorandum of Understanding Between the Government of the United States of America and the Government of the People's Republic of China on Effective Cooperation and Implementation of United Nations General Assembly Resolution 46/215 of December 20, 1991, Washington, D.C., 1993}

Done at Washington, D.C., 3 December 1993

Entered into force 3 December 1993

Primary source citation: Copy of text provided by the

U.S. Department of State

MEMORANDUM OF UNDERSTANDING BETWEEN THE GOVERNMENT OF THE UNITED STATES OF AMERICA AND THE GOVERNMENT OF THE PEOPLE'S REPUBLIC OF CHINA ON EFFECTIVE COOPERATION AND IMPLEMENTATION OF UNITED NATIONS GENERAL ASSEMBLY RESOLUTION 46/215 OF DECEMBER 20, 1991

The Representatives of the Government of the United States of America and the Government of the People's Republic of China,

Taking into account, in particular, the necessity for effective cooperation and implementation of United Nations General Assembly Resolution 46/215 of December 20, 1991, entitled "Large-Scale Pelagic Driftnet Fishing and its Impact on the Living Marine Resources of the World's Oceans and Seas" (“UNGA 46/215"),

Have agreed to the following temporary Memorandum of Understanding ("Memorandum"):

1. Officials of one Party upon encountering on the high seas of the North Pacific Ocean a fishing vessel flying the other Party's national flag, or claiming to be registered with the authorities of the other Party, that is found using or is equipped for use of a large-scale pelagic driftnet inconsistent with the provisions of UNGA 46/215, shall transmit to the appropriate officials of the other Party a request to conduct a cooperative visit and verification of said vessel. 
2. A qualified official of each Party shall be entitled to ride on board each high seas driftnet enforcement vessel of the other Party. Each such official shall embark and disembark the vessel at times and locations so as not to interfere with the schedule of the vessel.

3. If the authorized officials of the other Party are not able to join in the cooperative visit and verification, they shall so inform the requesting Party immediately and shall cooperate with and assist the authorized officials of the requesting Party in the conduct of the visit and verification. When the on-scene authorized officials of the requesting Party are informed that authorized officials of the other Party are not able to join in the visit and verification, or the authorized officials of the other Party do not so inform the requesting Party immediately, the authorized officials of the requesting Party shall initiate the visit and verification.

4. If the authorized officials of the other Party arrive within a reasonable span of time after receiving a transmission requesting a cooperative visit and verification of a fishing vessel found using or equipped for use of a large-scale pelagic driftnet on the high seas of the North Pacific Ocean, the authorized officials of the two Parties shall jointly visit and verify the fishing vessel.

5. The visiting officials authorized may verify the fishing vessel's flag and registry, and may examine the vessel except for crew living areas and engineering spaces, together with its equipment and records, fishing gear, catch and logs, to determine whether the vessel has engaged in activities inconsistent with the provisions of UNGA 46/215.

6. At the time this Memorandum enters into force, each Party shall provide the other Party with examples of credentials that its authorized officials shail present, upon request, to the captain of a visited vessel.

7. The results of visit and verification undertaken by the requesting Party on the high seas of the North Pacific Ocean with respect to vessels of the other Party found using or equipped for use of a large-scale pelagic driftnet inconsistent with the provisions of UNGA 46/215, including the evidence of any activities inconsistent with the provisions of UNGA 46/215, shall be provided to the appropriate officials of the other Party for further action.

8. If the results of the visit proved that the visited fishing vessel engaged in activities inconsistent with the provisions of UNGA 46/215 and that it was registered with the authorities of any Party to this Memorandum, the authorities of that Party shall take enforcement action with respect to the fishing vessel. In taking such enforcement action, that Party shall receive and take into consideration any evidence of activities inconsistent with the provisions of UNGA 46/215 provided by the other Party and shall inform the other Party of the enforcement actions taken.

9. If it is determined that the visited fishing vessel has engaged in activities inconsistent with the provisions of UNGA 46/215, and that the vessel was not registered with the authorities of either Party, the Party that initiated the visit and verification may take enforcement action with respect to that vessel in accordance with applicable rules of international law and practice, and shall-inform the other Party of any such action taken.

10. The authorized officials conducting the visit and verification shall conduct their operations in accordance with applicable rules of international law and practice, so that the fishing vessels suffer the minimum interference and inconvenience.

11. Any problem which occurs in the implementation of this Memorandum shall be solved through consultation by the two Parties.

12. This Memorandum will enter into force on the date of signature and shall remain in force for one year from that date. This Memorandum may be extended until a certain date agreed by the two Parties.

DONE AT Washington, in duplicate, this third day of December, 1993, in the English and Chinese languages, each version being equally authentic. 


\title{
Amendment to the Agreement Between the Government of the United States of America and the Government of the People's Republic of China Concerning Fisheries off the Coasts of the United States, Beijing, 1994
}

\author{
Done at Beijing 4 March and 31 May 1994
}

Entered into force 3 April 1995

Primary source citation: Copy of text provided by the

U.S. Department of State

\section{EMBASSY OF THE \\ UNITED STATES OF AMERICA}

March 4, 1994

Embassy of the United States of America,

Beijing

No. 079

The Embassy of the United States of America presents its compliments to the Ministry of Foreign Affairs of the People's Republic of China and refers to the Agreement between the Government of the United States of America and the Government of the People's Republic of China concerning fisheries off the coasts of the United States, with Annexes, done at Washington July 23, 1985, as amended and extended (the Agreement).

The Embassy has the honor to propose, on behalf of the Government of the United States of America, that the Agreement, currently scheduled to expire July 1, 1994, be extended for an additional two years period until July 1 , 1996. If this proposal is acceptable, the Embassy has the further honor to propose that this Note and a favorable reply from the Government of the People's Republic of China shall constitute an Agreement between the two governments, which shall enter into force on a date to be determined in a subsequent exchange of Diplomatic Notes following the completion of all necessary international procedures of both parties.

The Embassy requests that the Ministry transmit the enclosed information to the appropriate authorities of the People's Republic of China.

The Embassy takes this opportunity to renew to the Ministry of Foreign Affairs of the People's Republic of China the assurances of its highest consideration. 


\section{DEPARTMENT OF STATE \\ OFFICE OF LANGUAGE SERVICES}

Translating Division

LS No. 144899

Chinese

$\mathrm{RM} 9 / 187$

Ministry of Foreign Affairs

People's Republic of China

No. 532

The Ministry of Foreign Affairs of the People's Republic of China presents its compliments to the Embassy of the United States of America and has the honor to acknowledge receipt of diplomatic note dated March 4, 1994 from the Embassy of the United States of America regarding the Agreement between the Government of the People's Republic of China and the Government of the United States of America concerning fisheries off the coasts of the United States, with Annexes, done at Washington July 23, 1985, as amended and extended. The content of the Note is as follows:

Quote.

The Embassy has the honor to propose, on behalf of the Government of the United States of America, that the Agreement, currently scheduled to expire July 1, 1994, be extended for an additional two years period until July 1, 1996. If this proposal is acceptable, the Embassy has the further honor to propose that this Note and a favorable reply from the Government of the People's Republic of China shall constitute an Agreement between the two governments, which shall enter into force on a date to be determined in a subsequent exchange of Diplomatic Notes following the completion of all necessary international procedures of both parties.

Unquote.

On behalf of the Government of the People's Republic of China, the Ministry of Foreign Affairs of the People's Republic of China accepts the Embassy's proposal.

[Complimentary close]

Beijing, People's Republic of China, May 31, 1994

[Ministry stamp]

\section{CERTIFICATION OF TRANSLATOR}

I hereby certify that the above translation bearing LS No. 144899 was prepared by the Office of Language Services of the Department of State and that it is a correct translation to the best of my knowledge and belief.

Dated:

[Signature]

8/8/94

Acting Chief, Translating Division 


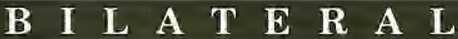

Costa Rica

ENVIRONMENTAND NATURAL RESOURCES 



\title{
Statement of Intent for Bilateral
} Sustainable Development, Cooperation and Joint Implementation of Measures to Reduce $\mathbb{E}$ missions of Greenhouse Gases Between the Government of the United States of America and the Government of the Republic of Costa Rica, Washington, D.C., 1994

\author{
Done at Washington, D.C. 30 September 1994
}

Entered into force 30 September 1994

Primary source citation: Copy of text provided by the U.S. Department of State

\section{STATEMENT OF INTENT FOR BILATERAL SUSTAINABLE DEVELOPMENT, COOPERATION AND JOINT IMPLEMENTATION OF MEASURES TO REDUCE EMISSIONS OF GREENHOUSE GASES BETWEEN THE GOVERNMENT OF THE UNITED STATES OF AMERICA AND THE GOVERNMENT OF THE REPUBLIC OF COSTA RICA}

WHEREAS, the Government of the United States of America, as represented by the United States Department of Energy (DOE) and the United States Environmental Protection Agency (EPA), on the one hand, and the Government of the Republic of Costa Rica, as represented by the Costa Rica Ministry of Natural Resources, Energy and Mines, on the other hand, ("the Participants"), recognize that enhancing environmental protection, and, in particular, controlling greenhouse gas emissions to limit potential adverse climate change impacts, would be mutually beneficial;

WHEREAS, the Participants recognize that limiting the adverse impacts of climate change requires a global solution, to which both the United States and Costa Rica can make significant contributions, and the Participants have a mutual interest in working together in this area;

WHEREAS, the Participants recognize that the Framework Convention on Climate Change, which the governments of both countries have ratified, and other international agreements including the Convention on Biological Diversity, to which the governments of both countries are signatories, encourage countries to pursue the rapid development of and joint implementation of cooperative, mutually voluntary, and cost-effective projects, particularly technology cooperation projects aimed at reducing or sequestering emissions of greenhouse gases and at promoting sustainable development and biological diversity conservation; 
WHEREAS the Participants will mutually benefit from the deployment and use of sustainable energy and greenhouse gas emission reduction and sequestration technologies and methods;

WHEREAS the Participants recognize the potential for additional investment in environmentally, socially and economically sound development through the participation of the private sector in joint implementation of measures and technology cooperation projects to reduce emissions of greenhouse gases;

WHEREAS, the Participants recognize that many methods and technologies that limit greenhouse gas emissions, also contribute to the control of local and regional environmental problems and that cost-effective, world-wide greenhouse gas emission reductions may be achieved by encouraging such reductions in countries where responsive solutions are available at least cost with possible financial and technical assistance and investment from individuals and organizations in other industrialized countries;

The Participants declare as follows:

The Participants hereby intend to facilitate the development of joint implementation projects which will encourage the following: market deployment of greenhouse gas-reducing technologies, including energy efficiency and renewable energy technologies; education and training programs; increased diversification of energy sources; conservation, restoration, and enhancement of forest carbon sinks, especially in areas that promote biodiversity conservation and ecosystem protection; reduction of greenhouse gas emissions and other pollution; and the exchange of information regarding sustainable forestry and energy technologies;

This cooperation should provide the basis for future similar arrangements among countries, particularly in the Western Hemisphere, and contribute to the international establishment of an accessible joint implementation regime that is sensitive to environmental, developmental, social and economic priorities. This cooperation will encourage partnerships involving the Participants, the private sector, non-governmental organizations, and other entities.

The Participants intend that the forms of cooperation under this framework may include, but are not limited to, the following:

A. The design of Costa Rica's criteria to facilitate acceptance of joint implementation projects - including a model statement of acceptance - consistent with the Groundrules for the U.S. Initiative on Joint Implementation (USIJI) and Costa Rica's domestic priorities for measures to reduce greenhouse gas emissions and increase sinks via joint implementation, including biodiversity conservation and ecosystem protection, reduction of local pollution, sustainable land-use practices, improved rural income opportunities, and local participation in project planning and execution;

B. Identification and support of projects that are likely to meet the criteria for joint implementation project selection developed by the USIJI, by Costa Rica, and for the pilot phase adopted by the Conference of the Parties of the United Nations Framework Convention on Climate Change;

C. The design of methodologies and mechanisms to establish procedures for monitoring and external verification of greenhouse gas reductions, and the tracking and attribution of such reductions, consistent with the criteria for project selection being developed by the USIJI, Costa Rica and by the Conference of the Parties of the United Nations Framework Convention on Climate Change;

D. Outreach and promotion of joint implementation and other sustainable development activities in the private, public, and non-governmental sectors, including dissemination of information about the USIJI and about Costa Rica's criteria for joint implementation projects, and supporting technical assistance resources through workshops, conferences, and information networks;

E. Education and training activities for personnel in related energy and land-use sectors, both private and governmental, to strengthen human resources and institutional infrastructure and facilitate private joint venture activities;

F. Improvement of information networks to share information on technologies, potential partners, projects, technical resources, relevant policies, financing resources, and other information deemed useful to support joint implementation and sustainable development; 
G. The promotion of the development of a hemispheric partnership on sustainable development and joint implementation projects which may be addressed at the Summit of the Americas in December 1994, and subsequent related activities;

H. The expansion of existing relevant intergovernmental initiatives for technical, economic, and scientific collaboration in the area of greenhouse gas emissions reduction;

I. The exploration of credible certification of emissions reductions, especially the determination of reasonable greenhouse gas emissions baselines at the project level, and its relevance to potential related market mechanisms;

J. The design of innovative financial arrangements for activities and projects implemented in accordance with this Statement of Intent, for the purposes of:

1. facilitating increased private sector investment in sustainable development and joint implementation projects;

2. promoting new partnerships for project financing;

3. advocating on behalf of approved project portfolios for funding; and

4. identifying additional sources of project funding and the policy framework needed to facilitate access to them, i.e., financial incentives.

The Participants intend to develop a Memorandum of Understanding to delineate further the intended cooperative activities listed above, as deemed necessary.

The Participants intend to examine the need for provisions to insure against loss of greenhouse gas emissions reductions achieved through jointly implemented projects.

The Participants intend that any joint implementation project or other joint activity or arrangement undertaken pursuant to this Statement of Intent will be on terms accepted by all parties to the transaction. Furthermore, the Participants intend to include appropriate patent and other intellectual property rights provisions, as well as provisions to protect business confidential information, in any such plans or arrangements. In particular, in the event that any activity involves access to and the sharing or transfer of technology subject to patents or other intellectual property rights, such access and sharing or transfer will be provided on terms which recognize and are consistent with the adequate and effective protection of intellectual property rights.

Done at Washington, in duplicate, on this 30th day of September 1994.

\section{FOR THE GOVERNMENT OF THE}

UNITED STATES OF AMERICA:

[Signature]

\section{FOR THE GOVERNMENT OF \\ THE REPUBLIC OF COSTA RICA:}

[Signature] 



\section{B I L A T E $\mathbf{R}$ A $\mathbf{L}$}

\section{CZECH RePUBLIC}

ENVIRONMENT AND NATURAL RESOURCES 



\section{Agreement Between the U.S. National Oceanic and Atmospheric Administration and the Ministry of Education, Youth, and Sports of the Czech Republic for Cooperation in the GLOBE Program, Prague, 1995}

Done at Prague 20 April 1995

Entered into force 20 April 1995

Primary source citation: Copy of text provided by the U.S. Department of State

\section{AN AGREEMENT BETWEEN THE U.S. NATIONAL OCEANIC AND ATMOSPHERIC ADMINISTRATION AND THE MINISTRY OF EDUCATION, YOUTH, AND SPORTS OF THE CZECH REPUBLIC FOR COOPERATION IN THE GLOBE PROGRAM}

\section{Preamble}

The U.S. National Oceanic and Atmospheric Administration, acting on behalf of itself and other U.S. Government agencies participating in the GLOBE Program (hereinafter, "the U.S. side"), and the Ministry of Education, Youth, and Sports of the Czech Republic (hereinafter, "the Czech side"),

Intending to increase the awareness of students throughout the world about the global environment,

Seeking to contribute to increased scientific understanding of the Earth, and

Desiring to support improved student achievement in science and mathematics,

Have agreed to cooperate in the Global Learning and Observations to Benefit the Environment (GLOBE) Program as follows:

\section{Article 1 - The GLOBE Program}

The GLOBE Program is an international environmental science and education program that will bring students, teachers, and scientists together to study the global environment. GLOBE will create an international 
network of students in grades K-12 (or equivalent) studying environmental issues, making environmental measurements, and sharing useful environmental data with the international environmental science community.

\section{Article 2 - Respective Responsibilities}

A. The U.S. side will:

1. Identify U.S. schools that will participate in the GLOBE Program (details regarding GLOBE schools in Appendix A);

2. Select, in consultation with international scientists and educators, the GLOBE environmental measurements and types of measurement equipment (described in Appendix B);

3. Select Principal Investigator Teams for the GLOBE environmental measurements, and support the U.S. members of the Teams;

4. Calibrate, if necessary, measurement equipment that cannot be calibrated by GLOBE teachers and students;

5. Develop, in consultation with international scientists and educators, GLOBE educational materials;

6. Translate GLOBE instructional materials related to measurement procedures and data reporting protocols into the six United Nations languages, and provide these plus all broader GLOBE educational materials to the Czech side for further reproduction as necessary;

7. Conduct annual regional training sessions for GLOBE Country Coordinators and GLOBE teachers who will serve as trainers for additional GLOBE teachers in the Czech Republic, and provide a copy of GLOBE training materials to the Czech side;

8. Design, develop, operate, and maintain GLOBE data processing capabilities and other necessary technology and equipment;

9. Provide GLOBE software, as necessary, for use on Czech GLOBE school computers. (To the maximum extent possible, textual material appearing on computer screens will be accessible in the student's choice among the six United Nations languages.);

10. Accept environmental data reported from GLOBE schools around the world, and develop and provide resultant global environmental images (visualization products) to the Czech side; and

11. Evaluate the overall GLOBE Program periodically, in consultation with international GLOBE Country Coordinators, and modify the overall program as appropriate.

B. The Czech side will:

1. Select Czech schools to participate in the GLOBE Program (details regarding GLOBE schools in Appendix A) and provide an updated list of Czech GLOBE schools to the U.S. side at the beginning of each school year;

2. Ensure that Czech GLOBE schools conduct the fundamental activities of GLOBE schools detailed in Appendix A (take GLOBE environmental measurements, report data, and receive and use resultant global environmental images, using GLOBE educational materials under the guidance of teachers trained to conduct the GLOBE Program);

3. Name a Czech Government Point of Contact responsible for policy-level communications with the Director of the GLOBE Program; the point of contact will be the Ministry of Education, Youth, and Sports; 
4. Name a Country Coordinator responsible for day-to-day management, oversight, and facilitation of the GLOBE Program in the Czech Republic;

5. Ensure that the Country Coordinator and some GLOBE teachers attend GLOBE regional training and in turn provide GLOBE training to at least one teacher in each Czech GLOBE school;

6. Ensure that GLOBE instructional materials related to measurement procedures and data reporting protocols are utilized in Czech GLOBE schools, and that broader GLOBE educational materials are appropriately translated, adapted, reproduced, and distributed to all Czech GLOBE schools;

7. Ensure that Czech GLOBE schools have the necessary measurement equipment to take GLOBE environmental measurements (described in Appendix B);

8. Ensure that teachers and students at Czech GLOBE schools calibrate GLOBE measurement equipment according to procedures provided in GLOBE instructional materials;

9. Ensure that Czech GLOBE schools have the necessary computer and communications systems (described in Appendix $\mathrm{C}$ ) to report GLOBE environmental measurements and to receive and use GLOBE visualization products, or make agreed alternative arrangements for such reporting and receipt. (At a minimum, the Czech Country Coordinator will need access to Internet so that all measurement data from Czech GLOBE schools will be reported via Internet.); and

10. Evaluate GLOBE operations in the Czech Republic periodically and assist the U.S. side in conducting periodic evaluation of the overall GLOBE Program.

\section{Article 3 - Financial Arrangements}

Each side will bear the costs of fulfilling its respective responsibilities under this Agreement. Obligations of each side pursuant to this Agreement are subject to its respective funding procedures and the availability of appropriated funds, personnel, and other resources. The conduct of activities under this Agreement will be consistent with the relevant laws and regulations of the two sides.

\section{Article 4 - Exchange of Data and Goods}

GLOBE environmental measurement data, visualization products, software, and educational materials will be available worldwide without restriction as to their use or redistribution.

\section{Article 5 - Release of Information about the GLOBE Program}

Each side may release information on the GLOBE Program as it may deem appropriate without prior consultation with the other.

\section{Article 6 - Customs and Immigration}

Each side will, to the extent permitted by its laws and regulations, facilitate the movement of persons and goods necessary to implement this Agreement into and out of its territory and accord entry to such goods into its territory free of customs duties and other similar charges. 


\section{Article 7 - Final Provisions}

This Agreement will enter into force upon signature of the two sides and will remain in force for five years. It will be automatically extended for further five-year periods, unless either side decides to terminate it and so notifies the other side with three months' written notice. This Agreement may be terminated at any time by either side upon three months' prior written notice to the other side. This Agreement may be amended by written agreement of the two sides.

Appendices A, B, and C are a part of this Agreement. They may be amended or updated by agreement between the U.S. National Oceanic and Atmospheric Administration and the Ministry of Education, Youth, and Sports. authentic.

Done at Prague, on April 20, 1995, in duplicate in the English and Czech languages, both texts being equally

FOR THE NATIONAL OCEANIC AND

ATMOSPHERIC ADMINISTRATION:

[Signature]
FOR THE MINISTRY OF EDUCATION, YOUTH, AND SPORTS:

[Signature]

\section{Appendix A GLOBE Schools}

Each partner country will be responsible for identifying its participating schools. Schools should be selected so as to satisfy the objectives of the GLOBE Program. In particular, countries should emphasize the selection of schools that will maximize the number of students worldwide participating in the program. Also, countries should consider involving schools in locations that will yield measurement data that is important to the international environmental science community.

Students at all GLOBE schools throughout the world will conduct the following fundamental activities: they will make environmental measurements at or near their schools; report their data to a GLOBE data processing site; receive vivid graphical global environmental images (visualization products) created from their data and the data from other GLOBE schools around the world; and study the environment by relating their observations and the resulting visualization products to broader environmental topics. All of these activities will be conducted under the guidance of specially trained teachers (GLOBE-trained teachers).

GLOBE educational materials will be used in GLOBE schools under the guidance of GLOBE-trained teachers. These materials will detail procedures for taking environmental measurements and protocols for reporting data; explain the significance of the measurements; guide the use of the visualization products; and integrate the measurement aspects of the program into a broader study of the environment.

Schools throughout the United States and the rest of the world that are not GLOBE schools may become GLOBE Affiliate schools by observing the GLOBE Program in operation through the Internet. Students at these schools will benefit from the use of GLOBE visualization products and educational materials accessible on-line. All GLOBE Affiliate schools will be encouraged to become participating GLOBE schools.

\section{Appendix B GLOBE Environmental Measurements and Equipment}

GLOBE environmental measurements will contribute in a significant way to the scientific understanding of the dynamics of the global environment. Every GLOBE school will conduct a core set of GLOBE environmental measurements in the following critical areas: Atmosphere/Climate, Hydrology/Water Chemistry, and Biology/Geology. Where possible, a GLOBE school may coordinate its activities with those of other neighboring GLOBE schools, so that the complete set of GLOBE measurements will be available from a locality. As the GLOBE Program evolves, elective measurements not common to all GLOBE schools may be added in order to address local environmental issues. 
Students at all age levels will be active participants in the GLOBE Program. The actual participation will be designed so as to be grade-appropriate for grades K-5, 6-8, and 9-12 (or equivalent). Younger students will make limited measurements which may be qualitative rather than quantitative. Older students will make additional measurements and more sophisticated measurements, as appropriate for their grade level. Measurement equipment will not need to be standardized; rather, performance specifications will be provided.

Following is an example list of core measurements and equipment. The full list will be initially determined and periodically updated as provided in Article 2.A.2, based on experience gained in implementing the GLOBE Program.

\section{Measurements}

Atmosphere/climate:

Air temperature

Precipitation

Cloud cover/type

\section{Equipment needed}

\author{
$\mathrm{Max} / \mathrm{min}$ thermometer \\ Calibration thermometer \\ Instrument shelter \\ Rain gauge \\ Cloud charts
}

\section{Biology/geology:}

Habitat study

Tree height

Tree canopy

Tree diameter

Species identification

Phenology
pH paper, pen, or meter

Alcohol thermometer

Gypsum block sensors

Soil moisture meter

\section{Appendix C GLOBE Computer and Communications Systems}

In order to derive maximum benefit from the GLOBE Program, all schools will be encouraged to use an international information network, initially using the Internet, along with classroom computers. The World Wide Web multi-media information-access capability has been selected as the basis for IBM-compatible and Apple Macintosh computer systems to support the required GLOBE school activities of data entry, data analysis, and use of GLOBE environmental images. Following is a description of GLOBE computer and communications systems consistent with current GLOBE requirements.

Overall attributes of the minimum GLOBE school computer configuration that can execute the necessary software are:

For IBM-compatible systems: a $386 \mathrm{SX}$ or higher level processor, at least 4 megabytes of RAM memory ( 8 megabytes preferred), a VGA-capable monitor and display driver (Super VGA preferred), a hard disk storage system with as large a capacity as possible (preferably 300 megabytes or larger), and a direct Internet connection or dial-up capability that can use SLIP or PPP protocols with a 14,400 bps modem (preferably supporting V.42bis data compression which can enable 57,600 bps operation). The Windows 3.1 or later operating system is necessary. A printer is desirable.

For Apple Macintosh systems: a $6803020 \mathrm{MHz}$ or faster processor, at least 4 megabytes of RAM memory ( 8 megabytes preferred), a hard disk storage system with as large a capacity as possible (preferably 300 megabytes 
or larger), and a direct Internet connection or dial-up capability that can use SLIP or PPP protocols with a 14,400 bps modem (preferably supporting V.42bis data compression which can enable 57,600 bps operation). A printer is desirable.

Software for a higher performance GLOBE school computer system is also being developed that will operate on higher performance, multi-media IBM-capable systems and on Apple Macintosh systems. For IBM-compatible systems: a 486/66 or faster processor, 16 megabytes of RAM memory, 500 megabytes of hard disk space, a Super VGA monitor, a double-speed CD-ROM reader, a Soundblaster-compatible sound card, and an MPEG animation speed-up board will be required. For Apple Macintosh systems: a PowerPC processor, 16 megabytes of RAM memory, 500 megabytes of hard disk space, and a double-speed CD-ROM reader will be required. A communications capability the same as or better than for the minimum configurations above will also be required. A printer will be highly desirable.

It is recognized that there is a broad range of technological capabilities among potential GLOBE schools. The diversity of technology accessible by schools worldwide may require in some cases that environmental measurements be reported in hardcopy and that a variety of media be used to distribute visualization products, including photographs and broadcast television. All schools that want to participate in the program will be accommodated.

Technology associated with the GLOBE Program will continually evolve to higher levels and participants will be encouraged to upgrade over time. 


\section{B I L A T E $\mathbf{R}$ A $\mathbf{L}$}

\section{EGYPT}

ENVIRONMENT AND NATURAL RESOURCES 



\section{Agreement Between the National Oceanic and Atmospheric Administration of the United States of America and the Ministry of Education of the Arab Republic of Egypt for Cooperation in the GLOBE Program, Cairo, 1995}

Done at Cairo 20 March 1995

Entered into force 20 March 1995

Primary source citation: Copy of text provided by the

U.S. Department of State

\section{AGREEMENT BETWEEN THE NATIONAL OCEANIC AND ATMOSPHERIC ADMINISTRATION OF THE UNITED STATES OF AMERICA AND THE MINISTRY OF EDUCATION OF THE ARAB REPUBLIC OF EGYPT FOR COOPERATION IN THE GLOBE PROGRAM}

\section{PREAMBLE}

The National Oceanic and Atmospheric Administration of the United States of America, acting on behalf of itself and other U.S. Government agencies participating in the GLOBE Program (hereinafter, the U.S. side), and the Ministry of Education of the Arab Republic of Egypt (hereinafter, the Egyptian side),

Intending to increase the awareness of students throughout the world about the global environment,

Seeking to contribute to increased scientific understanding of the Earth, and

Desiring to support improved student achievement in science and mathematics,

Have agreed to cooperate in the Global Learning and Observations to Benefit the Environment (GLOBE) Program as follows: 


\section{ARTICLE 1 - THE GLOBE PROGRAM}

The GLOBE Program is an international environmental science and education program that will bring students, teachers, and scientists together to study the global environment. GLOBE will create an international network of students in grades K-12 (or equivalent) studying environmental issues, making environmental measurements, and sharing useful environmental data with the international environmental science community.

\section{ARTICLE 2 - RESPECTIVE RESPONSIBILITIES}

A. The U.S. side will:

1. Identify U.S. schools that will participate in the GLOBE Program (details regarding GLOBE schools in Appendix A);

2. Select, in consultation with international scientists and educators, the GLOBE environmental measurements and types of measurement equipment (described in Appendix B);

3. Select Principal Investigator Teams for the GLOBE environmental measurements, and support the U.S. members of the Teams;

4. Calibrate, if necessary, measurement equipment that cannot be calibrated by GLOBE teachers and students;

5. Develop, in consultation with international scientists and educators, GLOBE educational materials;

6. Translate GLOBE instructional materials related to measurement procedures and data reporting protocols into the six United Nations languages, and provide these plus all broader GLOBE educational materials to the Egyptian side for further reproduction as necessary;

7. Conduct annual regional training sessions for GLOBE Country Coordinators and GLOBE teachers who will serve as trainers for additional GLOBE teachers in Egypt, and provide a copy of GLOBE training materials to the Egyptian side;

8. Design, develop, operate, and maintain GLOBE data processing capabilities and other necessary technology and equipment;

9. Provide GLOBE software, as necessary, for use on Egyptian GLOBE school computers. (To the maximum extent possible, textual material appearing on computer screens will be accessible in the student's choice among the six United Nations languages.);

10. Accept environmental data reported from GLOBE schools around the world, and develop and provide resultant global environmental images (visualization products) to the Egyptian side; and

11. Evaluate the overall GLOBE Program periodically, in consultation with international GLOBE Country Coordinators, and modify the overall program as appropriate.

B. The Egyptian side will:

1. Select Egyptian schools to participate in the GLOBE Program (details regarding GLOBE schools in Appendix A) and provide an updated list of Egyptian GLOBE schools to the U.S. side at the beginning of each school year;

2. Ensure that Egyptian GLOBE schools conduct the fundamental activities of GLOBE schools detailed in Appendix A (take GLOBE environmental measurements, report data, and receive and use resultant global environmental images, using GLOBE educational materials under the guidance of teachers trained to conduct the GLOBE Program); 
3. Name an Egyptian Government Point of Contact responsible for policy-level communications with the Director of the GLOBE Program;

4. Name a Country Coordinator responsible for day-to-day management, oversight, and facilitation of the GLOBE Program in Egypt;

5. Ensure that the Country Coordinator and some GLOBE teachers attend GLOBE regional training and in turn provide GLOBE training to at least one teacher in each Egyptian GLOBE school;

6. Ensure that GLOBE instructional materials related to measurement procedures and data reporting protocols are utilized in Egyptian GLOBE schools, and that broader GLOBE educational materials are appropriately translated, adapted, reproduced, and distributed to all Egyptian GLOBE schools;

7. Ensure that Egyptian GLOBE schools have the necessary measurement equipment to take GLOBE environmental measurements (described in Appendix B);

8. Ensure that teachers and students at Egyptian GLOBE schools calibrate GLOBE measurement equipment according to procedures provided in GLOBE instructional materials;

9. Ensure that Egyptian GLOBE schools have the necessary computer and communications systems (described in Appendix C) to report GLOBE environmental measurements and to receive and use GLOBE visualization products, or make agreed alternative arrangements for such reporting and receipt. (At a minimum, the Egyptian Country Coordinator will need access to Internet so that all measurement data from Egyptian GLOBE schools will be reported via Internet.); and

10. Evaluate GLOBE operations in Egypt periodically and assist the U.S. side in conducting periodic evaluation of the overall GLOBE Program.

\section{ARTICLE 3 - FINANCIAL ARRANGEMENTS}

Each side will bear the costs of fulfilling its respective responsibilities under this agreement. Obligations of each side pursuant to this agreement are subject to its respective funding procedures and the availability of appropriated funds, personnel, and other resources.

The conduct of activities under this agreement will be consistent with the relevant laws and regulations of the two sides.

\section{ARTICLE 4 - EXCHANGE OF DATA AND GOODS}

GLOBE environmental measurement data, visualization products, software, and educational materials will be available worldwide without restriction as to their use or redistribution.

\section{ARTICLE 5 - RELEASE OF INFORMATION ABOUT THE GLOBE PROGRAM}

Each side may release information on the GLOBE Program as it may deem appropriate without prior consultation with the other.

\section{ARTICLE 6 - CUSTOMS AND IMMIGRATION}

Each side will, to the extent permitted by its laws and regulations, facilitate the movement of persons and goods necessary to implement this agreement into and out of its territory and accord entry to such goods into its territory free of customs duties and other similar charges. 


\section{ARTICLE 7 - ENTRY INTO FORCE, AMENDMENTS, WITHDRAWAL}

This agreement will enter into force upon signature of the two sides and will remain in force for five years. It will be automatically extended for further five-year periods, unless either side decides to terminate it and so notifies the other side with three months written notice. This agreement may be terminated at any time by either side upon three months prior written notice to the other side. This agreement may be amended by written agreement of the two sides.

Done at Cairo on the twentieth day of March, 1995, in duplicate, in the English and Arabic languages, both texts being equally authentic.

For the National Oceanic and

Atmospheric Administration:

[Signature]
For the Ministry of

Education:

[Signature]

\section{APPENDIX A GLOBE Schools}

Each partner country will be responsible for identifying its participating schools. Schools should be selected so as to satisfy the objectives of the GLOBE Program. In particular, countries should emphasize the selection of schools that will maximize the number of students worldwide participating in the program. Also, countries should consider involving schools in locations that will yield measurement data that is important to the international environmental science community.

Students at all GLOBE schools throughout the world will conduct the following fundamental activities: they will make environmental measurements at or near their schools; report their data to a GLOBE data processing site; receive vivid graphical global environmental images (visualization products) created from their data and the data from other GLOBE schools around the world; and study the environment by relating their observations and the resulting visualization products to broader environmental topics. All of these activities will be conducted under the guidance of specially trained teachers (GLOBE-trained teachers).

GLOBE educational materials will be used in GLOBE schools under the guidance of GLOBE-trained teachers. These materials will detail procedures for taking environmental measurements and protocols for reporting data; explain the significance of the measurements; guide the use of the visualization products; and integrate the measurement aspects of the program into a broader study of the environment.

Schools throughout the United States and the rest of the world that are not GLOBE schools may become GLOBE Affiliate schools by observing the GLOBE Program in operation through the Internet. Students at these schools will benefit from the use of GLOBE visualization products and educational materials accessible on-line. All GLOBE Affiliate schools will be encouraged to become participating GLOBE schools.

\section{APPENDIX B GLOBE Environmental Measurements and Equipment}

GLOBE environmental measurements will contribute in a significant way to the scientific understanding of the dynamics of the global environment. Every GLOBE school will conduct a core set of GLOBE environmental measurements in the following critical areas: Atmosphere/Climate, Hydrology/Water Chemistry, and Biology/Geology. Where possible, a GLOBE school may coordinate its activities with those of other neighboring GLOBE schools, so that the complete set of GLOBE measurements will be available from a locality. As the GLOBE Program evolves, elective measurements not common to all GLOBE schools may be added in order to address local environmental issues.

Students at all age levels will be active participants in the GLOBE Program. The actual participation will be designed so as to be grade-appropriate for grades K-5, 6-8, and 9-12 (or equivalent). Younger students will make limited measurements which may be qualitative rather than quantitative. Older students will make additional measure- 
ments and more sophisticated measurements, as appropriate for their grade level. Measurement equipment will not need to be standardized; rather, performance specifications will be provided.

Following is an example list of core measurements and equipment. The full list will be initially determined and periodically updated as provided in Article 2.A.2, based on experience gained in implementing the GLOBE Program.

\section{MEASUREMENTS}

Atmosphere/Climate:

Air Temperature

Precipitation

Cloud Cover/Type

Hydrology/Water Chemistry:

Water $\mathrm{pH}$

Water Temperature

Soil Moisture

\section{Biology/Geology:}

Habitat Study

Tree Height

Tree Canopy

Tree Diameter

Species Identification

Phenology

\section{EQUIPMENT NEEDED}

\author{
Max/Min Thermometer \\ Calibration Thermometer \\ Instrument Shelter \\ Rain Gauge \\ Cloud Charts
}

pH Paper, Pen, or Meter

Alcohol Thermometer

Gypsum Block Sensors

Soil Moisture Meter

\author{
Compass \\ Meter Measuring Tape \\ Surveying Markers or Stakes \\ Clinometer \\ Densiometer \\ Diameter Tape \\ Dichotomous Keys \\ $35 \mathrm{~mm}$ Camera
}

\section{APPENDIX C \\ GLOBE Computer and Communications Systems}

In order to derive maximum benefit from the GLOBE Program, all schools will be encouraged to use an international information network, initially using the Internet, along with classroom computers. The World Wide Web multi-media information-access capability has been selected as the basis for IBM-compatible and Apple Macintosh computer systems to support the required GLOBE school activities of data entry, data analysis, and use of GLOBE environmental images. Following is a description of GLOBE computer and communications systems consistent with current GLOBE requirements.

Overall attributes of the minimum GLOBE school computer configuration that can execute the necessary software are:

For IBM-compatible systems: a $386 \mathrm{SX}$ or higher level processor; at least 4 megabytes of RAM memory ( 8 megabytes preferred); a VGA-capable monitor and display driver (Super VGA preferred); a hard disk storage system with as large a capacity as possible (preferably 300 megabytes or larger); and a direct Internet connection or dial-up capability that can use SLIP or PPP protocols with a 14,400 bps modem (preferably supporting V.42bis data compression which can enable 57,600 bps operation). The Windows 3.1 or later operating system is necessary. A printer is desirable.

For Apple Macintosh systems: a 6803020 Mhz or faster processor; at least 4 megabytes of RAM memory ( 8 megabytes preferred); a hard disk storage system with as large a capacity as possible (preferably 300 megabytes or larger); and a direct Internet connection or dial-up capability that can use SLIP or PPP protocols with a 14,400 bps modem (preferably supporting V.42bis data compression which can enable 57,600 bps operation). A printer is desirable.

Software for a higher performance GLOBE school computer system is being developed that will operate on higher performance, multi-media IBM-compatible systems and on Apple Macintosh systems. For IBM-compatible systems: 
a 486/66 or faster processor; 16 megabytes of RAM memory; 500 megabytes of hard disk space; a Super VGA monitor; a double-speed CD-ROM reader; a Soundblaster-compatible sound card; and an MPEG animation speed-up board will be required. For Apple Macintosh systems: a PowerPC processor; 16 megabytes of RAM memory; 500 megabytes of hard disk space; and a double-speed CD-ROM reader will be required. A communications capability the same as or better than for the minimum configurations above will also be required. A printer will be highly desirable.

It is recognized that there is a broad range of technological capabilities among potential GLOBE schools. The diversity of technology accessible by schools worldwide may require in some cases that environmental measurements be reported in hardcopy and that a variety of media be used to distribute visualization products, including photographs and broadcast television. All schools that want to participate in the program will be accommodated.

Technology associated with the GLOBE Program will continually evolve to higher levels and participants will be encouraged to upgrade over time. 


\section{B I L A T E $\mathbf{R}$ A $\mathbf{L}$}

European Community

ENVIRONMENTAND NATURAL RESOURCES 



\title{
Memorandum of Understanding Between the National Science
} Foundation in Washington, D.C., for the United States of America and the European Science Foundation in Strasbourg, France on the Participation of the European Science Foundation Consortium in the Ocean Drilling Program as a Regular Member, Washington, D.C., and Strasbourg, 1993

\author{
Done at Washington, D.C. 14 June 1993 and \\ Strasbourg 1 July 1993 \\ Entered into force 1 July 1993, effective 1 October 1993 \\ Primary source citation: Copy of text provided by the \\ U.S. Department of State
}

\section{MEMORANDUM OF UNDERSTANDING} BETWEEN THE NATIONAL SCIENCE FOUNDATION IN WASHINGTON, D.C., FOR THE UNITED STATES OF AMERICA AND THE EUROPEAN SCIENCE FOUNDATION IN STRASBOURG, FRANCE ON THE PARTICIPATION OF THE EUROPEAN SCIENCE FOUNDATION CONSORTIUM IN THE OCEAN DRILLING PROGRAM AS A REGULAR MEMBER

The Ocean Drilling Program (ODP) is a multinational program of scientific research in the oceans which uses drilling and logging to improve fundamental understanding of the geological history, structure and evolution of the oceanic lithosphere (sediments and crust). The Ocean Drilling Program is a successor to the Deep Sea Drilling Project, which began in 1968, and the International Phase of Ocean Drilling, which began in 1975. During the period October 1983-October 1984, the National Science Foundation, through its contractors, refitted the JOIDES Resolution for scientific ocean drilling and for scientific program operations. Early in U.S. Fiscal Year 1985, the initial nine-year phase of ocean drilling began. By 1991, eight international partners representing 20 nations had become regular supporting members of the ODP. 
The Ocean Drilling Program is conducted by contractors, responsible to the National Science Foundation, who carry out the functions of science planning, science operations, and vessel operations. The Joint Oceanographic Institutions for Deep Earth Sampling (JOIDES) is the international body responsible for developing scientific plans and providing general scientific direction for the Ocean Drilling Program. A Science Planning Contractor organizes and provides administrative support to JOIDES. In May 1990, JOIDES published a Long Range Plan which identifies scientific priorities and calls for continued international cooperation in ocean drilling extending through the year 2002. JOIDES has subsequently endorsed use of the JOIDES Resolution as the primary facility for ODP coring and logging through at least 1998. Facilities, including any alternate or additional drilling platforms utilized through 1998, during subsequent years are to be determined by availability, cost, and scientific requirements identified by JOIDES planning.

Accordingly, the National Science Foundation and the European Science Foundation endorse continued cooperation in ocean drilling activities during the period 1 October 1993 to 30 September 2003, in accordance with the following articles:

\section{Article 1 - MEMBERSHIP STATUS}

The European Science Foundation Consortium, hereafter referred to as the Consortium, elects to be a regular member with rights, privileges, and financial commitments as defined. All cooperative activities under this agreement, including exchange of technical information, equipment and data, shall be conducted in accordance with international law, as well as the international obligations, national laws and regulations of each party and within the limits of available funds.

\section{Article 2 - DURATION}

The Consortium endorses continued cooperation in ocean drilling activities, with commitment, in principle, as a regular member to support of Ocean Drilling Program coring and logging programs in the period 1 October 1993 to 30 September 1998. Subsequent support is to be determined based on available technologies, facilities and membership costs in the period 1998 to 2003.

\section{Article 3 - SCIENTIFIC PLANNING}

Scientific planning and direction of the Ocean Drilling Program shall be the responsibility of JOIDES. The Consortium will be a member of JOIDES with the right to be represented on each committee, panel, or working group thereof. International membership and representation in JOIDES is restricted to regular members, including consortia, but excluding the individual members of consortia. The contractors will submit, to the Executive Committee of JOIDES, the annual program plan and budgets for approval prior to their adoption by the National Science Foundation.

\section{Article 4 - OCEAN DRILLING PROGRAM COUNCIL}

Each country comprising the Consortium will be a member of the Ocean Drilling Program Council. The members of the Council will be representatives of each country contributing to the support of the Ocean Drilling Program, regardless of whether it is participating as an individual member or as a member of a consortium. Members of the Council and their alternates will be designated by the participating countries. There will be one representative of each participating country, except that additional representation from the United States may be appropriate.

The Council shall serve as a consultative body reviewing financial, managerial, and other matters involving the overall support of the Ocean Drilling Program. The Council shall provide a forum for exchange of views among the contributing countries. No formal voting procedures will be established. 
The National Science Foundation representative will serve as permanent Chairman of the Council. A formal agenda will be prepared for each meeting and written records of each meeting will be kept. The National Science Foundation will provide secretariat services to the Council.

The Council will normally meet once each year. The annual meeting shall include a financial report and discussion, an audit report, a review of scientific and technical achievements for the past year, draft program plans and budgets for the coming year, and other topics of mutual interest. Normally, all regular meetings of the Council will be scheduled in conjunction with the JOIDES Executive Committee meeting for review and approval of the annual program plans and budgets.

Liaison representatives of prime contractors and important scientific planning entities will be available to the Council.

\section{Article 5 - RIGHT TO MAKE PROPOSALS; DATA PRIVILEGES}

The Consortium will have the right:

a) to make proposals to JOIDES of scientific projects or technical objectives of interest to the Consortium.

b) to participate in the analysis, and have access to the data, of geophysical and other site surveys performed in support of the program.

c) to engineering plans, data or other information developed under contracts supported as program costs, subject to Article 1 limitations.

Site surveys may be contributed by the Consortium as its scientific interests and available resources allow. Site survey requirements will be identified by JOIDES.

\section{Article 6 - VISA AND CUSTOMS FACILITATION}

The National Science Foundation will facilitate through collaboration with the appropriate authorities the granting of visas and other forms of official permission for entry to and exit from the United States of personnel, equipment, and supplies when required for participation or utilization in the Ocean Drilling Program.

\section{Article 7 - PARTICIPATION ON BOARD THE ODP DRILLSHIP}

The Science Operations Contractor, with the advice of JOIDES, selects the scientific team for each cruise. It is expected that approximately half of the scientists invited to serve as co-chief scientists will be representatives of the United States. It is expected that a scientist representing the Consortium will be invited to serve as co-chief scientist on an equal numerical basis with all other non-U.S. partners. The Consortium has the right to have a scientist represented in the shipboard scientific staff on each cruise of the ODP drillship. Normally, space will be available for two scientists representing the Consortium on the research cruises of the ODP drillship. It is recognized that some cruises may be of special scientific interest to Consortium scientists and increased participation by scientists of the Consortium on these cruises may be appropriate. At a minimum, total participation over the term of the Ocean Drilling Program will be proportional to the Consortium's contribution to Program costs.

\section{Article 8 - INITIAL REPORTS OF THE OCEAN DRILLING PROGRAM}

Scientists from the Consortium will have access, through the Consortium, to Ocean Drilling Program data and core samples. The Consortium will endeavor to ensure that the participating Consortium scientists and institutions shall provide the scientific data resulting from site surveys and laboratory analyses in time for 
preparation of the Proceedings of the Ocean Drilling Program or their equivalent. One hundred copies of each volume of the official scientific publications will be provided to the European Science Foundation for free distribution among scientific establishments in the Consortium. These volumes may be published in the Consortium member countries in full or in part, without payments to or additional agreements with the United States. The Consortium will provide the National Science Foundation with copies of all publications from the Consortium that are based on program material.

\section{Article 9 - FINANCIAL CONTRIBUTION}

The European Science Foundation will support the Ocean Drilling Program with financial contributions payable to the National Science Foundation in U.S. dollars in amounts and periods to be specified by Annex A to this Memorandum of Understanding.

The financial contribution of all participants will be commingled to support the total program costs. "Program costs" are determined by the National Science Foundation, and are those costs incurred in support of contractors performing functions for joint planning and operations of the Ocean Drilling Program, and program direction and management costs incurred by the National Science Foundation which relate to international participation. Activities which may be carried out by the National Science Foundation's contractors in direct support of United States scientific undertakings are not program costs and will not be funded from commingled accounts.

\section{Article 10 - SALARIES, TRAVEL, AND EXPENSES}

Salaries and travel expenses for participants representing the Consortium will be borne by the Consortium. Costs of accommodations for Consortium scientists and members of technical parties aboard the drillship are program costs and will be funded by the Ocean Drilling Program. The National Science Foundation's contractors will render Consortium scientists needed assistance when going from an airport to the drillship.

\section{Article 11 - CONSULTATION}

Meetings of the National Science Foundation and representatives of the Consortium may be held at any time upon the request of either party to discuss the terms and conditions of this Memorandum and other matters of mutual interest.

\section{Article 12 - TERMINATION NOTICE}

Obligations arising from this Memorandum of Understanding may be terminated by either party giving the other party written notice at least one year in advance. Provisions for refunds of contributions, arising out of unilateral termination, are specified in Annex A.

Done in Washington, D.C. and Strasbourg, France

by:

[Signature]

Professor Peter Fricker

Secretary General

European Science Foundation

on:

July 1, 1993 by:

[Signature]

Frederick M. Bernthal

Acting Director

National Science Foundation

on:

June 14, 1993 


\section{ANNEX \\ to the Memorandum of Understanding Between the National Science Foundation and the European Science Foundation on the Participation of the European Science Foundation Consortium in the Ocean Drilling Program as a Regular Member}

Financial Contribution for U.S. Fiscal Year 1994

The European Science Foundation will support the Ocean Drilling Program with a total contribution of United States two million nine hundred fifty thousand dollars (U.S. $\$ 2,950,000$ ) in cash for the period October 1, 1993 to September 30,1994 , calculated at the rate of $\$ 245,833.33$ per month of drilling operations. Should the Ocean Drilling Program be terminated before September 30, 1994, the European Science Foundation will be reimbursed at the rate of $\$ 245,833.33$ for each month of curtailment. Payment shall be made in four equal installments on or about January 1, April 1, July 1 and October 1, 1994.

Should the European Science Foundation Consortium withdraw from the program under the terms of Article 12 above, no refunds of contributions will be made.

Contributions for subsequent years will be adjusted in proportion to actual changes in program costs experienced in the Ocean Drilling Program, as determined by the National Science Foundation.

by:

[Signature]

Professor Peter Fricker

Secretary General

European Science Foundation

on:

July 1, 1993

Date by:

[Signature]

Frederick M. Bernthal

Acting Director

National Science Foundation

on:

June 14, 1993

Date 



\section{B I $L A$ A $T$ E $R$ A $L$}

\section{FinLaNd}

ENVIRONMENT AND NATURAL RESOURCES 



\section{Agreement Between the U.S. National Oceanic and Atmospheric}

Administration and the National Board of Education of Finland for Cooperation in the GLOBE Program, Helsinki, 1995

\section{Done at Helsinki 23 March 1995}

Entered into force 23 March 1995

Primary source citation: Copy of text provided by the U.S. Department of State

\section{AN AGREEMENT BETWEEN THE U.S. NATIONAL OCEANIC AND ATMOSPHERIC ADMINISTRATION AND THE NATIONAL BOARD OF EDUCATION OF FINLAND FOR COOPERATION IN THE GLOBE PROGRAM}

\section{PREAMBLE}

THE U.S. NATIONAL OCEANIC AND ATMOSPHERIC ADMINISTRATION,

ACTING ON BEHALF OF ITSELF AND OTHER U.S. GOVERNMENT AGENCIES PARTICIPATING IN THE GLOBE PROGRAM (HEREINAFTER, THE U.S. SIDE), AND THE NATIONAL BOARD OF EDUCATION OF FINLAND (HEREINAFTER, THE FINNISH SIDE),

INTENDING TO INCREASE THE AWARENESS OF STUDENTS THROUGHOUT THE WORLD ABOUT THE GLOBAL ENVIRONMENT,

SEEKING TO CONTRIBUTE TO INCREASED SCIENTIFIC UNDERSTANDING OF THE EARTH, AND DESIRING TO SUPPORT IMPROVED STUDENT ACHIEVEMENT IN SCIENCE AND MATHEMATICS, HAVE AGREED TO COOPERATE IN THE GLOBAL LEARNING AND OBSERVATIONS TO BENEFIT THE ENVIRONMENT (GLOBE) PROGRAM AS FOLLOWS:

\section{ARTICLE 1 - THE GLOBE PROGRAM}

THE GLOBE PROGRAM IS AN INTERNATIONAL ENVIRONMENTAL SCIENCE AND EDUCATION PROGRAM THAT WILL BRING STUDENTS, TEACHERS, AND SCIENTISTS TOGETHER TO STUDY THE GLOBAL ENVI- 
RONMENT. GLOBE WILL CREATE AN INTERNATIONAL NETWORK OF STUDENTS IN GRADES K-12 (OR EQUIVALENT) STUDYING ENVIRONMENTAL ISSUES, MAKING ENVIRONMENTAL MEASUREMENTS, AND SHARING USEFUL ENVIRONMENTAL DATA WITH THE INTERNATIONAL ENVIRONMENTAL SCIENCE COMMUNITY.

\section{ARTICLE 2 - RESPECTIVE RESPONSIBILITIES}

A. THE U.S. SIDE WILL:

1. IDENTIFY U.S. SCHOOLS THAT WILL PARTICIPATE IN THE GLOBE PROGRAM (DETAILS REGARDING GLOBE SCHOOLS IN APPENDIX A);

2. SELECT, IN CONSULTATION WITH INTERNATIONAL SCIENTISTS AND EDUCATORS, THE GLOBE ENVIRONMENTAL MEASUREMENTS AND TYPES OF MEASUREMENT EQUIPMENT (DESCRIBED IN AP. PENDIX B);

3. SELECT PRINCIPAL INVESTIGATOR TEAMS FOR THE GLOBE ENVIRONMENTAL MEASUREMENTS, AND SUPPORT THE U.S. MEMBERS OF THE TEAMS;

4. CALIBRATE, IF NECESSARY, MEASUREMENT EQUIPMENT THAT CANNOT BE CALIBRATED BY GLOBE TEACHERS AND STUDENTS;

5. DEVELOP, IN CONSULTATION WITH INTERNATIONAL SCIENTISTS AND EDUCATORS, GLOBE EDUCATIONAL MATERIALS;

6. TRANSLATE GLOBE INSTRUCTIONAL MATERIALS RELATED TO MEASUREMENT PROCEDURES AND REPORTING PROTOCOLS INTO THE SIX UNITED NATIONS LANGUAGES, PROVIDE THESE PLUS ALL BROADER GLOBE EDUCATIONAL MATERIALS TO FINLAND FOR FURTHER REPRODUCTION AS NECESSARY;

7. CONDUCT ANNUAL REGIONAL TRAINING SESSIONS FOR GLOBE COUNTRY COORDINATORS AND GLOBE TEACHERS WHO WILL SERVE AS TRAINERS FOR ADDITIONAL GLOBE TEACHERS IN FINLAND, AND PROVIDE A COPY OF GLOBE TRAINING MATERIALS TO FINLAND;

8. DESIGN, DEVELOP, OPERATE, AND MAINTAIN GLOBE DATA PROCESSING CAPABILITIES AND OTHER NECESSARY TECHNOLOGY AND EQUIPMENT;

9. PROVIDE GLOBE SOFTWARE, AS NECESSARY, FOR USE ON FINLAND'S GLOBE SCHOOL COMPUTERS. (TO THE MAXIMUM EXTENT POSSIBLE, TEXTUAL MATERIAL APPEARING ON COMPUTER SCREENS WILL BE ACCESSIBLE IN THE STUDENT'S CHOICE AMONG THE SIX UNITED NATIONS LANGUAGES.);

10. ACCEPT ENVIRONMENTAL DATA REPORTED FROM GLOBE SCHOOLS AROUND THE WORLD, AND DEVELOP AND PROVIDE RESULTANT GLOBAL ENVIRONMENTAL IMAGES (VISUALIZATION PRODUCTS) TO FINLAND; AND

11. EVALUATE THE OVERALL GLOBE PROGRAM PERIODICALLY, IN CONSULTATION WITH INTERNATIONAL GLOBE COUNTRY COORDINATORS, AND MODIFY THE OVERALL PROGRAM AS APPROPRIATE.

B. THE FINNISH SIDE WILL:

1. SELECT FINNISH SCHOOLS TO PARTICIPATE IN THE GLOBE PROGRAM (DETAILS REGARDING GLOBE SCHOOLS IN APPENDIX A) AND PROVIDE AN UPDATED LIST OF FINLAND'S GLOBE SCHOOLS TO THE U.S. SIDE AT THE BEGINNING OF EACH SCHOOL YEAR;

2. ENSURE THAT FINLAND'S GLOBE SCHOOLS CONDUCT THE FUNDAMENTAL ACTIVITIES OF GLOBE SCHOOLS DETAILED IN APPENDIX A(TAKE GLOBE ENVIRONMENTAL MEASUREMENTS, REPORT DATA, AND RECEIVE AND USE RESULTANT GLOBAL ENVIRONMENTAL IMAGES, USING GLOBE EDUCA- 
TIONAL MATERIALS UNDER THE GUIDANCE OF TEACHERS TRAINED TO CONDUCT THE GLOBE PROGRAM);

3. NAME A GOVERNMENT OF FINLAND POINT OF CONTACT RESPONSIBLE FOR POLICY-LEVEL COMMUNICATIONS WITH THE DIRECTOR OF THE GLOBE PROGRAM;

4. NAME A COUNTRY COORDINATOR RESPONSIBLE FOR DAY-TO-DAY MANAGEMENT, OVERSIGHT, AND FACILITATION OF THE GLOBE PROGRAM IN FINLAND;

5. ENSURE THAT THE COUNTRY COORDINATOR AND SOME GLOBE TEACHERS ATTEND GLOBE REGIONAL TRAINING AND IN TURN PROVIDE GLOBE TRAINING TO AT LEAST ONE TEACHER IN EACH FINNISH GLOBE SCHOOL;

6. ENSURE THAT GLOBE INSTRUCTIONAL MATERIALS RELATED TO MEASUREMENT PROCEDURES AND REPORTING PROTOCOLS ARE UTILIZED IN FINLAND'S GLOBE SCHOOLS, AND THAT BROADER GLOBE EDUCATIONAL MATERIALS ARE APPROPRIATELY TRANSLATED, ADAPTED, REPRODUCED, AND DISTRIBUTED TO ALL FINNISH GLOBE SCHOOLS;

7. ENSURE THAT FINLAND'S GLOBE SCHOOLS HAVE THE NECESSARY MEASUREMENT EQUIPMENT TO TAKE GLOBE ENVIRONMENTAL MEASUREMENTS (DESCRIBED IN APPENDIX B);

8. ENSURE THAT TEACHERS AND STUDENTS AT FINLAND'S GLOBE SCHOOLS CALIBRATE GLOBE MEASUREMENT EQUIPMENT ACCORDING TO PROCEDURES PROVIDED IN GLOBE INSTRUCTIONAL MATERLALS;

9. ENSURE THAT FINLAND'S GLOBE SCHOOLS HAVE THE NECESSARY COMPUTER AND COMMUNICATIONS SYSTEMS (DESCRIBED IN APPENDIX C) TO REPORT GLOBE ENVIRONMENTAL MEASUREMENTS AND TO RECEIVE AND USE GLOBE VISUALIZATION PRODUCTS, OR MAKE AGREED ALTERNATIVE ARRANGEMENTS FOR SUCH REPORTING AND RECEIPT. (AT A MINIMUM, THE FINNISH COUNTRY COORDINATOR WILL NEED ACCESS TO INTERNET SO THAT ALL MEASUREMENT DATAFROM FINLAND'S GLOBE SCHOOLS WILL BE REPORTED VIA INTERNET.); AND

10. EVALUATE GLOBE OPERATIONS IN FINLAND PERIODICALLY AND ASSIST THE U.S. IN CONDUCTING PERIODIC EVALUATION OF THE OVERALL GLOBE PROGRAM.

\section{ARTICLE 3 - FINANCIAL ARRANGEMENTS}

EACH SIDE WILL BEAR THE COSTS OF FULFILLING ITS RESPECTIVE RESPONSIBILITIES UNDER THIS AGREEMENT. OBLIGATIONS OF EACH SIDE PURSUANT TO THIS AGREEMENT ARE SUBJECT TO ITS RESPECTIVE FUNDING PROCEDURES AND THE AVAILABILITY OF APPROPRIATED FUNDS, PERSONNEL, AND OTHER RESOURCES. THE CONDUCT OF ACTIVITIES UNDER THIS AGREEMENT WILL BE CONSISTENT WITH THE RELEVANT LAWS AND REGULATIONS OF THE TWO SIDES.

\section{ARTICLE 4 - EXCHANGE OF DATA AND GOODS}

GLOBE ENVIRONMENTAL MEASUREMENT DATA, VISUALIZATION PRODUCTS, SOFTWARE, AND EDUCATIONAL MATERIALS WILL BE AVAILABLE WORLDWIDE WITHOUT RESTRICTION AS TO THEIR USE OR REDISTRIBUTION.

\section{ARTICLE 5 - RELEASE OF INFORMATION ABOUT THE GLOBE PROGRAM}

EACH SIDE MAY RELEASE INFORMATION ON THE GLOBE PROGRAM AS IT MAY DEEM APPROPRIATE WITHOUT PRIOR CONSULTATION WITH THE OTHER. 


\section{ARTICLE 6 - CUSTOMS AND IMMIGRATION}

EACH SIDE WILL, TO THE EXTENT PERMITTED BY ITS LAWS AND REGULATIONS, FACILITATE THE MOVEMENT OF PERSONS AND GOODS NECESSARY TO IMPLEMENT THIS AGREEMENT INTO AND OUT OF ITS TERRITORY AND ACCORD ENTRY TO SUCH GOODS INTO ITS TERRITORY FREE OF CUSTOMS DUTIES AND OTHER SIMILAR CHARGES.

\section{ARTICLE 7 - ENTRY INTO FORCE, AMENDMENTS, WITHDRAWAL}

THIS AGREEMENT WILL ENTER INTO FORCE UPON SIGNATURE OF THE TWO SIDES AND WILL REMAIN IN FORCE FOR FIVE YEARS. IT WILL BE AUTOMATICALLY EXTENDED FOR FURTHER FIVE-YEAR PERIODS, UNLESS EITHER SIDE DECIDES TO TERMINATE IT AND NOTIFIES THE OTHER SIDE WITH THREE MONTHS WRITTEN NOTICE. THIS AGREEMENT MAY BE TERMINATED AT ANY TIME BY EITHER SIDE UPON THREE MONTHS PRIOR WRITTEN NOTICE TO THE OTHER SIDE. THIS AGREEMENT MAY BE AMENDED BY WRITTEN AGREEMENT OF THE TWO SIDES.

DONE AT HELSINKI, ON 23 MARCH 1995, IN DUPLICATE IN THE ENGLISH AND FINNISH LANGUAGES, EACH ONE BEING EQUALLY AUTHENTIC.

FOR THE U.S. NATIONAL OCEANIC AND ATMOSPHERIC ADMINISTRATION:

[SIGNATURE]

FOR THE NATIONAL BOARD OF EDUCATION OF THE FEDERAL REPUBLIC OF FINLAND:

[SIGNATURE]

\section{APPENDIX A - GLOBE SCHOOLS}

EACH PARTNER COUNTRY WILL BE RESPONSIBLE FOR IDENTIFYING ITS PARTICIPATING SCHOOLS. SCHOOLS SHOULD BE SELECTED SO AS TO SATISFY THE OBJECTIVES OF THE GLOBE PROGRAM. IN PARTICULAR, COUNTRIES SHOULD EMPHASIZE THE SELECTION OF SCHOOLS THAT WILL MAXIMIZE THE NUMBER OF STUDENTS WORLDWIDE PARTICIPATING IN THE PROGRAM. ALSO, COUNTRIES SHOULD CONSIDER INVOLVING SCHOOLS IN LOCATIONS THAT WILL YIELD MEASUREMENT DATA THAT IS IMPORTANT TO THE INTERNATIONAL ENVIRONMENTAL SCIENCE COMMUNITY.

STUDENTS AT ALL GLOBE SCHOOLS THROUGHOUT THE WORLD WILL CONDUCT THE FOLLOWING FUNDAMENTAL ACTIVITIES: THEY WILL MAKE ENVIRONMENTAL MEASUREMENTS AT OR NEAR THEIR SCHOOLS; REPORT THEIR DATA TO A GLOBE DATA PROCESSING SITE; RECEIVE VIVID GRAPHICAL GLOBAL ENVIRONMENTAL IMAGES (VISUALIZATION PRODUCTS) CREATED FROM THEIR DATA AND THE DATA FROM OTHER GLOBE SCHOOLS AROUND THE WORLD; AND STUDY THE ENVIRONMENT BY RELATING THEIR OBSERVATIONS AND THE RESULTING VISUALIZATION PRODUCTS TO BROADER ENVIRONMENTAL TOPICS. ALL OF THESE ACTIVITIES WILL BE CONDUCTED UNDER THE GUIDANCE OF SPECIALLY TRAINED TEACHERS (GLOBE-TRAINED TEACHERS).

GLOBE EDUCATIONAL MATERIALS WILL BE USED IN GLOBE SCHOOLS UNDER THE GUIDANCE OF GLOBE-TRAINED TEACHERS. THESE MATERIALS WILL DETAIL PROCEDURES FOR TAKING ENVIRONMENTAL MEASUREMENTS AND PROTOCOLS FOR REPORTING DATA; EXPLAIN THE SIGNIFICANCE OF THE MEASUREMENTS; GUIDE THE USE OF THE VISUALIZATION PRODUCTS; AND INTEGRATE THE MEASUREMENT ASPECTS OF THE PROGRAM INTO A BROADER STUDY OF THE ENVIRONMENT.

SCHOOLS THROUGHOUT THE UNITED STATES AND THE REST OF THE WORLD THAT ARE NOT GLOBE SCHOOLS MAY BECOME GLOBE AFFILIATE SCHOOLS BY OBSERVING THE GLOBE PROGRAM IN OPERATION THROUGH THE INTERNET. STUDENTS AT THESE SCHOOLS WILL BENEFIT FROM THE USE OF 
GLOBE VISUALIZATION PRODUCTS AND EDUCATIONAL MATERIALS ACCESSIBLE ON-LINE. ALL GLOBE AFFILIATE SCHOOLS WILL BE ENCOURAGED TO BECOME PARTICIPATING GLOBE SCHOOLS.

\section{APPENDIX B - GLOBE ENVIRONMENTAL MEASUREMENTS AND EQUIPMENT}

GLOBE ENVIRONMENTAL MEASUREMENTS WILL CONTRIBUTE IN A SIGNIFICANT WAY TO THE SCIENTIFIC UNDERSTANDING OF THE DYNAMICS OF THE GLOBAL ENVIRONMENT. EVERY GLOBE SCHOOL WILL CONDUCT A CORE SET OF GLOBE ENVIRONMENTAL MEASUREMENTS IN THE FOLLOWING CRITICAL AREAS: ATMOSPHERE/CLIMATE, HYDROLOGY/WATER CHEMISTRY, AND BIOLOGY/GEOLOGY. WHERE POSSIBLE, A GLOBE SCHOOL MAY COORDINATE ITS ACTIVITIES WITH THOSE OF OTHER NEIGHBORING GLOBE SCHOOLS, SO THAT THE COMPLETE SET OF GLOBE MEASUREMENTS WILL BE AVAILABLE FROM A LOCALITY. AS THE GLOBE PROGRAM EVOLVES, ELECTIVE MEASUREMENTS NOT COMMON TO ALL GLOBE SCHOOLS MAY BE ADDED IN ORDER TO ADDRESS LOCAL ENVIRONMENTAL ISSUES.

STUDENTS AT ALL AGE LEVELS WILL BE ACTIVE PARTICIPANTS IN THE GLOBE PROGRAM. THE ACTUAL PARTICIPATION WILL BE DESIGNED SO AS TO BE GRADE-APPROPRIATE FOR GRADES K-5, 6-8, AND 9-12 (OR EQUTVALENT). YOUNGER STUDENTS WILL MAKE LIMITED MEASUREMENTS WHICH MAY BE QUALITATIVE RATHER THAN QUANTITATIVE. OLDER STUDENTS WILL MAKE ADDITIONAL MEASUREMENTS AND MORE SOPHISTICATED MEASUREMENTS, AS APPROPRIATE FOR THEIR GRADE LEVEL. MEASUREMENT EQUIPMENT WILL NOT NEED TO BE STANDARDIZED; RATHER, PERFORMANCE SPECIFICATIONS WILL BE PROVIDED.

FOLLOWING IS AN EXAMPLE LIST OF CORE MEASUREMENTS AND THE EQUIPMENT THAT WILL BE NEEDED TO TAKE THESE MEASUREMENTS. THE FULL LIST WILL BE INITIALLY DETERMINED AND PERIODICALLY UPDATED AS PROVIDED IN ARTICLE 2.A.2, BASED ON EXPERIENCE GAINED IN IMPLEMENTING THE GLOBE PROGRAM.

\section{MEASUREMENTS (EQUIPMENT NEEDED) FOR GRADES K-5:}

ATMOSPHERE/CLIMATE STUDIES:

AIR TEMPERATURE (MAX/MIN THERMOMETER)

PRECIPITATION (RAIN GAUGE)

BAROMETRIC PRESSURE (BAROMETER)

CLOUD OBSERVATIONS (CLOUD KIT (WALL CHART, SLIDES, ETC.))

WEATHER IMAGE ANALYSIS (HARDCOPY IMAGES - SEE NOTE BELOW)

HYDROLOGY/WATER CHEMISTRY STUDIES:

WATER TEMPERATURE (THERMOMETER)

WATER PH (LITMUS PAPER/COLORIMETRIC)

WATER CHEMISTRY (WATER TESTING KIT)

HYDROLOGIC ASSESSMENT (HARDCOPY IMAGES)

\section{APPENDIX C - GLOBE COMPUTER AND COMMUNICATIONS SYSTEMS}

IN ORDER TO DERIVE MAXIMUM BENEFIT FROM THE GLOBE PROGRAM, ALL SCHOOLS WILL BE ENCOURAGED TO USE AN INTERNATIONAL INFORMATION NETWORK, INITLALLY USING THE INTERNET, ALONG WITH CLASSROOM COMPUTERS USING SOFTWARE CAPABLE OF MULTIMEDIA PRESENTATIONS. TECHNOLOGY ASSOCIATED WITH THE GLOBE PROGRAM WILL CONTINUALLY EVOLVE TO HIGHER LEVELS AND PARTICIPANTS WILL BE ENCOURAGED TO UPGRADE OVER TIME. FOLLOWING IS ADESCRIPTION OF GLOBE COMPUTER AND COMMUNICATIONS SYSTEMS CONSISTENT WITH CURRENT GLOBE REQUIREMENTS. 
THE U.S. SIDE WILL ADAPT OR DEVELOP SOFTWARE FOR IBM-COMPATIBLE AND APPLE MACINTOSH COMPUTER CONFIGURATIONS TO SUPPORT THE REQUIRED GLOBE SCHOOL ACTIVITIES OF DATA ENTRY, DATA ANALYSIS, AND USE OF VISUALIZATION PRODUCTS. CURRENT PLANNING CALLS FOR LIMITING THIS SOFTWARE DEVELOPMENT EFFORT TO IBM-COMPATIBLE OR APPLE MACINTOSH COMPUTERS CAPABLE OF RUNNING TCP/IP AND SUPPORTING WORLD WIDE WEB CLIENT SOFTWARE, SUCH AS MOSAIC, WITH GLOBE EXTENSIONS. OVERALL ATTRIBUTES OF THIS MINIMUM USABLE GLOBE SCHOOL COMPUTER CONFIGURATION ARE AS FOLLOWS:

A) FOR IBM-COMPATIBLE: 386 SX PROCESSOR, WINDOWS 3.1 IN ENHANCED MODE, 4MB OF RAM, 60MB OF AVAILABLE HARD DISK SPACE, AND A DIRECT INTERNET CONNECTION OR DIAL-UP CONNECTION USING SLIP OR PPP AND A 14,400BPS MODEM, PREFERABLY WITH V.42BIS, WHICH CAN ENABLE 57,600BPS OPERATION USING DATA COMPRESSION; AND

B) FOR APPLE MACINTOSH: 68030 20MHZ PROCESSOR, 4MB OF RAM, 60MB OF AVAILABLE HARD DISK SPACE, AND A DIRECT INTERNET CONNECTION OR DIAL-UP CONNECTION USING SLIP OR PPP AND A 14,400BPS MODEM, PREFERABLY WITH V.42BIS, WHICH CAN ENABLE 57,600BPS OPERATION USING DATA COMPRESSION.

A HIGHER PERFORMANCE GLOBE SCHOOL COMPUTER SYSTEM IS ALSO BEING DEVELOPED FOR THE FOLLOWING CONFIGURATION: A 486/66 PROCESSOR, 16MB OF RAM, 500MB OF AVAILABLE HARD DISK SPACE, SUPER VGA MONITOR, DOUBLE-SPEED CD-ROM READER, SOUND CARD, AND MPEG SPEED-UP BOARD.

IT IS RECOGNIZED THAT THERE IS A BROAD RANGE OF TECHNOLOGICAL CAPABILITIES AMONG POTENTIAL GLOBE SCHOOLS. THE DIVERSITY OF TECHNOLOGY ACCESSIBLE BY SCHOOLS WORLDWIDE MAY REQUIRE IN SOME CASES THAT ENVIRONMENTAL MEASUREMENTS BE REPORTED IN HARD COPY AND THAT A VARIETY OF MEDIA BE USED TO DISTRIBUTE VISUALIZATION PRODUCTS, INCLUDING PHOTOGRAPHS AND BROADCAST TELEVISION. ALL SCHOOLS THAT WANT TO PARTICIPATE IN THE PROGRAM WILL BE ACCOMMODATED. 


\section{B I L A $\mathbf{T}$ E $\mathbf{R}$ A $\mathbf{L}$}

\section{FRANCE}

ENVIRONMENTAND NATURAL RESOURCES 



\title{
Memorandum of Understanding Between the National Science
} Foundation in Washington, D.C., for the United States of America and Institut Francais de Recherche pour l'Exploitation de la Mer on the Participation of France in the Ocean Drilling Program, Washington, D.C., and Paris, 1993

\author{
Done at Washington, D.C. 22 July 1993 and Paris \\ 2 August 1993 \\ Entered into force 2 August 1993, effective \\ 1 October 1993
}

Primary source citation: Copy of text provided by the

U.S. Department of State

\section{MEMORANDUM OF UNDERSTANDING BETWEEN THE NATIONAL SCIENCE FOUNDATION IN WASHINGTON, D.C., FOR THE UNITED STATES OF AMERICA AND INSTITUT FRANCAIS DE RECHERCHE POUR L'EXPLOITATION DE LA MER ON THE PARTICIPATION OF FRANCE IN THE OCEAN DRILLING PROGRAM AS A REGULAR MEMBER}

The Ocean Drilling Program (ODP) is a multinational program of scientific research in the oceans which uses drilling and logging to improve fundamental understanding of the geological history, structure and evolution of the oceanic lithosphere (sediments and crust). The Ocean Drilling Program is a successor to the Deep Sea Drilling Project, which began in 1968, and the International Phase of Ocean Drilling, which began in 1975. During the period October 1983-October 1984, the National Science Foundation, through its contractors, refitted the JOIDES Resolution for scientific ocean drilling and for scientific program operations. Early in U.S. Fiscal Year 1985, the initial nine-year phase of ocean drilling began. By 1991, eight international partners representing 20 nations had become regular supporting members of the ODP. 
The Ocean Drilling Program is conducted by contractors, responsible to the National Science Foundation, who carry out the functions of science planning, science operations, and vessel operations. The Joint Oceanographic Institutions for Deep Earth Sampling (JOIDES) is the international body responsible for developing scientific plans and providing general scientific direction for the Ocean Drilling Program. A Science Planning Contractor organizes and provides administrative support to JOIDES. In May 1990, JOIDES published a Long Range Plan which identifies scientific priorities and calls for continued international cooperation in ocean drilling extending through the year 2002. JOIDES has subsequently endorsed use of the JOIDES Resolution as the primary facility for ODP coring and logging through at least 1998. Facilities, including any alternate or additional drilling platforms utilized through 1998, during subsequent years are to be determined by availability, cost, and scientific requirements identified by JOIDES planning.

Accordingly, the National Science Foundation and the Institut Francais de Recherche Pour l'Exploitation de la Mer endorse continued cooperation in ocean drilling activities during the period 1 October 1993 to 30 September 2003, in accordance with the following articles:

\section{Article 1 - MEMBERSHIP STATUS}

The Institut Francais de Recherche Pour l'Exploitation de la Mer elects to be a regular member with rights, privileges, and financial commitments as defined. All cooperative activities under this agreement, including exchange of technical information, equipment and data, shall be conducted in accordance with international law, as well as the international obligations, national laws and regulations of each party and within the limits of available funds.

\section{Article 2 - DURATION}

The Institut Francais de Recherche Pour l'Exploitation de la Mer endorses continued cooperation in ocean drilling activities, with commitment, in principle, as a regular member to support of Ocean Drilling Program coring and logging programs in the period 1 October 1993 to 30 September 1998. IFREMER will conduit a national review of the status and progress of the Ocean Drilling Program in 1995 for a decision in 1996. Formal notice of any change in programmatic commitment to the program resulting from this review will be provided as soon as possible but no less than one year in advance of any change in status. Subsequent support is to be determined based on available technologies, facilities and membership costs in the period 1998 to 2003.

\section{Article 3 - SCIENTIFIC PLANNING}

Scientific planning and direction of the Ocean Drilling Program shall be the responsibility of JOIDES. The Institut Francais de Recherche Pour l'Exploitation de la Mer will be a member of JOIDES with the right to be represented on each committee, panel, or working group thereof. International membership and representation in JOIDES is restricted to regular members, including consortia, but excluding the individual members of consortia. The contractors will submit, to the Executive Committee of JOIDES, the annual program plan and budgets for approval prior to their adoption by the National Science Foundation.

\section{Article 4 - OCEAN DRILLING PROGRAM COUNCIL}

The Institut Francais de Recherche Pour l'Exploitation de la Mer will be a member of the ocean Drilling Program Council. The members of the Council will be representatives of each country contributing to the support of the Ocean Drilling Program, regardless of whether it is participating as an individual member or as a member of a consortium. Members of the Council and their alternates will be designated by the participating countries. There will be one representative of each participating country, except that additional representation from the United States may be appropriate. 
The Council shall serve as a consultative body reviewing financial, managerial, and other matters involving the overall support of the Ocean Drilling Program. The Council shall provide a forum for exchange of views among the contributing countries. No formal voting procedures will be established.

The National Science Foundation representative will serve as permanent Chairman of the Council. A formal agenda will be prepared for each meeting and written records of each meeting will be kept. The National Science Foundation will provide secretariat services to the Council.

The Council will normally meet once each year. The annual meeting shall include a financial report and discussion, an audit report, a review of scientific and technical achievements for the past year, draft program plans and budgets for the coming year, and other topics of mutual interest. Normally, all regular meetings of the Council will be scheduled in conjunction with the JOIDES Executive Committee meeting for review and approval of the annual program plans and budgets.

Liaison representatives of prime contractors and important scientific planning entities will be available to the Council.

\section{Article 5 - INTELLECTUAL PROPERTY RIGHTS}

Protection of intellectual property rights and rights thereto shall be as set forth in Annex B.

\section{Article 6 - RIGHT TO MAKE PROPOSALS; DATA PRIVILEGES}

The Institut Francais de Recherche Pour l'Exploitation de la Mer will have the right:

a) to make proposals to JOIDES of scientific projects or technical objectives of interest to the Institut Francais de Recherche Pour l'Exploitation de la Mer.

b) to participate in the analysis, and have access to the data, of geophysical and other site surveys performed in support of the program.

c) to engineering plans, data or other information developed under contracts supported as program costs, subject to Article 1 limitations.

Site surveys may be contributed by France as its scientific interests and available resources allow. Site survey requirements will be identified by JOIDES.

\section{Article 7 - VISA AND CUSTOMS FACILITATION}

The National Science Foundation will facilitate through collaboration with the appropriate authorities the granting of visas and other forms of official permission for entry to and exit from the United States of personnel, equipment, and supplies when required for participation or utilization in the Ocean Drilling Program.

\section{Article 8 - PARTICIPATION ON BOARD THE ODP DRILLSHIP}

The Science Operations Contractor, with the advice of JOIDES, selects the scientific team for each cruise. It is expected that approximately half of the scientists invited to serve as co-chief scientists will be representatives of the United States. It is expected that a scientist representing France will be invited to serve as co-chief scientist on an equal numerical basis with all other non-U.S. partners. France has the right to have a scientist represented in the shipboard scientific staff on each cruise of the ODP drillship. Normally, space will be available for two scientists representing France on the research cruises of the ODP drillship. It is recognized that some cruises may be of special scientific interest to French scientists and increased participation by scientists of France on these cruises may be appropriate. 
At a minimum, total participation over the term of the Ocean Drilling Program will be proportional to the French contribution to Program costs.

\section{Article 9 - INITIAL REPORTS OF THE OCEAN DRILLING PROGRAM}

Scientists from France will have access, through the Institut Francais de Recherche Pour l'Exploitation de la Mer, to Ocean Drilling Program data and core samples. The Institut Francais de Recherche Pour l'Exploitation de la Mer will endeavor to ensure that the participating French scientists and institutions shall provide the scientific data resulting from site surveys and laboratory analyses in time for preparation of the Proceedings of the Ocean Drilling Program or their equivalent. One hundred copies of each volume of the official scientific publications will be provided to the Institut Francais de Recherche Pour l'Exploitation de la Mer for free distribution among scientific establishments in France. These volumes may be published in France in full or in part, without payments to or additional agreements with the United States. The Institut Francais de Recherche Pour l'Exploitation de la Mer will provide the National Science Foundation with copies of all publications from France that are based on program material.

\section{Article 10 - FINANCLAL CONTRIBUTION}

The Institut Francais de Recherche Pour l'Exploitation de la Mer will support the Ocean Drilling Program with financial contributions payable to the National Science Foundation in U.S. dollars in amounts and periods to be specified by Annex A to this Memorandum of Understanding.

The financial contribution of all participants will be commingled to support the total program costs. "Program costs" are determined by the National Science Foundation, and are those costs incurred in support of contractors performing functions for joint planning and operations of the Ocean Drilling Program, and program direction and management costs incurred by the National Science Foundation which relate to international participation. Activities which may be carried out by the National Science Foundation's contractors in direct support of United States scientific undertakings are not program costs and will not be funded from commingled accounts.

\section{Article 11 - SALARIES, TRAVEL, AND EXPENSES}

Salaries and travel expenses for participants representing France will be borne by France. Costs of accommodations for French scientists and members of technical parties aboard the drillship are program costs and will be funded by the Ocean Drilling Program. The National Science Foundation's contractors will render French scientists needed assistance when going from an airport to the drillship.

\section{Article 12 - CONSULTATION}

Meetings of the National Science Foundation and representatives of France may be held at any time upon the request of either party to discuss the terms and conditions of this Memorandum and other matters of mutual interest.

\section{Article 13 - TERMINATION NOTICE}

Obligations arising from this Memorandum of Understanding may be terminated by either party giving the other party written notice at least one year in advance. Provisions for refunds of contributions, arising out of unilateral termination, are specified in Annex A.

Done in Washington, D.C. and Paris, France in the English and French languages, both versions being equally authoritative. 
by:

Pour le Président Directeur Général

Le Directeur Général Délégué

[Signature]

Pierre Papon

Director-General

Institut Français de Recherche

pour l'Exploitation de la Mer

on:

2 Aout 1993

Date by:

[Signature]

Frederick M. Bernthal

Acting Director

National Science Foundation

on:

July 22,1993

Date

\section{ANNEX A \\ to the Memorandum of Understanding Between the National Science Foundation and the Institut Francais de Recherche Pour l'Exploitation de la Mer on the participation of France in the Ocean Drilling Program as a Regular Member}

Financial Contribution for U.S. Fiscal Year 1994

The Institut Français de Recherche pour l'Exploitation de la Mer will support the Ocean Drilling Program with a total contribution of United States two million nine hundred fifty thousand dollars (U.S. $\$ 2,950,000$ ) in cash for the period October 1, 1993 to September 30,1994, calculated at the rate of $\$ 245,833.33$ per month of drilling operations. Should the Ocean Drilling Program be terminated before September 30, 1994, the Institut Français de Recherche pour l'Exploitation de la Mer will be reimbursed at the rate of $\$ 245,833.33$ for each month of curtailment. Payment shall be made in four equal installments on or about January 1, April 1, July 1 and October 1, 1994.

Should France withdraw from the program under the terms of Article 13 above, no refunds of contributions will be made.

Contributions for subsequent years will be adjusted in proportion to actual changes in program costs experienced in the Ocean Drilling Program. Such detailed adjustments will be submitted by the National Science Foundation to the Institut Francais de Recherche pour l'Exploitation de la Mer in good time, 18 to 20 months prior to the U.S. Fiscal Year concerned by the adjustment, for appropriate discussion during the annual Ocean Drilling Program Council meeting.

by:

\section{[Signature]}

Pierre Papon

President-Director General Institut Français de Recherche pour l'Exploitation de la Mer

on:

6 October 1993

Date by:

[Signature]

Frederick M. Bernthal

Acting Director

National Science Foundation

on:

9 September 1993

Date 


\section{ANNEX B Intellectual Property Rights}

\section{PREAMBLE}

Pursuant to Article 5 of this Agreement;

The Parties shall ensure adequate and effective protection of intellectual property created or furnished under this Agreement and relevant implementing arrangements. The Parties agree to notify one another in a timely fashion of inventions or copyrighted works arising under this Agreement and to seek protection for such intellectual property in a timely fashion. Rights to such intellectual property shall be allocated as provided in this Annex.

\section{SCOPE}

A. This Annex is applicable to all cooperative activities undertaken pursuant to this Agreement, except as otherwise specifically agreed by the Parties or their designees.

B. For purposes of this Agreement, intellectual property shall have the meaning found in Article 2 of the Convention Establishing the World Intellectual Property Organization, done at Stockholm, July 14, 1967.

C. This Annex addresses the allocation of rights, interests, and royalties between the parties. Each Party shall ensure that the other Party can obtain the rights to intellectual property allocated in accordance with the Annex, by obtaining those rights from its own participants through contracts or other legal means, if necessary. This Annex does not otherwise alter or prejudice the allocation between a Party and its nationals, which shall be determined by that Party's laws and practices.

D. Disputes concerning intellectual property arising under this Agreement should be resolved through discussions between the concerned participating institutions or, if necessary, the Parties or their designees. Upon mutual agreement of the Parties, a dispute shall be submitted to an arbitral tribunal for binding arbitration in accordance with the applicable rules of international law. Unless the Parties or their designees agree otherwise in writing, the arbitration rules of UNCITRAL shall govern.

E. Termination or expiration of this agreement shall not affect rights or obligations under this Annex.

\section{ALLOCATION OF RIGHTS}

A. Each Party shall be entitled to a non-exclusive, irrevocable, royalty-free license in all countries to translate, reproduce, and publicly distribute scientific and technical journal articles, reports, and books directly arising from cooperation under this Agreement. All publicly distributed copies of a copyrighted work prepared under this provision shall indicate the names of the authors of the work unless an author explicitly declines to be named.

B. Rights to all forms of intellectual property, other than those rights described in Section II (A) above, shall be allocated as follows:

1. Visiting researchers, for example, scientists visiting primarily in furtherance of their education, shall receive intellectual property rights under the policies of the host institution. In addition, each visiting researcher named as an inventor shall be entitled to share in a portion of any royalties earned by the host institution from the licensing of such intellectual property.

2. a. For intellectual property created during joint research, for example, when the parties, participating institutions, or personnel have agreed in advance on the scope of work, the Parties or their designees shall jointly develop a technology management plan. The technology management plan shall consider the relative contributions of the Parties and their participants, the benefits of exclusive licensing by territory or for fields of use, requirements imposed by the Parties' domestic laws, and other factors deemed appropriate. 
b. If the Parties or their designees cannot reach agreement on a joint technology management plan within a reasonable time not to exceed six months from the time a party becomes aware of the creation of the intellectual property in question, each Party may designate one co-exclusive licensee to have world-wide rights. Each Party shall notify the other two months prior to making a designation under this paragraph. When both Parties (or their licensees) exploit the intellectual property in a country, they shall share equally the reasonable cost of intellectual property protection in that country.

c. A specific program of research will be regarded as joint research for purposes of allocating rights to intellectual property only when it is designated as such in the relevant implementing arrangement.

d. Notwithstanding paragraph II.B.2.(a) and (b), if type of intellectual property is available under the laws of one Party but not the other Party, the Party whose laws provide for this type of protection shall be entitled to all rights and interests worldwide. Persons named as inventors of property shall nonetheless be entitled to a share of royalties earned by either institution from the licensing of the property.

e. The allocation of rights hereabove defined shall take into account the financial participation of the parties contributing specific programs of technological development.

\section{BUSINESS-CONFIDENTIAL INFORMATION}

In the event that information identified in a timely fashion as business-confidential is furnished or created under the Agreement, each Party and its participants shall protect such information in accordance with applicable laws, regulations, and administrative practice. Information may be identified as "business-confidential" if a person having the information may derive an economic benefit from it or may obtain a competitive advantage over those who do not have it, the information is not generally known or publicly available from other sources, and the owner has not previously made the information available without imposing in a timely manner an obligation to keep it confidential. 



\section{GERMANY}

ENVIRONMENTAND NATURAL RESOURCES 



\section{Memorandum of Understanding Between the National Science}

Foundation in Washington, D.C., for the United States of America and the Deutsche Forschungsgemeinschaft on the Participation of the Federal Republic of Germany in the Ocean Drilling Program as a Regular Member, Washington, D.C., and Bonn, 1993

Done at Washington, D.C. 31 March 1993 and Bonn 3 May 1993

Entered into force 31 March 1993, effective 1 October 1993

Primary source citation: Copy of text provided by the U.S. Department of State

MEMORANDUM OF UNDERSTANDING BETWEEN THE NATIONAL SCIENCE FOUNDATION IN WASHINGTON, D.C., FOR THE UNITED STATES OF AMERICA AND THE DEUTSCHE FORSCHUNGSGEMEINSCHAFT ON THE PARTICIPATION OF THE FEDERAL REPUBLIC OF GERMANY IN THE OCEAN DRILLING PROGRAM AS A REGULAR MEMBER

The Ocean Drilling Program (ODP) is a multinational program of scientific research in the oceans which uses drilling and logging to improve fundamental understanding of the geological history, structure and evolution of the oceanic lithosphere (sediments and crust). The Ocean Drilling Program is a successor to the Deep Sea Drilling Project, which began in 1968, and the International Phase of Ocean Drilling, which began in 1975. During the period October 1983-October 1984, the National Science Foundation, through its contractors, refitted the JOIDES Resolution for scientific ocean drilling and for scientific program operations. Early in U.S. Fiscal Year 1985, the initial nine-year phase of ocean drilling began. By 1991, eight international partners representing 20 nations had become regular supporting members of the ODP. 
The Ocean Drilling Program is conducted by contractors, responsible to the National Science Foundation, who carry out the functions of science planning, science operations, and vessel operations. The Joint Oceanographic Institutions for Deep Earth Sampling (JOIDES) is the international body responsible for developing scientific plans and providing general scientific direction for the Ocean Drilling Program. A Science Planning Contractor organizes and provides administrative support to JOIDES. In May 1990, JOIDES published a Long Range Plan which identifies scientific priorities and calls for continued international cooperation in ocean drilling extending through the year 2002. JOIDES has subsequently endorsed use of the JOIDES Resolution as the primary facility for ODP coring and logging through at least 1998. Facilities, including any alternate or additional drilling platforms utilized through 1998, during subsequent years are to be determined by availability, cost, and scientific requirements identified by JOIDES planning.

Accordingly, the National Science Foundation and the Deutsche Forschungsgemeinschaft endorse continued cooperation in ocean drilling activities during the period 1 October 1993 to 30 September 2003, in accordance with the following articles:

\section{Article 1 - MEMBERSHIP STATUS}

The Deutsche Forschungsgemeinschaft elects to be a regular member with rights, privileges, and financial commitments as defined. All cooperative activities under this agreement, including exchange of technical information, equipment and data, shall be conducted in accordance with international law, as well as the international obligations, national laws and regulations of each party and within the limits of available funds.

\section{Article 2 - DURATION}

The Deutsche Forschungsgemeinschaft endorses continued cooperation in ocean drilling activities, with commitment, in principle, as a regular member to support of Ocean Drilling Program coring and logging programs in the period 1 October 1993 to 30 September 1998. Subsequent support is to be determined based on available technologies, facilities and membership costs in the period 1998 to 2003.

\section{Article 3 - SCIENTIFIC PLANNING}

Scientific planning and direction of the Ocean Drilling Program shall be the responsibility of JOIDES. The Federal Republic of Germany will be represented on each committee, panel, or working group thereof. The Bundesanstalt für Geowissenschaften und Rohstoffe (BGR) will be the member of JOIDES, will be represented on the JOIDES Executive and Planning Committees, and will nominate representatives of the Federal Republic of Germany for the JOIDES advisory panels and working groups. International membership and representation in JOIDES is restricted to regular members, including consortia, but excluding the individual members of consortia. The contractors will submit, to the Executive Committee of JOIDES, the annual program plan and budgets for approval prior to their adoption by the National Science Foundation.

\section{Article 4 - OCEAN DRILUING PROGRAM COUNCLL}

The Deutsche Forschungsgemeinschaft will be a member of the Ocean Drilling Program Council. The members of the Council will be representatives of each country contributing to the support of the Ocean Drilling Program, regardless of whether it is participating as an individual member or as a member of a consortium. Members of the Council and their alternates will be designated by the participating countries. There will be one representative of each participating country, except that additional representation from the United States may be appropriate.

The Council shall serve as a consultative body reviewing financial, managerial, and other matters involving the overall support of the Ocean Drilling Program. The Council shall provide a forum for exchange of views among the contributing countries. No formal voting procedures will be established. 
The National Science Foundation representative will serve as permanent Chairman of the Council. A formal agenda will be prepared for each meeting and written records of each meeting will be kept. The National Science Foundation will provide secretariat services to the Council.

The Council will normally meet once each year. The annual meeting shall include a financial report and discussion, an audit report, a review of scientific and technical achievements for the past year, draft program plans and budgets for the coming year, and other topics of mutual interest. Normally, all regular meetings of the Council will be scheduled in conjunction with the JOIDES Executive Committee meeting for review and approval of the annual program plans and budgets.

Liaison representatives of prime contractors and important scientific planning entities will be available to the Council.

\section{Article 5 - RIGHT TO MAKE PROPOSALS; DATA PRIVILEGES}

The Deutsche Forschungsgemeinschaft will have the right:

a) to make proposals to JOIDES of scientific projects or technical objectives of interest to the scientific community of the Federal Republic of Germany.

b) to participate in the analysis, and have access to the data, of geophysical and other site surveys performed in support of the program.

c) to engineering plans, data or other information developed under contracts supported as program costs, subject to Article 1 limitations.

Site surveys may be contributed by the Federal Republic of Germany as its scientific interests and available resources allow. Site survey requirements will be identified by JOIDES.

\section{Article 6 - VISA AND CUSTOMS FACILITATION}

The National Science Foundation will facilitate through collaboration with the appropriate authorities the granting of visas and other forms of official permission for entry to and exit from the United States of personnel, equipment, and supplies when required for participation or utilization in the Ocean Drilling Program.

\section{Article 7 - PARTICIPATION ON BOARD THE ODP DRILLSHIP}

The Science Operations Contractor, with the advice of JOIDES, selects the scientific team for each cruise. It is expected that approximately half of the scientists invited to serve as co-chief scientists will be representatives of the United States. It is expected that a scientist representing the Federal Republic of Germany will be invited to serve as co-chief scientist on an equal numerical basis with all other non-U.S. partners. The Federal Republic of Germany has the right to have a scientist represented in the shipboard scientific staff on each cruise of the ODP drillship. Normally, space will be available for two scientists representing the Federal Republic of Germany on the research cruises of the ODP drillship. It is recognized that some cruises may be of special scientific interest to Federal Republic of Germany scientists and increased participation by scientists of the Federal Republic of Germany on these cruises may be appropriate. At a minimum, total participation over the term of the Ocean Drilling Program will be proportional to the Federal Republic of Germany contribution to Program costs.

\section{Article 8 - INITIAL REPORTS OF THE OCEAN DRILLING PROGRAM}

Scientists from the Federal Republic of Germany will have access, through the Deutsche Forschungsgemeinschaft, to Ocean Drilling Program data and core samples. The Deutsche Forschungsgemeinschaft will endeavor to ensure that the participating Federal Republic of Germany scientists and institutions shall provide the scientific data 
resulting from site surveys and laboratory analyses in time for preparation of the Proceedings of the Ocean Drilling Program or their equivalent. One hundred copies of each volume of the official scientific publications will be provided to the Deutsche Forschungsgemeinschaft for free distribution among scientific establishments in the Federal Republic of Germany. These volumes may be published in the Federal Republic of Germany in full or in part, without payments to or additional agreements with the United States. The Deutsche Forschungsgemeinschaft will provide the National Science Foundation with copies of all publications from the Federal Republic of Germany that are based on program material.

\section{Article 9 - FINANCIAL CONTRIBUTION}

The Deutsche Forschungsgemeinschaft will support the Ocean Drilling Program with financial contributions payable to the National Science Foundation in U.S. dollars in amounts and periods to be specified by Annex A to this Memorandum of Understanding.

The financial contribution of all participants will be commingled to support the total program costs. "Program costs" are determined by the National Science Foundation, and are those costs incurred in support of contractors performing functions for joint planning and operations of the Ocean Drilling Program, and program direction and management costs incurred by the National Science Foundation which relate to international participation. Activities which may be carried out by the National Science Foundation's contractors in direct support of United States scientific undertakings are not program costs and will not be funded from commingled accounts.

\section{Article 10 - SALARIES AND TRAVEL EXPENSES}

Salaries and travel expenses for participants representing the Federal Republic of Germany will be borne by the Federal Republic of Germany. Costs of accommodations for Federal Republic of Germany scientists and members of technical parties aboard the drillship are program costs and will be funded by the Ocean Drilling Program. The National Science Foundation's contractors will render Federal Republic of Germany scientists needed assistance when going from an airport to the drillship.

\section{Article 11 - CONSULTATION}

Meetings of the National Science Foundation and representatives of the Federal Republic of Germany may be held at any time upon the request of either party to discuss the terms and conditions of this Memorandum and other matters of mutual interest.

\section{Article 12 - TERMINATION NOTICE}

Obligations arising from this Memorandum of Understanding may be terminated by either party giving the other party written notice at least one year in advance. Provisions for refunds of contributions, arising out of unilateral termination, are specified in Annex A.

Done in Washington, D.C. and Bonn, Germany

by:

by:

[Signature]

[Signature]

Wolfgang Frühwald

Walter E. Massey

President

Director

Deutsche Forschungsgemeinschaft

National Science Foundation

on:

on:

3.5.1993

3/31/93 
by:

[Signature]

B. Müller

Secretary-General

Deutsche Forschungsgemeinschaft

on:

3.5 .93

\section{ANNEX A \\ to the Memorandum of Understanding Between the National Science Foundation and the Deutsche Forschungsgemeinschaft on the Participation of the Federal Republic of Germany in the Ocean Drilling Program as a Regular Member} Financial Contribution for U.S. Fiscal Year 1994

The Deutsche Forschungsgemeinschaft will support the Ocean Drilling Program with a total contribution of United States two million nine hundred fifty thousand dollars (U.S. $\$ 2,950,000$ ) in cash for the period October 1,1993 to September 30, 1994

Should the Ocean Drilling Program be terminated before September 30, 1994, the Federal Republic of Germany will be reimbursed on the basis of one-twelfth of its contribution for each month of curtailment.

Should the Federal Republic of Germany withdraw from the Program, under the terms of Article 12 above, no refunds of contributions will be made.

Contributions for subsequent years will be adjusted to the changes in program costs experienced in the Ocean Drilling Program, as determined by the National Science Foundation. If a change in contribution is anticipated, the National Science Foundation will provide information as to the cost basis and the indices used to estimate increases or decreases.

by:

[Signature]

Wolfgang Frühwald

President

Deutsche Forschungsgemeinschaft

on:

3.5.1993

by:

[Signature]

B. Müller

Secretary-General

Deutsche Forschungsgemeinschaft

on:

3.5 .93 by:

[Signature]

Walter E. Massey

Director

National Science Foundation

on:

$3 / 31 / 93$ 



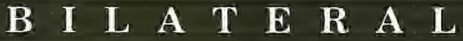

\author{
IRELAND
}

ENVIRONMENTAND NATURAL RESOURCES 



\section{Agreement Between the U.S. National Oceanic and Atmospheric Administration and the Department of Education of Ireland for Cooperation in the GLOBE Program, Dublin, 1995}

\section{Done at Dublin 12 June 1995}

Entered into force 12 June 1995

Primary source citation: Copy of text provided by the

U.S. Department of State

\section{AN AGREEMENT BETWEEN THE U.S. NATIONAL OCEANIC AND ATMOSPHERIC ADMINISTRATION AND THE DEPARTMENT OF EDUCATION OF IRELAND FOR COOPERATION IN THE GLOBE PROGRAM}

\section{PREAMBLE}

The U.S. National Oceanic and Atmospheric Administration, acting on behalf of itself and other U.S. Government agencies participating in the GLOBE Program (hereinafter, the U.S. side), and the Department of Education of Ireland (hereinafter, the Irish side),

Intending to increase the awareness of students throughout the world about the global environment,

Seeking to contribute to increased scientific understanding of the Earth, and

Desiring to support improved student achievement in science and mathematics,

Have agreed to cooperate in the Global Learning and Observations to Benefit the Environment (GLOBE) Program as follows:

\section{ARTICLE 1 - THE GLOBE PROGRAM}

The GLOBE Program is an international environmental science and education program that will bring students, teachers, and scientists together to study the global environment. GLOBE will create an international network of students in grades K-12 (or equivalent) studying environmental issues, making environmental measurements, and sharing useful environmental data with the international environmental science community. 


\section{ARTICLE 2 - RESPECTIVE RESPONSIBLITIES}

A. The U.S. side will:

1. Identify U.S. schools that will participate in the GLOBE Program (details regarding GLOBE schools in Appendix A);

2. Select, in consultation with international scientists and educators, the GLOBE environmental measurements and types of measurement equipment (described in Appendix B);

3. Select Principal Investigator Teams for the GLOBE environmental measurements, and support the U.S. members of the Teams;

4. Calibrate, if necessary, measurement equipment that cannot be calibrated by GLOBE teachers and students;

5. Develop, in consultation with international scientists and educators, GLOBE educational materials;

6. Translate GLOBE instructional materials related to measurement procedures and data reporting protocols into the six United Nations languages, and provide these plus all broader GLOBE educational materials to the Irish side for further reproduction as necessary;

7. Conduct annual regional training sessions for GLOBE Country Coordinators and GLOBE teachers who will serve as trainers for additional GLOBE teachers in Ireland, and provide a copy of GLOBE training materials to the Irish side;

8. Design, develop, operate, and maintain GLOBE data processing capabilities and other necessary technology and equipment;

9. Provide GLOBE software, as necessary, for use on Irish GLOBE school computers. (To the maximum extent possible, textual material appearing on computer screens will be accessible in the student's choice among the six United Nations languages.);

10. Accept environmental data reported from GLOBE schools around the world, and develop and provide resultant global environmental images (visualization products) to the Irish side; and

11. Evaluate the overall GLOBE Program periodically, in consultation with international GLOBE Country Coordinators, and modify the overall program as appropriate.

B. The Irish side will:

1. Select Irish schools to participate in the GLOBE Program (details regarding GLOBE schools in Appendix A) and provide an updated list of Irish GLOBE schools to the U.S. side at the beginning of each school year;

2. Ensure that Irish GLOBE schools conduct the fundamental activities of GLOBE schools detailed in Appendix A (take GLOBE environmental measurements, report data, and receive and use resultant global environmental images, using GLOBE educational materials under the guidance of teachers trained to conduct the GLOBE Program);

3. Name an Irish Government Point of Contact responsible for policy-level communications with the Director of the GLOBE Program;

4. Name a Country Coordinator responsible for day-to-day management, oversight, and facilitation of the GLOBE Program in Ireland;

5. Ensure that the Country Coordinator and some GLOBE teachers attend GLOBE regional training and in turn provide GLOBE training to at least one teacher in each Irish GLOBE school; 
6. Ensure that GLOBE instructional materials related to measurement procedures and data reporting protocols are utilized in Irish GLOBE schools, and that broader GLOBE educational materials are appropriately translated, adapted, reproduced, and distributed to all Irish GLOBE schools;

7. Ensure that Irish GLOBE schools have the necessary measurement equipment to take GLOBE environmental measurements (described in Appendix B);

8. Ensure that teachers and students at Irish GLOBE schools calibrate GLOBE measurement equipment according to procedures provided in GLOBE instructional materials;

9. Ensure that Irish GLOBE schools have the necessary computer and communications systems (described in Appendix C) to report GLOBE environmental measurements and to receive and use GLOBE visualization products, or make agreed alternative arrangements for such reporting and receipt. (At a minimum, the Irish Country Coordinator will need access to Internet so that all measurement data from Irish GLOBE schools will be reported via Internet.); and

10. Evaluate GLOBE operations in Ireland periodically and assist the U.S. side in conducting periodic evaluation of the overall GLOBE Program.

\section{ARTICLE 3 - FINANCIAL ARRANGEMENTS}

Each side will bear the costs of fulfilling its respective responsibilities under this agreement. Obligations of each side pursuant to this agreement are subject to its respective funding procedures and the availability of appropriated funds, personnel, and other resources. The conduct of activities under this agreement will be consistent with the relevant laws and regulations of the two sides.

\section{ARTICLE 4 - EXCHANGE OF DATA AND GOODS}

GLOBE environmental measurement data, visualization products, software, and educational materials will be available worldwide without restriction as to their use or redistribution.

\section{ARTICLE 5 - RELEASE OF INFORMATION ABOUT THE GLOBE PROGRAM}

Each side may release information on the GLOBE Program as it may deem appropriate without prior consultation with the other.

\section{ARTICLE 6 - CUSTOMS AND IMIIGRATION}

Each side will, to the extent permitted by its laws and regulations, facilitate the movement of persons and goods necessary to implement this agreement into and out of its territory and accord entry to such goods into its territory free of customs duties and other similar charges.

\section{ARTICLE 7 - ENTRY INTO FORCE, AMENDMENTS, WITHDRAWAL}

This agreement will enter into force upon signature of the two sides and will remain in force for five years. It will be automatically extended for further five-year periods, unless either side decides to terminate it and so notifies the 
other side with three months written notice. This agreement may be terminated at any time by either side upon three months prior written notice to the other side. This agreement may be amended by written agreement of the two sides.

Done at DUBLIN, in duplicate, on Monday, June 12, 1995.

For the National Oceanic and

Atmospheric Administration:

[Signature]
For the Department of

Education:

[Signature]

\section{APPENDIX A GLOBE Schools}

Each partner country will be responsible for identifying its participating schools. Schools should be selected so as to satisfy the objectives of the GLOBE Program. In particular, countries should emphasize the selection of schools that will maximize the number of students worldwide participating in the program. Also, countries should consider involving schools in locations that will yield measurement data that is important to the international environmental science community.

Students at all GLOBE schools throughout the world will conduct the following fundamental activities: they will make environmental measurements at or near their schools; report their data to a GLOBE data processing site; receive vivid graphical global environmental images (visualization products) created from their data and the data from other GLOBE schools around the world; and study the environment by relating their observations and the resulting visualization products to broader environmental topics. All of these activities will be conducted under the guidance of specially trained teachers (GLOBE-trained teachers).

GLOBE educational materials will be used in GLOBE schools under the guidance of GLOBE-trained teachers. These materials will detail procedures for taking environmental measurements and protocols for reporting data; explain the significance of the measurements; guide the use of the visualization products; and integrate the measurement aspects of the program into a broader study of the environment.

Schools throughout the United States and the rest of the world that are not GLOBE schools may become GLOBE Affiliate schools by observing the GLOBE Program in operation through the Internet. Students at these schools will benefit from the use of GLOBE visualization products and educational materials accessible on-line. All GLOBE Affiliate schools will be encouraged to become participating GLOBE schools.

\section{APPENDIX B GLOBE Environmental Measurements and Equipment}

GLOBE environmental measurements will contribute in a significant way to the scientific understanding of the dynamics of the global environment. Every GLOBE school will conduct a core set of GLOBE environmental measurements in the following critical areas: Atmosphere/Climate, Hydrology/Water Chemistry, and Biology/Geology. Where possible, a GLOBE school may coordinate its activities with those of other neighboring GLOBE schools, so that the complete set of GLOBE measurements will be available from a locality. As the GLOBE Program evolves, elective measurements not common to all GLOBE schools may be added in order to address local environmental issues.

Students at all age levels will be active participants in the GLOBE Program. The actual participation will be designed so as to be grade-appropriate for grades K-5, 6-8, and 9-12 (or equivalent). Younger students will make limited measurements which may be qualitative rather than quantitative. Older students will make additional measurements and more sophisticated measurements, as appropriate for their grade level. Measurement equipment will not need to be standardized; rather, performance specifications will be provided.

Following is an example list of core measurements and equipment. The full list will be initially determined and periodically updated as provided in Article 2.A.2, based on experience gained in implementing the GLOBE Program. 


\section{MEASUREMENTS}

Atmosphere/Climate:

Air Temperature

Precipitation

Cloud Cover/Type

Hydrology/Water Chemistry:

Water $\mathrm{pH}$

Water Temperature

Soil Moisture

\section{Biology/Geology:}

Habitat Study

Tree Height

Tree Canopy

Tree Diameter

Species Identification

Phenology

\section{EQUIPMENT NEEDED}

\author{
Max/Min Thermometer \\ Calibration Thermometer \\ Instrument Shelter \\ Rain Gauge \\ Cloud Charts
}

\author{
pH Paper, Pen, or Meter \\ Alcohol Thermometer \\ Gypsum Block Sensors \\ Soil Moisture Meter
}

\section{Appendix C \\ GLOBE Computer and Communications Systems}

In order to derive maximum benefit from the GLOBE Program, all schools will be encouraged to use an international information network, initially using the Internet, along, with classroom computers. The World Wide Web multi-media information-access capability has been selected as the basis for IBM-compatible and Apple Macintosh computer systems to support the required GLOBE school activities of data entry, data analysis, and use of GLOBE environmental images. Following is a description of GLOBE computer and communications systems consistent with current GLOBE requirements.

Overall attributes of the minimum GLOBE school computer configuration that can execute the necessary software are:

For IBM-compatible systems: a $386 \mathrm{SX}$ or higher level processor; at least 4 megabytes of RAM memory ( 8 megabytes preferred); a VGA-capable monitor and display driver (Super VGA preferred); a hard disk storage system with as large a capacity as possible (preferably 300 megabytes or larger); and a direct Internet connection or dial-up capability that can use SLIP or PPP protocols with a 14,400 bps modem (preferably supporting V.42bis data compression which can enable 57,600 bps operation). The Windows 3.1 or later operating system is necessary. A printer is desirable.

For Apple Macintosh systems: a $6803020 \mathrm{Mhz}$ or faster processor; at least 4 megabytes of RAM memory ( 8 megabytes preferred); a hard disk storage system with as large a capacity as possible (preferably 300 megabytes or larger); and a direct Internet connection or dial-up capability that can use SLIP or PPP protocols with a 14,400 bps modem (preferably supporting V.42bis data compression which can enable 57,600 bps operation). A printer is desirable.

Software for a higher performance GLOBE school computer system is being developed that will operate on higher performance, multi-media IBM-compatible systems and on Apple Macintosh systems. For IBM-compatible systems: a 486/66 or faster processor; 16 megabytes of RAM memory; 500 megabytes of hard disk space; a Super VGA monitor; a double-speed CD-ROM reader; a Soundblaster-compatible sound card; and an MPEG animation speed-up board will be required. For Apple Macintosh systems: a PowerPC processor; 16 megabytes of RAM memory; 500 megabytes of hard disk space; and a double-speed CD-ROM reader will be required. A communications capability the same as or better than for the minimum configurations above will also be required. A printer will be highly desirable. 
It is recognized that there is a broad range of technological capabilities among potential GLOBE schools. The diversity of technology accessible by schools worldwide may require in some cases that environmental measurements be reported in hardcopy and that a variety of media be used to distribute visualization products, including photographs and broadcast television. All schools that want to participate in the program will be accommodated.

Technology associated with the GLOBE Program will continually evolve to higher levels and participants will be encouraged to upgrade over time. 


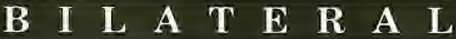

\section{$\operatorname{ISRAEL}$}

ENVIRONMENTAND NATURAL RESOURCES 



\title{
Agreement Between the National Oceanic and Atmospheric
} Administration of the United States of America and the Ministries of the Environment, and Education, Culture and Sport of the State of Israel for Cooperation in the GLOBE Program, Jerusalem, 1995

Done at Jerusalem 24 March 1995

Entered into force 24 March 1995

Primary source citation: Copy of text provided by the

U.S. Department of State

\begin{abstract}
AN AGREEMENT BETWEEN THE NATIONAL OCEANIC AND ATMOSPHERIC ADMINISTRATION OF THE UNITED STATES OF AMERICA AND THE MINISTRIES OF THE ENVIRONMENT, AND EDUCATION, CULTURE AND SPORT OF THE STATE OF ISRAEL FOR COOPERATION IN THE GLOBE PROGRAM
\end{abstract}

\section{PREAMBLE}

The U.S. National Oceanic and Atmospheric Administration, acting on behalf of itself and other U.S. Government agencies participating in the GLOBE Program (hereinafter the U.S. side), and the Ministries of the Environment, and Education, Culture and Sport of the State of Israel (hereinafter, the Israeli side),

Intending to increase the awareness of students throughout the world about the global environment,

Seeking to contribute to increase scientific understanding of the Earth, and

Desiring to support improved student achievement in science and mathematics,

Have agreed to cooperate in the Global Learning and Observations to Benefit the Environment (GLOBE) Program as follows: 


\section{ARTICLE 1 - THE GLOBE PROGRAM}

The GLOBE Program is an international environmental science and education program that will bring students, teachers, and scientists together to study the global environment. GLOBE will create an international network of students in grades K-12 (or equivalent) studying environmental issues, making environmental measurements, and sharing useful environmental data with the international environmental science community.

\section{ARTICLE 2 - RESPECTIVE RESPONSIBILITIES}

A. The U.S. side will:

1. Identify U.S. schools that will participate in the GLOBE Program (details regarding GLOBE schools in Appendix A);

2. Select, in consultation with international scientists and educators, the GLOBE environmental measurements and types of measurement equipment (described in Appendix B);

3. Select Principal Investigator Teams for the GLOBE environmental measurements, and support the U.S. members of the Teams;

4. Calibrate, if necessary, measurement equipment that cannot be calibrated by GLOBE teachers and students;

5. Develop, in consultation with international scientists and educators, GLOBE educational materials;

6. Translate GLOBE instructional materials related to measurement procedures and reporting protocols into the six United Nations languages, and provide these plus all broader GLOBE educational materials to the Israeli side for further reproduction as necessary;

7. Conduct annual regional training sessions for GLOBE Country Coordinators and GLOBE teachers who will serve as trainers for additional GLOBE teachers in Israel, and provide a copy of GLOBE training materials to the Israeli side;

8. Design, develop, operate, and maintain GLOBE data processing capabilities and other necessary technology and equipment;

9. Provide GLOBE software, as necessary, for use on Israeli GLOBE school computers. (To the maximum extent possible, textual material appearing on computer screens will be accessible in the student's choice among the six United Nations languages.);

10. Accept environmental data reported from GLOBE schools around the world, and develop and provide resultant global environmental images (visualization products) to the Israeli side; and

11. Evaluate the overall GLOBE Program periodically, in consultation with international GLOBE Country Coordinators, and modify the overall program as appropriate.

B. The Israeli side will:

1. Select Israeli schools to participate in the GLOBE Program (details regarding GLOBE schools in Appendix A) and provide an updated list of Israeli GLOBE schools to the U.S. side at the beginning of each school year;

2. Ensure that Israeli GLOBE schools conduct the fundamental activities of GLOBE schools detailed in Appendix A (take GLOBE environmental measurements, report data, and receive and use resultant global environmental images, using GLOBE educational materials under the guidance of teachers trained to conduct the GLOBE Program); 
3. Name an Israeli Government Point of Contact responsible for policy-level communications with the Director of the GLOBE Program;

4. Name a Country Coordinator responsible for day-to-day management, oversight, and facilitation of the GLOBE Program in Israel;

5. Ensure that the Country Coordinator and some GLOBE teachers attend GLOBE regional training and in turn provide GLOBE training to at least one teacher in each Israeli GLOBE school;

6. Ensure that GLOBE instructional materials related to measurement procedures and reporting protocols are utilized in Israeli GLOBE schools, and that broader GLOBE educational materials are appropriately translated, adapted, reproduced, and distributed to all Israeli GLOBE schools;

7. Ensure that Israeli GLOBE schools have the necessary measurement equipment to take GLOBE environmental measurements (described in Appendix B);

8. Ensure that teachers and students at Israeli GLOBE schools calibrate GLOBE measurement equipment according to procedures provided in GLOBE instructional materials;

9. Ensure that Israeli GLOBE schools have the necessary computer and communications systems (described in Appendix C) to report GLOBE environmental measurements and to receive and use GLOBE visualization products, or make agreed alternative arrangements for such reporting and receipt. (At a minimum, the Israeli Country Coordinator will need access to Internet so that all measurement data from Israeli GLOBE schools will be reported via Internet.); and

10. Evaluate GLOBE operations in Israel periodically and assist the U.S. side in conducting periodic evaluation of the overall GLOBE Program.

\section{ARTICLE 3 - FINANCLAL ARRANGEMENTS}

Each side will bear the costs of fulfilling its respective responsibilities under this agreement. Obligations of each side pursuant to this agreement are subject to its respective funding procedures and the availability of appropriated funds, personnel, and other resources.

\section{ARTICLE 4 - LEGAL ARRANGEMENTS}

The conduct of activities under this agreement will be consistent with the relevant laws and regulations of the two sides.

\section{ARTICLE 5 - EXCHANGE OF DATA AND GOODS}

GLOBE environmental measurement data, visualization products, software, and educational materials will be available worldwide without restriction as to their use or redistribution.

\section{ARTICLE 6 - RELEASE OF INFORMATION ABOUT THE GLOBE PROGRAM}

Each side may release information on the GLOBE Program as it may deem appropriate without prior consultation with the other. 


\section{ARTICLE 7 - CUSTOMS AND IMMIGRATION}

Each side will, to the extent permitted by its laws and regulations, facilitate the movement of persons and goods necessary to implement this agreement into and out of its territory and accord entry to such goods into its territory free of customs duties and other similar charges.

\section{ARTICLE 8 - ENTRY INTO FORCE, AMENDMENTS, WITHDRAWAL}

This agreement will enter into force upon signature of the two sides and will remain in force for five years. It will automatically extend for further five-year periods, unless either side decides to terminate it and so notifies the other side with three months written notice. This agreement may be terminated at any time by either side upon three months prior written notice to the other side. This agreement may be amended by written agreement of the two sides.

Done at Jerusalem on the twenty-fourth day of March, 1995, in triplicate, in the English and Hebrew languages, all texts being equally authentic.

For the U.S. National Oceanic and Atmospheric

Administration:

[Signature]

For the Ministry of Environment of the State of Israel:

[Signature]

For the Ministry of Education, Culture and Sport of the

State of Israel:

[Signature]

\section{APPENDIX A GLOBE Schools}

Each partner country will be responsible for identifying its participating schools. Schools should be selected so as to satisfy the objectives of the GLOBE Program. In particular, countries should emphasize the selection of schools that will maximize the number of students worldwide participating in the program. Also, countries should consider involving schools in locations that will yield measurement data that is important to the international environmental science community.

Students at all GLOBE schools throughout the world will conduct the following fundamental activities: they will make environmental measurements at or near their schools; report their data to a GLOBE data processing site; receive vivid graphical global environmental images (visualization products) created from their data and the data from other GLOBE schools around the world; and study the environment by relating their observations and the resulting visualization products to broader environmental topics. All of these activities will be conducted under the guidance of specially trained teachers (GLOBE-trained teachers).

GLOBE educational materials will be used in GLOBE schools under the guidance of GLOBE-trained teachers. These materials will detail procedures for taking environmental measurements and protocols for reporting data; explain the significance of the measurements; guide the use of the visualization products; and integrate the measurement aspects of the program into a broader study of the environment.

Schools throughout the United States and the rest of the world that are not GLOBE schools may become GLOBE Affiliate schools by observing the GLOBE Program in operation through the Internet. Students at these schools will benefit from the use of GLOBE visualization products and educational materials accessible on-line. All GLOBE Affiliate schools will be encouraged to become participating GLOBE schools. 


\section{APPENDIX B \\ GLOBE Environmental Measurements and Equipment}

GLOBE environmental measurements will contribute in a significant way to the scientific understanding of the dynamics of the global environment. Every GLOBE school will conduct a core set of GLOBE environmental measurements in the following critical areas: Atmosphere/Climate, Hydrology/Water Chemistry, and Biology/Geology. Where possible, a GLOBE school may coordinate its activities with those of other neighboring GLOBE schools, so that the complete set of GLOBE measurements will be available from a locality. As the GLOBE Program evolves, elective measurements not common to all GLOBE schools may be added in order to address local environmental issues.

Students at all age levels will be active participants in the GLOBE Program. The actual participation will be designed so as to be grade-appropriate for grades $\mathrm{K}-5,6-8$, and 9-12 (or equivalent). Younger students will make limited measurements which may be qualitative rather than quantitative. Older students will make additional measurements and more sophisticated measurements, as appropriate for their grade level. Measurement equipment will not need to be standardized; rather, performance specifications will be provided.

Following is an example list of core measurements and equipment. The full list will be initially determined and periodically updated as provided in Article 2.A.2, based on experience gained in implementing the GLOBE Program.

\section{MEASUREMENT}

\section{Atmosphere/Climate:}

Air Temperature

Precipitation

Cloud Cover/Type

\section{Hydrology/Water Chemistry:}

Water $\mathrm{pH}$

Water Temperature

Soil Moisture

\section{Biology/Geology:}

Habitat Study

Tree Height

Tree Canopy

Tree Diameter

Species Identification

Phenology

\section{EQUIPMENT NEEDED}

\author{
Max/Min Thermometer \\ Calibration Thermometer \\ Instrument Shelter \\ Rain Gauge \\ Cloud Charts
}

pH Paper, Pen, or Meter

Alcohol Thermometer

Gypsum Block Sensors

Soil Moisture Meter

Compass

Meter Measuring Tape

Surveying Markers or Stakes

Clinometer

Densiometer

Diameter Tape

Dichotomous Keys

$35 \mathrm{~mm}$ Camera

\section{APPENDIX C \\ GLOBE Computer and Communications Systems}

In order to derive maximum benefit from the GLOBE Program, all schools will be encouraged to use an international information network, initially using the Internet, along with classroom computers. The World Wide Web multi-media information-access capability has been selected as the basis for IBM-compatible and Apple Macintosh computer systems to support the required GLOBE school activities of data entry, data analysis, and use of GLOBE environmental images. Following is a description of GLOBE computer and communications systems consistent with current GLOBE requirements. 
Overall attributes of the minimum GLOBE school computer configuration that can execute the necessary software are:

For IBM-compatible systems: a $386 \mathrm{SX}$ or higher level processor; at least 4 megabytes of RAM memory (8 megabytes preferred); a VGA-capable monitor and display driver (Super VGA preferred); a hard disk storage system with as large a capacity as possible (preferably 300 megabytes or larger); and a direct Internet connection or dial-up capability that can use SLIP or PPP protocols with a 14,400 bps modem (preferably supporting V.42bis data compression which can enable 57,600 bps operation). The Windows 3.1 or later operating system is necessary. A printer is desirable.

For Apple Macintosh systems: $16803020 \mathrm{Mhz}$ or faster processor; at least 4 megabytes of RAM memory ( 8 megabytes preferred); a hard disk storage system with as large a capacity as possible (preferably 300 megabytes or larger); and a direct Internet connection or dial-up capability that can use SLIP or PPP protocols with a 14,400 bps modem (preferably supporting V.42bis data compression which can enable 57,600 bps operation). A printer is desirable.

Software for a higher performance GLOBE school computer system is being developed that will operate on higher performance, multi-media IBM-compatible systems and on Apple Macintosh systems. For IBM-compatible systems: a 486/66 or faster processor; 16 megabytes of RAM memory; 500 megabytes of hard disk space; a Super VGA monitor; a double-speed CD-ROM reader; a Soundblaster compatible sound card; and an MPEG animation speed-up board will be required. For Apple Macintosh systems: a PowerPC processor; 16 megabytes of RAM memory; 500 megabytes of hard disk space; and a double-speed CD-ROM reader will be required. A communications capability the same as or better than for the minimum configurations above will also be required. A printer will be highly desirable.

It is recognized that there is a broad range of technological capabilities among potential GLOBE schools. The diversity of technology accessible by schools worldwide may require in some cases that environmental measurements be reported in hardcopy and that a variety of media be used to distribute visualization products, including photographs and broadcast television. All schools that want to participate in the program will be accommodated.

Technology associated with the GLOBE Program will continually evolve to higher levels and participants will be encouraged to upgrade over time. 


\section{B I L A T E R A L}

JAPAN

ENVIRONMENT AND NATURAL RESOURCES 



\section{Memorandum of Understanding}

Between the Geological Survey of the Department of the Interior of the United States of America and the Public Works Research Institute of the Ministry of Construction of Japan Concerning Cooperation in the Field of Hydrology, Water Resources, and Global Climate Change, Reston and Tsukuba, 1992

\section{Done at Reston 3 January 1992 and Tsukuba \\ 3 February 1992}

Entered into force 3 February 1992

Primary source citation: TIAS 11851

MEMORANDUM OF UNDERSTANDING BETWEEN THE GEOLOGICAL SURVEY OF THE DEPARTMENT OF THE INTERIOR OF THE UNITED STATES OF AMERICA AND THE PUBLIC WORKS RESEARCH INSTITUTE OF THE MINISTRY OF CONSTRUCTION OF JAPAN CONCERNING COOPERATION IN THE FIELD OF HYDROLOGY, WATER RESOURCES, AND GLOBAL CLIMATE CHANGE

\section{ARTICLE I. Scope and Objectives}

The Geological Survey of the Department of the Interior of the United States of America (hereinafter referred to as "USGS"), and the Public Works Research Institute of the Ministry of Construction of Japan (hereinafter referred to as the "PWRI"), hereby agree to pursue cooperation in the field of hydrology, water resources, and global climate change in accordance with this Memorandum of Understanding (hereinafter referred to as the "Memorandum"). 
This Memorandum has been concluded pursuant to and will be governed by the Agreement between the Government of the United States of America and the Government of Japan on Cooperation in Research and Development in Science and Technology, signed at Toronto, Canada, on June 20, 1988.

The purpose of this Memorandum is to provide a framework for the exchange of scientific and technical knowledge and augmentation of scientific and technical capabilities of the USGS and the PWRI (hereinafter referred to as the "Parties") with respect to the hydrological sciences.

Objectives of the cooperative research are to:

1. Encourage, develop, and implement the exchange of information on hydrology and water resources between the Parties for the purpose of sharing scientific and technological knowledge.

2. Develop strong technical links between scientific and engineering researchers of the Parties and encourage exchanges of guest researchers.

3. Conduct joint research in the areas of hydrology and water resources. Publish findings from joint research efforts.

4. Conduct cooperative programs to improve technology in the field of hydrology and water resources. Publish results from cooperative programs.

The USGS may, with the consent of the PWRI, and to the extent permitted by existing United States laws and policies, include the participation of other United States entities in the development and undertaking of activities within the scope of this Memorandum.

The PWRI may, with the consent of the USGS, and to the extent permitted by existing Japanese laws and policies, include the participation of other Japanese entities in the development and undertaking of activities within the scope of this Memorandum.

\section{ARTICLE II. Cooperative Activities}

Forms of cooperative activities under this Memorandum may consist of exchanges of technical information, exchange visits, and cooperative research consistent with ongoing programs of the Parties. Specific areas of cooperation may include, but are not limited to, such subjects of mutual interest as:

1. Assessment of the hydrologic and water-resources effects of global climatic change, including the sensitivity of water-resource systems to climate variability and change, as well as effects on such processes as precipitation, runoff, evapotranspiration, snowmelt, soil erosion in mountainous areas, and sediment discharge.

2. Surface-water hydrology, particularly considering rainfall-runoff modeling including snowmelt simulation, and data exchanges in experimental basins.

3. Sediment transport mechanics, including river morphology.

4. Hydrologic instrumentation and equipment.

To facilitate these cooperative research activities, the Parties agree to:

1. Conduct periodic joint meetings, alternating locations between the United States and Japan.

2. Exchange data and information.

3. Exchange scientists and engineers.

4. Develop cooperative research programs on hydrology and water resources. 
5. Establish and maintain effective communications between the researchers and administrators of the Parties.

To ensure that program activities are effectively maintained, the Parties shall designate program co-leaders to coordinate and manage these activities. The program co-leaders shall, upon mutual agreement, identify investigators to participate in selected joint research projects. The selected project investigators will be responsible for developing project plans in coordination with the program co-leaders.

\section{ARTICLE III. Source of Funding}

Cooperative activities under this Memorandum will be subject to and dependent upon the availability of funds and personnel. The financial arrangements for specific joint projects will be agreed upon in writing by the Parties before each project is initiated.

\section{ARTICLE IV. Intellectual Property}

The protection and distribution of intellectual property created or furnished in the course of cooperative activities under this Memorandum shall be in accordance with the provisions in Annex IV to the Agreement between the Government of the United States of America and the Government of Japan on Cooperation in Research and Development in Science and Technology, signed at Toronto on June 20, 1988.

\section{ARTICLE V. Disclaimer}

Information transmitted by one Party to the other Party under this Memorandum shall be accurate to the best knowledge and belief of the transmitting Party; however, the transmitting Party does not warrant the suitability of the information transmitted for any particular use or application by the receiving Party or by any third party.

\section{ARTICLE VI. Planning and Review of Activities}

Upon entry into force of this Memorandum, the Parties will designate representatives who, at times mutually agreed upon by the Parties, will review the activities under this Memorandum. Activity reports will be exchanged and projects developed as appropriate. In case of modification of the cooperative activities, each Party will inform the other of its decisions and of its intentions regarding the continuation of operations.

\section{ARTICLE VII. Project Annexes}

The specifics of any activity carried out under this Memorandum shall be agreed upon by the Parties in writing. Activities are subject to the laws and regulations of the United States and Japan. Any activity involving other than the exchange of technical information or exchange visits of individuals shall be described in an agreed Annex to this Memorandum, which shall set forth, as appropriate, a work plan, staffing requirements, cost estimates, funding sources, and other undertakings, obligations, or conditions not included in this Memorandum. In case of any inconsistency between the terms of this Memorandum and the terms of an Annex hereto, the terms of this Memorandum shall be controlling, unless the Annex specifically provides that it is intended to alter a provision of this Memorandum. 


\section{ARTICLE VIII. Entry into Force and Termination}

This Memorandum shall enter into force upon signature by the Parties and remain in force for three (3) years from that date. It may be amended or extended by mutual written agreement, and may be terminated at any time by either Party upon ninety (90) days' advance written notice to the other Party. The termination of this Memorandum shall not affect the validity or duration of projects under this Memorandum which are initiated prior to such termination.

DONE at Reston and Tsukuba, in duplicate, in English, both texts being equally authentic.

for the

GEOLOGICAL SURVEY OF THE

DEPARTMENT OF THE INTERIOR

OF THE UNITED STATES OF AMERICA:

[Signature]

NAME: Dallas L. Peck

TITLE: Director

DATE: January 3, 1992 for the

PUBLIC WORKS RESEARCH INSTITUTE
OF THE MINISTRY OF CONSTRUCTION
OF JAPAN:

[Signature]

NAME: Toshio Iwasaki

TITLE: Director-General

DATE: February 3, 1992

\section{CERTIFIED TRUE COPY}

[Signature]

DATE: February 25, 1992

Shirley L. Long

Program Assistant

Office of International Geology

U.S. Geological Survey

\section{Addendum}

\section{U.S.-Japan Committee on Hydrology, Water Resources and Global Climate Change}

Pursuant to Article II of this Memorandum of Understanding, the Parties agree to organize a U.S.-Japan Committee on Hydrology, Water Resources and Global Climate Change, hereinafter referred to as "the joint committee," for the purpose of coordination and facilitation of the terms of this agreement. The joint committee will be composed of the following individuals from Japan: the Director General of the Public Works Research Institute or his designee, the Director of the Planning and Research Administration Department or his designee, and the designated leaders of joint projects agreed to under the terms of this Memorandum; and from the United States: the Director of the Geological Survey or his designee, the Chief Hydrologist of the Water Resources Division or his designee, and the designated leaders of joint projects agreed to under the terms of this Memorandum. 


\section{Protocol Extending the Memorandum of Understanding Between the Geological Survey of the Department of the}

Interior of the United States of America and the Public Works Research Institute of the Ministry of Construction of Japan Concerning
Cooperation in the Field of Hydrology,
Water Resources, and Global Climate
Change, Reston and Tsukuba, 1995

Done at Reston 26 January 1995 and Tsukuba 1 February 1995

Entered into force 1 February 1995

Primary source citation: Copy of text provided by the U.S. Department of State

\section{PROTOCOL EXTENDING THE MEMORANDUM OF}

UNDERSTANDING BETWEEN THE GEOLOGICAL SURVEY OF THE DEPARTMENT OF THE INTERIOR OF THE UNITED STATES OF AMERICA AND THE PUBLIC WORKS RESEARCH INSTITUTE

OF THE MINISTRY OF CONSTRUCTION OF JAPAN CONCERNING COOPERATION IN THE FIELD OF HYDROLOGY, WATER RESOURCES, AND GLOBAL CLIMATE CHANGE

The Geological Survey of the Department of the Interior of the United States of America and the Public Works Research Institute of the Ministry of Construction of Japan;

In view of the smooth and steady progress of the cooperation between the Parties; and in order to develop further the scientific and technical cooperation between the two countries in the study of hydrology, water resources, global climate change, and related sciences;

Recognizing that the Memorandum of Understanding between the Geological Survey of the Department of the Interior of the United States of America and the Public Works Research Institute of the Ministry of Construction of 
Japan Concerning Cooperation in the Field of Hydrology, Water Resources, and Global Climate Change, signed at Reston on January 3, 1992, and at Tsukuba on February 3, 1992 (hereinafter referred to as the "Memorandum") will terminate on February 3, 1995;

Acting pursuant to Article VIII;

Have agreed as follows:

\section{Article I}

The Memorandum will remain in force for an additional period of three years beginning on February 3, 1995.

\section{Article II}

This Protocol will enter into force upon signature of both Parties;

DONE at Reston and Tsukuba, in duplicate, in English, both texts being equally authentic.

for the

GEOLOGICAL SURVEY OF THE

DEPARTMENT OF THE INTERIOR

OF THE UNITED STATES OF AMERICA:

Signature [Signature]

Name Gordon P. Eaton

Title Director

Date January 26, 1995 for the

PUBLIC WORKS RESEARCH INSTITUTE OF THE MINISTRY OF CONSTRUCTION OF JAPAN:

$\begin{array}{ll}\text { Signature } & \text { [Signature] } \\ \text { Name } & \text { Takashi Ijima } \\ \text { Title } & \text { Director-General } \\ \text { Date } & \text { February } 1,1995\end{array}$




\title{
Memorandum of Understanding Between the National Science
} Foundation in Washington, D.C., for the United States of America and the Ocean Research Institute of the University of Tokyo in Tokyo, Japan on the Participation of Japan in the Ocean Drilling Program as a Regular Member, Washington, D.C., and Tokyo, 1993

\author{
Done at Washington, D.C. and Tokyo \\ 21 September 1993 \\ Entered into force 21 September 1993, effective \\ 1 October 1993 \\ Primary source citation: Copy of text provided by the \\ U.S. Department of State
}

\section{MEMORANDUM OF UNDERSTANDING}

Between the National Science Foundation in Washington, D.C., for the United States of America and the Ocean Research Institute of the University of Tokyo in Tokyo, Japan, on the participation of Japan in the Ocean Drilling Program as a Regular Member

The Ocean Drilling Program (ODP) is a multinational program of scientific research in the oceans which uses drilling and logging to improve fundamental understanding of the geological history, structure and evolution of the oceanic lithosphere (sediments and crust). The Ocean Drilling Program is a successor to the Deep Sea Drilling Project, which began in 1968, and the International Phase of Ocean Drilling, which began in 1975. During the period October 1983-October 1984, the National Science Foundation, through its contractors, refitted the JOIDES Resolution for scientific ocean drilling and for scientific program operations. Early in U.S. Fiscal Year 1985, the initial nine-year phase of ocean drilling began. By 1991, eight international partners representing 20 nations had become regular supporting members of the ODP.

The Ocean Drilling Program is conducted by contractors, responsible to the National Science Foundation, who carry out the functions of science planning, science operations, and vessel operations. The Joint Oceanographic Institutions for Deep Earth Sampling (JOIDES) is the international body responsible for developing scientific plans and providing general scientific direction for the Ocean Drilling Program. A Science Planning Contractor will organize and provide 
administrative support to JOIDES. In May 1990, JOIDES published a Long Range Plan which identifies scientific priorities and calls for continued international cooperation in ocean drilling extending through the year 2002. JOIDES has subsequently endorsed use of the JOIDES Resolution as the primary facility for ODP coring and logging through at least 1998.

Accordingly, the National Science Foundation and the Ocean Research Institute of the University of Tokyo agree to continue cooperation in the Ocean Drilling Program during at least the period 1 October 1993 to 30 September 1998, in accordance with the following articles:

\section{Article 1 - MEMBERSHIP STATUS}

The Ocean Research Institute of the University of Tokyo elects to be a regular member in the Ocean Drilling Program with rights, privileges, and financial commitments as defined. All cooperative activities under this agreement shall be conducted within the limits of available funds.

\section{Article 2 - DURATION}

The Ocean Research Institute of the University of Tokyo endorses continued cooperation in ocean drilling activities, with commitment, in principle, as a regular member to support of the Ocean Drilling Program in the period 1 October 1993 to 30 September 1998.

\section{Article 3 - SCIENTIFIC PLANNING}

Scientific planning and direction of the Ocean Drilling Program shall be the responsibility of JOIDES. The Ocean Research Institute of the University of Tokyo will be a member of JOIDES with the right to be represented on each committee, panel, or working group thereof. International membership and representation in JOIDES is restricted to regular members, including consortia, but excluding the individual members of consortia. The contractors will submit, to the Executive Committee of JOIDES, the annual program plan and budgets for approval prior to their adoption by the National Science Foundation.

\section{Article 4 - OCEAN DRILLING PROGRAM COUNCIL}

Japan is a participating country of the Ocean Drilling Program and a member of the Ocean Drilling Program Council. The members of the Council will be representatives of each country contributing to the support of the Ocean Drilling Program, regardless of whether it is participating as an individual member or as a member of a consortium. Members of the Council and their alternates will be designated by the participating countries. There will be one representative of each participating country, except that additional representation from the United States may be appropriate.

The Council shall serve as a consultative body reviewing financial, managerial, and other matters involving the overall support of the Ocean Drilling Program. The Council shall provide a forum for exchange of views among the contributing countries. No formal voting procedures will be established.

The National Science Foundation representative will serve as permanent Chairman of the Council. A formal agenda will be prepared for each meeting and written records of each meeting will be kept. The National Science Foundation will provide secretariat services to the Council.

The Council will normally meet once each year. The agenda of the annual meeting shall include a financial report and discussion, an audit report, a review of scientific and technical achievements for the past year, an examination of the draft program plans and budgets for the coming year, and other topics of mutual interest. Normally, all regular meetings of the Council will be scheduled in conjunction with the JOIDES Executive Committee meeting for review and approval of the annual program plans and budgets. 
Liaison representatives of prime contractors and important scientific planning entities will be available to the Council.

\section{Article 5 - RIGHT TO MAKE PROPOSALS; DATA PRIVILEGES}

The Ocean Research Institute of the University of Tokyo will have the right:

a) to make proposals to JOIDES of scientific projects or technical objectives of interest to Japan.

b) to participate in the analysis, and have access to the data, of geophysical and other site surveys performed in support of the program.

c) to have access to all engineering plans, data or other information developed under contracts supported as program costs.

Site surveys may be contributed by Japan as its scientific interests and available resources allow. Site survey requirements will be identified by JOIDES.

\section{Article 6 - VISA AND CUSTOMS FACILITATION}

The National Science Foundation will facilitate without undue delay through collaboration with the appropriate authorities the granting of visas and other forms of official permission for entry to and exit from the United States of personnel, equipment, and supplies when required for participation or utilization in the Ocean Drilling Program.

\section{Article 7 - PARTICIPATION ON BOARD THE ODP DRILLSHIP}

The Science Operations Contractor, with the advice of JOIDES, selects the scientific team for each cruise. It is expected that approximately half of the scientists invited to serve as co-chief scientists will be representatives of the United States. It is expected that a scientist representing Japan will be invited to serve as co-chief scientist on an Ocean Drilling Program cruise per annum. Normally, space will be available for two scientists representing Japan on the research cruises of the ODP drillship. It is recognized that some cruises may be of special scientific interest to Japanese scientists and increased participation by scientists of Japan on these cruises may be appropriate. Japan will have the opportunity to participate in technical parties on Ocean Drilling Program cruises.

\section{Article 8 - INITLAL REPORTS OF THE OCEAN DRILLING PROGRAM}

Scientists from Japan will have access, through the Ocean Research Institute of the University of Tokyo, to Ocean Drilling Program data and core samples. The Ocean Research Institute of the University of Tokyo will endeavor to ensure that the participating Japanese scientists and institutions shall provide the scientific data resulting from site surveys and laboratory analyses in time for preparation of the Proceedings of the Ocean Drilling Program or their equivalent. One hundred copies of each volume of the official scientific publications will be provided to the Ocean Research Institute of the University of Tokyo for free distribution among scientific establishments in Japan. These volumes may be published in Japan in full or in part, without payments to or additional agreements with the United States. The Ocean Research Institute of the University of Tokyo will provide the National Science Foundation with copies of all publications from Japan that are based on program material. 


\section{Article 9 - FINANCIAL CONTRIBUTION}

The Ocean Research Institute of the University of Tokyo will support the Ocean Drilling Program with financial contributions payable to the National Science Foundation in U.S. dollars in amounts and periods to be specified by Annex A to this Memorandum of Understanding.

The financial contributions of all participants will be commingled to support the total program costs. "Program costs" are determined by the National Science Foundation, and are those costs incurred in support of contractors performing functions for joint planning and operations of the Ocean Drilling Program, and program direction and management costs incurred by the National Science Foundation which relate to international participation. The costs incurred in the activities which may be carried out by the National Science Foundation's contractors in direct support of United States scientific undertakings are not program costs and will not be funded from commingled accounts.

\section{Article 10 - SALARIES, TRAVEL, AND EXPENSES}

Salaries and travel expenses for participants representing Japan will be borne by Japan. Costs of accommodations for Japanese scientists and members of technical parties aboard the drillship are program costs and will be funded by the Ocean Drilling Program. The National Science Foundation's contractors will render Japanese scientists needed assistance when going from an airport to the drillship.

\section{Article 11 - CONSULTATION}

Meetings of the representatives of the National Science Foundation and representatives of the Ocean Research Institute of the University of Tokyo may be held at any time upon the request of either party to discuss the terms and conditions of this Memorandum of Understanding and other matters of mutual interest.

\section{Article 12 - TERMINATION NOTICE}

Obligations arising from this Memorandum of Understanding may be terminated by either party giving the other party written notice at least one year in advance. Provisions for refunds of contributions, arising out of unilateral termination, are specified in Annex A.

Done in Washington, DC, U.S.A. and Tbkyo, Japan in the English and Japanese languages, both versions being equally authoritative.

by:

Tetsuya Hirano

Director

Ocean Research Institute of

the University of Tokyo

[Signature]

on:

September 21, 1993

Date by:

Frederick M. Bernthal

Acting Director

National Science Foundation

[Signature]

on:

21 September 1993

Date 


\section{ANNEX A \\ to the Memorandum of Understanding Between the National Science Foundation and the Ocean Research Institute of the University of Tokyo on the Participation of Japan in the Ocean Drilling Program as a Regular Member \\ Financial Contribution for the U.S. Fiscal Year 1994}

The Ocean Research Institute of the University of Tokyo will support, subject to the budget process, the Ocean Drilling Program with a total contribution of United States two million nine hundred fifty thousand dollars (U.S. $\$ 2,950,000$ ) for the period October 1, 1993 to September 30, 1994, calculated at the rate of $\$ 245,833.33$ per month of drilling operations. The National Science Foundation will bill the Ocean Research Institute for this sum in accordance with the following schedule:

- On or about October 1,$1993 ; \$ 983,334$

- On or about May 1,$1994 ; \$ 1,966,666$

Should the Ocean Drilling Program be terminated before September 30, 1994, Japan will be reimbursed on the basis of one-twelfth of its contribution for each month of curtailment. Should Japan withdraw from the Program, under the terms of Article 12 above, no refunds of contributions will be made.

Done in Washington, DC, U.S.A. and Tokyo, Japan in the English and Japanese languages, both of which shall be equally authoritative.

by:

Tetsuya Hirano

Director

Ocean Research Institute of

the University of Tokyo

[Signature]

on:

September 21, 1993

Date by:

Frederick M. Bernthal

Acting Director

National Science Foundation

[Signature]

on:

21 September 1993

Date 



\section{JAPAN}





\title{
Agreement Between the Government of the United States of America and the Government of Japan Establishing a Consultative Committee on Fisheries, Washington, D.C., 1992
}

\author{
Done at Washington, D.C., 27 January 1992 \\ Entered into force 27 January 1992 \\ Primary source citation: Copy of text provided by the \\ U.S. Department of State
}

The Department of State refers to the longstanding cooperation between the United States of America and Japan in the field of fisheries and fisheries research. The Department wishes to inform the Embassy of Japan that the Government of the United States of America intends to promote further such bilateral cooperation and for this purpose proposes the establishment of a Consultative Committee between the two Governments (hereinafter referred to as "the Committee") which may be organized along the following lines:

1. The Committee will consist of one representative from each Government as well as support staff and advisors and will discuss issues relating to fisheries resources and other living marine resources of mutual concern.

2. The Committee will meet on an annual basis, or at other times as may be considered appropriate. The venue for the Committee will be decided each time it is to meet.

3. The Committee may, from time to time, establish working groups of experts to consider further efforts to enhance bilateral cooperation in such areas as fisheries research, fisheries conservation, fisheries enforcement, etc.

The Department looks forward to a response to the above proposal from the Government of Japan.

Department of State,

Washington, January 27, 1992.

EMBASSY OF JAPAN WASHINGTON

E-8

January 27, 1992

The Embassy of Japan presents its compliments to the Department of State and has the honor to refer to the Department's Note Verbale of January 27, 1992, and has further the honor to inform the latter that the Government of Japan shares the views described in the aforementioned Note Verbale with respect to the promotion of bilateral cooperation in the field of fisheries and fisheries research. The Government of Japan also wishes to establish a 
Consultative Committee between the Governments of Japan and the United States of America (hereinafter referred to as "the Committee"), which may be organized along the following lines:

1. The Committee will consist of one representative from each Government as well as support staff and advisors and will discuss issues relating to fisheries resources and other living marine resources of mutual concern.

2. The Committee will meet on an annual basis, or at other times as may be considered appropriate. The venue for the Committee will be decided each time it is to meet.

3. The Committee may, from time to time, establish working groups of experts to consider further efforts to enhance bilateral cooperation in such areas as fisheries research, fisheries conservation, fisheries enforcement, etc.

[seal] 


\title{
Agreement Between the Government of the United States of America and the Government of Japan on Maritime Fishing Boundaries, Tokyo, 1994
}

\author{
Done at Tokyo 5 July 1994 \\ Entered into force $5 \mathrm{July} 1994$ \\ Primary source citation: Copy of text provided by the \\ U.S. Department of State
}

Translation

MINISTRY OF FOREIGN AFFAIRS

TOKYO, JAPAN

No. 112/NA-1

\section{NOTE VERBALE}

The Ministry of Foreign Affairs presents its compliments to the Embassy of the United States of America and has the honor to refer to recent consultations regarding the line of delimitation between the fishing zone of Japan established in accordance with the Law on Provisional Measures relating to the Fishing Zone in force as from July 1, 1977 (hereinafter "the Japanese Zone") and the Exclusive Economic Zone of the United States of America established in accordance with Proclamation 5030, March 10, 1983, by the President of the United States of America (hereinafter "the U.S. Zone"). following:

The Ministry of Foreign Affairs has further the honor to confirm that the Government of Japan recognizes the

1. The Japanese Zone and the U.S. Zone are contiguous in the area off the coasts of Minami Iwo Jima and Farallon de Pajaros.

2. Each government has established, in accordance with its laws and regulations, and consistent with international law, the outer limit of its zone in the aforementioned area as a line every point of which is equidistant, and located within 200 nautical miles, from the nearest points of the baseline which is provided in paragraph 1 of Article 2 of the Law on the Territorial Sea of Japan and from the nearest points on the baseline from which the breadth of the territorial sea of the United States of America is measured.

3. The coordinates for such line are shown in subparagraph (a) below in accordance with Tokyo Datum, which is applied in Japan, and in subparagraph (b) below in accordance with the World Geodetic System 1984 (WGS 84), which is applied in the United States of America, respectively. 
(a) Tokyo Datum
latitude (north)
longitude (east)
1. $23-53^{\prime} 18^{\prime \prime}$
145-05'57"
2. 23-44'15"
144-54'16"
3. 23-33' $35^{\prime \prime}$
144-40 $34^{\prime \prime}$
4. 23-15'53"
144-17'58"
5. $22-49^{\prime} 56^{\prime \prime}$
143-45'08"
6. 22-17' $56^{\prime \prime}$
143-05'12"
7. 21-53'41"
$142-35^{\prime} 13^{\prime \prime}$
8. 21-41'57"
142-20'49"
9. $21-39^{\prime} 50^{\prime \prime}$
$142-18^{\prime} 15^{\prime \prime}$
10. 21-28'03"
142-03'55"
11. $20-58^{\prime} 06^{\prime \prime}$
141-27'43"
12. $20-52^{\prime} 34^{\prime \prime}$
141-21'04"

(b) World Geodetic System 1984 (WGS 84)

latitude (north) longitude (east)
1. 23-53' $35^{\prime \prime}$
145-05'46"
2. 23-44' $32^{\prime \prime}$
144-54'05"
3. 23-33' $52^{\prime \prime}$
$144-40^{\prime} 23^{\prime \prime}$
4. 23-16'11"
144-17'47"
5. 22-50'13"
$143-44^{\prime} 57^{\prime \prime}$
6. 22-18'13"
143-05'02"
7. 21-53'58"
142-35'03"
8. 21-42'14"
142-20'39"
9. $21-40^{\prime} 08^{\prime \prime}$
142-18 $05^{\prime \prime}$
10. 21-28' $21^{\prime \prime}$
142-03' $45^{\prime \prime}$
11. $20-58^{\prime} 24^{\prime \prime}$
141-27'33"
12. $20-52^{\prime} 51^{\prime \prime}$
$141-20^{\prime} 54^{\prime \prime}$

4. The aforementioned line constitutes the line of delimitation between the Japanese and U.S. Zones, and each government will modify its charts and other relevant publications concerning the aforementioned coordinates as necessary.

5. This note verbale and its contents shall not be deemed to prejudice the positions or views of the Government of Japan or the Government of the United States of America with respect to matters relating to the law of the sea.

The Ministry of Foreign Affairs would appreciate a note verbale in response confirming that the Government of the United States of America recognizes the foregoing.

Tokyo, July 5, 1994. 
Embassy of the United States of America

Tokyo, Japan, July 5, 1994

No. 406

\section{NOTE VERBALE}

The Embassy of the United States of America presents its compliments to the Ministry of Foreign Affairs and has the honor to acknowledge receipt of the Ministry's Note Verbale No. 112/NA-1 dated July 5, 1994, which reads as follows:

The Ministry of Foreign Affairs presents its compliments to the Embassy of the United States of America and has the honor to refer to recent consultations regarding the line of delimitation between the fishing zone of Japan established in accordance with the Law on Provisional Measures relating to the Fishing Zone in force as from July 1, 1977 (hereinafter "the Japanese Zone") and the Exclusive Economic Zone of the United States of America established in accordance with Proclamation 5030, March 10, 1983, by the President of the United States of America (hereinafter "the U.S. Zone").

The Ministry of Foreign Affairs has the further honor to confirm that the Government of Japan recognizes the following:

1. The Japanese Zone and the U.S. Zone are contiguous in the area off the coasts of Minami Iwo Jima and Farallon de Pajaros.

2. Each government has established, in accordance with its laws and regulations, and consistent with international law, the outer limit of its zone in the aforementioned area as a line every point of which is equidistant, and located within 200 nautical miles, from the nearest points of the baseline which is provided in paragraph 1 of Article 2 of the Law on the Territorial Sea of Japan and from the nearest points on the baseline from which the breadth of the territorial sea of the United States of America is measured.

3. The coordinates for such line are shown in subparagraph (a) below in accordance with Tokyo Datum, which is applied in Japan, and in subparagraph (b) below in accordance with the World Geodetic System 1984 (WGS 84), which is applied in the United States of America, respectively.

(a) Tokyo Datum

latitude (north) longitude (east)

1. $23^{\circ} 53^{\prime} 18^{\prime \prime}$

$145^{\circ} 05^{\prime} 57^{\prime \prime}$

2. $23^{\circ} 44^{\prime} 15^{\prime \prime}$

$144^{\circ} 54^{\prime} 16^{\prime \prime}$

3. $23^{\circ} 33^{\prime} 35^{\prime \prime}$

$144^{\circ} 40^{\prime} 34^{\prime \prime}$

4. $23^{\circ} 15^{\prime} 53^{\prime \prime}$

$144^{\circ} 17^{\prime} 58^{\prime \prime}$

5. $22^{\circ} 49^{\prime} 56^{\prime \prime}$

$143^{\circ} 45^{\prime} 08^{\prime \prime}$

6. $22^{\circ} 17^{\prime} 56^{\prime \prime}$

$143^{\circ} 05^{\prime} 12^{\prime \prime}$

7. $21^{\circ} 53^{\prime} 41^{\prime \prime}$

$142^{\circ} 35^{\prime} 13^{\prime \prime}$

8. $21^{\circ} 41^{\prime} 57^{\prime \prime}$

$142^{\circ} 20^{\prime} 49^{\prime \prime}$

9. $21^{\circ} 39^{\prime} 50^{\prime \prime}$

$142^{\circ} 18^{\prime} 15^{\prime \prime}$

10. $21^{\circ} 28^{\prime} 03^{\prime \prime}$

$142^{\circ} 03^{\prime} 55^{\prime \prime}$

11. $20^{\circ} 58^{\prime} 06^{\prime \prime}$

$141^{\circ} 27^{\prime} 43^{\prime \prime}$

12. $20^{\circ} 52^{\prime} 34^{\prime \prime}$

$141^{\circ} 21^{\prime} 04^{\prime \prime}$ 
(b) World Geodetic System 1984 (WGS 84)

latitude (north) longitude (east)
1. $23^{\circ} 53^{\prime} 35^{\prime \prime}$
$145^{\circ} 05^{\prime} 46^{\prime \prime}$
2. $23^{\circ} 44^{\prime} 32^{\prime \prime}$
$144^{\circ} 54^{\prime} 05^{\prime \prime}$
3. $23^{\circ} 33^{\prime} 52^{\prime \prime}$
$144^{\circ} 40^{\prime} 23^{\prime \prime}$
4. $23^{\circ} 16^{\prime} 11^{\prime \prime}$
$144^{\circ} 17^{\prime} 47^{\prime \prime}$
5. $22^{\circ} 50^{\prime} 13^{\prime \prime}$
$143^{\circ} 44^{\prime} 57^{\prime \prime}$
6. $22^{\circ} 18^{\prime} 13^{\prime \prime}$
$143^{\circ} 05^{\prime} 02^{\prime \prime}$
7. $21^{\circ} 53^{\prime} 58^{\prime \prime}$
$142^{\circ} 35^{\prime} 03^{\prime \prime}$
8. $21^{\circ} 42^{\prime} 14^{\prime \prime}$
$142^{\circ} 20^{\prime} 39^{\prime \prime}$
9. $21^{\circ} 40^{\prime} 08^{\prime \prime}$
$142^{\circ} 18^{\prime} 05^{\prime \prime}$
10. $21^{\circ} 28^{\prime} 21^{\prime \prime}$
$142^{\circ} 03^{\prime} 45^{\prime \prime}$
11. $20^{\circ} 58^{\prime} 24^{\prime \prime}$
$141^{\circ} 27^{\prime} 33^{\prime \prime}$
12. $20^{\circ} 52^{\prime} 51^{\prime \prime}$
$141^{\circ} 20^{\prime} 54^{\prime \prime}$

4. The aforementioned line constitutes the line of delimitation between the Japanese and U.S. Zones, and each government will modify its charts and other relevant publications concerning the aforementioned coordinates as necessary.

5. This note verbale and its contents shall not be deemed to prejudice the positions or views of the Government of Japan or the Government of the United States of America with respect to matters relating to the law of the sea.

The Ministry of Foreign Affairs would appreciate a note verbale in response confirming that the Government of the United States of America recognizes the foregoing. foregoing.

The Embassy has the honor to confirm that the Government of the United States of America recognizes the

The Embassy avails itself of this opportunity to renew to the Foreign Ministry the assurances of its highest consideration. 


\section{B I L A T E $\mathbf{R}$ A $\mathbf{L}$}

\section{KAZAKHSTAN, REPUBLIC OF}

ENVIRONMENTAND NATURAL RESOURCES 



\section{Agreement Between the Government of the United States of America and the Government of the Republic of Kazakhstan on Cooperation in the Fields of Protection of the Environment and Natural Resources, Washington, D.C., 1995}

Done at Washington, D.C. 27 March 1995

Entered into force 27 March 1995

Primary source citation: Copy of text provided by the U.S. Department of State

\section{AGREEMENT BETWEEN THE GOVERNMENT OF THE UNITED STATES OF AMERICA AND THE GOVERNMENT OF THE REPUBLIC OF KAZAKHSTAN ON COOPERATION IN THE FIELDS OF PROTECTION OF THE ENVIRONMENT AND NATURAL RESOURCES}

The Government of the United States of America and the Government of the Republic of Kazakhstan, hereinafter referred to as the Parties;

Recognizing that many important environmental problems are global in nature and require the cooperation of all countries and peoples to resolve;

Attaching great significance to the protection and enhancement of the environment and to its preservation from the damage resulting from pollution and overuse;

Bearing in mind that sustainable economic and social development for the benefit of present and future generations already now requires effective measures to be taken for the protection and enhancement of the environment;

Considering the readiness of the Parties to cooperate to enable the Republic of Kazakhstan better to take into account environmental issues and the rational and sustainable use of natural resources in the transition to a market economy and thereafter;

Desiring to facilitate the establishment of closer, longer-term cooperation between interested organizations in the two countries in the field of protection of the environment and natural resources; 
Have agreed as follows:

\section{ARTICLE I}

1. The Parties shall work to develop cooperation in the field of protection of the environment and natural resources on national, regional, and global levels. Their activity shall focus on studying harmful impacts on the environment and jointly developing measures to improve the condition of the environment and to solve problems of the protection and rational and sustainable use of natural resources, including work on the areas of pollution prevention and remediation and preservation and conservation of natural resources.

2. The Parties shall work together to develop mutually agreed-upon policies in the field of protection of the environment and natural resources on a bilateral, regional and global basis.

3. The Parties shall develop cooperation in the field of protection of the environment and natural resources on a basis of equality, reciprocity and mutual benefit.

\section{ARTICLE II}

Cooperation may be implemented in the following main areas of mutual interest:

1. atmosphere, and water and soil resources;

2. environmental aspects of agricultural production;

3. preservation, conservation and management of natural resources, including the organization of preserves and other specially protected areas;

4. global environmental issues, including climate change, depletion of the ozone layer and conservation and restoration of the biological diversity of local, regional and global ecological systems, including forest ecosystems;

5. the impact of environmental factors on human health, human activity, and the condition of flora and fauna;

6. energy-saving measures and creation of alternative energy sources;

7. legal and administrative measures relating to the protection of the environment, including legislation, enforcement and access to the administrative and judicial systems;

8. participation of the public, including nongovernmental organizations, in environmental decision making;

9. economics and the management of environmental issues and the use of natural resources;

10. environmental testing and analysis and monitoring;

11. the Caspian and Aral Seas;

12. the effects of radioactive materials and;

13. any other areas of cooperation agreed by the Parties.

\section{ARTICLE III}

Cooperation between the Parties may be implemented by the following means:

1. joint scientific and technical projects; 
2. exchange of scientific and technical information, documentation and research results, and exchange of information on the condition of the environment;

3. exchange of experience in the area of environmental management and human resources;

4. bilateral meetings, symposia and workshops, and publication of reports, articles, and monographs;

5. exchange of delegations, scientists, experts, research scholars and specialists;

6. participation of specialists of the Parties in international conferences, symposia and exhibitions on the environment and ecology in the two countries;

7. any other means agreed by the Parties.

\section{ARTICLE IV}

The Parties shall duly encourage and facilitate the establishment and development of direct contacts and cooperation between governmental, public, and private institutions and organizations of the two countries, and encourage and facilitate the conclusion, where required, of separate agreements and contracts necessary to implement activities under this Agreement.

\section{ARTICLE V}

To administer this Agreement, each Party shall name a government agency to act as coordinator of its activities under this Agreement. Each coordinator shall review specific measures and programs of cooperation, coordinate the participation of organizations involved in implementation of these programs, and, as appropriate, shall make recommendations to the Parties on the subject matter of this Agreement. The coordinators may communicate and meet with each other as is necessary to carry out the purposes of this Agreement.

\section{ARTICLE VI}

1. Scientific and technological information of a non-proprietary nature resulting from cooperation under this Agreement as a result of commercial or industrial activities, shall be made available, unless otherwise agreed, to the world scientific community through customary channels and in accordance with normal procedures of the participating agencies and entities.

2. The treatment of intellectual property created or furnished in the course of cooperative activities under this Agreement is provided for in the Annex, which is an integral part of this Agreement, and shall apply to all activities conducted under the auspices of this Agreement unless agreed otherwise by the Parties or their designees in writing.

\section{ARTICLE VII}

This Agreement supersedes, as between the Government of the United States of America and the Government of the Republic of Kazakhstan, the Agreement between the Government of the United States of America and the Government of the Union of Soviet Socialist Republics on Cooperation in the Field of Environmental Protection of May 23, 1972. 


\section{ARTICLE VIII}

1. This Agreement enters into force upon signature and shall remain in force for five years, after which it shall be extended for successive five-year periods. Either Party may terminate this Agreement by providing written notification to the other Party through the diplomatic channel, such termination to take effect six months from the date of the notification.

2. Termination of this Agreement shall not affect the implementation of activities under this Agreement that are not fully completed upon the termination hereof.

\section{ARTICLE IX}

All activities under this Agreement shall be conducted in accordance with applicable laws, regulations and procedures of the United States of America and the Republic of Kazakhstan and shall be subject to the availability of funds and personnel.

In Witness Whereof the undersigned, being duly authorized by their respective Governments, have signed this Agreement.

Done at Washington, this twenty-seventh day of March 1995, in duplicate, in the English, Kazakh, and Russian languages, all texts being equally authentic.

\section{FOR THE GOVERNMENT OF THE \\ UNITED STATES OF AMERICA:}

$\begin{array}{ll}\text { [Signature] } & \text { [Signature] }\end{array}$

\author{
FOR THE GOVERNMENT OF THE \\ REPUBLIC OF KAZAKHSTAN:
}

\section{ANNEX}

\section{INTELLECTUAL PROPERTY}

Pursuant to Article VI of this Agreement:

The Parties shall endure adequate and effective protection of intellectual property created or furnished under this Agreement and relevant implementing arrangements thereto. The Parties agree to notify one another in a timely fashion of any inventions or copyrighted works arising under this Agreement and to seek protection for such intellectual property in a timely fashion. Rights to such intellectual property shall be allocated as provided in this Annex.

\section{SCOPE}

A. This Annex is applicable to all cooperative activities undertaken pursuant to this Agreement, except as otherwise specifically agreed to by the Parties or their designees.

B. For purposes of this Agreement, "intellectual property" shall have the meaning found in Article 2 of the Convention Establishing the World Intellectual Property Organization, done at Stockholm, July 14, 1967.

C. This Annex addresses the allocation of rights, interests, and royalties between the Parties. Each Party shall ensure that the other Party can obtain the rights to intellectual property allocated in accordance with the Annex, by obtaining those rights from its own participants through contracts or other legal means, if necessary. This Annex does not otherwise alter or prejudice the allocation between a Party and its nationals, which shall be determined by that Party's laws and practices. 
D. Disputes concerning intellectual property arising under this Agreement shall be resolved through discussions between the concerned participating institutions or, if necessary, the Parties or their designees. Upon mutual agreement of the Parties, a dispute shall be submitted to an arbitral tribunal for binding arbitration in accordance with the applicable rules of international law. Unless the Parties or their designees agree otherwise in writing, the arbitration rules of the UNCITRAL shall govern.

E. Termination or expiration of this Agreement shall not affect rights or obligations under this Annex.

\section{ALLOCATION OF RIGHTS}

A. Each Party shall be entitled to a non-exclusive, irrevocable, royalty-free license in all countries to translate, reproduce, and publicly distribute scientific and technical journal articles, reports, and books directly arising from cooperation under this Agreement. All publicly distributed copies of a copyrighted work prepared under this provision shall indicate the names of the authors of the work unless an author explicitly declines to be named.

B. Rights to all forms of intellectual property, other than those rights described in Part A of Section 2 above, shall be allocated as follows:

1. Researchers and scientists visiting in furtherance of their education shall receive intellectual property rights under the existing rules of the host institution. In addition, each visiting researcher named as an inventor or author shall have the right to national treatment regarding awards, benefits or other compensation, including royalties, in accordance with the existing rules of the host institution.

2. (a) For intellectual property created by the participants during joint research, for example, when the Parties, participating institutions, or participating personnel have agreed in advance on the scope of work, each Party shall be entitled to obtain all rights and interests in its own territory. The allocation of rights and interests in third countries will be determined in implementing arrangements. The rights to intellectual property shall be allocated with due regard for the economic, scientific, and technological contributions from each Party to the creation of intellectual property. If research is not designated as "joint research" in the relevant implementing arrangement, rights to intellectual property arising from the research shall be allocated in accordance with Part 3, paragraph 1 of Section 2. In addition, each person named as an inventor or author shall have the right to national treatment regarding awards, benefits and other compensation, including royalties, in accordance with the existing rules of the host institution.

(b) Notwithstanding Part B, paragraph 2(a) of Section 2, if a type of intellectual property is available under the laws of one Party but not the other Party, the Party whose laws provide for this type of protection shall be entitled to all rights and interests in all countries which provide rights in such intellectual property. Persons named as inventors or authors of the property shall nonetheless be entitled to national treatment in regard to awards, benefits, or other compensations, including royalties, in accordance with the rules as provided in Part B, paragraph 2(a) of Section 2.

\section{BUSINESS CONFIDENTIAL INFORMATION}

In the event that information identified in a timely fashion as business-confidential is furnished or created under the Agreement, each Party and its participants shall protect such information in accordance with applicable laws, regulations, and administrative practice. Information may be identified as "business-confidential" if a person having the information may derive an economic benefit from it or may obtain a competitive advantage over those who do not have it, the information is not generally known or publicly available from other sources, and the owner has not previously made the information available without imposing in a timely manner an obligation to keep it confidential. 


\section{Agreement Between the Government of the United States of America and the Government of the Republic of Kazakhstan for Cooperation in the GLOBE Program, Washington, D.C., 1995}

Done at Washington, D.C. 27 March 1995

Entered into force 27 March 1995

Primary source citation: Copy of text provided by the

U.S. Department of State

\section{AGREEMENT BETWEEN THE GOVERNMENT OF THE UNITED STATES OF AMERICA AND THE GOVERNMENT OF THE REPUBLIC OF KAZAKHSTAN FOR COOPERATION IN THE GLOBE PROGRAM}

\section{PREAMIBLE}

The Government of the United States of America and the Government of the Republic of Kazakhstan (hereinafter, the sides)

Intending to increase the awareness of students throughout the world about the global environment,

Seeking to contribute to increased scientific understanding of the Earth, and

Desiring to support improved student achievement in science and mathematics,

Have agreed to cooperate in the Global Learning and Observations to Benefit the Environment (GLOBE) Program as follows:

\section{ARTICLE 1 - THE GLOBE PROGRAM}

The GLOBE Program is an international environmental science and education program that will bring students, teachers, and scientists together to study the global environment. GLOBE will create an international network of students in grades K-12 (or equivalent) studying environmental issues, making environmental measurements, and sharing useful environmental data with the international environmental science community. 


\section{ARTICLE 2 - COOPERATING AGENCIES}

Agencies responsible for cooperation and coordination under this agreement are:

On the U.S. side, the U.S. National Oceanic and Atmospheric Administration, acting in conjunction with other U.S. Government agencies participating in the GLOBE Program;

On the Kazakhstani side, the Ministry of Ecology and Biological Resources, acting in conjunction with the Ministry of Education and other Kazakhstani agencies participating in the GLOBE Program.

\section{ARTICLE 3 - RESPECTIVE RESPONSIBILITIES}

A. The U.S. side will:

1. Identify U.S. schools that will participate in the GLOBE Program (details regarding GLOBE schools in Appendix A);

2. Select, in consultation with international scientists and educators, the GLOBE environmental measurements and types of measurement equipment (described in Appendix B);

3. Select Principal Investigator Teams for the GLOBE environmental measurements, and support the U.S. members of the Teams;

4. Calibrate, if necessary, measurement equipment that cannot be calibrated by GLOBE teachers and students;

5. Develop, in consultation with international scientists and educators, GLOBE educational materials;

6. Translate GLOBE instructional materials related to measurement procedures and data reporting protocols into the six United Nations languages, and provide these plus all broader GLOBE educational materials to the Kazakhstani side for further reproduction as necessary;

7. Conduct annual regional training sessions for GLOBE Country Coordinators and GLOBE teachers who will serve as trainers for additional GLOBE teachers in Kazakhstan, and provide a copy of GLOBE training materials to the Kazakhstani side;

8. Design, develop, operate, and maintain GLOBE data processing capabilities and other necessary technology and equipment;

9. Provide GLOBE software, as necessary, for use on Kazakhstani GLOBE school computers. (To the maximum extent possible, textual material appearing on computer screens will be accessible in the student's choice among the six United Nations languages.);

10. Accept environmental data reported from GLOBE schools around the world, and develop and provide resultant global environmental images (visualization products) to the Kazakhstani side; and

11. Evaluate the overall GLOBE Program periodically, in consultation with international GLOBE Country Coordinators, and modify the overall program as appropriate.

B. The Kazakhstani side will:

1. Select Kazakhstani schools to participate in the GLOBE Program (details regarding GLOBE schools in Appendix A) and provide an updated list of Kazakhstani GLOBE schools to the U.S. side at the beginning of each school year;

2. Ensure that Kazakhstani GLOBE schools conduct the fundamental activities of GLOBE schools detailed in Appendix A (take GLOBE environmental measurements, report data, and receive and use resultant 
global environmental images, using GLOBE educational materials under the guidance of teachers trained to conduct the GLOBE Program);

3. Name a Kazakhstani Government Point of Contact responsible for policy-level communications with the Director of the GLOBE Program;

4. Name a Country Coordinator responsible for day-to-day management, oversight, and facilitation of the GLOBE Program in Kazakhstan;

5. Ensure that the Country Coordinator and some GLOBE teachers attend GLOBE regional training and in turn provide GLOBE training to at least one teacher in each Kazakhstani GLOBE school;

6. Ensure that GLOBE instructional materials related to measurement procedures and data reporting protocols are utilized in Kazakhstani GLOBE schools, and that broader GLOBE educational materials are appropriately translated, adapted, reproduced, and distributed to all Kazakhstani GLOBE schools;

7. Ensure that Kazakhstani GLOBE schools have the necessary measurement equipment to take GLOBE environmental measurements (described in Appendix B);

8. Ensure that teachers and students at Kazakhstani GLOBE schools calibrate GLOBE measurement equipment according to procedures provided in GLOBE instructional materials;

9. Ensure that Kazakhstani GLOBE schools have the necessary computer and communications systems (described in Appendix C) to report GLOBE environmental measurements and to receive and use GLOBE visualization products, or make agreed alternative arrangements for such reporting and receipt. (At a minimum, the Kazakhstani Country Coordinator will need access to Internet so that all measurement data from Kazakhstani GLOBE schools will be reported via Internet.); and

10. Evaluate GLOBE operations in Kazakhstan periodically and assist the U.S. side in conducting periodic evaluation of the overall GLOBE Program.

\section{ARTICLE 4 - FINANCIAL ARRANGEMENTS}

Each side will bear the costs of fulfilling its respective responsibilities under this agreement. Obligations of each side pursuant to this agreement are subject to its respective funding procedures and the availability of appropriated funds, personnel, and other resources. The conduct of activities under this agreement will be consistent with the relevant laws and regulations of the two sides.

\section{ARTICLE 5 - EXCHANGE OF DATA AND GOODS}

GLOBE environmental measurement data, visualization products, software, and educational materials will be available worldwide without restriction as to their use or redistribution.

\section{ARTICLE 6 - RELEASE OF INFORMATION ABOUT THE GLOBE PROGRAM}

Each side may release information on the GLOBE Program as it may deem appropriate without prior consultation with the other. 


\section{ARTICLE 7 - CUSTOMS AND IMMIGRATION}

To the extent permitted by its laws and regulations, each side will facilitate the entry of persons and the duty-free importation of goods into its territory, as well as the departure of persons and the exportation of the aforementioned goods, necessary to implement its activities under this agreement.

\section{ARTICLE 8 - ENTRY INTO FORCE, AMENDMENTS, WITHDRAWAL}

This agreement will enter into force upon signature of the two sides and will remain in force for five years. It will be automatically extended for further five-year periods, unless either side decides to terminate it and so notifies the other side with three months written notice. This agreement may be terminated at any time by either side upon three months prior written notice to the other side. This agreement may be amended by written agreement of the two sides.

Done at Washington on the twenty-seventh day of March, 1995, in duplicate, in the English, Russian, and Kazakh languages, all texts being equally authentic.

FOR THE GOVERNMENT OF THE UNITED STATES OF AMERICA:

[Signature]
FOR THE GOVERNMENT OF THE REPUBLIC OF KAZAKHSTAN:

[Signature]

\section{APPENDIX A GLOBE Schools}

Each partner country will be responsible for identifying its participating schools. Schools should be selected so as to satisfy the objectives of the GLOBE Program. In particular, countries should emphasize the selection of schools that will maximize the number of students worldwide participating in the program. Also, countries should consider involving schools in locations that will yield measurement data that is important to the international environmental science community.

Students at all GLOBE schools throughout the world will conduct the following fundamental activities: they will make environmental measurements at or near their schools; report their data to a GLOBE data processing site; receive vivid graphical global environmental images (visualization products) created from their data and the data from other GLOBE schools around the world; and study the environment by relating their observations and the resulting visualization products to broader environmental topics. All of these activities will be conducted under the guidance of specially trained teachers (GLOBE-trained teachers).

GLOBE educational materials will be used in GLOBE schools under the guidance of GLOBE-trained teachers. These materials will detail procedures for taking environmental measurements and protocols for reporting data; explain the significance of the measurements; guide the use of the visualization products; and integrate the measurement aspects of the program into a broader study of the environment.

Schools throughout the United States and the rest of the world that are not GLOBE schools may become GLOBE Affiliate schools by observing the GLOBE Program in operation through the Internet. Students at these schools will benefit from the use of GLOBE visualization products and educational materials accessible on-line. All GLOBE Affiliate schools will be encouraged to become participating GLOBE schools.

\section{APPENDIX B GLOBE Environmental Measurements and Equipment}

GLOBE environmental measurements will contribute in a significant way to the scientific understanding of the dynamics of the global environment. Every GLOBE school will conduct a core set of GLOBE environmental measurements in the following critical areas: Atmosphere/Climate, Hydrology/Water Chemistry, and Biology/Geology. 
Where possible, a GLOBE school may coordinate its activities with those of other neighboring GLOBE schools, so that the complete set of GLOBE measurements will be available from a locality. As the GLOBE Program evolves, elective measurements not common to all GLOBE schools may be added in order to address local environmental issues.

Students at all age levels will be active participants in the GLOBE Program. The actual participation will be designed so as to be grade-appropriate for grades K-5, 6-8, and 9-12 (or equivalent). Younger students will make limited measurements which may be qualitative rather than quantitative. Older students will make additional measurements and more sophisticated measurements, as appropriate for their grade level. Measurement equipment will not need to be standardized; rather, performance specifications will be provided.

Following is an example list of core measurements and the equipment that will be needed to take these measurements. The full list will be initially determined and periodically updated as provided in Article 2.A.2, based on experience gained in implementing the GLOBE Program.

Measurements (Equipment Needed) for Grades K-5:

Atmosphere/Climate Studies:

Air Temperature (Max/Min Thermometer)

Precipitation (Rain Gauge)

Barometric Pressure (Barometer)

Cloud Observations (Cloud Kit (Wall Chart, Slides, Etc.))

Weather Image Analysis (Hardcopy Images - see note below)

Hydrology/Water Chemistry Studies:

Water Temperature (Thermometer)

Water $\mathrm{pH}$ (Litmus Paper/Colorimetric)

Water Chemistry (Water Testing Kit)

Hydrologic Assessment (Hardcopy Images)

\section{Biology/Geology Studies:}

Biometrics (Tape Measure, Simple Clinometers)

Species Identification (Simple Dichotomous Keys)

Soil Temperature (Thermometer)

Land Cover Assessment (Hardcopy Images)

\section{Measurements (Equipment Needed) for Grades 6-12:}

Atmosphere/Climate Studies:

Air Temperature (Max/Min Thermometer)

Precipitation (Rain Gauge)

Barometric Pressure (Barometer)

Dew Point (Sling Psychrometer)

Wind Speed/Direction (Anemometer, Wind Vane)

Trace Gases (to be determined)

Cloud Observations (Cloud Kit)

Weather Image Analysis (Hardcopy Images)

Hydrology/Water Chemistry Studies:

Water Temperature (Thermometer)

Water pH (Pens, pH Meter)

Water Chemistry (Water Testing Kit)

Soil Moisture (to be determined)

Hydrologic Assessment (Hardcopy Images)

\section{Biology/Geology Studies:}

Biometrics (Clinometer, Tape Measure)

Species Identification (Keys, Taxonomic Manuals)

Phenology (Camera, Film)

State-Of-Health (Texts, Color Plates, Local Resources)

Soil Temperature (Thermometer) 
Soil Types (Soil Manuals, Keys)

Global Positioning System (GPS) Measurements (to be made, as necessary, by the U.S. to determine the location of GLOBE study sites on the ground)

Land Use/Cover Assessment (Hardcopy Images)

Note: References to "Hardcopy Images" - These studies, where possible, will be conducted using hardcopy images produced from weather satellites such as GOES/Meteosat and land surface systems such as Landsat/SPOT satellite datasets which the U.S. will provide.

\section{APPENDIX C \\ GLOBE Computer and Communications Systems}

In order to derive maximum benefit from the GLOBE Program, all schools will be encouraged to use an international information network, initially using the Internet, along with classroom computers using software capable of multimedia presentations. Technology associated with the GLOBE Program will continually evolve to higher levels and participants will be encouraged to upgrade over time. Following is a description of GLOBE computer and communications systems consistent with current GLOBE requirements.

The U.S. Side will adapt or develop software for IBM-compatible and Apple Macintosh computer configurations to support the required GLOBE school activities of data entry, data analysis, and use of visualization products. Current planning calls for limiting this software development effort to IBM-compatible or Apple Macintosh computers capable of running TCP/IP and supporting World Wide Web client software, such as Mosaic, with GLOBE extensions. Overall attributes of this minimum usable GLOBE school computer configuration are as follows:

A) for IBM-compatible: $386 \mathrm{SX}$ processor, Windows 3.1 in enhanced mode, 4MB of RAM, 60MB of available hard disk space, and a direct Internet connection or dial-up connection using SLIP or PPP and 14,400bps modem, preferably with V.42bis, which can enable 57,600 bps operation using data compression; and

B) for Apple Macintosh: $6803020 \mathrm{MHz}$ processor, 4MB of RAM, 60MB of available hard disk space, and a direct Internet connection or dial-up connection using SLIP or PPP and a 14,400bps modem, preferably with V.42bis, which can enable 57,600 bps operation using data compression.

A higher performance GLOBE school computer system is also being developed for the following configuration: a 486/66 processor, 16MB of RAM, 500MB of available hard disk space, super VGA monitor, double-speed CD-ROM reader, sound card, and MPEG speed-up board.

It is recognized that there is a broad range of technological capabilities among potential GLOBE schools. The diversity of technology accessible by schools worldwide may require in some cases that environmental measurements be reported in hard copy and that a variety of media be used to distribute visualization products, including photographs and broadcast television. All schools that want to participate in the program will be accommodated. 



\section{Korea, Republic of}





\title{
Agreement Between the National Oceanic and Atmospheric Administration of the United States of America and the Ministry of Education of the Republic of Korea for Cooperation in the GLOBE Program, Seoul, 1995
}

\author{
Done at Seoul 21 April 1995 \\ Entered into force 21 April 1995 \\ Primary source citation: Copy of text provided by the \\ U.S. Department of State
}

\section{AGREEMENT BETWEEN THE NATIONAL OCEANIC AND ATMOSPHERIC ADMINISTRATION OF THE UNITED STATES OF AMERICA AND THE MINISTRY OF EDUCATION OF THE REPUBLIC OF KOREA FOR COOPERATION IN THE GLOBE PROGRAM}

\section{PREAMBLE}

The U.S. National Oceanic and Atmospheric Administration, acting on behalf of itself and other U.S. Government agencies participating in the GLOBE Program (hereinafter, the U.S. side), and the Ministry of Education of the Republic of Korea (hereinafter, the Korean side),

Intending to increase the awareness of students throughout the world about the global environment,

Seeking to contribute to increased scientific understanding of the Earth, and

Desiring to support improved student achievement in science and mathematics,

Have agreed to cooperate in the Global Learning and Observations to Benefit the Environment (GLOBE) Program as follows: 


\section{ARTICLE 1 - THE GLOBE PROGRAM}

The GLOBE Program is an international environmental science and education program that will bring students, teachers, and scientists together to study the global environment. GLOBE will create an international network of students in grades K-12 (or equivalent) studying environmental issues, making environmental measurements, and sharing useful environmental data with the international environmental science community.

\section{ARTICLE 2 - RESPECTIVE RESPONSIBILITIES}

A. The U.S. side will:

1. Identify U.S. schools that will participate in the GLOBE Program (details regarding GLOBE schools in Appendix A);

2. Select, in consultation with international scientists and educators, the GLOBE environmental measurements and types of measurement equipment (described in Appendix B);

3. Select Principal Investigator Teams for the GLOBE environmental measurements, and support the U.S. members of the Teams;

4. Calibrate, if necessary, measurement equipment that cannot be calibrated by GLOBE teachers and students;

5. Develop, in consultation with international scientists and educators, GLOBE educational materials;

6. Translate GLOBE instructional materials related to measurement procedures and reporting protocols into the six United Nations languages, and provide these plus all broader GLOBE educational materials to the Korean side for further reproduction as necessary;

7. Conduct annual regional training sessions for GLOBE Country Coordinators and GLOBE teachers who will serve as trainers for additional GLOBE teachers in Korea, and provide a copy of GLOBE training materials to the Korean side;

8. Design, develop, operate, and maintain GLOBE data processing capabilities and other necessary technology and equipment;

9. Provide GLOBE software, as necessary, for use on Korean GLOBE school computers. (To the maximum extent possible, textual material appearing on computer screens will be accessible in the student's choice among the six United Nations languages.);

10. Accept environmental data reported from GLOBE schools around the world, and develop and provide resultant global environmental images (visualization products) to the Korean side; and

11. Evaluate the overall GLOBE Program periodically, in consultation with international GLOBE Country Coordinators, and modify the overall program as appropriate.

B. The Korean side will:

1. Select Korean schools to participate in the GLOBE Program (details regarding GLOBE schools in Appendix A) and provide an updated list of Korean GLOBE schools to the U.S. side at the beginning of each school year;

2. Ensure that Korean GLOBE schools conduct the fundamental activities of GLOBE schools detailed in Appendix A (take GLOBE environmental measurements, report data, and receive and use resultant global environmental images, using GLOBE educational materials under the guidance of teachers trained to conduct the GLOBE Program); 
3. Name a Korean Government Point of Contact responsible for policy-level communications with the Director of the GLOBE Program;

4. Name a Country Coordinator responsible for day-to-day management, oversight, and facilitation of the GLOBE Program in the Republic of Korea;

5. Ensure that the Country Coordinator and some GLOBE teachers attend GLOBE regional training and in turn provide GLOBE training to at least one teacher in each Korean GLOBE school;

6. Ensure that GLOBE instructional materials related to measurement procedures and data reporting protocols are utilized in Korean GLOBE schools, and that broader GLOBE educational materials are appropriately translated, adapted, reproduced, and distributed to all Korean GLOBE schools;

7. Ensure that Korean GLOBE schools have the necessary measurement equipment to take GLOBE environmental measurements (described in Appendix B);

8. Ensure that teachers and students at Korean GLOBE schools calibrate GLOBE measurement equipment according to procedures provided in GLOBE instructional materials;

9. Ensure that Korean GLOBE schools have the necessary computer and communications systems (described in Appendix C) to report GLOBE environmental measurements and to receive and use GLOBE visualization products, or make agreed alternative arrangements for such reporting and receipt. (At a minimum, the Korean Country Coordinator will need access to Internet so that all measurement data from Korean GLOBE schools will be reported via Internet.); and

10. Evaluate GLOBE operations in the Rupublic of Korea periodically and assist the U.S. side in conducting periodic evaluation of the overall GLOBE Program.

\section{ARTICLE 3 - FINANCIAL ARRANGEMENTS}

Each side will bear the costs of fulfilling its respective responsibilities under this agreement. Obligations of each side pursuant to this agreement are subject to its respective funding procedures and the availability of appropriated funds, personnel, and other resources. The conduct of activities under this agreement will be consistent with the relevant laws and regulations of the two sides.

\section{ARTICLE 4 - EXCHANGE OF DATA AND GOODS}

GLOBE environmental measurement data, visualization products, software, and educational materials will be available worldwide without restriction as to their use or redistribution.

\section{ARTICLE 5 - RELEASE OF INFORMATION ABOUT THE GLOBE PROGRAM}

Each side may release information on the GLOBE Program as it may deem appropriate without prior consultation with the other.

\section{ARTICLE 6 - CUSTOMS AND IMMIGRATION}

Each side will, to the extent permitted by its laws and regulations, facilitate the movement of persons and goods necessary to implement this agreement into and out of its territory and accord entry to such goods into its territory free of customs duties and other similar charges. 


\section{ARTICLE 7 - ENTRY INTO FORCE, AMENDMENTS, WITHDRAWAL}

This agreement will enter into force upon signature of the two sides and will remain in force for five years. It will be automatically extended for further five-year periods, unless either side decides to terminate it and so notifies the other side with three months written notice. This agreement may be terminated at any time by either side upon three months prior written notice to the other side. This agreement may be amended by written agreement of the two sides.

Done at Seoul on the twenty-first day of April, 1995, in duplicate.

For the National Oceanic and

Atmospheric Administration:

[Signature]
For the Ministry of

Education:

[Signature]

\section{APPENDIXA GLOBE Schools}

Each partner country will be responsible for identifying its participating schools. Schools should be selected so as to satisfy the objectives of the GLOBE Program. In particular, countries should emphasize the selection of schools that will maximize the number of students worldwide participating in the program. Also, countries should consider involving schools in locations that will yield measurement data that is important to the international environmental science community.

Students at all GLOBE schools throughout the world will conduct the following fundamental activities: they will make environmental measurements at or near their schools; report their data to a GLOBE data processing site; receive vivid graphical global environmental images (visualization products) created from their data and the data from other GLOBE schools around the world; and study the environment by relating their observations and the resulting visualization products to broader environmental topics. All of these activities will be conducted under the guidance of specially trained teachers (GLOBE-trained teachers).

GLOBE educational materials will be used in GLOBE schools under the guidance of GLOBE-trained teachers. These materials will detail procedures for taking environmental measurements and protocols for reporting data; explain the significance of the measurements; guide the use of the visualization products; and integrate the measurement aspects of the program into a broader study of the environment.

Schools throughout the United States and the rest of the world that are not GLOBE schools may become GLOBE Affiliate schools by observing the GLOBE Program in operation through the Internet. Students at these schools will benefit from the use of GLOBE visualization products and educational materials accessible on-line. All GLOBE Affiliate schools will be encouraged to become participating GLOBE schools.

\section{APPENDIX B GLOBE Environmental Measurements and Equipment}

GLOBE environmental measurements will contribute in a significant way to the scientific understanding of the dynamics of the global environment. Every GLOBE school will conduct a core set of GLOBE environmental measurements in the following critical areas: Atmosphere/Climate, Hydrology/Water Chemistry, and Biology/Geology. Where possible, a GLOBE school may coordinate its activities with those of other neighboring GLOBE schools, so that the complete set of GLOBE measurements will be available from a locality. As the GLOBE Program evolves, elective measurements not common to all GLOBE schools may be added in order to address local environmental issues.

Students at all age levels will be active participants in the GLOBE Program. The actual participation will be designed so as to be grade-appropriate for grades $\mathrm{K}-5,6-8$, and 9-12 (or equivalent). Younger students will make limited measurements which may be qualitative rather than quantitative. Older students will make additional measure- 
ments and more sophisticated measurements, as appropriate for their grade level. Measurement equipment will not need to be standardized; rather, performance specifications will be provided.

Following is an example list of core measurements and equipment. The full list will be initially determined and periodically updated as provided in Article 2.A.2, based on experience gained in implementing the GLOBE Program.

\section{Measurements}

\section{Grades K-5:}

\section{Atmosphere/Climate}

Air Temperature

Precipitation

Barometric Pressure

Cloud Observations

Weather Image Analysis*

Hydrology/Water Chemistry

Water Temperature

Water $\mathrm{pH}$

Water Chemistry

Hydrologic Assessment*

\section{Biology/Geology}

Biometrics

Species Identification

Soil Temperature

Land Cover Assessment*

\section{Grades 6-12:}

\section{Atmosphere/Climate}

Air Temperature

Precipitation

Barometric Pressure

Dew Point

Wind Speed/Direction

Trace Gases

Cloud Observations

Weather Image Analysis*

\section{Hydrology/Water Chemistry}

Water Temperature

Water $\mathrm{pH}$

Water Chemistry

Soil Moisture

Hydrologic Assessment*

\section{Biology/Geology}

Biometrics

Species Identification

Phenology

State-of-Health

Soil Temperature

Soil Types

GPS**

Land Use/Cover Assessment*

\section{Equipment Needed}

\author{
Max/Min Thermometer \\ Rain Gauge \\ Barometer \\ Cloud Kit (Wall Chart, Slides, etc.) \\ Hardcopy Images
}

Thermometer

Litmus Paper/Colorimetric

Water Testing Kit

Hardcopy Images

Tape Measure, Simple Clinometers

Simple Dichotomous Keys

Thermometer

Hardcopy Images

Max/Min Thermometer

Rain Gauge

Barometer

Sling Psychrometer

Anemometer, Wind Vane

(To Be Determined)

Cloud Kit

Hardcopy Images

Thermometer

$\mathrm{pH}$ Pens, $\mathrm{pH}$ Meter

Water Testing Kit

( $\mathrm{Tb}$ Be Determined)

Hardcopy Images

Clinometer, Tape Measure

Dichotomous Keys, Taxonomic Manuals

Camera, Film

Texts, Color Plates, Local Resources

Thermometer

Soil Manuals, Keys

Provided by the U.S.

Hardcopy Images

\footnotetext{
* These studies, where possible, will be conducted using hardcopy images produced from weather satellites such as GOES/Meteosat and land surface systems such as Landsat/SPOT satellite datasets which the U.S. will provide.

** Global Positioning System (GPS) measurements will be made, as necessary, by the U.S. to determine the location of GLOBE study sites on the ground.
} 


\section{APPENDIX C \\ GLOBE Computer and Communications Systems}

In order to derive maximum benefit from the GLOBE Program, all schools will be encouraged to use an international information network, initially using the Internet, along with classroom computers using software capable of multimedia presentations. Technology associated with the GLOBE Program will continually evolve to higher levels and participants will be encouraged to upgrade over time. Following is a description of GLOBE computer and communications systems consistent with current GLOBE requirements.

The U.S. side will adapt or develop software for IBM-compatible and Apple Macintosh computer configurations to support the required GLOBE school activities of data entry, data analysis, and use of visualization products. Current planning calls for limiting this software development effort to IBM-compatible or Apple Macintosh computers capable of running TCP/IP and supporting World Wide Web client software, such as MOSAIC, with GLOBE extensions. Overall attributes of this minimum usable GLOBE school computer configuration are as follows: a) for IBM-compatible: $386 \mathrm{SX}$ processor, Windows 3.1 in enhanced mode, $4 \mathrm{MB}$ of RAM, $60 \mathrm{MB}$ of available hard disk space, and a direct Internet connection or dial-up connection using SLIP or PPP and a 14,400bps modem, preferably with V.42bis, which can enable 57,600bps operation using data compression; and b) for Apple Macintosh: $6803020 \mathrm{MHz}$ processor, $4 \mathrm{MB}$ of RAM, $60 \mathrm{MB}$ of available hard disk space, and a direct Internet connection or dial-up connection using SLIP or PPP and a $14,400 \mathrm{bps}$ modem, preferably with V.42bis, which can enable $57,600 \mathrm{bps}$ operation using data compression.

A higher performance GLOBE school computer system is also being developed for the following configuration: a 486/66 processor, 16MB of RAM, 500MB of available hard disk space, super VGA monitor, double-speed CD-ROM reader, sound card, and MPEG speed-up board.

It is recognized that there is a broad range of technological capabilities among potential GLOBE schools. The diversity of technology accessible by schools worldwide may require in some cases that environmental measurements be reported in hard copy and that a variety of media be used to distribute visualization products, including photographs and broadcast television. All schools that want to participate in the program will be accommodated. 


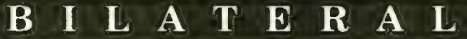

KOREA, REPUBLIC OF 



\title{
Amendment to the Agreement Between the Government of the United States of America and the Government of the Republic of Korea Concerning Fisheries off the Coasts of the United States, Washington, D.C., 1993
}

\author{
Done at Washington, D.C. 11 June and 13 October 1993 \\ Entered into force 24 March 1994 \\ Primary source citation: Copy of text provided by the \\ U.S. Department of State
}

\section{DEPARTMENT OF STATE \\ WASHINGTON}

June 11, 1993

His Excellency

Han Seung-Soo

Ambassador of the Republic of Korea

Excellency:

I have the honor to refer to the Agreement between Government of the United States of America and the Government of the Republic of Korea Concerning Fisheries off the Coasts of the United States, done at Washington July 26, 1982, as amended and extended (the Agreement).

I have the honor to propose, on behalf of the Government of the United States of America, that the Agreement, currently scheduled to expire December 31, 1993, be extended for an additional two year period until December 31 , 1995. If this proposal is acceptable to your Excellency, I have the further honor to propose that this note and your Excellency's favorable reply shall constitute an agreement between our two Governments, which shall enter into force on a date to be determined in a subsequent exchange of diplomatic notes following the completion of all necessary internal procedures of both parties.

Accept, Excellency, the renewed assurances of my highest consideration. 


\section{EMBAASSY OF THE REPUBLIC OF KOREA WASHINGTON, D. C.}

October 13, 1993

His Excellency

Warren Christopher

Secretary of State

of the United States of America

\section{Excellency,}

I have the honor to refer to the Note of June 11, 1993 which reads as follows:

"I have the honor to refer to the Agreement between the Government of the United States of America and the Government of the Republic of Korea Concerning Fisheries off the Coasts of the United States, done at Washington July 26, 1982, as amended and extended (the Agreement).

I have the honor to propose, on behalf of the Government of the United States of America, that the Agreement, currently scheduled to expire December 31, 1993, be extended for an additional two year period until December 31 , 1995. If this proposal is acceptable to your Excellency, I have the further honor to propose that this note and your Excellency's favorable reply shall constitute an agreement between our two Governments, which shall enter into force on a date to be determined in a subsequent exchange of diplomatic notes following the completion of all necessary internal procedures of both parties."

I have further the honor to inform Your Excellency that the foregoing proposal is acceptable to the Government of the Republic of Korea and to confirm that the above-mentioned Note in reply shall constitute an agreement between our two Governments, which shall enter into force on a date to be determined in a subsequent exchange of diplomatic notes following the completion of all necessary internal procedures of both parties.

Accept, Excellency, the renewed assurances of my highest consideration.

For Han Seung-Soo

Ambassador Extraordinary and

Plenipotentiary

of the Republic of Korea 


\section{B I L A T $\mathbf{E} \quad \mathbf{R}$ A $\mathbf{L}$}

\section{KYRGYZSTAN, REPUBLIC OF}





\section{Agreement Between the National Oceanic and Atmospheric}

Administration of the United States of America and the Ministry of Education of the Republic of Kyrgyzstan for Cooperation in the GLOBE Program, Washington, D.C., 1995

Done at Washington, D.C. 9 June 1995

Entered into force 9 June 1995

Primary source citation: Copy of text provided by the U.S. Department of State

\section{AGREEMENT BETWEEN THE NATIONAL OCEANIC AND ATMOSPHERIC ADMINISTRATION OF THE UNITED STATES OF AMERICA AND THE MINISTRY OF EDUCATION OF THE REPUBLIC OF KYRGYZSTAN FOR COOPERATION IN THE GLOBE PROGRAM}

\section{PREAMBLE}

The U.S. National Oceanic and Atmospheric Administration, acting on behalf of itself and other U.S. Government agencies participating in the GLOBE Program (hereinafter, the U.S. side), and the Ministry of Education of the Republic of Kyrgyzstan (hereinafter, the Kyrgyz side),

Intending to increase the awareness of students throughout the world about the global environment,

Seeking to contribute to increased scientific understanding of the Earth, and

Desiring to support improved student achievement in science and mathematics,

Have agreed to cooperate in the Global Learning and Observations to Benefit the Environment (GLOBE) Program as follows: 


\section{ARTICLE 1 - THE GLOBE PROGRAM}

The GLOBE Program is an international environmental science and education program that will bring students, teachers, and scientists together to study the global environment. GLOBE will create an international network of students in grades K-12 (or equivalent) studying environmental issues, making environmental measurements, and sharing useful environmental data with the international environmental science community.

\section{ARTICLE 2 - RESPECTIVE RESPONSIBILITIES}

A. The U.S. side will:

1. Identify U.S. schools that will participate in the GLOBE Program (details regarding GLOBE schools in Appendix A);

2. Select, in consultation with international scientists and educators, the GLOBE environmental measurements and types of measurement equipment (described in Appendix B);

3. Select Principal Investigator Teams for the GLOBE environmental measurements, and support the U.S. members of the Teams;

4. Calibrate, if necessary, measurement equipment that cannot be calibrated by GLOBE teachers and students;

5. Develop, in consultation with international scientists and educators, GLOBE educational materials;

6. Translate GLOBE instructional materials related to measurement procedures and data reporting protocols into the six United Nations languages, and provide these plus all broader GLOBE educational materials to the Kyrgyz side for further reproduction as necessary;

7. Conduct annual regional training sessions for GLOBE Country Coordinators and GLOBE teachers who will serve as trainers for additional GLOBE teachers in Kyrgyzstan, and provide a copy of GLOBE training materials to the Kyrgyz side;

8. Design, develop, operate, and maintain GLOBE data processing capabilities and other necessary technology and equipment;

9. Provide GLOBE software, as necessary, for use on Kyrgyz GLOBE school computers. (To the maximum extent possible, textual material appearing on computer screens will be accessible in the student's choice among the six United Nations languages.);

10. Accept environmental data reported from GLOBE schools around the world, and develop and provide resultant global environmental images (visualization products) to the Kyrgyz side; and

11. Evaluate the overall GLOBE Program periodically, in consultation with international GLOBE Country Coordinators, and modify the overall program as appropriate.

B. The Kyrgyz side will:

1. Select Kyrgyz schools to participate in the GLOBE Program (details regarding GLOBE schools in Appendix A) and provide an updated list of Kyrgyz GLOBE schools to the U.S. side at the beginning of each school year;

2. Ensure that Kyrgyz GLOBE schools conduct the fundamental activities of GLOBE schools detailed in Appendix A (take GLOBE environmental measurements, report data, and receive and use resultant global environmental images, using GLOBE educational materials under the guidance of teachers trained to conduct the GLOBE Program); 
3. Name a Kyrgyz Government Point of Contact responsible for policy-level communications with the Director of the GLOBE Program;

4. Name a Country Coordinator responsible for day-to-day management, oversight, and facilitation of the GLOBE Program in Kyrgyzstan;

5. Ensure that the Country Coordinator and some GLOBE teachers attend GLOBE regional training and in turn provide GLOBE training to at least one teacher in each Kyrgyz GLOBE school;

6. Ensure that GLOBE instructional materials related to measurement procedures and data reporting protocols are utilized in Kyrgyz GLOBE schools, and that broader GLOBE educational materials are appropriately translated, adapted, reproduced, and distributed to all Kyrgyz GLOBE schools;

7. Ensure that Kyrgyz GLOBE schools have the necessary measurement equipment to take GLOBE environmental measurements (described in Appendix B);

8. Ensure that teachers and students at Kyrgyz GLOBE schools calibrate GLOBE measurement equipment according to procedures provided in GLOBE instructional materials;

9. Ensure that Kyrgyz GLOBE schools have the necessary computer and communications systems (described in Appendix C) to report GLOBE environmental measurements and to receive and use GLOBE visualization products, or make agreed alternative arrangements for such reporting and receipt. (At a minimum, the Kyrgyz Country Coordinator will need access to Internet so that all measurement data from Kyrgyz GLOBE schools will be reported via Internet.); and

10. Evaluate GLOBE operations in Kyrgyzstan periodically and assist the U.S. side in conducting periodic evaluation of the overall GLOBE Program.

\section{ARTICLE 3 - FINANCIAL ARRANGEMENTS}

Each side will bear the costs of fulfilling its respective responsibilities under this agreement. Obligations of each side pursuant to this agreement are subject to its respective funding procedures and the availability of appropriated funds, personnel, and other resources. The conduct of activities under this agreement will be consistent with the relevant laws and regulations of the two sides.

\section{ARTICLE 4 - EXCHANGE OF DATA AND GOODS}

GLOBE environmental measurement data, visualization products, software, and educational materials will be available worldwide without restriction as to their use or redistribution.

\section{ARTICLE 5 - RELEASE OF INFORMATION ABOUT THE GLOBE PROGRAM}

Each side may release information on the GLOBE Program as it may deem appropriate without prior consultation with the other.

\section{ARTICLE 6 - CUSTOMS AND IMMIGRATION}

Each side will, to the extent permitted by its laws and regulations, facilitate the movement of persons and goods necessary to implement this agreement into and out of its territory and accord entry to such goods into its territory free of customs duties and other similar charges. 


\section{ARTICLE 7 - ENTRY INTO FORCE, AMENDMENTS, WITHDRAWAL}

This agreement will enter into force upon signature of the two sides and will remain in force for five years. It will be automatically extended for further five-year periods, unless either side decides to terminate it and so notifies the other side with three months written notice. This agreement may be terminated at any time by either side upon three months prior written notice to the other side. This agreement may be amended by written agreement of the two sides.

Done at Washington on the ninth day of June, 1995, in duplicate, in the English and Russian languages, both texts being equally authentic.

For the National Oceanic and

Atmospheric Administration:

[Signature]
For the Ministry of

Education:

[Signature]

6/9/95

\section{APPENDIX A GLOBE Schools}

Each partner country will be responsible for identifying its participating schools. Schools should be selected so as to satisfy the objectives of the GLOBE Program. In particular, countries should emphasize the selection of schools that will maximize the number of students worldwide participating in the program. Also, countries should consider involving schools in locations that will yield measurement data that is important to the international environmental science community.

Students at all GLOBE schools throughout the world will conduct the following fundamental activities: they will make environmental measurements at or near their schools; report their data to a GLOBE data processing site; receive vivid graphical global environmental images (visualization products) created from their data and the data from other GLOBE schools around the world; and study the environment by relating their observations and the resulting visualization products to broader environmental topics. All of these activities will be conducted under the guidance of specially trained teachers (GLOBE-trained teachers).

GLOBE educational materials will be used in GLOBE schools under the guidance of GLOBE-trained teachers. These materials will detail procedures for taking environmental measurements and protocols for reporting data; explain the significance of the measurements; guide the use of the visualization products; and integrate the measurement aspects of the program into a broader study of the environment.

Schools throughout the United States and the rest of the world that are not GLOBE schools may become GLOBE Affiliate schools by observing the GLOBE Program in operation through the Internet. Students at these schools will benefit from the use of GLOBE visualization products and educational materials accessible on-line. All GLOBE Affiliate schools will be encouraged to become participating GLOBE schools.

\section{APPENDIX B GLOBE Environmental Measurements and Equipment}

GLOBE environmental measurements will contribute in a significant way to the scientific understanding of the dynamics of the global environment. Every GLOBE school will conduct a core set of GLOBE environmental measurements in the following critical areas: Atmosphere/Climate, Hydrology/Water Chemistry, and Biology/Geology. Where possible, a GLOBE school may coordinate its activities with those of other neighboring GLOBE schools, so that the complete set of GLOBE measurements will be available from a locality. As the GLOBE Program evolves, elective measurements not common to all GLOBE schools may be added in order to address local environmental issues.

Students at all age levels will be active participants in the GLOBE Program. The actual participation will be designed so as to be grade-appropriate for grades K-5, 6-8, and 9-12 (or equivalent). Younger students will make limited 
measurements which may be qualitative rather than quantitative. Older students will make additional measurements and more sophisticated measurements, as appropriate for their grade level. Measurement equipment will not need to be standardized; rather, performance specifications will be provided.

Following is an example list of core measurements and equipment. The full list will be initially determined and periodically updated as provided in Article 2.A.2, based on experience gained in implementing the GLOBE Program.

\section{MEASUREMENTS}

\section{Atmosphere/Climate:}

Air Temperature

Precipitation

Cloud Cover/Type

Hydrology/Water Chemistry:

Water $\mathrm{pH}$

Water Temperature

Soil Moisture

\section{Biology/Geology: \\ Habitat Study}

Tree Height

Tree Canopy

Tree Diameter

Species Identification

Phenology

\section{EQUIPMENT NEEDED}

\author{
Max/Min Thermometer \\ Calibration Thermometer \\ Instrument Shelter \\ Rain Gauge \\ Cloud Charts
}

pH Paper, Pen, or Meter

Alcohol Thermometer

Gypsum Block Sensors

Soil Moisture Meter

\author{
Compass \\ Meter Measuring Tape \\ Surveying Markers or Stakes \\ Clinometer \\ Densiometer \\ Diameter Tape \\ Dichotomous Keys \\ $35 \mathrm{~mm}$ Camera
}

\section{APPENDIX C GLOBE Computer and Communications Systems}

In order to derive maximum benefit from the GLOBE Program, all schools will be encouraged to use an international information network, initially using the Internet, along with classroom computers. The World Wide Web multi-media information-access capability has been selected as the basis for IBM-compatible and Apple Macintosh computer systems to support the required GLOBE school activities of data entry, data analysis, and use of GLOBE environmental images. Following is a description of GLOBE computer and communications systems consistent with current GLOBE requirements.

Overall attributes of the minimum GLOBE school computer configuration that can execute the necessary software are:

For IBM-compatible systems: a $386 \mathrm{SX}$ or higher level processor; at least 4 megabytes of RAM memory (8 megabytes preferred); a VGA-capable monitor and display driver (Super VGA preferred); a hard disk storage system with as large a capacity as possible (preferably 300 megabytes or larger); and a direct Internet connection or dial-up capability that can use SLIP or PPP protocols with a 14,400 bps modem (preferably supporting V.42bis data compression which can enable 57,600 bps operation). The Windows 3.1 or later operating system is necessary. A printer is desirable.

For Apple Macintosh systems: a $6803020 \mathrm{Mhz}$ or faster processor; at least 4 megabytes of RAM memory ( 8 megabytes preferred); a hard disk storage system with as large a capacity as possible (preferably 300 megabytes or larger); and a direct Internet connection or dial-up capability that can use SLIP or PPP protocols with a 14,400 bps modem (preferably supporting V.42bis data compression which can enable 57,600 bps operation). A printer is desirable. 
Software for a higher performance GLOBE school computer system is being developed that will operate on higher performance, multi-media IBM-compatible systems and on Apple Macintosh systems. For IBM-compatible systems: a 486/66 or faster processor; 16 megabytes of RAM memory; 500 megabytes of hard disk space; a Super VGA monitor; a double-speed CD-ROM reader; a Soundblaster-compatible sound card; and an MPEG animation speed-up board will be required. For Apple Macintosh systems: a PowerPC processor; 16 megabytes of RAM memory; 500 megabytes of hard disk space; and a double-speed CD-ROM reader will be required. A communications capability the same as or better than for the minimum configurations above will also be required. A printer will be highly desirable.

It is recognized that there is a broad range of technological capabilities among potential GLOBE schools. The diversity of technology accessible by schools worldwide may require in some cases that environmental measurements be reported in hardcopy and that a variety of media be used to distribute visualization products, including photographs and broadcast television. All schools that want to participate in the program will be accommodated.

Technology associated with the GLOBE Program will continually evolve to higher levels and participants will be encouraged to upgrade over time. 


\title{
B I L A T $\mathbf{E}$ R A $\mathbf{L}$
}

\author{
LATVIA
}

F I S H E R I E S 



\title{
Agreement Between the Government of the United States of America and the Government of the Republic of Latvia Concerning Fisheries off the Coasts of the United States, Washington, D.C., 1993
}

\author{
Done at Washington, D.C. 8 April 1993
}

Entered into force 29 October 1993

Primary source citation: Copy of text provided by the U.S. Department of State

\section{AGREEMENT BETWEEN THE GOVERNMENT OF THE UNITED STATES OF AMERICA AND THE GOVERNMENT OF THE REPUBLIC OF LATVIA CONCERNING FISHERIES OFF THE COASTS OF THE UNITED STATES}

The Government of the United States of America and the Government of the Republic of Latvia (hereafter referred to as "the United States" and "Latvia", respectively, or "the Parties"),

Considering their common concern for the rational management, conservation and achievement of optimum yield of fish stocks off the coasts of the United States;

Recognizing that the United States has established by Presidential Proclamation of March 10, 1983 an exclusive economic zone within 200 nautical miles of its coasts within which the United States has sovereign rights to explore, exploit, conserve and manage all fish and that the United States also has such rights over the living resources of the continental shelf appertaining to the United States and anadromous species of fish of United States origin; and

Desirous of establishing reasonable terms and conditions pertaining to fisheries of mutual concern over which the United States has sovereign rights to explore, exploit, conserve and manage;

Have agreed as follows:

\section{ARTICLE I}

The purpose of this Agreement is to promote effective conservation, rational management and the achievement of optimum yield in the fisheries of mutual interest off the coasts of the United States, to facilitate the rapid and full 
development of the United States fishing industry and to establish a common understanding of the principles and procedures under which fishing may be conducted by nationals and vessels of Latvia for the living resources over which the United States has sovereign rights to explore, exploit, conserve and manage.

\section{ARTICLE II}

As used in this Agreement, the term

1. living resources over which the United States has sovereign rights to explore, exploit, conserve and manage" means all fish within the exclusive economic zone of the United States, all anadromous species of fish that spawn in the fresh or estuarine waters of the United States and migrate to ocean waters while present in the United States exclusive economic zone and in areas beyond national fisheries jurisdictions recognized by the United States and all living resources of the continental shelf appertaining to the United States;

2. "fish" means all finfish, mollusks, crustaceans, and other forms of marine animal and plant life, other than marine mammals and birds;

3. "fishery" means

a. one or more stocks of fish that can be treated as a unit for purposes of conservation and management and that are identified on the basis of geographical, scientific, technical, recreational and economic characteristics; and

b. any fishing for such stocks;

4. "exclusive economic zone" means a zone contiguous to the territorial sea of the United States, the seaward boundary of which is a line drawn in such a manner that each point on it is 200 nautical miles from the baseline from which the breadth of the territorial sea of the United States is measured;

5. "fishing" means
a. the catching, taking or harvesting of fish;
b. the attempted catching, taking or harvesting of fish;
c. any other activity that can reasonably be expected to result in the catching, taking or harvesting of fish;
d. any operations at sea, including processing, directly in support of, or in preparation for, any activity described in subparagraphs a. through $\mathrm{c}$. above, provided that such term does not include other legitimate uses of the high seas, including any scientific research activity;

6. "fishing vessel" means any vessel, boat, ship, or other craft that is used for, equipped to be used for, or of a type that is normally used for
a. fishing; or
b. aiding or assisting one or more vessels at sea in the performance of any activity relating to fishing, including preparation, supply, storage, refrigeration, transportation or processing; and

7. "marine mammal" means any mammal that is morphologically adapted to the marine environment, including sea otters and members of the orders Sirenia, Pinnipedia, and Cetacea, or primarily inhabits the marine environment such as polar bears. 


\section{ARTICLE III}

1. The United States is willing to allow access for fishing vessels of Latvia to harvest, in accordance with terms and conditions to be established in permits issued under Article VII, that portion of the total allowable catch for a specific fishery that will not be harvested by United States fishing vessels and is determined to be available to fishing vessels of Latvia in accordance with United States law.

2. The United States shall determine each year, subject to such adjustments as may be appropriate and in accordance with United States law:

a. the total allowable catch for each fishery based on optimum yield, taking into account the best available scientific evidence, and social, economic and other relevant factors;

b. the harvesting capacity of United States fishing vessels in respect of each fishery;

c. the portion of the total allowable catch for a specific fishery to which access will be provided, on a periodic basis each year, to foreign fishing vessels; and

d. the allocation of such portion that may be made available to Latvia.

3. The United States shall determine each year the measures necessary to prevent overfishing while achieving, on a continuing basis, the optimum yield from each fishery in accordance with United States law. Such measures may include, inter alia:

a. designated areas where, and periods when, fishing shall be permitted, limited, or conducted only by specified types of fishing vessels or with specified types and quantities of fishing gear;

b. limitations on the catch of fish based on area, species, size, number, weight, sex, incidental catch, total biomass or other factors;

c. limitations on the number and types of fishing vessels that may engage in fishing and/or on the number of days each vessel of the total fleet may engage in a designated area for a specified fishery;

d. requirements as to the types of gear that may, or may not, be employed; and

e. requirements designed to facilitate enforcement of such conditions and restrictions, including the maintenance of appropriate position-fixing and identification equipment.

4. The United States shall notify Latvia of the determinations provided for by this Article on a timely basis.

\section{ARTICLE IV}

In determining the portion of the surplus that may be made available to Latvia and to other countries, the United States will decide on the basis of the factors identified in United States law, including:

1. whether, and to what extent, such nation imposes tariff barriers or nontariff barriers on the importation, or otherwise restricts the market access, of both United States fish and fishery products, particularly fish and fishery products for which the foreign nation has requested an allocation;

2. whether, and to what extent, such nation is cooperating with the United States in both the advancement of existing and new opportunities for fisheries exports from the United States through the purchase of fishery products from United States processors and the advancement of fisheries trade through purchase of fish and fishery products from United States fishermen, particularly fish and fishery products for which the foreign nation has requested an allocation; 
3. whether, and to what extent, such nation and the fishing fleets of such nation have cooperated with the United States in the enforcement of United States fishing regulations;

4. whether, and to what extent, such nation requires the fish harvested from the exclusive economic zone for its domestic consumption;

5. whether, and to what extent, such nation otherwise contributes to, or fosters the growth of, a sound and economic United States fishing industry, including minimizing gear conflicts with fishing operations of United States fishermen, and transferring harvesting or processing technology which will benefit the United States fishing industry;

6. whether, and to what extent, the fishing vessels of such nation have traditionally engaged in fishing in such fishery;

7. whether, and to what extent, such nation is cooperating with the United States in, and making substantial contributions to, fishery research and the identification of fishery resources; pertaining to

8. whether, and to what extent, such nation is cooperating with the United States in matters

a. the implementation of United Nations General Assembly Resolution 46/215 of December, 1991 on Large-scale Pelagic Driftnet Fishing;

b. the conservation and management of anadromous species; and

c. the conservation of the pollock resource in the central Bering Sea; and

9. such other matters as the United States deems appropriate.

\section{ARTICLE V}

Latvia shall cooperate with and assist the United States in the development of the United States fishing industry and the increase of United States fishery exports by taking such measures as facilitating the importation and sale of United States fishery products, providing information concerning technical and administrative requirements for access of United States fishery products into Latvia, providing economic data, sharing expertise, facilitating the transfer of harvesting or processing technology to the United States fishing industry, facilitating appropriate joint venture and other arrangements, informing its industry of trade and joint venture opportunities with the United States, and taking other actions as may be appropriate.

\section{ARTICLE VI}

Latvia shall take all necessary measures to ensure:

1. that nationals and vessels of Latvia refrain from fishing for living resources over which the United States has sovereign rights to explore, exploit, conserve and manage except as authorized pursuant to this Agreement;

2. that all such vessels so authorized comply with the provisions of permits issued pursuant to this Agreement and applicable laws of the United States; and

3. that the total allocation referred to in Article III, paragraph 2.d. of this Agreement is not exceeded for any fishery. 


\section{ARTICLE VII}

Latvia may submit an application to the United States for a permit for each fishing vessel of Latvia that wishes to engage in fishing in the exclusive economic zone pursuant to this Agreement. Such application shall be prepared and processed in accordance with the Annex, which constitutes an integral part of this Agreement. The United States may require the payment of fees for such permits and for fishing in the exclusive economic zone. While such fees shall be applied without discrimination, the fee level may vary depending upon, inter alia, whether, in the judgement of the United States, vessels or nationals of Latvia are harvesting United States origin anadromous species at unacceptable levels, or whether Latvia is failing to take sufficient action to benefit the conservation and development of United States fisheries. Latvia undertakes to keep the number of applications to the minimum required, in order to aid in the efficient administration of the permit program.

\section{ARTICLE VIII}

Latvia shall ensure that nationals and vessels of Latvia refrain from harassing, hunting/capturing or killing, or attempting to harass, hunt, capture or kill, any marine mammal within the exclusive economic zone, except as may be otherwise provided by an international agreement respecting marine mammals to which the United States is a party, or in accordance with specific authorization for and controls on incidental taking of marine mammals established by the United States.

\section{ARTICLE IX}

Latvia shall ensure that in the conduct of the fisheries under this Agreement:

1. the authorizing permit for each vessel of Latvia is prominently displayed in the wheel house of such vessel;

2. appropriate position-fixing and identification equipment, as determined by the United States, is installed and maintained in working order on each vessel;

3. designated United States observers are permitted to board, upon request, any such fishing vessel, and shall be accorded the courtesies and accommodations provided to ship's officers while aboard such vessel, and owners, operators and crews of such vessels shall cooperate with observers in the conduct of their official duties, and, further, the United States shall be reimbursed for the costs incurred in the utilization of observers;

4. agents are appointed and maintained within the United States possessing the authority to receive and respond to any legal process issued in the United States with respect to an owner or operator of a vessel of Latvia for any cause arising out of the conduct of fishing activities for the living resources over which the United States has sovereign rights to explore, exploit, conserve and manage; and

5. all necessary measures are taken to minimize fishing gear conflicts and to ensure the prompt and adequate compensation of United States citizens for any loss, or damage to, their fishing vessels, fishing gear or catch, and resultant economic loss, that is caused by any fishing vessel of Latvia as determined by applicable United States procedures.

\section{ARTICLE X}

Latvia shall take all appropriate measures to assist the United States in the enforcement of its laws pertaining to fishing in the exclusive economic zone and to ensure that each vessel of Latvia that engages in fishing for living resources over which the United States has sovereign rights to explore, exploit, conserve and manage shall allow and assist the boarding and inspection of such vessel by any duly authorized enforcement officer of the United States and shall cooperate in such enforcement action as may be undertaken pursuant to the laws of the United States. 


\section{ARTICLE XI}

1. The United States will impose appropriate penalties, in accordance with the laws of the United States, on vessels of Latvia or their owners, operators, or crews that violate the requirements of this Agreement or of any permit issued hereunder.

2. Arrested vessels and their crews shall be promptly released, subject to such reasonable bond or other security as may be determined by the court.

3. In any case arising out of fishing activities under this Agreement, the penalty for violation of fishery regulations shall not include imprisonment except in the case of enforcement related offenses such as assault on an enforcement officer or refusal to permit boarding and inspection.

4. In cases of seizure and arrest of a vessel of Latvia by the authorities of the United States, notification shall be given promptly through diplomatic channels informing Latvia of the action taken and of any penalties subsequently imposed.

\section{ARTICLE XII}

1. The United States and Latvia shall cooperate in the conduct of scientific research required for the purpose of managing and conserving living resources over which the United States has sovereign rights to explore, exploit, conserve and manage, including the compilation of the best available scientific information for management and conservation of stocks of mutual interest.

2. The Parties shall cooperate in the development of a periodic research plan on stocks of mutual concern through correspondence or meetings as appropriate, and may modify it from time to time by agreement. The agreed research plans may include, but are not limited to, the exchange of information and scientists, regularly scheduled meetings between scientists to prepare research plans and review progress, and jointly conducted research projects.

3. The conduct of agreed research during regular commercial fishing operations on board a fishing vessel of Latvia in the exclusive economic zone shall not be deemed to change the character of the vessel's activities from fishing to scientific research. Therefore, it will still be necessary to obtain a permit for the vessel in accordance with Article VII.

4. Latvia shall cooperate with the United States in the implementation of procedures for collecting and reporting biostatistical information and fisheries data, including catch and effort statistics, in accordance with procedures which will be stipulated by the United States. Latvia shall similarly provide such economic data as may be requested by the United States.

5. Latvia shall cooperate with the United States in matters pertaining to the implementation of United Nations General Assembly Resolution 46/215 of December, 1991 on Large-scale Pelagic Driftnet Fishing, the conservation and management of anadromous species, and the conservation of the pollock resource in the central Bering Sea.

\section{ARTICLE XIII}

1. The United States and Latvia shall carry out periodic bilateral consultations regarding the implementation of this Agreement and the development of further cooperation in the field of fisheries of mutual concern, including cooperation within the framework of appropriate multilateral organizations for the collection and analysis of scientific data respecting such fisheries.

2. At the request of either Party any dispute concerning the interpretation or application of this Agreement shall be the subject of consultations between them. 


\section{ARTICLE XIV}

The United States undertakes to authorize fishing vessels of Latvia allowed to fish pursuant to this Agreement to enter ports in accordance with United States laws for the purpose of purchasing bait, supplies, or outfits, or effecting repairs, changing crews, or for such other purposes as may be authorized.

\section{ARTICLE XV}

Should the United States indicate to Latvia that nationals and vessels of the United States wish to engage in fishing in areas within the fisheries jurisdiction of Latvia, Latvia shall allow such fishing on terms not more restrictive than those established in accordance with this Agreement.

\section{ARTICLE XVI}

Nothing contained in the present Agreement shall prejudice:

1. the views of either Party with respect to the existing territorial or other jurisdiction of the coastal State for all purposes other than the conservation and management of fisheries; or,

2. any other international rights and obligations of either Party.

\section{ARTICLE XVII}

The Agreement shall apply to the territories of Latvia, and to the United States, its territories and its possessions.

\section{ARTICLE XVIII}

1. This Agreement shall enter into force on a date to be agreed upon by exchange of notes, following the completion of internal procedures of both Parties, and shall remain in force until June 1, 1995 unless extended by exchange of notes between the Parties. Notwithstanding the foregoing, either Party may terminate this Agreement after giving written notice of such termination to the other Party six months in advance.

2. At the request of either Party, this Agreement shall be subject to review by the two Parties two years after its entry into force.

IN WITNESS WHEREOF, the undersigned, being duly authorized for this purpose, have signed this Agreement.

DONE at Washington, in duplicate, this eighth day of April, 1993 in the English and Latvian languages, each text being equally authentic.

FOR THE GOVERNMENT OF THE

UNITED STATES OF AMERICA:

[Signature]
FOR THE GOVERNMENT OF THE

REPUBLIC OF LATVIA:

[Signature] 


\section{ANNEX \\ Application and Permit Procedures}

The following procedures shall govern the application for and issuance of annual permits authorizing vessels of Latvia to engage in fishing for living resources over which the United States has sovereign rights to explore, exploit, conserve and manage:

1. Latvia may submit an application to the competent authorities of the United States for each fishing vessel of Latvia that wishes to engage in fishing pursuant to this Agreement. Such application shall be made on forms provided by the United States for that purpose.

2. Any such application shall specify

a. the name and official number or other identification of each fishing vessel for which a permit is sought, together with the name and address of the owner and operator thereof;

b. the tonnage, capacity, speed, processing equipment, type and quantity of fishing gear, and such other information relating to the fishing characteristics of the vessel may be requested;

c. a specification of each fishery in which each vessel wishes to fish;

d. the amount of fish or tonnage of catch by species contemplated for each vessel during the time such permit is in force;

e. the ocean area in which, and the season or period during which, such fishing would be conducted; and

f. such other relevant information as may be requested, including desired transshipping areas.

3. The United States shall review each application, shall determine what conditions and restrictions may be needed, and what fee will be required, and shall inform Latvia of such determinations. The United States reserves the right not to approve applications. If permit applications are disapproved, the United States authorities will inform Latvia of the reasons for such disapproval.

4. Latvia shall thereupon notify the United States of its acceptance or rejection of such conditions and restrictions and, in the case of a rejection, of its objections thereto.

5. Upon acceptance of the conditions and restrictions by Latvia and the payment of any fees, the United States shall approve the application and issue a permit for each fishing vessel of Latvia, which fishing vessel shall thereupon be authorized to fish in accordance with this Agreement and the terms and conditions set forth in the permit. Such permits shall be issued for a specific vessel and shall not be transferred.

6. In the event Latvia notifies the United States of its objections to specific conditions and restrictions, the Parties may consult with respect thereto and Latvia may thereupon submit a revised application.

7. The procedures in this Annex may be amended by agreement through an exchange of notes between the Parties. 


\title{
Amendment to the Agreement Between the Government of the United States of America and the Government of the Republic of Latvia Concerning Fisheries off the Coasts of the United States, Riga, 1995
}

\author{
Done at Riga 28 March and 4 April 1995 \\ Entered into force 24 November 1995 \\ Primary source citation: Copy of text provided by the \\ U.S. Department of State
}

\author{
EMBASSY OF THE \\ UNITED STATES OF AMIERICA
}

Riga, March 28, 1995

No. 016

The Embassy of the United States of America presents its compliments to the Ministry of Foreign Affairs of the Republic of Latvia and refers to the Agreement between the Government of the United States of America and the Government of the Republic of Latvia concerning fisheries off the coasts of the United States, with Annex, done at Washington April 8, 1993 (the Agreement).

The Embassy has the honor to propose, on behalf of the Government of the United States of America, that the Agreement, currently scheduled to expire June 1, 1995, be extended until December 31, 1997. If this proposal is acceptable, the Embassy has the further honor to propose that this note and a favorable reply from the Government of the Republic of Latvia shall constitute an Agreement between the two Governments, which shall enter into force on a date to be determined in a subsequent exchange of diplomatic notes following the completion of all necessary internal procedures of both parties.

The Embassy of the United States of America avails itself of this opportunity to renew to the Ministry of Foreign Affairs of the Republic of Latvia the assurances of its highest consideration. 


\section{MINISTRY OF FOREIGN AFFAIRS REPUBLIC OF LATVIA}

Riga, 4 April 1995

To the Embassy of the

United States of America

RIGA

No. $41 / 182-362$

The Ministry of Foreign Affairs of the Republic of Latvia presents its compliments to the Embassy of the United States of America and has the honour to acknowledge receipt of the Embassy's Note No.016 of March 28, 1995 concerning the Agreement between the Government of the Republic of Latvia and the Government of the United States of America concerning Fisheries Off the Coasts of the United States, with Annex, signed at Washington on 8 April, 1993 (the Agreement).

The Ministry, on behalf of the Government of the Republic of Latvia, confirms to the Embassy to extend the Agreement until December 31, 1997.

The Ministry has the honour to inform the Embassy that the legal requirements necessary for the entry into force of the Agreement On Extension of the Agreement between the Government of the Republic of Latvia and the Government of the United States of America concerning Fisheries Off the Coasts of the United States have been fulfilled.

The Ministry of Foreign Affairs of the Republic of Latvia avails itself of this opportunity to renew to the Embassy of the United States of America the assurances of its highest consideration. 


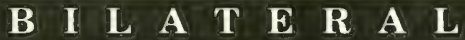

\section{Malaysia}

$\begin{array}{lllllllllllllll}M & A & R & I & N & E & P & O & L & L & U & T & I & O & N\end{array}$ 



\section{Agreement Between the Government of the United States of America and the Government of Malaysia Concerning the Transboundary Movement of Hazardous Wastes from Malaysia to the United States, Kuala Lumpur, 1995}

Done at Kuala Lumpur 10 March 1995

Entered into force 10 March 1995

Primary source citation: Copy of text provided by the

U.S. Department of State

\section{AGREEMENT BETWEEN THE GOVERNMENT OF THE UNITED STATES OF AMERICA AND THE GOVERNMENT OF MALAYSIA CONCERNING THE TRANSBOUNDARY MOVEMENT OF HAZARDOUS WASTES FROM MALAYSIA TO THE UNITED STATES}

The Government of the United States of America (the United States) and the Government of Malaysia (Malaysia), hereinafter referred to as 'the Parties,'

Recalling the Basel Convention on the Control of Transboundary Movements of Hazardous Wastes and their Disposal (the 'Basel Convention');

Recalling Article 4(5) of the Basel Convention, which provides that a party shall not permit hazardous wastes to be exported to a non-party;

Recalling also Article 11(1) of the Basel Convention, which provides that, notwithstanding Article 4(5), a party may enter into an agreement with a non-party provided that such agreement does not derogate from the environmentally sound management of hazardous wastes as required by the Convention and that such agreement stipulates provisions not less environmentally sound than those provided for by the Convention;

Have agreed as follows; 


\section{ARTICLE 1 DEFINITIONS}

For purposes of this Agreement:

(a) 'competent authority' means, in the case of the United States, the U.S. Environmental Protection Agency and in the case of Malaysia, the Malaysian Department of Environment of the Ministry of Science, Technology and the Environment.

(b) hazardous wastes' means those materials that are defined as hazardous wastes under either U.S. or Malaysian law.

(c) 'management' means the collection, transport and disposal (including recycling and recovery) of hszardous wastes, including after-care of disposal sites.

(d) 'environmentally sound management of hazardous wastes' means taking all practicable steps to ensure that hazardous wastes are managed in a manner which will protect human health and the environment against the adverse effects which may result from such wastes.

(e) 'contract' means the contract between the exporter and the intended facility of the United States for environmentally sound management of hazardous wastes.

(f) 'exporter' means any person under the jurisdiction of Malaysia who arranges for hazardous wastes to be exported.

(g) 'importer' means any person under the jurisdiction of the United States who arranges for hazardous wastes to be imported.

\section{ARTICLE 2 PURPOSE}

The purpose of this Agreement is to provide a framework for the transboundary movement of hazardous wastes that are shipped from Malaysia to the United States for management.

\section{ARTICLE 3 GENERAL OBLIGATION}

The Parties hereby undertake to comply with the terms and conditions applicable to them under this Agreement, in particular with regard to transboundary movements of hazardous wastes undertaken pursuant to this Agreement, and acknowledge that with regard to such movements Malaysia shall be bound by the relevant provisions of the Basel Convention.

\section{ARTICLE 4 NOTICE AND CONSENT}

1. The competent authority of Malaysia shall notify in writing the competent authority of the United States of proposed transboundary shipments of hazardous wastes to be carried out under this Agreement.

2. The notice referred to in paragraph 1 above may cover an individual shipment or a series of shipments extending over a twelve month or lesser period where the hazardous wastes in question have the same physical and chemical characteristics and are shipped regularly to the same facility via the same customs office of exit in Malaysia 
and the same customs office of entry in the United States. If any information in the notice changes, then a new notice shall be provided.

3. The notice referred to in paragraph 1 above shall contain the declarations and information, written in the English language, specified in Annex V A of the Basel Convention.

4. With respect to materials that are defined as hazardous wastes under U.S. law:

(a) the competent authority of the United States shall, in accordance with applicable U.S. law, respond to the competent authority of Malaysia in writing, consenting to the shipment with or without conditions, denying permission for the shipment, or requesting additional information. The competent authority of the United States shall make best efforts to respond within 30 days of receipt of the notice.

(b) the consent of the competent authority of the United States, including a conditional consent may be withdrawn or modified for good cause; in such case, the United States shall notify Malaysia as soon as possible. 'Good cause' means the introduction of new facts or developments that render incomplete the prior basis for consent or conditional consent.

5. With respect to materials that are defined as hazardous wastes under Malaysian law, but not under U.S. law:

(a) the United States shall not object to the import of materials that are not hazardous wastes under U.S. law. This provision shall serve as the U.S. written confirmation for imports of materials that are not hazardous wastes under U.S. law. This provision shall not apply to wastes which are contaminated by other materials to the extent that they are regulated as hazardous wastes under U.S. law or to materials that are probibited from import under U.S. law.

(b) where information provided in a notice under paragraph 1 above is based on fraudulent or inaccurate information, Article 7 of this Agreement may apply. Further, the United States reserves the right to rescind non-objection to these imports.

(c) nothing in this paragraph precludes the United States from taking enforcement action against appropriate persons or vessels (liability in rem) for violation of U.S. law.

6. Malaysia shall not allow a transboundary shipment to commence until:

(a) its competent authority has received confirmation from the exporter of the existence of a contract between the exporter and the intended facility in the United States specifying:

(1) the environmentally sound management of the hazardous wastes in question (which would be satisfied by specifying that the hazardous wastes will be managed in accordance with applicable U.S. law); and

(2) alternative arrangements, including which party to the contract is to pay for alternative arrangements for the proper management in an environmentally sound manner of the hazardous wastes in question in the United States or Malaysia in the case where the intended facility cannot or will not accept the hazardous wastes; and

(b) in the case of materials that are defined as hazardous wastes under U.S. law, its competent authority has received from the competent authority of the United States written consent to the shipment.

7. Malaysia shall not allow a transboundary shipment if it has reason to believe that the hazardous wastes in question will not be managed in an environmentally sound manner.

8. The management of hazardous wastes, once subject to the jurisdiction of the United States pursuant to this Agreement shall be subject to applicable U.S. law. 


\section{ARTICLE 5 COOPERATIVE EFFORTS}

1. The Parties shall cooperate to ensure, to the extent possible, that transboundary movement of hazardous wastes pursuant to this Agreement comply with applicable tracking document and manifest requirements.

2. The Parties shall cooperate to ensure, to the extent possible, that transboundary movements of hazardous wastes pursuant to this Agreement conform to the requirements of applicable law of both Parties and of this Agreement.

\section{ARTICLE 6 DUTY TO RE-IMPORT}

In the event a transboundary movement of hazardous wastes cannot be completed in accordance with the terms of the contract and provided that the alternative arrangements specified in the contract for the proper management in an environmentally sound manner of the hazardous wastes in question cannot be made (irrespective of whether the United States has given its consent), Malaysia shall, by itself or through the exporter, ensure that the wastes in question are taken back into Malaysia within 90 days from the time that the competent authority of the United States has so informed the competent authority of Malaysia.

\section{ARTICLE 7 ILLEGAL TRAFFIC}

1. In the case of a transboundary movement of hazardous wastes not in accordance with this Agreement as a result of conduct on the part of the exporter, Malaysia shall ensure that the hazardous wastes in question are taken back by the exporter, or, if necessary, by itself, to Malaysia, or, if impracticable, are managed pursuant to the provisions of the Basel Convention, within thirty days from the time that Malaysia receives notice about the illegal traffic or such other period of time as the parties may agree. To this end, the Parties shall not oppose, hinder, or prevent the return of those hazardous wastes to Malaysia.

2. In the case of a transboundary movement of hazardous wastes not in accordance with this Agreement as a result of conduct on the part of the importer, the United States shall take appropriate enforcement measures to require the importer to manage the hazardous wastes in question in an environmentally sound manner as soon as feasible from the time the illegal traffic has come to the attention of the United States. To this end, the Parties shall cooperate, as necessary, in the management of the hazardous wastes by the importer in an environmentally sound manner.

3. In the case where responsibility for the illegal traffic cannot be assigned either to the exporter or to the importer, the Parties shall cooperate to ensure that the hazardous wastes in question are managed as soon as possible in an environmentally sound manner in the state of export, the state of import, or elsewhere as appropriate.

\section{ARTICLE 8 INSURANCE}

The United States may require, as a condition of entry, that any import of hazardous wastes be covered by insurance or other financial guarantee in respect of damage caused during any part of the entire movement of hazardous wastes, including loading and unloading, and in case an alternative arrangement for its management in an environmentally sound manner or its return to Malaysia is necessary. 


\section{ARTICLE 9 \\ AMENDMENT}

This Agreement may be amended by written consent of the Parties.

\section{ARTICLE 10 ENTRY INTO FORCE}

This Agreement shall enter into force upon signature and shall remain in force until the date upon which the United States becomes a party to the Basel Convention. Either Party may terminate this Agreement upon written notification, such termination to take effect six months following the date of notification.

In witness whereof, the undersigned, being duly authorized by their respective Governments, have signed this Agreement.

Done at Kuala Lumpur in duplicate, this 10th day of March, 1995.

For the Government of the

United States of America:

[Signature]

Mr. John S. Wolf,

Ambassador of the United States

of America to Malaysia
For the Government

of Malaysia:

[Signature]

Dato' Dr Abu Bakar Jaafar,

Director General,

Department of Environment,

Malaysia 
Then 


\section{B I L A T E R A L}

\section{MEXICO}

\section{ENVIRONMENTAND NATURAL RESOURCES}


Commission (CNA) of the Secretariat of Agriculture and Hydraulic Resources (SARH) is the appropriate river control agency for the Colorado River in Mexico.

At the same time, the Commissioners pointed out that the two Governments in Minute No. 217, "Clearing of the Colorado River Channel Downstream from Morelos Dam", dated November 30, 1964, established an initial vegetation clearing program for 40 miles $(64 \mathrm{~km})$ of the Colorado River downstream of Morelos Dam to assure conveyance, between the levees, of the design flood of $140,000 \mathrm{cfs}(4,000 \mathrm{cms})$.

The Commissioners referred to the records of Gila River flood of 1993 noting a mean daily high of $25,000 \mathrm{cfs}$ $(710 \mathrm{cms})$ was registered at the Northerly International Boundary (NIB). They also referred to measurements for suspended sediment at the NIB hydrographic station, or an estimated 14,624,000 cubic yards $(11,179,000$ cubic meters) between January and October 1993. They noted that this suggests an impediment to the passage of normal and floodflows in the Colorado River at Morelos Dam and contributed sediment accumulation in Mexico's intake canal.

The Mexican Commissioner noted that under these sediment conditions in the Colorado River in the Morelos Dam area, and its canal intake there is a risk that Mexico may not be able to make full use of Colorado River waters corresponding to Mexico. In view of this, both Commissioners agreed to consider the need for emergency measures to remove an amount of sediment that will permit Mexico to adequately divert waters corresponding to Mexico.

The Commissioners then noted the information of the USBR and CNA, provided to the Commission at a technical meeting held on November 15, 1993 at Morelos Dam, that each agency has sediment removal equipment operating in nearby waterways within its jurisdiction. In particular, CNA in view of the emergency situation at Morelos Dam, has contracted for the removal of $1,569,448$ cubic yards (1,200,000 cubic meters) of sediment from its intake canal to accelerate this work and conclude it in an opportune manner.

The Commissioners then considered it necessary to also accelerate studies in the study reach of the Colorado River from Imperial Dam to the Gulf of California, to define flow conveyance conditions that require correction, especially sediment control, to present analyses of alternatives to correct deficiencies, to recommend work and costs corresponding to each country and recommend schedules for undertaking flood control plans contemplated by Article 13 of the 1944 Water Treaty, including operation and maintenance costs.

Based on the above considerations, the Commissioners submit the following resolutions for approval of the two Governments:

1. Regarding the emergency measures, the United States and Mexico at their respective expense, in the earliest time possible, will mobilize similar capacity equipment to carry out the work simultaneously, the sediment removal equipment operating in nearby waterways within their respective jurisdictions to perform sediment removal immediately upstream of the Morelos Dam flood control gates and downstream of the dam's intake canal diversion gates. The Government of Mexico, through the National Water Commission (CNA), has initiated and will continue the removal of sediment downstream of the diversion gates in the principal intake canal where the removal of $1,569,448$ cubic yards $(1,200,000 \mathrm{~cm})$ of sediment has already been contracted.

2. Also, as part of the emergency work, the United States Bureau of Reclamation (USBR), acting on behalf of the United States Government will remove sediment in the Mexican part of the Colorado River from Morelos Dam to the Northerly International Boundary (NIB). Because of the above, Mexico for this time only and without setting a precedent will acquire and prepare a disposal site along the right bank of the Colorado River, immediately upstream of Morelos Dam with the understanding that the USBR initially will deposit the sediment outside the Ockerson Levee, and Mexico will prepare a site in Mexico for permanent disposal of the sediments outside the Ockerson Levee. The operational aspects will be coordinated in the field by the International Boundary and Water Commission (IBWC) representatives in Yuma, Arizona and Mexicali, Baja California and the USBR and CNA.

3. The United States Section, in the earliest time possible and no later than 90 days from the day that this Minute enters into force, will present to the Mexican Section the alternatives, developed by the proper authorities in the United States to improve the conveyance capacity of the Colorado River from the mouth of the Gila River to Morelos Dam. Such alternatives would consider sediment removal and deposit 
of the material in the United States and a goal of undertaking the proposed actions in the earliest time possible consistent with applicable laws in the United States.

4. The Commission, should this be necessary, will coordinate efforts such that one agency may perform the work assigned to the other in accordance with stipulations in this Minute, such that the country for whom the work is performed will fully reimburse the other agency the cost of the work undertaken by that agency. For this purpose, that agency will in advance of the work, deposit in a bank in Yuma, Arizona or Mexicali, Baja California, an amount equal to the estimated work or a line of credit in favor of the IBWC from which corresponding payments would be made through the respective Section of the Commission based on work performed.

5. Regarding the short, medium and long term measures, the IBWC shall give greater priority to the studies in the reach of the Colorado River from Imperial Dam to the Gulf of California, to define before the end of 1994, flood conveyance conditions that require correction, especially sediment control to present analyses of alternatives to correct deficiencies, to recommend work and costs corresponding to each country, and recommend schedules for undertaking the flood control plan as provided in Article 13 of the 1944 Water Treaty, including its operation and maintenance costs. Any works recommended by the Commission in such studies shall be undertaken only upon the approval of the two Governments. Such activities would be subject to appropriation of necessary funds to carry them out.

6. This Minute requires the specific approval of the two Governments and shall enter into force on the day that the two Sections notify one another of this approval.

The meeting adjourned.

John M. Bernal

United States Commissioner

Manuel R. Ybarra

United States Section Secretary

\section{J. Arturo Herrera Solis}

Commissioner for Mexico

Jose de Jesus Luevano Grano

Mexican Section Secretary 
Commission (CNA) of the Secretariat of Agriculture and Hydraulic Resources (SARH) is the appropriate river control agency for the Colorado River in Mexico.

At the same time, the Commissioners pointed out that the two Governments in Minute No. 217, "Clearing of the Colorado River Channel Downstream from Morelos Dam", dated November 30, 1964, established an initial vegetation clearing program for 40 miles $(64 \mathrm{~km})$ of the Colorado River downstream of Morelos Dam to assure conveyance, between the levees, of the design flood of $140,000 \mathrm{cfs}(4,000 \mathrm{cms})$.

The Commissioners referred to the records of Gila River flood of 1993 noting a mean daily high of $25,000 \mathrm{cfs}$ (710 cms) was registered at the Northerly International Boundary (NIB). They also referred to measurements for suspended sediment at the NIB hydrographic station, or an estimated $14,624,000$ cubic yards $(11,179,000$ cubic meters) between January and October 1993. They noted that this suggests an impediment to the passage of normal and floodflows in the Colorado River at Morelos Dam and contributed sediment accumulation in Mexico's intake canal.

The Mexican Commissioner noted that under these sediment conditions in the Colorado River in the Morelos Dam area, and its canal intake there is a risk that Mexico may not be able to make full use of Colorado River waters corresponding to Mexico. In view of this, both Commissioners agreed to consider the need for emergency measures to remove an amount of sediment that will permit Mexico to adequately divert waters corresponding to Mexico.

The Commissioners then noted the information of the USBR and CNA, provided to the Commission at a technical meeting held on November 15, 1993 at Morelos Dam, that each agency has sediment removal equipment operating in nearby waterways within its jurisdiction. In particular, CNA in view of the emergency situation at Morelos Dam, has contracted for the removal of $1,569,448$ cubic yards $(1,200,000$ cubic meters) of sediment from its intake canal to accelerate this work and conclude it in an opportune manner.

The Commissioners then considered it necessary to also accelerate studies in the study reach of the Colorado River from Imperial Dam to the Gulf of California, to define flow conveyance conditions that require correction, especially sediment control, to present analyses of alternatives to correct deficiencies, to recommend work and costs corresponding to each country and recommend schedules for undertaking flood control plans contemplated by Article 13 of the 1944 Water Treaty, including operation and maintenance costs.

Based on the above considerations, the Commissioners submit the following resolutions for approval of the two Governments:

1. Regarding the emergency measures, the United States and Mexico at their respective expense, in the earliest time possible, will mobilize similar capacity equipment to carry out the work simultaneously, the sediment removal equipment operating in nearby waterways within their respective jurisdictions to perform sediment removal immediately upstream of the Morelos Dam flood control gates and downstream of the dam's intake canal diversion gates. The Government of Mexico, through the National Water Commission (CNA), has initiated and will continue the removal of sediment downstream of the diversion gates in the principal intake canal where the removal of $1,569,448$ cubic yards $(1,200,000 \mathrm{~cm})$ of sediment has already been contracted.

2. Also, as part of the emergency work, the United States Bureau of Reclamation (USBR), acting on behalf of the United States Government will remove sediment in the Mexican part of the Colorado River from Morelos Dam to the Northerly International Boundary (NIB). Because of the above, Mexico for this time only and without setting a precedent will acquire and prepare a disposal site along the right bank of the Colorado River, immediately upstream of Morelos Dam with the understanding that the USBR initially will deposit the sediment outside the Ockerson Levee, and Mexico will prepare a site in Mexico for permanent disposal of the sediments outside the Ockerson Levee. The operational aspects will be coordinated in the field by the International Boundary and Water Commission (IBWC) representatives in Yuma, Arizona and Mexicali, Baja California and the USBR and CNA.

3. The United States Section, in the earliest time possible and no later than 90 days from the day that this Minute enters into force, will present to the Mexican Section the alternatives, developed by the proper authorities in the United States to improve the conveyance capacity of the Colorado River from the mouth of the Gila River to Morelos Dam. Such alternatives would consider sediment removal and deposit 
of the material in the United States and a goal of undertaking the proposed actions in the earliest time possible consistent with applicable laws in the United States.

4. The Commission, should this be necessary, will coordinate efforts such that one agency may perform the work assigned to the other in accordance with stipulations in this Minute, such that the country for whom the work is performed will fully reimburse the other agency the cost of the work undertaken by that agency. For this purpose, that agency will in advance of the work, deposit in a bank in Yuma, Arizona or Mexicali, Baja California, an amount equal to the estimated work or a line of credit in favor of the IBWC from which corresponding payments would be made through the respective Section of the Commission based on work performed.

5. Regarding the short, medium and long term measures, the IBWC shall give greater priority to the studies in the reach of the Colorado River from Imperial Dam to the Gulf of California, to define before the end of 1994, flood conveyance conditions that require correction, especially sediment control to present analyses of alternatives to correct deficiencies, to recommend work and costs corresponding to each country, and recommend schedules for undertaking the flood control plan as provided in Article 13 of the 1944 Water Treaty, including its operation and maintenance costs. Any works recommended by the Commission in such studies shall be undertaken only upon the approval of the two Governments. Such activities would be subject to appropriation of necessary funds to carry them out.

6. This Minute requires the specific approval of the two Governments and shall enter into force on the day that the two Sections notify one another of this approval.

The meeting adjourned.

\section{John M. Bernal \\ United States Commissioner}

Manuel R. Ybarra

United States Section Secretary
J. Arturo Herrera Solis

Commissioner for Mexico

Jose de Jesus Luevano Grano

Mexican Section Secretary 


\section{Agreement Between the Government of the United States of America and the Government of the United Mexican States Concerning the Establishment of a Border Environment Cooperation Commission and a North American Development Bank, Washington, D.C., and Mexico City, 1993}

Done at Washington, D.C. and Mexico City

16 and 18 September 1993

Entered into force 1 January 1994

Primary source citation: Copy of text provided by the U.S. Department of State

\section{AGREEMENT BETWEEN THE GOVERNMENT OF THE UNITED STATES OF AMERICA AND THE GOVERNMENT OF THE UNITED MEXICAN STATES CONCERNING THE ESTABLISHMENT OF A BORDER ENVIRONMENT COOPERATION COMMISSION AND A NORTH AMERICAN DEVELOPMENT BANK}

The Government of the United States of America and the Government of the United Mexican States ("the Parties"):

Convinced of the importance of the conservation, protection and enhancement of their environments and the essential role of cooperation in these areas in achieving sustainable development for the well-being of present and future generations;

Recognizing the bilateral nature of many transboundary environmental issues, and that such issues can be most effectively addressed jointly;

Acknowledging that the border region of the United States and Mexico is experiencing environmental problems which must be addressed in order to promote sustainable development;

Recognizing the need for environmental infrastructure in the border region, especially in the areas of water pollution, wastewater treatment, municipal solid waste, and related matters; 
Affirming that, to the extent practicable, environmental infrastructure projects should be financed by the private sector, but that the urgency of the environmental problems in the border region requires that the Parties be prepared to assist in supporting these projects;

Affirming that, to the extent practicable, environmental infrastructure projects in the border region should be operated and maintained through user fees paid by polluters and those who benefit from the projects, and should be subject to local or private control;

Noting that the International Boundary and Water Commission, established pursuant to the Treaty between the United States and Mexico Relating to Utilization of Waters of the Colorado and Tijuana Rivers and of the Rio Grande, signed at Washington February 3,1944, plays an important role in efforts to preserve the health and vitality of the river waters of the border region;

Recognizing that there is a need to establish a new organization to strengthen cooperation among interested parties and to facilitate the financing, construction, operation and maintenance of environmental infrastructure projects in the border region;

Affirming the desirability of encouraging increased investment in the environmental infrastructure in the border region, whether or not such investment is made under the auspices of this Agreement;

Convinced of the need to collaborate with states and localities, non-governmental organizations, and other members of the public in the effort to address environmental problems in the border region;

Seeking to assist community adjustment and investment in the United States and Mexico;

Reaffirming the importance of the environmental goals and objectives embodied in the Agreement on Cooperation for the Protection and Improvement of the Environment in the Border Area, signed at La Paz, Baja California Sur August 14, 1983; and

Wishing to follow upon the goals and objectives of the North American Free Trade Agreement, signed at Washington, Ottawa, and Mexico December 8, 11, 14, and 17, 1992, and the North American Agreement on Environmental Cooperation, signed at Mexico, Washington, and Ottawa September 8, 9, 12, and 14, 1993;

Have agreed as follows:

\title{
INTRODUCTORY ARTICLE
}

The Parties agree to establish the Border Environment Cooperation Commission and the North American Development Bank, which shall operate in accordance with the following provisions:

\section{CHAPTER I BORDER ENVIRONMENT COOPERATION COMIISSION}

\author{
Article I \\ PURPOSE AND FUNCTIONS
}

\section{Section 1. Purpose}

(a) The purpose of the Commission shall be to help preserve, protect and enhance the environment of the border region in order to advance the well-being of the people of the United States and Mexico.

(b) In carrying out this purpose, the Commission shall cooperate as appropriate with the North American Development Bank and other national and international institutions, and with private sources supplying investment capital for environmental infrastructure projects in the border region. 


\section{Section 2. Functions}

In carrying out this purpose, the Commission may do any or all of the following:

(i) with their concurrence, assist states and localities and other public entities and private investors in:

(A) coordinating environmental infrastructure projects in the border region;

(B) preparing, developing, implementing, and overseeing environmental infrastructure projects in the border region, including the design, siting and other technical aspects of such projects;

(C) analyzing the financial feasibility or the environmental aspects, or both, of environmental infrastructure projects in the border region;

(D) evaluating social and economic benefits of environmental infrastructure projects in the border region;

(E) organizing, developing and arranging public and private financing for environmental infrastructure projects in the border region; and

(ii) certify, in accordance with Article II, Section 3 of this Chapter, applications for financing to be submitted to the North American Development Bank, or to other sources of financing that request such certification, for environmental infrastructure projects in the border region.

The Commission, with the concurrence of the United States Environmental Protection Agency and the Mexican Secretaria de Desarollo Social, may carry out these functions with respect to an environmental infrastructure project outside the border region upon finding that the project would remedy a transboundary environmental or health problem.

\section{Article II OPERATIONS}

\section{Section 1. Use of resources}

The resources and facilities of the Commission shall be used exclusively to implement the purpose and functions enumerated in Article I of this Chapter.

\section{Section 2. Requests for assistance}

(a) The Commission may seek and accept requests from states and localities, other public entities and private investors for assistance in carrying out the activities enumerated in Article I of this Chapter.

(b) Upon receipt of a request for assistance pursuant to paragraph (a) of this Section, the Commission may provide any and all such assistance as it deems appropriate. In providing such assistance, or in making certifications pursuant to Section 3 of this Article, the Commission shall give preference to environmental infrastructure projects relating to water pollution, wastewater treatment, municipal solid waste and related matters.

(c) In providing such assistance, the Commission shall consult with the Advisory Council established pursuant to Article III, Section 5 of this Chapter, and, as appropriate, with private investors and national and international institutions, particularly the North American Development Bank. 


\section{Section 3. Applications for certification}

(a) The Commission may accept applications from states and localities, other public entities and private investors for certification of environmental infrastructure projects in the border region with respect to which an applicant will be seeking financial assistance from the North American Development Bank or other sources of financing requesting such certification.

(b) The Commission may certify for such financing any project that meets or agrees to meet the technical, environmental, financial or other criteria applied, either generally or specifically, by the Commission to that project. To be eligible for certification, a project shall observe or be capable of observing the environmental and other laws of the place where it is to be located or executed. effects,

(c) For each project located in the border region and having significant transboundary environmental

(1) an environmental assessment shall be presented as part of the application process, and the Board of Directors shall examine potential environmental benefits, environmental risks, and costs, as well as available alternatives and the environmental standards and objectives of the affected area; and

(2) the Board of Directors, in consultation with affected states and localities, shall determine that the project meets the necessary conditions to achieve a high level of environmental protection for the affected area.

(d) Upon certification of a project for financial assistance from the North American Development Bank, the Commission shall submit a proposal for such assistance to the Bank for its consideration.

(e) Upon certification of a project for financial assistance from another source of financing requesting such certification, the Commission shall submit a proposal for such assistance to that source for its consideration.

\section{Section 4. Relationship with the public}

The Commission shall establish procedures in English and Spanish:

(1) ensuring, to the extent possible, public availability of documentary information on all projects for which a request for assistance or an application for certification is made;

(2) for giving written notice of and providing members of the public reasonable opportunity to comment on any general guidelines which may be established by the Commission for environmental infrastructure projects for which it provides assistance, and on all applications for certification received by the Commission; and

(3) whereby the Board of Directors could receive complaints from groups affected by projects that the Commission has assisted or certified and could obtain independent assessments as to whether the terms of this Chapter or the procedures established by the Board of Directors pursuant to this Chapter have been observed.

\section{Section 5. Reimbursement, fees and charges}

(a) The Commission may arrange for reimbursement of the costs of furnishing assistance on terms which the Commission deems appropriate.

(b) The Commission may establish reasonable fees or other charges for its assistance, including the processing of applications for certification. 


\section{Article III \\ ORGANIZATION AND MANAGEMENT}

\section{Section 1. Location of offices}

The Commission shall have its offices in the border region.

\section{Section 2. Structure of the Commission}

The Commission shall have a Board of Directors, a General Manager, a Deputy General Manager, an Advisory Council and such other officers and staff to perform such duties as the Commission may determine.

\section{Section 3. Board of Directors}

(a) All the powers of the Commission, including the power to determine its general operational and structural policies, shall be vested in the Board of Directors. The Board shall have ten directors: serve ex officio;

(1) the United States Commissioner of the International Boundary and Water Commission, who shall

(2) the Mexican Commissioner of the International Boundary and Water Commission, who shall serve ex officio;

(3) the Administrator of the Environmental Protection Agency of the United States, or his/her delegate, who shall serve ex officio;

(4) the Secretario de Desarollo Social of Mexico, or his/her delegate, who shall serve ex officio;

(5) six additional directors having expertise in environmental planning, economics, engineering, finance, or related matters, consisting of-

(i) a representative of one of the U.S. border states, appointed by the United States in such manner as it may determine;

(ii) a representative of one of the Mexican border states, appointed by Mexico in such manner as it may determine;

(iii) a representative of a U.S. locality in the border region, appointed by the United States in such manner as it may determine;

(iv) a representative of a Mexican locality in the border region, appointed by Mexico in such manner as it may determine;

(v) a member of the U.S. public who is a resident of the border region, appointed by the United States in such manner as it may determine; and

(vi) a member of the Mexican public who is a resident of the border region, appointed by Mexico in such manner as it may determine.

Each of the Parties, on an alternating basis, shall select one of the directors as Chairperson of the Board of Directors for a one-year term.

(b) The Board of Directors may delegate to the General Manager authority to exercise any powers of the Board, except the power to:

(i) certify environmental infrastructure projects in accordance with Article II, Section 3 of this Chapter; 
(ii) apply, either generally or specifically, technical, environmental, financial or other criteria to an environmental infrastructure project;

(iii) determine the salary and terms of contract of service of the General Manager and the Deputy General Manager; and

(iv) approve the annual program and budget and the annual report of the Commission.

(c) The Board of Directors shall hold quarterly regular sessions, and such other special sessions as may be called by the Board or the General Manager. At all regular sessions, the Board of Directors shall hold at least one public meeting. One public meeting each year shall be designated the Annual Meeting of the Board.

(d) A quorum for any meeting of the Board of Directors shall be a majority of the directors appointed by each of the Parties.

(e) All decisions of the Board of Directors shall require the approval of a majority of the members appointed by each Party. A written record of such decisions shall be made public in English and Spanish.

(f) The Board of Directors may adopt such rules and regulations as may be necessary or appropriate to conduct the business of the Commission.

(g) Directors shall serve as such without compensation from the Commission, but the Commission shall pay them reasonable expenses incurred in attending meetings of the Board of Directors.

\section{Section 4. General Manager}

(a) The Board of Directors shall appoint a General Manager and a Deputy General Manager, neither of whom shall be a director. The General Manager and the Deputy General Manager shall each be appointed for a term of three years and may be reappointed. The General Manager and the Deputy General Manager shall cease to hold office when the Board of Directors so decides with respect to either officer. The offices of General Manager and Deputy General Manager shall alternate between nationals of the Parties. The General Manager and the Deputy General Manager shall be nationals of different Parties at all times.

(b) The General Manager shall exercise all the powers delegated to him or her by the Board of Directors. The General Manager may participate in meetings of the Board, but shall not vote at such meetings. The General Manager shall be chief of the operating staff of the Commission and shall conduct, under the direction of the Board of Directors, the ordinary business of the Commission. Subject to the general control of the Board of Directors, the General Manager shall be responsible for the organization, appointment and dismissal of the officers and staff of the Commission.

(c) The General Manager, officers and staff of the Commission, in the discharge of their offices, shall owe their duty entirely to the Commission and to no other authority. The Parties shall respect the international character of this duty and shall refrain from all attempts to influence any of them in the discharge of their duties.

(d) In appointing the officers and staff, the General Manager shall, subject to the paramount importance of securing the highest standards of efficiency and technical competence, seek to achieve at each level a balanced proportion of nationals of each Party.

(e) The General Manager shall submit to the Board of Directors for its approval an annual program and budget for the Commission. The Advisory Council established pursuant to Section 5 of this Article shall receive at the same time as the Board of Directors drafts of the annual program and budget and may make comments to the Board on the same.

\section{Section 5. Advisory Council}

(a) The Advisory Council shall be composed of: 
(i) at least one resident of each of the U.S. border states, totalling not more than six such representatives, who shall represent states or localities, or local community groups, to be appointed by the United States in such manner as it may determine;

(ii) one resident of each of the Mexican border states, who shall represent states or localities, or local community groups, to be appointed by Mexico in such manner as it may determine;

(iii) three members of the public, including at least one representative of a U.S. non-governmental organization, appointed by the United States in such manner as it may determine; and

(iv) three members of the public, including at least one representative of a Mexican non-governmental organization, appointed by Mexico in such manner as it may determine.

(b) Council members shall be appointed for a term of two years and may be reappointed. Each of the Parties shall select from among the members it appoints a $\mathrm{Co}$-Chairperson of the Council. Council members shall serve as such without compensation from the Commission, but the Commission shall pay them reasonable expenses incurred in attending meetings of the Council.

(c) The Council shall meet quarterly during the regular sessions of the Board of Directors, and at such other times as the Council, with the consent of a majority of the members appointed by each of the Parties, or the Board shall determine.

(d) The Council may adopt such rules as may be necessary or appropriate to conduct the business of the Council.

(e) The Council may provide advice to the Board of Directors or the General Manager on any matter within the scope of this Chapter, including certifications pursuant to Article II, Section 3, of this Chapter, and on the implementation and further elaboration of this Chapter, and may perform such other functions as directed by the Board.

\section{Section 6. Relationship to the International Boundary and Water Commission}

(a) The Commission may enter into arrangements with the International Boundary and Water Commission ("IBWC") regarding facilities, personnel and services and arrangements for reimbursement of administrative and other expenses paid by one organization on behalf of the other.

(b) Nothing in this Chapter shall make the Commission liable for the acts or obligations of the IBWC, or the IBWC liable for the acts or obligations of the Commission.

(c) The Parties shall call upon the Commission and the IBWC to cooperate, as appropriate, with each other in planning, developing and carrying out border sanitation and other environmental activities.

\section{Section 7. Funding}

Each Party shall contribute an equal share of the budget of the Commission, subject to the availability of appropriated funds in accordance with its domestic legal requirements. The Commission shall establish an account or accounts to receive such contributions from the Parties.

\section{Section 8. Channel of communication}

Each Party shall designate an appropriate authority with which the Commission may communicate in connection with any matter arising under this Chapter.

\section{Section 9. Annual reports}

(a) The Commission shall submit to the Parties an annual report in English and Spanish on its operations. The report shall be prepared by the General Manager and shall be approved by the Board of Directors. The Advisory Council shall receive at the same time as the Board of Directors drafts of the annual report and may make comments to the Board on the same. The annual report shall include an audited statement of the Commission's accounts. 
(b) Copies of the annual report prepared under this section shall be made available to the public.

\section{Section 10. Limitations on disclosure}

(a) Notwithstanding any other provision of this Chapter, the Commission, including its officers and staff, shall not make public information with respect to which a Party has notified the Commission that public disclosure would impede its law enforcement.

(b) The Commission shall establish regulations to protect from disclosure business or proprietary information and information the disclosure of which would violate personal privacy or the confidentiality of government decision-making.

(c) A party that requests assistance or submits an application to the Commission may request that information contained therein be designated confidential by the Commission, and may request an advance determination from the Commission as to whether such information is entitled to confidentiality pursuant to subsection (b) above. If the Commission determines that such information is not entitled to confidentiality pursuant to subsection (b) above, the party may withdraw its request or application prior to further action by the Commission. Upon such withdrawal, the Commission shall not keep any copy of the information and shall not make public that it received such a request or application.

\section{Article IV \\ STATUS, IMMUNITIES AND PRIVILEGES}

\section{Section 1. Scope of article}

To enable the Commission to fulfill its purpose and the functions with which it is entrusted, the status, immunities and privileges set forth in this Article shall be accorded to the Commission in the territories of each Party.

\section{Section 2. Legal status}

(a) The Commission shall possess juridical personality and, in particular, full capacity:

(i) to contract;

(ii) to acquire and dispose of immovable and movable property; and

(iii) to institute legal proceedings.

(b) The Commission may exercise such other powers as shall be necessary in furtherance of its purpose and functions, consistent with the provisions of this Chapter.

\section{Section 3. Judicial proceedings}

The Commission, its property and its assets, wherever located, and by whomsoever held, shall enjoy the same immunity from suit and every form of judicial process as is enjoyed by foreign governments, except to the extent that the Commission may expressly waive its immunity for the purposes of any proceedings or by the terms of any contract.

\section{Section 4. Immunity of assets}

Property and assets of the Commission, wheresoever located and by whomsoever held, shall be considered public international property and shall be immune from search, requisition, confiscation, expropriation or any other form of taking or foreclosure by executive or legislative action.

\section{Section 5. Inviolability of archives}

The archives of the Commission shall be inviolable. 


\section{Section 6. Freedom of assets from restrictions}

To the extent necessary to carry out the purpose and functions of the Commission and to conduct its operations in accordance with this Chapter, all property and other assets of the Commission shall be free from restrictions, regulations, controls and moratoria of any nature, except as may otherwise be provided in this Chapter.

\section{Section 7. Privilege for communications}

The official communications of the Commission shall be accorded by each Party the same treatment that it accords to the official communications of the other Party.

\section{Section 8. Personal immunities and privileges}

(a) The directors, General Manager, Deputy General Manager, officers and staff of the Commission shall have the following privileges and immunities:

(i) immunity from legal process with respect to acts performed by them in their official capacity except when the Commission expressly waives this immunity;

(ii) when not local nationals, the same immunities from immigration restrictions, alien registration requirements and national service obligations and the same facilities as regards exchange provisions as are accorded by each Party to the representatives, officials, and employees of comparable rank of the other Party; and

(iii) the same privileges in respect of travelling facilities as are accorded by each Party to representatives, officials, and employees of comparable rank of the other Party.

\section{Section 9. Immunities from taxation}

(a) The Commission, its property, other assets, income, and the operations it carries out pursuant to this Chapter shall be immune from all taxation and from all customs duties. The Commission shall also be immune from any obligation relating to the payment, withholding or collection of any tax or customs duty.

(b) No tax shall be levied on or in respect of salaries and emoluments paid by the Commission to officers or staff of the Commission who are not local nationals.

\section{Section 10. Implementation}

Each Party, in accordance with its juridical system, shall take such action as is necessary to make effective in its own territories the principles set forth in this Article, and shall inform the Commission of the action which it has taken on the matter.

\section{Article V \\ CONSULTATIONS}

\section{Section 1. Principle of cooperation}

The Parties shall at all times endeavor to agree on the interpretation and application of this Chapter, and shall make every effort to resolve any matter that might affect the implementation of this Chapter.

\section{Section 2. Consultations}

Upon the written request of either Party or the Board of Directors in English and Spanish, the Parties shall consult regarding the interpretation or application of this Chapter. These consultations shall take place within 30 days after a written request for consultations. 


\section{Article VI \\ TERMINATION OF OPERATIONS}

(a) The Parties, by mutual agreement, may terminate the operations of the Commission. A Party may withdraw from the Commission by delivering to the Commission at its principal office a written notice of its intention to do so. Such withdrawal shall become finally effective on the date specified in the notice but in no event less than six months after the notice is delivered to the Commission. However, at any time before the withdrawal becomes finally effective, the Party may notify the Commission in writing of the cancellation of its notice of intention to withdraw. The Commission shall terminate its operations on the effective date of any notice of withdrawal from the Commission.

(b) After such termination of operations the Commission shall forthwith cease all activities, except those incident to the conservation, preservation, and realization of its assets and settlement of its obligations.

\section{CHAPTER II \\ NORTH AMERICAN DEVELOPMENT BANK}

\section{Article I \\ PURPOSES AND FUNCTIONS}

\section{Section 1. Purposes}

The purposes of the North American Development Bank shall be:

(a) to provide financing for projects certified by the Border Environment Cooperation Commission, as appropriate, and, at the request of the Commission, to otherwise assist the Commission in fulfilling its purposes and functions;

(b) to provide financing endorsed by the United States, as appropriate, for community adjustment and investment in support of the purposes of the North American Free Trade Agreement; and

(c) to provide financing endorsed by Mexico, as appropriate, for community adjustment and investment in support of the purposes of the North American Free Trade Agreement.

\section{Section 2. Functions}

To implement its purposes, the Bank shall utilize its own capital, funds raised by it in financial markets, and other available resources and shall fulfill the following functions:

(a) to promote the investment of public and private capital contributing to its purposes;

(b) to encourage private investment in projects, enterprises, and activities contributing to its purposes, and to supplement private investment when private capital is not available on reasonable terms and conditions; and

(c) to provide technical and other assistance for the financing and, in coordination with the Commission, the implementation of plans and projects.

In carrying out its functions, the Bank shall cooperate as appropriate with national and international institutions and with private sources supplying investment capital. 


\section{Article II \\ CAPITAL OF THE BANK}

\section{Section 1. Authorized capital}

(a) The authorized capital stock of the Bank initially shall be in the amount of $\$ 3,000,000,000$ in United States dollars and shall be divided into 300,000 shares having a par value of $\$ 10,000$ each, which shall be available for subscription by the Parties in accordance with Section 2 of this Article.

(b) The authorized capital stock shall be divided into paid-in shares and callable shares. $\$ 450,000,000$ shall be paid-in shares, and $\$ 2,550,000,000$ shall be callable for the purposes specified in Section 3(d) of this Article.

(c) The authorized capital stock may be increased when the Board of the Bank by a unanimous vote deems it advisable, subject to the domestic legal requirements of the Parties.

\section{Section 2. Subscription of shares}

(a) Each Party shall subscribe to shares of the capital stock of the Bank. The number of shares to be subscribed by the Parties shall be those set forth in Annex A of this Agreement, which specifies the obligation of each Party as to both paid-in and callable capital.

(b) Shares of capital stock initially subscribed by the Parties shall be issued at par. Other shares shall be issued at par unless the Board of the Bank decides in special circumstances to issue them on other terms.

(c) The liability of the Parties on capital shares shall be limited to the unpaid portion of their issue price.

(d) Shares of capital stock shall not be pledged or encumbered in any manner, and they shall be transferable only to the Bank.

\section{Section 3. Payment of subscriptions}

Payment of the subscriptions to the capital stock of the Bank as set forth in Annex A shall be made as follows:

(a) As soon as possible after this Agreement enters into force pursuant to Article I of Chapter III, but no later than thirty days thereafter, each Party shall deposit with the Bank an Instrument of Subscription in which it agrees to pay in either Party's currency to the Bank the amount of paid-in capital set forth for it in Annex A, and to accept the obligations of callable shares ("Unqualified Subscription"). Payment of the paid-in capital shall be due according to a schedule to be established by the Board of the Bank after entry into force of this Agreement.

(b) Notwithstanding the provisions of paragraph (a) of this Section regarding Unqualified Subscriptions, as an exceptional case, a Party may deposit an Instrument of Subscription in which it agrees that payment of all installments of paid-in capital, and its obligations with respect to all callable shares, are subject to subsequent budgetary legislation ("Qualified Subscription"). In such an instrument, the Party shall undertake to seek to obtain the necessary legislation to pay the full amount of paid-in capital and to accept the full amount of corresponding obligations for callable shares, by the payment dates determined in accordance with paragraph (a) of this Section. Payment of an installment due after any such date shall be made within sixty days after the requisite legislation has been obtained.

(c) If any Party which has made a Qualified Subscription has not obtained the legislation to make payment in full of any installment (or to accept obligations in respect of callable shares) by the dates determined in accordance with paragraph (a) of this Section, then a Party which has paid the corresponding installment on time and in full, may, after consultation with the Board of the Bank, direct the Bank in writing to restrict commitments against that installment. That restriction shall not exceed the percentage which the unpaid portion of the installment, due from the Party which has made the Qualified Subscription, bears to the entire amount of the installment to be paid by that Party, and shall be in effect only for the time that unpaid portion remains unpaid.

(d) The callable portion of the subscription for capital shares of the Bank shall be subject to call only when required to meet the obligations of the Bank created under Article III, Section 2(b) and (c) of this Chapter on 
borrowings of funds for inclusion in the Bank's capital resources or guarantees chargeable to such resources. In the event of such a call, payment shall be made in either Party's currency. Calls on unpaid subscriptions shall be uniform in percentage on all shares.

\section{Section 4. Capital resources}

As used in this Chapter, the term "capital resources" of the Bank shall be deemed to include the following:

(1) authorized capital, including both paid-in and callable shares, subscribed pursuant to Sections 2 and 3 of this Article;

(2) all funds raised by borrowings under the authority of Article V, Section 1(a) of this Chapter to which the commitment set forth in Section 3(d) of this Article is applicable;

(3) all funds received in repayment of loans made with the resources indicated in paragraphs (1) and (2) of this section;

(4) all income derived from loans made from the aforementioned funds or from guarantees to which the commitment set forth in Section 3(d) of this Article is applicable; and

(5) all other income derived from any of the resources mentioned above.

\section{Article III OPERATIONS}

\section{Section 1. Use of resources}

The resources and facilities of the Bank shall be used exclusively to implement the purposes and functions enumerated in Article I of this Chapter.

\section{Section 2. Methods of making or guaranteeing loans}

Subject to the conditions stipulated in this Article, the Bank may make or guarantee loans to either Party, or any agency or political subdivision thereof, and to any entity in the territory of a Party, in any of the following ways:

(a) by making or participating in direct loans with funds corresponding to the unimpaired paid-in capital and to its reserves and undistributed surplus;

(b) by making or participating in direct loans with funds raised by the Bank in capital markets, or borrowed or acquired in any other manner, for inclusion in the capital resources of the Bank; and

(c) by guaranteeing in whole or in part loans made to, or securities issued in connection with, projects.

\section{Section 3. Grants}

(a) Subject to the conditions stipulated in this Article, the Bank shall make grants to the United States or any agency or political subdivision thereof, and to any entity in the territory of the United States for purposes specified in Article I, Section 1(b) of this Chapter.

(b) Subject to the conditions stipulated in this Article, the Bank shall make grants to Mexico or any agency or political subdivision thereof, and to any entity in the territory of Mexico for purposes specified in Article I, Section 1(c) of this Chapter.

\section{Section 4. Limitations on operations}

(a) The total amount outstanding of loans and guarantees made by the Bank in its operations shall not at any time exceed the total amount of the unimpaired subscribed capital of the Bank, plus the unimpaired reserves and surplus included in the capital resources of the Bank, as defined in Article II, Section 4 of this Chapter, and other 
income of the capital resources assigned by decision of the Board of the Bank to reserves not available for loans or guarantees.

(b) The total amount of loans, guarantees and grants provided for the purposes specified in Article I, Section 1(b) of this Chapter, shall not exceed 10 percent of the sum of the paid-in capital actually paid to the Bank by the United States, and the amount of callable shares for which the United States has an unqualified subscription.

The total amount of grants made pursuant to Section 3(a) of this Article, plus 15 percent of the total amount of loans and guarantees made for the purposes specified in Article I, Section 1(b) of this Chapter, shall not exceed 10 percent of the paid-in capital actually paid to the Bank by the United States.

(c) The total amount of loans, guarantees and grants provided for the purposes specified in Article I, Section 1(c) of this Chanter, shall not exceed 10 percent of the sum of the paid-in capital actually paid to the Bank by Mexico, and the amount of callable shares for which Mexico has an unqualified subscription.

The total amount of grants made pursuant to Section 3(b) of this Article, plus 15 percent of the total amount of loans and guarantees made for the purposes specified in Article I, Section 1(c) of this Chapter, shall not exceed 10 percent of the paid-in capital actually paid to the Bank by Mexico.

\section{Section 5. Direct loan and grant financing}

In making grants or in making direct loans or participating in them, the Bank may provide financing in the currencies of the Parties to meet the costs and expenses related to the purposes of the grant or loan.

\section{Section 6. Rules and conditions for making or guaranteeing loans}

(a) The Bank may make or guarantee loans, subject to the following rules and conditions:

(1) in considering a request for a loan or a guarantee, the Bank shall take into account the ability of the borrower to obtain the loan from private sources of financing on terms which, in the opinion of the Bank, are reasonable for the borrower, taking into account all pertinent factors;

(2) in making or guaranteeing a loan, the Bank shall pay due regard to prospects that the borrower and its guarantor, if any, will be in a position to meet their obligations under the loan contract;

(3) in the opinion of the Bank, the rate of interest, other charges and the schedule for repayment of principal are appropriate for the purpose or project in question; and

(4) in guaranteeing a loan made by other investors, the Bank shall receive suitable compensation for its risk.

(b) In addition to the rules and conditions set forth in paragraph (a) of this Section, the following rules and conditions shall apply to loans or guarantees made pursuant to a certification from the Commission:

(1) the applicant for the loan or guarantee shall have submitted a detailed proposal to the Bank, and the Commission shall have presented a written report certifying the proposal;

(2) in making or guaranteeing a loan to a project, the Bank shall find that the project is economically/financially sound, and pay due regard to the prospects that the project will generate sufficient revenues, by user fees or otherwise, to be self-sustaining, or that funds will be available from other sources to meet debt servicing obligations; and

(3) loans made or guaranteed by the Bank shall be for financing specific projects.

(c) In addition to the rules and conditions set forth in paragraph (a) of this Section, loans and guarantees made for the purposes specified in Article I, Section 1(b) of this Chapter shall require an endorsement from the United States. 
(d) In addition to the rules and conditions set forth in paragraph (a) of this Section, loans and guarantees made for the purposes specified in Article I, Section 1(c) of this Chapter shall require an endorsement from Mexico.

\section{Section 7. Optional conditions for making or guaranteeing loans}

(a) In the case of loans or guarantees of loans to nongovernmental entities, the Bank may, when it deems it advisable, require that the Party in whose territory the project is to be carried out, or a public institution or a similar agency of the Party acceptable to the Bank, guarantee the repayment of the principal and the payment of interest and other charges on the loan.

(b) The Bank may attach such other conditions to the making of loans or guarantees as it deems appropriate.

\section{Section 8. Use of loans made or guaranteed by the Bank}

Party.

(a) The Bank shall impose no condition that the proceeds of a loan shall be spent in the territory of either

(b) The Bank shall take the necessary measures to ensure that the proceeds of any loan made, guaranteed, or participated in by the Bank are used only for the purposes for which the loan was granted, with due attention to considerations of economy and efficiency.

\section{Section 9. Payment provisions for direct loans}

Direct loan contracts made by the Bank in conformity with Sections 5 and 6 of this Article shall establish:

(a) All the terms and conditions of each loan, including among others, provision for payment of principal, interest and other charges, maturities, and dates of payment; and

(b) The currency or currencies in which payment shall be made to the Bank.

\section{Section 10. Guarantees}

(a) In making any guarantee pursuant to Section 2(c) of this Article, the Bank shall charge a guarantee fee, at a rate determined by the Bank, payable periodically on the amount of the loan outstanding.

(b) Guarantee contracts concluded by the Bank shall provide that the Bank may terminate its liability with respect to interest if, upon default by the borrower and by the guarantor, if any, the Bank offers to purchase, at par and interest accrued to a date designated in the offer, the bonds or other obligations guaranteed.

(c) In issuing guarantees, the Bank shall have power to determine any other terms and conditions.

\section{Section 11. Rules and conditions for making grants}

(a) Notwithstanding Article VI, Section 3 of this Chapter, and subject to the limitations specified in Section 4(b) of this Article, the Bank shall make grants for the purposes specified in Article I, Section 1(b) of this Chapter pursuant to an endorsement by the United States.

(b) Notwithstanding Article VI, Section 3 of this Chapter, and subject to the limitations specified in Section 4(c) of this Article, the Bank shall make grants for the purposes specified in Article I, Section 1(c) of this Chapter pursuant to an endorsement by Mexico.

\section{Section 12. Relationship with other entities}

(a) The Bank may make arrangements with other entities, including multilateral development banks, regarding facilities, personnel and services and arrangements for reimbursement of administrative expenses paid by either entity on behalf of the other.

(b) Nothing in this Agreement shall make the Bank liable for the acts or obligations of an entity referred to in paragraph (a) of this Section, or any such entity liable for the acts or obligations of the Bank. 


\section{Article IV CURRENCIES}

\section{Section 1. Use of currencies}

(a) The Parties may not maintain or impose restrictions of any kind upon the use by the Bank or by any recipient from the Bank, for payments in any country, of the following:

(1) currencies received by the Bank in payment of each Party's subscription to shares of the Bank's capital;

(2) currencies of the Parties purchased with the resources referred to in (1) of this paragraph;

(3) currencies obtained by borrowings, pursuant to the provisions of Article V, Section 1(a) of this Chapter, for inclusion in the capital resources of the Bank;

(4) currencies received by the Bank in payment on account of principal, interest, or other charges in respect of loans made from the funds referred to in (1), (2) or (3) of this paragraph; and currencies received in payment of commissions and fees on all guarantees made by the Bank; and

(5) currencies received from the Bank pursuant to Article V, Section 4(c) of this Chapter, in distribution of net profits.

(b) A Party's currency held by the Bank in its capital resources, which is not covered by paragraph (a) of this section, also may be used by the Bank or any recipient from the Bank for payments in any country without restriction of any kind.

(c) The Parties may not place any restrictions on the holding and use by the Bank, for making amortization payments or anticipating payment of, or repurchasing part or all of the Bank's own obligations, of currencies received by the Bank in repayment of direct loans made from borrowed funds included in the capital resources of the Bank.

\section{Section 2. Valuation of currencies}

(a) The amount of a currency other than the U.S. dollar paid for purposes of Section 3(a), (b) or (d) of Article II of this Chapter or Section 3 of this Article to discharge a U.S. dollar-denominated obligation shall be that amount which will yield to the Bank the U.S. dollar amount of such obligation.

(b) Whenever it shall become necessary under this Chapter to value any currency in terms of another currency, such valuation shall be determined by the Bank after consultation, if necessary, with the International Monetary Fund.

\section{Section 3. Methods of conserving currencies}

The Bank shall accept from either Party promissory notes or similar securities issued by the government of the Party, or by the depository designated by such Party, in lieu of any part of the currency of the Party representing the paid-in portion of its subscription to the Bank's authorized capital, provided such currency is not required by the Bank for the conduct of its operations. Such notes or securities shall be non-negotiable, non-interest-bearing, and payable to the Bank at their par value on demand. On the same conditions, the Bank shall also accept such notes or securities in lieu of any part of the subscription of a Party with respect to which part the terms of the subscription do not require payment in cash.

\section{Article V \\ MISCELLANEOUS POWERS AND DISTRIBUTION OF PROFITS}

\section{Section 1. Miscellaneous powers of the Bank}

In addition to the powers specified elsewhere in this Chapter, the Bank shall have the power to: 
(a) borrow funds and in that connection to furnish such collateral or other security therefor as the Bank shall determine, provided that, before making a sale of its obligations in the markets of a Party, the Bank shall have obtained the approval of that country and of the Party in whose currency the obligations are denominated.

(b) invest funds not needed in its operations in such obligations as it may determine;

(c) guarantee securities in its portfolio for the purpose of facilitating their sale; and

(d) exercise such other powers as shall be necessary or desirable in furtherance of its purposes and functions, consistent with the provisions of this Chapter.

\section{Section 2. Warning to be placed on securities}

Every security issued or guaranteed by the Bank shall bear on its face a conspicuous statement to the effect that it is not an obligation of any government, unless it is in fact the obligation of a particular government, in which case it shall so state.

\section{Section 3. Methods of meeting the losses of the Bank}

(a) In cases of arrears or default on loans made, participated in, or guaranteed by the Bank, the Bank shall take such action as it deems appropriate. The Bank shall maintain appropriate provisions against possible losses.

(b) Losses arising in the Bank's operations shall be charged first, to the provisions referred to in paragraph (a); second, to net income; third, against its general reserve and surpluses; and fourth, against the unimpaired paid-in capital.

(c) Whenever necessary to meet contractual payments of interest, other charges, or amortization on the Bank's borrowings payable out of its capital resources, or to meet the Bank's liabilities with respect to similar payments on loans guaranteed by it chargeable to its capital resources, the Bank may call upon both Parties to pay an appropriate amount of their callable capital subscriptions, in accordance with Article II, Section 3 of this Chapter. Moreover, if the Bank believes that a default may be of long duration, it may call an additional part of such subscriptions not to exceed in any one year one percent of the total subscriptions of the Parties to the capital resources, for the following purposes:

(1) to redeem prior to maturity, or otherwise discharge its liability on, all or part of the outstanding principal of any loan guaranteed by it chargeable to its capital resources in respect of which the debtor is in default; and

(2) to repurchase, or otherwise discharge its liability on, all or part of its own outstanding obligations payable out of its capital resources.

\section{Section 4. Distribution or transfer of net profits and surplus}

(a) The Board of the Bank may determine periodically what part of the net profits and of the surplus of the capital resources shall be distributed. Such distributions may be made only when the reserves have reached a level which the Board considers adequate.

(b) The distributions referred to in paragraph (a) of this section shall be made from the capital resources in proportion to the number of capital shares held by each Party.

(c) Payments pursuant to paragraph (a) of this section shall be made in such manner and in such currency or currencies as the Board of the Bank shall determine. If such payments are made to a Party in currencies other than its own, the transfer of such currencies and their use by the receiving country shall be without restriction by either Party. 


\section{Article VI \\ ORGANIZATION AND PAYMENT}

\section{Section 1. Structure of the Bank}

The Bank shall have a Board, a Manager, and such other officers and staff as may be considered necessary.

\section{Section 2. Board of the Bank}

(a) All the powers of the Bank shall be vested in the Board. Each Party shall appoint three representatives to the Board of the Bank, who shall serve at the pleasure of the appointing Party. Board members shall be persons of recognized competence and experience. Each Party, on an alternating basis, shall select one of its representatives as Chairperson for a one-year term.

(b) Each Board member shall appoint an alternate who shall have full power to act for him or her when he or she is not present. Alternates may participate in meetings but may vote only when they are acting in place of their principals. In unusual circumstances, when neither a Board member nor his or her alternate is able to attend a meeting, the Board member may designate a temporary alternate.

(c) Board members shall serve as such without compensation from the Bank, but the Bank may pay them reasonable expenses incurred in attending meetings of the Board of the Bank.

(d) The Board of the Bank shall meet at the principal office of the Bank as often as the business of the Bank may require.

(e) A quorum for any meeting of the Board of the Bank shall require two representatives, alternates, or temporary alternates from each Party.

(f) The Board of the Bank may appoint such committees as it deems advisable.

(g) The Board of the Bank shall determine the basic organization of the Bank, including the number and general responsibilities of the chief administrative and professional positions of the staff, and shall approve the budget of the Bank.

\section{Section 3. Decision-making}

All decisions of the Board of the Bank shall require the assent of at least two representatives, alternates, or temporary alternates of each Party.

\section{Section 4. Manager and staff}

(a) The Board of the Bank shall elect a Manager of the Bank who may serve pursuant to an agreement entered into pursuant to Article III, Section 12 of this Chapter. The Manager, under the direction of the Board of the Bank, shall conduct the business of the Bank and shall be chief of its staff. The Manager or his or her designee shall be the legal representative of the Bank. The term of office of the Manager shall be three years. The Manager may be elected to successive terms. He or she shall cease to hold office when the Board of the Bank so decides.

(b) The Manager, officers and staff of the Bank, in the discharge of their offices, shall owe their duty entirely to the Bank and to no other authority. The Parties shall respect the international character of this duty and shall refrain from all attempts to influence any of them in the discharge of their duties.

(c) In appointing the officers and staff the Manager shall, subject to the paramount importance of securing the highest standards of efficiency and technical competence, seek to achieve, at each level, a balance in the number of nationals from each Party.

(d) The Bank, its officers and staff shall not interfere in the political affairs of either Party, nor shall they be influenced in their decisions by the political character of the Party or Parties concerned. Only economic/financial 
considerations shall be relevant to their decisions, and these considerations shall be weighed impartially in order to achieve the purposes and functions stated in Article $\mathrm{I}$ of this Chapter.

\section{Section 5. Publication of reports and provision of information}

(a) The Bank shall publish an annual report containing an audited statement of its accounts. It shall also transmit quarterly to the Parties a summary statement of its financial position and a profit-and-loss statement showing the results of its operations.

(b) The Bank may also publish such other reports as it deems desirable to inform the public of its activities and to carry out its purposes and functions.

\section{Article VII \\ SUSPENSION AND TERMINATION OF OPERATIONS}

\section{Section 1. Suspension of operations}

In an emergency the Board of the Bank may suspend operations in respect of new loans and guarantees until such time as the Board of the Bank may have an opportunity to consider the situation and take pertinent measures.

\section{Section 2. Termination of operations}

(a) The Parties, by mutual agreement, may terminate the operations of the Bank. A Party may withdraw from the Bank by delivering to the Bank at its principal office a written notice of its intention to do so. Such withdrawal shall become finally effective on the date specified in the notice but in no event less than six months after the notice is delivered to the Bank. However, at any time before the withdrawal becomes finally effective, the Party may notify the Bank in writing of the cancellation of its notice of intention to withdraw. The Bank shall terminate its operations on the effective date of any notice of withdrawal from the Bank.

(b) After such termination of operations the Bank shall forthwith cease all activities, except those incident to the conservation, preservation, and realization of its assets and settlement of its obligations.

\section{Section 3. Liability of the Parties and payment of claims}

(a) The liability of the Parties arising from their subscriptions to the capital stock of the Bank shall continue until all direct and contingent obligations shall have been discharged.

(b) All creditors holding direct claims shall be paid out of the assets of the Bank and then out of payments to the Bank on unpaid or callable subscriptions. Before making any payments to creditors holding direct claims, the Board of the Bank shall make such arrangements as are necessary, in its judgment, to ensure a pro rata distribution among holders of direct and contingent claims.

\section{Section 4. Distribution of assets}

(a) No distribution of assets shall be made to either Party on account of their subscriptions to the capital stock of the Bank until all liabilities to creditors chargeable to such capital stock shall have been discharged or provided for. Moreover, such distribution must be approved by a decision of the Board of the Bank.

(b) Any distribution of the assets of the Bank to the Parties shall be in proportion to payments on capital stock held by each Party and shall be effected at such times and under such conditions as the Bank shall deem fair and equitable. The shares of assets distributed need not be uniform as to type of assets. No Party shall be entitled to receive its share in such a distribution of assets until it has settled all of its obligations to the Bank.

(c) A Party receiving assets distributed pursuant to this Article shall enjoy the same rights with respect to such assets as the Bank enjoyed prior to their distribution. 


\section{Article VIII \\ STATUS, IMIMUNITIES AND PRIVILEGES}

\section{Section 1. Scope of article}

To enable the Bank to fulfill its purposes and the functions with which it is entrusted, the status, immunities, and privileges set forth in this Article shall be accorded to the Bank in the territories of each Party.

\section{Section 2. Legal status}

The Bank shall possess juridical personality and, in particular, full capacity:

(a) to contract;

(b) to acquire and dispose of immovable and movable property; and

(c) to institute legal proceedings.

\section{Section 3. Judicial proceedings}

Actions may be brought against the Bank only in a court of competent jurisdiction in the territories of a Party in which the Bank has an office, has appointed an agent for the purpose of accepting service or notice of process, or has issued or guaranteed securities.

No action shall be brought against the Bank by the Parties or persons acting for or deriving claims from the Parties. However, the Parties shall have recourse to such special procedures to settle controversies between the Bank and its Parties as may be prescribed in this Chapter, in the by-laws and regulations of the Bank or in contracts entered into with the Bank.

Property and assets of the Bank shall, wheresoever located and by whomsoever held, be immune from all forms of seizure, attachment or execution before the delivery of final judgment against the Bank.

\section{Section 4. Immunity of assets}

Property and assets of the Bank, wheresoever located and by whomsoever held, shall be considered public international property and shall be immune from search, requisition, confiscation, expropriation or any other form of taking or foreclosure by executive or legislative action.

\section{Section 5. Inviolability of archives}

The archives of the Bank shall be inviolable.

\section{Section 6. Freedom of assets from restrictions}

To the extent necessary to carry out the purposes and functions of the Bank and to conduct its operations in accordance with this Chapter, all property and other assets of the Bank shall be free from restrictions, regulations, controls and moratoria of any nature, except as may otherwise be provided in this Chapter.

\section{Section 7. Privilege for communications}

The official communications of the Bank shall be accorded by each Party the same treatment that it accords to the official communications of the other Party.

\section{Section 8. Personal immunities and privileges}

All Board members, alternates, officers, and staff of the Bank shall have the following privileges and immunities: 
(a) immunity from legal process with respect to acts performed by them in their official capacity, except when the Bank waives this immunity;

(b) when not local nationals, the same immunities from immigration restrictions, alien registration requirements and national service obligations and the same facilities as regard exchange provisions as are accorded by the Parties to the representatives, officials, and employees of comparable rank of the Inter-American Development Bank; and

(c) the same privileges in respect of traveling facilities as are accorded by the Parties to representatives, officials, and employees of comparable rank of members of the Inter-American Development Bank.

\section{Section 9. Immunities from taxation}

(a) The Bank, its property, other assets, income, and the operations it carries out pursuant to this Chapter shall be immune from all taxation and from all customs duties. The Bank shall also be immune from any obligation relating to the payment, withholding or collection of any tax or customs duty.

(b) No tax shall be levied on or in respect of any salaries or emoluments paid by the Bank to Board members, alternates, officials or staff of the Bank who are not local nationals.

(c) No tax of any kind shall be levied on any obligation or security issued by the Bank, including any dividend or interest thereon, by whomsoever held:

(1) which discriminates against such obligation or security solely because it is issued by the Bank; or

(2) if the sole jurisdictional basis for such taxation is the place or currency in which it is issued, made payable or paid, or the location of any office or place of business maintained by the Bank.

(d) No tax of any kind shall be levied on any obligation or security guaranteed by the Bank, including any dividend or interest thereon, by whomsoever held:

(1) which discriminates against such obligation or security solely because it is guaranteed by the Bank; or

(2) if the sole jurisdictional basis for such taxation is the location of any office or place of business maintained by the Bank.

\section{Section 10. Implementation}

Each Party, in accordance with its juridical system, shall take such action as is necessary to make effective in its own territories the principles set forth in this Article, and shall inform the Bank of the action which it has taken on the matter.

\section{Article IX \\ INTERPRETATION AND ARBITRATION}

\section{Section 1. Interpretation}

The Parties shall at all times endeavor to agree on the interpretation and application of this Chapter, and shall make every effort to resolve any matter that might affect the implementation of this Chapter. 


\section{Section 2. Arbitration}

In the event the Parties are not able to reach agreement on any question of interpretation of this Chapter within a reasonable time, either Party may request in writing the initiation of an arbitral proceeding. An arbitration panel shall be established in accordance with the following procedures:

(1) the panel shall be composed of three members;

(2) panelists shall be selected from the financial services roster established pursuant to Article 1414 of the North American Free Trade Agreement;

(3) the Parties shall endeavor to agree on the chairperson of the panel within 15 days of the delivery of the request for the initiation of the arbitral proceeding. If the Parties are unable to agree on the chairperson within this period, the Party chosen by lot shall select from the financial services roster within five days as chairperson an individual who is not a national of that Party; and

(4) within 15 days of selection of the chairperson, each disputing Party shall select a panelist from among the roster members who are nationals of the other Party.

\section{Article XI \\ GENERAL PROVISIONS}

\section{Section 1. Principal office}

The principal office of the Bank shall be located in a place to be mutually agreed by the Parties so as to facilitate the operations of the Bank.

\section{Section 2. Relations with other organizations}

The Bank may enter into arrangements with other organizations with respect to the exchange of information or for other purposes consistent with this Chapter.

\section{Section 3. Channel of communication}

Each Party shall designate an official entity for purposes of communication with the Bank on matters connected with this Chapter.

\section{Section 4. Depositories}

Each Party shall designate its central bank to serve as a depository in which the Bank may keep its holdings of such Party's currency and other assets of the Bank. However, with the agreement of the Bank, a Party may designate another institution for such purpose.

\section{Section 5. Commencement of operations}

The Parties shall call the first meeting of the Board of the Bank as soon as this Agreement enters into force under Article I of Chapter III of this Agreement. 


\title{
CHAPTER III \\ ENTRY INTO FORCE, AMENDMENT, DEFINITIONS AND OTHER ARRANGEMENTS
}

\author{
Article I \\ ENTRY INTO FORCE
}

This Agreement shall enter into force on January 1, 1994, immediately after entry into force of the North American Free Trade Agreement, on an exchange of written notifications certifying the completion of necessary legal procedures.

\section{Article II}

\section{AMENDMENT}

The Parties may agree on any modification of or addition to this Agreement. In particular, the Parties shall from time to time consider whether to make such modifications of or additions to this Agreement as would be necessary to:

expand the functions of the Commission to include other kinds of environmental or other infrastructure projects;

expand the geographic scope of the Commission;

give the Commission the capacity to raise capital so that it might issue loans or guarantees for envirormental or other infrastructure projects; or

change the environmental preferences expressed in Article II, Section 2(b) of Chapter I of this Agreement.

When so agreed, and approved in accordance with the applicable legal procedures of each Party, a modification or addition shall constitute an integral part of this Agreement.

\section{Article III \\ RELATION TO OTHER AGREEMENTS OR ARRANGEMENTS}

(a) Nothing in this Agreement shall prejudice other agreements or arrangements between the Parties, including those relating to conservation or the environment.

(b) Nothing in this Agreement shall be construed to limit the right of any public entity or private person of a Party to seek investment capital or other sources of finance, or to propose, construct or operate an environmental infrastructure project in the border region without the assistance or certification of the Commission.

Article IV

\section{AUTHENTIC TEXTS}

The English and Spanish texts of this Agreement are equally authentic.

\section{Article V \\ DEFINITIONS}

For purposes of this Agreement, it shall be understood that: 
"Bank" means the North American Development Bank established pursuant to Chapter II of this Agreement;

"Board of Directors" means the Board established pursuant to Article III, Section 3, of Chapter I of this Agreement;

"Board of the Bank" means the Board established pursuant to Article VI, Section 2, of Chapter II of this Agreement;

"Border region" means the area within 100 kilometers of the international frontier between the United States and Mexico;

"Commission" means the Border Environment Cooperation Commission established pursuant to Chapter I of this Agreement;

"Environmental infrastructure project" means a project that will prevent, control or reduce environmental pollutants or contaminants, improve the drinking water supply, or protect flora and fauna so as to improve human health, promote sustainable development, or contribute to a higher quality of life;

"Mexico" means the United Mexican States;

"Mexican border states" means Baja California, Chihuahua, Coahuila, Nuevo Leon, Sonora and Tamaulipas;

"National" means a natural person who is a citizen or permanent resident of a Party, including:

1) with respect to Mexico, a national or a citizen according to Articles 30 and 34, respectively, of the Mexican Constitution; and

2) with respect to the United States, "national of the United States" as defined in the existing provisions of the Immigration and Nationality Act.

"Non-governmental organization" means any scientific, professional, business, non-profit or public interest organization or association which is neither affiliated with, nor under the direction of, a government;

"North American Development Bank" means the bank established by the Parties pursuant to Chapter II of this Agreement;

"United States" means the United States of America; and

"U.S. border states" means Arizona, California, New Mexico and Texas.

IN WITNESS WHEREOF, the undersigned, being duly authorized by their respective Governments, have signed this Agreement.

DONE at Washington and Mexico City, this 16th day and this 18th day of November 1993, in duplicate, in the English and Spanish languages.

FOR THE GOVERNMENT OF THE

UNITED STATES OF AMERICA

William J. Clinton
FOR THE GOVERNMENT OF THE UNITED MEXICAN STATES

Carlos Salinas de Gortari 


\section{ANNEXA}

INITIAL SUBSCRIPTIONS TO THE AUTHORIZED CAPITAL STOCK OF THE BANK

(In shares of U.S. $\$ 10,000$ each)

$\begin{array}{lccc} & \begin{array}{l}\text { Paid-in } \\ \text { Capital Shares }\end{array} & \begin{array}{l}\text { Callable } \\ \text { Shares }\end{array} & \begin{array}{l}\text { Total } \\ \text { Subscription }\end{array} \\ \text { United States } & 22,500 & 127,500 & 150,000 \\ \text { Mexico } & \underline{22,500} & \underline{127,500} & \underline{150,000} \\ \text { Total } & 45,000 & 255,000 & 300,000\end{array}$





\section{B I L A T E R A L}

MeXico

NON - B I NDING DOCUMENTS 



\section{Memorandum of Understanding Between the Southwest Fisheries Center of the National Marine Fisheries Service, U.S. Department of Commerce and the National Fisheries Institute of the Mexican Secretariat of Fisheries on Fishery Research and Technological Cooperation, Manzanillo, 1992}

Done at Manzanillo 19 September 1992

Primary source citation: Copy of text provided by the

National Marine Fisheries Service, U.S. Department of Commerce

\section{MEMORANDUM OF UNDERSTANDING MEXUS-PACIFICO}

Memorandum on fishery research and technological cooperation, concluded by the Southwest Fisheries Center of the National Marine Fisheries Service, Southwest Region, represented by the Science and Research Director and the National Fisheries Institute of the Mexican Secretariat of Fisheries, represented by the Director General. For the purposes of this Instrument, the above agencies shall be called "the Center" and "the Institute", respectively, in the following declarations and clauses.

\section{Declarations}

1. The Institute, through its Director General, declares that it is a decentralized organ of the Secretariat of Fisheries of Mexico under the terms of Article 41 of the internal regulations of that agency, and that it has, among other powers, those conferred upon it by the Federal Law for Fisheries and by other laws, in conformity with the manual of procedures and any other provisions established by the Secretary of Fisheries. It is also authorized to carry out activities in conjunction with other agencies and entities of the Federal Government and with the institutes of higher learning that may engage in research programs with it.

Mexican legislation of special relevance to this memorandum includes the Federal Law of the Sea, the Federal Law for Fisheries, and other applicable provisions. 
2. The Science and Research Director declares that the Southwest Fisheries Center is a unit of the National Marine Fisheries Service authorized to conduct fishery research in accordance with Federal laws concerning living marine fishery resources and their environment. Under these laws, the Center is authorized to carry out activities coordinated with other agencies and entities of the Federal Government and with other institutions for purposes of conducting fisheries research programs. U.S. legislation of relevance to this memorandum includes the American Fisheries Promotion Act of 1980, the Magnuson Fishery Conservation and Management Act of 1976, and the Marine Mammal Protection Act of 1972.

3. The purpose of this memorandum is to develop and coordinate a program of cooperation between the Parties for conducting research and technical cooperation projects on the western coast of the states of Baja California and Baja California Sur in Mexico and the coast of the state of California in the United States, with a view to furthering knowledge of the fishery resources of these areas.

In view of the foregoing, both Parties agree to comply with the following:

\section{Clauses}

First: The Center and the Institute agree that the purpose of this memorandum is the coordinated conduct of research and cooperative technical projects with a view to furthering knowledge of the fishery resources of the region described above, both on the high seas and in the exclusive economic zones of the two countries.

Second: The fishery resources on which research shall be conducted under this memorandum are the following:
1. Anchovy (Engraulis mordax)
2. Pacific sardine (Sardinops sagax caerulea)
3. Jack mackerel (Trachurus symmetricus)
4. Pacific mackerel (Scomber japonicus)
5. Squid (Loligo opalescens, Dosidicus gigas and Ommastrephes spp.)
6. Sea turtles, including the loggerhead (Caretta caretta)

Third: With a view to implementing this memorandum, a joint committee shall be established, composed of members of the Center and the Institute. The committee shall have the following duties:

1. To determine jointly the program of correlated research and technical projects;

2. To supervise the progress of the work and determine the number and purpose of research cruises; and

3. To compile and publish the research results.

Fourth: Specific subcommittees shall be established and shall prepare annual work programs in which the number and purpose of research cruises shall be determined.

Fifth: To carry out the two previous clauses, each Party will designate an individual in each of the research areas specified in the second clause.

Sixth: An annual meeting shall be held to evaluate the work done during the preceding year and to establish the program for each following year. The Parties agree that the meeting will be held during May. At these meetings, the list of research areas included in Clause 2 will be reviewed and may be modified or expanded, if necessary, by the mutual agreement of the Parties. 
Seventh: In the event that the programs agreed upon involve cruises or research in jurisdictional zones of Mexico or the United States, these shall comport with applicable national legislation. Applications for research permits shall be processed through diplomatic channels sufficiently in advance.

The terms and conditions set forth in applicable national legislation shall be defined in the respective permits.

Eighth: The two Parties agree that the results of any coordinated research conducted under this memorandum shall be submitted to the consideration of the fishery authorities of the two countries-both the National Marine Fisheries Service and the Secretariat of Fisheries.

Furthermore, they agree that these results shall not constitute a legal basis for any claim over any part of the marine environment or its resources under the terms of international law.

Ninth: The Center and the Institute agree that no part of this Memorandum of Understanding shall prejudice the positions held by their respective governments with respect to the Law of the Sea. Each Party also agrees to refrain from activities or unilateral measures that violate the sovereignty of the other Party.

Tenth: The activities planned under this memorandum shall be subject to the availability of both manpower and funds.

Eleventh: The Parties agree that this memorandum shall be in effect from the date of its signing. The memorandum can be modified by mutual consent or terminated by either Party with 6 months written notification. The Parties can also agree to additional undertakings regarding specific activities covered in this memorandum.

The Parties, aware of the content and scope of the declarations and clauses of this memorandum, hereby sign it in the city of Manzanillo on September 19, 1992. Done in duplicate in the English and Spanish languages, both texts being equally authentic.

For the Southwest Fisheries

Center

[Signature]

Dr. Izadore Barrett

Science and Research Director

Witnesses:

[Signature]

Dr. William W. Fox, Jr.

Assistant Administrator for Fisheries
For the National Institute of Fisheries

[Signature]

Dra. Margarita Lizarraga Saucedo

Director General

[Signature]

Lic. Carlos Camacho Gaos

Undersecretary for Fisheries

Promotion and Development 



\title{
B I L A T E R A L
}

\author{
Moldova
}

ENVIRONMENTANDNATURALRESOURCES 



\title{
Agreement Between the Government of the United States of America and the Government of Moldova for Cooperation in the GLOBE Program, Washington, D.C., 1995
}

\author{
Done at Washington, D.C. 30 January 1995 \\ Entered into force 30 January 1995 \\ Primary source citation: Copy of text provided by the \\ U.S. Department of State
}

\section{AGREEMENT BETWEEN THE GOVERNMENT OF THE UNITED STATES OF AMERICA AND THE GOVERNMENT OF MOLDOVA FOR COOPERATION IN THE GLOBE PROGRAM}

\section{PREAMBLE}

The Government of the United States of America and the Government of Moldova (hereinafter, the sides),

Intending to increase the awareness of students throughout the world about the global environment,

Seeking to contribute to increased scientific understanding of the Earth, and

Desiring to support improved student achievement in science and mathematics,

Have agreed to cooperate in the Global Learning and Observations to Benefit the Environment (GLOBE) Program as follows:

\section{ARTICLE 1 - THE GLOBE PROGRAM}

The GLOBE Program is an international environmental science and education program that will bring students, teachers, and scientists together to study the global environment. GLOBE will create an international network of students in grades K-12 (or equivalent) studying environmental issues, making environmental measurements, and sharing useful environmental data with the international environmental science community. 


\section{ARTICLE 2 - COOPERATING AGENCIES}

Agencies responsible for cooperation and coordination under this agreement are:

On the U.S. side, the U.S. National Oceanic and Atmospheric Administration, acting in conjunction with other U.S. Government agencies participating in the GLOBE Program;

On the Moldovan side, the Ministry of Education and the Department of Environmental Protection.

\section{ARTICLE 3 - RESPECTIVE RESPONSIBLITIES}

A. The U.S. side will:

1. Identify U.S. schools that will participate in the GLOBE Program (details regarding GLOBE schools in Appendix A);

2. Select, in consultation with international scientists and educators, the GLOBE environmental measurements and types of measurement equipment (described in Appendix B);

3. Select Principal Investigator Teams for the GLOBE environmental measurements, and support the U.S. members of the Teams;

4. Calibrate, if necessary, measurement equipment that cannot be calibrated by GLOBE teachers and students;

5. Develop, in consultation with international scientists and educators, GLOBE educational materials;

6. Translate GLOBE instructional materials related to measurement procedures and data reporting protocols into the six United Nations languages, and provide these plus all broader GLOBE educational materials to the Moldovan side for further reproduction as necessary;

7. Conduct annual regional training sessions for GLOBE Country Coordinators and GLOBE teachers who will serve as trainers for additional GLOBE teachers in Moldova, and provide a copy of GLOBE training materials to the Moldovan side;

8. Design, develop, operate, and maintain GLOBE data processing capabilities and other necessary technology and equipment;

9. Provide GLOBE software, as necessary, for use on Moldovan GLOBE school computers. (To the maximum extent possible, textual material appearing on computer screens will be accessible in the student's choice among the six United Nations languages.);

10. Accept environmental data reported from GLOBE schools around the world, and develop and provide resultant global environmental images (visualization products) to the Moldovan side; and

11. Evaluate the overall GLOBE Program periodically, in consultation with international GLOBE Country Coordinators, and modify the overall program as appropriate.

B. The Moldovan side will:

1. Select Moldovan schools to participate in the GLOBE Program (details regarding GLOBE schools in Appendix A) and provide an updated list of Moldovan GLOBE schools to the U.S. side at the beginning of each school year;

2. Ensure that Moldovan GLOBE schools conduct the fundamental activities of GLOBE schools detailed in Appendix A (take GLOBE environmental measurements, report data, and receive and use resultant 
global environmental images, using GLOBE educational materials under the guidance of teachers trained to conduct the GLOBE Program);

3. Name a Moldovan Government Point of Contact responsible for policy-level communications with the Director of the GLOBE Program;

4. Name a Country Coordinator responsible for day-to-day management, oversight, and facilitation of the GLOBE Program in Moldova;

5. Ensure that the Country Coordinator and some GLOBE teachers attend GLOBE regional training and in turn provide GLOBE training to at least one teacher in each Moldovan GLOBE school;

6. Ensure that GLOBE instructional materials related to measurement procedures and data reporting protocols are utilized in Moldovan GLOBE schools, and that broader GLOBE educational materials are appropriately translated, adapted, reproduced, and distributed to all Moldovan GLOBE schools;

7. Ensure that Moldovan GLOBE schools have the necessary measurement equipment to take GLOBE environmental measurements (described in Appendix B);

8. Ensure that teachers and students at Moldovan GLOBE schools calibrate GLOBE measurement equipment according to procedures provided in GLOBE instructional materials;

9. Ensure that Moldovan GLOBE schools have the necessary computer and communications systems (described in Appendix C) to report GLOBE environmental measurements and to receive and use GLOBE visualization products, or make agreed alternative arrangements for such reporting and receipt. (At a minimum, the Moldovan Country Coordinator will need access to Internet so that all measurement data from Moldovan GLOBE schools will be reported via Internet.); and

10. Evaluate GLOBE operations in Moldova periodically and assist the U.S. side in conducting periodic evaluation of the overall GLOBE Program.

\section{ARTICLE 4 - FINANCIAL ARRANGEMENTS}

Each side will bear the costs of fulfilling its respective responsibilities under this agreement. Obligations of each side pursuant to this agreement are subject to its respective funding procedures and the availability of appropriated funds, personnel, and other resources. The conduct of activities under this agreement will be consistent with the relevant laws and regulations of the two sides.

\section{ARTICLE 5 - EXCHANGE OF DATA AND GOODS}

GLOBE environmental measurement data, visualization products, software, and educational materials will be available worldwide without restriction as to their use or redistribution.

\section{ARTICLE 6 - RELEASE OF INFORMATION ABOUT THE GLOBE PROGRAM}

Each side may release information on the GLOBE Program as it may deem appropriate without prior consultation with the other. 


\section{ARTICLE 7 - CUSTOMS AND IMMIGRATION}

Each side will, to the extent permitted by its laws and regulations, facilitate the movement of persons and goods necessary to implement this agreement into and out of its territory and accord entry to such goods into its territory free of customs duties and other similar charges.

\section{ARTICLE 8 - ENTRY INTO FORCE, AMENDMENTS, WITHDRAWAL}

This agreement will enter into force upon signature of the two sides and will remain in force for five years. It will be automatically extended for further five-year periods, unless either side decides to terminate it and so notifies the other side with three months written notice. This agreement may be terminated at any time by either side upon three months prior written notice to the other side. This agreement may be amended by written agreement of the two sides.

Done at Washington, in duplicate, on January 30, 1995.

FOR THE GOVERNMENT OF THE

UNITED STATES OF AMERICA:

[Signature]
FOR THE GOVERNMENT OF MOLDOVA:

[Signature]

\section{APPENDIXA GLOBE Schools}

Each partner country will be responsible for identifying its participating schools. Schools should be selected so as to satisfy the objectives of the GLOBE Program. In particular, countries should emphasize the selection of schools that will maximize the number of students worldwide participating in the program. Also, countries should consider involving schools in locations that will yield measurement data that is important to the international environmental science community.

Students at all GLOBE schools throughout the world will conduct the following fundamental activities: they will make environmental measurements at or near their schools; report their data to a GLOBE data processing site; receive vivid graphical global environmental images (visualization products) created from their data and the data from other GLOBE schools around the world; and study the environment by relating their observations and the resulting visualization products to broader environmental topics. All of these activities will be conducted under the guidance of specially trained teachers (GLOBE-trained teachers).

GLOBE educational materials will be used in GLOBE schools under the guidance of GLOBE-trained teachers. These materials will detail procedures for taking environmental measurements and protocols for reporting data; explain the significance of the measurements; guide the use of the visualization products; and integrate the measurement aspects of the program into a broader study of the environment.

Schools throughout the United States and the rest of the world that are not GLOBE schools may become GLOBE Affiliate schools by observing the GLOBE Program in operation through the Internet. Students at these schools will benefit from the use of GLOBE visualization products and educational materials accessible on-line. All GLOBE Affiliate schools will be encouraged to become participating GLOBE schools.

\section{APPENDIX B GLOBE Environmental Measurements and Equipment}

GLOBE environmental measurements will contribute in a significant way to the scientific understanding of the dynamics of the global environment. Every GLOBE school will conduct a core set of GLOBE environmental measurements in the following critical areas: Atmosphere/Climate, Hydrology/Water Chemistry, and Biology/Geology. Where possible, a GLOBE school may coordinate its activities with those of other neighboring GLOBE schools, so 
that the complete set of GLOBE measurements will be available from a locality. As the GLOBE Program evolves, elective measurements not common to all GLOBE schools may be added in order to address local environmental issues.

Students at all age levels will be active participants in the GLOBE Program. The actual participation will be designed so as to be grade appropriate for grades $\mathrm{K}-5,6-8$, and 9-12 (or equivalent). Younger students will make limited measurements which may be qualitative rather than quantitative. Older students will make additional measurements and more sophisticated measurements, as appropriate for their grade level. Measurement equipment will not need to be standardized; rather, performance specifications will be provided.

Following is an example list of core measurements and equipment. The full list will be initially determined and periodically updated as provided in Article 2.A.2, based on experience gained in implementing the GLOBE Program.

\section{Measurements}

\section{Grades K-5:}

\title{
Equipment Needed
}

\author{
Atmosphere/Climate \\ Air Temperature \\ Precipitation \\ Barometric Pressure \\ Cloud Observations \\ Weather Image Analysis*
Hydrology/Water Chemistry
Water Temperature
Water $\mathrm{pH}$
Water Chemistry
Hydrologic Assessment*

\section{Biology/Geology} \\ Biometrics \\ Species Identification \\ Soil Temperature \\ Land Cover Assessment*
}

\section{Grades 6-12:}

\author{
Atmosphere/Climate \\ Air Temperature \\ Precipitation \\ Barometric Pressure \\ Dew Point \\ Wind Speed/Direction \\ Trace Gases \\ Cloud Observations \\ Weather Image Analysis*
Hydrology/Water Chemistry
Water Temperature
Water $\mathrm{pH}$
Water Chemistry
Soil Moisture
Hydrologic Assessment*

\author{
Max/Min Thermometer \\ Rain Gauge \\ Barometer \\ Cloud Kit (Wall Chart, Slides, etc.) \\ Hardcopy Images
}

Thermometer

Litmus Paper/Colorimetric

Water Testing Kit

Hardcopy Images

Tape Measure, Simple Clinometers

Simple Dichotomous Keys

Thermometer

Hardcopy Images

\author{
Max/Min Thermometer \\ Rain Gauge \\ Barometer \\ Sling Psychrometer \\ Anemometer, Wind Vane \\ (To Be Determined) \\ Cloud Kit \\ Hardcopy Images
}

Thermometer pH Pens, pH Meter

Water Testing Kit

(To Be Determined)

Hardcopy Images

"These studies, where possible, will be conducted using hardcopy images produced from weather satellites such as GOESMeteosat and land surface systems stch as Landsat/SPOT satellite datasets which the U.S. will provide. 


\author{
Biology/Geology \\ Biometrics \\ Species Identification \\ Phenology \\ State-of-Health \\ Soil Temperature \\ Soil Types \\ GPS** \\ Land Use/Cover Assessment*
}

\author{
Clinometer, Tape Measure \\ Dichotomous Keys, Taxonomic Manuals \\ Camera, Film \\ Texts, Color Plates, Local Resources \\ Thermometer \\ Soil Manuals, Keys \\ Provided by the U.S. \\ Hardcopy Images
}

\section{APPENDIX C \\ GLOBE Computer and Communications Systems}

In order to derive maximum benefit from the GLOBE Program, all schools will be encouraged to use an international information network, initially using the Internet, along with classroom computers using software capable of multimedia presentations. Technology associated with the GLOBE Program will continually evolve to higher levels and participants will be encouraged to upgrade over time. Following is a description of GLOBE computer and communications systems consistent with current GLOBE requirements.

The U.S. side will adapt or develop software for IBM-compatible and Apple Macintosh computer configurations to support the required GLOBE school activities of data entry, data analysis, and use of visualization products. Current planning calls for limiting this software development effort to IBM-compatible or Apple Macintosh computers capable of running TCP/IP and supporting World Wide Web client software, such as MOSAIC, with GLOBE extensions. Overall attributes of this minimum usable GLOBE school computer configuration are as follows: a) for IBM-compatible: $386 \mathrm{SX}$ processor, Windows 3.1 in enhanced mode, $4 \mathrm{MB}$ of RAM, $60 \mathrm{MB}$ of available hard disk space, and a direct Internet connection or dial-up connection using SLIP or PPP and a 14,400bps modem, preferably with V.42bis, which can enable 57,600bps operation using data compression; and b) for Apple Macintosh: $6803020 \mathrm{MHz}$ processor, 4MB of RAM, $60 \mathrm{MB}$ of available hard disk space, and a direct Internet connection or dial-up connection using SLIP or PPP and a $14,400 \mathrm{bps}$ modem, preferably with V.42bis, which can enable $57,600 \mathrm{bps}$ operation using data compression.

A higher performance GLOBE school computer system is also being developed for the following configuration: a 486/66 processor, 16MB of RAM, 500MB of available hard disk space, super VGA monitor, double-speed CD-ROM reader, sound card, and MPEG speed-up board.

It is recognized that there is a broad range of technological capabilities among potential GLOBE schools. The diversity of technology accessible by schools worldwide may require in some cases that environmental measurements be reported in hardcopy and that a variety of media be used to distribute visualization products, including photographs and broadcast television. All schools that want to participate in the program will be accommodated.

\footnotetext{
*These studies, where possible, will be conducted using hardcopy images produced from weather satellites such as GOES/Meteosat and land surface systems such as Landsat/SPOT satellite datasets which the U.S. will provide.

**Global Positioning System (GPS) measurements will be made, as necessary, by the U.S. to determine the location of GLOBE study sites on the ground.
} 


\section{B I L A T E R A $\mathbf{L}$}

\section{The NetherLands}

ENVIRONMENT AND NATURAL RESOURCES 



\section{Memorandum of Understanding Between the Government of the United States of America and the Government of the Netherlands for Cooperation in the GLOBE Program, Washington, D.C., 1995}

Done at Washington, D.C. 28 February 1995

Entered into force 28 February 1995

Primary source citation: Copy of text provided by the U.S. Department of State

\section{MEMORANDUM OF UNDERSTANDING BETWEEN THE GOVERNMENT OF THE UNITED STATES OF AMERICA AND THE GOVERNMENT OF THE NETHERLANDS FOR COOPERATION IN THE GLOBE PROGRAM}

\section{PREAMBLE}

The Government of the United States of America and the Government of the Netherlands (hereinafter, the sides),

Intending to increase the awareness of students throughout the world about the global environment,

Seeking to contribute to increased scientific understanding of the Earth, and

Desiring to support improved student achievement in science and mathematics,

Have agreed to cooperate in the Global Learning and Observations to Benefit the Environment (GLOBE) Program as follows:

\section{ARTICLE 1 - THE GLOBE PROGRAM}

The GLOBE Program is an international environmental science and education program that will bring students, teachers, and scientists together to study the global environment. GLOBE will create an international network of students in grades K-12 (or equivalent) studying environmental issues, making environmental measurements, and sharing useful environmental data with the international environmental science community. 


\section{ARTICLE 2 - COOPERATING AGENCIES}

Agencies responsible for cooperation and coordination under this Memorandum of Understanding are:

On the U.S. side, the U.S. National Oceanic and Atmospheric Administration, acting in conjunction with other U.S. Government agencies participating in the GLOBE Program;

On the Netherlands side, the Ministry of Housing, Spatial Planning and Environment. The Netherlands Country Coordinator is SME MilieuAdviseurs.

\section{ARTICLE 3 - RESPECTIVE RESPONSIBILITIES}

A. The U.S. side will:

1. Identify U.S. schools that will participate in the GLOBE Program (details regarding GLOBE schools in Appendix A);

2. Select, in consultation with international scientists and educators, the GLOBE environmental measurements and types of measurement equipment (described in Appendix B);

3. Select Principal Investigator Teams for the GLOBE environmental measurements, and support the U.S. members of the Teams;

4. Calibrate, if necessary, measurement equipment that cannot be calibrated by GLOBE teachers and students;

5. Develop, in consultation with international scientists and educators, GLOBE educational materials;

6. Translate GLOBE instructional materials related to measurement procedures and data reporting protocols into the six United Nations languages, and provide these plus all broader GLOBE educational materials to the Netherlands side for further reproduction as necessary;

7. Conduct annual regional training sessions for GLOBE Country Coordinators and GLOBE teachers who will serve as trainers for additional GLOBE teachers in the Netherlands and provide a copy of GLOBE training materials to the Netherlands side;

8. Design, develop, operate, and maintain GLOBE data processing capabilities and other necessary technology and equipment;

9. Provide GLOBE software, as necessary, for use on the Netherlands GLOBE school computers. (To the maximum extent possible, textual material appearing on computer screens will be accessible in the student's choice among the six United Nations languages.);

10. Accept environmental data reported from GLOBE schools around the world, and develop and provide resultant global environmental images (visualization products) to the Netherlands side; and

11. Evaluate the overall GLOBE Program periodically, in consultation with international GLOBE Country Coordinators, and modify the overall program as appropriate.

B. The Netherlands side will:

1. Select the Netherlands schools to participate in the GLOBE Program (details regarding GLOBE schools in Appendix A) and provide an updated list of the Netherlands GLOBE schools to the U.S. side at the beginning of each school year;

2. Ensure that the Netherlands GLOBE schools conduct the fundamental activities of GLOBE schools detailed in Appendix A (take GLOBE environmental measurements, report data, and receive and use 
resultant global environmental images, using GLOBE educational materials under the guidance of teachers trained to conduct the GLOBE Program);

3. Name the Netherlands Government Point of Contact responsible for policy-level communications with the Director of the GLOBE Program;

4. Name a Country Coordinator responsible for day-to-day management, oversight, and facilitation of the GLOBE Program in the Netherlands;

5. Ensure that the Country Coordinator and some GLOBE teachers attend GLOBE regional training and in turn provide GLOBE training to at least one teacher in each Netherlands GLOBE school;

6. Ensure that GLOBE instructional materials related to measurement procedures and data reporting protocols are utilized in Netherlands GLOBE schools, and that broader GLOBE educational materials are appropriately translated, adapted, reproduced, and distributed to all Netherlands GLOBE schools;

7. Ensure that Netherlands GLOBE schools have the necessary measurement equipment to take GLOBE environmental measurements (described in Appendix B);

8. Ensure that teachers and students at the Netherlands GLOBE schools calibrate GLOBE measurement equipment according to procedures provided in GLOBE instructional materials;

9. Ensure that the Netherlands GLOBE schools have the necessary computer and communications systems (described in Appendix C) to report GLOBE environmental measurements and to receive and use GLOBE visualization products, or make agreed alternative arrangements for such reporting and receipt. (At a minimum, the Netherlands Country Coordinator will need access to Internet so that all measurement data from the Netherlands GLOBE schools will be reported via Internet.); and

10. Evaluate GLOBE operations in the Netherlands periodically and assist the U.S. side in conducting periodic evaluation of the overall GLOBE Program.

\section{ARTICLE 4 - FINANCIAL AND LEGAL ARRANGEMENTS}

Each side will bear the costs of fulfilling its respective responsibilities under this Memorandum of Understanding. Obligations of each side pursuant to this Memorandum of Understanding are subject to its respective funding procedures and the availability of appropriated funds, personnel, and other resources.

The conduct of activities under this Memorandum of Understanding will be consistent with the relevant laws and regulations of the two sides.

\section{ARTICLE 5 - EXCHANGE OF DATA AND GOODS}

GLOBE environmental measurement data, visualization products, software, and educational materials will be available worldwide without restriction as to their use or redistribution.

\section{ARTICLE 6 - RELEASE OF INFORMATION ABOUT THE GLOBE PROGRAM}

Each side may release information on the GLOBE Program as it may deem appropriate without prior consultation with the other. 


\section{ARTICLE 7 - ENTRY INTO FORCE, AMENDMENTS, WITHDRAWAL}

This Memorandum of Understanding will enter into force upon signature of the two sides and will remain in force for five years. It will be automatically extended for further five-year periods, unless either side decides to terminate it and so notifies the other side with three months written notice. This Memorandum of Understanding may be terminated at any time by either side upon three months prior written notice to the other side. This Memorandum of Understanding may be amended as agreed in writing by the two sides.

Done at Washington, in duplicate, on February 28, 1995.

FOR THE GOVERNMENT OF THE UNITED STATES OF AMERICA:

[Signature]
FOR THE GOVERNMENT OF

THE NETHERLANDS:

[Signature]

\section{APPENDIX A GLOBE Schools}

Each partner country will be responsible for identifying its participating schools. Schools should be selected so as to satisfy the objectives of the GLOBE Program. In particular, countries should emphasize the selection of schools that will maximize the number of students worldwide participating in the program. Also, countries should consider involving schools in locations that will yield measurement data that is important to the international environmental science community.

Students at all GLOBE schools throughout the world will conduct the following fundamental activities: they will make environmental measurements at or near their schools; report their data to a GLOBE data processing site; receive vivid graphical global environmental images (visualization products) created from their data and the data from other GLOBE schools around the world; and study the environment by relating their observations and the resulting visualization products to broader environmental topics. All of these activities will be conducted under the guidance of specially trained teachers (GLOBE-trained teachers).

GLOBE educational materials will be used in GLOBE schools under the guidance of GLOBE-trained teachers. These materials will detail procedures for taking environmental measurements and protocols for reporting data; explain the significance of the measurements; guide the use of the visualization products; and integrate the measurement aspects of the program into a broader study of the environment.

Schools throughout the United States and the rest of the world that are not GLOBE schools may become GLOBE Affiliate schools by observing the GLOBE Program in operation through the Internet. Students at these schools will benefit from the use of GLOBE visualization products and educational materials accessible on-line. All GLOBE Affiliate schools will be encouraged to become participating GLOBE schools.

\section{APPENDIX B GLOBE Environmental Measurements and Equipment}

GLOBE environmental measurements will contribute in a significant way to the scientific understanding of the dynamics of the global environment. Every GLOBE school will conduct a core set of GLOBE environmental measurements in the following critical areas: Atmosphere/Climate, Hydrology/Water Chemistry, and Biology/Geology. Where possible, a GLOBE school may coordinate its activities with those of other neighboring GLOBE schools, so that the complete set of GLOBE measurements will be available from a locality. As the GLOBE Program evolves, elective measurements not common to all GLOBE schools may be added in order to address local environmental issues.

Students at all age levels will be active participants in the GLOBE Program. The actual participation will be designed so as to be grade-appropriate for grades K-5, 6-8, and 9-12 (or equivalent). Younger students will make limited measurements which may be qualitative rather than quantitative. Older students will make additional measure- 
ments and more sophisticated measurements, as appropriate for their grade level. Measurement equipment will not need to be standardized; rather, performance specifications will be provided.

Following is an example list of core measurements and equipment. The full list will be initially determined and periodically updated as provided in Article 2.A.2, based on experience gained in implementing the GLOBE Program.

\section{MEASUREMENTS}

\section{Atmosphere/Climate:}

Air Temperature

Precipitation

Cloud Cover/Type

Hydrology/Water Chemistry:

Water $\mathrm{pH}$

Water Temperature

Soil Moisture

\section{Biology/Geology: \\ Habitat Study}

Tree Height

Tree Canopy

Tree Diameter

Species Identification

Phenology

\section{EQUIPMENT NEEDED}

\author{
Max/Min Thermometer \\ Calibration Thermometer \\ Instrument Shelter \\ Rain Gauge \\ Cloud Charts
}

pH Paper, Pen, or Meter

Alcohol Thermometer

Gypsum Block Sensors

Soil Moisture Meter

\section{Compass}

Meter Measuring Tape

Surveying Markers or Stakes

Clinometer

Densiometer

Diameter Tape

Dichotomous Keys

$35 \mathrm{~mm}$ Camera

\section{APPENDIX C \\ GLOBE Computer and Communications Systems}

In order to derive maximum benefit from the GLOBE Program, all schools will be encouraged to use an international information network, initially using the Internet, along with classroom computers. The World Wide Web multi-media information-access capability has been selected as the basis for IBM-compatible and Apple Macintosh computer systems to support the required GLOBE school activities of data entry, data analysis, and use of GLOBE environmental images. Following is a description of GLOBE computer and communications systems consistent with current GLOBE requirements.

Overall attributes of the minimum GLOBE school computer configuration that can execute the necessary software are:

For IBM-compatible systems: a $386 \mathrm{SX}$ or higher level processor; at least 4 megabytes of RAM memory ( 8 megabytes preferred); a VGA-capable monitor and display driver (Super VGA preferred); a hard disk storage system with as large a capacity as possible (preferably 300 megabytes or larger); and a direct Internet connection or dial-up capability that can use SLIP or PPP protocols with a 14,400 bps modem (preferably supporting V.42bis data compression which can enable 57,600 bps operation). The Windows 3.1 or later operating system is necessary. A printer is desirable.

For Apple Macintosh systems: a 6803020 Mhz or faster processor; at least 4 megabytes of RAM memory ( 8 megabytes preferred); a hard disk storage system with as large a capacity as possible (preferably 300 megabytes or larger); and a direct Internet connection or dial-up capability that can use SLIP or PPP protocols with a 14,400 bps modem (preferably supporting V.42bis data compression which can enable 57,600 bps operation). A printer is desirable.

Software for a higher performance GLOBE school computer system is being developed that will operate on higher performance, multi-media IBM-compatible systems and on Apple Macintosh systems. For IBM-compatible systems: 
a 486/66 or faster processor; 16 megabytes of RAM memory; 500 megabytes of hard disk space; a Super VGA monitor; a double-speed CD-ROM reader; a Soundblaster-compatible sound card; and an MPEG animation speed-up board will be required. For Apple Macintosh systems: a PowerPC processor; 16 megabytes of RAM memory; 500 megabytes of hard disk space; and a double-speed CD-ROM reader will be required. A communications capability the same as or better than for the minimum configurations above will also be required. A printer will be highly desirable.

It is recognized that there is a broad range of technological capabilities among potential GLOBE schools. The diversity of technology accessible by schools worldwide may require in some cases that environmental measurements be reported in hardcopy and that a variety of media be used to distribute visualization products, including photographs and broadcast television. All schools that want to participate in the program will be accommodated.

Technology associated with the GLOBE Program will continually evolve to higher levels and participants will be encouraged to upgrade over time. 
NoRWAY

ENVIRONMENT AND NATURAL RESOURCES 



\section{Agreement Between the Department of}

Defense of the United States of America and the Ministry of Defense of the Kingdom of Norway for Cooperation on Environmental Protection in Defense Matters, Baltimore, 1994

Done at Baltimore 19 May 1994

Entered into force 19 May 1994

Primary source citation: Copy of text provided by the U.S. Department of State

\section{AGREEMENT BETWEEN THE DEPARTMENT OF DEFENSE OF THE UNITED STATES OF AMERICA AND THE MINISTRY OF DEFENSE OF THE KINGDOM OF NORWAY FOR COOPERATION ON ENVIRONMENTAL PROTECTION IN DEFENSE MATTERS}

Dated May 19, 1994

TABLE OF CONTENTS

PREAMBLE

ARTICLE I

DEFINITION OF TERMS AND ABBREVIATIONS

ARTICLE II

OBJECTIVE

ARTICLE III

SCOPE OF WORK

ARTICLE IV

MANAGEMENT (ORGANIZATION AND RESPONSIBILITY)

ARTICLE V

FINANCIAL PROVISIONS

ARTICLE VI

CONTRACTUAL PROVISIONS

ARTICLE VII

PROJECT EQUIPMENT

ARTICLE VIII

DISCLOSURE AND USE OF PROGRAM INFORMATION 
ARTICLE IX

ARTICLE X

ARTICLE XI

ARTICLE XII

ARTICLE XIII

ARTICLE XIV

ARTICLE XV

ARTICLE XVI

ARTICLE XVII

ARTICLE XVIII
CONTROLLED UNCLASSIFIED INFORMATION

VISITS TO ESTABLISHMENTS

SECURITY

THIRD PARTY SALES AND TRANSFERS

LIABILITY

CUSTOMS DUTIES, TAXES AND SIMILAR CHARGES

SETTLEMENT OF DISPUTES

LANGUAGE

GENERAL PROVISIONS

AMENDMENT, WITHDRAWAL, TERMINATION, ENTRY INTO FORCE

AND DURATION

\section{PREAMIBLE}

The Department of Defense of the United States of America and the Ministry of Defence of The Kingdom of Norway, hereinafter referred to as the "Parties":

Having a common interest in defense;

Recognize the benefits to be obtained from rationalization, standardization and interoperability of military equipments and methods for identifying and preventing environmental pollution;

Seek to make the best use of their respective research and development capacities, eliminate unnecessary duplication of work and obtain the most efficient and cost-effective results;

Recognize the need to collectively develop emerging technologies to address environmental issues;

Have agreed as follows:

\section{ARTICLE I}

\section{DEFINITION OF TERMS AND ABBREVIATIONS}

Classified

Information

Controlled

Unclassified

Project Information

Defense

Purposes

Designated Security

Authority (DSA)
Official information that requires protection in the interests of national security and is so designated by the application of a security classification marking.

Unclassified information to which access or distribution limitations have been applied in accordance with national laws and regulations, and which will be marked and handled in compliance with this Agreement.

Manufacture or other use in any part of the world by or for the armed forces of a Party, including the furnishing to a Third Party (subject to Article XII of this Agreement).

The security office approved by a national authority to be responsible for that nation's security aspects of this Agreement. 


\section{Environmental}

Technology Research and Development

Project (ETRDP)

\section{Project Background} Information

Project Foreground Information

Patent

Project Equipment

Project Information

Project Invention

Third Party
Specific information exchange or collaborative activity on basic research, exploratory and advanced development technologies in accordance with an Annex to this Agreement.

Information not generated in the performance of a ETRDP, working group or biannual meeting of the Parties.

Information generated in the performance of a ETRDP, working group or biannual meeting of the Parties.

Legal protection of the right to exclude others from making, using, or selling an invention. The term refers to any and all patents, including but not limited to patents of implementation, improvement, or addition, petty patents utility models, appearance design patents, registered designs, and inventor certificates or like statutory protection as well as divisions, reissues, continuations, renewals, and extensions, of any of these.

Any material, equipment, end item, subsystem, component, special tooling or test equipment used in a ETRDP.

Any data, knowledge, fact, or information provided, generated, or used in a ETRDP under this agreement regardless of form or type, including that of a scientific, technical, business, or financial nature, and also including photographs, reports, manuals, threat data, experimental data, test data, designs, specifications, processes, techniques, inventions, drawings, technical writings, sound recordings, pictorial representations, and other graphical presentations, whether in magnetic tape, computer memory, or any other form and whether or not subject to copyright, patent, or other legal protection.

Any invention or discovery formulated, made (conceived or first actually reduced to practice) in the course of work performed under a Project. The term first actually reduced to practice means the first demonstration, sufficient to establish to one skilled in the art to which the invention pertains, of the operability of an invention for its intended purpose and in its intended environment.

Any person or other entity whose government or whose governing authority is not a Party to this Agreement.

\section{ARTICLE II}

\section{OBJECTIVE}

1. The objective of this Agreement is to define and establish the general principles which shall apply to the initiation, conduct, and management of Annexes related to environmental technology research and development projects (ETRDP) between the Parties to provide for the exchange of research, development, test and evaluation information of mutual interest on environmental technology matters and for the performance of research, development, test and evaluation activities on environmental technology matters of mutual interest.

2. Detailed terms and conditions of each individual ETRDP shall be in accordance with this Agreement and be recorded in Annexes to this Agreement. Each Annex shall include, as a minimum, provisions concerning the objective, scope of work, management structure, financial arrangements, contractual arrangements (if required) and responsibilities of the Parties.

3. U.S. participation will include the OSD, Army, Navy and Air Force. 


\section{ARTICLE III}

\section{SCOPE OF WORK}

1. The scope of work for this Agreement shall encompass research and development collaboration and information exchange on basic research, exploratory and advanced development technologies whose maturation may lead to the development of environmental protection systems. ETRDPs may range from information exchange to conceptual studies to joint environmental experiments. Any specific prototypes, full-scale development or production programs which are based upon collaboration under one or more Annexes to this Agreement are outside the scope of this Agreement and shall require conclusion of separate agreements.

2. Experience, information and views on selected environmental issues will be initially exchanged in the following areas:

a. Efforts to reduce or eliminate adverse environmental impacts on air, water and land due to armed forces installations and activities.

b. Methods to measure, predict, and mitigate the effects of noise related to defense systems operations.

c. Efforts to monitor, remediate and restore environments contaminated by defense activities.

d. Guidelines and techniques for the disposal of defense material/wastes.

e. Factoring environmental considerations into the acquisition and procurement of equipment and facilities.

f. Efforts to implement pollution prevention and source reduction measures on naval ships and at defense installations.

g. Development of environmental training and education programs to increase environmental awareness in the armed forces.

h. Efforts to develop techniques needed for successful multiple resource management on defense installations in light of military operations.

3. Once these initial exchanges have taken place, individual ETRDPs will be established by the Parties to address specific areas of joint activity or information exchange.

\section{ARTICLE IV}

\section{MANAGEMENT}

1. In order to initiate work under this Agreement and to oversee ongoing joint activities, the Parties will meet biannually. The host Party will chair the meeting and provide secretarial support. At these meetings the Parties will receive reports on ongoing ETRDP activities from Steering Committees established pursuant to paragraph 3 below.

2. The Parties will also schedule working groups to address the environmental areas described in Article III, paragraph 2. When these working groups decide a particular area warrants further attention, the Parties will enter into an Annex to this Agreement to establish an ETRDP for that area.

3. Each ETRDP shall be directed and administered on behalf of the Parties by a Steering Committee (SC) and Project Officers (PO) appointed by each Party. The SC shall have overall authority over the POs, in accordance with this Agreement. The POs shall have primary responsibility for implementation, management, and direction of the ETRDP in accordance with this Agreement. 
4. The SC shall be responsible for:

a. Exercising executive-level policy and management direction during the course of ETRDP implementation.

b. Monitoring overall ETRDP implementation, including ETRDP execution, specifications, milestones, cost and financial requirements.

\section{ARTICLE V}

\section{FINANCIAL PROVISIONS}

1. Each Party shall contribute its equitable share of the full costs of each ETRDP, including overhead and administrative costs. The assignment of work shall represent an equitable sharing of work to be performed under each ETRDP. Each Party shall receive an equitable share of the results of each ETRDP.

2. The following costs shall be borne entirely by the Party incurring the costs:

a. Costs associated with any unique national requirements identified by a Party.

b. Costs associated with attendance at, and hosting of, biannual meetings and working groups.

c. Any other costs outside the scope of this Agreement and its Annexes.

3. A Party shall promptly notify the other Party if available funds are not adequate to fulfill its obligations under this Agreement or an Annex. If a Party notifies the other Party that it is terminating or reducing its funding for a ETRDP, both Parties shall immediately consult with a view toward continuation on a changed or reduced basis.

4. The financial arrangements for a specific ETRDP will be provided in the Annex for that ETRDP.

\section{ARTICLE VI}

\section{CONTRACTUAL PROVISIONS}

1. If either Party determines that contracting is necessary to fulfill that Party's obligations under the scope of work of an Annex of this Agreement, that Party shall contract in accordance with its national laws, regulations, policies and procedures.

2. When one Party individually contracts to undertake a task under an Annex to this Agreement, it shall be solely responsible for its own contracting, and the other Party shall not be subject to any liability arising from such contracts without its written agreement.

3. For all contracting activities performed by either Party, the POs shall be provided a copy of all Statements of Work prior to the development of solicitations to ensure that they are consistent with the provisions of this Agreement and the applicable Annex.

4. Each Party's Contracting Agency shall negotiate to obtain the rights to use and disclose Project Information required by ARTICLE VIII (Disclosure and Use of Project Information). Each Party's Contracting Agency shall insert into its prospective contracts (and require its subcontractors to insert in subcontracts) suitable provisions to satisfy the requirements of ARTICLE VIII (Disclosure and Use of Project Information), ARTICLE IX (Controlled Unclassified Information), ARTICLE XI (Security) and ARTICLE XII (Third Party Sales and Transfers) of this Agreement. During the contracting process, each Party's contracting officer shall advise prospective contractors of their obligation to immediately notify the Contracting Agency before contract award if they are subject to any license or agreement that will restrict that Party's freedom to disclose information or permit its use. The contracting officer will also advise 
prospective contractors to employ their best efforts not to enter into any new agreement or arrangement that shall result in restrictions.

5. In the event a Party's Contracting Agency is unable to secure adequate rights to use and disclose Project Information as required by ARTICLE VIII (Disclosure and Use of Project Information), or is notified by contractors or potential contractors of any restrictions on the disclosure and use of information, that Party's PO shall notify the other Party's PO of the restrictions.

6. Each Party's PO shall promptly advise the other Party's PO of any cost growth, schedule delay, or performance problems of any contractor for which its Contracting Agency is responsible.

\section{ARTICLE VII}

\section{PROJECT EQUIPMENT}

1. Each Party may provide Project Equipment identified as being necessary for executing an ETRDP to the other Party. Project Equipment shall remain the property of the providing Party. A list of all Project Equipment provided by one Party to another shall be developed and maintained by the Project Officers, and approved by the SC for each ETRDP.

2. The receiving Party shall maintain any such Project Equipment in good order, repair, and operable condition and return the items in as good condition as received, normal wear and tear excepted. The receiving Party shall pay the cost of damage (other than normal wear and tear) to or loss of Project Equipment.

3. All Project Equipment that is transferred shall be used by the receiving Party only for the purposes set out in the relevant Annex. In addition, in accordance with Article XII (Third Party Sales and Transfers) Project Equipment will not be re-transferred to a Third Party without the prior written consent of the providing Party.

4. Project Equipment transferred to one Party under this Agreement shall be returned to the providing Party prior to the termination or expiration of this Agreement.

5. Any Project Equipment which is jointly acquired on behalf of both Parties for use under this Agreement shall be disposed of during the ETRDP or when the ETRDP ceases, as agreed by the SC.

\section{ARTICLE VIII \\ DISCLOSURE AND USE OF PROJECT INFORMATION}

1. General

Both Parties recognize that successful collaboration depends on full and prompt exchange of information necessary for carrying out each ETRDP. The Parties intend to acquire sufficient Project Information and rights to enable collaboration on basic research, exploratory and advanced development technologies whose maturation may lead to the development of technologically superior environmental protection systems. The nature and amount of Project Information to be acquired shall be consistent with the objectives stated in ARTICLE II (Objectives) and the Annexes to this Agreement.

\section{Project Foreground Information}

a. Disclosure: Project Foreground Information shall be made available to both Parties in accordance with the provisions of this Agreement.

b. Use: Each Party may use this Project Foreground Information without charge for its Defense Purposes; however, if a Party intends to use the Project Foreground Information in a sale or other transfer to a Third Party, the provisions of ARTICLE XII (Third Party Sales and Transfers) of this Agreement shall apply. 


\section{Project Background Information}

a. Disclosure: Each Party, upon request, shall make available to the other Party any relevant information in its possession not generated in the performance of the Project, provided that:

(1) The Project Background Information is necessary to or useful in the Project. The Party in possession of the information shall determine whether it is "necessary to" or "useful in" the Project;

(2) The Project Background Information may be made available without incurring liability to holders of proprietary rights; and

(3) Disclosure is consistent with national disclosure policies and regulations of the furnishing Party.

b. Use: Project Background Information furnished by a Party may be used by the other Party for ETRDP purposes only.

\section{Proprietary Project Information}

a. All proprietary information shall be identified and marked.

b. The provisions of the Agreement to Facilitate Interchange of Patent Rights and Technical Information for Defense Purposes, dated April 6, 1955 between the U.S. and Norway shall apply to proprietary Project Information related to this Agreement.

\section{Patents}

a. Where a Party has or can secure the right to file a patent application with regard to a Project Invention, that Party shall consult with the other Party regarding the filing of such patent application. The Party having such rights shall in other countries, file, cause to be filed, or provide the other Party with the opportunity to file on behalf of the Party holding such rights, or its contractors, as appropriate, patent applications covering any such Project Invention. If a Party having filed or caused to be filed a patent application decides to stop prosecution of the application, that Party shall notify the other Party of that decision and permit the other Party to continue the prosecution.

b. Each Party shall be furnished with copies of patent applications filed and patents granted with regard to Project Inventions.

c. Each Party shall acquire a non-exclusive, irrevocable, royalty-free license to practice or have practiced, by or on behalf of the Party, throughout the world for Defense Purposes, any Project Invention.

d. Patent applications which contain classified information, to be filed under this Agreement, shall be protected and safeguarded in accordance with the Agreement Approving the Procedures for Reciprocal Filing of Classified Patent Applications in the U.S. and Norway, dated January 17, 1959. Insofar as possible, each Party shall extend to the other Party any relief from patent infringement claims arising in the course of work performed under the Project that it may be able to claim on its own behalf. The Parties shall, in accordance with their national laws and practices, give their authorization and consent for all use and manufacture in the course of work performed under the Project of any invention covered by a patent issued by their respective countries. Each Party is responsible for handling all patent infringement claims made in its territory and to inform the other Party of such claims and to consult with the other Party during the handling and prior to any settlement of such claims. 


\section{ARTICLE IX \\ CONTROLLED UNCLASSIFIED INFORMATION}

1. Except as otherwise provided in this Agreement or authorized in writing by the originating Party, Controlled Unclassified Information provided or generated pursuant to this Agreement shall be controlled as follows:

a. Such information shall be used only for the purposes authorized for use of Project Information as specified in ARTICLE VIII (Disclosure and Use of Project Information).

b. Access to such information shall be limited to personnel whose access is necessary for the permitted use under subparagraph (a) above, and subject to the provisions of ARTICLE XII (Third Party Sales and Transfers).

c. Each Party shall take all lawful steps, which may include national classification, available to it to keep such information free from further disclosure (including requests under any legislative provisions) unless the originating Party consents to such disclosure. In the event of unauthorized disclosure, or if it becomes probable that the information may have to be disclosed to a Third Party or a judicial body under any legislative provision, immediate notification shall be given to the originating Party.

2. To assist in providing the appropriate controls, the Parties shall agree in advance on the markings to be placed on the Controlled Unclassified Information.

3. Controlled Unclassified Information provided or generated pursuant to this Agreement shall be stored, handled and transmitted in a manner that ensures control as provided for in Paragraph 1. Prior to authorizing the release of Controlled Unclassified Information to contractors, the Parties shall ensure the contractors are legally bound to control such information in accordance with the provisions of this ARTICLE.

\section{ARTICLE X}

\section{VISITS TO ESTABLISHMENTS}

1. Each Party shall permit visits to its Government establishments, agencies and laboratories, and contractor industrial facilities by employees of the other Party or by employees of the other Party's contractor(s), provided that the visit is authorized by both Parties and the employees have appropriate security clearances and a need-to-know.

2. All visiting personnel shall be required to comply with security regulations of the host Party. Any information disclosed or made available to visitors shall be treated as if supplied to the Party sponsoring the visiting personnel, and shall be subject to the provisions of this Agreement.

3. Requests for visits by personnel of one Party to a facility of the other Party shall be coordinated through official channels, and shall conform with the established visit procedures of the host country. Requests for visits shall cite this Agreement and the appropriate ETRDP as the basis for the request.

4. Lists of personnel of each Party required to visit, on a continuing basis, facilities of the other Party shall be submitted through official channels in accordance with Recurring International Visit Procedures.

\section{ARTICLE XI}

\section{SECURITY}

It is the intent of the Parties that the Program carried out under this Agreement shall be conducted at the unclassified level. No classified information shall be provided or generated under this Agreement. 


\section{ARTICLE XII \\ THIRD PARTY SALES AND TRANSFERS}

1. The DoD shall retain the right to sell, transfer title to, disclose, or transfer possession of Project Foreground Information generated solely by the $\mathrm{DoD}$ in performance of work under ARTICLE III (Scope of Work), or any Annex to this Agreement, or any item produced either wholly or in part by it from such Project Foreground Information to Third Parties.

2. The MoD of Norway shall retain the right to sell, transfer title to, disclose, or transfer possession of Project Foreground Information generated solely by the DoD in performance of work under ARTICLE III (Scope of Work), or any Annex to this Agreement, or any item produced either wholly or in part by it from such Project Foreground Information to Third Parties.

3. The Parties recognize the possibility that Project Foreground Information resulting from joint performance of their work obligations under ARTICLE III (Scope of Work) may be generated either pursuant to working groups and biannual meetings or pursuant to Annexes to this Agreement. The Parties shall not sell, transfer title to, or transfer possession of jointly developed Project Foreground Information or Project Equipment to any Third Party without the prior written consent of the other Party. Furthermore, no Party shall permit any such sale or transfer, including by a contractor that has developed the foreground information or project equipment, without the prior written consent of the other Party. Such consent may be set forth in an Annex and shall require that the government of the intended recipient provides advance written assurances that it will:

a. Not retransfer, or permit the further retransfer of, any equipment or information provided; and,

b. Use, or permit the use of, the equipment or information provided for the purposes specified by the Parties.

4. In the event questions arise regarding the origin of Project Foreground Information that a Party intends to sell, transfer title to, disclose, or transfer to a Third Party, the matter shall be brought to the immediate attention of the other Party POs for information subject to an Annex to this Agreement, or to the other Party for information created during working groups or biannual meetings. If necessary, the matter shall be referred to the Parties for resolution prior to any sale or other transfer of such Project Foreground Information to a Third Party.

5. The Parties shall not sell, transfer title to, disclose, or transfer possession of Project Background Information or Project Equipment provided by another Party to any Third Party without the prior written consent of the Party which provided such equipment or Information. The providing Party shall be solely responsible for authorizing such transfers and, as applicable, specifying the method and conditions for implementing such transfers.

\section{ARTICLE XIII}

\section{LIABILITY}

1. Where applicable, claims against either Party or its personnel shall be dealt with in accordance with the terms of Article VIII of the NATO Status of Forces Agreement of 19 June 1951 (NATO SOFA). Civilian employees of the Parties shall be deemed for the purpose of Article VIII of the NATO SOFA to be members of a civilian component within the meaning of Article I of NATO SOFA while present in the territory of the other Party for the purpose of this Agreement.

2. Claims arising under or related to any contract awarded pursuant to ARTICLE VI (Contractual Provisions) shall be resolved in accordance with the provisions of the contract.

3. Employees and agents of contractors shall not be considered to be civilian personnel employed by a Party for the purpose of paragraph 1. 


\section{ARTICLE XIV \\ CUSTOMS DUTIES, TAXES AND SIMILAR CHARGES}

1. Customs duties, import and export taxes and similar charges shall be administered in accordance with each Party's respective laws and regulations. Insofar as existing national laws and regulations permit, the Parties shall endeavor to ensure that such readily identifiable duties, taxes and similar charges, as well as quantitative or other restrictions on imports and exports, are not imposed in connection with work carried out under each ETRDP.

2. Each Party shall use its best efforts to administer customs duties, import and export taxes, and similar charges are administered in a manner favorable to the efficient and economical conduct of the work. If any such duties, taxes, or similar charges are levied, the Party in whose country they are levied shall bear such costs.

\section{ARTICLE XV \\ SETTLEMENT OF DISPUTES}

Disagreements among the Parties arising under or relating to this Agreement shall be resolved only by consultation between the Parties and shall not be referred to an individual, to an international tribunal, or to any other forum for settlement.

\section{ARTICLE XVI}

\section{LANGUAGE}

1. The working language for implementing this Agreement shall be the English language.

2. All data and information generated under this Agreement and its implementing Contracts and provided by one Party to the other shall be furnished in the English language.

\section{ARTICLE XVII}

\section{GENERAL PROVISIONS}

1. All activities of the Parties under this Agreement and its Annexes shall be carried out consistent with their national laws and the obligations of the Parties shall be subject to the availability of appropriated funds for such purposes.

2. In the event of a conflict between an Article of this Agreement and any Annex to this Agreement, the Article shall govern.

\section{ARTICLE XVIII}

\section{AMENDMENT, WITHDRAWAL, TERMINATION, ENTRY INTO FORCE AND DURATION}

1. This Agreement may be amended by the written agreement of the Parties. Annexes to this Agreement may be established by written agreement to the Parties. 
2. This Agreement may be terminated at any time upon the written agreement of the Parties. In that event the Parties agree to terminate this Agreement, the Parties shall consult prior to the date of termination to ensure termination on the most economical and equitable terms.

3. Any Party may terminate this Agreement or any Annex upon 60 days written notification to the other Party. Such notice with regard to an Annex shall be the subject of immediate consultation by the Steering Committee to decide upon the appropriate course of action. In the event of such termination, the following rules apply:

a. The terminating Party shall continue participation, financial or otherwise, until the effective date of withdrawal.

b. Each Party shall pay the costs it incurs as a result of the withdrawal.

c. All Project Information and rights therein received under the provisions of this Agreement prior to the withdrawal shall be retained by the Parties, subject to the provisions of this Agreement.

4. Termination of this Agreement shall terminate its Annexes.

5. The respective rights and responsibilities of the Parties regarding ARTICLE VI (Project Equipment), ARTICLE VIII (Disclosure and Use of Program Information), ARTICLE IX (Controlled Unclassified Information), ARTICLE XI (Security), ARTICLE XII (Third Party Sales and Transfers), and ARTICLE XIII (Liability), shall continue notwithstanding termination of, and withdrawal from, or expiration of this Agreement or its Annexes.

6. This Agreement, which consists of the Preamble and 18 Articles, shall enter into force from the date of the last signature and shall remain in force for ten years. It may be extended by written agreement of the Parties.

IN WITNESS WHEREOF, the undersigned, being duly authorized, have signed this Agreement.

DONE in duplicate, in the English language.

\section{FOR THE}

DEPARTMENT OF DEFENSE

OF THE

UNITED STATES OF AMERICA:

[Signature]

Gary D. Vest

Principal Assistant Deputy Under Secretary of Defense (Environmental Security)

May 19, 1994

Baltimore, Maryland U.S.A.

\section{FOR THE \\ MINISTRY OF DEFENSE \\ OF THE \\ KINGDOM OF NORWAY:}

[Signature]

Oddvin Horneland

Special Advisor on Environmental Safety

Ministry of Defense of Norway

May 19, 1994

Baltimore, Maryland U.S.A. 


\title{
Agreement Between the Government of the United States of America and the Government of Norway for Cooperation in the GLOBE Program, Washington, D.C., 1995
}

\author{
Done at Washington, D.C. 5 April 1995 \\ Entered into force 5 April 1995 \\ Primary source citation: Copy of text provided by the \\ U.S. Department of State
}

\section{AGREEMENT BETWEEN THE GOVERNMENT OF THE UNITED STATES OF AMERICA AND THE GOVERNMENT OF NORWAY FOR COOPERATION IN THE GLOBE PROGRAM}

\begin{abstract}
PREAMBLE
The Government of the United States of America and the Government of Norway (hereinafter, the sides), Intending to increase the awareness of students throughout the world about the global environment, Seeking to contribute to increased scientific understanding of the Earth, and

Desiring to support improved student achievement in science and mathematics,

Have agreed to cooperate in the Global Learning and Observations to Benefit the Environment (GLOBE) Program as follows:

\section{ARTICLE 1 - THE GLOBE PROGRAM}

The GLOBE Program is an international environmental science and education program that will bring students, teachers, and scientists together to study the global environment. GLOBE will create an international network of students in grades K-12 (or equivalent) studying environmental issues, making environmental measurements, and sharing useful environmental data with the international environmental science community.
\end{abstract}




\section{ARTICLE 2 - COOPERATING AGENCIES}

Agencies responsible for cooperation and coordination under this agreement are:

On the U.S. side, the U.S. National Oceanic and Atmospheric Administration, acting in conjunction with other U.S. Government agencies participating in the GLOBE Program;

On the Norwegian side, the Ministry of Education, Research and Church Affairs.

\section{ARTICLE 3 - RESPECTIVE RESPONSIBILITIES}

A. The U.S. side will:

1. Identify U.S. schools that will participate in the GLOBE Program (details regarding GLOBE schools in Appendix A);

2. Select, in consultation with international scientists and educators, the GLOBE environmental measurements and types of measurement equipment (described in Appendix B);

3. Select Principal Investigator Teams for the GLOBE environmental measurements, and support the U.S. members of the Teams;

4. Calibrate, if necessary, measurement equipment that cannot be calibrated by GLOBE teachers and students;

5. Develop, in consultation with international scientists and educators, GLOBE educational materials;

6. Translate GLOBE instructional materials related to measurement procedures and data reporting protocols into the six United Nations languages, and provide these plus all broader GLOBE educational materials to the Norwegian side for further reproduction as necessary;

7. Conduct annual regional training sessions for GLOBE Country Coordinators and GLOBE teachers who will serve as trainers for additional GLOBE teachers in Norway, and provide a copy of GLOBE training materials to the Norwegian side;

8. Design, develop, operate, and maintain GLOBE data processing capabilities and other necessary technology and equipment;

9. Provide GLOBE software, as necessary, for use on Norwegian GLOBE school computers. (To the maximum extent possible, textual material appearing on computer screens will be accessible in the student's choice among the six United Nations languages.);

10. Accept environmental data reported from GLOBE schools around the world, and develop and provide resultant global environmental images (visualization products) to the Norwegian side; and

11. Evaluate the overall GLOBE Program periodically, in consultation with international GLOBE Country Coordinators, and modify the overall program as appropriate.

B. The Norwegian side will:

1. Select Norwegian schools to participate in the GLOBE Program (details regarding GLOBE schools in Appendix A) and provide an updated list of Norwegian GLOBE schools to the U.S. side at the beginning of each school year;

2. Ensure that Norwegian GLOBE schools conduct the fundamental activities of GLOBE schools detailed in Appendix A (take GLOBE environmental measurements, report data, and receive and use resultant 
global environmental images, using GLOBE educational materials under the guidance of teachers trained to conduct the GLOBE Program);

3. Name a Norwegian Government Point of Contact responsible for policy-level communications with the Director of the GLOBE Program;

4. Name a Country Coordinator responsible for day-to-day management, oversight, and facilitation of the GLOBE Program in Norway;

5. Ensure that the Country Coordinator and some GLOBE teachers attend GLOBE regional training and in turn provide GLOBE training to at least one teacher in each Norwegian GLOBE school;

6. Ensure that GLOBE instructional materials related to measurement procedures and data reporting protocols are utilized in Norwegian GLOBE schools, and that broader GLOBE educational materials are appropriately translated, adapted, reproduced, and distributed to all Norwegian GLOBE schools;

7. Ensure that Norwegian GLOBE schools have the necessary measurement equipment to take GLOBE environmental measurements (described in Appendix B);

8. Ensure that teachers and students at Norwegian GLOBE schools calibrate GLOBE measurement equipment according to procedures provided in GLOBE instructional materials;

9. Ensure that Norwegian GLOBE schools have the necessary computer and communications systems (described in Appendix C) to report GLOBE environmental measurements and to receive and use GLOBE visualization products, or make agreed alternative arrangements for such reporting and receipt. (At a minimum, the Norwegian Country Coordinator will need access to Internet so that all measurement data from Norwegian GLOBE schools will be reported via Internet.); and

10. Evaluate GLOBE operations in Norway periodically and assist the U.S. side in conducting periodic evaluation of the overall GLOBE Program.

\section{ARTICLE 4 - FINANCIAL ARRANGEMENTS}

Each side will bear the costs of fulfilling its respective responsibilities under this agreement. Obligations of each side pursuant to this agreement are subject to its respective funding procedures and the availability of appropriated funds, personnel, and other resources. The conduct of activities under this agreement will be consistent with the relevant laws and regulations of the two sides.

\section{ARTICLE 5 - EXCHANGE OF DATA AND GOODS}

GLOBE environmental measurement data, visualization products, software, and educational materials will be available worldwide without restriction as to their use or redistribution.

\section{ARTICLE 6 - RELEASE OF INFORMATION ABOUT THE GLOBE PROGRAM}

Each side may release information on the GLOBE Program as it may deem appropriate without prior consultation with the other. 


\section{ARTICLE 7 - CUSTOMS AND IMMIGRATION}

Each side will, to the extent permitted by its laws and regulations, facilitate the movement of persons and goods necessary to implement this agreement into and out of its territory and accord entry to such goods into its territory free of customs duties and other similar charges.

\section{ARTICLE 8 - ENTRY INTO FORCE, AMENDMENTS, WITHDRAWAL}

This agreement will enter into force upon signature of the two sides and will remain in force for five years. It will be automatically extended for further five-year periods, unless either side decides to terminate it and so notifies the other side with three months written notice. This agreement may be terminated at any time by either side upon three months prior written notice to the other side. This agreement may be amended by written agreement of the two sides.

Done at Washington, in duplicate, on April 5, 1995.

FOR THE GOVERNMENT OF THE

UNITED STATES OF AMERICA:

[Signature]

\section{FOR THE GOVERNMENT OF} NORWAY:

[Signature]

\section{APPENDIX A GLOBE Schools}

Each partner country will be responsible for identifying its participating schools. Schools should be selected so as to satisfy the objectives of the GLOBE Program. In particular, countries should emphasize the selection of schools that will maximize the number of students worldwide participating in the program. Also, countries should consider involving schools in locations that will yield measurement data that is important to the international environmental science community.

Students at all GLOBE schools throughout the world will conduct the following fundamental activities: they will make environmental measurements at or near their schools; report their data to a GLOBE data processing site; receive vivid graphical global environmental images (visualization products) created from their data and the data from other GLOBE schools around the world; and study the environment by relating their observations and the resulting visualization products to broader environmental topics. All of these activities will be conducted under the guidance of specially trained teachers (GLOBE-trained teachers).

GLOBE educational materials will be used in GLOBE schools under the guidance of GLOBE-trained teachers. These materials will detail procedures for taking environmental measurements and protocols for reporting data; explain the significance of the measurements; guide the use of the visualization products; and integrate the measurement aspects of the program into a broader study of the environment.

Schools throughout the United States and the rest of the world that are not GLOBE schools may become GLOBE Affiliate schools by observing the GLOBE Program in operation through the Internet. Students at these schools will benefit from the use of GLOBE visualization products and educational materials accessible on-line. All GLOBE Affiliate schools will be encouraged to become participating GLOBE schools.

\section{APPENDIX B GLOBE Environmental Measurements and Equipment}

GLOBE environmental measurements will contribute in a significant way to the scientific understanding of the dynamics of the global environment. Every GLOBE school will conduct a core set of GLOBE environmental measurements in the following critical areas: Atmosphere/Climate, Hydrology/Water Chemistry, and Biology/Geology. Where possible, a GLOBE school may coordinate its activities with those of other neighboring GLOBE schools, so 
that the complete set of GLOBE measurements will be available from a locality. As the GLOBE Program evolves, elective measurements not common to all GLOBE schools may be added in order to address local environmental issues.

Students at all age levels will be active participants in the GLOBE Program. The actual participation will be designed so as to be grade-appropriate for grades K-5, 6-8, and 9-12 (or equivalent). Younger students will make limited measurements which may be qualitative rather than quantitative. Older students will make additional measurements and more sophisticated measurements, as appropriate for their grade level. Measurement equipment will not need to be standardized; rather, performance specifications will be provided.

Following is an example list of core measurements and equipment. The full list will be initially determined and periodically updated as provided in Article 2.A.2, based on experience gained in implementing the GLOBE Program.

\section{MEASUREMENTS}

\section{Atmosphere/Climate:}

Air Temperature

Precipitation

Cloud Cover/Type

\section{Hydrology/Water Chemistry:}

Water $\mathrm{pH}$

Water Temperature

Soil Moisture

\section{Biology/Geology: \\ Habitat Study}

Tree Height

Tree Canopy

Tree Diameter

Species Identification

Phenology

\section{EQUIPMENT NEEDED}

\author{
Max/Min Thermometer \\ Calibration Thermometer \\ Instrument Shelter \\ Rain Gauge \\ Cloud Charts
}

pH Paper, Pen, or Meter

Alcohol Thermometer

Gypsum Block Sensors

Soil Moisture Meter
Compass

Meter Measuring Tape

Surveying Markers or Stakes

Clinometer

Densiometer

Diameter Tape

Dichotomous Keys

$35 \mathrm{~mm}$ Camera

\section{APPENDIX C \\ GLOBE Computer and Communications Systems}

In order to derive maximum benefit from the GLOBE Program, all schools will be encouraged to use an international information network, initially using the Internet, along with classroom computers. The World Wide Web multi-media information-access capability has been selected as the basis for IBM-compatible and Apple Macintosh computer systems to support the required GLOBE school activities of data entry, data analysis, and use of GLOBE environmental images. Following is a description of GLOBE computer and communications systems consistent with current GLOBE requirements.

Overall attributes of the minimum GLOBE school computer configuration that can execute the necessary software are:

For IBM-compatible systems: a $386 \mathrm{SX}$ or higher level processor; at least 4 megabytes of RAM memory ( 8 megabytes preferred); a VGA-capable monitor and display driver (Super VGA preferred); a hard disk storage system with as large a capacity as possible (preferably 300 megabytes or larger); and a direct Internet connection or dial-up capability that can use SLIP or PPP protocols with a 14,400 bps modem (preferably supporting V.42bis data compression which can enable 57,600 bps operation). The Windows 3.1 or later operating system is necessary. A printer is desirable. 
For Apple Macintosh systems: a $6803020 \mathrm{Mhz}$ or faster processor; at least 4 megabytes of RAM memory (8 megabytes preferred); a hard disk storage system with as large a capacity as possible (preferably 300 megabytes or larger); and a direct Internet connection or dial-up capability that can use SLIP or PPP protocols with a 14,400 bps modem (preferably supporting V.42bis data compression which can enable 57,600 bps operation). A printer is desirable.

Software for a higher performance GLOBE school computer system is being developed that will operate on higher performance, multi-media IBM-compatible systems and on Apple Macintosh systems. For IBM-compatible systems: a 486/66 or faster processor; 16 megabytes of RAM memory; 500 megabytes of hard disk space; a Super VGA monitor; a double-speed CD-ROM reader; a Soundblaster-compatible sound card; and an MPEG animation speed-up board will be required. For Apple Macintosh systems: a PowerPC processor; 16 megabytes of RAM memory; 500 megabytes of hard disk space; and a double-speed CD-ROM reader will be required. A communications capability the same as or better than for the minimum configurations above will also be required. A printer will be highly desirable.

It is recognized that there is a broad range of technological capabilities among potential GLOBE schools. The diversity of technology accessible by schools worldwide may require in some cases that environmental measurements be reported in hardcopy and that a variety of media be used to distribute visualization products, including photographs and broadcast television. All schools that want to participate in the program will be accommodated.

Technology associated with the GLOBE Program will continually evolve to higher levels and participants will be encouraged to upgrade over time. 



\section{B I L A T E R A L}

\section{Poland}

F I S H E R I E S 



\title{
Amendment to the Agreement Between the Government of the United States of America and the Government of the Republic of Poland Concerning Fisheries off the Coasts of the United States, Washington, D.C., 1993
}

\author{
Done at Washington, D.C. 8 June and 29 July 1993 \\ Entered into force 2 March 1994* \\ Primary source citation: Copy of text provided by the \\ U.S. Department of State
}

Department of State

Washington, June 8, 1993

The Department of State wishes to inform the Embassy of the Republic of Poland that the Government of the United States of America is prepared at this time to extend the Agreement for only an additional two year period. Therefore, on behalf of the Government of the United States of America, the Department of State proposes that the Agreement be extended until December 31, 1995 and that if this proposal is acceptable to the Government of the Republic of Poland, this note and your Embassy's favorable note in reply shall constitute an agreement between the two Governments, which shall enter into force on a date to be determined in a subsequent exchange of diplomatic notes following the completion of all necessary internal procedures of both parties.

The Department of State refers to diplomatic note no. 36-1-93 from the Embassy of the Republic of Poland, dated May 17, 1993, in which the Embassy proposed that the Agreement between Government of the United States of America and the Government of the Republic of Poland Concerning Fisheries off the Coasts of the United States, done at Washington August 1, 1985, as amended and extended (the Agreement), which is currently scheduled to expire December 31, 1993, be extended until Dec. 1, 1996.

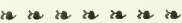

* This Agreement has been replaced by the Agreement of 15 and 20 December 1995. 


\author{
Department of State \\ of the United States of America \\ Washington, D.C.
}

Washington, July 29, 1993

No $36-4-93$

The Embassy of the Republic of Poland presents its compliments to the Department of State of the United States of America and has the honor to acknowledge receipt of the note of the Department of State dated June 8, 1993, which reads as follows:

"The Department of State refers to diplomatic note no 36-1-93 from the Embassy of the Republic of Poland, dated May 17, 1993 in which the Embassy proposed that Agreement between Government of the United States of America and the Government of the Republic of Poland Concerning Fisheries off the Coasts of the United States, done at Washington August 1, 1985, as amended and extended (the Agreement), which is currently scheduled to expire December 31, 1993, be extended until Dec. 1, 1996.

The Department of State wishes to inform the Embassy of the Republic of Poland that the Government of the United States of America is prepared at this time to extend the Agreement for only an additional two year period. Therefore, on behalf of the Government of the United States of America, the Department of State proposes that the Agreement be extended until December 31, 1995 and that if this proposal is acceptable to the Government of the Republic of Poland, this note and your Embassy's favorable note in reply shall constitute an agreement between the two Governments, which shall enter into force on a date to be determined in a subsequent exchange of diplomatic notes following the completion of ail necessary internal procedures of both parties."

The Government of the Republic of Poland agrees that the above cited note of the Department of State of the United States of America dated June 8, 1993 and the Embassy's present reply thereto shall constitute an agreement between the two Governments which shall enter into force on a date to be determined in a subsequent exchange of diplomatic notes following the completion of all necessary internal procedures of both parties.

The Embassy of the Republic of Poland avails itself of this opportunity to renew to the Department of State of the United States of America the assurances of its highest consideration.

[seal]

Ambasada Polski W Waszyngtonie 


\section{B I L A T E $\mathbf{R}$ A $\mathbf{L}$}

\section{ROMANIA}

ENVIRONMENT AND NATURAL RESOURCES 



\title{
Agreement Between the U.S. National Oceanic and Atmospheric Administration and the Ministry of Education of Romania for Cooperation in the GLOBE Program, Bucharest and Washington, D.C., 1995
}

\author{
Done at Bucharest 11 April 1995 and \\ Washington, D.C. 22 May 1995 \\ Entered into force 22 May 1995
}

Primary source citation: Copy of text provided by the U.S. Department of State

\section{AN AGREEMENT BETWEEN THE U.S. NATIONAL OCEANIC AND ATMOSPHERIC ADMINISTRATION AND THE MINISTRY OF EDUCATION OF ROMANIA FOR COOPERATION IN THE GLOBE PROGRAM}

\section{PREAMBLE}

The U.S. National Oceanic and Atmospheric Administration, acting on behalf of itself and other U.S. Government agencies participating in the GLOBE Program (hereinafter, the U.S. side), and the Ministry of Education of Romania (hereinafter, the Romanian side),

Intending to increase the awareness of students throughout the world about the global environment,

Seeking to contribute to increased scientific understanding of the Earth, and

Desiring to support improved student achievement in science and mathematics,

Have agreed to cooperate in the Global Learning and Observations to Benefit the Environment (GLOBE) Program as follows:

\section{ARTICLE 1 - THE GLOBE PROGRAM}

The GLOBE Program is an international environmental science and education program that will bring students, teachers, and scientists together to study the global environment. GLOBE will create an international network of 
students in grades K-12 (or equivalent) studying environmental issues, making environmental measurements, and sharing useful environmental data with the international environmental science community.

\section{ARTICLE 2 - RESPECTIVE RESPONSIBILITIES}

A. The U.S. side will:

1. Identify U.S. schools that will participate in the GLOBE Program (details regarding GLOBE schools in Appendix A);

2. Select, in consultation with international scientists and educators, the GLOBE environmental measurements and types of measurement equipment (described in Appendix B);

3. Select Principal Investigator Teams for the GLOBE environmental measurements, and support the U.S. members of the Teams;

4. Calibrate, if necessary, measurement equipment that cannot be calibrated by GLOBE teachers and students;

5. Develop, in consultation with international scientists and educators, GLOBE educational materials;

6. Translate GLOBE instructional materials related to measurement procedures and data reporting protocols into the six United Nations languages, and provide these plus all broader GLOBE educational materials to the Romanian side for further reproduction as necessary;

7. Conduct annual regional training sessions for GLOBE Country Coordinators and GLOBE teachers who will serve as trainers for additional GLOBE teachers in Romania, and provide a copy of GLOBE training materials to the Romanian side;

8. Design, develop, operate, and maintain GLOBE data processing capabilities and other nacessary technology and equipment;

9. Provide GLOBE software, as necessary, for use on Romanian GLOBE school computers. (To the maximum extent possible, textual material appearing on computer screens will be accessible in the student's choice among the six United Nations languages);

10. Accept environmental data reported from GLOBE schools around the world, and develop and provide resultant global environmental images (visualization products) to the Romanian side; and

11. Evaluate the overall GLOBE Program periodically, in consultation with international GLOBE Country Coordinators, and modify the overall program as appropriate.

B. The Romanian side will:

1. Select Romanian schools to participate in the GLOBE Program (details regarding GLOBE schools in Appendix A) and provide an updated list of Romanian GLOBE schools to the U.S. side at the beginning of each school year;

2. Ensure that Romanian GLOBE schools conduct the fundamental activities of GLOBE schools detailed in Appendix A (take GLOBE environmental measurements, report data, and receive and use resultant global environmental images, using GLOBE educational materials under the guidance of teachers trained to conduct the GLOBE Program);

3. Name a Romanian Government Point of Contact responsible for policy-level communications with the Director of the GLOBE Program; 
4. Name a Country Coordinator responsible for day-to-day management, oversight, and facilitation of the GLOBE Program in Romania;

5. Ensure that the Country Coordinator and some GLOBE teachers attend GLOBE regional training and in turn provide GLOBE training to at least one teacher in each Romanian GLOBE school;

6. Ensure that GLOBE instructional materials related to measurement procedures and data reporting protocols are utilized in Romanian GLOBE schools, and that broader GLOBE educational materials are appropriately translated, adapted, reproduced, and distributed to all Romanian GLOBE schools;

7. Ensure that Romanian GLOBE schools have the necessary measurement equipment to take GLOBE environmental measurements (described in Appendix B);

8. Ensure that teachers and students at Romanian GLOBE schools calibrate GLOBE measurement equipment according to procedures provided in GLOBE instructional materials;

9. Ensure that Romanian GLOBE schools have the necessary computer and communications systems (described in Appendix C) to report GLOBE environmental measurements and to receive and use GLOBE visualization products, or make agreed alternative arrangements for such reporting and receipt. (At a minimum, the Romanian Country Coordinator will need access to Internet so that all measurement data from Romanian GLOBE schools will be reported via Internet.); and

10. Evaluate GLOBE operations in Romania periodically and assist the U.S. side in conducting periodic evaluation of the overall GLOBE Program.

\section{ARTICLE 3 - FINANCIAL ARRANGEMENTS}

Each side will bear the costs of fulfilling its respective responsibilities under this agreement. Obligations of each side pursuant to this agreement are subject to its respective funding procedures and the availability of appropriated funds, personnel, and other resources.

The conduct of activities under this agreement will be consistent with the relevant laws and regulations of the two sides.

\section{ARTICLE 4 - EXCHANGE OF DATA AND GOODS}

GLOBE environmental measurement data, visualization products, software, and educational materials will be available worldwide without restriction as to their use or redistribution.

\section{ARTICLE 5 - RELEASE OF INFORMATION ABOUT THE GLOBE PROGRAM}

Each side may release information on the GLOBE Program as it may deem appropriate without prior consultation with the other.

\section{ARTICLE 6 - CUSTOMS AND IMMIGRATION}

Each side will, to the extent permitted by its laws and regulations, facilitate the movement of persons and goods necessary to implement this agreement into and out of its territory and accord entry to such goods into its territory free of customs duties and other similar charges. 


\section{ARTICLE 7 - ENTRY INTO FORCE, AMENDMENTS, WITHDRAWAL}

This agreement will enter into force upon signature of the two sides and will remain in force for five years. It will be automatically extended for further five-year periods, unless either side decides to terminate it and so notifies the other side with three months written notice. This agreement may be terminated at any time by either side upon three months prior written notice to the other side. This agreement may be amended by written agreement of the two sides.

Done at on

For the National Oceanic and Atmospheric Administration:

[Signature]

May 22, 1995

Washington
For the Ministry of

Education:

[Signature]

April 11, 1995

Bucharest

\section{APPENDIX A GLOBE Schools}

Each partner country will be responsible for identifying its participating schools. Schools should be selected so as to satisfy the objectives of the GLOBE Program. In particular, countries should emphasize the selection of schools that will maximize the number of students worldwide participating in the program. Also, countries should consider involving schools in locations that will yield measurement data that is important to the international environmental science community.

Students at all GLOBE schools throughout the world will conduct the following fundamental activities: they will make environmental measurements at or near their schools; report their data to a GLOBE data processing site; receive vivid graphical global environmental images (visualization products) created from their data and the data from other GLOBE schools around the world; and study the environment by relating their observations and the resulting visualization products to broader environmental topics. All of these activities will be conducted under the guidance of specially trained teachers (GLOBE-trained teachers).

GLOBE educational materials will be used in GLOBE schools under the guidance of GLOBE-trained teachers. These materials will detail procedures for taking environmental measurements and protocols for reporting data; explain the significance of the measurements; guide the use of the visualization products; and integrate the measurement aspects of the program into a broader study of the environment.

Schools throughout the United States and the rest of the world that are not GLOBE schools may become GLOBE Affiliate schools by observing the GLOBE Program in operation through the Internet. Students at these schools will benefit from the use of GLOBE visualization products and educational materials accessible on-line. All GLOBE Affiliate schools will be encouraged to become participating GLOBE schools.

\section{APPENDIX B GLOBE Environmental Measurements and Equipment}

GLOBE environmental measurements will contribute in a significant way to the scientific understanding of the dynamics of the global environment. Every GLOBE school will conduct a core set of GLOBE environmental measurements in the following critical areas: Atmosphere/Climate, Hydrology/Water Chemistry, and Biology/Geology. Where possible, a GLOBE school may coordinate its activities with those of other neighboring GLOBE schools, so that the complete set of GLOBE measurements will be available from a locality. As the GLOBE Program evolves, elective measurements not common to all GLOBE schools may be added in order to address local environmental issues.

Students at all age levels will be active participants in the GLOBE Program. The actual participation will be designed so as to be grade-appropriate for grades K-5, 6-8, and 9-12 (or equivalent). Younger students will make limited 
measurements which may be qualitative rather than quantitative. Older students will make additional measurements and more sophisticated measurements, as appropriate for their grade level. Measurement equipment will not need to be standardized; rather, performance specifications will be provided.

Following is an example list of core measurements and equipment. The full list will be initially determined and periodically updated as provided in Article 2.A.2, based on experience gained in implementing the GLOBE Program.

\section{MEASUREMENTS}

Atmosphere/Climate:

Air Temperature

Precipitation

Cloud Cover/Type

Hydrology/Water Chemistry:

Water $\mathrm{pH}$

Water Temperature

Soil Moisture

\section{Biology/Geology:}

Habitat Study

Tree Height

Tree Canopy

Tree Diameter

Species Identification

Phenology

\section{EQUIPMENT NEEDED}

\author{
Max/Min Thermometer \\ Calibration Thermometer \\ Instrument Shelter \\ Rain Gauge \\ Cloud Charts
}

pH Paper, Pen, or Meter

Alcohol Thermometer

Gypsum Block Sensors

Soil Moisture Meter

Compass

Meter Measuring Tape

Surveying Markers or Stakes

Clinometer

Densiometer

Diameter Tape

Dichotomous Keys

$35 \mathrm{~mm}$ Camera

\section{APPENDIX C \\ GLOBE Computer and Communications Systems}

In order to derive maximum benefit from the GLOBE Program, all schools will be encouraged to use an international information network, initially using the Internet, along with classroom computers. The World Wide Web multi-media information-access capability has been selected as the basis for IBM-compatible and Apple Macintosh computer systems to support the required GLOBE school activities of data entry, data analysis, and use of GLOBE environmental images. Following is a description of GLOBE computer and communications systems consistent with current GLOBE requirements.

Overall attributes of the minimum GLOBE school computer configuration that can execute the necessary software are:

For IBM-compatible systems: a $386 \mathrm{SX}$ or higher level processor; at least 4 megabytes of RAM memory (8 megabytes preferred); a VGA-capable monitor and display driver (Super VGA preferred); a hard disk storage system with as large a capacity as possible (preferably 300 megabytes or larger); and a direct Internet connection or dial-up capability that can use SLIP or PPP protocols with a 14,400 bps modem (preferably supporting V.42bis data compression which can enable 57,600 bps operation). The Windows 3.1 or later operating system is necessary. A printer is desirable.

For Apple Macintosh systems: a $6803020 \mathrm{Mhz}$ or faster processor; at least 4 megabytes of RAM memory ( 8 megabytes preferred); a hard disk storage system with as large a capacity as possible (preferably 300 megabytes or larger); and a direct Internet connection or dial-up capability that can use SLIP or PPP protocols with a $\mathbf{1 4 , 4 0 0}$ bps modem (preferably supporting V.42bis data compression which can enable 57,600 bps operation). A printer is desirable. 
Software for a higher performance GLOBE school computer system is being developed that will operate on higher performance, multimedia IBM-compatible systems and on Apple Macintosh systems. For IBM-compatible systems: a 486/66 or faster processor; 16 megabytes of RAM memory; 500 megabytes of hard disk space; a Super VGA monitor; a double-speed CD-ROM reader; a Soundblaster-compatible sound card; and an MPEG animation speed-up board will be required. For Apple Macintosh systems: a PowerPC processor; 16 megabytes of RAM memory; 500 megabytes of hard disk space; and a double-speed CD-ROM reader will be required. A communications capability the same as or better than for the minimum configurations above will also be required. A printer will be highly desirable.

It is recognized that there is a broad range of technological capabilities among potential GLOBE schools. The diversity of technology accessible by schools worldwide may require in some cases that environmental measurements be reported in hardcopy and that a variety of media be used to distribute visualization products, including photographs and broadcast television. All schools that want to participate in the program will be accommodated.

Technology associated with the GLOBE Program will continually evolve to higher levels and participants will be encouraged to upgrade over time. 


\section{B I L A T E $\mathbf{R}$ A $\mathbf{L}$}

Russia

ENVIRONMENT AND NATURAL RESOURCES 



\section{Agreement Between the Government of the United States of America and the Government of the Russian Federation on Cooperation in Research on Radiation Effects for the Purpose of Minimizing the Consequences of Radioactive Contamination on Health and the Environment, Moscow, 1994}

Done at Moscow 14 January 1994

Entered into force 14 January 1994

Primary source citation: Copy of text provided by the U.S. Department of State

AGREEMENT BETWEEN THE GOVERNMENT OF THE UNITED STATES OF AMERICA AND THE GOVERNMENT OF THE RUSSIAN FEDERATION ON COOPERATION IN RESEARCH ON RADIATION EFFECTS FOR THE PURPOSE OF MINIMIZING THE CONSEQUENCES OF RADIOACTIVE CONTAMINATION ON HEALTH AND THE ENVIRONMENT

The Government of the United States of America and the Government of the Russian Federation (hereinafter referred to as the "Parties"):

Desiring to establish close and long-term cooperation in the field of studying the radiation effects upon the health and the environment for the purpose of minimizing the effect of radioactive contamination;

Noting the benefits to humanity of increased scientific understanding of the radiation effects upon the health and the environment;

Have agreed as follows: 


\section{Article I}

The purpose of this Agreement is to establish a framework for cooperation between the participating organizations of the parties, as determined pursuant to Article IV of this Agreement, in research on radiation effects for the purpose minimization of the consequences of radioactive contamination on health and the environment.

\section{Article II}

The areas of cooperation under the Agreement may include, but are not limited to, the following:

1. Health effects studies including epidemiologic and other health-related studies of workers and community members potentially exposed to ionizing radiation;

2. Information and data management activities including information development and exchange of experience in radiation effects, data preservation and database and information system development;

3. Environmental studies including the identification and modeling of deposition, dispersion, and ecological transport of radionuclides and other hazardous contaminants as necessary to study and reconstruct doses to human populations and to assess the impact of radioactivity on the environment. Development and application of dosimetric systems and methodologies for retrospective reconstruction of doses to human populations;

4. Health communication of risk assessment including distribution of public health information pertaining to radiological contamination and measures to reduce present and future human exposure to radionuclides and associated hazardous substances;

5. Policy analysis including review of radiation detection and reporting mechanisms, as well as evaluation of safeguards to minimize radiation effects on human population;

6. Scientific research to develop information which can assist in minimization of the consequences of radioactive contamination on the environment and health;

7. Other areas of cooperation as may be mutually agreed by the Parties.

\section{Article III}

1. To implement this Agreement, there shall be established a Joint Coordinating Committee for Radiation Effects Research (the "JCCRER").

2. The JCCRER shall consist of an equal number of representatives from each Party. All decisions taken by the JCCRER shall be by mutual agreement of the Parties.

3. The JCCRER will decide on its membership and meeting schedule. Generally, it will be convened once a year, alternatively in the United States and Russia, unless agreed otherwise. Times, places and agendas for meetings will be agreed upon in advance by the Parties.

4. The JCCRER will, within the framework of its jurisdiction, coordinate and review all aspects of cooperation under this Agreement and shall take such action as is appropriate for this Agreement's effective implementation.

5. The JCCRER may organize, establish and arrange working groups, conferences and seminars of specialists for joint discussion and study of specific topics related to the purposes of this Agreement. Specific projects and programs for radiation effects research, exchanges of scientific and technical safety information, personnel and equipment, and procedures for addressing and resolving questions of such matters as payment of costs under this cooperation, and patent and/or publication rights for joint activities administered under this Agreement may be developed separately by the JCCRER in accordance with the laws and regulations of the Parties. 
6. The JCCRER shall generally establish on an annual basis a program of cooperation to be implemented during the following year.

7. The Executive Agents responsible for coordination of this Agreement shall be, for the United States of America, the United States Department of Energy, and for the Russian Federation, the State Committee of the Russian Federation for the Social Protection of Population and Rehabilitation of Regions Affected by Chernobyl and Other Radiation Catastrophes.

\section{Article IV}

The forms of cooperation to be approved by the JCCRER under this Agreement may include the following:

1. Joint data collection and information exchange, as well as experimental, developmental, demonstrational and design work by technical personnel at appropriate facilities and sites of the two countries;

2. Exchanges of appropriate instrumentation, equipment and materials for projects;

3. Exchange of technical specialists for participation in agreed activities;

4. Exchange of appropriate scientific and technical information, documentation and results of research;

5. Organization of seminars and other meetings on agreed topics; and

6. Such additional forms of cooperation, as mutually agreed.

\section{Article V}

1. Cooperation under this Agreement will be conducted according to the plans and programs of the following principal establishments and organizations, as agreed to pursuant to Article III.5:

In the United States of America:

- the Department of Energy;

- Nuclear Regulatory Commission;

- Department of Defense;

- Department of Health and Human Services;

- Environmental Protection Agency; and other government departments and nuclear industry establishments and organizations, as appropriate;

In the Russian Federation:

- State Committee of the Russian Federation for the Social Protection and Rehabilitation of Regions Affected by Chernobyl and Other Radiation Catastrophes;

- Ministry of the Russian Federation for Atomic Energy;

- Ministry of Health of the Russian Federation;

- Ministry of Agriculture of the Russian Federation;

- State Committee on Sanitary and Epidemiological Surveillance of the Russian Federation; 
- Federal Service of Russia on Nuclear and Radiation Safety;

- Russian Federal Service for Hydrometeorology and Environmental Monitoring;

- Federal Service of Russia on Forest Economy;

- Russian Ministry of Defense;

- Russian State Committee for Civil Defense Affairs, Emergencies and Elimination of Consequences of Natural Disasters;

- Russian Academy of Sciences, and other interested Russian ministries, departments, and organizations.

2. Each Party may adjust the list of its principal establishments and organizations participating in this cooperation, and shall inform the other Party of any such adjustments through the State Committee of the Russian Federation for the Social Protection of Population and Rehabilitation of Regions Affected by Chernobyl and Other Radiation Catastrophes and the United States Department of Energy.

\section{Article VI}

1. Provisions for the protection and allocation of intellectual property are set forth in the Annex to this Agreement and form an integral part of this Agreement and apply to all activities carried out hereunder.

2. For purposes of this Agreement, the obligations of Article III of the Annex shall also apply to "Confidential Information". Confidential information means information containing know-how, trade secrets, or technical commercial, or financial information that:

- has been held in confidence by its owner;

- is not generally known or available from other sources;

- has not been made available by its owner to other parties without an obligation concerning its confidentiality; and

- is not available to the receiving Party without obligations concerning its confidentiality.

\section{Article VII}

1. Cooperation under this Agreement will be conducted according to the international obligations, laws and regulations of the Parties and will be subject to the availability of funds.

2. Exchange of specialists and experts shall be governed by mutual agreement of the Parties in each case.

3. Any questions of interpretation and implementation relating to this Agreement shall be resolved by agreement of the Parties.

\section{Article VIII}

1. This Agreement will enter into force upon signature and will remain in force for five (5) years, subject to extension of additional five (5) year terms by written agreement of the Parties following joint review at the end of each five-year period.

2. In case of cessation of this Agreement, all joint projects and experiments being conducted at the cessation of this Agreement may be continued to their conclusion in accordance with the terms of this Agreement. 
3. This Agreement may be amended by mutual agreement in writing.

4. Either Party has the right to terminate this Agreement after giving the other Party six (6) months advance written notice.

IN WITNESS WHEREOF, the undersigned, being duly authorized by their respective Governments, have signed this Agreement.

Done at Moscow, in duplicate, this 14th day of January, 1994, in the English and Russian languages, each text being equally authentic.

\section{FOR THE GOVERNMENT OF \\ THE UNITED STATES OF AMERICA:}

[Signature]

\section{FOR THE GOVERNMENT OF \\ THE RUSSIAN FEDERATION:}

[Signature]

\section{ANNEX \\ INTELLECTUAL PROPERTY}

Pursuant to Article VI of this Agreement:

The Parties shall ensure adequate and effective protection of intellectual property created or furnished under this Agreement and relevant implementing arrangements. The Parties agree to notify one another in a timely fashion of any inventions or copyrighted works arising under this Agreement and to seek protection for such intellectual property in a timely fashion. Rights to such intellectual property shall be allocated as provided in this Annex.

\section{SCOPE}

A. This Annex is applicable to all cooperative activities undertaken pursuant to this Agreement, except as otherwise specifically agreed to by the Parties or their designees.

B. For purposes of this agreement, intellectual property shall have the meaning found in Article 2 of the Convention Establishing the World Intellectual Property Organization, done at Stockholm, July $14,1967$.

C. This Annex addresses the allocation of rights, interests, and royalties between the Parties. Each Party shall ensure that the other Party can obtain the rights to intellectual property allocated in accordance with the Annex, by obtaining those rights from its own participants through contracts or other legal means, if necessary. This Annex does not otherwise alter or prejudice the allocation between a Party and its nationals, which shall be determined by that Party's laws and practices.

D. Disputes concerning intellectual property arising under this Agreement should be resolved through discussions between the concerned participating institutions or, if necessary, the Parties or their designees. Upon mutual agreement of the Parties, a dispute shall be submitted to an arbitral tribunal for binding arbitration in accordance with the applicable rules of international law. Unless the Parties or their designees agree otherwise in writing, the arbitration rules of the UNCITRAL shall govern.

E. Termination or expiration of the Agreement shall not affect rights or obligations under this Annex.

\section{ALLOCATION OF RIGHTS}

A. Each Party shall be entitled to a non-exclusive, irrevocable, royalty-free license in all countries to translate, reproduce, and publicly distribute scientific and technical journal articles, reports, and books directly arising from cooperation under this Agreement. All publicly distributed copies of a copyrighted work prepared under this provision shall indicate the names of the authors of the work unless an author specifically declines to be named. 
B. Rights to all forms of intellectual property, other than those rights described in Section II(A) above shall be allocated as follows:

1. Researchers and scientists visiting in furtherance of their education shall receive intellectual property rights under the existing rules of the host institution. In addition, each visiting researcher or scientist named as an inventor shall have the right to national treatment regarding awards, benefits or other compensation, including royalties, in accordance with the existing rules of the host institution.

2. (a) For intellectual property created during joint research, for example, when the Parties, participating institutions, or participating personnel have agreed in advance on the scope of work, each Party shall be entitled to obtain all rights and interests in its own territory. Rights and interests in third countries will be determined in implementing arrangements. The rights to intellectual property shall be allocated with due regard for the economic, scientific and technological contributions from each Party to the creation of intellectual property. If research is not designated as "joint research" in the relevant implementing arrangement, rights to intellectual property arising from the research will be allocated in accordance with Paragraph II(B)(1). In addition, each person named as an inventor shall have the right to national treatment regarding awards, benefits and other compensation, including royalties, in accordance with the existing rules of the host institution.

(b) Notwithstanding Paragraph II(B)2(a), if a type of intellectual property is available under the laws of one party but not the other Party, the Party whose laws provide for this type of protection shall be entitled to all rights and interests worldwide. Persons named as inventors of the property shall nonetheless be entitled to royalties as provided in Paragraph II(B)2(a).

\section{BUSINESS-CONFIDENTIAL INFORMATION}

In the event that information identified in a timely fashion as business-confidential is furnished or created under the Agreement, each Party and its participants shall protect such information in accordance with applicable laws, regulations, and administrative practice. Information may be identified as "business-confidential" if a person having the information may derive an economic benefit from it or may obtain competitive advantage over those who do not have it, the information is not generally known or publicly available from other sources, and the owner has not previously made the information available without imposing in a timely manner an obligation to keep it confidential. 


\title{
Memorandum of Understanding Between the Forest Service of the United States Department of Agriculture and the Federal Forest Service of Russia on Cooperation in the Field of Forestry, Washington, D.C., 1994
}

\author{
Done at Washington, D.C. 13 May 1994 \\ Entered into force 13 May 1994 \\ Primary source citation: Copy of text provided by the \\ U.S. Department of State
}

\section{MEMORANDUM OF UNDERSTANDING BETWEEN THE FOREST SERVICE OF THE UNITED STATES DEPARTMENT OF AGRICULTURE AND THE FEDERAL FOREST SERVICE OF RUSSIA ON COOPERATION IN THE FIELD OF FORESTRY}

The Forest Service of the United States Department of Agriculture and the Federal Forest Service of Russia, hereafter referred to as "the Parties;"

Attaching great importance to the development of international scientific, technical and economic relations in the field of forestry and to the protection and sustainable productivity of forest resources;

Believing in the necessity of long-term cooperation in the field of forestry;

Noting the great importance of forests to the Earth's biosphere and as a stabilizing factor in the protection and conservation of the human habitat;

Recognizing that future social and economic progress demands careful attention to forest resources and requires strengthening the means of protection and improvement of the forest environment; and

Expressing their desire to achieve broader and deeper cooperation in the field of forestry, and in protection and sustainable productivity of forests;

Have agreed as follows: 


\section{Article 1}

1. The Parties will cooperate in the field of forestry and in the protection and sustainable use of forest resources on a basis of reciprocity and equality.

2. For the purposes of this Memorandum, "Forestry" means the science, principles and practice of managing, conserving, and using for human benefit the natural resources on and in association with forest lands.

3. For the purposes of this Memorandum, "Forest Resources" means the total forest ecosystem of trees, soils, water, and biodiversity, including commodity and non-commodity inventory on and in association with forest lands.

\section{Article 2}

1. Cooperation under this Memorandum is intended to solve important problems in the management of forest resources.

2. Cooperation may include, but not be limited to, the following:

A. Forest regeneration, including both natural and artificial systems, and issues of genetics and selection;

B. Forest protection against insects, disease and fires, including suppression, prevention, planning and related technical support;

C. Forest inventory;

D. Monitoring the condition of forests, using geographic information systerns and other appropriate systems;

E. Administrative, legal, and economic aspects of forest management;

F. Forest conservation and sustainable use, including the implementation of new technologies;

G. Watershed protection and restoration;

H. Forest conservation biology;

I. Development of training opportunities to support cooperative work in science and technology exchange; and

J. Research to advance forest management policy.

3. Particular attention in the course of cooperation will be given to those issues of mutual interest, which may contribute to solving global ecological problems.

\section{Article 3}

Cooperation may be implemented in the following forms:

A. Research;

B. Exchange of scientists, specialists and post-graduates;

C. Exchange of non-proprietary scientific and technical information, documentation and results of research; 

D. Exchange and provision of samples, materials and data;
E. Joint organization of symposia, conferences, workshops, seminars and lectures,
F. Publication of reports, articles and monographs; and
G. As may otherwise be agreed by the Parties.

\section{Article 4}

The Parties will encourage the establishment, continuation and development of direct contacts and cooperation in the field of forestry between interested institutions, organizations, private enterprises and individuals of both countries in accordance with their respective laws and policies.

\section{Article 5}

1. A United States-Russia Forestry Working Group (hereafter referred to as the "Forestry Working Group") will direct and coordinate implementation of this Memorandum. The Forestry Working Group will be composed of representatives of both Parties, who may be assisted by advisors and experts.

2. The Forestry Working Group will develop detailed programs of cooperation and provide information on institutions, organizations, and private enterprises which carry on activity in this field.

3. The Forestry Working Group will promote and facilitate direct contacts between scientists, and other professionals, institutions, organizations, and private enterprises to develop long-term cooperative relationships. The Forestry Working Group will serve to enhance previous cooperative relationships.

4. The Forestry Working Group will hold meetings at least once every two years, alternately in Russia and in the United States to review the progress in cooperation and to draw up a recommended program of cooperation for a two-year period. The Forestry Working Group may through correspondence amend and supplement the program during the two-year period to resolve emerging common concerns and define new fields of cooperation.

5. Programs, projects and activities will be included in cooperative agreements, implementing arrangements, or plans of work, as appropriate, and as may be agreed upon by the Parties.

\section{Article 6}

1. The Parties will decide how costs incurred through cooperation will be covered on a case-by-case basis.

2. The procedure for protection of intellectual property and rights thereto is set forth in Annex I, which constitutes an integral part of this Memorandum.

3. Agreements and contracts concluded between the institutions, organizations, and private enterprises of both countries will not be affected by the signing or expiration of this Memorandum.

\section{Article 7}

This Memorandum shall enter into force upon signature and shall remain in force for five (5) years. This Memorandum shall be extended automatically for successive five-year periods. This Memorandum may be terminated at any time by either Party upon six months' written notice to the other Party. The termination of this Memorandum shall not affect the validity or duration of the activities under this Memorandum that are initiated prior to such termination. This Memorandum may be amended by written agreement of the Parties. 
DONE in duplicate at Washington, D.C., this 13th day of May, 1994, in the English and Russian languages, both texts being equally authentic.

\section{FOR THE FOREST SERVICE \\ OF THE UNITED STATES \\ DEPARTMENT OF AGRICULTURE}

[Signature]

\author{
FOR THE FEDERAL \\ FOREST SERVICE \\ OF RUSSIA
}

[Signature]

\section{ANNEX I}

\section{INTELLECTUAL PROPERTY}

Pursuant to Article 6.2 of this Memorandum:

The Parties shall ensure adequate and effective protection of intellectual property created or furnished under this Memorandum and relevant implementing arrangements. The Parties agree to notify one another in a timely fashion of any inventions or copyrighted works arising under this Memorandum and to seek protection for such intellectual property in a timely fashion. Rights to such intellectual property shall be allocated as provided in this Annex.

\section{SCOPE}

A. This Annex is applicable to all cooperative activities undertaken pursuant to this Memorandum, except as otherwise specifically agreed to by the Parties of their designees.

B. For purposes of this Memorandum, "intellectual property" shall have the meaning found in Article 2 of the Convention Establishing the World Intellectual Property Organization, done at Stockholm, July 14, 1967.

C. This Annex addresses the allocation of rights, interests, and royalties between the Parties. Each Party shall ensure that the other Party can obtain the rights to intellectual property allocated in accordance with the Annex, by obtaining those rights from its own participants through contracts or other legal means, if necessary. This Annex does not otherwise alter or prejudice the allocation between a Party and its nationals, which shall be determined by that Party's laws and practices.

D. Disputes concerning intellectual property arising under this Memorandum should be resolved through discussions between the concerned participating institutions or, if necessary, the Parties or their designees. Upon mutual agreement of the Parties, a dispute shall be submitted to an arbitral tribunal for binding arbitration in accordance with the applicable rules of international law. Unless the Parties or their designees agree otherwise in writing, the arbitration rules of UNCITRAL shall govern.

E. Termination or expiration of this Memorandum shall not affect rights or obligations under this Annex.

\section{ALLOCATION OF RIGHTS}

A. Each Party shall be entitled to a non-exclusive, irrevocable, royalty-free license in all countries to translate, reproduce, and publicly distribute scientific and technical journal articles, reports, and books directly arising from cooperation under this Memorandum. All publicly distributed copies of a copyrighted work prepared under this provision shall indicate the names of the authors of the work unless an author explicitly declines to be named.

B. Rights to all forms of intellectual property, other than those rights described in Part A of Section 2 above, shall be allocated as follows: 
1. Researchers and scientists visiting in furtherance of their education shall receive intellectual property rights under the existing rules of the host institution. In addition, each visiting researcher named as an inventor or author shall have the right to national treatment regarding awards, benefits, or other compensation, including royalties, in accordance with the existing rules of the host institution.

2. (a) For intellectual property created by the participants during joint research, for example, when the Parties, participating institutions, or participating personnel have agreed in advance on the scope of work, each Party shall be entitled to obtain all rights and interests in its own territory. The allocation of rights and interests in third countries will be determined in implementing arrangements. The rights to intellectual property shall be allocated with due regard for the economic, scientific and technological contributions from each Party to the creation of intellectual property. If research is not designated as "joint research" in the relevant implementing arrangement, rights to intellectual property arising from the research will be allocated in accordance with Part B, paragraph 1 of Section 2. In addition, each person named as an inventor or author shall have the right to national treatment regarding awards, benefits and other compensation, including royalties, in accordance with the existing rules of the host institution.

(b) Notwithstanding Part B, paragraph 2(a) of Section 2, if a type of intellectual property is available under the laws of one Party but not the other Party, the Party whose laws provide for this type of protection shall be entitled to all rights and interests in all countries which provide rights to such intellectual property. Persons named as inventors or authors of the property shall nonetheless be entitled to national treatment in regard to awards, benefits, or other compensations, including royalties, in accordance with the rules as provided in Part B, paragraph 2(a) of Section 2.

\section{BUSINESS-CONFIDENTIAL INFORMATION}

In the event that information identified in a timely fashion as business-confidential is furnished or created under the Memorandum, each Party and its participants shall protect such information in accordance with applicable laws, regulations, and administrative practice. Information may be identified as "business-confidential" if a person having the information may derive an economic benefit from it or may obtain a competitive advantage over those who do not have it, the information is not generally known or publicly available from other sources, and the owner has not previously made the information available without imposing in a timely manner an obligation to keep it confidential. 


\title{
Agreement Between the Government of the United States of America and the Government of the Russian Federation on Cooperation in the Field of Protection of the Environment and Natural Resources, Washington, D.C., 1994
}

\author{
Done at Washington, D.C. 23 June 1994 \\ Entered into force 23 June 1994 \\ Primary source citation: Copy of text provided by the \\ U.S. Department of State
}

\section{AGREEMENT BETWEEN THE GOVERNMENT OF THE UNITED STATES OF AMERICA AND THE GOVERNMENT OF THE RUSSIAN FEDERATION ON COOPERATION IN THE FIELD OF PROTECTION OF THE ENVIRONMENT AND NATURAL RESOURCES}

The Government of the United States of America and the Government of the Russian Federation, hereinafter referred to as the Parties;

Determined to develop cooperation in the field of protection of the environment and natural resources, taking into account mutual interests and the experience obtained from implementation of the Agreement between the Government of the United States of America and the Government of the Russian Federation on Cooperation in the Field of Environmental Protection of May 23, 1972;

Recognizing that many important environmental problems are global in nature and require the cooperation of all countries and peoples to resolve;

Attaching great significance to the protection and enhancement of the environment and to its preservation from the damage resulting from pollution and overuse;

Bearing in mind that sustainable economic and social development for the benefit of present and future generations already now requires effective measures to be taken for the protection and enhancement of the environment; 
Considering the readiness of the Parties to cooperate to enable the Russian Federation better to take into account environmental issues and the rational and sustainable use of natural resources in the transition to a market economy and thereafter;

Desiring to facilitate the establishment of long-term cooperation between interested organizations in the two countries in the field of protection of the environment and natural resources;

Have agreed as follows:

\section{Article I}

1. The Parties shall assist in the development of cooperation in the field of protection of the environment and natural resources on national, regional and global levels. Their activity shall focus on studying harmful impacts on the environment and jointly developing measures to improve the condition of the environment and to solve problems of the protection and rational and sustainable use of natural resources, including work on the areas of pollution prevention and remediation and preservation and conservation of natural resources.

2. The Parties shall work together to develop mutually agreed-upon policies in the field of protection of the environment and natural resources on a bilateral, regional and global basis.

3. The Parties shall develop cooperation in the field of protection of the environment and natural resources on a basis of equality, reciprocity and mutual benefit.

\section{Article II}

Cooperation may be implemented in the following main areas of mutual interest:

1. atmosphere, and water and soil resources;

2. environmental aspects of agricultural production;

3. preservation, conservation and management of natural and cultural resources in the context of their relationship to the environment, including the organization of preserves and other specially protected areas;

4. marine and coastal areas and resources;

5. arctic and subarctic areas and resources;

6. environmental impact assessment;

7. global environmental issues, including climate change, depletion of the ozone layer and conservation and restoration of the biological diversity of local, regional and global ecological systems, including forest ecosystems;

8. the impact of environmental factors on human health and the condition of flora and fauna;

9. application of digital mapping and GIS (geographic information systems) technologies and use of sensor technology in addressing environmental issues;

10. energy-saving measures and creation of alternative energy sources;

11. legal and administrative measures relating to the protection of the environment, including legislation, enforcement and access to the administrative and judicial systems;

12. participation of the public, including non-governmental organizations, in environmental decision making; 
13. education in the field of environmental protection and natural resources;

14. economics and the management of environmental issues and the use of natural resources;

15. the role of the military in the field of protection of the environment and natural resources;

16. environmental emergencies;

17. earthquake prediction and assessment of seismic risks;

18. environmental monitoring; and

19. any other area of cooperation agreed by the Parties.

\section{Article III}

Cooperation between the Parties may be implemented by the following means:

1. joint scientific and technical projects;

2. exchange of scientific and technical information, documentation and research results, including exchange of information on the condition of the environment;

3. exchange of experience in the area of environmental management;

4. organizing and convening bilateral meetings, symposia and workshops, and publication of reports, articles, and monographs;

5. exchange of delegations, scientists, experts, research scholars and specialists;

6. participation of specialists of the Parties in international conferences, symposia and exhibitions on protection of the environment and ecology held in the two countries; and

7. any other means of cooperation agreed by the Parties.

\section{Article IV}

The Parties shall duly encourage and facilitate the establishment and development of direct contacts and cooperation between governmental, public, and private institutions and organizations of the two countries, and encourage and facilitate the conclusion, where required, of separate agreements and contracts necessary to implement activities under this Agreement.

\section{Article V}

1. To implement this Agreement, a Joint U.S. - Russian Committee on Cooperation in the Field of Pro- tection of the Environment and Natural Resources, hereinafter, the "Joint Committee", shall be established. As a rule, the Joint Committee shall meet once a year, alternately in Washington and Moscow. The Joint Committee shall review specific measures and programs of cooperation, coordinate the activities of organizations involved in implementation of these programs, and, as appropriate, make proposals to the Parties on the subject matter of this Agreement.

2. Each Party shall name a government agency, which agency shall designate a co-chair of the Joint Committee. In the period between sessions of the Joint Committee, the co-chairs will maintain contact between the American and Russian sections, coordinate the implementation of the pertinent programs of cooperation, update individual 
sections of these programs and coordinate the activity of organizations participating in cooperation in accordance with this Agreement.

\section{Article VI}

1. Scientific and technological information of a non-proprietary nature resulting from cooperation under this Agreement, other than information which is not disclosed for national security, commercial or industrial reasons, shall be made available, unless otherwise agreed, to the world scientific community through customary channels and in accordance with normal procedures of the participating agencies and entities.

2. The treatment of intellectual property created or furnished in the course of cooperative activities under this Agreement, unless agreed otherwise by the Parties in writing, is provided for in the Annex, which is an integral part of this Agreement.

\section{Article VII}

1. This Agreement shall enter into force upon signature and shall remain in force for five years, after which it will be extended for successive five-year periods, unless one of the Parties notifies the other of the termination thereof not later than six months before the Agreement's expiration.

2. Termination of this Agreement shall not affect the implementation of activities under this Agreement that are not fully completed upon the termination hereof.

\section{Article VIII}

This Agreement supersedes, as between the United States of America and the Russian Federation, the Agreement between the Government of the United States of America and the Government of the Union of Soviet Socialist Republics on Cooperation in the Field of Environmental Protection of May 23, 1972. The Parties may agree that an institutional structure developed under that Agreement may continue without being reconstituted.

\section{Article IX}

All activities under this Agreement shall be conducted in accordance with applicable laws, regulations and procedures of the United States of America and the Russian Federation and shall be subject to the availability of resources.

Done at Washington, this twenty-third day of June, 1994, in duplicate, in the English and Russian languages, both texts being equally authentic.

FOR THE GOVERNMENT OF THE UNITED STATES OF AMERICA:

[Signature]

\section{FOR THE GOVERNMENT OF THE RUSSIAN FEDERATION:}

[Signature] 


\section{ANNEX}

\section{INTELLECTUAL PROPERTY}

Pursuant to Article 6 of this Agreement:

The Parties shall ensure adequate and effective protection of intellectual property created or furnished under this Agreement and relevant implementing arrangements. The Parties agree to notify one another in a timely fashion of any inventions or copyrighted works arising under this Agreement and to seek protection for such intellectual property in a timely fashion. Rights to such intellectual property shall be allocated as provided in this Annex.

\section{SCOPE}

A. This Annex is applicable to all cooperative activities undertaken pursuant to this Agreement, except as otherwise specifically agreed to by the Parties or their designees.

B. For purposes of this Agreement, "intellectual property" shall have the meaning found in Article 2 of the Convention Establishing the World Intellectual Property Organization, done at Stockholm, July 14, 1967.

C. This Annex addresses the allocation of rights, interests, and royalties between the Parties. Each Party shall ensure that the other Party can obtain the rights to intellectual property allocated in accordance with the Annex, by obtaining those rights from its own participants through contracts or other legal means, if necessary. This Annex does not otherwise alter or prejudice the allocation between a Party and its nationals, which shall be determined by that Party's laws and practices.

D. Disputes concerning intellectual property arising under this Agreement should be resolved through discussions between the concerned participating institutions or, if necessary, the Parties or their designees. Upon mutual agreement of the Parties, a dispute shall be submitted to an arbitral tribunal for binding arbitration in accordance with the applicable rules of international law. Unless the Parties or their designees agree otherwise in writing, the arbitration rules of the UNCITRAL shall govern.

E. Termination or expiration of this Agreement shall not affect rights or obligations under this Annex.

\section{ALLOCATION OF RIGHTS}

A. Each Party shall be entitled to a non-exclusive, irrevocable, royalty-free license in all countries to translate, reproduce, and publicly distribute scientific and technical journal articles, reports, and books directly arising from cooperation under this Agreement. All publicly distributed copies of a copyrighted work prepared under this provision shall indicate the names of the authors of the work unless an author explicitly declines to be named.

B. Rights to all forms of intellectual property, other than those rights described in Part A of Section II above, shall be allocated as follows:

1. Researchers and scientists visiting in furtherance of their education shall receive intellectual property rights under the existing rules of the host institution. In addition, each visiting researcher named as an inventor or author shall have the right to national treatment regarding awards, benefits or other compensation, including royalties, in accordance with the existing rules of the host institution.

2. (a) For intellectual property created by the participants during joint research, for example, when the Parties, participating institutions, or participating personnel have agreed in advance on the scope of work, each Party shall be entitled to obtain all rights and interests in its own territory. The allocation of rights and interests in third countries will be determined in implementing arrangements. The rights to intellectual property shall be allocated with due regard for the economic, scientific and technological contributions from each Party to the creation of intellectual property. If research is not designated as "joint research" in the relevant implementing arrangement, rights to intellectual property arising from the research shall be allocated 
in accordance with Part B, paragraph 1 of Section II. In addition, each person named as an inventor or author shall have the right to national treatment regarding awards, benefits and other compensation, including royalties, in accordance with the existing rules of the host institution;

(b) Notwithstanding Part B, paragraph 2(a) of Section II, if a type of intellectual property is available under the laws of one Party but not the other Party, the Party whose laws provide for this type of protection shall be entitled to all rights and interests in all countries which provide rights to such intellectual property. Persons named as inventors or authors of the property shall nonetheless be entitled to national treatment in regard to awards, benefits, or other compensations, including royalties, in accordance with the rules as provided in Part B, paragraph 2(a) of Section II.

\section{BUSINESS CONFIDENTIAL INFORMATION}

In the event that information identified in a timely fashion as business-confidential is furnished or created under the Agreement, each Party and its participants shall protect such information in accordance with applicable laws, regulations, and administrative practice. Information may be identified as "business-confidential" if a person having the information may derive an economic benefit from it or may obtain a competitive advantage over those who do not have it, the information is not generally known or publicly available from other sources, and the owner has not previously made the information available without imposing in a timely manner an obligation to keep it confidential. 


\section{Agreement Between the Government of the United States of America and the Government of the Russian Federation for Cooperation in the GLOBE Program, Moscow, 1994}

\section{Done at Moscow 16 December 1994}

Entered into force 16 December 1994

Primary source citation: Copy of text provided by the

U.S. Department of State

\section{AN AGREEMENT BETWEEN THE GOVERNMENT OF THE UNITED STATES OF AMERICA AND THE GOVERNMENT OF THE RUSSIAN FEDERATION FOR COOPERATION IN THE GLOBE PROGRAM}

The Government of the United States of America and the Government of the Russian Federation (hereinafter, the sides),

Intending to increase the awareness of students throughout the world about the global environment,

Seeking to contribute to increased scientific understanding of the Earth,

Desiring to support improved student achievement in science and mathematics, and

Promoting students to undertake careers related to environmental studies,

Have agreed to cooperate in the Global Learning and Observations to Benefit the Environment (GLOBE) Program as follows:

\section{ARTICLE 1 - THE GLOBE PROGRAM}

The GLOBE Program is an international environmental science and education program that will bring students, teachers, and scientists together to study the global environment. GLOBE will create an international network of children and students, aged 5-18 years (Kindergarten to grade 12 or equivalent) studying environmental issues, making environmental measurements, and sharing useful environmental data with the international environmental science conmunity. 


\section{ARTICLE 2 - COOPERATING AGENCIES}

Agencies responsible for cooperation and coordination under this agreement are:

On the U.S. side, the U.S. National Oceanic and Atmospheric Administration, acting in conjunction with other U.S. Government agencies participating in the GLOBE Program;

On the Russian side, the Ministry of Environmental Protection and Natural Resources of the Russian Federation and the Ministry of Education of the Russian Federation.

\section{ARTICLE 3 - RESPECTIVE RESPONSIBILITIES}

I. The U.S. side will:

1. Identify U.S. schools that will participate in the GLOBE Program (details regarding GLOBE schools in Appendix I);

2. Select, in consultation with international scientists and educators, the GLOBE environmental measurements and types of measurement equipment (described in Appendices II and III);

3. Select Principal Investigator Teams for the GLOBE environmental measurements, and support the U.S. members of the Teams;

4. Calibrate, if necessary, measurement equipment that cannot be calibrated by GLOBE teachers and students;

5. Develop, in consultation with international scientists and educators, GLOBE educational materials;

6. Translate GLOBE instructional materials related to measurement procedures and reporting protocols into the six United Nations languages, and provide these plus all broader GLOBE educational materials free of charge to the Russian side for further reproduction as necessary;

7. Conduct annual regional training sessions for GLOBE Country Coordinators and GLOBE teachers who will serve as trainers for additional GLOBE teachers in the Russian Federation, and provide a copy of GLOBE training materials free of charge to the Russian side;

8. Design, develop, operate, and maintain GLOBE data processing and visualization product processing capabilities and other necessary technology and equipment;

9. Provide GLOBE software, as necessary, for use on Russian GLOBE school computers;

10. Accept environmental data reported from GLOBE schools around the world, and develop and provide to the Russian side resultant global environmental images (visualization products); and

11. Evaluate the overall GLOBE Program periodically, in consultation with international GLOBE Country Coordinators, and modify the overall program as appropriate.

II. The Russian side will:

1. Select Russian schools to participate in the GLOBE Program (details regarding GLOBE schools in Appendix I) and provide an updated list of Russian GLOBE schools to the U.S. side at the beginning of each school year;

2. Ensure that Russian GLOBE schools conduct the fundamental activities of GLOBE schools detailed in Appendix I; 
3. Name a Russian Government Point of Contact responsible for communications with the Director of the GLOBE Program;

4. Name a Country Coordinator responsible for day-to-day management, oversight, and facilitation of the GLOBE Program in the Russian Federation;

5. Ensure that the Country Coordinator and some GLOBE teachers attend GLOBE regional training and in turn provide GLOBE training to at least one teacher in each Russian GLOBE school;

6. Ensure that GLOBE instructional materials related to measurement procedures and reporting protocols are utilized in Russian GLOBE schools, and that broader GLOBE educational materials are appropriately translated, adapted, reproduced, and distributed free of charge to all Russian GLOBE schools;

7. Ensure that Russian GLOBE schools have the necessary measurement and other equipment to take GLOBE environmental measurements (described in Appendix II);

8. Ensure that teachers and students at Russian GLOBE schools calibrate GLOBE measurement equipment according to procedures provided in GLOBE educational materials;

9. Ensure that Russian GLOBE schools have the necessary computer and communications systems (described in Appendix III) to report GLOBE environmental measurements and to receive and use GLOBE visualization products via Internet; and

10. Evaluate GLOBE operations in the Russian Federation periodically and assist the U.S. side in conducting periodic evaluation of the overall GLOBE Program.

\section{ARTICLE 4 - FINANCIAL AND LEGAL ARRANGEMENTS}

Each side will bear the costs of fulfilling its respective responsibilities under this agreement. Activities of each side pursuant to this agreement are subject to its respective funding procedures and the availability of appropriated funds, personnel, and other resources. The conduct of activities under this agreement will be consistent with the relevant laws, regulations and procedures of the two sides.

\section{ARTICLE 5 - EXCHANGE OF DATA AND GOODS}

GLOBE environmental measurement data, visualization products, software, and educational materials will be available worldwide without restriction as to their use or redistribution, unless otherwise agreed.

\section{ARTICLE 6 - RELEASE OF INFORMATION ABOUT THE GLOBE PROGRAM}

Each side may release information on the GLOBE Program as it may deem appropriate without prior consultation with the other.

\section{ARTICLE 7 - CUSTOMS AND IMMIGRATION}

Each side will, in accordance with its laws and regulations, expedite customs and immigration procedures as required for implementation of this agreement. 


\section{ARTICLE 8 - ENTRY INTO FORCE, WITHDRAWAL, AMENDMENTS}

This agreement will enter into force upon signature of the two sides and will remain in force for five years. It will be automatically extended for further five-year periods, unless either side decides to terminate it and so notifies the other side with three months written notice. This agreement may be terminated at any time by either side upon three months prior written notice to the other side. This agreement may be amended by written agreement of the two sides.

Done at Moscow this sixteenth day of December, 1994, in duplicate, in the English and Russian languages, both texts being equally authentic.

\section{FOR THE GOVERNMENT OF THE} UNITED STATES OF AMERICA:

[Signature]

\author{
FOR THE GOVERNMENT OF THE \\ RUSSIAN FEDERATION:
}

[Signature]

\section{APPENDIX I GLOBE Schools}

Each partner country will be responsible for identifying its participating schools. Schools should be selected so as to satisfy the objectives of the GLOBE Program. In particular, countries should emphasize the selection of schools that will maximize the number of students worldwide participating in the program. Also, countries should consider involving schools in locations that will yield measurement data that is important to the international environmental science community.

Students at all GLOBE schools throughout the world will conduct the following fundamental activities: they will make environmental measurements at or near their schools; report their data to a GLOBE data processing site; receive graphical global environmental images (visualization products) created from their data and the data from other GLOBE schools around the world; and study the environment by relating their observations and the resulting visualization products to broader environmental topics. All of these activities will be conducted under the guidance of specially trained teachers (GLOBE-trained teachers).

GLOBE educational materials will be used in GLOBE schools under the guidance of GLOBE-trained teachers. These materials will detail procedures for taking environmental measurements and protocols for reporting data; explain the significance of the measurements; guide the use of the visualization products; and integrate the experimental aspects of the program into a broader study of the environment.

\section{APPENDIX II GLOBE Environmental Measurements and Equipment}

GLOBE environmental measurements will contribute in a significant way to the scientific understanding of the dynamics of the global environment. Every GLOBE school will conduct a core set of GLOBE environmental measurements in the following critical areas: Atmosphere/Climate, Hydrology/Water Chemistry, and Biology/Geology. Where possible, a GLOBE school may coordinate its activities with those of other schools, so that the complete set of GLOBE measurements will be available from a locality. As the GLOBE Program evolves, elective measurements not common to all GLOBE schools may be added in order to address local environmental issues.

Students at all age levels will be active participants in the GLOBE Program. The actual participation will be designed so as to be grade-appropriate for grades K-5, 6-8 and 9-12 (or equivalent). Younger students will make limited measurements, which may be qualitative rather than quantitative. Older students will make additional measurements and more sophisticated measurements, as appropriate for their grade level. Measurement equipment will not need to be standardized; rather, performance specifications will be provided. The list of core measurements and equipment will be initially determined and periodically updated as provided in Article 2.I.2, based on experience gained in implementing the GLOBE Program. 


\section{APPENDIX III \\ GLOBE Computer and Communications Systems}

Schools participating in the GLOBE Program should have the necessary technological capabilities. Computers and communications systems should be consistent with current GLOBE Program requirements. In order to derive maximum benefit from the GLOBE Program, it is advisable for all schools to use an international information network, initially using the Internet, along with classroom computers.

The U.S. side will adapt or develop software for IBM-compatible or Apple Macintosh computer configurations to support the required GLOBE school activities of data entry, data analysis, and use of visualization products. In the early stages, environmental measurement data may be reported in written form to the Country Coordinator who will transmit it to the U.S. via Internet, and a variety of media may be used to distribute visualization products, including photographs and broadcast television. 


\section{Agreement Between the Government of the United States of America and the Government of the Russian Federation on Cooperation in the Prevention of Pollution of the Environment of the Arctic, Moscow, 1994}

\section{Done at Moscow 16 December 1994}

Entered into force 16 December 1994

Depositary: United Nations

Primary source citation: Copy of text provided by the

U.S. Department of State

\section{AGREEMENT BETWEEN THE GOVERNMENT OF THE UNITED STATES OF AMERICA AND THE GOVERNIMENT OF THE RUSSIAN FEDERATION ON COOPERATION IN THE PREVENTION OF POLLUTION OF THE ENVIRONMENT IN THE ARCTIC}

The Government of the United States of America and the Government of the Russian Federation (hereinafter referred to as the Parties),

Recognizing the sensitivity of the Arctic environment and our mutual commitment to protect the Arctic environment and to promote the social and economic interests of local, especially indigenous populations, including their traditional way of life;

Concerned over the potential threats posed by contaminants in the Arctic region to the health of the indigenous and local populations of the region as well as to its flora and fauna;

Convinced that cooperation and sharing of experience between the Parties will contribute to understanding and effective response to any such threat both on a national basis and within broader international efforts to protect the Arctic environment;

Desiring to build upon the results of the American-Russian Summit held in Vancouver, April 3-4, 1993;

Noting the particular importance of relevant provisions of Part XII of the United Nations Convention on the Law of the Sea of 1982; the provisions of the Convention on the Prevention of Marine Pollution by Dumping of Wastes and Other Matter of 1972; and the provisions of the Arctic Environmental Protection Strategy of 1991; 
Have agreed as follows:

\section{Article 1}

The Parties shall cooperate in the prevention, reduction and control of pollution in the Arctic marine and terrestrial environment resulting from the accidental or intentional introduction of contaminants into that environment.

To this end the Parties shall cooperate in research, monitoring, assessment and other activities, bilaterally and in the appropriate multilateral fora.

\section{Article 2}

1. The Parties shall cooperate in the conduct of scientific research, monitoring, and assessment activities to determine the potential impacts of contaminants in the Arctic environment, including, inter alia:

1) the pathways by which such contaminants reach and are dispersed within the Arctic environment;

2) the effects of such contaminants, including rates of bio-accumulation, upon Arctic flora and fauna, including fish populations; and

3) the effects of such contaminants upon human health in the Arctic environment, especially upon local and indigenous populations.

2. The Parties further shall cooperate in the monitoring and assessment of levels of hazardous contamination in the Arctic environment, including, inter alia:

1) exchange of data and information on the effects of disposal and release of such contaminants introduced directly or indirectly into the Arctic environment;

2) determination of the level, chemical composition, and patterns of such contamination caused by releases from sites at which materials have been stored, processed or disposed; and

3) determination of the amount, concentrations and dynamics of such contaminants introduced into the marine zone, including through rivers and other watercourses, natural or artificial, and via ice transport and ice rafted sediment.

3. The Parties shall consult with regard to technical solutions for the elimination of radioactive and other types of contamination impacts.

4. The Parties shall cooperate in the conduct of joint scientific research to predict ecological impacts of the existing disposals of radioactive waste and consult with regard to technical solutions for the elimination of disposals in places where ecological safety is not insured.

5. Cooperation between the Parties in scientific research and monitoring referred to in this Article shall take place bilaterally, and within the appropriate international, including regional, mechanisms, in particular the Arctic Monitoring and Assessment Program of the Arctic Environmental Protection Strategy of 1991 and the International Arctic Seas Assessment Program of 1993 the International Atomic Energy Agency.

\section{Article 3}

1. Each Party shall facilitate joint activities under Article 2 in areas that are under its jurisdiction in accordance with international law and that are or are believed to be contaminated, under such reasonable conditions as it may establish. 
2. The Parties shall ensure that the data and information resulting from such research and monitoring are exchanged and made freely available on a reciprocal basis.

\section{Article 4}

The Parties shall promote the development of specific measures to give effect to this Agreement, including:

1) programs for the exchange of scientists, students and experts;

2) organization of seminars and meetings of experts;

3) organization of joint research activities, including marine scientific research cruises;

4) development of Geographic Information Systems, data bases and inventories on Arctic environmental data;

5) cooperation in emergency preparedness exercises and prompt exchange of information concerning major accidental releases of contaminants into the Arctic environment; and

6) exchange of information on technologies and assessment methodologies applicable within the framework of this Agreement and on the relevant environmental protection legislation and regulations.

\section{Article 5}

Activities under this Agreement, including specific projects and programs, shall be carried out by responsible agencies of each Party in accordance with the Agreement Between the Government of the Union of Soviet Socialist Republics and the Government of the United States on Cooperation in Ocean Studies of 1990 and the Agreement between the Government of the United States and the Government of the Russian Federation on Cooperation in the Field of Protection of the Environment and Natural Resources of 1994 and under the overall coordination of the United States-Russian Commission on Economic and Technological Cooperation or under any other coordinating body as may be agreed by the Parties.

\section{Article 6}

1. All activities undertaken pursuant to this Agreement shall be conducted in accordance with the applicable laws, regulations, and procedures in both countries and shall be subject to the availability of funds and personnel.

2. Scientific and technological information resulting from cooperation under this Agreement, other than information which is not disclosed for national security, commercial or industrial reasons, shall be made freely available, unless otherwise agreed.

3. Issues of intellectual property created or furnished in the course of joint activities under this Agreement shall be governed by Annex II of the Agreement between the Government of the United States of America and the Government of the Russian Federation on Science and Technology Cooperation, signed at Moscow December 16, 1993.

\section{Article 7}

The Parties shall resolve by consultation any differences as to the interpretation or application of this Agreement. 


\section{Article 8}

1. This Agreement shall enter into force upon signature and remain in force for a period of five years, and may be extended for additional five year periods upon written agreement of the Parties.

2. Either Party may terminate this Agreement by so notifying the other Party in writing. Such termination shall be effective six months from such written notification.

IN WITNESS WHEREOF, the undersigned, being duly authorized by their respective Governments, have signed this Agreement.

DONE at Moscow, in duplicate, this sixteenth day of December 1994, in the English and Russian languages, each text being equally authentic.

FOR THE GOVERNMENT OF

THE UNITED STATES OF AMERICA:

[Signature]
FOR THE GOVERNMENT OF

THE RUSSIAN FEDERATION:

[Signature] 


\section{B I L A T E R A L}

\section{Russia}





\title{
Amendment to the Agreement Between the Government of the United States and the Government of the Russian Federation on Mutual Fisheries Relations, Washington, D.C., 1993
}

\author{
Done at Washington, D.C. 11 March and \\ 15 September 1993 \\ Entered into force 4 April 1994 \\ Primary source citation: Copy of text provided by the \\ U.S. Department of State
}

[March 11, 1993]

His Excellency

Vladimir P. Lukin,

Ambassador of the Russian Federation

Excellency:

I have the honor to refer to the Sixth Meeting of the U.S.-Russia Intergovernmental Consultative Committee on Fisheries, held at Washington January 11 and 12, 1993, and to the Agreement on Mutual Fisheries Relations, with Annexes, signed at Moscow May 31, 1988 (the Agreement).

I have the honor to propose, on behalf of my Government, that Annex I of the Agreement be replaced in its entirety by the Annex attached to this note, and that the Agreement, now scheduled to expire on October 28, 1993, be extended through December 31, 1998.

I also have the honor to propose that Article V of the Agreement be amended to read as follows: "Permits for fishing in the zone of each party, and information on such fishing, shall be issued pursuant to Annex I, which constitutes an integral part of this Agreement."

I have the further honor to propose that, if this is acceptable to Your Excellency, this note and Your Excellency's note in reply shall constitute an agreement between our two Governments, which shall enter into force on a date to be determined in a subsequent exchange of diplomatic notes following the completion of all necessary internal procedures of both parties.

Accept, Excellency, the renewed assurances of my highest consideration.

For the Secretary of State:

[Signature]

Attachment:

Revised Annex I. 


\section{ANNEX I \\ PERMIT ISSUANCE PROCEDURES AND EXCHANGE OF INFORMATION ON FISHING OF THE PARTIES IN EACH OTHER'S ZONES}

The following procedures shall govern the issuance of annual permits to vessels of the other Party for the conduct of fishing for living marine resources in respect of which the other Party exercises management authority and the exchange of information on such fishing.

1. Permits for fishing in the zone of the other Party shall be issued in accordance with the laws and regulations of the other Party.

2. The other Party shall notify the requesting Party of the terms and conditions regarding fishing for living marine resources in its zone by vessels of the requesting Party, and of the tonnage of living marine resources harvested, processed, or otherwise taken on board, or transshipped by each permitted vessel.

3. Each Party shall cooperate to exchange data pertaining to living marine resources harvested in its zone by permitted vessels of the other Party and transshipped between their zones.

4. The procedure for the exchange of information and data specified in paragraphs 2 and 3 of this Annex will be developed by technical experts of the Committee formed pursuant to Article XIV.

5. Each Party shall make available information on fishing for living marine resources in its zone by permitted vessels of the other Party only to that other Party. Parties.

6. The provisions of this Annex may be amended by agreement through an exchange of notes between the

\section{DEPARTMENT OF STATE \\ OFFICE OF LANGUAGE SERVICES \\ Translating Division}

LS No. 142590

Russian

TM/

Washington, September 15, 1993

No. 62

His Excellency,

Warren CHRISTOPHER,

Secretary of State of the United States of America,

Washington, D.C.

Dear Mr. Secretary:

I have the honor to confirm receipt of your note of March 11, 1993, which reads as follows:

"Your Excellency:

"I have the honor to refer to the Sixth Meeting of the U.S.-Russia Intergovernmental Consultative Committee on Fisheries, held at Washington January 11 and 12, 1993, and to the Agreement on Mutual Fisheries Relations, with Annexes, signed at Moscow May 31, 1988 (the Agreement). 
"I have the honor to propose, on behalf of my Government, that Annex I of the Agreement be replaced in its entirety by the Annex attached to this note, and that the Agreement, now scheduled to expire on October 28,1993, be extended through December 31, 1998.

"I also have the honor to propose that Article V of the Agreement be amended to read as follows: Permits for fishing in the zone of each party, and information on such fishing, shall be issued pursuant to Annex I, which constitutes an integral part of this Agreement.'

'I have the further honor to propose that, if this is acceptable to Your Excellency, this note and Your Excellency's note in reply shall constitute an agreement between our two Governments, which shall enter into force on a date to be determined in a subsequent exchange of diplomatic notes following the completion of all necessary internal procedures of both parties.

“Accept, Excellency, the renewed assurances of my highest consideration.

\section{"Annex I}

“Permit issuance procedures and exchange of information on fishing of the parties in each other's zones.

"The following procedures shall govern the issuance of annual permits to vessels of one Party for the conduct of fishing for living marine resources in respect of which the other Party exercises management authority over fishing and the exchange of information on such fishing.

"1. Permits for fishing in the zone of the other Party shall be issued in accordance with the laws and regulations of the other Party pertaining to this matter.

"2. The other Party shall notify the requesting Party of the terms and conditions regarding fishing for living marine resources in its zone by vessels of the requesting Party, and of the tonnage of living marine resources harvested, processed, or otherwise taken on board, or transshipped by each permitted vessel.

“3. Each Party shall cooperate by exchanging data pertaining to living marine resources harvested in its zone by permitted vessels of the other Party and transshipped between their zones.

"4. The procedure for the exchange of the information and data specified in paragraphs 2 and 3 of this Annex will be developed by technical experts of the Committee formed pursuant to Article XIV.

"5. Each Party shall make available information on fishing for living marine resources in its zone by permitted vessels of the other Party only to that Party.

"6. The provisions of this Annex may be amended by agreement through an exchange of notes between the Parties."

I have the honor to inform you that the Government of the Russian Federation concurs that your note and this note in reply should be considered an agreement between our Governments on this matter. Considering that all necessary internal procedures have been followed in the Russian Federation, we assume that this agreement shall enter into force on the date on which the American Side informs us by diplomatic note of the completion of its necessary internal procedures.

Accept, Mr. Secretary, the renewed assurances of my highest consideration.

Sincerely,

Vladimir LUKIN

Ambassador of the Russian Federation to the U.S.A. Washington, D.C. 


\title{
Amendment to the Agreement Between the Government of the United States and the Government of the Russian Federation on Mutual Fisheries Relations, Washington, D.C., 1993-1994
}

\author{
Done at Washington, D.C. 22 December 1993 and \\ 5 January 1994 \\ Entered into force 5 January 1994, effective \\ 28 October 1993*
}

Primary source citation: Copy of text provided by the U.S. Department of State

\section{DEPARTMENT OF STATE \\ WASHINGTON}

January 5, 1994

His Excellency

Vladimir P. Lukin,

Ambassador of the Russian Federation

Excellency: follows:

I have the honor to acknowledge receipt of your note number 95, dated December 22, 1993, which reads as

"I have the honor to refer to the Agreement between the Russian Federation and the United States of America on Mutual Relations in the Field of Fisheries with its annexes, done in Moscow on May 31, 1988 (the 1988 Agreement).

"Before the entry into force of the accord amending and extending the 1988 Agreement, confirmed by an exchange of notes in Washington on March 11 and September 15, 1993, I have the honor to propose on behalf of the Government of the Russian Federation that the term of the 1988 Agreement be extended to May 1, 1994.

"If this proposal is acceptable to the Government of the United States of America, I also have the honor to propose that this note and Your Excellency's note containing a positive response concerning this matter constitute an agreement between our two governments, which shall enter into force as of the date of Your Excellency's note, i.e., as of October 28, 1993.

"Please accept once more, Your Excellency, the assurances of my highest consideration."

"This agreement has been terminated 
I have the further honor to inform Your Excellency that this proposal is acceptable to the Government of the United States of America and that Your Excellency's note and this note in reply shall constitute an agreement between our two Governments which shall either into force on the date of this note, effective from October 28, 1993.

Accept Excellency, the renewed assurances of my highest consideration.

For the Secretary of State:

[Signature]

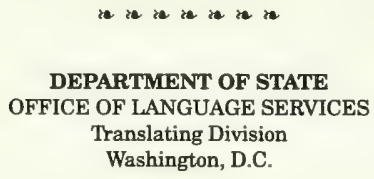

LS No. 143310

Russian

December 22, 1993

Embassy of the

Russian Federation in the

United States of America

Washington, D.C.

His Excellency

Warren Christopher

Secretary of State of the

United States of America

Washington, D.C.

No. 95

Your Excellency:

I have the honor to refer to the Agreement between the Russian Federation and the United States of America on Mutual Relations in the Field of Fisheries with its annexes, done in Moscow on May 31, 1988 (the 1988 Agreement).

Before the entry into force of the accord amending and extending the 1988 Agreement, confirmed by an exchange of notes in Washington on March 11 and September 15, 1993, I have the honor to propose on behalf of the Government of the Russian Federation that the term of the 1988 Agreement be extended to May 1, 1994.

If this proposal is acceptable to the Government of the United States of America, I also have the honor to propose that this note and Your Excellency's note containing a positive response concerning this matter constitute an agreement between our two governments, which shall enter into force as of the date of Your Excellency's note, i.e., as of October 28, 1993.

Please accept once more, Your Excellency, the assurances of my highest consideration.

[s] Vladimir Lukin Ambassador of the Russian Federation to the United States of America 



\section{B $\quad \begin{array}{llllllll} & \mathbf{L} & \mathbf{A} & \mathbf{T} & \mathbf{E} & \mathbf{R} & \mathbf{A} & \mathbf{L}\end{array}$}

Russia

NON - B I N D I NG DOCUM ENTS 



\title{
Protocol of the U.S.-Russia Workshop on Sea Otter Biology Under the Marine Mammal Project, 02.05-61 U.S.-Russia Environmental Agreement, Wasilla, 22 October 1993
}

\author{
Done at Wasilla, Alaska 22 October 1993 \\ Primary source citation: Copy of text provided by the \\ U.S. Fish and Wildlife Service, U.S. Department of \\ Interior
}

The Fourth U.S.-Russian joint sea otter meeting was held at Wasilla, Alaska, 18-22 October 1993.

Representing the U.S. side were: J. Bodkin, B.E. Ballachey, A. DeGange, D. Burn, A. Doroff, J. Estes, G. Esslinger, E. Faurot-Daniels, C. Faanes, D.L. Garshelis, C. Gorbics, L. Holland-Bartels, A. Johnson, B. Kelly, L. Lowry, J.A.K. Mazet, M. C. McCormick, J. Nickles, M. Reidman, M. Staedler, N. Stevens, G. VanBlaricom, J. Taggart, P. Ward.

Representing the Russian side were: A.G. Bazhin, A.M. Burdin, V. Burkanov, V. Nikulin, V.V. Oshurkov, D.A. Ryazanov, I.N. Shevchenko.

The meeting was opened on 18 October, 1993 in Wasilla, Alaska by J.L. Bodkin with welcoming remarks by Marine Mammals/Fisheries Chief, Alaska Fish and Wildlife Research Center, L. Holland-Bartels. The meetings sessions were chaired by B. Ballachey, J. Bodkin, A. DeGange and A. Doroff.

Sea Otter Research and Management Presentations

B.E. Ballachey provided an overview of research conducted by the U.S. Fish and Wildlife Service on sea otters in Prince William Sound, Alaska, following the Exxon Valdez oil spill of March 1989.

J. L. Bodkin presented preliminary results on the development of an aerial technique to estimate the abundance of sea otters. The method includes means to account for animals not observed on strip transects with intensive searches with strips. 
D.L. Garshelis summarized the results of boat-based surveys of sea otters conducted after the Exxon Valdez oil spill and presented a scenario that explained high numbers of otters by an increasing food base, which increased their carrying capacity.

J.A.K. Mazet presented a protocol for evaluating the effects of environmental petroleum hydrocarbons on sea otters using the American mink as a laboratory animal model. In addition, developing diagnostic tests for the detection of petroleum hydrocarbons in blood and on the fur of sea otters were discussed.

J.A. Estes discussed the evolutionary importance of sea otters in kelp forest communities. The influence of sea otters as top-level predators was evaluated by comparing marine plant/herbivore interactions between the northeast Pacific (sea otters present) and Australasia (otters absent). Australasian kelp forests experience chronically high levels of herbivory and probably have through the late Cenozoic. In apparent response, Australasian algae are well-defended by secondary metabolites and the herbivores have evolved a tolerance to these chemicals.

J.A. Estes summarized preliminary data on levels of PCBs and DDT/DDE from sea otters in central California, southeast Alaska, and the western Aleutian Islands. As expected, PCB and DDT/DDE levels were relatively high in central California and low in southeast Alaska. However, both classes of pollutants were higher than expected in the Aleutian Islands. The source of these materials in the Aleutian Islands is unknown.

A. DeGange summarized the sea otter management plan developed by the Fish and Wildlife Service for Alaska, presenting options for management and the conservation of nearshore marine resources.

A.M. Doroff presented data on juvenile sea otter post-weaning survival in eastern and western Prince William Sound following the Exxon Valdez oil spill of March 1989.

C. Faanes reported on the status of the translocated sea otter population in California and discussed possible future considerations of management decisions regarding the translocation.

C. Gorbics summarized the future direction of sea otter restoration related to the Exxon Valdez oil spill. A council of state and federal trustees will make decisions on how future settlement money will be spent. It is likely that the trustees will support some level of monitoring recovery of sea otter populations including monitoring of populations, physiological effects, and mortality patterns.

B.P. Kelly reported on the development of regional sea otter conservation plans by the Alaska Sea Otter Commission (ASOC). The ASOC is made up of Native subsistence hunters from communities throughout the sea otter's range in Alaska. A conservation plan for the Southeast Alaska region will be completed in the coming year. The plan will proscribe conservative harvest limits, so that the subsistence take will not be a threat to the sea otter population. Conflicts between sea otters and Native people for shellfish likely will intensify in the next few years.

E. Faurot-Daniels offered the perspective of a sea otter advocacy and conservation group (Friends of the Sea Otter) on the issue of Alaska Native take of sea otters. FSO does not challenge the right of Natives to take sea otters for subsistence purposes; their concern is in seeing that harvest guidelines not only utilize the best available biological knowledge, but that Native plans be sensitive to the social and political implications of various management decisions.

V. Nikulin reported on the preliminary results from a Bering Island study of seasonal aspects of birth rates in the sea otter population. During the period from November, 1992 to September, 1993, monthly counts of sea otters were conducted in a designated study area in the northern part of Bering Island. The period of maximum abundance of newborn pups occurred in May. The period of maximum abundance of all pups occurred in June.

V. Oshurkov reported on the benthic community structure of the Commander Islands and the long term changes in the distribution and abundance of some invertebrate species effected by sea otter predation. The mechanisms of competition and succession in nearshore algae communities was discussed.

I. Shevchenko reported on trends in the Commander Islands sea otter population for the last five years. Abundance decreased for the three most recent years by $49 \%$. In 1993 on the Commander Islands 2,300 sea otters were counted; pups comprised $21 \%(n=480)$. 
A. Bazhin addressed the monitoring of algal/sea urchin populations in rocky benthic communities that are influenced by sea otter predation. The work was conducted on the eastern coast of Kamchatka. As a result of sea otter foraging, urchin sizes are reduced in shallow water and increase with depth.

D. Ryazanov spoke on the cementum of sea otter teeth as a registering structure and its use in age determination and other aims. There are showing differences in age estimations had made by different persons. Brightness of cementum color corresponds to the color of the entire skeleton. There are substantial geography-related differences in cementum color.

A. Burdin presented data on long term changes in sea otter diet in the Asian range. He indicated that sea otter populations with different population status have different feeding strategies.

G. VanBlaricom presented a general synthesis of interactions of sea otters and shellfish prey. He suggested a general model, and proposed key variables that influence behavior of the model. The synthesis was based primarily on data from California, but is applicable to interactions in any location.

M. Riedman presented preliminary summaries of observations made on tagged sea otters in Monterey indicating that territorial males differed in their foraging strategies from adult females by foraging a greater distance from shore and frequently stealing food from females; the amount of prey males stole accounted for $1 / 4$ to $1 / 3$ of the total number of prey items males ingested.

\section{Collaborative Research and Future Workshop Meeting}

Both sides have determined and agreed on research programs to be conducted in 1994 and 1995 , both within their own countries and jointly.

$\underline{\text { Russian side proposed: }}$

1. To invite 2 U.S. specialists to review archived records of the Russian-America Company to obtain data on sea otter distribution, abundance and demography, during the hunting period. Work to be conducted in St. Petersburg, Petropavlovsk-Kamchatskiy and Moscow in 1994.

2. To invite in 1994 or $1995,2-3$ U.S. specialists to take part in the Kamchatka Institute of Ecology expedition at Kronotsky Cape to study local sea otter populations and benthic communities.

3. To provide tissue samples of sea otters from the Kurile and Commander Islands, and the Kamchatka Peninsula to the U.S. side for contaminants and histopathological analyses.

4. To provide information to the U.S. side on fiscal requirements for supporting conservation of sea otter populations in the Kurile and Commander Islands, and the Kamchatka Peninsula.

5. To invite 2 U.S. specialists to Russia in $\mathbf{1 9 9 5}$ to evaluate the effects of petroleum hydrocarbon exposure on sea otters.

6. To invite 2-3 U.S. sea otter specialists to participate in a joint study of sea otter abundance and reproductive biology in 1994 or 1995 at the Commander Islands.

The U.S. side proposed:

1. To invite 2 Russian researchers in the summer of 1994 to work in west/central Aleutian Islands and possibly in the Kurile Islands on the U.S. RV Alpha Helix. Work will entail collecting sea otter population data, and the study of benthic community ecology and related marine systems.

2. The same invitation and work mentioned in the above may be done in 1995 as well.

3. To provide sea otter premolars and canines from specimens whose time of death is known to Russian scientists for evaluation of registering structures. 
4. To continue cooperative research on sea otter diving behavior using time-depth recorders and radio transmitters at Bering Island in 1994 or 1995.

5. Agrees to support Russian sea otter research through the transfer of excess equipment as available.

It was jointly recommended:

One or more active U.S. sea otter research scientist would assist in development and review of Russian/U.S. manuscripts suitable for publication in U.S. or other peer reviewed journals.

The U.S. side will compile a bibliography of sea otter research in the U.S.

To hold the next sea otter work shop in Kamchatka, Russia in 1995 and that sea otter specialists from Canada, Mexico and Japan be invited to participate.

Signed 27 October 1993 in English and Russian texts, both versions being identical and equally authentic.

For the Russian side

For the U.S. side

[Signature]

Alexander M. Burdin

[Signature]

James L. Bodkin 


\title{
Protocol of the Twelfth Meeting of the Marine Mammal Project, U.S.-Russia Environmental Protection Agreement, Anchorage, 1993
}

\author{
Done at Anchorage 10 December 1993 \\ Primary source citation: Copy of text provided by the \\ U.S. Fish and Wildlife Service, U.S. Department of \\ Interior

\section{PROTOCOL \\ OF THE TWELFTH MEETING OF THE MARINE MAMMAL PROJECT, U.S.-RUSSIA ENVIRONMENTAL PROTECTION AGREEMENT}

\author{
Anchorage, Alaska, USA \\ 6-10 December 1993
}

The Twelfth Meeting was held at the U.S. National Biological Survey in Anchorage, Alaska, 6-10 December 1993. Representing the United States side were: R. V. Miller, Head of U.S. Delegation; T. R. Loughlin; J. D. Baker; R. L. Brownell, Jr.; L. F. Lowry; J. Lewis; D. Calkins; J. R. Nickles; D. Seagars; C. Gorbics; A. Doroff; L. Holland-Bartels;

G. Garner; J. Bodkin; B. Ballachey; and P. Ward.

Representing the Russian side were: V. A. Vladimirov, Head of the Russian Delegation; A. A. Berzin; A. I. Boltnev; A. M. Burdin; V. N. Burkanov; Yu. A. Bukhtiyarov; I. V. Mikno; and A. S. Perlov.

The Meetings sessions were co-chaired by R. V. Miller (U.S.A.) and V. A. Vladimirov (Russia).

Steller Sea Lions:

\section{$\underline{\text { Pinnipeds }}$}

Dr. T. R. Loughlin presented the results of joint NMFS/ADF\&G aerial and ship-based surveys of Steller sea lions in 1992-93. Pup counts at trend sites surveyed every second year declined approximately $15 \%$ between $1990-92$, and 20\% between 1991-93. Adult counts at Marmot Island decreased in 1993, after a period of relatively slow decline during 1991-92. Low resight rates of animals tagged and branded during 1987-88 indicate low juvenile survival. Dr. Loughlin also reported on recent prey studies including hydroacoustic, trawl sampling, and scat studies. Additional research was conducted on foraging behavior, energetics, pup growth and condition, and thermoregulation.

Mr. D. Calkins reported on aerial surveys and pup counts in the eastern Gulf of Alaska and Southeast Alaska. In the Eastern Gulf there has been a 5-10\% decline in non-pups since 1989, during which time pup counts remained stable. In 1993, approximately 500 pups were counted on the Wooded Islands outside Prince William Sound. This rookery was last surveyed in 1979 , when about 30 pups were present. In Southeast Alaska the Steller sea lion population remains stable. This area was not completely surveyed during 1993 due to inclement weather. A new field camp was established on Lowry Island where physiology, attendance and foraging behavior, immobilization tech- 
niques, and population parameters are under investigation. This site is in the area where sea lions are not declining and is now assumed to be the largest Steller sea lion rookery in the world.

Dr. A. S. Perlov described studies in the Kuril Islands during 1992. Counts at four major rookeries totalled 1,623 live and 29 dead pups. There were 3,200 pups at these same sites in 1963, and 1,400-1,900 pups during 1989-91. In the Lovushki Island group, a rookery with approximately 100 pups was found. This was previously recorded as a haulout site. Twelve other haulout sites throughout the Kuril Islands showed severe declines in 1992 . Counts on 13 islands totalled approximately 5,000 pups, juveniles and adults. The total population of the Kuril Islands is estimated to be 8,000-10,000 animals. A total of 73 sea lions branded and/or tagged on 4 Kuril Island rookeries were resighted in 1992. Most were seen on their natal islands, however several were found as far away as Robben Island and the Kamchatka Peninsula.

Dr. V. N. Burkanov discussed sea lion surveys, pup mortality studies, food habits research and pup tagging and survival during the first year of life on Cape Kozlov (Kamchatka Peninsula), Medny Island, and Atlasova Island (northern Kuril Islands). Numbers of sea lions on Medny Island have been stable for the past 3 years (500-600 adults and juveniles, and about 230 pups). Tag returns indicate that there is intermixture between the Kamchatka Peninsula and the Commander and Kuril Islands, and perhaps the Aleutian Islands and the Kamchatka Peninsula. Some very sparse data indicate that $10-20 \%$ of the Kamchatka population may have been incidentally taken in pollock fisheries off Kamchatka in 1991-92.

A general discussion followed during which Dr. V. A. Vladimirov proposed a joint effort to determine the primary factors which govern dynamics of sea lion populations throughout the species' range.

Dr. Loughlin noted that the American side will conduct aerial and ship-based surveys of northern sea lions throughout Alaska during summer 1994 as part of a coordinated effort to conduct a range-wide survey. Participants discussed the potential for surveys to be conducted on the Russian side also. It was agreed that the survey is necessary, but that funding and other constraints may preclude a complete survey of the Russian part of the population. Progress toward resolving this question will be maintained through correspondence.

\section{Northern Fur Seals:}

Dr. A. I. Boltnev reported on recent studies on the Commander Islands. In 1993, total pup production on Bering and Medny Islands was an estimated 68,000 . Over the last several years there has been a slight decline in pup production on the Commander Islands, although the trend varies among the rookeries. Numbers of adult males have fluctuated since the 1960 's, largely in response to varying subadult male harvest rates. Weights of pups and analyses of sub-adult male teeth indicate a deterioration of environmental conditions since the mid-1980's. Dr. Boltnev also noted a decline in the proportion of 3-5 year-old females present on the rookeries in 1991-92.

Dr. Perlov reported that the number of pups born on Robben Island continues to decline. Approximately 15,000 pups were born there in 1992; the 1993 estimate is still unavailable but is expected to be still lower. A decline in the number of young breeding females was noted on Robben Island. The number of adult males appears to be stable, and this is due to regulation of male harvest rates. Currently, about 1,500 young males are harvested annually. Dr. Perlov believes that the population decline is due to unfavorable conditions at sea. Tagging, tag resights, age and sex structure, and entanglement studies continue on Robben Island. No recent studies have been conducted on the Kuril Islands.

Dr. Vladimirov noted that the Robben Island population is presently in unsatisfactory condition. The situation on the Commander Islands is much better, probably due to significant immigration from the Pribilof Islands. Dr. Vladimirov then distributed a report on recent Russian fur seal population status.

Dr. Loughlin presented recent research results on the U.S. population. He discussed recent trends in pup production, bull counts, and entanglement rates. Pup production remains stable on St. Paul Island, is perhaps stabilizing on St. George Island, and is growing on Bogoslof and San Miguel Islands. He also listed the titles of several publications in press and in preparation regarding migration, growth, homing, fasting, food habits and foraging ecology of northern fur seals.

Dr. Vladimirov briefly discussed similar trends in entanglement rates on St. Paul and Robben Islands. He recommended that, as proposed for Steller sea lions, it would be useful to undertake a joint Russian/U.S. analysis of fur seal population dynamics. Dr. Loughlin agreed and recommended that the desire to conduct such analyses be included in the protocol.

Dr. Boltnev announced that a working group is planned for early 1994 in Kamchatka with the purpose of comparing population dynamics of northern fur seals and Steller sea lions. Dr. Boltnev would like to have American specialists, and perhaps Japanese and Canadian researchers, attend this working group. Dr. Boltnev also commented that Kamchatka TINRO will likely obtain time-depth recorders to study foraging behavior of fur seals and that aid of American specialists would be useful in the field.

Mr. I. V. Mikhno announced that a new nature preserve was established on the Commander Islands in 1993. 


\section{Larga seals:}

Mr. L. F. Lowry described ADF\&G aerial surveys of larga seals on the Chukchi Sea coast during 1989-91. Those surveys indicated that numbers of larga seals hauled out vary a great deal from day to day and between seasons. Since 1992, the NMML has conducted spring and summer aerial surveys along the northwest Alaska coast, as well as genetic studies in cooperation with ADF\&G and Dr. Burkanov. Mr. Lowry also presented data on the migration, dive depth, and daily haulout patterns of 5 satellite tagged larga seals during October-April 1991-1993. Seven additional tags were placed on seals in the Chukchi Sea in August 1993, and 5 of those are still operational.

Dr. Burkanov presented data from a joint project with ADF\&G in which four larga seals were fitted with satellite tags in the southwest region of Kamchatka in 1992. Transmitters operated during August to January and each seal exhibited widely different migration patterns. In 1993, six larga seals were satellite tagged on the east coast of Kamchatka. These transmitters are still operating and so far all animals except one remained near the area where they were tagged. The one seal which left moved north to the Chukhotka Peninsula. These studies indicate a great deal of mixing between supposedly distinct breeding populations, during the post-breeding period.

Mr. Yu. A. Bukhtiyarov noted that since 1990 ice conditions in the Sea of Okhotsk have changed, the ice break-up coming approximately 20 days earlier than usual. Ice conditions have adversely affected young of the year seals, most notably ringed seals.

\section{Harbor seals:}

Mr. Lowry began by describing recent joint research efforts of ADF\&G and NMFS undertaken partly in response to precipitous declines on Tugidak Island and other locations in the Gulf of Alaska.

Dr. Loughlin presented minimum population estimates in various regions of Alaska. Aerial surveys were conducted in Bristol Bay, the Gulf of Alaska, and southeast Alaska during 1991-93. Counts at trend sites in the Gulf of Alaska have declined from 22,808 in the 1970's to 2,417 in 1992. Preliminary analyses of counts in southeast Alaska during 1993 indicate only moderate, if any, declines since the mid-1980's.

Mr. J. Lewis reported on studies designed to compare a stable (southeast Alaska), a moderately declining (Prince William Sound) and a sharply declining population (Kodiak area). The ongoing work involves disease, genetics, physiological condition, and satellite telemetry studies. Preliminary analyses indicate that the animals handled were all healthy and in good condition.

Mr. Lowry discussed research on oil spill related mortality of harbor seals and potential for habitat restoration in Prince William Sound. Approximately 300 harbor seals out of a population of about 2,500 were estimated to have died as a direct result of oiling. Mr. Lowry also described satellite telemetry studies conducted during 1991-93.

Mr. Lewis added that approximately 2,800 harbor seals are taken in native subsistence harvests annually.

Dr. Vladimirov described an analysis involving correlations between a large-scale climate index (the Meridional Atmospheric Circulation Index) with abundance of several pinniped populations in the North Pacific and proposed to unite efforts of Russian and U.S. specialists to analyze the problem.

Dr. Burkanov noted that harbor seal research in Russia is limited to surveys of abundance. He suggested that it would be useful to compare trends in abundance in Russia and the U.S.

\section{Walrus:}

Dr. G. Garner commented on recent work involving avoiding bias in survey methods, chemical immobilization, satellite tagging, food habits, aerial survey analysis, Bristol Bay summer population abundance, and autumn distribution of walrus in the Chukchi Sea. He also announced that walrus research is now conducted by the new National Biological Survey.

Dr. F. Fay described recent analyses which established that age at sexual maturity could be estimated from dentin microstructure. Walrus which reach sexual maturity at a later age have a tendency to live longer. Another study analyzed digestion rates of mollusk soft parts ingested by walrus.

Mr. D. Seagars described the current and future activities of the USFWS walrus management program, including the main objectives of this program's conservation plan. He described results of a revised harvest monitoring program and contaminant studies showing elevated concentrations of cadmium in walrus kidneys.

Mr. Bukhtiyarov reported on data collected during a cooperative research cruise during spring 1991 in the Gulf of Anadyr and the Eastern Bering Sea. It was found that seasonal distribution of walruses is greatly affected by the physiological and reproductive status. Mr. Bukhtiyarov also questioned the reliability of several population indices which have been cited as evidence of a population decline. He presented numbers of walrus harvested in Russia in recent years (1990-2,435; 1991-1,860; 1992-1,750; and up to September 1993-about 500).

Dr. Burkanov raised the issue of potential disturbance of walruses associated with tourists visiting haulouts. Mr. Seagars and Dr. Fay expressed their intention to provide the Russian side with documents describing regulation of tourist activities on walrus haulouts in the U.S., Canada, and Norway. 
Discussion followed on the subject of progress toward an international convention for the conservation of pinnipeds, particularly walrus. Dr. Miller gave a brief history of efforts to achieve such an agreement, and stated that while we have not yet concluded an agreement, interest remains high for continuing joint efforts in that direction. It was suggested that it might be more productive to pursue separate agreements on walrus and seals. Mr. Mikhno suggested using the bilateral polar bear convention currently being developed as a model for a walrus convention.

\section{Other pinniped studies:}

Mr. J. D. Baker commented that past joint work on fur seal tooth microstructure involving the NMML and Dr. G. A. Klevezal of the Koltzov Institute of Developmental Biology has been very useful. He intends to continue research along these lines and would like to maintain whatever level of involvement is possible with the Koltzov Institute.

Dr. R. V. Miller described joint work of Dr. B. Stewart and Dr. Klevezal on northern elephant seal tooth microstructure. They intend to continue this work at whatever level is possible in 1994 and 1995.

\section{Sea Otters}

Dr. J. Bodkin presented an overview of current sea otter research in Alaska. Areas under study include foraging behavior, reproductive biology, survey methodology, population assessment and Dungeness crab/sea otter fisheries interactions. The primary management concern in Alaska is the increasing level of sea otter harvest for subsistence.

Dr. A. M. Burdin discussed sea otter population trends in Russia. The latest estimate for the Commander Islands was 4,500 otters (3,300 on Bering Island and 1,200 on Medny Island). In 1990-91 there was high mortality on the Commander Islands which he attributes to natural density-dependent processes. A 1993 survey on Kronotzkiy Peninsula (Kamchatka) yielded an estimate of 800 otters which is 300 less than the last estimate in 1990. Otters from the northern Kurils and south Kamchatka mix a great deal. The most recent estimate in 1990 was 9,000 otters in this area. Information on numbers of otters in the central and southern Kuril Islands was unavailable. On the Commander Islands, ongoing research is being conducted on food habits, cause of death, genetics, and recruitment of sea otters.

Dr. Boltnev expressed his opinion that the mass die off on the Commander Islands in 1990-91 was perhaps due to density-dependent effects.

Dr. Bodkin summarized the proceedings of the Fourth Russia/U.S. Sea Otter Workshop held in October 1993. Major topics included concern about increased subsistence harvests in Alaska, comparison of sea otter mortality in Prince William Sound following the Exxon Valdez oil spill with die offs on the Commander Islands, elevated levels of PCBs, DDT/DDE in Aleutian otters, development of a sea otter conservation plan in Alaska, and concern over increased poaching in Russia. Dr. Burkanov presented a brief description of the poaching problem and its rapid growth in the northern Kuril Islands. Other papers presented at the workshop are described in the workshop protocol.

Mr. Mikhno noted that a recent meeting on CITES issues was held in Moscow, during which the otter poaching issue was addressed.

Dr. B. Ballachey summarized studies on the effects of the Exxon Valdez oil spill on the Prince William Sound sea otter population. Up to 4,000 otters were estimated to have been killed immediately after the spill. Longer term effects were evident in increased juvenile mortality and an elevated occurrence of dead prime-aged animals found on beaches in the spill area. By 1993 there were indications that the population is recovering.

\section{Cetaceans}

Dr. A. A. Berzin summarized cooperative Russian-Japanese large whale surveys in the Sea of Okhotsk during 1989-93. It was estimated that 2,700 fin whales and 19,000 minke whales inhabit the Sea of Okhotsk. Right whales were also observed during these surveys. It was also noted that various anthropogenic factors including vessel traffic, oil exploration, and pollution, have adversely affected cetacean populations in Russian waters. Dr. Berzin also remarked on the need for information about recent research conducted in the U.S.

Dr. R. L. Brownell presented a short summary of the joint SWFC/TINRO gray whale study. All available catch records from the Chukotka subsistence harvest are being examined to analyze changes in numbers of pregnant females between seasons. Dr. Brownell then outlined a new joint project entitled, "Historical Review and Current Status of North Pacific Large Whales." Because the status of the Okhotsk-Korean gray whale, Okhotsk bowhead whale and western and eastern North Pacific right whale stocks are very poorly known, the following was proposed pending available funding: 1) to conduct a complete review of all commercial whaling activities in the North Pacific; and 2) to investigate study areas in the Okhotsk Sea, and the waters around the Kamchatka Peninsula, northern Kuril Islands and Alaska where systematic monitoring of some of these poorly known stocks may be possible.

Dr. Miller commented on surveys of small cetaceans including harbor porpoise in Washington and Alaska and beluga whales.

Mr. Lowry described a recent summer population estimate of 330 beluga whales for Cook Inlet, Alaska. Beluga whale research efforts in Alaska involve monitoring harvests, collecting biological samples from harvested animals, 
summer aerial surveys, and the development of a management plan to ensure that harvests do not adversely affect the population.

Dr. Loughlin presented results of killer whale and harbor porpoise censuses in Alaska. In summer 1992, 1,273 harbor porpoise were estimated to be in the Kodiak area and along the southern coast of the Alaska Peninsula, and 2,502 harbor porpoise were estimated to inhabit southeast Alaska. Killer whale photo identification studies and preliminary population estimates were conducted in the same areas as well as along the Aleutian Islands and the Bering Sea. In 1993, effort was made to resight killer whales missing from Prince William Sound since the Exxon Valdez oil spill.

Mr. Mikhno noted that Russia is taking part in various conventions directed toward conservation of small cetaceans in the Northern Basin and the Black Sea.

\section{PROPOSALS OF ACTIVITIES AND EXCHANGES}

From the U.S. Side:

1. The U.S. side invites one Russian scientist to come to Fairbanks, AK in autumn 1994 or 1995 to conduct joint analyses of data from satellite-tagged spotted seals.

2. Two Russian scientists are invited in the summer of 1994 and possibly 1995 , to work in west/central Aleutian Islands, and possibly in the Kuril Islands, on the U.S. RV Alpha Helix. Work will entail collecting sea otter population data, and the study of benthic community ecology and related marine ecosystems.

3. The U.S. side will provide sea otter premolars and canines from specimens of known time of death for evaluation of registering structures.

4. Both sides agree to continue cooperative research on sea otter diving behavior using time-depth recorders and radio transmitters at Bering Island in 1994 or 1995.

5. The U.S. side agrees to support Russian sea otter research through the transfer of excess equipment as available.

6. The U.S side invites 1-2 Russian specialists to participate in studies of nearshore marine benthic communities in relation to sea otters in Glacier Bay, Alaska, in 1994 or 1995. Final dates to be determined early in 1994.

7. The National Biological Survey (NBS) Genetics and Sea Otter Projects propose to collaborate with the Laboratory of Animal Ecology in Petropavlovsk-Kamchatskiy, Russia and the Institute of Biological Problems of the North, Magadan, Russian Academy of Sciences, to comparatively study the naturally recolonizing sea otter populations found in Russia with the recolonization process caused by translocation efforts in the U.S. This study will provide significant insight into conservation biology and impacts of translocation methodologies to genetic diversity. Molecular and biochemical genetic markers will be employed to compare genetic variability among the two recolonization types.

8. The U.S. side invites one Russian scientist to participate in aerial surveys of Steller sea lions during mid-June 1994 for 3 weeks.

9. One or two Russian scientists are invited to participate in ship-based surveys of Steller sea lions for 3-4 weeks during late June-early July 1994.

10. One Russian scientist is invited to take part in NMFS/ADF\&G aerial surveys of harbor seals for 3 weeks in late summer/early fall, 1994 .

11. One or two Russian scientists are invited to participate in NMFS/ADF\&G harbor seal satellite telemetry research for 3 weeks during late summer/early fall, 1994.

12. The USFWS invites 2-3 Russian walrus specialists to Alaska for 2-4 weeks during the second quarter of 1995 to participate in the walrus harvest monitoring program and the marking, tagging, and reporting program for harvested walrus. 
13. Both sides agree on the need for a meeting to discuss issues and problems related to cooperative walrus population surveys that have been conducted at 5-year intervals, starting in 1975, and the feasibility of a survey in 1995. Alternative indices of population status and trends need to be considered. Details for meeting time and location will be determined by the second quarter of 1994 .

14. Both sides agree on the need to initiate discussion of a bilateral walrus conservation agreement. Such an agreement would address issues of mutual concern regarding walrus research, management, and enforcement. Details for an initial meeting time and location will be determined by the second quarter of 1994 .

15. The NBS intends to develop a joint U.S./Russian proposal to: A) Examine physiological parameters of walrus condition that may be useful in assessing population status of Pacific Walrus; B) Collect biological samples of genetic materials that would be used to assess subpopulation status of various walrus stocks in the Bering and Chukchi Seas; and C) Continue monitoring summer haulouts of walrus in the Gulf of Anadyr.

16. Both sides agree to continue ongoing collaborative studies on gray whales harvested between 1980 and 1991 during 1994. Ajoint paper will be prepared.

17. The U.S. tentatively invites 1-2 Russian scientists for up to three weeks to participate in gray whale cow-calf surveys in California waters. Exact dates and work plan will be communicated to the Russian side by February 1994.

18. Both sides agree to initiate cooperative surveys on gray, bowhead, and right whales in the Okhotsk Sea and in the waters around Kamchatka and the northern Kuril Islands. The U.S. side will attempt to obtain funding for these surveys and will communicate information on study plans and availability of funds as soon as possible.

19. Both sides agree to work together to review all available whaling records for North Pacific large cetaceans.

20. Both sides agree to review the history of exploitation of southern hemisphere populations of large whales to better understand the status and rates of increase in North Pacific whale populations.

From the Russian side:

1. Two U.S. specialists are invited to St. Petersburg, Petropavlovsk-Kamchatskiy and Moscow in 1994 to review archived records of the Russian-America Company to obtain data on sea otter distribution, abundance and demography, during the hunting period. Exact dates to be determined in early 1994.

2. Two or three U.S. specialists are invited to take part in the Kamchatka Institute of Ecology expedition at Kronotsky Cape to study local sea otter populations and benthic communities in 1994 or 1995. Exact dates to be determined in early 1994.

3. The Russian side will provide tissue samples of sea otters from the Kuril and Commander Islands, and the Kamchatka Peninsula to the U.S. side for contaminants and histopathological analyses.

4. The Russian side agrees to provide information to the U.S. side on fiscal requirements for supporting conservation of sea otter populations in the Kuril and Commander Islands, and the Kamchatka Peninsula.

5. Two or three U.S. specialists are invited to participate in a joint study of sea otter abundance and reproductive biology in 1994 or 1995 at the Commander Islands. More information will be communicated at a later date.

6. Two U.S. specialists are invited to Russia in $\mathbf{1 9 9 5}$ to evaluate the effects of petroleum hydrocarbon exposure on sea otters; dates and places of this work will be communicated at a later date.

7. Both sides agreed to hold the next sea otter workshop in 1995 in Kamchatka. Exact dates and other details will be communicated at a later date.

8. If the Russian side is able to conduct a ship-board Steller sea lion survey in the Kuril Islands in summer, 1994, 1 or 2 American specialists will be invited to participate. Information on dates and other details will be communicated at a later date. 
9. One or two U.S. scientists are invited to participate in aerial or ship-based surveys of Steller sea lions on Kamchatka and the Commander Islands for up to 3 weeks in summer 1994. Exact dates and other details to be determined at a later date.

10. One or two U.S. scientists are invited to participate in Steller sea lion tag resight efforts on Kamchatka in fall 1994. Dates and other details will be communicated at a later date.

11. Two U.S. specialists are invited to take part in the International Working Group on Northern Fur Seal and Steller Sea Lion Population Dynamics, which is to be held by Kamchatka Branch of TINRO in PetropavlovskKamchatskiy during April 25-29, 1994.

12. One U.S. specialist is tentatively invited to participate in studies of northern fur seal foraging ecology for 2-3 weeks in 1994 on the Commander Islands, contingent on the acquisition of time-depth recorders by the Russian side (dates to be determined later).

13. Two U.S. specialists are invited to participate in satellite tagging of larga seals on the east coast of Kamchatka during July-August 1994. More information will be communicated at a later date.

14. One U.S. specialist is invited to participate in aerial surveys of larga seals in Karaginskiy Bay during April-May 1994. More information will be given in early 1994.

15. One or two U.S. specialists are invited to aid in the collection of food habits data and other samples from larga seals taken in the coastal harvest in Karaginskiy Bay, Kamchatka during May-June 1994. More information will be provided in early 1994 .

16. Two or three U.S. specialists are tentatively invited to take part in a planned commercial and scientific cruise to the Bering and perhaps Chukchi Seas to study larga and bearded seals, and perhaps walrus. This cruise would occur in April-May 1994 for 1-2 months, and may be contingent on the American side providing one refueling.

17. If the Russian side is able to arrange a research expedition to study food habits and reproductive biology of larga and bearded seals in Tauskaya Bay, Okhotsk Sea, during 3 weeks in July-August 1994, 2 American specialists will be invited to participate. Details will be provided later.

\section{OTHER MATTERS}

The protocol of the Fourth International Sea Otter Workshop is attached as an appendix to this protocol.

The next meeting of the Marine Mammal Project will take place in Petropavlovsk-Kamchatskiy, Russia in the third quarter of 1995; 8 American representatives are invited to attend. The exact time and other details will be communicated to the American side at least four months before the meeting.

This Protocol has been signed in English and Russian texts, both versions being identical and equally authentic.

For the Russian Side

[Signature]

V. A. Vladimirov
For the U.S. Side

[Signature]

R. V. Miller 


\title{
Protocol of the U.S./Russia Technical Consultation for the Conservation of Polar Bears of the Chukchi/Bering Sea Region, Nome, 1994
}

\author{
Done at Nome 9 September 1994 \\ Primary source citation: Copy of text provided by the \\ U.S. Fish and Wildlife Service, U.S. Department of \\ Interior

\section{PROTOCOL \\ U.S./RUSSIA TECHNICAL CONSULTATION FOR THE CONSERVATION OF POLAR BEARS OF THE CHUKCHI/BERING SEA REGION}

\section{Summary}

Representatives from Russia and the United States (attendance list attached) met in Nome, Alaska on September 6-9, 1994, for the expressed purposes of advancing technical discussion on the joint conservation of the shared population of polar bears occupying the Chukchi, Bering and portions of the Eastern Siberian Seas. The following summarizes the highlights of these talks and establishes a direction for future efforts.

The following are major points of agreement of the Parties:

* The 1973 International Agreement on the Conservation of Polar Bears shall serve as the basic framework for our joint conservation agreements.

* The Parties agree that in order to accomplish the objectives of a conservation doctrine, that both a Government to Government Agreement in conjunction with a Native to Native agreement will be developed. Further the Parties resolve to facilitate Alaska Native to Chukotka Native communication in preparation of a Native to Native Agreement.

* The Parties recognize that sound biological information, including scientific data and traditional ecological knowledge, will be fundamental to the agreement. Therefore, the Parties agree to continue and to expand cooperative research programs to enhance our knowledge of polar bears.

* Principles of sustained yield will be institutionalized in the agreement and serve as the basis for future harvest guidelines and allocation.

* Subsistence use of polar bears including the making and selling of articles of handicraft and clothing is a recognized legitimate use.

* Both Parties shall strive to minimize commercial exploitation of polar bears harvested for subsistence purposes. 
* Habitat protection and conservation shall be a cornerstone to a future agreement.

* Both Parties recognize the need to make their best efforts to curb illegal take or trade of polar bears or their products within their respective jurisdictions.

* Monitoring and verification programs shall be an integral component of a future agreement. All efforts shall be made to secure funding in support of the preparation and implementation of monitoring programs.

* Both Parties resolve to seek appropriate authorizations to begin formal negotiation of this agreement as soon as possible.

Therefore, the Parties resolve to exchange documents to further the mutually agreed principles of conservation listed above.

The Parties further resolve to conduct consecutive meetings of Government to Government and Native to Native Parties to further advance the agreements and that these meetings shall be conducted not later than 1 year from the date of signing of this meeting summary.

The Parties also discussed the matter of conservation and management of the shared population of Pacific walrus, and signed a separate Protocol of Intentions which is appended to this Protocol.

Signed on September 9, 1994, In Nome (Alaska, U.S.A.) in duplicate in the English and Russian languages, both texts being equally authentic.

\section{[Signature]}

David B. Allen

Acting Regional Director

U.S. Fish and Wildlife Service

United States of America
[Signature]

Grigoriy Kovalev

Deputy Chief

Main Dept of Biological Resources

Russian Federation 


\title{
Protocol of the Fifth U.S.-Russia Workshop on Sea Otter Biology, Paratunka, 1995
}

\author{
Done at Paratunka 12 September 1995 \\ Primary source citation: Copy of text provided by the \\ U.S. Fish and Wildlife Service, U.S. Department of \\ Interior
}

\section{U.S.-RUSSIA AGREEMENT ON COOPERATION IN THE FIELD OF ENVIRONMENTAL PROTECTION AREA V: PROTECTION OF NATURE AND THE ORGANIZATION OF RESERVES PROJECT 02.05-61 MARINE MAMMALS}

\section{PROTOCOL OF THE \\ FIFTH U.S.-RUSSIA WORKSHOP ON SEA OTTER BIOLOGY \\ Paratunka, Kamchatka, Russia September 7-12, 1995}

The Fifth U.S.-Russia Workshop on Sea Otter Biology was held at Paratunka, Kamchatka, September 7-12, 1995.

Representing the U.S. side were: J. Bodkin, A. Doroff, C. Gorbics, D. Jessup, M. Staedler, G. VanBlaricom, P. Ward.

Representing the Russian side were: A.G. Bazhin, A.M. Burdin, V.N. Burkanov, V.I. Gaydukov, E.A. Ivanyushina, S.I. Kornev, M.K. Maminov, A.P. Nikonorov, D.A. Ryazanov, I.N. Shevchenko, O.V. Trapezov, V.V. Vertyankin, V.A. Vladimirov, S.N. Zagrebelniy, N.P. Zimenko, M.Yu. Zasypkin.

The meeting was opened by Vladimir Burkanov.

Valeriy Vladimirov thanked the meeting organizers for their efforts and extended greetings to the group on behalf of Amirkhan M. Amirkhanov, Deputy Minister of Environmental Protection and Natural Resources, who expresses the Ministry's high evaluation of the collaboration between Russian and U.S. sea otter specialists.

James Bodkin expressed the appreciation of the U.S. side to the organizers of the Kamchatka meeting for hosting the U.S. delegation.

The group stood to commemorate the passing of Vladimir Oshurkov, a valued friend and scientist, and Vladimir Burkanov and Glenn VanBlaricom offered words on behalf of the group.

David Jessup described the work of the Veterinary Services Unit of the State of California's Office of Oil Spill Prevention and Response (OSPR). He spoke of the financing mechanism of the OSPR and its mobile response capabilities, current and planned rehabilitation centers and its research program. Portions of the doctoral thesis 
work of Jonna Mazet were presented, including a description of field techniques for the detection of petroleum products on sea otter fur. Equipment used for this purpose and the potential benefits were described in detail.

Oleg Trapezov examined the issue of holding captive sea otters in the conditions of western Siberia. He demonstrated that it is possible to create a breeding population in captivity. The most realistic method of creating such a population is by selecting from the wild individuals that lack fear of humans.

Michelle Staedler described the work she has conducted with Jack Ames on studying drift patterns of radio telemetried sea otter carcasses and "dummy otters" made out of tires. Three trials were done to date with all carcasses and dummies being released in the same area and then tracked by radio. The information gained from the work will assist in determining the use of radio-transmittered tires that would be deployed at an oil spill site to determine drift patterns of otter carcasses in areas affected by the spill.

David Jessup described the work of Jonna Mazet on the links between petroleum exposure and reproductive impairment in sea otters. American mink were used as a surrogate species in external and internal exposure trials to Alaska North Slope crude oil and Bunker fuel oil. Additional health problems were noted, and the experience of oil spills in California were cited.

Michelle Staedler spoke of studying a die-off of sea otters in Monterey Bay, California, and methods of investigating possible mortality factors. The die-off was an unusual occurance for such a small area in such a short amount of time. Several organizations were involved in collecting, studying and investigating the situation. In spite of many tests for both man made and natural toxins as well as bacteria, parasites, viruses etc., no definitive causes of death common to all animals have been identified to date. Tissues are being saved for future testing.

Vladimir Burkanov reported on the overall issues of sea otter protection in the Kamchatka region and on all the main concentration points of these animals. He presented information on measures adopted by Kamchatrybvod on sea otter protection measures in Kamchatka and the Commandor Islands. He noted that the problem of poaching is not as large as it was two years ago.

James Bodkin spoke of the history and status of founding and translocated sea otter populations. Methods of estimating genetic diversity using MtDNA were described. Haplotype diversity in founding populations of Amchitka and Prince William Sound, Alaska were compared to translocated populations in Washington, British Columbia and Southeast Alaska.

Angela Doroff addressed the group with a presentation on harvest levels and age-sex composition of subsistencehunted sea otters in Alaska. She described the marking, tagging and reporting program and data collected on gender and age. Data were presented on harvest percentages within management regions and the estimated population abundance of sea otters within management regions.

Glenn VanBlaricom addressed the group on potential fishery conflicts involving sea otters in the waters of Washington State. He began with an historical overview of a reduction in various sea otter prey species following the growth of the sea otter population and expansion of their range. The range of sea otters in Washington State was noted along with the ranges of sea otter prey species and their economic and recreational importance to Washington State Native and non-native residents. VanBlaricom reviewed possible management options available for use as sea otters expand to additional habitats, some where conflicts with human interests may occur.

Michelle Staedler described the interest of the Monterey Bay Aquarium in genome resource banking. A cryopreservation storage program of sperm, embryos, tissues. blood and DNA would assist in the preservation of sea otter genetic diversity. The aquarium would welcome the involvement of other sea otter scientists in this banking process and to contribute blood, sperm, eggs, and tissues of all three sea otter subspecies (Russian, Alaskan and Californian).

Glenn VanBlaricom spoke of the influence of sea otter predation and recreational harvest on red abalone (Haliotis rufescens) populations off central and northern California. Sea otters exert the greater effect on abalone demography, influencing abalone density, size structure, and pattern of microhabitat use. Recreational fishers also influence size structure and microhabitat use. Other factors, such as substratum configuration, also influence abalone demography.

Glenn VanBlaricom addressed the configuration and variation of kelp forests occupied by sea otters off Big Sur, California. All areas studied had established sea otter populations and low densities of large grazing invertebrates such as sea urchins. Variation in benthic communities was substantial on all scales, and generally did not correlate with environmental factors. Substratum configuration was the only factor clearly associated with spatial pattern in 
some locations. Models to explain observed variation are complicated and require integration of historical as well as environmental factors.

Angela Doroff presented data on the post-weaning survival of juvenile sea otters in Prince William Sound Alaska to assess population recovery following the 1989 Exxon Valdez oil spill. Juvenile females survived significantly better than males in the control (unoiled); there was evidence of intraspecific aggression which caused mortality for males. Survival rates were lower in the treatment (oiled) area than the control area. It was not possible to determine whether observed differences in survival were due to chronic effects of oil or potential differences in resource availabilty between the treatment and control areas.

James Bodkin spoke of using cementum layers in the first premolar tooth for estimating ages of sea otters. Estimates of accuracy and precision were provided by comparing estimated to known ages.

Sergei Zagrebelniy presented information on the status of sea otter protection on the Commandor Islands. In 1994 , the Commandor Islands Fish Inspection Service located eleven sea otters with bullet wounds, nineteen sea otters with fatal skull wounds, and twenty-one sea otter carcasses that had their hides removed. The registering of hides of dead sea otters declined by a factor of four. According to unofficial data, on Bering Island, poachers harvest about 60 sea otters annually.

Nadezhda Zimenko reported data on the foraging activity of sea otters in a defined aquatic territory near Glinka Harbor (Medniy Island). Through visual observations and mapping, zones of intensive and limited foraging use were delineated. Information on the species and measurements of prey was studied, along with relations of sea otter underwater and surface locations during foraging, in regards to the number and distribution of prey.

Elena Ivanyushina examined the species composition and size structure of the main sea otter prey harvested using underwater diving equipment in areas used to varying extent by sea otters for foraging. It was demonstrated that despite many years of utilizing the study plot for foraging, the plot was quite rich with foraging resources that support the sea otter group inhabiting the site.

Elena Ivanyushina compared bottom communities, with emphasis on sea otter prey, from various sites in the studied aquatic territory at Glinka Harbor (Medniy Island); compared them with data gathered the same year at nearby Cape Drovenskiy; compared them with the average indices for Medniy Island using data from 1992; and compared them with data from Glinka Harbor acquired in 1972. It was demonstrated, using large scale hydrobiological research, that there was a likelihood of an underestimation of the abundance of individual benthic groups.

Dmitriy Ryazanov presented the results of an experiment in age evaluation using PM1 stained sections, made independently by three researchers. The methodology was applied to define the age distribution of sufficiently large samples, but was not appropriate for determining an exact age on an individual basis. To improve the methodology, standardization of reading layers using samples from individuals of known age is essential.

Aleksandr Burdin reported on the results of two years of research on sea otter births at Bering Island. Monthly abundance censuses were conducted at the model plot in the northern part of Bering Island and the number of pups were counted. It was established that most pups are born in April-May. Therefore, annual sea otter abundance censuses conducted in June-July allow us to correctly evaluate the size of the annual additions to the population.

Dmitriy Ryazanov presented information from now accessible archaeological materials on the age composition of sea otters. The available information is incomplete, but allows us to make a number of assumptions on past sea otter distribution and abundance in Kamchatka. Verification and expansion of their beliefs is possible only with analogous archaeological efforts.

Mikhail Zasypkin reported on the results of studying sea otter genetic markers using electrophoresis in polyacrylic amino gel (PAAG). Forty-nine enzymes and eight non-enzyme proteins were researched. A high level of allozyme variation was detected (average heterogeneity $=0.057$ ) along with interspecies genetic heterogeneity. A hypothesis was suggested capable of explaining how in conditions of a long-term reduction in abundance, sea otters have not lost genetic variability.

Sergei Kornev presented data for the period 1984-93 on sea otter observations collected at a Kamchatrybvod station at Cape Lopatka. He presented data on seasonal distribution, abundance and natural deaths of sea otters for a 10 year period. Additionally, the dependence of distribution, abundance and mortality on seasons and a number of other abiotic factors were examined. Variations in the maximal abundance were noted from 1,800 in 1984 to 550 in 1989 
and 2,500 in 1993. From 1984 to 1993 1,710 sea otter carcasses were found at Cape Lopatka. Kornev also presented data on bear predation at sea otter haul out sites dependent on bear activity during the year, relative to food availability (salmon). The annual dynamics of visitations to haul out sites by bears and the numbers of sea otters taken were presented. The number of visits to haul out sites were compared for the winter and summer periods. The role of the bear in habitat areas shared with sea otters leads not only to the bear in its role of beach scavenger, but also as a substantial regulator of sea otter abundance in years that yield poor food availability for brown bears.

Carol Gorbics described the status of the Alaska sea otter stock considering geographic range, minimum population estimate, maximum productivity rate, population trend, and total human caused mortality. This information was used to develop a potential biological removal level describing the total number of animals that could he removed from the overall Alaska sea otter population while still allowing the population to remain within an optimum sustainable population range. This was compared with the total number of otters killed due to human activities to determine that the overall status of the population was stable on a state-wide basis. However, Native harvest may cause some localized declines to subpopulations due to increasing localized harvest.

Aleksandr Nikonorov reported on the history of sea otter groups in Kronotskiy Nature Reserve. Sea otters established themselves at Kronotskiy Nature Reserve in about 1970. The first groups were noticed in 1971. Up to the present day 102 sea otters carcasses have been recovered. A slow reduction in group abundance can be noted along with gradual changes in sea otter distribution. In the collections of Kronotskiy Nature Reserve are $\mathbf{4 5}$ sea otter skulls and two complete skeletons. Along the Kronotskiy coast, sea otters have many real and potential enemies (brown bear, wolverine, Steller's sea eagle).

Ilya Shevchenko presented data on abundance dynamics of sea otters from the Commandor Islands population for the period 1988-1993. Data were presented on sea otter abundance on Medniy Island (1988-1995). The minimal abundance was registered in 1993. In 1995 the abundance of sea otters remained at its previous low level. Sea otter linear density at control plots generally did not exceed $0.7-4.2$ females per kilometer.

Mikhail Maminov presented many years of data on the age of and seasonal weight variability in testicles and ovaries and the amount of spermatozoids among reproductively active sea otter males and females and for female otters in estrous. Data were gathered on the seasonal dynamics of pup abundance. This allowed for an expansion and refinement of the data on the age of sexual maturity, reproductive activity and sea otter pups on the Kurile Islands.

Vladimir Vertyankin reported on the results of a sea otter census at Kronotskiy Nature Reserve in 1995 and expanded on census data from previous years. The abundance of the Kronotskiy group in 1995 had declined in comparison with previous years and, based on a marine census, comprised 300 individuals. In April only 5 sea otters were noted which can be explained by difficult ice conditions. An opinion was voiced that sea otters migrate to southern Kamchatka in winter.

Vladimir Vertyankin presented a report on the abundance of sea otters of the Commandor Islands. The maximum abundance of sea otters was noted in 1990 at 6,200 individuals. The peak birth rate was noted in 1993 at 1,138 pups. The greatest sea otter density was noticed in the northern part of Bering Island. On Medniy Island significant changes in sea otter abundance have not occurred in recent years.

Vladimir Burkanov demonstrated that the distribution range of the main sea otter groupings in Kamchatka did not expand in the period 1983-1995. There is a potential for an expansion of the sea otter range in Kamchatka. The contemporary range of this species has not reached its historic borders.

Valeriy Gayukov reported on the status of sea otter law enforcement measures in the northern Kurile Islands of Paramushir and Shumshu. Despite the efforts of the fish inspection service, large scale sea otter poaching continues.

James Bodkin described the nearshore vertebrate predator project being implemented in Prince William Sound, Alaska to evaluate the process of the recovery of sea otter populations affected by the Exxon Valdez oil spill in 1989. 


\section{Proposed Collaborative Activities:}

\section{Joint proposals:}

1. Continue to exchange sea otter tissues for comparative studies of genetics, contaminants, and other aspects of natural history with maximum provision of life history data for the subject animals (gender, age, etc.).

\section{Russian side proposes:}

1. To consider inviting one U.S. specialist in $\mathbf{1 9 9 6}$ to complete efforts in researching the history of the sea otter harvest in Russian and Alaskan waters in the 18th and 20th centuries.

2. To consider inviting 2-3 U.S. specialists in 1996 for joint field research on Bering Island involving marking and the collection of biological materials from living and deceased sea otters.

3. To consider inviting 2-3 U.S. specialists in 1997 to participate in an expedition to study benthic communities and the sea otter population on the Kronotskiy Peninsula.

4. To consider inviting 2-3 U.S. specialists to participate in joint research of benthic communities of the Commandor Islands in 1996 and in 1997.

5. To consider inviting 2-3 U.S. specialists in 1997 to participate in an expedition studying the influence of sea otters on benthic communities of the Commandor Islands.

6. To consider inviting 1-2 U.S. specialists to participate in a sea otter vessel survey in Kamchatka and the Northern Kuriles in 1996 if a vessel is available.

7. That the U.S. side examine the possibility of conducting oil product origin and identification analysis when Russian sea otter habitat is contaminated by oil products.

8. Tb conduct genetic research of sea otter tissue using electrophoresis. The Russian side expresses its interest in receiving appropriate samples from sea otters of the U.S. population.

\section{U.S. side proposes:}

1. To consider inviting two or three Russian specialists to participate in studies of sea otters and benthic ecosystems in Southeast Alaska in 1996 or 1997.

2. To continue cooperative research on sea otter diving behavior using time depth recorders and radio transmitters at the Commander Islands in 1996 or 1997.

3. Tb consider hosting one or two Russian specialists at the Monterey Bay Aquarium for approximately one month in 1996 for familiarization with tagging and capture techniques and research efforts.

4. To invite one Russian specialist to participate in the continuation of studies of historical records of sea otter hunting in Russian and U.S. waters, and to participate in comparative studies of sea otter population dynamics and natural history.

5. To hold the next U.S.-Russia sea otter workshop in Seattle, Washington, U.S.A. or nearby location in 1997 and to invite the participation of sea otter specialists from Canada, Japan and Mexico.

Signed 12 September, 1995 in English and Russian texts, both versions being identical and equally authentic.

For the Russian Side

[Signature]

Valeriy Vladimirov

[Signature]

Vladimir N. Burkanov
For the U.S. side

[Signature]

James L. Bodkin

[Signature]

Glenn R. VanBlaricom 


\title{
Protocol of the First Technical Meeting Concerning the Intention of the United States and Russia to Conclude Bilateral Agreements on the Conservation and Management of the Pacific Walrus, Petropavlovsk-Kamchatskiy, 1995
}

\author{
Done at Petropavlovsk-Kamchatskiy \\ 20 September 1995 \\ Primary source citation: Copy of text provided by the \\ U.S. Fish and Wildlife Service, U.S. Department of \\ Interior
}

\begin{abstract}
PROTOCOL
OF THE FIRST TECHNICAL MEETING CONCERNING THE INTENTION OF THE UNITED STATES AND RUSSIA TO CONCLUDE BILATERAL AGREEMENTS ON THE CONSERVATION AND MANAGEMENT OF THE PACIFIC WALRUS
\end{abstract}

\section{Petropavlovsk-Kamchatskiy, Russia September 13-20, 1995}

Recognizing the intrinsic value of the Pacific walrus (Odobenus rosmarus divergens) as a common resource shared by all people, representatives of the United States and Russia met in Petropavlovsk-Kamchatskiy, Russia September 13-20, 1995, for discussions on the joint conservation and management of the shared population of Pacific walrus. The results of these talks established a basis for future efforts leading to bilateral Agreements.

This Protocol reflects the Protocol of Intentions signed on September 9, 1994, in Nome, Alaska, U.S.A. and the discussions conducted by the Native Peoples of Alaska and Chukotka in Nome during the Inuit Circumpolar Conference in July 1995.

Representatives of the Governments of the United States and Russia, hereinafter referred to as "the Sides," have agreed as follows:

1. To note the constructive work of both Sides on implementation of the decisions of the Protocol on Intentions of September 9, 1994, for establishing Bilateral Agreements on the Conservation and Management of Pacific Walrus.

2. Tb accomplish the objective of conservation and management of this shared population by developing both a Government-to-Government Bilateral Agreement and an Agreement between the Native People of both countries. In 
this regard, both Parties encourage the establishment of a Chukotka Regional Walrus Association. The Parties will assist in the full interaction between the Alaska Native and Chukotka Native Peoples in the preparation of a Native-to-Native Agreement.

3. To recognize that the Bilateral Agreements must provide for the conservation, research, habitat protection and Native subsistence use of the Pacific walrus.

4. That reliable biological information, including scientific data and traditional ecological knowledge, will be fundamental to these Bilateral Agreements. The Parties therefore agree to continue and expand cooperative research programs to enhance knowledge of the Pacific walrus, in particular:

* there is a need to continue conducting joint population surveys at five-year intervals, subject to environmental conditions and available funding;

* it is necessary to carry out coordinated programs to monitor the abundance, age, and sex composition of walrus taken annually in each country;

* to routinely exchange scientific and technical information.

5. That the Agreements will be based on principles such as sustained yield and maintenance of walrus at optimum sustainable population levels. These principles will be embodied in the Bilateral Agreements as the basis for future harvest guidelines.

6. To recognize the need for Native participation in the allocation of harvest levels.

7. To recognize that subsistence use of Pacific walrus, including the manufacture and selling of articles of handicrafts and clothing, is an established traditional use.

8. That habitat protection shall be a cornerstone to future agreements.

9. That the Sides will take measures to curb illegal take and trade of walrus or their products within their respective jurisdictions.

10. To provide information and technical assistance to the Native Peoples of Alaska and Chukotka for the purpose of maintaining their traditions and living standards.

11. To coordinate and collaborate in accordance with International Agreements to which both Sides are signatories.

12. To assure the active participation of the Native Peoples of Alaska and Chukotka in technical meetings between the Sides' and participation by the Sides in meetings between Native Peoples of Chukotka and Alaska.

13. The Natives Peoples addressed by these Agreements will include: the Yupiit (Eskimos), Chukchi residing in the coastal areas of the Chaun, Schmidt, Chukotskiy, Providenskiy and Iultin Regions of the Chukotka Autonomous District, and Koryaks of the Koryak Autonomous District, the Inupiat of Northwestern Alaska and North Slope of Alaska, and the Yupiit of St. Lawrence Island and Western Alaska, including Bristol Bay.

\section{THE SIDES RECOGNIZE THE NEED TO FURTHER DISCUSS THE FOLLOWING:}

1. The methods used to determine biologically-based sustainable harvest levels of walrus shall be based on the best available scientific information and shall utilize traditional knowledge.

2. The need to create a Scientific Consultative Walrus Committee consisting of representatives of both Governments and the Native Peoples of Alaska and Chukotka to address issues related to walrus conservation and management.

3. A definition of the specific geographic areas to be covered in the proposed Bilateral Agreements.

4. To define specific terms in the final Bilateral Agreements, including "commercial harvest," "habitat," "Native Peoples", etc. 
5. To take steps necessary to ensure that information from these and future deliberations is shared with interested and affected organizations.

\section{THE SIDES THEREFORE RESOLVE:}

To conduct the second meeting of the Sides in the U.S. in 1996 to discuss a proposed Government-to-Government Bilateral Agreement and a Native-to-Native Agreement between the Native Peoples of Alaska and Chukotka on conservation and management of the Pacific walrus population. The Sides agree to prepare and exchange draft documents for preliminary review two months before the meeting.

Signed on September 19, 1995 in Petropavlovsk-Kamchatskiy, Russia in the English and Russian languages, both texts being equally authentic.

For the Russian side:

\section{[Signature]}

Grigory K. Kovalev

Deputy Director,

Biological Resources Protection Department.

Ministry of Environmental and Natural

Resources Protection of Russian Federation
For the American side:

[Signature]

David B. Allen

Regional Director, Alaska Region

U.S. Fish and Wildlife Service

U.S. Department of the Interior 


\title{
Protocol of the U.S.-Russia Working Meeting for the Preparation of Draft Principles for the Conservation and Management of the Chukotka-Alaska Population of Polar Bears, Petropavlovsk-Kamchatskiy, 1995
}

\author{
Done at Petropavlovsk-Kamchatskiy \\ 20 September 1995 \\ Primary source citation: Copy of text provided by the \\ U.S. Fish and Wildlife Service, U.S. Department of \\ Interior
}

\section{PROTOCOL OF THE U.S.-RUSSIA WORKING MEETING FOR PREPARATION OF DRAFT PRINCIPLES FOR THE CONSERVATION AND MANAGEMENT OF THE CHUKOTKA-ALASKA POPULATION OF POLAR BEARS}

During the period September 14-20, 1995 representatives of the United States of America and the Russian Federation met in Petropavlovsk-Kamchatskiy, Russia for scientific and technical consultations to clarify their views in connection with the preparation of a future Agreement on the Conservation and Management of the Chukotka-Alaska Population of Polar Bears. A list of the delegation members is attached.

The two sides discussed the following:

- the results of joint polar bear research in Russia and the U.S. during 1995, leading to the conclusion that the Chukotka-Alaska population is prospering and may be used for subsistence purposes to satisfy the customary and traditional needs of the Native People not only of Alaska, but also of Chukotka.

- the status of polar bear conservation in the U.S. and Russia, noting that nature conservation agencies and organizations in the U.S. and Russia, and the Native People of Chukotka and Alaska are undertaking measures for the recovery and sustainability of the species' population abundance and the protection of its habitat and migration routes.

- legal aspects of national legislation on the conservation and management of their shared polar bear population, agreeing on the necessity of coordinating measures for the establishment of a mechanism for joint protection and further study of this population. 
- the use of the Chukotka-Alaska population of polar bears for subsistence and the manufacture of handicrafts and clothing by the local Native People, noting that this must be based on the principles of sustainable use.

- the results of joint efforts by the Native Peoples of Chukotka and Alaska to work out ways of conserving and using polar bears, noting the constructive approach taken to this problem and the interest of the Native People in hunting of polar bears, arising from the need to satisfy their traditional requirements and to establish scientifically-based standards for take.

The two sides also agreed on draft Principles for the Conservation and Management of the Chukotka-Alaska Population of Polar Bears. The text is attached. Additional consultations on Article 1.2 and Article 2 of the draft Principles will be conducted at a time to be agreed on by both sides.

It was mutually decided that the next meeting to adopt a draft text of a polar bear agreement will be held in the U.S. in the first quarter of 1996.

This Protocol was signed on September 19, 1995 in Petropavlovsk-Kamchatskiy, Russia in the English and Russian languages, both versions being equally authentic.

For the U.S. Fish and

Wildlife Service of the U.S.

Department of the Interior

[Signature]

David B. Allen

Alaska Regional Director
For the Ministry of Environmental Protection and Natural Resources of the Russian Federation

[Signature]

Grigoriy K. Kovalev

Deputy Director, Division of Biological Resource Conservation 


\section{Protocol of the Thirteenth Working Group Meeting Under Project 02.05-61 "Marine Mammals," of the U.S.-Russia Environmental Agreement, Paratunka, 1995}

Done at Paratunka 26 September 1995

Primary source citation: Copy of text provided by the U.S. Fish and Wildlife Service, U.S. Department of Interior

\section{PROTOCOL \\ OF THE THIRTEENTH MARINE MAMMAL WORKING GROUP MEETING UNDER PROJECT 02.05-61, "MARINE MAMMALS," OF THE U.S.-RUSSIA ENVIRONMENTAL AGREEMENT}

\section{Paratunka, Kamchatka, Russia September 22-26, 1995}

The Thirteenth U.S.-Russia Marine Mammal Working Group Meeting was held at Paratunka, Kamchatka, Russia during the period September 22-26, 1995.

Representing the United States side were: Robert V. Miller (Delegation Leader), Robert L. Brownell, Jr., Gerald W. Garner, Brendan P. Kelly, Steven G. Kohl and Thomas R. Loughlin.

Representing the Russian side were: Valeriy A. Vladimirov (Delegation Leader), Vsevolod M. Belkovich, Aleksandr M. Burdin, Vladimir N. Burkanov, Yuriy A. Bukhtiyarov, Vladimir V. Vertyankin, Grigoriy K. Kovalev, Igor V. Mikhno, Adolf S. Perlov, Aleksei M. Trukhin, Vladimir I. Chernook (Delegation Members); Stanislav E. Belikov, Alfred A. Berzin, Aleksandr V. Boiko, Vitaliy E. Kovalenko, Sergei I. Kornev, Dmitriy A. Ryazanov, Elena A. Radnayeva, Natalya G. Shevchenko and Evginiy G. Mamayev.

The Meeting Sessions were co-chaired by Robert V. Miller (U.S.) and Valeriy A. Vladimirov (Russia).

A moment of silence was observed in memory of Drs. Lev A. Popov and Vladimir V. Oshurkov (Russia), and Francis H. "Bud" Fay (U.S.), all of whom died in 1993-1994 and were well-known marine mammal specialists and long-time participants in activities under this project. 


\section{CETACEANS}

Drs. Aleksandr Burdin and Robert Brownell presented preliminary results of joint studies of gray and bowhead whales conducted in August 1995 in northeast Sakhalin Island and in the southern Shantar Archipelago. According to TINRO estimates the number of gray whales in the Korea-Okhotsk Sea population is 250 whales. The largest concentration of bowheads observed by TINRO was 72 whales in August 1988, and the Okhotsk population was estimated at about 300 whales. In 1995 Konstantin and Ulbanskiy Bays were surveyed. Gray and bowhead whale tissue samples were taken for genetic research. Conservation of the habitats of these two whale species is extremely important, as they are concentrated in shelf areas where there are plans to exploit mineral, oil and gas resources, build tidal electric power stations, and commercially harvest invertebrates and fish. There is a proposal to establish a marine reserve in the Shantar Archipelago. Compilation of a photographic catalogue for individual identification of gray and bowhead whales has begun; over 500 black-and-white and 300 color photos have been taken. It is planned to continue studies to determine wintering and breeding areas of whales, as well as several population parameters, including age, sex, birth rates, mortality and total abundance estimates.

Dr. Vladimir Burkanov postulated the possible migration of bowhead whales to wintering areas in the northeast part of the Okhotsk Sea.

Dr. Yuriy Bukhtiyarov cited three cases of whale mortality (supposedly right whales) as a result of crab fishing in the Okhotsk Sea over the past five years.

Mr. Grigoriy Kovalev informed the group that all exploitation of mineral resources planned on the continental shelf is to undergo an environmental impact assessment by the Russian Ministry of Environmental Protection and Natural Resources.

Dr. Stanislav Belikov reported on a new Russian law on protected territories which may also apply to whale conservation.

Dr. Brownell described research on organochlorine contamination in gray whales taken off Lorino during the native subsistence hunt. 20-25 tissue samples were collected by TINRO for toxicological analysis by the Northwest Fisheries Science Center in Seattle. An illegal shipment in 1993 of whale meat from Taiwan to Vladivostok was discussed. Tissue samples were taken from about 230 tons of meat, from which the species was determined to be Bryde's whale. Six individual whales from the shipment were identified. This information was passed on to the International Whaling Commission (IWC) by Russia and the U.S.

Professor Vsevolod Belkovich reported the establishment of a National Council on Marine Mammals in Russia. The goals of the Council are: coordination of marine mammal studies, determination of priority research themes and topics, and solicitation of financial support for research. Dr. Belkovich also proposed that specialists from all arctic countries combine their efforts in joint studies of the biology and population structure of beluga whales using modern methods of biochemistry, genetics, acoustic matrices and radio tagging. Studies conducted in the White Sea have shown that during the reproductive period beluga whales form large, rather distinctly structured localized groups. This makes it possible to conduct more accurate censuses.

\section{PINNIPEDS}

\section{WALRUS}

Mr. Kovalev reported briefly on the results of the U.S.-Russia consultative meeting on polar bear and walrus, which took place September 14-19, 1995 in Petropavlovsk-Kamchatskiy. Joint principles were developed for the conservation and management of the Chukotka-Alaska population of polar bears. As regards walrus, it was decided to prepare draft agreements on Pacific walrus conservation and management both at the intergovernmental and Native-to-Native levels.

Dr. Bukhtiyarov spoke about Pacific walrus population censuses and dynamics. By 1990 the abundance of this species had reached 250,000 . There are some indications of decreasing abundance and changes in important population characteristics, such as increase in number of older females and pup mortality, and decrease in overall fitness. The conjecture that these are due to deterioration of the food base is considered arguable. 
Dr. Gerald Garner spoke about utilization of walrus in the United States. Marine mammals in the U.S. are Federal species. The U.S. Fish and Wildlife Service is responsible for Pacific walrus, polar bears and sea otters, while the National Marine Fisheries Service oversees all other marine mammals. Only the coastal natives of Alaska have the right to hunt walrus. Authority to regulate subsistence take of marine mammals is dependent on the population in question being declared depleted. Dr. Garner said that the U.S. Fish and Wildlife Service has developed a number of documents on Pacific walrus management and research. The annual take of walrus is currently no more than $6,000-8,000$, including struck and lost. In 1994 a summary report on the results of walrus tagging was completed, in which it was noted that $95 \%$ of harvested walrus are tagged in accordance with the U.S. Fish and Wildlife Service walrus marking and tagging program. Dr. Garner also described some of the results of work carried out under a U.S. National Biological Service program developed 1 1/2 years ago. Feeding ecology as well as certain physiological parameters were studied with the help of satellite and VHF transmitters deployed on eight walruses.

Dr. Brendan Kelly spoke about studies of Alaska walrus conducted in Dr. Fay's laboratory. Up to $42 \%$ of all walruses taken during native hunts are lost; of these at least $55 \%$ die of wounds. Under the supervision of Dr. Francis Fay the laboratory developed a population dynamic model for Pacific walrus between 1930-1985, which includes several important parameters, including increase in base abundance, reproductive rates, natural mortality rates and number of animals taken for subsistence. There are, however, insufficient reliable data on the survival and mortality of young walrus, especially in the Chukchi Sea. Dr. Kelly also spoke about other walrus studies continued by his laboratory. These include: research on changes in growth rate over specific periods of time, experiments using artificially-constructed walrus stomachs to study the rate of digestion of various foods, and taxonomic analysis of a large quantity of walrus skulls from around the world.

Mr. Vitaliy Kovalenko presented information on summer season monitoring of walrus haulouts in Chukotka conducted annually since 1983. He reported data on the average and maximum walrus abundance on haulouts on Arakamchechen Island and Rudder Spit between 1990 and 1995. Since 1983 there has been a considerable decrease in walrus abundance on all Chukotka haulouts. During the period 1990-1995 it varied insignificantly, indicating a possible stabilization of abundance. In 1990 the maximum number of walrus on Arakamchechen Island was 10,350; on Rudder Spit -3,000-4,000. In 1995 (according to data as of September 15), these numbers were 6,500 and 400, respectively. Females comprise about $1 \%$ of the overall number on Arakemchechen Island, and about $19 \%$ of the animals on Rudder Spit.

Mr. Aleksandr Boiko reported KamchatRybVod data on the overall decrease in numbers of walrus by 12,000 15,000 animals as compared with the mid-1980s. This means a twofold decline in abundance, although in the past four years the number has increased slightly to a total of 7,500 .

\section{HARBOR SEALS}

Dr. Burkanov reported the results of research conducted by KamchatRybVod over the past two years. Unfortunately, only a small amount of information was collected on harbor seal distribution and abundance on Kamchatka and the Kuril Islands. Genetic samples were taken from animals on Bering Island for analysis by the Southwest Fisheries Center in La Jolla.

It was proposed to continue joint work on harbor seals with the University of Texas and the Alaska Department of Fish and Game. As has already been noted, there has been no monitoring of ice seal abundance in the Russian Far East due to decreased harvest of this species. Monitoring studies need to be reinstated in the Okhotsk and Bering Seas.

Through a grant from the International Fund for Animal Welfare (IFAW) Dr. Burdin began research in 1995 on abundance and feeding dynamics of harbor seals on Bering Island. The feeding habits of harbor seals were examined during the salmon run in Sarannoye Lake. Analysis of the total catch showed that 4-5\% of the salmon had wounds from harbor seals.

Mr. Vladimir Vertyankin reported the results of harbor seal surveys on Kamchatka and the Commander Islands: 300 animals inhabit Kronotskiy Nature Reserve, while 2,500 live on the Commander Islands. Southern Kamchatka is populated by a small number of harbor seals migrating from the Kuril Islands. The abundance of those populations has been relatively stable for many years.

Dr. Thomas Loughlin reported the results of harbor seal surveys conducted in Alaska by the National Marine Fisheries Service (NMFS). Alaska is so large that the state was divided into four parts and each part was surveyed 
once in four years. A correction coefficient for seals in the water (and therefore not counted) was established for different substratum rookery types. The number of harbor seals observed in Alaska was more than 51,000, and with the correction coefficient the total was calculated at 79,000. The Exxon Valdez oil spill has accelerated the continuing decline of harbor seal abundance in the Gulf of Alaska.

Mr. Vertyankin reported the results of a joint survey and radio tagging of harbor seals in Orca Bay, Alaska in 1995. The number of harbor seals in that area was estimated at $350-400$. A total of 25 harbor seals were captured and radio transmitter tags attached. Tag scanning results are currently being analyzed.

Dr. Kelly presented information on University of Alaska efforts to clarify the causes of decline of harbor seal abundance in Alaska. It is suspected that the decline results from a decreased food base. Body condition and blood composition were examined. A considerable decrease in survival rates of yearling harbor seals was observed.

\section{ICE SEALS}

Dr. Kelly spoke about ringed seal studies in the Beaufort Sea using radio and acoustic tags. Approximately 10,000 dives were analyzed. It was established that females mainly dove to depths greater than 100 meters, while the most frequent dive depth for males was less than 50 meters.

Dr. Bukhtiyarov reported the results of work conducted during the period April 4-18, 1995 in the Okhotsk Sea in the area of the Koni Peninsula from the ice-breaker "Krasin." The number and density of ice seals there was considerably lower than in 1968.

Professor Belkovich presented information about the possibility of conducting seal surveys using acoustic devices during mating, when the vocalization activity of the animals increases.

\section{STELLER SEA LIONS}

Dr. Burkanov reported the results of a survey and tagging of Steller sea lions from a ship in the Kuril Islands in June-July 1995. After a sharp decline in the 1980s, the number of Steller sea lions in the Kuril Islands has stabilized, and the number of pups has increased to 400 . A total of 300 pups were tagged. Approximately 60 Steller sea lions tagged in 1989-1991 were observed. Genetic samples were collected on four rookeries. Further, 100 pups on the southeast rookery of Medniy Island and 50 on Cape Kozlov (Kamchatka) were tagged.

Dr. Loughlin presented the results of Steller sea lion research in Alaska. A 1994 census showed a decline in the western coastal population and a slight increase in the eastern population to the southeast of Kodiak Island. Dr. Loughlin presented an overview of Steller sea lion research carried out by American scientists. He summarized the results of radio tagging of Steller sea lions on the Kuril islands conducted jointly with Dr. Adolf Perlov in 1991. These studies showed that the feeding behavior of Steller sea lions in the Kuril Islands and Alaska is quite similar.

Professor N. Suzuki spoke about the problem of Steller sea lion interactions with commercial fishing in Japan. Over the past ten years about 4,000 animals have either been taken or have died from entanglement in nets. Japan has no precise system for censusing marine mammals or monitoring their deaths. In 1994 the Government of Japan allocated funds for such studies. New regulations on taking of Steller sea lions have been issued, under which the annual harvest quota is not to exceed 114 animals.

Dr. Aleksandr Boltnev summarized the results of a 1994 Steller sea lion shipboard survey conducted by KamchatNIRO in Kamchatka and the Kuril Islands.

Dr. Perlov suggested that excessive harvest of Steller sea lions could be a possible cause of the current decline in its abundance.

Mr. Evgeniy Mamayev presented information on long-term studies of Steller sea lions on their reproductive rookeries on Medniy Island. Pictographic identification methods for subadult males revealed a high level of their rotation on the rookery. Analysis of the recovery of tags from young sea lions at the age of $1-3$ years showed a difference in the time periods when each age group arrives at its natal rookery; this time difference was estimated to be approximately a month. 


\section{NORTHERN FUR SEAL}

Dr. Aleksei Trukhin spoke about the results of fur seal research on Tyuleniy Island. Since 1987 its abundance has been at a low stable level, and there is currently no reason to assume it will increase in the future. There are five groups on the rookery, each physically and reproductively separate from the others. The reproductive isolation rate of the animals in these groups is $94 \%$ for females and $100 \%$ for males, which approximates the level for the population as a whole.

Dr. Boltnev reported on fur seal research conducted by the Marine Mammal Laboratory of KamchatNIRO. Fur seal abundance on each of the four rookeries of the Commander Islands remains stable. He also presented data on maternal investment in newborn pups of both sexes. The weight and physical condition of pups are probably related to the food resources affecting them through their mothers. Histological materials on the reproductive condition of males of various ages are currently being processed.

Dr. Loughlin reported the results of northern fur seal studies conducted by the National Marine Mammal Laboratory in Seattle. Research on St. Paul Island revealed a considerable decrease in the number of harem bulls, although the overall number of bulls remained at previous levels. In the last two years the total number of fur seals decreased slightly on St. George and stabilized on St. Paul Island. Several incidents of fur seal poaching on St. George Island were reported in 1993-1994. The 1994 subsistence take of bachelor bulls by Alaska natives was 1,616 on St. Paul and 161 on St. George Island.

Dr. Vladimirov distributed copies of the compendium "Results of Northern Fur Seal Research in Russia in 1993-1994" to the Working Group participants.

\section{SEA OTTERS}

Dr. Burdin summarized the results of the Fifth U.S.-Russia Sea Otter Workshop, held in Kamchatka September 7-12, 1995. Information was presented on sea otter research carried out in Russia and the U.S. in recent years, and plans for future joint work were laid out. A Workshop Protocol was signed in the Russian and English languages and copies given to both sides.

Dr. Kelly described efforts by the Alaska Sea Otter Commission to involve the Alaska native people in sea otter research and management. He has drafted management plans for sea otters in six regions of Alaska. The plans include harvest limits and other conservation measures. Also planned is the collection of biological samples from harvested sea otters and a study of sea otter foraging behavior using acoustic tags.

\section{OTHER STUDIES}

Dr. Burkanov reported the results of work carried out by Kamchatrybvod on marine mammals deaths in traps during drift fishing for salmon by Japanese vessels in the Russian Economic Zone in the vicinity of eastern Kamchatka and the Kuril Islands' shores. In 1994 and 1995 KamchatRybVod observers and inspectors recorded the following number of animals deaths in nets: Dolphins - 478 and 340 ; Seals -18 and 30 ; Seabirds $-36,845$ and 25,418 , respectively for each of the two years. Dr. Burkanov estimates that the number of deaths was underreported by $10 \%$.

Dr. Vladimir Chernook described a new technique for ice seal aerial surveys using video recording in both visual sight and infrared spectra, photography, and satellite information on ice conditions, with computer processing of data obtained. This technique allows both adults and pups to be counted, and the survey results are available immediately. The mobile combination of instruments is easily installed in any airplane, and this technique lowers the cost of aerial work.

Dr. Mikhail Zasypkin reported the results of biochemical genetic research on pinnipeds carried out since 1979 at the Institute of the Biological Problems of the North in Magadan. These approaches and techniques permit analysis of the population-genetic structure of harbor seal and walrus stocks, and of biochemical evolution in pinnipeds.

\section{OTHER TOPICS}

Mr. Igor Mikhno reviewed the procedures for submitting applications to conduct marine mammal studies using foreign vessels and aircraft in Russian waters, and gave the American side a sample form. 


\section{PROPOSED JOINT WORK}

\section{RUSSIAN SIDE:}

(The Russian side will consider the possibility of the following work in 1996-1997 subject to available technical and financial support):

\section{Cetaceans:}

Continuation of abundance and habitat surveys of bowhead and gray whales in the Okhotsk Sea begun in 1995, and continuation of photocatalogue compilation in 1996-1997 with the participation of 1-2 American specialists.

Development of a joint program of arctic beluga whale population studies and consolidation of efforts by scientists of different countries with the possibility of exchange of specialists to conduct joint field studies and process collected materials. (This proposal will be discussed in detail at the next Working Group meeting.)

Walrus:

Studies of walrus biology on Kamchatka haulouts with the participation of 1-2 American specialists.

The Russian side invites one U.S. National Biological Service database specialist to visit the Magadan Division of TINRO for one week during the 4th quarter of 1995 to assist the Russian side in creation of a data base for Pacific walrus.

The Russian side invites 1-2 American specialists for studies of the effects of tourism on walrus behavior and abundance distribution on Chukotka Peninsula haulouts.

Harbor Seals:

Joint studies on the harbor seal ecology on the Commander Islands in 1996 or 1997 with 3-4 American specialist participation.

Ice Seals:

Joint studies will be conducted on the reproductive ecology of ice seals in the Okhotsk and Bering Seas, together with tagging. Also: estimation of newborn walrus pup mortality from Russian icebreakers in 1997 with the participation of 1-2 American specialists.

Studies will be carried out on larga seal behavior during salmon spawning, and also on larga and bearded seal reproductive success in the summer-fall of 1996 or 1997 with the participation of 1-2 American specialists.

Steller Sea Lions:

Studies will be conducted on Steller sea lions in the Kuril Islands and Kamchatka in June-July 1996, including tagging, with the participation of one American specialist.

Migration studies of young Steller sea lions in Kamchatka and the Commander Islands will be carried out using and radio and satellite tags in 1996-1997, with the participation of 2-3 American specialists.

Sea Otters:

Consider inviting one U.S. specialist in 1996 to complete efforts in researching the history of the sea otter harvest in Russian and Alaskan waters in the 18th-20th centuries.

Consider inviting 2-3 U.S. specialists in 1996 for joint field research on Bering Island involving marking and the collection of biological materials from living and deceased sea otters.

Consider inviting 2-3 U.S. specialists in 1997 to participate in an expedition to study benthic communities and the sea otter population on the Kronotskiy Peninsula. 
Consider inviting 2-3 U.S. specialists to participate in joint research of benthic communities of the Commander Islands in 1996 and in 1997.

Consider inviting 2-3 U.S. specialists in 1997 to participate in an expedition studying the influence of sea otters on benthic communities of the Commander Islands.

Consider inviting 1-2 U.S. specialists to participate in a sea otter vessel survey in Kamchatka and the northern Kurils in 1996 if a vessel is available.

A request that the U.S. side examine the possibility of conducting oil product origin and identification analysis when Russian sea otter habitat is contaminated by oil products.

Conduct genetic research of sea otter tissue using electrophoresis. The Russian side expresses its interest in receiving appropriate samples from sea otters of the U.S. population.

\section{U.S. SIDE:}

(The following proposals should be considered tentative, subject to the availability of funds.)

\section{Cetaceans:}

The U.S. side invites 1-2 Russian scientists for up to 3 weeks to participate in gray whale cow-calf surveys in California waters. Exact dates and work plan will be communicated to the Russian side by February 1995.

Both sides agree to continue working together to review all available commercial whaling records for all north Pacific large cetaceans. This project includes both coastal and pelagic operations.

Both sides agree to continue the beluga whale genetic analyses begun in 1994. They agree to expand the scope of the work by Russian scientists obtaining specimen materials from as many parts of the range of the beluga whale as possible.

Walrus:

The U.S. Fish and Wildlife Service invites 2 Russian specialists to Alaska for 2 weeks during the second quarter of 1996 to observe the Walrus Harvest Monitoring Program and the Marking, Tagging, and Reporting Program for Native harvested walrus.

Both sides agree on the need to continue discussion toward a bilateral walrus conservation agreement. Details of a subsequent meeting in Alaska will be determined by the second quarter of 1996. Native-to-Native meetings in Chukotka and Alaska should be encouraged.

Both sides agree that it is desirable to begin monitoring studies of walrus behavior and abundance at haulout sites using standardized methodology. Therefore, the U.S. Fish and Wildlife Service invites up to 2 Russian specialists having experience in monitoring numbers of walrus on haulout sites to participate in counts and behavioral studies in Alaska during May 1996 or 1997.

Walrus aerial survey coordination should continue in the event it becomes a possibility in 1998 or later.

Both sides desire to establish a joint U.S.-Russia data base on the Pacific walrus that will include count and composition data from Russian and U.S. haulouts, joint U.S.-Russian aerial survey data, and data on the U.S. and Russian harvest. As part of this effort, the U.S. National Biological Service invites 2 Russian specialists to Alaska for 2 weeks during the second quarter of 1996 to participate in a joint synthesis of data to be included in the joint U.S.-Russia data base.

The U.S. side invites one Russian walrus specialist to visit the University of Alaska Fairbanks in the 1st quarter 1996 to collaborate on the analysis and reporting of data pertaining to Pacific walrus morphometries. It is anticipated that the work will require $4-5$ days to complete. 


\section{Pinnipeds:}

The two sides agree to continue age determination studies of pinnipeds and evaluation layering rates in cementum and dentine. Scientists from the Institute of Developmental Biology (Academy of Sciences) and Hubbs-Sea World Research Institute will continue their joint work with exchange of scientists to be determined by mutual agreement.

Both sides agree to continue joint studies on Steller sea lions, northern fur seals, harbor and larga seals in Alaska and the Russian Far East, whenever possible. Specific activities will be determined and arranged by mutual agreement throughout the year. These studies may include acquisition of specimen materials for physiological, genetic, age and growth or other studies, as necessary.

Harbor Seals:

The U.S. side invites 1-2 Russian scientists for 2 weeks to participate in studies with the Alaska Department of Fish and Game to assess foraging ecology of harbor seals using satellite telemetry in and adjacent to Prince William Sound, Alaska, during 1996-1997.

The U.S. side also invites one Russian scientist during August-September 1996 for 2 weeks to conduct joint studies on harbor seal aerial survey correction factor in Alaska.

Ice Seals:

The U.S. side invites one Russian specialist for 2-3 weeks in 1996 or 1997 to Fairbanks, Alaska, to work with Alaska Department of Fish and Game scientists to complete analyses of spotted seal satellite tag data. They will begin development of publications from these data. Exact dates for this work will be decided later.

\section{Steller Sea Lions:}

The U.S. side invites 1-2 Russian scientists to participate in ship-based research to investigate Steller sea lion physiology for 3-4 weeks during June-July 1996. The number of scientists and specific dates will be determined later once an appropriate vessel is obtained.

Fur Seals:

The U.S. side invites 1-2 Russian scientists to participate in northern fur seal research on the Pribilof Islands for 3-4 weeks during August-September 1996 or 1997. Dates and duration will be established in subsequent communications.

The U.S. side invites one Russian scientist to continue joint studies to analyze milk samples from lactating female fur seals for cooperative studies between the Commander and Pribilof Islands.

\section{Sea Otters:}

Joint proposal: Continue to exchange sea otter tissues for comparative studies of genetics, contaminants, and other aspects of natural history with maximum provision of life history data for the subject animals (gender, age, etc.).

Consider inviting 2-3 Russian specialists to participate in studies of sea otters and benthic ecosystems in southeast Alaska in 1996 or 1997.

Continue cooperative research on sea otter diving behavior using time depth recorders and radio transmitters at the Commander Islands in 1996 or 1997.

Consider hosting 1 or 2 Russian specialists at the Monterey Bay Aquarium for approximately 1 month in 1996 for familiarization with tagging and capture techniques and research efforts.

Invite one Russian specialist to participate in the continuation of studies of historical records of sea otter hunting in Russian and U.S. waters, and to participate in comparative studies of sea otter population dynamics and natural history. 
The American side proposed that the next (14th) meeting of the Marine Mammal Working Group take place in the United States in the 2nd quarter of 1997.

Signed at Paratunka, Kamchatka, Russia on September 27, 1995 in the English and Russian languages, both texts being equally authentic.

For the American Side:

(signed)

Robert V. Miller

Project 02.05-61 Leader
For the Russian Side:

(signed)

Valeriy A. Vladimirov

Project 02.05-61 Leader 


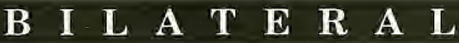

\section{SWEDEN}

ENVIRONMENT AND NATURAL RESOURCES 

Agreement Between the Department of Defense of the United States of America and the Armed Forces of the Kingdom of Sweden for Cooperation on Environmental Protection in Defense Matters, Stockholm, 1995

Done at Stockholm 24 April 1995

Entered into force 24 April 1995

Primary source citation: Copy of text provided by the U.S. Department of State

AGREEMENT BETWEEN THE DEPARTMENT OF DEFENSE OF THE UNITED STATES OF AMERICA AND THE ARMED FORCES OF THE KINGDOM OF SWEDEN FOR COOPERATION ON ENVIRONMENTAL PROTECTION IN DEFENSE MATTERS

\section{TABLE OF CONTENTS}

PREAMBLE

ARTICLE I DEFINITION OF TERMS AND ABBREVIATIONS

ARTICLE II OBJECTIVE

ARTICLE III SCOPE OF WORK

ARTICLE IV MANAGEMENT (ORGANIZATION AND RESPONSIBILITY)

ARTICLE V FINANCIAL PROVISIONS

ARTICLE VI CONTRACTUAL PROVISIONS

ARTICLE VII PROJECT EQUIPMENT

ARTICLE VIII DISCLOSURE AND USE OF PROJECT INFORMATION

ARTICLE IX CONTROLLED INFORMATION 
ARTICLE X VISITS TO ESTABLISHMENTS

ARTICLE XI SECURITY

ARTICLE XII THIRD PARTY SALES AND TRANSFERS

ARTICLE XIII LIABILITY

ARTICLE XIV CUSTOMS DUTIES, TAXES AND SIMILAR CHARGES

ARTICLE XV SETTLEMENT OF DISPUTES

ARTICLE XVI LANGUAGE

ARTICLE XVII GENERAL PROVISIONS

ARTICLE XVIII AMENDMENT, TERMINATION, ENTRY INTO FORCE

AND DURATION

\section{PREAMIBLE}

The Department of Defense of the United States of America and the Armed Forces of the Kingdom of Sweden, hereinafter referred to as the "Parties":

Having a common interest in defense;

Recognizing the benefits to be obtained from rationalization, standardization and interoperability of military equipments and methods for identifying and preventing environmental pollution;

Seeking to make the best use of their respective research and development capacities, eliminate unnecessary duplication of work and obtain the most efficient and cost-effective results;

Recognizing the need to collectively develop emerging technologies to address environmental issues;

Have agreed as follows:

\section{ARTICLE I \\ DEFINITION OF TERMS AND ABBREVIATIONS}

Classified Information Official information that requires protection in the interests of national security and is so designated by the application of a security classification marking.

Controlled Information Unclassified information to which access or distribution limitations have been applied in accordance with national laws and regulations, and which will be marked and handled in compliance with this Agreement.

Designated Security

Authority (DSA)

Governmental

Purposes
The security office approved by a national authority to be responsible for that nation's security aspects of this Agreement.

Manufacturing or other use in any part of the world by or for the government of either Party. (Any sales or transfers to Third Parties will be subject to Article XII of this Agreement.) 
Patent

Project Annex (PA)

Project Background Information

Project Foreground Information

Project Equipment

Project Information

Project Invention

Swedish Armed Forces

Third Party
Legal protection of the right to exclude others from making, using, or selling an invention. The term refers to any and all patents, including but not limited to patents of implementation, improvement, or addition, petty patents, utility models, appearance design patents, registered designs, and inventor certificates or like statutory protection as well as divisions, reissues, continuations, renewals, and extensions, of any of these.

An implementing arrangement, added after this Agreement has been in force, which details the terms of collaboration on a specific Project.

Information not generated in the performance of a Project.

Information generated in the performance of a Project.

Any material, equipment, end item, subsystem, component, special tooling or test equipment used in a Project.

Any data, knowledge, fact, or information provided, generated, or used in a Project under this agreement regardless of form or type, including that of a scientific, technical, business, or financial nature, and also including photographs, reports, manuals, threat data, experimental data, test data, designs, specifications, processes, techniques, inventions, drawings, technical writings, sound recordings, pictorial representations, and other graphical presentations, whether in magnetic tape, computer memory, or any other form and whether or not subject to copyright, patent, or other legal protection.

Any invention or discovery formulated, made (conceived or first actually reduced to practice) in the course of work performed under a Project. The term first actually reduced to practice means the first demonstration, sufficient to establish to one skilled in the art to which the invention pertains, of the operability of an invention for its intended purpose and in its intended environment.

An organization which is made up of the Swedish Army, Navy, and Air Forces.

Any person or other entity whose government or whose governing authority is not a Party to this Agreement.

\section{ARTICLE II}

\section{OBJECTIVE}

1. The objective of this Agreement is to define and establish the general principles which shall apply to the initiation, conduct, and management of Annexes related to environmental technology research and development projects between the Parties to provide for the exchange of research, development, test and evaluation information of mutual interest on environmental technology matters and for the performance of research, development, test and evaluation activities on environmental technology matters of mutual interest.

2. Detailed terms and conditions of each individual Project shall be in accordance with this Agreement and be recorded in Annexes to this Agreement. Each Project Annex shall include, as a minimum, provisions concerning the objective, scope of work, management structure, financial arrangements, contractual arrangements (if required) and responsibilities of the Parties in accordance with the format set forth in Annex A to the extent practicable.

3. U.S. participation will include the OSD, Army, Navy and Air Force.

4. Swedish participation will include the Armed Forces, supported by the following agencies: the Fortification Administration, the Swedish Defence Material Administration and the National Defence Research Establishment. 


\section{ARTICLE III}

\section{SCOPE OF WORK}

1. The scope of work for this Agreement shall encompass research and development collaboration and information exchange on basic research, exploratory and advanced development technologies whose maturation may lead to the development of environmental protection systems. Projects may range from information exchange to conceptual studies to joint environmental experiments. Information that may be used directly in the final design or in the manufacture of a prototype or production item or system will not be provided by either Party. Any specific prototypes, full-scale development or production programs which are based upon collaboration under one or more Project Annexes to this Agreement are outside the scope of this Agreement and shall require conclusion of separate agreements.

2. Experience, information and views on selected environmental issues will be initially exchanged in the following areas:

a. Efforts to reduce or eliminate adverse environmental impacts on air, water and land due to armed forces installations and activities.

b. Methods to measure, predict, and mitigate the effects of noise related to defense systems operations.

c. Efforts to monitor, remediate and restore environments contaminated by defense activities.

d. Guidelines and techniques for disposal of defense material/wastes.

e. Factoring environmental considerations into the acquisition and procurement of equipment and facilities.

f. Efforts to implement pollution prevention and source reduction measures on naval ships and at defense installations.

g. Development of environmental training and education programs to increase environmental awareness in the armed forces.

h. Efforts to develop techniques needed for successful multiple resource management on defense installations in light of military operations.

i. Efforts to conserve and enhance nature and wildlife in areas used for military activities.

3. Individual Projects will be established by the Parties to address specific areas of joint activity or information exchange.

\section{ARTICLE IV}

\section{MANAGEMENT}

1. The Parties shall appoint a Standing Steering Committee (SC), with an equal number of members from each Party, which will direct and administer Projects on an overall level on behalf of the Parties. The SC will meet alternatively in the United States and Sweden on a biannual or as-needed basis.

2. The SC will schedule working groups to address the environmental areas described in Article III. When these working groups decide a particular area warrants further attention, the Parties will enter into a Project Annex to this Agreement to establish a Project for that area.

3. The $\mathrm{SC}$ shall be responsible for:

a. exercising policy and management direction during the course of Project implementation. 
b. monitoring overall Project implementation, including Project execution, specifications, milestones, cost and financial requirements.

c. recommending amendments to this Agreement to the Parties.

d. exercising overall authority over Project Officers in accordance with this Agreement.

4. Project Officers (POs) shall be appointed for each Project. POs shall have the primary responsibility for implementation, management, and direction of a Project in accordance with this Agreement.

5. If needed, a separate Steering Committee may be designated in the Project Annex to provide specific policy and management direction to the POs during the execution of a specific Project.

\section{ARTICLE V}

\section{FINANCIAL PROVISIONS}

1. Each Party shall contribute its equitable share of the full costs of each Project, including overhead and administrative costs. The assignment of work shall represent an equitable sharing of work to be performed under each Project. Each Party shall receive an equitable share of the results of each Project.

2. The following costs shall be borne entirely by the Party incurring the costs:

a. Costs associated with any unique national requirements identified by a Party.

b. Costs associated with attendance at, and hosting of, meetings and working groups.

c. Any other costs outside the scope of this Agreement and its Project Annexes.

3. A Party shall promptly notify the other Party if available funds are not adequate to fulfill its obligations under this Agreement or a Project Annex. If a Party notifies the other Party that it is terminating or reducing its funding for a Project, both Parties shall immediately consult with a view toward continuation on a changed or reduced basis.

4. The financial arrangements for a specific Project will be provided in the Annex for that Project.

\section{ARTICLE VI \\ CONTRACTUAL PROVISIONS}

1. If either Party determines that contracting is necessary to fulfill that Party's obligations under the scope of work of a Project Annex of this Agreement, that Party shall contract in accordance with its national laws, regulations, policies and procedures.

2. When one Party individually contracts to undertake a task under a Project Annex to this Agreement, it shall be solely responsible for its own contracting, and the other Party shall not be subject to any liability arising from such contracts without its written agreement.

3. For all contracting activities performed by either Party, the POs shall be provided a copy of all Statements of Work prior to the development of solicitations to ensure that they are consistent with the provisions of this Agreement and the applicable Annex.

4. Each Party's Contracting Agency shall negotiate to obtain the rights to use and disclose Project Information required by ARTICLE VIII (Disclosure and Use of Project Information). Each Party's Contracting Agency shall insert into its prospective contracts (and require its subcontractors to insert in subcontracts) suitable provisions to satisfy 
the requirements of ARTICLE VIII (Disclosure and Use of Project Information), ARTICLE IX (Controlled Information), ARTICLE XI (Security) and ARTICLE XII (Third Party Sales and Transfers) of this Agreement. During the contracting process, each Party's contracting officer shall advise prospective contractors of their obligation to immediately notify the Contracting Agency before contract award if they are subject to any license or agreement that will restrict that Party's freedom to disclose information or permit its use. The contracting officer will also advise prospective contractors to employ their best efforts not to enter into any new agreement or arrangement that shall result in restrictions.

5. In the event a Party's Contracting Agency is unable to secure adequate rights to use and disclose Project Information as required by ARTICLE VIII (Disclosure and Use of Project Information), or is notified by contractors or potential contractors of any restrictions on the disclosure and use of information, that Party's PO shall notify the other Party's PO of the restrictions.

6. Each Party's PO shall promptly advise the other Party's PO of any cost growth, schedule delay, or performance problems of any contractor for which its Contracting Agency is responsible.

\section{ARTICLE VII}

\section{PROJECT EQUIPMENT}

1. Each Party may provide Project Equipment identified as being necessary for executing a Project to the other Party. Project Equipment shall remain the property of the providing Party. A list of all Project Equipment provided by one Party to another shall be developed and maintained by the Project Officers, and approved by the SC for each Project.

2. The receiving Party shall maintain any such Project Equipment in good order, repair, and operable condition and return the items in as good a condition as received, normal wear and tear excepted. The receiving Party shall pay the cost of damage (other than normal wear and tear) to or loss of Project Equipment.

3. All Project Equipment that is transferred shall be used by the receiving Party only for the purposes set out in the relevant Project Annex. In addition, in accordance with ARTICLE XII (Third Party Sales and Transfers) Project Equipment will not be re-transferred to a Third Party without the prior written consent of the providing Party.

4. Project Equipment transferred to one Party under this Agreement shall be returned to the providing Party prior to the termination or expiration of this Agreement.

\section{ARTICLE VIII}

\section{DISCLOSURE AND USE OF PROJECT INFORMATION}

\section{General}

Both Parties recognize that successful collaboration depends on full and prompt exchange of information necessary for carrying out each Project. The Parties intend to acquire sufficient Project Information and rights to enable collaboration on basic research, exploratory and advanced development technologies whose maturation may lead to the development of technologically superior environmental protection systems. The nature and amount of Project Information to be acquired shall be consistent with the objectives stated in ARTICLE II (Objectives) and the Project Annexes to this Agreement.

\section{Project Foreground Information}

a. Disclosure: Project Foreground Information shall be made available to both Parties in accordance with the provisions of this Agreement. 
b. Use: Each Party may use this Project Foreground Information without charge for its Governmental Purposes; however, if a Party intends to use the Project Foreground Information in a sale or other transfer to a Third Party, the provisions of ARTICLE XII (Third Party Sales and Transfers) of this Agreement shall apply.

3. Project Background Information

a. Disclosure: Each Party, upon request, shall make available to the other Party any relevant information in its possession not generated in the performance of the Project, provided that:

(1) The Project Background Information is necessary to or useful in the Project. The Party in possession of the information shall determine whether it is "necessary to" or "useful in" the Project;

(2) The Project Background Information may be made available without incurring liability to holders of proprietary rights; and

Disclosure is consistent with national disclosure policies and regulations of the furnishing Party.

b. Use: Project Background Information furnished by a Party may be used by the other Party for Project purposes only.

4. Proprietary Project Information

a. All proprietary information shall be identified and marked.

b. The provisions of the Agreement to Facilitate Interchange of Patent Rights and Technical Information for Defense Purposes, dated October 4, 1962 between the U.S. and Sweden shall apply to proprietary Project Information related to this Agreement.

5. Patents

a. Where a Party has or can secure the right to file a patent application with regard to a Project Invention, that Party shall consult with the other Party regarding the filing of such patent application. The Party having such rights shall in other countries, file, cause to be filed, or provide the other Party with the opportunity to file on behalf of the Party holding such rights, or its contractors, as appropriate, patent applications covering any such Project Invention. If a Party having filed or caused to be filed a patent application decides to stop prosecution of the application, that Party shall notify the other Party of that decision and permit the other Party to continue the prosecution.

b. Each Party shall be furnished with copies of patent applications filed and patents granted with regard to Project Inventions.

c. Each Party shall acquire a non-exclusive, irrevocable, royalty-free license to practice or have practiced, by or on behalf of the Party, throughout the world for Governmental Purposes, any Project Invention.

d. Patent applications which contain classified information, to be filed under this Agreement, shall be protected and safeguarded in accordance with the Agreement Approving the Procedures for Reciprocal Filing of Patent Applications in the U.S. and Sweden, dated November 17, 1964. Insofar as possible, each Party shall extend to the other Party any relief from patent infringement claims arising in the course of work performed under the Project that it may be able to claim on its own behalf. The Parties shall, in accordance with their national laws and practices, give their authorization and consent for all use and manufacture in the course of work performed under the Project of any invention covered by a patent issued by their respective countries. Each Party is responsible for handling all patent infringement claims made in its territory and to inform the other Party of such claims and to consult with the other Party during the handling and prior to the settlement of such claims. 


\section{ARTICLE IX \\ CONTROLLED INFORMATION}

1. Except as otherwise provided in this Agreement or authorized in writing by the originating Party, Controlled Information provided or generated pursuant to this Agreement shall be controlled as follows:

a. Such information shall be used only for purposes authorized for use of Project Information as specified in ARTICLE VIII (Disclosure and Use of Project Information).

b. Access to such information shall be limited to personnel whose access is necessary for the permitted use under subparagraph (a) above, and subject to the provisions of ARTICLE XII (Third Party Sales and Transfers).

c. Each Party shall take all lawful steps, which may include national classification, to keep such information free from further disclosure (including requests under any legislative provisions) except as provided in subparagraph (b) above, unless the originating Party consents to such disclosure. In the event of unauthorized disclosure, or if it becomes probable that the information may have to be disclosed to a Third Party or a judicial body under any legislative provision, immediate notification shall be given to the originating Party.

2. To assist in providing the appropriate controls, the Parties shall agree in advance on the markings to be placed on the Controlled Information, and shall incorporate these procedures into the Project Security Instruction.

3. Controlled Information provided or generated pursuant to this Agreement shall be stored, handled and transmitted in a manner that ensures control as provided for in Paragraphs 1 and 2, above. Prior to authorizing the release of Controlled Information to contractors, the Parties shall ensure the contractors are legally bound to control such information in accordance with the provisions of this Article.

4. The provisions of the Agreement between the Government of the United States of America and the Government of Sweden on Interchange of Patent Rights and Technical Information for Defense Purposes of 4 October 1962 shall also apply to any Controlled Information of a proprietary nature to this Agreement.

\section{ARTICLE X}

\section{VISITS TO ESTABLISHMENTS}

1. Each Party shall permit visits to its Government establishments, agencies and laboratories, and contractor industrial facilities by employees of the other Party or by employees of the other Party's contractors, provided that the visit is authorized by both Parties and the employees have appropriate security clearances and a need-to-know.

2. All visiting personnel shall be required to comply with security regulations of the host Party. Any information disclosed or made available to visitors shall be treated as supplied to the Party sponsoring the visiting personnel, and shall be subject to the provisions of this Agreement.

3. Requests for visits by personnel of one Party to a facility of the other Party shall be coordinated through official channels, and shall conform with the established visit procedures of the host country. Requests for visits shall cite this Agreement and the appropriate Project as the basis for the request.

4. Lists of personnel of each Party required to visit, on a continuing basis, facilities of the other Party shall be submitted through official channels in accordance with Recurring International Visit Procedures. 


\section{ARTICLE XI}

\section{SECURITY}

It is the intent of the Parties that the Program carried out under this Agreement shall be conducted at the unclassified level. No classified information shall be provided or generated under this Agreement.

\section{ARTICLE XII}

\section{THIRD PARTY SALES AND TRANSFERS}

1. The DoD shall retain the right to sell, transfer title to, disclose, or transfer possession of Project Foreground Information to Third Parties when such Project Foreground Information is generated solely by the DoD in performance of its work allocation under ARTICLE III (Scope of Work) and does not include any Project Background Information of the other Party.

2. The Armed Forces of Sweden shall retain the right to sell, transfer title to, disclose, or transfer possession of Project Foreground Information to Third Parties when such Information is generated solely by the Armed Forces of Sweden in performance of its work allocation under ARTICLE III (Scope of Work), and does not include any Project Background Information of the other Party.

3. Except to the extent permitted in paragraphs 1 and 2 above, the Parties shall not sell, transfer title to, disclose, or transfer possession of Project Foreground Information or Project Equipment to any Third Party, or permit such transfer, without the prior written consent of the other Party. Furthermore, neither Party shall permit any such sale, disclosure, or transfer, including by the owner of the item, without the prior written consent of the other Party. Such consent will not be given unless the government of the intended recipient agrees in writing with the Parties that it will:

a. Not retransfer, or permit the further retransfer of, any equipment or information provided; and,

b. Use, or permit the use of, the equipment or information provided for the purposes specified by the Parties.

4. In the event questions arise regarding the origin of Project Foreground Information that a Party intends to sell, transfer title to, disclose, or transfer to a Third Party, the matter shall be brought to the immediate attention of the other Party's PO. If necessary, the matter shall be referred to the SC for resolution prior to any sale or other transfer of such Project Foreground Information to a Third Party.

5. The Parties shall not sell, transfer title to, disclose, or transfer possession of Project Background Information or Project Equipment provided by another Party to any Third Party without the prior written consent of the Party which provided such equipment or Information. The providing Party shall be solely responsible for authorizing such transfers and, as applicable, specifying the method and conditions for implementing such transfers.

\section{ARTICLE XIII}

\section{LIABILITY}

1. Claims arising out of activities taking place under this agreement shall be dealt with as follows:

a. The Parties waive all their claims, other than contractual claims, against each other, and against the military members and civilian employees of each other for damage, loss or destruction of property owned or used by them, if such damage, loss or destruction: 
(2) arose from the use of any vehicle, vessel or aircraft owned by the other Party and used by it, provided that the vehicle, vessel, or aircraft causing the damage, loss or destruction was being used for official purposes, or that the damage, loss or destruction was caused to property being so used.

b. The Parties waive all their claims against each other and against the other's military members and civilian employees for injury or death suffered by any of its military members or civilian employees while such member or employee was engaged in the performance of official duties.

c. Nothing herein shall be construed as waiving the claims, or suits of individual military members of the respective Departments of Defense, its civilian employees, or third parties that might exist under applicable law.

d. Claims, other than contractual claims, not covered by paragraphs (a) and (b), shall be dealt with by each Party in accordance with its national laws. Each Party shall pay just and reasonable compensation in settlement of meritorious claims for damage, loss, personal injury or death caused by acts or omissions of its military members or civilian employees when acting in the performance of official duties.

2. Claims arising under or related to any contract awarded pursuant to ARTICLE VI (Contractual Provisions) shall be resolved in accordance with the provisions of the contract.

\section{ARTICLE XIV}

\section{CUSTOMS DUTIES, TAXES AND SLMIIAR CHARGES}

1. Customs duties, import and export taxes and similar charges shall be administered in accordance with each Party's respective laws and regulations. Insofar as existing national laws and regulations permit, the Parties shall endeavor to ensure that such readily identifiable duties, taxes and similar charges, as well as quantitative or other restrictions on imports and exports, are not imposed in connection with work carried out under each Project.

2. Each Party shall use its best efforts to administer customs duties, import and export taxes, and similar charges in a manner favorable to the efficient and economical conduct of the work. If any such duties, taxes, or similar charges are levied, the Party in whose country they are levied shall bear such costs.

\section{ARTICLE XV}

\section{SETTLEMENT OF DISPUTES}

Disagreements among the Parties arising under or relating to this Agreement shall be resolved only by consultation between the Parties and shall not be referred to an individual, to an international tribunal, or to any other forum for settlement.

\section{ARTICLE XVI}

\section{LANGUAGE}

1. The working language for implementing this Agreement shall be the English language.

2. All data and information generated under this Agreement and its implementing Contracts and provided by one Party to the other will normally be furnished in the original language of the source material. 


\section{ARTICLE XVII}

\section{GENERAL PROVISIONS}

1. All activities of the Parties under this Agreement and its Project Annexes shall be carried out consistent with their national laws and the obligations of the Parties shall be subject to the availability of appropriated funds for such purposes.

2. In the event of a conflict between an Article of this Agreement and any Project Annex to this Agreement, the Article shall govern.

\section{ARTICLE XVUI}

\section{AMENDMENT, TERMINATION, ENTRY INTO FORCE AND DURATION}

1. This Agreement may be amended by the written agreement of the Parties. Project Annexes to this Agreement may be established by written agreement of the Parties.

2. This Agreement may be terminated at any time upon the written agreement of the Parties. In the event that the Parties agree to terminate this Agreement, the Parties shall consult prior to the date of termination to ensure termination on the most economical and equitable terms.

3. Any Party may terminate this Agreement or any Project Annex upon 60 days written notification to the other Party. Such notice with regard to a Project Annex shall be the subject of immediate consultation by the Steering Committee to decide upon the appropriate course of action. In the event of such termination, the following rules apply:

a. The terminating Party shall continue participation, financial or otherwise, until the effective date of termination.

b. Each Party shall pay the costs it incurs as a result of the termination.

c. All Project Information and rights therein received under the provisions of this Agreement prior to the termination shall be retained by the Parties, subject to the provisions of this Agreement.

4. Termination of this Agreement shall terminate its Annexes.

5. The respective rights and responsibilities of the Parties regarding ARTICLE VII (Project Equipment), ARTICLE VIII (Disclosure and Use of Project Information), ARTICLE IX (Controlled Information), ARTICLE XI (Security), ARTICLE XII (Third Party Sales and Transfers), and ARTICLE XIII (Liability), shall continue notwithstanding termination or expiration of this Agreement or its Project Annexes.

6. This Agreement, which consists of the Preamble and 18 Articles, shall enter into force from the date of the last signature and shall remain in force for ten years. It may be extended by written agreement of the Parties.

IN WITNESS WHEREOF, the undersigned, being duly authorized, have signed this Agreement.

DONE in duplicate, in the English language. 
FOR THE

ARMED FORCES

OF THE

KINGDOM OF SWEDEN:

[Signature]

Owe Wiktorin

(Name)

Supreme Commander

(Title)

Stockholm

(Location)

April 24, 1995
FOR THE

DEPARTMENT OF DEFENSE

OF THE

UNITED STATES OF AMERICA

[Signature]

Gary D. Vest

(Name)

Principal Assistant Deputy Under

Secretary of Defense

(Environmental Security)

(Title)

Stockholm

(Location) 


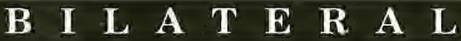

\section{TUNISIA}

ENVIRONMENTAND NATURAL RESOURCES 



\section{Agreement Between the National Oceanic and Atmospheric}

Administration of the United States of America and the Ministry of Environment of Tunisia for Cooperation in the GLOBE Program, Washington, D.C., 1995

Done at Washington, D.C. 27 July 1995

Entered into force 27 July 1995

Primary source citation: Copy of text provided by the U.S. Department of State

\section{AGREEMENT BETWEEN THE NATIONAL OCEANIC AND ATMOSPHERIC ADMINISTRATION OF THE UNITED STATES OF AMERICA AND THE MINISTRY OF ENVIRONMENT OF TUNISIA FOR COOPERATION IN THE GLOBE PROGRAM}

\section{PREAMBLE}

The U.S. National Oceanic and Atmospheric Administration, acting on behalf of itself and other U.S. Government agencies participating in the GLOBE Program (hereinafter, the U.S. side), and the Ministry of Environment of Tunisia (hereinafter, the Tunisian side),

Intending to increase the awareness of students throughout the world about the global environment,

Seeking to contribute to increased scientific understanding of the Earth, and

Desiring to support improved student achievement in science and mathematics,

Have agreed to cooperate in the Global Learning and Observations to Benefit the Environment (GLOBE) Program as follows: 


\section{ARTICLE 1 - THE GLOBE PROGRAM}

The GLOBE Program is an international environmental science and education program that will bring students, teachers, and scientists together to study the global environment. GLOBE will create an international network of students in grades K-12 (or equivalent) studying environmental issues, making environmental measurements, and sharing useful environmental data with the international environmental science community.

\section{ARTICLE 2 - RESPECTIVE RESPONSIBILITIES}

A. The U.S. side will:

1. Identify U.S. schools that will participate in the GLOBE Program (details regarding GLOBE schools in Appendix A);

2. Select, in consultation with international scientists and educators, the GLOBE environmental measurements and types of measurement equipment (described in Appendix B);

3. Select Principal Investigator Teams for the GLOBE environmental measurements, and support the U.S. members of the Teams;

4. Calibrate, if necessary, measurement equipment that cannot be calibrated by GLOBE teachers and students;

5. Develop, in consultation with international scientists and educators, GLOBE educational materials;

6. Translate GLOBE instructional materials related to measurement procedures and data reporting protocols into the six United Nations languages, and provide these plus all broader GLOBE educational materials to the Tunisian side for further reproduction as necessary;

7. Conduct annual regional training sessions for GLOBE Country Coordinators and GLOBE teachers who will serve as trainers for additional GLOBE teachers in Tunisia, and provide a copy of GLOBE training materials to the Tunisian side;

8. Design, develop, operate, and maintain GLOBE data processing capabilities and other necessary technology and equipment;

9. Provide GLOBE software, as necessary, for use on Tunisian GLOBE school computers. (To the maximum extent possible, textual material appearing on computer screens will be accessible in the student's choice among the six United Nations languages.);

10. Accept environmental data reported from GLOBE schools around the world, and develop and provide resultant global environmental images (visualization products) to the Tunisian side; and

11. Evaluate the overall GLOBE Program periodically, in consultation with international GLOBE Country Coordinators, and modify the overall program as appropriate.

B. The Tunisian side will:

1. Select Tunisian schools to participate in the GLOBE Program (details regarding GLOBE schools in Appendix A) and provide an updated list of Tunisian GLOBE schools to the U.S. side at the beginning of each school year;

2. Ensure that Tunisian GLOBE schools conduct the fundamental activities of GLOBE schools detailed in Appendix A (take GLOBE environmental measurements, report data, and receive and use resultant global environmental images, using GLOBE educational materials under the guidance of teachers trained to conduct the GLOBE Program); 
3. Name a Tunisian Government Point of Contact responsible for policy-level communications with the Director of the GLOBE Program;

4. Name a Country Coordinator responsible for day-to-day management, oversight, and facilitation of the GLOBE Program in Tunisia;

5. Ensure that the Country Coordinator and some GLOBE teachers attend GLOBE regional training and in turn provide GLOBE training to at least one teacher in each Tunisian GLOBE school;

6. Ensure that GLOBE instructional materials related to measurement procedures and data reporting protocols are utilized in Tunisian GLOBE schools, and that broader GLOBE educational materials are appropriately translated, adapted, reproduced, and distributed to all Tunisian GLOBE schools;

7. Ensure that Tunisian GLOBE schools have the necessary measurement equipment to take GLOBE environmental measurements (described in Appendix B);

8. Ensure that teachers and students at Tunisian GLOBE schools calibrate GLOBE measurement equipment according to procedures provided in GLOBE instructional materials;

9. Ensure that Tunisian GLOBE schools have the necessary computer and communications systems (described in Appendix C) to report GLOBE environmental measurements and to receive and use GLOBE visualization products, or make agreed alternative arrangements for such reporting and receipt. (At a minimum, the Tunisian Country Coordinator will need access to Internet so that all measurement data from Tunisian GLOBE schools will be reported via Internet.); and

10. Evaluate GLOBE operations in Tunisia periodically and assist the U.S. side in conducting periodic evaluation of the overall GLOBE Program.

\section{ARTICLE 3 - FINANCIAL ARRANGEMENTS}

Each side will bear the costs of fulfilling its respective responsibilities under this agreement. Obligations of each side pursuant to this agreement are subject to its respective funding procedures and the availability of appropriated funds, personnel, and other resources. The conduct of activities under this agreement will be consistent with the relevant laws and regulations of the two sides.

\section{ARTICLE 4 - EXCHANGE OF DATA AND GOODS}

GLOBE environmental measurement data, visualization products, software, and educational materials will be available worldwide without restriction as to their use or redistribution.

\section{ARTICLE 5 - RELEASE OF INFORMATION ABOUT THE GLOBE PROGRAM}

Each side may release information on the GLOBE Program as it may deem appropriate without prior consultation with the other.

\section{ARTICLE 6 - CUSTOMS AND IMMIGRATION}

Each side will, to the extent permitted by its laws and regulations, facilitate the movement of persons and goods necessary to implement this agreement into and out of its territory and accord entry to such goods into its territory free of customs duties and other similar charges. 


\section{ARTICLE 7 - ENTRY INTO FORCE, AMENDMENTS, WITHWRAWAL}

This agreement will enter into force upon signature of the two sides and will remain in force for five years. It will be automatically extended for further five-year periods, unless either side decides to terminate it and so notifies the other side with three months written notice. This agreement may be terminated at any time by either side upon three months prior written notice to the other side. This agreement may be amended by written agreement of the two sides.

Done at Washington on July 27, 1995, in duplicate, in the English and French languages, both texts being equally authentic.

For the National Oceanic and

Atmospheric Administration:

[Signature]
For the Ministry of

Environment:

[Signature]

\section{APPENDIX A GLOBE Schools}

Each partner country will be responsible for identifying its participating schools. Schools should be selected so as to satisfy the objectives of the GLOBE Program. In particular, countries should emphasize the selection of schools that will maximize the number of students worldwide participating in the program. Also, countries should consider involving schools in locations that will yield measurement data that is important to the international environmental science community.

Students at all GLOBE schools throughout the world will conduct the following fundamental activities: they will make environmental measurements at or near their schools; report their data to a GLOBE data processing site; receive vivid graphical global environmental images (visualization products) created from their data and the data from other GLOBE schools around the world; and study the environment by relating their observations and the resulting visualization products to broader environmental topics. All of these activities will be conducted under the guidance of specially trained teachers (GLOBE-trained teachers).

GLOBE educational materials will be used in GLOBE schools under the guidance of GLOBE-trained teachers. These materials will detail procedures for taking environmental measurements and protocols for reporting data; explain the significance of the measurements; guide the use of the visualization products; and integrate the measurement aspects of the program into a broader study of the environment.

Schools throughout the United States and the rest of the world that are not GLOBE schools may become GLOBE Affiliate schools by observing the GLOBE Program in operation through the Internet. Students at these schools will benefit from the use of GLOBE visualization products and educational materials accessible on-line. All GLOBE Affiliate schools will be encouraged to become participating GLOBE schools.

\section{APPENDIX B GLOBE Environmental Measurements and Equipment}

GLOBE environmental measurements will contribute in a significant way to the scientific understanding of the dynamics of the global environment. Every GLOBE school will conduct a core set of GLOBE environmental measurements in the following critical areas: Atmosphere/Climate, Hydrology/Water Chemistry, and Biology/Geology. Where possible, a GLOBE school may coordinate its activities with those of other neighboring GLOBE schools, so that the complete set of GLOBE measurements will be available from a locality. As the GLOBE Program evolves, elective measurements not common to all GLOBE schools may be added in order to address local environmental issues.

Students at all age levels will be active participants in the GLOBE Program. The actual participation will be designed so as to be grade-appropriate for grades K-5, 6-8, and 9-12 (or equivalent). Younger students will make limited measurements which may be qualitative rather than quantitative. Older students will make additional measure- 
ments and more sophisticated measurements, as appropriate for their grade level. Measurement equipment will not need to be standardized; rather, performance specifications will be provided.

Following is an example list of core measurements and equipment. The full list will be initially determined and periodically updated as provided in Article 2.A.2, based on experience gained in implementing the GLOBE Program.

\section{MEASUREMENTS}

\section{Atmosphere/Climate:}

Air Temperature

Precipitation

Cloud Cover/Type

\section{Hydrology/Water Chemistry:}

Water $\mathrm{pH}$

Water Temperature

Soil Moisture

\section{Biology/Geology: \\ Habitat Study}

Tree Height

Tree Canopy

Tree Diameter

Species Identification

Phenology

\section{EQUIPMENT NEEDED}

\author{
Max/Min Thermometer \\ Calibration Thermometer \\ Instrument Shelter \\ Rain Gauge \\ Cloud Charts
}

pH Paper, Pen, or Meter

Alcohol Thermometer

Gypsum Block Sensors

Soil Moisture Meter

\author{
Compass \\ Meter Measuring Tape \\ Surveying Markers or Stakes \\ Clinometer \\ Densiometer \\ Diameter Tape \\ Dichotomous Keys \\ $35 \mathrm{~mm}$ Camera
}

\section{APPENDIX C GLOBE Computer and Communications Systems}

In order to derive maximum benefit from the GLOBE Program, all schools will be encouraged to use an international information network, initially using the Internet, along with classroom computers. The World Wide Web multi-media information-access capability has been selected as the basis for IBM-compatible and Apple Macintosh computer systems to support the required GLOBE school activities of data entry, data analysis, and use of GLOBE environmental images. Following is a description of GLOBE computer and communications systems consistent with current GLOBE requirements.

Overall attributes of the minimum GLOBE school computer configuration that can execute the necessary software are:

For IBM-compatible systems: a $386 \mathrm{SX}$ or higher level processor; at least 4 megabytes of RAM memory ( 8 megabytes preferred); a VGA-capable monitor and display driver (Super VGA preferred); a hard disk storage system with as large a capacity as possible (preferably 300 megabytes or larger); and a direct Internet connection or dial-up capability that can use SLIP or PPP protocols with a $14,400 \mathrm{bps}$ modem (preferably supporting V.42bis data compression which can enable 57,600 bps operation). The Windows 3.1 or later operating system is necessary. A printer is desirable.

For Apple Macintosh systems: a $6803020 \mathrm{Mhz}$ or faster processor; at least 4 megabytes of RAM memory ( 8 megabytes preferred); a hard disk storage system with as large a capacity as possible (preferably 300 megabytes or larger); and a direct Internet connection or dial-up capability that can use SLIP or PPP protocols with a 14,400 bps modem (preferably supporting V.42bis data compression which can enable 57,600 bps operation). A printer is desirable.

Software for a higher performance GLOBE school computer system is being developed that will operate on higher performance, multi-media IBM-compatible systems and on Apple Macintosh systems. For IBM-compatible systems: 
a 486/66 or faster processor; 16 megabytes of RAM memory; 500 megabytes of hard disk space; a Super VGA monitor; a double-speed CD-ROM reader; a Soundblaster-compatible sound card; and an MPEG animation speed-up board will be required. For Apple Macintosh systems: a PowerPC processor; 16 megabytes of RAM memory; 500 megabytes of hard disk space; and a double-speed CD-ROM reader will be required. A communications capability the same as or better than for the minimum configurations above will also be required. A printer will be highly desirable.

It is recognized that there is a broad range of technological capabilities among potential GLOBE schools. The diversity of technology accessible by schools worldwide may require in some cases that environmental measurements be reported in hardcopy and that a variety of media be used to distribute visualization products, including photographs and broadcast television. All schools that want to participate in the program will be accommodated.

Technology associated with the GLOBE Program will continually evolve to higher levels and participants will be encouraged to upgrade over time. 


\section{B I L A T E $R$ A A L}

\section{TURKEY, REPUBLIC OF}

E N V I R O N E N T A ND NATURAL RESOURCES 



\section{Agreement Between the Government of the Republic of Turkey and the Government of the United States of America for Cooperation in the GLOBE Program, Ankara, 1995}

Done at Ankara 5 May 1995

Entered into force 5 May 1995

Primary source citation: Copy of text provided by the

U.S. Department of State

\section{AGREEMENT BETWEEN THE GOVERNMENT OF THE REPUBLIC OF TURKEY AND THE GOVERNMENT OF THE UNITED STATES OF AMERICA FOR COOPERATION IN THE GLOBE PROGRAM}

\section{PREAMBLE}

The Government of the Republic of Turkey and the Government of the United States of America (hereinafter, the sides),

Intending to increase the awareness of students throughout the world about the global environment,

Seeking to contribute to increased scientific understanding of the Earth, and

Desiring to support improved student achievement in science and mathematics,

Have agreed to cooperate in the Global Learning and Observations to Benefit the Environment (GLOBE) Program as follows:

\section{ARTICLE I- THE GLOBE PROGRAM}

The GLOBE Program is an international environmental science and education program that will bring students, teachers, and scientists together to study the global environment. GLOBE will create an international network of students in grades K-12 (or equivalent) studying environmental issues, making environmental measurements, and sharing useful environmental data with the international environmental science community. 


\section{ARTICLE II- COOPERATING AGENCIES}

Agencies responsible for cooperation and coordination under this agreement are:

On the Turkish side, the Ministry of National Education.

On the U.S. side, the U.S. National Oceanic and Atmospheric Administration, acting in conjunction with other U.S. Government agencies participating in the GLOBE Program.

\section{ARTICLE III- RESPECTIVE RESPONSIBILITIES}

A. The U.S. side will:

1. Identify U.S. schools that will participate in the GLOBE Program (details regarding GLOBE schools in Appendix A);

2. Select, in consultation with international scientists and educators, the GLOBE environmental measurements and types of measurement equipment (described in Appendix B);

3. Select Principal Investigator Teams for the GLOBE environmental measurements, and support the U.S. members of the Teams;

4. Calibrate, if necessary, measurement equipment that cannot be calibrated by GLOBE teachers and students;

5. Develop, in consultation with international scientists and educators, GLOBE educational materials;

6. Translate GLOBE instructional materials related to measurement procedures and data reporting protocols into the six United Nations languages, and provide these plus all broader GLOBE educational materials to the Turkish side for further reproduction as necessary;

7. Conduct annual regional training sessions for GLOBE Country Coordinators and GLOBE teachers who will serve as trainers for additional GLOBE teachers in Turkey, and provide a copy of GLOBE training materials to the Turkish side;

8. Design, develop, operate, and maintain GLOBE data processing capabilities and other necessary technology and equipment;

9. Provide GLOBE software, as necessary, for use on Turkish GLOBE school computers. (To the maximum extent possible, textual material appearing on computer screens will be accessible in the student's choice among the six United Nations languages.);

10. Accept environmental data reported from GLOBE schools around the world, and develop and provide resultant global environmental images (visualization products) to the Turkish side; and

11. Evaluate the overall GLOBE Program periodically, in consultation with international GLOBE Country Coordinators, and modify the overall program as appropriate.

B. The Turkish side will:

1. Select Turkish schools to participate in the GLOBE Program (details regarding GLOBE schools in Appendix A) and provide an updated list of Turkish GLOBE schools to the U.S. side at the beginning of each school year;

2. Ensure that Turkish GLOBE schools conduct the fundamental activities of GLOBE schools detailed in Appendix A (take GLOBE environmental measurements, report data, and receive and use resultant 
global environmental images, using GLOBE educational materials under the guidance of teachers trained to conduct the GLOBE Program);

3. Name a Turkish Government Point of Contact responsible for policy-level communications with the Director of the GLOBE Program;

4. Name a Country Coordinator responsible for day-to-day management, oversight, and facilitation of the GLOBE Program in Turkey;

5. Ensure that the Country Coordinator and some GLOBE teachers attend GLOBE regional training and in turn provide GLOBE training to at least one teacher in each Turkish GLOBE school;

6. Ensure that GLOBE instructional materials related to measurement procedures and data reporting protocols are utilized in Turkish GLOBE schools, and that broader GLOBE educational materials are appropriately translated, adapted, reproduced, and distributed to all Turkish GLOBE schools;

7. Ensure that Turkish GLOBE schools have the necessary measurement equipment to take GLOBE environmental measurements (described in Appendix B);

8. Ensure that teachers and students at Turkish GLOBE schools calibrate GLOBE measurement equipment according to procedures provided in GLOBE instructional materials;

9. Ensure that Turkish GLOBE schools have the necessary computer and communications systems (described in Appendix C) to report GLOBE environmental measurements and to receive and use GLOBE visualization products, or make agreed alternative arrangements for such reporting and receipt. (At a minimum, the Turkish Country Coordinator will need access to Internet so that all measurement data from Turkish GLOBE schools will be reported via Internet.); and

10. Evaluate GLOBE operations in Turkey periodically and assist the U.S. side in conducting periodic evaluation of the overall GLOBE Program.

\section{ARTICLE IV- FINANCIAL ARRANGEMENTS}

Each side will bear the costs of fulfilling its respective responsibilities under this agreement. Obligations of each side pursuant to this agreement are subject to its respective funding procedures and the availability of appropriated funds, personnel, and other resources. The conduct of activities under this agreement will be consistent with the relevant laws and regulations of the two sides.

\section{ARTICLE V- EXCHANGE OF DATA AND GOODS}

GLOBE environmental measurement data, visualization products, software, and educational materials will be available worldwide without restriction as to their use or redistribution.

\section{ARTICLE VI- RELEASE OF INFORMATION ABOUT THE GLOBE PROGRAM}

Each side may release information on the GLOBE Program as it may deem appropriate without prior consultation with the other. 


\section{ARTICLE VII- CUSTOMS AND IMMIGRATION}

Each side will, to the extent permitted by its laws and regulations, facilitate the movement of persons and goods necessary to implement this agreement into and out of its territory and accord entry to such goods into its territory free of customs duties and other similar charges.

\section{ARTICLE VIII- ENTRY INTO FORCE, AMENDMENTS, WITHDRAWAL}

This agreement will enter into force upon signature of the two sides and will remain in force for five years. It will be automatically extended for further five-year periods, unless either side decides to terminate it and so notifies the other side with three months written notice. This agreement may be terminated at any time by either side upon three months prior written notice to the other side. This agreement may be amended by written agreement of the two sides.

Done at Ankara 5th day of May, 1995, in duplicate.

For the Government of the

United States of America:

[Signature]

Marc Grossman

Ambassador of the

United States of America
For the Government of the

Republic of Turkey:

[Signature]

Nevzat Ayaz

Minister of National

Education

\section{APPENDIXA GLOBE Schools}

Each partner country will be responsible for identifying its participating schools. Schools should be selected so as to satisfy the objectives of the GLOBE Program. In particular, countries should emphasize the selection of schools that will maximize the number of students worldwide participating in the program. Also, countries should consider involving schools in locations that will yield measurement data that is important to the international environmental science community.

Students at all GLOBE schools throughout the world will conduct the following fundamental activities: they will make environmental measurements at or near their schools; report their data to a GLOBE data processing site; receive vivid graphical global environmental images (visualization products) created from their data and the data from other GLOBE schools around the world; and study the environment by relating their observations and the resulting visualization products to broader environmental topics. All of these activities will be conducted under the guidance of specially trained teachers (GLOBE-trained teachers).

GLOBE educational materials will be used in GLOBE schools under the guidance of GLOBE-trained teachers. These materials will detail procedures for taking environmental measurements and protocols for reporting data; explain the significance of the measurements; guide the use of the visualization products; and integrate the measurement aspects of the program into a broader study of the environment.

Schools throughout the United States and the rest of the world that are not GLOBE schools may become GLOBE Affiliate schools by observing the GLOBE Program in operation through the Internet. Students at these schools will benefit from the use of GLOBE visualization products and educational materials accessible on-line. All GLOBE Affiliate schools will be encouraged to become participating GLOBE schools. 


\section{APPENDIX B \\ GLOBE Environmental Measurements and Equipment}

GLOBE environmental measurements will contribute in a significant way to the scientific understanding of the dynamics of the global environment. Every GLOBE school will conduct a core set of GLOBE environmental measurements in the following critical areas: Atmosphere/Climate, Hydrology/Water Chemistry, and Biology/Geology. Where possible, a GLOBE school may coordinate its activities with those of other neighboring GLOBE schools, so that the complete set of GLOBE measurements will be available from a locality. As the GLOBE Program evolves, elective measurements not common to all GLOBE schools may be added in order to address local environmental issues.

Students at all age levels will be active participants in the GLOBE Program. The actual participation will be designed so as to be grade-appropriate for grades K-5, 6-8, and 9-12 (or equivalent). Younger students will make limited measurements which may be qualitative rather than quantitative. Older students will make additional measurements and more sophisticated measurements, as appropriate for their grade level. Measurement equipment will not need to be standardized; rather, performance specifications will be provided.

Following is an example list of core measurements and equipment. The full list will be initially determined and periodically updated as provided in Article 2.A.2, based on experience gained in implementing the GLOBE Program.

\section{MEASUREMENTS}

Atmosphere/Climate:

Air Temperature

Precipitation

Cloud Cover/Type

Hydrology/Water Chemistry:

Water $\mathrm{pH}$

Water Temperature

Soil Moisture

Biology/Geology:

Habitat Study

Tree Height

Tree Canopy

Tree Diameter

Species Identification

Phenology

\section{EQUIPMENT NEEDED}

\author{
Max/Min Thermometer \\ Calibration Thermometer \\ Instrument Shelter \\ Rain Gauge \\ Cloud Charts
}

pH Paper, Pen, or Meter

Alcohol Thermometer

Gypsum Block Sensors

Soil Moisture Meter

Compass

Meter Measuring Tape

Surveying Markers or Stakes

Clinometer

Densiometer

Diameter Tape

Dichotomous Keys

$35 \mathrm{~mm}$ Camera

\section{APPENDIX C \\ GLOBE Computer and Communications Systems}

In order to derive maximum benefit from the GLOBE Program, all schools will be encouraged to use an international information network, initially using the Internet, along with classroom computers. The World Wide Web multi-media information-access capability has been selected as the basis for IBM-compatible and Apple Macintosh computer systems to support the required GLOBE school activities of data entry, data analysis, and use of GLOBE environmental images. Following is a description of GLOBE computer and communications systems consistent with current GLOBE requirements. 
Overall attributes of the minimum GLOBE school computer configuration that can execute the necessary software are:

For IBM-compatible systems: a $386 \mathrm{SX}$ or higher level processor; at least 4 megabytes of RAM memory ( 8 megabytes preferred); a VGA-capable monitor and display driver (Super VGA preferred); a hard disk storage system with as large a capacity as possible (preferably 300 megabytes or larger); and a direct Internet connection or dial-up capability that can use SLIP or PPP protocols with a 14,400 bps modem (preferably supporting V.42bis data compression which can enable 57,600 bps operation). The Windows 3.1 or later operating system is necessary. A printer is desirable.

For Apple Macintosh systems: a $6803020 \mathrm{Mhz}$ or faster processor; at least 4 megabytes of RAM memory ( 8 megabytes preferred); a hard disk storage system with as large a capacity as possible (preferably 300 megabytes or larger); and a direct Internet connection or dial-up capability that can use SLIP or PPP protocols with a 14,400 bps modem (preferably supporting V.42bis data compression which can enable 57,600 bps operation). A printer is desirable.

Software for a higher performance GLOBE school computer system is being developed that will operate on higher performance, multi-media IBM-compatible systems and on Apple Macintosh systems. For IBM-compatible systems: a 486/66 or faster processor; 16 megabytes of RAM memory; 500 megabytes of hard disk space; a Super VGA monitor; a double-speed CD-ROM reader; a Soundblaster-compatible sound card; and an MPEG animation speed-up board will be required. For Apple Macintosh systems: a PowerPC processor; 16 megabytes of RAM memory; 500 megabytes of hard disk space; and a double-speed CD-ROM reader will be required. A communications capability the same as or better than for the minimum configurations above will also be required. A printer will be highly desirable.

It is recognized that there is a broad range of technological capabilities among potential GLOBE schools. The diversity of technology accessible by schools worldwide may require in some cases that environmental measurements be reported in hardcopy and that a variety of media be used to distribute visualization products, including photographs and broadcast television. All schools that want to participate in the program will be accommodated.

Technology associated with the GLOBE Program will continually evolve to higher levels and participants will be encouraged to upgrade over time. 
UNITED KINGDOM

ENVIRONMENTAND NATURAL RESOURCES 



\section{Memorandum of Understanding Between the National Science}

Foundation in Washington, D.C., for the United States of America and Natural Environment Research Council on the Participation of the United Kingdom in the Ocean Drilling Program as a Regular Member, Swindon, 1992

Done at Swindon 7 December 1992

Entered into force 7 December 1992, effective

1 October 1993

Primary source citation: Copy of text provided by the U.S. Department of State

MEMORANDUM OF UNDERSTANDING BETWEEN THE NATIONAL SCIENCE FOUNDATION IN WASHINGTON, D.C., FOR THE UNITED STATES OF AMERICA AND NATURAL ENVIRONMENT RESEARCH COUNCIL ON THE PARTICIPATION OF THE UNITED KINGDOM IN THE OCEAN DRILLING PROGRAM AS A REGULAR MEMBER

The Ocean Drilling Program (ODP) is a multinational program of scientific research in the oceans which uses drilling and logging to improve fundamental understanding of the geological history, structure and evolution of the oceanic lithosphere (sediments and crust). The Ocean Drilling Program is a successor to the Deep Sea Drilling Project, which began in 1968, and the International Phase of Ocean Drilling, which began in 1975. During the period October 1983-October 1984, the National Science Foundation, through its contractors, refitted the JOIDES Resolution for scientific ocean drilling and for scientific program operations. Early in U.S. Fiscal Year 1985, the initial nine-year phase of ocean drilling began. By 1991, eight international partners representing 20 nations had become regular supporting members of the ODP.

The Ocean Drilling Program is conducted by contractors, responsible to the National Science Foundation, who carry out the functions of science planning, science operations, and vessel operations. The Joint Oceanographic Institutions for Deep Earth Sampling (JOIDES) is the international body responsible for developing scientific plans and providing general scientific direction for the Ocean Drilling Program. A Science Planning Contractor organizes and provides administrative support to JOIDES. In May 1990, JOIDES published a Long Range Plan which identifies scientific priorities and calls for continued international cooperation in ocean drilling extending through the year 2002. JOIDES 
has subsequently endorsed use of the JOIDES Resolution as the primary facility for ODP coring and logging through at least 1998. Facilities, including any alternate or additional drilling platforms utilized through 1998, during subsequent years are to be determined by availability, cost, and scientific requirements identified by JOIDES planning.

Accordingly, the National Science Foundation and the Natural Environment Research Council endorse continued cooperation in ocean drilling activities during the period 1 October 1993 to 30 September 2003, in accordance with the following articles:

\section{Article 1 - MEMBERSHIP STATUS}

The Natural Environment Research Council elects to be a regular member with rights, privileges, and financial commitments as defined. All cooperative activities under this agreement, including exchange of technical information, equipment and data, shall be conducted in accordance with international law, as well as the international obligations, national laws and regulations of each party and within the limits of available funds.

\section{Article 2 - DURATION}

The Natural Environment Research Council endorses continued cooperation in ocean drilling activities, with commitment, in principle, as a regular member to support of Ocean Drilling Program coring and logging programs in the period 1 October 1993 to 30 September 1998. Subsequent support is to be determined based on available technologies, facilities and membership costs in the period 1998 to 2003.

\section{Article 3 - SCIENTIFIC PLANNING}

Scientific planning and direction of the Ocean Drilling Program shall be the responsibility of JOIDES. The Natural Environment Research Council will be a member of JOIDES with the right to be represented on each committee, panel, or working group thereof. International membership and representation in JOIDES is restricted to regular members, including consortia, but excluding the individual members of consortia. The contractors will submit, to the Executive Committee of JOIDES, the annual program plan and budgets for approval prior to their adoption by the National Science Foundation.

\section{Article 4 - OCEAN DRILLING PROGRAM COUNCIL}

The Natural Environment Research Council will be a member of the Ocean Drilling Program Council. The members of the Council will be representatives of each country contributing to the support of the Ocean Drilling Program, regardless of whether it is participating as an individual member or as a member of a consortium. Members of the Council and their alternates will be designated by the participating countries. There will be one representative of each participating country, except that additional representation from the United States may be appropriate.

The Council shall serve as a consultative body reviewing financial, managerial, and other matters involving the overall support of the Ocean Drilling Program. The Council shall provide a forum for exchange of views among the contributing countries. No formal voting procedures will be established.

The National Science Foundation representative will serve as permanent Chairman of the Council. A formal agenda will be prepared for each meeting and written records of each meeting will be kept. The National Science Foundation will provide secretarial services to the Council.

The Council will normally meet once each year. The annual meeting shall include a financial report and discussion, an audit report, a review of scientific and technical achievements for the past year, draft program plans and budgets for the coming year, and other topics of mutual interest. Normally, all regular meetings of the Council will be scheduled 
in conjunction with the JOIDES Executive Committee meeting for review and approval of the annual program plans and budgets.

Liaison representatives of prime contractors and important scientific planning entities will be available to the Council.

\section{Article 5 - INTELLECTUAL PROPERTY RIGHTS}

Protection of intellectual property rights and rights thereto shall be as set forth in Annex B.

\section{Article 6 - RIGHT TO MAKE PROPOSALS; DATA PRIVILEGES}

The Natural Environment Research Council will have the right:

a) to make proposals to JOIDES of scientific projects or technical objectives of interest to the Natural Environment Research Council.

b) to participate in the analysis, and have access to the data, of geophysical and other site surveys performed in support of the program.

c) to engineering plans, data or other information developed under contracts supported as program costs, subject to Article 1 limitations.

Site surveys may be contributed by the United Kingdom as its scientific interests and available resources allow. Site survey requirements will be identified by JOIDES.

\section{Article 7 - VISA AND CUSTOMS FACILITATION}

The National Science Foundation will facilitate through collaboration with the appropriate authorities the granting of visas and other forms of official permission for entry to and exit from the United States of personnel, equipment, and supplies when required for participation or utilization in the Ocean Drilling Program.

\section{Article 8 - PARTICIPATION ON BOARD THE ODP DRILLSHIP}

The Science Operations Contractor, with the advice of JOIDES, selects the scientific team for each cruise. It is expected that approximately half of the scientists invited to serve as co-chief scientists will be representatives of the United States. It is expected that a scientist representing the United Kingdom will be invited to serve as co-chief scientist on an equal numerical basis with all other non-U.S. partners. The United Kingdom has the right to have a scientist represented in the shipboard scientific staff on each cruise of the ODP drillship. Normally, space will be available for two scientists representing the United Kingdom on the research cruises of the ODP drillship. It is recognized that some cruises may be of special scientific interest to United Kingdom scientists and increased participation by scientists of the United Kingdom on these cruises may be appropriate. At a minimum, total participation over the term of the Ocean Drilling Program will be proportional to the United Kingdom contribution to Program costs.

\section{Article 9 - INITIAL REPORTS OF THE OCEAN DRILLING PROGRAM}

Scientists from the United Kingdom will have access, through the Natural Environment Research Council, to Ocean Drilling Program data and core samples. The Natural Environment Research Council will endeavor to ensure that the participating United Kingdom scientists and institutions shall provide the scientific data resulting from site surveys and laboratory analyses in time for preparation of the Proceedings of the Ocean Drilling Program or their 
equivalent. One hundred copies of each volume of the official scientific publications will be provided to the Natural Environment Research Council for free distribution among scientific establishments in the United Kingdom. These volumes may be published in the United Kingdom in full or in part, without payments to or additional agreements with the United States. The Natural Environment Research Council will provide the National Science Foundation with copies of all publications from the United Kingdom that are based on program material.

\section{Article 10 - FINANCLAL CONTRIBUTION}

The Natural Environment Research Council will support the Ocean Drilling Program with financial contributions payable to the National Science Foundation in U.S. dollars in amounts and periods to be specified by Annex A to this Memorandum of Understanding.

The financial contribution of all participants will be commingled to support the total program costs. "Program costs" are determined by the National Science Foundation, and are those costs incurred in support of contractors performing functions for joint planning and operations of the Ocean Drilling Program, and program direction and management costs incurred by the National Science Foundation which relate to international participation. Activities which may be carried out by the National Science Foundation's contractors in direct support of United States scientific undertakings are not program costs and will not be funded from commingled accounts.

The Natural Environment Research Council regards the National Science Foundation as being fully accountable for the proper expenditure of the commingled funds and will, through the Ocean Drilling Program Council, scrutinise the financial and audit reports, required under Article 4.

\section{Article 11 - SALARIES, TRAVEL, AND EXPENSES}

Salaries and travel expenses for participants representing the United Kingdom will be borne by the United Kingdom. Costs of accommodations for United Kingdom scientists and members of technical parties aboard the drillship are program costs and will be funded by the Ocean Drilling Program. The National Science Foundation's contractors will render United Kingdom scientists needed assistance when going from an airport to the drillship.

\section{Article 12 - CONSULTATION}

Meetings of the National Science Foundation and representatives of the United Kingdom may be held at any time upon the request of either party to discuss the terms and conditions of this Memorandum and other matters of mutual interest.

\section{Article 13 - TERMINATION NOTICE}

Obligations arising from this Memorandum of Understanding may be terminated by either party giving the other party written notice at least one year in advance. Provisions for refunds of contributions, arising out of unilateral termination, are specified in Annex A. 
Done in Swindon, England

by:

by:

[Signature]

[Signature]

John L. Knill

Robert W. Corell

Chairman

Natural Environment

Research Council

Assistant Director

National Science

Foundation

on:

on:

7 December 1992

December 7, 1992

Date

Date

\section{ANNEX A \\ to the Memorandum of Understanding Between the National Science Foundation and the Natural Environment Research Council on the Participation of the United Kingdom in the Ocean Drilling Program as a Regular Member Financial Contribution for U.S. Fiscal Year 1994}

The Natural Environment Research Council will support the Ocean Drilling Program with a total contribution of United States two million nine hundred fifty thousand dollars (U.S. $\$ 2,950,000$ ) in cash for the period October 1, 1993 to September 30,1994 , calculated at the rate of $\$ 245,833.33$ per month of drilling operations. Payment shall be made in one installment on or about March 1, 1994. Should the Ocean Drilling Program be terminated before September 30, 1994, the Natural Environment Research Council will be reimbursed on the basis of one-twelfth of its contribution for each month of curtailment.

Should the Natural Environment Research Council withdraw from the Program, under the terms of Article 13 above, no refunds of contributions will be made.

Contributions for subsequent years will be adjusted to the changes in program costs experienced in the Ocean Drilling Program, as determined by the National Science Foundation. If a change in contribution is anticipated, the National Science Foundation will provide information as to the cost basis and the indices used to estimate increases or decreases.

by:

[Signature]

John L. Knill

Chairman

Natural Environment

Research Council

on:

7 December 1992

Date by:

[Signature]

Robert W. Corell

Assistant Director

National Science Foundation

on:

December 7, 1992

Date 


\title{
ANNEX B \\ Intellectual Property Rights
}

\author{
PREAMBLe
}

\section{Pursuant to Article 5 of this Agreement;}

The Parties shall ensure adequate and effective protection of intellectual property created or furnished under this Agreement and relevant implementing arrangements. The Parties agree to notify one another in a timely fashion of inventions or copyrighted works arising under this Agreement and to seek protection for such intellectual property in a timely fashion. Rights to such intellectual property shall be allocated as provided in this Annex.

\section{SCOPE}

A. This Annex is applicable to all cooperative activities undertaken pursuant to this Agreement, except as otherwise specifically agreed by the Parties or their designees.

B. For purposes of this Agreement, intellectual property shall have the meaning found in Article 2 of the Convention Establishing the World Intellectual Property Organization, done at Stockholm, July $14,1967$.

C. This Annex addresses the allocation of rights, interests, and royalties between the parties. Each Party shall ensure that the other Party can obtain the rights to intellectual property allocated in accordance with the Annex, by obtaining those rights from its own participants through contracts or other legal means, if necessary. This Annex does not otherwise alter or prejudice the allocation between a Party and its nationals, which shall be determined by that Party's laws and practices.

D. Disputes concerning intellectual property arising under this Agreement should be resolved through discussions between the concerned participating institutions or, if necessary, the Parties or their designees. Upon mutual agreement of the Parties, a dispute shall be submitted to an arbitral tribunal for binding arbitration in accordance with the applicable rules of international law. Unless the Parties or their designees agree otherwise in writing, the arbitration rules of UNCITRAL shall govern.

E. Termination or expiration of this agreement shall not affect rights or obligations under this Annex.

\section{ALLOCATION OF RIGHTS}

A. Each Party shall be entitled to a non-exclusive, irrevocable, royalty-free license in all countries to translate, reproduce, and publicly distribute scientific and technical journal articles, reports, and books directly arising from cooperation under this Agreement. All publicly distributed copies of a copyrighted work prepared under this provision shall indicate the names of the authors of the work unless an author explicitly declines to be named.

B. Rights to all forms of intellectual property, other than those rights described in Section II (A) above, shall be allocated as follows:

1. Visiting researchers, for example, scientists visiting primarily in furtherance of their education, shall receive intellectual property rights under the policies of the host institution. In addition, each visiting researcher named as an inventor shall be entitled to share in a portion of any royalties earned by the host institution from the licensing of such intellectual property.

2.a. For intellectual property created during joint research, for example, when the parties, participating institutions, or personnel have agreed in advance on the scope of work, the Parties or their designees shall jointly develop a technology management plan. The technology management plan shall consider the relative contributions of the Parties and their participants, the benefits of exclusive licensing by territory or for fields of use, requirements imposed by the Parties' domestic laws, and other factors deemed appropriate. 
b. If the Parties or their designees cannot reach agreement on a joint technology management plan within a reasonable time not to exceed six months from the time a party becomes aware of the creation of the intellectual property in question, each Party may designate one co-exclusive licensee to have world-wide rights. Each Party shall notify the other two months prior to making a designation under this paragraph. When both Parties (or their licensees) exploit the intellectual property in a country, they shall share equally the reasonable cost of intellectual property protection in that country.

c. A specific program of research will be regarded as joint research for purposes of allocating rights to intellectual property only when it is designated as such in the relevant implementing arrangement.

d. Notwithstanding paragraph II.B.2.(a) and (b), if type of intellectual property is available under the laws of one Party but not the other Party, the Party whose laws provide for this type of protection shall be entitled to all rights and interests worldwide. Persons named as inventors of property shall nonetheless be entitled to a share of royalties earned by either institution from the licensing of the property.

\section{BUSINESS-CONFIDENTIAL INFORMATION}

In the event that information identified in a timely fashion as business-confidential is furnished or created under the Agreement, each Party and its participants shall protect such information in accordance with applicable laws, regulations, and administrative practice. Information may be identified as "business-confidential" if a person having the information may derive an economic benefit from it or may obtain a competitive advantage over those who do not have it, the information is not generally known or publicly available from other sources, and the owner has not previously made the information available without imposing in a timely manner an obligation to keep it confidential. 



\section{B I $\mathbf{L} \quad A \quad T \quad E \quad R \quad A \quad L$}

UNITED KINGDOM

F I S H E R I E $\mathbf{S}$ 



\title{
Convention Between the Government of the United States of America and the Government of the United Kingdom Concerning Sockeye Salmon Fisheries in the Fraser River System, Washington, 1930
}

\author{
Done at Washington 26 May 1930 \\ Entered into force 28 July 1937 \\ Primary source citation: United States Treaty \\ Series 918
}

The President of the United States of America and His Majesty the King of Great Britain, Ireland and the British dominions beyond the Seas, Emperor of India, in respect of the Dominion of Canada, recognizing that the protection, preservation and extension of the sockeye salmon fisheries in the Fraser River system are of common concern to the United States of America and the Dominion of Canada; that the supply of this fish in recent years has been greatly depleted and that it is of importance in the mutual interest of both countries that this source of wealth should be restored and maintained, have resolved to conclude a Convention and to that end have named as their respective plenipotentiaries:

The President of the United States of America: Mr. Henry L. Stimson, Secretary of State of the United States of America; and

His Majesty, for the Dominion of Canada: The Honorable Vincent Massey, a member of His Majesty's Privy Council for Canada and His Envoy Extraordinary and Minister Plenipotentiary for Canada at Washington;

Who, after having communicated to each other their full powers, found in good and due form, have agreed upon the following Articles:

\section{ARTiCle I}

The provisions of this Convention and the orders and regulations issued under the authority thereof shall apply, in the manner and to the extent hereinafter provided in this Convention, to the following waters:

1. The territorial waters and the high seas westward from the western coast of the United States of America and the Dominion of Canada and from a direct line drawn from Bonilla Point, Vancouver Island, to the lighthouse on Tatoosh Island, Washington - which line marks the entrance to Juan de Fuca Strait-and embraced between 48 and 49 degrees north latitude, expecting therefrom, however, all the waters of Barklay Sound, eastward of a straight line drawn from Amphitrite Point to Cape Beale and all the waters of Nitinat Lake and the entrance thereto.

2. The waters included within the following boundaries: 
Beginning at Bonilla Point, Vancouver Island, thence along the aforesaid direct line drawn from Bonilla Point to Tatoosh Lighthouse, Washington, described in paragraph numbered 1 of this Article, thence to the nearest point of Cape Flattery, thence following the southerly shore of Juan de Fuca Strait to Point Wilson, on Quimper Peninsula, thence in a straight line to Point Partridge on Whidbey Island, thence following the western shore of the said Whidbey Island, to the entrance to Deception Pass, thence across said entrance to the southern side of Reservation Bay, on Fidalgo Island, thence following the western and northern shore line of the said Fidalgo Island to Swinomish Slough, crossing the said Swinomish Slough, in line with the track of the Great Northern Railway, thence northerly following the shore line of the mainland to Atkinson Point at the northerly entrance to Burrard Inlet, British Columbia, thence in a straight line to the southern end of Bowen Island, thence westerly following the southern shore of Bowen Island to Cape Roger Curtis, thence in a straight line to Gower Point, thence westerly following the shore line to Welcome Point on Seechelt Peninsula, thence in a straight line to Point Young on Lasqueti Island, thence in a straight line to Dorcas Point on Vancouver Island, thence following the eastern and southern shores of the said Vancouver Island to the starting point at Bonilla Point, as shown on the United States Coast and Geodetic Survey Chart Number 6300, as corrected to March 14, 1930, and on the British Admiralty Chart Number 579,* copies of which are annexed to this Convention and made a part thereof.

\section{The Fraser River and the streams and lakes tributary thereto.}

The High Contracting Parties engage to have prepared as soon as practicable charts of the waters described in this Article, with the above described boundaries thereof and the international boundary indicated thereon. Such charts, when approved by the appropriate authorities of the Governments of the United States of America and the Dominion of Canada, shall be considered to have been substituted for the charts annexed to this Convention and shall be authentic for the purposes of the Convention.

The High Contracting Parties further agree to establish within the territory of the United States of America and the territory of the Dominion of Canada such buoys and marks for the purposes of this Convention as may be recommended by the Commission hereinafter authorized to be established, and to refer such recommendations as the Commission may make as relate to the establishment of buoys or marks at points on the international boundary to the International Boundary Commission, United States-Alaska and Canada, for action pursuant to the provisions of the Treaty between the United States of America and His Majesty, in respect of Canada, respecting the boundary between the United States of America and the Dominion of Canada, signed February 24, 1925.**

\section{ARTICLE II}

The High Contracting Parties agree to establish and maintain a Commission to be known as the International Pacific Salmon Fisheries Commission, hereinafter called the Commission, consisting of six members, three on the part of the United States of America and three on the part of the Dominion of Canada.

The Commissioners on the part of the United States of America shall be appointed by the President of the United States of America. The Commissioners on the part of the Dominion of Canada shall be appointed by His Majesty on the recommendation of the Governor General in Council.

The Commissioners appointed by each of the High Contracting Parties shall hold office during the pleasure of the High Contracting Party by which they were appointed.

The Commission shall continue in existence so long as this Convention shall continue in force, and each High Contracting Party shall have power to fill and shall fill from time to time vacancies which may occur in its representation on the Commission in the same manner as the original appointments are made. Each High Contracting Party shall pay the salaries and expenses of its own Commissioners, and joint expenses incurred by the Commission shall be paid by the two High Contracting Parties in equal moieties.

\section{ARTICLE III}

The Commission shall make a thorough investigation into the natural history of the Fraser River sockeye salmon, into hatchery methods, spawning ground conditions and other related matters. It shall conduct the sockeye salmon fish cultural operations in the waters described in paragraphs numbered 2 and 3 of Article I of this Convention,

\footnotetext{
"For charts, see 50 Stat. $130-61$.
}

**TS 720 , ante, p. 7 . 
and to that end it shall have power to improve spawning grounds, construct, and maintain hatcheries, rearing ponds and other such facilities as it may determine to be necessary for the propagation of sockeye salmon in any of the waters covered by this Convention, and to stock any such waters with sockeye salmon by such methods as it may determine to be most advisable. The Commission shall also have authority to recommend to the Governments of the High Contracting Parties removing or otherwise overcoming obstructions to the ascent of sockeye salmon, that may now exist or may from time to time occur, in any of the waters covered by this Convention, where investigation may show such removal of or other action to overcome obstructions to be desirable. The Commission shall make an annual report to the two Governments as to the investigations which it has made and other action which it has taken in execution of the provisions of this Article, or of other Articles of this Convention.

The cost of all work done pursuant to the provisions of this Article, or of other Articles of this Convention, including removing or otherwise overcoming obstructions that may be approved, shall be borne equally by the two Governments, and the said Governments agree to appropriate annually such money as each may deem desirable for such work in the light of the reports of the Commission.

\section{ARTICLE IV}

The Commission is hereby empowered to limit or prohibit taking sockeye salmon in respect of all or any of the waters described in Article I of this Convention, provided that when any order is adopted by the Commission limiting or prohibiting taking sockeye salmon in any of the territorial waters or on the High Seas described in paragraph numbered 1 of Article I, such order shall extend to all such territorial waters and High Seas, and, similarly, when in any of the waters of the United States of America embraced in paragraph numbered 2 of Article I, such order shall extend to all such waters of the United States of America, and when in any of the Canadian waters embraced in paragraphs numbered 2 and 3 of Article I, such order shall extend to all such Canadian waters, and provided further, that no order limiting or prohibiting taking sockeye salmon adopted by the Commission shall be construed to suspend or otherwise affect the requirements of the laws of the State of Washington or of the Dominion of Canada as to the procuring of a license to fish in the waters on their respective sides of the boundary, or in their respective territorial waters embraced in paragraph numbered 1 of Article I of this Convention, and provided further that any order adopted by the Commission limiting or prohibiting taking sockeye salmon on the High Seas embraced in paragraph numbered 1 of Article I of this Convention shall apply only to nationals and inhabitants and vessels and boats of the United States of America and the Dominion of Canada.

Any order adopted by the Commission limiting or prohibiting taking sockeye salmon in the waters covered by this Convention, or any part thereof, shall remain in full force and effect unless and until the same be modified or set aside by the Commission. Taking sockeye salmon in said waters in violation of an order of the Commission shall be prohibited.

\section{ARTICLE V}

In order to secure a proper escapement of sockeye salmon during the spring or chinook salmon fishing season, the Commission may prescribe the size of the meshes in all fishing gear and appliances that may be operated during said season in the waters of the United States of America and/or the Canadian waters described in Article I of this Convention. At all seasons of the year the Commission may prescribe the size of the meshes in all salmon fishing gear and appliances that may be operated on the High Seas embraced in paragraph numbered 1 of Article 1 of this Convention, provided, however, that in so far as concerns the High Seas, requirements prescribed by the Commission under the authority of this paragraph shall apply only to nationals and inhabitants and vessels and boats of the United States of America and the Dominion of Canada.

Whenever, at any other time than the spring or chinook salmon fishing season, the taking of sockeye salmon in waters of the United States of America or in Canadian waters is not prohibited under an order adopted by the Commission, any fishing gear or appliance authorized by the State of Washington may be used in waters of the United States of America by any person thereunto authorized by the State of Washington, and any fishing gear or appliance authorized by the laws of the Dominion of Canada may be used in Canadian waters by any person thereunto duly authorized. Whenever the taking of sockeye salmon on the High Seas embraced in paragraph numbered 1 of Article I of this Convention is not prohibited, under an order adopted by the Commission, to the nationals or inhabitants or vessels or boats of the United States of America or the Dominion of Canada, only such salmon fishing gear and 
appliances as may have been approved by the Commission may be used on such High Seas by said nationals, inhabitants, vessels or boats.

\section{ARTICLE VI}

No action taken by the Commission under the authority of this Convention shall be effective unless it is affirmatively voted for by at least two of the Commissioners of each High Contracting Party.

\section{ARTICLE VII}

Inasmuch as the purpose of this Convention is to establish for the High Contracting Parties, by their joint effort and expense, a fishery that is now largely nonexistent, it is agreed by the High Contracting Parties that they should share equally in the fishery. The Commission shall, consequently, regulate the fishery with a view to allowing, as nearly as may be practicable, an equal portion of the fish that may be caught each year to be taken by the fishermen of each High Contracting Party.

\section{ARTICLE VIII}

Each High Contracting Party shall be responsible for the enforcement of the orders and regulations adopted by the Commission under the authority of this Convention, in the portion of its waters covered by the Convention.

Except as hereinafter provided in Article IX of this Convention, each High Contracting Party shall be responsible, in respect of its own nationals and inhabitants and vessels and boats, for the enforcement of the orders and regulations adopted by the Commission, under the authority of this Convention, on the High Seas embraced in paragraph numbered 1 of Article I of the Convention.

Each High Contracting Party shall acquire and place at the disposition of the Commission any land within its territory required for the construction and maintenance of hatcheries, rearing ponds, and other such facilities as set forth in Article III.

\section{ARTICLE IX}

Every national or inhabitant, vessel or boat of the United States of America or of the Dominion of Canada, that engages in sockeye salmon fishing on the High Seas embraced in paragraph numbered 1 of Article I of this Convention, in violation of an order or regulation adopted by the Commission, under the authority of this Convention, may be seized and detained by the duly authorized officers of either High Contracting Party, and when so seized and detained shall be delivered by the said officers, as soon as practicable, to an authorized official of the country to which such person, vessel or boat belongs, at the nearest point to the place of seizure, or elsewhere, as may be agreed upon with the competent authorities. The authorities of the country to which a person, vessel or boat belongs alone shall have jurisdiction to conduct prosecutions for the violation of any order or regulation, adopted by the Commission in respect of fishing for sockeye salmon on the High Seas embraced in paragraph numbered 1 of Article I of this Convention, or of any law or regulation which either High Contracting Party may have made to carry such order or regulation of the Commission into effect, and to impose penalties for such violations; and the witnesses and proofs necessary for such prosecutions, so far as such witnesses or proofs are under the control of the other High Contracting Party, shall be furnished with all reasonable promptitude to the authorities having jurisdiction to conduct the prosecutions.

\section{ARTiCle X}

The High Contracting Parties agree to enact and enforce such legislation as may be necessary to make effective the provisions of this Convention and the orders and regulations adopted by the Commission under the authority thereof, with appropriate penalties for violations.

\section{ARTICLE XI}

The present Convention shall be ratified by the President of the United States of America, by and with the advice and consent of the Senate thereof, and by His Majesty in accordance with constitutional practice, and it shall become effective upon the date of the exchange of ratifications which shall take place at Washington as soon as possible and shall continue in force for a period of sixteen years, and thereafter until one year from the day on which either of the High Contracting Parties shall give notice to the other of its desire to terminate it. 
In witness whereof, the respective plenipotentiaries have signed the present Convention, and have affixed their seals thereto.

Done in duplicate at Washington on the twenty-sixth day of May, one thousand nine hundred and thirty.

HENRY L. STIMSON [SEAL]

VINCENT MASSEY [SEAL]





\section{B I $L A$ A $\quad$ E $R$ A $L$}

\section{UNITED KINGDOM}

(0) T H E R 



\section{Treaty Between the Government of the}

United States of America and the Government of the United Kingdom of Great Britain and Northern Ireland on the Delimitation in the Caribbean of a Maritime Boundary Relating to Puerto Rico/U.S. Virgin Islands and the British Virgin Islands, London, 1993

Done at London 5 November 1993

Entered into force 1 June 1995

Primary source citation: United States Treaty

Document 103-23

\section{TREATY BETWEEN THE GOVERNMENT OF THE UNITED STATES OF AMERICA AND THE GOVERNMENT OF THE UNITED KINGDOM OF GREAT BRITAIN AND NORTHERN IRELAND ON THE DELIMITATION IN THE CARIBBEAN OF A MARITIME BOUNDARY RELATING TO PUERTO RICO/U.S. VIRGIN ISLANDS AND THE BRITISH VIRGIN ISLANDS}

The Government of the United States of America and the Government of the United Kingdom of Great Britain and Northern Ireland (hereinafter the "Parties");

Recalling the tradition of co-operative relations and close ties between the people of the United States of America and the people of the United Kingdom of Great Britain and Northern Ireland;

Desiring to establish a maritime boundary between the United States of America (Puerto Rico and the U.S. Virgin Islands) and the United Kingdom of Great Britain and Northern Ireland (British Virgin Islands) in the Caribbean on the basis of equidistance;

Taking note of the Reciprocal Fisheries Agreement between the Government of the United States of America and the Government of the United Kingdom of Great Britain and Northern Ireland, signed on 27 March, 1979;

Have agreed as follows: 


\section{Article I}

The purpose of this Treaty is to establish, in accordance with international law, the maritime boundary between the United States of America (Puerto Rico and the U.S. Virgin Islands) and the United Kingdom of Great Britain and Northern Ireland (British Virgin Islands).

\section{Article II}

(1) The maritime boundary between the United States of America (Puerto Rico and the U.S. Virgin Islands) and the United Kingdom of Great Britain and Northern Ireland (British Virgin Islands) in the Caribbean is determined by geodetic lines connecting points 1 - 50, as specified in the Annex to this Treaty.

(2) The geodetic and computational bases used are the North American Datum 1983 ("NAD 83"). For the purpose of illustration only, the boundary line has been drawn on the map annexed to this Treaty.

\section{Article III}

On the side of the maritime boundary adjacent to the United Kingdom of Great Britain and Northern Ireland (British Virgin Islands), the United States shall not, and on the side of the maritime boundary adjacent to the United States of America (Puerto Rico and the U.S. Virgin Islands), the United Kingdom shall not, claim or exercise for any purpose sovereignty, sovereign rights, or jurisdiction with respect to the waters or seabed or subsoil.

\section{Article IV}

The maritime boundary established by this Treaty shall not affect or prejudice in any manner either Party's position with respect to the rules of international law relating to the law of the sea, including those concerned with the exercise of sovereignty, sovereign rights, or jurisdiction with respect to the waters or seabed and subsoil.

\section{Article V}

This Treaty shall be subject to ratification and shall enter into force on the date of the exchange of instruments of ratification. Treaty.

In witness whereof, the undersigned, being duly authorised by their respective Governments, have signed this

Done in duplicate at London this 5th day of November 1993.

FOR THE GOVERNMENT OF THE

UNITED STATES OF AMERICA:

[Signature]
FOR THE GOVERNMENT OF THE

UNITED KINGDOM

OF GREAT BRITAIN AND

NORTHERN IRELAND:

[Signature] 


\section{ANNEX}

The maritime boundary positions set forth in this Annex are on the North American Datum 1983 ("NAD 83"), The maritime boundary between the United States of America (Puerto Rico and the U.S. Virgin Islands) and the United Kingdom of Great Britain and Northern Ireland (British Virgin Islands) is defined by connecting the following geographic coordinates by geodetic lines:

\begin{tabular}{|c|c|c|}
\hline No. & North Latitude & West Longi \\
\hline 1. & $21^{\circ} 48^{\prime} 33^{\prime \prime}$ & $65^{\circ} 50^{\prime} 31^{\prime \prime}$ \\
\hline 2. & $21^{\circ} 41^{\prime} 20^{\prime \prime}$ & $65^{\circ} 49^{\prime} 13^{\prime \prime}$ \\
\hline 3. & $20^{\circ} 58^{\prime} 05^{\prime \prime}$ & $65^{\circ} 40^{\prime} 30^{\prime \prime}$ \\
\hline . & $20^{\circ} 46^{\prime} 56^{\prime \prime}$ & $65^{\circ} 38^{\prime} 14^{\prime \prime}$ \\
\hline 5. & $19^{\circ} 57^{\prime} 29^{\prime \prime}$ & $65^{\circ} 27^{\prime} 21^{\prime \prime}$ \\
\hline 6. & $19^{\circ} 37^{\prime} 29^{\prime \prime}$ & $65^{\circ} 20^{\prime} 57^{\prime \prime}$ \\
\hline 7. & $19^{\circ} 12^{\prime} 25^{\prime \prime}$ & $65^{\circ} 06^{\prime} 08^{\prime \prime}$ \\
\hline 3. & $18^{\circ} 45^{\prime} 14^{\prime \prime}$ & $65^{\circ} 00^{\prime} 22^{\prime \prime}$ \\
\hline 9. & $18^{\circ} 41^{\prime} 14^{\prime \prime}$ & $64^{\circ} 59^{\prime} 33^{\prime \prime}$ \\
\hline 10. & $18^{\circ} 29^{\prime} 22^{\prime \prime}$ & $64^{\circ} 53^{\prime} 50^{\prime \prime}$ \\
\hline 11. & $18^{\circ} 27^{\prime} 36^{\prime \prime}$ & $64^{\circ} 53^{\prime} 22^{\prime \prime}$ \\
\hline 12. & $18^{\circ} 25^{\prime} 22^{\prime \prime}$ & $64^{\circ} 52^{\prime} 39^{\prime \prime}$ \\
\hline 13. & $18^{\circ} 24^{\prime} 31^{\prime \prime}$ & $64^{\circ} 52^{\prime} 19^{\prime \prime}$ \\
\hline 14. & $18^{\circ} 23^{\prime} 51^{\prime \prime}$ & $64^{\circ} 51^{\prime} 50^{\prime \prime}$ \\
\hline 15. & $18^{\circ} 23^{\prime} 43^{\prime \prime}$ & $64^{\circ} 51^{\prime} 23^{\prime \prime}$ \\
\hline 16. & $18^{\circ} 23^{\prime} 37^{\prime \prime}$ & $64^{\circ} 50^{\prime} 18^{\prime \prime}$ \\
\hline 17. & $18^{\circ} 23^{\prime} 48^{\prime \prime}$ & $64^{\circ} 49^{\prime} 42^{\prime \prime}$ \\
\hline 18. & $18^{\circ} 24^{\prime} 11^{\prime \prime}$ & $64^{\circ} 49^{\prime} 01^{\prime \prime}$ \\
\hline 19. & $18^{\circ} 24^{\prime} 29^{\prime \prime}$ & $64^{\circ} 47^{\prime} 57^{\prime \prime}$ \\
\hline 20. & $18^{\circ} 24^{\prime} 18^{\prime \prime}$ & $64^{\circ} 47^{\prime} 00^{\prime \prime}$ \\
\hline 21. & $18^{\circ} 23^{\prime} 14^{\prime \prime}$ & $64^{\circ} 46^{\prime} 37^{\prime \prime}$ \\
\hline 22. & $18^{\circ} 22^{\prime} 38^{\prime \prime}$ & $64^{\circ} 45^{\prime} 21^{\prime \prime}$ \\
\hline 23 & $18^{\circ} 22^{\prime} 40^{\prime \prime}$ & $64^{\circ} 44^{\prime} 42^{\prime \prime}$ \\
\hline 24 & $18^{\circ} 22^{\prime} 42^{\prime \prime}$ & $64^{\circ} 44^{\prime} 36^{\prime \prime}$ \\
\hline 25 & $18^{\circ} 22^{\prime} 37^{\prime \prime}$ & $64^{\circ} 44^{\prime} 24^{\prime \prime}$ \\
\hline
\end{tabular}

No. North Latitude West Longitude

26. $18^{\circ} 22^{\prime} 40^{\prime \prime}$

$64^{\circ} 43^{\prime} 42^{\prime \prime}$

27. $18^{\circ} 22^{\prime} 30^{\prime \prime}$

$64^{\circ} 43^{\prime} 36^{\prime \prime}$

28. $18^{\circ} 22^{\prime} 25^{\prime \prime}$

$64^{\circ} 42^{\prime} 58^{\prime \prime}$

29. $18^{\circ} 22^{\prime} 27^{\prime \prime}$

$64^{\circ} 42^{\prime} 28^{\prime \prime}$

30. $18^{\circ} 22^{\prime} 16^{\prime \prime}$

$64^{\circ} 42^{\prime} 03^{\prime \prime}$

31. $18^{\circ} 22^{\prime} 23^{\prime \prime}$

$64^{\circ} 40^{\prime} 59^{\prime \prime}$

32. $18^{\circ} 21^{\prime} 58^{\prime \prime}$

$64^{\circ} 40^{\prime} 15^{\prime \prime}$

33. $18^{\circ} 21^{\prime} 51^{\prime \prime}$

$64^{\circ} 38^{\prime} 22^{\prime \prime}$

34. $18^{\circ} 21^{\prime} 22^{\prime \prime}$

$64^{\circ} 38^{\prime} 16^{\prime \prime}$

35. $18^{\circ} 20^{\prime} 39^{\prime \prime}$

$64^{\circ} 38^{\prime} 32^{\prime \prime}$

36. $18^{\circ} 19^{\prime} 16^{\prime \prime}$

$64^{\circ} 38^{\prime} 13^{\prime \prime}$

37. $18^{\circ} 19^{\prime} 07^{\prime \prime}$

$64^{\circ} 38^{\prime} 16^{\prime \prime}$

38. $18^{\circ} 17^{\prime} 24^{\prime \prime}$

$64^{\circ} 39^{\prime} 37^{\prime \prime}$

39. $18^{\circ} 16^{\prime} 43^{\prime \prime}$

$64^{\circ} 39^{\prime} 41^{\prime \prime}$

40. $18^{\circ} 11^{\prime} 34^{\prime \prime}$

$64^{\circ} 38^{\prime} 58^{\prime \prime}$

41. $18^{\circ} 03^{\prime} 03^{\prime \prime}$

$64^{\circ} 38^{\prime} 03^{\prime \prime}$

42. $18^{\circ} 02^{\prime} 57^{\prime \prime}$

$64^{\circ} 29^{\prime} 35^{\prime \prime}$

43. $18^{\circ} 02^{\prime} 52^{\prime \prime}$

$64^{\circ} 27^{\prime} 03^{\prime \prime}$

44. $18^{\circ} 02^{\prime} 30^{\prime \prime}$

$64^{\circ} 21^{\prime} 08^{\prime \prime}$

45. $18^{\circ} 02^{\prime} 31^{\prime \prime}$

$64^{\circ} 20^{\prime} 08^{\prime \prime}$

46. $18^{\circ} 02^{\prime} 01^{\prime \prime}$

$64^{\circ} 15^{\prime} 39^{\prime \prime}$

47. $18^{\circ} 00^{\prime} 12^{\prime \prime}$

$64^{\circ} 02^{\prime} 29^{\prime \prime}$

48. $17^{\circ} 59^{\prime} 58^{\prime \prime}$

$64^{\circ} 01^{\prime} 02^{\prime \prime}$

49. $17^{\circ} 58^{\prime} 47^{\prime \prime}$

$63^{\circ} 57^{\prime} 00^{\prime \prime}$

50. 17'57'51"

$63^{\circ} 53^{\prime} 53^{\prime \prime}$ 


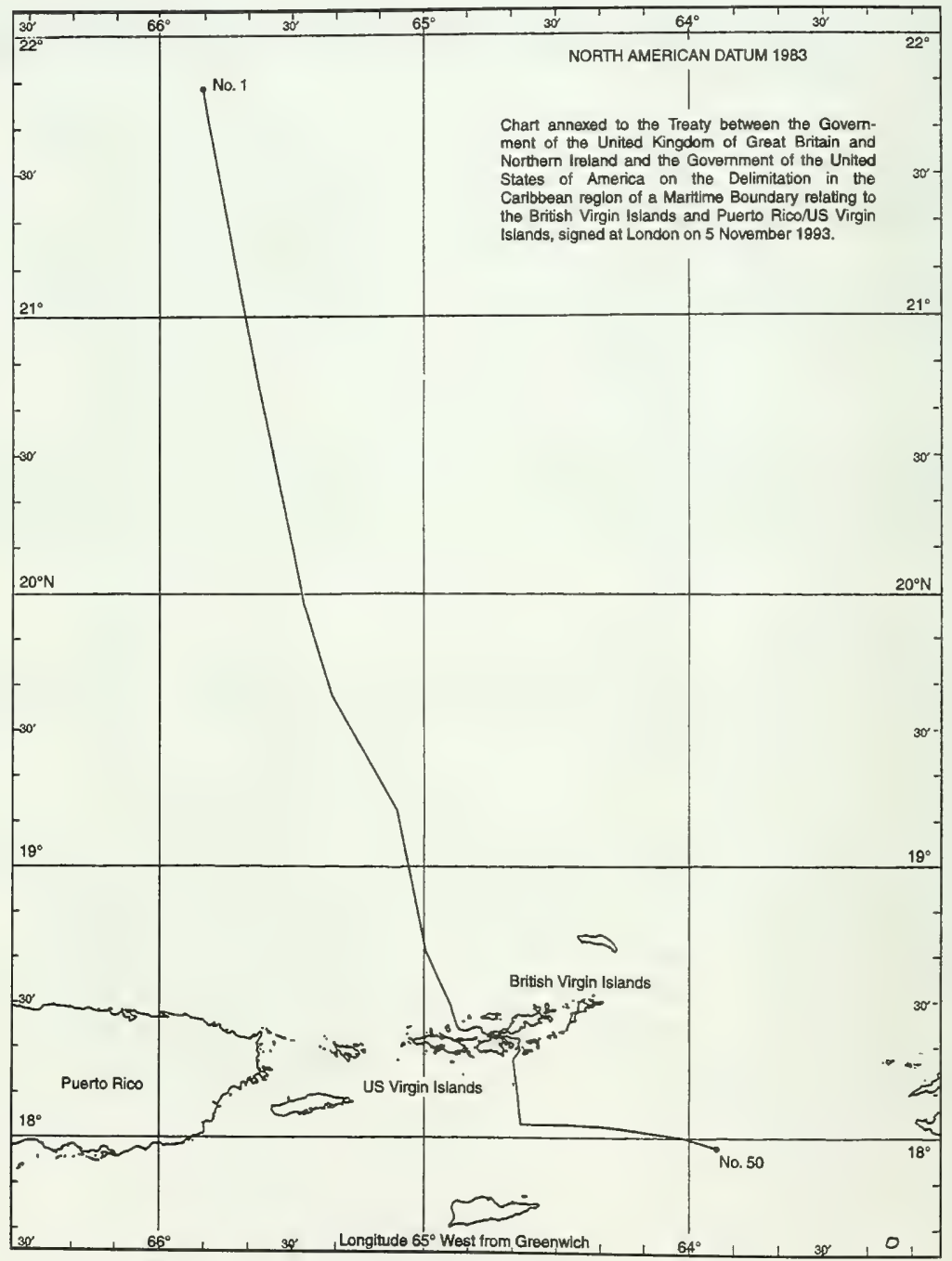




\title{
Treaty Between the Government of the United States of America and the Government of the United Kingdom of Great Britain and Northern Ireland on the Delimitation in the Caribbean of a Maritime Boundary Relating to the U.S. Virgin Islands and Anguilla, London, 1993
}

\author{
Done at London 5 November 1993 \\ Entered into force 1 June 1995 \\ Primary source citation: United States Treaty \\ Document 103-23
}

\section{TREATY BETWEEN THE GOVERNMENT OF THE UNITED STATES OF AMERICA AND THE GOVERNMENT OF THE UNITED KINGDOM OF GREAT BRITAIN AND NORTHERN IRELAND ON THE DELIMITATION IN THE CARIBBEAN OF A MARITIME BOUNDARY RELATING TO THE U.S. VIRGIN ISLANDS AND ANGUILLA}

The Government of the United States of America and the Government of the United Kingdom of Great Britain and Northern Ireland (hereinafter the "Parties");

Recalling the tradition of co-operative relations and close ties between the people of the United States of America and the people of the United Kingdom of Great Britain and Northern Ireland;

Desiring to establish a maritime boundary between the United States of America (U.S. Virgin Islands) and the United Kingdom of Great Britain and Northern Ireland (Anguilla) in the Caribbean on the basis of equidistance;

Have agreed as follows: 


\section{Article I}

The purpose of this Treaty is to establish, in accordance with international law, the maritime boundary between the United States of America (U.S. Virgin Islands) and the United Kingdom of Great Britain and Northern Ireland (Anguilla).

\section{Article II}

(1) The maritime boundary between the United States of America (U.S. Virgin Islands) and the United Kingdom of Great Britain and Northern Ireland (Anguilla) in the Caribbean is determined by a geodetic line connecting the following points:

1. $17^{\circ} 57^{\prime} 51^{\prime \prime} \mathrm{N} ., 63^{\circ} 53^{\prime} 53^{\prime \prime} \mathrm{W}$.

2. $17^{\circ} 56^{\prime} 37^{\prime \prime} \mathrm{N}_{\text {., }} 63^{\circ} 53^{\prime} 20^{\prime \prime} \mathrm{W}$.

(2) The geodetic and computational bases used are the North American Datum 1983 ("NAD 83"). For the purpose of illustration only, the boundary line has been drawn on the map annexed to this Treaty.

\section{Article III}

On the side of the maritime boundary adjacent to the United Kingdom of Great Britain and Northern Ireland (Anguilla), the United States shall not, and on the side of the maritime boundary adjacent to the United States of America (U.S. Virgin Islands), the United Kingdom shall not, claim or exercise for any purpose sovereignty, sovereign rights, or jurisdiction with respect to the waters or seabed or subsoil.

\section{Article IV}

The maritime boundary established by this Treaty shall not affect or prejudice in any manner either Party's position with respect to the rules of international law relating to the law of the sea, including those concerned with the exercise of sovereignty, sovereign rights, or jurisdiction with respect to the waters or seabed and subsoil.

\section{Article V}

This Treaty shall be subject to ratification and shall enter into force on the date of the exchange of instruments of ratification.

In witness whereof, the undersigned, being duly authorised by their respective Governments, have signed this Treaty.

Done in duplicate at London this 5 th day of November 1993.

FOR THE GOVERNMENT OF

THE UNITED STATES OF AMERICA:

[Signature]
FOR THE GOVERNMENT OF THE UNITED KINGDOM OF GREAT BRITAIN AND NORTHERN IRELAND:

[Signature] 


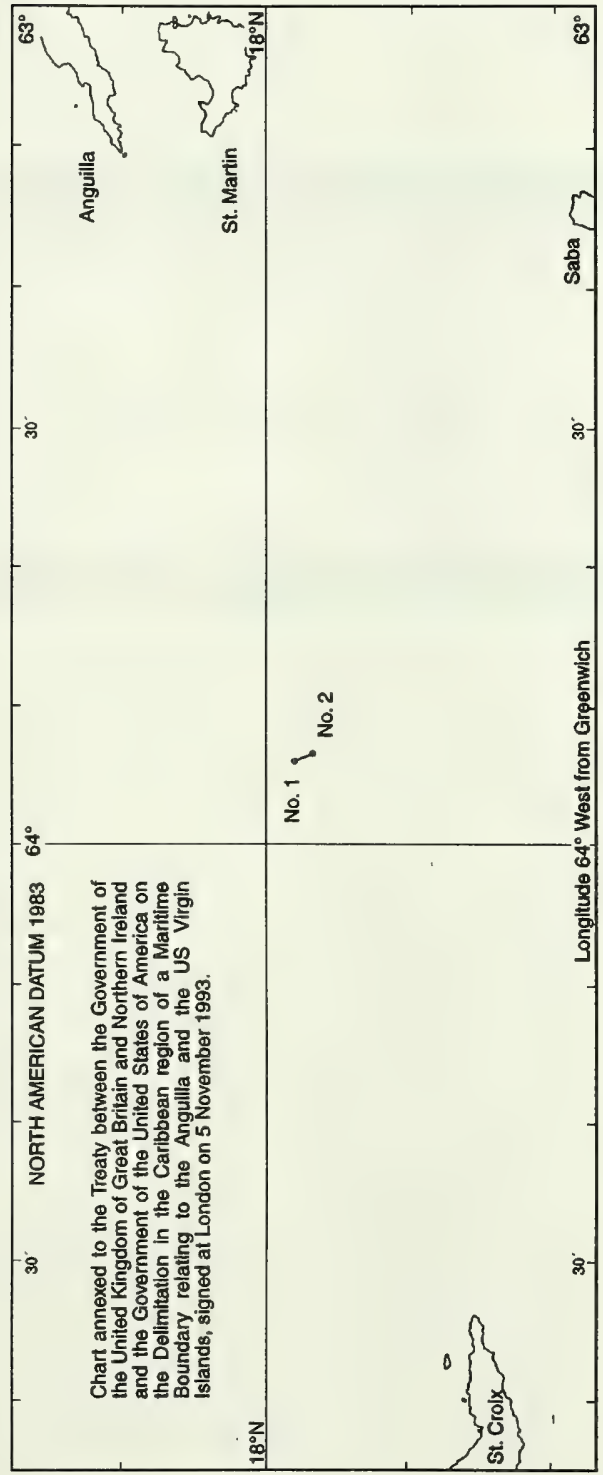



URUGUAY

ENVIRONMENT AND NATURAL RESOURCES 



\section{Agreement Between the National Oceanic and Atmospheric}

Administration of the United States of America and the Ministry of Housing, Land Use Planning, and the Environment of the Oriental Republic of Uruguay for Cooperation in the GLOBE Program, Montevideo, 1995

Done at Montevideo 21 April 1995

Entered into force 21 April 1995

Primary source citation: Copy of text provided by the U.S. Department of State

\section{AGREEMENT BETWEEN THE NATIONAL OCEANIC AND ATMOSPHERIC ADMINISTRATION OF THE UNITED STATES OF AMERICA AND THE MINISTRY OF HOUSING, LAND USE PLANNING, AND THE ENVIRONMENT OF THE ORIENTAL REPUBLIC OF URUGUAY FOR COOPERATION IN THE GLOBE PROGRAM}

\section{PREAMBLE}

The U.S. National Oceanic and Atmospheric Administration, acting on behalf of itself and other U.S. Government agencies participating in the GLOBE Program (hereinafter, the U.S. side), and the Ministry of Housing, Land Use Planning, and the Environment of the Oriental Republic of Uruguay (hereinafter, the Uruguayan side),

Intending to increase the awareness of students throughout the world about the global environment,

Seeking to contribute to increased scientific understanding of the Earth, and

Desiring to support improved student achievement in science and mathematics,

Have agreed to cooperate in the Global Learning and Observations to Benefit the Environment (GLOBE) Program as follows: 


\section{ARTICLE 1 - THE GLOBE PROGRAM}

The GLOBE Program is an international environmental science and education program that will bring students, teachers, and scientists together to study the global environment. GLOBE will create an international network of students in grades K-12 (or equivalent) studying environmental issues, making environmental measurements, and sharing useful environmental data with the international environmental science community.

\section{ARTICLE 2 - RESPECTIVE RESPONSIBILITIES}

A. The U.S. side will:

1. Identify U.S. schools that will participate in the GLOBE Program (details regarding GLOBE schools in Appendix A);

2. Select, in consultation with international scientists and educators, the GLOBE environmental measurements and types of measurement equipment (described in Appendix B);

3. Select Principal Investigator Teams for the GLOBE environmental measurements, and support the U.S. members of the Teams;

4. Calibrate, if necessary, measurement equipment that cannot be calibrated by GLOBE teachers and students;

5. Develop, in consultation with international scientists and educators, GLOBE educational materials;

6. Translate GLOBE instructional materials related to measurement procedures and data reporting protocols into the six United Nations languages, and provide these plus all broader GLOBE educational materials to the Uruguayan side for further reproduction as necessary;

7. Conduct annual regional training sessions for GLOBE Country Coordinators and GLOBE teachers vho will serve as trainers for additional GLOBE teachers in the Oriental Republic of Uruguay, and provide a copy of GLOBE training materials to the Uruguayan side;

8. Design, develop, operate, and maintain GLOBE data processing capabilities and other necessary technology and equipment;

9. Provide GLOBE software, as necessary, for use on Uruguayan GLOBE school computers. (To the maximum extent possible, textual material appearing on computer screens will be accessible in the student's choice among the six United Nations languages.);

10. Accept environmental data reported from GLOBE schools around the world, and develop and provide resultant global environmental images (visualization products) to the Uruguayan side; and

11. Evaluate the overall GLOBE Program periodically, in consultation with international GLOBE Country Coordinators, and modify the overall program as appropriate.

B. The Uruguayan side will:

1. Select Uruguayan schools to participate in the GLOBE Program (details regarding GLOBE schools in Appendix A) and provide an updated list of Uruguayan GLOBE schools to the U.S. side at the beginning of each school year;

2. Ensure that Uruguayan GLOBE schools conduct the fundamental activities of GLOBE schools detailed in Appendix A (take GLOBE environmental measurements, report data, and receive and use resultant global environmental images, using GLOBE educational materials under the guidance of teachers trained to conduct the GLOBE Program); 
3. Name a Uruguayan Government Point of Contact responsible for policy-level communications with the Director of the GLOBE Program;

4. Name a Country Coordinator responsible for day-to-day management, oversight, and facilitation of the GLOBE Program in the Oriental Republic of Uruguay;

5. Ensure that the Country Coordinator and some GLOBE teachers attend GLOBE regional training and in turn provide GLOBE training to at least one teacher in each Uruguayan GLOBE school;

6. Ensure that GLOBE instructional materials related to measurement procedures and data reporting protocols are utilized in Uruguayan GLOBE schools, and that broader GLOBE educational materials are appropriately translated, adapted, reproduced, and distributed to all Uruguayan GLOBE schools;

7. Ensure that Uruguayan GLOBE schools have the necessary measurement equipment to take GLOBE environmental measurements (described in Appendix B);

8. Ensure that teachers and students at Uruguayan GLOBE schools calibrate GLOBE measurement equipment according to procedures provided in GLOBE instructional materials;

9. Ensure that Uruguayan GLOBE schools have the necessary computer and communications systems (described in Appendix C) to report GLOBE environmental measurements and to receive and use GLOBE visualization products, or make agreed alternative arrangements for such reporting and receipt. (At a minimum, the Uruguayan Country Coordinator will need access to Internet so that all measurement data from Uruguayan GLOBE schools will be reported via Internet.); and

10. Evaluate GLOBE operations in the Oriental Republic of Uruguay periodically and assist the U.S. side in conducting periodic evaluation of the overall GLOBE Program.

\section{ARTICLE 3 - FINANCIAL ARRANGEMENTS}

Each side will bear the costs of fulfilling its respective responsibilities under this agreement. Obligations of each side pursuant to this agreement are subject to its respective funding procedures and the availability of appropriated funds, personnel, and other resources. The conduct of activities under this agreement will be consistent with the relevant laws and regulations of the two sides.

\section{ARTICLE 4 - EXCHANGE OF DATA AND GOODS}

GLOBE environmental measurement data, visualization products, software, and educational materials will be available worldwide without restriction as to their use or redistribution.

\section{ARTICLE 5 - RELEASE OF INFORMATION ABOUT THE GLOBE PROGRAM}

Each side may release information on the GLOBE Program as it may deem appropriate without prior consultation with the other.

\section{ARTICLE 6 - CUSTOMS AND IMMIGRATION}

Each side will, to the extent permitted by its laws and regulations, facilitate the movement of persons and goods necessary to implement this agreement into and out of its territory and accord entry to such goods into its territory free of customs duties and other similar charges. 


\section{ARTICLE 7 - ENTRY INTO FORCE, AMENDMENTS, WITHDRAWAL}

This agreement will enter into force upon an exchange of diplomatic notes confirming that the domestic requirements on each side have been met and will remain in force for five years. In the interim, the parties intend to apply this agreement provisionally. It will be automatically extended for further five-year periods, unless either side decides to terminate it and so notifies the other side with three months written notice. This agreement may be terminated at any time by either side upon three months prior written notice to the other side. This agreement may be amended by written agreement of the two sides.

Done at Montevideo on April 21, 1995, in duplicate, in the English and Spanish languages, both texts being equally authentic.

For the National Oceanic and

Atmospheric Administration:

[Signature]
For the Ministry of Housing,

Land Use Planning, and the Environment:

[Signature]

\section{APPENDIX A}

\section{GLOBE Schools}

Each partner country will be responsible for identifying its participating schools. Schools should be selected so as to satisfy the objectives of the GLOBE Program. In particular, countries should emphasize the selection of schools that will maximize the number of students worldwide participating in the program. Also, countries should consider involving schools in locations that will yield measurement data that is important to the international environmental science community.

Students at all GLOBE schools throughout the world will conduct the following fundamental activities: they will make environmental measurements at or near their schools; report their data to a GLOBE data processing site; receive vivid graphical global environmental images (visualization products) created from their data and the data from other GLOBE schools around the world; and study the environment by relating their observations and the resulting visualization products to broader environmental topics. All of these activities will be conducted under the guidance of specially trained teachers (GLOBE-trained teachers).

GLOBE educational materials will be used in GLOBE schools under the guidance of GLOBE-trained teachers. These materials will detail procedures for taking environmental measurements and protocols for reporting data; explain the significance of the measurements; guide the use of the visualization products; and integrate the measurement aspects of the program into a broader study of the environment.

Schools throughout the United States and the rest of the world that are not GLOBE schools may become GLOBE Affiliate schools by observing the GLOBE Program in operation through the Internet. Students at these schools will benefit from the use of GLOBE visualization products and educational materials accessible on-line. All GLOBE Affiliate schools will be encouraged to become participating GLOBE schools.

\section{APPENDIX B}

\section{GLOBE Environmental Measurements and Equipment}

GLOBE environmental measurements will contribute in a significant way to the scientific understanding of the dynamics of the global environment. Every GLOBE school will conduct a core set of GLOBE environmental measurements in the following critical areas: Atmosphere/Climate, Hydrology/Water Chemistry, and Biology/Geology. Where possible, a GLOBE school may coordinate its activities with those of other neighboring GLOBE schools, so that the complete set of GLOBE measurements will be available from a locality. As the GLOBE Program evolves, 
elective measurements not common to all GLOBE schools may be added in order to address local environmental issues.

Students at all age levels will be active participants in the GLOBE Program. The actual participation will be designed so as to be grade-appropriate for grades K-5, 6-8, and 9-12 (or equivalent). Younger students will make limited measurements which may be qualitative rather than quantitative. Older students will make additional measurements and more sophisticated measurements, as appropriate for their grade level. Measurement equipment will not need to be standardized; rather, performance specifications will be provided.

Following is an example list of core measurements and equipment. The full list will be initially determined and periodically updated as provided in Article 2.A.2, based on experience gained in implementing the GLOBE Program.

\section{MEASUREMENTS}

\section{Atmosphere/Climate:}

Air Temperature

Precipitation

Cloud Cover/Type

Hydrology/Water Chemistry:

Water pH

Water Temperature

Soil Moisture

\section{Biology/Geology: \\ Habitat Study}

Tree Height

Tree Canopy

Tree Diameter

Species Identification

Phenology

\section{EQUIPMENT NEEDED}

\author{
Max/Min Thermometer \\ Calibration Thermometer \\ Instrument Shelter \\ Rain Gauge \\ Cloud Charts
}

\author{
pH Paper, Pen, or Meter \\ Alcohol Thermometer \\ Gypsum Block Sensors \\ Soil Moisture Meter
}

\author{
Compass \\ Meter Measuring Tape \\ Surveying Markers or Stakes \\ Clinometer \\ Densiometer \\ Diameter Tape \\ Dichotomous Keys \\ $35 \mathrm{~mm}$ Camera
}

\section{APPENDIX C}

\section{GLOBE Computer and Communications Systems}

In order to derive maximum benefit from the GLOBE Program, all schools will be encouraged to use an international information network, initially using the Internet, along with classroom computers. The World Wide Web multi-media information-access capability has been selected as the basis for IBM-compatible and Apple Macintosh computer systems to support the required GLOBE school activities of data entry, data analysis, and use of GLOBE environmental images. Following is a description of GLOBE computer and communications systems consistent with current GLOBE requirements.

Overall attributes of the minimum GLOBE school computer configuration that can execute the necessary software are:

For IBM-compatible systems: a 386 SX or higher level processor; at least 4 megabytes of RAM memory ( 8 megabytes preferred); a VGA-capable monitor and display driver (Super VGA preferred); a hard disk storage system with as large a capacity as possible (preferably 300 megabytes or larger); and a direct Internet connection or dial-up capability that can use SLIP or PPP protocols with a 14,400 bps modem (preferably supporting V.42bis data compression which can enable 57,600 bps operation). The Windows 3.1 or later operating system is necessary. A printer is desirable. 
For Apple Macintosh systems: a $6803020 \mathrm{Mhz}$ or faster processor; at least 4 megabytes of RAM memory ( 8 megabytes preferred); a hard disk storage system with as large a capacity as possible (preferably 300 megabytes or larger); and a direct Internet connection or dial-up capability that can use SLIP or PPP protocols with a 14,400 bps modem (preferably supporting V.42bis data compression which can enable 57,600 bps operation). A printer is desirable.

Software for a higher performance GLOBE school computer system is being developed that will operate on higher performance, multi-media IBM-compatible systems and on Apple Macintosh systems. For IBM-compatible systems: a 486/66 or faster processor; 16 megabytes of RAM memory; 500 megabytes of hard disk space; a Super VGA monitor; a double-speed CD-ROM reader; a Soundblaster-compatible sound card; and an MPEG animation speed-up board will be required. For Apple Macintosh systems: a PowerPC processor; 16 megabytes of RAM memory; 500 megabytes of hard disk space; and a double-speed CD-ROM reader will be required. A communications capability the same as or better than for the minimum configurations above will also be required. A printer will be highly desirable.

It is recognized that there is a broad range of technological capabilities among potential GLOBE schools. The diversity of technology accessible by schools worldwide may require in some cases that environmental measurements be reported in hardcopy and that a variety of media be used to distribute visualization products, including photographs and broadcast television. All schools that want to participate in the program will be accommodated.

Technology associated with the GLOBE Program will continually evolve to higher levels and participants will be encouraged to upgrade over time. 


\section{AGREEMENTS INVOLVING NATIVE ALASKAN GROUPS}

\section{Marine Mammals}





\title{
Cooperative Agreement Between the National Oceanic and Atmospheric Administration and the Alaska Eskimo Whaling Commission, Washington, D.C., 1984
}

\author{
Done at Washington, D.C., 5 May 1984 \\ Primary source citation: Copy of text provided by the \\ National Oceanic and Atmospheric Administration of \\ the U.S. Department of Commerce
}

\section{COOPERATIVE AGREEMENT BETWEEN THE NATIONAL OCEANIC AND ATMOSPHERIC ADMINISTRATION AND THE ALASKA ESKIMO WHALING COMMISSION, AS AMENDED}

\section{PURPOSES}

The purposes of this agreement are to protect the bowhead whale and the Eskimo culture, to promote scientific investigation of the bowhead whale, and to effectuate the other purposes of the Marine Mammal Protection Act, the Whaling Convention Act and the Endangered Species Act as these acts may relate to aboriginal subsistence whaling.

In order to achieve these purposes, this agreement provides for:

(a) cooperation between members of the Alaska Eskimo Whaling Commission (AEWC) and the National Oceanic and Atmospheric Administration (NOAA) in management of the bowhead whale hunt for 1981 through 1987; and

(b) an exclusive enforcement mechanism that shall apply during the term of this agreement to any violation by whaling captains (or their crews) who are registered members of the AEWC of any provisions of the Marine Mammal Protection Act, the Endangered Species Act, or the Whaling Convention Act, as these acts may relate to aboriginal subsistence whaling, of the International Convention for the Regulation of Whaling, 1946, of regulations of the International Whaling Commission, or of any provisions of this agreement.

\section{RESPONSIBILITIES}

NOAA has primary responsibility within the United States Government for management and enforcement of programs concerning the bowhead whale. The AEWC is an association governing Alaskan Eskimo whalers who hunt for bowhead whales. The AEWC adopted a Management Plan on March 4, 1961, to govern hunting for bowhead whales by Alaskan Eskimos. Under this cooperative agreement, the AEWC will, in cooperation with NOAA manage the 1981 through 1987 bowhead whale hunts. The authority and responsibilities of the AEWC are contained in or limited by this agreement and the Management Plan as amended from time to time to the extent the Management Plan is not inconsistent with this agreement. If the AEWC fails to carry out its enforcement responsibilities or meet the conditions of this agreement or of the Management Plan as amended from time to time, NOAA may assert its federal 
management and enforcement authority and will regulate the bowhead whale hunt in a manner consistent with federal law, this agreement and the Management Plan to the extent necessary to carry out the responsibilities that are not being carried out. Such assertion of federal authority will be preceded by notice to AEWC of intent to regulate the bowhead whale hunt to the extent necessary to carry out those responsibilities and conditions, and will not be effected until the AEWC or its members have been given an opportunity to present their views on the need for such assertion in a public forum; provided, however, that in cases where irreparable harm to the bowhead whale resource might result, the assertion of federal authority may be effected immediately after notice, in which cases the public forum on the need for such assertion will be conducted as soon as practicable thereafter.

\section{INSPECTION AND REPORTING}

NOAA personnel shall monitor the hunt and the AEWC shall assist such personnel with such monitoring. The AEWC will provide an oral report to NOAA daily regarding the number of strikes and landings. The AEWC will also inform all whaling captains who are engaged in whaling activities of the number of whales struck or landed at all times. The AEWC will also provide a report to NOAA within 30 days after the conclusion of the spring hunt and the fall hunt containing at least the following information:

(1) The number, dates, and locations of every strike or landing;

(2) The length (as measured from the point of the upper jaw to the notch between the tail flukes), the extreme width of the flukes, and the sex of the bowhead whales landed;

(3) The length and sex of a fetus, if present, in a landed bowhead whale; and

(4) An explanation of circumstances associated with the striking of any bowhead whale not landed, and an estimate of whether a harpoon or bomb emplacement caused a wound which might be fatal to the animal (e.g., the harpoon entered a major organ of the body cavity and the bomb exploded).

NOAA will provide technical assistance in collection' of the above information. The AEWC shall assist appropriate persons in collection of specimens from landed whales, including but not limited to ovaries, ear plugs, and baleen plates. Such specimens shall be available to appropriate government officials. NOAA personnel cooperating with AEWC will work closely with the AEWC Commissioner in each whaling village to facilitate the accurate monitoring of the hunt.

\section{MANAGEMENT}

(1) No more than a total of 27 whales shall be struck in 1984. The AEWC and NOAA shall determine the total number of whales that may be struck in each year from 1985 through 1987 through annual negotiations that shall be concluded by March 15 of the year for which the quota is applicable. If the AEWC and NOAA are unable in these annual negotiations to agree on quotas for 1986 or 1987, the quota from the previous year shall apply. The AEWC Management Plan will provide that whaling captains and crews will use their best efforts to land every whale that is struck, and strike whales that are under 12 meters ( 39 feet) and presumed to be sexually immature.

(2) The AEWC may determine the allocation of these permitted strikes among the whaling villages.

\section{ENFORCEMENT}

(1) The AEWC agrees that whaling captains will be subject to civil monetary assessments for whales struck over any strike limit and whales landed over any landing limit that is prescribed in this agreement and the Management Plan as they may be amended from time to time. The AEWC will collect the assessments from the whaling captains and deposit them in a separate bank account from, which no disbursements shall be made without the express agreement of NOAA and the AEWC. In the event of a dispute between NOAA and the AEWC over the number of whales landed or struck, or the amount of the assessment, or other factual matters, NOAA will consult with the AEWC about the matter. If the dispute cannot be resolved, it will be referred to a NOAA administrative law judge for determination under a trial-type administrative proceeding of factual findings and the amount of assessment. The procedures contained in 15 C.F.R. sections $904.200^{\prime} 904.272$ will control these proceedings. The decision of the administrative law judge may be appealed to the Administrator of NOAA. Whaling captains may also be liable for civil 
assessments for other violations of the Management Plan as determined by the AEWC or by an administrative law judge under the procedures described above.

(2) In consideration of the AEWC's agreement hereunder, the Government of the United States agrees that the enforcement provision described in paragraph (1) of this section shall be the exclusive enforcement mechanism that shall apply during the term of this agreement to any violation by whaling captains or their crews who are registered members of the AEWC of any provisions of the Marine Mammal Protection Act, the Endangered Species Act, or the Whaling Convention Act as these Acts may relate to aboriginal subsistence whaling, of the International Convention for the Regulation of Whaling, 1946, of any regulations of the International Whaling Commission, or of any provisions of this agreement.

(3) The AEWC annually will furnish NOAA the names of all registered whaling captains.

\section{6. $\quad$ AUTHORITIES}

This cooperative agreement is concluded under the authorities governing management of living marine resources including but not limited to the Marine Mammal Protection Act of 1972 and the Whaling Convention Act of 1949 .

\section{DURATION}

This agreement is in effect from March 26, 1981 through December 31, 1987.

\section{CONSULTATION}

NOAA and the AEWC shall consult during the operation of this agreement concerning the matters addressed herein as well as all other matters related to bowhead whales which either party believes are suitable for such consultation. Specifically, NOAA shall consult with the AEWC on any action undertaken or any action proposed to be undertaken by any agency or department of the Federal Government that may affect the bowhead whale and shall use its best efforts to have such agency or department participate in such consultation with the AEWC.

\section{AEWC MANAGEMENT PLAN}

\section{Subpart A-Introduction}

\section{Subsection $100.1 \quad$ Purpose of Regulations.}

It is the purposes of the regulations contained herein to:

(a) insure an efficient subsistence harvest of bowhead whales;

(b) provide a means within the Alaska Eskimo customs and institution of limiting the bowhead whale harvest in order to prevent the extinction of such species; and

(c) provide for Eskimo regulation of all whaling activities by Eskimos who are members of the Alaska Eskimo Whaling Commission.

Subsection $100.2 \quad$ Scope of Regulations.

The regulations contained herein apply to the subsistence hunting of whales by Eskimos who are members of the Alaska Eskimo Whaling Commission.

\section{Subpart B-Alaska Eskimo Whaling Commission}

Subsection 100.11 Powers.

(a) The Alaska Eskimo Whaling Commission (hereinafter AEWC) is empowered to administer the regulations contained herein to insure that the purposes in Subsection 100.1 of these regulations are attained. 
(b) The AEWC is empowered to enforce the regulations by:

(1) denying any person who violates these regulations the right to participate in hunting bowhead whales.

(2) making civil assessments.

(3) acting as an enforcement agent for any governmental entity authorized to enforce these regulations.

(c) The AEWC is empowered to promulgate interim regulations that are in addition to, but not inconsistent with regulations contained herein.

Subsection 100.12 Duties.

(a) The AEWC shall administer and enforce the regulations contained herein (including any interim regulations).

(b) The AEWC shall conduct village education programs to facilitate compliance with these regulations, including training programs for whaling captains and crews.

(c) The AEWC shall initiate research for improvement of the accuracy and reliability of weapons.

\section{Subpart C-Regulations}

\section{Subsection 100.21 Definitions.}

(a) "bowhead whale" means a whale whose scientific name is baleana mysticetus and which migrates past whaling villages in Alaska.

(b) "captain" means the person in charge of a whaling crew.

(c) "harvest" means to kill and bring to shore or butchering area.

(d) "non-traditional weapons" means any instrument that could be used to harvest a bowhead whale that is not a traditional weapon.

(e) "traditional weapon" means a harpoon with line attached, darting gun, shoulder gun, lance or any other weapon approved by the AEWC as such a weapon in order to improve the efficiency of the bowhead whale harvest.

(1) "harpoon with line attached" means a harpoon with a rotating head which is attached to a line and float and which has no explosive charge. (See Figures 7 and 8 of Appendix $\mathrm{E}$ of the FEIS on the International Whaling Commission's Deletion of Native Exemption for the Subsistence Harvest of Bowhead Whales. (October 1977) (hereinafter FEIS).

(2) "darting gun harpoon" means a harpoon with an explosive charge and with a line and float attached. (See Appendix E of FEIS in Figure 4).

(3) "shoulder gun" means a whaling gun, adapted from the era of commercial whaling in the 19th century, which has an explosive charge and which has no attached line and float. (See Appendix E of the FEIS in Figure 5.)

(4) "lance" means a non-explosive sharply pointed weapon without a harpoon head.

(f) "whaling crew" means those persons who participate directly in the harvest or attempted harvest of the bowhead whale and are under the supervision of a captain. 
(g) "whaling village" means the Alaska Eskimo Whaling village in which resides a whaling captain and crew which participates in the harvest of bowhead whales and which is represented by a Commissioner of the AEWC.

(h) "whaling season" means customary period of time during which the bowhead whale is harvested, either in the Spring or Fall.

Subsection 100.22 Registration.

(e) Each captain shall register with the AEWC on forms provided by the AEWC for that purpose which disclose his name, address, age, qualifications as a captain, and his willingness to abide by the regulations of the AEWC and to require his crew to abide by those regulations.

(f) The AEWI shall take into account any reading or language difficulties in developing procedures and forms for registration.

Subsection 100.23 Reports.

(a) Each whaling captain shall be responsible for keeping a written record of the number of whales:

(1) attempted to be harvested by using traditional weapons but not harvested,

(2) harvested by the captain or his crew, and

(3) sighted by the captain and his crew.

(b) Each whaling captain shall report the date, place, and time of any striking not resulting in harvesting and shall describe:

(1) the size and type of bowhead whale,

(2) any known latter attempted harvest or actual harvest of said whale,

(3) the reason for the captain or crew not harvesting the whale, i.e., environmental factors, the failure of traditional weapons, or other reasons, and

(4) the conditions of the whale that was not harvested.

(c) Each whaling captain shall make such other reports as the AEWC requires in order to accomplish the purposes of the regulations herein or in order to advance the scientific knowledge of the bowhead whales.

Subsection 100.24 Permissible Harvesting Methods.

(a) No whaling captain or crew shall harvest or attempt to harvest the bowhead whale in any manner other than the traditional harvesting manner.

(b) "Traditional harvesting manner" means:

(1) only traditional weapons shall be used as defined in Subsection 100.21(e).

(2) the bowhead whale may be struck with a harpoon or darting gun with line and float attached.

(3) the shoulder gun may be used:

(i) after a line has been secured to the bowhead whale, or

(ii) when pursuing a wounded bowhead whale with a float attached to it.

(4) the lance may be used after a line has been secured to the bowhead whale. 
(c) Whaling captains and crews should harvest bowhead whales that are less than 40 feet plus(+) or minus(-) $15 \%$ in length.

Subsection 100.25 Traditional Proprietary Claim.

The bowhead whale shall belong to the captain and crew which first strikes the bowhead whale in the manner described in Subsection 100.24 .

Subsection 100.26 Level of Harvest.

(a) The AEWC shall establish the levels of harvest or attempted harvest for each whaling village during each season or seasons.

(b) In establishing the levels of harvest or attempted harvest, the AEWC shall consult each whaling village.

Subsection 100.31 Denial of Participation in Harvest and Fines.

(a) Any person who the AEWC determines has violated the regulations contained in subsection 100.24(a) and (b) and subsection 100.26 shall, after opportunity for a hearing before the AEWC, be prohibited from harvesting or attempting to harvest the bowhead whale for a period of not less than one whaling season nor more than five whaling seasons, and/or

(b) Any person who violates the regulations contained in subsection 100.24(a) and (b) and subsection 100.26 herein shall be subject to a fine of not less than $\$ 1,000$ nor more than $\$ 10,000$ as assessed by AEWC. The AEWC shall assess other fines at levels it deems appropriate, not to exceed $\$ 10,000$, for other violations of this Management Plan or federal law. No person shall harvest or attempt to harvest the bowhead whale until such fine has been paid.

\section{AEWC REGULATIONS FOR THE 1984 WHALING SEASON}

A. Under authority $\$ 100.26$ of the AEWC Management Plan, the AEWC establishes initial levels of attempted harvest (strikes) for bowhead whales for each whaling village during the 1984 season as follows:

$\begin{array}{lr}\text { Savoonga } & 3 \\ \text { Gambell } & 3 \\ \text { Kivalina } & 1 \\ \text { Wales } & 1 \\ \text { Pt. Hope } & 4 \\ \text { Wainwright } & 3 \\ \text { Barrow } & 8 \\ \text { Kaktovik } & 3 \\ \text { Nuigsut } & 1 \\ \text { Little Diomede } & \frac{0}{27}\end{array}$

B. The AEWC asks each village to transfer its unused strikes to another village.

\section{LIMITATION OF USE}

Nothing in this agreement shall be construed to support or contradict the position of either party regarding the jurisdiction of the International Convention for the Regulation of Whaling, 1946, or the Whaling Convention Act of 1949 with respect to aboriginal subsistence whaling by Alaskan Eskimos.

Date:

[Signature]

John V. Byrne, Administrator

National Oceanic and

Atmospheric Administration
[Signature]

John Oktollik, Chairman

Alaska Eskimo Whaling

Commission 


\section{Inuvialuit Game Council and North Slope Borough Management Agreement for Polar Bears of the Southern Beaufort Sea, Inuvik, 1988}

Done at Inuvik 29 January 1988

Entered into force 29 January 1988

Primary source citation: Copy of text provided by

the North Slope Borough

\section{INUVIALUIT GAME COUNCIL AND NORTH SLOPE BOROUGH MANAGEMENT AGREEMENT FOR POLAR BEARS OF THE SOUTHERN BEAUFORT SEA}

The Inuvialuit of Canada and the Inupiat of the United States,

Noting that both groups have traditionally harvested a portion of polar bears from the same population in the southern Beaufort Sea;

And Noting that the continued hunting of polar bears is essential to maintain the dietary, cultural and economic base of the groups;

And Noting that the maintenance of a sustained harvest for traditional users in perpetuity requires that the number of polar bears taken annually not exceed the productivity of the population;

And Noting that the International Agreement on the Conservation of Polar Bears makes provision for cooperation in the research and management of shared populations;

And Noting that nothing in this Agreement shall be read to abrogate the responsibilities of Federal, Provincial or State authorities under existing or future statutes;

And Noting that the Inuvialuit and the Inupiat will have a long-term fundamental influence on the maintenance and use of this resource and that the efforts of other parties will also be required to ensure effective conservation;

Have agreed as follows:

\section{ARTICLE I}

Definitions:

(a) The species considered in this Agreement is the polar bear (Ursus maritimus). 
(b) The area covered by this Agreement is the southern Beaufort Sea from approximately Baillie Islands, Canada, in the east to Icy Cape, USA in the west. of Alaska

(c) The people covered by this Agreement are the Inuvialuit of Canada and the Inupiat of the North Slope

(d) The settlements whose hunting practices may be affected by this Agreement are Barrow, Nuiqsut, Wainwright, Atqasuk and Kaktovik in the United States and Inuvik, Aklavik, Tuktoyuktuk and Paulatuk in Canada.

(e) Sustained yield is a level of taking which does not exceed recruitment and is consistent with population ranges determined to be optimal and sustainable.

(f) The Joint Commission shall consist of two (2) representatives designated by each of the Inuvialuit Game Council and the North Slope Borough Fish and Game Management Committee. The Technical Advisory Committee shall be appointed by the Joint Commission.

\section{ARTICLE II}

Objectives:

(a) To maintain a healthy viable population of polar bears in the southern Beaufort Sea in perpetuity.

(b) To provide the maximum amount of protection to female polar bears.

(c) To minimize detrimental effects of human activities, especially industrial activities, on important bear habitat.

(d) To manage polar bears on a sustained yield basis in accordance with all the best information available.

(e) To encourage the collection of adequate technical information on a timely basis to facilitate management decisions.

(f) To further refine the eastern and western boundaries of the population of polar bears.

(g) To encourage the wise use of polar bear products and by-products within the context of management on a sustained yield basis.

(h) To facilitate the exchange of polar meat and products between traditional users in Alaska and Canada (Enabling legislation required).

(i) To legalize the sale of polar bear hides and by-products by the traditional Alaskan users in Alaska (Enabling legislation required).

(j) To facilitate the export of polar bear hides and other polar bear products from the Western Arctic of Canada into the USA (Enabling legislation required).

(k) To consider at a later date a limited legalized Alaskan sport harvest of polar bears which emphasizes benefits to local hunters of the area (Enabling legislation required for Federal management).

\section{ARTICLE III}

Regulations: to conserve this population of polar bears, the Inuvialuit and the Inupiat have agreed as follows:

(a) All bears in dens or constructing dens are protected. 
(b) Family groups made up of female and cubs-of-the-year or yearlings are protected. The birthdate of cubs is fixed at January 1 and cubs less than five feet $(152 \mathrm{~cm}$.) in straight line body length are protected.

(c) The hunting season shall extend from December 1 to May 31 in Canada and from September 1 to May 31 in Alaska.

(d) The annual sustainable harvest shall be determined by the Technical Advisory Committee in consultation with the Joint Commission and shall be divided between Canada and Alaska according to annual review of scientific evidence. Allocation agreements shall be negotiated and ratified prior to September 1 annually. Each signatory to this Agreement shall determine for itself the distribution of the harvest within its jurisdiction.

(e) These regulations do not preclude either party from unilaterally introducing additional conservation practices within their own jurisdictions.

(f) Any readjustment of the boundaries pursuant to the above may necessitate a readjustment of user allocations under the management plan.

(g) The use of aircraft or large motorized vessels for the purpose of taking polar bears shall be prohibited.

(h) Each jurisdiction shall prohibit the exportation from, the importation and delivery into, and traffic within, its territory of polar bears or any part or product thereof taken in violation of this Agreement.

(i) Polar bears in villages during closed seasons should be deterred from the area.

(j) Polar bears threatening human safety or property may be taken at any time of the year and may be counted against the village allocation as ascribed by the Joint Commission.

\section{ARTICLE IV}

Collection of Data and Sharing of Information: name.

(a) The following data will be recorded for each bear killed: sex, date and location of the kill, and hunter's

(b) The following shall be collected from each bear killed: an undamaged post-canine tooth, ear tags or lip tatoos if the tags are missing, other specimens as agreed to by the hunters of either jurisdiction for additional studies.

(c) A summary of all harvest information from each jurisdiction shall be exchanged annually.

(d) The number of collars deployed for research purposes shall be limited to the minimum number necessary to provide accurate population information.

\section{ARTICLE V}

\section{Duration of Agreement:}

(a) This Agreement shall enter into force when it has been signed by the representative of both parties.

(b) This Agreement shall remain in force unless either Contracting Party requests it be terminated.

(c) Amendments to the Agreement may be proposed by either signatory and accepted or rejected by mutual agreement after consultation with the North Slope Borough Fish and Game Management Committee.

The Alaskan signatories of this document have no authority, to bind and do not purport to bind the North Slope Borough to any agreement which would otherwise be in violation of the exclusive federal treaty power established 
by the United States Constitution, but are acting solely as representatives of the local traditional user group of the polar bear resource in furthering the consultation, management, and information exchange goals of the International Agreement on the Conservation of Polar Bears.

SIGNED on this the 29th day of January, 1988 in the Town of Inuvik, Northwest Territories.

On behalf of the North Slope Inupiat

Nolan Solomon, Chairman North Slope

Borough, Fish \& Game

Management Committee

Benjamin P. Nageak, Director, North Slope

Borough, Department of Wildlife Management

On behalf of the Inuvialuit Game Council

Alex Aviugana, Chairman, Inuvialuit Game

Council

Andy Carpenter, Vice Chairman, Wildlife

Management Advisory Council (N.W.T.) 


\title{
Memorandum of Agreement Between the U.S. Fish and Wildlife Service, the Alaska Sea Otter Commission, and the Alaska Department of Fish and Game, Anchorage, 1994
}

Done at Anchorage 1 February 1994

Entered into effect 1 February 1994

Primary source citation: Copy of text provided by the U.S. Fish and Wildlife Service of the U.S. Department of the Interior

\section{MEMORANDUM OF AGREEMENT}

\author{
U.S. Fish and Wildlife Service \\ Anchorage, Alaska \\ Alaska Sea Otter Commission \\ Fairbanks, Alaska \\ Alaska Department of Fish and Game \\ Juneau, Alaska
}

THE UNITED STATES FISH AND WILDLIFE SERVICE (FWS), THE ALASKASEAOTTER COMMISSION (ASOC) AND THE ALASKA DEPARTMENT OF FISH AND GAME (ADF\&G), DO MUTUALLY AGREE AND DECLARE:

That there should be open and continuous communication and exchange of information among agencies and groups interested in the health, well being, and utilization of the northern sea otter (Enhydra lutris), and that a sound management policy for this species is best developed and implemented with mutual cooperation and assistance from the above parties.

Therefore:

The following Memorandum of Agreement (Agreement) is presented in recognition of this acknowledgment of mutual purpose and goals. 


\section{Purpose:}

This agreement is designed to assist the signatory agencies in the cooperative management of the northern sea otter by providing for the exchange of biological, management and socioeconomic information, and for support of the requirements of pertinent laws, regulations, and resolutions.

In furtherance of this purpose, the agreement provides for coordination and cooperation among the FWS, the ASOC, and the ADF\&G, Division of Wildlife Conservation, to achieve the following goals:

1. Conservation - Maintain healthy populations of the northern sea otter for ecosystem integrity, public enjoyment, scientific research, and Alaska Native harvest.

2. Habitat - Maintain healthy habitats for sea otters in Alaska.

3. Research - Obtain information necessary for the sound management and conservation of sea otters.

4. Harvest Monitoring and Reporting - Obtain accurate harvest information and biological samples which will provide information needed to make sound management decisions.

5. Education and Information Sharing - Provide a vehicle by which information regarding the effective management of the northern sea otter can be exchanged, shared, and/or made public.

6. Enforcement - Enforce provisions of pertinent laws and regulations in order to maintain healthy populations of sea otters.

7. Management Conflicts - Identify, and if possible, work towards resolution of management conflicts associated with sea otters.

8. Technical Committee - This agreement provides for the formation of a Technical Advisory Committee (Committee) comprised of two representatives appointed by each of the signatory organizations as well as outside scientific experts on sea otters, to provide advice concerning sea otter management in order to achieve the above goals.

\section{Authorities:}

The U.S. Fish and Wildlife Service enters into this Agreement pursuant to the authority granted in the Marine Mammal Protection Act, (MMPA) 16 USC 1382(c).

The Alaska Department of Fish and Game enters into this Agreement pursuant to authority granted in AS 16.05.050.

The Alaska Sea Otter Commission enters into this Agreement pursuant to authority granted in Commission By-Laws and member village council resolutions.

III. Applications to other Treaties, Conventions, or Agreements:

A. Nothing in this Agreement shall be deemed to alter, amend or abrogate the authority of Alaska Natives to take sea otters in a non-wasteful manner for subsistence or handicrafts under section 101 (b) of the MMPA, 16 U.S.C. 1361 (b), or to authorize any federal restriction of the harvest of sea otters by Alaska Natives unless the sea otter population is formally determined to be depleted pursuant to the Act.

B. Nothing in this Agreement shall be read to abrogate the management responsibility of the Service as charged under the MMPA (16 U.S.C. 1361-1407). Further, the provisions of this Agreement shall not be deemed to contravene the provisions of any existing international treaty, convention, statute or agreement which may otherwise apply to the northern sea otter.

C. If anything in this Agreement shall be deemed unlawful, or contrary to laws and regulations made and provided for in such case, it shall be null and void and not affect the remainder of the Agreement. 


\section{Definitions}

A. Cooperative management - for purposes of this agreement, cooperative management is defined as a formal arrangement between the FWS, the ADF\&G and the ASOC that recognizes the shared responsibility held by each for the conservation and management of sea otter populations.

\section{Now Therefore be it known that the Parties hereto agree as follows:}

A. The United States Fish and Wildlife Service agrees:

1. to recognize the ASOC as the representative of ASOC member Native village governments on issues pertaining to sea otter conservation and management;

2. to coordinate with other agencies and persons in carrying out its responsibilities under the MMPA including the Alaska Native exemption, as amended, as provided in 16 U.S.C. Sect. 1361-1470;

3. to develop and conduct scientific studies in cooperation with the ADF\&G and the ASOC, including, but not limited to:

a) determine the distribution, size, and trends of the sea otter population in different regions of Alaska;

b) assess the general health, welfare, and other life history parameters of the sea otter;

c) identify, describe, and protect important breeding, pupping, and feeding habitat and haul out areas of the sea otter;

d) investigate the impact of human activities on northern sea otters which may result in "taking" as defined by the MMPA, or habitat alteration resulting from development activities, oil spills, and other such activities;

4. to work with the ADF\&G and the ASOC to develop regional sea otter management plans;

5. to cooperate with the ASOC and designated user groups to ensure compliance with the provisions of the MMPA, and to provide such law enforcement input and activity as is necessary;

6. to notify and involve the ASOC and the ADF \&G prior to and during the development of sea otter management regulations or proposed amendments to the MMPA;

7. to incorporate, where appropriate, the written recommendations of the ASOC on FWS management planning documents or regulations concerning sea otter uses unless determined to violate the MMPA and/or other recognized principles of fish and wildlife conservation;

8. to implement Marking and Tagging and Reporting Regulations consistent with section 109(i) of the MMPA, as amended, and to utilize village residents as monitors to the maximum extent practicable;

9. (a) to uphold the federal government's trust responsibility to Alaska Natives; (b) to assure that sound biological management principles are used to guide the FWS and Alaska Natives in the management of sea otter populations, and; (c) to aid in securing funding and other opportunities for Alaska Natives to participate more actively in natural resources planning processes affecting sea otters;

10. to promote and encourage further research, communication, and agreements with foreign nations regarding the management and conservation of sea otters;

11. to cooperate with the $A S O C$ and the $A D F \& G$ in developing and implementing a biological sampling program for sea otters harvested by Alaska Natives;

12. to cooperate with the ASOC and the ADF\&G in developing and disseminating educational materials on the conservation, management, and utilization of sea otters. 
B. The Alaska Sea Otter Commission Agrees:

1. to recognize the FWS as the federal agency vested with legal authority for sea otter management under the MMPA as amended;

2. to inform and educate sea otter users with regard to the value and necessity of their compliance with applicable laws and regulations, and their cooperation with efforts to obtain biological information about sea otters;

3. to provide a method for transfer of local knowledge about sea otters and their uses to federal, state, and tribal agencies so that this information can be used in decisions about the conservation and management of sea otters;

4. to cooperate with the Service in the implementation of the sea otter marking and tagging program;

5. to work with coastal Alaska Native villages to promote responsible management practices and non-wasteful uses of sea otters, and to ensure that uses are consistent with the MMPA as amended;

6. to act as a liaison between village governments and federal and state agencies with regard to management concerns, research, educational information, village concerns, and federal laws and regulations;

7. to promote and encourage further research, communication and agreements with foreign nations regarding the conservation and utilization of sea otters by Alaska Natives;

8. to cooperate with the FWS and the ADF\&G in developing and implementing a biological sampling program for sea otters harvested by Alaska Natives;

9. to cooperate with the FWS and the ADF\&G in developing and disseminating educational materials on the conservation, management, and utilization of sea otters;

10. to work with the FWS and ADF\&G to develop and implement regional sea otter management plans.

C. The Alaska Department of Fish and Game agrees:

1. to recognize the FWS as the agency with legal responsibility for the management of the sea otter under the MMPA as amended;

2. to fulfill the responsibilities assigned and accepted by all parties of this agreement or through amendment to the agreement;

3. to cooperate with the FWS and the ASOC in:

a) developing and implementing a sea otter conservation plan;

b) conducting scientific studies to monitor the health, welfare, distribution, status and trends of the sea otter population;

c) ensuring that management of state owned lands and waters provides adequate protection of important sea otter habitats;

4. to encourage local programs for compliance with applicable laws, regulations, and agreements;

5. to promote and encourage further research, communication, and agreements with foreign nations regarding the management and conservation of the sea otter;

6. to cooperate with the ASOC and the FWS in developing and implementing a biological sampling program for sea otters harvested by Alaska Natives; 
7. to cooperate with the ASOC and the FWS in developing and disseminating educational materials on the conservation, management, and utilization of sea otters.

\section{It is further mutually agreed that:}

1. amendments to this agreement may be proposed at any time by submission in writing to the other affected parties, and shall become effective upon approval by the signatories hereto or their representatives;

2. the effective date of this Agreement shall be from the date of final endorsement. The Agreement shall remain in force until one party signifies in writing to the others the desire to terminate its participation and obligations. The Agreement shall become null and void 30 days after such notification. This Agreement shall be reviewed by all signatory parties annually on the anniversary date and recommended changes be incorporated by amendment, or the Agreement terminated in part or in whole;

3. nothing in this Agreement shall preclude any party from advocating positions related to the management of sea otter and its habitat which may be contrary to that of the signatory parties, whether related to the development of legislation, promulgation of regulations, pursuit of administrative or judicial actions or otherwise;

4. nothing in this agreement shall obligate any party in the expenditure of funds, or future payments of money, in excess of appropriations authorized by law;

5. each party agrees that it will be responsible for its own acts and the results thereof and each party shall not be responsible for the acts of the other party; and each party agrees it will assume to itself risk and liability resulting in any manner under this agreement;

6. no member of Congress, or the Commissioner, shall be admitted to any share or part of the agreement or to any benefit that may arise therefrom;

7. each party will comply with all applicable laws, regulations and executive orders relative to Equal Employment Opportunity.

[Signature]

Regional Director

U.S. Fish and Wildlife Service

Anchorage, Alaska

[Signature]

Chair

Alaska Sea Otter Commission

Fairbanks, Alaska

[Signature]

Commissioner

Alaska Department of Fish and Game

Juneau, Alaska 

For sale by the U.S. Govermment Printing Office

Superintendent of Documents, Mail Stop: SSOP, Washington, DC 20402-9328

ISBN 0-16-049316-1

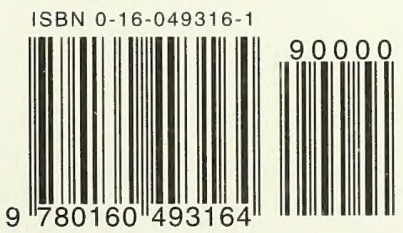






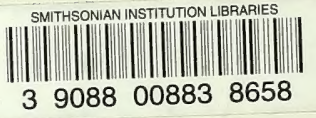

